Tom Sieber

\title{
Strategieorientierte Berichterstattung im Lagebericht
}




\section{Tom Sieber}

\section{Strategieorientierte Berichterstattung im Lagebericht}

Der Jahresabschluss ist das zentrale Instrument zur Bereitstellung von prognoserelevanten Informationen und er erfreut sich - dank normierter Struktur und verpflichtender Prüfung - hoher Beachtung seitens der Adressaten. Es liegen bereits empirische Studien vor, die belegen, dass Jahresabschlussinformationen von Investoren im Rahmen der Preisbildung von Finanztiteln berücksichtigt werden, diese also Wertrelevanz besitzen. Ein wesentlicher Nachteil des Jahresabschlusses ist jedoch seine Vergangenheitsorientierung, so dass die enthaltenen Informationen letztlich immer einen ,Blick in den Rückspiegel' darstellen.

Eine vergleichsweise hohe Prognoserelevanz besitzen demgegenüber Angaben zur Unternehmensstrategie, angefangen von den strategischen Zielen über die unternehmensinterne und -externe Analyse bis hin zum Implementierungsfortschritt strategischer Programme. Ein Instrument zur Kommunikation derartiger Informationen in der deutschen Rechnungslegung stellt aufgrund seiner inhaltlichen Flexibilität und seines verbal-qualitativen Charakters der Lagebericht nach HGB dar. Dank seiner Einbindung in die Pflichtpublizität und -prüfung erscheint er zudem deutlich verlässlicher als jede andere Form der Unternehmenskommunikation.

Vor diesem Hintergrund wird in dieser Arbeit untersucht, wie sich das Publizitätsverhalten deutscher Unternehmen in Bezug auf Strategieinformationen im Lagebericht im Zeitablauf darstellt und inwieweit das unternehmensindividuelle Niveau der Strategieberichterstattung Einfluss auf zentrale Kapitalmarktparameter ausübt.

Tom Sieber studierte Betriebswirtschaftslehre sowie Rechtswissenschaften an der Universität Gießen und ist seit 2004 bei einer Unternehmensberatung tätig. 
Strategieorientierte Berichterstattung im Lagebericht 


\section{Controlling \& Business Accounting}

Herausgegeben von Barbara E. Weißenberger

Band 8

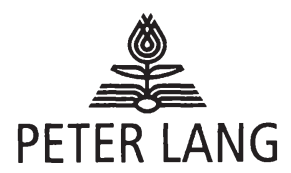

Frankfurt am Main - Berlin · Bern - Bruxelles · New York · Oxford · Wien 


\section{Tom Sieber}

\section{Strategieorientierte Berichterstattung im Lagebericht}

Eine empirische Untersuchung börsennotierter

Unternehmen in Deutschland

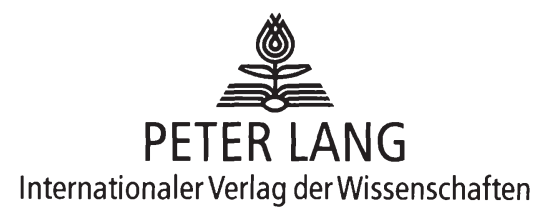

Tom Sieber - 978-3-631-75150-3

Downloaded from PubFactory at 01/11/2019 07:41:07AM

via free access 


\title{
Bibliografische Information der Deutschen Nationalbibliothek
} Die Deutsche Nationalbibliothek verzeichnet diese Publikation in der Deutschen Nationalbibliografie; detaillierte bibliografische Daten sind im Internet über http://dnb.d-nb.de abrufbar.

Open Access: The online version of this publication is published on www.peterlang.com and www.econstor.eu under the international Creative Commons License CC-BY 4.0. Learn more on how you can use and share this work: http://creativecommons.org/licenses/ by/4.0.

\section{(c) (i)}

This book is available Open Access thanks to the kind support of ZBW - Leibniz-Informationszentrum Wirtschaft.

Zugl.: Gießen, Univ., Diss., 2011

Umschlaggestaltung:

Olaf Glöckler, Atelier Platen, Friedberg

Gedruckt auf alterungsbeständigem, säurefreiem Papier.

\author{
D 26 \\ ISSN 1867-304X \\ ISBN 978-3-631-60733-6 \\ ISBN 978-3-631-75150-3 (eBook) \\ (C) Peter Lang GmbH \\ Internationaler Verlag der Wissenschaften \\ Frankfurt am Main 2011 \\ Alle Rechte vorbehalten.
}

Das Werk einschließlich aller seiner Teile ist urheberrechtlich geschützt. Jede Verwertung außerhalb der engen Grenzen des

Urheberrechtsgesetzes ist ohne Zustimmung des Verlages unzulässig und strafbar. Das gilt insbesondere für

Vervielfältigungen, Übersetzungen, Mikroverfilmungen und die Einspeicherung und Verarbeitung in elektronischen Systemen.

www.peterlang.de 


\section{Geleitwort}

Ein zentrales Instrument zur Bereitstellung von prognoserelevanten Informationen ist die externe Pflichtpublizität von Unternehmen im Rahmen des Jahresabschlusses. Im Gegensatz zu anderen Informationsquellen, z.B. ad-hoc-Mitteilungen oder Pressekonferenzen, zeichnet sich der Jahresabschluss durch eine von Standardsettern vorgegebene Struktur der Informationsbereitstellung aus, die zudem im Rahmen der Abschlussprüfung auf formale wie inhaltliche Normenkonformität geprüft wird. Es liegen inzwischen umfassende empirische Studien vor, die belegen, dass Jahresabschlussinformationen tatsächlich von Investoren im Rahmen der Preisbildung von Finanztiteln herangezogen werden, d.h. wertrelevant sind.

Ein bedeutsamer Nachteil des Jahresabschlusses ist jedoch die der Forderung nach Verlässlichkeit geschuldete Vergangenheitsorientierung, die sich z.B. im Grundsatz der Einzelbewertung von historisch erworbenen Vermögenswerten und Schulden in der Unternehmensbilanz ausdrückt, so dass die Informationen im Jahresabschluss letztlich einen ,Blick in den Rückspiegel` darstellen. Eine vergleichsweise hohe Prognoserelevanz besitzen demgegenüber Informationen über die strategische Geschäftspolitik, angefangen von den strategischen Zielen über die unternehmensinterne Analyse strategierelevanter Kontextfaktoren und Wirkungsketen bis hin zur Implementierung strategischer Programme.

Ein Instrument zur Kommunikation derartiger Informationen stellt in der deutschen Rechnungslegung der Lagebericht dar, der aufgrund der Einbindung in die Pflichtpublizität und die Pflichtprüfung im Vergleich zur freien Unternehmenskommunikation deutlich verlässlicher ist, andererseits aber nicht wie die oben genannten Finanzberichte dem Stichtagsprinzip unterliegt. Vor diesem Hintergrund untersucht die vorliegende Dissertationsschrift das Publizitätsverhalten deutscher Konzerne bezüglich der Strategieberichterstattung im Lagebericht. Grundlage ist das im Rahmen dieses Forschungsprojekts entwickelte Messinstrument des Strategy Disclosure Index (SDI), über den das Niveau der Strategieberichterstattung quantifiziert wird und dessen Aussagekraft mittels bereits vorliegender Daten aus dem Wettbewerb „Der Beste Geschäftsbericht" der Westfälischen Wilhelms-Universität Münster validiert werden konnte. Die Datengrundlage der Untersuchung umfasst dabei die Lageberichte von 100 deutschen Konzernen der Jahre 2002 bis 2008.

Zwei Forschungsfragen standen im Vordergrund:

1) Inwieweit geben Unternehmen strategierelevante Informationen im Rahmen des Lageberichts preis bzw. hat sich das Publizitätsverhalten in diesem Zusammenhang in den vergangenen Jahren verändert? und

2) Können Kapitalmarkteffekte einer Bereitstellung strategierelevanter Informationen im Lagebericht gemessen werden, insbesondere was die Markttransparenz und die Interaktion der Marktteilnehmer, aber auch die Bewertung der entsprechenden Eigenkapitaltitel angeht?

Die Antworten, die in der Arbeit auf diese Fragen gegeben werden, zeichnen ein differenziertes Bild der Strategieberichterstattung: Obwohl ihr Umfang zwischen 2002 und 2008 deutlich zunimmt, gibt es immer noch Unternehmen, die Strategienformationen im - Gagebericht nur 
sehr zurückhaltend publizieren, und zwar insbesondere dann, wenn sie unter zunehmendem Erfolgs- bzw. Wettbewerbsdruck stehen. Andererseits zeigt die Arbeit auch, dass eine umfassende Strategieberichterstattung vom Kapitalmarkt positiv honoriert wird, so z.B. mit niedrigeren Eigenkapitalkosten.

Die vorliegende Dissertationsschrift bietet deshalb spannende Perspektiven nicht nur für Rechnungsleger, sondern auch für Controller und Manager, die im Kontext der Integration der Finanzfunktionen zunehmend auch mit Fragen der Strategieberichterstattung gegenüber externen Adressaten konfrontiert werden. Auch vor dem Hintergrund der nationalen und internationalen Aktivitäten im Standardsetting zum Lagebericht (z.B. geplante Überarbeitung von DRS 15 durch das DRSC oder die (Weiter-)Entwicklung des Practice Statement Management Commentary unter IFRS) leistet die vorliegende Dissertationsschrift einen ganz wesentlichen Beitrag zur wissenschaftlichen Diskussion. Sie ist als Lektüre für Praktiker und Wissenschaftler gleichermaßen zu empfehlen. Ich wünsche der Arbeit deshalb die verdiente Aufnahme in der Community.

Gießen, im Mai 2011

Univ.-Prof. Dr. Barbara E. Weißenberger 


\section{Vorwort}

Mit der Fertigstellung der vorliegenden Arbeit ist es an der Zeit, in dreierlei Hinsicht Dank zu sagen für erfahrene Hilfestellungen. Dieser Verpflichtung komme ich gerne nach.

Zunächst geht mein ganz persönlicher Dank an Frau Univ.-Prof. Dr. Barbara E. Weißenberger für die intensive Betreuung meiner Arbeit und die viele Zeit, die sie aufgewendet hat, um eine bestmögliche Abstimmung und einen effizienten Ablauf der Bearbeitung sicherzustellen. Frau Weißenberger stand mir regelmäßig persönlich, telefonisch sowie nahezu rund um die Uhr via E-Mail zur Verfügung - dies ist keineswegs selbstverständlich und ich bin für wirklich kurze Wege, für zahlreiche nützliche Gedanken und konstruktive Diskussionen überaus dankbar.

Bei Univ.-Prof. Dr. Martin Glaum bedanke ich mich für die Übernahme des Zweitgutachtens. Bereits während der Bearbeitung des Forschungsprojekts hatte Herr Glaum nicht nur stets ein offenes Ohr für mich und meine Arbeit, sondern als Experte auf dem Gebiet der empirischen Rechnungslegungsforschung auch wertvolle Hinweise parat, die mich voranbrachten. Schließlich danke ich dem gesamten Team am Lehrstuhl von Frau Weißenberger für die freundliche Aufnahme als ,Externem', fruchtbare Diskussionen sowie spannende Kolloquiumssitzungen. Frau Brigitte Richter sei für ihre administrative Hilfe und guten Kaffee gedankt.

Neben den Angehörigen der Justus Liebig-Universität Gießen habe ich - zweitens - Unterstützung weiterer Personen erfahren, bei denen ich mich bedanken möchte.

Mein ganz herzlicher Dank richtet sich an den verehrten Univ.-Prof. Dr. Dr. h.c. Jörg Baetge sowie an Dr. Tatjana Oberdörster für die Bereitstellung von Daten im Rahmen meiner empirischen Arbeit. Eine so großzügige universitätsübergreifende Hilfestellung ist außergewöhnlich, deshalb hat mich die tatkräftige Unterstützung durch das ,Team Baetge' besonders gefreut.

Mein Arbeitgeber, Oliver Wyman Management Consulting, hat mir während des Verfassens meiner Dissertation jede erdenkliche Unterstützung zuteil werden lassen. Namentlich möchte ich Herrn Thomas Kautzsch und Dr. Lutz Jäde danken, dass sie dieses Vorhaben begleitet und gefördert haben. Meinen Kollegen Dr. Romed Kelp, Dr. Tobias Eichner, Dr. Andreas Pradler und Dr. Daniel Kronenwett danke ich für viele inhaltliche und prozessuale Tipps, die für den Fortschritt der Arbeit ebenso wertvoll waren wie die gemeinsamen Kaffeepausen. Schließlich hat das ,Printshop-Team` für meine Untersuchung Großartiges geleistet - herzlichen Dank!

Drittens und letztens danke ich meiner Familie, insbesondere meiner Mutter, Frau Hildegard Sieber, und meiner Schwester, Frau Christina Ansteeg, für ihre stets selbstlose Unterstützung in allen Lebenslagen. Meinem Vater, Dr.-Ing. Hans-Jürgen Sieber, sowie meinen Großeltern, Traute und Dr.-Ing. Karl Sieber, bin ich nicht nur für die mentale und finanzielle Absicherung meiner Ausbildung zu tiefem Dank verpflichtet - gerne hätte ich diesen persönlich überbracht.

Irina danke ich für ihr phantastisches Wesen und dafür, dass sie mir nicht nur den Rücken und den Kopf für meine Promotion freigehalten hat, sondern mich zudem mit der ihr ganz eigenen positiven, fröhlichen und anpackenden Art immer wieder motiviert und bestärkt, nach vorne zu schauen. Ihr und unseren beiden Töchtern, Ana \& Mia, sei diese Arbeit gewidmet. 
Tom Sieber - 978-3-631-75150-3

Downloaded from PubFactory at 01/11/2019 07:41:07AM

via free access 


\section{Inhaltsübersicht}

Abbildungsverzeichnis ............................................................. XVII

Tabellenverzeichnis ..................................................................... XVII

Abkürzungsverzeichnis ..............................................................

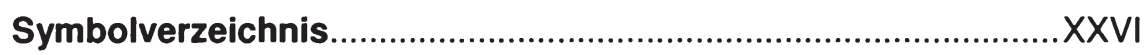

A Einführung in die Thematik der Arbeit .....................................

1 Grundsätzliche Überlegungen zur Ausgangssituation........................... 1

2 Abgrenzung des Bearbeitungsfeldes .................................................... 3

3 Aufbau der weiteren Ausführungen.................................................... 5

B Berichterstattung über strategieorientierte Informationen kapitalmarktorientierter Unternehmen ........................................

1 Bedeutung von Informationen im Kontext des Kapitalmarktes ............. 7

2 Strategisches Management zur Gestaltung der zukünftigen

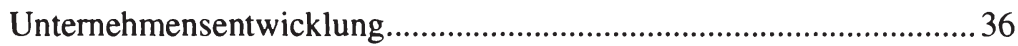

3 Externe Rechnungslegung als Instrument der Berichterstattung

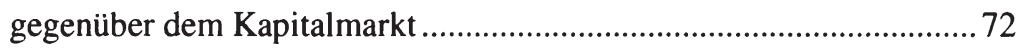

4 Berichterstattung über strategieorientierte Sachverhalte in der externen Rechnungslegung ............................................................... 104

5 Synopsis der Ausführungen als Überleitung zu einer empirischen Untersuchung der Strategieberichterstattung ................. 136

C Aufbau einer Untersuchung der strategieorientierten Berichterstattung börsennotierter Unternehmen .................... 139

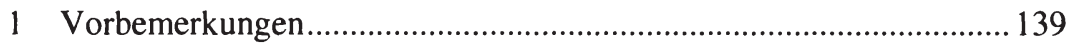

2 Kontext der bisherigen Forschung und Forschungslücken................. 141

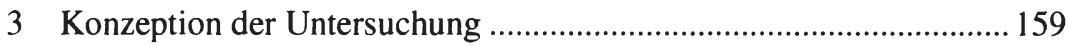

4 Zusammenfassung des Untersuchungsmodells ................................2 242 
D Ergebnisse der Untersuchung der Strategieberichterstattung börsennotierter Unternehmen ..................................2. 245

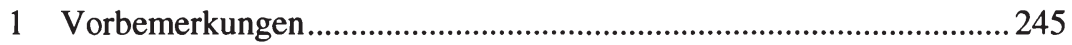

2 Deskriptive Auswertungen der Datenbasis ............................................. 246

3 Hypothesenprüfung zur Strategieberichterstattung ..............................265

4 Hypothesenprüfung zu den Bestimmungsfaktoren...............................268

5 Hypothesenprüfung zu den Kapitalmarkteffekten ................................301

6 Erweiterung der Betrachtung um moderierende Effekte ......................330

E Schlussbetrachtung der Arbeit und Ausblick..........................336

1 Gang der Arbeit in der Retrospektive ..................................................336

2 Synopsis der wesentlichen Erkenntnisse der Arbeit ............................. 337

3 Würdigung der wesentlichen Erkenntnisse der Arbeit und

Anhaltspunkte für zukünftige Forschungsarbeiten ...............................344

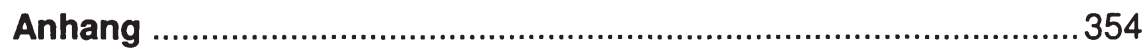

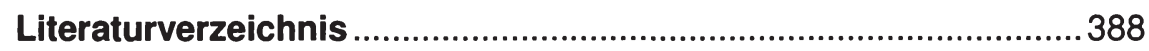




\section{Inhaltsverzeichnis}
Abbildungsverzeichnis $X V I I$
Tabellenverzeichnis $X V I I I$
Abkürzungsverzeichnis ............................................................ XXI
Symbolverzeichnis. $X X V I$

A Einführung in die Thematik der Arbeit ....................................... 1

1 Grundsätzliche Überlegungen zur Ausgangssituation .............................. 1

2 Abgrenzung des Bearbeitungsfeldes......................................................... 3

3 Aufbau der weiteren Ausführungen …………………………………..... 5

B Berichterstattung über strategieorientierte Informationen kapitalmarktorientierter Unternehmen ........................................

1 Bedeutung von Informationen im Kontext des Kapitalmarktes ............. 7

1.1 Kapitalmarkt als Ort des Zusammentreffens von Investoren

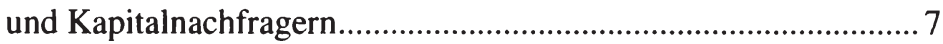

1.1.1 Organisierter Kapitalmarkt als Bezugsrahmen..................................... 7

1.1.2 Charakterisierung der handelnden Akteure am Kapitalmarkt ...............9

1.1.3 Bewertung als Basis von Transaktionen am Kapitalmarkt.................. 14

1.2 Informationen als Grundlage der Bewertung am

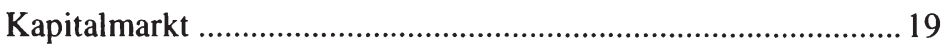

1.2.1 Informationstheoretischer Hintergrund ........................................... 19

1.2.2 Theorien zur Bedeutung von Informationen am Kapitalmarkt .......... 20

1.2.3 Anforderungen an Informationen am Kapitalmarkt ...........................2. 23

1.2.4 Private versus öffentliche Bereitstellung von Informationen ............... 30

1.3 Finanzberichterstattung als Informationsgrundlage der Akteure am Kapitalmarkt? ....................................................... 33

2 Strategisches Management zur Gestaltung der zukünftigen

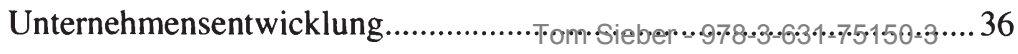


2.1 Inhaltliches Verständnis von »Strategie « ......................................36

2.1.1 Begriffliche Charakterisierung von »Strategie «...................................36

2.1.2 Einzug strategischen Denkens in die Betriebswirtschaft..................... 38

2.1.3 Ableitung eines Begriffsverständnisses von »Strategie« ...................... 39

2.2 Strategisches Management in der Unternehmenspraxis ................40

2.2.1 Zeitliche Entwicklung des strategischen Managements...................... 40

2.2.2 Operationalisierung des strategischen Managements........................... 42

2.2.3 Strategisches Management in prozessualer Perspektive .................... 48

2.2.4 Zusammenfassung des inhaltlichen Strategieverständnisses................ 61

2.3 Informationelle Perspektive der Strategie am Kapitalmarkt ........62

2.3.1 Ableitung der Bedeutung strategieorientierter Informationen ............ 62

2.3.2 Beurteilung der Nützlichkeit von Informationen zur Strategie ........... 64

2.3.3 Problembereiche strategieorientierter Informationen ........................... 68

3 Externe Rechnungslegung als Instrument der Berichterstattung gegenüber dem Kapitalmarkt ............................................................. 72

3.1 Rechnungslegung kapitalmarktorientierter Unternehmen .............72

3.1.1 Rechnungslegung als Kern der Unternehmenspublizität ................. 72

3.1.2 Grundlegende Normen der deutschen Rechnungslegung....................73

3.1.3 Elemente der Rechnungslegung im Kapitalmarktkontext ....................74

3.2 Rolle der Rechnungslegung im Kapitalmarktkontext ...................77

3.2.1 Theoretische Ansätze zur Erklärung des Verhältnisses von Rechnungslegung und Kapitalmarkt ................................................... 77

3.2.2 Anforderungen an kapitalmarktorientierte Rechnungslegung............ 79

3.2.3 Faktische Relevanz der Rechnungslegung am Kapitalmarkt ..............87

3.3 Der Lagebericht als Element der Rechnungslegung......................89

3.3.1 Rolle des Lageberichts innerhalb der Rechnungslegung..................... 89

3.3.2 Rechtsgrundlagen der deutschen Lageberichterstattung .................... 91

3.3.3 Informationelle Bedeutung des Lageberichts ..................................... 98

3.4 Würdigung der Erkenntnisse und überleitende Anmerkungen... 102 
4 Berichterstattung über strategieorientierte Sachverhalte in der externen Rechnungslegung 104

4.1 Leistungsfähigkeit der externen Rechnungslegung im Kapitalmarktkontext 104

4.1.1 Wettbewerb um Kapital als begründende Entwicklung 104

4.1.2 Beurteilung der Wertorientierung der Rechnungslegung 105

4.1.3 Wertorientierte Berichterstattung als Lösungsansatz

4.2 Umsetzung einer wertorientierten Berichterstattung

4.2.1 Value Reporting zur Überwindung informationeller Grenzen 112

4.2.2 Vorschläge zur inhaltlichen Ausgestaltung 115

4.2.3 Ausgewählte Empirie zur Umsetzung in Deutschland 118

4.3 Der Lagebericht als Kernmedium der Berichterstattung über strategieorientierte Inhalte

4.3.1 Besondere Eignung des Lageberichts zur Darstellung wertorientierter Inhalte

4.3.2 Status der Kodifizierung einer strategieorientierten Berichterstattung im Lagebericht

4.3.3 Supranationale Impulse für eine Berichterstattung über strategieorientierte Inhalte

4.4 Freiwillige »Strategieberichterstattung « im Lagebericht

5 Synopsis der Ausführungen als Überleitung zu einer

empirischen Untersuchung der Strategieberichterstattung

\section{Aufbau einer Untersuchung der strategieorientierten} Berichterstattung börsennotierter Unternehmen

1 Vorbemerkungen.

2 Kontext der bisherigen Forschung und Forschungslücken

2.1 Leitende Fragen der Untersuchung............................................ 141

2.2 Aufbau des Untersuchungsmodells ............................................ 142

2.3 Überblick über den bisherigen Stand der Forschung................. 143

2.3.1 Arbeiten zum Niveau der (Lage-) Berichterstattung 3 - $31-75150-3$ 143 
2.3.2 Arbeiten zu den Bestimmungsfaktoren der Berichterstattung......... 148

2.3.3 Arbeiten zu den Kapitalmarktwirkungen der Berichterstattung....... 152

2.4 Erklärungsanspruch der eigenen Untersuchung ......................... 157

3 Konzeption der Untersuchung …........................................................ 159

3.1 Formulierung der Hypothesen der Untersuchung........................ 159

3.1.1 Niveau der Strategieberichterstattung ............................................. 160

3.1.2 Bestimmungsfaktoren der Strategieberichterstattung.................... 162

3.1.3 Kapitalmarkteffekte der Strategieberichterstattung....................... 178

3.1.4 Darstellung des gesamthaften Hypothesengerüsts ........................ 187

3.2 Informationelle Basis der Untersuchung ................................... 188

3.2.1 Zusammenstellung der Untersuchungsobjekte............................ 188

3.2.2 Messung des Niveaus der Strategieberichterstattung ..................... 191

3.2.3 Erhebung der Rohdaten der Untersuchung................................... 211

3.2.4 Logik der zeitlichen Datenverknüpfung ...................................... 213

3.3 Operationalisierung der Variablen............................................217

3.3.1 Terminologie zur Variablenoperationalisierung........................... 217

3.3.2 Variablen der Strategieberichterstattung ..................................... 218

3.3.3 Variablen der Bestimmungsfaktoren .......................................... 219

3.3.4 Variablen der Kapitalmarkteffekte ............................................... 223

3.3.5 Kontrollvariablen der Hypothesenprüfung .................................... 226

3.4 Methodische Grundlagen der Hypothesenprüfung ..................... 227

3.4.1 Auswahl von Verfahren zur Hypothesenprüfung .......................... 227

3.4.2 Anzuwendende Verfahren der Hypothesenprüfung ....................... 228

3.4.3 Formale Aspekte der Hypothesenprüfung................................... 240

4 Zusammenfassung des Untersuchungsmodells ...................................242

D Ergebnisse der Untersuchung der Strategieberichterstattung börsennotierter Unternehmen ..............................245

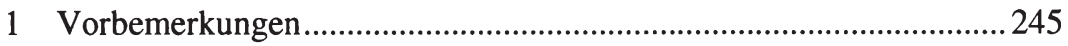

2 Deskriptive Auswertungen der Datenbasissiaber...97.8.3.631.7.5.150.3.. 246 
2.1 Deskriptive Auswertungen zu den Stichproben-Unternehmen ..246

2.1.1 Kategoriale Merkmale der Stichprobe. 246

2.1.2 Größenmerkmale und Bildung von Teil-Stichproben 248

2.1.3 Aussagefähigkeit der Stichprobe 251

2.2 Deskriptive Auswertungen zur Lageberichterstattung 253

2.3 Deskriptive Auswertungen zum Strategy Disclosure Index.......255

2.4 Qualität der Messung der Strategieberichterstattung..................258

2.4.1 Prüfung der Reliabilität des Strategy Disclosure Index .................. 258

2.4.2 Prüfung der Validität des Strategy Disclosure Index ..................... 261

3 Hypothesenprüfung zur Strategieberichterstattung ........................... 265

3.1 Unterschiedlichkeit der individuellen Berichtsniveaus ..............265

3.2 Zeitliche Dynamik der Strategieberichterstattung .......................266

4 Hypothesenprüfung zu den Bestimmungsfaktoren............................268

4.1 Untersuchung einzelner Bestimmungsfaktoren...........................268

4.1.1 Untersuchung makroökonomischer Bestimmungsfaktoren ............ 268

4.1.2 Untersuchung der Unternehmenscharakteristika..........................2 273

4.1.3 Untersuchung der finanziellen Faktoren ................................... 285

4.1.4 Untersuchung der Faktoren des Aktienkapitals.............................. 288

4.2 Untersuchung des Gesamtmodells der Bestimmungsfaktoren ... 295

4.2.1 Einleitende Anmerkungen zum Gesamtmodell .............................. 295

4.2.2 Berechnung des Gesamtmodells der Bestimmungsfaktoren ............ 296

4.3 Überblick über die Ergebnisse der Hypothesenprüfung.............. 300

5 Hypothesenprüfung zu den Kapitalmarkteffekten ..............................301

5.1 Methodische Vorbemerkung zu den Regressionsmodellen.........301

5.2 Untersuchung der einzelnen Kapitalmarkteffekte .......................303

5.2.1 Untersuchung der Markttransparenzeffekte .................................. 303

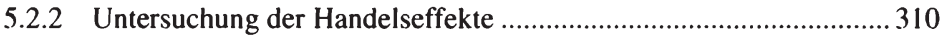

5.2.3 Untersuchung der Bewertungseffekte ………978.-3-631-75150-3.... 314 
5.3 Überblick über die Ergebnisse der Hypothesenprüfung.............. 324

5.4 Prüfung der Aussagefähigkeit der Regressionsmodelle .............. 325

5.4.1 Konformität mit zentralen Modellprämissen...................................... 325

5.4.2 Prüfung der Untersuchungsvariablen auf Endogenität....................... 326

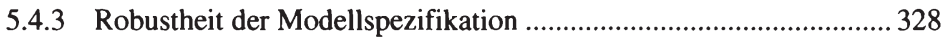

6 Erweiterung der Betrachtung um moderierende Effekte ..................... 330

E Schlussbetrachtung der Arbeit und Ausblick.......................336

1 Gang der Arbeit in der Retrospektive ................................................ 336

2 Synopsis der wesentlichen Erkenntnisse der Arbeit ............................ 337

2.1 Theoretischer Hintergrund der Strategieberichterstattung ......... 337

2.2 Empirische Untersuchung der Strategieberichterstattung .......... 339

3 Würdigung der wesentlichen Erkenntnisse der Arbeit und Anhaltspunkte für zukünftige Forschungsarbeiten ............................. 344

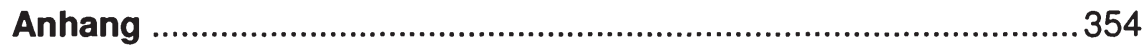

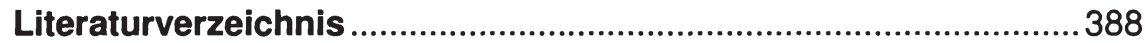




\section{Abbildungsverzeichnis}

Abbildung 1: Illustration des Aufbaus der Arbeit.............................................6

Abbildung 2: Selektion des relevanten Teilbereichs des Kapitalmarktes............ 8

Abbildung 3: Wertkonzeptionen im Überblick............................................... 17

Abbildung 4: Prozess des strategischen Managements ...................................51

Abbildung 5: Vorstellungsmodell zur Nützlichkeit von Strategieangaben ......65

Abbildung 6: Instrumente der externen Rechnungslegung im Zeitablauf........ 94

Abbildung 7: Übersicht über Teil-Berichte des Lageberichts nach HGB ........ 97

Abbildung 8: Einordnung des Value Reportings ............................................. 115

Abbildung 9: Verortung strategieorientierter Inhalte im Lagebericht ............. 134

Abbildung 10: Grobes Modell der Untersuchung............................................. 142

Abbildung 11: Erklärungsanspruch der Untersuchung..................................... 158

Abbildung 12: Detailliertes Modell der Untersuchung.................................... 159

Abbildung 13: Hypothesengerüst der Untersuchung ........................................ 187

Abbildung 14: Index-Pyramide der Deutschen Börse AG ............................... 189

Abbildung 15: Vorgehensweise der Stichprobenzusammenstellung................ 190

Abbildung 16: Prinzipieller Aufbau des Kriterienkataloges des SDIndex ....... 203

Abbildung 17: Mathematische Formeln zur Errechnung der SDScores........... 208

Abbildung 18: Logik des SDIndex bzw. SDScores und der Teil-Scores ......... 212

Abbildung 19: Phasenverschiebung in Bezug auf Kapitalmarkteffekte........... 214

Abbildung 20: Operationalisierung des Untersuchungsmodells..................... 217

Abbildung 21: Verfahren der Hypothesenprüfung je nach Skalenniveau ........ 228

Abbildung 22: Formale Darstellung der linearen Regressionsanalyse............. 231

Abbildung 23: Struktur der Darstellung der empirischen Ergebnisse .............. 245

Abbildung 24: Optionen der Einbindung von Kontrollvariablen ...................... 302

Abbildung 25: Prinzipdarstellung von Moderatoreffekteh - 978-3-631-75150-3 330 


\section{Tabellenverzeichnis}

Tabelle 1: Ausgewählte Arbeiten auf Basis von Disclosure Indizes..........201

Tabelle 2: $\quad$ Normativer Berichtskatalog der Untersuchung (Überblick) .... 204

Tabelle 3-1: Datenquellen der Untersuchung: Bestimmungsfaktoren........... 215

Tabelle 3-2: Datenquellen der Untersuchung: Kapitalmarkteffekte .............. 216

Tabelle 3-3: Datenquellen der Untersuchung: Strategieberichterstattung .... 216

Tabelle 4: Variablen der Strategieberichterstattung ...................................218

Tabelle 5: $\quad$ Variablen der Bestimmungsfaktoren (Teil 1)........................... 221

Tabelle 5: Variablen der Bestimmungsfaktoren (Teil 2) ...........................222

Tabelle 6: Variablen der Kapitalmarkteffekte .........................................225

Tabelle 7: $\quad$ Prämissen des linearen Regressionsmodells (Teil 1) ................ 234

Tabelle 7: $\quad$ Prämissen des linearen Regressionsmodells (Teil 2) ............... 235

Tabelle 8: $\quad$ Maße zur Prüfung der Regressionsfunktionen ......................... 239

Tabelle 9: $\quad$ Nomenklatur statistischer Signifikanzniveaus........................... 241

Tabelle 10: Zusammenfassender Untersuchungsplan................................... 243

Tabelle 11: Branchen- und Indexzugehörigkeit der Stichprobe ................... 247

Tabelle 12: Ausgewählte Größenmerkmale der Stichprobe .........................248

Tabelle 13: Bildung von Teil-Stichproben .................................................250

Tabelle 14: Aussagefähigkeit der quantitativen Struktur der Stichprobe.... 251

Tabelle 15: Aussagefähigkeit der qualitativen Struktur der Stichprobe...... 252

Tabelle 16: Umfang der Geschäfts- und Lageberichterstattung ................... 254

Tabelle 17: Messwerte des Strategy Disclosure Index (SDScores)............. 256

Tabelle 18: Prüfung der SDScores auf Normalverteilung ........................... 257

Tabelle 19: Reliabilität des Messinstruments SDIndex ...............................259

Tabelle 20: Korrelationsmatrix der SDScores und der Teil-Scores ............ 260

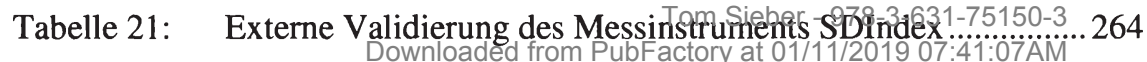


Tabelle 22: Faktorenanalyse der Messinstrumente der Strategieinhalte ..... 264

Tabelle 23: Streuungsanalyse der SDScores................................................265

Tabelle 24: Varianzanalyse der SDScores in Abhängigkeit der Zeit .......... 266

Tabelle 25: Einzelvergleiche der SDScores in Abhängigkeit der Zeit ........ 267

Tabelle 26: Bivariate Analyse der konjunkturellen Indikatoren................... 269

Tabelle 27: Bivariate Analyse der Kapitalmarktindikatoren ........................2270

Tabelle 28: Faktorenanalyse der Kapitalmarktindikatoren...........................2271

Tabelle 29: Partielles Regressionsmodell makroökonomischer Faktoren... 271

Tabelle 30: Bivariate Analyse der Größenindikatoren ................................. 273

Tabelle 31: Einfluss der Branchenausrichtung auf das Berichtsverhalten .. 274

Tabelle 32: Einfluss der Branchenzugehörigkeit auf d. Berichtsverhalten . 275

Tabelle 33: Einfluss des Unternehmensalters auf das Berichtsverhalten .... 277

Tabelle 34: Einfluss der Rechnungslegung auf das Berichtsverhalten........279

Tabelle 35: Einfluss der Person des CEO auf das Berichtsverhalten .......... 280

Tabelle 36: Einfluss von CEO-Wechseln auf das Berichtsverhalten .......... 282

Tabelle 37: Partielles Regressionsmodell d. Unternehmenscharakteristika 284

Tabelle 38: Bivariate Analyse der Indikatoren des Erfolges ........................ 285

Tabelle 39: Bivariate Analyse der Finanzierungsindikatoren...................... 286

Tabelle 40: Partielles Regressionsmodell der finanziellen Faktoren........... 287

Tabelle 41: Einfluss der Indexzugehörigkeit auf das Berichtsverhalten .....288

Tabelle 42: Einfluss einer Auslandsnotierung auf das Berichtsverhalten ...289

Tabelle 43: Bivariate Analyse der Indikatoren der Kapitalstruktur..............2290

Tabelle 44: Einfluss des Großaktionärstypus auf das Berichtsverhalten.....291

Tabelle 45: Einfluss von Insidertransaktionen auf das Berichtsverhalten... 292

Tabelle 46: Partielles Regressionsmodell der Faktoren d. Aktienkapitals .. 294

Tabelle 47-1: Regressionsmodell der quantitativen Bestimmungsfaktoren ... 297

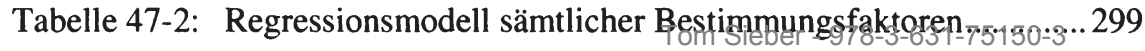


Tabelle 48: Ergebnisse der Hypothesenprüfung: Bestimmungsfaktoren .... 300

Tabelle 49: Regressionsmodell der Analystenanzahl ................................... 305

Tabelle 50: Regressionsmodell der Empfehlungs- u. Schätzungsvarianz ... 308

Tabelle 51: Regressionsmodell der Schätzgüte .......................................... 309

Tabelle 52: Regressionsmodell des Handelsvolumens ................................ 312

Tabelle 53: Regressionsmodell der Volatilität der Aktienrenditen .............. 313

Tabelle 54-1: Regressionsmodell der Eigenkapitalkosten: bivariat................. 315

Tabelle 54-2: Regressionsmodell der Eigenkapitalkosten: multivariat .......... 317

Tabelle 55: Regressionsmodell der Bid-Ask-Spreads ................................ 320

Tabelle 56: Regressionsmodell der Indikatoren der Marktbewertung ........ 323

Tabelle 57: Ergebnisse der Hypothesenprüfung: Kapitalmarkteffekte ....... 324

Tabelle 58: Prüfstatistiken der Regressionsmodelle..................................... 325

Tabelle 59: Prüfstatistiken des Residuentests auf Endogenität .................... 327

Tabelle 60: Ergebnisse alternativer Modellspezifikationen.......................... 329

Tabelle 61: Identifikation zu analysierender Moderatoreffekte ................... 331

Tabelle 62: Ergebnisse der Moderatoranalyse ............................................ 333 


\section{Abkürzungsverzeichnis}

Es werden nachfolgend diejenigen Abkürzungen aufgeführt, die im Rahmen der vorliegenden Arbeit wiederholt verwendet werden. Für weitere Abkürzungen, welche nicht wiederholt verwendet werden, findet sich die Erläuterung jeweils innerhalb des spezifischen Kontextes.

a.F. alte Fassung

Abb.

Abbildung

Abs.

Absatz

$\mathrm{AG} / \mathrm{SE}$

Aktiengesellschaft / Societas Europaea (europäische AG)

AICPA

American Institute of Certified Public Accountants

AktG

Aktiengesetz

allg.

allgemein

Art.

Artikel

ASE

American Stock Exchange

ANOVA

Analysis of Variance (Einfaktorielle Varianzanalyse)

BaFin

Bundesanstalt für Finanzdienstleistungsaufsicht

BFH

Bundesfinanzhof

BGBl. / RGBl. Bundesgesetzblatt / Reichsgesetzblatt

BilMoG

Bilanzrechtsmodernisierungsgesetz

BilReG

Bilanzrechtsreformgesetz

BilRiLiG

Bilanzrichtliniengesetz

BIP

Bruttoinlandsprodukt

BMJ

Bundesministerium der Justiz

BörsG

Börsengesetz

BörsO

Börsenordnung

BörsZulV

Börsenzulassungsverordnung

BSC

Balanced Scorecard 


$\begin{array}{ll}\text { Bsp. } & \text { Beispiel } \\ \text { bspw. } & \text { beispielsweise } \\ \text { BT } & \text { Deutscher Bundestag } \\ \text { bzgl. } & \text { bezüglich } \\ \text { bzw. } & \text { beziehungsweise } \\ \text { ca. } & \text { circa }\end{array}$

CEO Chief Executive Officer

cet. par. ceteris paribus

d.h. das heißt

Dax Dax 30; Auswahlindex der 30 größten (Marktkapitalisierung) und umsatzstärksten (Handelsumsatz) Unternehmen klassischer und technologieorientierter Branchen, die im Prime Standard der Dt. Börse notiert sind

Dax $100 \quad$ Gesamtheit der 30 Dax- und ehemals 70 MDax-Unternehmen (Dax 100 abgelöst durch HDax im Zuge der Reduktion des MDax von 70 auf 50 Werte per 24.03.2003)

DCGK Deutscher Corporate Governance Kodex

ders. derselbe

dies. dieselbe

Dow Jones Dow Jones Industrial Average; Auswahlindex der 30 größten an der NYSE notierten US-amerikanischen Unternehmen

DRS Deutscher Rechnungslegungs Standard

DRSC Deutsches Rechnungslegungs Standard Committee

DSR Deutscher Standardisierungsrat

dt. deutsch

E-DRS 20 Entwurf eines Deutschen Rechnungslegungs Standards Nr. 20 (später veröffentlicht als DRS 15)

EBIT(DA) Ergebnis vor Zinsen und Steuern (sowie Abschreibungen)

EG / EU Europäische Gemeinschaft / Europäische Union

EGHGB Einführungsgesetz zum Handelsgesetzbuch

EPS 
et al. et alii

etc. et cetera

EUR Euro, Gemeinschaftswährung der Europäischen Union

EuroStoxx Dow Jones Euro Stoxx 50; Auswahlindex der 50 größten börsennotierten Unternehmen innerhalb der Mitgliedsstaaten der Europäischen Währungsunion (Eurozone)

EWG Europäische Wirtschaftsgemeinschaft

f. / ff. folgende / fortfolgende

FASB Financial Accounting Standards Board

Fn. Fußnote

FuE Forschung und Entwicklung

FWB Frankfurter Wertpapierbörse

gem. gemäß

ggf. gegebenenfalls

GoB Grundsätze ordnungsgemäßer Buchführung

grdl. / grds. grundlegend / grundsätzlich

GuV Gewinn- und Verlustrechnung (Erfolgsrechnung)

$\mathrm{H} \quad$ Hypothese

h.M. herrschende Meinung

HDax Gesamtheit der 110 in Dax, MDax, TecDax notierten Werte

HGB Handelsgesetzbuch

Hrsg. Herausgeber

I/B/E/S The Institutional Brokers Estimate System;

Datenbank mit Informationen zu Analystenschätzungen

i.d.R. in der Regel

i.e.S. / i.w.S. im engeren Sinne / im weiteren Sinne

i.S.v. im Sinne von

i.V.m. in Verbindung mit

i.W. im Wesentlichen 
IAS

IASB / IASC

IDW

IFRS

inkl.

insb.

insg.

Jg.

KapCoRiLiG

$\mathrm{KGaA}$

KonTraG

LSE

lt.

m.w.N.

MD\&A

MDax

mind.

Mio. / Mrd.

n.F.

NIVRA

$\mathrm{Nr}$.

NYSE

OECD

o.W.

p.a.

PublG

RefE-BilReG
International Accounting Standard

International Accounting Standards Board / Committee

Institut der Wirtschaftsprüfer in Deutschland e.V.

International Financial Reporting Standard

inklusive

insbesondere

insgesamt

Jahrgang

Kapitalgesellschaften- und Co.-Richtliniengesetz

Kommanditgesellschaft auf Aktien

Gesetz für Kontrolle u. Transparenz im Unternehmensbereich London Stock Exchange

laut

mit weiteren Nachweisen

Management Discussion and Analysis

Auswahlindex der 50 auf die Werte des Dax 30 folgenden Unternehmen klassischer Branchen

mindestens

Millionen / Milliarden

neue Fassung

Königlich Niederländisches Institut der Wirtschaftsprüfer

Nummer

New York Stock Exchange

Organisation für wirtschaftliche Zusammenarbeit

und Entwicklung

ohne Wertung

per annum

Publizitätsgesetz

Referentenentwurf zum Bilanzrechtsreformgesetz (BilReG)

Tom Sieber - 978-3-631-75150-3 
RegE-BilReG Regierungsentwurf zum Bilanzrechtsreformgesetz (BilReG)

Rz. / Rn.

Randziffer / Randnummer

S.

Seite(n) bzw. Satz (bei Angabe von Gesetzesquellen)

SDax

Auswahlindex der 50 größten auf die Werte des MDax folgenden Unternehmen klassischer Branchen

SDI / SDIndex Strategy Disclosure Index, Messinstrument zur Erfassung der strategieorientierten Berichterstattung im Lagebericht

SDS / SDScores ermittelte Punktwerte des Messinstruments SDIndex

SEC United States Securities and Exchange Commission

SFAC Statement of Financial Accounting Concepts des FASB

sog. So genannt

Sp. Spalte

Tab. Tabelle

TecDax Auswahlindex der 30 größten auf die Werte des Dax 30 folgenden Unternehmen technologieorientierter Branchen

TransPuG Transparenz- und Publizitätsgesetz

Tz. Textziffer

u.a. unter anderem

u.U. unter Umständen

US / USA United States / United States of America

US-GAAP United States Generally Accepted Accounting Principles

v.a. vor allem

vgl. vergleiche

vs. versus

WpHG Wertpapierhandelsgesetz

Xetra Exchange Electronic Trading, elektronisches Handelssystem der Deutschen Börse AG

z.B. zum Beispiel

z.T. zum Teil 


\section{Symbolverzeichnis}

Es werden nachfolgend diejenigen Symbole aufgeführt, die im Rahmen der vorliegenden Arbeit wiederholt verwendet werden.

$\alpha$

Alpha, Symbol der Irrtumswahrscheinlichkeit

$\beta$

Beta, Symbol des standardisierten Regressionskoeffizienten

d

Wert des Tests auf Autokorrelation nach Durbin-Watson

df

Freiheitsgrade

$\mathrm{F}$

Wert der F-Statistik

[Faktor] Variable ist ein Faktor, ermittelt auf Basis einer Faktorenanalyse

Ln Logarithmus naturalis (natürlicher Logarithmus)

$\mu \quad$ My, Symbol des Mittelwerts / arithmetischen Mittels

n Anzahl Merkmalsträger / Beobachtungen in der Stichprobe

p p-Wert bzw. Angabe des Signifikanzniveaus

$\mathrm{r} \quad$ Korrelationskoeffizient (nach Pearson oder Spearman)

$\mathbf{R}^{2} \quad$ Bestimmtheitsmaß der linearen Regression

$\mathrm{R}^{2}$ adj. korrigiertes Bestimmtheitsmaß der linearen Regression

$\sigma$ bzw. $\sigma^{2}$ Sigma, Symbol der Standardabweichung bzw. der Varianz

$\mathrm{t}$

Wert der t-Statistik bzw. Symbol für zeitliche Periodenangaben

$\mathrm{T}$

Toleranzwert (Prüfung auf Multikollinearität)

VIF Variance Inflation Factor (Prüfung auf Multikollinearität)

$\chi^{2}$

Chi, Symbol der Chi-Quadrat-Statistik, verwendet als $\mathrm{Chi}^{2}$ 


\section{A Einführung in die Thematik der Arbeit}

\section{Grundsätzliche Überlegungen zur Ausgangssituation}

Die traditionelle Betriebswirtschaftslehre und - in der Folge - auch die Unternehmenspraxis in Deutschland haben sich in den letzten 30 Jahren grundlegend gewandelt und sich zu einer wertorientierten Managementlehre bzw. -disziplin entwickelt. Auslöser dieses Wandels war eine zunächst v.a. in den USA geführte Diskussion über die Funktion des Unternehmens als Instrument zur Erreichung von Zielen verschiedener Anspruchsgruppen. In jenem Zusammenhang gelangte der Unternehmenswert, als maßgebliche Orientierungsgröße unternehmerischen Handels, in den Mittelpunkt der Betrachtung. ' In diesem wurde diejenige Größe erkannt, die die Interessen der unterschiedlichen Anspruchsgruppen eines Unternehmens grds. vereinen könnte: So wird der Erhalt eines Unternehmens bzw. die nachhaltige Steigerung des Unternehmenswertes i.d.R. als Voraussetzung dafür gesehen, dass die Individualziele der Gruppen überhaupt erfüllt werden können. ${ }^{2}$

Zur Umsetzung einer Philosophie der Orientierung am Wert des Unternehmens wurden verschiedene wertorientierte Steuerungskonzepte vorgestellt. ${ }^{3}$ Im Kern unterscheiden sich diese jedoch nur in der Methodik der Errechnung des Unternehmenswertes. ${ }^{4}$ Gemein ist den Konzepten hingegen, dass sie es den Managern ermöglichen, den Unternehmenswert als übergeordnete Zielgröße allen Handels zu operationalisieren und in der täglichen Steuerung sichtbar bzw. anwendbar zu machen. Wertorientierte Steuerungskonzepte haben in der Folge rasch Einzug in

1 Vgl. Rappaport (1986), S. 60ff. Rappaport leistet insofern Pionierarbeit, da er als erster Autor eine Schaffung von Unternehmenswert bzw. eine Wertsteigerung in das Zentrum der Bemühungen der Unternehmensleitung rückt.

2 Vgl. hier grdl. Hahn/Hungenberg (2001), S. 151, 191ff. Der Unternehmenswert als Zielgröße wird im angelsächsischen Sprachraum als ,Shareholder Value' bezeichnet, Wertorientierung wird daher im Deutschen als ,Shareholder Value-Orientierung ' bezeichnet. Jener Begriff hat intensive Beachtung in der allg. Öffentlichkeit gefunden und wird z.T. auch kritisch als Sammelbegriff für Fehlentwicklungen marktwirtschaftlicher Systeme verwendet. Vgl. hierzu bspw. die umfassende Arbeit von Aglietta/Rebérioux (2005).

Anspruchsgruppen eines Unternehmens sind i.W. die Kunden, Mitarbeiter, Lieferanten, Aktionäre sowie der Staat, vgl. für einen Überblick Hahn/Hungenberg (2001), S. 12.

3 Vgl. insb. die Konzepte von Copeland et al. (2002), Lewis (1995) sowie Stewart (1991), für einen Überblick Hahn/Hungenberg (2001), S. 192ff. sowie v.a. S. $217 \mathrm{f}$.

$4 \quad$ Vgl. einführend bspw. Crasselt et al. (2000) oder auch Böcking/Nowak (1999). 
die Managementpraxis erhalten - auch deutsche Unternehmen erkannten Logik und Charme der Wertorientierung und implementierten entsprechende Systeme. ${ }^{5}$ Folgerichtig gewinnt - vor dem Hintergrund des Postulats einer konsequenten Ausrichtung der Unternehmensführung auf Wertsteigerungen - die Perspektive des Kapitalmarktes an Bedeutung, da dieser den Unternehmenswert realiter abbildet. In der Idealvorstellung würde jede Aktion des Managements, die Einfluss auf den Unternehmenswert hat, unmittelbar vom Kapitalmarkt reflektiert und die Abschätzung des Marktwertes entsprechend angepasst. Der Kapitalmarkt besäße in diesem Modell stets vollkommene sowie unmittelbare Informationen über alle Projekte der Unternehmensleitung bzw. Transparenz über Ausmaß und zeitliche Verteilung damit einhergehender Konsequenzen für den Unternehmenswert. ${ }^{6}$

Die Realität ist gleichwohl eine andere: Akteure am Kapitalmarkt werden kaum in der Lage sein, alle Informationen zeitnah zu verarbeiten und in der Marktbewertung zu reflektieren. Aber selbst wenn die geforderte Verarbeitungs- und Bewertungsleistung vollbracht würde, hätten die Akteure $^{7}$ in der Realität stets nur zu einem Teil der insg. vorhandenen Informationen Zugang. Das Geschehen am Kapitalmarkt ist demzufolge gekennzeichnet von sog. Informationsasymmetrien. Das Management eines Unternehmens hat über jede Information, die es erhält, die Entscheidung zu treffen, ob diese veröffentlicht wird oder nicht. Es ist vorstellbar, dass das Management aus der Vielzahl von Informationen diverse Sachverhalte nicht öffentlich kommuniziert, die Begründungen mögen vielfältig sein: So kann es sein, dass die Informationen als nicht relevant eingestuft werden oder das Management allein von ihnen profitieren will. ${ }^{8}$ Im Endergebnis erhalten die

5 Ein früher Einsatz erfolgte bei der Siemens AG, vgl. Neubürger (2000); Neubürger/Sen (2001). Zur Verbreitung jener Konzepte Anfang der 2000er Jahre Pellens et al. (2000a). Dies entspricht der sog. starken Form der Informationseffizienz der Kapitalmärkte, vgl. grdl. Fama (1970), in der alle verfügbaren Informationen in der Bewertung reflektiert sind. Fama selbst nennt dies einen theoretischen ,Benchmark', vgl. ebenda, S. 415. Jener Begriff der ,Akteure“ wird nicht genauer spezifiziert, er umfasst hier grds. die Gesamtheit der Kapitalmarktteilnehmer, also (private) Investoren, Analysten, Händler etc. Vgl. bereits Fama (1970), S. 409: ,specialists on the NYSE apparently use their monopolistic access to information [...] to generate monopoly profits." Scholes (1970), S. 10f. weist darauf hin, dass v.a. die Manager monopolistischen Zugang zu Informationen über ihr Unternehmen haben. Darüber hinaus wäre aber ebenfalls denkbar, dass die Manager selbst nicht immer vollständige Information über alle wertrelevanten Aspekte besitzen.

Tom Sieber - 978-3-631-75150-3 
Kapitalmärkte also zumeist keine ausreichenden Informationen über alle wertrelevanten Aspekte des Unternehmensgeschehens und können daher den tatsächlichen Unternehmenswert auch kaum korrekt in der Bewertung widerspiegeln. ${ }^{9}$

Es scheint insofern folgerichtig, die klassische Perspektive der Wertorientierung zu erweitern: Wertorientiert führende Manager können sich nicht auf die interne Wertsteigerung beschränken und gelegentlich extern, gegenüber den Investoren am Kapitalmarkt eine umfassende Ausrichtung auf den ,Shareholder Value“ vermelden. ${ }^{10}$ Für faktische Wertsteigerung ist es gleichfalls erforderlich, Investoren bewertungsrelevante Informationen zur Verfügung zu stellen - dann erst könnte sich eine durch realisierte wertsteigernde Maßnahmen im Unternehmen gerechtfertigte Bewertungsveränderung am Kapitalmarkt überhaupt einstellen.

Dem Problemkreis der Bereitstellung wertrelevanter Informationen für Akteure am Kapitalmarkt soll sich die vorliegende Arbeit vertieft widmen.

\section{Abgrenzung des Bearbeitungsfeldes}

Im Hinblick auf das übergeordnete Arbeitsinteresse, die Bereitstellung von bewertungsrelevanten Unternehmensinformationen, ist das konkrete Bearbeitungsfeld sinnvoll abzustecken, um in einem vertretbaren Rahmen aussagekräftige Erkenntnisse hervorbringen zu können.

Zunächst soll eine Einschränkung der betrachteten Unternehmensinformationen dahingehend erfolgen, dass ausschließlich strategieorientierte Informationen Berücksichtigung finden: Es wäre zu unterstellen, dass die Strategie - und in der Folge Informationen über strategieorientierte Sachverhalte - aufgrund ihres inhärenten Bezuges zur langfristigen Ausrichtung und zur Entwicklung des Unternehmens eine besondere Relevanz für die Investoren am Kapitalmarkt besitzt. Das Management definiert im Rahmen der strategischen Planung die Ziele und

9 Dieser tatsächliche Unternehmenswert sei als theoretischer Bezugspunkt verstanden. Er würde sich einstellen, falls die starke Form der Informationseffizienz Realität wäre, vgl. nochmals Fama (1970), S. 409ff.

10 Vgl. Jörg et al. (2004) mit dem interessanten empirischen Beleg, dass der, Shareholder Value' meist erst dann als explizites Ziel des Managements genannt bzw. in der Kapitalmarktkommunikation verwendet wird, wenn zuvor die Marktbewertung gesunken ist. 
Prioritäten für die zukünftige Entwicklung des Unternehmens und trifft insofern implizit auch Entscheidungen über zukünftige Erfolgspotenziale sowie Periodenerfolge, welche wiederum die den Investoren zufließenden Zahlungsströme determinieren. Wird angenommen, dass diese zukünftigen Zahlungsströme für eine Bewertung am Kapitalmarkt Relevanz besitzen, erscheint es auf den ersten Blick einleuchtend, der Strategie hohen Stellenwert in der Betrachtung einzuräumen.

Die zweite Dimension, in der das Untersuchungsfeld eingegrenzt werden soll, ist das Medium der Bereitstellung strategieorientierter Informationen. Es werden mit der vorliegenden Arbeit ausschließlich solche Informationen berücksichtigt, die innerhalb des jährlichen Geschäftsberichts bereitgestellt werden. In diesem Kontext spielt die in den $\S \S 289$ bzw. 315 HGB normierte, verpflichtende Lageberichterstattung eine zentrale Rolle: Die Lageberichterstattung ist ein seit Jahrzehnten etablierter Baustein der externen Rechnungslegung in Deutschland und somit nicht zuletzt auch ein zentraler Bestandteil in der Kommunikation kapitalmarktorientierter Unternehmen gegenüber Investoren auf nationalen sowie internationalen Kapitalmärkten. Darüber hinaus tritt jener Lagebericht als ein flexibel zu verwendendes Instrument auf, in dem das Management eines Unternehmens „frei von den Fesseln der GoB“"11 einen qualitativ-verbalen Bericht zur aktuellen Lage und künftig erwarteten bzw. angestrebten Entwicklung abzugeben hat. ${ }^{12}$

Unter Berücksichtigung dieser zwei Dimensionen kann als Ziel der vorliegenden Arbeit folglich festgehalten werden, die strategieorientierte Berichterstattung im Lagebericht deutscher börsennotierter Unternehmen theoretisch und empirisch zu betrachten. ${ }^{13}$ Um ein möglichst vollständiges Bild der Thematik zu erarbeiten, sind verschiedene inhaltliche Aspekte zu beleuchten, die nachfolgend dargestellt werden, um den Aufbau der weiteren Ausführungen zu skizzieren.

11 Ballwieser (1997a), S. 155, ähnlich auch Baetge et al. (2009b), S. 727.

12 Dies entspricht den Anforderungen der $\S 289$ bzw. 315 HGB, vgl. ebenda.

13 Das formulierte Ziel macht deutlich, dass neben den beiden genannten, eher inhaltlichen Dimensionen der Abgrenzung zwei weitere Festlegungen getroffen wurden, die jedoch eher technischer Art sind: Einerseits wird auf kapitalmarktorientierte, d.h. primär börsennotierte Unternehmen abgestellt, welche i.d.R. in der Rechtsform der Aktiengesellschaft (AG) oder z.T. auch in den Rechtsformen der KGaA und der SE bestehen. Weiterhin ist, aufgrund des gewählten Mediums der Bereitstellung strategieorientierter Informationen, des HGB-Lageberichts, auf deutsche Unternehmen zu fokussieren; vgl. Abschnitt B 3.1. 


\section{Aufbau der weiteren Ausführungen}

Wie ausgeführt, lässt sich das genannte Untersuchungsinteresse zunächst in eine theoretische und eine empirische Betrachtung aufteilen. Diese Trennung spiegelt sich auch im Aufbau der Arbeit, den Abb. 1 illustriert: Während der Hauptteil B zur Aufgabe hat, die theoretischen Grundlagen zu legen, dienen die Hauptteile C und D der Ausgestaltung und Durchführung einer empirischen Untersuchung.

Im Hinblick auf die erforderlichen theoretischen Grundlagen kann in einfacher Herangehensweise die zuvor formulierte Zielsetzung der vorliegenden Arbeit in ihre drei Kern-Bestandteile - Kapitalmarkt, Strategie sowie Rechnungslegung zerlegt werden, um den Aufbau der theoretischen Ausführungen vorzustellen:

Im Anschluss an diesen Einführungsteil wird deshalb zu Beginn von Hauptteil B der Kapitalmarkt als (fiktiver) Ort des Zusammentreffens von Kapitalangebot und -nachfrage charakterisiert. Zu zeigen ist, welchen Stellenwert Informationen am Kapitalmarkt besitzen bzw. welche Anforderungen an diese gestellt werden. Anschließend ist das strategische Management als Gestaltungsprozess der zukünftigen Unternehmensentwicklung darzustellen und weiterhin die Bedeutung strategieorientierter Informationen für den Kapitalmarkt herauszuarbeiten.

Die Rechnungslegung, als zentrales Instrument der Berichterstattung gegenüber dem Kapitalmarkt, ist Gegenstand von Abschnitt B 3. Nach einer Übersicht über Vorschriften zur externen Rechnungslegung der kapitalmarktorientierten Unternehmen ist der Lagebericht als das qualitativ-verbale Element der Rechnungslegung zu fokussieren und seine informationelle Leistungsfähigkeit aufzuzeigen.

Da sich in den vergangenen Jahren vermehrt die Ansicht verbreitet hat, dass die Rechnungslegung - trotz ihrer Bedeutung dank gesetzlicher Normierung - den Informationsbedarf der Kapitalmarktakteure nicht vollumfänglich befriedigt, ist die (freiwillige) Erweiterung der Berichtsinhalte der Rechnungslegung um wertorientierte Inhalte unter dem Stichwort ,Value Reporting ' diskutiert worden. Ein wesentlicher Aspekt ist dabei stets auch die Bereitstellung strategieorientierter Berichtsinhalte innerhalb der Rechnungslegung. Nach einer Darstellung des ,Value Reportings“ in B 4 kann schließlich der Lagebericht als das Kernmedium einer ,Strategieberichterstattung ' abgeleitet und insofern das theoretische Fundament der vorliegenden Arbeit komplettiert werden. Sieber - 978-3-631-75150-3 


\section{Investoren}

\section{Unternehmen}

B 1 - Kapitalmarkt als Ort des Zusammentreffens von Investoren und Unternehmen

\section{B Theoretische \\ Grundlagen}

B 2 - Strategisches

Management zur

Cestaltung der Unter-

nehmensentwicklung

B 3 - Rechnungslegung als Kern der Berichterstattung

B 4 - Strategieinhalte in der externen Rechnungslegung

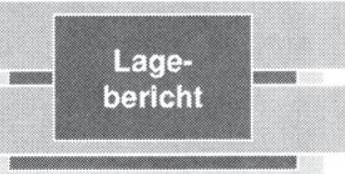

Aufbau einer Untersuchung der strategieorientierten Berichterstattung im Lagebericht

\section{Empirische}

Untersuchung

Ergebnisse der empirischen Untersuchung zur Strategieberichterstattung im Lagebericht

Abbildung 1: Illustration des Aufbaus der Arbeit ${ }^{14}$

Aufbauend auf diesem Fundament erscheint die Durchführung einer Standortbestimmung zur Strategieberichterstattung deutscher börsennotierter Unternehmen als konsequenter zweiter Schritt, der Gegenstand der Hauptteile C und D dieser Arbeit ist. Die folgenden vier Forschungsfragen sollen die Untersuchung leiten:

Zunächst ist zu beantworten, ob sich (1) ein Messinstrument konstruieren lässt, mit dem strategieorientierte Berichterstattung im Lagebericht gemessen werden kann. Dieses könnte nachfolgend verwendet werden, um (2) die Strategieberichterstattung im Status quo wie auch im Zeitablauf zu messen. Im Anschluss daran drängt sich eine ,kausale' Blickrichtung auf: Interessant wäre die Beantwortung der Frage, ob sich (3) Faktoren identifizieren lassen, die das Berichterstattungsverhalten systematisch determinieren. Zudem scheint es bedeutsam zu erfahren, ob und inwieweit (4) der Kapitalmarkt auf strategieorientierte Angaben reagiert.

Wie noch zu zeigen sein wird, ist diese Arbeit in der Lage, durch Beantwortung dieser Fragen zur Schließung einer bestehenden Forschungslücke beizutragen.

14 Quelle: eigene Darstellung; ohne Hauptteile A (Einführung), E (Schlussbetrachtung).

Tom Sieber - 978-3-631-75150-3 


\section{B Berichterstattung über strategieorientierte Informationen kapitalmarktorientierter Unternehmen}

1 Bedeutung von Informationen im Kontext des Kapitalmarktes

\subsection{Kapitalmarkt als Ort des Zusammentreffens von Investoren und Kapitalnachfragern}

\subsubsection{Organisierter Kapitalmarkt als Bezugsrahmen}

In eher allgemeiner Definition umfasst der Begriff des Kapitalmarktes grds. die Gesamtheit aller Möglichkeiten des direkten finanziellen Austausches zwischen Überschuss- bzw. Defiziteinheiten. ${ }^{15}$ Diese Gesamtheit zerfällt bei detaillierterer Betrachtung, wie Abb. 2 zeigt, in zwei wesentliche Teil-Märkte, von denen insb. der sog. organisierte Kapitalmarkt - der grds. auch als Börse bezeichnet werden kann - für die Ausführungen in der vorliegenden Arbeit von Bedeutung ist:

Dieser Kapitalmarkt i.e.S. beschreibt sodann einen (fiktiven) Ort, der durch das direkte Zusammentreffen von Angebot an sowie Nachfrage nach verschiedenen Arten von Finanzierungstiteln gekennzeichnet ist. ${ }^{16}$ Diese Finanzierungstitel, die den Kapitalmarkt i.e.S. begründen, repräsentieren „Bündel aus Ansprüchen, die Unternehmen denjenigen Wirtschaftssubjekten einräumen, die ihnen Geld zu Investitionszwecken im weitesten Sinne überlassen“17.

Bei noch genauerer Betrachtung kann der Kapitalmarkt i.e.S. außerdem nach der Art der angebotenen und nachgefragten Titel in einen Markt für Schuld- sowie einen Markt für Beteiligungstitel differenziert werden, weiterhin wäre die Unterteilung in einen Primär- und einen Sekundärmarkt möglich - je nachdem, ob es sich um eine Emission neuer oder den Handel bereits emittierter Titel handelt. ${ }^{18}$ Für das hier zugrunde gelegte Begriffsverständnis des Kapitalmarktes sind diese

15 Vgl. dazu Brealey/Myers (2000), S. 61f. bzw. S. 187ff., auch Bessler (1989), S. 19ff.

16 Vgl. Schneider (1981), S. 20; Perridon/Steiner (2003), S. 158ff. Der Kapitalmarkt kann nicht als real existierender Marktplatz verstanden werden, es handelt sich eher um einen Sammelbegriff für zahlreiche (zumeist nicht räumlich präsente) Einzelmärkte, auf denen verschiedene Arten von Finanzierungstiteln gehandelt werden. Loistl (1999), S. 3. Ähnlich Franke/Hax (2004), S. 30.

18 Vgl. im Detail Brealey/Myers (2000), S. 9ff., Franke/Hax (2004), S. 30ff. sowie S. 53ff. 
Differenzierungen jedoch nicht von übergeordneter Bedeutung - es wird grds. davon ausgegangen, dass die als Defiziteinheiten charakterisierten Unternehmen zur Finanzierung der betrieblichen Zwecke und zur Realisierung ihrer Zukunftspläne finanzielle Mittel benötigen, die sie unter Inanspruchnahme der Börse aufnehmen können. ${ }^{19}$ Unabhängig davon, ob Kapitalnachfrager eine Aufnahme von Eigen- oder Fremdkapital am Kapitalmarkt vornehmen, sind stets die als Überschusseinheiten benannten Investoren zu adressieren und - als notwendige Voraussetzung - von der Sinnhaftigkeit einer Bereitstellung finanzieller Mittel bzw. dem Erwerb der als Wertpapiere verbrieften Finanzierungstitel zu überzeugen. ${ }^{20}$

Den relevanten Teilbereich des Kapitalmarktes i.e.S. innerhalb des gesamthaften Systems der Finanzmärkte zeigt Abb. 2 im Überblick.

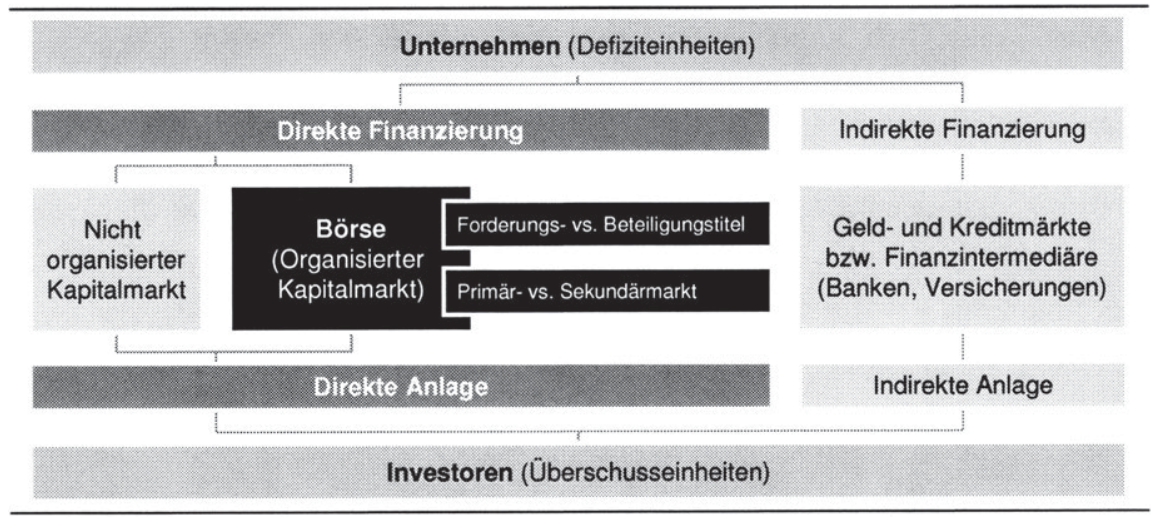

Abbildung 2: Selektion des relevanten Teilbereichs des Kapitalmarktes ${ }^{21}$

Vgl. Franke/Hax (2004), S. 30.

20 Vgl. Franke/Hax (2004), S. 30ff. Strenggenommen ist hier eine Emission neuer Wertpapiere und damit die Funktion des Primärmarktes angesprochen, da nur bei Emission von Titeln den Unternehmen finanzielle Mittel zufließen und nicht dann, wenn die Investoren untereinander die Wertpapiere am Sekundärmarkt handeln. Dies kann aber vernachlässigt werden, da ein Unternehmen als regelmäßiger Kapitalnachfrager auch seine Wahrnehmung am Sekundärmarkt zu pflegen hat, um im Bedarfsfall über die Möglichkeit der Inanspruchnahme des Primärmarktes zu verfügen, vgl. Haubrok/Duda (2001).

21 Quelle: eigene Darstellung in Anlehnung an Bessler (1989), S. 20. Angemerkt sei, dass neben Unternehmen grds. auch andere Institutionen als Defiziteinheiten vorstellbar sind, z.B. staatliche Institutionen. Der Markt für Eigenkapital- bzw. Beteiligungstitel wird jedoch i.d.R. nur von Unternehmen beansprucht. Zudem könnten Unternehmen grds. auch als Investoren am Markt auftreten, davon wird hier allerdings abstrahiert. 


\subsubsection{Charakterisierung der handelnden Akteure am Kapitalmarkt}

Im Rahmen der vorherigen Ausführungen ist bereits deutlich geworden, dass der Kapitalmarkt nicht nur durch das Zusammentreffen des Angebots an bzw. Nachfrage nach verschiedenen Arten von Finanzierungstiteln, sondern auch durch die damit verbundenen Akteure charakterisiert wird: Unternehmen als Kapitalnachfrager sowie private bzw. institutionelle Investoren als Kapitalanbieter. ${ }^{22}$ Durch das Zusammentreffen am Kapitalmarkt erhalten beide Parteien die Möglichkeit, durch den Abschluss von Transaktionen, deren Gegenstand die angesprochenen Finanzierungstitel sind, ihre jeweiligen Zielvorstellungen zu realisieren.

Beide Parteien und ihre jeweiligen mit einem Engagement am Kapitalmarkt verfolgten Zielvorstellungen seien nachfolgend charakterisiert:

\section{(a) Unternehmen als Kapitalnachfrager}

Um die Rolle von Unternehmen am Kapitalmarkt charakterisieren zu können, ist der Vollständigkeit halber zunächst auf das Konstrukt Unternehmen einzugehen, da eine grdl. Charakteristik auch für den weiteren Verlauf der vorliegenden Arbeit hilfreich scheint:

Die Existenz von Unternehmen zu begründen, gelingt in der traditionellen, neoklassischen Mikroökonomik nicht. ${ }^{23}$ In jenem Modell finden alle Koordinationsleistungen grds. auf Märkten statt, weitere Gestaltungsinstitutionen sind für eine Erreichung des angestrebten Gleichgewichts unbedeutsam. Unternehmen, deren Existenz als exogene Prämisse vorgegeben ist, üben demzufolge keinen Einfluss auf die Marktkoordination aus. Sie werden als monolithische Einheiten gesehen, deren Zweck in schlichter Transformation von Produktionsfaktoren in definierte

22 Es sei der Vollständigkeit halber explizit angenommen, dass in dem zugrunde gelegten Kapitalmarktverständnis weder auf der Angebotsseite noch auf der Nachfrageseite Beschränkungen möglich sind, d.h. es wird unterstellt, dass sowohl hinreichend zahlreiche Kapitalanbieter als auch -nachfrager vorhanden sind und der Einfluss des Einzelnen insofern als verschwindend gering zu bezeichnen ist.

Die zentralen Prämissen sind zu skizzieren: vollständige Information bzw. Transparenz, gleichmäßige Verteilung von Informationen und Rationalität der Akteure (Ideal ,Homo oeconomicus'), zudem Präferenzlosigkeit der Akteure, jene wählen stets die Alternative mit dem größten Nutzen; keine Beschränkungen hinsichtlich der Informationsaufnahme und -verarbeitung, Preismechanismus als einziger Koordinationsmechanismus sowie ein simultanes Gleichgewicht aller Märkte, vgl. als Überblick z.B. Demmler (2000), S. 9ff.

Tom Sieber - 978-3-631-75150-3 
Endprodukte auf der Basis gegebener Produktionsfunktion besteht. Folgerichtig ignoriert die Neoklassik die Frage der Existenz von Unternehmen auch weitestgehend, diese ,werden als folkloristische Besonderheiten gesehen, für deren Erklärung der Ökonom sich unzuständig erklärt““24.

Ausgehend von diesen Unzulänglichkeiten der Neoklassik befasst sich die sog. ,Neue Institutionenökonomik‘ explizit mit einer Erklärung der Existenz von Institutionen sowie Konsequenzen institutioneller Arrangements. ${ }^{25}$ Hierzu werden wesentliche Annahmen der neoklassischen Theorie modifiziert, in erster Linie unter Aufrechterhaltung des methodologischen Individualismus - die Annahmen bzgl. der Wirtschaftssubjekte. ${ }^{26}$ Das Ideal eines ,Homo oeconomicus “ wird vor dem Hintergrund der Berücksichtigung von Transaktionskosten aufgegeben, die durch Verweis auf die Notwendigkeit von Austauschprozessen fundiert werden: Austausch von Verfügungsrechten sowie Gütern zwischen Wirtschaftssubjekten induziert in dieser Sicht stets Transaktionskosten. ${ }^{27}$ Jene werden demzufolge als „costs of running the economic system“ ${ }^{28}$ bezeichnet. Ebenfalls aufgegeben wird die Annahme vollständiger sowie gleichverteilter Information aller Wirtschaftssubjekte, stattdessen geht die Neue Institutionenökonomie ausdrücklich von der asymmetrischen Verteilung von Information aus, die jedoch durch Beschaffung und Verarbeitung von Informationen reduziert werden kann - was allerdings mit Kosten verbunden ist, so dass Kosten-Nutzen-Abwägungen erforderlich sind. ${ }^{29}$

24

Hax (1991), S. 54.

Vgl. grdl. Coase (1937); Richter/Bindseil (1995). Ausgangspunkt dieser ist, dass marktwirtschaftliche Ordnungen durch die Existenz von Unternehmen geprägt sind - die Erklärung der Existenz ist daher das erklärte Ziel der Neuen Institutionenökonomik.

Vgl. Richter/Bindseil (1995), S. 132f. Der methodologische Individualismus sieht Wirtschaftssubjekte und ihre Ziele als maßgeblich für ökonomische Entscheidungen an. Ein Kollektivismus i.S.v. Staat bzw. Gesellschaft wird abgelehnt, nur Verbindungen von Individuen zu Institutionen werden berücksichtigt. Vgl. auch Langerfeldt (2003), S. 56.

Vgl. Löchel (1995), S. 20f.; Voigt (2002), S. 30f. Die Kritik am ,Homo oeconomicus“ wird z.T. relativiert, bspw. Bretzke (1983), S. 42 preist diesen als normatives Idealbild. Transaktionskosten entstehen sowohl im Rahmen marktlicher Koordination als auch bei institutionsinterner Koordination. Beispiele sind Such- / Informationskosten (Vertragsanbahnung), Verhandlungs- / Entscheidungskosten (Vertragsabschluss), Überwachungs/ Durchsetzungskosten (Vertragsdurchsetzung), grdl. Richter/Furubotn (1996), S. 58ff.

Arrow (1983), S. 134.

Vgl. Hax (1991), S. 56. 
Als Konsequenz wird Information niemals gleichmäßig verteilt sein, schon deshalb, da die Fähigkeit zur Informationsverarbeitung annahmegemäß beschränkt ist. ${ }^{30}$ In einem derartigen Kontext, beschrieben durch unvollständige Information bzw. begrenzte kognitive Fähigkeiten, muss notwendigerweise Unsicherheit entstehen. Auf Basis einer Annahme opportunistischen Verhaltens der Wirtschaftssubjekte bestehen für die besser informierten Akteure stets Anreize, existierende Informationsvorsprünge zum eigenen Vorteil zu nutzen. ${ }^{31}$

Jene Marktunvollkommenheiten sowie die Gefahr opportunistischen Verhaltens können schließlich die Existenz von Institutionen erklären: Diese fungieren als Regelsysteme, mit welchen das Verhalten der Akteure mit Hilfe von Sanktionen bzw. Anreizen gezielt beeinflusst werden kann. ${ }^{32}$ Unternehmen stellen derartige Institutionen dar, die als Vertragsgeflechte von Individuen definiert werden. Individuen gehen Koalitionen ein, um so ihre jeweiligen Ziele zu erreichen, unter ständiger Abwägung der Vor- und Nachteile einer Beteiligung an der jeweiligen Koalition. Aus diesen Koalitionen formt sich letztlich ein Vertragsgebilde, das Unternehmen. Dieses dient insofern als Instrument zur Erfüllung der Ziele unabhängiger Akteure - ohne allerdings selbst Ziele zu haben; Unternehmensziele ergeben sich sodann als verdichtete Ziele aller beteiligten Akteure. ${ }^{33}$ Die Akteure werden sich so lange an einer Koalition beteiligen, wie ihre individuelle KostenNutzen-Relation positiv ist. ${ }^{34}$ Dem koalitionstheoretischen Gedanken folgt auch die sog. Stakeholder-Theorie, welche die Koalitionsteilnehmer in verschiedene Kategorien von Anspruchsgruppen einordnet und diese als ,group [...] who can affect or is affected by the achievements of the firm's objectives" definiert. ${ }^{35}$

30) Vgl. Feldmann (1995), S. 45. Simon (1967), S. 241 bzw. (1997), S. 88 prägt den Begriff ,bounded rationality": Das Ideal vollkommenen Rationalverhaltens ist nicht erreichbar. Vgl. z.B. Hax (1991), S. 56. Dies wird als endogene Form der Unsicherheit bezeichnet.

32 Vgl. Held/Nutzinger (2003), S. 118f.; Langerfeldt (2003), S. 55. , Regelsystem “ dient als Sammelbegriff für Gesetzmäßigkeiten, Normen etc. Durch das Handeln von Individuen gem. ihren jeweiligen Zielen entstehen aufgrund des Zusammenwirkens Institutionen. Vgl. Jensen (1983), S. 326, sowie Jensen/Meckling (1976), S. 310f.; Ordelheide (1993), Sp. 1845; Picot (1991), S. 146; Kirsch (1969), S. 667ff. Erwähnt wurde, dass der Unternehmenswert als Oberziel dienen kann, da er die Erreichung der Individualziele erlaubt. Vgl. Barnard (1974), S. 85. Dies wird auch als ,Anreiz-Beitrags-Theorie' bezeichnet. Freeman (1984), S. 24 sowie S. 24ff., ähnlich auch Hahn/Hungenberg (2001), S. 12. 
Im Vergleich zur Erklärung des Konstrukts ,Unternehmen“ per se wirkt eine Ableitung der generellen Zielstellung, mit der Unternehmen am Kapitalmarkt auftreten, schlicht: Ausgehend von der Prämisse, dass Unternehmen im Rahmen der Leistungserstellung - und damit letztlich auch zur betriebswirtschaftlichen Absicherung ihrer Existenz - steten Bedarf an finanziellen Mitteln haben, bspw. als Kapital für Investitionen oder zur Finanzierung abzusetzender Produkte, nutzen diese den Kapitalmarkt, um die jeweils benötigten finanziellen Beträge in Form von Eigen- oder Fremdkapital aufzunehmen. ${ }^{36}$ Spezifischer formuliert zielen die Unternehmen darauf $a b$, unter Beachtung der Nebenbedingung steter Liquidität, eine optimale Kombination von Ein- bzw. Auszahlungen im Unternehmen zu erreichen, wobei der Kapitalmarkt insb. für den Ausgleich temporärer finanzieller Unterdeckungen in Anspruch genommen werden kann - unter Berücksichtigung der gegenwärtigen bzw. der angestrebten Kapitalstruktur des Unternehmens entweder durch die Emission von Schuld- oder Beteiligungstiteln. ${ }^{37}$

\section{(b) Investoren als Kapitalanbieter am Kapitalmarkt}

Bei Betrachtung der komplementären Perspektive des Kapitalmarkts, derjenigen der Kapitalanbieter, kann zunächst nach der Art der erworbenen Titel zwischen Fremd- oder Eigenkapitalgebern differenziert werden: Erstere stellen ihr Kapital befristet zur Verfügung und erwarten neben einer Sicherung ihres Kapitals eine angemessene Verzinsung sowie termingerechte Rückzahlung ihrer Einlage. ${ }^{38}$

In dieser Arbeit soll jedoch schwerpunktmäßig auf die Eigenkapitalgeber abgestellt werden, da die empirische Untersuchung auf den Aktienmarkt, als Marktsegment für die Emission und den Handel von Beteiligungstiteln, fokussiert. Die Eigenkapitalgeber stellen den Unternehmen unbefristet finanzielle Mittel für die

Vgl. Franke/Hax (2004), S. 1 bzw. auch S. 30ff. Wenngleich Unternehmen den Kapitalmarkt auch zur Anlage von finanziellen Mitteln nutzen, steht die Finanzierung über den Kapitalmarkt realiter eindeutig - und für die vorliegende Arbeit - im Vordergrund.

Vgl. Franke/Hax (2004), S. 16f. Hier ist die sog. Funktion der Fristentransformation des Kapitalmarktes angesprochen. Zwar mag ein Unternehmen über mehrere Perioden hinweg über die finanziellen Mittel zur Durchführung einer Investition verfügen, benötigt werden die Mittel aber zum Zeitpunkt der Investition. Den Ausgleich der unterschiedlichen Fristigkeiten von Zahlungsströmen kann der Kapitalmarkt bewirken. Zur Transformationsleistung vgl. Brealey/Myers (2000), S. 11f., auch Bessler (1989), S. $21 \mathrm{ff}$. 
Fortführung der Unternehmenstätigkeit zur Verfügung und übernehmen so eine Haftungsfunktion. ${ }^{39}$ Für die Überlassung finanzieller Mittel erwarten diese eine Erhaltung sowie Wertsteigerung des eingesetzten Kapitals, daher fokussieren die (Eigen-) Kapitalgeber zur Beurteilung von Anlagealternativen auf die ihnen im Verlauf des Anlagezeitraumes zufließenden Zahlungen aus dem Unternehmen. ${ }^{40}$

Die Entscheidung eines Kapitalgebers, einem Unternehmen Kapital in Form von Eigenkapital zur Verfügung zu stellen, sich also an diesem zu beteiligen, erfolgt schließlich grds. vor dem Hintergrund persönlicher Zielstellungen, weil Kapitaldispositionen vorgenommen werden, um eigene Ziele zu erreichen: ${ }^{41}$ Sofern der Konsum als generelles Ziel aller Wirtschaftssubjekte zur Befriedigung aktueller und zukünftiger Bedürfnisse akzeptiert wird, werden stets finanzielle Mittel benötigt, um Konsum zu realisieren. Im Falle einer Anlage wird also auf Konsum verzichtet in der Erwartung, zu einem späteren Zeitpunkt mehr Mittel für Konsum zur Verfügung zu haben. Dem Konsum kommt folglich die Aufgabe zu, die Zieladäquanz vorgenommener bzw. beabsichtigter Dispositionen zu beurteilen. ${ }^{42}$ Allerdings sind die Konsummöglichkeiten der Gegenwart und der Zukunft, die mit der Kapitalanlage determiniert werden, zu operationalisieren bzw. vergleichbar zu machen, daher werden die einem Kapitalgeber während der Dauer seines finanziellen Engagements aus einer betreffenden Anlage zufließenden Zahlungsströme zum zentralen Beurteilungsmaßstab jeglicher Anlageentscheidung. ${ }^{43}$

39) Vgl. Franke/Hax (2004), S. 32ff. Eigenkapitalgeber tragen stets das Risiko der Haftung.

40) Vgl. nochmals Franke/Hax (2004), S. 2; Brealey/Myers (2000), S. 121. Für die Kapitalgeber sind folglich die aus der Anlage zu erwartenden finanziellen Rückflüsse relevant.

41 Vgl. Moxter (1966), S. 37.

42 Dabei gilt stets die Abwägung zwischen Gegenwarts- sowie Zukunftskonsum: Subjekte tauschen Gegenwartskonsum gegen die Kapitalanlage ein, um ggf. in der Zukunft mehr Konsum tätigen zu können. Vgl. Demmler (2000), S. 137f.; Schildbach (1975), S. 16.

Es sind zwei Komponenten des Zahlungsstromes zu trennen: der periodische Nettoausschüttungsstrom, der während der Anlagedauer zufließt, sowie der einmalige Wiederveräußerungserlös am Ende der Anlagedauer, vgl. Moxter (1995), S. 35f., ders. (1984), S. 139. Periodische Zahlungsströme sind Dividenden und sonstige Ausschüttungen, der Veräußerungserlös als finaler Zahlungsstrom stellt die Wertentwicklung der Anlage dar. Es ist grds. anzunehmen, dass diese Zahlungsströme von den Kapitalgebern nicht beeinflusst werden können, die Zielgröße stellt folglich ein Datum aus der Perspektive eines Anlegers dar. Weitere Zielvorstellungen neben finanziellen Größen seien ebenfalls ausgeschlossen, z.B. emotionale Bindung, Machtaspekte, vgl. Franke/Hax (2004), S. $145 f$. 
Zur Beurteilung einzelner Anlagealternativen müssen Investoren jene Zahlungsströme daher im Detail spezifizieren, um sodann diejenige Anlagealternative zu wählen, deren Zahlungsstromprofil ihre Zielvorstellungen bestmöglich erfüllt für eine derartige Spezifikation von Zahlungsstromprofilen sind Informationen unerlässlich: ${ }^{44}$ Daten zur Höhe und zeitlichen Struktur künftiger Zahlungsströme sowie der mit Höhe bzw. Struktur verbundenen Unsicherheit. ${ }^{45}$ Es scheint offensichtlich, dass es sich bei diesen Informationen um Prognosen handeln muss, da zukünftige Zahlungsströme und ihre konkrete Beschaffenheit zu ermitteln sind.

\subsubsection{Bewertung als Basis von Transaktionen am Kapitalmarkt}

Am Kapitalmarkt treffen also Kapitalanbieter sowie -nachfrager zusammen, um ihre individuellen Zielvorstellungen zu realisieren, die in der Befriedigung eines Bedarfs an Kapital bzw. in einer Kapitalanlage bestehen. Mittel zur Realisierung der jeweiligen Zielvorstellungen ist der Eigenkapitalanteil eines Unternehmens, der am Kapitalmarkt, verbrieft in Form eines Wertpapiers, gehandelt wird. ${ }^{46}$

Dabei weist der Kapitalmarkt im Vergleich zu Gütermärkten eine Besonderheit auf: Das Objekt des Handels ist weitestgehend normiert, d.h. die Rechtsposition des Investors, die durch Eigentum an einem Wertpapier begründet wird, ist grds. identisch, unabhängig von einer konkret gewählten Anlagealternative. ${ }^{47}$ Folglich ist der Preis des Anteils der zentrale beschreibende Parameter von Transaktionen am Kapitalmarkt, der schließlich eine Verbindung zur Unternehmensbewertung herstellt, da sich der Preis direkt aus dem jeweiligen Unternehmenswert ergibt. ${ }^{48}$

44 Vgl. Kahle (2002), S. 96f. Wagner (1982), S. 753f. weist darauf hin, dass die Investoren keinen Restriktionen unterliegen, z.B. können sie bei einer Veränderung des Zahlungsstromprofils - durch neue Informationen etc. - ihre Anlageentscheidung überdenken. Vgl. auch FASB (2006a), CON1-2. Das FASB (Financial Accounting Standards Board) ist der US-amerikanische Standardsetter, der die US-GAAP erlässt.

Jener Eigenkapitalanteil wird i.d.R. als Aktie bezeichnet. Es wird deutlich, dass hier auf den Sekundärmarkt abgestellt wird, da primär der Handel von Aktien von Interesse ist. Realiter können Aktien grds. mit unterschiedlichen Rechtspositionen ausgestattet sein, insb. seien die sog. Vorzugsaktien erwähnt, vgl. bspw. Brealey/Myers (2000), S. 389ff. In einfacher Darstellung entspricht der Preis der Aktie dem Anteil am Eigenkapitalwert des Unternehmens, den er repräsentiert. Das Produkt aus Anzahl emittierter Anteile und Preis je Anteil entspricht dem Eigenkapitalwert, vgl. Brealey/Myers (2000), S. 62ff. 
Nachfolgend sind aus diesem Grund - im Hinblick auf den Unternehmenswert drei Wertkonzeptionen voneinander zu unterscheiden, die im Kapitalmarktkontext bedeutsam sind: Während Investoren den sog. inneren Wert zur Fundierung von Anlageentscheidungen betrachten, zeigt die Bewertung eines Unternehmens am Kapitalmarkt den aktuellen Börsen- bzw. Marktwert des Eigenkapitals an. ${ }^{49}$ Eine Wertuntergrenze stellt der sog. bilanzielle Wert des Eigenkapitals dar. Auf diese drei genannten Wertkonzeptionen sei kurz eingegangen:

Investoren ermitteln einen inneren Wert grds. als Zukunftserfolgswert im Zuge der Gesamtbewertung ${ }^{50}$ durch risikoadäquate Diskontierung künftiger Zahlungsströme. Der innere Wert ist folglich gleich dem Barwert der Zahlungsströme, die aus einer Kapitalanlage generiert werden. Es ist offensichtlich, dass dieser Wert aufgrund des inhärenten Zukunftsbezuges stets mit Unsicherheiten behaftet sein muss: Investoren stellen auf Basis ihrer jeweiligen Zukunftserwartungen individuelle Schätzungen an - sowohl in Bezug auf die Zählergröße Zahlungsströme als auch bzgl. des Nenners, des risikoadjustierten Diskontierungssatzes. ${ }^{51}$ Einen übergreifenden, allgemeingültigen bzw. objektiv richtigen inneren Wert kann es daher nicht geben, da stets individuelle Bewertungen vorgenommen werden.

Neben einer Diskontierung von Zahlungsströmen kann alternativ auch auf Übergewinngrößen abgestellt werden, weil es in praxi i.d.R. nicht möglich sein wird, zukünftige Zahlungsströme hinreichend genau zu schätzen. ${ }^{52}$ Dazu wird ein über die Verzinsung des eingesetzten Kapitals hinausgehender Gewinnteil für einige

4) Vgl. Glaum/Friedrich (2006), S. 169; Labhart/Volkart (2001), S. 113. Durch Vergleich von Markt- und innerem Wert können Anlageentscheidungen fundiert werden.

50) Für Investoren kommt grds. nur eine Gesamtbewertung in Frage, weil für eine Einzelbewertung i.d.R. die Datengrundlage Externer unzureichend ist, vgl. bspw. Steiner/Bruns (2000), S. 227ff. Zum Einzel- und Gesamtbewertungsverfahren vgl. Hahn/Hungenberg (2001), S. 405ff. Die Verfahrenswahl determiniert grds. den Informationsbedarf.

51 Jene Zahlungsströme entsprechen dem ,Free Cashflow“, daher wird die Vorgehensweise als ,Discounted Cashflow'-Verfahren (DCF) bezeichnet. Alternativ können im Zuge des ,Discounted Dividend'-Verfahrens zukünftige Ausschüttungsgrößen diskontiert werden. In praxi ist das DCF-Verfahren dominierend, vgl. Glaum/Friedrich (2006), S. 167. Vgl. für einen soliden Überblick zu den Residualgewinnverfahren Crasselt et al. (2000). Francis et al. (2000), S. 45ff. bevorzugen Übergewinnverfahren bei beschränkter Datenverfügbarkeit, da der Restwert hier durchschnittlich nur ca. $21 \%$, beim Dividenden-Diskontierungsmodell aber $65 \%$, beim DCF-Modell $82 \%$ des ermittelten Wertes ausmacht. Die Diskontierung von Übergewinnen wird im Rahmen der Untersuchung relevant sein. 
Perioden diskret prognostiziert sowie diskontiert, der innere Wert ergibt sich sodann als Summe des Investitionskapitals, der diskontierten Übergewinne sowie eines Restwertes. Auch so errechnet sich folglich ein Zukunftserfolgswert, beide Ergebnisse können unter gewissen Voraussetzungen identisch sein. ${ }^{53}$

Neben den Ansätzen zur Gesamtbewertung kann der Unternehmenswert auch im Zuge einer Einzelbewertung ermittelt werden - diese steht Externen jedoch grds. nicht zur Verfügung. Mit dem sog. Reinvermögenszeitwert wird versucht, einen inneren Wert mit Hilfe der Zeitwertbewertung einzelner Vermögensgegenstände zu approximieren. ${ }^{54}$ Dies gelingt allerdings stets nur unvollständig, ${ }^{55}$ da nicht für alle Aktiva sowie Passiva Zeitwerte ermittelbar sind und außerdem eine Berücksichtigung von Synergien bzw. eines originären Geschäftswertes kaum realisierbar ist. Schließlich stellt der Bilanzwert, der Wert des bilanziellen Eigenkapitals, die Wertuntergrenze dar. Er ergibt sich als Differenz aus bilanziellem Vermögen und Schulden und kann aus der Bilanz eines Unternehmens abgelesen werden. ${ }^{56}$ Im Gegensatz zu der rechnerischen bzw. bilanziellen Ermittlung der genannten Wertkonzeptionen ist der Börsenwert bzw. der Marktwert des Eigenkapitals derjenige Wert, der sich am Kapitalmarkt durch Angebot sowie Nachfrage einstellt.

Diese Wertkonzeptionen fasst die folgende Abb. 3 zusammen: Im idealtypischen Modell entspräche der Marktwert exakt dem inneren Wert - dieser stellt folglich den Maßstab der Bewertung dar und er ist derjenige Wert, der sich bei Kenntnis

53 Vgl. Volkhart et al. (1998); Dillon/Owers (1997). Der Zusammenhang wurde von Preinreich (1938) sowie Lücke (1955) dargestellt und wird daher auch als ,Preinreich-LückeTheorem' bezeichnet. Vgl. z.B. Coenenberg/Schultze (2002), S. 603. Die Empirie zeigt die Überlegenheit des Residualgewinns, vgl. AAA (2001); Francis et al. (2000), S. $45 \mathrm{ff}$. Auf dieses Theorem wird im weiteren Verlauf der Arbeit nochmals Bezug genommen. Vgl. Ballwieser (2004), S. 192f. sowie am Bsp. der Deutschen Lufthansa Kley (2001), S. 2258. Der Reinvermögenszeitwert wird auch als Substanzwert bezeichnet.

Das Reinvermögen ergibt sich folglich als Residuum der Zeitwerte von Vermögen und Schulden in der sog. Marktwertbilanz. Vgl. z.B. Küting/Dawo (2003), S. 406f., ebenso Jäger/Himmel (2003), S. 436f. Sellhorn (2000), S. 885 schlägt weiterhin vor, die Marktwertbilanz um den Zukunftserfolgswert des originären Geschäftswerts zu ergänzen. Zur Bedeutung eines ,Fair Value-Accountings‘ für Investoren vgl. bspw. Landsman (2007). Die Problematik der Fair Value-Bewertung innerhalb des Rechnungswesens stellen bereits grdl. Barth/Landsman (1995) umfassend dar.

Vgl. z.B. Coenenberg (2005), S. 283f. Zu beachten ist dabei jedoch, dass dieser Bilanzwert ebenfalls von Ansatz- und Bewertungseinflüssen determiniert wird. 
aller relevanten Informationen sowie einer effizienten Informationsverarbeitung als Wert eines Unternehmens am Kapitalmarkt einstellen würde. ${ }^{57}$

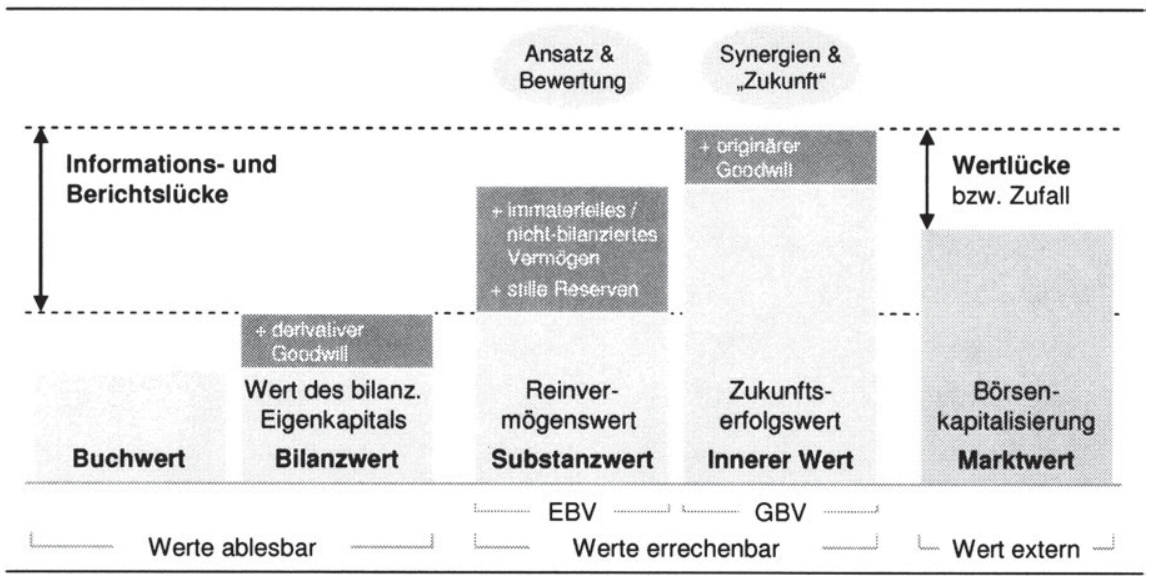

Abbildung 3: Wertkonzeptionen im Überblick ${ }^{58}$

Realiter scheint dieser Zustand kaum erreichbar, da nicht alle kursrelevanten Informationen uneingeschränkt zur Verfügung stehen sowie gleichfalls nicht vollkommen und unverzüglich vom Kapitalmarkt reflektiert werden; zudem können Zufallseinflüsse Differenzen zwischen Markt- und innerem Wert verursachen. ${ }^{59}$ Derartige Unterschiedlichkeiten zwischen Markt- und innerem Wert werden als sog. Wertlücken bezeichnet, ${ }^{60}$ weiterhin lässt sich eine Berichtslücke darstellen, die darauf hinweist, dass Unternehmen ausschließlich Bilanzwerte berichten und andere bewertungsrelevante Sachverhalte generell unveröffentlicht bleiben. ${ }^{61}$

57 Vgl. Schultze et al. (2007), S. 564, auch Ruhwedel/Schultze (2002a), S. 605.

58 Quelle: eigene Darstellung in Anlehnung an Schultze et al. (2007), S. 565 und Heumann (2005), S. 260. ,EBV‘ und ,GBV‘ stehen für Einzel- bzw. Gesamtbewertungsverfahren. Vgl. Günther/Beyer (2001), S. 1624ff. Börsenbewertungen werden vielmehr auch durch subjektive Einschätzungen über zukünftige Entwicklungen oder psychologische, markttechnische Faktoren geprägt, vgl. ebenda, S. 1624 sowie Daniel et al. (1998), S. 1839f. Vgl. bspw. Böcking/Wesner (2004), S. 104.

61 Mit der Veröffentlichung der Bilanzwerte ist die Finanzberichterstattung angesprochen, vgl. Eccles et al. (2001), S. 161 sowie 165ff., Fischer (2002), S. 214, auch Schmid et al. (2005), S. 119f. Folge einer Berichtslücke ist grds., dass Investoren ein Unternehmen zu niedrig bewerten, da sie kaum Einblick in Leistungsdaten, Strategien und Zukunftspläne erhalten, vgl. Eccles et al. (2001), S. 162. Umgekehrt gilt, dass Schwachstellen nicht erkennbar werden, die Marktbewertung könnte in der Folge auch zu hoch sein. 
Es ist also festzuhalten, dass der innere Wert als der eigentlich „objektiv richtige Wert ${ }^{\text {“62 }}$, welcher als Basis für Anlageentscheidungen dient und durch Vergleich mit dem jeweiligen aktuellen Marktwert die Identifikation möglicher Über- bzw. Unterbewertungen ermöglicht, stets individuell abzuleiten ist. ${ }^{63}$ Hierfür werden zukünftige Erfolgsgrößen ${ }^{64}$ benötigt, die allerdings weder unmittelbar vorhanden sind noch von Seiten der Unternehmen veröffentlicht werden. Folgerichtig sind - aufbauend auf allen verfügbaren bzw. bereitgestellten Informationen - jeweils individuelle Überlegungen der Investoren bzgl. der zukünftigen Unternehmensentwicklung anzustellen, um sodann die benötigten künftigen Erfolgsgrößen ableiten zu können, als ,Input' für die jeweiligen Prognosemodelle, welche für die Fundierung von Entscheidungen über Anlagealternativen genutzt werden.

Es ist allerdings grds. zu beachten, dass innerhalb jener Prognosemodelle der Investoren stets nur wenige zukünftige Perioden diskret geplant werden, wodurch einzelne Erfolgsgrößen als Wertkomponente ein hohes Gewicht erhalten: Folglich reagieren die Prognosemodelle in höchstem Maße sensitiv auf Änderungen der Schätzwerte. ${ }^{65}$ Es scheint offensichtlich, dass in der Konsequenz der Qualität der Prognosen und insofern auch der informationellen Basis der Prognosen eine zentrale Bedeutung zukommt. ${ }^{66}$

Mit der informationellen Basis der Bewertung von Unternehmen durch Akteure am Kapitalmarkt sowie den sich daraus ergebenden Anforderungen an ebendiese Informationen setzt sich der nachfolgende Abschnitt B 1.2 auseinander.

Wäre eine Berichtslücke geschlossen, könnte der Kapitalmarkt ein Unternehmen sodann bewerten wie das Management, vgl. Ruhwedel/Schultze (2002a), S. 607ff., dies. (2004), S. 492. Es sei bereits jetzt darauf hingewiesen, dass dies die generelle Zielsetzung wertorientierter Berichterstattung ist. Die Verbindung zum sog. ,Management Approach“ in der Finanzberichterstattung wird erkennbar, vgl. hierzu Weißenberger/Maier (2006). Labhart (1999), S. 112ff. Erwähnt wurde, dass es einen übergreifenden, allg. als richtig akzeptierten inneren Wert nicht geben kann - die zitierte Formulierung muss daher zunächst verwundern. Wären die Annahmen zu zukünftigen Erfolgsgrößen Konsens sowie die Einschätzungen bzgl. des Risikos identisch, würden individuelle Berechnungen des inneren Wertes jedoch grds. vergleichbare - und somit objektivierte - Werte ermitteln. Vgl. bspw. Baetge/Noelle (2001), S. 178f. ,Erfolgsgrößen “ umfasst hier Zahlungsgrößen sowie Übergewinne, eine Ermittlung des Reinvermögenszeitwertes wird wegen geringer Praktikabilität ausgeklammert. Vgl. beispielhaft die Argumentation bei Labhart/Volkart (2001), S. 115ff.

Vgl. Ewert/Wagenhofer (2000), S. 25. 


\subsection{Informationen als Grundlage der Bewertung am Kapitalmarkt}

Zuvor ist ersichtlich geworden, dass Information als das verbindende Element des Kapitalmarkts gelten mag: Einerseits führen Informationsasymmetrien dazu, dass die Existenz von Unternehmen überhaupt erst erklärbar wird, die sodann als Kapitalnachfrager auftreten. Andererseits sind Informationen zur Schätzung von Zahlungsstromprofilen unabdingbar zur Fundierung von Anlageentscheidungen.

Es soll nun auf die Rolle von Information am Kapitalmarkt eingegangen werden, zudem sind inhaltliche Anforderungen und Bereitstellungsoptionen abzuleiten.

\subsubsection{Informationstheoretischer Hintergrund}

Unter Information werden im Bereich menschlichen Handelns grds. Nachrichten verstanden, denen in einem bestimmten Kontext Bedeutung zukommt. ${ }^{67}$ Diese Bedeutung folgt daraus, dass durch Aufnahme sowie Verarbeitung der Nachricht eine zielorientierte Handlung, wie z.B. eine Anlageentscheidung, vorbereitet und ausgelöst werden kann. Informationen gelten also als zweckorientiertes Wissen; Zweckgerichtetheit bzw. die Fähigkeit von Informationen, Veränderungen beim Empfänger hervorzurufen, wird als ihr konstituierendes Merkmal betrachtet.

Wird der Erhalt einer neuen Information schließlich als ein Zuwachs an zweckorientiertem Wissen verstanden, folgt daraus, dass diese in der Lage sein kann, eine Beseitigung oder Reduktion von Ungewissheit zu bewirken. ${ }^{68}$ Im Hinblick auf den Kapitalmarkt ergibt sich insofern, dass - da zur Fundierung von Kapitalanlageentscheidungen Prognosen erforderlich sind, die die Beurteilung der Vorteilhaftigkeit verschiedener Anlageoptionen ermöglichen - Informationen dazu geeignet sein müssen, die bestehenden Einschätzungen der Investoren in Bezug auf ein konkretes Zahlungsstromprofil eines Unternehmens zu beeinflussen.

67 Vgl. hierzu und im Folgenden Bode (1997), S. 454ff., auch Bonse (2004), S. 61f. sowie Wittmann (1959), S. 14ff. Zeichen bzw. Signale werden grds. wirkungsunabhängig als Nachrichten verstanden, eine Nachricht erhält dann einen Informationsgehalt, wenn sie eine erwartungsbeeinflussende Wirkung besitzt. 
Erkennbar wird, dass im Kapitalmarktkontext im hier verwendeten Verständnis primär von einer einseitigen Informationsbeziehung auszugehen ist: Investoren erhalten Informationen der Unternehmen, welche ggf. Einfluss auf ihr Verhalten ausüben. Ein Rückkanal, also Informationen, die von den Investoren in Richtung der Unternehmen fließen, besteht grds. nur mittelbar: Investoren legen durch ihr Handeln, also durch die Transaktionen am Kapitalmarkt, implizit ihren Bestand an Informationen und ihre jeweiligen Bewertungsvorstellungen dar. ${ }^{69}$

\subsubsection{Theorien zur Bedeutung von Informationen am Kapitalmarkt}

Zur Untersuchung der Bedeutung von Informationen am Kapitalmarkt kann ein Rückgriff auf das Konzept der sog. Kapitalmarkteffizienz erfolgen, welches auf Fama (1970) zurückgeht und sich reger Beachtung sowohl in der theoretischen Diskussion als auch in der empirischen Forschung erfreut. ${ }^{70}$ Kernelement ist die recht knapp gehaltene Definition der Kapitalmarkteffizienz: „A market in which prices always 'fully reflect' available information is called 'efficient' ${ }^{\text {' } 671}$.

Kritik wurde v.a. angesichts des vagen Charakters der Formulierungen ,fully reflect" sowie , information available' geübt. ${ }^{72}$ Dennoch geben diese wichtige Hinweise zum Stellenwert von Informationen am Kapitalmarkt: Es ist offensichtlich, dass in einem streng neoklassischen Marktverständnis hierzu keine Aussage ab-

69 Vgl. Healy/Palepu (2001), S. 406. Zudem ist ein Informationsstrom ausgehend von sog. Informationsintermediären (insb. Finanzanalysten, Banken, Öffentlichkeit) in Richtung der Investoren zu erkennen. Jene filtern, interpretieren und ergänzen die von den Unternehmen ausgehenden Informationen, die einzige originäre Quelle der Informationen zur Schätzung von Zahlungsströmen sind jedoch die Unternehmen.

Ein unmittelbarer Rückkanal der Investoren in Richtung der Unternehmen wäre grds. jedoch vorstellbar, insb. im Falle von Großinvestoren, davon sei hier aber abstrahiert. Vgl. Beaver (1983), S. 344f.

71 Fama (1970), S. 383. Im Original ebenfalls mit Hervorhebungen. Neben jenem Begriff der ,Kapitalmarkteffizienz' hat sich weiterhin der gleichbedeutende verwendete Begriff der ,Informationseffizienz' etabliert.

Vgl. grdl. Beaver (1983), v.a. S. 346f., ebenso zur Kritik an der Definition der Kapitalmarkteffizienz. Jedoch schreibt Fama (1970), S. 384 selbst: „The definitional statement that in an efficient market prices fully reflect available information is so general that it has no empirically testable implications." (Im Original ebenfalls mit Hervorhebung).

Tom Sieber - 978-3-631-75150-3 
leitbar wäre, da die Markteffizienz a priori gegeben ist. ${ }^{73}$ Folglich sind Modelle erforderlich, die Marktimperfektionen explizit zulassen. Drei Ansätze sind nachfolgend skizziert, die die Bedeutung von Informationen aufzuzeigen vermögen:

Merton (1987) weist in seinem Ansatz auf bestehende Informationsasymmetrien am Kapitalmarkt hin, insb. unter den Investoren: Nicht jeder Investor kennt alle am Kapitalmarkt verfügbaren Titel, kann aber nur diejenigen in seinem Portfolio halten, welche er kennt - vollständige Diversifikation ist ergo nicht erreichbar. ${ }^{74}$

Die Risikoposition des Investors steigt daher mit sinkender Anzahl an bekannten Titeln. Aus Sicht eines Kapitalnachfragers bedeutet dies, dass nur eine limitierte Investorenbasis verfügbar ist, die für eine Bereitstellung von finanziellen Mitteln in Frage kommt. Um jene zu verbreitern, kann ein Unternehmen Maßnahmen ergreifen, die u.a. die Informationsdistribution umfassen. Das würde nicht nur den Bekanntheitsgrad des Nachfragers erhöhen, sondern auch die Empfangs- und die Interpretationskosten auf Seiten der Investoren reduzieren und folglich könnten mehr Investoren die betreffenden Titel bei der Portfoliostrukturierung beachten. Die höhere Informationsdistribution führt sodann im Modell Mertons dank einer breiteren Investorenbasis cet. par. zu geringeren Kapitalkosten.

Barry/Brown (1985) lassen dagegen Informationsasymmetrien auf der Ebene der Titel, also der Unternehmen, zu, da sich diese annahmegemäß hinsichtlich ihrer Informationsqualität unterscheiden - Investoren haben in diesem Modell jedoch einen identischen Bestand an Informationen. ${ }^{75}$ Es folgt, dass der Informationsgehalt ein titelspezifisches, unsystematisches Risiko darstellt. Investoren wären daher selbst bei stark heterogener Informationsqualität indifferent hinsichtlich der Titelalternativen, wenn sie das titelspezifische Informationsrisiko durch Diversifikation eliminieren könnten. Eine höhere Informationsqualität einzelner Unter-

73 Diese Voraussetzung stellt die Prüfung der Markteffizienzhypothese per se in Frage. Da für den Test der Markteffizienz Überrenditen in Relation zu den kapitalmarkttheoretisch korrekten Renditen zu untersuchen wären, besteht ein ,Joint Hypotheses'-Problem: Ein Test der Markteffizienz ist zugleich ein Test des Kapitalmarktmodells et vice versa, vgl. Labhart/Volkart (2001) S. 119f. Im neoklassischen Finanzmarkt wäre jede beliebige Information unmittelbar korrekt interpretiert in den Bewertungsmodellen reflektiert. 
nehmen würde sich in diesem Modell schließlich nicht lohnen, da nur das nichtdiversifizierbare Risiko am Markt abgegolten wird. Wäre jedoch das aus der Informationsqualität resultierende Risiko nicht vollständig diversifizierbar, würde es das systematische Risiko erhöhen und insofern eine Prämie für Investoren begründen. Dieses titelspezifische Risiko, das sog. ,Estimation Risk', ist, wie empirisch nachgewiesen werden kann, in der Tat nicht völlig diversifizierbar. ${ }^{76}$ Auf kapitalmarkttheoretischer Basis berechnete Kapitalkosten sind für Unternehmen mit guter Informationsqualität also zu hoch, die mit schwächerer Qualität setzen zu geringe Kosten an. Durch konsistentes Informationsmanagement können also auch in diesem Modell Effekte erzielt bzw. die Kapitalkosten gesteuert werden.

Modelle der sog. Market Microstructure Theory setzen sich schließlich mit dem Mechanismus des Prozesses der Preisbildung für Finanzierungstitel am Kapitalmarkt auseinander: Dieser Prozess bleibt in der klassischen Finanztheorie ohne Beachtung, da sich annahmegemäß immer der Gleichgewichtspreis einstellt. Angenommen wird, dass eine in ihrem Aussagegehalt schwache und intransparente Informationsbereitstellung zu geringerem Vertrauen der Investoren in die Preisbildung am Markt führen muss, da für diese stets die Gefahr besteht, dass besser informierte Investoren Informationsvorsprünge zur Erzielung höherer Renditen verwerten können. ${ }^{77}$ Dies hat negativen Einfluss auf die Liquidität im Markt, in der Folge steigen die Kapitalkosten des betrachteten Unternehmens an - aktives Informationsmanagement sollte daher Investoren in einem transparenten Prozess mit einem identischen sowie umfassenden Set an Informationen versorgen. ${ }^{78}$

,Estimation Risk' bezeichnet das Risiko der Investoren, in ihrer Einschätzung der Entwicklung eines Unternehmens falsch zu liegen. Barry/Brown teilen Wertpapiere in zwei Klassen ein: hohe vs. niedrige Informationsqualität. Der Fokus liegt auf Aktien, aber die Ausdehnung auf alle Wertpapierarten, die im Marktportfolio enthalten sind, ist möglich, vgl. Barberis (2000) bzw. für internationale Diversifikation Hasan/Simaan (2000).

Dies wird in der Literatur auch als sog. ,lemons problem “ bezeichnet: „The information or ,lemons ' problems arises from information differences [...] it can potentially lead to a breakdown in functioning of the capital market", so Healy/Palepu (2001), S. 407f. Das ,lemons problem` geht ursprünglich auf Akerlof (1970) zurück. bereitstellung sowohl für aktuelle wie auch für potenzielle Investoren. Zur Überprüfung werden empirische Analysen des Handelsvolumens sowie weiterer liquiditätsbezogener Parameter durchgeführt, vgl. beispielhaft Welker (1995); Leuz/Verrecchia (2000). 
Mit diesen exemplarischen Modellen kann folglich - trotz jeweils individueller Schwerpunktsetzung - eine generelle Bedeutung von Informationen am Kapitalmarkt abgeleitet werden, da in allen Fällen der Nachweis erbracht wird, dass die Menge und die Qualität verfügbarer Informationen zu feststellbaren Effekten am Kapitalmarkt führen. Neben diesen modelltheoretischen Arbeiten liegt weiterhin eine Vielzahl von empirischen Studien vor, die sich mit diesem Themenkomplex befassen: Stellvertretend sei hier bereits die Untersuchung von Botosan (1997a) erwähnt, welche einen signifikanten Zusammenhang zwischen dem Niveau der Informationsbereitstellung von Unternehmen und den Kapitalkosten aufzeigt. ${ }^{79}$

Abschließend kann folglich für den weiteren Verlauf dieser Arbeit festgehalten werden, dass Informationen am Kapitalmarkt offensichtlich von Bedeutung sind und ohne diese ein Funktionieren des Marktmechanismus fraglich erscheint. ${ }^{80}$

\subsubsection{Anforderungen an Informationen am Kapitalmarkt}

Sofern also für das Funktionieren von Kapitalmärkten die Verfügbarkeit von Informationen als notwendige Voraussetzung akzeptiert wird, stellt sich die Frage nach den an Informationen zu stellenden inhaltlichen Anforderungen, d.h. nach der Art der Information sowie der qualitativen und quantitativen Beschaffenheit.

\section{(a) Ableitung des inhaltlichen Informationsbedarfes}

Ein inhaltlicher Informationsbedarf lässt sich grds. beschreiben als die „Summe derjenigen Informationen, die zur Erfüllung eines informationellen Interesses [...]

79 Vgl. grdl. Botosan (1997a), die - wohlgemerkt mit Fokus auf nur eine Industrie - nachweist, dass für Unternehmen mit niedriger Informationsqualität die Eigenkapitalkosten um 28 Basispunkte sinken, wenn der Index der Qualität um einen Basispunkt steigt. Die Unternehmen werden anhand der Anzahl beobachtender Analysten als ,transparent " und ,intransparent " charakterisiert, wie von Lang/Lundholm (1996), S. 467f. vorgeschlagen.

Die Arbeit von Botosan hat vielfach Beachtung in der relevanten Literatur gefunden, da sie als einer der ersten empirischen Belege für den Einfluss der Informationsqualität auf die Eigenkapitalkosten von Unternehmen galt. Neben dieser Arbeit hat Botosan weitere Untersuchungen zum Zusammenhang von Informationsqualität und Kapitalkosten vorgelegt, auch unter Aufgabe des Branchenfokus, vgl. bspw. Botosan/Plumlee (2002). 
erforderlich sind““81. Unter Rückgriff auf obige Definition von Informationen als Nachrichten, denen in einem bestimmten Kontext Bedeutung zukommt, wäre zu ergänzen, dass der Kontext determiniert, welche Informationen bedeutsam sind und somit den spezifischen Informationsbedarf ausmachen. ${ }^{82}$ In einer Situation der Anlageentscheidung ist daher anzunehmen, dass der Informationsbedarf alle Informationen umfasst, die zum Treffen dieser Entscheidung hilfreich sind. Der konkrete Informationsbedarf von Investoren in Entscheidungssituationen in Bezug auf Anlageoptionen resultiert unmittelbar aus den Zielvorstellungen, die mit der Investition verbunden sind. Unterstellt wird, dass es sich um rein finanzielle Zielsetzungen handelt, eine Entscheidung wird auf Basis zukünftiger Zahlungsstromprofile getroffen - der konkrete Informationsbedarf muss folglich Angaben umfassen, die möglichst gute sowie sichere Prognosen derselbigen erlauben. ${ }^{83}$

\section{(b) Qualitative Anforderungen an Informationen}

Da eine Nachricht dann zur Information wird, wenn diese in einem bestimmten Kontext eine Entscheidung fundieren kann, ist ihre Qualität konsequenterweise anhand des Kriteriums zu beurteilen, ob sie im Rahmen einer zu treffenden Entscheidung nützlich ist, also ob sie zu einer informationellen Verbesserung der jeweiligen Entscheidungssituation führt. ${ }^{84}$

Diese ,Entscheidungsnützlichkeit ‘ wird daher - insb. im Rahmen ökonomischer Fragestellungen - als ,ökonomische Brauchbarkeit“ ${ }^{485}$ bezeichnet. Jene ist immer dann gegeben, wenn durch den Erhalt sowie die Verarbeitung einer Information eine bestehende Rangfolge von Alternativen verändert oder Unsicherheit bei der Alternativenwahl reduziert werden kann. ${ }^{86}$ Um das Konzept der Entscheidungs-

81 Berthel (1992), Sp. 873, vgl. ebenda, Sp. 873ff. für eine grdl. Einführung.

82 Vgl. Berthel (1992), Sp. 872f.

83 Vgl. hier grdl. Brealey/Myers (2000), S. 35f. „Forward-looking disclosures are a crucial source of information when valuing a company", so Bozzolan et al. (2008), S. 435.

Jenes Kriterium findet sich in den sog. „Qualitative Characteristics“ der US-Rechnungslegungsvorschriften US-GAAP. In den „Statements of Financial Accounting Concepts“ (SFAC) Nr. 2 wird gefordert, dass Informationen der „Decision Usefulness“ zu genügen haben, operationalisiert v.a. durch die Relevanz sowie Verlässlichkeit einer Information, vgl. hierzu gleichfalls ausführlich FASB (2006a), CON2-2 sowie CON2-12ff., Tz. 32ff. Baetge (1970), S. 168.

86 Vgl. Busse von Colbe (1993), S. 13. 
nützlichkeit zu operationalisieren, werden Informationen stets mit Hilfe zweier Qualitätskriterien beurteilt: ihrer Relevanz sowie ihrer Verlässlichkeit: ${ }^{87}$

Die Entscheidungsrelevanz von Informationen betrifft die grds. Relevanz einer Information aufgrund ihrer Eigenschaft als Bestandteil im Entscheidungskalkül der Adressaten: Informationen gelten immer dann als relevant, sofern durch sie eine Entscheidung fundiert oder aber die Qualität einer Entscheidung verbessert werden kann. ${ }^{8}$ Dies kann sich entweder auf eine künftig zu treffende, also in der Zukunft liegende Entscheidung, oder eine zuvor bereits getroffene Entscheidung beziehen. Folglich ist eine Information relevant, wenn sie eine Prognosefunktion (Vorhersagewert) oder Kontrollfunktion (Bestätigungswert) übernehmen kann, durch ihre Aufnahme und Verarbeitung also bestimmte Vorhersagen unterstützt oder frühere Vorhersagen bzw. Erwartungen kontrolliert werden können. ${ }^{89}$

Im Kapitalmarktkontext lässt sich Relevanz vergleichsweise pragmatisch darstellen: So erfüllt eine Information genau dann eine Prognosefunktion, wenn sie Anlageoptionen bzgl. der Determinanten des Zahlungsstromprofils konkretisiert, diese also besser prognostiziert werden können als in der Ausgangssituation, ehe der Empfänger im Besitz der jeweiligen Information war. ${ }^{90}$ Die Kontrollfunktion nimmt Information dann wahr, wenn eine bereits getroffene Anlageentscheidung bzw. mit ihr verbundene Erwartungen überprüft, bestätigt oder korrigiert werden können. Folglich dienen entscheidungsrelevante Informationen dazu, Unsicherheiten eines Investors - bzgl. der Vergangenheit oder der Zukunft - abzubauen.

Zur Darstellung der Verlässlichkeit von Informationen ist es zweckmäßig, noch einmal Bezug auf die neoinstitutionale Theorie zu nehmen: Da sich die Akteure bzgl. ihrer Ziele unterscheiden, kann es im Rahmen arbeitsteiliger Beziehungen, definiert als ein ,contract under which one or more persons (the principal(s)) engage another person (the agent) to perform some service on their behalf which

87 Vgl. FASB (2006a), CON2-2 mit der Definition „Relevance and reliability are the two primary qualities that make accounting information useful for decision making." Die US-Rechnungslegungsstandards setzen sich in den „Statements of Financial Accounting Concepts“ (SFAC) ausführlich mit den Anforderungen an Informationen auseinander.

Vgl. FASB (2006a), CON2-2 bzw. CON2-16, Tz. $52 \mathrm{f}$.

Vgl. bspw. Damodaran (2001), S. $106 f$. 
involves delegating some decision making authority to the agent ${ }^{\text {“91 }}$, grds. zu opportunistischem Verhalten kommen. Als Konsequenz entstehen sog. PrinzipalAgenten-Konflikte, d.h. Situationen, in denen Agenten das Nutzenniveau ihres Pinzipals beeinträchtigen sowie externe Effekte hervorrufen. ${ }^{92}$ Bezogen auf den Kapitalmarktkontext bedeutet dies, dass stets Möglichkeiten gegeben sind, dass die Manager eines Unternehmens nicht im Sinne der Nutzenmaximierung ihrer Investoren handeln. Es existiert daher grds. Unsicherheit, ob Informationen über das Handeln der Manager - als wesentlicher Treiber der Zahlungsströme - verlässlich sind. Die Verlässlichkeit beeinflusst zudem die Relevanz: Informationen können lediglich dann als entscheidungsnützlich klassifiziert werden, wenn auch ihre Verlässlichkeit ausreichend beurteilt und bejaht werden kann. ${ }^{93}$

Einleuchtend scheint also, dass Relevanz und Verlässlichkeit von Informationen durchaus in einem konfliktären Verhältnis zueinander stehen können. Investoren benötigen in Entscheidungssituationen primär zukunftsorientierte Informationen, da diesen beim Abschätzen zukünftiger Zahlungsstromprofile hohe Relevanz zukommt. Gerade zwischen Zukunftsorientierung und Verlässlichkeit besteht allerdings ein elementares Spannungsverhältnis: ${ }^{94}$ Wären im Sinne der Verlässlichkeit vergangenheitsorientierte Angaben zu präferieren, ist für zukunftsorientierte Informationen vollkommene Verlässlichkeit grds. nicht zu erreichen. ${ }^{95}$

91 Vgl. grdl. Jensen/Meckling (1976), S. 308f., das wörtliche Zitat befindet sich auf S. 308. Insb. im Falle der Trennung von Eigentum und Leitung, was konstituierendes Merkmal von (Eigen-) Kapitalmärkten ist, sind Agency-Konflikte zu erwarten. Vgl. erneut Jensen/Meckling (1976), S. 308f., auch Picot (1991) S. 150f. Anleger gelten in dieser Beziehung als Prinzipale, die Verfügungsmacht auf Manager delegieren. Unter Berücksichtigung von Informationsasymmetrien bzw. Unsicherheiten als Kontext sehen Agenten annahmegemäß Anreize für Handlungen, die den Nutzen der Prinzipale beeinträchtigen. Allg. Folge sind sog. Agency Costs, z.B. für die Kontrolle der Manager. $\mathrm{Zu}$ beachten ist, dass Informationen selbst beim Ausklammern opportunistischen Verhaltens nur dann entscheidungsnützlich sind, wenn die Verlässlichkeit klar zu beurteilen ist. So könnte ein Manager zwar aus seiner Sicht wahrheitsgemäß berichten, da er aber womöglich inkompetent ist, kann die Information nicht als verlässlich gelten. Folglich wäre diese auch nicht entscheidungsnützlich. Vgl. bspw. Weißenberger (2003), S. 47. Vgl. hier Baetge (1970), S. 168f., der ebenfalls einen Zielkonflikt zwischen Objektivität und ökonomischer Brauchbarkeit beschreibt, zudem FASB (2006a), CON2-23, Tz. 90f. Vgl. Ballwieser (2002a), S. 118; Moxter (2003), S. 229; Eccles et al. (2001), S. 167ff.; Fischer (2002), S. 215. Verlässlichkeit ist also nicht gleichbedeutend mit , Richtigkeit". 
Aus diesem Grund besteht die Möglichkeit, eine Beurteilung der Verlässlichkeit von Informationen anhand von zwei Hilfskriterien, Neutralität und Transparenz, vorzunehmen: ${ }^{96}$ Neutralität wird dabei verstanden als willkürfreie, objektive Informationsbereitstellung, die weder durch persönliche Motive verzerrt, noch einseitig darauf ausgerichtet ist, sogleich Handlungen des Adressaten auszulösen. ${ }^{97}$

Transparenz dagegen postuliert die klare bzw. unmissverständliche Präsentation der Informationen und im Idealfall ein Darlegen des Prozesses ihrer Herleitung einschließlich des Kontextes und der Prämissen. ${ }^{98}$ Dies würde es den Adressaten ermöglichen, den Hintergrund einer Information zu verstehen und sodann abzuwägen, ob eine konkrete Aussage nachvollziehbar erscheint und folglich als verlässliche Information eingestuft werden kann. ${ }^{99}$

Es ist also festzuhalten, dass eine Information in qualitativer Sichtweise nützlich sein muss, um eine Entscheidung zu fundieren. Dafür hat sie die Anforderungen der Relevanz sowie der Verlässlichkeit zu erfüllen, wobei letztere im Bezug auf zukunftsorientierte Informationen mittels zweier Hilfskriterien, der Transparenz und der Neutralität der Information, überprüft werden kann.

\section{(c) Quantitative Anforderungen an Information}

Neben der Qualität ist zudem die Quantität von Informationen zu betrachten, um abzuleiten, welcher Informationsmix für die Akteure am Kapitalmarkt bereitzustellen ist, um eine Schätzung künftiger Zahlungsstromprofile zu ermöglichen.

Als zentrales Kriterium zur quantitativen Abgrenzung von Informationen ist auf den Grundsatz der Wesentlichkeit abzustellen, der besagt, dass eine Information

96 Vgl. FASB (2006a), CON2-2, CON2-18, Tz. 58ff. zur Operationalisierung der Verlässlichkeit durch Vertrauenswürdigkeit (Faithfulness), Nachprüfbarkeit (Verifiability) und Neutralität (Neutrality). Die ersten beiden Kriterien werden grds. zusammengefasst.

Vgl. FASB (2006a), CON2-2 bzw. CON2-24f., Tz. 98ff., v.a. Tz. 100. Das unmittelbare Auslösen einer Handlung ist Merkmal des Befehls, vgl. Ballwieser (2002a), S. 117. Objektivität ist als intersubjektive Nachprüfbarkeit zu verstehen, so Baetge (1970), S. 16f. Vgl. z.B. Baetge et al. (2009b), S. 746f. Letztlich führt eine transparente Darstellung sodann zu einer erhöhten Vertrauenswürdigkeit bzw. einer Offenlegung der Herleitung der Angaben zur Nachprüfbarkeit der übermittelten Informationen.

Zudem würde - im Falle von prognostischen Angaben - eine Beurteilung der Prognosekompetenz des Veröffentlichers möglich. Als Basis für die Auswertung neuer Prognoseangaben wird ein Interpretationsschema erarbeitet, so Busse von Colbe (1968), S. 116. 
dann wesentlich ist, wenn dem Empfänger durch die Nichtvermittlung ein Nachteil entstehen würde. ${ }^{100}$ Investoren benötigen in Entscheidungssituationen also in quantitativer Hinsicht zunächst sämtliche Informationen, die relevant und zudem hinreichend verlässlich, d.h. neutral formuliert sowie auch transparent bereitgestellt sind. Zur Bestimmung konkreter Informationsmengen erscheint schließlich ein Rückgriff auf die Theorie der Informationsökonomie zweckmäßig, in der die Bestimmung optimaler Informationsmengen ein zentrales Element darstellt: ${ }^{101}$

Zunächst wurde angenommen, dass - bei Annahme einer Nicht-Existenz von Informationskosten - zusätzliche Information stets Nutzenzuwachs verursacht, der marginale Informationsnutzen einer weiteren Einheit Information wäre folglich niemals negativ. ${ }^{102}$ Dieses als trivial kritisierte „Feinheits-Theorem“ kann jedoch im Kapitalmarktkontext nicht akzeptiert werden: ${ }^{103}$ Es sind durchaus Situationen denkbar, in denen die Verfügbarkeit zusätzlicher Informationseinheiten eine Reduktion des Gesamtnutzens des Akteurs bewirken und daher abgelehnt würde. ${ }^{104}$ Jene Feststellungen führen schlussendlich zu der Erkenntnis, dass eine generelle

100 Es erfolgt erneut ein Rückgriff auf die Anforderungen des FASB an Informationen, vgl. FASB (2006a), CON2-3 und CON2-28f., Tz. 123ff., der die Forderung der ,Materiality“ aufstellt, auch Leffson (1986), S. 436. Strenggenommen handelt es sich bei der Wesentlichkeit gleichfalls in erster Linie um eine qualitative Anforderung, die jedoch im Hinblick auf die Quantität an Informationen interpretiert werden kann, vgl. ebenda.

101 Vgl. hierzu Ballwieser (1991), S. 100.

102 Vgl. Blackwell (1951) mit der These einer Nicht-Negativität (marginalen) Informationsnutzens: Gewählt würde immer das Informationssystem mit der größeren Feinheit; auch als ,Blackwell-' bzw. ,Feinheitstheorem' bezeichnet, vgl. Ballwieser (1991), S. 112f. Wagenhofer/Ewert (2007), S. 64f. weisen darauf hin, dass dieses Theorem kontextunabhängig ist, es knüpft allein an die Eigenschaften des Informationssystems an.

103 Laut Ballwieser (1985b), S. 50 eine triviale Annahme, denn jenes „besagt im Kern, dass bei kostenloser Informationsproduktion und -verarbeitung mehr Informationen besser sind als weniger". Dies kann nur im theoretischen Ein-Personen-Kontext gelten.

Vgl. Wagenhofer/Ewert (2007), S.75f. Bereits eine Berücksichtigung von Informationskosten relativiert die Implikationen des Feinheitstheorems im Ein-Personen-Kontext. Im Mehr-Personen-Kontext, d.h. bei Interdependenz der Handlungen einzelner Akteure, bestünde weiterhin ex ante ein nicht diversifizierbares Informationsrisiko (Unsicherheit über das Signal des Informationssystems). Dieses ist annahmegemäß identisch mit dem Überschussrisiko, das durch Diversifikation am Markt hätte reduziert werden können.

Es kann also gezeigt werden, dass Investoren es vorziehen würden, selbst eine kostenlos verfügbare Information nicht zu erhalten (sog. ,Informationsablehnungstheorem") und sogar bereit wären, für die Unterdrückung einer Information zu zahlen. Vgl. ausführlich zum Ablehnungstheorem Wagenhofer/Ewert (2007), S. 76ff.; Ewert (1989), S. $261 \mathrm{f}$. 
optimale Informationsmenge nicht abgeleitet werden kann - vielmehr wäre anzunehmen, dass subjektspezifische Optima existieren. Selbst bei kostenloser Informationsverbreitung sind beschränkte Aufnahme- sowie Verarbeitungskapazitäten als Grund dafür zu sehen, dass unbegrenzte Nachfrage nach Informationen und damit vollkommene Informationsverbreitung nicht realistisch erscheint. ${ }^{105}$

Das soeben Festgestellte gilt in besonderem Maße, wenn durch Einführung von Transaktionskosten bspw. für die Produktion, Verbreitung, Beschaffung und die Verarbeitung von Information der Realitätsbezug des Modells erhöht wird. Die zur Fundierung von Anlageentscheidungen benötigte Informationsmenge wäre schließlich durch jeden Investor individuell unter Bezugnahme auf die konkrete Entscheidungssituation festzulegen. Ergo wäre dieser gefordert, die gewünschte Informationsmenge unter Berücksichtigung der damit einhergehenden Kosten zu beschaffen und zu verarbeiten. Dass eine derartige Vorgehensweise im Kapitalmarktkontext weder praktikabel noch effizient ist, steht wohl außer Frage.

Lösungsmöglichkeiten können im nächsten Abschnitt aufgezeigt werden. Dabei soll davon ausgegangen werden, dass Investoren dem Bild des ,durchschnittlich verständigen Investors' gleichen, um einen Bezugspunkt bzgl. der soeben angesprochenen Informationsverarbeitungskapazität bzw. -kompetenz zu erhalten. ${ }^{106}$ Für dieses Leitbild der Investoren wird unterstellt, dass bei der Informationsbeschaffung grds. Transaktionskostenminimierung angestrebt wird, konsequenterweise rücken daher öffentlich zugängliche und standardisierte Informationen in den Fokus der Betrachtung: Während öffentliche Zugänglichkeit die Kosten der Beschaffung reduziert, führt eine Standardisierung zur Reduktion der Kosten der Informationsauswertung bzw. -verarbeitung.

I1! Vielmehr wäre von einer Informationsüberlastung bzw. einem sog. „Information Overload" auf Seiten der Informationsadressaten auszugehen, den Kroeber-Riel/Esch (2000), S. 9ff. - zwar aus der Marketing-Perspektive - aber treffend und verallgemeinerbar beschreiben, ähnlich auch Berthel (1992), Sp. 873; Esch (2004), S. $31 \mathrm{ff}$. kundig, um Anlageentscheidungen mittels öffentlich bereitgestellter Informationen zu treffen, und ist daher auch Leitbild zahlreicher Debatten zur Weiterentwicklung der USamerikanischen Rechnungslegung. Auf jenes Leitbild nimmt ebenfalls die SEC, die USamerikanische Wertpapieraufsichtsbehörde, Bezug, vgl. SEC (2010), § 210.1-02, innerhalb der deutschsprachigen Literatur Köster (1992), S. 46; Rolvering (2002), S. 7. 


\subsubsection{Private versus öffentliche Bereitstellung von Informationen}

Für die Bereitstellung von Informationen stehen grds. zwei alternative Wege zur Verfügung, die private sowie die öffentliche Bereitstellung. ${ }^{107}$

Bei einer privaten Bereitstellung erfolgt die Veröffentlichung ausschließlich auf Basis privater Arrangements, die insb. Menge, Qualität sowie Gegenleistung der Informationslieferung regeln - die optimale Menge an Information resultiert sodann aus den Kosten der Informationsproduktion bzw. der Zahlungsbereitschaft des Empfängers. ${ }^{108}$ Eine Bereitstellung von Unternehmensinformationen erfolgt also rein aufgrund marktlicher Koordination, determiniert allein durch Angebot und Nachfrage - eine übergreifende Regulierung erfolgt nicht. ${ }^{109}$

Neben einer privaten Vertragsregelung kann auch die sog. ,Signalling-Theorie als Begründung für eine private Bereitstellung von Unternehmensinformationen herangezogen werden: Hintergedanke dieser ist die Überlegung, dass eine Freigabe von Informationen nicht nur für den Empfänger, sondern auch für den Bereitsteller einen Wert besitzen sollte: ${ }^{110} \mathrm{Da}$ am Kapitalmarkt annahmegemäß für alle Unternehmen grds. eine identische zukünftige Entwicklung unterstellt wird, könnten die Unternehmen, welche sich besser als der Durchschnitt entwickeln, Anreize sehen, sich durch eine freiwillige Publikation positiver Nachrichten zu differenzieren. Der Charme dieser Theorie besteht v.a. darin, dass die Verläss-

107 Vgl. Kirchner (2000), S. 44. Vorausgesetzt ist, dass Unternehmen eine Gleichverteilung von Informationen an Adressaten anstreben, d.h. Bevorzugungen ausgeschlossen sind. Dies ist im modernen Kapitalmarktrecht grds. gesetzlich bzw. regulatorisch verankert. Vgl. im Folgenden ausführlich Feldhoff (1992), S. 108ff. Im Falle der privaten Bereitstellung von Informationen erscheint der Empfänger zugleich als Auftraggeber. Vgl. Schildbach (1986), S. 89f.

110 Vgl. grdl. Ross (1979), S. 182ff., zudem Feldhoff (1992), S. 109. Auf dieser Theorie der freiwilligen Informationsbereitstellung in der Absicht, positive Effekte am Kapitalmarkt hervorzurufen, beruht schließlich auch die sog. ,Voluntary Disclosure"-Theorie, die v.a. in der US-amerikanischen Literatur vorangetrieben wurde. Grdl. Beiträge lieferten z.B. Verrecchia (1983), ders. (1990), ders. (1999), ders. (2001); Dye (1985); Skinner (1994). Hinsichtlich möglicher positiver Kapitalmarkt-Effekte werden insb. die Auswirkungen auf die Kapitalkosten der Unternehmen betrachtet sowie andere Größen, die annahmegemäß als ,Stellvertretergrößen ' der Kapitalkosten angesehen werden. Die zuvor bereits erwähnten empirischen Arbeiten von Christine Botosan, vgl. Fn. 79, stehen eindeutig in der Tradition dieser Forschungsrichtung, die - insb. in methodischer Hinsicht - auch im weiteren Verlauf dieser Arbeit, u.a. für die eigene Untersuchung, bedeutsam sein wird. 
lichkeit der Informationen de facto nicht zu beachten ist, da eine bewusste Fehlinformation weitestgehend ausgeschlossen werden kann: „There is also evidence that investors view voluntary disclosures [...] as credible information. "II' Unternehmen hingegen, die keine Informationen freiwillig bereitstellen, werden vom Markt annahmegemäß gleichbehandelt - auch diejenigen, welche ausschließlich schlechte Nachrichten mitzuteilen hätten. Folglich besteht ein Anreiz, in jedem Fall Informationen bereitzustellen, da eine Nicht-Veröffentlichung als schlechtes Signal interpretiert würde. ${ }^{112}$

Kritisiert wurde das grdl. Modell der freiwilligen Informationsbereitstellung v.a. wegen der Annahme kostenloser Informationsveröffentlichung: ${ }^{113}$ Durch die Berücksichtigung ,indirekter Kosten“ einer Veröffentlichung erfuhr die SignallingTheorie sodann eine wesentliche Erweiterung, die maßgeblich durch Verrecchia vorangetrieben wurde. ${ }^{114}$ In der Folge ändert sich das Kalkül der Unternehmen dahingehend, dass positive Informationen nur dann veröffentlicht werden, wenn der Nutzen die gesamten Kosten übersteigt. ${ }^{115}$ Ergo erscheint die Interpretation einer Nicht-Veröffentlichung als grds. negative Nachricht fragwürdig - schließlich könnte es sich auch um eine positive Nachricht mit unvorteilhafter KostenNutzen-Relation handeln. Weiterhin ist das Grundmodell dahingehend zu hinterfragen, wie der Kapitalmarkt nicht-veröffentlichte Informationen interpretieren soll, wenn die Existenz der Nachricht nicht bekannt ist und ob die Annahme der grds. Richtigkeit freiwillig veröffentlichter Informationen nicht zu rigide ist. ${ }^{116}$

Es scheint offensichtlich, dass die marktliche Koordination oder die vollständig freiwillige Bereitstellung von Unternehmensinformationen als alleiniger Mechanismus nicht ausreichend ist - eine optimale Informationsversorgung wird sich

111 Healy/Palepu (2001), S. 407.

112 Einen grds. empirischen Beleg liefern Skinner (1994), insb. S. 57, Francis et al. (2008).

11.3 Vgl. zur Kritik an der Annahme kostenloser Veröffentlichung von Informationen bspw. Brotte, (1997), S. 97ff. Diese Kritik bezieht sich weniger auf die direkten Kosten (z.B. Druck), sondern eher auf die indirekten Kosten (z.B. negative Konkurrenzreaktionen). Vgl. grdl. Verrecchia (1983). Der Autor bezeichnet die indirekten Kosten der Veröffentlichung als ,Proprietary Costs', die durch die Veröffentlichung sensitiver Informationen entstehen, z.B. über neue Entwicklungen, strategische Ziele etc. 
nicht einstellen. ${ }^{117}$ Daraus nun zu folgern, freiwillige Bereitstellung sei grds. unwirksam oder nicht nutzenstiftend für die Veröffentlicher, wäre indes voreilig. ${ }^{118}$ Jedoch muss für die elementare Basis-Versorgung des Kapitalmarkts mit Unternehmensinformationen eine öffentliche Lösung, d.h. eine staatliche Regulierung, als augenscheinlich unausweichlich gelten. ${ }^{119}$ Bereitgestellte Informationen sind sodann nicht mehr Ergebnis freiwilliger Entscheidungen, sondern vielmehr der Verpflichtung zur Veröffentlichung einer definierten Menge und Qualität an Informationen. Die Rechtfertigung einer Verpflichtung kann vor dem Hintergrund potenziellen (Kapital-) Marktversagens als durchaus begründet gelten. ${ }^{120}$

Die Verpflichtung zur Veröffentlichung von Unternehmensinformationen sowie die Festlegung bzw. Normierung von Umfang und Inhalt der bereitzustellenden Informationen bewirkt schließlich den Zustand einer Standardisierung, welcher wiederum einen mindernden Einfluss auf die Transaktionskosten der Investoren besitzt. ${ }^{121}$ Weiterhin kann die Prinzipal-Agenten-Theorie einen Beitrag zur Begründung standardisierter Informationsbereitstellung leisten, da diese potenziell zur Reduktion von Informationsasymmetrien führt, indem sie - bezogen auf die konkret normierten Inhalte - zumindest die notwendige Voraussetzung für einen Zustand gleichmäßig verteilter Informationen darstellt. ${ }^{122}$

117 Vgl. bspw. Lev (1988), S. 11; grdl. Einhorn (2005).

118 Vgl. z.B. Wagenhofer (1990a), S. 1, der dennoch freiwillige Publizitätsanreize feststellt.

119 Vgl. grdl. Weizsäcker (1982), S. 326ff. Charakterisierendes Merkmal ist der Eingriff in die individuelle Handlungsfreiheit. Derartige Eingriffe sind jedoch stets zu begründen.

120 Zur Begründung des Marktversagens bspw. Fülbier (1999), S. 469ff. Da Unternehmensinformationen als öffentliche Güter anzusehen sind, könnten Interessierte nicht von der Nutzung ausgeschlossen werden - jene würden die Informationen dennoch in ihr Kalkül einbeziehen, ohne selbst Zahlungsbereitschaft für diese zu besitzen. Die Folge wäre eine Unterversorgung mit Unternehmensinformationen. Zu öffentlichen Gütern sowie ihren Merkmalen vgl. u.a. auch Luckenbach (2000), S. 168f. Eine Klassifizierung von Unternehmensinformationen als öffentliche Güter wird mitunter diskutiert, vgl. hierzu bspw. Gonedes/Dopuch (1974), Schmidt (1982), S. 740 sowie Feldhoff (1992), S. 107.

121 Regulierung kann auch aufgrund von Kostenaspekten befürwortet werden: Individuelle Lösungen verursachen Kosten der Vertragsgestaltung, was weniger zahlungskräftige Investoren aber benachteiligen würde. Vgl. bspw. Lev (1988), S. 6. Eine normierte Bereitstellung senkt Transaktionskosten auf Investorenseite, vgl. Ballwieser (2002b), S. 296.

Vgl. hierzu auch Ballwieser (2002b), S. 298f. Brotte (1997), S. 104f. sieht weiterhin ein gesamtwirtschaftliches Interesse an gleichmäßiger Informationsversorgung und schlussfolgert, dass Regulierung nicht a priori ineffizient bzw. unnötig sei. 
Die Vorteile der öffentlichen Lösung bei der Bereitstellung von Unternehmensinformationen durch Verpflichtung bzw. Normierung scheinen überaus attraktiv: Neben einer verbesserten Interpretations- sowie Vergleichsmöglichkeit aufgrund von Einheitlichkeit ist zudem auf eine erhöhte Verlässlichkeit der Informationen aufgrund des verbindlichen Charakters hinzuweisen. Weiterhin sprechen Skaleneffekte in der Erstellung, Auswertung und Prüfung sowie Lerneffekte auf Seiten der Ersteller und Auswertenden dank konsistenter bzw. beständiger Regelungen der Berichterstattung für eine öffentliche, verbindliche Bereitstellung. ${ }^{123}$

\subsection{Finanzberichterstattung als Informationsgrundlage der Akteure am Kapitalmarkt?}

Der Kapitalmarkt ist als Ort eines Zusammentreffens von Angebot an und Nachfrage nach finanziellen Mitteln definiert worden, für dessen Funktionsfähigkeit die Bereitstellung von Informationen unausweichlich erscheint: ${ }^{124}$ Investoren benötigen diese, um Schätzungen künftiger Zahlungsstromprofile vornehmen bzw. den inneren Wert eines Anlageobjektes ermitteln zu können - mit dem Ziel, Entscheidungen über Anlagealternativen zu treffen. Informationen, die hierbei hilfreich sind, können als entscheidungsnützlich charakterisiert werden.

Um diese Anforderung jedoch zu erfüllen, müssen Unternehmensinformationen nicht nur primär Prognosewert besitzen, um den unmittelbaren Bezug zur Zielgröße der zukünftigen Zahlungsstromprofile sicherzustellen, sondern zudem verlässlicher Natur sein. Darüber hinaus sollte die Bereitstellung der erforderlichen Unternehmensinformationen gesetzlich vorgeschrieben und der Inhalt der zu berichtenden Informationen normiert werden, da die rein marktliche Bereitstellung zwangsläufig zu einer unzureichenden Informationsversorgung führen muss.

12.3 Vgl. im Detail Baetge et al. (2009a), S. 52ff., die von „Malregeln“ (S. 52) sprechen. Es sei der Vollständigkeit halber angemerkt, dass die Kostensituation auf Unternehmensseite durch evtl. indirekte Kosten einer Veröffentlichung beeinflusst werden könnte, vgl. Ballwieser (2001a), S. 650 sowie außerdem Abschnitt B 2.3.3 dieser Arbeit, der sich mit möglichen Problemen der Veröffentlichung spezifischer Angaben auseinandersetzt. markets“, wenn eine ausreichende Informationsversorgung nicht sichergestellt ist. 
Gerade den letztgenannten Kriterien der Verlässlichkeit sowie der Verbindlichkeit scheint die Finanzberichterstattung auf Basis der externen Rechnungslegung in hervorragender Weise zu entsprechen. Die verbindliche Bereitstellung von Informationen über zentrale Erfolgsgrößen, geregelt durch Rechnungslegungsvorschriften, könnte den Informationsbedarf der Investoren insofern prinzipiell befriedigen. ${ }^{125}$ Offensichtlich ist also die „Rechnungslegung [...] ein Instrument, mit dessen Hilfe Unternehmen ihre Beziehungen zum Kapitalmarkt gestalten“126.

Der Zukunftsbezug - und damit die Entscheidungsrelevanz - der Informationen der Rechnungslegung dürfte auf den ersten Blick allerdings als gering eingestuft werden. Wenngleich in eher normativer Formulierung die „vornehmste Aufgabe des Reporting die Bereitstellung bewertungsrelevanter Information sein muss“, wirkt die externe Rechnungslegung als Informationsgrundlage zur Prognose zukünftiger Zahlungsgrößen zunächst weitgehend ungeeignet. ${ }^{127}$

Dennoch könnten Unternehmen dem Kapitalmarkt Informationen zur Verfügung stellen, die bei einer Schätzung von Zahlungsstromprofilen nützlich sein sollten: Gedacht sei hierbei insb. an Informationen über die zukünftige Ausrichtung des Unternehmens, also zur Strategie, da sich Unternehmen explizit im Rahmen der strategischen Planung mit der Ausgestaltung ihrer eigenen Zukunft beschäftigen. Derartige Informationen könnten - in einfacher Sichtweise - dazu dienen, dem Kapitalmarkt eine Vorstellung von der Unternehmenssituation in der Zukunft zu vermitteln, die wiederum die zukünftig aus dem Unternehmen an die Investoren fließenden Zahlungsströme determiniert. Informationen über die Strategie eines Unternehmens würden insofern einen gewissen Rahmen aufspannen, der bei der Schätzung konkreter zukünftiger Zahlungsgrößen Unterstützung leisten könnte. Auch wenn für Strategieinformationen gleichfalls gelten muss, dass sie aufgrund ihres Prognosecharakters per se eine geringere Verlässlichkeit aufweisen, könnte durch neutrale bzw. transparente Darstellung des Prozesses der Informationsent- 
stehung, der Prämissen bzw. der Kontextinformationen erreicht werden, dass bereitgestellte Informationen als entscheidungsnützlich zu charakterisieren wären. Zusammenfassend können folglich Angaben über die angestrebte Zukunft eines Unternehmens als kapitalmarktinduzierter Informationsbedarf und das bewährte System der normierten Finanzberichterstattung bzw. externen Rechnungslegung als kapitalmarktadäquates Bereitstellungsinstrument wichtiger Unternehmensinformationen charakterisiert werden. Es erscheint daher konsequent, die Frage zu stellen, ob nicht eine Bereitstellung strategieorientierter Informationen innerhalb des Rahmens der externen Rechnungslegung realisierbar ist: Die Verlässlichkeit des Systems der Rechnungslegung verknüpft mit der prognostischen Perspektive strategieorientierter Informationsinhalte könnte sodann bewirken, dass eine entsprechende ,strategieorientierte Berichterstattung ' in der Tat entscheidungsnützlichen Charakter für den Kapitalmarkt besitzt.

Um sich dieser Thematik anzunähern, sind die beiden Einzelaspekte der Unternehmensstrategie und der externen Rechnungslegung Gegenstand der folgenden Ausführungen: Zunächst beschreibt Abschnitt B 2 das strategische Management in der Unternehmenspraxis und leitet sodann die informationelle Bedeutung der Strategie her. Im Anschluss daran geht B 3 auf die Rolle der Rechnungslegung im Kapitalmarktkontext ein und präsentiert mit dem Lagebericht ein Instrument der Rechnungslegung, das aufgrund seines primär qualitativ-verbalen Charakters für eine Bereitstellung von strategieorientierten Angaben prinzipiell geeignet erscheint. Die Synthese dieser zwei Einzelaspekte erfolgt schließlich in Abschnitt B 4, der sich explizit mit einer strategieorientierten Berichterstattung innerhalb des Lageberichts auseinandersetzt. 
2 Strategisches Management zur

Gestaltung der zukünftigen Unternehmensentwicklung

\subsection{Inhaltliches Verständnis von "Strategie“}

Nachfolgend ist ein Überblick über das strategische Management zu vermitteln; nicht nur, um der herausragenden Bedeutung der Unternehmensstrategie gerecht zu werden, sondern auch, um ein solides Verständnis der Begrifflichkeit und der inhaltlichen Ausgestaltung der Strategie als Grundlage dieser Arbeit abzuleiten.

\subsubsection{Begriffliche Charakterisierung von "Strategie“}

Der Begriff der ,Strategie ' in der betriebswirtschaftlichen Literatur ist grds. von gewisser Unschärfe gekennzeichnet, diverse Ansätze zur terminologischen Abgrenzung existieren parallel: „There is not much agreement about strategy.“128 Daher wird der Begriff Strategie heute i.d.R. als Oberbegriff angesehen, denn es ist eine ,einheitliche Definition von Strategie und strategischer Planung bisher weder in Wissenschaft noch Praxis zustande gekommen "129. Gleichwohl muss dies nicht bedeuten, dass eine theoretische Beschäftigung mit der Begrifflichkeit überflüssig wäre. Zwar gilt, eine ,einwandfreie und erschöpfende Definition für

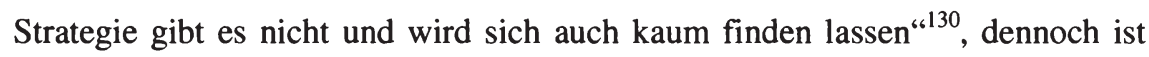
eine inhaltliche und kontextspezifische Auseinandersetzung mit dem Begriff der ,Strategie' hilfreich, was als Ziel der folgenden Ausführungen gelten kann.

Beginnt man bei der Etymologie dieses Begriffs führt dies in das Altgriechische, in dem ,stratos ' mit Heer und , agein ' mit ,führen ' zu übersetzen ist. ${ }^{131}$ So wurde schließlich der Begriff des ,strategos ' abgeleitet, der bereits deutliche Verwandtschaft mit ,Strategie' zeigt. Der ,strategos' kann als der Führer des Heeres interpretiert werden. ${ }^{132}$ Zudem wurde das militärische Oberkommando als ,Strategia ‘ bezeichnet, das sich primär mit militärischen, später aber auch mit politischen

128 Whittington (2001), S. 2. Diese prägnante Aussage entstammt der Arbeit des Autors, die den interessanten Titel „What is Strategy - and does it matter?“ trägt. Welge/Al-Laham (1993), S. 193.

130 Hinterhuber (2004), S. 17.

131 Auseinandersetzungen mit ,Strategie“ beginnen i.d.R. mit der etymologischen Begriffserläuterung - dem wird hier gefolgt. Vgl. bspw. Müller-Stewens/Lechner (2005), S. 8. 
Fragestellungen auseinandersetzte. ${ }^{133}$ Der Ursprung des heute verwendeten Begriffs der Strategie liegt folglich eindeutig im militärischen Bereich.

Diese Erkenntnis fortführend kann der Begriff in einen übergeordneten Bezugsrahmen eingegliedert werden. Eine Systematisierung ist von Clausewitz vorgestellt worden, der Strategie als Bindeglied in einem dreigliedrigen System aus Politik, Strategie sowie Taktik sah. ${ }^{134}$ Während Politik als übergeordnetes Zielsystem künftig zu erreichende Zustände vorgibt, umfasst Taktik alle operativen Tätigkeiten, die - unter Verwendung der zur Verfügung stehenden Mittel - zur Verwirklichung dieser Ziele erforderlich sind. ${ }^{135}$ Taktik dient in diesem Bild der Anwendung der durch die Strategie vorgegebenen, geplanten Mittel. Clausewitz charakterisiert Strategie folgerichtig als die „Lehre vom Gebrauch der Gefechte zum Zweck des Krieges“"136. Strategie bildet also einen Rahmen, in dem sodann konkretes taktisches Handeln erfolgt, das jedoch lediglich derivativen Charakter besitzt. Beachtenswert an der Arbeit Clausewitz' ist neben der Errichtung eines Systems dreier interdependenter Ebenen die Betonung des übergeordneten Zielsystems, das die Strategie inhaltlich leitet: „Man fängt keinen Krieg an [...] ohne sich zu sagen, was man mit und was man in demselben erreichen will.“،137

Es ist folglich festzuhalten, dass Strategie vom begrifflichen Ursprung her eine militärische Führungsaufgabe beschreibt - zudem besitzt sie primär planerischen Charakter, umfasst in diesem Begriffsverständnis jedoch weder die Zielbildung noch die konkrete Umsetzung, hat aber Schnittstellen zu diesen beiden Ebenen.

133 Vgl. Evered (1983), S. 58f., ähnlich Porter (1996), S. 63f.; Hahn/Simanek (2000), S. 18.

134 Vgl. grdl. Oetinger et al. (2003). Carl von Clausewitz war selbst als militärischer Führer tätig. In Diensten der preußischen Armee nahm er u.a. an den napoleonischen Kriegen teil. Aufgrund zahlreicher (meist posthum erschienener) Veröffentlichungen über Sinn und Zweck des Krieges sowie die Kunst der Kriegsführung hat dieser sich den Ruf eines ,Militärphilosophen' erarbeitet. Weiterhin wird Clausewitz heute i.d.R. als geistiger Urvater der modernen Strategielehre angesehen. Vgl. im Detail bspw. Schössler (1991). Vgl. Hinterhuber (2004), S. 23ff. Auch in einem weiteren klassischen Definitionsansatz des preußischen Generalfeldmarschalls Moltke wird eine Orientierung an einem übergeordneten Zielsystem erkennbar: „Fortbildung des ursprünglich leitenden Gedankens entsprechend den [...] sich ändernden Verhältnissen“, zitiert nach Hinterhuber (2004), S. 23. Clausewitz, (1905), S. 69.

137 Clausewitz (1905), S. 609, mit dieser Aussage schneidet Clausewitz auch die Trennung von Ziel und Zweck einer Handlung an: Erst nennt er Zweck, dann Ziel des Krieges.

Tom Sieber - 978-3-631-75150-3 


\subsubsection{Einzug strategischen Denkens in die Betriebswirtschaft}

Nicht zuletzt aufgrund seines militärischen Ursprungs hat dieser Strategiebegriff Verwendung im ökonomischen Kontext gefunden. ${ }^{138}$ Dies ist insofern nachvollziehbar, als militärische Theorien erste Grundlagen von betriebswirtschaftlichen Strategiekonzepten darstellten. ${ }^{139}$ Als Begründer dieser Transformationsleistung sind im deutschsprachigen Raum insb. Neumann/Morgenstern zu benennen, die erstmals im Jahre 1944 eine Anwendbarkeit strategischen Denkens innerhalb der Wirtschaftswissenschaften feststellten. ${ }^{140}$ Dabei wurde nicht nur das inhaltliche Verständnis von Strategie per se, sondern auch die Systematisierung übertragen: Analog werden Strategien nicht als Selbstzweck verstanden, sondern als Mittel zur Erreichung der durch die Politik vorgegebenen Ziele. Strategie erscheint also auch hier als eine „vom Endziel her abgeleitete, kohärente Schrittfolge“'141, als Richtungsvorgabe für in der Taktik oder Operation umzusetzende Aktivitäten.

Konkretere praktische Anwendung innerhalb der Betriebswirtschaftslehre erhielt strategisches Denken schließlich ab Mitte des 20. Jahrhunderts im Rahmen der Spieltheorie. ${ }^{142}$ Prägend für diese ist die sog. Interdependenz des Entscheidungsproblems, d.h. das konkrete Ergebnis einer Entscheidungssituation eines Akteurs wird determiniert durch Handlungen anderer Akteure. Der Entscheidungsträger muss daher bei einer Auswahl von Aktionen innerhalb des Spielfeldes beachten, welche Aktionen Mitspieler potenziell wählen können, um auf seine Aktionen zu reagieren. Ziel ist dabei, stets eine vollständige Beschreibung davon zu erstellen, welche Aktionen ein Spieler ggf. auszuführen plant, und zwar für jedes einzelne Entscheidungsproblem, das sich im Verlaufe eines Spiels stellen könnte. ${ }^{143} \mathrm{Zwar}$ wurde die Spieltheorie z.T. aufgrund ihres deterministischen Charakters im An-

138 Vgl. Bracker (1980), S. 219, auch Evered (1983), S. 59ff.

139 Vgl. Hinterhuber (1990) S. 3. Unterschiede zwischen dem militärischen sowie betriebswirtschaftlichen Strategiebegriff arbeitet Gälweiler (2005), S. 60f. heraus. Dennoch sind auch Ansätze bekannt, die unmittelbar militärstrategisches Vokabular und auch Denken im ökonomischen Kontext verwenden, vgl. z.B. Durö/Sandström (1986); Kotler/Achrol (1984), auch Danner (2003), S. 182.

140 Vgl. bspw. Hungenberg (2001), S. 4; Müller-Stewens/Lechner (2005), S. 8f.

141 Gälweiler (2005), S. 68.

142 Vgl. grdl. Knyphausen-Aufsess (2002), Sp. 1869; Welge/Al-Laham (2003), S. 12.

143 Für eine vertiefende Darstellung der Spieltheorie vgl. Holler/llling (2006), hier S. 34ff.

Tom Sieber - 978-3-631-75150-3 
gesicht dynamischer Umweltbedingungen kritisiert, doch bewirkte sie nach ihrer Einführung nicht weniger als einen radikalen Wandel des Verständnisses unternehmerischen Handelns: Sie zeigte erstmals, dass eigenes Handeln nicht nur von eigenen Zielen sowie Fähigkeiten determiniert wird, sondern auch Handlungen anderer Akteure zu berücksichtigen sind, um angestrebte Ziele zu erreichen. Das Handeln anderer Akteure stellt folglich einen Rahmen dar, der eigenes Handeln beeinflusst - der aber auch durch eigenes Handeln beeinflusst wird. ${ }^{144}$ Strategie, verstanden als Handlungsablauf eines Akteurs, ist in diesem Bild proaktiv sowie planerisch - und nicht nur reaktiv -, gleichwohl sind Aktionen anderer Akteure bei eigenen Planungen explizit zu beachten. ${ }^{145}$ Es ist somit zentrale Aufgabe der Strategie, eigene Potenziale bzw. Fähigkeiten mit den Bedingungen der Umwelt abzustimmen, um die zuvor gesetzten Ziele zu verwirklichen. ${ }^{146}$

\subsubsection{Ableitung eines Begriffsverständnisses von "Strategie«}

Um aufbauend auf dieser inhaltlichen Auseinandersetzung mit der Strategie ein Arbeitsverständnis abzuleiten, erscheint es zweckmäßig, auf die Charakteristika strategischen Denkens abzustellen: Zunächst ist also zu bemerken, dass Strategie nicht einem Selbstzweck, sondern zur Erreichung übergeordneter Ziele dient.

Diese Zielorientierung unterstreicht der instrumentale Charakter der Strategie als Bindeglied zwischen Zielen und Taktik/Operation. Operation hat schließlich zur Aufgabe, eigene Potenziale in der durch die Strategie vorgegebenen Ausrichtung einzusetzen - folglich können Potenziale als Steuergröße strategischen Handelns gelten. Wenn jedoch Strategie als ein Instrument zur Erreichung von Zielen verstanden ist, dann ist bei Erarbeitung und Umsetzung stets das Umfeld zu berücksichtigen, in dem die jeweiligen Ziele zu erreichen sind. Andernfalls läuft eine Strategie stets Gefahr, keinen Bezug zu den Bedingungen ihrer Umwelt zu besitzen, eine Zielerreichung kann sodann allenfalls noch zufällig gelingen.

\footnotetext{
144 Vgl. Knyphausen-Aufsess (2002), Sp. 1869; Holler/Illing, (2006), S. 34.

145 Vgl. Staehle (1999), S. 603.
}

146 In diesen Ausführungen kann die militärische Tradition strategischen Denkens erkannt werden: So sind - zur Zielerreichung - stets Vorstellungen über mögliche Aktionen und Reaktionen des Feindes notwendig, um die eigenen Truppen optimal steuern zu können. 


\subsection{Strategisches Management in der Unternehmenspraxis}

\subsubsection{Zeitliche Entwicklung des strategischen Managements}

Der Ausbau des strategischen Gedankenguts zu einem umfassenden Konzept für die Unternehmenspraxis lässt sich insb. vor dem Hintergrund sich verändernder Rahmenbedingungen der Unternehmensumwelt erläutern: Betriebliche Planung, verstanden als eine ,gedankliche Vorwegnahme künftigen Geschehens “147, hatte bis weit in die 1960er Jahre hinein überwiegend eine rein finanzwirtschaftliche Perspektive inne, d.h. Unternehmen beschränkten sich darauf, Zielvorstellungen bzgl. zentraler finanzwirtschaftlicher Kennziffern für die Folgeperiode(n) zu ermitteln. Diese Finanzplanung war auf ein geradezu idealtypisch stabiles Umfeld ausgerichtet, in dem Unternehmen mit einem relativ geringen Komplexitätsgrad agierten. Zweck der Finanzplanung war folgerichtig die Aufstellung sowie Einhaltung eines finanziellen Budgets für eine oder nur wenige Folgeperiode(n). ${ }^{148}$

Aufgrund ihres Ansatzes gelangt die Finanzplanung dann an ihre Grenzen, wenn eine längerfristige Vorausschau notwendig ist oder eine Stabilität des Umfeldes nicht mehr gegeben ist. Die Langfristplanung nimmt sich der Anforderung einer Horizonterweiterung an, indem Trendextrapolationen einer vorhersehbaren $\mathrm{Zu}$ kunft vorgenommen und sodann in mehrjährige Planungen umgesetzt werden. ${ }^{149}$ Die Unzulänglichkeit und mangelnde Aussagefähigkeit von Planungskonzepten, die auf Fortschreibung der Vergangenheit beruhen, scheint nachvollziehbar. ${ }^{150}$

Aus der Erkenntnis, dass die Vergangenheit keine geeignete Basis für Prognosen und eine zuverlässige Planung der künftigen Entwicklung komplexer Systeme in einem instabilen Umfeld bietet, resultiert sodann der Kerngedanke strategischen Handelns: Zentrale, erfolgskritische Umweltbedingungen sind zu identifizieren, $\mathrm{zu}$ verstehen sowie mit internen Potenzialen in Einklang zu bringen, um eine geeignete Position innerhalb dieser Umwelt zu wählen bzw. flexibel auf mögliche

147 Hahn/Hungenberg (2001), S. 61.

148 Vgl. Bea/Haas (2005), S. 12, auch Henzler (1988b), S. 1298f.

149 Vgl. Zahn (1979), S. 24f. und 28ff.; Klausmann (1982), S. 225 sowie Hahn/Klausmann, (1989), Sp. 414. Im Grunde handelt es sich dabei um eine reine Fortschreibung der Vergangenheit, eben unter Anwendung linearer Trendextrapolationen. 
Diskontinuitäten reagieren zu können. ${ }^{151}$ Der Fokus strategischer Planung liegt konsequenterweise darauf, Austauschbeziehungen zwischen dem Unternehmen und seiner Umwelt zu erkennen und hinsichtlich daraus folgender Implikationen zu verstehen, um sodann innerhalb dieses Umfeldes bestmöglich zu agieren. ${ }^{152}$

Ihren (zumindest vorläufigen) Abschluss findet die Evolution der betrieblichen Planungskonzepte schließlich im Konzept des strategischen Managements. Im Vergleich zur strategischen Planung betont dieses - durch eine Einbindung von Steuerungs- bzw. Kontrollprozessen - den Bezug zur Umsetzung geplanter Entwicklungen sowie die Bedeutung der sozialen Ebene der Führung. ${ }^{153}$ Mit diesem Schritt zu einem derart ausgestalteten, ganzheitlichen strategischen Management erreicht strategisches Denken im Kontrast zu den Vorläuferkonzepten ein neues Niveau: ${ }^{154}$ Dies manifestiert sich darin, dass eine Strategie nicht nur nach außen, auf die Interaktionen mit Kunden oder Konkurrenten, sondern auch nach innen, in das Unternehmen hinein, ausgerichtet ist. Durch Berücksichtigung interner Potenziale und Fähigkeiten sowie Einbindung und Mobilisierung der Mitarbeiter wird die Anpassungsfähigkeit des Systems Unternehmen innerhalb seines dynamischen Umfeldes gewährleistet. Zudem wird die Umsetzung strategischer Konzepte als Erfolgsvoraussetzung erkannt, ohne die das primäre Ziel strategischen Handelns, die Erreichung einer überlegenen Wettbewerbsposition bzw. eines bedeutsamen Wettbewerbsvorteils, nicht realisiert werden kann. ${ }^{155}$

Die Beschäftigung mit Strategie hat in der Form des strategischen Managements schließlich den Status einer eigenständigen wissenschaftlichen Disziplin erlangt und sich als ,Sammelbegriff für eine Reihe von unternehmensbezogenen Konzepten und Ideen“ etabliert. ${ }^{156}$ Die Anwendung des strategischen Managements in der Unternehmenspraxis konkretisiert der nachfolgende Abschnitt B 2.2.2.

\footnotetext{
151 Vgl. Welge/Al-Laham (2003), S. 10, auch Henzler (1988b), S. 1288.

$152 \mathrm{Vgl}$. Bea/Haas (2005), S. 50.

153 Vgl. Ansoff et al. (1999), S. 142 und für weitere Kritikpunkte Scholz (1987), S. 2.

154 Vgl. zu den nachfolgend beschriebenen Merkmalen des strategischen Managements im Detail Kirsch (1990), S. 323ff.

155 Vgl. Hinterhuber (1999), S. 65 sowie Hungenberg (2001), S. $5 f$.

156 Vgl. zur Entwicklung strategischen Denkens im Überblick Henzler (1988b), S. 1286f. 


\subsubsection{Operationalisierung des strategischen Managements}

\section{(a) Wettbewerbsvorteil als Zielgröße strategischen Managements}

In Anlehnung an den militärischen Ursprung strategischen Denkens ist Strategie ergo darauf ausgelegt, einen Sieg bzw. Erfolg zu erzielen. ${ }^{157}$ Erfolg im betriebswirtschaftlichen Sinne liegt vor, wenn das Oberziel unternehmerischen Handels, d.h. eine „Erhaltung und erfolgreiche Weiterentwicklung der Unternehmung“, 158 erreicht wird. Aufgrund des weitgehend abstrakten Charakters dieses Oberzieles ist eine Operationalisierung in konkrete Unternehmensziele erforderlich. Unternehmen können jene Ziele allerdings grds. nicht unmittelbar beeinflussen - vielmehr sind sog. Leistungstreiber bzw. Vorsteuergrößen zu fokussieren, durch die mittelbar die Erreichung definierter Ziele realisiert werden kann. ${ }^{159}$

Der zentrale Leistungstreiber, der die Erreichung dieses Oberziels unterstützt, ist der Wettbewerbsvorteil, der aufgrund elementarer Bedeutung auch das unmittelbare Ziel des strategischen Managements repräsentiert. ${ }^{160}$ Der Wettbewerbsvorteil ist folglich als der Ausgangspunkt jeder Beschäftigung mit Strategie zu verstehen und dieser wird erst dann erreicht, wenn eine ,value creating strategy not simultaneously implemented by any current or potential competitors "161 ${ }^{\text {realisiert }}$ wird. In der Literatur herrscht Konsens darüber, den Wettbewerbsvorteil als Ziel „of every competitive strategy “162 anzusehen - Day/Wensley (1988) formulieren: ,the notion that superior performance requires a business to gain and hold an

157 Vgl. Barney (1996), S. 27.

158 Vgl. Hahn/Hungenberg (2001), S. 13. Strategie ist folglich im unternehmerischen Sinne als Instrument zur (mittelbaren) Erreichung des Oberziels zu verstehen.

159 Vgl. Horváth/Kaufmann (1998), S. 42. So kann ein Unternehmen den Residualgewinn, als Operationalisierung des Oberziels, nicht aus sich selbst heraus beeinflussen.

160 Vgl. Hoffman (2000), S. 3f.; Hungenberg (2001), S. 14f. Z.T. wird in der Literatur auch das Erfolgspotenzial als Ziel des strategischen Managements genannt, Pfohl/Zettelmeyer (1987), S. 150f. oder Küpper (2001), S. 10ff. Erfolgspotenziale beziehen sich jedoch auf das unternehmenseigene Wissen und Können, während ein Wettbewerbsvorteil grds. am Markt orientiert ist und damit eine erfolgsnähere Vorsteuergröße darstellt, vgl. Glöckler (1995), S. 33. Winand (1989), S. 443 stellt fest, dass das Erfolgspotenzial ungeeignet als Steuerungsgröße für das strategische Management ist.

161 Barney (1991), S. 102. Bharadwaj et al. (1993), S. 84 sehen - korrekterweise - auch die Möglichkeit einer zwar gleich ausgerichteten, dafür aber besser ausgeführten Strategie. 
advantage over competitors is central to contemporary strategic thinking “163 und bestätigen so, dass Wettbewerbsvorteile zentrale Vorsteuergrößen für den Unternehmenserfolg sind. Diese elementare Bedeutung von Wettbewerbsvorteilen erschließt sich zudem vor dem Hintergrund der Rahmenbedingungen, unter denen Wettbewerb insb. auf reiferen Märkten stattfindet: ${ }^{164}$ Angesichts hoher Wettbewerbsintensität wird vermutet, dass Unternehmen dann keine Überlebenschance haben, wenn sie nicht über mindestens einen Wettbewerbsvorteil verfügen. ${ }^{165}$

In inhaltlicher Hinsicht lassen sich zwei Sichtweisen von Wettbewerbsvorteilen unterscheiden, die für die Beschäftigung mit Wettbewerbsstrategien interessante Ansatzpunkte bieten: So postuliert der ,market-based view of strategy“ (MBV) zunächst, dass die Struktur der Branche, in der ein Unternehmen agiert, herausragenden Einfluss auf den Unternehmenserfolg besitzt. ${ }^{166}$ Durch Ableitung von branchenspezifischen ,Triebkräften des Wettbewerbs ' wird die Wettbewerbsintensität der Branche ermittelt, der Unternehmenserfolg lässt sich sodann erklären als ,a function of two factors: the attractiveness of the industry in which the firm competes and its relative position in that industry“167. Der Wettbewerbsvorteil stellt den erklärenden Faktor für eine überlegene Position innerhalb der Branche dar und dieser resultiert wiederum aus dem Mehrwert, den ein Unternehmen für seine Kunden schafft. ${ }^{168}$ Inhaltlich ist der Wettbewerbsvorteil in dieser Hinsicht folglich definiert als eine im Vergleich zur Konkurrenz überlegene Leistung, die nicht nur bedeutsam, sondern auch wahrnehmbar für Kunden sowie von dauerhafter Natur ist. ${ }^{169}$ In diesem Verständnis manifestiert sich der nach außen, zum

163 Day/Wensley (1988), S. 1.

164 Vgl. Simon (1988), S. 1ff. Seither hat sich Wettbewerb auf reifen Märkten tendenziell noch verschärft. Vgl. bspw. Esch (2004), S. 27ff., der Charakteristika reifer Märkte benennt. Es ist einleuchtend, dass auf jungen Märkten die Wettbewerbsintensität grds. geringer ist, v.a. dank hohen Marktwachstums und einer niedrigeren Anzahl an Anbietern. Vgl. auch Simon (1988), S. 3ff.

166 Vgl. grdl. Porter (1994), S. 431 ff.; Eschenbach et al. (2003), S. 19ff. Jener MBV-Ansatz wurde maßgeblich von Porter vorangetrieben bzw. zu einem umfassenden Strategieverständnis ausgebaut. Die Ursachen von Wettbewerbsvorteilen in der Branchenstruktur zu suchen, folgt dem ,Structure-Conduct-Performance-Paradigma' der Industrieökonomik. Porter (1994), S. 431. Der Begriff der ,Triebkräfte' geht auf Porter (1999), S. 34 zurück. 
Markt gerichtete Blick, da sich qua definitione Wettbewerbsvorteile nur aus der Wahrnehmung der Kunden bzw. dem Vergleich mit Konkurrenten ergeben.

Kritisiert wurde der MBV-Ansatz insb. aufgrund der zentralen Annahme, jedes Unternehmen verfüge über eine identische Ausstattung an Ressourcen, die es im Wettbewerb seiner Branche einsetzt. ${ }^{170}$ Aus dieser Kritik heraus entwickelte sich der sog. , resource-based view of strategy ' (RBV). ${ }^{171}$ Aufbauend auf einer Studie von Barney (1991), welcher den Einfluss der Ressourcenausstattung von Unternehmen auf deren Erfolg analysierte, werden Wettbewerbsvorteile damit erklärt, dass ein Unternehmen dann seiner Konkurrenz dauerhaft überlegen ist, wenn es über Ressourcen verfügt, die wertvoll, selten, begrenzt imitierbar und einzigartig sind. ${ }^{172}$ Deutlich wird, dass der RBV-Ansatz Ursachen für Wettbewerbsvorteile im Unternehmen selbst, in der spezifischen Ressourcenausstattung vermutet. ${ }^{173}$ Daraus folgt auch, dass in diesem Ansatz keine Definition oder Abgrenzung der Industrie nötig ist, denn im Gegensatz zum MBV-Ansatz bedarf es keines Vergleichs mit Wettbewerbern, um einen Wettbewerbsvorteil zu ermitteln. ${ }^{174}$

Obgleich die Ansätze diametral unterschiedliche Ursachen für Wettbewerbsvorteile sehen, haben beide ihre Berechtigung: „Keine der Antworten wird dem Gesamtbild völlig gerecht, doch eine Kombination der Ansätze beschreibt sowohl den Status eines Wettbewerbsvorteils als auch seinen Entwicklungsprozess. “175 Für das strategische Management ist diese Äußerung bedeutsam, da sie klarstellt, dass die simultane Betrachtung von Ressourcen und Marktbedingungen erfolgen

170 Vgl. grdl. Barney (1991), S. 100. Auch konzentrierte sich die Kritik auf die Annahme, dass die vorhandenen Ressourcen als nahezu vollständig mobil angesehen werden. Dies muss angesichts realiter beschränkter Faktormobilität als restriktive Annahme gelten.

171 Vgl. Stabell/Fjeldstad (1998), S. 413. Die Ursprünge dieses Ansatzes reichen allerdings weiter zurück, vgl. Besanko et al. (2003), S. 426. Barney (2001), S. 54 beschreibt diese Ressourcen als ,tangible and intangible assets a firm uses to choose and implement its strategies". Es handelt sich hier um die Weiterentwicklung der Definition, die Barney in seinen ersten Arbeiten verwendet, vgl. bspw. Barney (1991), S. 101.

Vgl. Barney (1991), S. 100ff. Ressourcen können zudem heterogen sowie immobil sein, vgl. Priem/Butler (2001), S. 23; Wernerfelt (1984), S. 171ff. bzw. grdl. Penrose (1980).

Vgl. Krüger/Homp (1997), S. 67. Dies ist eine wesentliche Erkenntnis: Auf Basis überlegener Potenziale ist somit auch Wachstum außerhalb traditioneller Branchen möglich. Diese Potenziale konstituieren sog. Kernkompetenzen, vgl. hier Prahalad/Hamel (1990). 
muss: Interne Stärken sowie Schwächen sind mit externen Chancen und Risiken abzugleichen als Bedingung für Erfolg. Eine Beschränkung auf eine der beiden Perspektiven ist für die Begründung eines Wettbewerbsvorteils unzureichend. ${ }^{176}$

Strategisches Management darf sich allerdings nicht darauf konzentrieren, einen Wettbewerbsvorteil zu generieren - auch seine dauerhafte Absicherung ist nötig, um einen ,sustainable competitive advantage` zu erreichen. Diese Forderung resultiert aus der Erkenntnis, dass Vorteile, die von Konkurrenten schnell imitiert werden können, kaum Wert schaffen. ${ }^{177}$ Gerade in dynamischen Umfeldern stellt dies eine Herausforderung dar, weil sich folglich auch der Prozess der Schaffung und Aushöhlung von Wettbewerbsvorteilen beschleunigt. ${ }^{178}$ Erfolgskritisch wird deshalb, dass Unternehmen über eine ,ability to integrate, build and reconfigure internal and external competences to address rapidly changing environments "179 verfügen. Nach Auffassung von Rodriguez et al. (2002) verbleiben letztlich nur zwei potenzielle Quellen für dauerhafte Wettbewerbsvorteile: Innovation sowie Reputation. ${ }^{180}$ Eine weitere Perspektive fügt D'Aveni (1994) hinzu, der Manager dazu auffordert, die Quellen der Wettbewerbsvorteile in einer Branche proaktiv anzugreifen. Nur durch ein Angreifen sowie Zerstören dieser Quellen - auch der eigenen - und durch eine fortwährende Entwicklung neuer Wettbewerbsvorteile könnten Unternehmen in der sog. ,Hypercompetition' bestehen. ${ }^{181}$

176 Vgl. hierzu Barney (1991), S. 100. In diesem Zusammenhang wird von einem UmweltSystem-Fit gesprochen, d.h. ein Unternehmen hat seine Fähigkeiten optimal im Umfeld einzubringen. Zentrale Instrumente der strategischen Analyse betonen daher gleichfalls die simultane Berücksichtigung beider Perspektiven, vgl. Zajac et al. (2000), S. 431.

177 Vgl. Coyne (1986), S. 57ff.

178 Vgl. Day (1998), S. 67; Brown/Eisenhardt (1997), S. 1f. Auch Aspekte der Nachhaltigkeit sowie der Knappheit von (natürlichen, sozialen) Ressourcen führen zu veränderten Bedingungen für Unternehmen und deren Strategie, vgl. Rodriguez et al. (2002), S. 139. Vgl. Teece et al. (1997), S. 510ff., wörtliches Zitat auf S. 516. In dieser Aussage ist der Bezug zum RBV-Ansatz erkennbar, da hier aber externe Marktbedingungen explizit berücksichtigt sind, liegt eine simultane Anwendung der Ansätze vor, vgl. ebenda, S. 527. Vgl. Rodriguez et al. (2002), S. 143f. Dies stellt einen Bezug zur klassischen Ökonomie her: Während Schumpeter Überrenditen durch Innovation postulierte, erklärte Ricardo diese durch überlegene Ressourcenausstattungen - Reputation wird als nicht imitierbare Ressource betrachtet. Vgl. als Überblick Samuelson/Nordhaus (2001), S. 275f. Bzgl. der Schumpeter'schen Forderung nach, Schöpferischer Zerstörung 'vgl. ders. (2005). 
Wenngleich die Überlegungen zur Dynamik des Wettbewerbs nicht ohne Kritik bleiben können, zeigen sie einen wichtigen Aspekt strategischen Managements auf: Dieses ist keine einmalige Aufgabe, sondern vielmehr ein ständiger Prozess, der zum Ziel hat, unter Beachtung sich stetig wandelnder Umweltbedingungen marktorientierte Wettbewerbsvorteile aufzubauen, zu erhalten sowie neu zu entwickeln - v.a. auf Basis interner Ressourcen. ${ }^{182}$ Jener Prozessgedanke wird nachfolgend vertieft, um einzelne Phasen strategischen Managements aufzuzeigen.

\section{(b) Ebenen des strategischen Managements}

Strategisches Management in der Praxis kann sich - den generischen Elementen aufbauorganisatorischer Strukturen folgend - auf drei unterschiedliche Ebenen fokussieren: $\mathrm{Zu}$ unterscheiden sind sodann die Ebene des Gesamtunternehmens, die Ebene des Geschäftssegments bzw. des Geschäftsbereichs und die Ebene des Funktionsbereichs. ${ }^{183}$ Dementsprechend werden die einzelnen Konzepte auch als Unternehmens- (,corporate strategy'), Geschäftssegments- (, business strategy') oder als Funktionsbereichsstrategie (,functional strategy') bezeichnet. ${ }^{184}$

Diese Dreigliedrigkeit der Unternehmensorganisation ist dabei als logische Konsequenz aus einer gesteigerten Komplexität der betriebswirtschaftlichen Realität der letzten Jahrzehnte anzusehen. ${ }^{185}$ Zunehmende Diversifikation der Geschäftstätigkeit von Unternehmen und höhere Wettbewerbsintensität in den adressierten Märkten machten die Differenzierung der Organisationen in mehrere Geschäftsfelder notwendig; die gesamthafte strategische Steuerung auf der Ebene des Gesamtunternehmens schien aufgrund der Unterschiedlichkeit der Anforderungen und Bedingungen in den jeweiligen Märkten nicht mehr adäquat. ${ }^{186}$ In der Folge reagierten Unternehmen - unter der Voraussetzung hinrerchender Komplexität

182 Vgl. Besanko et al. (2003), S. 466f.; Teece et al. (1997), S. 523f. Die Kritik richtete sich v.a. auf die implizite Annahme, Unternehmen besäßen totale Freiheit hinsichtlich der zu vollziehenden Aktionen. Realiter werden sog. ,path dependencies' bestehen, die Unternehmen sind durch in der Vergangenheit getroffene Entscheidungen eingeschränkt. Vgl. grdl. zu aufbauorganisatorischen Elementen Krüger (1994), S. 95ff.

184 Vgl. Hax/Majluf (1996), S. 24f.

185 Vgl. einführend zu organisationellen Veränderungen Weißenberger (2003), S. 37ff.

186 Nach Auffassung von z.B. Colley et al. (2002), S. 3f. resultieren aus dieser Komplexität Schwierigkeiten für die oberste Unternehmensleitung, Entscheidungen für eine Vielzahl von Märkten zu treffen, die spezifische Betrachtung einzelner Geschäfte ist erforderlich. 
der bestehenden Organisationen - mit der definitorischen und organisatorischen Abgrenzung von Geschäftssegmenten, für die jeweils spezifische Strategien entwickelt werden. Diese Geschäftssegmente sind zu verstehen als organisatorische Einheiten, die klar voneinander abgrenzbare Produkt-Markt-Kombinationen darstellen, also eigenständige Geschäfte bzw. ,Unternehmen im Unternehmen ‘ ${ }^{187}$

Konsequenterweise ist also die eigentlich bedeutsame Perspektive strategischen Managements diejenige der Geschäftssegmentstrategie, denn diese setzt sich mit der Gestaltung, dem Erhalt und der Verbesserung der Wettbewerbsposition eines Segments in einem konkreten Markt auseinander. ${ }^{188}$ Wettbewerb, im Sinne eines Aufeinandertreffens mit Konkurrenten, findet schließlich primär auf der Ebene des Geschäftssegments statt und nicht auf der Ebene des Gesamtunternehmens, aus diesem Grunde ist der Begriff der, Wettbewerbsstrategie ' in erster Linie der Ebene des Geschäftssegments zuzuordnen. ${ }^{189}$

Auf der übergeordneten Ebene des strategischen Managements, im Rahmen der Strategie für das Gesamtunternehmen, erfolgt sodann eine Erarbeitung und Festlegung der strategischen Grundausrichtung für die Gesamtheit der Segmente. Es wird folglich transparent, dass es sich dabei nicht um Wettbewerbsstrategie im klassischen Sinne handeln kann, sofern das Gesamtunternehmen als die Summe seiner Produkt-Markt-Kombinationen gesehen wird. Vielmehr konzentriert sich die Unternehmensstrategie auf Inhalte wie die Gestaltung und Optimierung des Geschäftsfeldportfolios bzw. die Allokation von übergreifenden Ressourcen des Unternehmens auf die Geschäftsfelder. ${ }^{190}$ Das Portfoliomanagement, verstanden als die strategische Ausrichtung der Entwicklung des Gesamtunternehmens, kann

187 Abell (1980), S. 14ff. Dies zeigt sich auch eindeutig in der angelsächsischen Literatur, welche strategische Geschäftsfelder schlicht als ,Businesses ‘ bezeichnet. Vgl. Simmonds (1988), S. 17f.; Wheelen/Hunger (1992), S. 196. Im Folgenden werden die Begriffe Geschäftssegment, Geschäftsbereich oder Segment synonym verwendet. Vgl. Porter (1987), S. 46ff. Strenggenommen folgt diese Sichtweise dem besprochenen MBV-Ansatz, der annimmt, dass Wettbewerbsvorteile marktseitig konstituiert werden. $\mathrm{Zu}$ beachten ist jedoch, dass in dieser Sicht mögliche Synergieeffekte, die sich aus dem Zusammenwirken verschiedener Geschäftsbereiche ergeben können - und insofern auch als Rechtfertigung für eine Konzernierung mehrerer Geschäftsbereiche dienen -, ausgeklammert werden. Vgl. z.B. Weißenberger (2004), S. 14f. zu möglichen negativen Konsequenzen einer rein auf Geschäftsbereiche fokussierten Betrachtung. Vgl. stellvertretend für viele Müller-Stewens/Lechner (2005), S. 165. 
sodann drei generischen Richtungen folgen: Unterschieden werden Wachstums-, Stabilisierungs- und Desinvestitionsstrategien. ${ }^{191}$

Auf der dritten Ebene des strategischen Managements im Unternehmen dient die Funktionsbereichsstrategie schließlich zur Konkretisierung bzw. Umsetzung von Geschäftsbereichsstrategien. ${ }^{192}$ Funktionsbereichsstrategien besitzen somit nicht den Charakter originärer Strategien; Funktionalstrategien werden grds. aus übergeordneten strategischen Festlegungen hergeleitet und brechen diese als Voraussetzung der Umsetzung in kurzfristige Ziele herunter. Der Bezug jener Strategieebene zur Operativen wird insofern erkennbar. ${ }^{193}$ Für eine weitere Beschäftigung mit dem strategischen Management spielt die Ebene der funktionalen Strategien also keine Rolle, da diese i.W. der Detaillierung von Geschäftsbereichsstrategien dient und grds. Fragen der Unternehmensentwicklung i.d.R. nicht tangiert. ${ }^{194}$

\subsubsection{Strategisches Management in prozessualer Perspektive}

Für die weitere Auseinandersetzung mit dem strategischen Management scheint es sinnvoll, Verständnis für die mit diesem verbundenen Aufgabeninhalte herzustellen: Der Prozess des strategischen Managements wird damit angesprochen.

\section{(a) Zur Formalisierbarkeit strategischen Handelns}

Als Auftakt der Betrachtung der prozessualen Sicht strategischen Managements ist dessen generelle Formalisierbarkeit zu hinterfragen: $\mathrm{Zu}$ diskutieren ist, ob die Zerlegung des Strategiebegriffs in einzelne Phasen sinnhaft ist oder ob sich jener per se einer Formalisierbarkeit entzieht. Zwei konträre Ansichten existieren: ${ }^{195}$

Das ,klassische' Strategieverständnis ist weitgehend präskriptiv ausgerichtet, es basiert auf einer synoptischen Planungslogik und versteht Strategie daher als das

\footnotetext{
191 Vgl. grdl. Ansoff (1965), S. 132ff. Bzgl. der Wachstumsstrategien beschreibt dieser vier Optionen: Marktdurchdringung oder -erweiterung, Produkterweiterung, Diversifikation. Jene Systematisierung ist auch heute in praxi elementarer Kern strategischen Handelns.

193 Vgl. Welge/Al-Laham (2003), S. 409.

194 Vgl. Hungenberg (2001), S. 14ff. Funktionalbereichsstrategien besitzen folgerichtig nur derivativen Charakter. Ausnahmen sind grds. denkbar, z.B. bei Fertigungsdienstleistern. 
Resultat eines strukturierten und bewusst durchlaufenen Planungsprozesses; die Strategie erscheint sodann als rational geplantes Set von Maßnahmen bzw. Aufgaben. ${ }^{196}$ Diese recht technokratisch anmutende Sichtweise wird von ihren Kritikern folglich als sog. ,Designschule' beschrieben, da impliziert wird, dass eine Strategie quasi am Reißbrett planbar sei, indem eine vorgegebene Sequenz von eindeutig abgrenzbaren Arbeitsschritten konsequent abgearbeitet wird. ${ }^{197}$

Eine vollkommen gegensätzliche Auffassung wird v.a. von Mintzberg vertreten, die sich aus Kritik an dieser Rationalitätsprämisse präskriptiver Strategieansätze entwickelte. Während nicht bestritten wird, dass Strategie grds. Ergebnis formalrationaler Prozesse sein kann, wird hinzugefügt, dass sie dies realiter eher selten ist. Drei Arten von Strategien werden beschreiben: geplante Strategien, die umgesetzt werden (1), geplante Strategien, die nicht realisiert werden (2), realisierte Strategien, die nicht geplant wurden (3). Nur geplante, realisierte Strategien entsprechen dem klassischen Bild - mit dem Terminus der unrealisierten Strategien deutet Mintzberg aber darauf hin, dass Strategien trotz stringenter Planung in der Implementierung auch scheitern können. ${ }^{198}$ Emergente Strategien komplettieren das Bild, d.h. solche, die ungeplant entstehen und umgesetzt werden - trotz ihres Ursprungs kann es sich gleichwohl um konsistente Handlungsmuster handeln. ${ }^{199}$ Mintzberg zeigt folglich auf, dass Strategien nicht zwangsläufig einen rationalen sowie formalen Planungsprozess durchlaufen müssen, um eine Implementierung zu rechtfertigen und zum angestrebten Ziel zu führen - sie können dies aber.

Dieser Ansatz nimmt ergo die Gegenposition zur Planungsschule ein und widerspricht der grds. Annahme der Formalisierbarkeit der strategischen Planung. Das ist insofern bemerkenswert, da ein Beitrag zur Simplifizierung des strategischen Managements geleistet wird. Kritisiert wird insb. der technokratische Ablauf der

\footnotetext{
196 Vgl. Macharzina/Wolf (2005), S. 257, ebenso Welge/Al-Laham (2003), S. 13.

197 Vgl. grdl. Mintzberg et al. (2003), S. 37ff.; Hahn/Simanek (2000), S. 20f. Zur Kritik an ,Prozess-Schulen` und dem ,Primat der Planung`vgl. Steinmann/Hasselberg (1988).

198 Hinderungsgrund für eine Realisierung geplanter Strategien könnten bspw. Widerstände interner Strukturen sein: ,Structure may be malleable, but it cannot be altered at will just because a leader has conceived a new strategy", so Mintzberg (1990), S. 183. Jene Aussage widerspricht der ,Structure follows Strategy'-Sicht von Chandler (1966), S. 14.

199 Die Auffassung blieb jedoch nicht ohne Kritik, vgl. Ansoff (1991), S. 454: „Mintzberg prescribes a world free of explicit strategy formulation and free of strategic managers.“ 
Planungsschule und das strategische Management gewinnt somit nicht nur mehr konzeptionelle Offenheit, sondern auch deutlich größere Praxisnähe. ${ }^{200}$

Ohne den Wert des Ansatzes negieren zu wollen, bietet dieser für die inhaltliche Auseinandersetzung mit strategischem Management keine geeignete Grundlage, da andernfalls alles bedeutsame unternehmerische Handeln, geplant sowie ungeplant, als strategisch verstanden werden kann. ${ }^{201}$ Für den Zweck der inhaltlichen Auseinandersetzung rückt daher die Planungsschule - trotz berechtigter Kritik in den Fokus der Betrachtung: Wenngleich es sich dabei offensichtlich um eine Überidealisierung handelt, stellt das Denkmodell des Strategieprozesses eine geeignete Basis bereit, um das Aufgabenspektrum des strategischen Managements ganzheitlich zu betrachten. Dieser Argumentation wird hier explizit gefolgt.

\section{(b) Phasenmodell des strategischen Managements}

Inhaltlich ist ein Strategieprozess zunächst grds. als modellhaftes Vorgehen anzusehen, mit dem strategische Aktivitäten entwickelt bzw. umgesetzt werden. ${ }^{202}$ Der Begriff Prozess, als ein ,identifiable flow of information through interrelated stages of analysis directed toward the achievement of an objective ${ }^{\text {‘203 }}$, stellt erneut die Zielorientierung in den Vordergrund, das Ziel des Strategieprozesses ist folglich in der Realisierung eines Wettbewerbsvorteils zu sehen. In der Literatur sind einige Modelle vorgestellt worden, zwei davon sind kurz anzusprechen. ${ }^{204}$

In ihrem Prozessmodell trennen Thompson/Strickland (2003) fünf aufeinanderfolgende Phasen, die den Prozess des strategischen Managements konstituieren: Dabei ist der Strategieentwicklung i.e.S. als dritte Phase neben der Entwicklung von Vision bzw. Mission zudem die konkrete Zielformulierung vorgelagert. Die vierte Phase bildet die Implementierung, worauf sodann die Erfolgsmessung und Korrekturmaßnahmen folgen. ${ }^{205}$ Jene Sichtweise, die Phase der Zieldefinition in

\footnotetext{
200 Vgl. Müller-Stewens/Lechner (2005), S. 69f. Diese Ansicht hat z.B. für die empirische Strategieforschung Relevanz, u.a. zur Analyse konkreter Unternehmensentwicklungen.

202 Vgl. Pearce (1981), S. 39; Hahn/Hungenberg (2001), S. 45, früher Kosiol (1967), S. 79.

203 Pearce (1981), S. 45.

204 Vgl. für einen Überblick Bea/Haas (2005), S. 53f.

205 Vgl. Thompson/Strickland (2003), S. 7.
} 
den Prozess des strategischen Managements zu inkludieren, ist in der Literatur umstritten. Der Ansicht Clausewitz' folgend ist dieses abzulehnen, da normative Zielvorgaben als Fundament der Strategie charakterisiert wurden, nicht aber als inhaltlicher Bestandteil der Strategie selbst. ${ }^{206}$ Entsprechend lehnt Hahn (1999b) den Strategieprozess an den allgemeinen Führungsprozess an und verzichtet daher konsequenterweise auf den Einbezug der Zielbildung als explizite Phase. ${ }^{207}$ Ergo basiert in dieser Sichtweise - ausgehend von den Zielvorgaben der Unternehmensführung - die Phase der Strategieformulierung sowie -auswahl auf einer strategischen Analyse; eine Implementierung der definierten Strategie im Sinne operativer Umsetzung und eine Phase der Kontrolle finalisieren das Modell. ${ }^{208}$

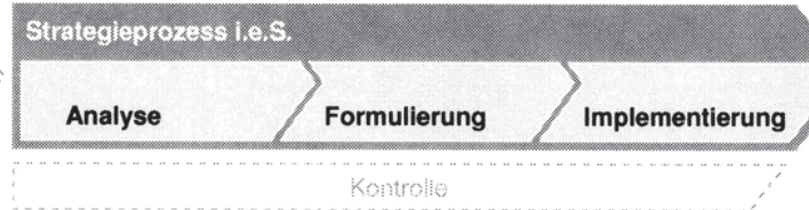

\section{Abbildung 4: Prozess des strategischen Managements ${ }^{209}$}

Obgleich der Sichtweise von Hahn grds. gefolgt wird, sieht das dieser Arbeit zugrunde liegende Prozessmodell - das Abb. 4 darstellt - eine explizite Phase der Kontrolle nicht vor. ${ }^{210}$ Eine Kontrolle als eigenständige Phase des Strategieprozesses erschiene letztlich nur dann sinnvoll, sofern das strategische Management einen eindeutig definierten Endpunkt besäße, so dass sich ex post eine Phase der Beurteilung anschließen könnte. Kontrolle wird hier jedoch so verstanden, dass diese sowohl im Rahmen der Analyse und auch der Strategieformulierung sowie -implementierung permanent Informationen für mögliche Korrekturen liefert. ${ }^{211}$

$206 \quad$ Vgl. bspw. Hungenberg (2002), Sp. 1889.

207 Vgl. bspw. Bleicher (1994), S. 491f., der explizit auf die Einbeziehung der Entwicklung von Mission und Zielen verzichtet, da dies Teil des normativen Managements sei.

208 Vgl. im Detail Hahn/Hungenberg (2001), S. 32ff., S. 96ff., auch Hahn (1999b), S. 34ff.

209) Quelle: eigene Darstellung in Anlehnung an Hungenberg (2001), S. 9.

210 Bei Hahn zielt eine Kontrolle in erster Linie auf die operativen Ergebnisse der Strategie und nicht auf die Strategie selber ab, vgl. ders. (1999b), S. 36.

211 Vgl. bspw. Schreyögg/Steinmann (1985), S. 391f., welche die Notwendigkeit einer fortlaufenden strategischen Kontrolle betonen, um ständiges Gegensteuern zu ermöglichen. 
Nachfolgend werden die Phasen des zugrunde gelegten Prozessmodells inhaltlich skizziert, um zu zeigen, wie eine Strategie in der Unternehmenspraxis erarbeitet wird bzw. um wesentliche Inhalte einzelner Phasen darzustellen. Auch wenn das Verständnis des Strategieprozesses i.e.S. auf den drei in Abb. 4 enthaltenen Elementarphasen beruht, scheint es aufgrund der Vollständigkeit und des engen Bezugs zueinander geboten, in aller Kürze auf die Zielbildung und Kontrolle einzugehen. Wohlgemerkt seien diese nicht als Phasen des Prozesses, sondern als das Fundament bzw. als fortwährende Tätigkeit innerhalb des Prozesses verstanden.

\section{(c) Zielbildung als Fundament des strategischen Managements}

Es wurde eingangs bemerkt, dass Unternehmen als Institution letztlich nur dann begründbar sind, wenn diese ihren zahlreichen Anspruchsgruppen als Instrument zur Erreichung individueller Zielvorstellungen dienen - die Ziele eines Unternehmens ergeben sich aus der Verdichtung von Individualzielen. ${ }^{212}$ Die so abgeleiteten Unternehmensziele lassen sich schließlich in eine Hierarchie einordnen, klassischerweise werden drei Ebenen differenziert: Die Vision, das Leitbild und die strategischen Ziele. Letztere sind zwar für die Strategie maßgeblich, werden jedoch ihrerseits durch die beiden vorgelagerten Zielebenen determiniert:

Auf der obersten Ebene bildet die unternehmerische Vision den langfristig anzustrebenden Zielzustand des Unternehmens ab und gibt somit die Ausrichtung des Strategieprozesses vor. ${ }^{213}$ Visionen werden i.d.R. bewusst vage sowie zukunftsorientiert formuliert, haben aber fundamentale Bedeutung für den Prozess ${ }^{214}$, da so „Unternehmensplanung [...] nicht im luftleeren Raum beginnen“ muss. ${ }^{215}$ Als Konkretisierung einer Vision ist das Leitbild Ausdruck der Unternehmenspolitik und fixiert das Wertesystem eines Unternehmens. Es dient insofern der Verwirklichung der Vision bzw. führt zu ihrer Operationalisierung, zudem stellt es einen Orientierungsrahmen für das strategische Management bereit. ${ }^{216}$ In diesem leitet das Management sodann strategische Ziele ab, als normative Vorstellungen über

212 Vgl. erneut Jensen (1983), S. 326 sowie ergänzend Jensen/Meckling (1976), S. 310f.

Vgl. zur Zielhierarchie Henzler (1988a), S. 29f.; Hahn/Hungenberg (2001), S. 108f.

Vgl. nochmals Henzler (1988a), S. 29; Hahn/Hungenberg (2001), S. 112.

Hammer (1998), S. 25.

216

Vgl. Hahn/Hungenberg (2001), S. 112. Ein Leitbild beinhaltet z.T. auch Restriktionen. 
künftig angestrebte Zustände der Unternehmensentwicklung, die konsequenterweise mit Vision bzw. Leitbild in Einklang stehen. Die Gesamtheit strategischer Ziele stellt folglich den Ausgangspunkt strategischen Handelns dar, diese dienen insofern dem strategischen Management als zentraler Orientierungspunkt. ${ }^{217}$

\section{(d) Strategische Analyse als erste Phase des Strategieprozesses}

Vor dem Hintergrund der exogen gegebenen Ziele ist eine Strategie zu deren Erreichung zu entwickeln. Dafür ist allerdings die möglichst umfassende Kenntnis des Umfeldes erforderlich, in dem sich das Unternehmen befindet - dies ist die Aufgabe der strategischen Analyse. Diese bildet als Startpunkt des Strategieprozesses i.e.S. die informationelle Voraussetzung für die Ableitung einer Strategie und aller nachfolgenden Aufgaben. ${ }^{218}$ Es ist zu bedenken, dass strategische Entscheidungen stets unter Unsicherheit zu treffen sind, daher ist die Anforderung an die strategische Analyse, Unsicherheiten zu reduzieren durch die Zusammenstellung eines möglichst umfassenden Bildes über die zentralen Einflussfaktoren des Unternehmensgeschehens. ${ }^{219}$ Dieses Bild wäre eindeutig als unvollständig zu klassifizieren, falls entweder eine Konzentration auf Umfeldfaktoren oder auf interne Ressourcen erfolgen würde. ${ }^{220}$ Vielmehr wurde bereits abgeleitet, dass es Charakteristikum strategischen Managements ist, interne Potenziale mit externen Umfeldbedingungen abzugleichen. Erst der Abgleich legt strategische Schlüsselfaktoren offen, diejenigen „Elemente, Determinanten oder Bedingungen [...], die den Erfolg oder Misserfolg unternehmerischen Handelns [...] beeinflussen “221.

217 Vgl. Hahn/Hungenberg (2001) S. 17f. Strategische Ziele lassen sich gliedern: Sachziele stellen auf sachliche Aspekte, bspw. Produkte, ab, Wertziele beziehen sich auf monetäre Größen und Sozialziele auf angestrebte Verhaltensweisen gegenüber Stakeholdern. Vgl. Hungenberg (2002), Sp. 1890. Auch Hahn/Hungenberg (2001), S. $318 \mathrm{ff}$. Vgl. Steinmann/Schreyögg (2000), S. 176.

220) Vgl. so Welge/Al-Laham (2003), S. 183; Hofer/Schendel (1984), S. 4: „Basic characteristics of the match an organization achieves with its environment is called its strategy." Kreikebaum/Grimm (1983), S. 7. Diese Zweiteilung manifestiert sich auch in einem der bekanntesten Instrumente strategischer Analysen, der sog. ,SWOT-Matrix ', vgl. Ansoff (1965), S. 90ff., auch Andrews (1987), S. $41 \mathrm{ff}$. In einer Vierfeldermatrix werden interne Stärken (,,strengths“) bzw. Schwächen (,weaknesses“) des Unternehmens sowie externe Chancen (,opportunities") bzw. Bedrohungen (,threats") der aktuellen und zukünftigen Unternehmensumwelt gegenübergestellt. Der ,Fit ${ }^{*}$-Gedanke wird erkennbar, demgemäß Unternehmen eine bestmögliche Anpassung an ihre Umwelt sicherzustellen haben.

Tom Sieber - 978-3-631-75150-3 
Gegenstand der externen Analyse ist es, Informationen über Art, Stärke und Zusammenspiel der Entwicklungen zu erhalten, denen das Unternehmen ausgesetzt ist, um so den externen Handlungsraum einer Strategie transparent zu machen. ${ }^{222}$ Aufgrund der Komplexität bzw. Vielschichtigkeit der gesamten Umwelt scheint eine Strukturierung angezeigt: Dementsprechend hat eine Analyse der globalen Umwelt, des Wettbewerbs, sog. strategischer Gruppen sowie der Konkurrenz zu erfolgen. ${ }^{223}$ Wesentliche Bedeutung kommt dabei naturgemäß einer Betrachtung des Wettbewerbs zu, in erster Linie meint dies eine Analyse der sog. Triebkräfte des Wettbewerbs, d.h. die Aufnahme sämtlicher Faktoren, die die Wettbewerbsintensität innerhalb der Branche determinieren. ${ }^{224} \mathrm{Da}$ weder Umfeld noch Wettbewerb statisch sind, greift - wie zuvor vermerkt - eine Momentaufnahme letztlich zu kurz - eine Dynamisierung der Betrachtung des Wettbewerbs scheint geboten, da zur Absicherung einer erreichten Position die stete Erneuerung eigener Wettbewerbsvorteile erforderlich ist. Folgerichtig bedarf es nicht einmalig, sondern vielmehr fortlaufend aktueller Informationen über Wettbewerber sowie die von ihnen gewählten Strategien bzw. über das allg. wirtschaftliche Umfeld. ${ }^{225}$

Eine Fokussierung der externen Analyse erfolgt weiterhin durch die Betrachtung strategischer Gruppen, d.h. Unternehmen in einer Branche, die als unmittelbarer, direkter Wettbewerb anzusehen sind und insofern von besonderer Bedeutung für die eigene Strategie sind. ${ }^{226}$ Den höchsten Grad der Konkretisierung im Rahmen

222 Vgl. Müller-Stewens/Lechner (2005), S. 158 sowie für einen umfassenden Überblick zu Instrumenten der Analyse ebenda, S. 158ff., auch Schreyögg (1984), S. 100. Vgl. Welge/Al-Laham (2003), S. 185. Es ist erkennbar, dass sich der Fokus der externen Analyse immer weiter eingrenzt: von der globalen Umwelt bis zum einzelnen, unmittelbaren Konkurrenten. Die globale Umwelt gilt i.d.R. als nicht beeinflussbarer Rahmen. Vgl. grdl. Porter (1979a), S. 137ff. Diese Triebkräfte stellen neben der SWOT-Analyse ein weiteres ,klassisches‘ Instrument der strategischen Analyse dar.

Vgl. nochmals D’Aveni (1994), S. 71ff. Der Autor beschreibt eine Eskalationsleiter, auf der sich Wettbewerb innerhalb einer Branche üblicherweise abspielt. Zur Kritik an der Sicht von D'Aveni bspw. McNamara et al. (2003). Der Hinweis auf die Notwendigkeit einer steten Aktualisierung der Analyse kann aber kaum ausreichend gewürdigt werden. Vgl. Homburg/Sütterlin (1992), S. 635ff. Abgrenzungsmerkmal strategischer Gruppen sind v.a. die verfolgte Strategie oder aber auch bestehende Mobilitätsbarrieren, so Porter (1979b), S. 215ff., auch Mascarenhas/Aaker (1989), S. 475f. Zu Mobilitätsbarrieren vgl. McGee/Thomas (1986). Die Bedeutung jener Gruppen ergibt sich aus der Idee, dass die Gruppenzugehörigkeit Einfluss auf die Profitabilität hat, vgl. Porter (1999), S. 183ff. 
der externen Analyse besitzt sodann die Untersuchung einzelner Konkurrenten dies wird als Voraussetzung für die Wahl adäquater Strategien angesehen. ${ }^{227}$

Im Rahmen der internen Analyse sind sodann eigene Stärken sowie Schwächen, vor dem Hintergrund der Erkenntnisse der externen Analyse, zu untersuchen. ${ }^{228}$ Klassische Analysen der internen Bedingungen konzentrieren sich zunächst auf die Auswertung finanzieller Kennzahlen, um Indizien für mögliche Stärken bzw. Schwächen zu entdecken. ${ }^{229}$ Problematisch erscheint jedoch, dass diese Größen vergangenheitsbezogen sind, was aber angesichts der Ausrichtung der Strategie auf die Zukunft kaum zweckmäßig sein kann. Auch stellen jene Daten i.d.R. das konkrete Ergebnis der betrieblichen Tätigkeit dar und geben keine Hinweise auf kritische Vorsteuergrößen, die im Rahmen des strategischen Managements von Relevanz sind ${ }^{230}$ Folglich sind weiterführende Analysen erforderlich, wie bspw. eine Wertkettenanalyse, die anhand der betrieblichen Aktivitäten Anhaltspunkte für Differenzierungs- oder Kostenvorteile offenbart, welche zu Wettbewerbsvorteilen ausgebaut werden können. ${ }^{231}$ Kern der internen Analyse ist schließlich, die Beschaffenheit von Ressourcen zu ermitteln: Zu denjenigen Ressourcen, die zu betrachten sind, zählen insb. finanzielle, physische, Human- und technologische Ressourcen sowie die Reputation. ${ }^{232}$ Nach ihrer Identifikation sind Ressourcen hinsichtlich Stärken und Schwächen zu klassifizieren, bspw. mit Hilfe des sog. ,VRIO Framework', das auf insg. vier Fragen basiert: Die Frage nach dem Wert, der Seltenheit, der Imitierbarkeit sowie den organisatorischen Voraussetzungen der als relevant identifizierten Ressourcen. ${ }^{233}$

227 Vgl. bspw. Simon (1988), S. 5. Hier besitzt auch die Rechnungslegung hohe Bedeutung in Form des sog. ,Competitor Accounting ', vgl. grdl. Hoffjan (2003a), ders. (2003b).

228 Die parallele Gültigkeit von MBV- und RBV-Ansatz wird hier deutlich erkennbar. Vgl. Penrose (1980) S. 75; Chatterjee/Wernerfelt (1991), S. 34; Grant (1991), S. 114ff. sowie Knyphausen-Aufsess (1993), S. 771 f. Beispiel sind relative Kennziffern im Sinne des sog. ,Return on Investment" (RoI), vgl. als Überblick bspw. Siegert (1995), S. 580ff. Vgl. bspw. Coenenberg (2005), S. 923. Vgl. Porter (2000), S. 63, ebenso Hergert/Morris (1989), S. 178f.

Vgl. Grant (2000), S. $112 \mathrm{ff}$.

233 Vgl. Barney (1996), S. 145ff. Der Begriff VRIO ergibt sich aus den Anfangsbuchstaben von „,value“, „rarity“, „,imitability“ und „organization“, der vier Elemente des Konzepts. 
Die Informationen der Umwelt- sowie der Unternehmensanalyse können sodann verknüpft werden, indem durch Frühaufklärung Aussagen über potenzielle Entwicklungen mit strategischer Relevanz abgeleitet werden. ${ }^{234}$ Als Grundlage dient das ,Konzept der schwachen Signale', das postuliert, dass sich Diskontinuitäten grds. durch ,Signale' ankündigen. ${ }^{235} \mathrm{Ziel}$ ist daher die frühzeitige Identifikation und Interpretation dieser Signale, um möglichst rechtzeitig reagieren zu können, wenn eine strategisch bedeutsame Entwicklung bzw. „forthcoming development, either inside or outside of the organization, which is likely to have an important impact on the ability of the enterprise to meet its objectives" ${ }^{\text {(236 }}$ erkannt wurde. ${ }^{237}$ Aufbauend auf derartigen Erkenntnissen können Prognosen für die Zukunft entwickelt werden. ${ }^{238}$ Dabei ist zu beachten, dass Prognosen und Szenarien stets auf zahlreichen Annahmen zur Zukunft basieren; sie müssen daher zwangsläufig unvollständig bleiben, da gar nicht alle Möglichkeiten künftiger Entwicklungen berücksichtigt werden können - vielmehr muss das Blickfeld auf wenige relevante Aspekte begrenzt werden, strategische Analyse bedeutet also stets Selektion.

\section{(e) Strategieformulierung als Kern des Strategieprozesses}

Aufbauend auf den Erkenntnissen der Analyse bzw. den abgeleiteten Szenarien über die künftige Entwicklung von Umwelt und Unternehmen, wird - dem Prozessmodell der Abb. 4 folgend - eine Wettbewerbsstrategie formuliert. Konkret umfasst dies neben der Aufstellung und Detaillierung von Strategiealternativen und deren Bewertung hinsichtlich der Zielerreichung die Auswahl sowie Verabschiedung einer Strategie. ${ }^{239}$ Bedeutung besitzt insb. die Bewertung alternativer

234 Vgl. als Überblick Welge/Al-Laham (2003), S. 293; Hahn/Hungenberg (2001), S. 333ff. Vgl. Ansoff (1975), S. 22f.; Ansoff/McDonnell (1990), S. 369ff.; Hahn/Krystek (1979). Ansoff (1980), S. 133.

237 Vgl. Krystek/Müller-Stewens (1999), S. 182. Frühaufklärung beinhaltet eine Ermittlung von Trends (z.B. ökonomisch, technologisch) durch das sog. ,Scanning' sowie die nachfolgende Vertiefung durch sog. ,Monitoring'. Eine Bewertung der Relevanz dieser Entwicklungen erfolgt im Rahmen des ,Assessing ‘. Vgl. auch Ginter/Duncan (1990), S. 92; Wheelen/Hunger (1992), S. 118f.

Vgl. Makridakis et al. (1980), S. 13f. Prognosen sind zukünftige Zustände, die eintreten, wenn bestimmte Gegebenheiten eintreffen. Sie werden durch qualitative (z.B. SzenarioTechnik) oder quantitative Verfahren abgeleitet, auch Hahn/Hungenberg (2001), S. 331. Vgl. Hungenberg (2002), Sp. 1890. 
Strategien, da dies die finale Auswahl determiniert. Für eine Bewertung diverser Optionen liegen sowohl qualitative als auch quantitative Konzepte vor.

Qualitative Verfahren sind insb. zur Vorauswahl von Strategieoptionen hilfreich, um zu überprüfen, ob spezifische Voraussetzungen für eine bestimmte Strategie erfüllt sind: ${ }^{240}$ Ein relevantes Verfahren ist das Konzept des strategischen Fits, ${ }^{241}$ verbreitet ist bspw. ein Ansatz von Peters/Waterman (2000), der unterstellt, dass sich die Strategie möglichst harmonisch in ein System aus sieben Faktoren einzufügen hat, um zu überdurchschnittlichem Unternehmenserfolg zu führen. ${ }^{242}$ Auf diesem Ansatz aufbauend hat Krüger (1994) das Konzept der sog. strategischen Stimmigkeit vorgestellt und identifiziert als kritische Voraussetzung für den Erfolg einer Strategieoption deren mehrdimensionale Abgestimmtheit. ${ }^{243}$

Sofern als singuläres Oberziel sämtlichen strategischen Handelns die Steigerung des Unternehmenswertes akzeptiert ist, ist zusätzlich zur qualitativen Bewertung eine quantitativ-monetäre Bewertung von Strategiealternativen nur konsequent. Hier bieten sich neben den klassischen Verfahren der Investitionsrechnung wertorientierte Konzepte an: Eine Strategie ist dann wertsteigernd, sofern der Unternehmenswert nach ihrer Implementierung höher ist als zuvor. ${ }^{244}$ Durch diverse methodische Erweiterungen kann der Realitätsbezug der monetären Betrachtung weiter erhöht werden und so eine intensive quantitative Bewertung erfolgen. ${ }^{245}$

240 Vgl. Hungenberg (2001), S. 208. Ein weiteres Beispiel ist die sog. Nutzwertanalyse.

241 Vgl. Zajac et al. (2000), S. 431; Venkataraman/Camillus (1984), S. 513; Scholz (1987), S. 62. Das entspricht der Kontingenztheorie, die grds. die Notwendigkeit der Anpassung eines Systems an seine Umwelt postuliert.

242 Vgl. Peters/Waterman (2000), S. 30ff. Diese sieben Faktoren lauten Strategie (strategy), Struktur (structure), Systeme (systems), Spezialfertigkeiten (skills) und Stammpersonal (staff), Stil (style/culture) sowie Selbstverständnis (shared values/superordinate goals).

243 Vgl. Krüger (1994), S. 28ff. Dieser kritisiert das Konzept der ,7S ‘ als undifferenziert, unscharf und unvollständig, vgl. Krüger (1989), S. 13f. In einem Alternativentwurf sind Erfolgssegmente (u.a. die Strategie) mehrdimensional abzustimmen: Neben segmentinterner Abstimmung ist die Abstimmung zwischen Erfolgssegmenten notwendig. Sodann erfolgt eine Abstimmung der Segmente an die Umwelt bzw. die Segment-Kontingenz. Vgl. Rappaport (1998), S. 60f. Das Delta ist der ,Strategy Shareholder Value Added“.

245 Zur Kritik vgl. bspw. del Sol/Ghemawat (1999), S. 43ff. Die Autoren schlagen u.a. vor, durch Berücksichtigung von Real-Optionen bspw. die künftigen Möglichkeiten, die sich erst aus der Implementierung einer konkreten Strategie ergeben, zu quantifizieren.

Tom Sieber - 978-3-631-75150-3 


\section{(f) Strategieimplementierung als Übergang zur Operativen}

Die Implementierung einer ausgewählten Strategie ist als eine notwendige Voraussetzung für Erfolg anzusehen - dabei wäre es jedoch zu kurz gegriffen, unter Implementierung die reine Umsetzung zu verstehen, mindestens ebenso bedeutsam scheint eine Durchsetzung der Strategie: ${ }^{246}$ Zunächst bezeichnet Umsetzung die sachbezogene Ebene, also insb. die Konkretisierung einer Strategie in Maßnahmenpläne, i.d.R. verbunden mit einer Zeit- bzw. Budgetplanung. Diese Pläne können direkt der Operativen zur Umsetzung der Strategie übergeben werden.

Die Durchsetzung birgt für den Strategieerfolg größere Risiken: Diese spricht die verhaltensbezogene Ebene der Implementierung an und umfasst neben der Vermittlung der Strategie gegenüber Anspruchsgruppen auch deren Einweisung und Schulung, um nicht nur Verständnis zu erzeugen, sondern zudem Akzeptanz und Konsens bzgl. der Strategie zu erreichen. ${ }^{247}$ Schließlich ist es erforderlich, einen Teil der Anspruchsgruppen zu Promotoren jener Strategie zu entwickeln oder zumindest den Einfluss der Opponenten zu begrenzen. ${ }^{248}$ In diesem Kontext kommt dem Einsatz von Anreizsystemen hohe Bedeutung zu, definiert als „Summe aller bewusst gestalteten Arbeitsbedingungen, die bestimmte Verhaltensweisen [...] verstärken (und) die Wahrscheinlichkeit des Auftretens anderer [...] mindern“ ${ }^{\text {249 }}$ und insofern die Ziele von Eigentümern und Management zur Übereinstimmung bringen könnten. ${ }^{250}$ Bei der Ausgestaltung eines adäquaten Anreizsystems ist als Bemessungsgrundlage daher die Zielsetzung der Eigentümer zu reflektieren, um so Zielidentität herzustellen. ${ }^{251}$ Wenn strategisches Management eine Schaffung von Wettbewerbsvorteilen zum Ziel hat, müsste dies konsequenterweise auch als

246 Vgl. hier grdl. Hungenberg (2001), S. 293ff., auch Hahn/Hungenberg (2001), S. $251 \mathrm{ff}$.

Vgl. Kolks (1990), S. 114ff. Zu den Phasen der Kommunikation vgl. grdl. auch Schulz von Thun (2006), der Kommunikation, Verständnis und Akzeptanz voneinander trennt.

248 Vgl. zum Promotoren-Opponenten-Modell grds. Witte (1973); Krüger (2009), S. $205 \mathrm{ff}$. Krüger geht davon aus, dass sämtliches Verhalten durch ,mentale Modelle‘ zu erklären ist, vereinfacht verstanden als Modell im Bewusstsein des Menschen, vgl. Bach (2000).

Wild (1973), S. 47. Die Notwendigkeit ihres Einsatzes ergibt sich daraus, dass Prinzipal sowie Agent unterschiedliche Interessen haben. Anreizsysteme könnten zur Lösung sog. Moral-Hazard-Probleme beitragen, vgl. grdl. Weißenberger (2003), S. $52 \mathrm{ff}$.

Vgl. Hungenberg (1999), S. 723; Hungenberg (2001), S. 291. 
Grundlage dienen - was allerdings aufgrund eingeschränkter Messbarkeit nicht sinnvoll erscheint. ${ }^{252}$ Alternativ könnte folgerichtig eine Kennzahl zum Einsatz kommen, die das Oberziel der Unternehmenswertsteigerung repräsentiert. ${ }^{253}$

\section{(g) Kontrolle als fortwährende Tätigkeit strategischen Managements}

Auch wenn die strategische Kontrolle nicht als explizite Phase des strategischen Planungsprozesses bezeichnet wurde, ist ihre kritische Bedeutung für den Unternehmenserfolg offensichtlich: „Planung ohne Kontrolle ist [...] sinnlos, Kontrolle ohne Planung unmöglich.“ ${ }^{254} \mathrm{Da}$ die Tätigkeit der Kontrolle in dem zugrunde gelegten Verständnis als stets parallel verlaufende Rückkopplung gesehen wird und nicht als Endstufe des Strategieprozesses - ist sie mehr als eine reine Feedback-Funktion, sie erfüllt zudem eine Feedforward-Funktion: ${ }^{255}$ Die „Kontrolle tritt aus dem Status eines nachgeordneten, an fertige Planungen angeschlossenen Prüfverfahrens heraus und begleitet den gesamten Planungs- und Realisierungsprozess quasi als Alarmsystem von Anfang an“256. Kontrolle übernimmt sodann in Summe drei Aufgaben entlang des gesamten Prozesses: die strategische Überwachung, die Kontrolle der Prämissen sowie die Kontrolle der Durchführung. ${ }^{257}$ Strategische Überwachung erfolgt im Rahmen der strategischen Analyse als eine ständige, ungerichtete Beobachtung von Umwelt bzw. Unternehmen, um bislang nicht berücksichtigte Chancen und Risiken aufzudecken. Jene Tätigkeit hat folglich planungsübergreifenden Charakter, d.h. sie versetzt das Management in die Lage, neue Entwicklungen zu jedem Zeitpunkt im Strategieprozess aufzugreifen. Eine bereits in der Phase der Implementierung befindliche Strategie bleibt somit flexibel, eine Reaktion auf relevante Veränderungen der Umwelt ist möglich. ${ }^{258}$

\footnotetext{
252 Vgl. Hungenberg (2001), S. 193ff., ähnlich Becker (1987), S. 110.

Vgl. Hungenberg (2001), S. $195 \mathrm{ff}$.

254 Vgl. Wild (1982), S. 44.

$255 \mathrm{Vgl}$. Bea/Haas (2005), 230f.

256 Schreyögg/Steinmann (1985), S. 397.

2.57 Vgl. Schreyögg/Steinmann (1985), S. 401f.; Hasselberg (1989), S. 95; Preble (1992), S. 394; Julian (1993), S. 18f., z.T. in Anlehnung an Schreyögg/Steinmann (1985).

258 Vgl. Schreyögg/Steinmann (1985), S. 402f., welche diese Form der Kontrolle als ,Auf-
} fangnet $z$ ' für die beiden anderen Formen der Kontrolle beschreiben. 
Innerhalb des Strategieprozesses ist sodann zunächst auf die Prämissenkontrolle abzustellen: Bereits gesetzte Prämissen sind stets auf ihre Gültigkeit, bislang unbeachtete Prämissen auf ihre Strategierelevanz zu überprüfen. Diese Prämissenkontrolle dient also der permanenten „Überprüfung der den strategischen Plänen zugrunde liegenden Ausgangsannahmen auf ihre weitere Gültigkeit hin “259. Sie hat herausgehobene Bedeutung und erlaubt Planänderungen, noch bevor schwerwiegende, möglicherweise irreversible Fehler geschehen. ${ }^{260}$ Kern der Prämissenkontrolle sind die Annahmen, die von hoher Wichtigkeit für den Strategieerfolg sind. ${ }^{261}$ Derartige Kontrolle sollte stets parallel mitlaufen, sie besitzt insofern ein „kompensatorisches Verhältnis “ ${ }^{\text {262 }}$ zur Planung. Ihre Berechtigung erlangt diese Kontrolle auch aus dem sog. Ambiguitätsproblem der Planung, das Resultat der Unsicherheit ist und sich im strategischen Kontext erheblich verstärkt: Aus dem Setzen von Prämissen zur Reduktion von Unsicherheit in der Planung sowie der damit einhergehenden Selektivität resultiert ein zusätzliches, strukturelles Risiko und macht stete Überwachung dieser Vereinfachungen folglich unabdingbar. ${ }^{263}$

Durchführungskontrolle schließlich überwacht die Ergebnisse der Durchführung der Strategie, daher beginnt sie erst mit deren Umsetzung. ${ }^{264}$ Kontrolle bedeutet hier das Vergleichen eines realisierten Ist mit dem zuvor geplanten Soll bzw. das Feststellen sowie Analysieren von Abweichungen, also klassische Ergebniskontrolle. ${ }^{265}$ In diesem Verständnis ist sie der Komplementär der Planung, indem sie Soll-Größen für Vergleiche liefert. Kontrolle besitzt somit Ähnlichkeiten zu der Feedback-orientierten operativen Kontrolle, weil sie aber zur zukunftsbezogenen Umsteuerung dient, hat sie zusätzlich auch Feedforward-Charakter. ${ }^{266}$

261 Vgl. Schreyögg/Steinmann (1985), S. 401.

262 Schreyögg/Steinmann (1985), S. 396.
}

263 Vgl. Schreyögg/Steinmann (1985), S. 396. Zur exogen gegebenen Zukunftsunsicherheit kommt eine endogene ,Prämissenunsicherheit" hinzu, die als Methodenunsicherheit anzusehen ist. Zur Zukunfts- und Methodenunsicherheit Weißenberger (1997), S. 97ff. Vgl. Hasselberg (1989), S. 162f.

265 Vgl. Hahn/Hungenberg (2001), S. 47f.

266 Vgl. Schreyögg/Steinmann (1985), S. 403; Hasselberg (1989), S. 163f. Zur Forderung vorwärtsgerichteter Kontrolle im Rahmen der Strategie bereits Horovitz (1979), S. 6. 


\subsubsection{Zusammenfassung des inhaltlichen Strategieverständnisses}

Die Ausführungen in B 2.2 haben das dieser Arbeit zugrunde liegende Strategieverständnis abgeleitet sowie ausgestaltet, auf das im weiteren Verlauf - insb. im Rahmen der eigenen empirischen Untersuchung - rekurriert wird. Die zentralen Charakteristika sind zusammenzufassen: Es wurde gezeigt, dass das strategische Management, als ganzheitliches Konzept zur Gestaltung der zukünftigen Unternehmensentwicklung im Kern auf die Etablierung sowie Sicherung eines dauerhaften Wettbewerbsvorteils ausgerichtet ist, weil dieser eine geeignete Zielgröße darstellt, um die Erreichung der Oberziele eines Unternehmens zu unterstützen.

Relevante aufbauorganisatorische Ebene im Unternehmen, für welche ein Wettbewerbsvorteil angestrebt wird - und folglich in instrumentaler Perspektive eine Wettbewerbsstrategie abzuleiten ist -, ist die des Geschäftsbereichs, definitorisch klar abgegrenzter Einheiten, die jeweils spezifische Märkte adressieren.

Ein derartiger Wettbewerbsvorteil entsteht jedoch weder rein marktseitig, noch ist eine überlegene Ressourcenausstattung ausreichend: Erforderlich ist vielmehr der Abgleich der externen Markt- mit der internen Ressourcenperspektive. Auch ist strategisches Management keine einmalige Aufgabe, Dynamik der Umweltbedingungen macht ein kontinuierliches strategisches Management erforderlich.

Das Vorstellungsbild des Strategieprozesses ist schließlich zweckmäßig, um den Aufgabenumfang strategischen Managements entlang von drei elementaren Prozessstufen aufzuzeigen: Ausgehend von vorgegebenen Zielen erfolgt im Rahmen der Analyse die intensive Bestandsaufnahme der gegenwärtigen Unternehmensund Umfeldbedingungen sowie die Ableitung möglicher Entwicklungsszenarien. Auf dieser Basis können alternative Strategien entwickelt bzw. bewertet werden, die Auswahl einer adäquaten Strategie, ihre Detaillierung und umsetzungsfähige Operationalisierung - als Vorbedingungen ihrer technischen sowie mentalen Implementierung - komplettieren den Aufgabenumfang des Strategieprozesses. Es scheint konsequent zu fordern, dass eine kohärente Strategie alle drei Stufen des Prozesses zu durchlaufen hat. Sodann wäre es zugleich sinnvoll, im Hinblick auf umfassende Informationen zur Strategie, ebenfalls auf die drei Elementarphasen abzustellen, um insofern ein vollständiges Bild der Ausgangslage, der Strategie-

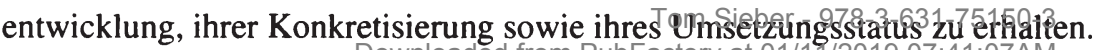




\subsection{Informationelle Perspektive der Strategie am Kapitalmarkt}

\subsubsection{Ableitung der Bedeutung strategieorientierter Informationen}

Die Bedeutung der Strategie per se kann zunächst unmittelbar aus der soeben erfolgten inhaltlichen Abgrenzung hergeleitet werden: Sofern Strategie darauf ausgerichtet ist, das generelle Oberziel einer langfristigen, erfolgreichen Weiterentwicklung zu erreichen, wird ihre Relevanz sogleich greifbar. Konsequenterweise bestätigt sich dies bei Operationalisierung des generellen Oberziels in Form der Steigerung des Unternehmenswerts: Wird als zentrale Voraussetzung für dessen Steigerung dauerhafter sowie nachhaltiger Erfolg im Wettbewerb akzeptiert und wird die Strategie als Mittel verstanden, genau diese Wettbewerbsvorteile aufzubauen und zu sichern, dient die Strategie mittelbar der Erreichung des Oberziels des Unternehmens, der Erhaltung und Steigerung des Unternehmenswerts. ${ }^{267}$

Neben jener intuitiv anmutenden, begriffsimmanenten Ableitung der Bedeutung der Strategie wird - in informationeller Perspektive - ein ,großes Interesse an der künftigen strategischen Ausrichtung des Unternehmens، ${ }^{، 268}$ auch in der Literatur unisono bestätigt. Das gilt in besonderer Weise für die Akteure am Kapitalmarkt, es gilt folglich: „ebenso wie das Management benötigen Finanzanalysten und Investoren Einblicke in die Strategie einer Publikumsgesellschaft.“269 Daher wird ein regelmäßiger Bericht über die Strategie sowie aktuelle bzw. zukünftige Entwicklungen als zentrale Aufgabe des Managements angesehen. ${ }^{270}$ Dies erscheint nachvollziehbar: Die Bereitstellung von Informationen über die angestrebte Entwicklung eines Unternehmens könnte eine Leitplankenfunktion bei der Prognose künftiger Zahlungsströme übernehmen und in der Folge zur Reduktion von Unsicherheit bei Anlageentscheidungen beitragen. ${ }^{271}$ Höhere Transparenz über den Entwicklungspfad eines Unternehmens würde zu einer Minderung des Gewichts

267 Vgl. zu dieser Argumentation exemplarisch auch Hahn/Hungenberg (2001), S. $151 \mathrm{f}$.

268 Baetge/Noelle (2001), S. 178. Ähnlich bspw. Ruhwedel/Schultze (2002a), S. 624f.

269 Labhart/Volkart (2001), S. 118, auch Pellens et al. (2000a), S. 181; Eccles et al. (2001). Den empirischen Beleg in Bezug auf Analysten liefern Glaum/Friedrich (2006), S. 166f. Autors regelmäßig und idealerweise in vergleichbarer Struktur erfolgen.

271 Vgl. Fischer et al. (2001a), S. 1210, die die Unterstützung bei Prognosen von Zahlungsströmen betonen, ähnlich Barron et al. (1999), S. 98; Bozzolan et al. (2008), S. 435. 
diskret geplanter Zahlungsströme und weiterhin zu einem besser fundierten Verständnis bei der Interpretation eines Restwerts führen. ${ }^{272}$ In inhaltlicher Hinsicht wird konsequenterweise nicht nur die Darstellung übergeordneter Ziele, zentraler Erkenntnisse der strategischen Analyse und einer konkret formulierten Strategie, sondern auch der Maßnahmen und Programme zu ihrer Umsetzung gefordert. ${ }^{273}$

Folgerichtig wurde die Bedeutung der Strategie empirisch - mit Fokus auf den Kapitalmarkt - bereits nachgewiesen: ${ }^{274}$ So zeigte eine Untersuchung von Ernst \& Young (1997) die herausragende Relevanz von strategieorientierten Angaben für den Kapitalmarkt auf. ${ }^{275}$ Weitere Arbeiten ermittelten zudem ein spezifisches inhaltliches Interesse an wesentlichen Indikatoren der strategischen Analyse. ${ }^{276}$ Außerdem existiert erhebliches Interesse seitens der Kapitalmarktakteure an Informationen bzgl. der Phase der Strategieformulierung, wie Eccles/Kahn (1998) belegen. ${ }^{277}$ Ähnliche Erkenntnisse sind ebenfalls bereits im Hinblick auf den dt. Kapitalmarkt vorgelegt worden: So zeigt Heumann (2005) $)^{278}$ in einer Befragung

272 Vgl. bspw. Labhart/Volkart (2001), S. 124ff. Die Autoren sind der Meinung, dass Angaben über Werttreiber aussagekräftiger seien als Prognosen zukünftiger Gewinne. Die Angaben könnten zudem die Betrachtungsperspektive bei der Bewertung verlängern. Vgl. Baetge/Heumann (2006a), S. 44; Fischer et al. (2001a), S. 1210f. Erkennbar wird, dass Angaben zu allen Phasen des in B 2.2.3 definierten Prozesses benötigt werden. Vgl. als Überblick Low/Siesfeld (1998), S. 25f., welche das Interesse von Kapitalmarktakteuren an nicht-finanziellen Informationen, insb. der Strategie, empirisch belegen. Vgl. Ernst \& Young (1997), insb. S. 7ff. ,Informationen zur Umsetzung von Strategien ‘ werden als zentraler nicht-finanzieller Indikator abgeleitet, gefolgt von der, Qualität der Strategie'. Weiterhin werden Angaben zu internen Ressourcen als relevant eingestuft. Vgl. Eccles/Kahn (1998), S. 8. Die Autoren bestätigen die Relevanz von Informationen der strategischen Analyse: Hohe Bedeutung besitzen demnach Angaben zu Stärken und Schwächen des Unternehmens sowie der Abgleich mit externen Chancen bzw. Risiken (dies entspricht den Elementen der SWOT-Analyse, vgl. auch Fn. 221). Als Indikatoren mit zentraler Relevanz werden aufgezählt: Marktanteil, Marktwachstum und Intellectual Property. Diese Befragung von Eccles/Kahn fokussierte auf US-Investoren.

277 Vgl. hier erneut Eccles/Kahn (1998). Für 62\% der Befragten besitzen Angaben über die strategischen Ziele hohe Bedeutung. Dieses Resultat bestätigt eine Studie mit Fokus auf den Schweizer Kapitalmarkt: 86\% der Investoren sowie 87\% der Analysten sehen Aussagen über strategische Ziele als bedeutsam an, vgl. Eccles/Weibel (2002), S. 703ff. Vgl. detailliert Heumann (2005), S. 203ff. Der Autor befragte verschiedene Akteure am Kapitalmarkt, u.a. Analysten bzw. Fondsmanager. Besondere Bedeutung wurde nachgewiesen für Informationen aus den Kategorien ,Ziele und Strategien " sowie ,Umfeld". Vgl. ähnlich zum Informationsbedarf von Finanzanalysten auch Achleitner et al. (2002), S. 37, zum Informationsbedarf von Analysten im Detail zudem Wichels (2002), S. 133f. 
von Investoren die hohe Bedeutung von Angaben zu Zielen, Strategien und dem Unternehmensumfeld zur Fundierung von Anlageentscheidungen. Jedoch weist der Autor auch darauf hin, dass die informationellen Bedarfe der Investoren bei weitem nicht befriedigt werden und stellt folglich ein erhebliches Defizit in der Strategiekommunikation der Unternehmen gegenüber dem Kapitalmarkt fest. ${ }^{279}$

Es ist zu konstatieren, dass Informationen zu strategieorientierten Sachverhalten grds. von Bedeutung zu sein scheinen - und zwar insb. für die Eigentümer bzw. Akteure am Kapitalmarkt. ${ }^{280}$ Jedoch finden sich erste Anzeichen dafür, dass Investoren derartige Angaben bis dato nur unzureichend bereitgestellt werden. ${ }^{281}$

\subsubsection{Beurteilung der Nützlichkeit von Informationen zur Strategie}

Wie unterstellt wurde, könnten strategieorientierte Inhalte am Kapitalmarkt insb. im Rahmen von Prognosen zur Reduktion von Unsicherheit beitragen, indem sie ein verbessertes Verständnis der künftig angestrebten Unternehmensentwicklung und spezifisch künftiger Zahlungsströme vermitteln. Insofern könnten Strategieinformationen genutzt werden, um Entscheidungen von Investoren zu fundieren, und wären ergo auf den ersten Blick als entscheidungsnützlich zu bewerten; eine detaillierte Prüfung soll mit Hilfe der operationalisierenden Kriterien erfolgen: ${ }^{282}$ Zur Bewertung einer Information hinsichtlich ihrer Entscheidungsrelevanz ist es erforderlich, dass eine „Entscheidung [...] mit dieser Information besser als ohne sie gefällt ${ }^{، 283}$ werden kann, d.h. eine informationelle Verbesserung durch den Erhalt der Information eintritt. Mit Blick auf strategieorientierte Angaben ist insb. auf die Prognosefunktion abzustellen, weil es sich primär um zukunftsgerichtete

279 Vgl. auch Heumann (2005), S. 215ff. 73\% der Investoren bestätigten, dass die Qualität der verfügbaren Angaben in der Kategorie ,Ziele und Strategien“ unzureichend ist.

280 Vgl. nochmals zur Bestätigung Baetge/Heumann (2006a), S. 44. Natürlich besteht eine Schnittmenge zwischen Kapitalmarktakteuren und den Eigentümern.

281 Vgl. hierzu u.a. Coleman/Eccles (1997), S. 4f.; Dempsey et al. (1997); Baetge/Heumann (2006b), S. 348ff.; Labhart (1999), S. 242 sowie insb. auch Abschnitt B 4 dieser Arbeit.

282 Es wird auf die allg. qualitativen Anforderungen an Informationen zurückgegriffen, vgl. Abschnitt B 1.2.3 im Detail zur Operationalisierung der Entscheidungsnützlichkeit mit Hilfe der Entscheidungsrelevanz sowie der Verlässlichkeit. 
Angaben handeln wird. ${ }^{284}$ Eine Prognosefunktion erfüllt Information dann, wenn sie die Entscheidungssituation eines Empfängers bzgl. künftiger Unternehmenszustände verbessert, also Vorhersagewert besitzt. Dies wäre dann gegeben, wenn die Angaben bei der Konkretisierung künftiger Zahlungsströme hilfreich sind. ${ }^{285}$

Der direkte Bezug von Strategieinformationen zu Zahlungsgrößen ist auf einen ersten Blick natürlich gering. Gleichwohl kann ein indirekter Bezug festgestellt werden, wie Abb. 5 offenbart: Strategie besitzt im Rahmen der Implementierung einen unmittelbaren Einfluss auf die realisierten Finanzergebnisse. Diese werden dem Kapitalmarkt üblicherweise mit Hilfe der externen Rechnungslegung bzw. Finanzberichterstattung präsentiert und als Grundlage der Schätzung zukünftiger Zahlungsströme verwandt. Die Bereitstellung strategieorientierter Informationen und eine darauf basierende Schätzung künftiger Zahlungsströme könnte folglich auf direkterem Wege zu einer Reflexion der ,Zukunft ‘ am Kapitalmarkt führen.

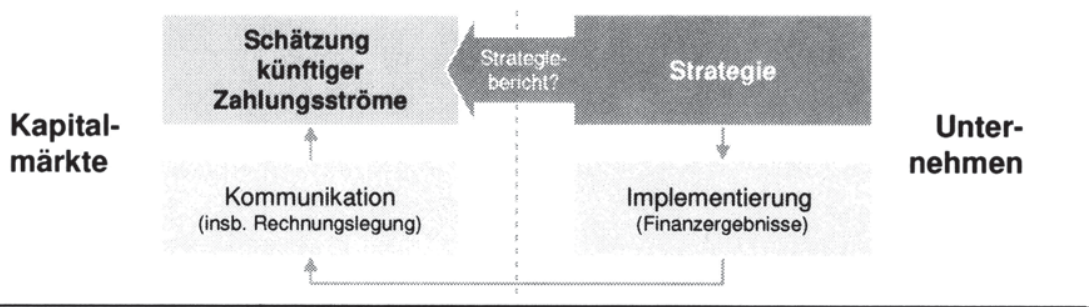

\section{Abbildung 5: Vorstellungsmodell zur Nützlichkeit von Strategieangaben ${ }^{286}$}

Für alle einzelnen Phasen des strategischen Managements lassen sich schließlich Informationselemente identifizieren, welche für die Empfänger am Kapitalmarkt bei der Prognose von Zahlungsströmen Relevanz besitzen könnten: ${ }^{287}$ Angaben zu strategischen Zielen würden zu erhöhter Transparenz über angestrebte Unternehmenszustände und über die langfristig geplante Entwicklungsrichtung führen

284 Vgl. zur Prognosefunktion bzw. zum Vorhersagewert von Information bspw. Ballwieser (2003), S. 341, früher auch Busse von Colbe (1993), S. 13f.

285 Der Vorhersagewert besitzt erwartungsbeeinflussende Wirkung, vgl. Bretzke (1979), S. 339; Dörner (1996), S. 231. Erwartungsbeeinflussung ist im IFRS-Framework fixiert, vgl. IASB (2009a), Tz. 26, „when it influences the economic decisions of users“.

286 Quelle: eigene Darstellung in Anlehnung an Scheele (2006), S. 104.

287 Vgl. hierzu sowie im Folgenden Scheele (2006), S. 103ff. Die Zielformulierung wird inkludiert, obwohl sie nicht originäre Phase strategischen Managements ist, vgl. B 2.2.3. 
und wären insofern als Rahmen finanzieller Prognosemodelle - trotz ihres primär abstrakten, komprimierten Charakters - hilfreich bzw. relevant. ${ }^{288}$ Informationen aus dem Bereich der strategischen Analyse erlaubten es den Empfängern, selbst Aussagen bzgl. externer bzw. interner Bedingungen abzuleiten, zentrale Erfolgsfaktoren zu identifizieren sowie vom Management bei der Strategieformulierung gesetzte Prämissen inhaltlich nachzuvollziehen. Besonderen Vorhersagewert besitzt konsequenterweise jedoch die selektierte Strategie, da sie nicht nur die konkreten Pläne des Managements darlegt, sondern zusätzlich eine Plausibilisierung finanzieller Zielgrößen bzw. Zahlungsstromprognosen ermöglicht. Angaben aus der Phase der Implementierung erfüllen gleichfalls eine Prognosefunktion, da sie die Fähigkeit eines Unternehmens zur Implementierung zuvor bereits gewählter Strategien offenbaren - was letztlich als Bedingung für die Relevanz (weiterer) strategieorientierter Informationen, die später präsentiert würden, gelten kann. ${ }^{289}$

Strategieorientierten Informationen ist auf Basis dieser Argumentation grds. ein Vorhersagewert zuzuschreiben, da diese innerhalb des Entscheidungskalküls der Investoren Relevanz besitzen könnten. ${ }^{290}$ Die Bereitstellung strategieorientierter Informationen sollte folglich zur Reduktion eklatanter Informationsasymmetrien führen, da genau diejenigen Informationen bereitgestellt würden, welche aus der Perspektive des Managements von wesentlicher Bedeutung sind. ${ }^{291}$

Die Relevanz strategieorientierter Informationen kann jedoch auch mit Hilfe der Kontrollfunktion hergeleitet werden: Diese Angaben scheinen geeignet, frühere Prognosen mit der de facto eingetretenen Entwicklung zu vergleichen. ${ }^{292}$ Weiterhin können Informationen über die angestrebte Ausrichtung eines Unternehmens die in der Vergangenheit gebildeten Annahmen hinsichtlich künftiger Zahlungs-

288 Vgl. Welge/Al-Laham (2003), S. 107. Kapitalgeber benötigen Angaben zu strategischen Prioritäten des Unternehmens, um die Kompatibilität ihrer Zielvorstellungen mit denen des Unternehmens zu ermitteln.

289 Dies deutet bereits auf die Kontrollfunktion der Information hin, vgl. im Folgenden.

290 Vgl. Baetge/Heumann (2006a), S. 44, welche dies als empirisch untermauert ansehen.

291 Vgl. Günther/Beyer (2001), S. 1629. Der Management Approach wird bei der Strategiekommunikation deutlich, vgl. Kajüter (2004a), S. 199; Kirsch/Scheele (2003), S. $2735 f$. Grdl. auch Weißenberger (2007), S. 324; Weißenberger/Maier (2006).

292 Auch das IFRS-Framework, F.27 weist auf die „,confirmatory roles of information“ hin, IASB (2009a), Tz. 27. Das IASB ist ein Standardsetter - ähnlich dem erwähnten FASB. 
ströme beeinflussen. Eine Information, welche frühere Einschätzungen bestätigt oder korrigiert, wird darüber hinaus Auswirkungen auf zukünftige Erwartungen haben - Vorhersage- und Bestätigungswert scheinen insofern eng verknüpft. ${ }^{293}$

Hinsichtlich der Verlässlichkeit, dem zweiten Kriterium der Entscheidungsnützlichkeit, existiert aufgrund der inhärenten Zukunftsorientierung von Strategieinhalten ein erheblicher Zielkonflikt mit der Entscheidungsrelevanz: „Oft sind die sichersten Informationen nahezu nutzlos, während die potenziell nützlichsten Informationen hochgradig unsicher sind.“294 Dieser konfliktäre Zustand zwischen Relevanz und Verlässlichkeit ist kaum auflösbar, es muss angenommen werden, dass Prognoseinformationen von geringer Verlässlichkeit sind - auch wenn ihre Relevanz auf den ersten Blick hoch zu sein scheint. ${ }^{295}$ Daher ist zur Beurteilung der Verlässlichkeit auf die Anforderung der Transparenz und der Neutralität zurückzugreifen: Wenn eine transparente Darstellung strategieorientierter Sachverhalte bzw. des Prozesses ihrer Entstehung erfolgt, ohne unmittelbar Handlungen beim Empfänger zu induzieren, wären sie folglich als verlässlich einzustufen. ${ }^{296}$

Bei der Beurteilung der Verlässlichkeit sind zudem Lerneffekte zu erwarten, der Kapitalmarkt erarbeitet sich unternehmensindividuelle Schemata zur Bewertung strategieorientierter Informationen. Die Verlässlichkeit kann außerdem erheblich durch Strukturierung bzw. Standardisierung der Angaben erhöht werden - dabei wäre jedoch darauf zu achten, dass die notwendige Flexibilität gewahrt bliebe. ${ }^{297}$ Strategieangaben besitzen für Investoren also grds. eine Entscheidungsrelevanz, wenngleich diese nicht unmittelbar zur Prognose von Zahlungsströmen hilfreich

293 Jenen Zusammenhang zwischen Vorhersage- und Bestätigungswert bestätigt das IASB, vgl. IASB (2009a), Tz. 27. Es scheint klar, dass bspw. mehrfache Nicht-Erreichung der Ziele zur Anpassung der Erwartungen und Einstufung der Prognosekompetenz führt.

294 Fey (2001), S. 57.

295 Vgl. Bretzke (1979), S. 338; Hayn/Matena (2005), S. 428ff. Baetge (1970), S. 173 zeigt einen Trade-off zwischen Relevanz und Verlässlichkeit von Prognose-Informationen.

296 Vgl. die Operationalisierung der Verlässlichkeit in Abschnitt B 1.2.3. Zur Erhöhung der Transparenz und Erleichterung der Plausibilitätsprüfung wird die Angabe von Prämissen und Kennzeichnung prognostischer bzw. subjektiver Aussagen vorgeschlagen, vgl. z.B. Heumann (2005), S. 109. Für Neutralität wird die angemessene Darstellung empfohlen.

297 Vgl. Haller/Dietrich (2001a), S. 1051f. Standardisierung würde die Plausibilisierung der Angaben wesentlich erleichtern und Strukturierung würde zu erhöhter Vergleichbarkeit führen, vgl. Baetge/Kümmel (2003), S. 55f.; Lehner (2004), S. 19f. 
sind. Auch sind Einschränkungen in Bezug auf die Verlässlichkeit zu beachten, diese können aber keine Begründung für eine Ablehnung solcher Informationen sein - der Kapitalmarkt wäre in der Lage, prognostische Informationen generell und auch Strategieinformationen - bei adäquater Darstellung - zu interpretieren.

\subsubsection{Problembereiche strategieorientierter Informationen}

Wenngleich die Bedeutung sowie Entscheidungsnützlichkeit strategieorientierter Informationen für den Kapitalmarkt offensichtlich scheint, sind in der Literatur zwei wesentliche Einwände zu vernehmen, welche als Argumente gegen die $\mathrm{Be}$ reitstellung derartiger Angaben ins Feld geführt werden:

Als zentraler Hinderungsgrund für die Kommunikation strategieorientierter Angaben gilt v.a. die Befürchtung negativer Wettbewerbswirkungen. ${ }^{298}$ Es wird ein Spannungsfeld zwischen der Bereitstellung aussagekräftiger Informationen und dem Schutz strategischer Wettbewerbsvorteile geltend gemacht; befürchtet wird, dass Wettbewerber aus den publizierten Inhalten sensitive und wettbewerbsrelevante Informationen gewinnen könnten. ${ }^{299}$ Es scheint plausibel, dass - aufgrund höherer Verlässlichkeit - in erster Linie von einem Unternehmen selbst bereitgestellte Angaben aufgegriffen würden, bspw. für Konkurrenzanalyen - strategieorientierten Informationen käme dabei sicherlich besondere Bedeutung $\mathrm{zu}^{300}$

In der Literatur wird diese Befürchtung der Unternehmenspraxis grds. akzeptiert, doch werden auch Gegenargumente genannt, die die Veröffentlichung strategieorientierter Informationen rechtfertigen: ${ }^{301}$ Zunächst wird darauf verwiesen, dass

298 Vgl. Günther et al. (2003), S. 456. Die Autoren zeigen empirisch die erwartete Wettbewerbsschädlichkeit als Kernargument gegen die Bereitstellung von Strategieangaben.

299 Vgl. bspw. Günther/Beyer (2001), S. 1628, ähnlich auch Heinen (2002), S. 22.

300 Vgl. Greinert (2004), S. 54f.; Labhart/Volkart (2001), S. 118f. oder Henselmann (2005), S. 300, der in der Strategie eine besondere kritische Informationskomponente sieht. Es erscheint nachvollziehbar, dass Informationen, die für Investoren entscheidungsnützlich sind, für Wettbewerber nicht irrelevant sein werden. Mit ähnlicher Argumentation auch Krystek/Müller (1998). Moxter (2003), S. 295f. ergänzt, dass Investoren kaum Interesse daran haben würden, dass aufgrund der Offenlegung von Strategieinformationen die Erfolgswahrscheinlichkeit ihrer Anlage gefährdet wird.

301 Vgl. Baetge/Heumann (2006b), S. 349. Außerdem Beiersdorf/Buchheim (2006), S. 98; Fink/Keck (2005), S. 138; Kaiser (2005a), S. 408, sowie gleichlautend dies. (2005b).

Tom Sieber - 978-3-631-75150-3 
auch ohne die explizite Veröffentlichung derartiger Angaben de facto zahlreiche entsprechend relevante Angaben diffundieren, welche von Konkurrenten aufgegriffen werden könnten. ${ }^{302}$ Auch wird angemerkt, dass Unternehmen selbst und v.a. proaktiv strategieorientierte Informationen preisgeben - meist jedoch unsystematisch und unter impliziter Billigung einer ungleichen Verteilung relevanter Informationen. ${ }^{303}$ Ergo muss der Unternehmenspraxis entgegengehalten werden, dass eine als Kernargument vorgebrachte Wettbewerbssensitivität von strategieorientierten Informationen in der Realität bereits dauerhaft missachtet wird. Umfassende, im Rahmen der Kapitalmarktkommunikation bereitgestellte Angaben zu strategieorientierten Sachverhalten würden hingegen nicht nur Einheitlichkeit der Information, sondern auch deren Verlässlichkeit sicherstellen. Dies wird z.T. auch als Argument genutzt, um eine verpflichtende, standardisierte ,Strategieberichterstattung ', z.B. als Teilaspekt der Lageberichterstattung, zu fordern. ${ }^{304} \mathrm{Da}-$ rüber hinaus scheint die Diskussion bisweilen zu einseitig geführt, positive Auswirkungen einer Strategiekommunikation bleiben weitgehend unbeachtet. ${ }^{305}$

Weiterhin wird auf Seiten der Unternehmen befürchtet, dass sich aus einer Veröffentlichung von strategieorientierten Informationen Haftungskonsequenzen für das Management ergeben könnten. ${ }^{306}$ In Deutschland wären sodann die Binnenhaftung von Organmitgliedern sowie die Organaußenhaftung zu beachten: Nach $\S 93$ Abs. 1 S. 3 AktG haben Organmitglieder die Pflicht zur Verschwiegenheit über vertrauliche Angaben einer Gesellschaft, was nach h.M. strategieorientierte

302 Vgl. Subramanian/Ishak (1998), S. 18. Die Autoren weisen v.a. auf die informationellen Effekte von Vertriebsmannschaften hin. Dies scheint intuitiv nachvollziehbar und kann sicher ausgeweitet werden auf allg. Gespräche innerhalb einer bestimmten Branche, gedacht sei auch an Mitarbeiter, die von einem Unternehmen zur Konkurrenz wechseln. Diese Argumentation findet sich auch beim deutschen Rechnungslegungs-Standardsetter DSR, vgl. DSR (2004b), zu ,Frage 10.) Geschäft und Strategie‘. Auch im Rahmen von z.B. Analystengesprächen werden Informationen bereitgestellt, die nicht jeder Investor erhält, vgl. Walmsley et al. (1992) zu den Bewertungseffekten solcher Ereignisse.

304 Vgl. so bspw. bei DSR (2006), S. 8f. sowie die nachfolgenden Ausführungen.

305 Diese Ansicht findet sich u.a. bei Meyer (2005), S. 107; Müller (1998), S. 135. Zudem kritisieren Ewert/Wagenhofer (1992), S. 301, dass es viel zu grob sei, nur von negativen Konsequenzen auszugehen, ähnlich bereits Moxter (1962), S. 13.

306 Vgl. Böcking/Müssig (2003), S. 40. Die Autoren erwarten v.a. dann Probleme, wenn die Pflicht zur Veröffentlichung von Strategieinformationen supranational geregelt würde, da das Haftungsrecht stets nationalstaatlich geregelt ist. 
Information inkludiert. ${ }^{307}$ Legt ein Organmitglied schuldhaft derartige Angaben offen, wäre es gem. $§ 93$ Abs. 2 S. 1 AktG schadenersatzpflichtig. ${ }^{308}$ Die Frage des Verschuldens dürfte realiter jedoch nicht ohne weiteres zu beantworten sein. In der Literatur wird daher darauf verwiesen, dass im Falle standardisierter, verpflichtender Veröffentlichung von Strategieinformationen dem Sachverhalt einer Pflichtverletzung die Grundlage entzogen würde. ${ }^{309}$

Eine Organaußenhaftung ergibt sich zudem aus $\S \S 37 \mathrm{~b}$ bzw. c WpHG aufgrund einer fehlerhaften oder unterlassenen Information der Kapitalmärkte. ${ }^{310}$ Die entsprechenden Tatbestandsvoraussetzungen regelt $\S 15 \mathrm{WpHG}$, um an bestehende Regelungen der ,Insiderinformation “ anzuknüpfen. ${ }^{311}$ Ergänzend dazu wird seit geraumer Zeit eine Verschärfung des Haftungsrechts diskutiert, ein sog. Kapitalmarktinformationshaftungsgesetz wurde vorgelegt, aber nicht verabschiedet. ${ }^{312}$

307 Vgl. § 93 Abs. 1 S. 3 AktG, der die Verpflichtung zur Verschwiegenheit über Betriebsund Geschäftsgeheimnisse regelt. Davon betroffen sind insb. vertrauliche Angaben und Geheimnisse der Gesellschaft, vgl. Hüffer (2006), § 93, Tz. 7. Strategieinformationen wären als solche Informationen zu charakterisieren, vgl. Kersting/Sohbi (1998), S. 302. Strenggenommen gilt § $93 \mathrm{AktG}$ nur für Vorstandsmitglieder, § $116 \mathrm{AktG}$ regelt jedoch die Sorgfaltspflichten der Aufsichtsräte und nimmt auf $\S 93$ AktG explizit Bezug. Vgl. § 93 Abs. 2 S. 1 AktG, der eine Schadenersatzpflicht vorsieht. Außerdem folgt aus $\S 404$ AktG die Strafbarkeit derartigen Handelns. Haftungsvoraussetzung ist die Pflichtverletzung und das Verschulden, der Grundsatz der Sorgfalt bzw. die Loyalitätspflichten lt. § 93 Abs 1 S. 3 AktG müssen verletzt sein, vgl. Schneider/Schneider (2005), S. 60.

Vgl. Kersting/Sohbi, (1998) S. 302. Im Umkehrschluss könnte dies bedeuten, dass unsystematische Veröffentlichung eine Pflichtverletzung gem. § 93 Abs. 1 AktG darstellt.

Vgl. §§ 37b bzw. c WpHG. Diese wurden durch das 4. Finanzmarktförderungsgesetz im Jahre 2002 eingefügt und können als Reaktion des Gesetzgebers u.a. auf die Ereignisse am ,Neuen Markt‘ gelten, vgl. Gerber (2004), S. 1794; Sünner (2004), S. $2460 f f$.

Ein weiteres Haftungsrecht ist in $\S 331 \mathrm{Nr}$. 1 HGB kodifiziert und ahndet die unrichtige Wiedergabe der Verhältnisse der Gesellschaft im Lagebericht durch Organmitglieder.

Vgl. § 15 WpHG. Der Gesetzgeber hat in $\S \S 37 \mathrm{~b}$ bzw. c WpHG keine neue begriffliche Definition verwendet und daher in $\S 15$ den Begriff der ,Insiderinformation ' eingeführt, der neben Insidertatsachen auch sog. ,Ad-hoc-publizitätspflichtige Tatsachen “ umfasst. Dieser greift auch für zukunftsorientierte Angaben, vgl. Steck/Schmitz (2005), S. 190. Insiderinformationen liegen gem. § 13 Abs 1 S. 2 WpHG v.a. dann vor, wenn ein durchschnittlich verständiger Anleger diese Angaben in seinem Entscheidungskalkül berücksichtigen würde. Für Strategieinformationen trifft dies zu, vgl. Ziemons (2004), S. 538.

Vgl. bspw. Köhler et al. (2004), S. 2625f.; Sünner (2004), S. 2462f. Mit dem Gesetzentwurf zum Kapitalmarktinformationshaftungsgesetz (KapInHaG) sollte insb. die Haftung der Organmitglieder ausgedehnt werden, damit jene nach außen für unrichtige Angaben haften. Der Entwurf wird derzeit nicht weiterverfolgt, vgl. Duve/Basak (2005), S. 2645.

Tom Sieber - 978-3-631-75150-3 
Für eine Veröffentlichung von Strategieinformationen erscheint die Debatte über Haftungsgefahren nicht unbedeutend zu sein, da es sich bei derartigen Angaben primär um qualitativ-verbale Angaben handelt und diese zudem durch subjektive Einschätzungen bzw. Urteile geprägt sind. Daher wird die ex post durchgeführte Beurteilung der korrekten Wiedergabe bzw. der objektiven Richtigkeit stets problematisch sein. Jedoch hat auch hinsichtlich des Einwands möglicher Haftungskonsequenzen zu gelten, dass dieser eher gegen die Praxis der unsystematischen, unregelmäßigen Veröffentlichung spricht als gegen eine Bereitstellung strategieorientierter Informationen per se: Die systematische, standardisierte sowie an die breite Öffentlichkeit gerichtete Bereitstellung könnte Rechtssicherheit schaffen und Haftungsfragen sodann auf tatsächliche Verstöße beschränken.

In den vorhergehenden Ausführungen ist deutlich geworden, welche Bedeutung strategisches Management - verstanden als Prozess der Gestaltung der künftigen Unternehmensentwicklung - für Unternehmen grds. besitzt. Konsequenterweise sollten strategieorientierte Informationen, also Angaben zu den Elementarphasen des Strategieprozesses, auch für Akteure am Kapitalmarkt von Interesse sein, da jene zukunftsorientierte Informationen für ihre finanziellen Prognosemodelle benötigen, um letztlich Entscheidungen bzgl. der Anlagealternativen fundieren zu können. Strategieorientierte Informationen wären insofern für Investoren als entscheidungsrelevant anzusehen, ihre per se eingeschränkte Verlässlichkeit könnte durch eine adäquate Darstellung dieser Angaben verbessert werden. Gravierende Argumente gegen eine Bereitstellung lassen sich jedenfalls nicht erkennen.

Wie bereits in Abschnitt B 1.3 angedeutet, rückt sodann das System der externen Rechnungslegung in den Fokus der Betrachtung: Es stellt einen normierten bzw. verbindlichen Rahmen für die Informationsbereitstellung zur Verfügung und ist mit dem bewährten Instrument des Lageberichts auch technisch in der Position, dem Kapitalmarkt strategieorientierte Inhalte zu kommunizieren. Der Charakter der Rechnungslegung könnte die Problematik der Verlässlichkeit entschärfen. Abschnitt B 3 stellt nachfolgend also das System der externen Rechnungslegung der kapitalmarktorientierten Unternehmen in der gebotenen Kürze dar und vertieft sodann das Instrument des Lageberichts, um dessen prinzipielle Eignung als

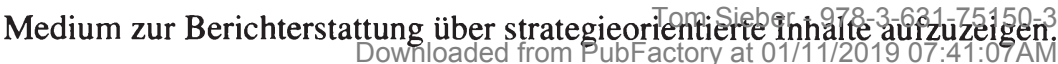




\section{Externe Rechnungslegung als Instrument der Berichterstattung gegenüber dem Kapitalmarkt}

\subsection{Rechnungslegung kapitalmarktorientierter Unternehmen}

\subsubsection{Rechnungslegung als Kern der Unternehmenspublizität}

In einer sehr vereinfachenden Darstellung ist Rechnungslegung zunächst nichts anderes als Information über ein Unternehmen. Somit ist sie Bestandteil der sog. Unternehmenspublizität, welche als die Gesamtheit der von einem Unternehmen über sich selbst veröffentlichten Informationen definiert ist. ${ }^{313}$ Innerhalb dieser Gesamtheit an veröffentlichten Informationen kann derjenige Teil der Publizität, der regelmäßig erfolgt, als die sog. Berichterstattung abgegrenzt werden. ${ }^{314}$

Die Rechnungslegung ist schließlich definiert als diejenige Form der Berichterstattung, die aufgrund handelsrechtlicher Verpflichtung erfolgt, wobei sich diese Verpflichtung i.d.R. aus der Rechtsform bzw. der Größe eines Unternehmens ergibt. Darüber hinaus können auch aus der Inanspruchnahme eines Kapitalmarkts gesetzliche Vorschriften zu regelmäßiger Publizität resultieren. ${ }^{315}$ Im Folgenden sind spezifisch die wesentlichen handels- sowie kapitalmarktrechtlichen Normen zur Rechnungslegung der kapitalmarktorientierten Unternehmen dargestellt. ${ }^{316}$

313 Vgl. Alvarez/Wotschofsky (2000a) S. 3ff. m.w.N.; Merkt (2001), S. 22; Pellens (2001), Sp. 1742f. Merkmale sind v.a.: Vielzahl von Adressaten, Verbreitung über verschiedene Medien sowie nur das Unternehmen als Publizierender. Sämtliche Information, die nicht vom Unternehmen selbst veröffentlicht wird, ist in diesem Verständnis ausgeklammert.

314 Für eine Systematisierung der Publizität vgl. Pellens et al. (2004), S. 798. Es wird nach dem Zeitraum (regelmäßig/unregelmäßig), dem Grund (gesetzlich/freiwillig) sowie dem Inhalt (formal: quantitativ/qualitativ, inhaltlich: Vergangenheit/Zukunft) differenziert. Die Einteilung der gesetzlichen Publizität in handels- sowie kapitalmarktrechtliche Verpflichtung ist Merkt (2001), S. 23f. entnommen. Für weitere Formen dieser gesetzlichen Publizität, die hier ausgeklammert sind, vgl. ebenda, S. 168 bzw. S. 176ff. m.w.N.

Kernelement der Kapitalmarktpublizität ist die Zwischenberichtspublizität. Ziel ist die Gewährleistung eines funktionsfähigen Kapitalmarktes. Relevante Normen sind BörsG, BörsZulV und WpHG. Vgl. Kirchner (2002), Sp. 1938f.; Pellens (2001), Sp. 1744f.

Bei kapitalmarktorientierten Unternehmen handelt es sich stets um große Kapitalgesellschaften, vgl. § 267 Abs. 3 S. 2 HGB. Dies gilt für alle Unternehmen, die einen organisierten Markt nach $\S 2$ Abs. 5 WpHG in Anspruch nehmen oder die Zulassung zu einem solchen beantragt haben. Ein Markt i.S.v. § 2 WpHG muss regelmäßig stattfinden, staatlich geregelt und für Publikum zugänglich sein. Eine Definition kapitalmarktorientierter Unternehmen wurde in 2009 im Rahmen des BilMoG mit $\$ 264 d$ in das HGB eingefügt. 


\subsubsection{Grundlegende Normen der deutschen Rechnungslegung}

Einschlägige Vorschriften zur verpflichtenden Berichterstattung börsennotierter Unternehmen in Deutschland folgen insb. aus dem Handels- bzw. Gesellschaftsrecht, namentlich HGB sowie AktG. ${ }^{317}$ Darüber hinaus sind die Verlautbarungen des Dt. Rechnungslegungs Standard Committee (DRSC), eines privatrechtlichen Rechnungslegungsgremium, für die Praxis der Rechnungslegung von Relevanz. Primäre Aufgabe des DRSC ist die Entwicklung von Empfehlungen für eine Anwendung der Grundsätze der Konzernrechnungslegung, diese erfüllt das DRSC durch die Verabschiedung der sog. Dt. Rechnungslegungs Standards (DRS). ${ }^{318}$

Weitere wesentliche Vorschriften für die deutsche Rechnungslegung sind in den International Financial Reporting Standards (IFRS) zu sehen. Diese stellen zwar keine Gesetzesvorschriften i.e.S. dar, da sie ebenfalls von einer privatrechtlichen Organisation, dem IASB, verabschiedet werden. ${ }^{319}$ Aus diesem Grund haben sie zunächst keine obligatorische Wirkung, doch erhalten sie indirekt Einfluss über die Mitgliedsorganisationen des IASB - in Europa haben die IFRS, für die vom IASB grds. weltweite Gültigkeit angestrebt wird, durch die Verabschiedung der sog. IAS-Verordnung der Europäischen Union zentrale Bedeutung erhalten. ${ }^{320}$

317 Vgl. Böcking (2001), Sp. 1775 bzw. für einen umfassenden, aktuellen Überblick Baetge et al. (2009a), S. 22ff., dies. (2009b), S. 26f., 44f. Neben jenen Normen besitzt der BFH Bedeutung für die Rechnungslegung, vgl. Baetge et al. (2009b), S. 110; Moxter (1999).

318 Das DRSC wurde 1998 auf Grundlage des im Rahmen des KonTraG eingeführten § 342 HGB geschaffen. Seine Aufgaben erfüllt das DRSC durch den Dt. Standardisierungsrat (DSR). Neben Ausarbeitung von DRS sind die Beratung des BMJ bei Gesetzgebungsvorhaben zur Rechnungslegung und die Teilnahme in internationalen Standardisierungsgremien als Aufgaben des DRSC zu benennen, zur Rolle des DSR Baetge et al. (2009b), S. 48f. Aufgrund des privatrechtlichen Status des DRSC sind verabschiedete DRS nicht als Rechtsnormen i.e.S. anzusehen, aber „Bindungswirkungen erhalten sie [...] durch die allgemeine Akzeptanz der Rechnungslegungspraxis“, so Böcking (2001), Sp. 1785.

319 Die Vorgängerorganisation des ,International Accounting Standards Board“ ist 1973 auf Initiative von berufsständigen Organisationen aus neun Ländern gegründet worden. Es setzt sich aus Vertretern wirtschaftsprüfender Berufe zusammen, vgl. Kleekämper et al. (2002). Zur Erarbeitung von IFRS bzw. Komitologieverfahren Buchheim et al. (2004). Vgl. EG (2002), Verordnung (EG) Nr. 1606/2002. Zum Ziel einer weltweiten Gültigkeit vgl. IASB, (2009b), Tz. 6. Dieses Ziel wird auch von der ,International Organisation of Securities Commissions" (IOSCO) unterstützt, die ihren Mitgliedern empfohlen hat, die IAS/IFRS als Zulassungsvoraussetzung einer Börsennotierung einzuführen, vgl. Pellens et al. (2004), S. 751; Barckow (1999), S. 1179f.; auch Fuchs/Stibi (2000), S. 3ff. 


\subsubsection{Elemente der Rechnungslegung im Kapitalmarktkontext}

Im Rahmen ihrer Rechnungslegungspublizität haben die börsennotierten Unternehmen den Jahresabschluss mit den Kernelementen ${ }^{321}$ Bilanz, Erfolgsrechnung $(\mathrm{GuV})$ sowie Anhang aufzustellen und diesen, um einen Lagebericht ergänzt, zu publizieren. ${ }^{322}$ Die simultane Publikation von Abschluss und Lagebericht erfolgt - nach Abschluss des jeweiligen Geschäftsjahres - im sog. Geschäftsbericht. ${ }^{323}$

Mutterunternehmen von Konzernen unterliegen zudem der Konzernrechnungslegungspflicht bzw. -publizität. ${ }^{324}$ Seit Verabschiedung des BilReG ${ }^{325}$ setzt sich der Konzernabschluss aus Konzernbilanz, -GuV, -anhang, Kapitalflussrechnung und Eigenkapitalspiegel zusammen. ${ }^{326}$ Gerade beim Konzernabschluss zeigt sich zudem die wachsende Bedeutung internationaler Standards in den letzten Jahren deutlich: Als wegweisend kann § 292a HGB gelten, der kapitalmarktorientierte Mutterunternehmen unter bestimmten Bedingungen von einer Aufstellung eines HGB-Abschlusses befreite, sofern der Abschluss nach international anerkannten

321 Vgl. § 264 Abs. 1 HGB. Zusätzliche Elemente sind der Bericht des Aufsichtsrats nach § 171 AktG, Angaben zur Ergebnisverwendung gem. §§ 58 Abs. 4, 119 Abs. 1, 170 Abs. 2, 171 Abs. 1 S. 1, 174 AktG, der Bestätigungsvermerk des Abschlussprüfers (bzw. eine Versagung) nach § 322 HGB, die Entsprechenserklärung zum DCGK gem. § 161 AktG. Gem. § 325 Abs. 1 HGB ist der Abschluss innerhalb von zwölf Monaten nach Ende des Geschäftsjahres bekannt zu geben bzw. beim Handelsregister einzureichen. Z.T. werden kürzere Veröffentlichungsfristen genannt, so z.B. DCGK (2009), Tz. 7.1.2 mit 90 Tagen und EU (2004b), Richtlinie 2004/109/EG mit vier, § 13 Abs. 1 PublG mit fünf Monaten. Der Begriff ,Geschäftsbericht' stammt aus $§ 148 \mathrm{AktG}$ a.F. und findet sich seit BiRiLiG 1985 weder im AktG noch HGB, ist aber geläufig, vgl. z.B. Heumann (2006), S. 259.

Vgl. grdl. §§ 290 bis 315 HGB. Unabhängig von den diversen Größenbefreiungen nach $\S 293$ Abs. 1 bis 4 HGB haben kapitalmarktorientierte Mutterunternehmen i.S.v. $\S 264 d$ HGB gem. § 293 Abs. 5 HGB einen Konzernabschluss inkl. -lagebericht aufzustellen. Jenes sog. Bilanzrechtsreformgesetz (BilReG) trat im Dezember 2004 in Kraft, der Dt. Bundestag verabschiedete am 29.10.2004 einen nur geringfügig geänderten Regierungsentwurf (RegE-BilReG), den die Bundesregierung im Juni 2004 erstmals vorstellte. Im bilanzrechtlichen Teil wurde insb. eine Anpassung des nationalen Bilanzrechts an vier EU-Rechtsakte (IAS-Verordnung, Modernisierungs-, Schwellenwert- sowie Fair-ValueRichtlinie) vorgenommen. Mit dem BilReG wurden jedoch nur obligatorische Teile der Richtlinen in nationales Recht transformiert, die Wahlrechtsausübung erfolgte in einem gesonderten Änderungsgesetz, dem sog. Bilanzrechtsmodernisierungsgesetz (BilMoG), das am 03.04.2009 verabschiedet wurde und am 29.05.2009 in Kraft getreten ist.

Vgl. § 297 Abs. 1 S. 1 HGB n.F. (nach BilReG). Durch das BilReG wurden die vorher durch das TransPuG geänderten Regelungen des § 297 Abs. 1 S. 2 HGB bzgl. einzelner Bestandteile des Konzernabschlusses und des Anwendungskreises modifiziert. 
Regelungen erfolgte. ${ }^{327}$ Die Verabschiedung der IAS-Verordnung in 2002 verpflichtet kapitalmarktorientierte Unternehmen in der EU schließlich, für die Geschäftsjahre ab 2005 grds. Konzernabschlüsse gemäß IAS/IFRS aufzustellen. ${ }^{328}$ Der endgültige Einzug dieser Standards in nationale Rechnungslegungsnormen für kapitalmarktorientierte Unternehmen manifestiert sich in $\S 315 \mathrm{a}$ HGB, der den Konzernabschluss gemäß der IAS-Verordnung regelt. ${ }^{329}$ Bemerkenswert ist in diesem Zusammenhang, dass die IFRS ausschließlich den Konzernabschluss regeln, für den Lagebericht jedoch keine Vorschriften vorsehen. ${ }^{330}$ Daher greift § 315a Abs. 1 HGB, der die Aufstellung des Lageberichts gem. § 315 HGB verlangt. Für jenen Zustand der parallelen Anwendung von IFRS und HGB hat sich der Begriff des sog. ,Zwei-Säulen-Modells‘ etabliert. ${ }^{331}$ Im Kontrast zu den eher quantitativ-monetär ausgelegten Elementen Bilanz und $\mathrm{GuV}$ ist der Lagebericht ein Instrument, das den Abschluss um qualitativ-verbale Erklärungen ergänzt. ${ }^{332}$

Neben den handelsrechtlichen Vorschriften zur Rechnungslegung folgt die Verpflichtung zur Aufstellung des Zwischenberichts aus dem Kapitalmarktrecht: ${ }^{333}$

327 Dies betrifft die IAS/IFRS bzw. US-GAAP, vgl. Dt. Bundestag (1998), BT-Drucksache 13/9909 (KapAEG), S. 7 i.V.m. S. 12. Nach § 292a HGB a.F. waren nur börsennotierte Mutterunternehmen befreit, das KapCoRiLiG weitete dieses auf kapitalmarktorientierte Mutterunternehmen aus. Bedingungen nannte der (nunmehr aufgehobene) DRS 1, vgl. Baetge et al. (2009a), S. 96f. Auch Normen der Dt. Börse AG förderten die Verbreitung der Standards, vgl. Glaum (2000), S. 30, der daher „signs of privatization“ ausmacht. Vgl. § 292a HGB a.F., Fn. 1. Die Regelung des § 292a war bis Ende 2004 befristet und wurde sodann durch Verabschiedung des BilReG, das die IAS-Verordnung in nationales Recht umsetzte, aufgehoben. Vgl. auch Art. 58 Abs. 3 S. 4 EGHGB n.F. (nach BilReG). Neben der Anwendungspflicht der IAS/IFRS für kapitalmarktorientierte Unternehmen sah die IAS-Verordnung Wahlrechte für die Mitgliedstaaten bzgl. der Abschlüsse nichtkapitalmarktorientierter Unternehmen nach IAS/IFRS vor, vgl. Kirsch (2003), S. $275 f$. Fey/Deubert (2006), Hayn (2005), S. 425 sehen die IFRS als dominierend in Europa an. Dies wird nachfolgend noch im Detail thematisiert, vgl. Abschnitt B 3.3 i.V.m. B 4.3.

331 Vgl. Coenenberg (2005), S. 907f. Der Lagebericht ist lt. § 264 Abs. 1 S. 1 HGB Pflichtbestandteil der Rechnungslegung von mittelgroßen sowie großen Kapitalgesellschaften. Außerdem fordert $\S 290$ Abs. 1 HGB für alle Konzerne die Aufstellung eines Konzernlageberichts, abschließend regelt $\S 315 \mathrm{a}$ Abs. 1 unmissverständlich, dass auch alle nach IFRS bilanzierenden Mutterunternehmen einen Konzernlagebericht zu erstellen haben.

Vgl. bspw. Hachmeister (2002), Sp. 1433f.; Baetge et al. (2009b), S. 726f. Mit Hilfe des Lageberichts soll der Abschluss verdichtet sowie sachlich bzw. zeitlich ergänzt werden: Neben vergangenheitsbezogenen Angaben zur Unternehmensentwicklung enthält dieser zukunftsgerichtete Informationen zur voraussichtlichen Entwicklung des Unternehmens. Vgl. ausführlich Alvarez/Wotschofsky (2000b) sowie dies. (2000c), auch Knorr (2001). 
Dieser Bericht wurde in $\S 44 \mathrm{~b}$ Abs. 1 BörsG a.F. eingeführt, welcher zumindest die Veröffentlichung eines Zwischenberichts innerhalb des Geschäftsjahres verlangte, um regelmäßige, zeitnahe Informationsversorgung über die Entwicklung des Unternehmens innerhalb der Periode und die voraussichtliche Entwicklung im Gesamtjahr sicherzustellen. ${ }^{334}$ Kapitalmarktrechtliche Anforderungen an die Rechnungslegung kapitalmarktorientierter Unternehmen ergeben sich seit Einführung des 4. FiMaFöG zudem aus Vorschriften der Dt. Börse, die im Rahmen der Neusegmentierung des Marktes ihre Publizitätsanforderungen erweiterte: So haben die im ,Prime Standard" notierten Unternehmen einen konsolidierten Abschluss nach IAS/IFRS sowie Quartalsberichte zu erstellen und vorzulegen. ${ }^{335}$

Für die vorliegende Arbeit kann festgehalten werden, dass die Rechnungslegung das Kernelement der Berichterstattung börsennotierter Unternehmen ist, da diese nicht nur verpflichtend vorzulegen ist, sondern auch Berichtsumfänge und Veröffentlichungsfristen überaus konkret normiert sind. Nachfolgend wird daher auf ihre Rolle und inhaltliche Ausgestaltung im Kapitalmarktkontext abgestellt. ${ }^{336}$

334 Neben § 44b BörsG a.F. verlangte § 53 S. 1 BörsZulV einen Bericht, der zumindest die ersten sechs Monate des Geschäftsjahres umfassen sollte. Sodann schrieb DRS 6 (2001) den zwischenberichterstattenden Unternehmen in DRS 6.11 eine Vorlage von Quartalsberichten vor. Vgl. Merkt/Göthel (2003), S. 23ff., kritisch Collingwood (2001), S. 66ff. Mit dem Transparenzrichtlinie-Umsetzungsgesetz, welches am 20.01.2007 in Kraft trat, wurde die Zwischenberichterstattung aus dem BörsG gelöst, und in das WpHG ( $\S 37 \mathrm{w}$, 37x) integriert. Die Konkretisierung erfolgt in DRS 16, vgl. Strieder/Ammedick (2007).

Vgl. Neufeld (2003), S. 18ff. Das 4. Finanzmarktförderungsgesetz (FiMaFöG) trat am 01.07.2002 in Kraft. Seither sind die Publizitätsanforderungen der Dt. Börse AG in der BörsO geregelt und besitzen so den Status einer Norm öffentlichen Rechts. Ziel war die Verbesserung der Durchsetzbarkeit bzw. Erhöhung von Rechtssicherheit und Vertrauen. Der ,Prime Standard“ ist ein sog. Transparenzlevel der Dt. Börse AG, das die Basis der Auswahlindizes (u.a. Dax) bildet, vgl. Dt. Börse AG (2009a), S. 9f.; Abschnitt C 3.2.1.

Es wird auf den Konzernabschluss fokussiert, da nur dieser geeignet scheint, die gesetzliche Informationsfunktion für Konzerne zu erfüllen, im Abschluss der Mutter werden konzerninterne Verflechtungen nicht berücksichtigt, vgl. Baetge et al. (2009a), S. 12ff., auch $\S 264$ Abs. 2 S. 1 und 297 Abs. 2 S. 2 HGB; Pellens et al. (2004), S. 122, S. 136. Weiterhin könnte als Begründung gelten, dass die Mehrheit der Großunternehmen heute konzerniert ist, vgl. Küting/Weber (2003), S. 72f. m.w.N. Darüber hinaus zeigt Görling (1993), S. 542ff., dass bereits im Jahre 1993 nahezu 97\% aller an Wertpapierbörsen im amtlichen Handel bzw. geregelten Markt gehandelten Unternehmen konzerniert sind.

Die Zwischenberichterstattung wird nicht fokussiert betrachtet, es wird auf die umfangreichere Jahres-Berichterstattung abgestellt, vgl. Coenenberg/Alvarez (2002), Sp. 2758. 


\subsection{Rolle der Rechnungslegung im Kapitalmarktkontext}

\subsubsection{Theoretische Ansätze zur Erklärung des Verhältnisses von Rechnungslegung und Kapitalmarkt}

Sofern eine Darstellung der Rolle von Rechnungslegungsinformationen im Kontext des Kapitalmarktes benötigt wird, können einige grundlegende betriebswirtschaftliche Ansätze beleuchtet werden, die sich mit dem Verhältnis von Kapitalmarkt und Rechnungslegung befassen und es theoretisch zu erklären versuchen:

Zunächst kann das Konzept der Informationseffizienz des Kapitalmarktes einen Bezug zur Rechnungslegungstheorie herstellen: Zwar besitzen die schwache wie auch die strenge Form der Informationseffizienz nur eine geringe Bedeutung für die Rechnungslegung, jedoch ist die - der Realität am ehesten entsprechende halbstrenge Form von Interesse, da in diesem Falle durch Auswertung öffentlich verfügbarer Information keine Überrenditen erzielt werden. ${ }^{337}$ Die Publikationspflicht der Rechnungslegung bewirkt also die Produktion von Informationen, die ohne Verpflichtung nicht entstehen würden. Wenngleich also eine Erzielung von Überrenditen durch Rechnungslegungsinformationen ausgeschlossen ist, ist unbestritten, dass diese weitergehende, gesamtwirtschaftliche Relevanz besitzen. ${ }^{338}$ Aufgrund des inhaltlich geringen Erklärungsbeitrages der InformationseffizienzThese ist - im Zuge der Fortentwicklung der Institutionenökonomie - das Verhältnis von Rechnungslegung bzw. Kapitalmarkt überdacht worden. ${ }^{339}$ Postuliert wird, dass, sofern Informationen am Markt asymmetrisch verteilt sind, durch ein eigennütziges Handeln opportunistischer Akteure ggf. Ineffizienzen entstehen. ${ }^{340}$ Kapitalgeber fordern sodann Rechenschaft über die Verwendung bereitgestellter

337 Vgl. grdl. Fama (1970). Zu diesen öffentlich verfügbaren Informationen zählen insb. die publizierten Informationen der Rechnungslegung. Die wissenschaftliche Diskussion hat sich intensiv mit der halbstrengen Form der Informationseffizienz befasst, da sie als am ehesten realistisch angesehen wird, vgl. v.a. Fama (1970), S. 415 sowie Beaver (1983), S. 344f. Es muss festgehalten werden, dass die These der Informationseffizienz nur sehr geringe Bedeutung für die praktische Ausgestaltung der Rechnungslegung besitzt, weil ihre empirische Gültigkeit als fragwürdig einzustufen ist, so Ballwieser (1987), S. 178.

338 Vgl. Ballwieser (1975), S. 175; Hax (1988), S. 192f.; Walz (1993), S. 85f.

339) Vgl. insb. Schneider (1997), S. 233ff.

340) Dies stellt die Basis sog. Prinzipal-Agenten-Konflikte dar, vgl. Jensen/Meckling (1976), vgl. auch die Ausführungen in Abschnitt B 1.1.2. 
Mittel, um eine Ausbeutung zu verhindern. ${ }^{341}$ Rechnungslegung entwickelt sich in diesem Kontext zu einem Instrument der Managerkontrolle und leistet einen Beitrag zur Lösung von Kompetenzabgrenzungsproblemen zwischen Parteien. ${ }^{342}$ Rechnungslegung lässt sich in dieser Perspektive als ein kapitalmarktbezogenes Anreizsystem beschreiben. Obgleich auch dieser Ansatz keine Hinweise zur inhaltlichen Ausgestaltung einer insofern ,optimalen“ Rechnungslegung liefert, ist die Gefahr verborgener Handlungen gemeinhin als realistisch akzeptiert. ${ }^{343}$

Neben diesen Ansätzen kann auch die Informationsökonomie oder die ,Ökonomische Analyse des Bilanzrechts ' zur Erklärung herangezogen werden. ${ }^{344}$ Ebenso greift das Shareholder Value-Konzept, das eine „Ausrichtung der Finanzberichterstattung auf den Kapitalmarkt" postuliert, die genannten Gedanken auf. ${ }^{345}$

Als Fazit ist festzuhalten, dass diverse Versuche unternommen worden sind, um das Verhältnis von Kapitalmarkt und Rechnungslegung theoretisch zu erklären, was allerdings keinem der Ansätze vollständig gelingt. Dennoch liefern sie erste verwertbare Anhaltspunkte zum Verständnis der Beziehung und die vorliegende Arbeit kann sich - auf Basis der soeben skizzierten theoretischen Erklärungsansätze - mit der Feststellung begnügen, dass Rechnungslegung und Kapitalmarkt offensichtlich interdependente Institutionen darstellen und folglich davon auszugehen ist, dass jene sich wechselseitig beeinflussen bzw. in einem symbiotischen Verhältnis miteinander stehen. ${ }^{346}$ Darauf aufbauend behandelt der folgende Abschnitt inhaltliche Anforderungen an kapitalmarktorientierte Rechnungslegung.

341 Vgl. Busse von Colbe (1993), S. 14, Analysen zu asymmetrisch verteilter Information und Agency-Problemen bei Ewert (1986), Pfaff (1989), S. 1013ff.; Wagenhofer (1996).

342 Unterschieden werden bspw. Kompetenzabgrenzungen zwischen Eigner/Manager oder Eigner/Manager/Gläubiger bzw. Mehrheits-/Minderheitseigner, Prüfer/Eigner/Manager, vgl. hierzu Schneider (1997), S. 5; Schildbach (1986), S. 61 ff. sowie S. 84.

343 Vgl. Böcking (1998) S. 25f.; Siegel (1986), S. 423; Schneider (1997), S. 396. Kritisiert wird die „formale Strenge und Eleganz“ sog. Agency-Modelle, die eher durch Plausibilitätsüberlegungen zu ersetzen seien. Die Akzeptanz der Gefahr versteckter Handlungen zeigt sich insb. in der Bedeutung der Rechenschaftsfunktion der Rechnungslegung. Vgl. als Überblick Böcking (1998), S. 25ff.; Wagner (1993a), S. VII. Zur Informationsökonomie vgl. insb. Ballwieser (1985a), Ewert (1989).

345 Busse von Colbe (1995), S. 717, ders. (1996), S. 428; grdl. Rappaport (1998), S. $57 \mathrm{ff}$.

346 Vgl. Baetge et al. (1997), S. 176; Busse von Colbe (1987), S. 192f.; Hartmann-Wendels (1991), S. 29, auch Wagner (1993b), S. 10. 


\subsubsection{Anforderungen an kapitalmarktorientierte Rechnungslegung}

Wie Abschnitt B 3.2.1 andeutete, liegt eine klare Aussage darüber, wie kapitalmarktorientierte Rechnungslegung auszugestalten ist, in der Theorie nicht vor. ${ }^{347}$ Folglich kann eine Übernahme internationaler Rechnungslegungsstandards auch nicht mit einem einfachen Verweis auf deren vermeintlich höhere Kapitalmarktorientierung gerechtfertigt werden. ${ }^{348}$ Darüber hinaus ist bei der konkreten Ausgestaltung von Rechnungslegungsnormen, die dem Postulat hoher Kapitalmarktorientierung entsprechen sollten, stets die grds. Anforderung zu berücksichtigen, dass den „damit steigenden Kosten auch ein steigender Nutzen entspricht“349.

Um sich also dem Zielobjekt einer kapitalmarktorientierten Rechnungslegung zu nähern, scheint es zweckmäßig, drei wesentliche operationalisierende Kriterien zu betrachten, im Einzelnen ihre inhaltliche Ausrichtung, den Regelungsrahmen und insb. die konkrete Zwecksetzung, die mit den Informationen verfolgt wird:

Zunächst kann als inhaltlicher Konsens gelten, dass Rechnungslegung in kapitalmarktorientierter Perspektive v.a. dazu dienen muss, ,Informationen für Kapitalund Kreditmärkte zu liefern“ sowie Ergebnisgrößen, ,an denen gesetzliche oder vertragliche Rechtsfolgen anknüpfen“350. Für den Kapitalmarkt haben Angaben der Rechnungslegung nicht nur die Aufgabe, bessere Prognosen der zukünftigen

347 Vgl. Böcking (1998), S. 27. Der Autor sieht zudem Defizite hinsichtlich Erkenntnissen über die Erwartungsbildung und Informationsauswertung der Adressaten bzw. über den Einfluss von Bilanzierungsmethoden auf das Verhalten der Adressaten. Das Postulat der kapitalmarktorientierten Rechnungslegung scheint insofern nur schwer realisierbar.

348 Vgl. Böcking (1998) S. 18. Üblicherweise wird eine Notwendigkeit zur Harmonisierung mit mangelnder Investorenorientierung der HGB-Rechnungslegung begründet. Zentrale Aspekte der Begründung: unterschiedliche Rechnungslegungszwecke (Gläubigerschutz vs. Investoreninformation) und mangelnde Vergleichbarkeit (,code law' vs. ,case law'), vgl. als Übersicht bspw. Glaum (2000), S. 26f. Baetge et al. (2010), S. 70 verweisen darauf, dass die Überlegenheit eines Standards nur empirisch festgestellt werden kann. Als Beispiele seien Arbeiten von Leuz/Verrecchia (2000), Gassen/Sellhorn (2006) genannt.

34) Hax (1988), S. 187 sowie Ordelheide (1995), S. 483ff. und auch ders. (1997), S. $235 \mathrm{ff}$. Ob Kosten-Nutzen-Kalküle bei der Gestaltung von Rechnungslegungsnormen in der Tat von Bedeutung sind, ist offen. Hax (1988), S. 187 meint, dass das Zustandekommen [...] eher durch die Interessen der [...] Beteiligten erklärt werden kann, und zwar sowohl der eigentlichen Entscheidungsträger [...] als auch der [...] Experten und Verbände". In dem Framework des IASB (2009a), Tz. 44 werden Kosten-Nutzen-Abwägungen explizit als leitendes Ideal der Standardsetzung genannt, vgl. Coenenberg/Straub (2008), S. 25.

Beide wörtlichen Zitate sind Hax (1988), S. 190f. entnommen. 
Entwicklung sicherzustellen, sondern sie ermöglichen zudem eine Rückwirkung auf die Tätigkeit des Unternehmens, da sie im Rahmen interner Entscheidungen beachtet werden - also sollten sie zur Reduktion von Ineffizienzen beitragen. ${ }^{351}$

Im Hinblick auf einen Regelungsrahmen scheint eine verbindliche Vorgabe von übergeordneten Regelungen zur Erstellung von Rechnungslegungsinformationen unmittelbar sinnvoll, um einheitliche Standards zu etablieren - zumal deren Befolgung i.d.R. keine außerordentliche Belastung der Unternehmen verursacht. ${ }^{352}$ Weiterführende Vorschriften der Prüfung, Publizität und der Konzernrechnungslegung sind allerdings grds. mit höheren Kosten für die Ersteller versehen, daher sind sie als Regelwerke definiert, die Ersteller freiwillig oder aufgrund vertraglicher Vereinbarung befolgen. Da deren Anwendung erkenn- bzw. nachvollziehbar ist, können Täuschungen der Adressaten grds. ausgeschlossen werden. ${ }^{353}$

Die Frage nach der Zwecksetzung der Rechnungslegung hinterlässt zunächst ein unklares Bild: Während für unmittelbare Rechtsfolgen einwertige, retrospektive und quantitative Erfolgsgrößen erforderlich sind, benötigen die Investoren mehrwertige, retro- und zugleich prospektive sowie quantitative und qualitative Angaben. Diese ,duale Zwecksetzung ' könnte schließlich durch eine Aufteilung der Einzelzwecke auf die Kerninstrumente der Rechnungslegung erreicht werden: ${ }^{354}$ der Abschluss für die Ermittlung objektivierter Gewinne in der Finanzberichterstattung, der Lagebericht für die Vermittlung von Kapitalmarktinformationen. ${ }^{355}$

$\mathrm{Zu}$ unterscheiden sind in dieser Sichtweise folglich die Gewinnermittlung bzw. Rechenschaftsfunktion von der Informationsgewährung bzw. Funktion der Ent-

351 Vgl. Hax (1988) S. 193. Eine Kontrolle der Manager durch die Eigner wird erleichtert.

352 Vgl. Böcking (1998), S. 28. Es sind v.a. die Grundsätze ordnungsgemäßer Buchführung (GoB) angesprochen, welche in $\S \S 238$ bis 256 HGB normiert sind, eine GoB-konforme Buchführung stellt eine geeignete Grundlage für die externe Rechnungslegung dar.

Vgl. Hax (1988), S. 199f.; Hartmann-Wendels (1991), S. 364f. Ein Kapitalmarktzugang stellt eine wesentliche vertragliche Vereinbarung dar, welche zu erweiterten Rechnungslegungsanforderungen führen kann. Verwiesen sei auch auf die Ausführungen in B 3.1. Vgl. Moxter (1986), S. 67f.; Moxter (1995), S. 32 sowie Schildbach (1987), S. 13. Dies wird als ,Abkopplungsthese' bezeichnet, kritisch dazu Streim (1994), S. 403f. zwischen Gewinnermittlung und Informationsgewährung, sondern auch zwischen regulierter Rechnungslegung sowie kapitalmarktinduzierter Publizität ziehen. Letzteres wird hier als ,Business Reporting ' bezeichnet, vgl. dazu den nachfolgenden Abschnitt B 4.2. 
scheidungsunterstützung. Unter Rückgriff auf die qualitativen Anforderungen an Informationen, Entscheidungsrelevanz sowie Verlässlichkeit ist die Analyse der Zwecke der Rechnungslegung zu vertiefen: Rechenschaft bei mangelnder Verlässlichkeit scheint ebenso wertlos wie die Bereitstellung von Informationen für den Kapitalmarkt, die nicht zur Entscheidungsunterstützung dienlich sind.

\section{(a) Rechenschaftsablage durch Gewinnermittlung}

In einfacher Definition ist Rechnungslegung das Ablegen von „Rechenschaft zur Bemessung von Ansprüchen und Verpflichtungen mit Hilfe eines Rechnungs-

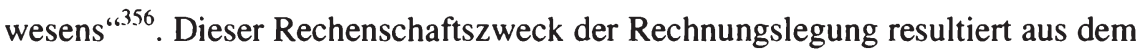
Bedürfnis von Kapitalgebern nach Klarheit über die Verwendung bereitgestellter Mittel. ${ }^{357}$ Die Rechenschaftsfunktion kann daher auch als der klassische Grund für die Verpflichtung zur Publikation von Rechnungslegungsdaten gelten: ${ }^{358} \mathrm{Sie}$ ,ist so alt wie die Arbeitsteilung [...] - wer anderen Aufgaben überträgt, verlangt Rechenschaft über die Ausführung seines Auftrages. Rechnungslegung ist der

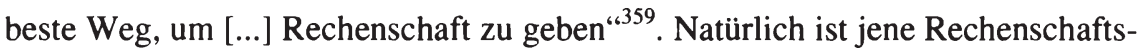
funktion auch heute unverzichtbar - vielmehr wird sie ständig bedeutsamer, je mehr die Trennung von Eigentum und Leitung erfolgt, um sodann Informationsasymmetrien zwischen Kapitalgeber und Manager zu begrenzen. Rechenschaftsbegründete Rechnungslegung bewirkt insofern eine wesentliche Schutzfunktion gegenüber den Vertragspartnern des berichtenden Unternehmens. ${ }^{360}$

Ihrem Auftrag zur Rechenschaftsablage entspricht die Rechnungslegung primär durch Ermittlung einer möglichst objektiven Gewinngröße. Maßgeblich für eine Wirksamkeit als Rechenschaftsinstrument ist neben der Objektivität, dass dieses Instrument vom Berichtenden selbst nicht manipuliert werden kann. ${ }^{361}$ Das stellt

\footnotetext{
356 Schneider (1997), S. 5.

357 Vgl. Coenenberg/Straub (2008), S. 17.

358 Vgl. bspw. die frühen Bemerkungen bei Ijiri (1975), S. 32; Watts (1977), S. 63.

359) Schneider (1974), S. 158f. Der Bezug zur Prinzipal-Agenten-Theorie wird erkennbar.

360) Zur Schutzfunktion der Rechnungslegung vgl. grdl. Moxter (2003), S. 3ff.

361 Vgl. z.B. Laux (2006), S. 21: Ein ,Jahresabschluss wird der Rechenschaftsaufgabe [...] gerecht, wenn er den Kapitalgebern objektive Informationen über die Unternehmung liefert", auch Hax (1989), S. 163. Dies meint nicht bilanzpolitische Spielräume, die aber zu begrenzen sind, so Healy/Wahlen (1999), S. 366; Dye/Verrecchia, (1995), S. 389f. 
den Bezug zur Verlässlichkeit von Information her: „Gewinne bilden grds. umso bessere ,Rechenschaftsauslöser', je ,vergleichbarer' sie sind.“362 Im Grunde bedeutet dies eine vorsichtige sowie imparitätisch ausgerichtete Rechnungslegung, die keine Verzerrungen verursacht. ${ }^{363}$ Ergo sind eher verlässliche Bilanzierungsmethoden anzuwenden, z.B. bei der Bewertung. ${ }^{364}$ Um als Basis einer effektiven Kontrolle der Manager zu dienen, sollten Rechnungsinformationen weiterhin die Auswirkungen deren Handelns darstellen, eine Trennung von Management- und Unternehmensleistung gilt jedoch als nicht praktikabel. ${ }^{365}$

Neben dieser primär vergangenheitsorientierten Verhaltenskontrolle bewirkt die Rechenschaftsfunktion wie angedeutet auch eine Ex-ante-Wirkung der Steuerung künftigen Verhaltens. ${ }^{366}$ Manager erhalten Anreize, im Sinne der Eigentümer zu handeln, und inkludieren deren Ziele in ihr eigenes Entscheidungskalkül, da die Rechenschaftsberechtigten Ex-post-Kontrollen durchführen sowie Fehlverhalten

362 Moxter (1982), S. 221, im Original ebenfalls mit Hervorhebungen. Die Vergleichbarkeit sollte intertemporal, intersubjektiv und mit Erwartungen der Adressaten gegeben sein.

Teilweise wird eine Fokussierung der Rechnungslegung auf die Ermittlung möglichst exakter Gewinngrößen postuliert, vgl. so Schneider (1997), S. 398ff. In diesem Kontext kritisiert dieser die „Fragwürdigkeit dickbäuchiger Anhänge“, Schneider (1981), S. 29. Eine derartige Gewinngröße scheint aber nur in der Theorie sinnhaft, denn die Gewinnermittlung müsste dennoch exakt nachvollziehbar sein - dies kann schon aufgrund von Bilanzierungswahlrechten in praxi nicht erfüllt werden. Opportunistische Ausnutzung wäre zu befürchten, vgl. Böcking (1998), S. 31f. Hingegen fordert Schneider (1997), S. 396f., die Abschaffung von managerfreundlichen Wahlrechten, die er nur dazu geeignet sieht, dass Manager „zumindest zeitweise [...] Fehler vertuschen können“.

363 Eine imparitätisch ausgerichtete Rechnungslegung wird in der Literatur z.T. abgelehnt, vgl. bspw. Leffson (1987), S. 84f. mit dem Argument, das Management könne nur dann beurteilt werden, wenn alle Wirkungen seiner Entscheidungen einfließen, ebenso Streim et al. (2003), S. 475. Wagenhofer (1996), S. 1069 merkt allerdings an, dass Kapitalgeber eher die Imparität bevorzugen würden, vgl. zudem Wagenhofer/Ewert (2007), S. 150f. Vgl. Coenenberg/Straub (2008), S. 19ff. Als verlässliche Wertansätze gelten historische oder fortgeführte Kostenansätze, zusätzlich auch Zeitwertansätze in Form beobachtbarer Marktpreise, vgl. hierzu Bieker (2006), S. 194. Eine Zeitwertbewertung wäre also dann nicht zu befürworten, wenn keine objektivierten Marktpreise vorhanden sind.

Vgl. zum Prinzip der Entscheidungsverbundenheit u.a. Laux (2006), S. 89, Hax (1989), S. 162. Eine Trennung von Management- und Unternehmensleistung wird u.a. auch von internationalen Standardsettern diskutiert, vgl. z.B. FASB (2006a), CON1-15, Tz. 50f., das zwischen ,management performance' und ,enterprise performance' differenziert. Es stellt sich die Frage der Realisierbarkeit, v.a. aufgrund externer Einflüsse. Die Risikoverteilung zwischen Manager und Eigner wäre zu beachten, so Demski (1976), S. 230ff. Vgl. bspw. Coenenberg/Straub (2008), S. 18. 
aufdecken könnten. ${ }^{367}$ Aus Rechenschaftsgründen erstellte Rechnungslegungsinformationen dienen insofern nicht nur zur Beurteilung von in der Vergangenheit getroffenen Entscheidungen, sondern induzieren weiterhin neue Entscheidungen der Rechenschaftsberechtigten darüber, ob diese das bestehende Vertragsverhältnis fortführen wollen. ${ }^{368}$ Es scheint also ein Zusammenhang von Rechenschaftsablage- und Entscheidungsunterstützung zu bestehen.

Allerdings ist festzuhalten, dass der Rechenschaftszweck der Rechnungslegung in erster Linie die Abrechnung der Aktivitäten der vorherigen Periode impliziert, entsprechende Angaben sind folgerichtig ,vergangenheitsbezogen, überwiegend quantitativ und vor allem einwertig ausgerichtet ${ }^{\star 369}$. Allerdings kann grds. auch eine zukunftsgerichtete Wirkung des Rechenschaftszweckes festgestellt werden.

\section{(b) Prospektive Inhalte zur Entscheidungsunterstützung}

Mit Blick auf die Unterstützung von Entscheidungen sollten Rechnungslegungsinformationen geeignet sein, „decisions about business enterprises and about investments in or loans to business enterprises ${ }^{\text {‘370 }} \mathrm{zu}$ fundieren. Eine adäquate Informationsgrundlage wäre schließlich retrospektiv sowie gleichfalls prospektiv, quantitativ und zugleich qualitativ ausgestaltet, mehrwertig anstatt einwertig und orientiert sich nicht nur an aktuellen, sondern auch an potenziellen Investoren. ${ }^{371}$

Die prospektive Komponente steht im Rahmen der Entscheidungsunterstützung konsequenterweise eindeutig im Vordergrund, da sich der Kapitalmarkt bzw. die Investoren ungleich stärker für Informationen interessieren werden, die eine Abschätzung der Unternehmensentwicklung - und natürlich zukünftiger Zahlungs-

367 Vgl. hier Coenenberg/Straub (2008), S. 18f., Hettich (2006), S. 11, weiterhin Rosenfield (1974), S. 132.

368 Vgl. zur Rechenschaft zur Entscheidungsverbesserung bspw. Ballwieser (1985a), S. 34f. Leffson (1987), S. 57ff. bestätigt, dass Rechenschaft eine prospektive Wirkung besitzt.

369) Böcking (1998), S. 31.

370) FASB (2006a), CON 1-7, Tz. 16. Zur Entscheidungsnützlichkeit im informationsökonomischen Sinne grdl. Ballwieser (2006), S. 13; Bamberg/Coenenberg (2006), S. 153.

371 Vgl. bspw. Hettich (2006), S. 11; Rosenfield (1974), S. 132, zudem Coenenberg (1995), S. 2077f. bzw. Böcking (1998), S. 44f. Dass kapitalmarktorientierte Führung bzw. Ausrichtung der Rechnungslegung zusätzlich eine Integration von internem sowie externem Rechnungswesen unterstützt, merkt u.a. Weißenberger (2007), S. 327f. an, ähnlich auch Ruhwedel/Schultze (2004). 
stromgrößen ermöglichen. ${ }^{372}$ Vor diesem Hintergrund ist die Frage nach der Art prospektiver Informationen in der Rechnungslegung zu adressieren: Zwar wären Prognosen künftiger Zahlungsströme durch eine Offenlegung von Finanzplänen unmittelbar möglich, allerdings sind diese aufgrund inhärenter Subjektivität abzulehnen. ${ }^{373}$ Prognosen sind vielmehr auf weitestgehend objektivierten Daten zu basieren, daher hat auch Rechnungslegung zur Entscheidungsunterstützung die primär vergangenheitsorientierte Abbildung des Geschehens zu akzeptieren. ${ }^{374}$

Die vergangenheitsbezogene Rechnungslegung ist jedoch in der Lage, eine Indikatorfunktion für die Bildung von Erwartungen bzgl. zukünftigen Erfolgsgrößen zu übernehmen: „Understanding a company's past is essential for forecasting its future. ${ }^{\text {‘375 }}$ Zur Entscheidungsunterstützung ausgerichtete Rechnungslegung soll also darauf abzielen, die Vergangenheit bzw. insb. die Lage eines Unternehmens darzustellen. Investoren könnten auf dieser Basis Hinweise zur künftigen Unternehmensentwicklung erhalten und Prognosen der Zahlungsströme ableiten. ${ }^{376}$

Allerdings könnten zusätzliche prognoseorientierte Informationen über die vom Management für das Unternehmen angestrebte Entwicklung Schätzungen der Investoren deutlich unterstützen und dazu beitragen, dass Unsicherheiten bzgl. der Unternehmenszukunft reduziert werden. Hinsichtlich der generellen Problematik

372 Vgl. zur Relevanz zukunftsorientierter Informationen Barron et al. (1999), S. 94f., Vanstraelen (2003). Zur Problematik der Prognosepublizität früh Busse von Colbe (1968). Vgl. Coenenberg/Straub (2008), S. 20 sowie Coenenberg (2005), S. 1219. Vgl. zur Diskussion einer finanzplanorientierten Rechnungslegung auch Moxter (1982), S. $251 \mathrm{ff}$. Vgl. Coenenberg/Straub (2008), S. 20. Dieses Objektivierungsbedürfnis der Adressaten macht grds. eine vergangenheitsorientierte Abbildung des Geschehens erforderlich.

Koller et al. (2005), S. 159, auch für den Hinweis, dass Zahlungsstromprognosen in der Praxis zumeist auf Basis einer Prognose von Ergebnisgrößen erfolgen. Zur Prognoserelevanz von (nachhaltigen) Erfolgsgrößen im Hinblick auf künftige Zahlungsströme vgl. Barth et al. (2001), S. 27 oder Lorek/Willinger (1996), S. 81ff., kontrovers Bowen et al. (1986), S. 713ff. Eine Übersicht über die Ermittlung nachhaltiger bzw. prognosefähiger Ergebnisse findet sich bei AK DVFA (2003), S. 1913ff. Ohlson (1999), S. 145ff. liefert den modelltheoretischen Nachweis für die Wert- sowie Prognoseirrelevanz nicht-nachhaltiger bzw. transitorischer Gewinne, ähnlich auch Stark (1997), S. $219 \mathrm{ff}$.

Vgl. so Coenenberg/Straub (2008), S. 21f. Grds. könnten künftig realisierbare Erfolgspotenziale im Rahmen der Berichterstattung auch durch eine umfassende Zeitbewertung abgebildet werden, vgl. Abschnitt B 1.1.3. Allerdings würde dies zu erhöhter Volatilität der Erfolgsgröße und so zu verminderter Prognosefähigkeit bzw. Verlässlichkeit führen. Zeitbewertung wäre daher auf Bereiche zu begrenzen, wo dies verlässlich möglich ist. 
der Prognosepublizität ist weiterhin auf eine Erziehungswirkung des Marktes zu verweisen: ${ }^{377}$ Allzu optimistische und schließlich nicht eingehaltene Prognosen werden vom Kapitalmarkt abgestraft, Unternehmen haben also die Möglichkeit, Vertrauen sowie Reputation am Kapitalmarkt aufzubauen, dieser erarbeitet sich zudem ein unternehmensspezifisches Interpretationsschema für Prognosen. ${ }^{378}$

\section{(c) Zweckdualität der Rechnungslegung als geeigneter Kompromiss}

Wie erkennbar ist, überschneiden sich diese Basiszwecke in einem wesentlichen Punkt, denn beide zielen darauf ab, Informationsasymmetrien zu reduzieren und die Entscheidungssituation der Adressaten zu verbessern. Aufgrund dieser Überschneidung scheint es prinzipiell denkbar, die Zwecke der Rechenschaft und der Entscheidungsunterstützung zu vereinen. ${ }^{379}$ Dazu ist allerdings eine Gewichtung der Verlässlichkeit relativ zur Entscheidungsrelevanz vorzunehmen, ${ }^{380}$ der Ausgleich hat grds. durch Wertungsentscheidung und folglich zweckadäquat zu erfolgen: ${ }^{381}$ Rechenschaftsorientierte Informationen sind auf in der Vergangenheit getroffene Entscheide ausgerichtet und können im Sinne der Entscheidungsnützlichkeit nur vage Anhaltspunkte für die Zukunft liefern - entscheidungsrelevante Angaben sind hingegen stets weniger verlässlich. Es zeigt sich daher, dass beide Zwecke in der Folge grds. nicht zu gleichen Informationen führen können. ${ }^{382}$

Trotz der beschriebenen Überschneidung jener Zwecke im Hinblick auf den Entscheidungsbezug ist eine gewisse Divergenz also evident, daher sind im Grunde zwei Rechenwerke notwendig, um beiden Zwecken zu entsprechen. ${ }^{383}$ Derartige

377 Zur Prognosepublizität und den damit einhergehenden Problemen umfassend Busse von Colbe (1968), S. $91 \mathrm{ff}$. Gedacht sei an Vertrauen in Prognosen des Managements, etc.

378 Vgl. Böcking (1998), S. 44f., empirisch dazu auch Ruhwedel et al. (2009). Letztere verweisen darauf, dass eine ,Prognose-Reputation' v.a. in schwierigen Zeiten wichtig wäre. Diese Ansicht vertritt Ballwieser (2002a), S. 115, anders Busse von Colbe (1994), S. 45. Erinnert sei daran, dass Relevanz und Verlässlichkeit die Nützlichkeit determinieren. Dass Verlässlichkeit und Entscheidungsrelevanz in einem Spannungsverhältnis stehen, ist als Kernproblem der Rechnungslegung bekannt, vgl. Ballwieser (2006), S. 14ff.

381 Vgl. zum Problem der Zweckadäquanz Ballwieser (2001b), S. 161; Hettich (2006), S. 7. $3 \times 2$ Vgl. Coenenberg/Straub (2008), S. 22, empirische Belege bei Gjesdal (1981), S. 208ff.

383 Vorgeschlagen wurde neben Bereitstellung zweier Rechenwerke auch die Entkopplung von Bilanz und $\mathrm{GuV}$, damit jedes Element einem Zweck gerecht werden kann. Vgl. z.B. Schmidt (2000) oder Wolk et al. (2001), S. 335. Ablehnend Coenenberg/Straub (2008), S. 23, da offen bliebe, ob ein Instrument einem Zweck gerecht werden kann. 
Vorschläge stellen allerdings keine realisierbare Alternative dar. ${ }^{384}$ Es erscheint sodann als sinnvoller Kompromiss, beiden Zwecken simultan gerecht zu werden und daher sowohl die Informationsvermittlung als auch die Rechenschaftsablage als Zweck der externen Rechnungslegung zu berücksichtigen, zumal nach h.M innerhalb der einschlägigen Literatur eine völlig ,unüberwindbare Disharmonie zwischen den beiden Rechnungszwecken [...] nicht festgestellt werden. ${ }^{، 385}$ kann.

Gegenwärtig erhält die Debatte um den zentralen Zweck der Rechnungslegung neue Brisanz durch die fortlaufende Ausarbeitung eines gemeinsamen Rahmenwerkes für IFRS und US-GAAP: ${ }^{386}$ Sowohl das IASB als auch sein US-Pendant FASB sehen den Hauptzweck einer Finanzberichterstattung in der Bereitstellung entscheidungsnützlicher Informationen. ${ }^{387}$ Rechenschaft wird als eigenständiger Zweck aufgegeben mit der Begründung, entscheidungsnützliche Informationen könnten die zu Rechenschaftszwecken benötigten Inhalte mit erzeugen. ${ }^{388}$ Dies entspricht der Ansicht, ,accounting must evolve from its traditional stewardship role to the new role of forecounting “389, IASB sowie FASB zielen also auf eine Vermittlung von Informationen zur Entscheidungsunterstützung ab. ${ }^{390}$

Einseitige Zukunftsorientierung erscheint aber - wie oben dargestellt - nicht unproblematisch: ,exclusive focus on a decision-usefulness objective has led to an excessive emphasis on the forecasting of future cash flows, and insufficient em-

384 Dies ist schon deshalb weder realistisch noch praktikabel, da Standardsetter die KostenNutzen-Relation berücksichtigen, vgl. explizit FASB (2006a), CON 2-30, Tz. 133. Coenenberg/Straub (2008), S. 24 m.w.N.

386 FASB sowie IASB haben sich im sog. ,Norwalk Agreement' eine Harmonisierung ihrer Standards als Ziel gesetzt sowie diverse Projekte zum Abbau von Unterschiedlichen definiert, vgl. Hayn (2005), S. 425ff. sowie zum aktuellen Status Gassen et al. (2008).

Die Stadt Norwalk im US-Bundesstaat Connecticut ist der Sitz des FASB.

$\mathrm{Zu}$ den Sichtweisen von FASB sowie IASB vgl. FASB (2006b), identisch IASB (2006), jeweils OB.28. Die dt. Rechnungslegung entspricht historisch der Philosophie der sog. Zweckdualität, d.h. in einem Rechenwerk entscheidungsnützliche und zugleich Rechenschaftsinformationen bereitzustellen. Im angelsächsischen Raum werden die Zwecke als ,decision usefulness' bzw. ,stewardship' bezeichnet, Coenenberg/Straub (2008), S. 17. Im aktuellen Rahmenwerk ist ,stewardship“ explizit als Rechnungszweck genannt, vgl. IASB (2009a), Tz. 14 - wenn auch bereits der ,decision usefulness` untergeordnet, vgl. Pellens et al. (2006a), S. 107.

389 Cormier/Magnan (2005), S. 243. Im Original mit Hervorhebung.

390 So ist es im Conceptual Framework-Project festgeschrieben, vgl. IASB (2006), OB.3f. 
phasis on reliability. “' ${ }^{391}$ Die Umsetzung dieser Zielsetzung der beiden Standardsetter entspräche daher einer „Absage an eine zweckduale Rechnungslegung“392, die zwar einen Kompromiss bedeutet und keinem der Basiszwecke optimal gerecht wird, aber immer als noch die beste Lösung gelten muss. ${ }^{393}$ Darüber hinaus scheint es weiterhin interessant, das System der Rechnungslegung für die Bereitstellung explizit zukunftsorientierter Informationen zu nutzen - ohne jedoch die Leistungsfähigkeit derselbigen zur Rechenschaftsablage zu konterkarieren.

\subsubsection{Faktische Relevanz der Rechnungslegung am Kapitalmarkt}

Ziel des vorhergehenden Abschnitts war, sich dem Konstrukt einer kapitalmarktorientierten Rechnungslegung mittels des operationalisierenden Kriteriums der Zwecksetzung anzunähern. Festgestellt wurde, dass die Rechnungslegung durch Bereitstellung objektiver und retrospektiver Erfolgsgrößen beiden Basiszwecken offensichtlich prinzipiell gerecht wird, entsprechende Angaben können durchaus als entscheidungsnützlich für die Akteure am Kapitalmarkt klassifiziert werden.

Daher ist auch nicht überraschend, dass die Bereitstellung von Unternehmensinformationen mit Hilfe des Systems der externen Rechnungslegung eine hohe Bedeutung zur Fundierung von Anlageentscheidungen besitzt, wie empirisch nach-

391 Lennard (2007), S. 52. Beleg ist insb. die Ausweitung der Zeitwertbewertung bzw. die sog. Fair Value-Diskussion, vgl. bspw. Schildbach (2007), S. 14f. Kritisch zur Vernachlässigung der Verlässlichkeit in der Rechnungslegung Baetge/Hollmann (2004), S. 374f. Küting (2005), S. 1 beklagt die „nicht hinnehmbare Entobjektivierung der Bilanz“.

In Stellungnahmen zu den Papieren der Standardsetter wird eine Aufgabe des Rechenschaftszwecks mehrheitlich abgelehnt, vgl. IASB (2007a) bzw. FASB (2007) sowie als Bsp. das Papier der EFRAG (2007) mit einer Ablehnung der Aufgabe der Rechenschaft. Hitz (2005), S. 331. Jene ist It. Coenenberg/Straub (2008), S. 24 aber bereits seit Jahren durch Inkaufnahme der Entobjektivierung eingeläutet worden, so Baetge/Zülch (2001).

303 Insb. unter Kosten-Nutzen-Aspekten, vgl. Coenenberg/Straub (2008), S. 25f. Dies entspricht grds. auch dem Kalkül der Standardsetter. Die Überbetonung der Entscheidungsnützlichkeit hat z.T. bereits negativ auf die Kosten-Nutzen-Relation gewirkt, u.a. aufgrund eines hohen Erstellungsaufwands. Eine simultane Beachtung des Rechenschaftszwecks hingegen habe positiven Einfluss auf die Kosten-Nutzen-Relation, vgl. ebenda.

Letztlich ist Zweckdualität auch für die weltweite Einheitlichkeit der Rechnungslegung essentiell, da Bedingung für eine Übernahme in der EU ist, dass die Standards simultan ,wirtschaftliche Entscheidungen und die Bewertung der Leistung einer Unternehmensleitung [...] ermöglichen“, so EG (2002), Verordnung 1606/2002 (EG), Art. 3 Abs. 2.

Tom Sieber - 978-3-631-75150-3 
gewiesen ist. ${ }^{394}$ Trotz der immanenten „Polarität zwischen Vergangenheitsbezug der Informationsgrundlagen und der Zukunftsorientierung der zu lösenden Ent-

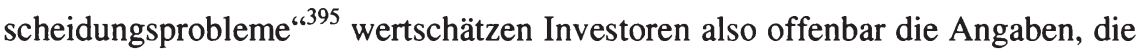
ihnen in Geschäftsberichten zur Verfügung gestellt werden, wobei allerdings die einzelnen Bestandteile mit unterschiedlicher Intensität berücksichtigt werden: ${ }^{396}$

Investoren fordern grds. ein ausgewogenes Set an quantitativen und qualitativen Berichtsinstrumenten, dabei findet bemerkenswerterweise insb. der Lagebericht als das rein qualitativ-verbale Instrument der Rechnungslegung besonders starke Beachtung. ${ }^{397}$ Es besteht daher Anlass zu der Vermutung, dass - unter Rückgriff auf B 3.2.2 - Investoren im Rahmen ihrer Anlageentscheidungen zur Schätzung zukünftiger Zahlungsströme quantitative Angaben der Rechnungslegung als informationelle Basis verwenden, da diese eine verlässliche, objektive Grundlage bereitstellen, mit deren Hilfe diese Schätzungen vorgenommen werden können.

Neben den quantitativen Informationen aus Bilanz bzw. GuV scheint der Lagebericht sodann dazu geeignet, frei von engen Vorschriften der Rechnungslegung ein gesamthaftes Bild der Lage eines Unternehmens zu zeichnen und in verbalen Ausführungen Informationen bereitzustellen, die quantitative Schätzungen unterstützen, fundieren und eingrenzen können. Der Lagebericht scheint also das Element der Finanzberichterstattung zu sein, das - bei Aufrechterhaltung der Basiszwecke sowie der Zweckdualität der Rechnungslegung - für eine Bereitstellung prospektiver Angaben zur Entscheidungsunterstützung genutzt werden könnte, während dem Abschluss die Erfüllung des Rechenschaftszwecks obläge. ${ }^{398}$

Aufbauend auf dieser Erkenntnis ist nun das Instrument Lagebericht und dessen informationelle Bedeutung bzw. Leistungsfähigkeit im Detail zu beleuchten.

394 Vgl. grdl. Ball/Brown (1968); Beaver (1968), umfassend Kothari (2001), kürzlich Ernst et al. (2009). Mit Fokus auf Analysten Glaum/Friedrich (2006), Day (1986), S. 302.

395 Küting (2002), S. 5.

396 Vgl. hierzu aktuell Ernst et al. (2009), S. 21 ff. m.w.N. umfassend zum dt. Kapitalmarkt.

397 Vgl. Pellens et al. (2006b), S. 23, zur Bestätigung vgl. Ernst et al. (2009), S. 29ff. Dies obwohl der Lagebericht eben nicht Bestandteil ,kapitalmarktorientierter' Standards ist.

398 Das entspricht zwar auch einer Abkopplung, jedoch bilden Bilanz und GuV eine Einheit zur Ermittlung möglichst objektiver Erfolgsgrößen. Der Lagebericht hingegen ist als das Medium zur Bereitstellung entscheidungsrelevanter Informationen anzusehen, vgl. auch Baetge et al. (2009b), S. 727 sowie bereits Baetge et al. (1989), S. 8. 


\subsection{Der Lagebericht als Element der Rechnungslegung}

\subsubsection{Rolle des Lageberichts innerhalb der Rechnungslegung}

Zuvor wurde festgehalten, dass sich die quantitativ ausgerichteten Bausteine der Rechnungslegung, des zentralen Informationsinstruments des Kapitalmarkts, im skizzierten Spannungsfeld zwischen Entscheidungsunterstützung sowie Verlässlichkeit schwertun, Informationen bereitzustellen, auf deren Basis eine fundierte Prognose zukünftiger Zahlungsströme abgeleitet werden könnte. In dieser reinen Fokussierung auf quantitativ-monetäre Informationen blieb aber das Element der Berichterstattung weitgehend unbeachtet, das insb. für eine Bereitstellung nichtfinanzieller, prospektiver Informationen geeignet scheint: der Lagebericht. ${ }^{399}$

Es ist nachvollziehbar, dass dieser in der Diskussion zur kapitalmarktorientierten Ausgestaltung der Rechnungslegung keine übergeordnete Rolle spielt, da - wie erwähnt - die Berichterstattung deutscher börsennotierter Unternehmen als sog. Zwei-Säulen-Modell zu charakterisieren ist: Obwohl ein IFRS-Abschluss aufgestellt wird, ist der Lagebericht nach wie vor nationalstaatlich kodifiziert. ${ }^{400}$ Der internationale Standardsetter beschäftigt sich folgerichtig bis dato grds. nicht mit den Lageberichtsinstrumenten, das Regelwerk der IFRS sieht kein zum dt. Lagebericht äquivalentes Berichtselement vor - obgleich dieser innerhalb des aufgezeigten Spannungsfeldes möglicherweise wertvolle Beiträge leisten könnte. ${ }^{401}$

399 Vgl. Baetge et al. (2009b), S. 727; Heumann (2005), S. 12; Böcking (1998), S. 30.

$4(x)$ Europäische Bilanzrichtlinien fordern einen Lagebericht als eigenständiges Berichtsinstrument neben einem Abschluss. Für dt. Unternehmen folgen einschlägige Vorschriften aus $\S \S 264,290$ HGB. Inhaltlich ist der Lagebericht in $\S 289$, der Konzernlagebericht in $\S 315$ HGB geregelt, auf den abgestellt wird, da er für notierte Unternehmen primär relevant ist. Die Äquivalenz der $\S \S 289,315$ bestätigen Baetge et al. (2009b), S. 725. In der Literatur ist Kritik an jenem ,strukturellen Defizit der IFRS im Bereich der nichtfinanziellen Berichterstattung' zu finden, vgl. ausführlich Prigge (2006), S. 7ff. sowie S. 222. Dieser kritisiert, dass so Redundanzen verursacht würden: Während bis dato keine Regelung zum ,IFRS-Lagebericht' vorliegt und daher nationale Normen relevant sind, fordern die IFRS Angaben, die im HGB-Lagebericht zu machen sind. Zur Begründung für die (bewusste) Konzentration des IASB auf die Darstellung finanzieller Sachverhalte vgl. Abschnitt B 4.1.3, insb. Fn. 487.

401 Es sei bereits angemerkt, dass das IASB im Rahmen eines seit 2002 laufenden Projekts ,Management Commentary` über eine Einführung eines qualitativ-verbalen Berichtsinstruments diskutiert - bislang allerdings ohne sich auf einen inhaltlichen Katalog bzw. formale Aspekte einigen zu können, vgl. weiterführend Abschnitt B 4.3.3 dieser Arbeit.

Tom Sieber - 978-3-631-75150-3 
Der Lagebericht als zweite, eigenständige Säule der externen Rechnungslegung hat zur Aufgabe, das Zahlenwerk des Abschlusses in erster Linie zu ergänzen, aber auch zu verdichten sowie zu erläutern. ${ }^{402}$ Ziel ist es, den Adressaten durch Bereitstellung weiterführender Angaben eine bessere Beurteilung der wirtschaftlichen Lage eines Unternehmens zu ermöglichen und somit zum Verständnis des Jahresabschlusses beizutragen: „Ausführliche verbale Aussagen und zusätzliche Erläuterungen zu den Zahlen sind daher eine notwendige Bedingung, damit [...] Anleger [...] rein numerisch dargestellte Sachverhalte einfach nachvollziehen “403 können. Der überwiegend quantitativ ausgerichtete Jahresabschluss und der rein qualitativ-verbal bzw. nicht-finanziell ausgerichtete Lagebericht sind folglich in einem komplementären Verhältnis zueinander zu betrachten. ${ }^{404}$

Der Lagebericht hat lange Zeit sowohl in der Rechnungslegungspraxis als auch in der einschlägigen betriebswirtschaftlichen Literatur eine eher untergeordnete Rolle eingenommen, als Begründung ist das zuvor angesprochene Zwei-SäulenModell bzw. ,strukturelle Defizit der IFRS-Rechnungslegung ${ }^{405}$ zu nennen, das dazu geführt hat, dass eine Konzentration auf die Standards der internationalen Rechnungslegung erfolgte, die nationalstaatlichen Normen zum Lagebericht jedoch weitgehend unbeachtet geblieben sind. Erst innerhalb der letzten Jahre hat der Lagebericht wieder vermehrt Aufmerksamkeit erlangt. ${ }^{406}$ Dies ist insb. auch diversen Reformschritten der jüngeren Vergangenheit zu verdanken, welche darauf abzielten, den Informationsgehalt dieses Instruments zu erhöhen, indem die Berichtsinhalte erweitert und ausführlicher umschrieben wurden als zuvor. ${ }^{407}$

Den gegenwärtigen Status der Rechtsnormen zum Lagebericht stellt Abschnitt B 3.3.2 dar, ehe anschließend dessen informationelle Bedeutung zu würdigen ist.

402 Dies entspricht der Generalnorm der Lageberichterstattung der $\S 289$ sowie 315 HGB, vgl. Baetge et al. (2009b), S. 726, auch mit dem Hinweis „Der Lagebericht ist ein eigenständiges Rechnungslegungsinstrument und nicht Bestandteil des Jahresabschlusses“. Hank (1999), S. 131, ähnlich auch Ballwieser (2001b), S. 163.

404 Vgl. Baetge et al. (2009b), S. 726f.; Amir/Lev (1996); Lev/Zarowin (1999); Hirschey et al. (2001) sowie Deloitte/EIU (2004), dies. (2007) mit der Erkenntnis, dass Stärken und Schwächen eines Unternehmens allein mit finanziellen Daten kaum zu erfassen sind. Vgl. Beiersdorf/Buchheim (2006), S. 96f., ähnlich auch Prigge (2006), S. 222f.

406 Vgl. Kajüter (2004a), S. 197; Haller/Dietrich (2001c), S. 164; Rodewald (2001), S. 2155.

Vgl. BMJ (2003), RefE-BilReG, Begründung, S. 25 sowie Kajüter (2004a), S. 198. 


\subsubsection{Rechtsgrundlagen der deutschen Lageberichterstattung}

\section{(a) Europäischer Rahmen der deutschen Rechtsnormen}

Den wesentlichen rechtlichen Rahmen der Lageberichterstattung in Europa und des deutschen Lageberichts nach HGB stellen die EG-Bilanzrichtlinie von 1978 und die EG-Konzernbilanzrichtlinie von 1983 dar, die beide mit dem Ziel verabschiedet wurden, eine Angleichung der nationalen Rechnungslegungsnormen für Kapitalgesellschaften in der Europäischen Union zu bewirken. ${ }^{408}$ So fordert der als Generalnorm der europäischen Lageberichterstattung angesehene Art. 46 der EG-Bilanzrichtlinie, „zumindest den Geschäftsverlauf und die Lage der Gesellschaft so darzustellen, dass ein den tatsächlichen Verhältnissen entsprechendes Bild entsteht ${ }^{\text {“409 }}$. Erst diese Richtlinie hat den Lagebericht zum eigenständigen Instrument der Berichterstattung aufgewertet, zuvor war dies nicht der Fall. ${ }^{410}$

Als Kern-Aufgabe eines Lageberichts definiert Art. 46 sodann die Bereitstellung von Informationen zur wirtschaftlichen Gesamtbeurteilung eines Unternehmens - unabhängig von konkreten Abschlusszahlen - u.a. durch eine Vermittlung subjektiver Urteile seitens des Managements. Außerdem ist nicht nur auf Vorgänge von besonderer Bedeutung nach Ultimo, sondern insb. auch auf die voraussichtliche zukünftige Entwicklung des berichtenden Unternehmens einzugehen. ${ }^{411}$

408 Angesprochen ist die 4. EG-Richtlinie (hier Art. 46) bzw. die 7. EG-Richtlinie (hier Art. 36), vgl. Kirsch (2002), S. 744, früher Schmitz (1988). EG-/EU-Richtlinien sind an Mitgliedstaaten gerichtet, mit der Pflicht zur Transformation jeweiliger Inhalte als Mindeststandard unter Beachtung eingeräumter Wahlrechte, vgl. z.B. Hennrichs (1997), S. 73.

Vgl. im Detail EG (1978), Richtlinie 78/660/EWG; EG (1983), Richtlinie 83/349/EWG. EG (1978), Richtlinie 78/660/EWG, Art. 46 Abs. 1 (Bilanzrichtlinie). Jene Generalnorm wirkt eng verwandt mit $\S 160$ Abs. 1 S. 1 AktG (1965), dem inhaltlichen Vorgänger des HGB-Lageberichts, vgl. Reittinger (1983), S. 7. Der Wortlaut des Art. 46 scheint zudem dem Postulat des sog. „True and Fair View“ des Lageberichts in Großbritannien zu entsprechen, vgl. Baetge et al. (1989), S. 7. Diese Richtlinie verbindet also deutsche und britische Berichtstraditionen, so Haller/Walton (2000), S. 34; Niehus (1985), S. 537.

Vgl. Baetge (1993), Sp. 1327. Zum Zeitpunkt dieser Richtlinie war der dt. Lagebericht gem. AktG noch Teil des sog. Geschäftsberichts. Nach Art. 2 Abs. 1 der Bilanzrichtlinie ist er aber kein Bestandteil des Abschlusses, sondern eigenständig, vgl. Abb. 6 (S. 94).

411 Vgl. EG (1978), Richtlinie 78/660/EWG, Art. 46 Abs. 2. Dieser Abschnitt konstituiert neben dem aus der Generalnorm folgenden Wirtschaftsbericht - einen sog. Nachtragsund Prognosebericht. Gem. Abs. 2 soll auf Inhalte, eingegangen werden '. Der Charakter dieser Soll-Vorschrift war umstritten, vgl. Semler (1980), S. 198f.; Maul (1984), S. 189. 
In dieser vorgestellten Fassung blieben die Bilanzrichtlinien nahezu unverändert für einen Zeitraum von über 20 Jahren. ${ }^{412}$

Ein grdl. Reformprozess der Lageberichtsbestimmungen wurde in 2003 mit der sog. Modernisierungsrichtlinie eingeleitet, zur Harmonisierung der nationalstaatlichen Bilanzrichtlinien mit den IFRS, um potenzielle Konflikte zu vermeiden, sowie zur Erweiterung der Lageberichterstattung. ${ }^{413}$ Die EU versuchte mit dieser Richtlinie, eine Vorreiterrolle bei der einheitlichen Gestaltung und Verbesserung der Qualität der Lageberichterstattung einzunehmen. ${ }^{414}$ Als Konsequenz wurde der Inhalt der Berichterstattung um die Darstellung des Geschäftsergebnisses ergänzt sowie der generelle Charakter der Berichterstattung verschärft. ${ }^{415}$ Darüber hinaus forderte die EU eine Einbindung von finanziellen bzw. nicht-finanziellen Leistungsindikatoren in die Lageberichterstattung und die obligatorische Risikoberichterstattung. ${ }^{416}$ Letztgenannte stellte allerdings für die nationalen Normen der Lageberichterstattung in Deutschland aufgrund der bereits im Rahmen des KonTraG eingeführten Risikoberichterstattung keine grdl. Neuerung dar.

412 Abgesehen von den - eher unbedeutenden - Zweigniederlassungs-, Mittelstands- sowie Kapitalgesellschaften- und Co.-Richtlinien, vgl. z.B. Fey (1994), S. 485; Kirsch (2002), S. 745 oder auch im Detail EG (1989), Richtlinie 89/666/EWG, EG (1990a), Richtlinie 90/604/EWG sowie EG (1990b), Richtlinie 90/605/EWG.

413 Vgl. EU (2003), Richtlinie 2003/51/EG. Diese diente der Überarbeitung der (Konzern-) Bilanzrichtlinie. Der Reformprozess, der zur Richtlinie 2003/51/EG führte ist teilweise als ,Paradigmenwechsel“ bezeichnet worden, so z.B. Böcking et al. (2003), S. 403, aber auch als ,kosmetische Neuregulierung des Lageberichts“, so Bieker/Schmidt (2002), S. 216. Zur Zielsetzung vgl. u.a. Busse von Colbe (2002), S. 1531f. bzw. zum Einfluss auf den Lagebericht zusammenfassend Kirsch/Scheele (2004), S. 3ff.

414 Vgl. EU (2006), Richtlinie 2006/46/EG, Richtlinienbegründung, insb. Tz. 13 unter Hinweis auf die Heterogenität publizierter Lageberichte in den einzelnen Mitgliedsstaaten.

415 Vgl. EU (2006), Richtlinie 2006/46/EG, Art. 46 Abs. 1. Jener Art. 46 wird um das ,Geschäftsergebnis` erweitert. Dies hat lt. Kirsch/Scheele (2004), S. 7f. nur deklaratorischen Hintergrund, ähnlich Böcking et al. (2003), S. 403f. Der Charakter der Berichterstattung wird dahingehend verschärft, dass fortan zu , analysieren' ist. Dies hat ausgewogen sowie umfassend und der Komplexität des Geschäfts angemessen zu erfolgen.

Vgl. EU (2006), Richtlinie 2006/46/EG, Art. 46 Abs. 1. Die Bilanzrichtlinie fordert nun eine Beschreibung von Risiken bzw. Ungewissheiten, vgl. bspw. Kirsch/Scheele (2005), S. 1150. Auslegungsbedürftig erschien insb. der Begriff ,Ungewissheit', weil dieser ggf. mehrwertig verstanden werden könnte i.S.v. Risiken und Chancen. Nach Böcking et al. (2003), S. 404 ist die Ungewissheit im Gegensatz zum Risiko nicht durch eine Eintrittswahrscheinlichkeit präzisierbar, anders Kajüter (2004b), S. 428: ,Ungewissheit" ist klarstellend, d.h. nicht nur konkrete, sondern auch schwer prognostizierbare Gefahren.

Tom Sieber - 978-3-631-75150-3 
Zusätzlich wurden - in dem Zeitfenster rund um die Modernisierungsrichtlinie einige ergänzende Richtlinien verabschiedet, die allerdings zumeist nur geringen Einfluss auf die Lageberichterstattung nahmen. Im Kern wurde entweder der jeweilige Anwendungsbereich erweitert oder es wurden inhaltliche Bausteine hinzugefügt. Im Einzelnen erscheinen erwähnenswert: die Fair Value-Richtlinie ${ }^{417}$ (2001) mit der Ergänzung einer Finanzrisikoberichterstattung, die Übernahmerichtlinie $^{418}$ (2004) mit dem Ziel, eine periodische Berichterstattung zu Kapitalsowie Kontrollstrukturen der Unternehmen zu etablieren, die Transparenzrichtlinie $^{419}$ (2004) zur Festlegung von Mindeststandards der Publizitätsvorschriften kapitalmarktorientierter Unternehmen mit dem Ziel der Erhöhung des Anlegerschutzes und der Markteffizienz bzw. letztlich die Änderungsrichtlinie ${ }^{420}$ (2006), die eine verpflichtende Corporate Governance-Erklärung einführte.

In Summe zeigt sich also, dass der europäische Gesetzgeber für die Lageberichterstattung in der EU in Ergänzung der grdl. Normen der 1980er Jahre v.a. in den letzten Jahren wesentliche Impulse gesetzt hat. Die z.T. aus den EU-Richtlinien abgeleiteten nationalen deutschen Regelungen für die Lageberichterstattung sind im Folgenden - zur Komplettierung der Rechtsgrundlage - darzustellen.

417 Vgl. Kirsch/Dohrn (2005), S. 132ff. Einzugehen ist auf verwendete Finanzinstrumente, Risikomanagementziele und -methoden, außerdem hat eine Offenlegung von Zielen des Risikomanagements sowie eine Darstellung von Preisänderungs-, Ausfall-, Liquiditätssowie Cashflowrisiken zu erfolgen. Vgl. grdl. EU (2001), Richtlinie 2001/65/EG. Vgl. umfassend bspw. Maul/Muffat-Jeandet (2004); Kindler/Horstmann (2004); Krause (2004). Der Lagebericht soll Informationen über etwaige Übernahmehindernisse liefern, z.B. Zusammensetzung des Kapitals, Kontrollrechte, Stimmrechtsbeschränkungen etc. Zum Wortlaut vgl. grdl. EU (2004a), Richtlinie 2004/25/EG.

419) Vgl. Buchheim/Ulbrich (2004). Diese betrifft die Regelung der periodischen Publizität kapitalmarktorientierter Unternehmen, u.a. die Vorlage eines Jahresfinanzberichts max. vier Monate nach Ablauf des Geschäftsjahres, mit den Elementen Abschluss, Richtigkeitserklärung und Lagebericht, der so obligatorischer Bestandteil der Finanzberichterstattung wird. Zum Wortlaut vgl. auch hier EU (2004b), Richtlinie 2004/109/EG.

Vgl. umfassend Lentfer/Weber (2006). Diese fügte einen neuen Art. 46a in die Bilanzrichtlinie ein, der den Lagebericht so um eine Corporate Governance-Erklärung ergänzt. Kapitalmarktorientierte Unternehmen müssen u.a. Angaben zur Unternehmensführung machen unter Verweis auf den Führungskodex (Befolgung oder Begründung für NichtAnwendung). Für den Lagebericht gem. HGB erscheint die Richtlinie unproblematisch, da diese Inhalte bereits mit der Entsprechenserklärung nach $\S 161$ AktG bzw. Angaben gem. § 285 Nr. 16 HGB abgedeckt sind, vgl. Lanfermann (2004). Der Wortlaut ist dem Original, EU (2006), Richtlinie 2006/46/EG, zu entnehmen. 


\section{(b) Deutsche Rechtsnormen der Lageberichterstattung}

Bis zum Jahre 1985 war die deutsche Lageberichterstattung im AktG kodifiziert und verpflichtete alle Gesellschaften in der Rechtsform der AG bzw. KGaA zur Aufstellung eines Berichts, der über Geschäftsverlauf und Lage der Gesellschaft sowie Vorgänge von besonderer Bedeutung nach Geschäftsjahresende berichten sollte. Erst durch das sog. Bilanzrichtliniengesetz (BiRiLiG), das die EU-Bilanzrichtlinien im Jahre 1985 in nationales Recht umsetzte, wurde der Begriff ,Lagebericht' jedoch explizit eingeführt und die Lageberichterstattung als eine eigenständige Rechtsnorm in den $\S \S 289$ und 315 HGB kodifiziert. ${ }^{421}$ Diesen Wandel in den relevanten Normen bzw. der Rechnungslegungsinstrumente zeigt Abb. 6.

\begin{tabular}{|c|c|c|c|}
\hline \multicolumn{2}{|c|}{ Nach AktG 1965} & \multicolumn{2}{c|}{ Nach BiRiLiG 1985 } \\
\hline Jahresabschluss & Geschäftsbericht & Jahresabschluss & Lagebericht \\
\hline Bilanz & Allgemeiner Teil & Bilanz \\
\hline GuV & Erläuterungsteil & GuV \\
\hline & & Anhang \\
\hline
\end{tabular}

Abbildung 6: Instrumente der externen Rechnungslegung im Zeitablauf ${ }^{422}$

Inhaltlich formuliert § 289 Abs. 1 HGB das Gebot, ,ein den tatsächlichen Ver-

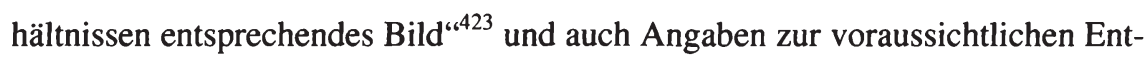
wicklung darzustellen. ${ }^{424}$ Neben einer sachlichen kommt dem Lagebericht somit auch eine zeitliche Ergänzungsfunktion zum Jahresabschluss zu. ${ }^{425}$ Nach dieser umfangreichen Neufassung der Lageberichtsnormen erfolgte in den Jahren nach

421 Vgl. Bauchowitz (1979), S. 8, auch Baetge (1993), Sp. 1327f. Bis zum Inkrafttreten des BiRiLiG verlangte das AktG von 1937 einen Geschäftsbericht mit einem allg. Teil bzw. einem Erläuterungsteil. Diese Anforderungen wurden unverändert auch in das AktG von 1965 übernommen. Der allg. Teil wurde durch das BiRiLiG als Lagebericht bezeichnet, der Erläuterungsteil ging im Anhang auf, vgl. Selch (2003), S. $10 \mathrm{f}$.

422 Quelle: eigene Darstellung in Anlehnung an Lück (1986), Rn. 1.

423 Vgl. § 289 Abs. 1 HGB sowie $\S 315$ Abs. 1 HGB. Dies ist der sog. ,Wirtschaftsbericht‘. Folgende Anmerkungen stellen auf $\S 289$ ab, sind für $\S 315$ aber gültig, vgl. Fn. 400 .

424 Vgl. Selch (2003), S. 358f. Der Prognosebericht stellte zur damaligen Zeit auch für den dt. HGB-Lagebericht ein neues Element dar, zuvor erfolgte eine Darstellung der Lage gem. AktG weitgehend statisch, Prognosen waren nicht explizit vorgesehen.

Vgl. Baetge et al. (1989), S. 10. Das BiRiLiG setzt die EU-Richtlinien grds. richtliniengetreu um. Kloos (1993), S. 463 weist jedoch auf die zeitliche Verzögerung hin.

Tom Sieber - 978-3-631-75150-3 
1985 lediglich eine Ergänzung des Zweigniederlassungsberichts im § 289 HGB Abs. 2 als Reaktion auf die entsprechende EU-Richtlinie. ${ }^{426}$

Die offensichtlich unbedeutende Stellung des Lageberichts und Unzufriedenheit mit der inhaltlichen Aussagekraft der Lageberichterstattung Ende der 1990er ${ }^{427}$ Jahre führte schließlich im Rahmen der Einführung des KonTraG zum Einfügen eines zweiten Halbsatzes in $\S 289$ Abs. 1 HGB, welcher bei der Darstellung von Lage und Geschäftsverlauf im Lagebericht auch das Eingehen auf Risiken der künftigen Entwicklung forderte. ${ }^{428}$ Dies stellte eine weitreichende Neuerung der Lageberichterstattung dar, insb. auch deshalb, weil für diesen Risikobericht eine intensivere Prüfungspflicht verankert wurde. ${ }^{429}$ Die Konkretisierung der Risikoberichterstattung erfolgte im Jahre 2001 durch die Veröffentlichung des DRS 5.

Zur Umsetzung der Vorgaben der Modernisierungs- und Fair Value-Richtlinien in das HGB wurde schließlich 2004 das sog. Bilanzrechtsreformgesetz (BilReG) verabschiedet, das den stärksten Einfluss auf die Lageberichterstattung seit dem BiRiLiG hatte. ${ }^{430}$ Es zielte darauf ab, den Informationsgehalt des Lageberichts durch Bereitstellung entscheidungsrelevanter Informationen zu erhöhen und die

426 Vgl. Fey (1994), S. 487f. zur Darstellung des - unkoordiniert wirkenden - Verlaufs der Ereignisse: Zunächst galt der Zweigniederlassungsbericht für alle Kapitalgesellschaften, jedoch später aufgrund der EU-Mittelstandsrichtlinie in 1994 bzw. des ÄndG-DMBilG Befreiung der kleinen Kapitalgesellschaften i.S.v. § 267 Abs. 1 HGB von der Erstellung eines Lageberichts. Schließlich erfolgte eine erneute Ausdehnung des Anwendungsbereichs auf alle GmbH \& Co. KG durch das KapCoRiLiG, vgl. Kirsch (2002), S. 745.

427 Vgl. bspw. Schildbach et al. (1990), S. 2297ff.; Baetge et al. (1997), S. 176ff.

428 Vgl. umfassend Küting/Hütten (1997) sowie dies. (2000), auch Baetge/Schulze (1998). Das Gesetz für Kontrolle und Transparenz (KonTraG) schuf eine verpflichtende Risikoberichterstattung unabhängig von Vorgaben der EU. Das KonTraG erforderte jedoch die Definition des Risikobegriffs: Nach h.M. bezeichnete ein Risiko die Gefahr ungünstiger Entwicklungen. Ein Blick auf den Entstehungszeitpunkt des KonTraG kann diese Sicht unterstützen: Das KonTraG entstand als Reaktion auf Insolvenzen diverser Großunternehmen, vgl. Kajüter (2004b), S. 427. Dieser Risikobegriff ist konform mit dem Begriff im Abschluss nach $\S 252$ Abs. 1 Nr. 4 HGB, welcher eindeutig negativ zu interpretieren ist und nicht mehrwertig im Sinne ,positiver Risiken'bzw. Chancen zu verstehen ist. Vgl. Küting/Hütten (2000), S. 251, auch Kajüter (2002), S. 243f. Im Zuge des KonTraG erfolgte eine Modifikation der Prüfungsvorschriften zur Lageberichterstattung in $\S 317$ Abs. 2 S. 2 HGB. Neben einer Einklangprüfung ist zudem zu prüfen, ob die Risiken der künftigen Entwicklung zutreffend dargestellt sind, also ein inhaltlicher Prüfungsaspekt.

430 Vgl. grdl. Buchheim/Knorr (2006); Kirsch/Scheele (2005). Auch hier erfolgt seitens des dt. Gesetzgebers ein deutliches Überschreiten der Mindeststandards. 
Qualität sowie Vergleichbarkeit der Lageberichterstattung zu verbessern. ${ }^{431}$ Eine weitere, wichtige Änderung der Lageberichterstattung, die sich aus dem BilReG ergab, war neben der Erweiterung des Berichts über die Lage und den aktuellen Geschäftsverlauf insb. die Verschmelzung des Risiko- und des Prognoseberichts - unter nunmehr expliziter Einbeziehung der Darstellung von Chancen. ${ }^{432}$

In zeitlicher Perspektive erfolgte die Verabschiedung des BilReG durch den Dt. Bundestag Ende Oktober 2004, das Gesetz trat am 10.12.2004 in Kraft. Bereits im Dezember 2003 war allerdings ein entsprechender Referentenentwurf (RefEBilReG) bzgl. der Änderungen der $\S 289$ bzw. 315 HGB vorgelegt worden. Da trotz umfangreicher Neuerungen eine konkrete Fixierung der Inhalte der Lageberichterstattung in den modifizierten Normen der $\S 289$ bzw. 315 nicht vorgenommen wurde, veröffentlichte das BMJ schon drei Tage vor dem Inkrafttreten des BilReG, am 07.12.2004, den DRS 15 zur Lageberichterstattung. ${ }^{433}$

Den Entwurf eines Standards zur Lageberichterstattung hatte der DSR ebenfalls bereits im November 2003 vorgelegt (E-DRS 20) in der Absicht, die inhaltliche bzw. formale Gestaltung der Lageberichterstattung zu konkretisieren und die bestehende Heterogenität von Inhalt und Struktur veröffentlichter Lageberichte zu überwinden zu helfen. Aufgrund von diversen Diskussionen zum E-DRS 20 verabschiedete der DSR im Juli 2004 sodann eine überarbeitete Version dieses Entwurfs, eine zusätzliche Modifikation folgte schließlich im Oktober 2004, um die in der Zwischenzeit erfolgten Anpassungen des BilReG zu reflektieren. Im Anschluss an die grdl. Änderungen durch das BilReG erfuhren die dt. Normen zur

431 Vgl. Dt. Bundestag (2004), BT-Drucksache 15/3419, RegE-BilReG, S. 30: Begründung zu Art. 1 (Änderung des HGB) zu Nr. 9, § 289 HGB bzw. zusätzlich die Vorlage in den Richtlinen: EU (2003), Richtlinie 2003/51/EG bzw. EU (2001), Richtlinie 2001/65/EG.

432 Vgl. Kajüter (2004b), S. 431, der das als eine „bedeutsame Korrektur“ beschreibt, da die Risikoberichterstattung bis dahin zu einseitig verlustorientiert ausgerichtet war. Folglich wird diese „,bisherige unglückliche Aufteilung der zukunftsbezogenen Berichterstattung auf zwei verschiedene Absätze“, so Krawitz (2006), S. 231, aufgehoben und ein gesamthafter Prognosebericht etabliert. Dieser wird interpretiert als eine Entwicklungsprognose inkl. Sensitivitätsanalyse, vgl. Freidank/Steinmeyer (2005), S. 2513f. Dieser zeigt auch verschärfte Berichtsintensität: Gefordert sind Beurteilungen bzw. Erläuterungen, was als Hinweis auf den Management Approach zu werten ist, vgl. Weißenberger/Maier (2006).

Vgl. die Veröffentlichung des BilReG im Bundesgesetzblatt, BGBl. (2004), S. 3166ff. sowie die Bekanntgabe des DRS 15 im Bundesanzeiger Nr. 40a vom 26.02.2005. 
Lageberichterstattung durch das sog. VorstOG ${ }^{434}$ bzw. die Umsetzung der Übernahmerichtlinie ${ }^{435}$ nur marginale Erweiterungen. ${ }^{436}$ Die Gesamtheit der Teil-Berichte der gegenwärtig in $\S \S 289$ und 315 kodifizierten dt. Lageberichterstattung stellt die folgende Abb. 7 überblicksartig dar, wobei insb. den Teil-Berichten des Wirtschafts- sowie des Prognoseberichts herausragende Bedeutung zukommt.

\begin{tabular}{lccc}
\hline Wirtschaftsbericht & Nachtragsbericht & Prognosebericht & Zusatzberichte \\
Darstellung und & Darstellung von & Darstellung von & - Forschung- und \\
Analyse von & besonderen & - Prognose der vor- & Entwicklung \\
- Geschäftsverlauf & Ereignissen nach & aussichtlichen bzw. & - Zweignieder- \\
- Geschäftsergebnis & dem Bilanzstichtag & beabsichtigten & lassungen \\
- Lage & & Entwicklung inkl. & - Übernahme- \\
Einbeziehen von & & - Sensitivitătsanalyse & situation \\
- finanziellen und & & - Chancen-Risiko- & - Vorstandsver- \\
- nicht-finanziellen & & Management & gütungssystem \\
Leistungsindikatoren & & Beurteilung & \\
\hline
\end{tabular}

Abbildung 7: Übersicht über Teil-Berichte des Lageberichts nach $\mathrm{HGB}^{437}$

Es ist daher festzuhalten, dass die grdl. Normen zur dt. Lageberichterstattung in $\S \S 289$ bzw. 315 HGB im Zeitablauf signifikante Erweiterungen erfahren haben, was in erster Linie auf die Umsetzung von Impulsen der EU zurückzuführen ist. Jedoch hat der dt. Gesetzgeber auch eigene Akzente zur Weiterentwicklung der Lageberichterstattung gesetzt. Als wesentlicher Zeitpunkt der Überarbeitung der relevanten dt. Normen ist insb. das Jahr 2004 anzusehen, dies dürfte sich sodann ab dem Jahr 2005 auch im faktischen Niveau der Lageberichte widerspiegeln.

434 Börsennotierte Unternehmen haben die Grundzüge des Vergütungssystems für ihre Vorstandsmitglieder darzulegen (sog. Vergütungsbericht), der für Geschäftsjahre nach 2005 gefordert ist. Eine Konkretisierung leistet DRS 17, vgl. Baetge et al. (2009b), S. 726ff.

435 Börsennotierte Unternehmen sollen Bieter in die Lage versetzen, ,vor Abgabe eines Angebots ein [...] Bild über die mögliche Zielgesellschaft und ihre Struktur sowie etwaige Übernahmehindernisse" zu erhalten, so die Begründung zum Übernahmerichtlinie-Umsetzungsgesetz in Dt. Bundestag (2006), BT-Drucksache 16/1003, S. 24. Es folgte daher ein Bericht bzgl. Kapital-/Kontrollstrukturen im Lagebericht, konkretisiert in DRS 15a. Die Umsetzung jener Richtlinie finalisiert das BilMoG, das am 29.05.2009 in Kraft trat.

436 Durch das BilMoG erfolgte eine Ergänzung des § 315 Abs. 2 Nr. 5 HGB (Beschreibung Konzernrechnungslegungsprozess), der DSR plant daher die Überarbeitung der DRS $5 f$. (Risikoberichterstattung), DRS 15, 15a, vgl. Baetge et al. (2009a), S. 496. Erster Schritt war die Aufnahme des DRS 15a in DRS 15 (18.02.2010), vgl. DSR (2010), DRS 15 n.F. Quelle: eigene Darstellung in leichter Anlehnung an Steinmeyer (2009), S. 130. 


\subsubsection{Informationelle Bedeutung des Lageberichts}

Aufgrund seiner Konzentration auf qualitativ-verbale, nicht-finanzielle Berichtsinhalte kommt dem Lagebericht im Kontrast zum weitgehend quantitativ ausgerichteten Jahresabschluss bereits auf den ersten Blick erhebliche informationelle Bedeutung zu. ${ }^{438}$ Als eigenständiges Element der Rechnungslegung bietet dieser genug Flexibilität, das unternehmerische Geschehen über die reine Aggregation finanzieller Angaben hinaus gesamthaft sowie ,frei von den Fesseln der GoB ““439 darzustellen und er erscheint folglich als wichtiges Instrument zur Überwindung informationeller Grenzen der Abschlüsse. Durch Bereitstellung verdichteter und ergänzender Informationen ist er dazu vorgesehen, Adressaten vor Irrtümern und falschen Schlussfolgerungen aus der Lektüre des Abschlusses zu bewahren und sie bei der Einschätzung der Lage und Entwicklung einer Gesellschaft - und den auf dieser Basis zu treffenden Entscheidungen - zu unterstützen. ${ }^{440}$ Neben jener bemerkenswerten Leistungsfähigkeit des Lageberichts zur Fundierung von Entscheidungen besitzt er als eigenständiges Element der Rechnungslegung zudem eine Rechenschaftsfunktion, da das Management das wirtschaftliche Geschehen im Unternehmen erläutert und seine Sicht der Lage und Entwicklung darstellt. ${ }^{441}$

Die informationelle Bedeutung nicht-finanzieller Unternehmensinformationen, die der Lagebericht klassischerweise zeigt, ist empirisch bereits mehrfach belegt worden: ${ }^{442}$ So ergab bspw. eine Studie von Ernst \& Young, dass nicht-finanzielle Informationen einen Anteil von nahezu einem Drittel an den zur Fundierung von Anlageentscheidungen insg. verwendeten Informationen repräsentieren. ${ }^{443}$ Auch eine Erhebung des US-amerikanischen Standardsetters AICPA zeigt die zentrale

438 Vgl. Kirsch/Scheele (2005), S. 1149f. Anders als der Abschluss stellt dieser keine Basis gesellschafts-/steuerrechtlicher Anspruchsbemessung dar, vgl. Baetge et al. (1989), S. 8. Ballwieser (1997a), S. 155; Baetge et al. (2009b), S. 727 „befreit vom engen Gerüst“. Die traditionellen Funktionen des Lageberichts der Verdichtung und Ergänzung werden hier deutlich. Insb. die zeitliche Ergänzung des vergangenheitsorientierten Abschlusses um zukunftsorientierte Angaben ist hervorzuheben, vgl. Baetge et al. (2010), S. 77. Erst durch spätere Reformschritte ist der Lagebericht sodann um eine Beurteilungs- und eine Analysefunktion ergänzt worden.

441 Vgl. u.a. Kropff (1980), S. 514ff.

442 Vgl. Brotte (1997), S. 44ff., auch Labhart (1999), S. 239ff.; Vaivio (1999), S. $412 f$.

443 Vgl. Ernst \& Young (1997), S. 13. Diese Ergebnisse beziehen sich strenggenommen auf Kapitalanlageentscheidungen in den USA und in Großbritannien. 
Bedeutung nicht-finanzieller Informationen sowie deren Kommentierung durch das Management für die Adressaten. ${ }^{444}$ Als Einschränkung bei einer Betrachtung der angesprochenen Studien muss jedoch gelten, dass die Entscheidungsrelevanz nicht-finanzieller Faktoren nicht eindeutig herausgearbeitet wurde, sondern vielmehr nur die allg. Relevanz nicht-finanzieller Informationen aufgezeigt wird. ${ }^{445}$ Unter Rückgriff auf den weitgehend akzeptierten Vorläufercharakter qualitativer Größen bzw. bestehende Ursache-Wirkungs-Zusammenhänge mit Finanzgrößen kann ein Werteinfluss nicht-finanzieller Angaben aber grds. vermutet werden. ${ }^{446}$ Umso erstaunlicher scheint daher, dass von der Möglichkeit der Vermittlung ergänzender, wertorientierter Inhalte in praxi kaum Gebrauch gemacht wird: ${ }^{447}$

So zeigten diverse empirische Untersuchungen auf, dass die Erwartungen an die Lageberichterstattung in der deutschen Berichterstattungspraxis oftmals nur unzureichend erfüllt werden. ${ }^{448}$ Im Einzelnen werden zahlreiche Defizite ermittelt:

444 Vgl. AICPA (1994), S. 25ff. Die Bedeutung nicht-finanzieller Informationen und deren Kommentierung durch das Management werden klar hervorgehoben. Vgl. hierzu auch Fey (2001), S. 58ff. sowie Jenkins (1994), S. 78ff. Die AICPA ist der US-amerikanische Berufsverband der ,Certified Public Accountants'. Als solcher veröffentlicht die AICPA Vorschläge bzw. Standards zur Rechnungslegung als Empfehlung für seine Mitglieder.

Als Reaktion auf die Studie des AICPA setzte das FASB das sog. ,Business Reporting Research Project ' auf, dessen Ergebnisse in 2001 vorgelegt wurden, vgl. die Darstellung bei Haller/Dietrich (200lb), S. 206ff. Es wurden sog. ,Best Practices` einer ergänzenden Berichterstattung für fünf Branchen erarbeitet. Insgesamt bestätigte sich die Bedeutung nicht-finanzieller Größen, vgl. im Detail FASB (2001a). Zudem initiierte die AICPA in 2002 das Projekt ,Enhanced Business Reporting ' mit dem Ziel, klare Leitlinien für eine ergänzende Berichterstattung zu erarbeiten, vgl. bspw. Kleinmanns (2004), S. 1022. Studien zur Entscheidungsrelevanz nicht-finanzieller Informationen wurden bislang nur mit spezifischem Fokus durchgeführt, z.B. zu konkreten Daten in begrenzten Bereichen, u.a. Branchen, vgl. Malone et al. (1993); Amir/Lev (1996); Riley et al. (2003); Laitinen (2004); Hughes (2000). Zur Entscheidungsrelevanz grds. Ruhwedel/Schultze (2004). Vgl. Ernst \& Young (1997), S. 10f. Küting (2000a), S. 157 und ders. (2000b) beschreibt nicht-finanzielle Daten als maßgebliche Werttreiber, die Entscheidungsrelevanz sei aber anderer Natur als bei finanziellen Daten, die als direkte Inputgröße für Prognosen nutzbar sind. Nicht-finanzielle Daten seien insb. flankierend für Prognosen zu verwenden, als Ergänzung finanzieller Daten aber unabdingbar, so Günter/Beyer (2001), S. 1627. Vgl. Labhart/Volkart (2001), S. 126, die ebenfalls einen großen Hebel nicht-finanzieller Kennzahlen auf den Wert postulieren, insb. in der längerfristigen Perspektive.

448 Vgl. Schildbach et al. (1990), S. 2300, im Detail Krumbholz (1994); Kajüter (2001), S. 107; Kajüter/Winkler (2003), S. 217. Dietsche/Fink (2008) vermerken die Heterogenität der Qualität bzw. Gestaltung der Lageberichte. Zu folgern wäre daher, dass z.T. bereits Verstöße gegen die ,Grundsätze ordnungsgemäßer Lageberichterstattung 'vorliegen. 
Neben vagen sowie z.T. recht allgemein gehaltenen Informationen zur Lage und zukünftigen Entwicklung und nur mangelhafter Darstellung der Risiken fehlt es - in rein struktureller Hinsicht - außerdem an der eindeutigen Bezeichnung von Lageberichten und klarer, mit den Vorjahren konsistenter Gliederung. ${ }^{449}$ Der Berichterstattung im Lagebericht ist folglich erhebliches Verbesserungspotenzial zu attestieren, jener ist ,obviously an area of the annual report capable of assuming a greater significance than it already does. Analysts in the study looked at it for [...] hints about the future, statements of management's intentions““ ${ }^{450}$

Von den Aufstellern werden v.a. zeitliche Engpässe als wesentliche Begründung dafür genannt, dass der Lagebericht eher „stiefmütterlich“ behandelt wird. ${ }^{451}$ Die damit oftmals einhergehende Argumentation, der Lagebericht werde erst mit Beginn der Abschlussprüfung erstellt und dies würde dann zu zeitlichen Engpässen führen, kann vor dem Hintergrund der bestehenden Prüfungspflicht des Lageberichts nicht überzeugen. ${ }^{452}$ Auch wird die Zurückhaltung in der Berichterstattung mit der Sensibilität der enthaltenen Informationen begründet, es wird befürchtet, dass Wettbewerber und andere Anspruchsgruppen des Unternehmens durch eine Offenlegung Einblicke erhalten, die sie für die Durchsetzung ihrer Positionen im Rahmen von Verhandlungssituationen nutzen könnten. ${ }^{453}$ Diese Argumentation

449 Vgl. Kajüter (2001), S. 107f.; Kajüter/Winkler (2003), S. 217f., mit Fokus auf zukunftsorientierte Aspekte Glaum/Friedrich (2006), S. 165f. Zur Risikoberichterstattung zudem Solfrian (2005), S. 917f., der feststellt, dass - sofern über Risiken berichtet wird - diese oftmals nicht so bezeichnet oder in anderen Teil-Berichten nur umschrieben werden. Er vermutet, Unternehmen seien besorgt, Adressaten könnten Risiken überbewerten. Er argumentiert aber, Adressaten sei bewusst, dass unternehmerisches Handeln nicht risikofrei ist und es verwundert, wenn laut Management keine Risiken bestehen. Da es im Ermessen des Managements liegt, wie über Risiken berichtet wird, könnte der Umfang der Berichterstattung als Indiz für Wahrnehmungsfähigkeit und Risikoeinstellung dienen.

450 Day (1986), S. 306. Die Aussage bezieht sich auf Geschäftsberichte in Großbritannien.

451 Kajüter (2004), S. 197, der ein ernüchterndes Bild von der Umsetzung der Lageberichtsnormen zeichnet: Als Argument für die späte Erstellung wird lt. Autor genannt, dass Inhalte vor der Prüfung nicht endgültig seien und sich noch Änderungen ergeben könnten. Vgl. Kajüter (2004), S. 197f. Lageberichte sind gem. § 317 Abs. 2 HGB Gegenstand der Abschlussprüfung, die verspätete Vorlage führt zu zeitlichem Verzug der Prüfung. Diese Prüfungspflicht beschreibt eine sog. ,Einklangsprüfung', die „Chancen und Risiken der [...] Entwicklung“" sind in § 317 Abs. 2 HGB explizit als Teil der Prüfung genannt.

Diese Argumentation wird z.T. auch bei Verstößen gegen die Offenlegungsvorschriften gem. § 325 HGB vorgebracht. Gedacht sei an Gewerkschaften, Zulieferer, Kunden etc. 
lässt insofern aufhorchen, als sie impliziert, dass Unternehmen die Aussagekraft bzw. Bedeutung der im Abschluss inkludierten Informationen als geringwertiger für ihre Adressaten einstufen - zu vermuten wäre, dass Unternehmen davon ausgehen, der Abschluss würde nur von fachlich ausreichend versierten Lesern verstanden. In Bezug auf die Wettbewerbssensibilität ist zudem einzuwenden, dass der Ersteller des Lageberichts immer noch einen zeitlichen Vorsprung hätte, sofern in der Tat ein Wettbewerber Nutzen aus den Angaben ziehen könnte. ${ }^{454}$

Es lässt sich folglich resümieren, dass die Aussagekraft des Berichtsinstruments Lagebericht realiter als nur schwach zu beurteilen ist bzw. für berichtspflichtige Unternehmen das Potenzial bestehen sollte, sich durch solide Berichtsqualität zu differenzieren. Argumentativ könnte insofern gelten, dass das Management eines Unternehmens durch umfassende sowie qualitativ hochwertige Darstellung bzw. Analyse des Geschäftsverlaufs, der Lage bzw. der angestrebten Entwicklung des Unternehmens demonstrieren kann, dass es Umfeld und Märkte, in denen dieses agiert, sowie die eigene Position in diesem Kontext hinreichend genau kennt. ${ }^{455}$

Eine unzureichende Berichterstattung könnte dementsprechend schließlich auch als Unkenntnis oder unfundiertes bzw. intransparentes Management interpretiert werden. ${ }^{456}$ Interessant wäre auch - vor dem Hintergrund der Ereignisse der Jahre 2008 und 2009 - den Lagebericht insb. in ,Krisensituationen“ als ein Instrument zur Bereitstellung zusätzlicher Informationen zu verwenden, da gerade dann der Abschluss nicht geeignet ist, ein den tatsächlichen Verhältnissen entsprechendes Bild von der Lage und des künftigen Entwicklungspotenzials der Gesellschaft zu vermitteln. ${ }^{457}$ Abschließend sei - der Vollständigkeit halber - auch die Möglichkeit erwähnt, die Imagewirkung der Berichterstattung für Marketing-strategische Zielsetzungen zu nutzen, wenngleich dies nicht im Vordergrund stehen sollte. ${ }^{458}$

\footnotetext{
4.54 Vgl. die Veröffentlichungsfristen in Abschnitt B 3.1.3. Ebenso kann die Argumentation der Wettbewerbssensitivität strategieorientierter Angaben in B 2.3.3 angewandt werden.

45.5 Vgl. dazu bereits Semler (1980), S. 177ff.

4.56 Vgl. Solfrian (2005), S. $916 \mathrm{f}$.

457 Vgl. bereits Kropff (1980), S. 514f. Auf Basis eines Abschlusses lassen sich insb. dann wenige Schlüsse ziehen, wenn erst am Jahresende eine Besserung der Lage eintritt. Zum Niederschlag rezessiver Tendenzen in der Berichterstattung vgl. Ruhwedel et al. (2009). Zur Imagewirkung des Geschäftsberichts vgl. umfassend Baetge/Kirchhoff (1997). 


\subsection{Würdigung der Erkenntnisse und überleitende Anmerkungen}

Es wurde dargestellt, dass die Rechnungslegung ein umfassendes Informationssystem zur Verfügung stellt, das hohe Bedeutung am Kapitalmarkt besitzt. Diese Bedeutung resultiert in erster Linie aus ihrem verbindlichen Charakter, aus der Normierung bzw. der Standardisierung der Inhalte sowie der Regelmäßigkeit der Vorlage. Allerdings sind die Investoren am Kapitalmarkt im Rahmen ihrer Anlageentscheidungen insb. auf entscheidungsnützliche Informationen angewiesen, d.h. primär zukunftsorientierte Angaben. Die Rechnungslegung dagegen ist i.W. als Instrument der Rechenschaftsablage positioniert, auch wenn die Perspektive der Investoren verstärkt in den Fokus der standardsetzenden Institutionen rückt.

Die Debatten zur kapitalmarktorientierten Ausrichtung bzw. Weiterentwicklung der Rechnungslegung scheinen jedoch zu einseitig auf die quantitativ-monetären Elemente konzentriert zu sein, v.a. der Lagebericht als das qualitativ-verbale Instrument wird - trotz einiger Reformschritte in der Vergangenheit - kaum seiner Leistungsfähigkeit entsprechend berücksichtigt. So könnte er konsistent als derjenige Baustein der Rechnungslegung eingesetzt werden, der nicht nur über die Lage des Unternehmens informiert, sondern weiterhin relevante nicht-finanzielle Informationen zur Verfügung stellt bzw. auch prognostische Angaben liefert, die zur Schätzung künftiger finanzieller Größen am Kapitalmarkt hilfreich wären. ${ }^{459}$

Wenngleich die Empirie zum Status der Lageberichterstattung ein weitestgehend ernüchterndes Bild zeichnet, da bestehende inhaltliche Möglichkeiten kaum ausgenutzt werden und die Qualität der bereitgestellten Angaben als i.d.R. schwach zu kritisieren ist, würdigt insb. Streim (1995) prägnant die hohe informationelle Bedeutung des Lageberichts, da seiner Ansicht nach die quantitativen Bausteine der Finanzberichterstattung, „Bilanz und $\mathrm{GuV}$ durch informationsunfreundliche Gewinnermittlungsregeln [...] dominiert werden, die überhaupt nicht zur Vermittlung eines den [...] Verhältnissen entsprechenden Bildes konzipiert sind ${ }^{\star 460}$.

459 Vgl. ähnlich Schultze et al. (2007), S. 569. Insofern könnte der Lagebericht Angaben zu vergangenen Erfolgen als Prognosebasis liefern sowie Informationen bzgl. der künftigen Ausrichtung des Unternehmens bereitstellen zur Fortschreibung der Prognosebasis. 
Folglich dürfte der Lagebericht - unter Rückgriff auf die in Abschnitt 2.3 bereits postulierte herausragende Relevanz strategieorientierter Informationen - gleichfalls als bestens geeignetes Medium zur Bereitstellung von Informationen zu den einzelnen Phasen des Prozesses des strategischen Managements gelten: Er bietet nicht nur die notwendige Flexibilität für qualitative und prognostische Angaben aus Sicht des Managements, sondern beinhaltet mit dem Prognosebericht bereits ein Berichtselement, das inhärenten Bezug zur Strategie besitzt.

An dieser Stelle ist sodann konsequenterweise auch die Frage zu stellen, inwieweit eine Berichterstattung über die gegenwärtige Lage eines Unternehmens und eine Prognose seiner zukünftigen Entwicklung überhaupt möglich bzw. sinnhaft ist, ohne jedoch auf die von der Unternehmensleitung angestrebte Entwicklungsrichtung für das Unternehmen, also die Strategie, inhaltlich einzugehen. ${ }^{461}$

Neben dieser primär inhaltlichen Sicht böte der Lagebericht für eine Berichterstattung über strategieorientierte Sachverhalte zudem interessante Vorzüge: Sein Charakter als verbindliches, prüfungspflichtiges bzw. regelmäßig vorzulegendes Element der externen Rechnungslegung sollte den Nachteil ggf. reduzierter Verlässlichkeit strategieorientierter Angaben zumindest teilweise heilen können, die Bedeutung sowie die Fähigkeit strategieorientierter Angaben zur Entscheidungsunterstützung dürften ohnehin außer Frage stehen.

Im folgenden Abschnitt, dem letzten Teil der theoretischen Grundlagen, soll die Möglichkeit zu einer Berichterstattung über strategieorientierte Sachverhalte im Rahmen des Lageberichts vertieft beleuchtet werden. Dies umfasst zunächst eine Analyse der Leistungsfähigkeit der Rechnungslegung vor dem Hintergrund verstärkter Wertorientierung und die Darstellung von Ansätzen zur Erweiterung der Berichtsumfänge zu einem sog. ,Value Reporting'. Schließlich ist aufzuzeigen, dass bereits Überlegungen relevanter Standardsetter zur expliziten Kodifizierung der Berichterstattung über strategieorientierte Sachverhalte angestellt wurden.

461 Ebenso fragen sich Buchheim/Knorr (2006), S. 422, ,wie die Unternehmensleitung die voraussichtliche Entwicklung darstellen und außerdem noch beurteilen soll, ohne Angaben [...] zu dieser Entwicklung zu machen". Eine Beurteilung der voraussichtlichen Entwicklung gemäß § 289 Abs. 1 S. 4 HGB scheint ohne die Angabe strategischer Ziele nicht möglich, so Freidank/Steinmeyer (2005), S. 2514, auch Müßig (2008), S. 199. 
4 Berichterstattung über strategieorientierte Sachverhalte in der externen Rechnungslegung

\subsection{Leistungsfähigkeit der externen}

Rechnungslegung im Kapitalmarktkontext

\subsubsection{Wettbewerb um Kapital als begründende Entwicklung}

Vielfach ist in den vergangenen Jahren über die Leistungsfähigkeit der externen Rechnungslegung, die Informationsinteressen der Adressaten an Kapitalmärkten zu befriedigen, diskutiert worden. ${ }^{462}$

Als Hintergrund dieser Debatte über die Leistung der externen Rechnungslegung bzw. der Finanzberichterstattung ist insb. die voranschreitende Integration internationaler Kapitalmärkte zu sehen. ${ }^{463}$ So führt zunehmende globale Konkurrenz um Kapital zur steigenden Bedeutung des Unternehmenswertes, da anzunehmen ist, dass sich Investoren nur dann längerfristig in einer Anlage engagieren, wenn diese eine angemessene Rendite auf das eingesetzte Kapital bietet. ${ }^{464}$ Diese Entwicklung führt in der Konsequenz schließlich zu stärkerer Beachtung von wertorientierten Steuerungskonzepten, welche es ermöglichen, die zentrale Zielgröße des Unternehmenswertes in der betrieblichen Realität greifbar zu machen und zu operationalisieren, und um so die Ausrichtung des Handelns auf Wertsteigerung zu erreichen. ${ }^{465}$ Sofern als Oberziel jedes Unternehmens also die Steigerung des Unternehmenswertes akzeptiert ist, müsste sich als Konsequenz eine Steigerung jenes inneren Wertes auch in der am Kapitalmarkt realisierten Bewertung wider-

462 Vgl. z.B. Günther et al. (2003), S. 448. Diese Informationsdefizite beschränken sich jedoch ausdrücklich nicht auf eine Rechnungslegung nach HGB, sondern betreffen auch vermeintlich investorenorientierte Systeme: Verwiesen sei auf empirische Arbeiten von Alford et al. (1993), die US-amerikanischer Rechnungslegung höheren Informationsgehalt zusprechen, konträr Harris et al. (1994), auch Möller/Keller (1999), S. 135. Ähnlich bei Baetge et al. (2010), S. 70. Angesichts der Widersprüche folgert Ballwieser (1997b), dass es eine politische Wertung sei, welcher Standard als überlegen angesehen wird. Zur Kritik am Informationsgehalt der Rechnungslegung u.a. Streim (2000), S. 111. Vgl. Pellens et al. (2000a), S. 178f.; Ruhwedel/Schultze (2002a), S. 602f., auch Glaum (2000), S. 28f. mit dem Hinweis auf die neue Qualität des Wettbewerbs um Kapital.

464 Vgl. Fischer/Wenzel (2002), S. 327 bzw. die Prämissen in Abschnitt B 1.1: Die Rendite auf das Kapital ist die Voraussetzung für höhere Konsummöglichkeiten in der Zukunft. Vgl. u.a. Böcking (1998), S. 18; Fischer et al. (2001a), S. 1209; Glaum (2000), S. 31. 
spiegeln, um letztlich die monetären Ansprüche der Investoren zu befriedigen. ${ }^{466}$ Wertorientiertes Management in einer erweiterten Sichtweise beinhaltet folglich nicht nur die interne Steuerung, sondern auch die externe Kommunikation wertrelevanter Sachverhalte. ${ }^{467}$ Die externe Finanzberichterstattung als wesentliches Informationsinstrument gegenüber dem Kapitalmarkt ist demzufolge anhand des Kriteriums zu beurteilen, inwieweit diese in der Lage ist, intern generierte Wertsteigerungen gegenüber dem Kapitalmarkt zu kommunizieren.

\subsubsection{Beurteilung der Wertorientierung der Rechnungslegung}

Dem Management steht in erster Linie das im vorherigen Abschnitt vorgestellte Instrumentarium der externen Rechnungslegung zur Verfügung, um die Akteure am Kapitalmarkt über Veränderungen des Unternehmenswertes zu unterrichten. Wie in B 1.3 bereits angedeutet, scheint die externe Rechnungslegung allerdings nicht unmittelbar als informationelle Basis von Anlageentscheidungen bzw. als Medium der Wertkommunikation hilfreich: Während die Rechnungslegung den Bilanzwert als zentralen Wertmaßstab abbildet, benötigen die Investoren für die Fundierung der Entscheidungen prognostische, risikoadjustierte Zahlungsstromprofile, um ihrerseits einen inneren Wert zu errechnen und um diesen schließlich mit der gegenwärtig realisierten Marktbewertung abzugleichen. ${ }^{468}$

Zwei Aspekte treten folglich in den Vordergrund, an denen eine Beurteilung der Wertorientierung der Rechnungslegung erfolgen kann: zum einen der Bezug zu Zahlungsstromgrößen zur Errechnung eines inneren Wertes durch die Investoren und die Fähigkeit zur Abbildung des inneren Wertes in Form des Bilanzwertes.

\footnotetext{
466 Vgl. Hahn/Hungenberg (2001), S. 13f. bzw. die Wertkonzeptionen in Abschnitt B 1.1.3.

467 Vgl. Ruhwedel/Schultze (2002a), S. 602. Dies gilt unter der Prämisse funktionierender, Informationen verarbeitender Kapitalmärkte, so Copeland et al. (2002), S. 40. Als Beleg für die Relevanz der ,Wert-Kommunikation“ ist die Entstehung von Investor RelationsAbteilungen zu sehen, empirisch für Fortune 500-Unternehmen Rao/Sivakumar (1999). Der errechnete innere Wert stellt den Grenzpreis einer Anlageentscheidung dar: Durch Vergleich mit der Marktbewertung werden Über- sowie Unterbewertungen transparent. Schätzungen des inneren Wertes erfordern Informationen zu den Determinanten der zukünftigen Zahlungsströme, die die Rechnungslegung jedoch kaum bereitstellen kann, so auch Labhart/Volkart (2001), S. 115; Rappaport (1998), S. 33, der davon ausgeht, dass realiter Fehlallokationen kaum zu vermeiden sind. Vgl. ggf. nochmals Abb. 3 (S. 17).

Tom Sieber - 978-3-631-75150-3 


\section{(a) Bezug der Rechnungslegung zu Zahlungsstromgrößen}

Die benötigte Entscheidungsgrundlage der Investoren, künftige und diskontierte, risikoadjustierte Zahlungsgrößen, ist in ihre drei Bestandteile - Zahlungsströme, Zinssatz bzw. Kapitalbasis und ,Zukunft ${ }^{\text {- }}$ zu zerlegen, um schließlich zu überprüfen, inwieweit sich die Rechnungslegung als Informationsquelle eignet:

Es erscheint bereits auf den ersten Blick nachvollziehbar, dass die Rechnungslegung keine unmittelbar geeignete Informationsgrundlage für eine Bestimmung von Zahlungsströmen darstellt. Das ist auch als Begründung dafür zu sehen, dass Verfahren der wertorientierten Steuerung die Ermittlung des inneren Wertes auf Basis buchhalterischer Daten vornehmen, um einen Orientierungspunkt für den inneren Wert zu erhalten. Jedoch ist zu beachten, dass buchhalterische Erfolgsgrößen nur mit Hilfe substanzieller Korrekturen zahlungsorientierten Daten entsprechen; ${ }^{469}$ analytische wie empirische Belege zeigen konsequenterweise, dass buchhalterische Gewinne nur schwachen Bezug zum Marktwert besitzen. ${ }^{470}$

Darüber hinaus ist die mangelnde Berücksichtigung des Risikos - und dementsprechend die Bestimmung risikogerechter Kapitalkosten sowie der Vermögensbasis - als Grund für die geringe Eignung der externen Rechnungslegung als informationelle Basis für Investorenentscheide zu benennen. ${ }^{471}$ Gerade der letztgenannte Aspekt hat sich im Zuge fortschreitenden Wandels von kapitalintensiver zu einer wissensbasierten Produktion verschärft: Zahlreiche erfolgsrelevante und werttreibende Faktoren sind im bilanziellen Vermögen nicht mit abgedeckt. ${ }^{472}$

469 Es muss erwähnt werden, dass buchhalterische Erfolgsgrößen unter bestimmen Voraussetzungen einer geldwerten Betrachtung entsprechen, wie grdl. Lücke (1955) sowie bereits Preinreich (1938) darstellen. Labhart/Volkart (2001), S. 115 bemerken jedoch, dass dieser Spezialfall bei gängigen Rechnungslegungssystemen kaum noch eintritt, da sich bewertungstechnische Verschiebungen nicht mehr innerhalb finiter Zeiträume auflösen. Vgl. Labhart/Volkart (2001), S. 116f. Einen Beleg für jenen schwachen Zusammenhang zwischen buchhalterischen Gewinnen und dem Marktwert bringt bspw. Lev (1989).

471 Vgl. Labhart/Volkart (2001), S. 115, S. 123 und v.a. Fn. 15, die primär auf die fehlende Einheitlichkeit sowie z.T. erhebliche Simplifizierungen bei der Ermittlung von Kapitalkosten hinweisen, bspw. auf die fehlende Berücksichtigung von Bereichsspezifika. 
Zudem ist die fehlende Zukunftsorientierung als Ursache dafür zu nennen, dass die Rechnungslegung den Informationsanforderungen von Kapitalmarktakteuren nicht gerecht wird: Investitionsentscheidungen sowie Bewertungsüberlegungen sind zukunftsorientiert ausgerichtet und folglich auf zukünftigen Erwartungen zu basieren, die Rechnungslegung aber ist primär auf die vergangenheitsorientierte Rechenschaftsablage ausgerichtet. ${ }^{473}$ Daher wird regelmäßig eine verpflichtende Offenlegung zukunftsgerichteter Größen seitens der Unternehmen gefordert, wie bspw. in Form von Gewinnprognosen, da insb. das Management hohe Prognosekompetenz besitzen dürfte. Auch würde es dem Kapitalmarkt so ermöglicht, das Management bzgl. der Prognosen zu beurteilen und Schlüsse auf dessen Qualität zu ziehen - eine ,erziehende ' Wirkung der Veröffentlichung wäre zu erwarten. ${ }^{474}$

\section{(b) Abbildung des inneren Wertes mit dem Bilanzwert}

Wie zuvor dargestellt wurde, stellt die Rechnungslegung eine unzureichende Informationsbasis für die Schätzung von Zahlungsströmen dar. Darüber hinaus ist aber auch die wesentliche Zielgröße der externen Rechnungslegung, der Bilanzwert, kein geeigneter Indikator des inneren Wertes, wie sich i.d.R. in einer deutlichen Differenz zwischen innerem und Bilanzwert manifestiert. Jene Wertlücke resultiert meist aus den Vorschriften zur Bilanzierung, ${ }^{475}$ eine Begründung dafür ist in den einschlägigen Ansatz- sowie Bewertungsvorschriften zu finden: ${ }^{476}$

Es kann - und dies wird durch die erwähnte Verschiebung innerhalb der betrieblichen Leistungserbringung zunehmend bedeutsam - als kaum realistisch angesehen werden, alle relevanten Potenziale, die einen Beitrag zu Wertsteigerungen leisten, als Vermögenswerte in der Bilanz abzubilden, da diese z.T. gar nicht als Vermögenswerte im Sinne der Rechnungslegung gelten und deshalb unmittelbar

473 Vgl. bspw. Schultze et al. (2007), S. 564.

474 Die Diskussion wird insb. in der angelsächsischen Literatur geführt, vgl. bspw. Penman (1980); Begley/Feltham (2002). Auch Unternehmensexterne, v.a. Analysten, publizieren Prognosen zu Gewinngrößen - diejenigen der Manager werden als valider angesehen.

475 Es ist festzustellen, dass dies keine HGB-spezifische Problematik ist. Gleichfalls ist die IFRS-Rechnungslegung nicht dazu geeignet, die Informationsbedürfnisse der Investoren zu befriedigen, eine Differenz zwischen Bilanzwert bzw. innerem Wert würde sich dennoch einstellen. Vgl. hierzu bspw. Streim (2000), S. 113.

476 Es sei - zur Illustration der folgenden Ausführungen - nochmals auf Abb. 3 (S. 17) der vorliegenden Arbeit verwiesen. 
erfolgswirksam zu berücksichtigen sind. ${ }^{477}$ Ähnlich verhält es sich auch mit den Potenzialen, die zwar u.U. hohen Einfluss auf die Leistungserbringung besitzen, aber wegen ihres qualitativen Charakters monetär nicht abbildbar sind. ${ }^{478}$

Neben diesen ansatzorientierten Ursachen führt zudem die Bewertung von angesetzten Vermögenswerten zu Wertdifferenzen: Dabei ist insb. auf die nicht vollständige Berücksichtigung von Zeitwerten für die Vermögenswerte in der Bilanz abzustellen. ${ }^{479}$ Darüber hinaus ist der nach wie vor gültige Grundsatz der Einzelbewertung für Buchvermögen anzusprechen, der zur Konsequenz hat, dass nicht einzeln zu bewertende Werte im originären Geschäftswert aufgehen und folglich nicht abgebildet werden können. ${ }^{480}$ Schließlich wird eine Berücksichtigung sog. Verbundeffekte zwischen einzelnen Vermögenswerten unmöglich gemacht.

Neben diesen Aspekten, die auf die Bilanzierung vorhandener Vermögenswerte abstellen, trägt auch die Nichtberücksichtigung der ,Zukunft' zu Wertlücken bei: Dies umfasst in der Zukunft liegende Geschäfte und Erfolgspotenziale sowie v.a. Strategien für die Zukunft, die nicht in der Bilanz abgebildet sind. Ein ,objektiv richtiger' innerer Wert ist ergo mit der Rechnungslegung nicht darstellbar. ${ }^{481}$

477 Die Diskussionswürdigkeit dieser Vorgehensweise zeigt sich prägnant am Beispiel von Forschungsaufwendungen, die als Investition in zukünftige Werte par excellence gelten sollten. In der Folge ergeben sich so stille Reserven aus nicht bilanzierten Vermögenswerten. Vgl. zu den Vermögens-Kriterien der IFRS Baetge/Beermann (1998), S. 164. Ursächlich hierfür ist insb. die primär quantitative Ausrichtung der IFRS, welche auf die Darstellung der wirtschaftlichen Lage anhand eines Periodenergebnisses abstellt.

479 So könnten bspw. immaterielle Vermögensgegenstände nur dann mit einem Fair Value bewertet werden, sofern ein aktiver Markt existiert und sich aus diesem ein Zeitwert ableiten lässt, vgl. IASB (2009d), IAS 38, Tz. 38.75 bzw. 38.8. Grds. entwickelt das IASB das Thema der Zeitwert-Bewertung weiter, für einzelne Posten sind vom Anschaffungskostenprinzip losgelöste Bewertungen möglich, vgl. Ballwieser et al. (2004), S. 532ff. Eine Ausweitung ist zu erwarten, aktuell ist aber ein durchgängiger Bewertungsmaßstab nicht etabliert, daher ist eine imparitätische Berücksichtigung zu konstatieren, was zu eingeschränkter Verlässlichkeit bzw. zu Informationsgrenzen der IFRS führt. Vgl. dazu bspw. kritisch Kley (2001), ders. (2003); Landsman (2007), jüngst Wagenhofer (2008). Vgl. bspw. Ballwieser et al. (2004), S. 541; Kessler (2005), S. 73f.

481 Vgl. hierzu ggf. nochmals Abschnitt B 1.1.3. Der innere Wert eines Unternehmens kann grds. durch Gesamtunternehmensbewertung als Zukunftserfolgswert abgeleitet werden. Eine Annäherung des IFRS-Bilanzwertes ist theoretisch möglich über den sog. Reinvermögenswert auf Einzelbewertungsbasis, d.h. durch Bewertung aller Vermögensgegenstände mit dem Zeitwert, vgl. für einen Überblick Heumann (2005), S. 27 und S. 50. 


\subsubsection{Wertorientierte Berichterstattung als Lösungsansatz}

Wenn die Rechnungslegung per se nicht geeignet ist, den ,tatsächlichen“ inneren Wert zu kommunizieren, könnte eine ergänzende, explizit kapitalmarktorientiert ausgerichtete Berichterstattung erfolgen, die eine Darstellung der für ein Unternehmen relevanten Werttreiber ermöglicht, um Investoren bei der Schätzung des inneren Werts und insofern bei ihren Allokationsentscheiden zu unterstützen. ${ }^{482}$

Für eine solche Ergänzungsleistung und kapitalmarktorientierte Ausrichtung der traditionellen Finanzberichterstattung erscheint eine Berichterstattung zu nichtfinanziellen Sachverhalten, wertorientierten Angaben sowie kritischen Erfolgsfaktoren und zukunftsorientierten Indikatoren der langfristigen Entwicklung des Unternehmens adäquat. ${ }^{483}$ Als Abgrenzungskriterium kann insofern gelten, dass es sich dabei um Informationen zu sämtlichen Ressourcen handelt, die bilanziell bislang nicht oder nicht vollständig als materielle sowie finanzielle Güter erfasst werden - und deshalb als Wertkomponente unberücksichtigt bleiben: „However, financial statements do not provide all the information that users may need to make economic decisions since they largely portray the financial effects of past events and do not necessarily provide non-financial information. ${ }^{\text {“484 }}$

An dieser Stelle wird die kapitalmarktinduzierte Bedeutung des Lageberichts bereits greifbar - er scheint das Berichtsinstrument zu sein, das geeignet wäre, die benötigten Informationen bereitzustellen, ohne jedoch das System der externen Rechnungslegung zu verlassen bzw. ohne dieses in seiner Struktur grds. in Frage zu stellen. ${ }^{485}$ Vielmehr wäre zu erwarten, dass das System der Rechnungslegung einen idealen Rahmen zur wertorientierten Berichterstattung innerhalb des Lageberichts bietet, indem sich deren zentrale Attribute der Verlässlichkeit bzw. Verbindlichkeit idealerweise positiv auf die erweiterten Berichtsinhalte auswirken.

482 Faktoren mit Einfluss auf den inneren Wert werden auch als Werttreiber bezeichnet. Sie gelten als zentrale Determinanten für unternehmerischen Erfolg, vgl. Krüger/Schwarz (1990), S. 179f. Die wertorientierte Berichterstattung muss in der Lage sein, Werttreiber zu identifizieren und zu kommunizieren, vgl. so Fischer/Wenzel (2004), S. $305 f$.

$4 \times 3$ Vgl. Fischer/Wenzel (2002), S. 327, auch Böcking (1998), S. 44.

IASB (2009a), Tz. 13. Das IASB gesteht folglich einen Mangel an nicht-finanziellen Informationen, den das IFRS-Regelwerk des IASB bewirkt, ein.

Vgl. ähnlich Haller/Dietrich (2001c), S. 166; Krawitz/Hartmann (2003), S. 303.

Tom Sieber - 978-3-631-75150-3 
Es wurde bereits aufgezeigt, dass die IFRS als wesentlicher Rechnungslegungsstandard der kapitalmarktorientierten Unternehmen in Europa gegenwärtig kein dediziertes Berichtsinstrument für nicht-finanzielle Inhalte bereithalten, ein dem Lagebericht nach HGB vergleichbares Instrument für die qualitativ-verbale Berichterstattung existiert nicht. ${ }^{486}$ Obwohl dies auf den ersten Blick unvollständig wirken mag, erfolgt die Konzentration der IFRS auf finanzielle Transparenz bewusst - schließlich wird in der Realität aufgrund nationalstaatlicher Vorschriften innerhalb der EU, spezifisch in Deutschland, stets ein Lagebericht aufgestellt. ${ }^{487}$ Jener kann schließlich als das wesentliche Berichtsinstrument der Kapitalmarktkommunikation zu wertorientierten bzw. nicht-finanziellen Inhalten gelten - und ist in seiner Bedeutung folglich kaum zu überschätzen. ${ }^{488}$

Die vorstehenden Ausführungen zu den bestehenden Unzulänglichkeiten der externen Rechnungslegung zur Kommunikation wertrelevanter Sachverhalte sind wohlgemerkt explizit aus der Kapitalmarktperspektive zu betrachten: Trotz einer Konzentration auf die besprochenen Einschränkungen ist die Rechnungslegung nicht ernsthaft in Frage zu stellen: Sie hat verschiedenen Zwecken zu dienen und diversen Adressatengruppen simultan gerecht zu werden und kann als durchaus

486 Wenngleich innerhalb der IFRS ein zum Lagebericht adäquates Instrument gegenwärtig nicht existiert, findet sich in IAS 1.13 dennoch ein Hinweis auf einen ,financial review by management", also einen qualitativ-verbalen Managementbericht, u.a. über Einflüsse von Umweltbedingungen bzw. über Ressourcen, die nicht in der Bilanz abgebildet sind, vgl. IASB (2009c), IAS 1, Tz. 13. Dieser besitzt aber keine Verbindlichkeit, vgl. Baetge et al. (2009a), S. 514; Krawitz/Hartmann (2003), S. 302. Zuvor existierte eine Berichtsempfehlung in IAS 1, heute nur noch die Feststellung, dass viele Unternehmen derartige Berichtsinhalte in praxi bereitstellen. Eine Motivation zur freiwilligen Aufstellung ist de facto nicht gegeben, eine Grundlage zur umfassenden Kommunikation nicht-finanzieller Inhalte ergibt sich aus den IAS/IFRS folglich nicht.

487 Das IASB gesteht daher bereits im Framework der IFRS Defizite bzgl. nicht-finanzieller Berichterstattung ein, vgl. IASB (2009a), Tz. 13. Dies wird v.a. begründet mit der Zielsetzung, wirtschaftliche Sachverhalte allein auf finanzieller Basis abzubilden, vgl. ebenda, Tz. 12. Ebenso kann der supranationale Charakter der IFRS als Begründung dienen: Da stets nationalstaatliche Rechtsnormen (z.B. Haftungsrecht) anzuwenden sind, scheint die vergangenheitsorientierte und finanziell ausgerichtete Berichterstattung eher als einheitlicher Rechnungslegungsrahmen durchsetzbar als eine Berichterstattung unter Verwendung qualitativer, nicht-finanzieller Inhalte. In Deutschland resultiert die Pflicht zur Aufstellung des Lageberichts daher aus $\S \S 289$ bzw. 315 HGB, vgl. Abschnitt B 3.1. 
bewährte Kompromisslösung gelten. ${ }^{489}$ Zudem ist - insb. vor dem Hintergrund komplexer realer Strukturen der Unternehmen - ihre Standardisierungsleistung, die nicht nur perioden- sowie branchenübergreifende Vergleichbarkeit, sondern auch eine solide Rechenschaftsablage gewährleistet, zu würdigen. ${ }^{490}$ Dass Bilanz und Erfolgsrechnung nicht dazu ausgelegt sind, strategische Erfolgsfaktoren der heutigen Zeit abzubilden, darf nicht erstaunen - wenngleich dies auch wiederum nicht als Begründung dienen kann, nicht-finanzielle Größen sowie immaterielle Werte in der Berichterstattung nur unzureichend abzubilden. Für wertorientiert denkende Manager scheint geboten, ergänzend zur normierten Rechnungslegung entscheidungsnützliche Angaben über wesentliche Werttreiber bereitzustellen. ${ }^{491}$

Das heißt allerdings nicht, dass eine Fortentwicklung der quantitativ-monetären Berichterstattung grds. keine Berechtigung hat - im Gegenteil. Es geht vielmehr um ein optimales Zusammenspiel von verbesserter finanzieller Berichterstattung sowie ihre Flankierung durch ergänzende, wertorientierte Informationen. ${ }^{492}$

Als Lösungsansatz scheint es also denkbar, die bestehenden Berichtsinstrumente der externen Rechnungslegung, spezifisch den Lagebericht, um wertorientierte Inhalte anzureichern. Dies könnte verschiedene positive Effekte hervorrufen, die sowohl für berichtende Unternehmen als auch für die Akteure am Kapitalmarkt attraktiv klingen: Zunächst würde die erweiterte Berichterstattung das Verständnis für die Unternehmensentwicklung fördern und unternehmensindividuelle Ursache-Wirkungs-Zusammenhänge transparenter machen. In der Folge könnte ein reduzierender Effekt auf die Risikoposition der Investoren vermutet werden, zudem kann intensive wertorientierte Berichterstattung als ein wahrzunehmendes, glaubhaftes Differenzierungsmerkmal seitens eines Kapitalnachfragers gelten. ${ }^{493}$

\footnotetext{
489 Bzgl. der Heterogenität der Adressaten sei z.B. auf Gläubiger verwiesen, die andere Informationsbedarfe haben als Aktionäre, vgl. z.B. Labhart/Volkart (2001), S. 116.

490 Vgl. Labhart/Volkart (2001), S. 116. Die ggf. als limitierend wahrgenommenen Normen sind hier als notwendige Eigenschaft interpretiert, als „Leitplanken der Aussagekraft“"

491 Vgl. im Detail Stauber (2004), S. $115 f f$. Unternehmen, die dies erkennen und sich dazu in der Lage fühlen, können Angaben bereitstellen, deren Publikation nicht verpflichtend ist. Dies würde als glaubhaftes Signal erkannt. Bessere Finanzberichterstattung erübrigt die Notwendigkeit ergänzender Berichterstattung grds. nicht, so Küting (2000a), S. 154.

492 Vgl. bspw. auch Amir/Lev (1996), S. 4, auch bereits Beermann et al. (1976), S. 197.

493 Vgl. mit dieser Argumentation bspw. Ruhwedel/Schultze (2002a), S. $604 \mathrm{f}$. 


\subsection{Umsetzung einer wertorientierten Berichterstattung}

\subsubsection{Value Reporting zur Überwindung informationeller Grenzen}

Ausgehend von der Erkenntnis der Unzulänglichkeit der Rechnungslegung zur Wertkommunikation wird seit Ende der 1990er Jahre unter dem Schlagwort des ,Value Reportings ' die Ergänzung der verpflichtenden Berichterstattung um primär freiwillige und wertorientierte Angaben diskutiert mit der Absicht, evidente Informationsmängel zu kompensieren. ${ }^{494}$ Obgleich eine einheitliche, akzeptierte Begriffsverwendung für Value Reporting bis dato nicht existiert, ${ }^{495}$ kann anhand vorzufindender Ansätze aber ein gemeinsames Verständnis erarbeitet werden: In erster Linie, wie der Begriff per se auch andeutet, beinhaltet Value Reporting die Kommunikation von wertrelevanten Aspekten an Unternehmensexterne, v.a. den Kapitalmarkt. ${ }^{496}$ Dies umfasst die Bereitstellung zusätzlicher Informationen, die zugleich ,vergangenheits- und zukunftsorientiert, monetär und nicht-monetär sowie ggf. mehrwertig“497 sein könnten. Das Value Reporting erfolgt mit der Zielsetzung, den Kapitalmarkt über die interne Wertgenerierung zu informieren und einfachere und präzisere Schätzungen des inneren Wertes zu ermöglichen. ${ }^{498}$ Insofern dient das Value Reporting dazu, Informationsasymmetrien zwischen dem

494 Als maßgebliche Vertreter sind zu benennen: Eccles et al. (2001), im deutschsprachigen Raum Fischer, vgl. Fischer/Wenzel (2002), dies. (2005); Günther/Beyer (2001); Labhart (1999); Müller (1998). Eine Ausrichtung der Berichterstattung auf die Kapitalmarktbedürfnisse scheint angesichts der eher schwachen Bedeutung der externen Eigenkapitalfinanzierung in Deutschland (vgl. hier Glaum (2000), S. 26) zu Beginn des Jahrtausends bemerkenswert, vgl. ähnlich Heumann (2006), S. 259; Bracklo/Bilstein (2002), S. 221. Vgl. Ruhwedel/Schultze (2002a), S. 603ff. Heumann (2006), S. 259: „Synonym werden die Begriffe ,Shareholder Value Reporting oder ,Wertorientierte Berichterstattung“ verwendet“, ebenso Ruhwedel/Schultze (2004), S. 490f. Wie oft in der modernen BWL wurde auch jenes Thema durch ein Beratungsunternehmen vorangetrieben: Eccles et al., Mitarbeiter von PwC, ließen „ValueReporting“ zudem als Markenzeichen registrieren.

Value Reporting ist grds. unabhängig von den konkret verwendeten Rechnungslegungsstandards und auch den sich daraus ergebenden Mindestanforderungen an die Berichterstattung, vgl. Pellens et al. (2000a), S. 180, auch Schultze et al. (2007), S. 563.

Vgl. Fischer/Wenzel (2002), S. 327, ebenso PwC (1999), S. 11: ,a comprehensive set of financial and non-financial performance measures [...] that provide both historical and predictive indicators of shareholder value". Zukunftsgerichtete Angaben sollten also inkludiert sein, vgl. Ruhwedel/Schultze (2002a), auch Schultze et al. (2007), S. 564. 
Management und dem Kapitalmarkt abzubauen und eine vorhandene Wertlücke zu reduzieren. ${ }^{499}$ Value Reporting oder wertorientierte Berichterstattung scheint folgerichtig eine konsequente Fortentwicklung der wertorientierten Steuerung zu einem umfassenden Wertmanagement zu sein: ${ }^{500}$ Intern generierter Wert wird in Marktwert transformiert und führt zu einer Annäherung von Markt- und innerem Wert, falls dieser glaubhaft - und verlässlich - kommuniziert werden kann. ${ }^{501}$

Es wird erkennbar, dass die externe Rechnungslegung in dieser Sichtweise nicht als ein starres Regelwerk, sondern vielmehr als ein grundlegender Rahmen einer Berichterstattung zu betrachten ist. Genügt dieser für die individuelle Berichterstattung nicht, um den Kapitalmarkt über die Entwicklung des inneren Wertes zu informieren, können Manager den Weg einer zusätzlichen und freiwilligen wertorientierten Berichterstattung einschlagen, um die aus ihrer Sicht wertrelevanten Informationen zu kommunizieren ,managers voluntarily find other ways besides financial statements to communicate their firm's performance and prospects “502.

499 Vgl. Schultze et al. (2007), S. 563f. Es wäre zu grob, Wertlücken nur mit Informationsasymmetrien zu begründen, vgl. z.B. Labhart (1999), S. $111 \mathrm{ff}$. Laut Eccles et al. (2002), S. 161f. lässt sich eine Wertlücke schließlich in fünf Kommunikationslücken aufspalten: Übereinstimmungs-, Wahrnehmungs-, Qualitäts-, Berichts- sowie Informationslücke.

Es sei angemerkt, dass grds. Informationen für die allg. Öffentlichkeit geliefert werden, die Informationsasymmetrien bzgl. der künftigen Unternehmensentwicklung reduzieren. Die Ausrichtung allein auf Investoren ist zu einseitig, so Fischer/Wenzel (2002), S. 331.

$5($ H) In Anlehnung an Böcking/Dutzi (2003), S. 222, welche wertorientierte Steuerung als die notwendige Voraussetzung für Value Reporting ansehen, auch Küting/Hütten (1996), S. 2671 f.; Black et al. (2001), S. 254f.; Ruhwedel/Schultze (2004), S. 489. Folglich könnte wertorientierte Berichterstattung auch als komplementäre Tätigkeit zur wertorientierten Steuerung angesehen werden, da der Nutzen einer Wertorientierung erst realisiert wird, wenn der Kapitalmarkt - auf Basis der Berichterstattung - seine Bewertung anpasst.

501 Vgl. Ruhwedel/Schultze (2002a), S. 606. Value Reporting kann auch zur Relativierung überzogener Erwartungen beitragen, wenn die Marktbewertung den inneren Wert übersteigt, also eine negative Wertlücke besteht. Es wird z.T. diskutiert, ob Value Reporting ein originärer Werttreiber ist oder nur als Kommunikationsmittel über Werttreiber dient. Zur ersten Sichtweise Labhart (1999), S. 200, anders Ruhwedel/Schultze (2002a). Dass die Berichterstattung grds. Einfluss auf den Marktwert haben kann, zeigen Arbeiten von Diamond/Verrecchia (1991); Baiman/Verrecchia (1996); Botosan (1997a), dies. (2000).

502 Tasker (1998), S. 161. Jene Aussage fasst die wesentliche Prämisse der ,Voluntary Disclosure'-Theorie, einer überwiegend innerhalb der US-amerikanischen Literatur vorangetriebenen Forschungsrichtung zur Analyse von Determinanten sowie - primär kapitalmarktseitigen - Auswirkungen freiwilliger Berichterstattung, zusammen.

Tom Sieber - 978-3-631-75150-3 
Das soeben vorgestellte Value Reporting ist i.W. eine kontinental-europäische Thematik, im angelsächsischen Raum wurde jedoch nahezu zeitgleich eine vergleichbare Diskussion unter dem Stichwort ,Business Reporting ' geführt. ${ }^{503}$ Jene Vokabel wurde im Jahre 1994 durch den US-Standardsetter AICPA geprägt, als im Rahmen einer Studie die Notwendigkeit der stärkeren Investorenorientierung der Berichterstattung aufgezeigt wurde. ${ }^{504}$ Die Identität der Ausrichtung ist eindeutig: Ziel des Business Reportings ist gleichfalls der Abbau von Informationsasymmetrien sowie die Bereitstellung von Angaben zu zentralen Einflussgrößen des Unternehmenswerts zur Verbesserung der Schätzbasis der Investoren. ${ }^{505}$ Die AICPA empfiehlt ergo die Weiterentwicklung vom ,Financial Accounting ' zum Business Reporting, ausgerichtet auf den Bedarf der Investoren, indem vermehrt nicht-finanzielle und zukunftsorientierte Informationen veröffentlicht werden. ${ }^{506}$ Aufgrund der Ähnlichkeit der beiden Konzepte wird in der Literatur die Ansicht vertreten, dass das Business Reporting ein um Value Reporting-Inhalte ergänztes Financial Accounting darstellt. ${ }^{507}$ Diese Sicht präsentiert Abb. 8 und sortiert das Value Reporting sodann in das Gesamtsystem der Unternehmenskommunikation ein. Zusammenfassend soll der Terminus Value Reporting also verstanden bzw. verwendet werden als die „Regelmäßige, strukturierte Berichterstattung [...], die

503 Vgl. bspw. Schultze (2005), S. 31 zur Gleichsetzung beider Begrifflichkeiten.

504 Vgl. AICPA (1994). Das Resultat jener Studie ist der sog. ,Jenkins-Report', Edmund L. Jenkins hatte den Vorsitz des Committees inne, vgl. zudem Jenkins (1994). Auslösender Impuls dieser Studie war gleichfalls die Erkenntnis mangelnder Eignung des Financial Accounting für eine rationale Entscheidungsfindung, vgl. Noll/Weygandt (1997), S. 59. Vgl. Labhart (1999), S. 30; AKEU (2002), S. 2337. AICPA (1994), S. 2 fordert wörtlich „information a company provides to help users with capital-allocation decisions“.

506 Vgl. Haller/Dietrich (2001b), S. 206ff.; Pellens et al. (2000a), S. 177ff. Zu beachten ist, dass finanzielle Prognosen in den USA wegen Klagemöglichkeiten problematisch sind, obwohl sog. ,safe harbour rules' gelten, also zukunftsorientierte Inhalte von der Haftung ausgenommen werden können, wenn diese ,,are identified as forward-looking statement and accompanied by ,meaningful cautionary statements “", vgl. Israeloff (1995), S. 15.

Vgl. Böcking (1998), S. 30 und 44; Fischer et al. (2001a), S. 1209. Zielstellung ist, dass das Financial Accounting die Value Reporting-Inhalte inkludiert und so einem Business Reporting gleichzusetzen ist, ähnlich bspw. Fischer/Wenzel (2002), S. $327 \mathrm{f}$.

In der Literatur wird auch eine Abgrenzung des Value Reportings von der Tätigkeit der Investor Relations gefordert: Diese wird hier als Teil der Unternehmenskommunikation verstanden, Value Reporting als Teil der rechnungslegungsbezogenen Berichterstattung. Die Verbreitung entsprechender Inhalte mag gleichwohl Aufgabe der Investor Relations sein, Inhalte werden dort aber nicht generiert, vgl. Günther/Otterbein (1996), S. 390. 
geeignet ist, [...] Informationsasymmetrien zwischen interner und externer Sicht des Unternehmens zu verringern und die Ermittlung des Unternehmenswertes durch die (potenziellen) Investoren zu ermöglichen bzw. zu verbessern““508.

Gesamtheit der Unternehmenskommunikation = Public Relations

Gesamtheit der Kapitalmarktkommunikation = Investor Relations

Erweiterte Rechnungslegung $=$ Business Reporting

Normierte Rechnungslegung

Ergănzende Berichtsinhalte

inkl. Lagebericht

= Value Reporting

Abbildung 8: Einordnung des Value Reportings ${ }^{509}$

\subsubsection{Vorschläge zur inhaltlichen Ausgestaltung}

Zur konkreten inhaltlichen Ausgestaltung des oben definierten Value Reportings liegen - analog zum Begriffsverständnis - einige Konzepte vor, die wichtigsten seien kurz dargestellt, um sodann inhaltliche Gemeinsamkeiten abzuleiten:

Müller (1998) definiert ,Shareholder Value Reporting ' als eine Zusatzberichterstattung über die Wertschaffung eines Unternehmens, welche er in drei Bereiche gliedert: (1) Wertschaffung am Kapitalmarkt, (2) intern generierter Wert sowie (3) künftig erwartete Wertschaffung dank strategischer Wettbewerbsvorteile..$^{510}$ Obgleich weder Begründung noch Herleitung für den Inhalt und die Struktur des Schemas vorgelegt werden, wird es - auch aufgrund seines Pioniercharakters oft in anderen Vorschlägen aufgegriffen. ${ }^{511}$ Die letztgenannte Berichtskategorie beinhaltet insb. Angaben zur Reduktion der Prognoseunsicherheit der Investoren durch zukunftsorientierte Berichterstattung - gemeint ist aber nicht die Abgabe einer quantitativen Prognose, sondern Transparenz über mittel- oder langfristig

\footnotetext{
508 Heumann (2005), S. 7f., insb. die Anforderung der Regelmäßigkeit ist hervorzuheben.

5(1) Quelle: eigene Darstellung in Anlehnung an Heumann (2005), S. 9. Jener beschreibt den Lagebericht als die Schnittstelle von normierter und erweiterter Berichterstattung.

510 Vgl. ausführlich Müller (1998), S. 129ff. Die Strukturierung lautet im Original ,Total Return Reporting، (Aktienkurs-/Renditeangaben), ,Value Added Reporting“ (Angaben zur wertorientierten Steuerung), ,Strategic Advantage Reporting (

511 Vgl. Fischer et al. (2001a) sowie dies. (2001b); Fischer/Wenzel (2002); Wenzel (2003); Fischer/Wenzel (2005); Fischer/Klöpfer (2006). Zur Kritik Ruhwedel/Schultze (2002a). 
wirkende, strategisch relevante Programme als Grundlage für eigene Prognosen der Investoren. ${ }^{512}$ Empfohlen wird somit eine indirekte Prognosepublizität über kritische Faktoren des Unternehmens als mögliche Grundlage späterer Erfolge.

Labhart (1999), der das Value Reporting als eigenständigen Werttreiber ansieht und dieses folglich in klassische Wertsteigerungs-Systeme einbezieht, betont die Bedeutung von nicht-finanziellen Daten als bewertungsrelevante Informationen und empfiehlt für eine konkrete Umsetzung eine Orientierung an dem Konzept der Balanced Scorecard: ${ }^{513}$ Ausgangspunkt ist eine Darstellung der strategischen Ausrichtung und der finanziellen Ziele, die durch vier nicht-finanzielle Berichtsmodule konkretisiert werden. Die Berichtsinhalte des Value Reportings folgen in dieser Sichtweise also der gewählten Strategie, Value Reporting ist insofern ein Bericht über die vom Unternehmen gewählte Strategie und deren Umsetzung. ${ }^{514}$

Pellens et al. (2000a) benennen Value Reporting als den Teil der Unternehmenspublizität, der sich mit der Rendite-Risiko-Relation aus Sicht der Investoren beschäftigt. Als Ziel wird daher die Vermittlung entscheidungsrelevanter Angaben über gesetzliche Pflichtumfänge hinaus gesehen. ${ }^{515}$ Auf Grundlage empirischer Studien zu den Informationsbedürfnissen ${ }^{516}$ von Investoren wird eine Reihe von

512 Vgl. Müller (1998), S. 136f. Inhalte dieser Kategorie sind u.a. Ziele des Unternehmens, Angaben über das Unternehmensumfeld, zu Chancen und Risiken und zur Strategie des Unternehmens. Fischer/Wenzel (2002), S. 329 greifen diesen Vorschlag auf und fordern neben zukunftsorientierten Inhalten (z.B. strategische Ziele, Entwicklungsprognose und konkreten Planwerten) zudem Daten zum Hintergrund des Unternehmens (z.B. Organe, Beschreibung, Anteilseignerstruktur). Zusätzlich werden z.T. Verfeinerungen wie bspw. branchenspezifische Informationsbausteine vorgeschlagen, vgl. bspw. Hutton (2001).

513 Vgl. Labhart (1999), S. 30f., auch Labhart/Volkart (2001), S. 118. Der Hinweis auf die Eignung der BSC zur Kommunikation strategieorientierter Informationen kann indes nicht überraschen, da ihre Perspektiven so gewählt sind, dass sie ein ausgewogenes Set interner Steuerungskennzahlen zur Verfügung stellen. Die Autoren bestätigen vielmehr die Konsistenz des internen sowie externen Informationsbedarfs. Gefordert wird jedoch explizit nicht die Publikation der internen Scorecard, sondern einer angepassten Version als Gerüst für das wertorientierte Reporting. Vgl. zur BSC Horváth/Kaufmann (1998), die diese als ein Werkzeug zur Umsetzung von Strategien ansehen - insofern scheint es nur konsequent, die BSC auch als Mittel zur Strategiekommunikation zu verwenden. Vgl. Labhart (1999), S. 263f. bzw. S. 146. Es werden v.a. die Perspektiven Kunde, Prozess, Innovation, Personal und IT vorgeschlagen, vgl. auch Klingebiel (2000), S. 176. Vgl. hierzu insb. Pellens et al. (2000a), S. 178 sowie S. $181 \mathrm{ff}$. 
Einzelkriterien abgeleitet, die - eingeteilt in vier Bereiche - zur informationellen Besserstellung der Investoren geeignet erscheinen. ${ }^{517}$ Diese Bereiche behandeln die Marktbewertung und die Entwicklung des Unternehmens, wobei im Rahmen des sog. ,Future Objectives Reportings“ v.a. strategiebezogene Bestandteile, also strategische Ziele, Chancen bzw. Risiken sowie Erwartungen des Managements und auch konkrete Plandaten an den Kapitalmarkt zu kommunizieren sind. ${ }^{518}$

Eccles et al. (2001) ergänzen sodann die Perspektive der Unternehmensberatung und charakterisieren Value Reporting prägnant als „A call to managers to adopt a philosophy of complete transparency - to report information to the market on all the measures they use internally to manage“"519. Defizite der Berichterstattung sehen sie insb. im Bereich markt- und strategiebezogener Angaben und kreieren daher ein „model for better disclosure“, dessen Struktur aber nicht systematisch abgeleitet wird. ${ }^{520}$ Einen früheren Vorschlag zur Strukturierung von Inhalten des Value Reportings legte zudem die von Jenkins geleitete Studie des AICPA vor: Ein fünfstufiges Modell sollte demnach als Ergänzung der Rechnungslegung angewandt werden, das finanzielle sowie nicht-finanzielle Daten, eine Analyse der Lage und Entwicklung aus Sicht des Managements, zukunftsorientierte Angaben und Informationen zum Management und zum Unternehmensumfeld vorsieht. ${ }^{521}$

517 Vgl. Pellens et al. (2000a), S. 178. Die Autoren wenden diese Systematisierung zugleich auf die Unternehmen des Dax 30 an, um den Status des Value Reportings zu prüfen.

518 Vgl. Pellens et al. (2000a), S. 181f. Neben einem Bericht bzgl. des ,Shareholder Return (d.h. Entwicklung des Marktwerts) ist zum ,Corporate Return', also zur internen Wertgenerierung zu berichten. Die letztgenannte Kategorie beinhaltet eine Vergangenheits-, eine Gegenwarts- sowie eine Zukunftskomponente.

519 Eccles et al. (2001), S. 5, im Original mit Hervorhebungen. In dieser Forderung spiegelt sich erneut der Management Approach wider, d.h. eine Ergänzung der Berichterstattung um Informationen aus dem Controlling bzw. um Angaben der internen Steuerung. Zum Management Approach in der Rechnungslegung vgl. grdl. Weißenberger/Maier (2006). Eccles et al. (2001), S. 212 bzw. S. 212 ff. Kritisch Ruhwedel/Schultze (2002a), S. 604. Vgl. FASB (2001a), S. 52; Haller/Dietrich (2001b), S. 208. Die Ableitung der Bereiche erfolgte durch Investorenbefragung, eine Überprüfung der Entscheidungs- bzw. Wertrelevanz der Kategorien wird nicht vorgenommen, so Ruhwedel/Schultze (2002a), S. 610. Im Verlauf des ,Business Reporting Project" wurden immaterielle, nicht bilanzierte Vermögenswerte als eigene Kategorie ergänzt, da mit der Entwicklung des Phänomens der sog. ,New Economy“ festgestellt werden konnte, dass bilanzielle Eigenkapitalwerte oft deutlich von den realisierten Marktwerten abwichen. Vgl. hierzu Günther/Beyer (2001), S. 1627f.; FASB (2001b), S. VII. 
Dieser kurze Überblick über wesentliche Ansätze zur inhaltlichen Ausgestaltung respektive zur Strukturierung wertorientierter Berichterstattung zeigt bereits eindeutig, dass der Schwerpunkt einer Zusatzberichterstattung in der Bereitstellung zukunftsorientierter Angaben zur Schätzung künftiger Zahlungsströme gesehen wird - was als Defizit der externen Rechnungslegung festgestellt wurde. ${ }^{522}$

In allen dargestellten Ansätzen wird die Bedeutung strategiebezogener Sachverhalte betont, welche als sog. ,leading indicators ' offensichtlich als in besonderer Weise aussagekräftig für künftige Wertsteigerungspotenziale anzusehen sind. ${ }^{523}$ Es bleibt daher aus Sicht der Value Reporting-Literatur zu resümieren: „Ebenso wie das Management benötigen [...] Investoren Einblick in die Strategie“‘524.

\subsubsection{Ausgewählte Empirie zur Umsetzung in Deutschland}

Parallel zur theoretisch-konzeptionellen Auseinandersetzung mit der Thematik Value Reporting in der deutschsprachigen Literatur wurden Untersuchungen zur realen Umsetzung wertorientierter Berichterstattung durchgeführt mit Fokus auf solche Unternehmen, die den deutschen Kapitalmarkt in Anspruch nehmen bzw. innerhalb der Auswahlindizes der Deutschen Börse AG börsennotiert waren. ${ }^{525}$

Die entsprechenden empirischen Ergebnisse zum Value Reporting am deutschen Kapitalmarkt zeichnen dabei grds. ein konsistentes Bild: So zeigen Fischer et al. (2001a) in ihrer Arbeit zwar eine Zunahme der freiwilligen, wertorientierten Informationsbereitstellung gegenüber den Vorjahren, kritisieren zugleich aber eine

522 Vgl. hierzu AKEU (2002), S. 2337f. Der ,Arbeitskreis Externe Unternehmensrechnung der Schmalenbach-Gesellschaft', der seinerseits Grundsätze für die Ausgestaltung eines Value Reportings vorgelegt hat, fordert neben Angaben über nicht bilanzierte Werte v.a. auch Informationen zur verfolgten Strategie eines Unternehmens. Baetge/Heumann (2006b), S. 350; Haller/Dietrich (2001c), S. 174; empirische Hinweise bereits bei Kellinghusen/Irrgang (1978); Dempsey et al. (1997); Schulz (1999). Labhart/Volkart (2001), S. 118.

525 Meist wurde auf die Unternehmen des - zu Beginn des Jahrtausends noch berechneten ,Dax 100' abgestellt, welcher die 100 größten an dt. Wertpapierbörsen notierten Unternehmen umfasste. Vgl. als Bsp. die Arbeit von Pellens et al. (2000a). Für Details zu den Auswahlindizes der Dt. Börse AG und zur Ablösung des Dax 100 durch den sog. HDax vgl. auch Abschnitt C 3.2.1 dieser Arbeit sowie grdl. Dt. Börse AG (2009a), S. $19 \mathrm{ff}$. 
oft heterogene sowie insg. schwache Umsetzung. ${ }^{526}$ Dieses Ergebnis wird zudem durch die Untersuchung von Pellens et al. (2000b) bestätigt, die zur Vermeidung fehlender Strukturiertheit, Konsistenz bzw. bestehender Unübersichtlichkeit einheitliche Strukturierungsvorschläge für die Praxis empfehlen. ${ }^{527}$

In einer ergänzenden Studie gelangen Fischer/Wenzel (2002) schließlich zu der Feststellung, dass im Hinblick auf Strategieinhalte ,noch immer ein mangelnder Zukunftsbezug, eine unzureichende Erfassung von Risiken sowie ein zu geringer Segmentbezug zu konstatieren “.528 ist. Einen interessanten Aspekt ergänzen auch Ruhwedel/Schultze (2002): Während sie ebenfalls ein insg. nur niedriges Niveau wertorientierter Berichterstattung im Dax 100 konstatieren, stellen sie weiterhin eine Reduktion von Berichtsumfängen im Zuge von negativen Kapitalmarktentwicklungen fest. ${ }^{529}$ Dies könnte als Hinweis auf eine Äußerung Schmalenbachs gesehen werden, der bereits in 1966 - also lange Zeit vor der Entwicklung wertorientierter Steuerungskonzepte - anmerkte: „Wenn man die Aktionäre braucht, dann behandelt man sie gut; sind sie nicht mehr brauchbar, dann behandelt man sie schlecht. ${ }^{\text {“530 }}$ Die wesentliche Erkenntnis der realiter verbesserungswürdigen Umsetzung wertorientierter Berichterstattung zum Beginn des Jahrtausends wird schließlich in jüngerer Zeit u.a. durch Heumann (2006) bestätigt, der außerdem Stetigkeit in der Berichterstattung einfordert, um auf diesem Wege Vertrauen in die Verlässlichkeit und Nachhaltigkeit bereitgestellter Inhalte zu erzeugen. ${ }^{531}$

Vor dem Hintergrund dieser empirischen Erkenntnisse zum Value Reporting in Deutschland erscheint es begründet, zu vermuten, dass auch in der heutigen Zeit deutliche Heterogenität in der wertorientierten Berichterstattung vorherrscht. ${ }^{532}$

526 Vgl. Fischer et al. (2001a), S. 1211f. Fokus der Untersuchung war das Börsensegment Nemax 50. Es wurde angestrebt, eine BSC anhand publizierter Geschäftsberichte zu bestimmen. Erkannt werden Branchenspezifika, das Gesamtniveau der Berichterstattung wird grds. als schwach bezeichnet. Ähnlich Fischer/Wenzel (2002) sowie dies. (2005). Vgl. Pellens et al. (2000b), zudem Ruhwedel/Schultze (2002a), S. 609. Diese Forderung findet sich u.a. auch bei AKEU (2002), S. 2337ff. sowie Baetge/Noelle (2001), S. 174. Vgl. Fischer/Wenzel (2002), S. 328. Dies gilt auch 2005, vgl. Wenzel (2005), S. $491 \mathrm{f}$. Vgl. Ruhwedel/Schultze (2002a), S. 613ff. Dies gilt insb. für Unternehmen des MDax. 530) Schmalenbach (1966), S. 12.

531 Vgl. Heumann (2006), S. 264f. Ähnliche Aussagen leitet Wenzel (2005), S. 230ff. ab.

532 Diese Vermutung ist als Voraussetzung der eigenen Untersuchung bedeutsam. 


\subsection{Der Lagebericht als Kernmedium der Berichterstattung über strategieorientierte Inhalte}

\subsubsection{Besondere Eignung des Lageberichts zur Darstellung wertorientierter Inhalte}

Zur Umsetzung einer über die verpflichtende Rechnungslegung hinausgehenden Berichterstattung stehen grds. verschiedene Medien bzw. Kommunikationswege zur Verfügung. ${ }^{533}$ Trotz jener offensichtlichen Vielfalt hat sich primär der Lagebericht als geeignetes Medium herausgestellt: ${ }^{534}$ Dieser wird als das wesentliche „Medium für die wertorientierte Unternehmenskommunikation“6535 angesehen.

Im Vorfeld dieser Entwicklung ist der Lagebericht lange von Theorie und Praxis vernachlässigt worden, er hat jedoch seinen Status als ,Stiefmütterchen handelsrechtlicher Rechnungslegung “ ${ }^{\text {} 536}$ ablegen und sich als Medium der wertorientiert ausgerichteten Kapitalmarktkommunikation positionieren können. ${ }^{537}$ Einen maßgeblichen Beitrag hierzu leisteten insb. auch einige regulatorische Anpassungen der Lageberichterstattung auf nationaler und internationaler Ebene. ${ }^{538}$

Die wesentlichen Argumente, die für den Lagebericht als zentrales Medium der wertorientierten Berichterstattung sprechen, sind in erster Linie sein qualitativverbaler Charakter sowie seine Offenheit für prognostische bzw. subjektive Be-

533 Vgl. Pellens et al. (2000a), S. 180; Friedlaender/Stabernack (1998). Gedacht sei an Broschüren, Präsentationen, Interviews etc. Zu der Rolle des Internets als Kommunikationsweg für Value Reporting vgl. Fischer et al. (2001b) oder Mendes da Silva/De Lira Alves (2004). Jenes bietet globale Reichweite bei geringen Distributionskosten bzw. unmittelbare Verfügbarkeit und entspricht dem Ideal eines modernen Reportings, vgl. Rappaport (1986), S. 58ff. Breitgestreute Distribution ist regulatorisch gefordert, vgl. Read (2000).

534 Die Eignung des Lageberichts bestätigen Pike et al. (1993); Vergoossen (1993), S. $239 \mathrm{f}$. und Günther et al. (2003), S. 456f.; Baetge/Heumann (2006b); Hayn/Matena (2005) und Müßig (2008), S. 199. Lt. Fink/Keck (2004), S. 1084 bewirkt das Medium Lagebericht, eingebettet in das System der externen Rechnungslegung, eine höhere wahrgenommene Zuverlässigkeit bereitgestellter Inhalte, mit gleicher Argumentation auch AKEU (2002). Kirsch/Scheele (2003), S. 2738.

536 Ballwieser (2005), S. 6.

537 Vgl. u.a. die Ausführungen bei Baetge/Heumann (2006a), S. 39; Kirsch/Scheele (2003), S. 2738; Schultze et al. (2007), S. 563f. Dies beweisen zudem einige Monographien, die sich in den letzten Jahren fokussiert mit dem Lagebericht befassen, vgl. bspw. Heumann (2005); Prigge (2006); Scheele (2006); Fink (2007) sowie Barth (2009). 
richtsinhalte, die im Abschluss nicht abgebildet werden können. ${ }^{539}$ Weiterhin erlaubt er dank flexibler Ausgestaltung außerhalb eines starr normierten Konzepts die klare Darstellung, eindeutige Beschreibung und die Beurteilung wesentlicher Sachverhalte bzgl. der Lage und Entwicklung des Unternehmens sowie die freiwillige Berichterstattung über nicht unmittelbar kodifizierte Sachverhalte. ${ }^{540}$ Der Lagebericht erscheint insofern „frei von den Fesseln der GoB ${ }^{\text {“541 }}$ als geeignetes Mittel zur Überwindung inhaltlicher Grenzen der Rechnungslegung und kann eingebunden in die Systematik der normierten Berichterstattung - eine wichtige Schnittstellenfunktion zwischen dieser und dem Value Reporting herstellen. ${ }^{542}$

Sein Status als Bestandteil der normierten Rechnungslegung unterstützt zudem die Glaubwürdigkeit und Verlässlichkeit der enthaltenen Berichtsinhalte. ${ }^{543}$ Dies gilt auch für die bestehende Pflicht zur Prüfung des Lageberichts - eine Prüfung der Angaben führt unmittelbar zu erhöhter Glaubwürdigkeit. ${ }^{544}$ Schließlich kann seine Rolle als Kerninstrument der Zusatzberichterstattung mit seiner ursprünglichen Positionierung als Ergänzung des Jahresabschlusses in sachlicher sowie zeitlicher Hinsicht erklärt werden: Durch Vermittlung von bewertungsrelevanten Angaben, die großteils qualitativ bzw. zukunftsgerichtet sind, wird er seiner vorgesehenen Ergänzungsleistung in hervorragender Weise gerecht.

Es ist also zu konstatieren, dass die zunehmende Wertorientierung sowohl in der Steuerung als auch in der Berichterstattung den Lagebericht zum zentralen In-

531) Dies wäre im Rahmen einer GoB-konformen Rechnungslegung (insb. Vorsichtsprinzip) nicht möglich, vgl. bspw. Hayn/Matena (2005), S. 427; Heumann (2005), S. 59.

540 Vgl. Kajüter (2004), S. 197f. Auch Baetge et al. (2010), S. 77 würdigen die Flexibilität der Lageberichterstattung, da nur ,rudimentäre Mindestvorschriften“ kodifiziert sind.

541 Ballwieser (1997a), S. 155. Ebenso charakterisiert Coenenberg (1995), S. 2077 die GoB als z.T. ,informationsfeindlich“. Ähnlich auch Fink/Keck (2005), S. 137f.; Hommelhoff (2002), S. 911, Rn. 26: „Damit ist die Lagedarstellung [...] von all' jenen Verzerrungen befreit, die über die Grundsätze ordnungsgemäßer Buchführung ihre Wurzel vor allem im Vorsichtsprinzip und seinen konkretisierenden Auffächerungen haben."

542 Vgl. Haller/Dietrich (2001c), S. 166; Heumann (2005), S. 12; Baetge/Heumann (2006a).

543 Vgl. Ballwieser (2002b), S. 298. Misstrauen der Adressaten könnte reduziert werden.

544 Eine Platzierung von Value Reporting-Inhalten im Lagebericht wird konsequenterweise empfohlen, vgl. bspw. AKEU (2002), S. 2340. Schultze et al. (2007), S. 563f. sehen den gesamten Geschäftsbericht als Medium an, auch der sog. freie Teil wäre denkbar, der jedoch nicht prüfungspflichtig ist - daher ist der Lagebericht zu bevorzugen. Zur Prüfung von Value Reporting-Inhalten Hayn/Matena (2005), S. 440ff.; Bischof/Molzahn (2006).

Tom Sieber - 978-3-631-75150-3 
strument einer wert- und zukunftsorientierten Informationsvermittlung macht und ihm insofern eine vollkommen neue Bedeutung zuteil werden lässt. ${ }^{545}$

\subsubsection{Status der Kodifizierung einer strategieorientierten Berichterstattung im Lagebericht}

Wie dargestellt wurde, erscheint der Lagebericht als zweite unabhängige Säule der externen Berichterstattung und entkoppelt von den GoB in idealer Weise für eine Bereitstellung qualitativ-verbaler Informationen geeignet. Demzufolge böte er sich gleichfalls für eine Berichterstattung zu strategieorientierten Inhalten an, die als primärer Berichtsinhalt verschiedener Value Reporting-Konzeptionen abgeleitet und deren Relevanz für die Kapitalmarktakteure aufgezeigt wurde. ${ }^{546}$

Im Status quo sind strategieorientierte Berichtsinhalte eindeutig als Element der freiwilligen Berichterstattung zu charakterisieren, eine explizite Forderung nach Strategieinhalten findet sich in den relevanten Rechtsgrundlagen der deutschen Lageberichterstattung bis dato nicht, was angesichts der generellen Zielsetzung der Lageberichterstattung, über die Lage der Gesellschaft und deren voraussichtliche Entwicklung zu berichten, bereits als fragwürdig beurteilt wurde. ${ }^{547}$

Bemerkenswert ist indes, dass sich der deutsche Gesetzgeber sowie der deutsche Standardsetter im Zuge der Erarbeitung des BilReG bzw. des konkretisierenden DRS 15 bereits intensiv mit einer Kodifizierung strategieorientierter Berichtsanforderungen auseinandergesetzt haben, wie die folgenden Ausführungen zeigen:

\section{(a) Kodifizierung von strategieorientierten Berichtsinhalten im HGB}

Eine explizite Forderung nach strategieorientierten Berichtsinhalten erfolgte im Rahmen des Referentenentwurfs zum BilReG, der für die Neufassung des $§ 289$ Abs. 1 S. 4 die folgende Formulierung vorschlug: „ferner sind im Lagebericht die wesentlichen Ziele und Strategien der gesetzlichen Vertreter der Kapitalgesell-

\footnotetext{
545 Vgl. Kajüter (2004), S. 197; Schultze et al. (2007), S. 563f.

546 Vgl. Streim (1995), S. 719ff., der explizit empfiehlt, den Lagebericht als Instrument zur externen strategieorientierten Kommunikation zu nutzen.

547 Es wird nochmals Bezug genommen auf die Formulierung in $\S \S 289$ Abs. 1, 315 Abs. 1 HGB, welche die ,Generalnorm der Lageberichterstattung 'beinhalten, vgl. auch S. 103. 
schaft zu beschreiben sowie die voraussichtliche Entwicklung mit ihren wesentlichen Chancen und Risiken zu beurteilen und zu erläutern. “" ${ }^{458}$ Der Gesetzgeber zielte mit diesem im Dezember 2003 vorgelegten Entwurf eindeutig auf die Erhöhung des Gehalts an strategieorientierten Informationen im Lagebericht ab. ${ }^{549}$ Diese Formulierung fand sich ebenso nahezu wortgleich im Regierungsentwurf zum BilReG, der im Oktober 2004 eingebracht wurde. ${ }^{550}$ Allerdings empfahl der Rechtsausschuss im Anschluß die ersatzlose Streichung des Berichtsteils mit der Begründung der voraussichtlich nur mangelnden Beachtung jener Norm, „da die Unternehmen hierzu keine konkreten Angaben machen werden und möglicherweise auch nicht machen können“" ${ }^{\text {“51 }}$. Schließlich enthielt die finale Fassung des BilReG, die am 09.12.2004 im Bundesgesetzblatt veröffentlicht wurde und am darauffolgenden Tag in Kraft trat, keine Berichterstattungspflicht für Strategieangaben. ${ }^{552}$ Diese Änderung wurde von Seiten der Rechnungslegungsforschung und -lehre heftig kritisiert, was die Bedeutung von bzw. die Aufmerksamkeit für strategieorientierte Berichtsinhalte erneut deutlich unterstreicht. ${ }^{553}$

\section{(b) Kodifizierung von Strategieinhalten in DRS 15 bzw. E-DRS 20}

Der Entwurf eines Rechnungslegungs Standards zur Lageberichterstattung (sog. E-DRS 20) kann - da er, wie zuvor in Abschnitt B 3.3.2 ausgeführt, zeitlich bereits vor dem RefE-BilReG vorgelegt wurde - als zentraler Ausgangspunkt der Kodifizierung strategieorientierter Berichtsinhalte in den einschlägigen Normen

\footnotetext{
548 BMJ (2003), RefE-BilReG, Entwurf zu § 289 Abs. 1 S. 4 HGB, S. 5.

549) Vgl. BMJ (2003), RefE-BilReG, Begründung zum RefE-BilReG, S. 25.

550 Vgl. Dt. Bundestag (2004), BT-Drucksache 15/3419, RegE-BilReG, Entwurf zu $§ 289$ Abs. 1 S. 4 HGB, S. 8. Vgl. auch Greinert (2004), S. 54 mit der spitzen, aber korrekten Anmerkung, dass die „Ziele für die Kapitalgesellschaft", nicht jedoch die persönlichen Ziele des Managements zu beschreiben sind. Dieser offensichtliche Fauxpas des RefEBilReG wurde bei Einbringung des Regierungsentwurfs in den Dt. Bundestag korrigiert.

551 Vgl. Dt. Bundestag (2004), BT-Drucksache 15/4054, Beschlussempfehlung und Bericht des Rechtsausschusses, S. 37f. Dieser Bericht wurde am 27.10.2004 vorgelegt.

592 Vgl. die Änderungen der HGB-Normen im BGBI. (2004), S. $3166 f f .$, zu § 289 Abs. 1 S. 4 HGB (S. 3167) und zu § 315 Abs. 1 S. 4 HGB (S. 3169) in der Fassung nach BilReG.

553 Vgl. exemplarisch die Anmerkungen bei Baetge/Prigge (2006), S. 404; Buchheim/Knorr (2006), S. 415ff.; Fink/Keck (2005), S. 138; Freidank/Steinmeyer (2005), S. 2514 sowie Kaiser (2005a), S. 408ff. Als Ursache für eine Streichung dieses Passus vermuten bspw. Baetge/Heumann (2006b), S. 349f. intensive Lobbyarbeit der Unternehmen, denkbar ist der Verweis auf die Wettbewerbssensitivität der Angaben, vgl. hierzu Abschnitt B 2.3.3. 
der deutschen Lageberichterstattung gelten: Obgleich die Modernisierungsrichtlinie keinen Berichtsteil zu Zielen und Strategien vorsah, wurde dieser vom DSR proaktiv vorgeschlagen. ${ }^{554}$ Eine entsprechende Darstellung hat gemäß E-DRS 20 nicht nur die finanziellen bzw. nicht-finanziellen Ziele, sondern auch diejenigen Faktoren, Entwicklungen, Chancen und Risiken zu umfassen, die das Erreichen der Ziele wesentlich determinieren. ${ }^{555}$ Folglich empfahl der DSR eindeutig, den Lagebericht zu einem Medium der strategieorientierten Berichterstattung zu entwickeln. ${ }^{556}$ Im Anschluss an die Streichung der expliziten Forderung derartiger Inhalte im parallel erarbeiteten BilReG wurde dies ebenfalls im finalen DRS 15 reflektiert, inhaltliche Anhaltspunkte zur Strategie blieben jedoch erhalten. ${ }^{557}$

Obwohl die Kodifizierung der Berichterstattung zu strategieorientierten Inhalten folglich im Rahmen der Erarbeitung des BilReG diskutiert wurde, ist diese unter Hinweis auf die mangelnde Relevanz und die Wettbewerbssensitivität verworfen worden. ${ }^{558}$ Der deutsche Gesetzgeber bzw. sein Standardsetter haben somit nach h.M. in der einschlägigen Literatur die Chance vertan, im internationalen Kontext eine Vorreiterrolle bzgl. einer Berichterstattung über strategieorientierte In-

554 Vgl. DSR (2003), Tz. 34ff. Insofern ging der DSR mit jenem E-DRS 20 über Vorgaben der EU hinaus, denn ein Berichtsteil zur Strategie war keine Voraussetzung einer richtliniengetreuen Umsetzung der Modernisierungsrichtlinie (siehe Richtlinie 2003/51/EG), vgl. Kirsch/Scheele (2003), S. 2737. Es entspricht jedoch grds. dem Anspruch des DSR, sich als Impulsgeber im Bereich der Rechnungslegungsvorschriften zu positionieren. Vgl. DSR (2003), Tz. 36ff. Darüber hinaus stellt der DSR den Management Approach als Lageberichtsgrundsatz auf und verlangt - konsequenterweise - eine Erläuterung von Zielen und Strategien aus Sicht des Managements, vgl. ebenda, Tz. 28.

556 Kritik wurde am E-DRS 20 geübt hinsichtlich des recht unkonkret wirkenden Strategiebegriffs in Tz. 1, vgl. Greinert (2004), S. 57f. sowie der zusammenhangslosen Berücksichtigung strategischer Elemente in mehreren Berichtsteilen, so Scheele (2006), S. 169. Zudem wurde grds. an der Berücksichtigung strategieorientierter Berichtsinhalte Kritik geübt, so bspw. vom IDW, vgl. DSR (2004a), Protokoll der Diskussion zu E-DRS 20.

557 Dies erfolgte zwangsläufig, da der DSR mit seinen Standards nicht über den gesetzlich gesetzten Rahmen hinausgehen darf. Dies zeigt sich auch bereits in E-DRS 20 n.F., vgl. DSR (2004b). Hinweise auf strategieorientierte Angaben finden sich in DRS 15, Tz. 29, der die Darstellung von Stärken und Schwächen, Chancen und Risiken - also Elementen der strategischen Analyse - fordert, sowie in DRS 15, Tz. 34, der einen Bericht über die Planung bzw. Erwartungen des Managements fordert - ohne dies explizit Strategie zu nennen, vgl. grdl. bei DSR (2005), DRS 15 bzw. aktuell DSR (2010), DRS 15 n.F.

558 Vgl. Dt. Bundestag (2004), BT-Drucksache 15/4054, Beschlussempfehlung und Bericht des Rechtsausschusses, v.a. S. 38: ,werden sich aus den entsprechenden Anforderungen keine wesentlichen zusätzlichen Informationen über das Unternehmen ergeben".

Tom Sieber - 978-3-631-75150-3 
halte einzunehmen sowie den Lagebericht wertorientierter auszugestalten. ${ }^{559}$ Die Option der freiwilligen Berichterstattung blieb davon gleichwohl unberührt. ${ }^{560}$

\section{(c) Normkonformität einer strategieorientierten Berichterstattung}

Unabhängig von der konkreten Kodifizierung der Lageberichterstattung können bereits auf Basis der in den grdl. Normen der $\S \S 289$ bzw. 315 HGB - sowohl in der Fassung vor als auch nach BilReG - genannten Funktionen des Lageberichts inhaltliche Bezüge zur Strategie hergestellt und somit die Normkonformität der Berichterstattung über strategieorientierte Sachverhalte abgeleitet werden: ${ }^{561}$

Unter Rückgriff auf die ,traditionellen' Funktionen des Lageberichts - einer Ergänzung und einer Verdichtung - eröffnet v.a. die zeitliche Ergänzungsfunktion die Möglichkeit zur Rechtfertigung strategieorientierter Berichtsinhalte, da diese per se prognostischer Natur sind und einen Abschluss insofern zeitlich ergänzen. Allerdings ist die sachliche Ergänzungsfunktion ebenfalls in der Lage, strategieorientierte Inhalte zu rechtfertigen, da es sich bei diesen in erster Linie um nichtfinanzielle, qualitativ-verbale Inhalte handelt, die im Abschluss nicht dargestellt werden (können) und insofern unmittelbar ergänzenden Charakter erhalten. ${ }^{562}$

Gleichfalls kann die Verdichtungsfunktion als Argumentation für eine strategieorientierte Berichterstattung genutzt werden, da vom Lagebericht gefordert wird, die quantitativen Angaben des Abschlusses zu einem kohärenten Gesamtbild zu verdichten sowie gesamthaft zu bewerten. ${ }^{563}$ Als übergeordneter Referenzpunkt

559) Das war das eigentliche Ziel des DSR, vgl. DSR (2003), Anhang C 2 (E-DRS 20), Tz. 3. Auch Baetge/Prigge (2006), S. 404; Fink/Keck (2005), S. 138; Scheele (2006), S. 176.

560) Argumentiert wurde, dass aus dem Wort ,zumindest“" in $§ 289$ Abs. 1 S. 4 HGB in der Fassung vor BilReG die Zulässigkeit freiwilliger Angaben klar abgeleitet werden kann, vgl. Baetge et al. (2009b), S. 727, S. 768, dies. (2009a), S. 513; Kajüter (2004a), S. 200. Dieses Wort wurde im Rahmen des BilReG gestrichen, vgl. Dt. Bundestag (2004), BTDrucksache 15/3419, RegE-BilReG, S. 30. Dabei handelt es sich allerdings nur um eine ,redaktionelle Vereinfachung،, vgl. ebenda. Ein generelles Verbot freiwilliger Berichterstattung kann daraus jedenfalls nicht abgeleitet werden, vgl. Ellrott, (2006), Rn. 112. Vgl. hier u.a. Scheele (2006), S. 158ff.; Fink/Keck (2004); Krumbholz (1994), S. 129ff.

562 Die Ergänzungsfunktion wurde mit Inkrafttreten des BiRiLiG in 1985 etabliert. Vorgesehen ist die Ergänzung in sachlicher Hinsicht, d.h. Aspekte der wirtschaftlichen Lage, die nicht zur Vermögens-, Finanz-, Ertragslage zählen, und in zeitlicher Sicht, zur Überwindung der Vergangenheitsorientierung. Vgl. Kirsch/Köhrmann (2007), Tz. $4 \mathrm{ff}$. Vgl. bspw. Baetge et al. (1989), S. 9. 
für diese Verdichtungsleistung bietet sich de facto nur die Strategie an, da letztlich alle Einzelaspekte der Lage eines Unternehmens in Bezug auf ihren Einfluss auf eine Erreichung eines gemeinsamen, übergeordneten Zieles hin zu würdigen wären. ${ }^{564}$ Wie in B 2.2.2 gezeigt, kann die Operationalisierung dieses allg. Oberziels des Unternehmens mit Hilfe des Wettbewerbsvorteils erreicht werden - die Strategie als Plan zur Erreichung dieses zentralen Zieles erscheint sodann als geeignete Strukturierungslösung für eine adäquate Berichterstattung zur Lage.

Auch die erst in den letzten Jahren dem Lagebericht zusätzlich zugeschriebenen Funktionen können als Rechtfertigung der strategieorientierten Berichterstattung dienen: So fordert die Beurteilungsfunktion das Management auf, seine eigenen Erwartungen bzgl. der künftigen Entwicklung im Prognosebericht transparent zu machen bzw. diese zu beurteilen. Es scheint auch in diesem Falle ausschließlich die verfolgte Unternehmensstrategie - als Ausdruck der langfristig angestrebten Entwicklungsrichtung des Unternehmens - geeigneter Beurteilungsmaßstab und Bezugsrahmen für die Ausführungen des Managements zu sein. ${ }^{565}$ Schließlich sollte aufgrund der Analysefunktion des Lageberichts eine systematische Untersuchung der gegenwärtig oder in der Zukunft für die Lage und Entwicklung des Unternehmens relevanten Faktoren erfolgen. Zu jenen Faktoren, die Einfluss auf die Lage bzw. die Entwicklung des Unternehmens haben, dürfte auch - vor dem Hintergrund ihrer abgeleiteten Bedeutung - die Strategie selbst zählen. ${ }^{566}$

564 Vgl. Baetge (1993), Sp. 1331. Der Autor definiert drei Teillagen: eine Vermögens-, eine Finanz- sowie eine Ertragslage. Diese sind gesamthaft, also verdichtet darzustellen. Die Strategie bietet sich als Referenzpunkt an, da sie nicht Teil einer dieser Teillagen ist. Die Verdichtungsfunktion wurde dem Lagebericht durch das BiRiLiG zugeschrieben. Vgl. zur Beurteilungsfunktion Kirsch/Köhrmann (2007), Rz. 7ff. Diese Funktion wurde dem Lagebericht durch das KonTraG im Rahmen der Risikoberichterstattung hinzugefügt. Das Management hat sodann zu beurteilen, ob berichtspflichtige Risiken bestehen. Seit dem BilReG ist die Beurteilung in $\S 289$ Abs. 1 S. 4 auch auf Chancen ausgeweitet. Es wird erkennbar, dass mit der auf S. 103 formulierten Frage, inwieweit eine Berichterstattung zur Lage sowie zur voraussichtlichen Entwicklung einer Gesellschaft überhaupt möglich ist, ohne jedoch auf die angestrebte Entwicklung, also die strategische Planung des Managements, einzugehen, implizit die Beurteilungsfunktion angesprochen wurde.

Vgl. zur Analysefunktion Böcking et al. (2003), S. 404ff. Diese wurde dem Lagebericht durch das BilReG zugeschrieben, das insg. dessen Berichtscharakter verschärfte. Es ist die Analysefunktion, die den Bericht für den Management Approach öffnet und die Ergänzung von Angaben der internen Steuerung bewirkt, vgl. DSR (2005), Tz. 15.28. 
Zusammenfassend ist zum rechtlichen Status der strategieorientierten Berichterstattung im Lagebericht festzustellen, dass trotz diverser Versuche, die explizite Kodifizierung innerhalb der einschlägigen Normen zu verankern, bis dato keine Verpflichtung zur Berichterstattung über strategieorientierte Sachverhalte ableitbar ist. Gleichwohl können die gesetzlich fixierten Funktionen des Lageberichts verwandt werden, um die entsprechende, freiwillig erfolgende Berichterstattung - unabhängig von der Existenz einer expliziten Verpflichtung - zu rechtfertigen. Es erscheint daher gleichfalls überlegenswürdig, ob sich auf Grundlage der dargestellten Funktionen des Lageberichts nicht sogar eine implizite Verpflichtung zu einer strategieorientierten Berichterstattung ableiten lässt. ${ }^{567}$

\subsubsection{Supranationale Impulse für eine Berichterstattung über strategieorientierte Inhalte}

Eine Normierung von Lageberichtsinstrumenten in den Mitgliedsstaaten der EU erfolgt, wie erwähnt, grds. im Rahmen nationalstaatlicher Normierungsakte, eine einheitliche, supranationale Regelung, insb. eine Vorgabe von Seiten des IASB ist bis zum heutigen Tage nicht zustande gekommen. Gleichwohl wurden in den letzten Jahren vereinzelte Initiativen unternommen, um die europäische Lageberichterstattungspraxis rechtssystemübergreifend zu harmonisieren bzw. diese inhaltlich weiterzuentwickeln. Erwähnenswert scheint hier insb. ein Vorschlag der European Accounting Study Group, der im Jahre 2000 vorgelegt wurde.

Weiterhin hat das IASB bereits in 2002 ein Projekt mit dem Titel ,Management Commentary ' initiiert, um einen eigenen Vorschlag zur Lageberichterstattung zu erarbeiten und ergo die quantitativ-finanzielle Orientierung der IFRS aufzulösen. Sowohl jener Beitrag der European Accounting Study Group wie auch der Stand der Diskussion des IASB sind nachfolgend darzustellen, eine Fokussierung auf Forderungen nach strategieorientierten Berichtsinhalten erscheint konsequent:

567 Vgl. zu diesem Gedanken insb. auch Fink/Keck (2004), S. 1085. Die Autoren verweisen darauf, dass eine Berichterstattung zur geplanten Unternehmensentwicklung in der Zukunft die ,modernen' Funktionen der Beurteilung sowie der Analyse überhaupt erst ermöglicht und andere Funktionen dem nicht entgegenstehen. 


\section{(a) Vorschlag einer strategiegeleiteten Lageberichterstattung}

Bereits im Jahre 2000 stellte die NIVRA, die Vereinigung der Wirtschaftsprüfer der Niederlande, ein von der European Accounting Study Group ausgearbeitetes Positionspapier vor, welches als Beitrag zur internationalen Harmonisierung von Lageberichten zu interpretieren ist. ${ }^{568}$ Der Lagebericht wird in diesem Papier explizit als ein Medium zur Bereitstellung von Zusatzinformationen zu den im Abschluss abgebildeten quantitativen Sachverhalten sowie als ein Mittel zur Überwindung informationeller Grenzen durch Ergänzung bzw. Verdichtung der Abschlussdaten positioniert. ${ }^{569}$

Bemerkenswert ist an dem Entwurf in erster Linie, dass nicht nur eine strategieorientierte Lageberichterstattung vorgeschlagen wird, sondern darüber hinaus die Strukturierung des Lageberichts entsprechend der strategischen Ausrichtung des Unternehmens empfohlen wird: „The structure of management's analysis should follow explicitly the strategy of the business" sowie „The economic rationale of the business strategy should be used as an explicit framework for a rigorous and balanced analysis. " ${ }^{\text {570 }}$ Statt die Unternehmensstrategie also lediglich als bedeutsamen Bestandteil eines Lageberichts anzusehen, wird diese hier zum zentralen Gliederungsprinzip erhoben, die Strategie wird zur strukturierenden Logik eines Lageberichts. ${ }^{571}$ Allerdings identifiziert jener Entwurf auch potenzielle Nachteile strategieorientierter Lageberichterstattung, die mögliche Wettbewerbssensitivität der Berichtsinhalte, Haftungsrisiken sowie die Verlässlichkeit der Informationen werden thematisiert. ${ }^{572}$

Zwar scheint der Entwurf der European Accounting Study Group auf den ersten Blick weitestgehend unkonkret, da er keine detaillierten Berichtsanforderungen

568 Vgl. grdl. NIVRA (2000). Das Positionspapier wurde erarbeitet durch die sog. European Accounting Study Group unter Mitwirkung verschiedener europäischer Standardsetter, u.a. waren auch zwei Vertreter Deutschlands an der Ausarbeitung beteiligt. Beide wörtlichen Zitate sind NIVRA (2000), S. 16 entnommen.

570 NIVRA (2000), S. 21. Eine konsequente Umsetzung des Management Approach macht folglich eine strategiegeleitete Lageberichterstattung unmittelbar erforderlich. Als KernBerichtsinhalte sind genannt: Vision, finanzielle und nicht-finanzielle Ziele, strategische Ausrichtung (Produkt-Markt-Kombinationen), Ressourceneinsatz, Risiken, Chancen. Vgl. Steinmeyer (2009), S. 394; NIVRA (2000), S. 21. 
spezifiziert, sondern i.W. auf den Vorschlag, die Unternehmensstrategie als primäre Strukturierungslogik des Lageberichts zu verwenden, fokussiert. Doch erfolgt jene Konzentration bewusst: Die Verfasser positionieren ihren Entwurf explizit als Gegenmodell zur fortwährenden Ausweitung der Berichtsinhalte. ${ }^{573}$

Einen weiteren Vorschlag für eine internationale Vereinheitlichung von Lageberichtsinstrumenten stellte im Jahr 2003 eine Arbeitsgruppe des IOSCO, des Verbandes der internationalen Wertpapieraufsichtsbehörden, vor. Vorgelegt werden allerdings lediglich Prinzipien für die internationale Lageberichterstattung, ohne klare Empfehlungen für eine konkrete inhaltliche Ausgestaltung zu unterbreiten. Interessant an dem Vorschlag ist jedoch, dass der Lagebericht ebenfalls explizit als verbales Berichtsmedium beschrieben wird, das primär qualitative Angaben vermittelt und insofern eine notwendige Ergänzung des Abschlusses darstellt. ${ }^{574}$ Wenngleich eine Berichterstattung zu strategieorientierten Inhalten nicht explizit gefordert ist, kann die Berücksichtigung derartiger Informationen als vollständig konform mit den formulierten Prinzipien gelten.

In beiden Entwürfen wird der Lagebericht folglich aufgrund seiner verbalen Erläuterungen als kritisches Pendant zum Jahresabschluss und somit als wesentlich für ein solides Verständnis der Lage einer berichtenden Gesellschaft positioniert. Aus internationaler Perspektive muss der Lagebericht also ebenfalls als ideal geeignet für eine Berichterstattung zu strategieorientierten Sachverhalten gelten. ${ }^{575}$ Wenngleich der Vorschlag der European Accounting Study Group deutlich über eine strategieorientierte Berichterstattung hinausgeht, da die Strategie sogar als die Richtschnur des Lageberichts empfohlen wird, unterstreicht dieser nicht nur eindrücklich die Relevanz, sondern auch die Notwendigkeit strategieorientierter Berichtsinhalte innerhalb von Lageberichtsinstrumenten.

573 Vgl. NIVRA (2000), u.a. S. 6f. Ziel war es insb., einen Diskussionsprozess zur Weiterentwicklung der internationalen Lageberichterstattung zu initiieren, das impliziert einen Verzicht auf konkrete Vorgaben für die Ausgestaltung des Lageberichts. Vgl. grdl. IOSCO (2003). Das Technical Committee der ,International Organization of Securities Commissions، (IOSCO, Verband der internationalen Wertpapieraufsichtsbehörden) erlässt vereinzelt Hinweise an Standardsetter und Unternehmen zur Rechnungslegung, die jedoch i.d.R. recht kurz und abstrakt gehalten sind.

Konsequenterweise umfasst das hier zitierte Papier auch nur sechs Seiten. 
(b) Vorschlag des IASB zur strategieorientierten Lageberichterstattung

Auch das IASB hat - als der für die Rechnungslegung kapitalmarktorientierter Unternehmen in Europa relevanter Standardsetter - die Debatte um eine den Abschluss ergänzende, primär qualitativ-verbale Berichterstattung aufgegriffen und daher Ende 2005 einen Entwurf zur eigenständigen Lageberichterstattung innerhalb des IFRS-Regelsystems vorgelegt. ${ }^{576}$ Dies ist insofern ein bemerkenswerter Schritt, als im Falle einer Realisierung eines entsprechenden Standards auch die Normierungskompetenz zum Lagebericht auf das IASB übergehen und insofern das beschriebene Zwei-Säulen-Modell der Vergangenheit angehören würde.

In seiner Begründung zu dem am 27.10.2005 veröffentlichten Diskussionspapier zur Lageberichterstattung verweist das IASB $^{577}$ auf die Notwendigkeit einer inhaltlichen Ergänzung der primär quantitativ-monetär orientierten Financial Statements um weitere Berichtselemente. ${ }^{578}$ Folgerichtig schlägt das IASB einen sog. ,Management Commentary “ vor, der zur Veröffentlichung nicht-finanzieller und verbaler Berichtsinhalte und folglich zur Überwindung informationeller Grenzen von IFRS-Abschlüssen dienen sollte. ${ }^{579}$ Dieser vorgelegte Entwurf ist gleichfalls prinzipienbasiert und gibt nur Mindestinhalte für die Lageberichterstattung vor -

576 Vgl. bspw. Fink (2006), S. 141, auch Kirsch/Scheele (2006), S. 89; IASB (2005), Tz. 7: "financial statements are not sufficient to meet the objectives of financial reporting." Das Management Commentary-Projekt wurde bereits im Oktober 2002 aufgesetzt, um die bekannte Lücke im IFRS-System zu schließen, vgl. IASB (2005), S. 3. Das Projektteam wurde mit Vertretern verschiedener nationaler Standardsetter sowie externer Experten besetzt, wobei insb. Staaten inkludiert wurden, welche bereits lange Erfahrung in der Lageberichterstattung haben, z.B. Deutschland, Kanada.

577 Interessant ist, dass das IASB nur als Herausgeber genannt ist und betont wird, dass das Diskussionspapier auf den Ausarbeitungen der Projektgruppe beruht: „A paper prepared for the IASB by staff of its partner standardsetters and others“, IASB (2005), Deckblatt sowie ,Accordingly, the recommendations do not necessarily represent the views of the IASB or its partner standardsetters", so IASB (2005), S. 2.

578 Vgl. IASB (2005), u.a. Tz. 4. Das Diskussionspapier, vorgelegt am 27.10.2005, basiert auf einem bereits im Dezember 2004 vorgelegten vorläufigen Entwurf. Ziel war es, eine Debatte über die Notwendigkeit und Ausgestaltung des Management Commentary zu initiieren, vgl. hierzu Beiersdorf/Buchheim (2006), S. 97. Dr. Regine Buchheim gehört als Vertreterin des DRSC dem Projektteam zum Management Commentary an.

579 Vgl. IASB (2005), Tz. 6ff. Trotz diverser Unterschiede im Detail kann grds. festgestellt werden, dass der Management Commentary vergleichbar dem dt. Lagebericht als zweite Säule der Berichterstattung positioniert wird, vgl. ebenda, Tz. 158 sowie S. 12. 
fünf Kernbestandteile sollen mit Hilfe des Management Commentary abgedeckt werden, wobei ,Ziele \& Strategien“ eine explizite Berichtskategorie darstellt. ${ }^{580}$

Nach einer Phase der Kommentierung dieses Entwurfs bis April 2006 sowie anschließender Diskussion veröffentlichte das IASB über drei Jahre später, im Juni 2009, einen sog. Exposure Draft zum Management Commentary. ${ }^{581}$ Dieser folgt dem Diskussionspapier weitgehend und sieht folgerichtig eine Berichtskategorie ,Ziele \& Strategien “ vor, allerdings wird das zuvor genannte Ziel eines eigenen Standards zur Lageberichterstattung mit dem Exposure Draft aufgegeben. ${ }^{582}$

Wenngleich der Projektverlauf und das bisherige Ergebnis dieses IASB-Projekts einen ernüchternden Eindruck hinterlassen mögen, ${ }^{583}$ wird die grds. Ausrichtung der vorliegenden Arbeit unterstützt: Sowohl das Projektteam als auch die Mehrheit der kommentierenden Institutionen bestätigen eindrucksvoll die Bedeutung und gleichfalls die Notwendigkeit strategieorientierter Berichtsinhalte innerhalb von Lageberichtsinstrumenten.

580 Vgl. IASB (2005), Tz. 100ff. Eine inhaltliche Anlehnung an DRS 15 bzgl. der Berichtskategorien ist erkennbar, vgl. die Gliederungsempfehlung in DSR (2005), DRS 15.93.

Das IASB überlässt unter Hinweis auf die Individualität von Unternehmen diesen eine Bestimmung von Detaillierungsgrad und Struktur des Berichts. Dieses Spannungsverhältnis von Standardisierung zur Sicherung von Vollständigkeit und Vergleichbarkeit sowie dem Erfordernis nach individueller Ausgestaltung nennt schon Stobbe (1988), S. 305 das ,Dilemma des Lageberichts“.

581 Vgl. IASB (2009e). Als Reaktion auf das Diskussionspapier erhielt das IASB insg. 117 Briefe zur Kommentierung, vgl. hier IASB (2007b). Es wird weitgehend bestätigt, dass Lageberichte zur Ergänzung einer Finanzberichterstattung notwendig sind, wenngleich nur rund $50 \%$ der Kommentare die Entwicklung des Management Commentary als eine Priorität des IASB ansehen, vgl. ebenda, S. 7. Auch die Frage nach der formalen Ausgestaltung (Leitlinie vs. Standard) ergibt ein geteiltes Bild, vgl. ebenda, S. 12. Die inhaltlichen Elemente, insb. die Berichtskategorie ,Ziele \& Strategien“, werden klar bestätigt, vgl. S. 37ff. Positive Anmerkungen hierzu von dt. Seite insb. von der Volkswagen AG, Munich Re AG und Allianz SE, kritisch dagegen das IDW, vgl. jeweils (2006).

582 Vgl. IASB (2009e). Dieser Exposure Draft stand bis zum 01.03.2010 für Kommentare seitens der Öffentlichkeit zur Verfügung, vgl. ebenda, S. 2. Das IASB stellt klar, dass es einen eigenen IFRS ,Management Commentary' nicht geben wird, als Ziel des Projekts wird nunmehr die Verabschiedung unverbindlicher Leitlinien genannt, vgl. ebenda, S. 4. Kajüter/Guttmeier (2009), S. 2333 sehen dies als eine interessante „Sonderstellung“.

583 Die Zeitdauer seit Aufsetzen jenes Projekts, die Abkehr vom zunächst angestrebten Ziel eines Standards sowie die Tatsache, dass sich drei von 14 Mitgliedern des Boards gegen eine Veröffentlichung des Exposure Drafts aussprachen, hinterlassen den ernüchternden Eindruck, vgl. IASB (2009e), S. 33 zu den "Alternative views on exposure draft"“.

Tom Sieber - 978-3-631-75150-3 
Aus Sicht der deutschen Rechnungslegung muss zudem konstatiert werden, dass dieser Entwurf des IASB inhaltlich weit hinter den detaillierten Formulierungen des DRS 15 zurückbleibt. ${ }^{584}$ Zwar gelänge es dem IASB grds., mit dem Management Commentary eine identifizierte Lücke im Regelwerk der Finanzberichterstattung der IFRS zu schließen, allerdings muss der vorliegende Exposure Draft als „Minimallösung“ kritisiert werden und es erscheint kaum realistisch, dass bei Verabschiedung in Form unverbindlicher Leitlinien die ursprünglichen Ziele der Harmonisierung und qualitativen Verbesserung der Lageberichterstattung innerhalb des Geltungsbereichs der IFRS erreicht werden können. ${ }^{585}$

\subsection{Freiwillige "Strategieberichterstattung « im Lagebericht}

Es wurde gezeigt, dass sich - vor dem Hintergrund von Unzulänglichkeiten der externen Rechnungslegung zur Wertkommunikation - die einschlägige Literatur unter dem Stichwort des Value Reportings intensiv mit der Anreicherung der Berichterstattung um wertorientierte Berichtsinhalte beschäftigt hat. Entsprechende Gestaltungsvorschläge betonen insb. die Berücksichtigung von qualitativen, prognostischen Angaben, darüber hinaus wird explizit eine Bereitstellung strategieorientierter Informationen gefordert - die diese charakterisierenden Merkmale in besonderer Weise erfüllen. Eine Aufnahme von strategieorientierten Berichtsinhalten in Gestaltungsvorschläge für ein Value Reporting erscheint weiterhin nur konsequent, wenn berücksichtigt wird, dass Informationen zur langfristig angestrebten Entwicklung eines Unternehmens in der Zukunft schon aus sich selbst heraus für die Investoren am Kapitalmarkt bedeutsam sein dürften als inhaltliche Unterstützung bei der Prognose zukünftiger Zahlungsstromgrößen.

Als Medium zur Bereitstellung strategieorientierter Berichtsinhalte ist der Lagebericht, eingebettet in das System der externen Rechnungslegung, besonders geeignet. Nicht nur ist er als Berichtserstattungsinstrument bewährt, sein Charakter könnte zudem helfen, potenzielle Einschränkungen im Hinblick auf die Verläss-

584 Vgl. grdl. im Original DSR (2010), DSR 15 n.F.; Kajüter/Guttmeier (2009), S. 2337.

585 Vgl. Kajüter/Guttmeier (2009), S. 2337f., das wörtliche Zitat ist S. 2337 entnommen. In Bezug auf die dt. Lageberichterstattung werden $§ 315$ HGB bzw. DRS 15 folglich maßgeblich bleiben, vgl. mit dieser Ansicht auch Baetge et al. (2010), S. 100. 
lichkeit strategieorientierter Berichtsinhalte abzumildern. Folglich erscheint der Lagebericht im Zuge verstärkt wertorientiert ausgerichteter Berichterstattung in neuem Lichte - als das Kernmedium einer ,Strategieberichterstattung ': Frei von enger inhaltlicher Reglementierung erlaubt dieser eine flexible Darstellung von qualitativ-verbalen, prognostischen und strategieorientierten Berichtsinhalten. ${ }^{586}$

Eine Strategieberichterstattung innerhalb des Lageberichts ist indes gegenwärtig weder national in Deutschland noch international kodifiziert, gleichwohl stehen die geltenden Normen einer freiwilligen Berichterstattung auch nicht entgegen. Zwar haben der deutsche Gesetzgeber wie auch der von ihm ins Leben gerufene Standardsetter DRS demonstriert, dass sie grds. gewillt wären, die Kodifizierung einer Strategieberichterstattung zu realisieren - jedoch wurden einschlägige Entwürfe nach kontroversen Diskussionen verworfen. Ein vergleichbares Bild zeigt sich auf internationaler Ebene: In seinen Bemühungen, einen einheitlichen Lagebericht zu schaffen und insofern die zu einseitige Ausrichtung der IFRS auf die Finanzberichterstattung aufzulösen, stellt auch das IASB eindeutig auf strategieorientierte Informationen ab, kommt aber im Endergebnis über einen allgemein gehaltenen und unverbindlichen Leitlinien-Katalog wohl nicht hinaus.

Dementsprechend erfolgt eine Berichterstattung zu strategieorientierten Inhalten im Lagebericht - wenn überhaupt - ausschließlich als Teil einer freiwilligen Berichterstattung. Da folglich die individuelle Bereitschaft des Managements eines Unternehmens zu einer über explizit normierte Anforderungen hinausgehenden freiwilligen Berichterstattung maßgeblich für eine tatsächliche Veröffentlichung strategieorientierter Informationen ist, ${ }^{587}$ wäre schließlich zu vermuten, ,dass die strategische Berichterstattung [...] noch in den Kinderschuhen steckt ${ }^{\text {“588 }}$. Jedoch sehen sich Manager grds. durchaus in der Lage, strategieorientierte Angaben zu präsentieren, wie eine Untersuchung von Fischer/Beckmann (2009) zeigen kann:

586 Vgl. Baetge/Prigge (2006), S. 404ff. Diese resümieren, dass ausreichend Möglichkeiten vorhanden wären, um die inhaltliche Qualität der Lageberichterstattung zu erhöhen, und fordern daher die Berichterstatter auf, tätig zu werden - ggf. wäre über Maßnahmen des Gesetzgebers nachzudenken, wenn eine Berichterstattung nicht freiwillig erfolgt.

587 Vgl. u.a. Schultze (2007), S. 570.

588 Günther et al. (2003), S. 458. Es ist u.a. das Ziel der anschließenden empirischen Untersuchung, den aktuellen Status der strategieorientierten Berichterstattung zu ermitteln. 
Demnach fühlen sich Aufsichtsräte deutscher Aktiengesellschaften mehrheitlich ausreichend über strategische Sachverhalte informiert. ${ }^{589}$ Weiterhin demonstriert der vielbeachtete Wettbewerb ,Der Beste Geschäftsbericht ', der bereits seit 1982 jährlich in Deutschland durchgeführt wird, dass Anlass dazu besteht, strategieorientierte Angeben im Lagebericht zu erwarten: So weist eine Vielzahl von Berichtskriterien, die bei der Analyse der Geschäfts-, spezifischer der Lageberichte börsennotierter Unternehmen geprüft werden, einen klaren Bezug zur Strategie auf. ${ }^{590}$ Das ist insofern nachvollziehbar, als sich - unter Rückgriff auf Abb. 7 - in inhaltlicher Sichtweise für jeden der vier Teil-Berichte des in der gegenwärtigen Fassung kodifizierten HGB-Lageberichts mögliche strategieorientierte Berichtsinhalte identifizieren lassen, wie die nachstehende Abb. 9 aufzuzeigen vermag.

\begin{tabular}{|c|c|c|c|c|}
\hline & $\begin{array}{c}\text { Wirtschafts- } \\
\text { bericht }\end{array}$ & $\begin{array}{c}\text { Nachtrags- } \\
\text { bericht }\end{array}$ & $\begin{array}{c}\text { Prognose- } \\
\text { bericht }\end{array}$ & $\begin{array}{l}\text { Zusatz- } \\
\text { berichte }\end{array}$ \\
\hline Kerninhalte & $\begin{array}{l}\text { Lage und } \\
\text { Geschäftsverlauf, } \\
\text { (nicht-) finanzielle } \\
\text { Indikatoren }\end{array}$ & $\begin{array}{l}\text { Besondere } \\
\text { Ereignisse nach } \\
\text { Bilanzstichtag }\end{array}$ & $\begin{array}{l}\text { Prognose der } \\
\text { Entwicklung und } \\
\text { Beurteilung }\end{array}$ & $\begin{array}{l}\text { Forschung und } \\
\text { Entwicklung, } \\
\text { Niederlassungen }\end{array}$ \\
\hline $\begin{array}{l}\text { Strategie. } \\
\text { inhalte }\end{array}$ & Schwerpunkt & [Ggf. möglich] & Schwerpunkt & [Ggf. möglich] \\
\hline Beispiel & $\begin{array}{l}\text { Externe Marktbe- } \\
\text { dingungen als Teil } \\
\text { der Lagedarstellung, } \\
\text { z.B. Marktwachstum }\end{array}$ & $\begin{array}{l}\quad \text { Nachtrag zur } \\
\text { aktuellen Strategie, } \\
\text { z.B. aufgrund eines } \\
\text { Konjunktureinbruchs }\end{array}$ & $\begin{array}{l}\text { Marktstrategischer } \\
\text { Fokus in der Zukunft } \\
\text { (Produkte, Regionen), } \\
\text { z.B. Markteintritt Indien }\end{array}$ & $\begin{array}{l}\text { FuE-Prioritäten, } \\
\text { Wertschőpfungs- } \\
\text { strategie, z.B. Aufbau } \\
\text { Produktion China }\end{array}$ \\
\hline
\end{tabular}

Abbildung 9: Verortung strategieorientierter Inhalte im Lagebericht ${ }^{591}$

589 Vgl. umfassend Fischer/Beckmann (2009). Im Fokus stehen die Aufsichtsräte deutscher börsennotierter Aktiengesellschaften. Obgleich sich diese ausreichend über strategische Sachverhalte informiert fühlen, wird in Bezug auf die Berichtsfrequenzen Steigerungspotenzial identifiziert. So wird bspw. die jeweilige Strategiedefinition i.d.R. nur einmal jährlich thematisiert, ebenso wie die Analyse der Umfeldbedingungen.

Theisen (2007), S. 169 fordert explizit die umfassende Bereitstellung von Informationen der strategischen Analyse: Ohne Branchen- sowie Umweltinformationen sieht er ,keine zuverlässige Basis für eine ordnungsgemäße Überwachung“ durch die Aufsichtsräte. Eine Bestätigung hierzu findet sich u.a. bei Baetge/Heumann (2006b), S. 345ff. Vgl. zudem die relevanten Bestandteile der Kriterienkataloge der Wettbewerbsrunden der Jahre 2002 bis 2008 in Anhang 9 der vorliegenden Arbeit. Dieser Wettbewerb und insb. seine strategieorientierten Berichtskriterien werden im weiteren Verlauf dieser Arbeit, u.a. im Rahmen der eigenen empirischen Untersuchung noch ausführlich betrachtet. 
Erwartungsgemäß ist der Schwerpunkt einer strategieorientierten Lageberichterstattung in erster Linie innerhalb des Wirtschafts- sowie des Prognoseberichts zu vermuten. Es kann daher auch nicht überraschen, dass die Adressaten des Lageberichts am Kapitalmarkt ihrerseits eine regelmäßige und umfassende Berichterstattung zur Strategie von den Unternehmen erwarten, wie zuletzt Prigge (2005) im Rahmen einer Befragung von Investoren ermitteln konnte. ${ }^{592}$

Vorstehende Abb. 9 macht zudem erneut den umfassenden, leitenden Anspruch der Strategie in der Lageberichterstattung offensichtlich, wie er auch in dem erwähnten Positionspapier der European Accounting Study Group beschrieben ist: Wie ein roter Faden durchzieht die Unternehmensstrategie alle Teil-Berichte des Lageberichts: „The economic rationale of the business strategy should be used as an explicit framework for a rigorous and balanced analysis. ${ }^{6593}$ Es ist folglich davon auszugehen, dass die Strategie - nicht zuletzt aufgrund ihres dargestellten Instrumentalcharakters als Werkzeug zur Erreichung des Oberziels eines Unternehmens - in hervorragender Weise dazu geeignet ist, eine derartige inhaltliche Klammerfunktion auszuüben.

592 Vgl. Prigge (2005), S. 105f. Befragte Kapitalmarktakteure forderten insb. Angaben zur Steuerung, zu den Zielen und Strategien der Unternehmen. Auf Basis dieser Ergebnisse schließt der Autor, dass derartige Angaben von Bedeutung für den Kapitalmarkt sind. NIVRA (2000), S. 21. 


\section{$5 \quad$ Synopsis der Ausführungen als Überleitung zu einer empirischen Untersuchung der Strategieberichterstattung}

An dieser Stelle seien die Erkenntnisse der bisherigen Ausführungen zusammengefasst: Gezeigt wurde, dass Kapitalmärkte als Bedingung für ihr Funktionieren Informationen benötigen, damit Investoren Prognosen bzgl. der zukünftigen Entwicklung von Unternehmen vornehmen bzw. Investitionsentscheidungen treffen können, da gilt: „A prediction can be made without making a decision, but a decision cannot be made without, at least implicitly, making a prediction. “" ${ }^{\text {“94 }}$

Es sind in erster Linie prognostische Informationen erforderlich, jedoch scheint der Zukunftsbezug der externen Rechnungslegung, der bewährten sowie verlässlichen Informationsgrundlage des Kapitalmarktes, auf den ersten Blick gering.

Die Unternehmen als Kapitalnachfrager beschäftigen sich ihrerseits im Rahmen des strategischen Managements mit der Zukunft und leiten ihre Strategie ab, verstanden als Plan zur Erreichung des generellen Oberziels jedes Unternehmens, der langfristigen erfolgreichen Weiterentwicklung. Informationen zur Strategie bzw. zu den einzelnen Phasen des Strategieprozesses weisen nicht nur einen inhärenten Zukunftsbezug auf, sondern sollten zudem - aufgrund ihrer Bedeutung für den künftigen Unternehmenserfolg - von Relevanz für die Investoren sein.

Die externe Rechnungslegung als normiertes, verbindliches sowie regelmäßiges Instrument der Informationsbereitstellung der Unternehmen bietet zur Berichterstattung über die primär qualitativ-verbalen Informationen zur Strategie ein geeignetes Instrument an, den Lagebericht. ${ }^{595}$ Eingebettet in das Gesamtsystem der externen Rechnungslegung scheint dieses Berichtsmedium flexibel genug für die Darstellung strategieorientierter Inhalte zu sein und würde diesen darüber hinaus Verlässlichkeit verleihen, woran es prognostischen Angaben per se mangelt.

\footnotetext{
594 Beaver et al. (1968), S. 680.
}

595 Es sei der Vollständigkeit halber auch erwähnt, dass mit diesen Ausführungen der $\mathrm{Zu-}$ sammenhang von Planung und Rechnungslegung angesprochen wird, der sich in der betrieblichen Praxis als äußerst eng darstellt. Dies nicht zuletzt deshalb, weil die Planung i.d.R. auf Informationen der Rechnungslegung aufsetzt. Der hier in den Fokus gestellte Aspekt beleuchtet den komplementären Aspekt des Zusammenhangs, die Bereitstellung von Planungsinformationen innerhalb des Systems der Rechnungslegung. Vgl. zur Rolle der Rechnungslegung als Informationslieferant der Planung Kussmaul (1999), S. 1579f. 
Einschlägige Entwürfe zur wertorientierten Ausgestaltung der Berichterstattung empfehlen folglich auch unisono, insb. strategieorientierte Informationen bereitzustellen, und relevante standardsetzende Institutionen auf nationaler bzw. internationaler Ebene haben demonstriert, dass sie strategieorientierte Berichtsinhalte innerhalb des Lageberichts für bedeutsam erachten, und sich konsequenterweise verschiedentlich um eine entsprechende Kodifizierung bemüht.

Bis zum heutigen Tage ist eine explizite Kodifizierung derartiger Berichtsinhalte jedoch nicht erfolgt, eine entsprechende Berichterstattung ist demnach als freiwillig anzusehen - wenngleich sich bestehende Vorschriften zur Lageberichterstattung auch dahingehend auslegen lassen, dass eine normkonforme Berichterstattung Informationen zur Strategie unerlässlich macht. Diese rechtliche Grundlage scheint schließlich die zentrale Annahme zu erlauben, dass das Niveau der Berichterstattung deutscher Unternehmen bzgl. strategieorientierter Inhalte eine deutliche Heterogenität aufweisen sollte. Sofern die Heterogenität des faktischen ,Niveaus der Strategieberichterstattung ' der Unternehmen akzeptiert wird, wäre konsequenterweise herauszufinden, ob sich systematische Bestimmungsfaktoren identifizieren lassen, die in der Lage sind, Unterschiedlichkeiten des Niveaus der Berichterstattung zu erklären. Wird weiterhin - wie zuvor postuliert - akzeptiert, dass die Investoren am Kapitalmarkt Angaben zur Strategie eines Unternehmens als überaus relevante Informationen einstufen bzw. diese im Rahmen ihrer Prognosen bevorzugt aufgreifen würden, wäre zudem zu analysieren, ob Investoren die berichterstattenden Unternehmen für eine Bereitstellung strategieorientierter Informationen, belohnen`.

Dies ist der Ausgangspunkt und zugleich der Auftakt einer eigenen empirischen Untersuchung: Im Zentrum des Interesses steht die Berichterstattung deutscher börsennotierter Unternehmen zu strategieorientierten Inhalten im Lagebericht. 
Tom Sieber - 978-3-631-75150-3

Downloaded from PubFactory at 01/11/2019 07:41:07AM

via free access 


\section{Aufbau einer Untersuchung der strategieorientierten Berichterstattung börsennotierter Unternehmen}

\section{Vorbemerkungen}

Die bisherigen Ausführungen im Rahmen dieser Arbeit legten die theoretischen Grundlagen für eine Durchführung einer eigenen empirischen Untersuchung zur Lageberichterstattung der kapitalmarktorientierten Unternehmen in Deutschland. Konkret sind die Lageberichte auf ihren Gehalt an strategieorientierter Angaben oder kurz auf das ,Niveau der Strategieberichterstattung ' zu untersuchen.

Nicht überraschen kann es vor dem Hintergrund der theoretischen Grundlagen, dass der Terminus technicus der ,Strategieberichterstattung ' in der Literatur bis dato weitgehend unbekannt ist. ${ }^{596}$ Die vorliegende Arbeit verwendet diesen Begriff im weiteren Verlauf regelmäßig, um sodann auf den Sachverhalt einer - als grds. freiwillig verstandenen - Berichterstattung über strategieorientierte Inhalte innerhalb der Lageberichte nach HGB zu referenzieren.

Die theoretischen Grundlagen haben zudem die zentralen, relevanten Literaturbereiche aufgezeigt, in die der entsprechende Sachverhalt zwingend einzuordnen ist: Zunächst stellt die Strategieberichterstattung dem theoretischen Hintergrund folgend einen Teilbereich der allgemeinen Lageberichterstattung dar und dementsprechend ist die vorliegende Literatur zur Lageberichterstattung auf ihren Bezug zur Strategieberichterstattung hin zu sichten. Weiterhin hat sich insb. im deutschsprachigen Raum die bereits tangierte Value Reporting-Literatur um eine Aufwertung des Lageberichts durch zusätzliche Inhalte verdient gemacht sowie neben Darstellungen der Berichtspraxis auch normative Empfehlungen zur Umsetzung eines Value Reportings erarbeitet. Aus diesem Grund ist die einschlägige Literatur dahingehend zu analysieren, inwieweit eine Strategieberichterstattung entsprechend der obigen Definition dargestellt bzw. untersucht worden ist. Als angelsächsisches Pendant der Value Reporting-Literatur ist zudem die Business Reporting-Literatur in die Betrachtung mit einzubeziehen.

596 Eine im Rahmen der Literaturrecherche erfolgte, breit angelegte Suche nach dem Stichwort der ,Strategieberichterstattung ' im betriebswirtschaftlichen Kontext lieferte kaum verwertbare Ergebnisse. Einzig Scheele (2006), S. 93 verwendet diesen Begriff explizit.

Tom Sieber - 978-3-631-75150-3 
Wesentliche Beiträge liefert zudem die Voluntary Disclosure-Literatur, die sich bereits seit den 1960er Jahren als recht intensiv verfolgte Forschungsrichtung in den USA präsentiert und in der Folge eine Vielzahl von Untersuchungen zur erweiterten Berichterstattung von Unternehmen hervorgebracht hat. ${ }^{597}$ In diversen Arbeiten werden daher neben Bestimmungsfaktoren der Berichterstattungspraxis außerdem mögliche Auswirkungen derselbigen auf relevante Kapitalmarktparameter analysiert und interpretiert.

Wenngleich der für die eigene Untersuchung interessierende Sachverhalt bislang keine explizite Betrachtung innerhalb der betriebswirtschaftlichen Forschung ${ }^{598}$ erhalten hat, verhelfen die drei zuvor genannten Blickrichtungen der relevanten Literatur der eigenen Untersuchung dennoch zu einem soliden wissenschaftlichmethodischem Fundament - die Untersuchung scheint sich auf den ersten Blick in ein breites Spektrum betriebswirtschaftlicher Forschung einreihen zu können.

Ziel dieses Hauptteils $\mathrm{C}$ ist sodann konsequenterweise, die eigene Untersuchung inhaltlich auszugestalten, indem zunächst der wissenschaftliche Kontext dargestellt (C 2) und schließlich die konkrete Konzeption vorgenommen (C 3) wird:

Die Darstellung des Kontexts umfasst die Ableitung zentraler Forschungsfragen, um den hier interessierenden Sachverhalt für eine empirische Untersuchung zu konkretisieren, sowie eine Reflexion dieser Fragen innerhalb der einschlägigen Literatur, um Hinweise auf den Stand der Forschung zu erhalten. Anschließend ist der Erklärungsanspruch der eigenen Untersuchung darzustellen. Nach dieser externen Perspektive nimmt die Konzeption der Untersuchung eine eher interne, technische Perspektive ein: Bestandteile der Untersuchungskonzeption sind die Aufstellung überprüfbarer Hypothesen zum Sachverhalt der Strategieberichterstattung, eine Zusammenstellung der informationellen Basis der Untersuchung, die Operationalisierung der Variablen sowie die methodischen Grundlagen.

597 Die Voluntary Disclosure-Literatur kann als Teilgebiet der noch deutlich breiter ausgeprägten Disclosure-Literatur aufgefasst werden, die sich - vergleichbar mit der deutschsprachigen Rechnungslegungs-Literatur - ganzheitlich mit (externer) Berichterstattung auseinandersetzt. Jene Voluntary Disclosure-Literatur stellt auf den Aspekt freiwilliger Berichterstattung ab, also Berichtsinhalte, die nicht aufgrund gesetzlicher Kodifizierung oder anderer Vorschriften (z.B. Börsenzulassungsverordnungen) bereitgestellt werden. 


\section{Kontext der bisherigen Forschung und Forschungslücken}

\subsection{Leitende Fragen der Untersuchung}

Die theoretischen Ausführungen in Teil B der vorliegenden Arbeit haben deutlich erkennbar werden lassen, dass der Lagebericht in herausragender Weise geeignet ist, als Medium der Strategieberichterstattung zu dienen. Darüber hinaus konnte gezeigt worden, dass der Lagebericht bereits heute - ohne das Vorliegen einer expliziten gesetzlichen Forderung - ausreichende Flexibilität für eine Darstellung strategieorientierter Informationen bietet.

Dies wurde als Ausgangspunkt einer eigenen empirischen Untersuchung herausgearbeitet, mit der - in methodischer Anlehnung an die genannten Perspektiven der US-amerikanischen Voluntary Disclosure-Literatur - der aktuelle Status und die zeitliche Entwicklung, die Bestimmungsfaktoren sowie mögliche Wirkungen der Strategieberichterstattung deutscher börsennotierter Unternehmen untersucht werden sollen. Im Einzelnen ist folglich die Beantwortung von vier Forschungsfragen in Bezug auf deutsche börsennotierte Unternehmen angestrebt:

- Kann das Niveau der Strategieberichterstattung deutscher börsennotierter Unternehmen im Lagebericht gemessen werden?

- Sofern eine Messung möglich ist, welchen Status hat die Strategieberichterstattung heute und welche zeitliche Entwicklung lässt sich erkennen?

- Können auf Basis des gemessenen Niveaus der Strategieberichterstattung systematische Bestimmungsfaktoren desselbigen identifiziert werden?

- Abschließend: Hat das Niveau der Strategieberichterstattung feststellbare Auswirkungen auf ausgewählte Kapitalmarktvariablen?

Jene vier Fragen lassen sich untereinander differenzieren, bevor auf dieser Basis der Aufbau eines ersten groben Untersuchungsmodells erfolgen kann: Während sich die Frage nach der Messbarkeit sowie die Frage nach Status bzw. zeitlicher Entwicklung der Strategieberichterstattung mit dem interessierenden Phänomen per se befassen, weisen die Fragen nach den Bestimmungsfaktoren und Effekten am Kapitalmarkt auf kausale Beziehungen hin. Die Frage nach der Messbarkeit kann zudem als eine conditio sine qua non aufgefasst werden, da bei negativem

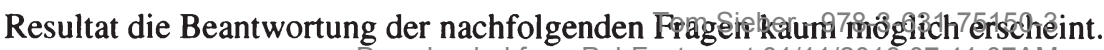




\subsection{Aufbau des Untersuchungsmodells}

Unter Berücksichtigung der oben aufgeführten leitenden Fragestellungen für die empirische Untersuchung gelangen drei zentrale Bausteine in den Fokus, die für den Aufbau eines ersten groben Untersuchungsmodells von Bedeutung sind:

Die Strategieberichterstattung per se ist dabei folgerichtig das zentrale Element, da sie letztlich den Kern der Untersuchung darstellt. Bis dato ist keine Kennzahl bekannt, anhand derer das Niveau der Strategieberichterstattung im Lagebericht abgelesen werden könnte. Aus diesem Grunde ist ein adäquates Messinstrument im Rahmen dieser Arbeit zu konstruieren, welches es ermöglicht, Aussagen über das unternehmensindividuelle Niveau der Strategieberichterstattung abzuleiten. Ein derartiges Messinstrument könnte letztlich - unter der Voraussetzung seiner Funktionsfähigkeit - als Grundlage von weiterführenden Analysen zur Strategieberichterstattung in temporaler wie auch kausaler Hinsicht dienen.

Zweiter Baustein jenes Untersuchungsmodells sind diejenigen Faktoren, welche das Berichterstattungsverhalten der Unternehmen möglicherweise systematisch beeinflussen. Dabei kommen verschiedene Kategorien von Faktoren in Betracht, die Einfluss auf die Strategieberichterstattung haben könnten, so wäre bspw. ein Einfluss der individuellen Unternehmenscharakteristika anzunehmen. Relevante Parameter des Kapitalmarktes komplettieren das Grobmodell der Untersuchung: Der dritte Baustein zielt auf eine Beantwortung der Frage, ob Strategieberichterstattung in der Lage ist, Einfluss auf zentrale Kapitalmarktvariablen auszuüben.

In einfacher Darstellung fasst Abb. 10 dieses Untersuchungsmodell zusammen.

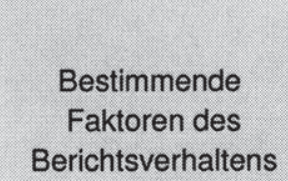

Bestimmende

Berichtsverhaltens
Niveau der

Strategiebericht-

erstattung
Einfluss

auf zentrale

Kapitalmarktvariablen

Abbildung 10: Grobes Modell der Untersuchung ${ }^{599}$ 


\section{3 Überblick über den bisherigen Stand der Forschung}

Im Folgenden ist der bisherige Stand der Forschung im Hinblick auf das Untersuchungsmodell zu analysieren, daran anschließend ist herauszuarbeiten, inwieweit die soeben bereits grob skizzierte eigene Untersuchung in empirischer Hinsicht Neuigkeitswert besitzt. Eine umfassende Studie, die das mit Abb. 10 dargestellte Untersuchungsmodell der Strategieberichterstattung gesamthaft abdeckt, ist bis dato allerdings nicht vorgestellt worden. Demzufolge ist das grobe Untersuchungsmodell in seine drei Elemente zu zerlegen, um sodann für die einzelnen Bausteine bzw. Teil-Beziehungen wesentliche Arbeiten zu sichten. Diese setzen sich jedoch überwiegend ganzheitlich mit dem Niveau der Berichterstattung auseinander, im Gegensatz zu der vorliegenden Arbeit wird kein spezifischer inhaltlicher Fokus gewählt, wie die folgenden Ausführungen aufzuzeigen vermögen.

\subsubsection{Arbeiten zum Niveau der (Lage-) Berichterstattung}

Untersuchungen zum Berichterstattungsverhalten von Unternehmen haben eine lange Tradition in Deutschland, sie werden regelmäßig durchgeführt, um den Informationsgehalt veröffentlichter Rechnungslegungsinstrumente zu ermitteln. ${ }^{600}$ Derartige Analysen sind z.T. auch Grundlage von Wettbewerben innerhalb der Wirtschaftspresse, was als Beleg für die Relevanz der Thematik gelten kann. ${ }^{601}$

Spezifisch in Bezug auf das Medium des Lageberichts adressieren verschiedene Untersuchungen das inhaltliche Niveau der Lageberichte zunächst gesamthaft: ${ }^{602}$ Exemplarisch sei die Arbeit von Dietsche/Fink aus dem Jahre 2008 erwähnt, die allerdings die Lageberichterstattung börsennotierter Unternehmen im Jahre 2005

\footnotetext{
${ }^{6(1)}$ Vgl. u.a. Berndsen (1978), S. 125f. Eine Übersicht über Untersuchungen zwischen 1969 und 1976 findet sich bei Wysocki (1976), S. 744; Coenenberg et al. (1978), S. 498.

601 Stellvertretend sei auf den bereits in Abschnitt B 4.4 skizzierten, etablierten Wettbewerb um ,Den Besten Geschäftsbericht “ verwiesen, der jährlich vom ,manager magazin “ unter wissenschaftlicher Leitung von Prof. Jörg Baetge durchgeführt wird. Vgl. hierzu Baetge (1992), Baetge et al. (1997), S. 177 sowie Baetge/Brötzmann (2003), S. 11, jüngst auch Baetge/Hippel (2009). Den Wettbewerbsaufbau sowie -verlauf stellt aktuell Oberdörster (2009), S. 88ff. dar. Zur Historie derartiger Wettbewerbe, welche bereits seit den 1950er Jahren in den USA durchgeführt werden, vgl. bspw. Hundhausen (1957), S. 143ff.

612 Es erscheint einleuchtend, dass es sich hierbei i.d.R. um dt. Veröffentlichungen handelt, da sich diese Arbeit auf die dt. Lageberichterstattung gem. HGB konzentriert. 
adressiert. ${ }^{603}$ Die Autoren überprüfen, ob die von Adressaten eines Lageberichts aufgestellten Anforderungen an die Berichterstattung erfüllt werden. Dies ist nur bedingt der Fall, es wird außerdem eine deutliche Heterogenität hinsichtlich der Qualität bzw. der Ausgestaltung der Berichte festgestellt sowie die gesamthafte Berichtsqualität als mittelmäßig klassifiziert. Eine weiterführende Aussage bzgl. der zeitlichen Entwicklung der Berichterstattung legen bspw. Schmidt/Wulbrand (2007) vor. ${ }^{604}$ Die Autoren untersuchen die Auswirkungen der Neuregelung der Lageberichterstattung auf die Qualität derselbigen, indem Lageberichte von 28 der Dax 30-Unternehmen in 2003 und 2005 verglichen werden. In Summe wird eine leichte Verbesserung festgestellt, allerdings zahlreichen Unternehmen noch Nachholbedarf hinsichtlich Transparenz und Präzision der Angaben attestiert.

Eine Reihe von Studien beschäftigt sich weiterhin gezielt mit einzelnen Teil-Berichten des Lageberichts, insb. finden sich Untersuchungen zur Prognose- sowie zur Risikoberichterstattung, was in methodischer Hinsicht gewisse Parallelen zu einer expliziten Untersuchung der Strategieberichterstattung aufweist: ${ }^{605}$

In einer Zeitpunktbetrachtung zur Prognoseberichterstattung für das Berichtsjahr 2005 sehen Quick/Reus (2009) betriebswirtschaftliche Anforderungen an solide Prognosen in den Lageberichten nicht erfüllt, die Prognoseberichte können nach Ansicht der Autoren in den meisten Fällen nicht überzeugen. ${ }^{606}$ Im Vergleich der Einzeljahre 2004 bis 2006 ermittelt Barth (2009) sodann zwar eine Ausweitung der Prognoseberichterstattung von kapitalmarktorientierten Unternehmen, stellt gleichwohl aber eine Heterogenität der Angaben fest. ${ }^{607}$ Gleichfalls erst kürzlich legen Ruhwedel et al. (2009) eine Zeitraumuntersuchung zur Prognoseberichterstattung der Dax 30-Unternehmen vor. Die Autoren vergleichen die Lageberichte des Jahres 2008 mit denjenigen des Jahres 2006. Dabei wird festgestellt, dass die

603 Vgl. Dietsche/Fink (2008). Die Bedeutung des Lageberichts als integralem Bestandteil der Kapitalmarktkommunikation wird bestätigt. Zur Analyse der Lageberichterstattung werden Anforderungen von Baetge/Prigge (2006) entnommen, als Basis dient DRS 15. Vgl. ausführlich Schmidt/Wulbrand (2007).

605 Unter Rückgriff auf Abb. 9 (S. 134) ist dies als, vertikale` Analyserichtung anzusehen. Vgl. im Detail Quick/Reus (2009). Diese leiten ein normatives Prognosemodell ab (Elemente: Prämissen, Verfahren, Horizont und Aussage), das zur Bewertung dient. der Untersuchung, auch wäre ein längerfristiger Betrachtungszeitraum wünschenswert. 
inhaltlichen Anforderungen lt. DRS 15 regelmäßig nicht erfüllt werden und sich offensichtlich die makroökonomischen Rahmenbedingungen der Jahre 2008 und 2009 auf das Berichtsverhalten der Unternehmen auswirkten. ${ }^{608}$ Einen weiteren interessanten Aspekt der Prognoseberichterstattung betrachten außerdem Pellens et al. (2007). Verglichen werden hier freiwillige Ergebnisprognosen der Dax 30Unternehmen in Printmedien mit Prognosen im Lagebericht. Gezeigt wird, dass im Lagebericht tendenziell unpräzisere und vorsichtigere Prognosen erfolgen. ${ }^{609}$

Bereits unmittelbar nach Einführung der Risikoberichterstattung zeigte Kajüter (2001) inhaltliche Mängel bei der Analyse der Lageberichte des Jahres 1999 der Dax 100-Unternehmen auf. ${ }^{610}$ In einer Folgestudie konstatieren Kajüter/Winkler (2003) eine leichte Verbesserung im Zeitablauf und ermitteln zudem eine höhere Berichtsqualität für Unternehmen des Dax im Vergleich zu denen des MDax. ${ }^{611}$ Weitere Erkenntnisse zur dt. Risikoberichterstattung sind von Fischer/Vielmeyer (2004) vorgelegt worden. Die Autoren errechnen einen ,Risk Disclosure Score“ durch Analyse der Lageberichte von Dax 100-Unternehmen, der die Qualität der Risikoberichterstattung misst. Wenngleich inhaltliche und formale Mängel festgestellt werden, erhöht sich dieser,Score' im Zeitablauf der Jahre 1999 bis 2002 deutlich, was auf eine Verbesserung der Berichte zurückgeführt werden kann.

Neben diesen Studien zur Lageberichterstattung per se sind in den letzten Jahren weitere Untersuchungen vorgelegt worden, die sich mit der externen Berichterstattung insgesamt beschäftigen und diese im Hinblick auf ihre Aussagekraft beurteilen. Jene Untersuchungen stehen inhaltlich in Zusammenhang mit der Value Reporting-Forschung und die jeweiligen Autoren zielen darauf ab, auf Basis von eigens aufgestellten normativen Kriterienkatalogen die Berichterstattungspraxis der Dax 30- oder Dax 100-Unternehmen dahingehend zu untersuchen, inwieweit

6)8 Vgl. im Detail Ruhwedel et al. (2009). Die Autoren kritisieren v.a. die geringe Präzision der Angaben und fehlende Darstellung von Prämissen. Auch Knauer/Wömpener (2010) sehen die Anforderungen des DRS 15 zur Prognoseberichterstattung nicht erfüllt. Vgl. Pellens et al. (2007), S. 24ff.

610 Vgl. Kajüter (2001), S. 108ff., der die Resultate „ernüchternd“" nennt. Die Risikoberichterstattung wurde im Rahmen des KonTraG eingeführt, vgl. hierzu auch Abschnitt B 3.1.

611 Vgl. Kajüter/Winkler (2003). Festgestellt wird zwar eine höhere Anzahl von berichteten Risiken im Zeitablauf, nach Meinung der Autoren bestehen jedoch nach wie vor Mängel bei der Risikoerläuterung sowie -kategorisierung. 
den jeweils formulierten Anforderungen realiter entsprochen wird. Stets werden auch strategieorientierte Berichtselemente inkludiert, da jene einen zentralen Bestandteil aller relevanten Value Reporting-Konzeptionen darstellen. Erwähnenswert sind in diesem Kontext insb. die Studien von Ruhwedel/Schultze (2002a) ${ }^{612}$, Pellens et al. $(2000)^{613}$, Fischer et al. $(2001 \mathrm{a})^{614}$ sowie Fischer et al. $(2001 \mathrm{~b})^{615}$. In jüngerer Zeit nehmen sich Schultze $(2005)^{616}$, Heumann $(2005)^{617}$ und Wenzel $(2005)^{618}$ der genannten Frage an. Den Untersuchungen ist gemein, dass sie stets Verbesserungspotenziale in der wertorientierten Berichterstattung identifizieren.

Eine Studie, die sich fokussiert mit der Strategieberichterstattung, verstanden als der Gehalt strategieorientierter Informationen im Lagebericht, auseinandersetzt, ist bislang nicht bekannt. Dies scheint auch insofern nachvollziehbar, als weder

612 Vgl. Ruhwedel/Schultze (2002a). Diese fokussieren auf den Dax 100 und untersuchen Geschäftsberichte des Jahres 2001 anhand eines eigenen Kriterienkataloges. Bei den Strategieinformationen sehen sie erhebliche Mängel in Inhalt sowie Struktur, wenngleich Dax-Unternehmen besser und ausführlicher berichten als MDax-Unternehmen.

613 Vgl. Pellens et al. (2000a), dies. (2000b). Die Autoren prüfen ihren „Value ReportingKatalog" in den Geschäftsberichten der Jahre 1997 bis 1999 der Dax-Unternehmen. Sie konstatieren zwar eine Verbesserung in der Berichterstattung, zeigen aber Defizite insb. im Bereich der zukunftsorientierten Berichtsinhalte auf. Zudem finden sich Hinweise, dass der Unternehmenserfolg Einfluss auf den Umfang der Berichterstattung hat.

614 Vgl. Fischer et al. (2001a). Die Arbeit fokussiert auf Unternehmen, die dem Nemax 50 angehörten. Es wird versucht, eine a priori aufgestellte Berichts-Scorecard aus den Berichten herauszuarbeiten, Inhalte bzgl. der Strategie werden jedoch als schwach und zudem heterogen ausgeprägt beurteilt. Interessant erscheint die Feststellung von branchenspezifischen Berichtsunterschieden innerhalb der gewählten Stichprobe.

615 Vgl. Fischer et al. (2001b). Die Studie fokussiert auf die Berichterstattung im Internet, die angewandten Kriterien sind vergleichbar mit Fischer et al. (2001a). Es wird ein Einfluss des angewandten Rechnungslegungsstandards ermittelt, auch Fischer et al. (2002).

616 Vgl. Schultze (2005). Dies ist die Folgestudie zu Ruhwedel/Schultze (2002a). Es werden die Geschäftsberichte 2000 bis 2002 der Dax 100-Unternehmen analysiert. Zwar scheint die Berichtsqualität verbessert, ist aber noch unbefriedigend. Bestätigt wird die Heterogenität der Berichte sowie Unterschiede zwischen Dax- und MDax-Unternehmen.

617 Vgl. im Detail Heumann (2005), S. 221 ff. Der Autor entwickelt einen Value ReportingKatalog, dessen Bestandteile er durch Befragung gewichtet. Eine Prüfung der Berichtsqualität von 44 Unternehmen in den Geschäftsberichten 2003 zeigt eine insg. schwache Qualität des Value Reportings. Es wird gezeigt, dass große Unternehmen sowie Dax 30Unternehmen besser berichten, die Branche jedoch keinen Einfluss zu haben scheint. In ihrer äußerst umfangreichen Arbeit konstruiert Wenzel (2005) einen Berichtskatalog und testet diesen in den Geschäftsberichten 1999 bis 2002. Die Autorin attestiert unzureichende Berichterstattung, insb. bzgl. zukunftsorientierter Informationen. Die Qualität der Berichte habe sich im Zeitraum jedoch erhöht. Vgl. ähnlich Fischer/Wenzel (2005). 
strategieorientierte Berichtsinhalte in einschlägigen deutschen (internationalen) Rechtsnormen zur Lageberichterstattung explizit kodifiziert sind, noch der relevante Terminus ,Strategiebericht' per se in der Literatur verwendet wird.

Es findet sich lediglich eine Arbeit, die weitgehend strategieorientierte Berichtsinhalte in das Zentrum des Untersuchungsinteresses stellt: Diese ist von Günther et al. (2003) vorgestellt worden, jedoch wird nicht auf das Medium Lagebericht fokussiert. ${ }^{619}$ Die Autoren beschränken sich bei der Auswahl der Untersuchungsobjekte zudem auf Unternehmen der ,New Economy ' und stellen in einer Zeitpunktbetrachtung für das Jahr 2001 eine insg. nur mangelhafte Strategieberichterstattung fest. Als wesentliche Ursache hierfür wird die vermeintliche Wettbewerbsschädlichkeit der Preisgabe derartiger Informationen ermittelt. ${ }^{620}$

Diese Übersicht über ausgewählte empirische Studien zur Lageberichterstattung führt zu Erkenntnissen, die für die eigene Untersuchung von Relevanz sind: Gezeigt wurde, dass Umfang und Qualität der Berichterstattung als mess- sowie bewertbar gelten können, sowohl ganzheitlich in Bezug auf verschiedene Berichtsinstrumente - und somit auch die Lageberichte -, zudem spezifisch in Bezug auf einzelne inhaltliche Aspekte der (Lage-) Berichterstattung. Dazu werden oftmals normative Kriterienkataloge abgeprüft und weiterführend auch Scoring-Modelle verwendet, um das Niveau der Berichterstattung quantitativ zu erfassen.

Außerdem ist festzuhalten, dass zwar vereinzelt - insb. in der Value ReportingLiteratur - strategieorientierte Berichtsinhalte berücksichtigt werden, in keinem bekannten Fall jedoch die explizite Konzentration auf Strategieberichterstattung im Lagebericht vorgenommen wird. Hingegen sind die zitierten Untersuchungen in der Analyse der Berichterstattung eher umfassend ausgestaltet, was gelegent-

619) Vgl. im Detail Günther et al. (2003). Die Autoren bestätigen allerdings den Lagebericht als effektivstes Kommunikationsinstrument der Rechnungslegung. Zu kritisieren ist an dem Beitrag die unscharfe Abgrenzung des Terminus ,strategierelevante Information'. Ein weiterer Beitrag zur Analyse spezifischer inhaltlicher Aspekte in der Lageberichterstattung sei ebenfalls erwähnt: So legen Baetge/Hippel (2009) eine Arbeit zur Berichterstattung über Indikatoren der nachhaltigen Entwicklung vor. Gemessen wird der Gehalt an ,Sustainable Development Key Performance Indicators“ (SD-KPIs) im Lagebericht.

620) Vgl. Günther et al. (2003). Diese Konzentration auf die sog. ,New Economy ‘ begründen die Autoren damit, dass hier eine besondere Relevanz immaterieller Werte bestünde und insofern eine Erweiterung der Berichterstattung geboten scheint. 
lich zu Undifferenziertheit führt. Allerdings enthalten einzelne Studien Anhaltspunkte bzgl. der Bestimmungsfaktoren der Berichterstattung, ${ }^{621}$ also des zweiten Bausteins des groben Untersuchungsmodells, der im Folgenden behandelt wird. Ein letzter Aspekt der Kritik betrifft die zeitliche Orientierung einzelner vorgestellter Untersuchungen: Betrachtungszeiträume von zwei bis drei Jahren wirken zu kurz, um nachhaltige Veränderungen des Berichtsverhaltens abzubilden.

\subsubsection{Arbeiten zu den Bestimmungsfaktoren der Berichterstattung}

In den dargestellten Arbeiten zur Analyse der (Lage-) Berichterstattung sind bereits vereinzelte Aspekte angedeutet worden, die Einfluss auf das Berichtsniveau zu haben scheinen. Vorab ist bei einer Beschäftigung mit jener Fragestellung jedoch zu vermerken, dass eine Identifikation von Determinanten des Berichtsverhaltens grds. nicht als eine Erklärung des Berichtsverhaltens zu verstehen ist, da eine Theorie der Berichterstattung nicht existiert. ${ }^{622}$ Vielmehr werden mit derlei Analysen plausible Hypothesen auf ihre empirische Evidenz hin untersucht. ${ }^{623}$

Zahlreiche Studien haben sich bereits sehr umfassend damit auseinandergesetzt, Einflussfaktoren des Publizitätsverhaltens in den diversen Berichtsinstrumenten der externen Rechnungslegung zu ermitteln. ${ }^{624} \mathrm{Zu}$ nennen sind für die deutsche Berichterstattungspraxis bspw. eine Untersuchung von Berndsen $(1978)^{625}$ sowie später Häger (1993) $)^{626}$, Krumbholz (1994) ${ }^{627}$, Armeloh (1998) ${ }^{628}$ bzw. Rolvering

621 Zusammengefasst sind dies v.a. die Größe, die Indexzugehörigkeit und die Profitabilität.

Vgl. Rolvering (2002), S. 15: „Ohne eine theoretische Fundierung [...] wäre [...] nicht zu entscheiden, ob ein vermuteter Zusammenhang zwischen der Berichterstattungsqualität [...] und einem bestimmten Einflussfaktor zufällig ist oder ob der Zusammenhang nicht auf einen dritten, gemeinsamen Faktor zurückzuführen ist. Auf dem Gebiet der Unternehmensberichterstattung existiert indes keine Theorie in Form von begründbaren Vorstellungen, die Ursache-Wirkungs-Zusammenhänge [...] erläutert.“

Vgl. auch Heumann (2005), S. 148f. Zu den Grenzen der Prüfung von Hypothesen bzgl. verschiedener Einflussfaktoren grdl. Popper (1969), S. 20; Diekmann (2004), S. 52ff. Eine Übersicht bieten bspw. Ahmed/Courtis (1999); Wagenhofer/Ewert (2007), S. 403. Vgl. Berndsen (1978), S. 130, als Überblick über diverse Studien Wysocki (1976).

Vgl. Häger (1993), 133, zu mittelgroßen Kapitalgesellschaften. Darüber hinaus sei auch Holdhof (1988), S. 118ff. erwähnt, der auf mittelständische Unternehmen abstellt. 
$(2002)^{629}$. Jüngere Arbeiten stellen meist auf Berichtsinhalte ab, die primär freiwillig im Rahmen eines Value Reportings veröffentlicht werden, um sodann entsprechende Bestimmungsfaktoren abzuleiten: Zu nennen sind hier bspw. Fischer $(2003)^{630}$, Heumann (2005) $)^{631}$ und Wenzel (2005) ${ }^{632}$ mit umfassenden Arbeiten.

Relevante Beiträge liefert darüber hinaus die Voluntary Disclosure-Literatur, die überwiegend im angelsächsischen Raum geprägt wird: Sie befasst sich im Kern mit der Frage, welche Informationen über den jeweils verpflichtenden Umfang der Rechnungslegungsvorschriften hinaus freiwillig bereitgestellt werden bzw. weiterführend - welche Faktoren maßgeblich für deren Veröffentlichung sind. ${ }^{633}$ Diverse Arbeiten nähern sich dieser Frage zunächst modelltheoretisch, in dieser Tradition stehen z.B. Bagnoli/Watts (2007). ${ }^{634}$ Unter Rückgriff auf Grundlagen von Verrecchia wird zudem die Ableitung optimaler Veröffentlichungsstrategien für Manager angestrebt. ${ }^{635}$ Wesentliche Determinanten dieser Modelle sind i.d.R. die Güte von potenziell freiwillig zu veröffentlichenden Informationen im Vergleich zu bereits öffentlich verfügbaren Angaben, die gesamten Kosten der Veröffentlichung sowie allg. der Umfang der verpflichtenden Berichterstattung. ${ }^{636}$

Darüber hinaus untersuchen zahlreiche vorgelegte empirische Arbeiten konkret beobachtbare Bestimmungsfaktoren des Berichtsverhaltens: Während sich bspw. Cheng/Courtenay (2006) ${ }^{637}$ auf Aspekte der Managementstruktur konzentrieren,

\footnotetext{
629 Vgl. ausführlich Rolvering (2002), S. 178ff., die auf Zwischenberichte fokussiert.

630) Vgl. Fischer (2003), S. 210ff. Der Autor ermittelt Bestimmungsfaktoren wertorientierter Berichtsinhalte, beschränkt sich dabei jedoch auf Unternehmen der Pharmabranche.

631 Vgl. Heumann (2005), S. 148. Der Autor prüft drei Hypothesen bzgl. der Bestimmungsfaktoren eines Value Reportings: Unternehmensgröße, Branche, Indexzugehörigkeit.

632 Vgl. für eine Auflistung Wenzel (2005), S. 439f. sowie Fischer/Wenzel (2005), S. 86f.

63. Anzumerken ist, dass es sich hier gleichfalls um sämtliche über die verpflichtenden Inhalte hinausgehenden Informationen handelt, nicht nur strategieorientierte Angaben.

634 Vgl. stellvertretend für viele Bagnoli/Watts (2007).

63.5 Vgl. grdl. Verrecchia (1983), ders. (1990) sowie für einen umfassenden Überblick über relevante Grundlagen-Veröffentlichungen ebenfalls Verrecchia (2001).

636 Wesentliche Arbeiten liegen weiterhin von Einhorn (2005), ders. (2007); Korn/Schiller (2003); Dye (1985), ders. (1998); Feltham/Xie (1992) sowie Wagenhofer (1990b) vor. Der Kostenbegriff umfasst sowohl die direkten als auch die indirekten Kosten der Veröffentlichung. Modellhaft zu Strategieinhalten vgl. auch Ferreira/Rezende (2007). 
stellen Chen et al. (2008) ${ }^{638}$ und andere auf Eigentumsverhältnisse ab. In Bezug auf Branchenaspekte sei z.B. Jones (2007) ${ }^{639}$ genannt. Erwähnenswert sind auch Arbeiten, die sich mit verschiedenen Aspekten einer Börsennotierung befassen: Während bspw. Firth (1979) ${ }^{640}$ und Meek/Gray (1989) ${ }^{641}$ der Frage nachgehen, inwieweit die Notierung an bestimmten Börsenplätzen das Berichtsverhalten determiniert, untersuchen Lang/Lundholm (2000) $)^{642}$ das Berichtsverhalten im Kontext von Kapitalerhöhungen. Brockman et al. $(2008)^{643}$ fokussieren hingegen das Berichtsverhalten in Verbindung mit Aktienrückkäufen, Cheng/Lo (2006) sowie andere stellen auf Aktientransaktionen von Unternehmensangehörigen ${ }^{644}$ ab.

Neben diesen überblicksartig genannten Arbeiten zu spezifischen Bestimmungsfaktoren liegen auch Untersuchungen zu einzelnen Ländern vor, stellvertretend sind hier zu nennen: Chow/Wong-Boren (1987) ${ }^{645}$ im Hinblick auf mexikanische Unternehmen, Cooke (1989) ${ }^{646}$ in Bezug auf Schweden, außerdem Mak (1991), Hossain et al. (1995) mit Fokus auf neuseeländische Unternehmen. ${ }^{647}$ Weiterhin Raffournier (1995) und Hail (2003) ${ }^{648}$ zum Schweizer Kapitalmarkt, Meek et al. $(1995)^{649}$ für eine US-amerikanische Perspektive sowie Kent/Ung $(2003)^{650} \mathrm{mit}$

638 Vgl. Chen et al. (2008), die auf Familiengesellschaften abstellen. Zu Eigentumsverhältnissen auch Ferguson et al. (2002) sowie Lakhal (2007), hier mit Fokus auf Frankreich.

639 Vgl. Jones (2002), die ,innovative Branchen“ fokussiert. Ähnlich Fischer et al. (2001a).

640 Vgl. Firth (1979). Dieser analysiert den Einfluss der Unternehmensgröße, des Status der Börsennotierung und des mandatierten Abschlussprüfers auf das Berichtsverhalten.

Vgl. Meek/Gray (1989) zu der Analyse des Einflusses einer Notierung an der Londoner Börse (LSE) auf das Berichtsverhalten kontinentaleuropäischer Unternehmen.

642 Vgl. Lang/Lundhom (2000) zum Thema Kapitalerhöhung, ähnlich Chong/Ho (2007).

643 Vgl. Brockman et al. (2008).

644 Vgl. Cheng/Lo (2006). Auch Bushman/Indjejikian (1995), Noe (1999) sowie Narayanan (2000). Zudem Aboody/Kasznik (2000) mit dem interessanten Aspekt des Berichtsverhaltens rund um Fälligkeitstermine von Aktienoptionsprogrammen des Managements.

Vgl. Chow/Wong-Boren (1987).

646 Vgl. Cooke (1989), der einen Einfluss von Unternehmensgröße und Branche feststellt.

647 Vgl. Mak (1991); Hossain et al. (1995). Früh bereits zu neuseeländischen Unternehmen McNally et al. (1982). Ähnlich Hossain et al. (1994) zu malayischen Unternehmen.

Vgl. Raffournier (1995), Hail (2003). Auch Bühner et al. (2003) zur (internetbasierten) Berichterstattung in der Schweiz; Wagenhofer (1990a), S. 220ff. ähnlich für Österreich.

Vgl. Meek et al. (1995), ähnlich Buzby (1975). Der Einfluss der Bestimmungsfaktoren Unternehmensgröße, Branche und Profitabilität wird in diesen Arbeiten stets bestätigt. 
Blick auf Australien. Zudem legen Agca/Oender (2007) ${ }^{651}$ jüngst eine Studie zur Türkei und Wang et al. (2008) $)^{652}$ zur Berichterstattung in China vor.

Wie gezeigt werden konnte, hat eine Analyse von Determinanten der Berichterstattung bereits breiten Raum in der Literatur eingenommen. Konsequenterweise sind dabei v.a. diejenigen Berichtsinhalte von besonderer Bedeutung, welche die Unternehmen freiwillig, in Ergänzung der kodifizierten Berichtsumfänge bereitstellen. Der konkrete Inhalt der spezifischen Berichtselemente, die freiwillig bereitgestellt werden, wird allerdings kaum differenziert, i.d.R. werden recht breite Definitionen von ,voluntary disclosures ' bzw. freiwilligen Angaben verwandt. ${ }^{653}$ Aggregiert man hingegen die in den einzelnen Arbeiten regelmäßig untersuchten Bestimmungsfaktoren, so ergibt sich eine umfangreiche Zusammenstellung von möglichen Determinanten des Berichtsverhaltens, die auch intuitiv nachvollziehbar erscheint: Untersucht werden insb. Größenaspekte der publizierenden Unternehmen, diverse quantitativ-finanzielle Parameter, wie z.B. die Profitabilität und die Verschuldung, bzw. qualitative Merkmale wie die Organisationsstruktur oder die Branchenzugehörigkeit. Auch werden Kennzahlen der Eigentumsstruktur sowie Charakteristika der Börsennotierung als Bestimmungsfaktoren geprüft.

Abschließend ist festzustellen, dass bereits in zahlreichen Studien Bestimmungsfaktoren des Berichtsverhaltens untersucht werden und daher wertvolle Anhaltspunkte für die eigene Untersuchung abgeleitet werden können. Bislang hat allerdings keine der vorgelegten Arbeiten eine Konzentration auf strategieorientierte Berichtsinhalte gewählt, um sodann entsprechende Determinanten zu erarbeiten. Weiterhin zeigen die zuvor vorgestellten Arbeiten nochmals nachdrücklich, dass eine Messung des Berichtsverhaltens offensichtlich möglich ist, da diese als notwendige Voraussetzung der Ermittlung von Bestimmungsfaktoren gelten kann.

651 Vgl. Agca/Oender (2007). Als Treiber des Berichtsverhaltens wird die Profitabilität und die Unternehmensgröße herausgearbeitet. Vgl. auch Patelli/Prencipe (2007) zu Italien.

652 Vgl. Wang et al. (2008). Die Autoren belegen den Einfluss der Profitabilität und weisen zudem auf die Rolle der Eigentümerstruktur hin: Im chinesischen Kontext scheinen sich v.a. Unternehmen in Staatsbesitz sowie Unternehmen, in denen ausländische Investoren signifikante Anteile besitzen, in ihrem Berichtsverhalten signifikant zu unterscheiden. richtskataloge normative Inhalte der Strategieberichterstattung abgeleitet werden. 


\subsubsection{Arbeiten zu den Kapitalmarktwirkungen der Berichterstattung}

Wie theoretisch hergeleitet wurde, dient - in verkürzter Darstellung - Berichterstattung in erster Linie der Reduktion von Informationsasymmetrien. Dies gilt in besonderer Weise für solche Informationselemente, die über den verpflichtenden Mindestumfang der Berichterstattung hinaus bereitgestellt werden. Wird weiterhin akzeptiert, dass Informationsasymmetrien maßgeblich zur Existenz von sog. Wertlücken beitragen, könnte freiwillige Berichterstattung in der Konsequenz zu Wertsteigerungen führen: „Schließlich können [...] Aktionäre nur dann von einer [...] höheren ökonomischen Bewertung des Eigenkapitals profitieren, wenn diese Wertsteigerungen [...] nach außen kommuniziert werden. ${ }^{\text {،654 }}$

Zur Untersuchung möglicher ökonomischer Auswirkungen einer erweiterten Berichterstattung liegen bereits diverse Arbeiten vor, die ebenfalls überwiegend der US-amerikanischen Voluntary Disclosure-Literatur zuzuordnen sind. ${ }^{655}$ Es sind verschiedene Untersuchungsrichtungen unterscheidbar, je nachdem welcher Indikator genutzt wird, um die Effekte der Berichterstattung zu analysieren:

Der Schwerpunkt der Betrachtung von Auswirkungen der Berichterstattung liegt zunächst auf dem Zusammenhang derselbigen mit den Eigenkapitalkosten eines Unternehmens, da diese als wesentlicher Hebel für Wertsteigerungen angesehen werden. ${ }^{656}$ Modelltheoretische Arbeiten liefern zwar erste Anhaltspunkte für die Annahme, dass zusätzliche Berichterstattung zu sinkenden Kapitalkosten führen könnte, eindeutig sind die Erkenntnisse indes nicht. ${ }^{657}$ Auch in empirischer Hin-

654 Fischer (2003), S. 16. Verwiesen sei auch auf die Ausführungen in Abschnitt B 4.

655 Deutschsprachige Arbeiten bzgl. der Kapitalmarkteffekte erweiterter Berichterstattung sind selten, daher wird hier nicht explizit auf diese eingegangen. Erwähnt werden sollen der Vollständigkeit halber lediglich die Untersuchungen von Wenzel (2005) sowie Barth (2009), wobei letztere im Rahmen einer Ereignisstudie auf abnormale Renditen abstellt.

656 Sinkende Eigenkapitalkosten führen cet. par. immer zur Steigerung des Unternehmenswertes. Vgl. zu den Bestandteilen der Kapitalkosten bspw. Hahn/Hungenberg (2001), S. 154ff.; Achleitner et al. (2001), S. 17f. Auch kann ein Einfluss der Berichterstattung auf die Fremdkapitalkosten unterstellt werden, so Lehner (2003), S. 214; Sengupta (1998).

Derlei Modelle fokussieren entweder auf das sog. ,estimation risk ' der Investoren oder betrachten die Kapitalmarktliquidität. Erstere nehmen an, dass das Risiko in Bezug auf künftige Renditen nicht diversifizierbar ist. Zunehmende Bereitstellung von Information führt so zur Verminderung der Renditeforderungen und damit der Kapitalkosten, vgl. bspw. Easley/O'Hara (2004). Die Grundlagen hierzu stammen von Barry/Brown (1985),

Tom Sieber - 978-3-631-75150-3 
sicht sind diverse Studien bekannt, die den Einfluss der Berichterstattung auf die Eigenkapitalkosten untersuchen: Beachtung hat insb. die bereits erwähnte Arbeit von Botosan (1997a) erhalten, welche die Berichterstattung in den Geschäftsberichten auf Basis eines eigens konstruierten ,Disclosure Index ' bewertet und sodann einen signifikant negativen Zusammenhang der jeweiligen Indexwerte mit den Eigenkapitalkosten feststellen kann. ${ }^{658}$ Weitere Studien dazu liegen u.a. von Brennan/Tamarowski (2000), Hail (2002), Gietzmann/Trombetta (2003) $)^{659}$ vor.

Stellvertretend für viele Arbeiten zu anderen kapitalmarktseitigen Wirkungen erweiterter Berichterstattung erscheinen die von Welker $(1995)^{660}$, Lang/Lundholm $(1996)^{661}$, Healy et al. (1999) ${ }^{662}$ oder Leuz/Verrecchia $(2000)^{663}$ erwähnenswert. Betrachtet man diese Arbeiten gesamthaft, so werden im Kern folgende kapitalmarktbezogenen Effekte freiwilliger Berichterstattung untersucht: das Handels-

Erweiterung sowie Bestätigung durch Coles/Loewenstein (1988); Coles et al. (1995). Es wird modelltheoretisch gezeigt, dass mehr Information die Kapitalkosten senkt. Kritisch ist die Annahme der Nicht-Diversifizierbarkeit zu sehen, vgl. Clarkson et al. (1996).

Ansätze der Kapitalmarktliquidität nehmen an, dass eine Zunahme an Informationen bestehende Informationsasymmetrien reduziert, die Liquidität des Kapitalmarktes erhöht bzw. cet. par. die Kapitalkosten sinken. Grdl. Arbeiten von Diamond/Verrecchia (1991) bzw. Baiman/Verrecchia (1996). Zu kritisieren ist die Annahme, dass mehr Information grds. zur Reduktion von Informationsasymmetrien führt. Barth et al. (1999) zeigen z.B., dass Informationsbeschaffungskosten ggf. gar zu höheren Kapitalkosten führen können. Einen Überblick zum Stand theoretischer Studien liefern Francis et al. (2008), S. 58f. Vgl. Botosan (1997a). Die Autorin setzt den Index in Beziehung zu Eigenkapitalkostensätzen, die indirekt in Anlehnung an Ohlson (1995) ermittelt werden, zur Anwendung vgl. u.a. Wagenhofer/Ewert (2007), S. 406. Kritisch ist an der Studie zu sehen, dass eine Beschränkung auf ein Jahr und eine Industrie erfolgt, vgl. u.a. Botosan/Plumlee (2002). Der Index basiert auf einem Scoringmodell, Messwerte werden als, Scores ' bezeichnet. Vgl. bspw. Brennan/Tamarowski (2000); Hail (2002); Gietzmann/Trombetta (2003). Vgl. Welker (1995). Der Autor fokussiert auf die Handelsliquidität betreffender Wertpapiere, ähnlich Peterson/Plenborg (2006) mit Fokus auf den dänischen Kapitalmarkt. Vgl. Lang/Lundholm (1996), welche auf die Anzahl an Analysten, die ein Unternehmen beobachten, abstellen bzw. auf die Eigenschaften der Gewinnprognosen von Analysten. Die ,Anzahl an Analysten“ als Effekt findet sich auch bei Brennan/Tamarowski (2000). Vgl. Healy et al. (1999). Diese analysieren die Auswirkungen der Berichterstattung auf das Interesse institutioneller Investoren, das Handelsvolumen und die Analystenanzahl. Vgl. Leuz/Verrecchia (2000). Die Autoren untersuchen den Bid-Ask-Spread von Aktien sowie die Liquidität und die Volatilität. Diese Größen verwenden sie als Proxies für die Eigenkapitalkosten. Interessant ist an der Studie, dass deutsche Unternehmen betrachtet werden, weil die damalige HGB-Rechnungslegung als geeignetes Umfeld für Zusatzinformationen gesehen wird - aufgrund des vermeintlich schwachen Informationsgehalts. 
volumen der Aktien eines Unternehmens, die Volatilität der Renditen sowie die Anzahl beobachtender Analysten und die Bid-Ask-Spreads. Regelmäßig werden diese Kennzahlen als Proxygrößen angesehen, um das Ausmaß der im Hinblick auf ein Unternehmen bestehenden Informationsasymmetrien abzubilden. ${ }^{664}$

Darüber hinaus setzt sich eine Reihe von Untersuchungen explizit mit der Frage einer Kapitalmarktrelevanz freiwilliger Informationen auseinander, indem direkt beobachtbare Börsendaten analysiert werden. Dabei werden üblicherweise zwei Sichtweisen unterschieden: eine kurzfristige Sichtweise der sog. Entscheidungsrelevanz sowie eine längerfristige der Bewertungsrelevanz. Die erste Sichtweise untersucht, ob spezifische Angaben das Entscheidungsverhalten von Investoren beeinflussen. ${ }^{655}$ Dazu wird im Kapitalmarktkontext i.d.R. das Kursverhalten in der kurzen Frist rund um einen Veröffentlichungszeitpunkt betrachtet. ${ }^{666}$ Wenngleich diese Untersuchungen als nicht unproblematisch anzusehen sind, befassen sich diverse Arbeiten zur Entscheidungsrelevanz mit Informationen strategischer Natur, die im Rahmen der externen Berichterstattung bereitgestellt werden: ${ }^{667}$ So ermitteln u.a. McConnell/Muscarella (1985) positive, abnormale Kursreaktionen auf eine Veröffentlichung von Investitionsplänen. ${ }^{668}$ Woolridge (1988) hingegen zeigt deutlich abnormale Kursreaktionen auf die Preisgabe von Informationen zu verschiedenen strategischen Themen, insb. bei Angaben zu Forschung und Ent-

So Leuz/Verrecchia (2000), S. 93: „We focus on proxies for the information asymmetry component: namely, the bid-ask spread, trading volume, and share price volatility.“ Vgl. für einen Überblick bspw. Coenenberg et al. (1978), S. 498f.

666 Es zeigt sich folglich, dass grds. Experimente (Ereignisstudien) notwendig sind, um eine Entscheidungsrelevanz zu ermitteln, wobei stets das Problem der Bestimmung des Veröffentlichungszeitraumes gegeben ist, vgl. Coenenberg/Moeller (1979), S. 439f., zudem May (1991), S. 313f. Eine recht aktuelle Untersuchung zum dt. Kapitalmarkt legt Barth (2009), S. 195ff. vor, welche die Entscheidungsrelevanz einer Prognoseberichterstattung untersucht und die unterstellten Kapitalmarktreaktionen (positive abnormale Rendite bei Erhöhung der Ergebnisprognose et vice versa) signifikant bestätigen kann.

667 Kritik am Konstrukt der Entscheidungsrelevanz stellt im Kern auf die Prämisse der Informationseffizienz ab, vgl. z.B. Coenenberg (1974), S. 648ff. Es ist bei derartigen Analysen mit bereinigten Renditen zu arbeiten, um andere, nicht durch Informationen verursachte Einflüsse auf die Renditen zu eliminieren bzw. die unsystematische Komponente der Rendite einer Aktie zu isolieren, vgl. hierzu Coenenberg (2005), S. 1224ff. Zu den Verfahren der Bereinigung von Renditen grdl. Sharpe (1963) bzw. ders. (1964). Vgl. McConnell/Muscarella (1985). Zudem zeigen die Autoren, dass eine Bekanntgabe der Reduktion von Investitionsplänen zu signifikant negativen Renditen führt. 
wicklung sowie zu zukünftigen Produktstrategien. ${ }^{669}$ Chan et al. (1990) gelingt der Nachweis spezifisch für die Hightech-Industrie: Gezeigt werden signifikant positive Kursreaktionen auf die Bekanntgabe von Entwicklungsprojekten. ${ }^{670}$

In der längerfristigen Perspektive wird sodann auf eine Bewertungsrelevanz von ,strategischen“ Informationen abgestellt, dazu werden i.d.R. Regressionsmodelle auf Basis von Aufwendungen für Forschung und Entwicklung und der Marktbewertung konstruiert. ${ }^{671}$ Solche Arbeiten haben u.a. Hirschey/Weygandt $(1985)^{672}$, Pakes $(1985)^{673}$, Shevlin $(1991)^{674}$, Jose et al. $(1986)^{675}$, Sougiannis $(1994)^{676}$ sowie Lev/Sougiannis (1996) $)^{677}$ bzw. Aboody/Lev (1998) $)^{678}$ vorgelegt. Wenngleich jene Studien aufgrund zu einseitiger Fokussierung auf Forschungsaufwendungen nicht geeignet scheinen, umfassende Schlussfolgerungen bzgl. der Relevanz von strategieorientierten Informationen für den Kapitalmarkt herzuleiten, können sie doch als erste Hinweise auf die Bedeutung derartiger Informationen gelten.

Zu erwähnen sind weiterhin empirische Arbeiten, die sich mit der Kapitalmarktrelevanz von Gewinnprognosen des Managements beschäftigen. Dies entspricht der grds. Annahme dieser Arbeit, dass zukunftsorientierte Informationen bei der Schätzung künftiger Erfolgsgrößen eine informationelle Unterstützungsleistung

669) Vgl. Woolridge (1988). Abgestellt wird auf Angaben zu Joint Ventures, Investitionen, Produktpolitik und Forschungsprojekten. Stets zeigen sich signifikant positive Renditen.

670) Vgl. Chan et al. (1990).

671 Vgl. Möller/Hüfner (2002), S. 415; Coenenberg (2005), S. 1232; Günther (1997), S. 31. Grdl. Ohlson (1995), auch Chwallek (1999), S. 139; Streim (2000), S. 122f.

672 Vgl. Hirschey/Weygandt (1985), die auf Werbe- und Entwicklungskosten abstellen.

673 Vgl. Pakes (1985), der sich auf Veröffentlichungen zu Patenten konzentriert.

674 Vgl. Shevlin (1991). Unter Verwendung eines komplexen Konstrukts belegt der Autor, dass Entwicklungsaufwendungen von den Investoren kapitalisiert werden.

$675 \mathrm{Vgl}$. Jose et al. (1986), die Brancheninterdependenzen betrachten: Innovationen zeigen dann negativen Einfluss, wenn der Aufwand über dem Benchmark der Branche liegt.

676 Vgl. Sougiannis (1994). Der Autor analysiert den Einfluss der FuE auf Gewinne und die Marktbewertung mittels Regressionen. Gezeigt wird so, dass Entwicklungsaufwand von USD 1 zu einem Gewinnanstieg von USD 2 über 7 Jahre führt, der Marktwert aber um USD 5 steigt. Der Bewertungseffekt wird aber i.W. durch den Gewinnanstieg getrieben.

677 Vgl. Lev/Sougiannis (1996). Geschätzt wird der auf FuE zurückgehende Anteil am Vermögen und Erfolg, um sodann eine Regression mit dem Marktwert durchzuführen. Ergebnis: ein signifikanter Zusammenhang von Marktwert und ,innovativem Vermögen'. 
erbringen könnten. Sofern daher - naturgemäß zukunftsorientierte - Gewinnprognosen des Managements für den Kapitalmarkt relevant sind, wäre dies grds. auf vom Management veröffentlichte Strategieinformationen übertragbar. Zum Einfluss von Gewinnprognosen auf die Preisbildung sei hier als Überblick nur festgehalten: „The existence of a market reaction to earnings forecasts has thus been established.“679 $\mathrm{Zu}$ diesem Komplex liegen erwähnenswerte Analysen insb. von Foster $(1973)^{680}$, Patell $(1976)^{681}$, Jaggi $(1978)^{682}$, Penman $(1980)^{683}$, Waymire $(1984)^{684}$, Ajinkya/Gift (1984) $)^{685}$ sowie Lev/Penman $(1990)^{686}$ vor.

Abschließend ist zu konstatieren, dass die Frage nach Kapitalmarkteffekten erweiterter Berichterstattung in der Literatur aus verschiedenartigen Blickwinkeln Beachtung gefunden hat. Obgleich eine spezifische Untersuchung zu möglichen Auswirkungen strategieorientierter Berichtselemente bis dato nicht vorliegt, sind zumindest erste Anhaltspunkte zur Untermauerung der Position vorhanden, dass zukunftsorientierte Information für den Kapitalmarkt Relevanz besitzt und jener schließlich - sei es in Form kurzfristiger abnormaler Renditen, langfristiger Bewertungsveränderungen oder auch in Form von Stellvertretergrößen - eine überlegene Berichterstattung erkennen kann bzw. reflektiert. Zudem hat die Sichtung der Literatur zu den Kapitalmarkteffekten einer freiwilligen Berichterstattung erneut Hinweise darauf geliefert, dass eine Messung des Berichtsverhaltens durchführbar ist und eine solche verwertbare Daten hervorbringt, die für weitere Analysen verwendet werden können. Schließlich kann für den weiteren Verlauf davon ausgegangen werden, dass eine Messung des Berichtsverhaltens bzw. insb. des Berichtsverhaltens zu strategieorientierten Inhalten möglich sein dürfte.

\footnotetext{
679 Lev/Ohlson (1982), S. 264.

680 Vgl. Foster (1973), der aufzeigen kann, dass Gewinnprognosen des Managements in der Presse signifikanten Einfluss auf (im Marktmodell bereinigte) Aktienrenditen haben.

681 Vgl. Patell (1976) mit einem ähnlichen Untersuchungsdesign wie Foster (1973).

682 Vgl. Jaggi (1978), vergleichbar zu Foster (1973), eine Bereinigung der Renditen erfolgt jedoch mit einer alternativen Methode. Ein signifikanter Zusammenhang wird ermittelt.

683 Vgl. Penman (1980), ebenfalls unter Rückgriff auf die Pionierarbeit von Foster (1973).

684 Vgl. Waymire (1984) mit spezifischem Fokus auf die Effekte, schlechter ' Nachrichten.

685 Vgl. Ajinkya/Gift (1984), die untersuchen, welchen Einfluss Unterschiedlichkeiten von Managementprognosen und Analystenprognosen auf die Aktienrenditen haben.

686 Vgl. Lev/Penman (1990), die aufzeigen, dass Unternehmen ohne Gewinnprognosen im Vergleich zu Unternehmen mit Gewinnprognosen nicht zwingend , bestraft ' werden. 


\subsection{Erklärungsanspruch der eigenen Untersuchung}

Bei dem vorausgegangenen Überblick über die drei relevanten Literaturbereiche ist in erster Linie deutlich geworden, dass bis dato keine explizite Untersuchung der Berichterstattung über strategieorientierte Informationen vorgestellt wurde.

Weder die Literatur bzgl. der Lageberichterstattung noch die Value ReportingLiteratur haben den genannten Sachverhalt bisher spezifisch adressiert, auch die Voluntary Disclosure-Literatur bleibt in Bezug auf die jeweils berücksichtigten inhaltlichen Aspekte erweiterter Berichterstattung weitgehend unfokussiert. Dies scheint vor dem Hintergrund der in der vorliegenden Arbeit angenommenen Bedeutung der Unternehmensstrategie - als Informationselement für den Kapitalmarkt sowie für die langfristige Unternehmensentwicklung - bemerkenswert.

An diesem Punkt setzt die eigene empirische Untersuchung an, ihr zentrales Anliegen ist eine explizite sowie umfassende Analyse der Strategieberichterstattung kapitalmarktorientierter Unternehmen in Deutschland. Diese inkludiert zunächst eine Ermittlung von Status sowie zeitlicher Entwicklung spezifischer Berichtsinhalte. Zudem erscheint eine Schwerpunktsetzung auf kausale Determinanten und Auswirkungen der Berichterstattung erforderlich, da die deutschsprachige Lageberichts- und Value Reporting-Literatur in jener Perspektive als unzureichend zu charakterisieren ist. Insofern verfolgt die eigene Untersuchung im Kern den Anspruch, die Methodik der Voluntary Disclosure-Literatur, also die simultane Berücksichtigung von Bestimmungsfaktoren und Kapitalmarkteffekten freiwilliger Berichterstattung, auf den deutschen Kapitalmarkt zu übertragen - dies anhand des spezifisch ausgewählten inhaltlichen Aspekts der Strategieinformationen.

Darüber hinaus soll diese Arbeit im Vergleich zu den üblicherweise betrachteten Zeiträumen den Mehrwert bieten, dass ein siebenjähriger Beobachtungszeitraum gewählt wird, da so langfristige Tendenzen in der Berichterstattungspraxis abgebildet werden können. ${ }^{687}$ Den Erklärungsanspruch der eigenen Untersuchung im Vergleich zu bisherigen Arbeiten stellt Abb. 11 schließlich graphisch dar.

687 Vgl. den passenden Kommentar von Hail (2002), S. 766: „Useful insights can also be expected from studying the change in disclosure level over time and its implications." Auch wurde in Teil B die Relevanz der Nachhaltigkeit von Strategieberichten vermerkt. 


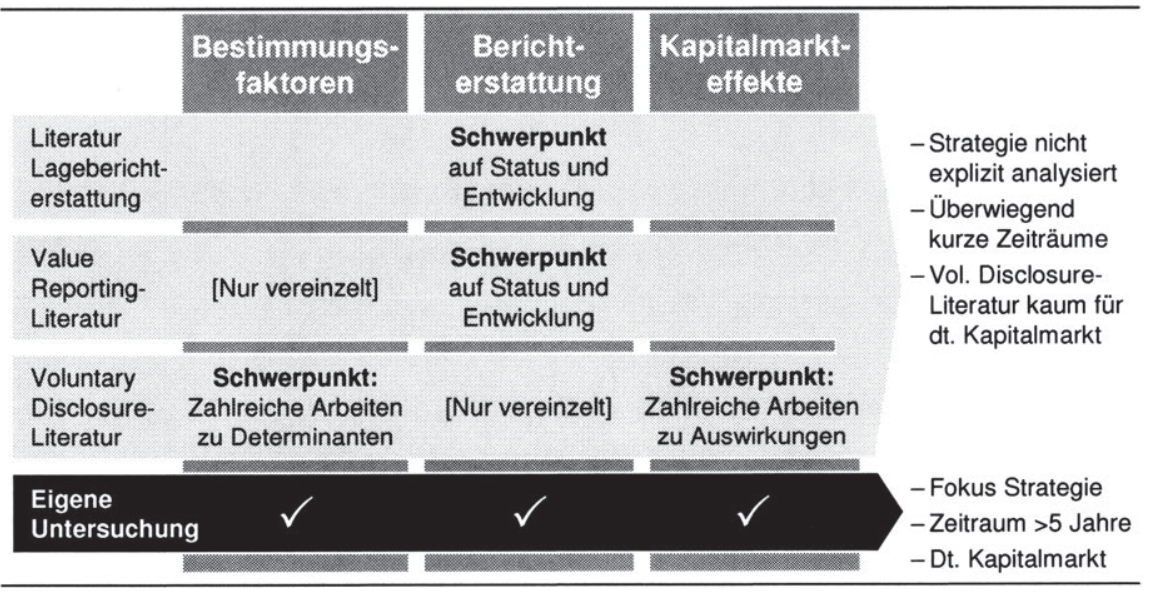

Abbildung 11: Erklärungsanspruch der Untersuchung ${ }^{688}$

Nachdem der Erklärungsanspruch der eigenen empirischen Untersuchung abgeleitet wurde, resultieren ihre wesentlichen Alleinstellungsmerkmale spiegelbildlich aus den zuvor diskutierten Defiziten der bisherigen Forschungsarbeiten. Die Alleinstellungsmerkmale lassen sich wie folgt zusammenfassen:

(1) Die eigene Untersuchung fokussiert explizit auf strategieorientierte Angaben als Spezialaspekt der externen Berichterstattung. Dies wurde begründet mit der Bedeutung der Strategie für die künftige Unternehmensentwicklung.

(2) Außerdem erfolgt eine konsequente Konzentration auf den deutschen Lagebericht nach HGB, dessen prinzipielle Eignung als Medium der Strategieberichterstattung zuvor theoretisch dargestellt wurde. ${ }^{689}$

(3) Diese Untersuchung stellt ein gesamthaftes Modell dar, mit dem das Niveau der Strategieberichterstattung, seine Bestimmungsfaktoren bzw. kapitalmarktbezogenen Auswirkungen simultan - über sieben Perioden - untersucht werden.

Ausgehend von dem genannten, im Kontext bisheriger Forschung hergeleiteten Erklärungsanspruch ist nachfolgend ein adäquates Studiendesign zu konzipieren.

688 Quelle: eigene Darstellung.

689 In Kontrast zu den in C 2.3.1 erwähnten Studien verfolgt die eigene Untersuchung also eine ,horizontale' Perspektive der Analyse: Der Lagebericht wird gesamthaft betrachtet, nicht ,vertikal', mit Fokus auf einen Teil-Bericht. Dies veranschaulicht Abb. 9 (S. 134). 


\section{$3 \quad$ Konzeption der Untersuchung}

Unter Berücksichtigung des zentralen Untersuchungsinteresses an der Strategieberichterstattung deutscher börsennotierter Unternehmen und aufbauend auf den zuvor dargestellten bisherigen wissenschaftlichen Arbeiten zu Determinanten sowie Effekten einer erweiterten Berichtserstattung ist die eigene Untersuchung im Folgenden inhaltlich auszugestalten. Dabei sind zunächst Forschungshypothesen abzuleiten (3.1), die Datenbasis (3.2) zu definieren und die Variablen der Untersuchung zu operationalisieren (3.3), um mit einer Selektion der anzuwendenden Forschungsmethodik (3.4) die technischen Voraussetzungen zu komplettieren.

\subsection{Formulierung der Hypothesen der Untersuchung}

Entsprechend dem in Abb. 10 aufgezeigten groben Modell dieser Untersuchung sind - zur Berücksichtigung aller elementaren Bausteine - drei Kategorien von Hypothesen zu unterscheiden: zum Niveau der Strategieberichterstattung per se (3.1.1), zum Teilmodell der Bestimmungsfaktoren der Strategieberichterstattung (3.1.2) sowie zum Teilmodell der Kapitalmarkteffekte (3.1.3). Basierend auf Erkenntnissen aus der Betrachtung der relevanten Literaturbeiträge sind diese Teilmodelle allerdings zunächst weiter zu untergliedern, um eine Formulierung von Hypothesen der Untersuchung übersichtlicher zu gestalten. ${ }^{690}$ Den Aufbau jenes detaillierten Untersuchungsmodells präsentiert die nachfolgende Abb. 12.

\begin{tabular}{c|c|c|}
\hline Bestimmungsfaktoren & Kapitalmarkteffekte \\
\hline $\begin{array}{c}\text { Unternehmenscharakteristika } \\
\text { (Nicht-finanzielle Faktoren) }\end{array}$ & $\begin{array}{c}\text { Niveau der } \\
\text { Strategie- } \\
\text { bericht- } \\
\text { erstattung }\end{array}$ & Transparenzeffekte \\
\hline Finanzielle Faktoren & Handelseffekte \\
\hline Aktienkapital-Faktoren & Bewertungseffekte \\
\hline
\end{tabular}

Abbildung 12: Detailliertes Modell der Untersuchung ${ }^{691}$

690) Vgl. die Erkenntnisse in C 2.3, bspw. zu möglichen Bestimmungsfaktoren auf S. 151 .

${ }^{691}$ Quelle: eigene Darstellung. Detaillierung des Grobmodells, das Abb. 10 (S. 142) zeigt.

Tom Sieber - 978-3-631-75150-3 


\subsubsection{Niveau der Strategieberichterstattung}

(a) Unterschiedlichkeit des Niveaus der Strategieberichterstattung

Wie gezeigt wurde, ist bereits in zahlreichen empirischen Studien eine Messung von Berichtsinhalten realisiert worden. Diese Messbarkeit muss als notwendige Bedingung gelten, wenn eine Untersuchung von Zusammenhängen zwischen der Berichterstattung und ihren Bestimmungsfaktoren respektive Auswirkungen angestrebt wird. Im Rahmen einer expliziten Untersuchung der Strategieberichterstattung deutscher Unternehmen gilt diese Bedingung sodann entsprechend.

Die Mehrzahl der Arbeiten setzt sich dabei mit der Berichterstattung als Ganzes auseinander, exemplarisch sind Arbeiten von Leuz/Verrecchia (2000) oder Gray et al. (1995) zu nennen. ${ }^{692}$ Auch das Niveau der Lageberichterstattung wurde bereits gemessen, beispielhaft sei eine Arbeit von Kajüter/Winkler (2003) erwähnt, die sich mit einem speziellen Bestandteil der Lageberichterstattung auseinandersetzt, dem Risikobericht ${ }^{693}$ Stets konnte in derartigen Untersuchungen auch eine deutliche Unterschiedlichkeit der unternehmensindividuellen Berichterstattungsniveaus gezeigt werden ${ }^{694}$ Eine ausreichende Varianz ermittelter Messwerte ist für die Durchführung einer empirischen Analyse von Bedeutung: „critical to the power of $[\ldots]$ empirical analysis (is a) sufficient cross-sectional variation in disclosure levels. “695 Diese Unterschiedlichkeit kann folglich als hinreichende Bedingung einer Analyse des Berichtsverhaltens angesehen werden. Um dies explizit abzubilden, wird Hypothese H 1.1 formuliert. Diese lautet dementsprechend:

\section{H 1.1: Unternehmen wählen ein individuelles Niveau der Strategiebericht- erstattung im Lagebericht, das Niveau der Strategieberichterstattung ist nicht für alle Unternehmen identisch.}

692 Vgl. Leuz/Verrecchia (2000), die sich mit der Berichterstattung börsennotierter Aktiengesellschaften in Deutschland auseinandersetzen sowie auch Gray et al. (1995), die als eine der Ersten das Niveau der freiwilligen Berichterstattung durch Messung erfassen. Vgl. Kajüter/Winkler (2003), die in ,vertikaler' Perspektive die Risikoberichterstattung im Zeitablauf messen, auch Barth (2009) in Bezug auf die Prognoseberichterstattung.

694 Vgl. zur Heterogenität in der Berichterstattung bspw. Fischer/Vielmeyer (2004), S. 473; Ruhwedel et al. (2009), S. 1308; S. 1312 oder auch Knauer/Wömpener (2010), S. 88.

695 Botosan (1997a), S. 326. Als weiteren kritischen Faktor empirischer Arbeiten nennt die Autorin eine ausreichend große Untersuchungsstichprobe. 


\section{(b) Zeitliche Entwicklung des Niveaus der Strategieberichterstattung}

Ergänzend zur Messung des Niveaus der Strategieberichterstattung für einen beliebigen Zeitpunkt scheint außerdem die Betrachtung der zeitlichen Entwicklung der Messwerte von Interesse. Dies folgt der grds. Annahme, dass Veränderungen einzelner Parametern in der Umwelt sowie innerhalb des Unternehmens selbst in der Konsequenz zu einer Veränderung des Berichtsverhaltens führen könnten.

Weiterhin ist darauf hinzuweisen, dass das Berichtsverhalten nicht rein reaktiver Natur ist, sondern Unternehmen Informationen bewusst einsetzen, um temporär die Erreichung konkreter Ziele zu unterstützen - dies belegen auch die Resultate der Untersuchung von Lang/Lundholm (2000), die zeigen, dass Unternehmen im Vorfeld von Kapitalerhöhungen ihre Berichterstattung z.T. stark ausweiten. ${ }^{696}$.

Eine Reihe von Arbeiten untersucht daher sowohl die Lageberichterstattung wie auch die freiwillige Berichterstattung in mehrjähriger Perspektive - wenngleich Einhorn/Ziv (2008) kritisieren, dass oft eine Beschränkung auf wenige Perioden erfolgt oder nur einperiodige Analysen erstellt werden. ${ }^{697}$ Dieses Defizit soll hier überwunden und die Strategieberichterstattung im Zeitablauf erhoben werden. ${ }^{698}$ Den Ergebnissen relevanter Arbeiten folgend ist von zeitlicher Dynamik auszugehen, ein steigendes Niveau wird unterstellt. ${ }^{699}$ Hypothese $\mathrm{H} 1.2$ lautet daher:

H 1.2: Das durchschnittliche Niveau der Strategieberichterstattung unterscheidet sich in Abhängigkeit von der Zeit, über die Zeit hinweg kann ein Anstieg des durchschnittlichen Niveaus festgestellt werden.

696 Vgl. Lang/Lundholm (2000), S. 623. Die Autoren untersuchen die sechsmonatige Vorlaufphase von Kapitalerhöhungen und stellen eine deutliche Ausweitung der Berichterstattung fest. Sie bezeichnen dies als ,hyping the stock“. Der Effekt ist aber nicht nachhaltig: Sobald das Berichtsniveau wieder sinkt, erfolgt eine Korrektur. Ob Manager aber bewusst ein Niveau der Strategieberichterstattung wählen, scheint diskussionswürdig. Vgl. Einhorn/Ziv (2008), S. 567. Beispielhaft für solche Arbeiten, die jeweils Zeitraumbetrachtungen vornehmen, seien Wenzel (2005) sowie Schultze (2005) für die dt. Value Reporting-Forschung genannt und Fischer/Vielmeyer (2004) zur Lageberichterstattung. Dies entspricht der modelltheoretischen Erkenntnis von Stocken (2000), S. 371f. Dieser weist darauf hin, dass mehrperiodige Betrachtungen erforderlich sind, da zur Wirkung freiwilliger Veröffentlichungen erst Glaubwürdigkeit aufgebaut werden muss. Vgl. auch die Ausführungen in B 4.2.3 sowie bspw. die Forderung bei Heumann (2006), S. 264f. 


\subsubsection{Bestimmungsfaktoren der Strategieberichterstattung}

Es wurde eingangs die Behauptung aufgestellt, dass sich systematische Faktoren sowohl im Umfeld eines Unternehmens als auch innerhalb desselbigen ermitteln lassen, die das jeweilige Niveau der Strategieberichterstattung determinieren. In Summe sind vier Kategorien von Bestimmungsfaktoren voneinander zu trennen, entsprechende Hypothesen für die Untersuchung werden nachfolgend abgeleitet.

\section{(a) Externe Einflüsse als Bestimmungsfaktoren}

Unternehmen sind in vielfacher Hinsicht mit ihrer Umwelt verknüpft, Parameter der Umwelt könnten daher in vielfältiger Weise Einfluss auf das Unternehmensgeschehen ausüben: Unternehmen werden folglich, sobald sie Transparenz über relevante Ereignisse erhalten, Maßnahmen zur Reaktion ergreifen. ${ }^{700}$ Sofern also Verhaltensreaktionen seitens der Unternehmen, ausgelöst durch Veränderungen von Umweltbedingungen, grds. akzeptiert sind, ist es gleichfalls plausibel anzunehmen, dass auch das Berichtsverhalten als eine Dimension unternehmerischen Verhaltens bzw. als möglicher Aktionsparameter Veränderung erfahren wird.

Eine wesentliche Umweltbedingung, die i.d.R. unmittelbaren Einfluss auf Unternehmen hat, ist die konjunkturelle Lage. $\mathrm{Zu}$ unterstellen ist, dass konjunkturelle Bedingungen zugleich Einfluss auf das Berichtsverhalten und damit das Niveau der Strategieberichterstattung besitzen. Hypothese H 2.1 lautet daher:

H 2.1: Die konjunkturellen Bedingungen besitzen einen Einfluss auf das Niveau der Strategieberichterstattung. Positive konjunkturelle Bedingungen führen zu einem Anstieg des Berichterstattungsniveaus.

Einen Anhaltspunkt hierzu lieferten kürzlich Ruhwedel et al. (2009), die in ihrer Untersuchung auf die Prognoseberichterstattung deutscher Aktiengesellschaften abstellen ${ }^{701}$ und beim Vergleich der Jahre 2006 bis 2008 einen Einfluss der konjunkturellen Bedingungen feststellen. Zu berücksichtigen ist bei der Prüfung der

700 Dies ist schließlich Ausgangspunkt der externen Analyse im Rahmen des Strategieprozesses, vgl. nochmals Abschnitt B 2.2.3 sowie grdl. Hahn/Hungenberg (2001), S. 319ff.

701 Vgl. Ruhwedel et al. (2009), S. 1308. Einen weiteren Anhaltspunkt liefert zudem der dt. Standardsetter, der zu Beginn des Jahres 2009 angesichts der globalen Wirtschaftskrise einen ,Hinweis zum Prognosebericht gemäß DRS 15`vorlegte, vgl. DSR (2009). Einen Einfluss des Umfeldes auf das Berichtsverhalten bestätigen auch Einhorn/Ziv (2008). 
Hypothese H 2.1 jedoch die zeitliche Verschiebung der jeweiligen Parameter: In der Strategieberichterstattung wird sich stets das konjunkturelle Umfeld zur Zeit der Aufstellung des Lageberichts niederschlagen, die Strategieangaben im Lagebericht des Jahres $t$ werden determiniert von den Bedingungen des Jahres $t+1$.

Sofern weiterhin davon ausgegangen wird, dass die konjunkturelle Situation entscheidenden Einfluss auf Bewertungsparameter der Kapitalmärkte besitzt, sollte sich ein Zusammenhang zwischen Kapitalmarktparametern und dem Niveau der Strategieberichterstattung gleichfalls nachweisen lassen. Hypothese H 2.2 lautet:

H 2.2: Die Bedingungen des Kapitalmarktes besitzen einen Einfluss auf das Niveau der Strategieberichterstattung. Positive Kapitalmarktbedingungen führen zu einem Anstieg des Berichterstattungsniveaus.

Anzumerken ist jedoch, dass sich in diesem Fall das soeben dargestellte Problem einer zeitlichen Verschiebung nicht zeigen wird: Es gilt grds. als akzeptiert, dass der Kapitalmarkt das konjunkturelle Geschehen mehrere Monate vorwegnimmt, das Niveau der Strategieberichterstattung des Jahres $t$ wäre also in Beziehung zu setzen zu Kapitalmarktparametern des Jahres $t^{702}$

\section{(b) Unternehmenscharakteristika als Bestimmungsfaktoren}

Neben den externen Einflüssen sind auch unternehmensinterne, nicht-finanzielle Parameter daraufhin zu untersuchen, inwieweit sie Einfluss auf das Niveau der Strategieberichterstattung ausüben. Das ist konsistent mit bisherigen Arbeiten zu den Bestimmungsfaktoren freiwilliger Berichterstattung, wie gezeigt wurde. ${ }^{703}$

Für die eigene empirische Untersuchung werden konkret vier Parameter ausgewählt, die empirisch überprüft werden sollen: die Größe $\mathrm{e}^{704}$ eines Unternehmens, die Branchenzugehörigkeit, managementbezogene Aspekte und Charakteristika der Rechnungslegungspraxis im Unternehmen. Im Einzelnen zu den Parametern:

$7 / 12$ Diese Annahme gründet sich auf einer Feststellung von Axe/Flinn (1925). Seither gelten Aktienindizes grds. als recht valide vorlaufende Konjunkturindikatoren, wobei bzgl. der Dauer des zeitlichen Vorlaufs keine Einigkeit besteht, i.d.R. aber von ca. sechs Monaten ausgegangen werden kann. Vgl. auch Lerch (1971), S. 83ff.; Rühle (1991), S. 88ff.

70.3 Vgl. dazu nochmals die Ausführungen in Abschnitt C 2.3.2 dieser Arbeit.

$7(14$ Zwar erfolgt eine Operationalisierung der,Größe' auch anhand finanzieller Indikatoren, doch scheint die Einordnung als Unternehmenscharakteristikum sinnvoll; vgl. Fn. 713. 
In der überwiegenden Anzahl von Arbeiten zur Berichterstattung wird die Größe des berichtenden Unternehmens als wesentlicher Bestimmungsfaktor gezeigt, es gilt: ,the variable most consistently reported as significant in studies examining differences across firms in their disclosure policy is firm size“ ${ }^{\text {،705 }}$. Diese ist daher auch als ein ,Sammelindikator ' für verschiedene Charakteristika anzusehen. ${ }^{706}$

Als Begründung für die Annahme, dass die Größe Einfluss auf das Berichtsverhalten ausüben sollte, werden unterschiedliche Überlegungen angestellt. So wird darauf verwiesen, dass große Unternehmen mit einer starken Nachfrage ${ }^{707}$ nach Informationen konfrontiert werden. Darüber hinaus wird unterstellt, dass die Produktion von Informationen in großen Unternehmen kostengünstiger sei, so dass diese Nachfrage durch ein adäquates Angebot ${ }^{708}$ befriedigt werden kann. Zudem werden wettbewerbliche Aspekte zur Begründung herangezogen: „smaller firms may feel that fuller disclosure of their activities will put them at a competitive disadvantage with other, larger companies in their industry. “"709

Um den Einfluss der Größe auf das Niveau der Strategieberichterstattung zu bestimmen, wird hier Hypothese H 2.3 formuliert, sie lautet folgerichtig:

H 2.3: Die Größe eines Unternehmens hat einen positiven Einfluss auf das Niveau der Strategieberichterstattung dieses Unternehmens.

Belege für jenen Zusammenhang lassen sich in der Literatur zahlreich finden, ${ }^{710}$ neben der frühen Arbeit von Cerf (1961) seien bspw. Cooke (1989), Meek et al.

705 Foster (1986), S. 44.

706 Vgl. Achleitner et al. (2005), S. 265 bzw. Wagenhofer/Ewert (2007), S. 399. Damit sind insb. nicht-beobachtbare Faktoren gemeint, die sich einer direkter Messung entziehen.

707 Vgl. u.a. Lang/Lundholm (1993), die argumentieren, dass sich große Unternehmen mit mehr Aufmerksamkeit von Analysten konfrontiert sehen, die Nachfragedruck erzeugen, auch Hossain et al. (1995). Diese haben Mehraufwand für eine Analyse der komplexen Strukturen großer Unternehmen und benötigen daher mehr Informationen, vgl. Bhushan (1989), S. 261. Auch eine verstärkte Aufmerksamkeit der allgemeinen sowie politischen Öffentlichkeit führe zu mehr Informationsnachfrage, so bspw. Debrensey et al. (2002). Vgl. bspw. Meek et al. (1995), S. 558f. Als Begründung nennen die Autoren besser ausgebaute Informations- und Kontrollsysteme im Vergleich zu kleineren Unternehmen. Firth (1979), S. 274.

710 Stets wurde in den exemplarisch aufgeführten Arbeiten die Berichterstattung gesamthaft betrachtet und ein Einfluss der Unternehmensgröße bestätigt. Diese kann folglich als ein geeigneter Indikator des Berichterstattungsniveaus gelten, vgl. auch Abschnitt D 5.1. 
(1995) und auch Frankel et al. (1999) erwähnt. ${ }^{711}$ Überwiegend wird in den relevanten Untersuchungen ein positiver Zusammenhang dargestellt.

$\mathrm{Zu}$ überlegen ist in der Vorbereitung der Überprüfung, mit welcher Kennzahl die Größe eines Unternehmens am besten approximiert werden kann. Innerhalb der Literatur existieren dazu verschiedene Vorschläge, für die eigene Untersuchung sollen daher vier alternative Kennzahlen verwendet werden: ${ }^{712}$ Umsatz, Bilanzsumme und Marktkapitalisierung bzw. die Anzahl der Mitarbeiter. Es ist folglich zu ermitteln, welche der Kennzahlen das Berichtsverhalten am besten erklärt. ${ }^{713}$

Aufgrund der Erkenntnis, dass sich einzelne Branchen in Bezug auf ihre Wettbewerbsintensität bzw. die Gefahr potenzieller Konkurrenz unterscheiden, kann gefolgert werden, dass auch die Branchenzugehörigkeit eines Unternehmens Einfluss auf das Berichtsverhalten ausüben wird. ${ }^{714}$ Auch wären - in Anlehnung an spieltheoretische Überlegungen - Berichtsinterdependenzen innerhalb einzelner Branchen zu vermuten, die dazu führen, dass Unternehmen einer Branche untereinander ein eher homogeneres Berichterstattungsverhalten aufweisen als Unternehmen aus verschiedenen Branchen zueinander: ${ }^{715}$ „different industries display

711 Vgl. grdl. Cerf (1961). Der Autor sucht Erklärungen für Unterschiede in der Berichterstattung und ermittelt die Bilanzsumme als die am besten erklärende Kennzahl. Vgl. zudem Cooke (1989), Meek et al. (1995), Frankel et al. (1999), Lang/Lundholm (1993) sowie auch Raffournier (1995) mit dem Fokus auf die Berichterstattung Schweizer Unternehmen bzw. mit ähnlichem Blickwinkel Cormier/Magnan (1999).

712 Die nachfolgend genannten Parameter nutzen bspw. Firth (1979), Hossain et al. (1995).

713 Vgl. Meek et al. (1995), S. 558, die dieses Approximationsproblem thematisieren. Ergo wird die ,Größe " auch durch finanzielle Parameter operationalisiert, ihr Einfluss auf das Unternehmensverhalten sollte jedoch unterschiedlicher Natur sein als derjenige von rein finanziellen Faktoren, wie z.B. der Profitabilität. Hinsichtlich der operationalisierenden Parameter ist auf Multikollinearität zu achten, vgl. Moore/Buzby (1972) bzw. C 3.4.2.

714 Unterschiedlichkeiten können bereits aus verschiedenen Wachstumsaussichten einzelner Branchen resultieren, vgl. z.B. Kent/Ung (2003), S. 275. Diese merken an, dass Berichte über Wachstumschancen neue Konkurrenten attrahieren; zu unterscheiden ist die Wettbewerbsintensität zwischen aktuellen Wettbewerbern von der Gefahr des Eintritts neuer Konkurrenten, vgl. Wagenhofer/Ewert (2007), S. 350f.; Fischer/Wenzel (2002), S. 330. So auch Wagenhofer/Ewert (2007), S. 400 sowie Cooke (1989), S. 180. Gedacht sei an ein aggressiv berichtendes Unternehmen innerhalb einer Branche, was dazu führt, dass Adressaten von anderen Unternehmen vergleichbare Information einfordern. Dies kann die Entwicklung spezifischer Branchenindikatoren zur Folge haben, wie z.B. des ARPU (, average revenue per user"), der insb. in der Telekommunikationsbranche eine stark beachtete Kennzahl darstellt, vgl. Simpson (2009), auch Glaum/Friedrich (2006), S. 167. 
different patterns of disclosure. ${ }^{\text {" }}{ }^{16}$ Im Hinblick auf das Untersuchungsinteresse der vorliegenden Arbeit lautet Hypothese H 2.4a folgerichtig:

H 2.4a: Das Niveau der Strategieberichterstattung der Unternehmen unterscheidet sich in Abhängigkeit von der Branchenzugehörigkeit.

Anhaltspunkte für diese Überlegungen finden sich in der Literatur zahlreich, den Einfluss der Branchenzugehörigkeit untersuchen z.B. Verrecchia (1983), Cooke (1989), ders. (1991), Meek et al. (1995), Chen et al. (2002) sowie auch Harris (1998). ${ }^{717}$ In der deutschsprachigen Literatur weisen u.a. Fischer/Wenzel (2005) signifikante Unterschiede im Berichtsverhalten für einzelne Branchen nach. ${ }^{718}$

Wenn also davon ausgegangen wird, dass die Branchenzugehörigkeit einen Einfluss auf das Berichtsverhalten ausübt, könnte diese Perspektive auf weitere, fix gegebene Merkmale eines Unternehmens ausgeweitet werden, die das Berichtsverhalten gleichfalls determinieren sollten. In erster Linie rückt dabei das Unternehmensalter in den Mittelpunkt der Betrachtung, da dieses als kulturprägendes Merkmal auch Einfluss auf das Berichtsverhalten haben könnte. ${ }^{719}$ Dies zu überprüfen ist Inhalt der Hypothese $\mathrm{H}$ 2.4b, wobei unterstellt wird, dass die jüngeren Unternehmen mehr Informationen bereitstellen. Hypothese $\mathrm{H} 2.4 \mathrm{~b}$ lautet daher:

H 2.4b: Das Niveau der Strategieberichterstattung unterscheidet sich in Abhängigkeit vom Alter eines Unternehmens. Die Berichterstattung jüngerer Unternehmen wird als umfangreicher angenommen.

Die Branchenzugehörigkeit bzw. das Unternehmensalter werden nachfolgend als zwei Teilaspekte der Hypothese H 2.4 angesehen, die gesamthaft einen Einfluss von sog. Unternehmensstammdaten auf das Berichtsverhalten unterstellt.

716 Botosan (1997a), S. 327.

717 Vgl. Verrecchia (1983), der anmerkt, dass die Kosten möglicher Wettbewerbsnachteile durch Veröffentlichung - die sog. proprietären Kosten, vgl. grdl. Wagenhofer (1990b) zwischen Branchen variieren. Empirisch Meek et al. (1995) am Beispiel der Chemieindustrie; Cooke (1989) mit Fokus auf schwedische Unternehmen, ders. (1991) für Japan; Harris (1998) bzgl. Segmentdaten; Chen et al. (2002) für Hightech-Unternehmen.

718 Vgl. Fischer/Wenzel (2005), S. 459f., die ein höheres Berichtsniveau bei Versorgungs- / Telekommunikationsfirmen sehen, als Ursache wird Regulierungseinfluss vermutet.

719 Vgl. Bushee et al. (2003) mit einem empirischen Beleg, zudem Chen et al. (2002). Zum Einfluss des historischen Hintergrunds eines Unternehmens vgl. Gibbins et al. (1990). 
Das Niveau der Strategieberichterstattung könnte außerdem durch die generelle Berichterstattungspraxis eines Unternehmens determiniert werden. So scheint es plausibel zu unterstellen, dass Unternehmen, die grds. eine tendenziell eher progressive Berichtsphilosophie zeigen, auch im Hinblick auf strategische Berichtsinhalte ein höheres Berichtsniveau aufweisen werden. Diese Überlegung ist konsistent zu der These von Einhorn/Ziv (2008), welche postulieren, dass ein einmal gewähltes Berichtsverhalten als ein dauerhaftes ,commitment“ zu interpretieren ist, das dazu führt, dass Unternehmen sich gezwungen sehen, dieses auch in der Zukunft konsequent weiterzuverfolgen. ${ }^{720}$ Im Rahmen der Untersuchung ist ergo eine geeignete Maßgröße zu verwenden, die die individuelle Berichterstattungsphilosophie eines Unternehmens zum Ausdruck bringt - dies kann bspw. anhand der Befolgung internationaler Rechnungslegungsstandards approximiert werden: Unternehmen, die Standards anwenden, die als eher informationsorientiert angesehen sind, dürften auch in Bezug auf strategieorientierte Angaben informationsfreudiger sein. ${ }^{721}$ Die zu untersuchende Hypothese H 2.5 lautet folglich:

H 2.5: Das Niveau der Strategieberichterstattung unterscheidet sich in Abhängigkeit von den Rechnungslegungspraktiken der Unternehmen. Unternehmen, die eine eher progressive Rechnungslegungsstrategie verfolgen, weisen ein höheres Niveau der Berichterstattung auf.

Dass die Informationsqualität der Finanzberichterstattung einen Einfluss auf das Berichtsverhalten hinsichtlich zusätzlicher Informationen hat, zeigt insb. Tasker (1998) eindeutig auf. ${ }^{722}$ Eine Untersuchung der Auswirkungen einer frühzeitigen Umstellung deutscher Unternehmen auf internationale Standards nehmen bspw.

720) Vgl. Einhorn/Ziv (2008), S. 567ff., ähnlich Leuz/Verrecchia (2000), S. $94 \mathrm{f}$.

721 Erinnert sei daran, dass dt. börsenorientierte Unternehmen erst seit 2005 zur Aufstellung des Abschlusses nach internationalen Standards verpflichtet sind. Zuvor war dies gem. § 292a HGB jedoch ,befreiend“ möglich, vgl. Fey/Deubert (2006), zudem B 3.1. Dass bei jenen Standards eine höhere Entscheidungsnützlichkeit der Angaben erwartet wird, vermuten Pellens/Tomaszewski (1999), S. 201f. Eine Studie von C\&L (1998), S. 28f. zeigt, dass $69 \%$ der Befragten dem HGB-Abschluss geringe Informationsqualität beimessen.

Vgl. grdl. Tasker (1998), S. 160ff. Die Autorin zeigt einen Einfluss des Informationsgegehalts der Rechnungslegung auch dann, wenn weitere mögliche Bestimmungsfaktoren des Berichtsverhaltens kontrolliert werden, wie z.B. die Größe. Modelltheoretisch weist z.B. Einhorn (2005) den Einfluss der Finanz- auf die freiwillige Berichterstattung nach. 
Leuz/Verrecchia (2000) vor und bestätigen, dass durch Anwendung tendenziell informationsorientierter Standards ein glaubwürdiges Signal gesendet wird bzw. dies als generelle Verpflichtung zu höherer Berichtsqualität interpretiert wird. ${ }^{723}$ Für den dt. Kapitalmarkt zeigt z.B. Wenzel (2005) einen Einfluss des Standards auf das Berichtsverhalten im Hinblick auf Inhalte des Value Reportings. ${ }^{724}$

Im Rahmen dieser Untersuchung werden drei unterschiedliche Aspekte als Indikatoren für die individuellen Rechnungslegungspraktiken identifiziert: der Zeitpunkt des Wechsels auf einen internationalen Standard, der konkret verwendete Standard im Jahresabschluss sowie die Reputation des mandatierten Prüfers.

Weiteren Einfluss auf das Berichtsverhalten in Bezug auf strategieorientierte Inhalte sollte annahmegemäß das Management eines Unternehmens besitzen. Dies folgt der Überlegung, dass dieses wesentliche Verantwortung für die Weiterentwicklung des Unternehmens und schließlich für dessen strategische Ausrichtung übertragen bekommen hat. ${ }^{725}$ Konsequenterweise ist folglich davon auszugehen, dass das Management bzw. der CEO auch die Angaben einer Strategieberichterstattung kontrollieren wird, für welche dieser letztlich gleichfalls verantwortlich zeichnet. Zudem scheint - aus einer externen Perspektive - die Person des CEO stets untrennbar mit der Strategie verknüpft. Hypothese H 2.6 lautet sodann:

H 2.6: Das Niveau der Strategieberichterstattung der Unternehmen unterscheidet sich in Abhängigkeit von Persönlichkeitsmerkmalen des Vorstandsvorsitzenden (CEO). ${ }^{726}$

Anhaltspunkte für jene Überlegung finden sich bspw. bei Clarkson et al. (1999), die einen signifikanten Einfluss des Managements auf das Berichtsverhalten auf-

723 Vgl. Leuz/Verrecchia (2000). Dagegen nimmt Verrecchia (1990) an, dass Unternehmen mit weniger informativen Standards eher Zusatzinformationen berichten werden.

724 Vgl. Wenzel (2005), S. 457f., ähnlich auch Rolvering (2002), S. 23f.

725 Diese Aussage findet sich u.a. bei Gibbins et al. (1990), S. 139. Vgl. Hahn/Hungenberg (2001), S. 13, die die langfristige ,erfolgreiche Weiterentwicklung der Unternehmung“ als zentrale Aufgabe des Managements sehen. Hahn (1999a), S. 2 nennt eine Festlegung der Strategie die wichtigste Führungsaufgabe des Top-Managements.

726 Nachfolgend wird stets das Akronym ,CEO` verwendet, gemeint ist damit jedoch regelmäßig die Person des Vorstandsvorsitzenden deutschen Rechts i.S.v. § 77 AktG. 
zeigen. ${ }^{727}$ Tasker (1998) stellt das Alter des CEO als Determinante des Berichtsverhaltens in den Fokus und ermittelt in der Tat signifikante Zusammenhänge. ${ }^{728}$ Weiterhin zeigen Karamanou/Vafeas (2005), dass Organisationsstrukturen eines Unternehmens das Berichtsverhalten determinieren; ${ }^{729}$ Cheng/Courtenay (2006) bestätigen dies bzgl. der Struktur des Vorstandes. ${ }^{730}$ Zudem seien Haniffa/Cooke (2002) angesprochen, die sich mit ethnischen Merkmalen des Managements auseinandersetzen und in diesen gleichfalls relevante Bestimmungsfaktoren des Berichtsverhaltens identifizieren. ${ }^{731}$ In der vorliegenden Untersuchung sollen daher zwei Aspekte differenziert werden: Neben dem Einfluss von drei verschiedenen Charakteristika des amtierenden CEO, im Einzelnen das Alter, der Ausbildungshintergrund sowie die Nationalität, ist zudem der Einfluss der Person per se, also eines Austauschs des jeweiligen CEO, zu betrachten. ${ }^{732}$

\section{(c) Finanzielle Parameter als Bestimmungsfaktoren}

Neben den soeben behandelten nicht-finanziellen Parametern erscheint es zudem plausibel zu unterstellen, dass finanzielle Parameter ebenfalls als Determinanten des Berichtsverhaltens eines Unternehmens in Frage kommen. Die Annahme des Einflusses finanzieller Parameter auf das Berichtsverhalten stellt darüber hinaus eine zentrale Grundlage der Signalling-Theorie dar: ${ }^{733}$ Diejenigen Unternehmen, die eine überragende finanzielle Leistung erbracht haben, werden dies berichten.

727 Vgl. Clarkson et al. (1999). Gezeigt wird, dass sich bei den Unternehmen, die den CEO austauschen, das Berichtsverhalten in der Folge signifikant verändert. Sie unterschieden rein binär: ,CEO-Wechsel“ oder kein Wechsel. Vgl. auch bereits Gibbins et al. (1990). Vgl. Tasker (1998), S. 146. Die Autorin unterstellt, dass das Berichtsverhalten letztlich durch sog. ,Career Concerns` des CEO determiniert ist. Bei jüngeren Managern erwartet sie ein Signalling, d.h. breite Berichterstattung, bei älteren Managern das Gegenteil. Vgl. Karamanou/Vafeas (2005). Effektive Strukturen fördern nach Ansicht der Autoren die Berichterstattung. Ob dies nicht jedoch eher ein Treiber der Effizienz und damit des Ergebnisses ist, was wiederum das Berichtverhalten bestimmt, ist nicht auszuschließen.

730) Vgl. Cheng/Courtenay (2006).

731 Vgl. Haniffa/Cooke (2002). Die Autoren stellen bei einer Analyse von Unternehmen in Malaysia fest, dass ein hoher Anteil an Malaien zu intensiverer Berichterstattung führt. Das wird von Gibbins et al. (1990), S. 139 angeregt. Sie vermuten, ,a change in CEO, particularly replacement by a new CEO [...], may precipitate a change in disclosure".

733 Vgl. Ross (1979); Abschnitt B 1.2.4. Diese Theorie geht davon aus, dass Unternehmen, die über positive Informationen verfügen, dies auch berichten. Nicht-berichtende Unternehmen haben annahmegemäß eher negative Informationen - und werden so bewertet. 
Folgerichtig stellt die wirtschaftliche Unternehmensleistung bzw. -situation eine oft untersuchte Bestimmungsgröße für das Publizitätsverhalten dar. ${ }^{734}$ Wird davon ausgegangen, dass Informationen über die wirtschaftliche Situation stets in Verbindung mit weiteren Angaben bereitgestellt werden, so sollte sich dies auch auf die Berichterstattung über strategieorientierte Inhalte auswirken. ${ }^{735}$ Folglich besteht Anlass zu der Vermutung, dass das Niveau der Strategieberichterstattung durch die finanzielle Situation determiniert wird - Hypothese H 2.7 lautet daher:

H 2.7: Der wirtschaftliche Erfolg eines Unternehmens hat einen positiven Einfluss auf das Niveau der Strategieberichterstattung.

Jener Zusammenhang zwischen wirtschaftlicher Situation und Berichtsverhalten ist bereits häufig thematisiert worden, einen positiven Zusammenhang ermitteln modelltheoretisch v.a. Dye und auch Verrecchia. ${ }^{736}$ Eine empirische Bestätigung bringen z.B. Patell (1976), Penman (1980), Lev/Penman (1990), Tasker (1998), Frankel et al. (1999) sowie Wang et al. (2008). ${ }^{737}$ Andere empirische Arbeiten kommen hingegen zu weniger eindeutigen Aussagen bzw. sehen gar Anzeichen für einen gegenteiligen Zusammenhang, wie bspw. Ajinkya/Gift (1984), Skinner (1994) und Lang/Lundholm (1993). ${ }^{738}$ Folgerichtig muss gelten: „The empirical evidence on the relation between firm performance and disclosure is mixed.“739 Dennoch sollte hier weiterhin von einem positiven Zusammenhang ausgegangen werden. Für die konkrete Operationalisierung des wirtschaftlichen Erfolgs eines

734 Vgl. bspw. Fischer (2003), S. 212ff., auch Meek et al. (1995); Raffournier (1995).

Vgl. Hutton et al. (2003), S. 888. Die Autoren zeigen, dass Manager Informationen über finanzielle Parameter stets zusammen mit „qualitative ,soft talk“" senden (S. 867). Sind die finanziellen Parameter , gut ${ }^{\text {, }}$, sollten diese Begleitinformationen Glaubwürdigkeit erzeugen. Im gegenteiligen Fall dienen diese dazu, Ursachen darzustellen bzw. zu zeigen, dass zukünftig Besserung eintreten wird, auch Wagenhofer/Ewert (2007), u.a. S. 401. Vgl. grdl. die Studien von Dye (1985), ders. (1986) und Verrecchia (1983), ders. (1990). Auch Darrough/Stoughton (1990), Wagenhofer (1990b), Feltham/Xie (1993).

737 Vgl. die Studien von Patell (1976), Penman (1980), Lev/Penman (1990), Tasker (1998), Frankel et al. (1999) sowie in jüngerer Zeit auch Wang et al. (2008).

Vgl. Ajinkya/Gift (1984); Skinner (1994); Baginski et al. (1992) sowie Lang/Lundholm (1993). Es sei der Vollständigkeit halber vermerkt, dass sich die Arbeiten z.T. bzgl. der Operationalisierung, freiwilliger Berichterstattung ' unterscheiden. So verwenden bspw. Lang/Lundhom (1993) Ergebnisprognosen des Managements als Maßstab, Frankel et al. (1999) nutzen hingegen die Anzahl der Analysten-Telefonkonferenzen als Indikator. 
Unternehmens kommen grds. diverse Kennzahlen in Frage, neben absoluten zudem relative Angaben des Rechnungswesens. ${ }^{740}$

In Ergänzung zu dem soeben vermuteten Einfluss des Erfolgs könnten sich auch Parameter der Finanzierung auf das Berichtsverhalten auswirken. Dies erscheint in zweifacher Hinsicht plausibel: Zum einen ist die Kapitalstruktur ein aussagekräftiger Indikator der finanziellen Konstitution eines Unternehmens. ${ }^{741}$ Darüber hinaus werden Finanzierungsbedarfe - und damit Veränderungen in der Kapitalstruktur - stets mit der Forderung potenzieller Kapitalgeber nach Bereitstellung zusätzlicher Informationen einhergehen. In theoretischer Sicht kann insofern das Prinzipal Agenten-Modell zur Erklärung des Zusammenhangs zwischen Kapitalstruktur und Berichterstattung beitragen: Postuliert wird, dass Agency-Kosten in Unternehmen mit ausgeprägter Verschuldung höher sind und Kapitalgeber daher weitere Informationen einfordern, um das Geschehen kontrollieren zu können. ${ }^{742}$ Diesen Zusammenhang soll Hypothese H 2.8 abbilden, sie lautet demzufolge:

H 2.8: Der Verschuldungsgrad eines Unternehmens steht in positivem Zusammenhang mit dem Niveau der Strategieberichterstattung.

Arbeiten zum Zusammenhang zwischen Berichtsverhalten sowie Finanzierungsaspekten setzen sich ergo konsequenterweise meist mit dem Verschuldungsgrad in einer statischen und dynamischen Sicht auseinander. ${ }^{743}$ So kann der Einfluss

740) Die Erfolgssituation wird meist durch Rentabilitätsgrößen operationalisiert, so bspw. bei Wagenhofer/Ewert (2007), S. 401ff. Absolute Größen scheinen ebenfalls prinzipiell geeignet, vgl. dazu Coenenberg (2005), S. 1025ff.

741 Insofern gelten auch hier die Aussagen der einschlägigen Literatur zur Veröffentlichung von Informationen bzgl. der wirtschaftlichen Entwicklung eines Unternehmens, die zuvor genannt wurden. Auch das Instrument der Kapitalstrukturanalyse demonstriert, dass der Kapitalstruktur hohe Bedeutung zukommt, vgl. Coenenberg (2005), S. 993f., der die „Abschätzung der Finanzierungsrisiken“ als Ziel der Kapitalstrukturanalyse ansieht.

Vgl. Jensen/Meckling (1976), Smith/Warner (1979). Erwartet wird, dass in Situationen hoher Verschuldung stets die Gefahr des Vermögenstransfers besteht, also entweder die Aktionäre oder die Fremdkapitalgeber übervorteilt werden.

Dieser Verschuldungsgrad ist die Kerngröße der Kapitalstrukturanalyse, die Aufschluss über „Quellen und Zusammensetzung nach Art, Sicherheit und Fristigkeit des Kapitals zum Zwecke der Abschätzung der Finanzierungsrisiken" gibt, so Coenenberg (2005), S. 993. Grds. weist ein geringerer Verschuldungsgrad auf tendenziell einfache Akquisition von Kapital hin. Unternehmen mit höherer Verschuldung müssen aktuelle Kapitalgeber absichern und potenzielle Investoren überzeugen, so Wagenhofer/Ewert (2007), S. 401. 
von bestehenden und zusätzlichen Fremd- bzw. Eigenfinanzierungen auf das Berichtsverhalten differenziert werden. ${ }^{744}$ Anhaltspunkte dafür, dass Finanzierungsaspekte bestimmend für das Berichtsverhalten sind, liefern bspw. Hossain et al. (1995), Frankel et al. (1999), Clarkson et al. (1999), Lang/Lundholm (2000). ${ }^{745}$ Neben unterschiedlichen Abgrenzungen der Verschuldung eines Unternehmens zur Ableitung des Verschuldungsgrades kann mit Hilfe des Indikators der Eigenkapitalquote außerdem die reziproke Perspektive zur Prüfung des Einflusses von Finanzierungsstrukturen auf die Berichterstattung eingenommen werden. ${ }^{746}$

\section{(d) Aktienkapitalbezogene Bestimmungsfaktoren}

Da sich diese Untersuchung gezielt mit einer Strategieberichterstattung börsennotierter Unternehmen auseinandersetzt, ist schließlich auch der Einfluss solcher Faktoren zu untersuchen, die mit der Börsennotierung in Zusammenhang stehen:

Einige Arbeiten stellen in diesem Kontext zunächst auf eine Zugehörigkeit eines Unternehmens zu einem bestimmten Börsenindex, wie bspw. dem Dax 30, ab. ${ }^{747}$ Vermutet wird, dass Unternehmen, die Bestandteil eines als ,höherwertig ' wahrgenommenen Indizes sind, ein höheres Niveau der Berichterstattung besitzen. ${ }^{748}$ Dies ist auf die Strategieberichterstattung zu übertragen, Hypothese H 2.9 lautet:

H 2.9: Das Niveau der Strategieberichterstattung unterscheidet sich in Abhängigkeit von der Börsenindexzugehörigkeit, die Zugehörigkeit zu einem ,höherwertigen“ Index induziert ein höheres Berichtsniveau.

744 Vgl. u.a. die Arbeiten von Fischer (2003), S. 212f., grdl. Meek et al. (1995); Raffournier (1995), außerdem auch Wagenhofer/Ewert (2007), S. 401.

745 Vgl. Hossain et al. (1995) mit Fokus auf einen statischen Verschuldungsgrad, Frankel et al. (1999) bzgl. Fremdfinanzierung. Lang/Lundholm (2000) zum Berichtsverhalten im Kontext von Eigenkapitalerhöhungen, weiterhin Choi (1973); Clarkson et al. (1999).

746 Bei einer Abgrenzung der konkreten Verschuldung kann bspw. auf die langfristige Verschuldung oder auf die Nettoverschuldung abgestellt werden, vgl. Abschnitt C 3.3.3.

747 Vgl. für den dt. Kapitalmarkt Rolvering (2002), S. 21f. bzgl. Zwischenberichterstattung; Armeloh (1998), S. 244ff. zur Berichterstattung im Anhang. Weiterhin Wenzel (2005), S. 461f. für Inhalte des Value Reportings.

748 Die relevanten, der Untersuchung zugrunde liegenden Aktienindizes werden von der Dt. Börse definiert, vgl. Dt. Börse AG (2009a), S. 7f. und den folgenden Abschnitt C 3.2.1. Angemerkt sei, dass die grds. Anforderungen an die Berichterstattung für Unternehmen aller Indexkategorien identisch sind, insofern bleibt die Freiwilligkeit als Treiber gültig. Zur Rangfolge bzw. ,Wertigkeit' von Aktienindizes vgl. ebenfalls Abschnitt C 3.2.1. 
Ein nahezu klassischer Beleg für den Einfluss der Indexzugehörigkeit findet sich bereits bei Leftwich et al. (1981). ${ }^{749}$ Auch deutsche Studien können den Einfluss auf die Berichterstattung nachweisen. ${ }^{750}$ Für diese Untersuchung ist allerdings zu beachten, dass aufgrund der Regelungen zur Indexzusammensetzung ein $\mathrm{Zu}$ sammenhang mit Größenaspekten nicht ausgeschlossen werden kann. ${ }^{751}$

Ein weiterer Bestimmungsfaktor des Niveaus der Strategieberichterstattung wird im Listingstatus vermutet, dies bezieht sich auf die Frage, ob Eigenkapitalanteile eines Unternehmen zusätzlich an ausländischen Börsen notiert sind, statt nur an einer inländischen Börse. ${ }^{752}$ Für die Notierung eines inländischen Unternehmens an einer Auslandsbörse sind grds. zahlreiche mögliche Motive bereits aufgezeigt worden. ${ }^{753}$ Zusammenfassend ist davon auszugehen, dass ein Auslandslisting zu einer effizienteren Kapitalstruktur führen kann. ${ }^{754}$ Allerdings scheint auch nachvollziehbar, dass Auslandsnotierungen darüber hinaus zu geographischen sowie z.T. zu temporalen Informationsasymmetrien führen können. ${ }^{755}$ Folglich wäre zu vermuten, dass Unternehmen durch Bereitstellung von Informationen versuchen werden, das Erreichen ihrer Ziele zu unterstützen. ${ }^{756}$ Hypothese H 2.10 lautet:

74) Vgl. Leftwich et al. (1981). Die Autoren zeigen dies anhand von Daten zur Zwischenberichterstattung an der NYSE im Jahre 1948, als diese Berichte freiwilliger Natur waren. Im Vergleich zur zweiten großen Börse der USA der damaligen Zeit, der ASE, erfolgte häufiger eine derartige Berichterstattung von Unternehmen an der NYSE. Gezeigt wird, dass Unternehmen, die zur NYSE wechseln, meist sodann ebenfalls Berichte vorlegen.

750) Vgl. bspw. nochmals die Arbeit von Ruhwedel/Schultze (2002a) zum Value Reporting.

751 Diesen Hinweis bringt auch Armeloh (1998), S. 245. Zu den Regularien der Zusammensetzung der Indizes vgl. grdl. Dt. Börse AG (2009a), S. 19ff. sowie Abschnitt C 3.2.1.

752 Es ist von Bedeutung, darauf abzustellen, dass es sich um eine Notierung handelt. Diese ist vom reinen Handel der Titel z.B. im Freiverkehr zu unterscheiden, vgl. auch Grote et al. (2009), S. 30. Für einen möglichen Einfluss auf die Berichtsqualität ist entscheidend, dass die Initiative vom Unternehmen ausgeht - dies ist nur bei einer Notierung der Fall. Vgl. Grote et al. (2009), S. 26. Zu nennen sind v.a. der Zugang zu effizienteren Kapitalmärkten, die Erwartung geringerer Kapitalkosten und weitere Finanzierungsaspekte, wie Akquisitionsfinanzierungen, vgl. Saudagaran (1988); Leuz (2003); Hail/Leuz (2005). Vgl. Biddle/Saudagaran (1991), S. 69ff. Dies gilt außerdem auf Investorenebene: „firms assist investors in their efforts to diversify [...] through international equity placements and through having shares listed on overseas stock exchanges", so Glaum (2000), S. 29. 
H 2.10: Das Niveau der Strategieberichterstattung der Unternehmen unterscheidet sich in Abhängigkeit von einer zusätzlichen Notierung an einer ausländischen Wertpapierbörse. Zusätzlich an einer Auslandsbörse notierte Unternehmen besitzen ein höheres Berichtsniveau.

Die Auslandsnotierungen deutscher Unternehmen fokussieren überwiegend auf US-amerikanische Kapitalmärkte, daher ist eine Arbeit von Frost/Kinney (1996) zu erwähnen, die Unterschiede in der Berichterstattung von einheimischen sowie ausländischen Unternehmen in den USA zeigen. ${ }^{757}$ Den Einfluss auf die Berichterstattung belegen weiterhin Cooke (1989), Hope (2003), Ahmed (1995), Gray et al. (1993), Marston (2008) sowie Ferguson et al. (2002) spezifisch für China. ${ }^{758}$

Außerdem ist die Aktionärsstruktur hinsichtlich ihres Einflusses auf die Berichterstattung zu untersuchen. Dies folgt der Überlegung, dass Anteilseigner, sofern sie einen entsprechenden Anteil am Aktienkapital des Unternehmens halten, die Berichtspolitik beeinflussen werden. Angesprochen wird ergo die Konzentration der Eigentumsstruktur, Hypothese H 2.11 a lautet dementsprechend:

H 2.11a: Der Konzentrationsgrad der Aktionärsstruktur hat einen negativen Einfluss auf das Niveau der Strategieberichterstattung.

Im Hinblick auf die Richtung des Zusammenhangs von Eigentumskonzentration und Strategieberichterstattung sind verschiedene Interpretationen denkbar, auch bisherige empirische Erkenntnisse sind entsprechend zu beurteilen: Zunächst ist grds. anzunehmen, dass eine geringe Konzentration der Eigentumsstruktur einen positiven Einfluss auf das Niveau der Berichterstattung haben sollte, weil Unter-

757 Vgl. Frost/Kinney (1996), relevante Vorarbeiten bei Frost/Pownall (1994). Einen Beleg für die Bedeutung der US-Kapitalmärkte für dt. Unternehmen bringen jüngst Grote et al. (2009), S. 25ff., auch Pagano et al. (2002). Vermerkt sei hier, dass dt. Unternehmen ihre an die Notierung an US-Börsen gestellten Erwartungen mehrheitlich nicht erfüllt sehen, nach einer Studie von Glaum et al. (2006) strebten insg. sieben von 15 Unternehmen ein Delisting an. Rechtliche Regelungen erschwerten die Umsetzung aber, vgl. ebenda. Vgl. Cooke (1989), ders. (1991) sowie Hope (2003), Ahmed (1995), Gray et al. (1995), Marston (2008) bzw. Ferguson et al. (2002). Außerdem auch Meek/Saudagaran (1990), Saudagaran/Meek (1997). In jüngerer Zeit Bozzolan et al. (2008), die zeigen, dass ausländische Unternehmen an der NYSE mehr zukunftsorientierte Angaben bereitstellen. Meek/Gray (1989) belegen, dass an der LSE notierte kontinentaleuropäische Firmen geforderte Berichtsinhalte überschreiten, nationale Schwerpunkte aber erkennbar bleiben. 
nehmen in diesem Falle zahlreiche Informationen senden würden, um potenzielle Investoren zu erreichen bzw. jene auf sich aufmerksam zu machen. Dies belegen z.B. Malone et al. (1993), die zeigen, dass die Anzahl der Aktionäre positiv mit dem Niveau der Berichterstattung verknüpft ist, Chaw/Gray (2002) weisen eine negative Beziehung zwischen Konzentration und Berichtsverhalten nach. ${ }^{759}$

Alternative Ansichten sind dann zu akzeptieren, wenn die Art des konzentrierten Eigentums in jene Betrachtung inkludiert wird. So wird regelmäßig ein positiver Zusammenhang postuliert, wenn Eigentumskonzentration durch ein Engagement von Finanzinvestoren begründet ist. Angenommen wird, dass diese Interesse daran haben sollten, tendenziell zahlreiche wertrelevante Informationen zu senden, um den Wert ihres Anteils zu steigern. ${ }^{760}$ Den entsprechenden Beleg liefern z.B. Healy et al. (1999) und Marston (2008). ${ }^{761}$ Auch findet sich die Argumentation, dass Konzentration aufgrund von Familieneigentum negativen Einfluss auf das Niveau der Berichterstattung haben sollte, wie u.a. Ho/Wong (2001) oder Lakhal (2007) am Bsp. Frankreichs zeigen. ${ }^{762}$ Einen entgegengesetzten Zusammenhang belegen Ferguson et al. (2002) zudem aufgrund von Konzentration durch Staats-

759) Diese Argumentation scheint nachvollziehbar, weil bei hoher Konzentration wesentliche (private) Informationen für die maßgeblichen Eigentümer bereits verfügbar sein werden, vgl. z.B. Lapointe-Antunes et al. (2006), S. 478f. Im Falle geringerer Konzentration gilt die Annahme, dass Unternehmen viele Informationen senden müssen, um potenzielle Investoren zu erreichen und durch weiterführende Angaben Vertrauen aufzubauen. Zudem kann erst durch breite Streuung - als Voraussetzung - hohe Bekanntheit erzielt werden.

760) Vgl. El-Gazzar (1998), der argumentiert, dass Finanzinvestoren Unternehmen mit einem hohen Bestand an privaten Informationen bevorzugen, um deren Veröffentlichung voranzutreiben und sodann von einer Neubewertung auf Basis der neuen Informationen zu profitieren, ähnlich Bushee/Noe (2000), S. 176. Bei ,institutionellem Engagement ‘ wird i.d.R. primär finanzielles Interesse angenommen, vgl. bspw. del Guerico (1996), S. $46 f$.

761 Vgl. Healy et al. (1999), Marston (2008). Vgl. auch die Untersuchung von Bushee/Noe (2000), wenngleich die Autoren diesen kausalen Zusammenhang in umgekehrter Weise untersuchen: Unternehmen mit hohem Niveau der Berichterstattung weisen eine höhere Konzentration ihrer Kapitalstruktur auf, verursacht durch institutionelle Investoren. Dies folgt der These von u.a. Diamond/Verrecchia (1991), dass ein hohes Berichtsniveau zu höherer Liquidität führt und so die Titel für institutionelle Investoren attraktiver werden. Vgl. Ho/Wong (2001), Haniffa/Cooke (2002). Zudem Lakhal (2007), der aufzeigt, dass französische Manager weniger Informationen bereitstellen, wenn sie unter der Kontrolle eines Großinvestors oder einer Familie stehen. Ähnlich bzgl. italienischer Unternehmen auch Patelli/Prencipe (2007). Spezifisch mit einem Fokus auf das Berichtsverhalten von Familienunternehmen vgl. Arbeiten von Chen/Jaggi (2000), Ali et al. (2007). 
besitz bei börsennotierten Unternehmen. ${ }^{763}$ Schließlich wurde eine durch hohen Anteilsbesitz strategischer Investoren begründete Eigentumskonzentration empirisch untersucht, negative Zusammenhänge sind nachgewiesen worden. ${ }^{764}$

Diese unterschiedlichen Tatbestände der Eigentumskonzentration sind innerhalb der Untersuchung zu berïcksichtigen, Hypothese $\mathrm{H} 2.11 \mathrm{~b}$ lautet:

H 2.11b: Das Niveau der Strategieberichterstattung unterscheidet sich in Abhängigkeit vom Typus des größten Einzelaktionärs.

Ein gesonderter Aspekt der Aktionärsstruktur, der einen Einfluss auf das Niveau der Strategieberichterstattung haben sollte, ist der Anteilsbesitz der Manager des Unternehmens selbst, der Insider-Besitz. Da ein grds. Zusammenhang zwischen anteiligem Eigentum und dem Verhalten der Manager als evident gelten kann, ${ }^{765}$ wäre davon auszugehen, dass die Insider gleichfalls Einfluss auf die Strategieberichterstattung nehmen werden, Hypothese H 2.12 lautet daher:

H 2.12: Aktienkäufe (-verkäufe) von Insidern stehen in positivem (negativem) Zusammenhang mit dem Niveau der Strategieberichterstattung.

Empirische Untersuchungen zum Insidereigentum stellen überwiegend auf einen Zusammenhang mit dem wirtschaftlichen Erfolg eines Unternehmens ab und ermitteln zumeist eine positive Verknüpfung. ${ }^{766}$ Einzelne Studien befassen sich jedoch auch mit den Auswirkungen des Insidereigentums auf die Berichterstattung und so zeigen bspw. Denis/Denis (1994), dass Unternehmen mit hohem Insider-

763 Vgl. Ferguson et al. (2002), S. 131f. Als Begründung nennen die Autoren in diesem Fall besonders hohe Bewertungsunsicherheiten (z.B. bzgl. Managementqualität) bzw. relativ geringe indirekte Kosten einer Veröffentlichung, da entsprechende Märkte oftmals noch geschützt seien oder zumindest keine internationale Konkurrenz möglich ist.

764 Vgl. bspw. Patel et al. (2002). Dieses Ergebnis basiert auf einer Analyse aus 19 Staaten.

765 Dies ist auch die wesentliche Annahme von Aktienoptionsprogrammen und Mitarbeiteraktien. Theoretische Grundlagen liefert nicht zuletzt die Agency-Theorie, da eine strikte Trennung von Eigentum sowie Leitung auf diese Weise überwunden werden kann. Vgl. zur Anreizwirkung von Aktienoptionsprogrammen grdl. Weißenberger (2003), S. 275f., welche die Anreizwirkung insb. realer Aktienoptionspläne modelltheoretisch herleitet.

766 Grds. gilt die Aussage, dass Unternehmenserfolg positiv mit dem Anteil der Insider am Kapital verknüpft ist - zumindest innerhalb gewisser Grenzen. Vgl. Morck et al. (1988), zudem Anderson/Reeb (2003), Amit/Villalonga (2006), die jedoch primär auf Familieneigentum abstellen, das z.T. aber mit dem Insidereigentum definitorisch zusammenfällt. 
anteil tendenziell als intransparenter zu charakterisieren sind. ${ }^{767}$ Auch bestätigen Bushman/Indjejikian (1995) sowie Levine/Smith (2003) modellhaft, dass InsiderManager durch eine Veröffentlichung zusätzlicher Informationen eigene Profite steuern können. ${ }^{768}$ Empirisch untersuchen den Einfluss des Insidereigentums auf das Berichtsverhalten z.B. Brockman et al. (2008): Im Kontext von Aktienrückkäufen können diese zeigen, dass eine gezielte Steuerung der Informationsflüsse aus dem Unternehmen heraus v.a. dann zu erwarten ist, wenn die Manager selbst hohe Anteile am Unternehmen halten. ${ }^{769}$

Nach der Formulierung von zwölf Hypothesen zu den Bestimmungsfaktoren des Niveaus der Strategieberichterstattung sind im Folgenden zusätzlich Hypothesen zum zweiten Teilmodell dieser Untersuchung, also zu den Kapitalmarkteffekten der Strategieberichterstattung, abzuleiten. Im Anschluss daran kann ein gesamthaftes Hypothesengerüst dargestellt werden, das sämtliche Hypothesen bzgl. der drei Bausteine des Untersuchungsmodells zusammenfasst.

767 Vgl. Denis/Denis (1994) sowie auch Chau/Gray (2002). Vgl. grdl. zum Zusammenhang zwischen Eigentum und Leitung auch Denis/Sarin (1999).

768 Vgl. Levine/Smith (2003), Bushman/Indjejikian (1995). Interessant ist an der Arbeit v.a. die Aussage, dass dieser Zusammenhang auch dann gilt, wenn erst zu dem Zeitpunkt, in dem Manager durch Veröffentlichung Informationsvorteile verlieren, ein Kauf erfolgt.

Vgl. Brockman et al. (2008). Gezeigt wird, dass Manager vor einem Aktienrückkauf die Berichterstattung bzgl. negativer Informationen erhöhen und nach einem Rückkauf insb. positive Nachrichten veröffentlichen. Die Wahrscheinlichkeit für dieses Verhalten steigt in Abhängigkeit von der Höhe des Insideranteils am Unternehmen, vgl. Gelb (2000).

Weiterhin kann Noe (1999) Insidertransaktionen als ein glaubhaftes Signal der Manager bzgl. der langfristigen Wachstumsperspektiven eines Unternehmens bestätigen. 


\subsubsection{Kapitalmarkteffekte der Strategieberichterstattung}

Die zweite grds. Behauptung dieser empirischen Untersuchung lautete, dass die Strategieberichterstattung beobachtbare Effekte am Kapitalmarkt hervorruft. Daher sollen Hypothesen für drei Kategorien von Kapitalmarkteffekten aufgestellt werden, im Einzelnen sind dies Transparenz-, Handels- und Bewertungseffekte.

\section{(a) Transparenzeffekte am Kapitalmarkt}

In einfacher Sichtweise kann zunächst grds. unterstellt werden, dass Strategieberichterstattung zur Ausweitung der am Kapitalmarkt verfügbaren Informationen führt. Eine geeignete Methode, die Verarbeitung und Wirkungen zusätzlicher Informationselemente zu prüfen, besteht darin, das Verhalten von Finanzanalysten zu betrachten. ${ }^{770}$ Jene agieren als sog. Informationsintermediäre zwischen Unternehmen sowie Investoren, durch Auswertung verfügbarer Informationen leisten sie einen Beitrag zur Reduktion von Unsicherheit, indem sie Einschätzungen der Lage und Prognosen zur künftigen Entwicklung der Unternehmen vorlegen. ${ }^{771}$

Folgerichtig wurde die Bedeutung von Analysten für die Effizienz eines Kapitalmarktes wiederholt empirisch nachgewiesen - es wird davon ausgegangen, dass Unternehmen grds. eine intensive Beachtung durch Analysten anstreben, damit Unternehmensinformationen ihre Wirkung bestmöglich entfalten können. ${ }^{772}$ Den

770 Dies ist eine ,Ersatzbetrachtung ‘, da das Verhalten von Investoren nicht oder nur schwer beobachtbar ist: Im Gegensatz zu Finanzanalysten machen Investoren nicht transparent, auf welche Unternehmen sie fokussieren. Analysten gelten daher auch als repräsentative Kapitalmarktakteure: „Given their importance as intermediaries who receive and process financial information, it makes sense to view analysts [...] as representatives of the group to whom financial reporting is and should be addressed", so Schipper (1991), S. 105.

771 Vgl. Healy/Palepu (2001), S. 405f., auch Achleitner et al. (2001), S. 47f. Interessanterweise sind hier die Funktionen zu erkennen, die der Lagebericht gem. Generalnorm hat: Vermittlung von Informationen zu Lage und zukünftiger Entwicklung der Gesellschaft. Diese Verdichtungsleistung von Information würdigt u.a. auch Schipper (1991), S. 105.

Vgl. grdl. Achleitner et al. (2002), S. 32 m.w.N. Empirische Belege für den Effizienzbeitrag der Analysten auch bei Chung/Jo (1996), S. 501ff.; Doukas et al. (2000), S. 57ff. Die Beobachtung eines Unternehmens durch Analysten besitzt eine ,Signalwirkung ' für den Kapitalmarkt: Eine eher geringe Analystenabdeckung signalisiert Unsicherheit, Investoren könnten davon ausgehen, dass höhere Informationsasymmetrien bestehen, und eine angemessene Kompensation für das von ihnen zu übernehmende Risiko verlangen. Folglich stellen Doukas et al. (2000), S. 54 fest, dass ein Analyst ,acts as a monitor to reduce agency costs associated with the separation of ownership and control". 
Analysten entstehen für die Beschaffung und Verarbeitung der Informationen jedoch Kosten, daher ist zu vermuten, dass ,high levels of disclosure [...] increase the number of investment analysts who follow the firm [...] by reducing the analysts' cost of information“"773. Diese Erkenntnis ist schließlich auf die Strategieberichterstattung übertragbar, da diese Teil der Gesamtheit aller bereitgestellten Informationen eines Unternehmens ist. Hypothese H 3.1 lautet daher:

H 3.1: Ein höheres Niveau der Strategieberichterstattung führt zu einer größeren Anzahl an Analysten, die das Unternehmen analysieren.

Ein positiver Zusammenhang zwischen einer Ausdehnung der Berichterstattung und der Anzahl an Analysten, die ein berichtendes Unternehmen analysieren, ist empirisch bestätigt durch u.a. Lang/Lundholm (1996), Francis et al. (1997) bzw. Bushee/Miller (2005). ${ }^{774}$ Hinsichtlich der Art der Bereitstellung zusätzlicher Berichtsinhalte belegen bspw. Clarkson et al. (1999), dass Lageberichtsinstrumente relevante Angaben für Analysten beinhalten bzw. von diesen beachtet werden. ${ }^{775}$ Unternehmen scheinen insofern in der Lage, durch Berichterstattung die Anzahl der sie beobachtenden Analysten - zumindest ansatzweise - steuern zu können.

Unter Rückgriff auf die in den theoretischen Ausführungen postulierte Leistung strategieorientierter Informationen zur Unterstützung bei der Prognose künftiger Zahlungsströme sollte weiterhin davon ausgegangen werden, dass im Falle einer umfassenden Strategieberichterstattung die Prognoseunsicherheit von Analysten im Hinblick auf die künftige Entwicklung eines Unternehmens reduziert werden könnte. ${ }^{776}$ Folglich sollten - auf Basis der verfügbaren strategie- sowie zukunfts-

77. Brennan/Tamarowski (2000), S. 37. Ähnlich auch Achleitner et al. (2005), S. 266ff. Die Aussage liefert die Begründung dafür, dass die Anzahl der Analysten als Kapitalmarkteffekt angesehen wird. Grds. scheint die umgekehrte Kausalität aber ebenso vorstellbar, vgl. z.B. Bushee et al. (2003). Im Rahmen der Prüfung von SDIndex auf Endogenität in Abschnitt D 5 wird ein möglicher Einfluss der Analystenanzahl auf SDIndex adressiert. Vgl. Lang/Lundholm (1996), die das Niveau von Investor Relations-Angaben ermitteln und sodann die Auswirkungen auf die Anzahl von Analysten analysieren. Vergleichbare Arbeiten von Francis et al. (1997), Healy et al. (1999) Bushee/Miller (2005). Vgl. Clarkson et al. (1999), S. 130f. Diese Analyse erfolgt anhand des kanadischen Pendants dt. Lageberichte, der sog. , Management Discussion \& Analysis‘ (MD\&A). Barron et al. (1999), S. 94f. zeigen die Relevanz zukunftsorientierter Angaben im MD\&A auf. 
orientierten Informationen - die Schätzungen zukünftiger Zahlungsströme bzw. die Gewinnschätzungen von Finanzanalysten in Bezug auf überdurchschnittlich strategieberichterstattende Unternehmen eine deutlich verringerte Streuung aufweisen als bei den Unternehmen, welche nur ein niedriges Niveau an Strategieinformationen senden; Hypothese H 3.2 lautet:

H 3.2: $\quad$ Ein höheres Niveau der Strategieberichterstattung führt zu geringerer Varianz der Analystenschätzungen in Bezug auf dieses Unternehmen.

Eine empirische Untermauerung dieser Hypothese liefern bspw. Lang/Lundholm (1996), die bestätigen, dass ,firms with more forthcoming disclosure in their industry have greater analyst following, more consensus among analyst's earnings forecasts, more accurate forecasts and less variable forecast revisions “ ${ }^{\text {“777 }}$. Einen weiteren Beleg für dieses These liefert Hope (2002) mit seiner Untersuchung der sog. ,Forecast Accuracy“ in 22 Ländern weltweit. ${ }^{778}$

Jedoch sind darüber hinaus auch gegensätzliche Zusammenhänge zwischen dem Niveau der Strategieberichterstattung und der Schätzungsvarianz vorstellbar: So könnte eine umfangreiche Bereitstellung von Informationen zwar zur Reduktion von Informationsasymmetrien zwischen Management und Analysten führen, zugleich aber auch höhere Informationsasymmetrien zwischen den Analysten hervorrufen - und in der Folge eine höhere Varianz der Analystenschätzungen verursachen. ${ }^{779}$ Trotz dieser durchaus beachtenswerten Argumentation wird für die eigene empirische Untersuchung zur strategieorientierten Berichterstattung dennoch von einem negativen Einfluss auf die Schätzungsvarianz ausgegangen.

777 Lang/Lundholm (1996), S. 490; Brennan/Tamarowski (2000), S. $31 \mathrm{ff}$. Auch Barron et al. (1999), S. 98 zeigen einen substantiellen Einfluss der Qualität der Berichterstattung im MD\&A auf die ,dispersion in analysts' earnings forecasts“. Vgl. umfasssend Hope (2002), ähnlich ders. (2003). Auch Vanstraelen et al. (2003), hier mit explizitem Fokus auf zukunftsorientierte Informationen. Auf Informationsasymmetrien zwischen Analysten weisen z.B. Glosten/Milgrom (1985) hin. Dass diese die Streuung der Schätzungen erhöhen können, merken u.a. Byard/Shaw (2003), S. 372f. m.w.N. an, empirisch bspw. Francis et al. (1997).

Grds. könnten Unterschiede der Analysten-Schätzungen - bei identischer Informationsgrundlage - auch durch Unterschiede in den Prognosemodellen begründet sein. Jedoch stellen Glaum/Friedrich (2006), S. 167f. im Rahmen einer Befragung von 25 Analysten fest, dass die Prognosemodelle als durchaus vergleichbar zu charakterisieren sind. 


\section{(b) Auswirkungen auf den Aktienhandel}

Unter Rückgriff auf die eingangs skizzierte ökonomische Theorie kann verkürzt festgehalten werden, dass die im Hinblick auf ein Unternehmen bestehenden Informationsasymmetrien grds. zur Verringerung der Liquidität des Handels eines betreffenden Kapitalmarkttitels führen können. ${ }^{780}$ Im Umkehrschluss wäre folglich anzunehmen, dass es durch eine Ausweitung der Informationsbereitstellung gleichfalls zur Verbesserung der Liquidität am Kapitalmarkt respektive zu einer Erhöhung des Handelsvolumens kommen könnte. ${ }^{781}$ Eine spezifische Hypothese soll diesen Zusammenhang abbilden. Hypothese H 3.3 lautet folgerichtig:

\section{H 3.3: Ein höheres Niveau der Strategieberichterstattung führt zu einem} höheren Handelsvolumen der Aktien eines Unternehmens.

Modelltheoretisch stellen Diamond/Verrecchia (1991) dar, dass eine Reduktion von Informationsasymmetrien die Liquidität des Handels mit einem Wertpapier steigern kann - sie zeigen zudem, dass der entsprechende Titel in der Folge insb. für institutionelle Investoren attraktiv wird und diese Wertpapierkäufe tätigen. ${ }^{782}$

Empirische Belege für den Zusammenhang von Berichterstattung und Handelsvolumen finden sich u.a. bei Leuz/Verrechia (2000) ${ }^{783}$ und Frankel et al. (1999), Healy et al. (1999) sowie Bushee/Miller (2005). ${ }^{784}$ Wenngleich der Hinweis von Easley et al. (1996) ${ }^{785}$ zu beachten ist, dass die Wahrscheinlichkeit informationsbasierten Handelns mit der Höhe des Handelsvolumens abnimmt, soll die eigene

780 Es sei auf die Ausführungen in Abschnitt B 1 sowie C 2.3.3, insb. Fn. 657 dieser Arbeit verwiesen. Die Gefahr einer, adverse selection“ ist bei starken Informationsasymmetrien besonders hoch. Es kann gezeigt werden, dass die Akteure schließlich nicht mehr bereit sein werden, Transaktionen durchzuführen und in der Konsequenz das Handelsvolumen sinkt. Vgl. grdl. Glosten/Milgrom (1985) oder auch Copeland/Galai (1983).

781 Vgl. zur Argumentation Barry/Brown (1985), Merton (1987), Kim/Verrecchia (1994).

782 Vgl. Diamond/Verrecchia (1991), insb. S. 1348. Bushee/Noe (2000) belegen gleichfalls, dass Aktien mit geringeren Informationsasymmetrien für institutionelle Investoren eher interessant sind, da eine entsprechend hohe Liquidität gegeben ist. Vgl. Leuz/Verrecchia (2000), S. 99. Die Autoren weisen nach, dass eine Bereitschaft zu Handeln invers mit der Existenz von Informationsasymmetrien verknüpft ist. Vgl. Frankel et al. (1999), Healy et al. (1999) oder auch Bushee/Miller (2005).

78.5 Vgl. Easley et al. (1996). Diese Aussage wird empirisch belegt. Einen Nachweis für den Kontext des dt. Kapitalmarktes bringen bspw. Grammig et al. (1999). 
Untersuchung unter Verweis auf Verrecchia (1999) die mit H 3.3 geäußerte Vermutung bzw. den mit dieser Hypothese postulierten Zusammenhang analysieren: „In the absence of compelling reasons to the contrary, the conventional wisdom is that more disclosure results in more liquid markets. ${ }^{\text {“786 }}$ Folgerichtig wird eine positive Verknüpfung zwischen dem Niveau der Strategieberichterstattung und dem jeweiligen Handelsvolumen eines Unternehmens vermutet.

Weiterhin wird in der Literatur die Vermutung geäußert, dass erweiterte Berichterstattung sowie die damit verbundene Reduktion von Informationsasymmetrien die Eintrittswahrscheinlichkeit bzw. den möglichen Einfluss unerwarteter Unternehmensinformationen auf die Bewertung reduziert. Anzunehmen wäre, dass die Volatilität der Aktienrenditen der am Kapitalmarkt als eher transparent wahrgenommenen Unternehmen geringer ist. ${ }^{787}$ Nicht zuletzt gilt eine Verringerung der Volatilität explizit als Motiv erweiterter Berichterstattung, da hochvolatile Kurse aus Sicht eines Unternehmens grds. als nachteilig anzusehen sind. ${ }^{788}$ Diesen beschriebenen Zusammenhang greift Hypothese H 3.4 auf, sie lautet demzufolge:

H 3.4: Ein höheres Niveau der Strategieberichterstattung führt zu einer verringerten Volatilität der Aktienrenditen eines Unternehmens.

Bisherige empirische Arbeiten gelangen indes nicht zu eindeutigen Ergebnissen: Einen negativen Zusammenhang zwischen erweiterter Berichterstattung und der Volatilität demonstriert bspw. Patell (1976), während Lang/Lundholm (1993) zu konträren Aussagen gelangen. ${ }^{789}$ Zur Interpretation kann weiterhin der Rückgriff auf das Verhalten von institutionellen Investoren erfolgen, da anzunehmen wäre, dass diese grds. Unternehmen mit intensiver Berichterstattung präferieren. ${ }^{790}$ In

786 Verrecchia (1999), S. 282.

787 Vgl. Lang/Lundholm (1993), auch Healy et al. (1999).

788 Vgl. Bushee/Noe (2000), S. 177f. Titel, die eine hohe Volatilität der Rendite aufweisen, gelten stets als risikobehaftet, so Froot et al. (1992). Baiman/Verrecchia (1995) merken außerdem an, dass hohe Volatilität die Effizienz aktienbasierter Vergütungsprogramme beeinträchtigt, ähnlich auch Jorgensen (1998).

789 Vgl. Patell (1976) und Frankel et al. (1999), Bushee et al. (2003) sowie Lang/Lundholm (1993), ebenso Bushee/Noe (2000), S. 173.

790 Vgl. Bushee/Noe (2000), S. 173f. Als Begründung dient die Möglichkeit der Kontrolle: „corporate disclosure as a low-cost mechanism for monitoring firm performance". 
Abhängigkeit von den jeweiligen Investitionsstrategien finden sich Indizien sowohl für eine Erhöhung als auch für eine Verringerung der Volatilität. ${ }^{791}$

\section{(c) Auswirkungen auf die Bewertung}

Wie in Abschnitt C 2.3.3 ausgeführt, ist die Betrachtung der Eigenkapitalkosten eine zentrale Perspektive in der Auseinandersetzung mit Wirkungen erweiterter Berichterstattung. Um eine Ermittlung der Eigenkapitalkostensätze zu umgehen, werden daher oftmals in der Literatur einige der bislang in diesem Abschnitt behandelten Kapitalmarkteffekte als Stellvertretergrößen genutzt, um Änderungen der Eigenkapitalkosten zu approximieren. ${ }^{792}$ So prüfen z.B. Diamond/Verrecchia (1991) bzw. Leuz/Verrecchia (2000) mit Hilfe des Handelsvolumens indirekt die Effekte erweiterter Berichterstattung auf die Eigenkapitalkosten. ${ }^{793}$

Ein zweiter Teil der theoretischen bzw. empirischen Forschung stellt aber direkt auf die Eigenkapitalkosten ab und postuliert schließlich, dass erweiterte Berichterstattung unmittelbaren Einfluss auf jene besitzt, da die Risikokomponente, die

791 Vgl. Bushee/Noe (2000), S. 176ff. Während institutionelle sowie private Investoren mit langfristig ausgerichteten, konservativen Investitionsstrategien einen verringernden Einfluss auf die Volatilität haben sollten, könnten aggressiv agierende Investoren diese erhöhen. Sowohl private als auch institutionelle Investoren besitzen grds. Einfluss auf die Kurse, derjenige institutioneller Investoren ist allerdings größer, vgl. Chan/Lakonishok (1995). Daher wird meist auf die Wirkung institutioneller Investoren auf die Volatilität abgestellt. Bei institutionellen Investoren handelt es sich um Kreditinstitute, Fondsgesellschaften und Versicherungen - also um solche Kapitalmarktteilnehmer, die als Institutionen Kapital investieren. Diese sind abzugrenzen von Finanzinvestoren, die nach Bushee/Noe (2000), S. 176 als ,dedicated institutions ' große Positionen erwerben, langfristig engagiert sind und daher besseren Zugang zu privaten Informationen haben - sie sind nicht auf öffentliche Berichterstattung angewiesen, um Kontrolle auszuüben. Aufgrund langer Haltefristen ist die Liquiditätswirkung dieser Investoren jedoch gering.

Vgl. Botosan (2002), S. 23f. Diese unterscheidet zwei Forschungsrichtungen: Diejenige, welche direkte Auswirkungen auf die Eigenkapitalkosten untersucht, sowie eine weitere Richtung, die auf Proxygrößen wie Handelsvolumen und Volatilität abstellt. Vgl. hierzu nochmals Abschnitt C 2.3.3 sowie insb. die Anmerkungen in Fn. 657 bzw. Fn. 664.

Vgl. Leuz/Verrecchia (2000), S. 92, mit der Argumentation, dass Unternehmen mit ausgeprägten Informationsasymmetrien höhere Eigenkapitalkosten zu akzeptieren haben in Form eines Abschlags auf die Marktbewertung, damit überhaupt ein Handel stattfinden kann: ,information asymmetries manifest themselves as a liquidity premium in the price at which trades are executed." Durch Erweiterung der Berichterstattung kann der Preisabschlag allerdings reduziert werden. Vgl. hierzu auch Diamond/Verrecchia (1991) oder Baiman/Verrecchia (1996) mit ähnlicher Argumentation.

Eine weitere wichtige Proxygröße sind sog. Bid-Ask-Spreads, vgl. Hypothese H 3.6. 
durch Schätzungen künftiger Zahlungsströme begründet ist, reduziert wird. ${ }^{794} \mathrm{Im}$ Sinne der theoretischen Ausführungen dieser Arbeit sollte die Strategieberichterstattung daher in besonderer Weise dazu geeignet sein, Schätzungen zukünftiger Zahlungsströme zu unterstützen und insofern das Schätzrisiko reduzieren, da die künftige Unternehmensentwicklung im Rahmen des strategischen Managements gestaltet wird. Die formulierte Strategie als Resultat des strategischen Planungsprozesses kann folglich eine wichtige Leitplankenfunktion bei der Schätzung zukünftiger finanzieller Parameter übernehmen bzw. das Schätzrisiko deutlich vermindern. Diese Auswirkung adressiert Hypothese H 3.5, sie lautet folgerichtig:

H 3.5: Ein höheres Niveau der Strategieberichterstattung eines Unternehmens führt zu geringeren Eigenkapitalkostensätzen.

Wie erwähnt, erfährt der Zusammenhang zwischen erweiterter Berichterstattung und den Kapitalkosten hohe Beachtung in der Literatur, denn ,the theory that relates the level of disclosure and the firm's cost of capital is compelling “795. Dieser Zusammenhang wird bspw. von Easley/O'Hara (2004) modelltheoretisch betrachtet, diverse Arbeiten setzen sich mit dem Einfluss der Berichterstattung auf die Kapitalkosten auch empirisch auseinander. ${ }^{796}$ Maßgebliche Untersuchungen sind von Botosan durchgeführt worden: In einer vielbeachteten Studie konnte sie bestätigen, dass erweiterte Berichterstattung einen signifikant negativen Einfluss auf die Eigenkapitalkosten der Unternehmen ausübt, die als weniger transparent zu charakterisieren sind. ${ }^{797}$ In einer umfassender angelegten Studie zeigen später Botosan/Plumlee (2002) einen durch ergänzende Berichterstattung begründeten

794 Vgl. Barry/Brown (1985), Coles et al. (1995), auch Coles/Loewenstein (1988). Es wird unterstellt, dass Investoren Schätzungen auf Basis öffentlich verfügbarer Informationen anstellen. Die Bereitstellung privater Informationen wird schließlich vom Kapitalmarkt honoriert, die Renditeerwartungen sinken, vgl. modelltheoretisch Easley/O'Hara (2004). Das wörtliche Zitat ist Leuz/Verrecchia (2000), S. 92 entnommen.

796 Vgl. Easley/O'Hara (2004) sowie Lambert et al. (2007), S. 410f., die direkte (Zahlungsstromschätzungen) und indirekte (interne Entscheidungen) Auswirkungen trennen.

Vgl. grdl. Botosan (1997a). Die Autorin zeigt in einer Untersuchung von Industrieunternehmen, dass das Niveau eines erarbeiteten ,Disclosure Index “ in signifikant negativem Zusammenhang mit den Kapitalkosten steht. Jene Aussage trifft aber nur für diejenigen Unternehmen zu, die von wenigen Analysten beobachtet werden. Zudem betrachtet die Autorin nur einen einperiodigen Untersuchungszeitraum und auch nur Unternehmen der Maschinenbau-Branche. Zur Diskussion der Ergebnisse u.a. Ewert (1999), S. 44. 
Effekt auf die Kapitalkosten von bis 0,7 Prozentpunkten. ${ }^{798}$ Weitere erwähnenswerte Belege für den postulierten Zusammenhang legen Francis et al. (2004), ${ }^{799}$ Gebhardt et al. (2001), Hail (2002) oder Gietzman/Ireland (2005) vor. ${ }^{800}$ Wenngleich nicht alle Arbeiten zu übereinstimmenden Ergebnissen gelangen, ${ }^{801}$ kann grds. gelten, dass ,the sum of total evidence [...] lends considerable support to the hypothesis that greater disclosure reduces cost of equity capital ${ }^{4802}$. Dieser Aussage folgend wird ein negativer Einfluss der Strategieberichterstattung erwartet.

Eine weitere, in der Literatur oftmals betrachtete Wirkung erweiterter Berichterstattung ist der Einfluss auf die Handelsspannen der jeweiligen Aktien, die sog. Bid-Ask-Spreads. ${ }^{803}$ In der Theorie wird angenommen, dass diese Spannen eher breiter werden, je stärker Marktteilnehmer die im Hinblick auf ein Unternehmen bestehenden Informationsasymmetrien wahrnehmen. ${ }^{804}$ Da sich jene Spreads vor diesem Hintergrund als die am häufigsten betrachtete Stellvertretergröße für die Eigenkapitalkosten präsentieren, erscheint die Einordnung einer entsprechenden Hypothese in die Kategorie der Bewertungseffekte nachvollziehbar. Es wird ver-

798 Vgl. Botosan/Plumlee (2002). Bei dieser Untersuchung wurden die Unternehmensgröße sowie das Marktrisiko eines Wertpapiers als Einflussfaktoren kontrolliert. Im Gegensatz zu Botosan (1997a) analysieren die Autorinnen 43 Branchen über elf Jahre.

Vgl. Francis et al. (2004). Die Autoren ermitteln einen Einfluss des Informationsniveaus auf die Eigenkapitalkosten, auch dann, wenn das Untersuchungsmodell hinsichtlich verschiedener Größen, wie bspw. Unternehmensgröße, Umsatzvolatilität, kontrolliert wird. Vgl. Gebhardt et al. (2001), Hail (2002), Gietzman/Ireland (2005), die methodisch miteinander verwandt sind. Die vorliegende Arbeit folgt dem Vorschlag zur Ermittlung von sog. impliziten Eigenkapitalkosten von Hail, der in Anhang 11 umfassend dargestellt ist. Vgl. Leuz/Verrecchia (2000), S. 92: „, so far, the empirical results have been mixed“. Wörtlich Botosan (2006), S. 39, die in dieser Arbeit den Stand der Forschung analysiert. Vgl. Glosten/Milgrom (1985), welche die Bid-Ask-Spreads neben dem Handelsvolumen und der Volatilität als geeignete Proxygrößen der Informationsasymmetrien bezeichnen. I.d.R. wird die Bezeichnung ,Bid-Ask-Spread 'verwendet, ebenso in Arbeiten deutscher Autoren, nur gelegentlich findet sich die Bezeichnung ,Geld-Brief-Spanne'.

Vgl. Coller/Yohn (1997), S. 181ff. In einem Modell von Kim/Verrecchia (1994) gilt die Annahme, dass grds. informierte und uninformierte Investoren am Markt tätig sind. Die ,Market Maker', die den Handel für einzelne Titel sicherstellen, gelten als uninformiert. Da sie im Handel mit informierten Investoren Verluste erzielen, werden sie je nach Ausmaß der Informationsasymmetrien die Spannen erhöhen, um Verluste zu kompensieren. 
mutet, dass sich durch eine Veröffentlichung freiwilliger Informationen eine Reduktion der Bid-Ask-Spreads ergibt, Hypothese H 3.6 lautet folglich: ${ }^{805}$

H 3.6: Ein höheres Niveau der Strategieberichterstattung eines Unternehmens geht einher mit verringerten Bid-Ask-Spreads.

Empirische Belege für diesen Zusammenhang - in Bezug auf erweiterte Berichterstattung - liefern bspw. Amihud/Mendelson (1986) ${ }^{806}$, Glosten/Harris (1988), Welker (1995), Sengupta (1999), Healy et al. (1999) ${ }^{807}$ Leuz/Verrecchia (2000) liefern den Nachweis für den deutschen Kapitalmarkt. ${ }^{808}$ Aus diesem Grund vermutet Hypothese H 3.6 gleichfalls einen negativen Einfluss der Strategieberichterstattung auf die Bid-Ask-Spreads deutscher berichterstattender Unternehmen.

Eine letzte Hypothese nimmt sich sodann der Marktbewertung an und untersucht schließlich, ob die freiwillige Berichterstattung seitens eines Unternehmens über strategieorientierte Berichtsinhalte zu verbesserter Bewertung am Kapitalmarkt führt. Diese Hypothese dient folgerichtig der marktseitigen Überprüfung des Bewertungseffekts einer Strategieberichterstattung, Hypothese H 3.7 lautet daher:

H 3.7: Unternehmen, die ein höheres Niveau der Strategieberichterstattung aufweisen, erfahren eine höhere Bewertung am Kapitalmarkt.

Diese Hypothese kann unter Zuhilfenahme von Bewertungsmultiplikatoren überprüft werden, wobei allerdings zu beachten ist, dass nur der Vergleich zwischen den Unternehmen einer bestimmten Branche statthaft ist. So verfahren u.a. auch Bushee/Miller (2005), die spezifisch auf die Kennzahl Tobin's Q abstellen, was im Rahmen dieser Untersuchungen ebenfalls vorgesehen ist. ${ }^{809}$

805 Vgl. Coller/Yohn (1997), S. 182f. Zudem könnten Unternehmen auch ein direktes Interesse an einer Reduktion der Spanne haben, da diese maßgeblich die Transaktionskosten der Investoren und somit die Attraktivität eines finanziellen Engagements beeinflussen. Vgl. Amihud/Mendelson (1986), welche die Bid-Ask-Spreads als die geeignetste Stellvertretergröße der Eigenkapitalkosten betrachten.

807 Vgl. Welker (1995), Healy et al. (1999) sowie für Fremdkapitaltitel Sengupta (1998).

$808 \mathrm{Vgl}$. Leuz/Verrecchia (2000). Die Autoren bestätigen diese Hypothese für frühzeitig auf internationale Rechnungslegungsstandards umstellende Unternehmen. Eine Bestätigung - ebenfalls für den dt. Kapitalmarkt - liefern Gassen/Sellhorn (2006), S. 382.

809 Vgl. Bushee/Miller (2005). ,Tobin's Q' bezeichnet das Verhältnis von Marktwert sowie Buchwert eines Unternehmens. Die Kennzahl stellt einen Indikator für Wertlücken dar. 


\subsubsection{Darstellung des gesamthaften Hypothesengerüsts}

In Abschnitt C 3.1 sind in Summe 21 Hypothesen zur Strategieberichterstattung börsennotierter Unternehmen herausgearbeitet worden, die Abb. 13 als gesamthaftes Hypothesengerüst darstellt. Dieses zeigt außerdem die Art der jeweiligen Hypothese und die Richtung des ggf. unterstellten Zusammenhangs. Darauf aufbauend ist nachfolgend die Datenbasis dieser Untersuchung zu definieren.

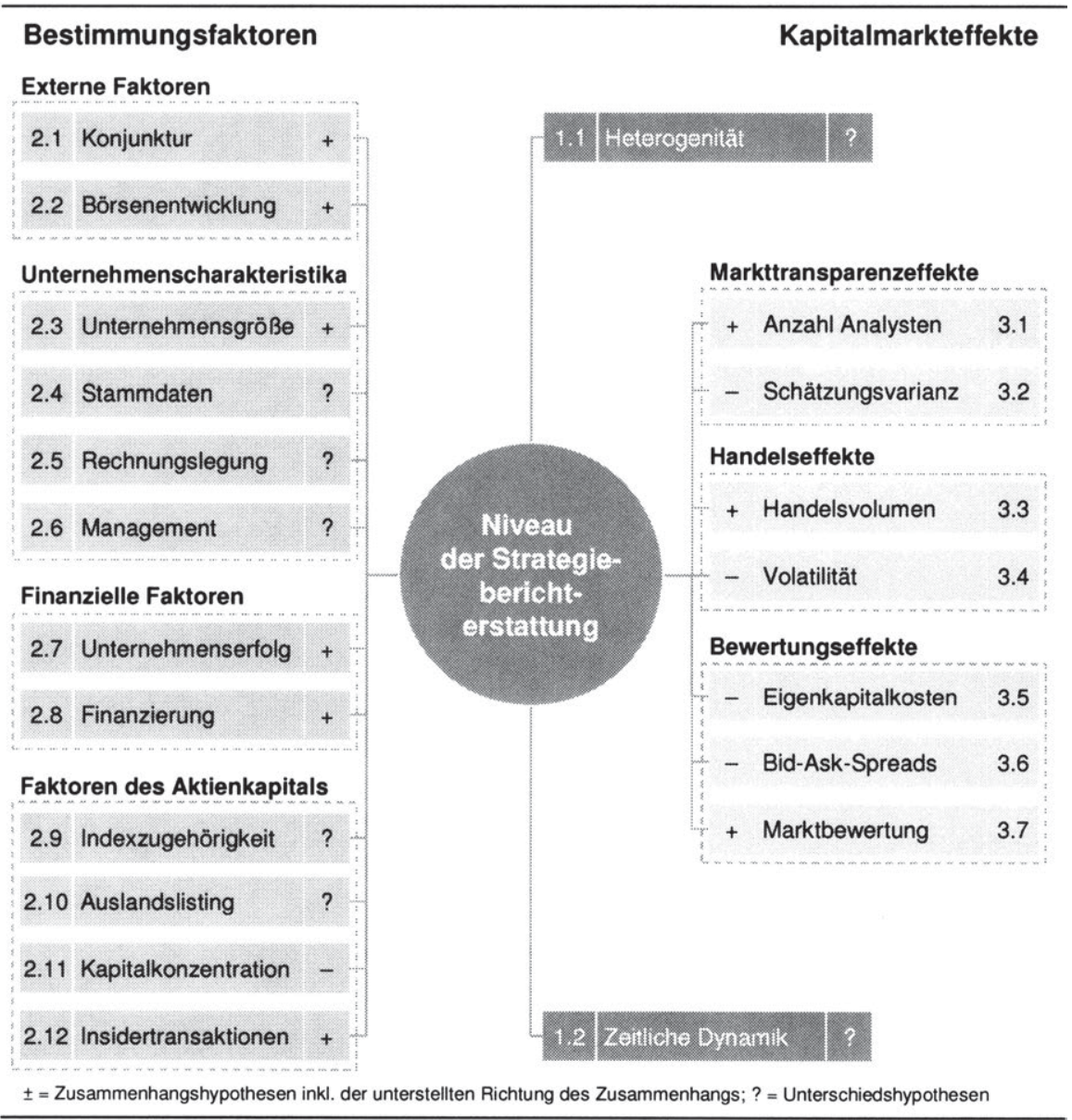

Abbildung 13: Hypothesengerüst der Untersuchung ${ }^{810}$

810) Quelle: eigene Darstellung. Weitere Detaillierung des Modells aus Abb. 10 (S. 142). 


\subsection{Informationelle Basis der Untersuchung}

\subsubsection{Zusammenstellung der Untersuchungsobjekte}

Die eigene empirische Untersuchung soll sich auf Unternehmen konzentrieren, welche an deutschen Börsenplätzen notiert sind. Jene Konzentration ist mit dem Untersuchungsinteresse konsistent und lässt sich zudem in zweifacher Hinsicht begründen: Einerseits steht der Lagebericht nach HGB, zu dessen Vorlage insb. die deutschen kapitalmarktorientierten Unternehmen verpflichtet sind, im Fokus dieser Arbeit. Weiterhin kann die konsequente Untersuchung der Bestimmungsfaktoren bzw. Kapitalmarkteffekte der Strategieberichterstattung nur bei börsennotierten Unternehmen erfolgen, da hier die entsprechende informationelle Basis gegeben ist. ${ }^{811}$ Folgerichtig stellt die eigene Untersuchung auf diejenigen Unternehmen ab, die per Halbjahresultimo 2009 in den wesentlichen Auswahlindizes des sog. ,Prime Standard' der Deutschen Börse notiert waren. ${ }^{812}$ Diese Auswahlindizes sind der Dax, MDax, TecDax sowie SDax, welche in Summe 160 Unternehmen umfassen. ${ }^{813}$ Der Dax als der bedeutendste Börsenindex in Deutschland

811 Einerseits ist dies begründet durch umfangreiche Transparenzanforderungen an börsennotierte Unternehmen, vgl. Abschnitt B 3.1.3; andererseits durch zusätzliche Produktion von Informationen über börsennotierte Unternehmen durch Dritte, z.B. Finanzanalysten, Informationsdienstleitster bzw. Datenbank-Anbieter oder die Wirtschaftspresse.

812 Die vier Indizes werden aus Unternehmen gebildet, die innerhalb des Transparenzlevels ,Prime Standard' notiert sind, vgl. zu den einzelnen Indexprodukten detailliert Dt. Börse AG (2009a), S. 7ff. Im ,Prime Standard' waren per Juni 2009382 Unternehmen notiert, so die offizielle Angabe bei Dt. Börse AG (2009c), S. 40. Alle Unternehmen des ,Prime Standard ' unterliegen identischen Publizitätsvorschriften. Zudem führt die Dt. Börse das Transparenzlevel ,General Standard“ (319 Unternehmen) sowie ,Entry Standard ' (114), die Unternehmen beinhalten, die die Anforderungen des ,Prime Standard ' nicht erfüllen. Der ,Prime Standard" sowie eine neue Branchensystematik wurden erst zum 24.03.2003 auf Basis der Neufassung der Börsenordnung (BörsO) umgesetzt, die zum 01.01.2003 in Kraft trat. In diesem Zusammenhang ersetzte der TecDax auch den Nemax 50, der zum 05.06.2003 eingestellt wurde, vgl. hierzu bspw. Mitenthal/Anders (2003), S. 1894f.

Alle diese Indizes sind eingetragene Markenzeichen der Dt. Börse AG, auf eine Kennzeichnung wird hier allerdings grds. verzichtet. Während Dax bzw. TecDax je 30 Unternehmen beinhalten, sind im MDax und im SDax je 50 Unternehmen vertreten. Für eine Aufnahme in einen Index müssen Unternehmen einen Streubesitz von mind. 10\% ihres Kapitals aufweisen sowie entweder den Sitz in Deutschland haben oder, falls der Sitz in einem EU- oder EFTA-Staat (,European Free Trade Association') ist, den Schwerpunkt des Aktienhandels in Deutschland haben, vgl. ausführlich Dt. Börse AG (2009a), S. 20f. Eine Liste der 160 Unternehmen per Halbjahresultimo 2009 findet sich in Anhang 1.

Tom Sieber - 978-3-631-75150-3 
inkludiert die 30 größten bzw. umsatzstärksten börsennotierten Unternehmen. ${ }^{814}$ Unterhalb des Dax 30 erfolgt die Unterscheidung nach Branchen: Unternehmen, die in Größe sowie Umsatz auf die 30 im Dax enthaltenen folgen, sind entweder im MDax gelistet, wenn sie sog. ,klassischen' Branchen angehören, oder aber im TecDax, sofern es sich um Unternehmen aus technologieorientierten Branchen handelt. Diese drei Auswahlindizes, Dax, MDax und TecDax, bilden zusammen den HDax, welcher Nachfolger des Dax 100 ist. Weitere Werte aus klassischen Branchen, die nicht im MDax enthalten sind, werden im SDax notiert.

Zur Branchenkategorisierung unterscheidet die Dt. Börse AG grds. neun SuperSektoren, welche sich in 18 Sektoren und in insg. 63 Sub-Sektoren gliedern, auf deren Ebene die Trennung in ,klassisch' bzw. ,Technologie ' erfolgt. ${ }^{815}$ Die vollständige ,Index-Pyramide‘ lässt sich sodann entsprechend Abb. 14 darstellen.

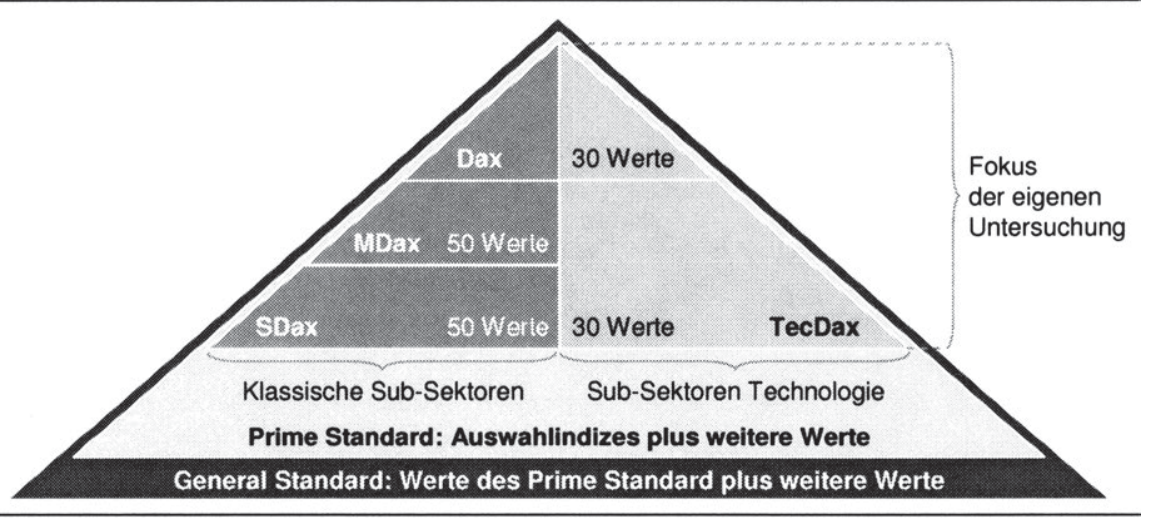

Abbildung 14: Index-Pyramide der Deutschen Börse AG $^{816}$

Die Grundgesamtheit dieser Untersuchung entspricht folgerichtig der Summe an Unternehmen, die per Halbjahresultimo 2009 in jenen vier Auswahlindizes enthalten sind. Jedoch werden lediglich acht Super-Sektoren betrachtet, die Finanz-

814 Der ,Dax “ wird auch als ,Dax 30` bezeichnet, da er 30 Unternehmen beinhaltet. Hier erfolgt die Bezeichnung grds. mit ,Dax‘. Die Termini ,Größe‘ und ,Umsatz‘ sind im Verständnis der Dt. Börse AG zu interpretieren: Für die Zusammensetzung der vier Indizes sind die Marktkapitalisierung als Größenkriterium und der Handelsumsatz relevant, vgl. im Einzelnen Dt. Börse AG (2009a), S. 20f.

815 Vgl. im Detail Dt. Börse AG (2009a), 47ff. sowie zusätzlich die Übersicht in Anhang 2.

816 Quelle: Darstellung angelehnt an Dt. Börse AG (2009a), S. 7, ohne ,Entry Standard ‘

Tom Sieber - 978-3-631-75150-3 
bzw. Versicherungsbranche wird exkludiert, da diese Unternehmen gesonderten Publizitätsvorschriften unterliegen. ${ }^{817}$ Eine zusätzliche Reduktion der Stichprobe ergibt sich aus der Festsetzung des Zeitraumes der eigenen Untersuchung auf die Jahre 2002 bis 2008. Zur Sicherstellung der Vollständigkeit der Datengrundlage können nur diejenigen Unternehmen in die Stichprobe übernommen werden, die in diesen sieben Jahren Lageberichte nach HGB vorgelegt haben sowie während des gesamten Zeitraums börsennotiert waren, um mögliche Kapitalmarkteffekte abzuleiten. Ein siebenjähriger Untersuchungszeitraum erscheint zudem nur konsequent, um der langfristigen Ausrichtung strategischer Sachverhalte gerecht zu werden und um längerfristige Tendenzen der Strategieberichterstattung abbilden zu können. Den Prozess der Stichprobenzusammenstellung präsentiert Abb. 15.

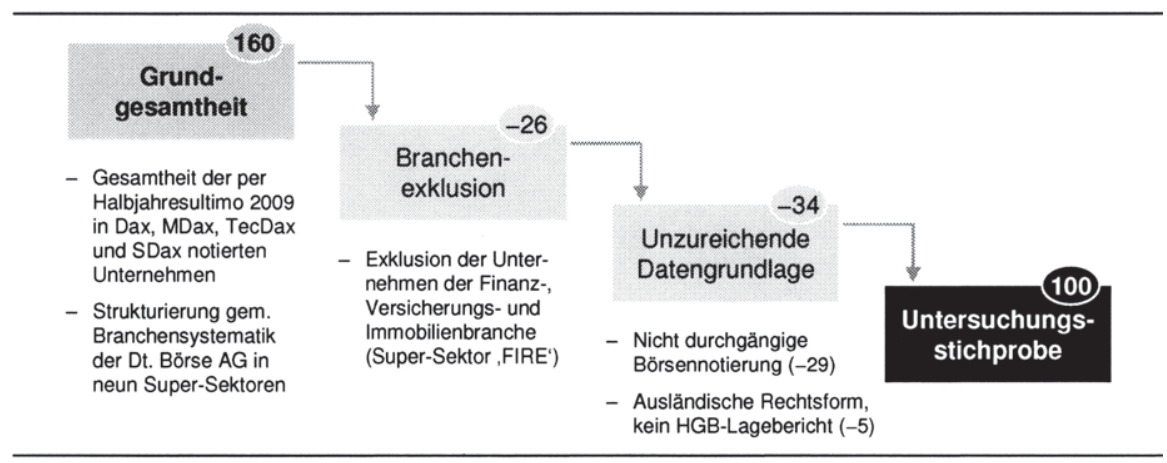

Abbildung 15: Vorgehensweise der Stichprobenzusammenstellung ${ }^{818}$

Unter Beachtung jener genannten Reduktionen können aus der Grundgesamtheit insg. 100 Merkmalsträger in die Stichprobe aufgenommen werden, diese Untersuchung basiert ergo in Summe auf 700 Beobachtungen. Zur empirischen Überprüfung der 21 Forschungshypothesen wird schließlich mit einer aus diesen 700 ,Unternehmensjahren' zusammengesetzten Stichprobe gearbeitet. ${ }^{819}$

817 Dies ist konsistent mit zahlreichen Arbeiten, vgl. u.a. Fischer/Vielmeyer (2004), Kajüter (2001), Achleitner et al. (2005), Cheng/Courtenay (2006), zudem Hail (2002).

818 Quelle: eigene Darstellung. Eine Auflistung der Unternehmen der Grundgesamtheit sowie Details zur Stichprobenzusammenstellung stellt Anhang 1 dieser Arbeit dar.

819 Das Untersuchungsdesign eines, gepoolten Samples ‘ verwenden bspw. auch Gebhardt et al. (2001), Botosan/Plumlee (2001), Petersen/Plenborg (2006). Die de facto vorliegende Panelstruktur der Stichprobe (100 Objekte, sieben Jahre) ist zu beachten, vgl. D 5.4.3. 


\subsubsection{Messung des Niveaus der Strategieberichterstattung}

Im Rahmen der bisherigen Ausführungen zur eigenen Untersuchung ist deutlich geworden, dass der Messung des Niveaus der Strategieberichterstattung zentrale Bedeutung zukommt, da eine etablierte Kennzahl für das Niveau der Berichterstattung zu strategieorientierten Inhalten in der Literatur bisher nicht existiert. ${ }^{820}$

Zudem ist offensichtlich, dass ein einfaches Ablesen des Niveaus der Strategieberichterstattung nicht möglich ist, vielmehr ist daher ein geeignetes Instrument zu konzipieren, welches Aussagen über die unternehmensspezifische Berichterstattung zulässt. Dieses Vorgehen ist konsistent mit der Aussage Schmalenbachs (1963), der postuliert: „Was man messen kann, soll man messen; was man nicht messen kann, soll man messbar machen. ${ }^{\text {(821 }}$ Dem folgend ist eine adäquate Vorgehensweise zur Messung des Niveaus der Strategieberichterstattung abzuleiten.

Dabei wird zunächst dargestellt, weshalb eine Fokussierung auf den Lagebericht zur Messung der Strategieberichterstattung sinnvoll ist. Sodann ist die Methodik der Messung abzuleiten und ein normativer Berichtskatalog aufzustellen, der als Maßstab der Messung angewendet wird. Abschließend ist aufzuzeigen, wie auf dieser Basis eine Kennzahl für das Niveau der Strategieberichterstattung hergeleitet werden kann, die unmittelbar Eingang in die Untersuchung finden wird.

\section{(a) Untersuchung der Strategieberichterstattung im Lagebericht}

Im theoretischen Teil dieser Arbeit wurde festgestellt, dass das Management im Lagebericht zur Unternehmensstrategie Stellung nehmen könnte, um die künftig angestrebte Entwicklung der Gesellschaft zu vermitteln. Dies war der Ausgangspunkt, explizit die Strategieberichterstattung deutscher Unternehmen im Lagebericht, als elementaren Bestandteil des Geschäftsberichts, zu untersuchen, der für die Aufnahme strategieorientierter Inhalte hervorragend geeignet wäre.

Eine Fokussierung der eigenen Untersuchung auf den Geschäftsbericht wird zudem durch seine herausgehobene Bedeutung in der Kapitalmarktkommunikation

820) Vgl. hierzu nochmals die Übersicht über die relevante Literatur in Abschnitt C 2.3 bzw. die Alleinstellungsmerkmale der eigenen Untersuchung in Abschnitt C 2.4.

821 Schmalenbach (1963), S. 145. Diese Aussage kann gleichfalls als Grundlage moderner Controlling-Konzeptionen angesehen werden, vgl. Weißenberger (2002), S. $399 \mathrm{ff}$. 
gerechtfertigt ${ }^{822}$ - er ist das wesentliche Element der Finanzkommunikation: „the annual report is generally considered to be one of the most important sources of corporate information. ${ }^{\text {(823 }}$ Auch empirische Studien bestätigen die Rolle als bevorzugtes Instrument zur Beurteilung der aktuellen Lage sowie zukünftigen Entwicklung von Unternehmen, insb. Finanzanalysten und institutionelle Investoren stufen den Geschäftsbericht als wesentliches Informationsinstrument ein. ${ }^{824}$ Der Geschäftsbericht wird daher auch als ein „Disclosure Package“ bezeichnet, weil er eine Vielzahl von Einzelinformationen in einem Baustein der Unternehmenskommunikation vereint. ${ }^{825}$ Als maßgeblich für das hohe Ansehen des Geschäftsberichts wird primär der verbindliche Charakter dieses Instruments angesehen. ${ }^{826}$ Darüber hinaus gilt auch die Flexibilität der Veröffentlichung sowie inhaltlichen Gestaltung als gewichtiges Argument für seine Bedeutung - es wird offensicht-

822 Vgl. z.B. Hütten (2000), S. 84f.; Hütten/Küting (2001), S. 490; Bracklo/Bilstein (2002), S. 230ff. Weiterhin zur Aufgabe der Informationsvermittlung des Geschäftsberichts ausführlich Küting et al. (1995a), S. 1806 sowie dies. (1995b).

Unter dem Begriff ,Geschäftsbericht' wird stets die gemeinsame Veröffentlichung eines Konzernabschlusses und Konzernlageberichts verstanden, siehe auch Abschnitt B 3.1.3. In der englischsprachigen Literatur wird hierfür der Begriff, annual report " verwandt. Botosan (1997a), S. 331, auch Botosan (2002), S. 22f. Ähnlich in der deutschsprachigen Literatur zudem Drill (1995), S. 117, Frei (1998), S. 177, Schlienkamp (1998), S. 221; Kirchhoff (2001), S. 43f.; Ordelheide (1998), S. 506. Dieser wird als das „Flaggschiff“ der Unternehmenskommunikation gesehen, so Meyer (1997), S. 5; Hütten (2000), S. 84. Vgl. z.B. die Arbeiten von Fochler/Fugger (1997), S. 136f., Hail (2002), S. 746; speziell zu Analysten Gibson (1987), S. 74; Pike et al. (1993); Previts et al. (1994). Chang et al. (1983) bestätigen durch Befragung von über 4.000 Privatanlegern sowie 900 Analysten gleichfalls den Geschäftsbericht als das wichtigste Informationsinstrument. Vergoossen (1993), S. 239 prägnant: „The most recent annual report is considered to be significantly more important than any other sources of information." Ähnlich Day (1986), S. 295.

Mit Fokus auf Deutschland zeigen Schulz (1999), Günther/Otterbein (1996) bzw. Ernst et al. (2009), dass dem Geschäftsbericht große Bedeutung innerhalb der Informationsinstrumente beigemessen wird. Tiemann (1997), S. 45 beschreibt den Geschäftsbericht als das wichtigste Investor Relations-Instrument. Stauber (2004), S. 110f. verweist hier auf die Rolle jährlicher Wettbewerbe zur Qualitätseinschätzung von Geschäftsberichten wie bspw. der des ,manager magazins', so auch Meyer (1997), S. 214f.; Frei (1998), S. 177. Wörtlich bei Gray et al. (1995), S. 45, im Original jedoch nicht in Großschreibung.

Vgl. z.B. AKEU (2002), S. 2337, der die ausführlichen und umfassenden Darstellungsmöglichkeiten des Geschäftsberichts sowie den verbindlichen Charakter würdigt. Daher wird der Geschäftsbericht auch als primäres Medium einer erweiterten Berichterstattung empfohlen. Auch Clarkson et al. (1999), S. 117ff. gehen davon aus, dass die Formalität des Informationskanals ,Geschäftsbericht ' die Glaubwürdigkeit und Verlässlichkeit der enthaltenen Informationen erhöht. 
lich, dass sich dieser Aspekt in erster Linie auf den Lagebericht bezieht, der für die Berichterstattung zu Strategieinhalten als geeignet herausgearbeitet wurde. ${ }^{827}$ Jedoch stellt der Geschäfts- und insb. der Lagebericht - trotz der unbestrittenen Bedeutung - natürlich nur eines von zahlreichen Instrumenten der Kapitalmarktkommunikation börsennotierter Unternehmen dar. Insofern ist zu argumentieren, weshalb trotz der Konzentration auf den Lagebericht Aussagen über das gesamthafte Niveau einer Strategieberichterstattung statthaft sind: Der Geschäftsbericht gilt in der Literatur verbreitet als zuverlässiger Indikator ${ }^{828}$ der gesamten Unternehmensberichterstattung, denn ,although the annual report is only one means of corporate reporting, it should serve as a good proxy for the level of voluntary disclosure provided by a firm across all disclosure avenues. ${ }^{\text {( } 829}$ Dies basiert auf der Annahme, dass Unternehmen grds. individuelle Veröffentlichungsstrategien wählen und sodann sämtliche Veröffentlichungen entsprechend dieser Strategie koordinieren. ${ }^{830}$ Dabei wird folglich auf die jeweilige Entscheidung eines Unter-

827 Vgl. Günther/Otterbein (1996), S. 404; Frey (2001), S. 112 und Abschnitt B 4.3. Dieser gilt als ,perhaps the most useful part of the annual report", so Knutson (1992), S. 7.

828 Vgl. Lang/Lundholm (1993); Botosan (1997a); Hail (2002), S. 746. Implizit teilen diese Auffassung alle Autoren, die sich auf den Geschäftsbericht konzentrieren, um Aussagen über das Berichtsverhalten herzuleiten. Vgl. umfassend die Beispiele in Abschnitt C 2.3. Lapointe-Autunes et al. (2006), S. 466 fassen die Begründung zusammen: „The decision to focus on annual reports is justified by the results of Lang and Lundholm (1993) and Botosan (1997) who find evidence of a [...] correlation between annual reports and other forms of disclosure, $[\ldots]$ a measure of disclosure level produced by examining any one aspect of corporate reporting could proxy for the general level of disclosure provided by a firm." Auf dieser Basis kann eine Konzentration auf den Lagebericht fundiert werden. Botosan (1997a), S. 329.

831) Vgl. Lang/Lundholm (1993). Die Autoren beschreiben dies als ,Disclosure Policy', der letztlich sämtliche Publikationen folgen. Vergleichbar auch Einhorn (2005), S. 613. Hail (2002), S. 746 bestätigt, dass eine Konzentration auf Geschäftsberichte als Indikator für die gesamte Berichterstattung zu konsistenten Aussagen führt, und verweist zudem auf den Vorteil der Vergleichbarkeit dieses Berichterstattungsinstruments dank einheitlicher Struktur und obligatorischer, periodischer Vorlage: ,The restriction to a single source of corporate information, although quite rigid, offers several advantages." Alternativ wären sämtliche Veröffentlichungskanäle, formale sowie informale, im Zusammenhang zu betrachten, was jedoch kaum realisierbar sein dürfte. Folglich scheint gerade der jährliche Geschäftsbericht ein solider ,Proxy' für alle Veröffentlichungen eines Unternehmens zu sein. Ebenso stellt daher Knutson (1992), S. 7 fest: „At the top of every analyst's list is the annual report [...]. It is the major reporting document and every other [...] report is in some respect subsidiary or supplementary to it." 
nehmens abgestellt, über den Umfang der verpflichtenden Berichterstattung hinaus freiwillige Berichtsinhalte bereitzustellen - diese Entscheidung manifestiert sich geradezu in besonderer Weise im Lagebericht, der im Gegensatz zu anderen Publikationsinstrumenten verpflichtende und gleichermaßen auch freiwillige Berichtsinhalte enthält. ${ }^{831}$ Die Eignung des Lageberichts als Grundlage einer Untersuchung des Berichtsverhaltens wird schließlich durch die in der Literatur anzutreffende Empfehlung unterstützt, Untersuchungen freiwilliger Berichterstattung stets im Kontext verpflichtender Berichterstattung durchzuführen, also simultane Analysen obligatorischer und freiwilliger Berichtselemente vorzunehmen: „The information flow through each of the two [...] communication channels in capital markets, firms' mandatory and voluntary disclosures, cannot be [...] understood without taking into consideration the interaction between them." ${ }^{432}$

Weiterhin erscheint nachvollziehbar, bei einer Betrachtung der Berichterstattung zu strategieorientierten Sachverhalten auf Informationen abzustellen, die seitens eines Unternehmens selbst bereitgestellt werden. Die langfristige Gestaltung der Unternehmensentwicklung ist als zentrale Aufgabe des Managements abgeleitet worden, eine Berichterstattung über diese angestrebte Entwicklungsrichtung hat sodann konsequenterweise in erster Linie durch das Management zu erfolgen. ${ }^{833}$ Der langfristige sowie periodenübergreifende Charakter von strategieorientierten Sachverhalten ermöglicht es zudem, auf Basis des nur einmal jährlich veröffentlichten Mediums Lagebericht valide Rückschlüsse in Bezug auf das gesamthafte Kommunikationsverhalten eines Unternehmens zur Strategie abzuleiten.

Auf der Grundlage dieser Argumentation fokussiert die eigene Untersuchung der Strategieberichterstattung also auf die im Lagebericht enthaltenen Informationen

831 Vgl. hierzu die Ausführungen in den Abschnitten B 4.3 und B 4.4 dieser Arbeit.

832 Einhorn (2005), S. 613. Diese Ansicht unterstreicht die Relevanz des Geschäftsberichts als Analysebasis für Aussagen zum Berichterstattungsverhalten von Unternehmen. Dies gilt insb. für Analysen des Berichtsverhaltens bzgl. freiwilliger Angaben: „In particular, firms' strategies for providing voluntary disclosures cannot be studied in isolation without considering the impact of their mandatory disclosures", ebenda, S. 613f.

833 Vgl. mit ähnlicher Argumentation Einhorn (2005), S. 613. Obwohl auch andere Parteien als das Unternehmen selbst regelmäßig Informationen über dieses veröffentlichen, z.B. Finanzanalysten und die Fachpresse, ist zu fordern, dass v.a. strategische Informationen direkt vom Unternehmen veröffentlicht werden, um Glaubwürdigkeit sicherzustellen.

Tom Sieber - 978-3-631-75150-3 
zur Unternehmensstrategie. Eine empirische Prüfung der im theoretischen Teil angestellten Überlegung, dass der Lagebericht nicht nur formal zur Strategieberichterstattung geeignet ist, sondern seine inhaltliche Ausrichtung entsprechende Informationen geradezu erfordert, scheint insofern methodisch fundiert und eine Ableitung von generellen Aussagen zur Strategieberichterstattung gerechtfertigt.

Die insg. 700 Lageberichte der Jahre 2002 bis 2008 der 100 Unternehmen innerhalb der Stichprobe werden von den Unternehmen direkt bezogen, entweder auf dem Postweg oder als offizielle, im Internet bereitgestellte Versionen. ${ }^{834}$

\section{(b) Optionen der Messung des Niveaus der Strategieberichterstattung}

Wie dargestellt, verfolgt diese Untersuchung das Ziel, das Niveau der strategieorientierten Angaben im Lagebericht deutscher börsennotierter Unternehmen zu erheben, um auf dieser Basis allgemeingültige Aussagen zur Strategieberichterstattung abzuleiten. Eine wesentliche Voraussetzung hierfür ist offensichtlich in der Messung des Niveaus der Berichterstattung über strategieorientierte Inhalte zu finden, da ein schlichtes Ablesen nicht möglich ist bzw. sich derartige Inhalte aufgrund ihres i.d.R. verbal-qualitativen Charakters einer direkten Messung entziehen: „Disclosure is an abstract concept that cannot be measured directly. “ 835

In der einschlägigen Literatur werden folglich grds. zwei alternative Vorgehensweisen genutzt, um das Niveau der Berichterstattung entweder gesamthaft oder in Bezug auf spezifische Aspekte zu ermitteln. Die Mehrheit der Arbeiten in der angelsächsischen Literatur basiert auf extern verfügbaren ,Disclosure Rankings‘,

834 Die 700 Lageberichte werden also aus den jeweils publizierten Geschäftsberichten entnommen. In methodischer Hinsicht ist anzumerken, dass die Identität jener Berichte mit den beim Bundesanzeiger eingereichten Exemplaren nicht überprüft wurde, da dies bei großen Publikumsgesellschaften als erfüllt vorausgesetzt werden konnte. Vgl. zu dieser Thematik bspw. Meisinger/Wenzler (1992), S. 445, auch Ballwieser (1997a), S. 153.

Ggf. vom Kalenderjahr abweichende Geschäftsjahre werden grds. dem Kalenderjahr zugeordnet, in dem der Schwerpunkt des Geschäftsjahres liegt. Mit ähnlicher Vorgehensweise vgl. bspw. Fischer/Vielmeyer (2004), S. 467f. Geschäftsberichte bzgl. Rumpfgegeschäftsjahren innerhalb des Untersuchungszeitraumes werden dann als eigenständige Geschäftsberichte betrachtet, sofern der jeweilige Zeitraum eines Rumpfgeschäftsjahres sechs Monate übersteigt. Vgl. im Detail C 3.2.3 sowie Anhang 5.

835 Cooke/Wallace (1989), S. 51, die die Verwendung eines spezifischen Messinstruments zur Ermittlung des Niveaus der Berichterstattung als einen „suitable proxy“ beurteilen. Ähnlicher Hinweis auch bei Collins et al. (2002); Schipper/Vincent (2003), S. 97. 
mit denen das Niveau der Berichterstattung approximiert wird. ${ }^{836}$ Zudem werden andere, relativ einfach zu ermittelnde Hilfsgrößen für das Berichterstattungsverhalten angewendet, wie z.B. die Anzahl vom Management selbst veröffentlichter Ergebnisprognosen oder die Anzahl durchgeführter Telefonkonferenzen. ${ }^{837}$

Die alternative Vorgehensweise nimmt eine wesentlich detailliertere, inhaltliche Betrachtung der Berichterstattung vor und leitet auf Basis eines normativ aufgestellten Kriterienkataloges einen ,Disclosure Index ${ }^{638}$ ab, um auf der Grundlage eines derartigen quantitativen Instruments das individuelle Niveau der Berichterstattung eines Unternehmens zu bestimmen. ${ }^{839}$ Dazu werden spezifische Berichterstattungsangaben - entsprechend dem jeweiligen Untersuchungsinteresse - inhaltsanalytisch geprüft und das Vorhandensein sowie die inhaltliche Ausprägung einzelner Informationen bewertet. Der Konzeption des Disclosure Index folgend können sodann unternehmensindividuelle ,Disclosure Scores“ ermittelt werden,

836 Vgl. zu dieser Feststellung auch Banghoj/Plenborg (2008), S. 167. Die meisten Arbeiten basieren auf dem sog. ,AIMR Ranking،, welches die US-amerikanische ,Association of Investment Management and Research' (AIMR) jährlich auf Grundlage der Analyse der Geschäftsberichte vorlegt. Es handelt sich hierbei im Kern um „Analysts' evaluations of firms' disclosure practices provided in the annual report", so Healy et al. (1999), S. 488. Vgl. zum Prozess der Ermittlung dieses ,AIMR Ranking“ ebenda, S. 490ff. Beispielhaft für die Verwendung des ,AIMR Ranking، sind Lang/Lundholm (1993) zu nennen, auch Welker (1995), Healy et al. (1999), Bushee/Noe (2000) sowie Botosan/Plumlee (2002). Zur Kritik siehe z.B. Leuz/Verrecchia (2000), S. 94: „A concern with disclosure ratings, however, is that they represent only analysts' perceptions of voluntary disclosures."

Seit 2004 firmiert die AIMR als ,CFA Institute“ (Institut der ,Chartered Financial Analysts‘ (CFA)). Ihre Wurzeln liegen in der 1947 gegründeten ,Financial Analysts Federation" (FAF), die mit dem ,Institute of Chartered Financial Analysts" (ICFA) fusionierte und dann als AIMR auftrat. Zur Geschichte und Mission vgl. CFA Institute (2009).

Beispiele für Studien, welche die Anzahl der durchgeführten Telefonkonferenzen als Indikatorgröße für das Berichtsverhalten verwenden, sind Tasker (1998) und Frankel et al. (1999), Bushee et al. (2003), Marston (2008). Brooks et al. (1997), Francis et al. (1997) nutzen die Anzahl von CEO-Präsentationen. Coller/Yohn (1997) sowie Lang/Lundholm (2000) sind Beispiele für Arbeiten, die freiwillige Ergebnisprognosen verwenden.

838 Ein Index sei hier grds. als Messinstrument für ein komplexes Merkmal verstanden, der sich auf Basis mehrerer Items ermitteln lässt, vgl. so Bortz/Döring (2006), S. 143ff. Ein Disclosure Index wird schließlich als ,extensive list of selected items which may be disclosed in company reports“ beschrieben, so Marston/Shrives (1991), S. 195.

Beispielhaft sei auf frühe Arbeiten verwiesen, die als methodische Vorreiter für die Anwendung von Berichterstattungs-Indizes gelten können. Diese Vorgehensweise wählen insb. Cerf (1961), Singhvi/Desai (1971), Choi (1973), Buzby (1975). Nachfolgend wird diese Methodik wieder aufgegriffen durch Chow/Wong-Boren (1987), Botosan (1997a). 
die das jeweilige Niveau der Berichterstattung oder „Levels of Disclosure“ bzgl. konkreter Sachverhalte widerspiegeln. ${ }^{840}$ Obgleich die Methode der spezifischen bzw. unmittelbaren Inhaltsanalyse der Berichterstattung innerhalb der relevanten Literatur deutlich seltener verwendet wird als die alternative Methodik auf Basis extern verfügbarer Kennzahlen, soll die eigene Untersuchung - in Anlehnung an bisherige Arbeiten - auf einem zu konstruierenden ,Strategy Disclosure Index ‘ aufsetzen. ${ }^{841}$ Die Begründung folgt konsequenterweise aus der Methodik selbst:

Als zentraler Vorteil der Analyse der Berichterstattung anhand eines eigens konstruierten Instruments muss insb. gelten, dass nur auf diesem Wege spezifische, auf das jeweilige Untersuchungsinteresse abgestimmte Berichtsinhalte überprüft werden können und so das individuelle Berichtsverhalten zu relevanten Sachverhalten auf eine Kennziffer verdichtet wird. ${ }^{842}$ Die Untersuchung ist folglich nicht auf Analyseergebnisse Dritter angewiesen, die i.d.R. breite Berichtsumfänge abbilden oder aber oftmals gar nicht für alle Merkmalsträger verfügbar sind. ${ }^{843} \mathrm{Die}$ Untersuchung spezifischer inhaltlicher Aspekte liefert dagegen unmittelbar kon-

840 Vgl. für jüngere Arbeiten, welche die Berichterstattung mit Hilfe von Disclosure Indizes analysieren, Meek et al. (1995), die zudem den zitierten Begriff verwenden, siehe ebenda, S. 558. Auch Hossain et al. (1995), Ferguson et al. (2002), Bhojraj et al. (2004) oder Jones (2007). Das Gros dieser Arbeiten befasst sich insg. mit dem Niveau der Berichterstattung. Vgl. jüngst Banghoj/Plenborg (2008) mit einem breiten Disclosure-Katalog.

Eine Bezeichnung des eigenen Messinstruments als ,Strategy Disclosure Index ‘ erfolgt in Anlehnung an Botosan (1997b). In der deutschsprachigen Literatur verwenden bisher nur Fischer/Vielmeyer (2004) den Begriff ,Disclosure Index ‘ für eine Untersuchung der Risikoberichterstattung dt. Unternehmen. Im Rahmen der Analyse der Prognoseberichterstattung legt jüngst auch Barth (2009) eine Arbeit vor, die auf einem Index basiert.

842 Externe Daten wie bspw. die Berichtskataloge der AIMR nehmen meist eine sehr breite Perspektive ein, eine Fokussierung der Analyse auf spezifischere Sachverhalte im Sinne des jeweiligen Untersuchungsinteresses ist nur dann überhaupt möglich, wenn detailliert Transparenz über einzelne Bewertungsschritte vorhanden ist.

84. Der Hinweis findet sich bspw. bei Banghoj/Plenborg (2008), S. 167f. Diese vermerken, dass jene Rankings weder international einheitlich, noch für nicht börsennotierte Unternehmen verfügbar sind. Gerade in kleineren Ländern (hier: Dänemark) sind daher selbst konstruierte Indizes zwingend erforderlich, ähnlich auch Baetge et al. (2010), S. 75.

Leuz/Verrecchia (2000), S. 94f. merken kritisch an, dass sich externe Rankings auf Einschätzungen von Analysten beziehen und eben nur deren Wahrnehmung wiedergeben eine systematische Überlegenheit lässt sich auf dieser Grundlage nicht rechtfertigen.

Francis et al. (2008), S. 62 bescheinigen externen Ratings intransparentere Prozesse der Ermittlung entsprechender Kennzahlen und bestätigen zudem, dass derartige Daten fast ausschließlich für große Unternehmen verfügbar sind. Auch Botosan (1997a), S. 326f. 
krete Daten zum Niveau der relevanten Angaben, wie bspw. strategieorientierter Informationen - und macht diese einer umfassenden bzw. systematischen Untersuchung überhaupt erst zugänglich: ${ }^{844}$ Ein spezifisch definiertes Messinstrument bewirkt folglich ,increased confidence that the metric truly captures what is intended ${ }^{4845}$ und unter Verweis auf frühe Arbeiten mit Disclosure Scores resümiert Botosan (1997a): „Prior studies that use disclosure indices [...] have documented consistently strong and corroborative results. This prior work [...] demonstrates that disclosure indices are a useful research tool.“846

Als ein weiteres gewichtiges Argument für eine Verwendung eines spezifischen und selbst definierten Messinstruments zur Messung des Niveaus der Strategieberichterstattung kann außerdem die Möglichkeit gelten, in einer simultanen Betrachtung sowohl quantitative als auch qualitative Aspekte der Berichterstattung zu erheben. Dies kann durch eine entsprechende zweckorientierte Ausgestaltung des konkret zugrunde gelegten normativen Berichtskatalogs geschehen: „Theory is sufficiently broad as to allow the notion 'increased levels of disclosure' to be interpreted as either an increase in the quantity of disclosure or an increase in the quality of disclosure (or both). “847

Dennoch müssen auch Einwände gegen selbst konstruierte Kennzahlen der Berichterstattung behandelt werden. In erster Linie wird hier grds. die Subjektivität einer Bewertung genannt: „However, [...] disclosure level is not easily measured because [...] application of a disclosure index requires subjective assessments by the researcher applying the technique. ${ }^{، 848}$ Zudem ist die Nachvollziehbarkeit der

844 Vgl. Francis et al. (2008), S. 62f. Ähnlich Fischer/Vielmeyer (2004), S. 465.

845 Healy/Palepu (2001), S. 427, stellvertretend für viele auch Francis et al. (2008), S. 62.

846 Botosan (1997a), S. 335. Die Autorin macht sich, wie bereits erwähnt (siehe Fn. 79), in jener Arbeit die festgestellte Leistungsfähigkeit eines Disclosure Index zunutze. der Terminus ,Niveau“ wegen der ,expositional convenience“ verwendet wird und sich nicht exklusiv auf die Quantität oder Qualität der Berichterstattung bezieht. Vgl. ebenso Bushee/Noe (2000), S. 173; Banghoj/Plenborg (2008), S. 167; Botosan (1997a), S. 324. Dieser Sichtweise wird hier explizit gefolgt, daher wurde innerhalb der bisherigen Ausführungen stets die Formulierung, Niveau der Strategieberichterstattung ' verwandt. Der nachfolgend abzuleitende normative Berichtskatalog wird die Strategieberichterstattung sowohl in quantitativer wie auch in qualitativer Hinsicht berücksichtigen. 
Bewertung zu berücksichtigen. Innerhalb der einschlägigen Literatur wird aber grds. akzeptiert, dass diese potenziellen Einschränkungen der Aussagekraft eines spezifischen Messinstruments bereits im Rahmen der Definition bzw. Ableitung desselbigen vermieden werden können. ${ }^{849}$ Weiterhin hat im Nachgang zum Einsatz des Instruments eine Validierung der Messwerte zu erfolgen: „As a result, it is important to assess the validity of the resulting measure. ${ }^{، 850}$ Bei der nun darzulegenden Konstruktion eines proprietären Messinstruments, also des ,Strategy Disclosure Index ' sind diese Anforderungen an die Objektivität und Transparenz bzw. Nachvollziehbarkeit folglich ausdrücklich zu beachten. Zusätzlich ist nach Erhebung der Messwerte eine Validierung der Daten einzuplanen, um somit eine möglichst hohe Aussagekraft des Messinstruments sicherzustellen. ${ }^{851}$

\section{(c) Inhaltliche Sicht: Kriterienkatalog einer Strategieberichterstattung}

Im Rahmen der eigenen Untersuchung soll also das Niveau der Strategieberichterstattung von deutschen börsennotierten Unternehmen unter Anwendung eines ,Strategy Disclosure Index ‘ (SDI) bzw. durch die Ermittlung von unternehmensindividuellen ,Strategy Disclosure Scores “ (SDS) dargestellt werden. ${ }^{852}$ Benötigt wird für die methodisch korrekte Anwendung dieses Instruments ein Soll-Objekt der Berichterstattung, also ein normativer Berichtskatalog, der sodann als Basis einer empirischen Überprüfung der Strategieberichterstattung aller StichprobenUnternehmen dient. ${ }^{853}$ Bevor allerdings ein eigener normativer Kriterienkatalog aufgestellt wird, sind zunächst erprobte, ${ }^{854}$ innerhalb der Disclosure-Literatur bereits verwendete Kriterienkataloge dahingehend zu untersuchen, inwieweit diese inhaltliche Aspekte zur Strategie inkludieren, um ggf. auf diesen aufzusetzen.

849 Vgl. z.B. Francis et al. (2008), S. 63. Die eigene Untersuchung folgt daher einem transparenten und nachvollziehbaren Bewertungsprozess, der nachfolgend beschrieben wird.

850

851

852

853

854 Botosan (1997a), S. 335, exemplarisch für viele Beiträge in der einschlägigen Literatur. Eine Prüfung der Validität der hier erhobenen Messwerte erfolgt in D 3.1.2.

Im weiteren Verlauf werden - der Einfachheit halber - auch die Kurzformen ,SDI' bzw. ,SDIndex ‘ sowie ,SDS‘ bzw. ,SDScore‘ verwendet. Sowohl für die Kurzform wie auch für die explizite Schreibweise wird im Folgenden auf Anführungszeichen verzichtet. SDScores stellen die konkret ermittelten Messwerte des Messinstruments SDIndex dar. Vgl. z.B. Coenenberg et al. (1978), die die Entwicklung eines Soll-Objektes postulieren. Erwähnt wurde, dass die Strategieberichterstattung bisher weder gezielt noch umfassend analysiert wurde, doch besitzen einige Studien Berichtselemente Bezug zur Strategie. 
Wie nachfolgende Tab. 1 aufzeigt, kann eine Reihe bereits vorgelegter Arbeiten, die sich in z.T. sehr umfassender Sicht mit dem Niveau der allgemeinen Unternehmensberichterstattung auseinandersetzen, erste inhaltliche Anhaltspunkte für eine Analyse der Berichterstattung zu strategieorientierten Aspekten liefern. ${ }^{855}$

Bei der Betrachtung dieser Studien wird jedoch deutlich, dass grds. nur einzelne Berichtselemente bzgl. strategieorientierter Informationen berücksichtigt werden bzw. diese zumeist auch in unterschiedlichen Kategorien von Berichtselementen enthalten sind. ${ }^{856}$ Eine explizite Kategorie mit Inhalten zur ,Strategie ' findet sich nur vereinzelt und oftmals werden sodann nicht ausschließlich Strategieelemente betrachtet. Zudem werden recht breite Definitionen von ,Strategie ' verwandt. ${ }^{857}$

Darüber hinaus wird keine dieser Studien der im Rahmen der theoretischen Ausführungen aufgestellten Forderung gerecht, dass eine adäquate Strategieberichterstattung ein prozessual ganzheitliches Verständnis von Strategie zu vermitteln hat: Bis dato sind in der einschlägigen Literatur nur vereinzelte Informationselemente der strategischen Analyse sowie zur Strategieformulierung berücksichtigt worden, eine gesamthafte Sicht der Strategie wird grds. nicht eingenommen. ${ }^{858}$

Schließlich ist zu kritisieren, dass der Begriff der Strategie in den vorliegenden Kriterienkatalogen weitestgehend undifferenziert verwandt wird, ohne bspw. zu spezifizieren, auf welche Ebene der Strategie die jeweilige Arbeit abstellt. ${ }^{859}$

855 Bei jener Zusammenstellung wurde darauf geachtet, einen aussagekräftigen Querschnitt bisheriger Arbeiten vorzulegen, welche auf Disclosure Indizes basieren. Arbeiten, die in Anlehnung an vorhergehende Studien erstellt wurden, sind daher nicht aufgeführt. Dies betrifft u.a. die Arbeit von Ferguson et al. (2002), die ihren Index an Meek et al. (1995) anlehnen, auch Petersen/Plenborg (2006), Cheng/Courtenay (2006), Wang et al. (2008). Gleichfalls nicht aufgeführt sind die eher, klassischen ' Arbeiten unter Verwendung von Scoring-Modellen, zu finden v.a. bei Cerf (1961), Singhvi/Desai (1971), Buzby (1975). Beispielhaft sei die Arbeit von Hossain et al. (1995) erwähnt, welche strategieorientierte Berichtselemente in insgesamt drei von elf Berichtskategorien vorsehen.

857 Vgl. bspw. Meek et al. (1995). Die Kategorie ,Strategic Information ' beinhaltet im konkreten Falle u.a. Informationen zur Historie des Unternehmens sowie Prognoseangaben bzgl. künftiger Cashflows und auch Informationen zum gegenwärtigen Auftragsbestand. Eine gesamthafte Perspektive sollte Informationen zu Unternehmenszielen, zu zentralen Ergebnissen der strategischen Analyse, zur formulierten Strategie bzw. ihrer Umsetzung vermitteln. Jene Sichtweise vertreten u.a. auch Baetge/Heumann (2006a), S. 44. Vgl. zu einzelnen Phasen des Strategieprozesses im Detail den Abschnitt B 2.2.3 dieser Arbeit. 


\begin{tabular}{|c|c|c|c|c|c|}
\hline & \multicolumn{3}{|c|}{ Kriterienkatalog } & \multicolumn{2}{|c|}{ Ableitung Disclosure Score } \\
\hline & $\begin{array}{l}\text { Kriterien / } \\
\text { Kategorien }\end{array}$ & $\begin{array}{l}\text { Kategorien mit } \\
\text { Strategieinhalten }\end{array}$ & $\begin{array}{l}\text { Spezifische Strategieinhalte } \\
\text { (Kern-Berichtskriterien) }\end{array}$ & $\begin{array}{l}\text { Bewertung } \\
\text { der Kriterien }\end{array}$ & $\begin{array}{l}\text { Berechnung } \\
\text { Endresultat }\end{array}$ \\
\hline $\begin{array}{l}\text { Chow/ } \\
\text { Wong- } \\
\text { Boren } \\
(1987) \\
\end{array}$ & $24 / 1$ & - & $\begin{array}{l}\text { - Unternehmensziele } \\
\text { - Entwicklungsprojekte }\end{array}$ & $\begin{array}{l}\text { Binäre } \\
\text { Kodierung (ein } \\
\text { Punkt, falls Ver- } \\
\text { öffentlichung) } \\
\end{array}$ & $\begin{array}{l}\text { Multiplikation } \\
\text { mit Gewichten } \\
\text { und sodann } \\
\text { Summation } \\
\end{array}$ \\
\hline $\begin{array}{l}\text { Cooke } \\
\text { (1989) }\end{array}$ & $146 / 8$ & $\begin{array}{l}\text { Projections and } \\
\text { Budgetary } \\
\text { Disclosure }\end{array}$ & $\begin{array}{l}\text { - Unternehmensziele } \\
\text { - Zentrale Einflussfaktoren } \\
\text { - Industrietrends } \\
\text { - Wettbewerbsposition }\end{array}$ & $\begin{array}{l}\text { Binäre } \\
\text { Kodierung }\end{array}$ & $\begin{array}{l}\text { Ungewichtete } \\
\text { Summation, } \\
\text { Normierung } \\
\text { der Scores }\end{array}$ \\
\hline $\begin{array}{l}\text { Hossain } \\
\text { et al. (1995) }\end{array}$ & $95 / 11$ & $\begin{array}{l}\text { - Corporate } \\
\text { Information } \\
\text { - Future Prospects } \\
\text { - Acquisitions }\end{array}$ & $\begin{array}{ll}\text { - Unternehmensziele } \\
\text { - Industrietrends } \\
\text { - Einflussfaktoren der } \\
\text { Geschäftstätigkeit } \\
\text { - Marktwachstum } \\
\end{array}$ & $\begin{array}{l}\text { Binäre } \\
\text { Kodierung }\end{array}$ & $\begin{array}{l}\text { Ungewichtete } \\
\text { Summation, } \\
\text { Maximum von } \\
95 \text { Punkten }\end{array}$ \\
\hline $\begin{array}{l}\text { Meek } \\
\text { et al. (1995) }\end{array}$ & $85 / 3$ & $\begin{array}{l}\text { Strategic } \\
\text { Information }\end{array}$ & $\begin{array}{l}\text { - Untemehmensstrategie } \\
\text { - Akquisitionen } \\
\text { - Forschung und Entwicklung } \\
\text { - Prognoseinformationen }\end{array}$ & $\begin{array}{l}\text { Binäre } \\
\text { Kodierung }\end{array}$ & $\begin{array}{l}\text { Ungewichtete } \\
\text { Summation, } \\
\text { Normierung }\end{array}$ \\
\hline $\begin{array}{l}\text { Gray } \\
\text { et al. (1995) }\end{array}$ & $128 / 12$ & $\begin{array}{l}\text { Corporate } \\
\text { Strategy }\end{array}$ & $\begin{array}{l}\text { - Unternehmensziele } \\
\text { - Unternehmensstrategie } \\
\text { - Finanzielle Prognose }\end{array}$ & $\begin{array}{l}\text { Binäre } \\
\text { Kodierung }\end{array}$ & $\begin{array}{l}\text { Ungewichtete } \\
\text { Summation, } \\
\text { Normierung }\end{array}$ \\
\hline $\begin{array}{l}\text { Botosan } \\
\text { (1997a) }\end{array}$ & $62 / 5$ & $\begin{array}{l}\text { - Background } \\
\text { Information }\end{array}$ & $\begin{array}{l}\text { - Unternehmensziele } \\
\text { - Eintrittsbarrieren } \\
\text { - Wettbewerbsumfeld } \\
\text { - Kernprodukte und -märkte }\end{array}$ & $\begin{array}{l}\text { Grds. binäre } \\
\text { Kodierung, Zu- } \\
\text { satzpunkte bei } \\
\text { Detaillierung }\end{array}$ & $\begin{array}{l}\text { Summation, } \\
\text { Normierung }\end{array}$ \\
\hline $\begin{array}{l}\text { Hail } \\
\text { (2002) }\end{array}$ & $27 / 3$ & $\begin{array}{l}\text { Background and } \\
\text { Non-financial } \\
\text { Information }\end{array}$ & $\begin{array}{l}\text { Wettbewerbsumfeld } \\
\text { - Kritische Erfolgsfaktoren }\end{array}$ & $\begin{array}{l}\text { Grds. binär, bis } \\
\text { zu } 2 \text { Punkte je } \\
\text { Kriterium je } \\
\text { nach Qualität }\end{array}$ & $\begin{array}{l}\text { Ungewichtete } \\
\text { Summation, } \\
\text { Rang-Bildung }\end{array}$ \\
\hline $\begin{array}{l}\text { Vanstraelen } \\
\text { et al. (2003) }\end{array}$ & $65 / 6$ & $\begin{array}{l}\text { Environment of } \\
\text { the Company } \\
\text { - Strategy } \\
\text { - } \quad \text { Trends } \\
\end{array}$ & $\begin{array}{ll}\text { - Eintrittsbarrieren } \\
\text { - Wettbewerbsumfeld } \\
\text { - Kritische Erfolgsfaktoren } \\
\text { - Unternehmensziele } \\
\end{array}$ & $\begin{array}{l}\text { Binäre } \\
\text { Kodierung }\end{array}$ & $\begin{array}{l}\text { Ungewichtete } \\
\text { Summation }\end{array}$ \\
\hline $\begin{array}{l}\text { Bhojraj } \\
\text { et al. (2004) }\end{array}$ & $\begin{array}{l}\text { Insg. drei } \\
\text { Kriterien }\end{array}$ & $\begin{array}{l}\text { Zwei Berichts- } \\
\text { kriterien zur } \\
\text { Strategie } \\
\text { (branchenspez.) } \\
\end{array}$ & $\begin{array}{l}\text { Strategie Kundenbasis } \\
\text { - Strategien bzgl. neuer } \\
\text { Geschäftsbereiche }\end{array}$ & $\begin{array}{l}\text { Binäre } \\
\text { Kodierung }\end{array}$ & $\begin{array}{l}\text { Ungewichtete } \\
\text { Summation }\end{array}$ \\
\hline $\begin{array}{l}\text { Jones } \\
\text { (2007) }\end{array}$ & $53 / 5$ & $\begin{array}{l}\text { Background } \\
\text { - Non-financial } \\
\text { Data } \\
\text { - Management's } \\
\text { Analysis } \\
\end{array}$ & $\begin{array}{ll} & \text { Unternehmensziele } \\
\text { - Eintrittsbarrieren } \\
\text { - Wettbewerbsumfeld } \\
\text { - Industrietrends } \\
\text { - } \text { Chancen und Risiken }\end{array}$ & $\begin{array}{l}\text { Grds. binäre } \\
\text { Kodierung, ggf. } \\
\text { Zusatzpunkt bei } \\
\text { quantitativen } \\
\text { Informationen } \\
\end{array}$ & $\begin{array}{l}\text { Implizite } \\
\text { Gewichtung, } \\
\text { Summation }\end{array}$ \\
\hline $\begin{array}{l}\text { Francis } \\
\text { et al. (2008) }\end{array}$ & $35 / 4$ & $\begin{array}{l}\text { - Historical } \\
\text { Results } \\
\text { - } \begin{array}{l}\text { Projected } \\
\text { Information }\end{array} \\
\end{array}$ & $\begin{array}{l}\text { - Industrietrends } \\
\text { - Unternehmensstrategie } \\
\text { - } \text { Marktanteilsziel }\end{array}$ & $\begin{array}{l}\text { Grds. binäre } \\
\text { Kodierung; } \\
\text { z.T. Kodierung } \\
\text { über Median } \\
\end{array}$ & $\begin{array}{l}\text { Ungewichtete } \\
\text { Summation, } \\
\text { Normierung }\end{array}$ \\
\hline $\begin{array}{l}\text { Banghoj/ } \\
\text { Plenborg } \\
\text { (2008) }\end{array}$ & $62 / 5$ & $\begin{array}{ll}\text { - } & \text { Strategy } \\
\text { - } & \text { Competition } \\
\text { and Outlook } \\
\text { - Marketing } \\
\text { Strategy } \\
\end{array}$ & $\begin{array}{l}\text { - Unternehmensziele } \\
\text { - Unternehmensstrategie } \\
\text { - Wettbewerbsumfeld } \\
\text { - Eintrittsbarrieren } \\
\text { - Marktwachstum }\end{array}$ & $\begin{array}{l}\text { Binäre } \\
\text { Kodierung }\end{array}$ & $\begin{array}{l}\text { Ungewichtete } \\
\text { Summation }\end{array}$ \\
\hline
\end{tabular}


Folglich ist für die eigene Untersuchung ein eigener normativer Berichtskatalog aufzustellen, der als Grundlage für die Messung des Niveaus strategieorientierter Berichtsinhalte innerhalb eines Lageberichts dienen kann und eine ganzheitliche Perspektive der Strategie einnimmt. ${ }^{860}$ Der Anspruch dieses Katalogs muss sein, dass bei Berücksichtigung aller Einzelkriterien ein umfassendes Bild der Unternehmensstrategie gezeichnet wird. ${ }^{861}$ Das sollte - den grds. Bemerkungen in Abschnitt B 2.2.3 folgend - genau dann erfüllt sein, wenn die einzelnen Phasen des Strategieprozesses inhaltlich reflektiert werden: Nur eine Berichterstattung bzgl. Unternehmenszielen, wesentlichen Erkenntnissen der strategischen Analyse, der auf jener Basis abgeleiteten und detaillierten Strategie sowie gleichermaßen zum Prozess und Status der Implementierung erscheint geeignet, die angestrebte Leitplankenfunktion bei der Schätzung künftiger Zahlungsströme zu übernehmen. ${ }^{862}$ Dieser Katalog hat folglich konsequenterweise der logischen Struktur des oben hergeleiteten Strategieprozesses zu entsprechen und unterscheidet sich insofern fundamental von den bisherigen Untersuchungen, die strategieorientierte Inhalte inkludieren. Zudem berücksichtigt der eigene Kriterienkatalog explizit die relevanten Ebenen der Strategie im Unternehmen und erfasst entsprechende Inhalte separat. Den prinzipiellen Aufbau des eigenen Kriterienkataloges zeigt Abb. 16.

860 Dieser inkludiert die in der Literatur genannten Kriterien, die grds. relevante Inhalte behandeln, doch scheinen sie unzureichend, um dem eigenen Anspruch gerecht zu werden. Strenggenommen müsste vorab der jeweilige Adressatenkreis des Berichtskatalogs festgelegt werden, wie Barth (2009), S. 121 fordert. Ausgehend von der theoretischen Basis dieser Arbeit scheint eine Orientierung an externen Investoren sinnhaft, wenngleich alle geforderten strategischen Inhalte grds. auch für andere Anspruchsgruppen relevant sein sollten, wenn der Sichtweise Hahns gefolgt wird, dass die Erhaltung sowie erfolgreiche Weiterentwicklung des Unternehmens - als Oberziel des strategischen Managements die notwendige Voraussetzung für die Erreichung der individuellen Ziele aller einzelnen Anspruchsgruppen des Unternehmens darstellt, vgl. Hahn/Hungenberg (2001), S. 13f.

Dies kann zudem als Begründung für die ausführliche Darstellung der einzelnen Phasen des Strategieprozesses in B 2.2.3 gelten. Allerdings ist grds. anzunehmen, dass auch isolierte Berichtsinhalte zur Strategie Informationsnutzen für die Adressaten entfalten. Jedoch scheint es für ein umfassendes Verständnis der Unternehmensstrategie wesentlich, Transparenz über Ziele und die externen bzw. internen Bedingungen der Geschäftstätigkeit zu besitzen. Sodann wird eine auf dieser Basis abgeleitete Strategie nachvollziehbar und eigene Schlussfolgerungen können angestellt werden. Inhalte zur Umsetzung zeigen die Glaubwürdigkeit des Managements und auch dessen Umsetzungskompetenz auf.

Vgl. ebenso Baetge/Heumann (2006a), S. 44. Die Autoren sind gleichfalls der Meinung, dass Inhalte aus allen Phasen des Strategieprozesses für die Adressaten relevant sind. 


\begin{tabular}{lccc}
\hline & Analyse & Formulierung & Implementierung \\
$\begin{array}{l}\text { Unter- } \\
\text { nehmen }\end{array}$ & $\begin{array}{c}\text { Allgemeine } \\
\text { Rahmen- } \\
\text { bedingungen }\end{array}$ & $\begin{array}{c}\text { Strategische } \\
\text { Ausrichtung } \\
\text { Gesamtunternehmen }\end{array}$ & $\begin{array}{c}\text { Umsetzung \& } \\
\text { Durchsetzung }\end{array}$ \\
$\begin{array}{l}\text { Geschäfts- } \\
\text { bereich }\end{array}$ & $\begin{array}{c}\text { Geschäfts- } \\
\text { spezifische } \\
\text { Bedingungen }\end{array}$ & $\begin{array}{c}\text { Geschäfts- } \\
\text { bereichsstrategien } \\
\text { als Detaillierung }\end{array}$ \\
\hline
\end{tabular}

Abbildung 16: Prinzipieller Aufbau des Kriterienkataloges des SDIndex ${ }^{863}$

Ausgehend von dieser Struktur werden normative Kriterien für eine Prüfung der Strategieberichterstattung aller Stichproben-Unternehmen als konkrete Berichtsanforderungen formuliert, um eine nachvollziehbare und transparente Grundlage der Untersuchung abzuleiten. ${ }^{864}$ Eine Auflistung dieser Untersuchungskriterien, der normative Berichtskatalog, ist als Überblick in Tab. 2 wiedergegeben. ${ }^{865}$ Anhand dieses Katalogs werden die Lageberichte der Unternehmen der Geschäftsjahre 2002 bis 2008 inhaltlich analysiert. Dabei ist anzumerken, dass dieser Berichtskatalog über den gesamten siebenjährigen Untersuchungszeitraum hinweg Gültigkeit besitzt, eine jahresspezifische Differenzierung erfolgt nicht, um so die Vergleichbarkeit der Resultate einzelner Jahre sicherzustellen. ${ }^{866}$

86.3 Quelle: eigene Darstellung in Anlehnung an den Strategieprozess in Abb. 4 (S. 51 ).

864 Die Ableitung des Berichtskataloges erfolgte prozessual durch Sammlung der Berichtselemente zu strategieorientierten Inhalten aus diversen vorliegenden Studien. Neben den in Tab. 1 (S. 201) genannten Arbeiten wurden weitere Kriterienkataloge berücksichtigt, u.a. Fischer et al. (2002); Ruhwedel/Schultze (2002b); Barth (2009), S. 25If. Die so abgeleitete, unstrukturierte Auflistung von Kriterien wurde sodann entsprechend der Logik des Strategieprozesses geordnet. Parallel hierzu wurden in einer explorativen Studie mit eng begrenztem Stichprobenumfang $(n=12)$ die Probanden gebeten, in einem Zeitfenster von 30 Minuten ihrerseits normative Berichtselemente aufzulisten bzw. zu strukturieren. Die Resultate der Studie und der Auflistung aus der Literatur konvergierten deutlich, so dass der Berichtskatalog in Tab. 2 (S. 204) als konsensuales Ergebnis zu betrachten ist. Der Untersuchungsfragebogen, der aus dem Berichtskatalog abgeleitet werden kann, sowie die expliziten Berichtsanforderungen werden in Anhang 6 dieser Arbeit dargestellt. Dieser Untersuchungsbogen wurde für jedes Unternehmen der Stichprobe für jedes Jahr des Untersuchungszeitraums einzeln ausgefüllt auf Basis des jeweiligen Lageberichts. invariant sind, d.h. im Jahre 2002 bestehen identische Informationsbedarfe wie in 2008. 


\begin{tabular}{|c|c|c|c|c|c|}
\hline & \multicolumn{3}{|c|}{ Inhaltliche Aspekte der Strategieberichterstattung } & \multicolumn{2}{|c|}{ Anzahl Kriterien } \\
\hline & Kategorie & & -Kategorie & Sub-Kat. & Kategorie \\
\hline \multirow{6}{*}{$\begin{array}{l}\text { Strategische } \\
\text { Analyse }\end{array}$} & \multirow{3}{*}{$\begin{array}{l}\text { Allgemeine } \\
\text { Rahmen- } \\
\text { bedingungen }\end{array}$} & 1 & Politisch-rechtliches, soziales Umfeld & 2 & \multirow{3}{*}{$\begin{array}{c}6 \\
(15 \%)\end{array}$} \\
\hline & & 2 & Makroökonomische Rahmenbedingungen & 2 & \\
\hline & & 3 & Strategische Ausgangslage Unternehmen & 2 & \\
\hline & \multirow{3}{*}{$\begin{array}{l}\text { Geschäfts- } \\
\text { spezifische } \\
\text { Bedingungen }\end{array}$} & 1 & Marktumfeld & 5 & \multirow{3}{*}{$\begin{array}{c}14 \\
(35 \%)\end{array}$} \\
\hline & & 2 & Wettbewerbsumfeld & 5 & \\
\hline & & 3 & Strategische Ausgangslage Segment & 4 & \\
\hline \multirow{4}{*}{$\begin{array}{l}\text { Strategie- } \\
\text { formulierung } \\
\text { \& -detaillierung }\end{array}$} & \multirow{2}{*}{$\begin{array}{l}\text { Unternehmens- } \\
\text { strategie }\end{array}$} & 1 & Unternehmensstrategische Richtschnur & 2 & \multirow{2}{*}{$\begin{array}{c}5 \\
(12,5 \%)\end{array}$} \\
\hline & & 2 & Formulierung Unternehmensstrategie & 3 & \\
\hline & \multirow{2}{*}{$\begin{array}{l}\text { Geschäfts- } \\
\text { strategie }\end{array}$} & 1 & Formulierung Geschäftsstrategie & 3 & \multirow{2}{*}{$\begin{array}{c}10 \\
(25 \%)\end{array}$} \\
\hline & & 2 & Konkretisierung Geschäftsstrategie & 7 & \\
\hline \multirow{2}{*}{$\begin{array}{l}\text { Strategie- } \\
\text { implementierung }\end{array}$} & & 1 & Umsetzung von Strategien (Sachebene) & 3 & \multirow{2}{*}{$\begin{array}{c}5 \\
(12,5 \%)\end{array}$} \\
\hline & & 2 & Durchsetzung von Strategien (Verhaltensebene) & 2 & \\
\hline Summe & & & & & $40(100 \%)$ \\
\hline
\end{tabular}

Tabelle 2: $\quad$ Normativer Berichtskatalog der Untersuchung (Überblick)

Der in der obigen Tab. 2 skizzierte Berichtskatalog beinhaltet insg. 40 Kriterien bzw. Berichts-Items, die in fünf Kategorien zusammengefasst werden können. ${ }^{867}$ Die Kriterien decken je zur Hälfte die der Strategieentscheidung vor- bzw. nachgelagerten Phasen des Strategieprozesses ab: Während 20 Kriterien den Bereich der Analyse behandeln, sprechen weitere 20 Kriterien den Bereich der Strategieformulierung und -implementierung an. Die relativ hohe Bewertung der Analyse folgt der in B 2.2.3 postulierten Bedeutung dieser Phase des Strategieprozesses.

Weiterhin zeigt der Berichtskatalog in Tab. 2 die konsequente Berücksichtigung der Ebenen der Strategie: Beide Hauptkategorien der Analyse und der Strategieformulierung differenzieren nach strategieorientierten Inhalten in Bezug auf das Gesamtunternehmen und das jeweilige Geschäftssegment, wobei - im Sinne der Relevanz der ,Business Strategy ${ }^{\text {}}-$ mehr Kriterien diese Inhalte adressieren. ${ }^{868}$

867 Es ist anzumerken, dass der eigene Berichtskatalog im Sinne der Theorie der Inhaltsanalyse ein Kategoriensystem darstellt, die 40 Kriterien werden i.e.S. Kategorien genannt, vgl. Berelson (1952), S. 147f. Diese Arbeit nutzt ein alternatives Begriffsverständnis.

868 Geforderte Berichtsinhalte sind folglich für jedes Geschäftssegment einzeln zu erfassen, eine Punktvergabe erfolgt, wenn eine Berichterstattung für alle maßgeblichen Segmente feststellbar ist. Für Unternehmen mit nur einem Geschäftssegment (sog. Monosegmentunternehmen) gilt ein reduzierter Katalog mit 35 Kriterien, vgl. Anhang 6 bzw. Fn. 886. 
Schließlich bietet der eigene Berichtskatalog die Möglichkeit zur simultanen Berücksichtigung quantitativer sowie qualitativer Aspekte: Während die in Tab. 2 gezeigten Kategorien und Sub-Kategorien primär den Umfang einer geforderten Strategieberichterstattung im Sinne des zugrunde gelegten formalen Prozessverständnisses reflektieren, erfolgt die Berücksichtigung qualitativer Aspekte innerhalb der 12 Sub-Kategorien in Form einer sukzessiven Spezifizierung bzw. Vertiefung der normativen Berichtsinhalte der jeweiligen Sub-Kategorie. ${ }^{869}$

\section{(d) Prozessuale Sicht: Ermittlung der Strategy Disclosure Scores}

Der soeben aufgestellte Berichtskatalog bildet die inhaltliche Basis des SDIndex und dient also als Bewertungsraster für die Ableitung unternehmensindividueller Strategy Disclosure Scores der einzelnen Geschäftsjahre des Untersuchungszeitraums. ${ }^{870} \mathrm{Zu}$ definieren sind allerdings weiterhin das methodische Vorgehen und der konkrete mathematische Algorithmus zur Ermittlung individueller Scores wie Tab. 1 zeigt, liegen dazu bereits Vorschläge in der relevanten Literatur vor.

Im Kern ist festzulegen, wie eine Bewertung einzelner Berichtskriterien erfolgt und wie sich sodann ein gesamthafter SDScore errechnet: Die Untersuchung der jeweiligen Berichtsinhalte der 100 Merkmalsträger wird mit Hilfe einer Inhaltsanalyse der Lageberichte vorgenommen, da jene Erhebungsmethode generell da$\mathrm{zu}$ verwendet werden kann, um qualitativ-verbale Inhalte einer quantifizierenden Analyse zu unterziehen. ${ }^{871}$ Die Vorzüge einer Inhaltsanalyse bestehen v.a. in der Nicht-Reaktivität der Erhebung, auch erfordert diese keine Kooperation mit den

869 So erfolgt bspw. die Spezifizierung der Berichtsinhalte in der Sub-Kategorie ,Marktumfeld ' von der ,Beschreibung des relevanten Marktes“ über die ,Annahmen zur künftigen Entwicklung ' bis zur, Quantifizierung der Marktentwicklung‘. Vgl. auch Anhang 6 für Details zu einzelnen (Sub-) Kategorien und Kriterien des eigenen Berichtskataloges.

870) Die Bedeutung eines ,Kategoriensystems“ für die Qualität einer Inhaltsanalyse ist unbestritten in der Literatur, bspw. Berelson (1952), S. 147: „Content analysis stands or falls by its categories." Die Umwandlung von Berichtsinhalten in numerische Daten wird als ,Kodierung ' bezeichnet, der Durchführende als ,Kodierer', vgl. Merten (1995), S. 325f. Vgl. Friedrichs (1990), S. 314f.; Schnell et al. (1995), S. 372f. Letztere nehmen eine Bewertung der Inhaltsanalyse vor. Prägnant umschreibt Früh (2004), S. 117 die Inhaltsanalyse als „empirische Methode zur systematischen, intersubjektiv nachvollziehbaren Beschreibung inhaltlicher und formaler Merkmale von Mitteilungen“. Vgl. ausführlich zur Erhebungsmethode der Inhaltsanalyse auch Merten (1995). 
Merkmalsträgern bzw. den Untersuchungsobjekten - eine beliebige Anzahl von Wiederholungen desselben Untersuchungsdesigns wäre also grds. möglich. ${ }^{872}$

Auf Basis der inhaltlichen Analyse der Lageberichte werden sodann Punktwerte vergeben, sofern die normativen Berichtsangaben identifiziert werden können. ${ }^{873}$ Die Literatur empfiehlt hierzu weitgehend konsensual den Einsatz einer binären Kodierung, d.h. die Vergabe eines Punktes bei Vorhandensein einer spezifischen Angabe bzw. keines Punktes bei Fehlen der Information: ${ }^{874}$ „The contents of the annual reports were then compared to the items on the checklist and coded 1 or 0 , depending upon whether the annual report contained or did not contain [...] each disclosure item. ${ }^{4875}$ Die jeweiligen Berichtskriterien werden aber grds. nur einmal zur Bewertung berücksichtigt, unabhängig von der konkreten Häufigkeit ihrer Nennung: „To make sure that the index captured the level of disclosure and not the frequency [...] I only coded the firm as disclosing an item once, even if it was discussed multiple times.“ ${ }^{\text {(876 }}$ Neben der reinen Ermittlung des Umfangs der Berichterstattung wird in der Literatur zudem vorgeschlagen, zur Abbildung der Berichtsintensität in Abhängigkeit vom Detaillierungsgrad der Inhalte zusätzlich Punkte zu vergeben ${ }^{877}$ Folglich wäre bei der Bewertung eines konkreten inhaltlichen Kriteriums nach der Art der Berichterstattung zu differenzieren. Obgleich sich diese Vorgehensweise in einigen Arbeiten bewährt hat, wird hier - wie angemerkt - eine qualitative Abstufung auf Basis der einzelnen Kriterien innerhalb der Kategorien des eigenen Katalogs vorgenommen, welche stets binär bewertet werden. Dieses Vorgehen bietet den zentralen Vorteil, kompensatorische Effekte auf das Endergebnis durch mehrfache Punktvergabe vermeiden zu können.

872 Vgl. bspw. Schnell et al. (1995) S. 379ff.

873 Formal erfordert die Inhaltsanalyse a priori eine Definition der zu untersuchenden Texte und stellt die Anforderung, dass diese relevant, existent und zugänglich sind. Dies kann für die hier betrachteten Lageberichte bejaht werden. Vgl. grdl. Kromrey (2006), S. 337. Vgl. hier nochmals Tab. 1 (S. 201), im Detail zur Vorgehensweise bspw. Cooke (1989).

875 Gray et al. (1995), S. 54.

876 Jones (2007), S. 496.

877 Vgl. mit diesem Vorschlag u.a. Botosan (1997a) und den zugrunde liegenden Kriterienkatalog bei dies. (1997b). Arbeiten, welche dieser Methodik folgen, vergeben i.d.R. für eine reine Nennung eines Aspekts einen Punkt, für dessen Detaillierung einen weiteren Punkt und bspw. für die Quantifizierung des Sachverhalts weitere Punkte. Vgl. zu dieser Vorgehensweise im Kontext des dt. Value Reporting bspw. Ruhwedel/Schultze (2002b). 
Bei Durchsicht der relevanten Literatur ist weiterhin festzustellen, dass Autoren vereinzelt die jeweiligen Berichtskataloge unternehmensspezifisch anpassen, um dem Faktum Rechnung zu tragen, dass ggf. nicht alle Berichtselemente für jedes Unternehmen zutreffend sind. Ziel dieses Vorgehens ist folgerichtig, jeweils die korrekte Soll-Größe für die Bewertung der Berichterstattung anzuwenden, damit die Merkmalsträger ,were not penalised for nondisclosure of an item if it was deemed to be irrelevant to their business activities “878. Dieser Einwand ist zwar generell beachtenswert, doch ist er für die eigene Untersuchung als unzutreffend zu beschreiben - die geforderten Strategieangaben sollten grds. gültig sein sowie branchenübergreifend von jedem Unternehmen berichtet werden können. ${ }^{879}$

Im Rahmen der Methodendiskussion zur Ableitung von Kennzahlen der Berichterstattung hat zudem die Frage einer Gewichtung von Berichtskriterien intensive Beachtung gefunden. ${ }^{880}$ So wurde in einzelnen Arbeiten der relevanten Literatur der Versuch unternommen, die relative Bedeutung einzelner Berichtsinhalte abzuleiten und diese Gewichtungsfaktoren sodann bei der Bewertung des Berichtsverhaltens zu berücksichtigen. ${ }^{881}$ Für den SDIndex zur Messung des Niveaus der Strategieberichterstattung wird jedoch keine Gewichtung vorgesehen, ,the unweighted [...] approach assumes each item of disclosure is equally important ${ }^{4882}$.

878 Hossain et al. (1995), S. 77. Ähnlich auch Gray et al. (1995), S. 54.

879) Diese Argumentation kann anhand des Untersuchungsbogens (vgl. Anhang 6) überprüft werden. Einzig die Unternehmensstrukturen sind zu beachten, vgl. Fn. 868 und Fn. 886.

880 Vgl. methodisch Bortz/Döring (2006), S. 145ff.

881 Vgl. z.B. Botosan (1997a), S. 333, welche für besonders detaillierte Prognosen mehrere Punkte vergibt, zuvor auch Buzby (1975), S. 26. Innerhalb der deutschsprachigen Value Reporting-Literatur führt in jüngerer Zeit insb. Heumann (2005) eine umfangreiche Befragung zur Bedeutung einzelner Berichtsaspekte durch als Basis für eine Gewichtung von Berichtsinhalten. Vgl. ebenfalls Wenzel (2005) mit vergleichbarer Vorgehensweise. Ebenso Ruhwedel/Schultze (2002a), S. 613f., die in ihrer Arbeit implizit Gewichtungen für einzelne Berichtskriterien berücksichtigen, vgl. im Detail dies. (2002b).

Zur Problematik der Gewichtung prägnant bspw. auch Hossain et al. (1995), S. 77: „the weighted indices are subject to widespread criticism in the literature. [...] a great deal of subjectivity exists in the assignment of weights. "Ähnlich Cooke/Wallace (1989), S. 51.

Gary et al. (1995), S. 54. Diese sehen eine Gewichtung als obsolet an, wenn der Katalog umfangreich ist: „If there is a large number of items in the index [...] it may be expected that companies will be ranked in the same way irrespective of whether the items are weighted or unweighted.“ Cooke (1989), S. 182: „subjective weights of user groups will average each other out." Daher wird auf eine Gewichtung von SDIndex verzichtet. 
Eine relative Gewichtung einzelner Berichtskriterien dürfte zudem kaum für alle potenziellen Adressaten simultan realisierbar sein, die subjektive Verzerrung des Messinstruments wäre zu befürchten: ,the subjectivity that would be involved in assigning weights when user preferences are unknown and when users [...] are likely to assign different weights to similar items. ${ }^{4883}$ Folglich scheint ein ungewichtetes Instrument gerade dann adäquat, wenn - wie im vorliegenden Falle keine spezifische Gruppe von Adressaten im Fokus einer Untersuchung steht. ${ }^{884}$ Zusammenfassend ermittelt der eigene SDIndex also auf Basis der in Tab. 2 aufgelisteten Kategorien von Berichtskriterien das Niveau der jeweiligen Strategieberichterstattung, indem diese binär bewertet werden und entsprechende Punktwerte ungewichtet summiert werden. ${ }^{885}$ Eine Formel zur Berechnung eines individuellen SDScores eines Merkmalsträgers ist in Abb. 17 unter (1) dargestellt. ${ }^{886}$

(1)

$$
\begin{array}{llll}
S D_{t, j}=\sum_{i=1}^{n} s_{i, t, j} & \text { mit: } & S D_{t, j}: & \text { Anzahl der Strategy Disclosures des Unternehmens } j \text { in } t \\
& s_{i, t, j}: & \text { Bericht zu Aspekt } i \text { durch Unternehmen } j \text { in } t ;\{0 \vee 1\} \\
S D S_{t, j}=\frac{S D_{t, j}}{S D^{\max }} & \text { mit: } & S D S_{t, j}: & \text { Strategy Disclosure Score des Unternehmens } j \text { in } t ;\{0 ; 1\} \\
& S D^{\max }: & \text { Maximal mögliche Anzahl an Strategy Disclosures }
\end{array}
$$

\section{Abbildung 17: Mathematische Formeln zur Errechnung der SDScores ${ }^{887}$}

Das auf einen Wertebereich von null bis eins normierte Niveau der Strategieberichterstattung eines der 100 Unternehmen der Stichprobe für eines der Jahre des Untersuchungszeitraumes - also der jahresspezifische SDScore - ergibt sich somit als Quotient der konkreten Anzahl berichteter strategieorientierter Elemente und der Maximalanzahl an Berichtskriterien, wie (2) in Abb. 17 offenbart. Diese Normierung erfolgt, um Interpretationen der Resultate zu erleichtern. Zusätzlich

883 Meek et al. (1995), S. 562, ähnlich Chang et al. (1983), S. 80.

884 Bereits Spero (1979), S. 57 empfiehlt, Gewichtungen zu vermeiden. Coy/Dixon (2004), S. 82 formulieren: ,the use of weightings in a disclosure index is unnecessary."

Kriterien des Katalogs mit Geschäftssegmentbezug werden je Geschäftssegment einzeln überprüft und bewertet. Nur, wenn die geforderten Angaben für alle maßgeblichen Segmente (gem. berichteter Konzernstruktur) vorhanden sind, erfolgt die Punktvergabe. Für Monosegmentunternehmen gelten fünf der 40 Kriterien (bzgl. ,Konzern') nicht, um die

Vergleichbarkeit sicherzustellen, vgl. auch den Untersuchungsbogen in Anhang 6.

Quelle: eigene Darstellung. 
zu einer Normierung der SDScores kann auch eine Berechnung von Rangziffern durchgeführt werden, um sodann mit diesen weitere Analysen durchzuführen. ${ }^{888}$

Es sei abschließend darauf hingewiesen, dass eine Interpretation der errechneten SDScores als Aussage über das gesamthafte Niveau der strategieorientierten Berichterstattung im Kern grds. nicht statthaft ist. Jene Kennzahl zeigt - der vorgenommenen Beschränkung auf den Lagebericht als Untersuchungsobjekt folgend - nur das spezifische Niveau der Strategieberichterstattung an. ${ }^{889}$ Zur Ableitung absoluter Aussagen wäre schließlich die gesamte Publizität eines Unternehmens im Hinblick auf strategieorientierte Inhalte zu überprüfen - dies erscheint jedoch weder praktikabel noch erforderlich, da der Geschäftsbericht als guter Indikator des gesamten Berichtsverhaltens charakterisiert werden konnte. ${ }^{890}$ Daher erlaubt SDIndex zwar in erster Linie nur Aussagen zum relativen Niveau der Strategieberichterstattung im Lagebericht, diese kann ihrerseits jedoch als ein valider Indikator der gesamten Strategieberichterstattung eines Unternehmens gelten. ${ }^{891}$

888 Den Vorschlag zur Bildung von Rangziffern machen bspw. Botosan/Plumlee (2002), S. 24f. oder auch Hail (2002), S. 751: „I perform my analysis using the fractional rank of a firm's disclosure score as it is less sensitive to the influence of outliers and makes the regression coefficients easier to interpret. Using absolute disclosure values instead does not qualitatively change the results." In einem mehrjährigen Untersuchungszeitraum erscheint eine Bildung von Rangziffern weiterhin insofern interessant, als möglicherweise systematische Einflüsse der Zeit reduziert werden können. Innerhalb der eigenen Untersuchung wird dieser Vorschlag aufgegriffen zur Prüfung der Robustheit von SDIndex. Vgl. hierzu nochmals Abschnitt C 2.3 dieser Arbeit sowie mit ähnlicher Argumentation zudem Fischer/Vielmeyer (2004), S. 465. Die Autoren weisen richtigerweise darauf hin, dass bei der Beschränkung auf ein Berichtsinstrument die Vollständigkeit der Publizität nicht verifiziert werden kann. Daher ist eine auf Basis eines Geschäftsberichts ermittelte Aussage zur Berichterstattung nicht als absolute Aussage anzusehen. Aufgrund einer Indikatorfunktion des Geschäftsberichts für die gesamte Berichterstattung kann jedoch davon ausgegangen werden, dass so abgeleitete Aussagen zum Berichtsverhalten durchaus valide sind - dies bestätigen auch die bereits erwähnten methodisch ähnlichen Studien.

890) Dieser Hinweis findet sich nochmals bei Lapointe-Antunes et al. (2006), S. 503f.: ,due to the fact that self-constructed measures typically rely on disclosures provided in the annual report $[. .$.$] any disclosure that firms provide in analyst meetings, conference calls$ or through other means are omitted from the analysis. However, Lang and Lundholm (1993) find evidence of a high and significantly positive correlation between the level of annual report disclosure and other forms of disclosure." Das ist eine der wesentlichen Annahmen dieser Untersuchung, die Argumentation findet sich in Abschnitt C 3.2.2a.

${ }^{891}$ Diese Einschränkung ist im Folgenden, bei einer Ableitung von Aussagen auf Basis von SDIndex im Rahmen der eigenen Untersuchung jedoch stets in Erinnerung zu behalten. 
Schließlich muss akzeptiert werden, wie in der Literatur wiederholt angemerkt wird, dass die beschriebene Vorgehensweise der inhaltlichen Analyse von Lageberichten zur Ableitung von Kennziffern grds. dem subjektiven Einfluss des Erhebenden unterliegt. ${ }^{892}$ Aus diesem Grunde scheint es zwingend erforderlich, die erhobenen Werte einer Validitätsprüfung zu unterziehen. ${ }^{893}$ Einige Arbeiten empfehlen dazu eine wiederholte Durchführung des gesamten Erhebungsverfahrens durch mehrere bzw. voneinander unabhängige Kodierer und eine Ermittlung des Durchschnitts der Ergebnisse, um subjektive Einflüsse zu identifizieren sowie zu eliminieren. ${ }^{894}$ Da diese Form der Validierung in aller Regel insb. aufgrund des zusätzlichen Zeitaufwandes nicht durchführbar sein dürfte, wird regelmäßig eine Validierung ermittelter Ergebnisse mit Hilfe externer Daten sowie zusätzlich die Anwendung statistischer Methoden zur Überprüfung der Reliabilität eines Messinstruments vorgeschlagen. ${ }^{895}$ Für das eigene Messinstrument des SDIndex wird daher, zur Sicherstellung der Konformität mit methodischen Standards, gleichermaßen eine Prüfung der Reliabilität des Messinstruments sowie der Validität der erhobenen Messwerte vorgesehen, die nachfolgend darzustellen sind.

Nach diesen Ausführungen in Abschnitt C 3.2.2 ist das zentrale Messinstrument der eigenen Untersuchung, der SDIndex, konzipiert. Der nun folgende Abschnitt befasst sich mit der konkreten Erhebung von Messwerten der Strategieberichterstattung sowie der anderen für die Untersuchung benötigten Rohdaten.

892 Jenen Einwand bringen u.a. Healy/Palepu (2001), S. 425f.; Cheng/Courtenay (2006), S. 271f. Grds. wäre eine Kodierung von Berichten durch mehrere Kodierer parallel zur Reduktion subjektiver Einflüsse vorstellbar, jedoch präferiert die Literatur zur empirischen Sozialforschung das Arbeiten mit einem Kodierer, vgl. bspw. Kromrey (2006), S. 340. Vgl. z.B. Lapointe-Antunes (2006), S. 504f.; Botosan (1997a). Diese Empfehlung findet sich regelmäßig in der Literatur, manche Arbeiten verzichten dennoch auf eine Prüfung. Bei Banghoj/Plenborg (2008), Fn. 11 findet sich sogar die gegensätzliche Sicht: „Scores are robust as all were conducted by a single individual following the specified criteria." Vgl. Hossain et al. (1994), ebenso Chow/Wong-Boren (1987), S. 536.

895 Statistische Methoden zur Prüfung der Reliabilität konzentrieren sich insb. auf eine Berechnung des sog. Cronbach-Koeffizienten, vgl. mit Hinweisen zur Durchführung bspw. Lapointe-Antunes (2006), S. 504, zudem Cheng/Courtenay (2006), S. 271; Hail (2002), S. 756f. Dieser Koeffizient wird ebenfalls zur Überprüfung des hier vorgestellten Messinstruments SDIndex verwendet, vgl. im Detail Abschnitt D 3.1.1 dieser Arbeit.

Darüber hinaus erfolgt eine Validierung der auf Basis des Messinstrument SDIndex ermittelten SDScores mit Hilfe externer Daten, vgl. dazu Abschnitt D 3.1.2 dieser Arbeit. 


\subsubsection{Erhebung der Rohdaten der Untersuchung}

Die Erhebung der Datengrundlage der eigenen Untersuchung gliedert sich - dem überblicksartigen Untersuchungsmodell in Abb. 10 folgend - in drei wesentliche Bereiche: Neben einer Ermittlung der Strategy Disclosure Scores sind Daten zur Untersuchung der Bestimmungsfaktoren und Kapitalmarkteffekte zu erheben. Es erscheint nachvollziehbar, dass alle erforderlichen Daten grds. für den gesamten Untersuchungszeitraum, also die Kalenderjahre 2002 bis 2008, benötigt werden.

Die Ermittlung der individuellen Strategy Disclosure Scores der Jahre 2002 bis 2008 für die in C 3.2.1 zusammengestellten Stichproben-Unternehmen erfolgte im Zeitraum September bis Dezember 2009. ${ }^{896}$ Als Grundlage dieser Ermittlung dienten folglich die Lageberichte innerhalb der jeweiligen Geschäftsberichte, die für die einzelnen Geschäftsjahre aufgestellt wurden. ${ }^{897}$ Innerhalb der Stichprobe weisen jedoch 17 Unternehmen in mindestens einem Jahr ein vom Kalenderjahr abweichendes Geschäftsjahr auf, zudem wurden insg. vier Rumpfgeschäftsjahre während des Untersuchungszeitraumes festgestellt. ${ }^{898}$ Diese Sonderfälle wurden bei Zuordnung der Geschäftsberichte zu den Kalenderjahren des Untersuchungs-

${ }^{896}$ Der Vollständigkeit halber sei erläutert, dass die Geschäftsberichte des Geschäftsjahres 2008 grds. im Verlaufe des Jahres 2009 vorgelegt wurden. Zum Zeitpunkt der Datenerhebung stellen die Geschäftsberichte 2008 also die aktuellsten verfügbaren Berichte dar. Die einzelnen Scores der Stichproben-Unternehmen in 2002 bis 2008 zeigt Anhang 7-1. Die insg. 700 Geschäftsberichte der Geschäftsjahre 2002 bis 2008 wurden im Zeitraum Juni/Juli 2009 bezogen. Jene Berichte wurden weitestgehend von den Internetseiten der entsprechenden Unternehmen direkt heruntergeladen. Falls Berichte früherer Jahre nicht mehr verfügbar waren, wurden die Investor Relations-Abteilungen zwecks Zusendung kontaktiert. Diese erfolgte meist in elektronischer Form, in wenigen Fällen postalisch.

Zur Sicherung der Konformität mit methodischen Standards der Inhaltsanalyse wurden sämtliche Geschäftsberichte gedruckt und relevante Textstellen markiert, um Punktvergaben in den Untersuchungsbögen anhand der Seitenzahlen nachvollziehbar zu machen. Die Reihenfolge der Analysen wurde zudem randomisiert, d.h. es wurden weder die Berichte eines Unternehmens noch alle Lageberichte eines Jahres nacheinander analysiert. Grds. wurden alle Geschäftsjahre, die im Laufe der zweiten Jahreshälfte endeten (bspw. zum 30.09.2005), mit Geschäftsjahren gleichgesetzt, die zum Jahresultimo endeten, und somit also an das Kalenderjahr angepasst. Geschäftsjahre, die in der ersten Jahreshälfte endeten, wurden auf das vorausgegangene Ultimo zurückgesetzt. Diese Behandlung abweichender Geschäftsjahre entspricht dem üblichen Vorgehen, vgl. bspw. Barth (2009). Auch Leuz/Verrecchia (2000), S. 108 bereinigen so die Geschäftsjahre ihrer Stichprobe. Anhang 5 listet die Geschäftsjahres-Zeiträume aller Unternehmen auf und zeigt die Zuordnung der Geschäftsjahre zu den Kalenderjahren des Untersuchungszeitraumes. 
zeitraumes explizit berücksichtigt. Für jedes der 100 ausgewählten StichprobenUnternehmen wurden schließlich sieben Untersuchungsbögen erstellt. Diese 700 Untersuchungsbögen wurden sodann in eine gesamthafte Datenbank übertragen, um eine quantitative Weiterverarbeitung der Messwerte des SDIndex zu ermöglichen und zur Berechnung spezifischer Teil-Scores. ${ }^{899}$ Den Aufbau des SDIndex sowie die daraus abgeleiteten SDScores bzw. Teil-Scores verdeutlicht Abb. 18.

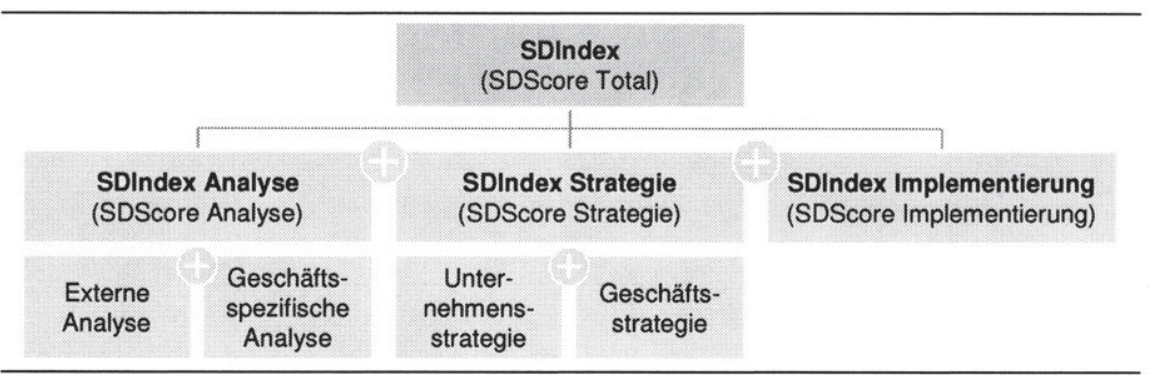

\section{Abbildung 18: Logik des SDIndex bzw. SDScores und der Teil-Scores ${ }^{900}$}

Die weiteren Datenbedarfe, welche neben dem SDIndex für eine Untersuchung der Bestimmungsfaktoren der Strategieberichterstattung benötigt werden, lassen sich unmittelbar aus dem detaillierten Untersuchungsmodell in Abb. 13 ableiten. Demnach werden Daten zu jenen vier Kategorien von Faktoren benötigt, die das individuelle Strategieberichterstattungsniveau der Unternehmen möglicherweise erklären können: Konkret sind also Daten zu makroökonomischen Bedingungen, qualitative Unternehmensdaten sowie finanzwirtschaftliche Parameter aus GuV und Bilanz sowie Angaben zum Aktienkapital der Merkmalsträger erforderlich.

Für die eigene Untersuchung der Bestimmungsfaktoren wurden adäquate Daten aus unterschiedlichen Quellen gewonnen, wie folgende Tab. 3-1 auf Seite 215 in der Struktur des Untersuchungsmodells auflistet. Spiegelbildlich nennt Tab. 3-2 auf Seite 216 die hier genutzten Rohdatenquellen zur Untersuchung potenzieller

899 Weitere Schritte der Bearbeitung umfassten insb. die Normierung der ermittelten (Teil-) Scores auf Wertebereiche von null bis eins. Hierzu wurden die erreichten Punkte durch die Anzahl maximal erreichbarer Punkte dividiert. Dies erfolgte sowohl für das Gesamtergebnis als auch für die drei Teil-Ergebnisse auf Basis der in der jeweiligen Kategorie erreichbaren Punkte. Zudem wurden u.a. jahresspezifische Rangziffern gebildet. 
Kapitalmarkteffekte, die den komplementären Teil des Untersuchungsmodells repräsentieren - ebenfalls in der bereits verwendeten Struktur. ${ }^{901}$ Wie die beiden Tabellen aufzeigen, wurde - zur Sicherstellung einer durchgängig hohen Datenqualität für die eigene Untersuchung - bei der Selektion konsequent darauf geachtet, stets auf solche Datenquellen zurückzugreifen, die aufgrund des Stellenwerts der betreffenden Publikationen bzw. der Reputation des Bereitstellers der Informationen als höchst zuverlässig gelten können. ${ }^{902}$ Eine Verwendung dieser Datenquellen bzw. Identifikation und Erhebung der darin enthaltenen Sekundärdaten konzentrierte sich auf den Zeitraum September/Oktober $2009 .^{903}$

Der Vollständigkeit halber, um alle drei Bausteine des Untersuchungsmodells zu reflektieren, fasst Tab. 3-3 auf Seite 216 die Datenquellen der Kennziffern zum Niveau der Strategieberichterstattung zusammen. Im nun folgenden Abschnitt C 3.3 sind die auf Grundlage dieser Datenbasis abgeleiteten Variablen, die für die Überprüfung der Hypothesen verwendet werden sollen, zu definieren. Zuvor ist allerdings auf eine ,Besonderheit ' hinsichtlich der zeitlichen Datenverknüpfung innerhalb des Untersuchungsmodells hinzuweisen.

\subsubsection{Logik der zeitlichen Datenverknüpfung}

In den vorhergehenden Ausführungen ist die Datengrundlage der eigenen Untersuchung abgeleitet worden. Bevor nun im Folgenden konkrete Variablen und die sie operationalisierenden Indikatoren definiert werden können, erscheint es zu-

(01 Die Quellenangaben in der folgenden Tab. 3 (S. 215f.) beziehen sich auf die jeweiligen Rohdaten. Es waren allerdings stets umfangreiche Berechnungen durchzuführen, um so spezifische Größen und/oder Kennziffern zu ermitteln. Dies erfolgte mit Hilfe eines umfassenden Excel-Modells. Eine eigene Berechnung von den in der Untersuchung zu verwendenden Daten ist einer reinen Übernahme aggregierter Kennziffern vorzuziehen, da nur auf diesem Wege die Nachvollziehbarkeit bzw. Konsistenz der Untersuchungsdaten gewährleistet ist. Vergleichbar für diese Argumentation u.a. Eichner (2009), S. 185.

(1)2 Dies erscheint insofern gewährleistet, als sämtliche Daten aus international anerkannten Datenbanken bzw. direkt aus offiziellen Quellen (z.B. Dt. Börse AG, BaFin, Geschäftsberichte) bezogen wurden. Zur Verlässlichkeit renommierter Datenbanken, u.a. der hier relevanten Worldscope-Datenbank, vgl. bspw. Jostarndt (2007), S. $15 f$.

903 Vereinzelt wurden Daten im Verlaufe der Untersuchung nachgepflegt, insb. wurden zu Beginn des Jahres 2010 Kapitalmarktdaten für 2009 bezogen, die erst per Ultimo erhältlich/berechenbar waren, bspw. das Handelsvolumen 2009. Zur Begründung vgl. C 3.2.4. 
nächst geboten, die generelle Logik einzuführen, wie die spezifischen Daten zu den Bestimmungsfaktoren sowie den Kapitalmarkteffekten mit Messwerten zum Niveau der Strategieberichterstattung in Beziehung gesetzt werden sollen:

Wie bereits erläutert, erfolgt die Ermittlung der SDScores für jedes einzelne Jahr des Untersuchungszeitraumes anhand der mit den jeweiligen Geschäftsberichten vorgelegten Lageberichte. Da die Vorlage dieser Geschäftsberichte grds. erst im Laufe des dem Geschäftsjahr nachfolgenden Kalenderjahres abgeschlossen wird, können mögliche Kapitalmarkteffekte einer Strategieberichterstattung im Lagebericht des Geschäftsjahres $t$ auch erst im Kalenderjahr $t+l$ unterstellt werden. Diesem Gedanken folgend sind SDScores der Periode $t$ mit Kapitalmarktdaten der Periode $t+1$ in Beziehung zu setzen, es ist also eine ,Phasenverschiebung ' in Bezug auf das Teilmodell der Kapitalmarkteffekte durchzuführen. ${ }^{904}$ Eine solche Phasenverschiebung ist allerdings ausschließlich auf der Seite der Kapitalmarkteffekte zu berücksichtigen, da weiterführend anzunehmen ist, dass SDIndex in $t$ durch die Ausprägungen der Bestimmungsfaktoren in $t$ determiniert wird. ${ }^{905}$

Die beschriebene Logik der Phasenverschiebung in Bezug auf die Kapitalmarkteffekte verdeutlicht Abb. 19 graphisch. Im Rahmen der folgenden Hypothesenprüfung wird diese Verschiebung zudem stets erkennbar gemacht. ${ }^{906}$

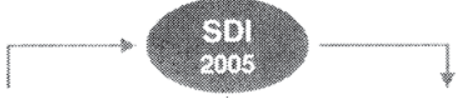

Bestimmungsfaktoren

2005
Kapitalmarkteffekte

2006

Strategiebericht

Abbildung 19: Phasenverschiebung in Bezug auf Kapitalmarkteffekte ${ }^{907}$

904 Diese Vorgehensweise wurde konsequenterweise auch auf Geschäftsjahre angewendet, die vom Kalenderjahr abweichen. Vgl. nochmals Abschnitt C 3.2.3 bzw. den Anhang 5.

905 Die Phasenverschiebung ist auch bedeutsam, um einer möglichen Endogenität der Kernvariablen SDIndex im Teilmodell der Effekte entgegenzuwirken, vgl. detailliert C 3.4.2.

906 Im Teilmodell der Kapitalmarkteffekte ist der zeitliche Bezug der Variablen anhand der Symbolik $(t)$ bzw. $(t+1)$ erkennbar. Im ersten Teilmodell basieren alle Variablen auf $t$.

907 Quelle: eigene Darstellung. Trotz dieser beispielhaften Jahreszahlen in Abb. 19 wird die Phasenverschiebung konsistent für alle Jahre des Untersuchungszeitraums angewendet. 


\begin{tabular}{|c|c|c|c|c|}
\hline \multicolumn{3}{|c|}{ Bestimmungsfaktoren } & \multicolumn{2}{|l|}{ Datenbedarf und -quelle } \\
\hline Kategorie & $\mathbf{H}$ & Einzelfaktor & Konkreter Datenbedarf & Datenquelle \\
\hline \multirow[t]{2}{*}{$\begin{array}{l}\text { Makro- } \\
\text { ökonomische } \\
\text { Faktoren }\end{array}$} & 2.1 & $\begin{array}{l}\text { Konjunktur- } \\
\text { entwicklung }\end{array}$ & $\begin{array}{l}\text { Historisch realisierte Daten zum Brutto- } \\
\text { inlandsprodukt (BIP) ausgewählter } \\
\text { Regionen (DE, EU, OECD) }\end{array}$ & $\begin{array}{l}\text { OECD- } \\
\text { Datenbank }\end{array}$ \\
\hline & 2.2 & Börsenentwicklung & $\begin{array}{l}\text { Historische Indexstände ausgewählter } \\
\text { Aktienindizes (dt. Auswahlindizes Dax, } \\
\text { MDax, SDax, TecDax sowie EuroStoxx } \\
\text { 50, Dow Jones Industrial Average) }\end{array}$ & $\begin{array}{l}\text { (Reuters) } \\
\text { Datastream- } \\
\text { Datenbank }\end{array}$ \\
\hline \multirow[t]{4}{*}{$\begin{array}{l}\text { Unternehmens- } \\
\text { charakteristika }\end{array}$} & 2.3 & Unternehmensgröße & $\begin{array}{l}\text { Daten zu Indikatoren der Unternehmens- } \\
\text { größe, im Einzelnen } \\
\text { - Umsatz } \\
\text { - Summe Vermögenswerte bzw. } \\
\text { Bilanzsumme (,Total Assets“) } \\
\text { - Anzahl Mitarbeiter } \\
\text { - Marktwert des Eigenkapitals }\end{array}$ & $\begin{array}{l}\text { Worldscope- } \\
\text { Datenbank }\end{array}$ \\
\hline & 2.4 & Stammdaten & $\begin{array}{l}\text { Einordnung der Unternehmen gemäß } \\
\text { dreistufiger Branchensystematik der } \\
\text { Dt. Börse AG; zusätzlich Angaben } \\
\text { zum Unternehmensalter }\end{array}$ & $\begin{array}{l}\text { Dt. Börse AG } \\
\text { (2009a), S. 47ff., } \\
\text { Worldscope- } \\
\text { Datenbank (Alter) }\end{array}$ \\
\hline & 2.5 & Rechnungslegung & $\begin{array}{l}\text { Rechnungslegungsphilosophie, ange- } \\
\text { wandter Standard sowie Abschlussprüfer }\end{array}$ & Geschäftsberichte \\
\hline & 2.6 & Management / CEO & $\begin{array}{l}\text { Informationen zu Vorstandsvorsitzenden } \\
\text { der Unternehmen: } \\
\text { - Persönlichkeitsmerkmale } \\
\text { - Zeitraum der Verantwortlichkeit } \\
\text { - Begründung für Austausch }\end{array}$ & $\begin{array}{l}\text { Geschäftsberichte, } \\
\text { Factiva-Datenbank } \\
\text { (Presseartikel) }\end{array}$ \\
\hline \multirow[t]{2}{*}{$\begin{array}{l}\text { Finanzielle } \\
\text { Faktoren }\end{array}$} & 2.7 & Unternehmenserfolg & $\begin{array}{l}\text { Profitabilitätskennziffern und } \\
\text { Daten zur Unternehmensentwicklung }\end{array}$ & $\begin{array}{l}\text { Worldscope- } \\
\text { Datenbank }\end{array}$ \\
\hline & 2.8 & Finanzierung & $\begin{array}{l}\text { Verschuldungskennziffern der } \\
\text { Unternehmen sowie Eigenkapitalquote }\end{array}$ & $\begin{array}{l}\text { Worldscope- } \\
\text { Datenbank }\end{array}$ \\
\hline \multirow[t]{4}{*}{$\begin{array}{l}\text { Faktoren des } \\
\text { Aktienkapitals }\end{array}$} & 2.9 & Indexzugehörigkeit & $\begin{array}{l}\text { Historische Indexzugehörigkeit der } \\
\text { Untersuchungsobjekte (jeweils Ultimo) }\end{array}$ & $\begin{array}{l}\text { Dt. Börse AG } \\
(2009 b)\end{array}$ \\
\hline & 2.10 & Auslandslisting & $\begin{array}{l}\text { Zweit-Listings deutscher Unternehmen an } \\
\text { der New York Stock Exchange (NYSE) }\end{array}$ & $\begin{array}{l}\text { Geschäftsberichte, } \\
\text { Factiva-Datenbank }\end{array}$ \\
\hline & 2.11 & Kapitalkonzentration & $\begin{array}{l}\text { Detaillierte Daten zum Anteil fix } \\
\text { gehaltener Aktien } \\
\quad \text { - Größe des Anteils } \\
\text { - Halter des Anteils }\end{array}$ & $\begin{array}{l}\text { BaFin-Datenbank } \\
\text { gem. } \$ 26 \mathrm{WpHG} \text {, } \\
\text { Worldscope- } \\
\text { Datenbank }\end{array}$ \\
\hline & 2.12 & Insidertransaktionen & $\begin{array}{l}\text { Daten zu Wertpapier-Transaktionen von } \\
\text { Unternehmens-Insidern } \\
\quad \text { - Stückzahl bzw. Volumen } \\
\text { - Rolle des Insiders }\end{array}$ & $\begin{array}{l}\text { BaFin-Datenbank } \\
\text { gem. } \$ 15 \mathrm{WpHG}\end{array}$ \\
\hline
\end{tabular}

Tabelle 3-1: Datenquellen der Untersuchung: Bestimmungsfaktoren ${ }^{908}$

Eine gesamthafte Darstellung der Untersuchungsvariablen, der jeweiligen Quellen und Zeiträume der Datenverfügbarkeit findet sich in Anhang 8 dieser Arbeit. 


\begin{tabular}{|c|c|c|c|c|}
\hline \multicolumn{3}{|c|}{ Kapitalmarkteffekte } & \multicolumn{2}{|l|}{ Datenbedarf und -quelle } \\
\hline Kategorie & $\mathbf{H}$ & Einzeleffekt & Konkreter Datenbedarf & Datenquelle \\
\hline \multirow[t]{2}{*}{$\begin{array}{l}\text { Markt- } \\
\text { transparenz- } \\
\text { effekte }\end{array}$} & 3.1 & $\begin{array}{l}\text { Anzahl } \\
\text { beobachtender } \\
\text { Analysten }\end{array}$ & $\begin{array}{l}\text { Anzahl der ein Unternehmen } \\
\text { beobachtenden Analysten } \\
\text { im Jahresdurchschnitt }\end{array}$ & $\begin{array}{l}\text { I/B/E/S History- } \\
\text { Datenbank }\end{array}$ \\
\hline & 3.2 & Schätzungsvarianz & $\begin{array}{c}\text { Daten zu Analystenschätzungen } \\
\text { - Kauf- und Verkaufsempfehlungen } \\
\text { - Schätzungen bzgl. Umsatz sowie } \\
\text { Ergebnis pro Aktie (EPS) } \\
\text { - Realisierte Jahreswerte für } \\
\text { Ergebnis pro Aktie (EPS) }\end{array}$ & $\begin{array}{l}\text { I/B/E/S History- } \\
\text { Datenbank, } \\
\text { Worldscope- } \\
\text { Datenbank }\end{array}$ \\
\hline \multirow[t]{2}{*}{$\begin{array}{l}\text { Handels- } \\
\text { effekte }\end{array}$} & 3.3 & Handelsvolumen & $\begin{array}{l}\text { Daten zum jährlichen Handelsvolumen an } \\
\text { den wesentlichen dt. Börsenplätzen } \\
\text { (Xetra, Frankfurter Wertpapierbörse) }\end{array}$ & $\begin{array}{l}\text { Datastream- } \\
\text { Datenbank } \\
\text { (Tagesdaten der } \\
\text { Volumina u. Kurse) }\end{array}$ \\
\hline & 3.4 & Volatilität & $\begin{array}{l}\text { Schwankungsbreite der jährlichen } \\
\text { Aktienkurse eines Unternehmens }\end{array}$ & $\begin{array}{l}\text { Datastream- } \\
\text { Datenbank }\end{array}$ \\
\hline \multirow[t]{3}{*}{$\begin{array}{l}\text { Bewertungs- } \\
\text { effekte }\end{array}$} & 3.5 & Eigenkapitalkosten & $\begin{array}{l}\text { Ex-ante-Eigenkapitalkosten eines } \\
\text { Unternehmens, Berechnung mit Hilfe } \\
\text { eines adaptierten Residualgewinnmodells, } \\
\text { vgl. Anhang } 11 \text { dieser Arbeit }\end{array}$ & $\begin{array}{l}\text { I/B/E/S History- } \\
\text { und Datastream- } \\
\text { Datenbank }\end{array}$ \\
\hline & 3.6 & Bid-Ask-Spreads & $\begin{array}{l}\text { Durchschnittliche jährliche Bid-Ask- } \\
\text { Spreads relativ zu Bid-Kursen }\end{array}$ & $\begin{array}{l}\text { Datastream } \\
\text { (Tagesdaten der } \\
\text { Bid- u. Ask-Kurse) }\end{array}$ \\
\hline & 3.7 & Marktbewertung & $\begin{array}{l}\text { Daten zu Indikatoren der realisierten } \\
\text { Marktbewertung } \\
\text { - Marktwert-/Buchwert-Ratio } \\
\text { - Multiplikator (Umsatz), } \\
\text { Branchendaten zur Adjustierung }\end{array}$ & $\begin{array}{l}\text { Datastream- und } \\
\text { Worldscope- } \\
\text { Datenbank bzw. } \\
\text { Dt. Börse AG } \\
\text { (Branchendaten) }\end{array}$ \\
\hline
\end{tabular}

Tabelle 3-2: Datenquellen der Untersuchung: Kapitalmarkteffekte

\begin{tabular}{|c|c|c|c|}
\hline \multicolumn{2}{|c|}{ Strategieberichterstattung } & \multicolumn{2}{|l|}{ Datenbedarf und -quelle } \\
\hline Kategorie & $\mathbf{H}$ & Konkreter Datenbedarf & Datenquelle \\
\hline $\begin{array}{l}\text { Niveau der } \\
\text { Strategiebericht- } \\
\text { erstattung }\end{array}$ & $\begin{array}{l}1.1 \\
1.2\end{array}$ & $\begin{array}{l}\text { Datenpunkte (SDScores) zum } \\
\text { Niveau der Strategieberichterstattung, } \\
\text { entsprechend dem in C } 3.2 .2 \text { konstruierten } \\
\text { Messinstrument SDIndex auf Basis des } \\
\text { vorgestellten Kriterienkataloges bzw. } \\
\text { unter Verwendung des Untersuchungs- } \\
\text { bogens, der in Anhang } 6 \text { dargestellt ist }\end{array}$ & $\begin{array}{l}\text { Geschäftsberichte, } \\
\text { spezifisch: HGB- } \\
\text { Lageberichte }\end{array}$ \\
\hline
\end{tabular}

\section{Tabelle 3-3: Datenquellen der Untersuchung: Strategieberichterstattung}




\subsection{Operationalisierung der Variablen}

\subsubsection{Terminologie zur Variablenoperationalisierung}

Bei der Konzeption der eigenen Untersuchungen wurden zu Beginn zwei Teilmodelle kreiert, die hypothetisch in Beziehung zum Niveau der Strategieberichterstattung stehen: das Teilmodell der Bestimmungsfaktoren sowie der Kapitalmarkteffekte. Das erste Teilmodell zerfällt in insg. zwölf Einzelfaktoren, die im Rahmen der empirischen Hypothesenprüfung grds. einzeln zu untersuchen sind. Für diese Untersuchung werden Variablen benötigt, die ihrerseits durch mehrere Indikatoren operationalisiert werden können. Dieser Struktur, die in Abb. 20 beschrieben ist, folgt auch das Teilmodell der sieben Kapitalmarkteffekte, die u.U. durch das Niveau der Strategieberichterstattung hervorgerufen werden. Aufgabe des Abschnitts C 3.3 ist es folglich, die erforderlichen Variablen bzw. die sie beschreibenden Indikatoren vorzustellen und inhaltlich zu definieren.

\begin{tabular}{|c|c|c|}
\hline Bestimmungsfaktoren & & Kapitalmarkteffekte \\
\hline $\begin{array}{c}\text { Einzelfaktor } \\
\text { z.B. Konjunktur (H 2.1) }\end{array}$ & $\begin{array}{l}\text { Konzept- } \\
\text { ebene }\end{array}$ & $\begin{array}{c}\text { Einzeleffekt } \\
\text { z.B. Marktbewertung }(\mathrm{H} 3.7)\end{array}$ \\
\hline$\downarrow$ & & 1 \\
\hline $\begin{array}{c}\text { Variable } \\
\text { z.B. BIP } \\
\text { Indikator } \\
\text { z.B. BIP Deutschland }\end{array}$ & $\begin{array}{l}\text { Operationale } \\
\text { Ebene }\end{array}$ & $\begin{array}{c}\text { Variable } \\
\text { z.B. Multiple-Bewertung } \\
\text { Indikator } \\
\text { z.B. EBITDA-Multiple }\end{array}$ \\
\hline
\end{tabular}

\section{Abbildung 20: Operationalisierung des Untersuchungsmodells ${ }^{909}$}

Dazu erscheint es sinnvoll, zunächst die Variablen der Strategieberichterstattung abzuleiten, die einerseits im Teilmodell der Bestimmungsfaktoren als abhängige Parameter, im Teilmodell der Kapitalmarkteffekte andererseits als unabhängige Parameter verwendet werden. Nachfolgend werden schließlich die Variablen der beiden Teilmodelle definiert bzw. operationalisiert.

(N9) Quelle: eigene Darstellung. Zur übersichtlichen Gestaltung des Untersuchungsmodells wurden Einzelfaktoren sowie -effekte in Kategorien zusammengefasst, bspw. bilden die Konjunktur- bzw. die Börsenentwicklung die Kategorie ,Makroökonomische Faktoren '. Diese ,Zwischenebene " wird hier nicht gesondert ausgewiesen, da sie in erster Linie der Sicherstellung der Übersichtlichkeit des Gesamtmodells geschuldet ist. 


\subsubsection{Variablen der Strategieberichterstattung}

Das Niveau der Strategieberichterstattung als Ergebnis der in Abschnitt C 3.2.2 detailliert erläuterten Messung strategieorientierter Lageberichtsinhalte stellt den zentralen Baustein des Untersuchungsmodells dar. So wird unterstellt, dass sich dieses Niveau einerseits mit Hilfe der definierten Bestimmungsfaktoren erklären lässt und es andererseits feststellbare Effekte am Kapitalmarkt hervorruft. Zum Zwecke einer Nutzung der Daten zum Niveau der Strategieberichterstattung im Rahmen der Hypothesenprüfung erfolgt eine Normierung der jährlichen Scores und der Teil-Scores auf einen Wertebereich von null bis eins. ${ }^{910}$ Zusätzlich - als alternative Untersuchungsvariable - werden die 100 Datenpunkte zur Strategieberichterstattung, die für jedes der sieben Jahre erhoben wurden, in Rangziffern transformiert, wie es auch in der Literatur regelmäßig vorgeschlagen wird: „We convert the [...] scores to [...] fractional disclosure ranks, defined as the rank of a given firm's disclosure score divided by the number of observations. “911

Tab. 4 stellt die für die Strategieberichterstattung definierten Variablen dar.

\begin{tabular}{|c|c|c|c|c|}
\hline \multicolumn{5}{|c|}{ Strategieberichterstattung: Operationalisierung der Variablen } \\
\hline Variable & Definition & Einzelindikatoren & Niveau $\mathrm{Z}$ & Zeitraum \\
\hline $\begin{array}{l}\text { Kern-Variable: Ermittelte } \\
\text { Werte des Messinstruments } \\
\text { SDIndex (= SDScores) }\end{array}$ & $\begin{array}{l}\text { SDScores normiert auf Wertebereich } \\
\text { von null bis eins; Teil-Scores für drei } \\
\text { Kategorien des Berichtskataloges }\end{array}$ & $\begin{array}{l}\text { Jährliche SDScores } \\
\text { (normiert), drei Teil- } \\
\text { Scores (normiert) }\end{array}$ & Ordinal $^{912}$ & $\begin{array}{r}\text { Jeweils } \\
2002-08\end{array}$ \\
\hline $\begin{array}{l}\text { Alternativ: Rangziffern } \\
\text { der SDScores (SDRang) }\end{array}$ & $\begin{array}{l}\text { Rangziffern der Unternehmen in } \\
\text { Abhängigkeit von den SDScores }\end{array}$ & $\begin{array}{l}\text { Jährlicher SDRang } \\
\text { (Ränge } 1 \text { bis 100) }\end{array}$ & Ordinal & 2002-08 \\
\hline $\begin{array}{l}\text { Alternativ: Veränderung } \\
\text { der SDScores ( } \Delta \text { SDScore) }\end{array}$ & $\begin{array}{l}\text { Jährliche relative Veränderung der } \\
\text { erreichten SDScores }\end{array}$ & $\begin{array}{l}\text { Relative Differenz } \\
\text { SDScores (Betrag) }\end{array}$ & Ordinal & $2002-08$ \\
\hline
\end{tabular}

\section{Tabelle 4: $\quad$ Variablen der Strategieberichterstattung}

910 Obwohl die Normierung per se keinen Einfluss auf die Aussagekraft der Analyse hat, ist sie durchaus gängige Praxis, vgl. z.B. Cooke (1989), S. 182; Francis et al. (2008), S. 72.

911 Botosan/Plumlee (2002), S. 30. Dieses Vorgehen wird u.a. bei Bushee/Noe (2000), S. 182, Gietzman/Ireland (2005), S. 620, Hail (2002), S. 751 verwendet. Literaturkonform werden hier normierte Scores und Rangziffern errechnet. Eine materielle Änderung der Resultate ist bei Verwendung von Rangziffern grds. nicht zu erwarten. Die Berechnung von Rangziffern erfolgt i.d.R., um systematische Veränderungen des Berichtsniveaus zu eliminieren (vgl. Fn. 888) sowie zur Berechnung von Rangregressionen, vgl. C 3.4.2.

912 In enger Auslegung besitzen die Kennzahlen der Strategieberichterstattung nur ordinales Messniveau. Eine Interpretation als intervallskalierte, metrische Daten ist aufgrund der Konstruktion von SDIndex aber möglich und in der Literatur üblich, vgl. Smith (2003), S. 61. Es wird in D 2.3 geprüft, ob die SDScores für metrische Analysen geeignet sind. 


\subsubsection{Variablen der Bestimmungsfaktoren}

Innerhalb des Teilmodells der Bestimmungsfaktoren des Niveaus der Strategieberichterstattung sind die benötigten Variablen und die sie operationalisierenden Indikatoren für die zwölf Einzelfaktoren zu definieren. Im Grunde können diese unabhängigen Variablen bereits weitestgehend aus den formulierten Hypothesen sowie dem Untersuchungsmodell abgeleitet werden. Es ist daher Ziel dieses Abschnitts, die exakte Definition bzw. konkrete Operationalisierung der jeweiligen Variablen zu vervollständigen. Diese Angaben sind im Überblick in Tab. 5 auf S. 221f. aufgeführt, gleichwohl soll hier auf wesentliche Aspekte der Variablenkodierung - u.a. von nicht-numerischen Daten - eingegangen werden: ${ }^{913}$

In der relevanten Literatur, die sich mit Bestimmungsfaktoren des Berichtsverhaltens befasst, wird die Unternehmensgröße (H 2.3) meist mit dem natürlichen Logarithmus finanzwirtschaftlicher Parameter wie dem Jahresumsatz oder aber der Summe der Vermögenswerte operationalisiert. ${ }^{914}$ Gelegentlich wird auch der Marktwert des Eigenkapitals, also die Marktkapitalisierung, als ein Indikator der Unternehmensgröße genutzt. ${ }^{915}$ In der eigenen Untersuchung werden beide Vorschläge aufgegriffen, zwei Variablen berücksichtigen unternehmensinterne bzw. auch -externe Indikatoren zur Operationalisierung der Unternehmensgröße.

Zur Operationalisierung der Branche (H 2.4a) stehen ebenfalls verschiedene Indikatoren zur Verfügung: Während die US-amerikanische Literatur überwiegend auf die Klassifizierung nach sog. SIC-Codes zurückgreift, hat sich innerhalb der deutschen Literatur die in Abschnitt C 3.2.1 bereits skizzierte Systematik der Dt. Börse AG etabliert. ${ }^{916}$ Demzufolge wird hier ebenfalls die Branche mit Hilfe der mehrstufigen Systematik der Dt. Börse AG in kategorialer Form abgebildet. ${ }^{917}$

\footnotetext{
913 Vgl. zudem Anhang 8, der konkrete Variablenbezeichnungen und Datenquellen nennt.

914 Vgl. bspw. Hossain et al. (1995), S. 77 oder auch Clarkson et al. (1999), S. $112 \mathrm{f}$.

915 Vgl. bspw. Ettredge et al. (2002), ebenso Debrency et al. (2002), Celik et al. (2006).

916 Die sog. SIC-Codes (,Standard Industrial Classification*) werden nach wie vor von der SEC zur Branchenklassifikation genutzt, obgleich bereits seit 1997 ein offizielles Nachfolgeschema, das ,North American Industry Classification System (NAICS), vorliegt.

Für die dt. Literatur vgl. bspw. Pellens et al. (2000a); Wenzel (2005), S. 446f.

917 Die auf drei Stufen differenzierte Branchensystematik der Dt. Börse AG ist in Anhang 2 dargestellt, die Struktur der Stichprobe entsprechend dieser Systematik zeigt Anhang 3. 
Hypothese H. 2.6 unterstellt einen Einfluss der Person des CEO auf das Niveau der Strategieberichterstattung und vermutet sodann neben einzelnen Persönlichkeitsmerkmalen einen Einfluss aufgrund eines CEO-Wechsels. ${ }^{918}$ Während grds. eine Operationalisierung der Persönlichkeitsmerkmale Alter, Ausbildung sowie Nationalität eindeutig ist, liegt die Herausforderung bei der Operationalisierung der Variablen ,CEO-Wechsel ' in der Ermittlung der Wechsel-Begründung. ${ }^{919}$ In Anlehnung an einen Vorschlag von Gilson (1989) können jedoch alle im Untersuchungszeitraum beobachteten Wechsel eindeutig dichotom kodiert werden. ${ }^{920}$

Hinsichtlich einer Operationalisierung der Indexzugehörigkeit der Unternehmen (H 2.9) bietet sich unmittelbar die Kategorisierung entsprechend der von der Dt. Börse AG definierten Auswahlindizes, in Form einer kategorialen Variablen, an. Dabei ist allerdings zu beachten, dass die Auswahlindizes keine Rangfolge i.e.S. bilden, wie Abb. 14 bereits zeigt. Darüber hinaus ist - anders als die Branchenklassifikation - eine Zugehörigkeit zu einem Auswahlindex keinesfalls statisch, vielmehr ist eine jahresspezifische Indexzugehörigkeit zu ermitteln. ${ }^{921}$

Weiter wurde in Hypothese H 2.10 angenommen, dass Unternehmen, die zusätzlich an einer ausländischen Wertpapierbörse notiert sind, ein höheres Niveau der Strategieberichterstattung besitzen. Zur Operationalisierung jener Variablen wird in der Literatur i.d.R. eine dichotome Kodierung verwandt. ${ }^{922}$ Grote et al. (2009) folgend wird auf Notierungen an der US-amerikanischen NYSE fokussiert. ${ }^{923}$

918 Hinsichtlich des Einflusses eines CEO-Wechsels auf das Niveau der Strategieberichterstattung werden die Anzahl der Wechsel, dessen Zeitpunkt und Begründung betrachtet.

919 Diese Erkenntnis findet sich auch bei Jenter/Kanaan (2006), S. 17.

920 Vgl. Gilson (1989), S. 248f., welcher empfiehlt, Ablösungen von CEOs, die nicht durch Pensionierung (sofern das Alter des CEO 60 Jahre überschreitet), Tod, Krankheit, Umsetzung einer langfristig kommunizierten Nachfolgeregelung oder eine Beförderung erklärbar sind, als erzwungen zu charakterisieren. Diesem Vorschlag wird hier gefolgt.

921 Die Dt. Börse AG verändert die Zusammensetzung der vier Auswahlindizes periodisch (,Ordentliche Anpassung') bzw. z.T. aperiodisch (,Außerordentliche Anpassung'). Vgl. zum Prozess, zu den Kriterien und Regelungen der Anpassung Dt. Börse AG (2009a), S. 19ff. Die jahresspezifische Indexzugehörigkeit der 100 Stichproben-Unternehmen per Ultimo zeigt Anhang 4, für unterjährige Anpassungen im Detail Dt. Börse AG (2009b).

Vgl. bspw. Clarkson et al. (1999), S. 125 oder Debrency et al. (2002).

923 Vgl. Grote et al. (2009), S. 30. Argumentiert wird, dass - wenn überhaupt - eine ZweitNotierung an der bedeutendsten internationalen Wertpapierbörse relevant sein sollte. 
Bestimmungsfaktoren: Operationalisierung der Variablen

\begin{tabular}{|c|c|c|c|c|}
\hline Einzelfaktor und Variablen & Definition & Einzelindikatoren & Niveau & Zeitr. ${ }^{924}$ \\
\hline \multicolumn{5}{|l|}{ Makroökonomische Faktoren } \\
\hline \multicolumn{5}{|c|}{ H 2.1: Konjunkturentwicklung (+) } \\
\hline BIP (Volumen) & $\begin{array}{l}\text { Jährliches realisiertes Volumen } \\
\text { Bruttoinlandsprodukt für drei regionale } \\
\text { bzw. geographische Aggregationsstufen }\end{array}$ & $\begin{array}{l}\text { BIP DE, BIP EU-7, } \\
\text { BIP OECD }\end{array}$ & $\begin{array}{l}\text { Jeweils } \\
\text { metrisch }\end{array}$ & $2002-08$ \\
\hline \multicolumn{5}{|c|}{ H 2.2: Börsenentwicklung (+) } \\
\hline Indexstand & $\begin{array}{l}\text { Stand des Börsenindex zum } \\
\text { jeweiligen Jahresultimo in Punkten } \\
\text { für insg. sechs Indizes }\end{array}$ & $\begin{array}{l}\text { Dax, MDax, SDax, } \\
\text { TecDax, EuroStoxx } \\
\text { 50, Dow Jones Ind. }\end{array}$ & Metrisch & $2002-08$ \\
\hline \multicolumn{5}{|l|}{ Unternehmenscharakteristika } \\
\hline \multicolumn{5}{|c|}{ H 2.3 Unternehmensgröße (+) } \\
\hline $\begin{array}{l}\text { Interne } \\
\text { Größenparameter }\end{array}$ & $\begin{array}{l}\text { Drei übliche Parameter zur Darstellung } \\
\text { der Unternehmensgröße, logarithmiert } \\
\text { zur Reduktion der Schiefe der Verteilung }\end{array}$ & $\begin{array}{l}\text { Umsatz } \\
\text { Mitarbeiter } \\
\text { Bilanzsumme }\end{array}$ & Metrisch & 2002-08 \\
\hline $\begin{array}{l}\text { Externer } \\
\text { Größenparameter }\end{array}$ & $\begin{array}{l}\text { Realisierte Marktkapitalisierung in EUR } \\
\text { (Ultimo), logarithmiert }\end{array}$ & $\begin{array}{l}\text { Markt- } \\
\text { kapitalisierung }\end{array}$ & Metrisch & 2002-08 \\
\hline \multicolumn{5}{|c|}{ H 2.4: Unternehmensstammdaten (?) } \\
\hline Branchenausrichtung & $\begin{array}{l}\text { Eingruppierung gem. den Sub-Sektoren } \\
\text { in klassische und technologieorientierte } \\
\text { Branchen (dichotom) }\end{array}$ & $\begin{array}{l}\text { Klassisch vs. } \\
\text { Technologie }\end{array}$ & Nominal & $\begin{array}{r}2002-08 \\
\text { (statisch) }\end{array}$ \\
\hline Branchenzugehörigkeit & $\begin{array}{l}\text { Systematisierung gem. Branchenlogik } \\
\text { der Dt. Börse AG ( } 9 \text { bzw. } 18 \text { Kategorien) }\end{array}$ & $\begin{array}{l}9 \text { Super-Sektoren } \\
18 \text { Sektoren }\end{array}$ & $\begin{array}{l}\text { Jeweils } \\
\text { nominal }\end{array}$ & $\begin{array}{r}2002-08 \\
\text { (statisch) }\end{array}$ \\
\hline Unternehmensalter & $\begin{array}{l}\text { Alter der Unternehmen in Jahren, } \\
\text { ab Gründungsjahr }\end{array}$ & Alter in Jahren & Metrisch & 2002-08 \\
\hline \multicolumn{5}{|l|}{ H 2.5: Rechnungslegung (?) } \\
\hline $\begin{array}{l}\text { Rechnungslegungs- } \\
\text { philosophie }\end{array}$ & $\begin{array}{l}\text { Jahr des Wechsels von HGB } \\
\text { auf IFRS bzw. US-GAAP }\end{array}$ & $\begin{array}{l}\text { Jahreszahl des } \\
\text { Standard-Wechsel }\end{array}$ & Ordinal & 2002-08 \\
\hline $\begin{array}{l}\text { Rechnungslegungs:- } \\
\text { standard }\end{array}$ & $\begin{array}{l}\text { Im Jahresabschluss angewandter } \\
\text { Rechnungslegungsstandard (dichotom) }\end{array}$ & $\begin{array}{l}\text { HGB vs. } \\
\text { IFRS/US-GAAP }\end{array}$ & Nominal & 2002-08 \\
\hline Abschlussprüfer & Prüfer des Jahresabschlusses (dichotom) & ,Big 4'vs. Rest & Nominal & 2002-08 \\
\hline \multicolumn{5}{|l|}{ H 2.6: Management (?) } \\
\hline Persönlichkeit CEO & $\begin{array}{l}\text { Angaben zu Persönlichkeitsmerkmalen } \\
\text { des jeweiligen CEO: Alter in Jahren, } \\
\text { Ausbildung (vier Kategorien), } \\
\text { Nationalität (dichotom, DE vs. Ausland) }\end{array}$ & $\begin{array}{l}\text { Alter in Jahren } \\
\text { Ausbildung } \\
\text { Nationalität }\end{array}$ & $\begin{array}{l}\text { Metrisch } \\
\text { Nominal } \\
\text { Nominal }\end{array}$ & $\begin{array}{l}2002-08 \\
2002-08 \\
2002-08\end{array}$ \\
\hline $\begin{array}{l}\text { CEO-Wechsel/ } \\
\text { Verantwortlichkeit }\end{array}$ & $\begin{array}{l}\text { Angaben zum Zeitraum der Verantwort- } \\
\text { lichkeit eines jeweiligen CEO sowie } \\
\text { Typologie des Wechsels (dichotom, } \\
\text { Routinewechsel vs. Entlassung CEO) }\end{array}$ & $\begin{array}{l}\text { Anzahl der CEOs } \\
\text { Wechselzeitpunkt } \\
\text { Wechselgrund }\end{array}$ & $\begin{array}{l}\text { Metrisch } \\
\text { Ordinal } \\
\text { Nominal }\end{array}$ & $\begin{array}{l}2002-08 \\
2002-08\end{array}$ \\
\hline
\end{tabular}

\section{Tabelle 5: Variablen der Bestimmungsfaktoren (Teil 1)}

'24 Die Zeitraumangaben beziehen sich grds. auf die jeweiligen Geschäftsjahre, für welche die Strategieberichterstattung analysiert wurde. So liegen bspw. Daten für das BIP 2008 bzw. den Jahresumsatz im Geschäftsjahr 2008 erst zu Beginn des Jahres 2009 vor, also zu dem Zeitpunkt, zu dem die Berichterstattung erstellt wird. 
Bestimmungsfaktoren: Operationalisierung der Variablen (Forts.)

\begin{tabular}{|c|c|c|c|c|}
\hline \multicolumn{2}{|c|}{ Einzelfaktor und Variablen Definition } & \multirow[t]{2}{*}{ Einzelindikatoren } & \multirow[t]{2}{*}{ Niveau } & \multirow[t]{2}{*}{ Zeitraum } \\
\hline \multicolumn{2}{|l|}{ Finanzielle Faktoren } & & & \\
\hline \multicolumn{5}{|c|}{ H 2.7: Unternehmenserfolg (+) } \\
\hline Profitabilität & $\begin{array}{l}\text { Operative Erfolgsmaße: Ergebnis vor } \\
\text { Zinsen, Steuern (und Abschreibungen) } \\
\text { bzw. Jahresüberschuss in Relation zum } \\
\text { Jahresumsatz }\end{array}$ & $\begin{array}{l}\text { EBITDA- und } \\
\text { EBIT-Marge, } \\
\text { Netto-Marge } \\
\text { (Jahresüberschuss) }\end{array}$ & $\begin{array}{l}\text { Jeweils } \\
\text { metrisch }\end{array}$ & $\begin{array}{r}\text { Jeweils } \\
2002-08\end{array}$ \\
\hline Rentabilität & $\begin{array}{l}\text { Nettoergebnis in Relation zur } \\
\text { Bilanzsumme }\end{array}$ & Return on Assets & $\begin{array}{l}\text { Jeweils } \\
\text { metrisch }\end{array}$ & $\begin{array}{r}\text { Jeweils } \\
2002-08\end{array}$ \\
\hline $\begin{array}{l}\text { Unternehmens- } \\
\text { entwicklung }\end{array}$ & $\begin{array}{l}\text { Wachstum des Umsatzes bzw. der } \\
\text { Bilanzsumme relativ zur Vorperiode }\end{array}$ & $\begin{array}{l}\text { Wachstum Umsatz } \\
\text { bzw. Bilanzsumme }\end{array}$ & $\begin{array}{l}\text { Jeweils } \\
\text { metrisch }\end{array}$ & $\begin{array}{r}\text { Jeweils } \\
2002-08\end{array}$ \\
\hline \multicolumn{5}{|l|}{ H 2.8: Finanzierung (+) } \\
\hline Eigenkapitalquote & $\begin{array}{l}\text { Eigenkapital in Relation zur } \\
\text { Bilanzsumme }\end{array}$ & Eigenkapitalquote & Metrisch & $2002-08$ \\
\hline $\begin{array}{l}\text { Relative (langfristige) } \\
\text { Verschuldung }\end{array}$ & $\begin{array}{l}\text { Summe (langfristiger) Verbindlichkeiten } \\
\text { relativ zu Kapitalgrößen (Bilanzsumme } \\
\text { bzw. Eigenkapital) }\end{array}$ & $\begin{array}{l}\text { u.a. (LT) Debt to } \\
\text { Assets, (LT) Debt } \\
\text { to Equity }\end{array}$ & $\begin{array}{l}\text { Jeweils } \\
\text { metrisch }\end{array}$ & $\begin{array}{r}\text { Jeweils } \\
2002-08\end{array}$ \\
\hline $\begin{array}{l}\text { Relative } \\
\text { Nettoverschuldung }\end{array}$ & $\begin{array}{l}\text { Nettofinanzverschuldung relativ zur } \\
\text { Bilanzsumme }\end{array}$ & Net Debt to Assets & Metrisch & 2002-08 \\
\hline
\end{tabular}

Faktoren des Aktienkapitals

H 2.9: Indexzugehörigkeit (?)

Jahresspezifische Zugehörigkeit zu

Auswahlindizes (4 Kategorien)

H 2.10: Auslandslisting (?)
Dax, MDax, TecDax, SDax

Notierung

Nominal 2002-08

Nominal 2002-08

\section{H 2.11: Kapitalkonzentration (-)}

Inverser Freefloat

Anteil am Grundkapital, der nicht an Wertpapierbörsen gehandelt wird

Anteil direkter

Großaktionäre

Typ größter Einzelaktionär
Anteil am Grundkapital, der von Großaktionären (GA) gehalten wird (Überschreiten Meldeschwelle von 3\%)

Typisierung des größten Einzelaktionärs (4 Kategorien)
Anteil in Prozent

Anteil aller GA, alle $\mathrm{GA}$ mit $>5 \%$, fünf größter bzw. größter Aktionär

Stratege, Finanz., Privat, Staat
Metrisch 2002-08

Jeweils Jeweils metrisch 2002-08

Nominal 2002-08
Nominal $^{925} 2002-08$

H 2.12: Insidertransaktionen (+)

Monetäres Volumen

Monetäres Kauf- bzw. Verkaufsvolumen der Insider (alle Insider / Management), relativ zur Marktkapitalisierung

Volumen in

Prozent der Markt-

Jeweils

metrisch

Jeweils kapitalisierung

Stück-Volumen

Kauf- bzw. Verkaufsvolumen (in Stück) der Insider (alle Insider / Management), relativ zur Anzahl ausgegebener Aktien
Volumen in

Prozent der

Aktienanzahl metrisch 2002-08
Jeweils Jeweils

\section{Tabelle 5: $\quad$ Variablen der Bestimmungsfaktoren (Teil 2)}

925 Es wäre nicht korrekt, das Skalenniveau der Indexzughörigkeit als ordinal anzusehen. Zwar bilden Dax, MDax und SDax eine klare Rangfolge, durch Hinzufügen des TecDax ist diese Rangfolge aber durchbrochen. Vgl. hierzu auch die Index-Pyramide in Abb. 14 (S. 189). Das Skalenniveau der Indexzugehörigkeit ist daher als nominal zu betrachten. 


\subsubsection{Variablen der Kapitalmarkteffekte}

Im Kontrast zu den Variablen in Abschnitt C 3.3.3 inkludiert das Teilmodell der Kapitalmarkteffekte ausschließlich numerische Variablen. Die Definitionen der Variablen bzw. der operationalisierenden Indikatoren stellt Tab. 6 auf S. 225 zusammen, auf einzelne Variablendefinitionen ist im Folgenden kurz einzugehen:

In Hypothese H 3.2 wurde unterstellt, dass intensivere Strategieberichterstattung dazu führen sollte, dass die Empfehlungen der Analysten geringere Varianz aufweisen. Um dieses zu untersuchen, werden Kauf- sowie Verkaufsempfehlungen numerisch kodiert, indem jeder der fünf Empfehlungskategorien ein Zahlenwert zugeordnet und die Standardabweichung der Empfehlungen errechnet wird. ${ }^{926}$

Wie zuvor in Abschnitt C 2.3.3 erwähnt, ist die Untersuchung des Einflusses der Berichterstattung auf die Eigenkapitalkosten einer der wesentlichen Interessenschwerpunkte der Voluntary Disclosure-Literatur. Dies bestätigt nicht zuletzt die Beachtung, welche die Untersuchung von Botosan (1997a) gefunden hat, mit der diese einen signifikant negativen Einfluss des Niveaus der freiwilligen Berichterstattung auf die Eigenkapitalkosten nachweisen konnte. ${ }^{927}$ Zur Ermittlung der Eigenkapitalkosten sind grds. verschiedene Ansätze ${ }^{928}$ verfügbar; für die eigene Untersuchung wird eine rechnungslegungsorientierte Berechnungsmethode verwendet, die sich schon in vorherigen Studien als leistungsfähig erwiesen hat: das sog. Residualeinkommensmodell: ${ }^{929}$ Basis dieses Modells ist die angenommene

926 In enger Anlehnung an gängige Analystenpraxis in den USA werden Empfehlungen mit Zahlenwerten von eins bis fünf kodiert, wobei ,Strong Buy“ mit eins bzw. ,Sell‘ mit fünf belegt wurde, vgl. z.B. Nasdaq (2010). Die so errechneten Standardabweichungen zeigen sich invariant gegenüber linearen Transformationen des Kodierungsschemas.

Vgl. nochmals die bereits zitierte Arbeit von Botosan (1997a). Ebenso untersuchen z.B. Hail (2002); Botosan/Plumlee (2002) eine angenommene Reduktion von Kapitalkosten aufgrund einer geringeren Risikoprämie dank erweiterter Berichterstattung.

928 Eine Darstellung verschiedener methodischer Ansätze findet sich bei Botosan/Plumlee (2002), vgl. auch Botosan (1997a), S. 336ff. für einen Überblick.

929 Die Berechnungsmethode basiert auf dem Dividenden-Diskontierungsmodell und wurde vorgestellt von Ohlson (1995); Feltham/Ohlson (1995). Relevante Grundlagen lieferten Preinreich (1938) sowie Edwards/Bell (1961). In der Literatur wird regelmäßig auch der Terminus ,Edwards-Bell-Ohlson-Modell“ verwendet, vgl. z.B. Gietzman/Ireland (2005), S. 609. Kritisch zu dieser Methodik Easton (2006) - diese Kritik bezieht sich aber i.W. auf die Wachstumsannahme im mittel- und längerfristigen Zeithorizont.

Vgl. im Detail Anhang 11 dieser Arbeit zur Berechnung der Eigenkapitalkostensätze.

Tom Sieber - 978-3-631-75150-3 
Identität des Marktwerts des Eigenkapitals mit der Summe der in der Zukunft erwarteten, diskontierten Dividenden. Da in praxi die Schätzung aller zukünftigen Dividenden als unmöglich gelten darf, kann unter Hinzunahme der Prämisse des ,Clean Surplus-Accounting ${ }^{930}$ eine Variante dieses Dividenden-Diskontierungsmodells hergeleitet werden, die überwiegend auf Angaben der Rechnungslegung beruht. ${ }^{931}$ Formal wird auf diese Weise der heutige Marktwert des Eigenkapitals mit der Summe des heutigen Buchwerts und des Barwerts künftiger Residualgewinne gleichgesetzt und die Ableitung von Eigenkapitalkostensätzen ermöglicht. Die so errechneten Eigenkapitalkostensätze dienen zur Operationalisierung der entsprechenden Variablen, die zur Prüfung der Hypothese H 3.5 benötigt wird.

Die folgende Hypothese H 3.6 stellt auf die Höhe der Differenz zwischen Geldund Briefkurs ab, welche börsentäglich beobachtet werden kann. Konform mit der einschlägigen Literatur ist jene Variable als sog. relativer Bid-Ask-Spread zu operationalisieren, also durch Inbezugsetzen der absoluten Differenz mit dem jeweiligen Bid-Kurs. ${ }^{932}$ In der Literatur wird die so errechnete Höhe des Bid-AskSpreads häufig als Indikator für die in Bezug auf ein Unternehmen bestehenden Informationsasymmetrien interpretiert und daher als solider Proxy für die Höhe der Eigenkapitalkosten eines Unternehmens angesehen. ${ }^{933}$ Da im Rahmen dieser Untersuchung die Kapitalkosten mit H 3.5 explizit adressiert werden, können die Bid-Ask-Spreads als ihre Stellvertretergröße zusätzlich untersucht werden. ${ }^{934}$

Die Gesamtheit der im Teilmodell der Kapitalmarkteffekte definierten Variablen und der konkretisierenden Indikatoren ist in der folgenden Tab. 6 dargestellt.

930 Diese Prämisse postuliert, dass sich der Buchwert des Eigenkapitals in der Periode $t+l$ vollständig aus der Summe des Buchwertes in $t$, dem Ergebnis aus $t$ sowie einer in $t$ gezahlten Dividende ergibt. Dieser Zusammenhang ist in der dt. Literatur als ,PreinreichLücke-Theorem' bekannt, vgl. bspw. Weißenberger (2003), S. 144ff., auch Anhang 11. Vgl. für die Herleitung Hail (2002), S. 747ff., Gebhardt et al. (2001). Gietzman/Ireland (2005) verweisen auf die Problematik der Datenverfügbarkeit hinsichtlich zukünftiger Dividenden. Ergo wird hier - abweichend vom klassischen Dividenden-Diskontierungsmodell, das einen infiniten Zeitraum vorsieht - ein endlicher Zeithorizont angenommen. Anhang 11 stellt die Herleitung des Residualeinkommensmodells umfassend dar. Vgl. bspw. Coller/Yohn (1997) oder Welker (1995), Healy et al. (1999). Die Robustheit verschiedener Berechnungsmöglichkeiten zeigen Heflin et al. (2005), S. 858f. Vgl. bspw. Ahmihud/Mendelson (1986), Leuz/Verrecchia (2000). 
Kapitalmarkteffekte: Operationalisierung der Variablen

\begin{tabular}{|c|c|c|c|c|}
\hline Einzeleffekt und Variablen & Definition & Einzelindikatoren & Niveau & Zeitr. $^{935}$ \\
\hline \multicolumn{5}{|l|}{ Markttransparenzeffekte } \\
\hline \multicolumn{5}{|c|}{ H 3.1: Anzahl beobachtender Analysten (+) } \\
\hline $\begin{array}{l}\text { Anzahl beobachtender } \\
\text { Analysten }\end{array}$ & $\begin{array}{l}\text { Absolute Anzahl der ein Unternehmen } \\
\text { beobachtenden Analysten }\end{array}$ & $\begin{array}{l}\text { Anzahl Analysten, } \\
\text { Durchschnitt p.a. }\end{array}$ & Metrisch & 2002-09 \\
\hline \multicolumn{5}{|l|}{ H 3.2: Schätzungsvarianz (-) } \\
\hline $\begin{array}{l}\text { Varianz der } \\
\text { Empfehlungen }\end{array}$ & $\begin{array}{l}\text { Streuung der Analysten-Empfehlungen } \\
\text { (Kaufen / Halten etc.); Kodierung von } \\
\text { eins bis fünf, Standardabweichung }\end{array}$ & $\begin{array}{l}\text { Standardab- } \\
\text { weichung der } \\
\text { Empfehlungen }\end{array}$ & Metrisch & $2002-09$ \\
\hline $\begin{array}{l}\text { Streuung der } \\
\text { Schätzungen }\end{array}$ & $\begin{array}{l}\text { Variationskoeffizient der von Analysten } \\
\text { veröffentlichten Schätzungen des } \\
\text { Ergebnisses pro Aktie (EPS) }\end{array}$ & $\begin{array}{l}\text { Variations- } \\
\text { koeffizient der } \\
\text { EPS-Schätzungen }\end{array}$ & Metrisch & 2002-09 \\
\hline $\begin{array}{l}\text { Zusätzlicher Aspekt: } \\
\text { Schätzgüte der } \\
\text { Analysten (bzw. } \\
\text { Prognosefehler) }\end{array}$ & $\begin{array}{l}\text { Relative Abweichung der von Analysten } \\
\text { in } t \text { veröffentlichten Schätzungen des } \\
\text { Ergebnisses pro Aktie für Periode } t+2 \\
\text { von den in } t+2 \text { realisierten Werten }\end{array}$ & $\begin{array}{l}\text { Güte der EPS- } \\
\text { Schätzungen in } \\
\text { Prozent }\end{array}$ & Metrisch & $2002-08$ \\
\hline
\end{tabular}

\section{Handelseffekte}

\section{H 3.3: Handelsvolumen (+)}

Jährliches Handels- Monetäres jährliches Handelsvolumen volumen der Aktie der Aktien eines Unternehmens an den wesentlichen deutschen Börsenplätzen (FWB, Xetra) kumuliert, logarithmiert

Jährliches Handels- Metrisch volumen $(\mathrm{Ln})^{9.36}$

2002-09 volumen (Ln)

\section{H 3.4: Volatilität (-)}

Schwankungsbreite der Schwankungsintervall der Aktienkurse Aktienkurse eines Jahres, bezogen auf mittleren Kurs

Jährl. Volatilität in

Prozent (auch Ln)
Metrisch 2002-09

\section{Bewertungseffekte}

\section{H 3.5: Eigenkapitalkosten (-)}

Eigenkapitalkosten (ex ante)

\section{H 3.6: Bid-Ask-Spreads (-)}

Bid-Ask-Spreads

\section{H 3.7: Marktbewertung (+)}

\begin{tabular}{|c|c|c|c|c|}
\hline $\begin{array}{l}\text { Marktwert- / Buchwert- } \\
\text { Ratio }\end{array}$ & $\begin{array}{l}\text { Verhältnis aus totalem Marktwert und } \\
\text { Buchwert des Eigenkapitals }\end{array}$ & Tobin's Q & Metrisch & $2002-08$ \\
\hline Multiple-Bewertung & $\begin{array}{l}\text { Durchschnittliche Marktkapitalisierung } \\
\text { p.a. in Bezug zum Jahresumsatz }\end{array}$ & $\begin{array}{l}\text { Umsatz-Multiple } \\
\text { (branchenadjustiert) }\end{array}$ & Metrisch & $2002-08$ \\
\hline
\end{tabular}

\section{Tabelle 6: Variablen der Kapitalmarkteffekte}

935 Im Teilmodell der Kapitalmarkteffekte liegt das Gros der Daten bis Ultimo 2009 vor. In Abschnitt C 3.2.4 wurde dies unter dem Stichwort der, Phasenverschiebung ' begründet.

936 Eine Logarithmierung der Werte der Variablen Handelsvolumen scheint erforderlich, da vergleichbare Daten i.d.R. stark rechtsschiefe Verteilungen aufweisen. Vgl. z.B. Weber (2007), S. 91f., zur praktischen Anwendung Schira (2009), S. 378ff. Auch die Werte der Volatilität, der Kapitalkosten und der Spreads werden hier (zusätzlich) logarithmiert. 


\subsubsection{Kontrollvariablen der Hypothesenprüfung}

Es ist gängige Praxis in der relevanten Literatur, bei einer Prüfung hypothetisch vermuteter Zusammenhänge zwischen unabhängigen und abhängigen Variablen mittels Regressionsanalysen weitere Parameter, deren potenzieller Einfluss nicht explizit spezifiziert wurde, als sog. Kontrollvariablen zu berücksichtigen. ${ }^{937}$ Es ist Ziel dieses Vorgehens, die als Forschungshypothesen vermuteten Zusammenhänge möglichst eindeutig bzw. realitätsnah zu modellieren, um schließlich aussagekräftigere empirische Ergebnisse ermitteln zu können. Das Einbeziehen von Kontrollvariablen ,ermöglicht es, auch den gemeinsamen Einfluss und die Interdependenzen von mehreren Erklärungsvariablen zu analysieren“9938.

Folgerichtig werden im Rahmen dieser Arbeit ebenfalls Kontrollvariablen in die Regressionsmodelle inkludiert. Wenngleich, wie bereits bei der Betrachtung des wissenschaftlichen Kontexts dieser Arbeit bzw. bei der Formulierung der Hypothesen erkennbar wurde, in der einschlägigen Literatur ein derart umfangreiches Modell zur Erklärung von Ursache sowie Wirkung freiwilliger Berichterstattung bisher kaum untersucht wurde, ${ }^{939}$ liegen für die einzelnen Teilaspekte des Untersuchungsmodells verschiedene Studien vor, aus denen Hinweise auf zu berücksichtigende Kontrollvariablen zu entnehmen sind. So schlagen z.B. Coller/Yohn (1997) in einer Arbeit zum Einfluss der Berichterstattung auf die relativen GeldBrief-Spannen vor, innerhalb eines Regressionsmodells für das Handelsvolumen zu kontrollieren. ${ }^{940}$ Auf Basis der vorliegenden empirischen Arbeiten sind daher die relevanten Kontrollvariablen für die jeweils zu untersuchende Beziehung zu identifizieren, um den Stand der Forschung zu reflektieren. Da das hier zu überprüfende Modell - mit Ausnahme einer Kontrollvariablen Jahr ${ }^{941}$ - jedoch keine generellen, für alle Hypothesen relevanten Kontrollen erfordert, erfolgt die Ableitung spezifischer Kontrollen jeweils im Rahmen der Hypothesenprüfung.

\footnotetext{
937 Auch diese Untersuchung wendet Regressionsanalysen an, wie in C 3.4 erläutert wird.

938 Grote et al. (2009), S. 45. Der Realitätsbezug des Untersuchungsmodells wird so erhöht.

939 Erwähnenswert sind im deutschsprachigen Raum insb. die Untersuchungen von Wenzel (2005) zum Value Reporting sowie Barth (2009) zur Prognoseberichterstattung.

940 Vgl. Coller/Yohn (1997), S. 181ff., ebenso beispielhaft Glosten/Harris (1988), S. 129f.

941 Die Kontrollvariable Jahr berücksichtigt einen systematischen Einfluss der Zeit auf das Niveau der Strategieberichterstattung. Zur Erforderlichkeit dieser Kontrolle vgl. D 3.2.

Tom Sieber - 978-3-631-75150-3
} 


\subsection{Methodische Grundlagen der Hypothesenprüfung}

Es sei kurz rekapituliert, dass das Ziel der eigenen Untersuchung zweigeteilt ist: Einerseits sollten Bestimmungsfaktoren der Strategieberichterstattung abgeleitet bzw. andererseits Wirkungen der Strategieberichterstattung am Kapitalmarkt ermittelt werden. Die interessierenden Beziehungen innerhalb des eigenen Untersuchungsmodells wurden im vorherigen Abschnitt - basierend auf einschlägigen empirischen Arbeiten - als Hypothesen formuliert. Im Folgenden ist abzuklären, welche statistischen Verfahren zur Hypothesenprüfung anzuwenden sind.

\subsubsection{Auswahl von Verfahren zur Hypothesenprüfung}

Die anwendbaren Verfahren für eine statistische Hypothesenprüfung werden in erster Linie durch das Skalenniveau der zugrunde liegenden Daten bestimmt. ${ }^{942}$ Wie im Rahmen der Variablendefinition bereits dargestellt, stehen für die Überprüfung der Hypothesen in dieser Untersuchung überwiegend Daten metrischen Niveaus zur Verfügung: ${ }^{943}$ Während im Teilmodell der Kapitalmarkteffekte die verwendeten Daten ausschließlich metrisches Messniveau aufweisen, finden im Teilmodell der Bestimmungsfaktoren des Niveaus der Strategieberichterstattung zusätzlich nominal skalierte Daten Verwendung. ${ }^{944}$ Unter der Annahme, dass die Kennzahl des SDIndex als metrisch skaliert gelten kann, lassen sich die anwendbaren Verfahren zur Hypothesenprüfung wie in Abb. 21 dargestellt eingrenzen, da die abhängigen Variablen folglich stets metrisches Skalenniveau besäßen. ${ }^{945}$

942 Das ,Skalenniveau' von Daten beschreibt die jeweiligen Eigenschaften der betreffenden Skala, auf der Daten gemessen werden. Metrische Skalen bzw. metrisch skalierte Daten erlauben u.a. arithmetische Operationen wie Addition und Subtraktion sowie die Mittelwertbildung. Der Vollständigkeit halber sei erwähnt, dass die metrisch skalierten Daten dieser Untersuchung überwiegend ratioskaliert sind. Diese Bezeichnung geht zurück auf Stevens (1946), der in seiner - bis heute meistverwandten - Klassifikation von Skalenniveaus neben Nominal- und Ordinalskalen Intervall- und Rationalskalen als zwei Arten von metrischen Skalen unterscheidet. Vgl. zur Kritik Prytulak (1975). Eine Einführung zu den Skalenniveaus findet sich bspw. Backhaus et al. (2008), S. $8 \mathrm{ff}$.

Zudem besitzt u.a. die Art einer Hypothese Einfluss auf die anzuwendenden Verfahren. Vgl. zu den Skalenniveaus der Variablen die Tabellen 5 und 6 auf S. 221f. bzw. S. 225. Ordinal skalierte Daten werden ebenfalls als Nominaldaten bzw. als ,nicht-metrisch ' angesehen. Bzgl. der Skalierung der Messwerte von SDIndex sei auf Fn. 912 verwiesen. Insofern wäre hier nur die untere Zeile der Tabelle in Abb. 21 (S. 228) relevant. 
Sodann wären im ersten Teilmodell der Bestimmungsfaktoren, in dem SDIndex als einzige abhängige Variable fungiert, je nach konkretem Skalenniveau der unabhängigen Variablen, Mittelwertvergleiche oder auch Regressionsanalysen einzusetzen. Im zweiten Teilmodell dagegen, das mögliche Kapitalmarkteffekte der Strategieberichterstattung untersucht, tritt SDIndex - neben einzelnen Kontrollvariablen - als unabhängige Größe auf. Ergo sind, dank des metrischen Niveaus aller abhängigen Variablen, ausschließlich Regressionsanalysen zu verwenden.

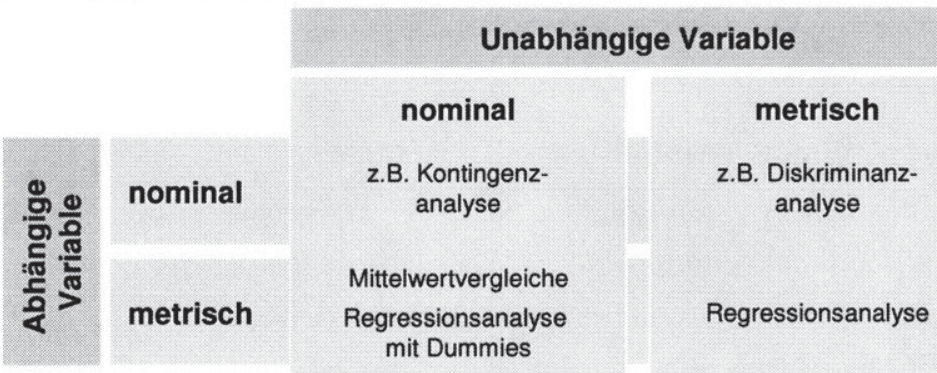

Abbildung 21: Verfahren der Hypothesenprüfung je nach Skalenniveau ${ }^{946}$

\subsubsection{Anzuwendende Verfahren der Hypothesenprüfung}

Wie zuvor angemerkt, basiert die Prüfung der 21 Hypothesen der eigenen Untersuchung also auf Mittelwertvergleichen bzw. regressionsanalytischen Modellen. Beide Gruppen von Verfahren sind nachfolgend vorzustellen als Grundlage für die Durchführung der Hypothesenprüfung in Hauptteil D dieser Arbeit.

\section{(a) Mittelwertvergleiche zur Prüfung von Unterschiedshypothesen}

Bei Durchsicht der in Abschnitt C 3.1 formulierten Hypothesen wird erkennbar, dass einzelne Hypothesen innerhalb des Teilmodells der Bestimmungsfaktoren auf potenzielle Unterschiede zwischen Untergruppen der Stichprobe in der Ausprägung der abhängigen Variablen abstellen. Es wird vermutet, dass diese Unterschiede durch die jeweilige unabhängige Variable hervorgerufen werden. ${ }^{947} \mathrm{Zur}$

946 Quelle: eigene Darstellung in Anlehnung an Backhaus et al. (2008), S. 12.

947 Vgl. bspw. Hypothese H 2.9, die Unterschiede im Niveau der Strategieberichterstattung aufgrund der jeweiligen Indexzugehörigkeit der Stichproben-Unternehmen vermutet. Im Überblick stellt Abb. 13 (S. 187) die Art der einzelnen Hypothesen dar. 
Prüfung derartiger Unterschiedshypothesen sind Mittelwertvergleiche i.d.R. eine geeignete Art von Verfahren, welche auch in dieser Arbeit angewandt werden. ${ }^{948}$ Im einfachsten Falle liegt eine nominal bzw. ordinal skalierte, kategoriale unabhängige Variable in dichotomer Ausprägung vor, die eine Spaltung einer Stichprobe in zwei Untergruppen und somit die Durchführung eines t-Tests erlaubt. ${ }^{949}$ Formal betrachtet überprüft jener t-Test schließlich die Nullhypothese, dass kein Unterschied in den Mittelwerten der beiden Teil-Stichproben vorliegt, es gilt:

$$
H_{0}: \quad \mu_{1}-\mu_{2}=0 \quad \text { bzw. } \quad H_{1}: \quad \mu_{1}-\mu_{2} \neq 0
$$

Dieser Test ermittelt sodann aus dem Quotienten der Mittelwertdifferenz sowie der Streuung der Mittelwerte einen empirischen t-Wert, anhand dessen geprüft werden kann, ob ein signifikanter Unterschied der Ausprägungen vorliegt. ${ }^{950}$

Sofern eine kategoriale unabhängige Variable, welche eine Aufteilung der Stichprobe determiniert, jedoch mehr als zwei Ausprägungen aufweist, kann eine einfaktorielle Varianzanalyse verwendet werden, um Unterschiede im Hinblick auf die abhängige Variable zu betrachten. ${ }^{951}$ Auch hier wird die Nullhypothese überprüft, dass zwischen einzelnen Gruppen keine Unterschiede vorliegen, es gilt: ${ }^{952}$

$$
H_{0}: \quad \mu_{1}=\mu_{2}=\ldots=\mu_{p} \quad \text { bzw. } \quad H_{1}: \quad \mu_{1} \neq \mu_{2} \neq \ldots \neq \mu_{p}
$$

948 Vgl. Janssen/Laatz (2007), S. 334ff.; Bühl (2006), S. 299ff. Es wird unmittelbar erkennbar, dass bei diesem Testverfahren die abhängige Variable metrisches Skalenniveau aufweisen muss, da ansonsten die Verteilungsparameter Mittelwert oder Varianz nicht vorlägen bzw. nicht berechnet werden könnten, vgl. bspw. Janssen/Laatz (2007), S. 347f.

949) Vgl. im Detail zum t-Test und den Anwendungsvoraussetzungen Bortz (2005), S. 140ff. Wesentliche Voraussetzungen sind die Normalverteilung und Intervallskalierung der abhängigen Variablen bzw. die Unabhängigkeit der Stichproben. Zur Prüfung der Normalverteilungseigenschaft der abhängigen Variablen, also SDIndex, vgl. Abschnitt D 2.3.

Bei fehlender Normalverteilung bzw. bei nicht-metrischem Messniveau kann der t-Test durch ein Test-Verfahren nach Mann-Whitney ersetzt werden, vgl. Bortz (2005), S. 150.

950) Vgl. Bortz (2005), S. 140f.

951 Vgl. im Detail Bortz (2005), S. 247ff. Im Falle zweier Teil-Stichproben stimmen t-Test und einfaktorielle Varianzanalyse überein, vgl. ebenda, S. 262f. Einfaktorielle Varianzanalysen werden z.T. auch als ,ANOVA' bezeichnet (,Analysis of Variance'). Je nach Anzahl unabhängiger Variablen, deren Bedeutung für eine abhängige Variable simultan, d.h. in einem Versuchsplan, untersucht wird, sind auch mehrfaktorielle Varianzanalysen möglich. Nicht möglich ist hingegen eine Durchführung mehrerer t-Test als Alternative zur ANOVA, da zufällig signifikante Ergebnisse nicht auszuschliessen werden könnten. Vgl. Bortz (2005), S. 249, sowie S. 249ff. im Detail zur einfaktoriellen Varianzanalyse, dort auch zu den Anwendungsvoraussetzungen der ANOVA. 
Im Ergebnis untersuchen Varianzanalysen folglich, welcher Anteil der Gesamtvarianz aller Messwerte auf die Gruppenzugehörigkeit zurückzuführen ist. ${ }^{953}$ Bei Ablehnung der Nullhypothese, also bei Bestehen signifikanter Mittelwertunterschiede, werden Varianzanalysen i.d.R um Einzelvergleiche erweitert, um so zu ermitteln, zwischen welchen Untergruppen relevante Unterschiede vorliegen. ${ }^{954}$ Im Rahmen der eigenen Untersuchung wird ein durch Scheffé vorgestelltes Verfahren angewendet, um entsprechende Einzelvergleiche durchzuführen. ${ }^{955}$

Eine interessante Alternative zur Hypothesenprüfung auf Basis von Mittelwertvergleichen bietet die Möglichkeit einer sog. Dummy-Kodierung nicht-metrisch skalierter Daten. Auf diesem Wege wird die Einbeziehung nominal bzw. ordinal skalierter Daten in regressionsanalytische Verfahren möglich, obwohl diese im Grundsatz metrisch skalierte Variablen erfordern, wie nachfolgend gezeigt wird.

\section{(b) Regressionsanalyse als Kernverfahren der Hypothesenprüfung}

Verfahren der Regressionsanalyse ermöglichen grds. Analysen von Beziehungen zwischen einer abhängigen sowie mehreren unabhängigen Variablen zur Untersuchung von zuvor postulierten Kausalbeziehungen. ${ }^{956}$ Formal prüft das Grundmodell der multiplen Regressionsanalyse insofern den funktionalen Zusammenhang zwischen dem Regressanden und den jeweils spezifizierten Regressoren, es

953 Vgl. Bortz (2005), S. 250. Bei ausreichend großem Anteil wird die Nullhypothese verworfen und die Alternativhypothese akzeptiert, dass die unabhängige Variable zu Unterschieden in der Ausprägung der abhängigen Variablen führt.

954 Einzelvergleiche werden in der Literatur auch als ,Kontraste ' oder ,Post Hoc-Tests“ bezeichnet. Konkrete Verteilungsparameter der definierten Gruppen werden sodann untereinander jeweils auf signifikante Unterschiede hin geprüft, vgl. Bortz (2005), S. 263f. Vgl. grdl. Scheffé (1953) und ders. (1963), S. 68ff. Daneben stehen auch Verfahren von Newman-Keuls, Duncan oder Tukey zur Verfügung. Für einen Überblick zu diesen Verfahren vgl. bspw. Keselman et al. (1979), Ryan (1980), Ramsey (1981), ders. (2002).

Das Verfahren nach Scheffé findet hier Anwendung, weil es sich als robust erwiesen hat und darüber hinaus als eher konservativ einzustufen ist, vgl. Bortz (2005), S. 274.

Da eine interessierende (abhängige) Variable (der Regressand) in der Realität meist von mehreren (unabhängigen) Variablen (den Regressoren) beeinflusst wird, scheint die sog. multiple Regressionsanalyse - also das Einbeziehen zahlreicher erklärender Parameter im Vergleich zur Einfachregression realitätsnäher bzw. für die eigene Untersuchung geeignet. Vgl. zur Unterscheidung z.B. Backhaus et al. (2008), S. 52ff. bzw. auch die Ausführungen zu Kontrollvariablen in Abschnitt C 3.3.5. Der zentrale Vorteil der multiplen Regression ist folglich, dass sie „allows us to effectively hold other factors fixed while examining the effects of a particular independent variable“, Wooldridge (2009), S. 104. 
gilt der in Abb. 22 mit (1) bezeichnete Ausdruck. Im Rahmen einer Regressionsanalyse werden schließlich konkrete Funktionsparameter bzw. sog. Regressionskoeffizienten errechnet, die es erlauben, durch mathematische Verknüpfung der Werte der unabhängigen Variablen Funktionswerte der abhängigen Variablen unter expliziter Einhaltung des unterstellten funktionalen Zusammenhangs - zu schätzen, wie in Abb. 22 durch (2) aufgezeigt wird, wobei hier ein linearer $\mathrm{Zu}$ sammenhang angenommen ist. Die konkrete Schätzung der Regressionsfunktion erfolgt sodann unter der generellen Zielsetzung möglichst geringer Differenzen (sog. Residuen) zwischen den errechneten und den tatsächlichen Werten der abhängigen Variablen, wie (3) aufzeigt. ${ }^{957}$

(1) Funktionaler Zusammenhang:

$$
Y=f\left(X_{1}, X_{2}, \ldots, X_{j}, \ldots X_{J}\right)
$$

(2) Grundmodell der linearen Regression:

$$
\hat{Y}=b_{0}+b_{1} x_{1}+b_{1} x_{1}+\ldots+b_{j} x_{j}+\ldots+b_{1} x_{J}
$$

(3) Zielfunktion der multiplen Regression:

$$
\sum_{k=1}^{K} e_{k}^{2}=\sum_{k=1}^{K}\left[y_{k}-\left(b_{0}+b_{1} x_{1}+b_{1} x_{1}+\ldots+b_{j} x_{j}+\ldots+b_{J} x_{J}\right)\right]^{2} \rightarrow \min .
$$

$\begin{array}{lllll}\text { mit: } & e_{k}: & \text { Wert der Residualgröße } & b_{1)}: & \text { Konstanter Term } \\ & y_{k}: & \text { Werte des Regressanden } & b_{j}: & \text { Regressionskoeffizienten } \\ & x_{j k}: & \text { Werte der Regressoren } & J: & \text { Anzahl Regressoren }\end{array}$

\section{Abbildung 22: Formale Darstellung der linearen Regressionsanalyse ${ }^{958}$}

Das Resultat der Regressionsanalyse ist folglich eine quantifizierte Regressionsfunktion, die Aufschluss darüber gibt, inwieweit verschiedene erklärende Parameter eine konkrete Zielgröße beeinflussen bzw. zu erklären in der Lage sind. ${ }^{959}$

957 Diese Zielstellung der Minimierung der (quadrierten) Abweichungen bzw. Residuen begründet die Bezeichnung der ,Methode der kleinsten Quadrate" (KQ, im Englischen als ,Ordinary Least Squares`(OLS) bezeichnet), welche als das wichtigste Schätzverfahren für Regressionsanalysen gilt, vgl. mit diesem Hinweis bspw. Chenhall/Moers (2007a), S. 176. Eine Beurteilung der Güte einer Schätzung der Werte des Regressanden erfolgt anhand der Residuenquadrate, vgl. Backhaus et al. (2008), S. 63ff. Residuen umfassen insofern alle theoretisch denkbaren Faktoren mit Einfluss auf den Regressanden, die im Regressionsmodell nicht explizit spezifiziert sind, so Chenhall/Moers (2007a), S. 176. 
$\mathrm{Zu}$ vermerken ist allerdings, dass mit Hilfe statistischer Verfahren generell bzw. mit der Regressionsanalyse im Speziellen zwar Zusammenhänge geprüft werden können, eine ,Kausalität' i.e.S. auf diesem Wege jedoch grds. nicht zweifelsfrei nachweisbar ist, wenngleich die ermittelten Regressionskoeffizienten sowie ein multipler Korrelationskoeffizient als notwendige Bedingung für eine tatsächliche Kausalität zwischen den untersuchten Variablen anzusehen sind. ${ }^{960}$

Die Regressionsanalyse erfordert grds. sowohl für die unabhängige(n) wie auch für die abhängige Variable ein metrisches Skalenniveau, sie erfährt jedoch - wie soeben bereits angedeutet - durch Umkodierung qualitativer Daten in Variablen binärer Ausprägung eine erhebliche Ausweitung ihres Anwendungsbereichs. Mit Hilfe dieser Vorgehensweise der sog. Dummy-Kodierung können nominale oder ordinale unabhängige Variablen in Regressionsmodelle einbezogen werden. ${ }^{961}$

Diese nicht-metrisch skalierten Variablen repräsentieren i.d.R. qualitative Merkmale der Merkmalsträger innerhalb einer Stichprobe: „Specific codes on dummy variables designate membership in particular groups or the presence [...] of particular characteristics. “962 Im Rahmen der eigenen Untersuchung können ergo verschiedene kategoriale Variablen im Zuge einer Dummy-Kodierung mit Hilfe der Regressionsanalyse auf ihren Einfluss auf die jeweils abhängige Variable hin geprüft werden. ${ }^{963}$ Dieses ermöglicht nicht nur eine regressionsanalytische Prüfung eines Zusammenhangs des betreffenden Parameters mit der jeweils abhängigen

960 Dieser multiple Korrelationskoeffizient $R$ dient in quadrierter Form als übergreifendes Gütekriterium des Regressionsmodells. Im Falle der Einfachregression entspricht dieser dem Korrelationskoeffizienten $r$ der beiden Variablen. Vgl. bspw. Bortz (2005), S. 236. Ob Kausalitäten empirisch nachzuweisen sind, gehört zu den klassischen Streitpunkten der Statistik, vgl. hierzu grdl. Sarris (1967), Blalock (1968), auch Bunge (1987). Vgl. Backhaus et al. (2008), S. 55ff. Eine Umkodierung qualitativer Daten in Variablen binärer bzw. dichotomer Ausprägung wird als ,Dummy-Kodierung' oder als Kodierung von Dummy-Variablen bezeichnet. Eine übersichtliche Darstellung zu Regressionsanalysen unter Einbeziehung von Dummy-Variablen findet sich bei Hardy (1993).

Es wird deutlich, dass durch eine Dummy-Kodierung die Verfahren der Varianzanalyse theoretisch ersetzt werden könnten, dies muss jedoch sowohl didaktisch wie auch sachlogisch nicht immer sinnvoll sein, vgl. Backhaus et al. (2008), S. 55. Die formale Äquivalenz von regressions- und varianzanalytischem Ansatz zeigt Bortz (2005), S. $490 \mathrm{f}$. Hardy (1993), S. 7.

963 Nicht-metrisch skalierte Daten sind im Teilmodell der Bestimmungsfaktoren von Interesse; Dummy-Variablen werden für H 2.4-2.6; 2.9-2.12 kodiert, vgl. Abschnitt C 3.1.2. 
Größe, sondern zudem Erkenntnisse über den Einfluss auf den Regressanden bei einer Wechselwirkung mit anderen, insb. auch metrisch skalierten Variablen. ${ }^{964}$

Der erste Schritt zur Vorbereitung bzw. Durchführung einer Regressionsanalyse ist schließlich die Formulierung eines geeigneten Regressionsmodells, was grds. ausschließlich theoriebegründet, d.h. rein auf Basis fachlicher Überlegungen zu erfolgen hat. ${ }^{965}$ In der einschlägigen Literatur werden sodann zumeist Funktionsgleichungen in Form der Darstellung in (2) der Abb. 22 aufgestellt, um den vermuteten Zusammenhang der jeweiligen Variablen abzubilden.

Alle im Rahmen der eigenen Untersuchung relevanten Regressionsmodelle sind - wie in (3) in generischer Form gezeigt - als lineare Modelle spezifiziert, daher ist an dieser Stelle auf die zentralen, linearen Modellen zugrunde liegenden Prämissen einzugehen, die Tab. 7 gemeinsam mit den angewendeten Vermeidungsbzw. Identifikationsstrategien überblicksartig zeigt. ${ }^{966}$ Bei Erfüllung dieser Annahmen liefert die KQ-Methode schließlich lineare Schätzfunktionen für die Regressionsparameter, die nicht nur unverzerrt, sondern zudem effizient sind. ${ }^{967}$

Die Prüfung der als ,Robustheit ' bezeichneten Konformität von geschätzten Regressionsfunktionen mit den in Tab. 7 aufgeführten wesentlichen Prämissen des linearen Modells ist daher als essentiell zu bezeichnen. Grobe Verletzungen der Modellprämissen könnten nicht nur verzerrte Regressionskoeffizienten bzw. in-

964 In Abschnitt D 4.1 - bei erstmaliger Anwendung der Dummy-Kodierung für die eigene Untersuchung - findet sich eine ausführliche Beschreibung der Vorgehensweise.

965 Vgl. Backhaus et al. (2008), S. 57f.

966 In der methodenorientierten Literatur wird i.d.R. empfohlen, bei regressionsanalytischen Untersuchungen zunächst grds. mit linearen Modellen zu arbeiten, falls nicht eindeutige Hinweise auf andere Formen des Zusammenhangs existieren. Es sei der Vollständigkeit halber erwähnt, dass lineare Regressionsanalysen lineare Funktionen ermitteln, anhand derer sodann die Werte der abhängigen Variablen geschätzt werden können.

Bemerkenswerterweise finden sich in zahlreichen Arbeiten, insb. auch Monographien, die zur Hypothesenprüfung Regressionsmodelle verwenden, keine Anmerkungen zu den Modellprämissen. Siehe z.B. die bereits zitierte Untersuchung von Wenzel (2005), auch Thiele (2007) verzichtet auf die Darstellung der Prämissenkonformität seiner Modelle. Innerhalb der relevanten Disclosure-Literatur wird darüber hinaus oftmals auch mit sog. Rangregressionen gearbeitet, vgl. dazu die nachfolgenden Ausführungen.

967 Dieser Effizienzbegriff bezieht sich auf die kleinstmögliche Varianz unter allen linearen sowie unverzerrten Schätzern. In der englischsprachigen Literatur wird dies als ,BLUE“ bezeichnet (,Best Linear Unbiased Estimators‘), vgl. grdl. Wooldridge (2009), S. 104.

Tom Sieber - 978-3-631-75150-3 
effiziente Schätzungen hervorrufen, sondern letztlich zu grds. ungültigen Testergebnissen und damit falschen Aussagen empirischer Untersuchungen führen. ${ }^{968}$

Zentrale Prämissen des linearen Modells und Identifikationsverfahren

\begin{tabular}{|c|c|c|c|}
\hline $\begin{array}{l}\text { Prämissen- } \\
\text { gruppe }\end{array}$ & $\begin{array}{l}\text { Einzelne } \\
\text { Modellprämisse }\end{array}$ & $\begin{array}{l}\text { Verletzung und Folgen } \\
\text { für Regressionsmodell }\end{array}$ & $\begin{array}{l}\text { Vermeidungs- bzw. Identifikationsstrategie } \\
\text { im Rahmen der Untersuchung }\end{array}$ \\
\hline \multirow[t]{2}{*}{$\begin{array}{l}\text { Modell- } \\
\text { spezifikation }\end{array}$} & $\begin{array}{l}\text { Korrekte } \\
\text { Spezifikation } \\
\text { des Modells }\end{array}$ & $\begin{array}{l}\text { Unzureichendes Modell, } \\
\text { Under- bzw. Overfitting } \\
\text { (sog. ,kitchen sink models'); } \\
\text { Folge: Ineffizienz } \\
\text { der Schätzwerte }\end{array}$ & $\begin{array}{l}\text { Sachlogisches Vorgehen im Rahmen der } \\
\text { Spezifikation des Modells, Einbezug der } \\
\text { relevanten Parameter oder auch } \\
\text { Weglassen irrelevanter Parameter; } \\
\text { Beachten von Grenzwerten }\end{array}$ \\
\hline & $\begin{array}{l}\text { Linearität der } \\
\text { Beziehung }\end{array}$ & $\begin{array}{l}\text { Fehlende Linearität } \\
\text { der Beziehung; } \\
\text { Folge: Verzerrung der } \\
\text { Schätzwerte der Parameter }\end{array}$ & $\begin{array}{l}\text { Inspektion bivariater Plots (jeweilige unab- } \\
\text { hängige mit abhängiger Variablen), auf } \\
\text { Linearitätsannahme hin untersuchen; ggf. } \\
\text { Transformation in alternativen funktionalen } \\
\text { Zusammenhang oder Rangregression }^{970}\end{array}$ \\
\hline $\begin{array}{l}\text { Beschaffen- } \\
\text { heit der un- } \\
\text { abhängigen } \\
\text { Variablen }\end{array}$ & $\begin{array}{l}\text { Keine (perfekte) } \\
\text { Multikollinearität }\end{array}$ & $\begin{array}{l}\text { Multikollinearität der } \\
\text { unabhängigen Variablen, } \\
\text { einzelne Variablen wären } \\
\text { durch andere ersetzbar, kein } \\
\text { eigener Erklärungsbeitrag; } \\
\text { Folge: geringe Präzision } \\
\text { der Schätzwerte }\end{array}$ & $\begin{array}{l}\text { Berücksichtigung im Rahmen modell- } \\
\text { theoretischer Überlegungen sowie Analyse der } \\
\text { Korrelationskoeffizienten, ob } r>, 700^{971} \text {, } \\
\text { Beachtung der Kennzahlen der Toleranz mit } \\
T<, 100 \text { bzw. Varianz-Inflations-Faktor mit } \\
V I F>10^{972} \text {; ggf. Re-Spezifikation des } \\
\text { Regressionsmodells, falls Prämisse verletzt }\end{array}$ \\
\hline
\end{tabular}

Tabelle 7: $\quad$ Prämissen des linearen Regressionsmodells (Teil 1)

968 Vgl. Backhaus et al. (2008), S. 81ff.; Auer (2005), S. 37ff.; Cohen et al. (2003), S. $117 f$.

969 Hierzu zählen insb. die z.B. von Long (1997), S. 54f. geforderte Minimalanzahl von 100 Beobachtungen in der Stichprobe sowie mind. zehn Beobachtungen je Variable.

970 Jene Empfehlung zur Prüfung der Linearität der Beziehung findet sich bspw. bei Cooke (1998), S. 210. Backhaus et al. (2008), S. 82 stellen nicht-lineare Transformationen dar. Zur Absicherung werden hier Rangregressionen berechnet, vgl. insb. Abschnitt D 5.4.1.

971 Als erste Basis der Analyse dient eine gesamthafte Korrelationsmatrix aller metrischen unabhängigen Variablen der Untersuchung, wie in Anhang 13 dieser Arbeit vorgesehen. Der genannte Schwellenwert von $r>, 700$ kann als konservativ gelten, Kennedy (2003), S. 209 schlägt bspw. einen weniger konservativen Schwellenwert von $r>, 800$ vor.

972 Bei (perfekter) Multikollinearität sind einzelne Regressoren als lineare Funktion anderer Regressoren beschreibbar und liefern insofern keinen eigenen Erklärungsbeitrag für die Varianz mehr. Multikollinearität tritt in der Praxis regelmäßig auf, daher scheint es relevant, ihr Ausmaß strikt zu kontrollieren. Dies kann durch die Betrachtung der bivariaten Korrelationen zwischen allen unabhängigen Variablen in einer Korrelationsmatrix bzw. eine Berechnung der Kennzahl der Toleranz $T$ erfolgen. Diese Toleranz $T$ errechnet sich für jede einzelne Variable als multipler Korrelationskoeffizient aus der Regression jener Variablen auf alle übrigen im Modell enthaltenen unabhängigen Variablen: $\left(T_{j}=1-R_{j}^{2}\right)$.

$V I F$ ist definiert als der Kehrwert der Toleranz T, vgl. Backhaus et al. (2008), S. 87ff. Diese Grenzwerte werden u.a. von Wooldridge (2009), S. 99f. genannt, ebenso Gujarati (1995), S. 318f. Gelegentlich werden auch noch konservativere Grenzwerte von VIF >5 postuliert, vgl. z.B. Menard (2001), S. 76. 


\begin{tabular}{|c|c|c|c|}
\hline $\begin{array}{l}\text { Prämissen- } \\
\text { gruppe }\end{array}$ & $\begin{array}{l}\text { Einzelne } \\
\text { Modellprämisse }\end{array}$ & $\begin{array}{l}\text { Verletzung und Folgen } \\
\text { für Regressionsmodell }\end{array}$ & $\begin{array}{l}\text { Vermeidungs- bzw. Identifikationsstrategie } \\
\text { im Rahmen der Untersuchung }\end{array}$ \\
\hline \multirow[t]{5}{*}{$\begin{array}{l}\text { Störgröße / } \\
\text { Residuen }\end{array}$} & $\begin{array}{l}\text { Unkorreliertheit von } \\
\text { Störgröße und } \\
\text { unabhängigen } \\
\text { Variablen (sog. } \\
\text { Endogenität) }\end{array}$ & $\begin{array}{l}\text { Endogenität: Korrelation } \\
\text { zwischen Störgröße und } \\
\text { unabhängigen Variablen; } \\
\text { Folge: Verzerrung der } \\
\text { Koeffizienten }\end{array}$ & $\begin{array}{l}\text { Berücksichtigung bei Modellspezifikation } \\
\text { durch sachlogische Überlegungen, zudem Ab- } \\
\text { sicherung durch Durbin-Wu-Hausman-Test } \\
\text { und - falls notwendig - Anwendung sog. } \\
\text { Instrumenten-Variablen-Schätzungen }\end{array}$ \\
\hline & $\begin{array}{l}\text { Erwartungswert der } \\
\text { Störgröße von null }\end{array}$ & $\begin{array}{l}\text { Systematischer Messfehler, } \\
\text { Störgröße umfasst nicht nur } \\
\text { zufällige Effekte; Folge: } \\
\text { Ineffizienz und Verzerrung }\end{array}$ & $\begin{array}{l}\text { KQ-Schätzung liefert grds. Erwartungswert } \\
\text { von null, konstanter Term im Regressions- } \\
\text { modell nimmt systematischen Messfehler auf. } \\
\text { daher Modellspezifikation mit Konstante }\end{array}$ \\
\hline & $\begin{array}{l}\text { Konstante Varianz } \\
\text { der Residuen (sog. } \\
\text { Homoskedastizität) }\end{array}$ & $\begin{array}{l}\text { Heteroskedastizität } \\
\text { sowie Existenz von } \\
\text { Residuen-Ausreißern; } \\
\text { Folge: Ineffizienz des } \\
\text { Modells }\end{array}$ & $\begin{array}{l}\text { Heteroskedastizität: visuelle Inspektion der } \\
\text { Residuenplots; Testverfahren möglich, bspw. } \\
\text { Breusch-Pagan-, White- oder Glesjer-Test' } \\
\text { ggf. Transformation des Regressanden ( } \mathrm{Ln} \text { ); } \\
\text { Ausreißer: Ebenfalls visuelle Inspektion sowie } \\
\text { Beachtung von Cooks Distanzmaß }{ }^{976}\end{array}$ \\
\hline & $\begin{array}{l}\text { Störgrößen } \\
\text { untereinander } \\
\text { nicht korreliert }\end{array}$ & $\begin{array}{l}\text { Störgrößen beeinflussen } \\
\text { sich, Autokorrelation; } \\
\text { Folge: Verzerrung }\end{array}$ & $\begin{array}{l}\text { Inspektion des Residuenplots (standardisierte } \\
\text { Residuen gegen Schätzwerte der abhängigen } \\
\text { Variablen) sowie Test nach Durbin-Watson }\end{array}$ \\
\hline & $\begin{array}{l}\text { Normalverteilung } \\
\text { der Residuen }\end{array}$ & $\begin{array}{l}\text { Mangelnde Normalver- } \\
\text { teilung der Residuen; } \\
\text { Folge: Ungültigkeit von } \\
\text { Signifikanztests } \\
\text { (d.h. F- bzw. t-Test) }\end{array}$ & $\begin{array}{l}\text { Signifikanztests erfordern Normalverteilung } \\
\text { der Parameter (entspricht Normalverteilung } \\
\text { der Residuen), Prüfung durch Inspektion und } \\
\text { ggf. Testverfahren; Absicherung durch } \\
\text { zentralen Grenzwertsatz der Statistik }\end{array}$ \\
\hline
\end{tabular}

\section{Tabelle 7: $\quad$ Prämissen des linearen Regressionsmodells (Teil 2)}

973 Vgl. Wooldridge (2002), S. $118 \mathrm{ff}$. zu der verwendeten Variante des Hausman-Tests.

974 Vgl. bspw. Auer (2005), S. 441 ff., kritisch Chenhall/Moers (2007a), S. 187ff. Zum Verfahren einer Verwendung von Instrumenten-Variablen vgl. auch Abschnitt D 5.4.2.

975. Trotz der Verfügbarkeit von Testverfahren für die Identifikation von Heteroskedastizität wird eine visuelle Inspektion der Residuenplots als zuverlässige Identifikationsmöglichkeit empfohlen, vgl. bspw. Backhaus et al. (2008), S. 85f.; Wooldridge (2009), S. 264f. Besonders attraktiv ist aufgrund einfacher Anwendbarkeit das Verfahren nach Glesjer, bei dem eine Regression der absoluten Residuen auf die Regressoren des ursprünglichen Modells erfolgt, vgl. Glesjer (1969), auch Maddala (2001), S. 202f. Gleiches gilt für die modifizierte Form des White-Tests, vgl. Wooldridge (2009), S. $271 \mathrm{ff}$.; White (1980).

976 Vgl. Menard (2001), S. 80ff. Ausreißer liegen nach h.M. bei Werten für das Distanzmaß nach Cook von über eins vor, darüber hinaus Kontrolle aller Fälle mit Residuen $>3$.

977 Vgl. Durbin/Watson (1950) bzw. ders. (1951). Dieser Test ermittelt einen Wert $d$, der in etwa im Wertebereich von $\{1,8 ; 2,2\}$ liegen sollte, um die Nullhypothese der fehlenden Autokorrelation nicht verwerfen zu müssen, vgl. Cohen et al. (2003), S. 136f.

Dieser Grenzwertsatz postuliert, dass die Summenvariable von mehreren unabhängigen Zufallsvariablen bei hinreichend großer Stichprobe normalverteilt ist und liefert folglich eine Rechtfertigung für die Annahme, dass Zufallsvariablen, die sich aus Überlagerung zahlreicher zufälliger Effekte ergeben, annähernd normalverteilt sind, vgl. Backhaus et al. (2008), S. 81 bzw. 91. Eine visuelle Inspektion sollte erfolgen, um die Symmetrie der tatsächlichen Verteilung zu prüfen. Formale Tests stellt Kmenta (1997), S. 265ff. dar. 
Bemerkenswerterweise werden in der Literatur die Modellprämissen jedoch oftmals nicht ausreichend berücksichtigt, wie bspw. auch Healy/Palepu (2001) für Arbeiten der hier im Fokus stehenden Voluntary Disclosure-Literatur feststellen: „However, many of these studies [...] suffer from endogeneity and measurement error problems, making it difficult to interpret their findings. “979

Es scheint geboten, die Konformität der eigenen Modelle mit den Prämissen zu überprüfen und folglich deren Robustheit sicherzustellen. ${ }^{980}$ Hohe Bedeutung für die Güte der Regressionsmodelle besitzen insb. die Prämissen fehlender Multikollinearität sowie der Homoskedastizität, die für jedes Modell im Folgenden überprüft werden. Zur Vermeidung von Multikollinearität werden Modelle mit $V I F$-Werten oberhalb des genannten Grenzwertes nicht akzeptiert, Gleiches gilt für Modelle mit signifikanten Ergebnissen des Tests auf Heteroskedastizität. ${ }^{981}$ Im Einklang mit der relevanten Literatur verlangt - aufgrund des hier gewählten Modellaufbaus - zudem die Gefahr potenzieller Endogenität der im Teilmodell der Kapitalmarkteffekte auf ihren Einfluss zu überprüfenden Variablen SDIndex besondere Beachtung. Hintergrund ist die wesentliche Annahme, dass Manager die Entscheidung über ihr Berichtsverhalten nicht losgelöst von den Effekten anstellen, die sie damit am Kapitalmarkt auszulösen erhoffen. ${ }^{982}$

979 Healy/Palepu (2001), S. 407.

980 In der deutschsprachigen Standardliteratur fehlen oft ausführliche Hinweise zur Durchführung entsprechender Tests, dies gilt z.B. für Backhaus et al. (2008), Auer (2005). Dies wird bei den Regressionen in Teil D sichergestellt, berichtete Ergebnisse sind stets als prämissenkonform zu verstehen. In D 5.4 erfolgt eine konsolidierte Darstellung. Derartige Variablen, die das Berichtsverhalten abbilden, werden daher auch als, choice variables ' bezeichnet, so Chenhall/Moers (2007a), S. 174. Ebenso Lapointe-Antunes et al. (2006), S. 468f.: „Endogeneity will be of concern if the disclosure quality decision is made simultaneously to the earnings quality decision." $\mathrm{Zu}$ möglichen Ursachen von Endogenität neben dieser ,Simultanität“ vgl. Proppe (2007), S. 232.

Eine ,choice variable` muss allerdings nicht unmittelbar zum Auftreten von Endogenität führen. Leuz/Verrecchia (2000), S. 100 empfehlen daher eine Prüfung auf Endogenität, dies erfolgt hier in Abschnitt D 5.4. Chenhall/Moers (2007b), S. 219 bestätigen die Relevanz der Prüfung: ,endogeneity is a serious matter as if it exists, we can no longer be confident that the results from the regression support the causality implied in the structural equation." Zur Identifikation ist theoriegeleitet vorzugehen, vgl. Larcker/Rusticus (2007), Chenhall/Moers (2007b). U.a. wird Botosan (1997a) für die Nicht-Überprüfung der Exogenität ihrer Disclosure-Größe kritisiert, so Hail (2002), S. 744. Dass die Gefahr endogener Größen oft übergangen wird, merken Hamilton/Nickerson (2003), S. 51 an. 
Um dieser zu begegnen, wird eine explizite Prüfung der Regressionsmodelle der Kapitalmarkteffekte auf Endogenität eingeplant unter Anwendung der zuvor erwähnten Prozedur nach Durbin-Wu-Hausman. ${ }^{983}$ Darüber hinaus kann bereits im Rahmen der Modellspezifikation auf eine Vermeidung von Endogenität hingearbeitet werden: ${ }^{984}$ Neben der Inklusion von Kontrollvariablen sollte auch die als ,Phasenverschiebung ' beschriebene Logik der Verknüpfung der Untersuchungsvariablen SDIndex mit den einzelnen Variablen der Kapitalmarkteffekte zu einer Reduktion bzw. zum Nicht-Auftreten von Endogenität beitragen. ${ }^{985}$

Ein abschließender Aspekt behandelt die hier bislang unterstellte Linearität der Beziehungen zwischen den Regressoren und dem Regressanden. Obgleich zahlreiche einschlägige Untersuchungen innerhalb der Disclosure-Literatur auf Basis linearer Modelle arbeiten, werden gelegentlich auch sog. Rangregressionen verwandt, um dem Umstand Rechnung zu tragen, dass keine Gewissheit über einen linearen Zusammenhang der Variablen besteht, grds. aber von einer monotonen Beziehung ausgegangen werden kann. ${ }^{986}$ Bei Anwendung des Grundmodells der KQ-Regression erfolgt eine Rangregression mit Hilfe der Rangbildung für sämtliche spezifizierten Parameter: „Given a dependent variable [...] observations are placed in order and ranked from 1 to $n[. .$.$] . The procedure is to rank both depen-$

Die Bedeutung der Prüfung auf Endogenität wird in der Literatur z.T. jedoch auch relativiert: „My answer is that we shouldn't expend great effort worrying about endogeneity, but we shouldn't fully ignore it either", so bspw. van Lent (2007), S. 203.

Die angewendete Prozedur wird u.a. bei Davidson/MacKinnon (1993), S. 237f. erläutert und beruht auf den Grundlagen von Hausman (1978), Wu (1973), Durbin (1954). Dieser Ansatz wird in Abschnitt D 5.4 aufgezeigt, in dem eine Prüfung auf Endogenität erfolgt. So bspw. der Hinweis bei van Lent (2007): ,consider endogeneity upfront“.

985 Eine zeitliche Differenz zwischen der Wahl der Berichterstattungsstrategie und dem tatsächlichen Eintreten angestrebter Kapitalmarkteffekte von in etwa einem Jahr könnte als ein Argument dafür gelten, SDIndex als exogene Variable in den Modellen der Kapitalmarkteffekte anzusehen. Dieses Argument ist bei Eichner (2009), S. 172 oder Jostarndt (2007), S. 103 zu finden. Es wäre auch zu hinterfragen, ob Managern bei der Wahl eines Berichtsniveaus die potenziellen Effekte der Strategieberichterstattung transparent sind. Vgl. Cooke (1998), S. 210. Der Autor verweist grds. auf die Bedeutung der Prüfung der Beziehungen: „This emphases the point that it is important to examine the structure of the data and the relationships between the [...] variables“, ebenda, S. 223.

Innerhalb der einschlägigen Literatur unterstellen u.a Botosan (1997a), Hail (2002) bzw. Vanstraelen (2003) lineare Zusammenhänge. Relevante Arbeiten mit Rangregressionen legen bspw. Cheng et al. (1992), Lang/Lundholm (1993) und Baetge et al. (2010) vor. 
dent and independent variables. “987 Diese Rangdaten werden schließlich genutzt, um eine Regressionsfunktion zu errechnen: „The result is that the rank of the dependent variable is predicted using the ranks of the independent variables."

Als nachteilig muss beim Einsatz von Rangregressionen insb. gelten, dass durch die Rangbildung Informationsgehalt der Variablen verloren geht. Das metrische Messniveau der jeweiligen Variablen wird bewusst aufgegeben, gebildete Rangdaten sind lediglich als ordinal skaliert anzusehen. ${ }^{989}$ Insofern ist ein Verlust an Aussagekraft zu verzeichnen, da eine inhaltliche Interpretation der errechneten Parameter der Regressionsfunktion nicht mehr möglich ist. Es erscheint insofern sinnvoll, für die eigene Untersuchung weiterhin von linearen Zusammenhängen auszugehen, allerdings zur Absicherung der ermittelten Ergebnisse - im Rahmen einer Robustheitsprüfung - zusätzlich Rangregressionen vorzusehen. ${ }^{990}$

Im Nachgang zur Schätzung der Regressionsfunktion - unter der Voraussetzung der Gültigkeit der Prämissen des linearen Modells - sind geschätzte Funktionen dahingehend zu beurteilen, ob sie für Entscheidungen zu den Hypothesen sowie zur Ableitung von Aussagen geeignet sind. Zur Beurteilung sind neben globalen Gütemaßen die geschätzten Regressionskoeffizienten zu berücksichtigen. ${ }^{991}$ Die Kerngrößen der Modellbeurteilung listet Tab. 8 im Überblick auf, die zentralen Größen zur Beurteilung von Regressionsmodellen seien zudem kurz genannt: Im Hinblick auf die Beurteilung eines Regressionsmodells ist v.a. das korrigierte Bestimmtheitsmaß $R^{2}$ hervorzuheben: Als globales Gütemaß bringt es zum Ausdruck, wie gut sich die ermittelte Regressionsfunktion an die empirischen Werte anpassen kann bzw. welchen Anteil an der Varianz der zu erklärenden Variablen die Gesamtheit aller Regressoren zu erklären in der Lage ist. Für die Prüfung der Signifikanz eines berechneten Regressionsmodells kommt sodann die F-Statistik

987 Cooke (1998), S. 212. Grdl. zum Verfahren der Rangregression Iman/Conover (1979).

988 Conover/Iman (1981), S. 127.

989 Vgl. Cooke (1998), S. 213f. für eine ausführlichere Bewertung der Rangregression. Zudem Siegel/Castellan (1988), die grds. empfehlen, mit metrischen Daten zu arbeiten sowie parametrische Testverfahren zu verwenden, sofern dies grds. möglich ist.

990 Diese Vorgehensweise wendet Botosan (1997a), S. 343f. an, um die Spezifikation ihres Modells zu prüfen (,,Specification Test“). Bei der Hypothesenprüfung in Teil D werden daher - bei Korrelationsanalysen - stets auch die Koeffizienten nach Spearman notiert. 
zum Einsatz, welche die Nullhypothese überprüft, dass keiner der im Modell inkludierten Parameter einen Einfluss auf die zu erklärende Größe besitzt.

\begin{tabular}{|c|c|c|}
\hline Ebene und Indikator & Symbol & Erläuterung \\
\hline \multicolumn{3}{|l|}{ Regressionsmodell } \\
\hline \multirow[t]{2}{*}{ Bestimmtheitsma $B$} & $R^{2}$ & Anpassung der Regressionsfunktion (,goodness of fit ${ }^{*}$ ) an empirische Werte \\
\hline & & $\begin{array}{l}\text { Residuenanalyse, d.h. der Abweichungen der geschätzten Werte von den } \\
\text { empirischen Werten; Quotient aus (quadrierter) erklärter Streuung sowie } \\
\text { (quadrierter) Gesamtstreuung bzw. Quadrat des Korrelationskoeffizienten der } \\
\text { geschätzten und empirischen Werte; normiert auf einen Wertebereich }\{0 ; 1\}\end{array}$ \\
\hline $\begin{array}{l}\text { Korrigiertes } \\
\text { Bestimmtheitsmaß }\end{array}$ & $R^{2}$ adj. & $\begin{array}{l}\text { Beeinflussung von } R^{2} \text { durch Modellspezifikation, daher Berechnung von } \\
R^{2} \text { adj., welches die Anzahl an Regressoren } m \text { sowie an Beobachtungen } n \\
\text { berücksichtigt: }{ }^{992} \quad R^{2} \text { adj. }=R^{2}-m \times(n-m-1)^{-1} \times\left(1-R^{2}\right)\end{array}$ \\
\hline \multirow{2}{*}{$\begin{array}{l}\text { F-Statistik } \\
\text { (F-Wert) }\end{array}$} & $F$ & Signifikanzprüfung des geschätzten Modells bzw. des Bestimmtheitsmaßes \\
\hline & & $\begin{array}{l}\text { Prüfung der Nullhypothese, dass alle Regressionskoeffizienten gleich null } \\
\text { sind und folglich kein Zusammenhang zwischen den Regressoren und dem } \\
\text { Regressanden besteht, durch Berechnung eines empirischen F-Wertes und } \\
\text { Vergleich mit theoretischem F-Wert für ein bestimmtes Signifikanzniveau }\end{array}$ \\
\hline
\end{tabular}

Regressionskoeffizienten

Beta $\quad \beta$

Standardisierte Regressionskoeffizienten, die sich ergeben würden, wenn vor Durchführung der Regression alle Variablen standardisiert worden wären

Ziel: erleichterte(r) Interpretation / Vergleich der Regressionskoeffizienten

t-Statistik $\quad t \quad$ Signifikanzprüfung eines einzelnen Regressionskoeffizienten

(t-Wert) Prüfung der Nullhypothese, dass ein Koeffizient gleich null ist und keinen Einfluss auf den Regressanden ausübt, Berechnung des empirischen t-Wertes und Vergleich mit theoretischem t-Wert für ein bestimmtes Signifikanzniveau

\section{Tabelle 8: $\quad$ Maße zur Prüfung der Regressionsfunktionen}

Abschließend sei bemerkt, dass zur Ermittlung der Regressionsfunktionen - und aller anderen statistischen Auswertungen - im Rahmen dieser Untersuchung die bewährte Statistik-Software SPSS/PASW in der Version 18 eingesetzt wird. Zur konkreten Berechnung der jeweiligen a priori spezifizierten Regressionsmodelle kommt stets die sog. ,Einschluss-Methode' zum Einsatz, die für eine konsequent theoriegeleitete Hypothesenprüfung am ehesten geeignet erscheint. ${ }^{993}$

992 Vgl. Janssen/Laatz (2007), S. 427f.

993 Weitere Vorgehensweisen beruhen darauf, der Statistik-Software die Kern-Aufgabe zu überlassen, durch spezielle Methoden der Regressionsanalyse alternative Modelle zu errechnen, die anschließend interpretiert werden. Vgl. Backhaus et al. (2008), S. 101: „Es besteht die Gefahr, dass sachlogische Überlegungen in den Hintergrund treten [...], d.h. dass der Untersucher mehr dem Computer als seinem gesunden Menschenverstand vertraut." Auch Bortz (2005), S. 462 verlangt, dass bei einem Einsatz derartiger Methoden zumindest eine gründliche Vorstrukturierung durch den Untersucher zu erfolgen hat.

Tom Sieber - 978-3-631-75150-3 


\subsubsection{Formale Aspekte der Hypothesenprüfung}

Im vorherigen Abschnitt sind bereits die zentralen Begriffe der Teststatistik eingeführt worden, die nachfolgend - als Grundlage für eine Hypothesenprüfung in der gebotenen Kürze formal dargestellt werden sollen.

Innerhalb der empirischen Forschung wird eine bestimmte Vermutung in Bezug auf eine Grundgesamtheit als sog. statistische Hypothese bzw. Alternativhypothese $\left(H_{1}\right)$ bezeichnet. $\mathrm{Zu}$ jeder Alternativhypothese wird eine jener $\mathrm{H}_{1}$ inhaltlich exakt entgegengerichtete, eine sog. konkurrierende Hypothese aufgestellt. Die in Abschnitt C 3.1 formulierten Hypothesen der eigenen Untersuchung sind daher stets als Alternativhypothesen anzusehen. Die korrespondierende Nullhypothese $\left(\mathrm{H}_{0}\right)$ bildet die Basis der Hypothesenprüfung, anhand derer entschieden wird, ob eine Alternativhypothese schließlich akzeptiert bzw. eine $\mathrm{H}_{0}$ verworfen wird. ${ }^{994}$

Die Entscheidung über die Tragfähigkeit einer Alternativhypothese erfolgt grds. auf Basis statistischer Testverfahren, die anhand einer Stichprobe versuchen, die postulierte Vermutung zu bestätigen. ${ }^{995}$ Bestätigt der Stichprobentest eine Vermutung $\mathrm{H}_{1}$, ist anzugeben, mit welcher Wahrscheinlichkeit mit diesem Ergebnis zu rechnen ist unter der Bedingung, dass $\mathrm{H}_{0}$ fälschlicherweise verworfen wurde.

Aus Gründen der Vergleichbarkeit empirischer Forschung ist es üblich, eine $\mathrm{H}_{0}$ erst zu verwerfen, wenn diese sog. Irrtumswahrscheinlichkeit einen Schwellenwert von $\alpha=5 \%$ unterschreitet. ${ }^{996}$ Resultate, deren Eintrittswahrscheinlichkeit unter der Bedingung der Richtigkeit einer verworfenen $\mathrm{H}_{0}$ - geringer ist als der Schwellenwert von $\alpha=5 \%$, werden sodann als , signifikant ${ }^{\star}$ bezeichnet. ${ }^{997}$ In der

994 Vgl. im Detail Bortz (2005), S. 109f., Auer (2005), S. 118f. und aus eher wissenschaftstheoretischer Perspektive Kromrey (2006), S. 53f. Prägnant formuliert dazu Wooldridge (2009), S. 272 für den Fall, dass eine Alternativhypothese nicht akzeptiert werden kann: „Remember that we never accept $\mathrm{H}_{0}$; we simply fail to reject it.“

Vgl. Bortz (2005), S. 110. Während sich Hypothesen also auf eine Grundgesamtheit beziehen, erfolgt die Prüfung derselbigen anhand einer jener Grundgesamtheit entnommenen Stichprobe. Eine Prüfung erfolgt konkret durch Errechnung der t-Werte für einzelne Parameter bzw. F-Statistiken für gesamthafte Regressionsmodelle, vgl. Tab. 8 (S. 239). Als Begründer dieser Konvention gelten in der Literatur Cowles/Davis (1982). Dennoch ist Wooldridge (2009), S. 133 zuzustimmen: „There is no 'correct' significance level.“

Vgl. Bortz (2005), S. 112f. Umgekehrt kann eine angenommene Alternativhypothese als ,auf dem $\alpha=5 \%$-Niveau abgesichert“ bezeichnet werden. 
eigenen Untersuchung wird dieser Konvention gefolgt, daher werden Ergebnisse mit Irrtumswahrscheinlichkeiten kleiner $\alpha=5 \%$ als ,signifikant ' bezeichnet, zusätzlich werden Resultate kleiner $\alpha=10 \%$ als ,schwach signifikant " akzeptiert.

In der modernen empirischen Forschung ist es zudem möglich und auch üblich, Hypothesentests nicht nur für ein ex ante gegebenes Signifikanzniveau $\alpha$ durchzuführen, sondern primär die Frage „Given the observed value of the $t$ statistic, what is the smallest significance level at which the null hypothesis would be rejected?“ zu beantworten sowie sog. p-Werte anzugeben: „This level is known as

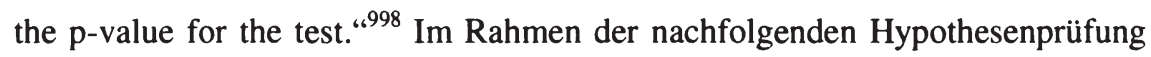
werden deshalb stets die jeweils errechneten p-Werte vermerkt, die Nomenklatur im Hinblick auf statistische Signifikanz fasst Tab. 9 zusammen.

\begin{tabular}{|c|c|c|}
\hline \multicolumn{3}{|c|}{ Nomenklatur statistischer Signifikanzniveaus der Untersuchung (p-Werte) } \\
\hline p-Wert & Symbolik & Interpretation \\
\hline$p \geq 0,10$ & n.s. & Das Resultat ist statistisch nicht signifikant (zweiseitig) \\
\hline $\mathrm{p}<0,10$ & $*$ & Das Resultat ist statistisch schwach signifikant (zweiseitig) \\
\hline $\mathrm{p}<0,05$ & $* *$ & Das Resultat ist statistisch signifikant (zweiseitig) \\
\hline $\mathrm{p}<0,01$ & $* * *$ & Das Resultat ist statistisch hoch signifikant (zweiseitig) \\
\hline
\end{tabular}

Tabelle 9: Nomenklatur statistischer Signifikanzniveaus

Abschließend ist zu vermerken, dass im Rahmen der eigenen Untersuchung ausschließlich zweitseitige Tests durchgeführt werden, obgleich die Formulierung einzelner Hypothesen gerichtet erfolgte und einseitige Tests daher grds. denkbar wären. ${ }^{999}$ Diese Untersuchung entspricht folglich einem als eher konservativ einzustufenden Forschungsansatz, dem letztlich auch von der Mehrheit der Autoren empirischer Studien gefolgt wird. ${ }^{1000}$

998 Beide wörtlichen Zitate sind Wooldridge (2009), S. 133 entnommen. Die gleiche Frage gilt für die F-Statistik, ein entsprechender p-Wert folgt der identischen Interpretation.

999 Vgl. zu Unterschieden zwischen ein- und zweiseitigen Testverfahren z.B. Bortz (2005), S. 117f. Auch mit der Aussage, dass einseitige Tests bereits bei kleineren Unterschieden signifikant werden. Eine anschauliche Darstellung des Vorgehens und der Implikationen ein- und zweiseitiger Tests bietet außerdem Wooldridge (2009), S. 123ff.

1000 Dass ein derartiger Ansatz als konservativ zu bewerten ist, schlussfolgern ebenso Bortz (2005), S. 117f. und Calvo-Mora et al. (2005), S. 755f. Letztere belegen, dass die Mehrzahl der Autoren empirischer Studien generell zweiseitige Tests durchführen. 


\section{$4 \quad$ Zusammenfassung des Untersuchungsmodells}

Die folgenden Ausführungen stellen den Abschluss von Hauptteil C dar, der den Aufbau einer empirischen Untersuchung zur Strategieberichterstattung deutscher kapitalmarktorientierter Unternehmen zum Ziel hatte. Die Struktur dieses dritten Hauptteils entsprach einer klaren Logik: Nach dem Überblick über die relevante Literatur, der Einordnung der eigenen Forschungsfragen und der Ableitung eines ersten Untersuchungsmodells in Abschnitt C 2 erfolgte die konkrete Konzeption der Untersuchung in C 3: Dies beinhaltete eine Formulierung von Hypothesen in C 3.1 auf Basis der Erkenntnisse aus C 2 sowie eine Spezifikation der benötigten Datengrundlage bzw. ihre Erhebung in C 3.2. Daran anschließend wurden - aufbauend auf den Daten - die Variablen operationalisiert (C 3.3) und relevante, für die Hypothesenprüfung anzuwendende statistische Verfahren erörtert (C 3.4).

Ziel ist nun, die vier Elemente der Abschnitte C 3.1 bis 3.4 zu einem zusammenfassenden Untersuchungsmodell zu aggregieren, das auch für Hauptteil D als ein ,Fahrplan' der Hypothesenprüfung zugrunde gelegt werden kann. Jenen Plan der Untersuchung stellt Tab. 10 dar. Dieser nennt für jede der 21 Hypothesen die für die Prüfung erforderliche abhängige sowie die entsprechende(n) unabhängige(n) Variable(n). Da die Auswahl der jeweils zu verwendenden Testverfahren durch das Skalenniveau der Variablen determiniert wird, ist dies ebenfalls vermerkt. ${ }^{1001}$

Darüber hinaus legt Tab. 10 den Ablauf der Hypothesenprüfung offen: Jede der 12 Hypothesen innerhalb des Teilmodells der Bestimmungsfaktoren ist zunächst isoliert zu überprüfen (1. Ebene), je nach Möglichkeit auf Basis von Mittelwertvergleichen bzw. Regressionsanalysen. Sodann sind für die vier Kategorien von Bestimmungsfaktoren partielle Regressionsmodelle zu berechnen (2. Ebene) und abschließend wird auf der obersten Ebene eine umfassende Regressionsanalyse aller potenziellen Determinanten eingeplant, um ein möglichst vollständiges Bild von den Einflussgrößen der Strategieberichterstattung zu erhalten (3. Ebene). Im zweiten Teilmodell erfolgt eine Prüfung auf nur zwei Ebenen: Da alle Variablen metrisch skaliert sind, sollen Einfachregressionen (1. Ebene) und - bei Inklusion von Kontrollvariablen - multiple Regressionen (2. Ebene) durchgeführt werden.

1001 SDIndex ist - unter Vorbehalt - als metrisch skaliert bezeichnet, vgl. Tab. 10 (S. 243).

Tom Sieber - 978-3-631-75150-3 


\begin{tabular}{|c|c|c|c|c|c|}
\hline \multicolumn{6}{|c|}{ Untersuchungsplan zum Niveau der Strategieberichterstattung } \\
\hline Teilmodell und Kategorie & \multicolumn{2}{|c|}{ Variablen inkl. Skalenniveau } & \multicolumn{3}{|c|}{ Testverfahren } \\
\hline Hypothese & Unabhängige Variablen & Abhängige & 1. Ebene & 2. Ebene & 3. Ebene \\
\hline \multicolumn{6}{|l|}{ Messinstrument SDIndex (D 2.3) } \\
\hline Deskriptive Auswertungen & & $\mathrm{SDI}(\mathrm{m})$ & Univariat & & \\
\hline \multicolumn{6}{|c|}{ Niveau der Strategieberichterstattung (D 3) } \\
\hline H 1.1 Unterschiedlichkeit & & $\mathrm{SDI}(\mathrm{m})$ & Univariat & & \\
\hline H 1.2 Zeitliche Dynamik (?) & Zeit (o) & $\mathrm{SDI}(\mathrm{m})$ & ANOVA & & \\
\hline
\end{tabular}

\section{Bestimmungsfaktoren (D 4)}

Makroökonomische Faktoren
H 2.1 Konjunkturelle
( \pm ) Konjunktur- Entwicklung indikatoren $(\mathrm{m})$
$\mathrm{SDI}(\mathrm{m})$
H 2.2 Börsenentwicklung ( \pm ) Börsenindizes (m) SDI (m)
H 2.2 Börsenentwicklung ( \pm ) Börsenindizes (m) SDI (m)

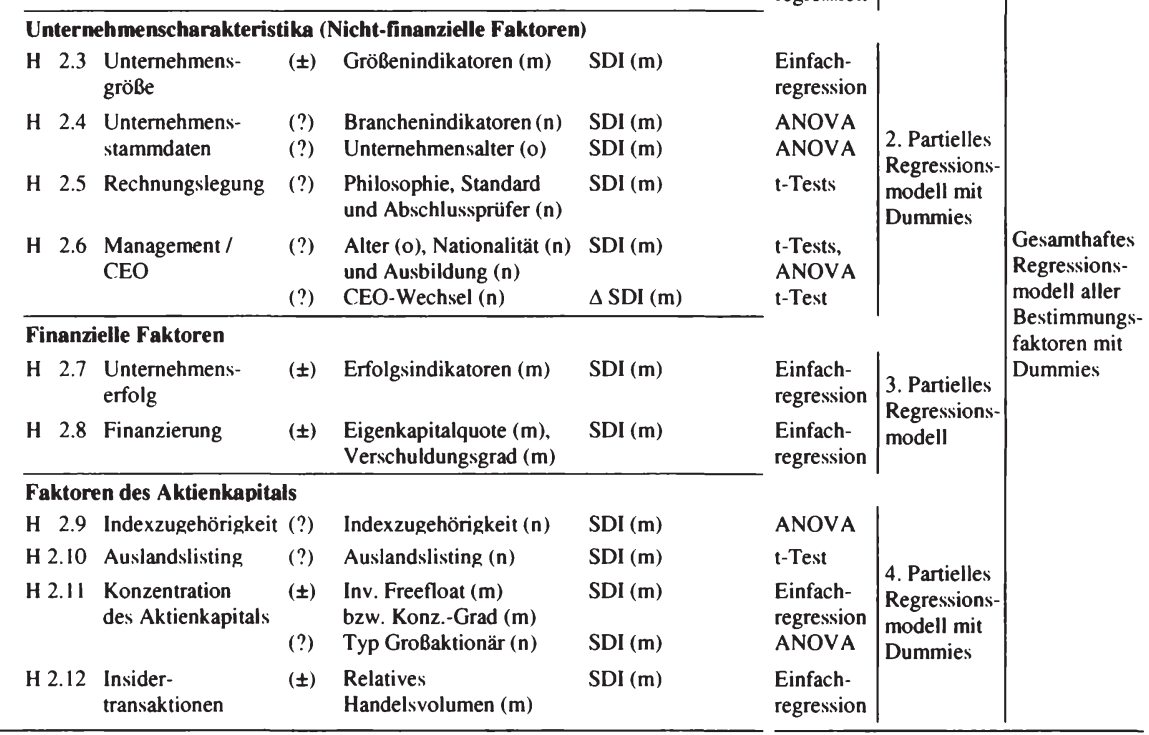

\section{Kapitalmarkteffekte (D 5)}

Transparenzeffekte

\begin{tabular}{|c|c|c|c|c|c|c|}
\hline $\mathbf{H}$ & 3.1 & Analystenanzahl & $( \pm)$ & SDI (m), Kontrollen & $\emptyset$ Anzahl p.a. (m) & Einfach- bzw. multiple Regression \\
\hline$\underline{\mathbf{H}}$ & 3.2 & Schätzungsvarianz & $( \pm)$ & SDI (m), Kontrollen & Varianz Schätzung & Einfach- bzw. multiple Regression \\
\hline \multicolumn{7}{|c|}{ Handelseffekte } \\
\hline $\mathrm{H}$ & 3.3 & Handelsvolumen & $( \pm)$ & SDI (m), Kontrollen & Volumen p.a. (m) & Einfach- bzw. multiple Regression \\
\hline$\underline{\mathbf{H}}$ & 3.4 & Volatilität & $( \pm)$ & SDI (m), Kontrollen & Volatilitätsmaß & Einfach- bzw. multiple Regression \\
\hline \multicolumn{7}{|c|}{ Bewertungseffekte } \\
\hline H & 3.5 & Eigenkapitalkosten & $( \pm)$ & SDI (m), Kontrollen & EK-Kosten (m) & Einfach- bzw. multiple Regression \\
\hline H & 3.6 & Bid-Ask-Spreads & $( \pm)$ & SDI (m), Kontrollen & $\emptyset$ Spreads p.a. (m) & Einfach- bzw. multiple Regression \\
\hline H & 3.7 & Marktbewertung & $( \pm)$ & SDI (m), Kontrollen & Bewertung (m) & Einfach- bzw. multiple Regression \\
\hline
\end{tabular}

$\pm=$ Zusammenhangshypothesen, ? = Interschiedshypothesen / Skalenniveaus: $(m)=$ metrisch. $(0)=$ ordinal. $(n)=$ nominal 
Tom Sieber - 978-3-631-75150-3

Downloaded from PubFactory at 01/11/2019 07:41:07AM

via free access 


\section{Ergebnisse der Untersuchung der Strategiebericht- erstattung börsennotierter Unternehmen}

\section{Vorbemerkungen}

Aufgrund der Komplexität des Untersuchungsmodells und des Umfangs der empirischen Auswertungen ist die inhaltliche Struktur des folgenden Hauptteils der vorliegenden Arbeit zu erläutern. Diese Struktur verdeutlicht Abb. 23 graphisch.

D 2

2.1 StichprobenUnternehmen

\section{Deskriptive Auswertungen}

2.2 Geschäfts- \& Lageberichtserstattung
2.3 Strategy Disclosure Index

D 3

Niveau der Strategieberichterstattung

D 4

Bestimmungsfaktoren

4.1

4.2

Analysen Einzelfaktoren, partielle Regressionsmodelle

Gesamthaftes Regressionsmodell aller Faktoren
Kapitalmarkteffekte

D 5

5.1

Einfache

bzw. multivariate

Regressionsmodelle

5.2

der Kapitalmarkteffekte

D 6

Erweiterung um moderierende Effekte

Abbildung 23: Struktur der Darstellung der empirischen Ergebnisse ${ }^{1002}$

Zunächst stellt Abschnitt D 2 die rein deskriptive Auswertung relevanter Datenbereiche dar: Während D 2.1 Angaben zu den Stichproben-Unternehmen beinhaltet, präsentiert D 2.2 einen ersten Teil der Analyse der 700 betrachteten Lageberichte. Datenpunkte zur Erhebung des Niveaus der Strategieberichterstattung, also zum Messinstrument SDIndex per se, folgen sodann in Abschnitt D 2.3.

Die Prüfung des Untersuchungsmodells i.e.S. beginnt in Abschnitt D 3 mit den Hypothesen H 1.1-1.2 zum Niveau der Strategieberichterstattung. Abschnitt D 4 zeigt die Prüfung der Hypothesen zu den Bestimmungsfaktoren (H 2.1-2.12), zunächst für einzelne Faktoren in D 4.1 sowie schließlich gesamthaft in D 4.2. Analog bildet D 5 die Hypothesen zu den Kapitalmarkteffekten (H 3.1-3.7) ab.

$1(12$ Quelle: eigene Darstellung, aufbauend auf Abb. 10 (S. 142) sowie Abb. 12 (S. 159). 


\section{Deskriptive Auswertungen der Datenbasis}

\subsection{Deskriptive Auswertungen zu den Stichproben-Unternehmen}

\subsubsection{Kategoriale Merkmale der Stichprobe}

In einem ersten Schritt der Analyse der Datenbasis der eigenen Untersuchung ist die Stichprobe anhand wesentlicher kategorialer Merkmale auszuwerten. Unter Rückgriff auf Abschnitt C 3.2, in welchem die Stichprobe der Untersuchung zusammengestellt wurde, können die Branchen- sowie die Indexzugehörigkeit der Stichproben-Unternehmen als die zentralen kategorialen Merkmale gelten. Jedes Unternehmen der Stichprobe ist während des gesamten Untersuchungszeitraums den verschiedenen Ausprägungen dieser beiden Merkmale eindeutig zuordenbar.

Nachstehende Tab. 11 zeigt die Branchen- sowie Indexzugehörigkeit der Unternehmen sowohl für die zusammengesetzte Stichprobe wie auch für die einzelnen Jahre des Untersuchungszeitraums. Dabei ist zu erkennen, dass der Schwerpunkt der Stichprobe auf Industrieunternehmen liegt, 39\% der Merkmalsträger können diesem Sektor zugerechnet werden. Wie auch zu erwarten gewesen wäre, ist die Zugehörigkeit zu einer konkreten Branche über den Untersuchungszeitraum hinweg konstant, die jeweiligen Werte je Ausprägung ändern sich nicht. ${ }^{1003}$

Deutlich dynamischer zeigt sich eine Auswertung nach der Indexzugehörigkeit der Merkmalsträger. Da die Dt. Börse AG die Zusammensetzung der Auswahlindizes wie erwähnt z.T. mehrfach im Jahr anpasst, ist eine jahresspezifische Betrachtung geboten. ${ }^{1004}$ Als relevant wurde hier die Zugehörigkeit zu einem Index am Ende eines jeweiligen Geschäftsjahres angesehen. Wie Tab. 11 weiterhin demonstriert, ist die Abdeckung jener vier Auswahlindizes in den einzelnen Jahren des Untersuchungszeitraumes zufriedenstellend: Während ab Untersuchungsjahr 2004 in allen drei Indizes unterhalb des Dax eine Abdeckung von rund 50\% pro

1003 Es ist dennoch Wert darauf zu legen, dies zu überprüfen, da es in Einzelfällen zu einer Umgruppierung von Unternehmen durch die Dt. Börse AG kommen kann, v.a. bei einer erheblichen Verschiebung des Geschäftsschwerpunkts, vgl. auch Dt. Börse AG (2009a), S. 11. Anhang 3 zeigt die Branchenstruktur der Stichprobe und die Branchenzugehörigkeit der Stichproben-Unternehmen en detail.

1004 Vgl. hierzu nochmals die Fn. 921 sowie Anhang 4, der die jahresspezifische Indexzugehörigkeit der Stichproben-Unternehmen (per Ultimo) darstellt. 
Index und Jahr erreicht wird, ist die Abdeckung des Dax mit etwa 70\% pro Jahr etwas höher. ${ }^{1005}$ Von 700 beobachteten Unternehmensjahren sind insg. nur $14 \%$ (95 Unternehmensjahre) keinem Index zuzuordnen, 605 Beobachtungen (86\%) können mit einem der Auswahlindizes der Dt. Börse AG verknüpft werden. ${ }^{1006}$

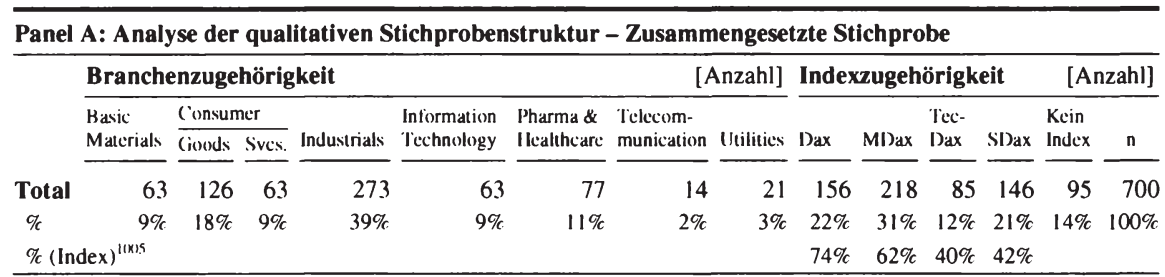

Panel B: Analyse der qualitativen Stichprobenstruktur - Einzelne Jahre 2002 bis 2008

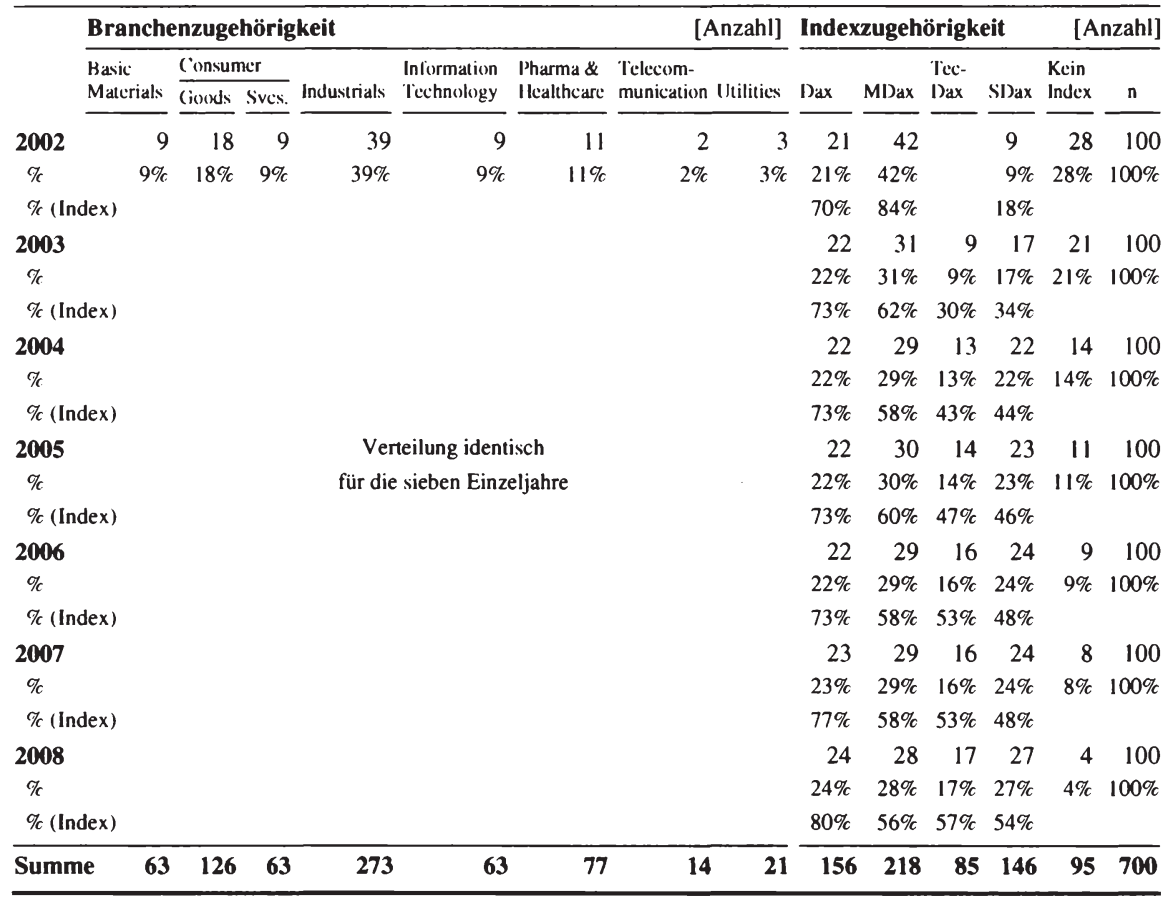

\section{Tabelle 11: Branchen- und Indexzugehörigkeit der Stichprobe}

1005 Die Berechnung ist bezogen auf die Anzahl der Unternehmen, die in die vier Auswahlindizes aufgenommen werden können. Vgl. zur Indexhierarchie sowie Gesamtzahl von Unternehmen je Index auch Abb. 14 (S. 189), vertiefend Dt. Börse AG (2009a), S. 7.

1006 Beide Merkmale sind weiterhin, wie formuliert, Gegenstand von einzelnen Hypothesen (H 2.4, H 2.9), die im weiteren Verlauf zu prüfen sein werden, vgl. Abschnitt D 4.1. 


\subsubsection{Größenmerkmale und Bildung von Teil-Stichproben}

Verbreitet gelten Indikatoren der Unternehmensgröße als zentrale Parameter, um Unternehmen nicht nur zu charakterisieren, sondern diese auch voneinander zu differenzieren. Folgerichtig hat die für die vorliegende Arbeit relevante Literatur eine Bedeutung der Größe für das Berichterstattungsverhalten auch regelmäßig bestätigt. ${ }^{1007}$ Dies war der Hintergrund für die Formulierung einer spezifischen Hypothese H 2.3, um zu prüfen, ob dieser differenzierende Einfluss der Unternehmensgröße auch für die Strategieberichterstattung ermittelt werden kann.

Zunächst stellt Tab. 12 jedoch die Charakterisierung der Stichprobe anhand der beiden Größenindikatoren Umsatzvolumen sowie Anzahl Mitarbeiter dar.

\begin{tabular}{|c|c|c|c|c|c|c|c|c|c|c|c|c|c|c|}
\hline & \multicolumn{3}{|c|}{ Umsatzvolumen } & & \multicolumn{4}{|c|}{ [in EUR 1.000 Mio.] } & \multicolumn{4}{|c|}{ Anzahl Mitarbeiter } & \multicolumn{2}{|c|}{ [in 1.000] } \\
\hline & \multirow[b]{2}{*}{$\mu$} & \multicolumn{2}{|c|}{ Extrema } & \multicolumn{3}{|c|}{ Perzentile } & & \multirow[b]{2}{*}{$\mathrm{n}$} & \multirow[b]{2}{*}{$\mu$} & Extrema & \multicolumn{2}{|l|}{ Perzentile } & & \multirow[b]{2}{*}{$\mathrm{n}$} \\
\hline & & Min & Max & $25 \%$ & $50 \%$ & $75 \%$ & & & & Min Max & $25 \% \quad 50 \%$ & $75 \%$ & & \\
\hline Total & 10,47 & 00 & 151,6 & 0,50 & 1,63 & 7,51 & 21,98 & 700 & 41,62 & $, 02 \quad 536,3$ & $2,40 \quad 8,04$ & 36,8 & 85,88 & 700 \\
\hline \multicolumn{15}{|c|}{ Panel B: Analyse der quantitativen Stichprobenstruktur - Einzelne Jahre 2002 bis 2008} \\
\hline & \multicolumn{3}{|c|}{ Umsatzvolumen } & & \multicolumn{4}{|c|}{ [in EUR 1.000 Mio.] } & Anzahl $\mathbf{N}$ & Mitarbeiter & & & \multicolumn{2}{|c|}{ [in 1.000] } \\
\hline & & \multicolumn{2}{|c|}{ Extrema } & \multicolumn{3}{|c|}{ Perzentile } & \multirow[b]{2}{*}{ 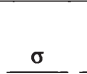 } & \multirow[b]{2}{*}{ 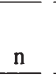 } & \multirow[b]{2}{*}{$\mu$} & Extrema & \multicolumn{2}{|l|}{ Perzentile } & \multirow[b]{2}{*}{$\sigma$} & \multirow[b]{2}{*}{$\mathrm{n}$} \\
\hline & $\mu$ & Min & Max & $25 \%$ & $50 \%$ & $75 \%$ & & & & Min Max & $25 \% \quad 50 \%$ & $\underline{75 \%}$ & & \\
\hline 2002 & 9,57 &, 00 & 149,5 & , 40 & 1,41 & 7,20 & 21,61 & 100 & 39,99 & $, 02426,0$ & $1,99 \quad 7,94$ & 32,7 & 81,12 & 100 \\
\hline 2003 & 9,38 & ,00 & 136,4 &, 42 & 1,42 & 6,39 & 20,60 & 100 & 39,57 & $, 03417,0$ & $1,96 \quad 7,69$ & 33,6 & 81,25 & 100 \\
\hline 2004 & 9,69 & 01 & 142,0 &, 43 & 1,53 & 6,82 & 21,25 & 100 & 39,69 & $, 02430,0$ & $2,05 \quad 7,80$ & 34,7 & 82,71 & 100 \\
\hline 2005 & 10,19 & ,02 & 149,7 &, 45 & 1,62 & 7,05 & 22,23 & 100 & 41,89 & $, 11502,4$ & $2,42 \quad 7,84$ & 36,3 & 90,85 & 100 \\
\hline 2006 & 11,29 & ,03 & 151,6 &, 51 & 1,67 & 9,04 & 24,08 & 100 & 42,79 & $, 17520,1$ & $2,65 \quad 8,01$ & 41,0 & 91,66 & 100 \\
\hline 2007 & 11,30 & ,02 & 108,8 & ,61 & 1,79 & 10,2 & 21,79 & 100 & 43,17 & $, 17536,3$ & $2,73 \quad 8,65$ & 43,6 & 87,12 & 100 \\
\hline 2008 & 11,86 & ,03 & 113,8 & ,67 & 1,91 & 11,4 & 22,62 & 100 & 44,25 & $, 14 \quad 512,5$ & $2,86 \quad 8,91$ & 51,2 & 88,25 & 100 \\
\hline
\end{tabular}

Tabelle 12: Ausgewählte Größenmerkmale der Stichprobe

Wie festzustellen ist, weist diese Stichprobe eine erhebliche Bandbreite hinsichtlich der in Tab. 12 dargestellten Größenindikatoren auf: Während sich das Um-

1007 Vgl. so bspw. Cerf (1961), Meek et al. (1995), Wagenhofer (1990a), Raffournier (1995) oder auch Chow/Wong-Boren (1987).

1008 Die negative Entwicklung des Umsatzmaximums von Untersuchungsjahr 2006 auf 2007 ist mit der Auflösung der DaimlerChrysler AG bzw. der Entkonsolidierung der heutigen Chrysler Group LLC im Konzernabschluss der heutigen Daimler AG zu begründen.

Tom Sieber - 978-3-631-75150-3 
satzvolumen der Stichproben-Unternehmen zwischen 0 und ca. EUR $152 \mathrm{Mrd}$. bewegt, beschäftigen die Unternehmen zwischen ca. 20 und über 500.000 Mitarbeiter. Folglich ist anhand dieser beiden Kriterien davon auszugehen, dass die Stichprobe in ihrer Struktur eine ausreichende Heterogenität aufweist.

Neben den bislang betrachteten Indikatoren der Unternehmensgröße hat sich in der einschlägigen Literatur insb. die Summe der Vermögenswerte bzw. die sog. Bilanzsumme als ein differenzierendes Merkmal etabliert. ${ }^{1009}$ Dieser Erkenntnis folgend stellt Tab. 13 die Untersuchungsstichprobe in Bezug auf den genannten Indikator Bilanzsumme dar. Darüber hinaus erfolgt - anhand dieses Indikators die Bildung zweier Teil-Stichproben identischen Umfangs, als Differenzierungskriterium wird folglich der jeweilige jahresspezifische Median der Bilanzsumme verwendet. ${ }^{1010}$ In der Folge ergeben sich so zwei signifikant voneinander unterschiedliche Teil-Stichproben, wie ein Levene-Test auf Varianzgleichheit und ein t-Test auf Mittelwertgleichheit demonstrieren. ${ }^{1011}$ Die entsprechenden Resultate zeigt gleichfalls nachfolgende Tab. 13.

Im weiteren Verlauf dieser Arbeit sind dementsprechend Hypothesenprüfungen nicht nur für die zusammengesetzte, sondern auch für die zwei klar voneinander differenzierten Teil-Stichproben durchführbar. Dies erlaubt möglicherweise das Ableiten spezifischer, nur für eine der Teil-Stichproben gültiger Aussagen.

1(N) Die ,Summe der Vermögenswerte" bzw. äquivalent die ,Bilanzsumme" wird oft - auch im deutschsprachigen Kontext - im finanzwirtschaftlichen Jargon mit ,Total Assets ' bezeichnet. Die hohe Bedeutung der Bilanzsumme in Bezug auf das Berichterstattungsverhalten zeigen u.a. Cooke (1989) sowie Frankel et al. (1999).

1010) Die Aufteilung der Untersuchungsstichprobe in zwei identisch große Teil-Stichproben folgt einem Vorschlag von Botosan (1997a), S. 329. Diese teilt ihre Stichprobe anhand des Medians der ein Unternehmen beobachtenden Analysten in zwei Teile.

1011 Anhang 10 dieser Arbeit zeigt - entsprechend der jahresspezifischen Ableitung der TeilStichproben - die Eingruppierung der 100 Unternehmen in die beiden Teil-Stichproben jeweils für jedes einzelne Jahr des Untersuchungszeitraums. 


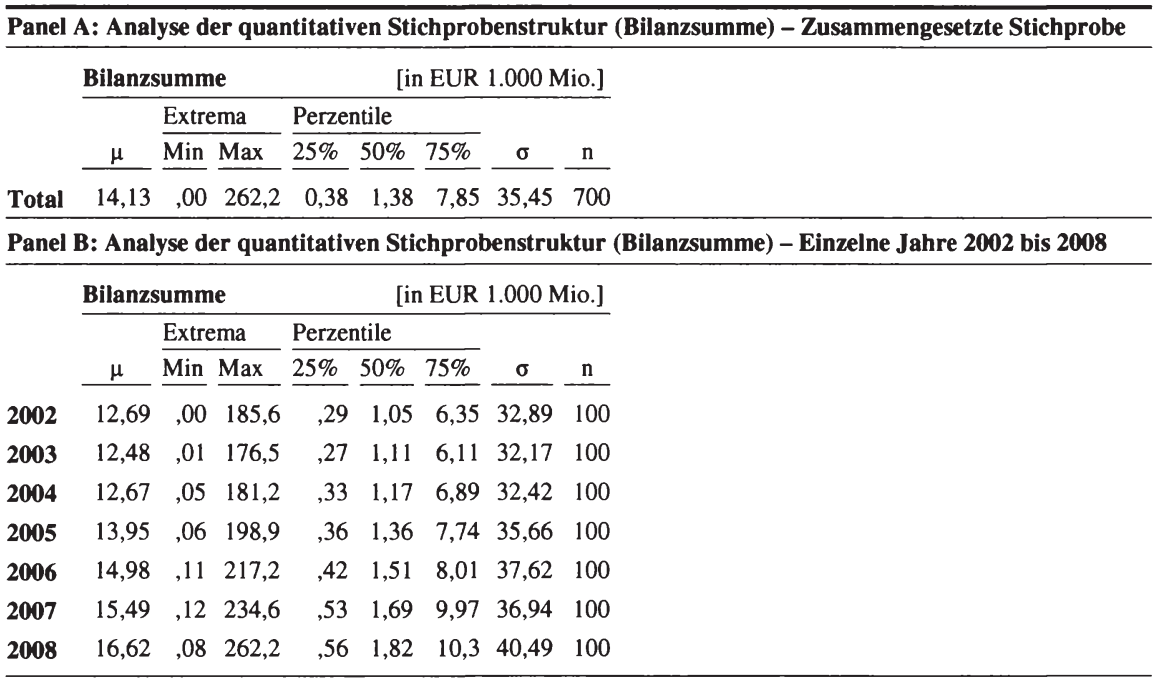

Panel C: Bildung zweier Teil-Stichproben anhand der jährlichen Medianwerte der Bilanzsumme

Teil-Stichprobe der kleinen Unternehmen Teil-Stichprobe der großen Unternehmen

Bilanzsumme [in EUR 1.000 Mio.] Bilanzsumme [in EUR 1.000 Mio.]

Extrema Perzentile $\quad$ Extrema Perzentile

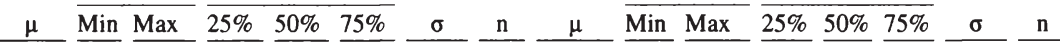
$\begin{array}{lllllllllllllllll}\text { Total }^{1012} & , 53 & , 00 & 1,82 & , 21 & , 38 & , 82 & , 41 & 350 & 27,72 & 1,06 & 262,2 & 3,11 & 7,84 & 24,8 & 46,33 & 350\end{array}$

Levene-Test $\quad \frac{\mathrm{F}}{313,8} \frac{\mathrm{p} \text {-Wert }}{, 000 * * *}$ t-Test $\quad \frac{\mathrm{df}}{349,1} \frac{\mathrm{p} \text {-Wert }}{, 000 * * *}$

Panel D: Analyse der quantitativen Struktur der Teil-Stichproben - Einzelne Jahre 2002 bis 2008

Teil-Stichprobe der kleinen Unternehmen

Bilanzsumme
[in EUR 1.000 Mio.] Teil-Stichprobe der großen Unternehmen

\begin{tabular}{|c|c|c|c|c|c|c|c|c|c|c|c|c|c|c|c|}
\hline \multirow[b]{2}{*}{$\mu$} & \multicolumn{2}{|c|}{ Extrema } & \multicolumn{3}{|c|}{ Perzentile } & \multirow[b]{2}{*}{ 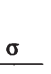 } & \multirow[b]{2}{*}{$\mathrm{n}$} & & \multicolumn{2}{|c|}{ Extrema } & \multicolumn{3}{|c|}{ Perzentile } & & \multirow[b]{2}{*}{$\mathrm{n}$} \\
\hline & Min & $\operatorname{Max}$ & $25 \%$ & $50 \%$ & $75 \%$ & & & & Min & Max & $25 \%$ & $\underline{50 \%}$ & $75 \%$ & & \\
\hline, 39 & ,00 & 1 & , & ,30 & 68 & 29 & 0 & 8 & 06 & 6 & 2,64 & 6,28 & 19,6 & 6,1 & \\
\hline, 4 & ,01 & 1, & 14 & ,27 & 6 & & 50 & & 1,12 & 176,5 & 2,63 & 6,08 & 18,7 & 43 & \\
\hline, 4 & ,05 & 1,1 & 15 & ,36 &, 7 & נינ, & $\pi$ & & 1,18 & 181,2 & 2,60 & 6,74 & 20,0 & 42, & \\
\hline, 53 & ,06 & 1,3 & ,20 & ,36 & 8 & & 50 & & 1,38 & 9 & 2,80 & 7,64 & 21,2 & 46 & \\
\hline, 5 & ,11 & 1,4 & ,26 & ,42 & 9 & & 50 & & 55 & & 11 & 7,97 & 28,5 & & \\
\hline ,6 & ,12 & 1,6 & 31 & ,54 & 1, & & 50 & & 70 & 20 & 3,37 & 9,87 & 30,0 & 40, & \\
\hline ,71 & ,08 & 1,82 & ,34 &, 57 & 1,09 & 49 & 50 & 32,52 & 1,82 & 262,2 & 3,39 & 9,92 & 27,8 & 52,88 & \\
\hline
\end{tabular}

\section{Tabelle 13: Bildung von Teil-Stichproben}

1012 Das Maximum der Bilanzsumme kleiner Unternehmen ist größer als das Minimum der großen Unternehmen, da der jährliche Median genutzt wurde. Vgl. Panel D für Details. 


\subsubsection{Aussagefähigkeit der Stichprobe}

Als Abschluss der Ausführungen zur deskriptiven Beschaffenheit der Stichprobe ist zu überprüfen, ob diese als repräsentativ für eine übergeordnete Gesamtheit gelten kann. Da eine Repräsentativität i.e.S. aufgrund des hier verwendeten Prozesses der Stichprobenzusammenstellung nicht gegeben ist, ist darzustellen, ob die gewählte Stichprobe aufgrund ihrer Beschaffenheit mit einer übergeordneten Gesamtheit vergleichbar ist und somit als aussagefähig für diese gelten kann. ${ }^{1013}$ Es bietet sich für die eigene Untersuchung unmittelbar an, einen derartigen Vergleich zwischen der Untersuchungsstichprobe und der Gesamtheit aller in HDax sowie SDax notierten Unternehmen anzustellen, da die Stichprobe dieser Grundgesamtheit entnommen worden ist. ${ }^{1014}$ Zunächst zeigt Tab. 14 daher vier finanzwirtschaftliche Parameter per Jahresultimo 2008 für die Grundgesamtheit sowie für die Stichprobe. Wie ein für jeden Parameter durchgeführter t-Test bestätigt, unterscheiden sich die jeweiligen Mittelwerte nicht signifikant voneinander. ${ }^{1015}$

\begin{tabular}{|c|c|c|c|c|c|c|c|c|c|c|}
\hline \multicolumn{11}{|c|}{ Analyse finanzwirtschaftlicher Parameter 2008 der Stichprobe und der Grundgesamtheit } \\
\hline \multirow[b]{3}{*}{ Parameter } & \multicolumn{3}{|c|}{ Grundgesamtheit (N) } & \multicolumn{5}{|c|}{ [in EUR 1.000 Mio. bzw. in 1.000] } & & \\
\hline & \multirow[b]{2}{*}{$\mu$} & \multicolumn{2}{|c|}{ Extrema } & \multicolumn{3}{|c|}{ Perzentile } & \multirow[b]{2}{*}{$\sigma$} & \multirow[b]{2}{*}{ n } & & \\
\hline & & Min & Max & $25 \%$ & $50 \%$ & $75 \%$ & & & & \\
\hline Marktwert ${ }^{1016}$ & 4,19 &, 01 & 71,13 &, 24 & .71 & 2,48 & 10,01 & 160 & & \\
\hline Bilanzsumme $e^{1017}$ & 39,00 & ,08 & 2.194 & 64 & 1,72 & 7,50 & 196,6 & 160 & & \\
\hline Umsatz & 9,66 & .03 & 113,8 & .55 & 1,51 & 6,71 & 20,44 & 160 & & \\
\hline \multirow[t]{2}{*}{ Mitarbeiter } & 32,04 &, 00 & 512,5 & 1,78 & 5,85 & 22,72 & 73,67 & 160 & \multicolumn{2}{|c|}{$\mathrm{p}$-Werte } \\
\hline & \multicolumn{2}{|c|}{ Stichprobe (n) } & \multicolumn{6}{|c|}{ [in EUR 1.000 Mio., Mitarbeiter in 1.000] } & Levene & t-Test \\
\hline Marktwert & 5,29 & ,05 & 71,13 &, 29 &, 85 & 3,22 & 11,76 & 100 & ,228 n.s. & ,438 n.s. \\
\hline Bilanzsumme & 16,62 &, 08 & 262.2 &, 56 & 1,82 & 10,28 & 40,49 & 100 &, $037 * *$ & ,165 n.s. \\
\hline Umsatz & 11,86 &, 03 & 113,8 & 67 & 1,91 & 11,37 & 22,62 & 100 & ,320 n.s. & ,430 n.s. \\
\hline Mitarbeiter & 44,25 &, 14 & 512,5 & 2,86 & 8.91 & 51,19 & 88,25 & 100 &, 163 n.s. & ,250 n.s. \\
\hline
\end{tabular}

\section{Tabelle 14: Aussagefähigkeit der quantitativen Struktur der Stichprobe}

1013 Vgl. zur Problematik des Begriffs, Repräsentativität ' u.a. Schnell et al. (2005), S. 304ff. Repräsentativität i.e.S. setzt insb. eine Zufallsauswahl der Merkmalsträger voraus.

1014 Grundlage der Prüfung ist also die definierte Gesamtheit per Halbjahresultimo 2009.

1015 Der t-Test überprüft formal die Nullhypothese, dass die jeweiligen Mittelwerte identisch sind. Ermittelte p-Werte oberhalb eines bestimmten Signifikanzniveaus führen daher zur Ablehnung der Alternativhypothese der Mittelwertinhomogenität, vgl. hierzu C 3.4.2.

1016 Der Marktwert der bei der Dt. Börse AG notierten Unternehmen betrug per Ultimo 2008 rund EUR 797 Mrd., die Stichprobe deckt ca. 66\% ab, vgl. Dt. Börse AG (2009c), S. 41. 
$\mathrm{Zu}$ einem identischen Ergebnis kommt der Vergleich der Gruppen in Bezug auf wesentliche qualitative Merkmale, insb. die Branchen- bzw. Indexzugehörigkeit, wie Tab. 15 zeigt. Eine Durchführung von $\mathrm{Chi}^{2}$-Unabhängigkeitstests erlaubt die Ablehnung der Nullhypothese der Gleichverteilung der Gruppen erneut nicht. ${ }^{1018}$

Es ist folglich davon auszugehen, dass die Stichprobe als durchaus aussagefähig für die Gesamtheit der in HDax und SDax notierten Unternehmen gelten kann.

\begin{tabular}{|c|c|c|c|c|c|c|c|c|}
\hline$\overline{\text { Panel A: }}$ & alyse der Bran & strukt & ler Stic & e und & Grun & nthe & & \\
\hline & & & rundg & heit (l & & & chprobe & \\
\hline & & & & $\mathrm{Oh}$ & IRE & & & Zu N \\
\hline Branche & & $\#$ & in $\%$ & $\#$ & in $\%$ & $\#$ & in $\%$ & in $\%$ \\
\hline Basic $\mathrm{I}$ & terials & 14 & 8,8 & 14 & 10,4 & 9 & 9,0 & $64 \%$ \\
\hline Consur & Goods & 18 & 11,3 & 18 & 13,4 & 18 & 18,0 & $100 \%$ \\
\hline Consur & Services & 13 & 8,1 & 13 & 9,7 & 9 & 9,0 & $69 \%$ \\
\hline FIRE $^{10}$ & & 26 & 16,3 & 0 & 0,0 & 0 & 0,0 & - \\
\hline Industr & & 59 & 36,9 & 59 & 44,0 & 39 & 39,0 & $66 \%$ \\
\hline Inform & on Technology & 10 & 6,3 & 10 & 7,5 & 9 & 9,0 & $90 \%$ \\
\hline Pharm & Healthcare & 14 & 8,8 & 14 & 10,4 & 11 & 11,0 & $79 \%$ \\
\hline Teleco & nunication & 3 & 1,9 & 3 & 2,2 & 2 & 2,0 & $67 \%$ \\
\hline Utilitie & & 3 & 1,9 & 3 & 2,2 & 3 & 3,0 & $100 \%$ \\
\hline Total & & 160 & $100 \%$ & 134 & $100 \%$ & 100 & $100 \%$ & $75 \%$ \\
\hline & & & & & & $\mathrm{Chi}^{2}$ & ,960 & \\
\hline Panel B & alyse der Inc & ktu & tichp & d der & undges & & & \\
\hline Index & & & Frundg & heit $(1$ & & & chprobe & \\
\hline HDax & Dax & 30 & 18,8 & 24 & 17,9 & 24 & 24,0 & $100 \%$ \\
\hline & MDax & 50 & 31,3 & 44 & 32,8 & 30 & 30,0 & $68 \%$ \\
\hline & TecDax & 30 & 18,8 & 30 & 22,4 & 19 & 19,0 & $63 \%$ \\
\hline SDax & & 50 & 31,3 & 36 & 26,9 & 27 & 27,0 & $75 \%$ \\
\hline Total & & 160 & $100 \%$ & 134 & $100 \%$ & 100 & $100 \%$ & $75 \%$ \\
\hline & & & & & & $\mathrm{Chi}^{2}$ & ,683 & \\
\hline
\end{tabular}

Tabelle 15: Aussagefähigkeit der qualitativen Struktur der Stichprobe

1018 Vgl. Backhaus et al. (2008), S. 307f. Als Voraussetzung des Tests dürfen maximal 20\% der Felder der geprüften Kreuztabelle (hier 2 x 8-Matrix) erwartete Häufigkeiten kleiner als $\mathrm{n}=5$ aufweisen. Aus diesem Grund wurden die zwei Sektoren ,Telecommunication * und ,Utilities ‘ zur Test-Durchführung als ,Netzindustrien ‘ zusammengelegt. Das scheint sachlogisch begründbar, weil die jeweiligen Geschäftsmodelle auf Netzwerken beruhen. Die Tests erfolgten auf Basis der um ,FIRE‘ reduzierten Grundgesamtheit $(\mathrm{N}=134)$.

1019 Die Struktur entspricht der Branchensystematik der Dt. Börse AG, vgl. dies. (2009a), S. 47f.; Details zur Branchensystematik und -struktur der Stichprobe in Anhang 2 bzw. 3.

1020 Dieser Super-Sektor ,FIRE` umfasst die Finanz- (Finance), Versicherungs- (Insurance) und Immobilienbranche (Real Estate), vgl. im Detail Anhänge 1, 2 und 3 dieser Arbeit. 


\subsection{Deskriptive Auswertungen zur Lageberichterstattung}

Wie in Abschnitt C 3.2.3 erwähnt, wurden zum Zweck der Datenerhebung exakt 700 Lageberichte deutscher börsennotierter Unternehmen der sieben Geschäftsjahre 2002 bis 2008 inhaltlich analysiert. Dabei wurden, neben der eigentlichen Prüfung des aufgestellten normativen Berichtskataloges zusätzliche Datenpunkte erhoben, die bereits einen ersten Eindruck von der Entwicklung der Lage- sowie spezifischer der Strategieberichterstattung vermitteln können.

Zunächst wurden im Rahmen der Erhebung in Summe drei Seitenzahl-Angaben erfasst: die Gesamtzahl der Seiten des Geschäftsberichts, des Lageberichts sowie des Jahresabschlusses. ${ }^{1021}$ Wie Tab. 16 aufzeigt, ist im Laufe der Jahre der Umfang der Geschäftsberichte deutlich angestiegen, wobei der Lagebericht den am stärksten in seinem Umfang gewachsenen Bestandteil des Geschäftsberichts repräsentiert und schließlich im Jahre 2008 bereits nahezu ein Drittel des Gesamtumfangs eines durchschnittlichen Geschäftsberichts für sich beansprucht. ${ }^{1022}$

Bemerkenswert scheint weiterhin, dass sich dieses Umfangswachstum der Lageberichte erst mit dem Berichtsjahr 2005 einstellt, also exakt zu jenem Zeitpunkt, zu dem der Gesetzgeber sowie der Standardsetter in Deutschland mit der Verabschiedung des BilReG und dem konkretisierenden DRS 15 eine erhebliche Ausweitung der Lageberichterstattung beschlossen, sich allerdings gegen eine - zunächst angedachte und zudem intensiv diskutierte - explizite Kodifizierung von strategieorientierten Berichtsinhalten entschieden. ${ }^{1023}$

1021 Ein ,Auszählen` der Berichtsumfänge ist innerhalb der empirischen Rechnungslegungsforschung durchaus gebräuchlich, vgl. bspw. kürzlich Knauer/Wömpener (2010), S. 88f. sowie Ruhwedel et al. (2009), S. 1307ff.

1022 Die Auszählung der Seitenzahlen wurde um reine Imageelemente bereinigt (bspw. Fotostrecke über mehrere Seiten innerhalb des Lageberichts). Das Wachstum des Jahresabschlusses kann vor dem Hintergrund erweiterter Berichtspflichten im Anhang sowie erhöhter Komplexität durch Umstellung der Rechnungslegung nicht überraschen.

Die Tatsache, dass ein durchschnittlicher Geschäftsbericht im Jahre 2008 einen Umfang von bis zu 200 Seiten aufweist, scheint indes beeindruckend - wenngleich gesondert zu untersuchen wäre, ob ein Wachstum des Umfangs von 2002 bis 2008 um 50\% auch eine Aufwertung der inhaltlichen Aussagekraft um 50\% bewirkt hat. Es liegt jedoch der Verdacht nahe, dass Geschäftsberichte verbreitet als Medium zur Vermittlung eines Images bzw. zur Produktpräsentation genutzt werden, vgl. ähnlich Baetge/Kirchhoff (1997).

Vgl. hierzu nochmals die Ausführungen in Abschnitt B 4.3 dieser Arbeit.

Tom Sieber - 978-3-631-75150-3 
Außerdem inkludiert folgende Tab. 16 einen weiteren interessanten Aspekt, der als erster Hinweis auf die Entwicklung der Strategieberichterstattung verstanden werden kann: Im Rahmen der eigenen Erhebung wurde zusätzlich festgehalten, welche Unternehmen in ihren Lageberichten einen separaten Gliederungspunkt zu ihrer Strategie vorsahen. ${ }^{1024}$ Während dies im Jahre 2002 bei nur ca. $19 \%$ der Lageberichte der Fall war, verfügten hingegen im Untersuchungsjahr 2008 über $50 \%$ der Unternehmen in den Lageberichten bereits über einen expliziten inhaltlichen Baustein zur Strategie. Ohne dem nachfolgenden Abschnitt vorgreifen zu wollen, der sich mit der deskriptiven Auswertung des Messinstruments Strategy Disclosure Index beschäftigt, soll bereits anhand dieses einfachen Indikators angenommen werden, dass die Unternehmen tatsächlich im Rahmen ihrer Lageberichterstattung Informationen zu ihrer Strategie bereitstellen. Außerdem könnte angesichts des stetig ansteigenden Umfangs der Lageberichte gefolgert werden, dass das Niveau der Berichterstattung zu strategieorientierten Sachverhalten im Lagebericht innerhalb des siebenjährigen Betrachtungszeitraums grds. eine eher positive Entwicklung genommen hat.

\begin{tabular}{|c|c|c|c|c|c|c|c|c|c|c|}
\hline \multicolumn{11}{|c|}{ Umfangs- und Gliederungsanalyse der Geschäfts- und Lageberichte } \\
\hline & \multicolumn{3}{|c|}{ Mittelwerte Seitenzahlen } & \multicolumn{2}{|c|}{ [Summe] } & \multicolumn{3}{|c|}{ Prozentuale Verteilung } & \multirow{2}{*}{$\begin{array}{r}\text { [\%] } \\
\text { Summe } \\
\text { Bericht }\end{array}$} & \multirow{2}{*}{$\begin{array}{l}\text { Strategiebericht } \\
\text { max. } 2 \text {. Gliederungs- } \\
\text { ebene im LB [\%] }\end{array}$} \\
\hline & $\begin{array}{c}\text { Jahres- } \\
\text { abschluss }\end{array}$ & $\begin{array}{l}\text { Lage- } \\
\text { bericht }\end{array}$ & $\begin{array}{c}\text { Freier } \\
\text { Teil }\end{array}$ & $\begin{array}{l}\text { Summe } \\
\text { Bericht }\end{array}$ & $\mathrm{n}$ & $\begin{array}{l}\text { Jahres- } \\
\text { abschluss }\end{array}$ & $\begin{array}{l}\text { Lage- } \\
\text { bericht }\end{array}$ & $\begin{array}{c}\text { Freier } \\
\text { Teil }\end{array}$ & & \\
\hline 2002 & 43,85 & 34,92 & 43,08 & 121,85 & 100 & $36 \%$ & $29 \%$ & $35 \%$ & $100 \%$ & $19 \%$ \\
\hline 2003 & 45,63 & 33,74 & 44,89 & 124,26 & 100 & $37 \%$ & $27 \%$ & $36 \%$ & $100 \%$ & $20 \%$ \\
\hline 2004 & 47,81 & 34,36 & 45,56 & 127,73 & 100 & $37 \%$ & $27 \%$ & $36 \%$ & $100 \%$ & $23 \%$ \\
\hline 2005 & 55,61 & 40,31 & 43,61 & 139,53 & 100 & $40 \%$ & $29 \%$ & $31 \%$ & $100 \%$ & $36 \%$ \\
\hline 2006 & 60,08 & 46,88 & 45,91 & 152,87 & 100 & $39 \%$ & $31 \%$ & $30 \%$ & $100 \%$ & $47 \%$ \\
\hline 2007 & 67,64 & 54,47 & 45,79 & 167,90 & 100 & $40 \%$ & $32 \%$ & $28 \%$ & $100 \%$ & $54 \%$ \\
\hline 2008 & 70,06 & 56,87 & 52,49 & 179,42 & 100 & $39 \%$ & $32 \%$ & $29 \%$ & $100 \%$ & $56 \%$ \\
\hline$\Delta$ p.a. & $+8,1 \%$ & $+8,5 \%$ & $+3,3 \%$ & $+6,7 \%$ & & & & & & $+19,7 \%$ \\
\hline
\end{tabular}

Tabelle 16: Umfang der Geschäfts- und Lageberichterstattung

1024 Gewertet wurden nur Gliederungspunkte auf der ersten sowie auf der zweiten Ebene der Gliederung der jeweiligen Lageberichte. Hinsichtlich der konkreten Formulierung dieses Gliederungspunktes wurden verschiedene Möglichkeiten wie bspw. ,Konzernstrategie‘, ,Unsere Strategie‘, ,Strategische Ausrichtung X AG‘ gewertet - ein eindeutiger inhaltlicher Bezug zur Strategie musste folglich klar ersichtlich sein. 


\subsection{Deskriptive Auswertungen zum Strategy Disclosure Index}

Nachfolgend werden die Ergebnisse der Erhebung des Strategy Disclosure Index in den Lageberichten des Untersuchungszeitraums 2002 bis 2008 dargestellt.

Wie in C 3.2.3 erläutert und in Abb. 18 verdeutlicht, lässt sich das Ergebnis, der jeweilige jahresspezifische SDScore eines Unternehmens, auf zwei zusätzlichen Ebenen detaillieren. Demzufolge können der gesamthafte SDScore sowie die ihn ausmachenden Teil-Scores der Analyse, der Strategieformulierung bzw. der Implementierung betrachtet werden. Weiterhin können die Teil-Scores der Analyse und der Formulierung in je zwei Unterkategorien zerlegt werden. ${ }^{1025}$

Die erhobenen Werte der einzelnen Jahre sowie der zusammengesetzten Stichprobe stellt Tab. 17 dar. ${ }^{1026}$ Es ist festzustellen, dass das Niveau der Strategieberichterstattung deutlich ausgeweitet wurde, der Durchschnitt der SDScores steigt von $28 \%$ in 2002 auf $41 \%$ in 2007. Diese positive Tendenz zeigt sich besonders deutlich ab dem Untersuchungsjahr 2005, im Berichtsjahr 2008 setzt sie sich jedoch nicht mehr fort. Diese Erkenntnis gilt ebenfalls für die drei Teil-Scores der Erhebung. Weiterhin ist ersichtlich, dass die höchsten Teil-Scores in den Einzeljahren grds. im Bereich der Analyse erzielt werden - obgleich das Niveau in der Kategorie der Strategieformulierung stets nur geringfügig niedriger ist. Angaben zur Implementierung werden aber lediglich in geringem Umfang bereitgestellt.

Wird dem Messinstrument SDIndex also zugestanden, in der Tat das Niveau der Strategieberichterstattung erfassen zu können, ist das in Tab. 17 dargestellte Resultat auch als Beleg für die Relevanz dieser Untersuchung zu werten: ${ }^{1027}$ Dieses gibt erneut Anlass zu der Erkenntnis, dass der Lagebericht zur Strategieberichterstattung verwendet wird. Schließlich offenbart Tab. 17, dass die individuellen SDScores deutlich variieren, wie ein Vergleich der Extrema zeigt: Die SDScores liegen für die zusammengesetzte Stichprobe zwischen 3\% und 83\%. Es ergeben sich folglich auf Basis dieser deskriptiven Auswertung erste Anhaltspunkte, dass

\footnotetext{
1025 Der Score Analyse gliedert sich in ,Externe- " sowie ,Geschäftsspezifische Analyse', der Score Strategie in ,Konzern-' bzw. ,Geschäftsbereichsstrategie ‘ vgl. Abb. 18 (S. 212).

$1026 \mathrm{Vgl}$. Anhang 7-1 für die unternehmensindividuellen SDScores der Jahre 2002 bis 2008.

1127 Ob das Messinstrument SDIndex tatsächlich die Strategieberichterstattung messen kann, ist im Rahmen der Validierung der Messwerte in Abschnitt D 3.1.2 noch zu überprüfen. 
Unternehmen individuell ein Niveau der Strategieberichterstattung wählen bzw. dieses als einen Aktionsparameter ansehen, den sie entsprechend ihrer konkreten Präferenzen setzen können. Welche Faktoren sodann ursächlich für die Wahl des Berichtsniveaus sind, wird im folgenden Abschnitt zu untersuchen sein.

\begin{tabular}{|c|c|c|c|c|c|c|c|c|c|c|c|c|c|c|c|c|}
\hline \multicolumn{17}{|c|}{ Panel A: Analyse der Strategy Disclosure Scores - Zusammengesetzte Stichprobe } \\
\hline & \multicolumn{4}{|c|}{ Teil-Scores } & \multicolumn{4}{|c|}{ normiert $\left.^{1028},\{0 ; 1\}\right]$} & \multicolumn{5}{|c|}{ Gesamt-Scores } & \multicolumn{3}{|c|}{ [normiert, $\{0 ; 1\}]$} \\
\hline & Teil- & & Extrer & & Perzer & ntile & & & & Extre & $\mathrm{ma}$ & Perze & entile & & & \\
\hline & Score & $\mu$ & Min & Max & $25 \%$ & $50 \%$ & $75 \%$ & $\sigma$ & $\mu$ & Min & $\underline{\operatorname{Max}}$ & $25 \%$ & $50 \%$ & $75 \%$ & $\sigma$ & n \\
\hline \multirow[t]{3}{*}{ Total } & Analyse &, 38 & ,06 & ,85 &, 30 & ,39 & ,45 &, 13 & & & & & & & & \\
\hline & Strategie & ,36 &, 00 &, 87 & ,20 &, 33 & ,47 &, 18 & ,34 & 03 &, 83 &, 25 &, 33 &, 40 &, 12 & 700 \\
\hline & Implem. & ,09 &, 00 & ,80 &, 00 &, 00 &, 20 &, 15 & & & & & & & & \\
\hline
\end{tabular}

Panel B: Analyse der Strategy Disclosure Scores - Einzelne Jahre 2002 bis 2008

\begin{tabular}{|c|c|c|c|c|c|c|c|c|c|c|c|c|c|c|c|c|}
\hline & \multicolumn{4}{|c|}{ Teil-Scores } & \multicolumn{4}{|c|}{$\left[\right.$ normiert $\left.^{1028},\{0 ; 1\}\right]$} & \multicolumn{5}{|c|}{ Gesamt-Scores } & \multicolumn{3}{|c|}{ [normiert, $\{0 ; 1\}]$} \\
\hline & \multirow{2}{*}{$\begin{array}{l}\text { Teil- } \\
\text { Score }\end{array}$} & \multirow[b]{2}{*}{$\mu$} & \multicolumn{2}{|c|}{ Extrema } & \multicolumn{3}{|c|}{ Perzentile } & \multirow[b]{2}{*}{$\sigma$} & \multirow[b]{2}{*}{$\mu$} & \multicolumn{2}{|c|}{ Extrema } & \multicolumn{2}{|c|}{ Perzentile } & & \multirow[b]{2}{*}{$\sigma$} & \multirow[b]{2}{*}{$\mathbf{n}$} \\
\hline & & & Min & Max & $25 \%$ & $50 \%$ & $75 \%$ & & & Min & Max & $25 \%$ & $50 \%$ & $75 \%$ & & \\
\hline \multirow[t]{3}{*}{2002} & Analyse &, 32 & $\overline{, 06}$ & 65 &, 25 &, 32 &, 40 &, 11 & & & & & & & & \\
\hline & Strategie &, 28 & 00 &, 87 &, 18 &, 33 &, 40 &, 16 & ,28 & 03 & ,63 &, 20 &, 28 & 3 &, 10 & 100 \\
\hline & Implem. &, 06 &, 00 &, 40 &, 00 &, 00 &, 00 &, 11 & & & & & & & & \\
\hline \multirow[t]{3}{*}{2003} & $\overline{\text { Analyse }}$ & .33 & .06 & .65 & .25 &, 35 &, 40 & $\overline{, 11}$ & & & & & & & & \\
\hline & Strategie &, 29 &, 00 &, 60 &, 20 &, 33 &, 40 &, 16 &, 29 &, 06 &, 53 &, 21 &, 28 & 3,35 &, 10 & 100 \\
\hline & Implem. &, 08 &, 00 &, 60 &, 00 &, 00 &, 20 &, 15 & & & & & & & & \\
\hline \multirow[t]{3}{*}{2004} & Analyse & .35 & .15 & .65 & 28 &, 35 &, 40 & $\overline{, 11}$ & & & & & & & & \\
\hline & Strateg &, 32 &, 00 &, 73 &, 20 &, 33 &, 40 &, 15 &, 30 &, 11 &, 55 &, 23 &, 30 & ,35 & 09 & 100 \\
\hline & Implem. &, 06 &, 00 &, 60 &, 00 &, 00 &, 15 &, 12 & & & & & & & & \\
\hline \multirow[t]{3}{*}{2005} & Analyse & .38 &, 11 & .65 &, 30 &, 35 & .45 & $\overline{, 11}$ & & & & & & & & \\
\hline & $\mathrm{S}$ &, 36 &, 00 &, 73 &, 25 &, 33 &, 49 &, 17 & ,34 & , 14 &, 58 &, 26 &, 33 & ,40 &, 11 & 100 \\
\hline & Implem. &, 09 &, 00 &, 60 &, 00 &, 00 &, 20 &, 15 & & & & & & & 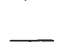 & \\
\hline \multirow[t]{3}{*}{2006} & Analyse & .41 &, 17 & .75 & .35 & .40 & .50 & .12 & & & & & & & & \\
\hline & Strategie &, 40 &, 07 &, 87 &, 27 &, 40 &, 53 &, 19 & ,37 &, 14 &, 75 &, 29 &, 35 & , 45 &, 12 & 100 \\
\hline & Implem. &, 11 &, 00 &, 60 &, 00 &, 00 &, 20 &, 14 & & & & & & & 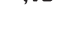 & \\
\hline \multirow[t]{3}{*}{2007} & Analyse & .45 & 20 &, 85 &, 35 &, 44 & .55 &, 14 & & & & & & & & \\
\hline & Strategie &, 45 & 07 &, 87 &, 33 &, 42 &, 59 &, 19 &, 41 &, 15 &, 83 &, 30 &, 40 & , 49 &, 13 & 100 \\
\hline & Implem. &, 13 &, 00 &, 80 &, 00 &, 00 &, 20 &, 17 & & & & & & & - & \\
\hline \multirow[t]{3}{*}{2008} & Analyse & .43 & .15 & .85 & .35 & .40 & .50 & .14 & & & & & & & & \\
\hline & Strategie &, 40 &, 00 &, 80 &, 27 &, 40 &, 53 &, 18 & ,38 &, 13 &, 83 & ,29 & ,38 &, 45 &, 13 & 100 \\
\hline & Implem. &, 13 & 00 &, 80 &, 00 &, 00 & 20 &, 18 & & & & & & & & \\
\hline
\end{tabular}

\section{Tabelle 17: Messwerte des Strategy Disclosure Index (SDScores)}

Bevor allerdings das mit Hilfe des zuvor konstruierten Untersuchungsbogens erhobene Niveau der Strategieberichterstattung für die Hypothesenprüfung genutzt

1028 Die Normierung erfolgte auf Basis der Anzahl Items je Kategorie, vgl. Tab. 2 (S. 204).

Tom Sieber - 978-3-631-75150-3 
bzw. überhaupt im Rahmen einer metrischen Analyse verwendet werden kann, ist seine Normalverteilungseigenschaft zu prüfen. ${ }^{1029}$ Dazu bietet sich die Durchführung sog. Verteilungstests nach Kolmogorov-Smirnov und Shapiro-Wilk an, bei denen die SDScores der einzelnen Jahre des Untersuchungszeitraumes einer theoretischen Normalverteilung gegenübergestellt werden und folglich die Nullhypothese einer Normalverteilung geprüft wird. ${ }^{1030}$ Bei den in Tab. 18 gezeigten Testergebnissen ist zu vermerken, dass diese zumindest Anzeichen dafür liefern, SDIndex als hinreichend normalverteilt anzusehen, da diese Tests recht sensitiv auf die Größe der Stichprobe bzw. auf Ausreißer reagieren. ${ }^{1031}$ Eine Anwendung parametrischer Tests zur Hypothesenprüfung scheint ergo formal abgesichert. ${ }^{1032}$

\begin{tabular}{|c|c|c|c|c|c|c|c|c|}
\hline \multicolumn{9}{|c|}{ Prüfung der Normalverteilungseigenschaft der Strategy Disclosure Scores } \\
\hline & \multicolumn{3}{|c|}{ Kolmogorov-Smirnov } & \multirow{2}{*}{$\frac{[\alpha=, 05]}{n}$} & \multicolumn{3}{|c|}{ Shapiro-Wilk } & \multirow{2}{*}{$\frac{[\alpha=, 05]}{n}$} \\
\hline & Statistik & df & p-Wert & & Statistik & df & p-Wert & \\
\hline 2002 & 097 & 100 &, $024 * *$ & 100 & ,970 & 100 &, $026 * *$ & 100 \\
\hline 2003 &, 092 & 100 & $.037 * *$ & 100 & ,976 & 100 &, $065 *$ & 100 \\
\hline 2004 & .094 & 100 & $.031 * *$ & 100 & ,982 & 100 & , 176 n.s. & 100 \\
\hline 2005 & .085 & 100 &, $075 *$ & 100 &, 972 & 100 &, $033 * *$ & 100 \\
\hline 2006 & .093 & 100 &, $031 * *$ & 100 & ,984 & 100 & ,281 n.s. & 100 \\
\hline 2007 & .072 & 100 & ,200 n.s. & 100 & ,982 & 100 & ,207 n.s. & 100 \\
\hline 2008 &, 083 & 100 &, 090 n.s. & 100 & ,983 & 100 & ,219 n.s. & 100 \\
\hline
\end{tabular}

Tabelle 18: Prüfung der SDScores auf Normalverteilung

1129 Vgl. Brosius (2007), S. 178f. In der relevanten Literatur findet sich der Hinweis z.B. bei Fischer/Vielmeyer (2004), S. 467, welche Index-basierte Messinstrumente als ,pseudometrische Maße“ definieren, vgl. auch Fn. 912. Autoren, die Indizes nutzen, verzichten i.d.R. aber auf die Prüfung der Normalverteilungseigenschaft, vgl. z.B. Botosan (1997a). 1030) Vgl. Adam (1996), S. 420f.; Bleymüller et al. (2002), S. 61, auch Cooke (1998), S. 210.

1031 Vgl. Bortz (2005), S. 165ff. Bei beiden Testverfahren werden grds. hohe p-Werte angestrebt, um die Nullhypothese der Normalverteilung nicht verwerfen zu müssen.

Die dargestellten Resultate sind insofern akzeptabel, als beide Tests höchst sensitiv auf hohe Stichprobenumfänge bzw. auf Ausreißer reagieren, vgl. Bortz (2005), S. 165f. Zusätzlich wurden die Histogramme der jeweiligen SDScores inspiziert sowie die Schiefeund Kurtosis-Parameter geprüft, wie z.B. von Muthén/Kaplan (1985), S. 187 empfohlen wird. Es zeigt sich, dass von einer hinreichenden Normalverteilung auszugehen ist, vgl. auch das Histogramm der SDScores der zusammengesetzten Stichprobe in Anhang 7-2.

1032 Dies auch vor dem Hintergrund, dass i.d.R. keine Prüfung der Normalverteilungseigenschaft erfolgt, vgl. u.a. Hail (2002); Cheng/Courtenay (2006); Petersen/Plenborg (2006); Gegenbeispiel Cooke (1989). Gregoire/Driver (1987), S. 159f. bzw. Vasu (1979) zeigen aber, dass auch bei Abweichung von der Normalverteilung parametrische Tests möglich sind. Ein Verfahren zur Reskalierung ordinaler Daten stellen Harwell/Gatti (2001) vor.

Tom Sieber - 978-3-631-75150-3 


\subsection{Qualität der Messung der Strategieberichterstattung}

Wenngleich die Ausführungen zu den deskriptiven Ergebnissen bereits erste Indikationen dafür geliefert haben, dass von der Existenz einer Strategieberichterstattung innerhalb der Lageberichte ausgegangen werden kann, ist dennoch eine formale Prüfung vorzunehmen, ob das konzipierte Messinstrument des SDIndex tatsächlich in der Lage ist, die Berichterstattung zu strategieorientierten Inhalten zu messen. Dieses wurde explizit als Forschungsfrage 1 formuliert, deren Beantwortung durch eine Untersuchung der Reliabilität bzw. der Validität des Messinstruments SDIndex erfolgen soll, wie in der relevanten Literatur bei Anwendung vergleichbarer Messinstrumente wiederholt empfohlen wird. ${ }^{1033}$

\subsubsection{Prüfung der Reliabilität des Strategy Disclosure Index}

Mit der Prüfung der Reliabilität bzw. Zuverlässigkeit eines Messinstruments ist die interne Konsistenz desselbigen zu untersuchen. Zu prüfen ist, inwieweit das Messinstrument bei wiederholter Anwendung konsistente Messwerte liefert. ${ }^{1034}$

In der einschlägigen Literatur hat sich hier die Verwendung eines Koeffizienten, des sog. Cronbachs Alpha etabliert. ${ }^{1035}$ Jene Vorgehensweise folgt der zentralen Annahme, dass das konkrete Berichtsverhalten eines Unternehmens stets in allen $\mathrm{zu}$ unterscheidenden inhaltlichen Kategorien eines Messinstruments konsistent sein sollte, denn: „disclosure strategies of a firm are expected to be similar along all avenues. “" ${ }^{1036}$ Von dieser Prämisse ausgehend ist Cronbachs Alpha sodann in methodischer Hinsicht als ein ,,measure of internal consistency that uses [...] the various categories of the disclosure index to assess the degree to which correlation among the measurements is attenuated due to random error ${ }^{\text {“1037 }} \mathrm{zu}$ beschreiben. Es wird schließlich angenommen, dass jede einzelne Kategorie eines

1033 Vgl. stellvertretend Botosan (1997a), S. 335f.; Lapointe-Antunes et al. (2006), S. 475f.; Hail (2002), S. 756. In der deutschsprachigen Literatur, die Disclosure Scores erarbeitet, wird auf diese Prüfung verzichtet, vgl. bspw. Barth (2009); Fischer/Vielmeyer (2004). Vgl. Schnell et al. (2007), S. 151.

1035 Vgl. grdl. Cronbach (1951).

1036 Cheng/Courtenay (2006), S. 271, ähnlich auch Botosan (1997a), S. 335f. 
spezifischen Messinstruments für sich einen äquivalenten Test und demzufolge eine unabhängige Messwiederholung des eigentlichen Instruments darstellt. ${ }^{1038}$

Zur Prüfung der Reliabilität des Messinstruments SDIndex ist gleichfalls dieses Cronbachs Alpha zu verwenden, auf Basis der drei übergeordneten inhaltlichen Kategorien von SDIndex. ${ }^{1039}$ Die Ergebnisse der Berechnung nennt Tab. 19 sowohl für die zusammengesetzte Stichprobe als auch für die Einzeljahre. ${ }^{1040}$ Zur Interpretation ist zu vermerken, dass Alpha zwar auf den Bereich $\{0 ; 1\}$ normiert ist, allerdings keine allgemeingültige Interpretation der Werte vorliegt. ${ }^{1041}$ Nach Ansicht von Carmines/Zeller (1979) ist jedoch grds. davon auszugehen, dass bei einem Wert von Alpha=,800 die Korrelationsergebnisse nicht signifikant durch zufällige Messfehler beeinflusst werden sollten. ${ }^{1042}$

Prüfung der Reliabilität des Messinstruments

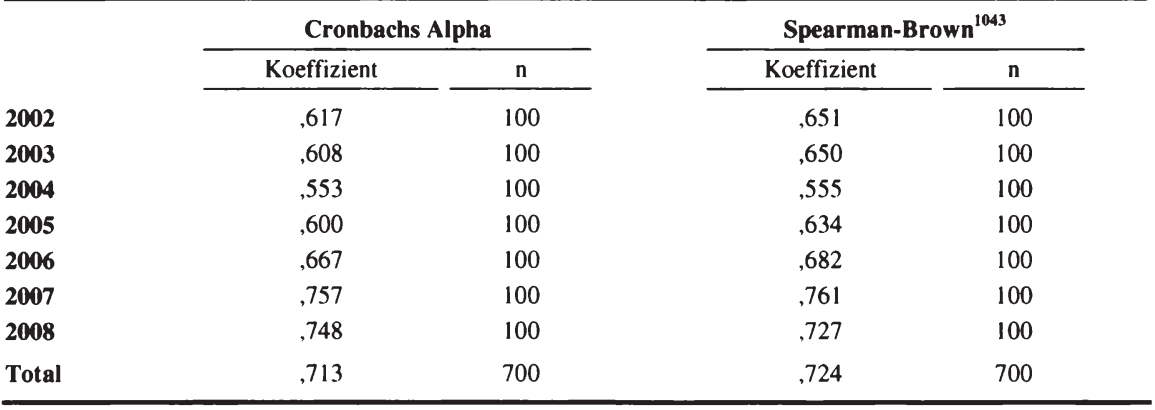

\section{Tabelle 19: Reliabilität des Messinstruments SDIndex}

\footnotetext{
1038 Vgl. Schnell et al. (2007), S. 152.
}

1039 Die Berechnung von Alpha erfolgte also auf Basis der drei einzelnen Berichtskategorien der Analyse, der Strategieformulierung und der Implementierung, vgl. Abb. 18 (S. 212).

1040) Dies ist konsistent mit der Literatur, z.B. Lapointe-Antunes et al. (2006), S. 504: ,global alpha and annual alphas when we segregate our sample into five annual subgroups“.

11041 Vgl. Botosan (1997a), S. 335; Lapointe-Antunes (2006), S. 504.

1042 Vgl. Carmines/Zeller (1979), S. 23. Abweichend sieht Nunnally (1994) einen kritischen Wert für Cronbachs Alpha bei ,700; noch liberaler bspw. Wittenberg (1998), S. 201.

104. Der Koeffizient nach Spearman-Brown wurde hier zusätzlich errechnet, um eine weitere Methode der Reliabilitätsprüfung parallel anzuwenden. Dieser gehört zu der Gruppe der ,Split-Half-Methoden', bei welchen das Messinstrument willkürlich in zwei Hälften gespalten wird und sich aus einer Korrelation zwischen beiden Testhälften mit Hilfe einer einfachen Formel der Koeffizient der Reliabilität errechnen lässt. Vgl. hierzu sowie zur Problematik der Aufspaltung von Instrumenten Zeller/Carmines (1980), S. 54ff. Für die Interpretation können die Angaben zu Cronbachs Alpha analog verwendet werden. 
Da die für das eigene Messinstrument errechneten Koeffizienten leicht unterhalb des von Carmines/Zeller vorgeschlagenen, als eher konservativ zu beurteilenden Grenzwertes liegen, kann für SDIndex nicht grds. ausgeschlossen werden, dass Zufallsfehler der Messung die einzelnen Messwerte beeinflussen und deren Aussagekraft beeinträchtigen. Jedoch kann - in Übereinstimmung mit der relevanten Literatur - auf Basis dieses Resultats dennoch eine hinreichende Zuverlässigkeit des Messinstruments festgestellt und eine weitere Verwendung der mit SDIndex ermittelten Messwerte bzw. der SDScores befürwortet werden. ${ }^{1044}$

Der Vollständigkeit halber zeigt Tab. 20 schließlich die einzelnen Korrelationskoeffizienten der Teil-Scores mit den gesamthaften SDScores. Diese recht trivial anmutende Methodik der Reliabilitätsprüfung wird mitunter in der Literatur empfohlen, da sie ebenfalls der oben zitierten Annahme folgt, dass sich individuelle Berichterstattungsstrategien konsistent in sämtlichen Berichtskategorien niederschlagen sollten. ${ }^{1045}$ Wie erkennbar ist, sind alle Teil-Scores untereinander sowie mit dem SDScore positiv und hoch signifikant korreliert, was - in Ergänzung zu den Resultaten für Cronbachs Alpha - zumindest als Indikation gewertet werden kann, dass mit SDIndex ein reliables Messinstrument vorliegt. ${ }^{1046}$

\begin{tabular}{|c|c|c|c|c|c|}
\hline \multicolumn{6}{|c|}{$\begin{array}{l}\text { Korrelationsanalyse der Kategorien des Messinstruments der Strategieberichterstattung SDIndex } \\
\text { Bivariate Korrelationsanalyse der Teil-Scores des Messinstruments SDIndex untereinander. Werte unterhalb der Diagonale stellen dic } \\
\text { Korrelationskoeffizienten nach Pearson. Werte oberhalb der Diagonale die Rang-Korrelationskoeffizienten nach Spearman dar. }\end{array}$} \\
\hline $\mathrm{n}=700$ & & 1 & 2 & 3 & 4 \\
\hline $\begin{array}{ll}1 & \text { SDI } \\
& \text { Total }\end{array}$ & $\begin{array}{l}\text { Koeffizient } \\
\text { p-Wert }\end{array}$ & & $\begin{array}{l}, 824 * * * \\
(.(0)(0))\end{array}$ & $\begin{array}{l}, 851 * * * \\
(.000)\end{array}$ & $\begin{array}{l}, 480 * * * \\
(.00(0))\end{array}$ \\
\hline $2 \begin{array}{l}\text { SDI } \\
\text { Analyse }\end{array}$ & $\begin{array}{l}\text { Koeffizient } \\
\text { p-Wert }\end{array}$ & $\begin{array}{l}, 857 * * * \\
(, 000)\end{array}$ & & $\begin{array}{l}, 458 * * * \\
(.000)\end{array}$ & $\begin{array}{l}, 306 * * * \\
(.000)\end{array}$ \\
\hline $3 \begin{array}{l}\text { SDI } \\
\text { Strategie }\end{array}$ & $\begin{array}{l}\text { Koeffizient } \\
\text { p-Wert }\end{array}$ & $\begin{array}{l}, 852 * * * \\
(, 000)\end{array}$ & $\begin{array}{l}, 493 * * * \\
(, 000)\end{array}$ & & $\begin{array}{l}, 339 * * * \\
(.00(0))\end{array}$ \\
\hline $4 \begin{array}{l}\text { SDI } \\
\text { Implementierung }\end{array}$ & $\begin{array}{l}\text { Koeffizient } \\
\text { p-Wert }\end{array}$ & $\begin{array}{l}, 552 * * * \\
(.000)\end{array}$ & $\begin{array}{l}, 378^{* * *} \\
(, 0(0))\end{array}$ & $\begin{array}{l}, 361 * * * \\
(.000)\end{array}$ & \\
\hline
\end{tabular}

\section{Tabelle 20: Korrelationsmatrix der SDScores und der Teil-Scores}

1044 Dies bestätigen bspw. Schnell et al. (2007), S. 153. Als Beispiel für Arbeiten, die Messinstrumente verwenden, deren Alpha unterhalb des Grenzwertes von Alpha=,700 liegt, sei Botosan (1997a) mit einem errechneten Koeffizienten von Alpha=,640 genannt.

1045 Vgl. bspw. Cheng/Courtenay (2006), S. 271; Botosan (1997a), S. 335f.

1046 Diese Aussage findet sich auch bei Hail (2002), S. 756f. Es sei darauf hingewiesen, dass Cronbachs Alpha methodisch ebenfalls auf Korrelationsanalysen beruht. 


\subsubsection{Prüfung der Validität des Strategy Disclosure Index}

Die Prüfung der Validität bzw. Gültigkeit eines Messinstruments zielt darauf ab, zu untersuchen, ob das Messinstrument inhaltlich den Sachverhalt misst, den es messen soll. ${ }^{1047}$ Im vorliegenden Fall ist daher zu prüfen, ob das Messinstrument SDIndex tatsächlich in der Lage ist, strategische Berichtsinhalte im Lagebericht zu erfassen. Eine Prüfung dieser sog. externen bzw. empirischen Validität kann erfolgen, indem der statistische Zusammenhang zwischen dem eigenen, dem zu validierenden und einem anderen, externen Messinstrument betrachtet wird. ${ }^{1048}$

Um das Problem der Validierung eines eigens konzipierten Messinstruments gar nicht erst aufkommen zu lassen, wird in der einschlägigen Literatur gelegentlich dazu geraten, kein eigenes Instrument zu konstruieren, sondern stattdessen vollständig auf extern verfügbare Daten zurückzugreifen, die einen interessierenden Sachverhalt abbilden. ${ }^{1049}$ Dass dieser Vorschlag für spezifische Fragestellungen bzw. für spezifische Stichproben i.d.R. jedoch keine realistische Alternative darstellt, wurde in C 3.2.2 diskutiert und in der Literatur wiederholt ${ }^{1050}$ angemerkt.

Für die konkrete externe Validierung der Messwerte sind schließlich zwei grds. Optionen denkbar: einerseits eine Validierung mit Hilfe eines alternativen Messinstruments, welches zeitlich parallel oder aber zu einem anderen Zeitpunkt zum identischen Sachverhalt angewendet wird, anderseits eine Validierung der Mess-

1047 Unter Bezug auf die ,American Psychological Association “ werden in der Literatur zur Sozialforschung üblicherweise drei Formen der Validität genannt: Inhalts-, Kriteriumsund Konstruktvalidität. Im vorliegenden Fall ist insb. die Kriteriumsvalidität bedeutsam. Vgl. für einen Überblick bspw. Schnell et al. (2005), S. $155 \mathrm{ff}$.

1048 Vgl. Schnell et al. (2005), S. 155.

1049) Diese Empfehlung findet sich bspw. bei Healy/Palepu (2001), S. $426 \mathrm{f}$.

Dieser Vorschlag ist jedoch aus der Perspektive der US-amerikanischen Autoren Healy und Palepu zu beurteilen: Mit den bereits angesprochenen AIMR-Scores liegen für eine überwiegende Mehrzahl kapitalmarktorientierter US-Unternehmen detaillierte Daten zur Beurteilung der Berichterstattung vor, vgl. die Argumentation in Abschnitt C 3.2.2.

Vgl. bspw. Banghoj/Plenborg (2008), S. 167, die freiwillige Berichterstattung dänischer Unternehmen untersuchen und feststellen, dass externe Daten nicht verfügbar seien und daher ein eigenes Messinstrument zu konzipieren sei. Im Rahmen der Konstruktion des Messinstruments SDIndex wurde zudem argumentiert, dass ein spezifisches Instrument annahmegemäß gezielter auf den jeweils relevanten Sachverhalt ausgerichtet sein sollte, vgl. Abschnitt C 3.2.2. Zudem liegt bis dato kein externes Messinstrument vor, welches gezielt auf strategische Sachverhalte in der Berichterstattung abstellt. 
werte mit Hilfe von externen Proxygrößen, wie z.B. der Anzahl der über ein jeweiliges Unternehmen veröffentlichten Zeitungsartikel. ${ }^{1051}$ Während die zuerst genannte Option eine weitere aktive Messung erfordert, wird angenommen, dass unmittelbar extern verfügbare Proxygrößen ebenfalls einer konsistenten Berichterstattungsstrategie der Unternehmen folgten und schließlich als aussagekräftige Indikatoren anzusehen seien: „Since disclosure strategies are coordinated across various avenues, I expect [...] the disclosure index to be positively correlated with [...] the number of Wall Street Journal articles written about the firm. “1052

Zur Validierung des Messinstruments SDIndex soll die erstgenannte Option verfolgt werden. Externe Messwerte konnten mit Hilfe einer Neuberechnung eines Teilergebnisses auf Basis originärer Daten des renommierten Wettbewerbs ,Der Beste Geschäftsbericht' für den kompletten Zeitraum der eigenen Untersuchung gewonnen werden. ${ }^{1053}$ Jener Wettbewerb basiert methodisch ebenfalls auf einem vorgegebenen Kriterienkatalog, welcher im Rahmen einer Inhaltsanalyse innerhalb der Geschäftsberichte der teilnehmenden Unternehmen abgeprüft wird. ${ }^{1054}$

Auf Grundlage der relevanten Aspekte der Kriterienkataloge dieses Wettbewerbs konnte also ein spezifisches Teilergebnis der Strategieberichterstattung im Lage-

1051 In der Literatur finden sich beide Vorgehensweisen: So validieren bspw. einige Autoren ihre eigenen Messinstrumente mit Hilfe von externen Messwerten, vgl. u.a. Hail (2002), oder Lapointe-Antunes et al. (2006), die ihre Messwerte mit externen Scores des ,Swiss Banking Institutes ' validieren. Botosan (1997a), S. 335f. nutzt dagegen Proxygrößen zur Validierung ihres Messinstruments, konkret die Anzahl aller innerhalb eines bestimmten Zeitraums publizierten Artikel im Wall Street Journal. Gebräuchliche Proxies sind auch die Anzahl der Analysten-Telefonkonferenzen oder -präsentationen, z.B. Tasker (1998). Botosan (1997a), S. 335.

1053 Jener Wettbewerb wird seit 1982 unter wissenschaftlicher Leitung von Prof. Baetge ausgeschrieben und seit 1995 in Kooperation mit dem ,manager magazin' durchgeführt.

Die inhaltliche Analyse der Geschäftsberichte erfolgt jährlich wiederkehrend durch ein Forschungsteam der Westfälischen Wilhelms-Universität Münster, das die Rohdaten zur Validierung des SDIndex freundlicherweise bereitgestellt hat. Die Konsistenz des Messverfahrens über lange Zeit bzw. die Analyse durch unabhängige Kodierer sind als KernQualitätsmerkmale dieser Rohdaten zu nennen, vgl. Baetge et al. (2010), S. 76.

Vgl. zur Methodik der Berechnung eines Teilergebnisses zur Strategieberichterstattung auf Basis dieser Rohdaten als ,Validierungs-Scores' des SDIndex den Anhang 9.

Teilnehmer dieses Wettbewerbs sind die in HDax und SDax notierten Unternehmen des jeweiligen Kalenderjahres. Ein breiter Kriterienkatalog dient zur Prüfung von Berichtsinhalten des Anhangs bzw. des Lageberichts, da hier aufgrund unkonkreter Normierung erhebliche Gestaltungsspielräume gesehen werden, vgl. Baetge et al. (2010), S. 76f. 
bericht errechnet sowie dessen statistischer Zusammenhang mit den Werten des Messinstruments SDIndex zum Zwecke der Validierung ermittelt werden. ${ }^{1055}$ In methodischer Hinsicht erfolgt eine solche Validierung eines Messinstruments üblicherweise durch die Bildung der Korrelationsmatrix der Verteilungen der jeweiligen Messwerte. ${ }^{1056}$ Die Ergebnisse der Validierung der Werte des SDIndex mit den berechneten Werten des ,Besten Geschäftsberichts‘ liefert Tab. 21. Auf Basis dieser Validierung kann schließlich grds. davon ausgegangen werden, dass SDIndex strategische Inhalte in Lageberichten hinreichend genau misst, da zwei voneinander unabhängige Messvorgänge mit unterschiedlichen Instrumenten zu Messwerten gelangen, die höchst signifikante Zusammenhänge aufweisen. ${ }^{1057}$

Die Ergebnisse der Validierung eröffnen für die weitere Hypothesenprüfung zudem grds. die Option, das eigene Messinstrument durch die auf Basis der Daten des ,Besten Geschäftsberichts“ ermittelten Werte sowie kombinierte Messwerte zu ersetzen. Dazu wird eine Faktorenanalyse durchgeführt und somit ein Faktor der Strategieberichterstattung extrahiert - dies wird in Tab. 22 aufgezeigt.

Wie die vorhergehenden Ausführungen verdeutlicht haben, scheint mit SDIndex ein reliables und valides Messinstrument zur Erfassung von strategieorientierten Informationen im Lagebericht zur Verfügung zu stehen. Daher wird die erste der

1055 Die relevanten Bestandteile der jahresspezifischen Kriterienkataloge jenes Wettbewerbs und die Methodik zur Berechnung der Validierungs-Scores zeigt Anhang 9 en detail. Es ist nochmals zu vermerken, dass es sich hier um eine Neuberechnung auf Basis vorhandener Berichtskriterien handelt, da der ,Beste Geschäftsbericht ' eine recht breite inhaltliche Perspektive einnimmt. Die Konstruktion des SDIndex sollte insofern überlegen sein, als dieser eine fokussierte sowie umfassende Sichtweise der Strategie abdeckt. Zur Validierung scheinen die berechneten Teilergebnisse des Wettbewerbs jedoch geeignet. Vgl. bspw. die Validierung bei Lapointe-Antunes et al. (2006), S. 504. Die Autoren errechnen zur Validierung einen Korrelationskoeffizienten von $r=, 557 * *$ (Pearson) und schließen daraus, dass ihr Instrument die interessierenden Inhalte valide misst. Ähnlich Botosan (1997a), S. 336 mit $r=, 370 * *$ (Pearson, einseitig) auf Basis von AIMR-Scores. Diese Korrelationsanalysen wurden gleichfalls für alle sieben Einzeljahre berechnet. Es ergeben sich in jedem Jahr positive und höchst signifikante Zusammenhänge, die sieben Koeffizienten bewegen sich in der Bandbreite von ,442*** (2002) bis ,679*** (2006). Wie erwähnt, rekrutieren sich die Teilnehmer dieses Wettbewerbs aus den im jeweiligen Jahr in HDax sowie SDax notierten Unternehmen. Da die eigene Untersuchung eine abweichende Methode der Stichproben-Zusammensetzung gewählt hat, können nur $75 \mathrm{Be}$ obachtungen nicht validiert werden, mit insg. 625 von 700 Beobachtungen (89\%) ist die Schnittmenge beider Messinstrumente jedoch als ausreichend anzusehen. 
vier formulierten Forschungsfragen positiv beantwortet: Die Prüfung von Hypothesen über kausale Zusammenhänge mit SDIndex ist als sinnvoll anzusehen.

\section{Korrelationsanalyse der alternativen Messinstrumente der Strategieberichterstattung}

Bivariate Korrelationsanalyse der Messwerte (Scores) des Messinstruments SDIndex mit den ermittelten Messwerten zur Strategieberichterstattung aus den Daten des Wettbewerbs ,Der Beste Geschäftsbericht ' (DBG). Zusätzlich Bildung von Rangziffern der jeweiligen Messwerte (Rang). Werte unterhalb der Diagonale stellen die Korrelationskoeffizienten nach Pearson, Werte oberhalb der Diagonale die Rang-Korrelationskoeffizienten nach Spearman dar.

\begin{tabular}{|c|c|c|c|c|c|c|}
\hline & & & 1 & 2 & 3 & 4 \\
\hline \multirow[t]{2}{*}{1} & SDI (Score) & $\begin{array}{l}\text { Koeffizient } \\
\text { p-Wert }\end{array}$ & & $\begin{array}{l}-, 911 * * * \\
(, 000)\end{array}$ & $\begin{array}{l}, 560 * * * \\
(, 000)\end{array}$ & $\begin{array}{c}-, 542 * * * \\
(, 000)\end{array}$ \\
\hline & & $\mathrm{n}$ & & 700 & 625 & 625 \\
\hline \multirow[t]{2}{*}{2} & SDI (Rang) & $\begin{array}{l}\text { Koeffizient } \\
\text { p-Wert }\end{array}$ & $\begin{array}{l}-, 877 * * * \\
(.000)\end{array}$ & & $\begin{array}{c}-, 549 * * * \\
(, 000)\end{array}$ & $\begin{array}{l}, 565 * * * \\
(, 000)\end{array}$ \\
\hline & & $\mathrm{n}$ & 700 & & 625 & 625 \\
\hline \multirow[t]{2}{*}{3} & DBG (Score) & $\begin{array}{l}\text { Koeffizient } \\
\text { p-Wert }\end{array}$ & $\begin{array}{l}, 586 * * * \\
(, 000)\end{array}$ & $\begin{array}{l}-.548 * * * \\
(.000)\end{array}$ & & $\begin{array}{c}-, 983 * * * \\
(, 000)\end{array}$ \\
\hline & & $\mathrm{n}$ & 625 & 625 & & 625 \\
\hline \multirow[t]{2}{*}{4} & DBG (Rang) & $\begin{array}{l}\text { Koeffizient } \\
\text { p-Wert }\end{array}$ & $\begin{array}{l}-, 547 * * * \\
(, 000)\end{array}$ & $\begin{array}{l}, 565 * * * \\
(.000)\end{array}$ & $\begin{array}{l}-, 943 * * * \\
(, 000)\end{array}$ & \\
\hline & & $\mathrm{n}$ & 625 & 625 & 625 & \\
\hline
\end{tabular}

\section{Tabelle 21: Externe Validierung des Messinstruments SDIndex}

Wie die in Tab. 21 gezeigten Koeffizienten deutlich machen, stehen für weitere Analysen folglich vier Parameter zur Verfügung, die - aufgrund der statistischen Zusammenhänge - grds. auch zu vergleichbaren Ergebnissen führen sollten.

Faktorenanalyse zur Extraktion eines gemeinsamen Faktors der Strategieberichterstattung

Faktorenanalyse der beiden alternativen Messinstrumente der Strategieberichterstattung nach der Methode der Hauptkomponentenanalyse

\begin{tabular}{|c|c|c|c|c|c|c|}
\hline \multicolumn{4}{|c|}{ Prüfgrößen $^{1058}$} & \multicolumn{3}{|c|}{ Erklärte Gesamtvarianz } \\
\hline \multicolumn{2}{|l|}{$\mathrm{KMO}$} & \multicolumn{2}{|c|}{ Bartlett-Test } & Faktor & $\begin{array}{l}\text { Summe quadrierter } \\
\text { Faktorladungen }\end{array}$ & $\begin{array}{c}\text { Prozent } \\
\text { der Varianz }\end{array}$ \\
\hline \multirow[t]{3}{*}{ MSA } &, 500 & $\mathrm{Chi}^{2}$ & 262,4 & 1 & 1,586 & 79,324 \\
\hline & & df & 1 & 2 & & \\
\hline & & p-Wert &, $000 * * *$ & & & \\
\hline
\end{tabular}

\section{Tabelle 22: Faktorenanalyse der Messinstrumente der Strategieinhalte}

1058 Die Ermittlung der hier verwendeten Prüfgrößen wird bei Durchführung einer Faktorenanalyse empfohlen, vgl. bspw. Dziuban/Shirkey (1974), S. 360f.; Stewart (1981), S. 57f. Das MSA-Kriterium (,Measure of Sampling Adequacy') zeigt an, ob die Faktorbildung sinnvoll ist, der Wertebereich ist auf $\{0 ; 1\}$ normiert, vgl. grdl. Kaiser (1970), S. 405ff.

Bei Werten von MSA $<<, 500$ sollte ein ermittelter Faktor nicht verwendet werden, vgl. Cureton/D'Agostino (1993), S. 389. Die Weiterverwendung des hier ermittelten Faktors erfolgt daher unter Berücksichtigung der ggf. eingeschränkten Aussagekraft. 


\section{$3 \quad$ Hypothesenprüfung zur Strategieberichterstattung}

\subsection{Unterschiedlichkeit der individuellen Berichtsniveaus}

Da eine Messbarkeit des Niveaus der Strategieberichterstattung, als notwendige Bedingung der analytischen Auseinandersetzung mit diesem Konstrukt, bestätigt werden konnte, ist weiterführend die hinreichende Bedingung der Untersuchung zu überprüfen, die mit Hypothese H 1.1 abgebildet wurde: Jene postulierte, dass Unternehmen individuelle Niveaus der Strategieberichterstattung wählen und die Messwerte des SDIndex daher eine gewisse Unterschiedlichkeit zeigen. Um dies zu prüfen, stellt die nachfolgende Tab. 23 - ergänzend zu den in D 2.3 gezeigten SDScores - schwerpunktmäßig auf den Aspekt der Streuung der Messwerte ab.

\begin{tabular}{|c|c|c|c|c|c|c|c|c|c|c|c|c|c|c|c|}
\hline \multicolumn{16}{|c|}{ Streuungsparamet } \\
\hline & \multicolumn{8}{|c|}{ SDScores } & & & & & \multirow{2}{*}{\multicolumn{3}{|c|}{$\frac{\text { [normiert, }\{0 ; 1\}]}{\mathrm{Chi}^{2}}$}} \\
\hline & \multirow[t]{2}{*}{ 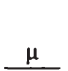 } & \multicolumn{2}{|c|}{ Extrema } & \multicolumn{5}{|c|}{ Perzentile } & \multicolumn{4}{|c|}{ Streuungsparameter ${ }^{1059}$} & & & \\
\hline & & Min & Max & $1 \%$ & $25 \%$ & $50 \%$ & $75 \%$ & $99 \%$ & $\sigma$ & $\sigma^{2}$ & SW & IQA & VK & $\begin{array}{c}\mathrm{Chi}^{2} \\
\mathrm{p} \text {-Wert }\end{array}$ & $\mathrm{n}$ \\
\hline 2002 & .28 & ,03 & ,63 & ,03 & ,20 & ,28 & ,33 & .63 & , 10 & 010 & 60 & .13 & ,36 & ,000 & 100 \\
\hline 2003 & .29 & ,06 &, 53 & .06 &, 21 & .28 &, 35 &, 53 & .09 & .010 &, 47 &, 14 & ,31 & ,000 & 100 \\
\hline 2004 &, 30 &, 11 & .55 &, 11 &, 23 &, 30 & ,35 &, 55 &, 09 &, 009 & .44 &, 12 &, 30 &, 000 & 100 \\
\hline 2005 & .34 &, 14 & .58 &, 14 &, 26 & .33 & .40 &, 58 &, 11 &, 012 &, 44 &, 14 &, 32 &, 000 & 100 \\
\hline 2006 & .37 &, 14 & .75 &, 14 &, 29 &, 35 & .45 &, 75 &, 12 &, 014 & ,61 &, 16 &, 32 &, 000 & 100 \\
\hline 2007 & .41 & 15 &, 83 &, 15 &, 30 & , 40 &, 49 &, 83 & 13 &, 018 & ,68 &, 19 &, 32 & .000 & 100 \\
\hline 2008 & .38 & , 13 & .83 &, 13 & .29 & ,38 & ,45 &, 83 &, 13 &, 017 & ,70 &, 16 & ,34 & ,000 & 100 \\
\hline Total &, 34 & ,03 & ,83 &, 11 & .25 &, 33 & ,40 & 69 & .12 & 015 & ,80 &, 15 & ,35 & ,000 & 700 \\
\hline
\end{tabular}

Tabelle 23: Streuungsanalyse der SDScores

Wie die Lage- und insb. die Streuungsparameter aufzuzeigen vermögen, ist von erheblicher Heterogenität der Messwerte auszugehen. Diese Aussage wird durch $\mathrm{Chi}^{2}$-Tests auf Gleichverteilung abgesichert. ${ }^{1060}$ Eine Gleichverteilung der Messwerte scheint ebenfalls nicht gegeben. Folglich ist $\mathbf{H} 1.1$ zu akzeptieren, zudem kann die hinreichende Bedingung einer empirischen Untersuchung als erfüllt angesehen werden: Eine ausreichende Heterogenität der SDScores ist vorhanden.

\footnotetext{
1059 Notiert sind neben der Varianz und der Standardabweichung die Spannweite (SW), der Interquartilsabstand (IQA) sowie der Variationskoeffizient (VK).

1060) Vgl. Backhaus et al. (2008), S. 307. Es wird die Nullhypothese auf Gleichverteilung getestet, dies erfolgt anhand von in zehn Klassen gruppierten SDScores (je 0,1). Ein alternativer Test nach Kolmogorov-Smirnov kommt zum gleichen Resultat. Dieser Test wird durchgeführt, um auszuschließen, dass die ermittelte Streuung aufgrund gleichverteilter Daten errechnet wurde. Vgl. ergänzend zur Streuung der Scores auch Tab. 18 (S. 257). 


\subsection{Zeitliche Dynamik der Strategieberichterstattung}

Wie bereits die Auflistung der jährlichen SDScores sowie der drei Teil-Scores in Tab. 17 bzw. 23 andeutete, ist das Niveau der Strategieberichterstattung über die sieben Jahre des Untersuchungszeitraums hinweg nicht konstant. Ob jedoch tatsächlich signifikante Veränderungen der Strategieberichterstattung über die Zeit gegeben sind, ist durch eine einfaktorielle Varianzanalyse zu prüfen, bei der die Varianz der Mittelwerte der Scores in Abhängigkeit vom Faktor Zeit untersucht werden. ${ }^{1061}$ Die Durchführung der Analyse in Tab. 24 zeigt, dass die kategoriale unabhängige Variable, d.h. die sieben Jahre des Untersuchungszeitraums, in der Lage ist, rund 14\% der Varianz der abhängigen Variablen zu erklären. Es liegen also signifikante Mittelwertunterschiede zwischen den einzelnen Gruppen vor.

\begin{tabular}{|c|c|c|c|c|c|}
\hline \multicolumn{6}{|c|}{ Analyse des Niveaus der Strategieberichterstattung in Abhängigkeit der Zeit (ANOVA) } \\
\hline & Quadratsumme & df & $\begin{array}{l}\text { Quadrierte } \\
\text { Mittelwerte }\end{array}$ & $\mathbf{F}$ & p-Wert \\
\hline Zwischen den Gruppen & 1,528 & 6 & 255 & 19,6 &, $000 * * *$ \\
\hline Innerhalb der Gruppen & 8,977 & 693 & 013 & & \\
\hline Total & 10,505 & 699 & & & \\
\hline
\end{tabular}

Tabelle 24: Varianzanalyse der SDScores in Abhängigkeit der Zeit

Aufgrund der hohen Signifikanz der Varianzanalyse besteht die Möglichkeit der spezifischeren Prüfung durch sog. Einzelvergleiche, angewendet wird hierzu ein Verfahren nach Scheffé ${ }^{1062}$ Wie Tab. 25 präsentiert, lassen sich auf diese Weise im Zeitraum 2002 bis 2008 vier homogene Untergruppen identifizieren, die sich hinsichtlich der Gruppenmittelwerte unterscheiden. ${ }^{1063}$ Diese Mittelwerte zeigen darüber hinaus eine steigende Tendenz. Auf Grundlage dieser Ergebnisse ist die Hypothese $\mathbf{H} 1.2$ schließlich zu akzeptieren, welche ein sich veränderndes sowie ein ansteigendes Niveau der Strategieberichterstattung über die Zeit unterstellte.

1061 Vgl. zur Methodik der einfaktoriellen Varianzanalysen grdl. Bortz (2005), S. 247f., eher anwendungsorientiert Brosius (2007), S. 235ff. Formal wird die Nullhypothese geprüft, dass sich Gruppen der Stichprobe bzgl. einer abhängigen Variablen nicht unterscheiden.

1062 Dieses ist im Vergleich zu anderen Verfahren nicht nur als robust, sondern auch als eher konservativ zu beschreiben, so Bortz (2005), S. 274; grdl. Scheffé (1950), ders. (1951). Das Verfahren beruht auf paarweisen Mittelwertvergleichen aller möglichen Gruppen. der Berichtsjahre noch etwas deutlicher, vgl. grdl. Waller/Duncan (1969), S. 1484f. 
Bei einer Betrachtung von Tab. 25 fällt weiterhin auf, dass sich das Niveau der Strategieberichterstattung insb. zwischen den Jahren 2002 bis 2004 sowie 2006 bis 2008 deutlich unterscheidet. Es ist sodann zu vermuten, dass im Hinblick auf die Bereitstellung strategieorientierter Informationen innerhalb der Lageberichte v.a. ab dem Jahre 2005 eine deutliche Ausweitung der Inhalte stattgefunden hat. Es scheint daher statistisch bestätigt, dass mit Inkrafttreten des BilReG bzw. der somit kodifizierten Prognoseberichterstattung auch vermehrt strategieorientierte Inhalte innerhalb von Lageberichten bereitgestellt wurden. Erweitert um die deskriptiven Auswertungen zum SDIndex in Abschnitt D 2.3 geben jene Resultate Anlass dazu, auch die zweite Forschungsfrage als beantwortet anzusehen.

\begin{tabular}{|c|c|c|c|c|c|c|c|c|c|c|}
\hline Einzelv & gleiche & $\mathrm{m} \mathrm{Niv}$ & $\operatorname{der} S$ & tegieb & hterstat & in $\mathbf{A b}$ & gigkeit & er Zeit & t Hoc- & \\
\hline & Scheff & & [SD & res, 10 & $\alpha=, 05]$ & Wall & uncan & & res, $\{0$ & $\alpha=, 05]$ \\
\hline Jahr & $n$ & 1 & 2 & 3 & 4 & $n$ & 1 & 2 & 3 & 4 \\
\hline 2002 & 100 & .277 & & & & 100 & ,277 & & & \\
\hline 2003 & 100 & .289 & .289 & & & 100 & ,289 & & & \\
\hline 2004 & 100 &, 302 &, 302 & & & 100 & .302 & & & \\
\hline 2005 & 100 & &, 338 &, 338 & & 100 & &, 338 & & \\
\hline 2006 & 100 & & & .370 & .370 & 100 & & & .370 & \\
\hline 2008 & 100 & & &, 382 &, 382 & 100 & & & .382 & , 382 \\
\hline 2007 & 100 & & & & , 408 & 100 & & & & ,408 \\
\hline $\mathrm{p}$-Wert & &, 892 &, 165 & ,298 & ,487 & &, 147 & 1,000 & .483 & , 103 \\
\hline
\end{tabular}

Tabelle 25: Einzelvergleiche der SDScores in Abhängigkeit der Zeit

Wird also grds. davon ausgegangen, dass eine Tendenz zu verstärkter Strategieberichterstattung im Laufe des Untersuchungszeitraumes ${ }^{1064}$ besteht - u.U. auch als Folge der Beschäftigung gesetzgebender Institutionen mit der Thematik - so ist der Faktor Zeit konsequenterweise innerhalb regressionsanalytischer Modelle als Kontrollvariable Jahr zu inkludieren. ${ }^{1065}$ Dies wird hier explizit befolgt.

1064 Wohlgemerkt gilt dies auf Basis einer Mittelwertbetrachtung. Wie Anhang 7-1 aufzeigt, lässt sich für einzelne Unternehmen über die Jahre nur ein nahezu konstantes, z.T. sogar sinkendes Niveau der Strategieberichterstattung feststellen, vgl. im Detail Anhang 7-1.

1065 Nicht immer wird in der Literatur für die Zeit kontrolliert, wenngleich dies im Falle von als Querschnittsdaten betrachteten, zeitabhängigen Daten erfolgen sollte, vgl. hier bspw. Gietzman/Ireland (2005) oder Lapointe-Antunes (2006).

Durch die stete Kontrolle für Jahr wird die zeitliche Dimension der in C 3.2.1 erwähnten Panelstruktur der Stichprobe in den Regressionsmodellen konsequent berücksichtigt.

Tom Sieber - 978-3-631-75150-3 


\section{Hypothesenprüfung zu den Bestimmungsfaktoren}

\subsection{Untersuchung einzelner Bestimmungsfaktoren}

Wie Abb. 23 bereits andeutete, ist es das Ziel dieses Abschnitts, das Teilmodell der Bestimmungsfaktoren des Niveaus der Strategieberichterstattung umfassend zu analysieren und in der Folge die dritte der vier Forschungsfragen beantworten zu können. Für eine Beantwortung der Frage nach den Determinanten des Berichtsverhaltens ist im ersten Schritt zu überprüfen, inwieweit einzelne mögliche Bestimmungsfaktoren das Niveau der Strategieberichterstattung zu erklären vermögen. Diese Prüfung erfolgt auf Basis von bivariaten Korrelationsanalysen sowie in einfaktoriellen Versuchsplänen (Ebene 1), anschließend werden relevante Faktoren der jeweiligen Kategorien in partiellen Regressionsmodellen (Ebene 2) zusammengefasst, ehe in Abschnitt D 4.2 sodann eine gesamthafte Prüfung des ersten Teilmodells, d.h. aller Bestimmungsfaktoren simultan, erfolgt (Ebene 3).

\subsubsection{Untersuchung makroökonomischer Bestimmungsfaktoren}

\section{(a) Analyse einzelner makroökonomischer Faktoren}

In der Kategorie der makroökonomischen Bestimmungsfaktoren für das Niveau der Strategieberichterstattung sind zwei Arten von Indikatoren zu prüfen: einerseits der Einfluss der konjunkturellen Bedingungen (H 2.1) und andererseits der Einfluss der jährlichen Entwicklung wesentlicher Kapitalmärkte (H 2.2).

Mit den jährlichen Werten des Bruttoinlandsprodukts Deutschlands, der EU und der OECD liegen drei Indikatoren für die konjunkturellen Bedingungen auf drei unterschiedlichen politisch-ökonomischen sowie geographischen Aggregationsstufen vor, welche annahmegemäß Einfluss auf das Berichtsniveau ausüben. ${ }^{1066}$ Es scheint aufgrund dieser Aggregationslogik sogleich nachvollziehbar, dass die entsprechenden Werte nicht unabhängig voneinander sein können, wie eine bivariate Korrelationsanalyse in Panel A der Tab. 26 auch bestätigt.

1066 Vgl. zu den jeweiligen Mitgliedsstaaten sowie weiteren Details der beiden Institutionen Weidenfeld/Wessels (2006), OECD (2009). Die Akronyme EU bzw. OECD stehen für ,Europäische Union“ und ,Organisation for Economic Co-Operation and Development”. 


\begin{tabular}{|c|c|c|c|c|c|c|}
\hline \multicolumn{7}{|c|}{$\begin{array}{l}\text { Bivariate Korrelationsanalyse einzelner Indikatoren der konjunkturellen Bedingungen. Werte unterhalb der Diagonale stellen die } \\
\text { Komelationskeffizienten nach Pearson. Werte oberhalh der Diagonale die Rang-Korrelationskoeffizienten nach Spearman dar. }\end{array}$} \\
\hline $\mathrm{n}=700$ & & 1 & 2 & 3 & 4 & 5 \\
\hline $1 \mathrm{SDI}$ & $\begin{array}{l}\text { Koeffizient } \\
\text { p-Wert }\end{array}$ & & $\begin{array}{l}, 295 * * * \\
(.()(x))\end{array}$ & $\begin{array}{l}, 289 * * * \\
(.(0)(0))\end{array}$ & $\begin{array}{l}, 198 * * * \\
(.(0)(0))\end{array}$ & $\begin{array}{l}, 289 * * * \\
(.0(0))\end{array}$ \\
\hline 2 BIP DE & $\begin{array}{l}\text { Koeffizient } \\
\text { p-Wert }\end{array}$ & $\begin{array}{l}, 330 * * * \\
(.()(x))\end{array}$ & & $\begin{array}{l}929 * * * \\
(.(0)(0))\end{array}$ & $\begin{array}{l}, 607 * * * \\
(.()(x))\end{array}$ & $\begin{array}{l}, 929 * * * \\
(.(0)(0))\end{array}$ \\
\hline 3 BIP EU & $\begin{array}{l}\text { Koeffizient } \\
\text { p-Wert }\end{array}$ & $\begin{array}{l}.303 * * * \\
(.(\%)(0))\end{array}$ & $\begin{array}{l}, 942 * * * \\
(.)(x))\end{array}$ & & $\begin{array}{l}, 821 * * * \\
(.(O)(0))\end{array}$ & $\begin{array}{l}1,000 * * * \\
(.(0)(0))\end{array}$ \\
\hline 4 BIP OECD & $\begin{array}{l}\text { Koeffizient } \\
\text { p-Wert }\end{array}$ & $\begin{array}{l}.151 * * * \\
(.(K)())\end{array}$ & $\begin{array}{l}, 452 * * * \\
(.0(0))\end{array}$ & $\begin{array}{l}, 718^{* * * *} \\
(.(0)(0))\end{array}$ & & $\begin{array}{l}, 821 * * * \\
(.0(0))\end{array}$ \\
\hline 5 Faktor & $\begin{array}{l}\text { Koeffizient } \\
\text { p-Wert }\end{array}$ & $\begin{array}{l}, 296 * * * \\
(.(0)(0))\end{array}$ & $\begin{array}{l}, 905 * * * \\
(.(x)())\end{array}$ & $\begin{array}{l}, 994 * * * \\
(.00(0))\end{array}$ & $\begin{array}{l}, 787 * * * \\
(.0(0))\end{array}$ & \\
\hline
\end{tabular}

Panel B: Faktorenanalyse zur Extraktion eines Faktors der konjunkturellen Bedingungen

raktorenanalyse der in P'anel $\Lambda$ gekennzeichneten drei makrö̈konomischen Indikatoren nach der Methode der Hauptkomponentenanalyse

\begin{tabular}{|c|c|c|c|c|c|c|}
\hline \multicolumn{4}{|c|}{ Prïfgrößen } & \multicolumn{3}{|c|}{ Erklärte Gesamtvarianz } \\
\hline \multicolumn{2}{|l|}{$\mathrm{KMO}$} & \multicolumn{2}{|c|}{ Bartlett-Test } & Komp. & $\begin{array}{l}\text { Summe quadrierter } \\
\text { Faktorladungen }\end{array}$ & $\begin{array}{c}\text { Prozent } \\
\text { der Varianz }\end{array}$ \\
\hline \multirow[t]{3}{*}{ MSA } & ,359 & $\mathrm{Chi}^{2}$ & $3.815,6$ & 1 & 2,427 & 80,886 \\
\hline & & $\mathrm{df}$ & 3 & 2 & & \\
\hline & & p-Wert & $.000 * * *$ & 3 & & \\
\hline
\end{tabular}

\section{Tabelle 26: Bivariate Analyse der konjunkturellen Indikatoren}

Darüber hinaus offenbart Tab. 26 einen gleichgerichteten und signifikanten $\mathrm{Zu}$ sammenhang der makroökonomischen Indikatoren mit SDIndex. Um dies abzubilden, werden die drei Indikatoren mit Hilfe einer Faktorenanalyse zu einem gemeinsamen Faktor der konjunkturellen Bedingungen verdichtet, der im weiteren Verlauf der Hypothesenprüfung zu verwenden ist. ${ }^{1067}$ Jener extrahierte Faktor ist in der Lage, immerhin rund $80 \%$ der Varianz der Konjunkturdaten zu erklären.

Eine vergleichbare Vorgehensweise bietet sich ebenfalls für die Indikatoren der Kapitalmarktbedingungen an. Neben den Indexdaten der wesentlichen deutschen Auswahlindizes der Dt. Börse AG liegen Daten für den europäischen Auswahlindex EuroStoxx sowie den US-amerikanischen Leitindex Dow Jones Industrial

1067 Dies erfolgt, obwohl der hier ermittelte Wert MSA=,359 als nur knapp ausreichend zu beurteilen ist. Sachlogisch scheint ein Indikator für ein ,Welt-BIP', der die deutsche und die europäische Perspektive stärker gewichtet, aus Sicht dt. Unternehmen aber sinnvoll. 
Average vor. ${ }^{1068}$ Wie Tab. 27 aufzeigt, weisen jene Indexgrößen nicht nur untereinander, sondern auch mit SDIndex gleichgerichtete Zusammenhänge auf.

\begin{tabular}{|c|c|c|c|c|c|c|c|c|c|c|}
\hline \multicolumn{11}{|c|}{$\begin{array}{l}\text { Bivariate Korrelationsanalyse einzelner Indikatoren der Kapitalmarktbedingungen. Werte unterhalb der Diagonale stellen dic } \\
\text { Korreiationskoeffizienten nach Pearson, Werte oberhalb der Diagonale die Rang-Korrelationskoeffizienten nach Spearman dar. }\end{array}$} \\
\hline & 700 & & 1 & 2 & 3 & 4 & 5 & 6 & 7 & 8 \\
\hline 1 & SDI & $\begin{array}{l}\text { Koeffizient } \\
\text { p-Wert }\end{array}$ & & $\begin{array}{l}, 344 * * * \\
(, 000)\end{array}$ & $\begin{array}{l}, 344 * * * \\
(.000)\end{array}$ & $\begin{array}{l}.281 * * * \\
(.000)\end{array}$ & $\begin{array}{l}, 241 * * * \\
(, 000)\end{array}$ & $\begin{array}{l}, 247 * * * \\
(.000)\end{array}$ & $\begin{array}{l}, 224 * * * \\
(.000)\end{array}$ & $\begin{array}{l}, 247 * * * \\
(,(0)(0))\end{array}$ \\
\hline 2 & Dax & $\begin{array}{l}\text { Koeffizient } \\
\text { p-Wert }\end{array}$ & $\begin{array}{l}, 337 * * * \\
(, 000)\end{array}$ & & $\begin{array}{l}1,00 * * * \\
(, 000)\end{array}$ & $\begin{array}{l}, 929 * * * \\
(.000)\end{array}$ & $\begin{array}{l}, 857^{* * *} \\
(.000)\end{array}$ & $\begin{array}{l}, 893^{* * *} \\
(, 000)\end{array}$ & $\begin{array}{l}, 821 * * * \\
(, 000)\end{array}$ & $\begin{array}{l}, 893 * * * \\
(, 000)\end{array}$ \\
\hline 3 & MDax & $\begin{array}{l}\text { Koeffizient } \\
\text { p-Wert }\end{array}$ & $\begin{array}{l}, 319 * * * \\
(.000)\end{array}$ & $\begin{array}{l}, 975 * * * \\
(, 000)\end{array}$ & & $\begin{array}{l}, 929 * * * \\
(.000)\end{array}$ & $\begin{array}{l}, 857 * * * \\
(.000)\end{array}$ & $\begin{array}{l}, 893 * * * \\
(, 000)\end{array}$ & $\begin{array}{l}, 821 * * * \\
(, 000)\end{array}$ & $\begin{array}{l}, 893 * * * \\
(, 000)\end{array}$ \\
\hline 4 & SDax & $\begin{array}{l}\text { Koeffizient } \\
\text { p-Wert }\end{array}$ & $\begin{array}{l}, 283 * * * \\
(.000)\end{array}$ & $\begin{array}{l}, 927 * * * \\
(.000)\end{array}$ & $\begin{array}{l}, 985 * * * \\
(.000)\end{array}$ & &, $857 * * *$ & $\begin{array}{l}, 929 * * * \\
(.000)\end{array}$ & $\begin{array}{l:}, 893 * * * * \\
(, 000)\end{array}$ & $\begin{array}{l}, 929 * * * \\
(.000))\end{array}$ \\
\hline 5 & TecDax & $\begin{array}{l}\text { Koeffizient } \\
\text { p-Wert }\end{array}$ & $\begin{array}{l}, 300 * * * \\
(, 000)\end{array}$ & $\begin{array}{l}, 975 * * * \\
(, 000)\end{array}$ & $\begin{array}{l}, 929 * * * \\
(.000)\end{array}$ & $\begin{array}{l}, 883 * * * \\
(.000)\end{array}$ & & $\begin{array}{l}, 964 * * * \\
(, 000)\end{array}$ & $\begin{array}{l:}, 893 * * * \\
(.000)\end{array}$ & $\begin{array}{l}, 964 * * * \\
(.000)\end{array}$ \\
\hline 6 & $\begin{array}{l}\text { Euro- } \\
\text { Stoxx }\end{array}$ & $\begin{array}{l}\text { Koeffizient } \\
\text { p-Wert }\end{array}$ & $\begin{array}{l}, 252 * * * \\
(.000)\end{array}$ & $\begin{array}{l}, 924 * * * \\
(.000)\end{array}$ & $\begin{array}{l}, 953 * * * \\
(.000)\end{array}$ & $\begin{array}{l}, 962 * * * \\
(.000)\end{array}$ & $\begin{array}{l}, 927 * * * \\
(.000)\end{array}$ & & \begin{tabular}{l}
, $964 * * *$ \\
\hdashline .000$)$
\end{tabular} & $\begin{array}{l}1,00 * * * \\
(, 0(0))\end{array}$ \\
\hline 7 & $\begin{array}{l}\text { Dow- } \\
\text { Jones }\end{array}$ & $\begin{array}{l}\text { Koeffizient } \\
\text { p-Wert }\end{array}$ & $\begin{array}{l}, 216 * * * * \\
(.000)\end{array}$ & $\begin{array}{l}875 \text { *** } \\
(.000) \\
\ldots \ldots\end{array}$ & $\begin{array}{l}, 888 * * * \\
(, 000) \\
\ldots \ldots \ldots \ldots\end{array}$ & $\begin{array}{l}, 901 * * * \\
(, 000)\end{array}$ & $\begin{array}{l}, 928 * * * \\
(, 000) \\
\ldots \ldots \ldots . . . .\end{array}$ & $\begin{array}{l}, 947 * * * \\
(.000) \\
. \ldots \ldots \ldots . . .\end{array}$ & & $\begin{array}{l}, 964 * * * \\
(.000)\end{array}$ \\
\hline 8 & Faktor & $\begin{array}{l}\text { Koeffizient } \\
\text { p-Wert }\end{array}$ & $\begin{array}{l}, 293 * * * \\
(.000)\end{array}$ & $\begin{array}{l}, 974 * * * \\
(.000)\end{array}$ & $\begin{array}{l}, 984 * * * \\
(, 000)\end{array}$ & $\begin{array}{l}, 971 * * * \\
(, 000)\end{array}$ & $\begin{array}{l}, 968^{* * *} \\
(.000)\end{array}$ & $\begin{array}{l}, 980 * * * \\
(, 000)\end{array}$ & $\begin{array}{l}, 950 * * * \\
(.000)\end{array}$ & \\
\hline
\end{tabular}

\section{Tabelle 27: Bivariate Analyse der Kapitalmarktindikatoren}

Vorstehende Tab. 27 offenbart zudem eindrücklich, wie gleichgerichtet sich der deutsche, der europäische sowie der US-amerikanische Aktienmarkt entwickeln. Es scheint daher sinnvoll, auch für die Indikatoren der Kapitalmarktbedingungen mittels einer Faktorenanalyse eine Verdichtung der Informationen vorzunehmen. Die Durchführung einer Faktorenanalyse präsentiert nachfolgende Tab. 28. Der auf diesem Wege extrahierte Faktor erklärt über 94\% der Gesamtvarianz und bestätigt somit die Sinnhaftigkeit einer Faktorextraktion. ${ }^{1069}$

1068 Der europäische Auswahlindex EuroStoxx 50 (EuroStoxx) umfasst die 50 nach Marktkapitalisierung größten börsennotierten Unternehmen innerhalb der Mitgliedsstaaten der Europäischen Währungsunion. Der amerikanische Dow Jones Industrial Average (Dow Jones) beinhaltet die 30 größten an der New Yorker NYSE notierten Unternehmen.

1069 Als sachlogische Begründung soll erneut dienen, dass sich Manager dt. Unternehmen falls Kapitalmarktbedingungen Einfluss auf das Berichtsverhalten haben - nicht nur auf den dt. Aktienmarkt konzentrieren werden, sondern gleichfalls die Bedingungen auf den europäischen und US-amerikanischen Aktienmärkten beachten werden. 
Faktorenanalyse zur Extraktion eines Faktors der Kapitalmarktbedingungen

laaktorenanalyse der in Tab. 27 gekennzeichneten Indikatoren der Kapitalmarktbedingungen nach der Methode der Haupkomponentenanalyse

\section{Prüfgrößen}

$\frac{\text { KMO }}{\text { MSA } \quad, 545} \frac{\text { Bartlett-Test }}{\text { Chi }^{2} \quad 16.677,9}$

df

p-Wert
Erklärte Gesamtvarianz

\begin{tabular}{|c|c|c|}
\hline Komp. & $\begin{array}{l}\text { Summe quadrierter } \\
\text { Faktorladungen }\end{array}$ & $\begin{array}{c}\text { Prozent } \\
\text { der Varianz }\end{array}$ \\
\hline 1 & 5,661 & 94,350 \\
\hline$\ldots$ & & \\
\hline 6 & & \\
\hline
\end{tabular}

Tabelle 28: Faktorenanalyse der Kapitalmarktindikatoren

Nachdem mit den extrahierten Faktoren geeignete Größen zur Prüfung des Einflusses der makroökonomischen Rahmenbedingungen auf das Strategieberichtsverhalten vorliegen, kann die Durchführung einer Regressionsanalyse erfolgen.

\section{(b) Partielles Regressionsmodell der makroökonomischen Faktoren}

Wie im Untersuchungsplan in Tab. 10 bereits angekündigt, werden die Faktoren des makroökonomischen Umfeldes mit einem partiellen Regressionsmodell zusammengefasst, um potenzielle Überlappungen zwischen den beiden Faktoren zu eliminieren. Dieses partielle Regressionsmodell ist in Tab. 29 als Modell 4 dargestellt, die zusätzlich enthaltenen Modelle zeigen Einfachregressionen der beiden Einzelfaktoren auf - zur Sicherstellung der Robustheit der Berechnungen.

Regressionsanalyse zum Einfluss makroökonomischer Bedingungen auf die Strategieberichterstattung

$F(x)=$ Niveau der Strategieberichterstattung

\begin{tabular}{|c|c|c|c|c|c|c|c|c|}
\hline & \multicolumn{2}{|c|}{$\begin{array}{l}\text { Modell 1: } \\
\text { Konjunktur }\end{array}$} & \multicolumn{2}{|c|}{$\begin{array}{c}\text { Modell 2: } \\
\text { Kapitalmärkte }\end{array}$} & \multicolumn{2}{|c|}{$\begin{array}{c}\text { Modell 3: } \\
\text { Makroökonomik }\end{array}$} & \multicolumn{2}{|c|}{$\begin{array}{c}\text { Modell 4: } \\
\text { Partialmodell }\end{array}$} \\
\hline & Koeff. $\beta$ & $\mathrm{p}$ & Koeff. $\beta$ & $\mathrm{p}$ & Koeff. $\beta$ & $\mathrm{p}$ & Koeff. $\beta$ & $\mathrm{p}$ \\
\hline \multicolumn{9}{|c|}{ Makroökonomische Faktoren (+) } \\
\hline Konjunktur [Faktor] &, $287 * * *$ & $(.0(0))$ & & &, $157 * *$ & $(.021)$ & ,011 n.s. & $(.881)$ \\
\hline Börsenentwicklung [ & ktor] & &, $286 * * *$ & $(.(0)(0))$ &, $153 * *$ & $(.(025)$ &, $117^{*}$ & $(.(079)$ \\
\hline \multicolumn{9}{|l|}{ Kontrollvariablen } \\
\hline Konstante & & $(.()(x))$ & & $(.()(0))$ & & $(.(x)(x))$ & & $(.()(x))$ \\
\hline Jahr & & & & & & &, $274 * * *$ & $(.0(0))$ \\
\hline$R^{2}$ &, 082 & & ,082 & & ,089 & &, 132 & \\
\hline$R^{2} a d j$ &, $081 * * *$ & $(.(K)(x))$ &, $080 * * *$ & $(.(0)(0))$ &, $086 * * *$ & $(.(x))$ &, $128 * * *$ & $(.(0)(0))$ \\
\hline Durbin Watson $d$ & 1,823 & & 1,819 & & 1,834 & & 1,923 & \\
\hline$n\left(n_{\max }=700\right)$ & 700 & & 700 & & 700 & & 700 & \\
\hline
\end{tabular}


Die in Tab. 29 dargestellten Regressionsanalysen verdeutlichen schließlich, dass sowohl der Faktor der konjunkturellen Bedingungen als auch der zweite Faktor der Börsenentwicklung in bivariaten Regressionsanalysen deutliche und positive Zusammenhänge mit der zentralen Untersuchungsvariablen SDIndex aufweisen, wie es im Rahmen der Hypothesenformulierung auch unterstellt wurde. Die $\mathrm{Zu}$ sammenhänge schwächen sich im gemeinsamen Modell 3 jedoch ab, da der extrahierte Faktor der konjunkturellen Bedingungen sowie der Faktor der Börsenentwicklung untereinander hoch korreliert sind. ${ }^{1070}$

Wie das eigentliche Partialmodell, Modell 4 in Tab. 29, weiterhin aufzeigt, sind beide Faktoren zudem mit der Kontrollvariablen Jahr verknüpft, so dass sich der Einfluss der Faktoren im für die Zeit kontrollierten Falle weitgehend auflöst. ${ }^{1071}$

Nichtsdestotrotz gelingt es dem Faktor der Börsenentwicklung weiterhin, einen eigenen, signifikanten Beitrag zur Erklärung des Niveaus der Strategieberichterstattung zu leisten, daher wird dieser im Rahmen der folgenden Untersuchungen als der maßgebliche Indikator für das jeweilige makroökonomische Umfeld verwendet. In Summe kann mit Hilfe dieses einzelnen Faktors sowie der Kontrollvariablen Jahr ein Anteil an der Gesamtvarianz des Niveaus der Strategieberichtrichterstattung von nahezu $13 \%$ erklärt werden, wie Modell 4 offenbart. ${ }^{1072}$

Im weiteren Verlauf der Auswertungen könnte auf die Berücksichtigung makroökonomischer Faktoren verzichtet werden, weil diese bereits durch die Kontrollvariable Jahr repräsentiert werden. Dennoch wird aufgrund der dargestellten Ergebnisse der Faktor der Börsenentwicklung innerhalb der Analysen inkludiert.

1070 Vgl. zum Korrelationskoeffizienten der beiden makroökonomischen Faktoren auch den Anhang 13 der vorliegenden Arbeit, Feld 31/30.

Der Nachweis dieses Zusammenhangs stellt ein interessantes Nebenergebnis der Untersuchung dar. Zum Zusammenhang von Aktienmärkten, Konjunktur und Arbeitsmärkten vgl. bspw. die ausführliche Untersuchung von Kappler/Westerheide (2003).

1071 Die separat durchgeführte Einfachregression von SDIndex auf die Kontrollvariable Jahr errechnet ein korrigiertes Bestimmtheitsmaß von ca. $12 \%$, folglich ist hier ein originärer Einfluss der interessierenden Variablen sichergestellt, der gleichwohl sehr gering ist.

1072 Diese Ergebnisse sind konform mit empirischen Arbeiten, die einen Einfluss der makroökonomischen Bedingungen auf die Prognoseberichterstattung im dt. Lagebericht feststellen, bspw. jüngst Knauer/Wömpener (2010), S. 92. 


\subsubsection{Untersuchung der Unternehmenscharakteristika}

\section{(a) Analyse der Einzelfaktoren der Unternehmenscharakteristika}

Innerhalb der Kategorie der Unternehmenscharakteristika werden in Summe vier Einzelfaktoren unterschieden, die das Niveau der Strategieberichterstattung u.U. systematisch determinieren: Dies sind neben der Größe eines Unternehmens und Unternehmensstammdaten wie der Branchenzugehörigkeit bzw. dem Alter auch Aspekte der Rechnungslegungspraxis sowie Persönlichkeitsmerkmale des CEO. Als Indikatoren für die Unternehmensgröße (H 2.3) stehen in Summe drei Parameter zur Verfügung: Das jährliche Umsatzvolumen, die Anzahl der Mitarbeiter sowie die Bilanzsumme. Die einzelnen (logarithmierten) Indikatoren sind nicht nur mit SDIndex hoch korreliert, sondern können auch - wie Tab. 30 aufzeigt als nahezu perfekte Substitute füreinander angesehen werden, daher empfiehlt es sich, diese zu einem Faktor zu verdichten. Die Extraktion des Faktors der Größe, der nachfolgend verwendet wird, ist ebenfalls Tab. $30 \mathrm{zu}$ entnehmen.

\begin{tabular}{|c|c|c|c|c|c|c|c|}
\hline \multicolumn{8}{|c|}{ Panel A: Korrelationsanalyse der Indikatoren der Unternehmensgröße } \\
\hline \multicolumn{8}{|c|}{$\begin{array}{l}\text { Bivariate Korrelationsanalyse einzelner Indikatoren der Untemehmensgröße. Werte unterhalb der Diagonale stellen die } \\
\text { Korrelationskoeffizienten nach Pearson. Werte oberhalb der Diagonale dic Rang-Korrelationskoeffizienten nach Spearman dar. }\end{array}$} \\
\hline & 700 & & 1 & 2 & 3 & 4 & 5 \\
\hline \multirow[t]{2}{*}{1} & SDI & Koeffizient & &, $386 * * *$ &, $345 * * *$ &, $428 * * *$ &, $385 * * *$ \\
\hline & & p-Wert & & $(.(0)(x))$ & $(.0(0))$ & $(.00(0))$ & $(.()(0))$ \\
\hline \multirow[t]{2}{*}{2} & Umsatz & Koeffizient &, $401 * * *$ & &, $933 * * *$ &, $971 * * *$ &, $985 * * *$ \\
\hline & (Ln) & p-Wert & $(.(K)(X))$ & & $(.000)$ & $(.(x(x))$ & $(.(0)(x))$ \\
\hline \multirow[t]{2}{*}{3} & Mitarbeiter & Koeffizient &, $380 * * *$ &, $946 * * *$ & &, $929 * * *$ &, $968 * * *$ \\
\hline & (Ln) & p-Wert & $(.(O)(0))$ & $(.0(0))$ & & $(.(0(0))$ & $(.(0)(0))$ \\
\hline \multirow[t]{2}{*}{4} & Bilanzsumme & Koeffizient &, $457 * * *$ &, $967 * * *$ &, $929 * * *$ & &, $979 * * *$ \\
\hline & (Ln) & p-Wert & $(.(O)(0))$ & $(.(K)())$ & $(.()(X))$ & & $(.(x)(0))$ \\
\hline \multirow[t]{2}{*}{5} & Faktor & Koeffizient &, $414 * * *$ &, $989 * * *$ &, $968 * * *$ &, $978 * * *$ & \\
\hline & & p-Wert & $(.0(0))$ & $(.(O)(X))$ & $(.0(0))$ & $(.000)$ & \\
\hline
\end{tabular}

Panel B: Faktorenanalyse zur Extraktion eines Faktors der Unternehmensgröße

Faktorenanalyse der in Panel $\Lambda$ gekennzeichneten Indikatoren der UntemehmensgröBe nach der Methode der Hauptkomponentenanalyse

\begin{tabular}{|c|c|c|c|c|c|c|}
\hline \multicolumn{4}{|c|}{ Prüfgrößen } & \multicolumn{3}{|c|}{ Erklärte Gesamtvarianz } \\
\hline \multicolumn{2}{|l|}{ KMO } & \multicolumn{2}{|c|}{ Bartlett-Test } & Komp. & $\begin{array}{l}\text { Summe quadrierter } \\
\text { Faktorladungen }\end{array}$ & $\begin{array}{c}\text { Prozent } \\
\text { der Varianz }\end{array}$ \\
\hline \multirow[t]{3}{*}{ MSA } & .764 & $\mathrm{Chi}^{2}$ & $3.478,2$ & 1 & 2,894 & 96,454 \\
\hline & & df & 3 & 2 & & \\
\hline & & p-Wert &, $000 * * *$ & 3 & & \\
\hline
\end{tabular}


Wie bereits in Abschnitt C 3.2.1 angemerkt, stellt die Branchenzugehörigkeit ein eindeutiges Differenzierungskriterium der Merkmalsträger dar. ${ }^{1073}$ Es ist folglich zu untersuchen, ob dieses Merkmal zudem signifikanten Einfluss auf das Niveau der Strategieberichterstattung ausübt (H 2.4a). Zur Operationalisierung der Zugehörigkeit zu einer Branche liegt zunächst ein dichotomer Indikator vor, der die Branchensektoren entsprechend der Systematik der Dt. Börse AG in ,Klassische Branchen' oder ,Technologiebranchen' unterscheidet. ${ }^{1074}$ Zur Überprüfung eines Einflusses dieser sog. Branchenausrichtung auf das Niveau der Strategieberichterstattung ist insofern ein t-Test zu verwenden, den Tab. 31 zeigt. Es wird offensichtlich, dass zwar Unterschiede der Mittelwerte bzw. Varianzen der SDScores vorhanden sind, jedoch lediglich die Nullhypothese der Varianzhomogenität der Stichproben bei einem $\mathrm{p}$-Wert von $\mathrm{p}=, 018$ abgelehnt werden kann. Ein eindeutig signifikanter Mittelwertunterschied zeigt sich dagegen nicht, wenngleich festzustellen bleibt, dass eher technologieorientierte Sektoren im Durchschnitt ein vergleichsweise niedrigeres sowie geringer streuendes Niveau der Strategieberichterstattung aufweisen als die eher als klassisch zu charakterisierenden Branchen.

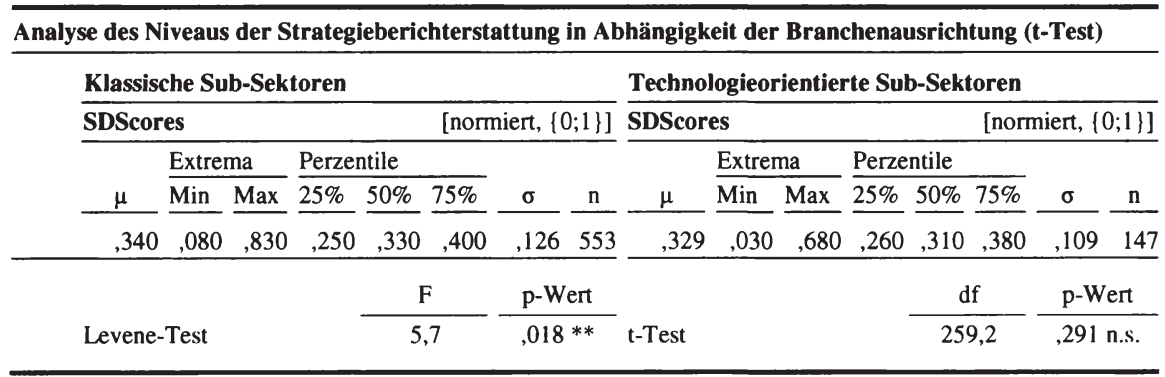

Tabelle 31: Einfluss der Branchenausrichtung auf das Berichtsverhalten

Das Ergebnis klingt auf den ersten Blick überraschend, weil intuitiv zu erwarten gewesen wäre, dass es primär technologieorientierte (und somit zumeist jüngere)

1073 Es sei verwiesen auf Tab. 15 (S. 252), die die Branchenstruktur der Stichprobe gem. der Systematik der Dt. Börse AG zeigt. Weitere Details sind in Anhang 2 bzw. 3 enthalten.

1074 Es wurde bereits erläutert, dass die Dt. Börse AG ein dreistufiges System zur Branchensystematisierung definiert: Neun Super-Sektoren untergliedern sich in 18 Sektoren, die wiederum in 63 Sub-Sektoren heruntergebrochen werden könnten. Diese Sub-Sektoren bilden sodann die Basis für eine dichotome Eingruppierung in klassische sowie technologieorientierte Branchen, vgl. Dt. Börse AG (2009a), S. 51ff.; Anhang 2 dieser Arbeit.

Tom Sieber - 978-3-631-75150-3 
Unternehmen sein würden, die tendenziell freigiebig über Aspekte ihrer Unternehmensstrategie berichten. ${ }^{1075}$ Gegensätzlich dazu könnte jedoch auch vermutet werden, dass Unternehmen in Branchen, in denen technologische Aspekte hohe Bedeutung zur Absicherung der eigenen Wettbewerbsposition besitzen, eher darauf bedacht sind, den Wettbewerbern keine verwertbaren Angaben im Rahmen der Berichterstattung zur Verfügung zu stellen. ${ }^{1076}$

Weiterhin kann die Branchenzugehörigkeit der Unternehmen in inhaltlicher Hinsicht unterschieden werden, hierzu können die bereits dargestellten neun SuperSektoren der Dt. Börse AG verwendet werden. Zur statistischen Prüfung kommt daher die einfaktorielle Varianzanalyse in Betracht, die Resultate zeigt Tab. 32.

Panel A: Analyse der Strategieberichterstattung in Abhängigkeit der Branchenzugehörigkeit (ANOVA)

\begin{tabular}{|c|c|c|c|c|c|}
\hline & Quadratsumme & df & $\begin{array}{l}\text { Quadrierte } \\
\text { Mittelwerte }\end{array}$ & $\mathbf{F}$ & p-Wert \\
\hline Zwischen den Gruppen & .670 & 7 & 096 & 6,7 &, $000 * * *$ \\
\hline Innerhalb der Gruppen & 9,836 & 692 &, 014 & & \\
\hline Total & 10,505 & 699 & & & \\
\hline
\end{tabular}

Panel B: Einzelvergleiche zur Branchenzugehörigkeit (Post Hoc-Tests)

\begin{tabular}{|c|c|c|c|c|c|c|c|}
\hline [SDScores, $\{0 ; 1]$ & Scheffé & & {$[\alpha=, 05]$} & Walle & Incan & & {$[\alpha=, 05]$} \\
\hline Branche & $\mathrm{n}$ & 1 & 2 & $n$ & 1 & 2 & 3 \\
\hline Information Technology & 63 &, 302 & & 63 & ,302 & & \\
\hline Consumer Services & 63 &, 302 & & 63 & ,302 & & \\
\hline Consumer Goods & 126 &, 316 & & 126 & ,316 & & \\
\hline Industrials & 273 &, 335 & ,335 & 273 & ,335 & .335 & \\
\hline Pharma \& Healthcare & 77 &, 367 &, 367 & 77 &, 367 &, 367 & \\
\hline Basic Materials & 63 & &, 390 & 63 & & ,390 & ,390 \\
\hline Utilities & 21 & & ,397 & 21 & & ,397 & ,397 \\
\hline Telecommunication & 14 & &, 436 & 14 & & &, 436 \\
\hline $\mathrm{p}$-Wert & & 066 & ,436 & & & & \\
\hline
\end{tabular}

Tabelle 32: Einfluss der Branchenzugehörigkeit auf das Berichtsverhalten

Wie dieser Tab. zu entnehmen ist, bestehen signifikante Unterschiede zwischen den einzelnen Gruppen, welche anhand der Branchenzugehörigkeit determiniert

1075 Das Unternehmensalter wird nachfolgend noch spezifisch untersucht, vgl. S. $272 \mathrm{ff}$.

1076 Diese Argumentation folgt einer vielfach geäußerten Annahme in der Literatur, vgl. für einen empirischen Beleg im Hinblick auf die sog. ,New Economy' Günther et al. (2003) bzw. die Diskussion der Wettbewerbssensitivität strategieorientierter Inhalte in B 2.3.3. 
werden. Eine weitergehende Untersuchung in Form von Einzelvergleichen zeigt, dass entsprechend dem durchschnittlichen Niveau der Strategieberichterstattung zwei bzw. drei Gruppen von Branchen differenziert werden können. Bemerkenswert ist dabei, dass insb. Unternehmen der sog. Versorgungs- sowie Grundstoffindustrien hohe SDScores aufweisen, während die Unternehmen der Fertigungsindustrien im Durchschnitt ein niedrigeres Niveau der Strategieberichterstattung wählen. ${ }^{1077}$ Wie zuvor bereits geschlussfolgert zeigt sich in jener Analyse zudem erneut, dass Technologieunternehmen im Vergleich ein eher niedrigeres Niveau der Strategieberichterstattung aufweisen.

Es ist auf Grundlage der aufgezeigten Ergebnisse schließlich davon auszugehen, dass die Branchenzugehörigkeit signifikanten Einfluss auf die Strategieberichterstattung ausübt. Um diesen Einfluss im Rahmen einer regressionsanalytischen Untersuchung prüfen bzw. um die kategoriale Variable der Branchenzugehörigkeit in eine Regressionsanalyse aufnehmen zu können, sind deren Ausprägungen in Form von Dummy-Variablen zu kodieren. ${ }^{1078} \mathrm{Da}$ in Summe acht Branchen zu unterscheiden sind, ist eine Kodierung von insg. sieben Dummy-Variablen notwendig: ,a categorial variable with $\mathrm{j}$ categories requires $\mathrm{j}-1$ dummy variables in order to capture all the distributional information contained in the original set of distinctions. “" ${ }^{1079}$ Diejenige Ausprägung der kategorialen Variablen, die nicht als eigene Dummy-Variable kodiert wird, stellt eine Referenzgruppe dar, ermittelte Regressionskoeffizienten sind stets in Relation zu dieser zu interpretieren. ${ }^{1080}$

1077 Als Versorgungs- und Grundstoffindustrien werden im Einzelnen die Branchen ,Pharma \& Healthcare', ,Basic Materials', ,Utilities“ und ,Telecommunication ‘ gezählt.

1078 Einen umfassenden Überblick zur Durchführung von „Multiple regression analysis with qualitative information" liefert Wooldridge (2009), S. 225ff.

1079 Hardy (1993), S. 7f. Dummy-Variablen liegen grds. nur in dichotomer Ausprägung vor: „Using binary coding, dummy variables are always dichotomous variables.“ Daher wird auch die Bezeichnung „,binary variables“ verwendet, so bei Wooldridge (2009), S. 225.

Für j Kategorien sind nur j-1 Dummy-Variablen erforderlich, weil mit diesen jede Ausprägung der originären Variablen abgebildet werden kann. Würden hingegen $\mathrm{j}$ DummyVariablen kodiert, wäre perfekte Multikollinearität gegeben, da jede beliebige DummyVariable eine perfekte Linearkombination aller anderen Variablen wäre, insofern wären die Informationen vollkommen redundant. Im Detail auch Wooldridge (2009), S. $235 f$.

1080 Vgl. hierzu Hardy (1993), S. 9: ,regression coefficients [...] will be evaluated relative to this single reference group.“ Wooldridge (2009), S. 235 nennt dies die „base group“. 
Als Referenzgruppe der Dummy-Kodierung der Branchenzugehörigkeit soll hier die Branche ,Telecommunication ' gewählt werden, die den höchsten Mittelwert aller Sektoren aufweist. Folglich müssten im Rahmen einer Regressionsanalyse die anderen Sektoren grds. negative Regressionskoeffizienten hervorbringen.

Als weiteres Unternehmensstammdatum - neben einer Branchenzugehörigkeit kann zudem das Unternehmensalter angesehen werden (H 2.4b). Es stellt für die Unternehmen eine fixe Größe dar, die nicht nur nicht manipulierbar ist, sondern der außerdem ein Einfluss auf die Unternehmenskultur sowie das -verhalten und damit auch auf das Berichtsverhalten zugeschrieben werden kann. Folglich sind die Unternehmen in der Untersuchungsstichprobe anhand der jahresspezifischen Quartile in vier Altersklassen einzuteilen und auf dieser Basis eine einfaktorielle Varianzanalyse durchzuführen, um einen Einfluss des Alters auf die Strategieberichterstattung statistisch abzuklären. Die Ergebnisse präsentiert Tab. 33.

\begin{tabular}{|c|c|c|c|c|c|}
\hline & Quadratsumme & df & $\begin{array}{l}\text { Quadrierte } \\
\text { Mittelwerte }\end{array}$ & $\mathbf{F}$ & p-Wert \\
\hline Zwischen den Gruppen &, 251 & 3 & .084 & 5,6 &, $001^{* * *}$ \\
\hline Innerhalb der Gruppen & 10,255 & 696 & 015 & & \\
\hline Total & 10.505 & 699 & & & \\
\hline
\end{tabular}

Panel B: Einzelvergleiche zum Unternehmensalter (Post Hoc-Tests)

\begin{tabular}{|c|c|c|c|c|c|c|}
\hline [SDScores, $\{0: 1\}]$ & Scheffé & & {$[\alpha=, 05]$} & Waller & can & {$[\alpha=, 05]$} \\
\hline Altersklasse & $\mathrm{n}$ & 1 & 2 & $\mathrm{n}$ & 1 & 2 \\
\hline Altersklasse 2 (<50\% Perzentil) & 168 &, 306 & & 168 & ,306 & \\
\hline Altersklasse $4 \quad(>75 \%$ Perzentil) & 168 & &, 343 & 168 & &, 343 \\
\hline Altersklasse 3 (<75\% Perzentil) & 182 & &, 345 & 182 & &, 345 \\
\hline Altersklasse $1 \quad(<25 \%$ Perzentil) & 182 & &, 356 & 182 & & ,356 \\
\hline p-Wert & & 1.000 & ,795 & & & \\
\hline
\end{tabular}

Tabelle 33: Einfluss des Unternehmensalters auf das Berichtsverhalten

Aufgrund der Resultate könnte davon ausgegangen werden, dass das Alter eines Unternehmens Einfluss auf die Strategieberichterstattung ausübt. Außerdem bestätigen die ergänzend berechneten Einzelvergleiche in Tab. 33, dass die jungen Unternehmen zwar im Durchschnitt die höchsten Scores erreichen, allerdings ist dieser Unterschied nicht statistisch signifikant. Signifikante Differenzen ergeben 
sich dagegen bei Unternehmen der zweiten Altersklasse. Da dieses Ergebnis als Indikation dafür anzusehen ist, dass das Unternehmensalter Einfluss auf das Berichtsverhalten ausübt, ist dieses - als Dummy-kodierte Variable - gleichfalls in nachfolgende Regressionsanalysen mit einzubeziehen. ${ }^{1081}$

Der dritte Einzelfaktor der Unternehmenscharakteristika behandelt Aspekte der Rechnungslegung (H 2.5). Vermutet wurde, dass die Unternehmen mit eher progressiver ,Rechnungslegungspraxis“ ein höheres Niveau der Strategieberichterstattung aufweisen. Dazu sind drei Indikatoren verfügbar: Zunächst ist die sog. Rechnungslegungs-Philosophie, konkretisiert durch den Wechselzeitpunkt eines Unternehmens von einer HGB-Rechnungslegung auf internationale Rechnungslegungsstandards, zu prüfen, die dichotom kodiert vorliegt. ${ }^{1082}$ Zudem erfolgt die Kategorisierung der Unternehmen gemäß der in den Jahren des Untersuchungszeitraums jeweils angewandten Rechnungslegungsstandards sowie abschließend die Prüfung des Einflusses des mandatierten Abschlussprüfers auf das Strategieberichtsverhalten, beide ebenfalls kodiert als dichotome Variablen. ${ }^{1083}$

Aus den vorhergehenden Ausführungen erschließt sich, dass eine Untersuchung der drei einzelnen Aspekte auf Basis spezifischer t-Tests erfolgen kann. Geprüft wird sodann die Nullhypothese, dass zwischen den jeweils definierten Gruppen keine signifikanten Unterschiede bestehen. Die Resultate der Tests zeigt Tab. 34. Dieser ist zu entnehmen, dass die Kategorisierung der Stichproben-Unternehmen anhand des Kriteriums des angewendeten Rechnungslegungsstandards wie auch anhand der mandatierten Prüfungsgesellschaft Gruppen beschreibt, deren Mittelwerte signifikant unterschiedlich sind. In beiden Fällen weist jeweils die Gruppe der Unternehmen mit progressiver Rechnungslegungspraxis ein deutlich höheres Berichtsniveau auf. Keinen Einfluss auf das Berichtsverhalten der Unternehmen

1081 Als Referenzkategorie wird dabei die Gruppe der ältesten Unternehmen bestimmt.

1082 Die Variable nimmt den Wert eins an, wenn Unternehmen im Rahmen des Konzernabschlusses 2003 bereits einen internationalen Rechnungslegungsstandard, also IAS/IFRS oder US-GAAP anwenden. Im umgekehrten Falle nimmt die Variable den Wert null an.

1083 Die Variable ,Rechnungslegungsstandard' nimmt den Wert ein an, sofern internationale Standards befolgt werden, vgl. ähnlich zur Zusammenfassung von IAS/IFRS sowie USGAAP Leuz/Verrecchia (2000) oder Baetge et al. (2010). ,Abschlussprüfer' nimmt den Wert eins an, wenn die Prüfung des Jahresabschlusses durch eines der großen Prüfungsunternehmen erfolgt. Dazu werden Ernst \& Young, KPMG, PWC und Deloitte gezählt. 
besitzt hingegen die sog. Rechnungslegungsphilosophie, wie Tab. 34 gleichfalls zeigt. Auf Basis der Ergebnisse der drei Tests kann dennoch davon ausgegangen werden, dass Aspekte der Rechnungslegungspraxis der Unternehmen grds. einen Einfluss auf das unternehmensindividuelle Niveau der Strategieberichterstattung haben, eine weiterführende Analyse ist daher zu befürworten. ${ }^{1084}$

Panel A: Analyse der Strategieberichterstattung in Abhängigkeit d. Rechnungslegungs-Philosophie (t-Test)

Frühe Umstellung auf internationalen Standard Späte Umstellung auf internationalen Standard

\begin{tabular}{llll}
\hline SDScores & [normiert, $\{0 ; 1\}$ S SDScores & [normiert, $\{0 ; 1\}]$ \\
\hline
\end{tabular}

\begin{tabular}{|c|c|c|c|c|c|c|c|c|c|c|c|c|c|c|}
\hline \multirow[b]{2}{*}{$\mu$} & \multicolumn{2}{|c|}{ Extrema } & \multicolumn{3}{|c|}{ Perzentile } & \multirow[b]{2}{*}{$\sigma$} & \multirow[b]{2}{*}{$\mathrm{n}$} & \multirow[b]{2}{*}{$\mu$} & \multicolumn{2}{|c|}{ Extrema } & \multicolumn{2}{|c|}{ Perzentile } & \multirow[b]{2}{*}{$\sigma$} & \multirow[b]{2}{*}{$\mathbf{n}$} \\
\hline & Min & Max & $25 \%$ & $50 \%$ & $75 \%$ & & & & Min & Max & $25 \%$ & $50 \% \quad 75 \%$ & & \\
\hline \multirow[t]{2}{*}{.341} &, 030 & 830 &, 250 & ,330 & , 400 &, 124 & 539 & .329 &, 110 & ,680 &, 250 & , 330 , 400 &, 118 & 161 \\
\hline & & & & & $=$ & $p-W$ & & & & & & $\mathrm{df}$ & $p-W$ & \\
\hline \multicolumn{3}{|c|}{ Levene-Test } & & & 1 & .724 & n.s. & t-Test & & & & 274,7 &, 286 & \\
\hline
\end{tabular}

Panel B: Analyse der Strategieberichterstattung in Abhängigkeit des angewandten Standards (t-Test)

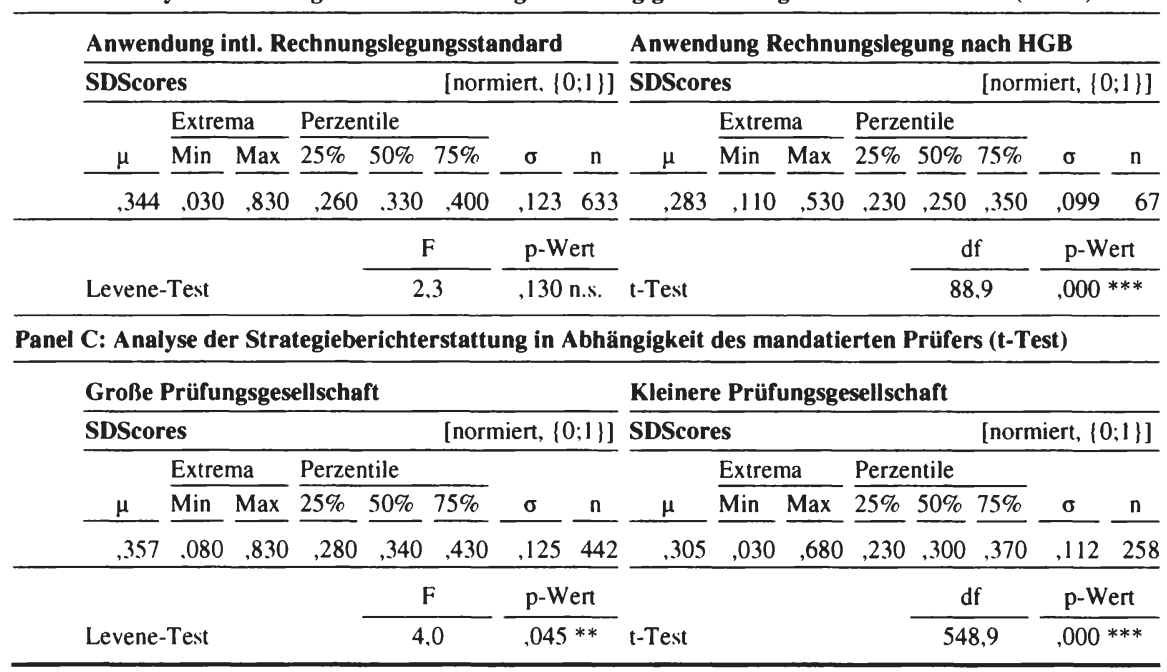

\section{Tabelle 34: Einfluss der Rechnungslegung auf das Berichtsverhalten}

Wie in Abschnitt B 2.2 $2^{1085}$ ausgeführt, trägt das Management, konkret die Person des CEO, letztendlich für die Ausarbeitung der Unternehmensstrategie und folg-

1084 Das bedeutet erneut das Einbeziehen dieser qualitativen Informationen in nachfolgende Regressionsmodelle. Da die Informationen zur Rechnungslegungspraxis bereits originär in binärer Kodierung vorliegen, ist eine separate Dummy-Kodierung nicht erforderlich.

Vgl. ebenda oder auch Abschnitt C 3.1.2, insb. Fn. 725. 
lich auch für das Niveau der Strategieberichterstattung Verantwortung. Daher ist zu prüfen, ob ein Einfluss der Persönlichkeitsmerkmale des CEO auf das Niveau der Strategieberichterstattung (H 2.6) festzustellen ist. Im Einzelnen liegen drei Indikatoren vor, um Persönlichkeitsmerkmale eines CEO abzubilden: das Alter, der Ausbildungshintergrund und die Nationalität. Diese Merkmale sind in Form kategorialer Variablen vorhanden, so dass also die Verfahren der Varianzanalyse zum Einsatz kommen können. Die entsprechenden Ergebnisse stellt Tab. 35 dar.

\begin{tabular}{|c|c|c|c|c|c|c|c|c|c|c|c|c|c|c|c|}
\hline \multicolumn{8}{|c|}{ CEO älter als Median } & \multicolumn{8}{|c|}{ CEO jünger als Median } \\
\hline \multicolumn{5}{|c|}{ SDScores } & \multicolumn{3}{|c|}{ [normiert, $\{0 ; 1\}]$} & \multicolumn{5}{|c|}{ SDScores } & \multicolumn{3}{|c|}{ [normiert, $\{0 ; 1\}]$} \\
\hline \multirow[b]{2}{*}{$\mu$} & \multicolumn{2}{|c|}{ Extrema } & \multicolumn{3}{|c|}{ Perzentile } & \multirow[b]{2}{*}{$\sigma$} & \multirow[b]{2}{*}{$\mathbf{n}$} & \multirow[b]{2}{*}{$\mu$} & \multicolumn{2}{|c|}{ Extrema } & \multicolumn{2}{|c|}{ Perzentile } & & \multirow[b]{2}{*}{$\sigma$} & \multirow[b]{2}{*}{$\mathrm{n}$} \\
\hline & Min & $\underline{\operatorname{Max}}$ & $25 \%$ & $50 \%$ & $75 \%$ & & & & Min & Max & $25 \%$ & $50 \%$ & $75 \%$ & & \\
\hline \multirow[t]{2}{*}{,352 } &, 080 &, 830 &, 250 & ,350 &, 430 &, 127 & 335 &, 325 &, 030 &, 750 &, 250 &, 300 &, 380 &, 117 & 365 \\
\hline & & & & $\mathrm{F}$ & 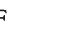 & $\mathrm{p}-\mathrm{W}$ & ert & & & & & $d$ & If & $\mathrm{p}-\mathrm{W}$ & \\
\hline \multicolumn{3}{|c|}{ Levene-Test } & & \multicolumn{2}{|c|}{4,1} & \multicolumn{2}{|c|}{, $043 * *$} & \multicolumn{3}{|l|}{ t-Test } & & 679 & 9,3 & \multicolumn{2}{|c|}{, $005 * * *$} \\
\hline
\end{tabular}

Panel B: Analyse der Strategieberichterstattung in Abhängigkeit der Nationalität des CEO (t-Test)

CEO mit deutscher Nationalität

SDScores [normiert, $\{0 ; 1\}]$ SDScores

\section{CEO mit ausländischer Nationalität}

\begin{tabular}{|c|c|c|c|c|c|c|c|c|c|c|c|c|c|c|c|}
\hline \multirow[b]{2}{*}{$\mu$} & \multicolumn{2}{|c|}{ Extrema } & \multicolumn{3}{|c|}{ Perzentile } & \multirow[b]{2}{*}{$\sigma$} & \multirow[b]{2}{*}{$\mathbf{n}$} & \multirow[b]{2}{*}{$\mu$} & \multicolumn{2}{|c|}{ Extrema } & \multicolumn{3}{|c|}{ Perzentile } & \multirow[b]{2}{*}{$\sigma$} & \multirow[b]{2}{*}{$\mathrm{n}$} \\
\hline & $\overline{\mathrm{Min}}$ & $\operatorname{Max}$ & $25 \%$ & $50 \%$ & $75 \%$ & & & & $\overline{\mathrm{Min}}$ & Max & $25 \%$ & $50 \%$ & $75 \%$ & & \\
\hline, 334 &, 030 & ,750 & 250 & ,330 & ,400 &, 116 & 636 &, 381 &, 110 &, 830 & 280 &, 350 & ,450 & 169 & 64 \\
\hline
\end{tabular}

Levene-Test

$\frac{\mathbf{F}}{12,9} \frac{\mathrm{p} \text {-Wert }}{, 000 * * *}$ t-Test

$\frac{\mathrm{df}}{69,1} \frac{\mathrm{p}-\text { Wert }}{, 003 * * *}$

Panel C: Strategieberichterstattung in Abhängigkeit des Ausbildungshintergrundes des CEO (ANOVA)

\begin{tabular}{|c|c|c|c|c|c|}
\hline & Quadratsumme & df & $\begin{array}{l}\text { Quadrierte } \\
\text { Mittelwerte }\end{array}$ & $\mathbf{F}$ & p-Wert \\
\hline Zwischen den Gruppen &, 249 & 3 &, 083 & 5,6 &, $001 * * *$ \\
\hline Innerhalb der Gruppen & 10,256 & 696 &, 015 & & \\
\hline Total & 10,505 & 699 & & & \\
\hline
\end{tabular}

Panel D: Einzelvergleiche zum Ausbildungshintergrund des CEO (Post Hoc-Tests)

[SDScores, $\{0 ; 1\}]$

Ausbildungshintergrund

Juristische Ausbildung

Technische Ausbildung

Kaufmännische Ausbildung

Naturwissenschaftliche Ausbildung

p-Wert

\begin{tabular}{|c|c|c|}
\hline Scheffé & & {$[\alpha=, 05]$} \\
\hline $\mathrm{n}$ & 1 & 2 \\
\hline 64 & ,321 & \\
\hline 268 & ,325 & \\
\hline 298 &, 342 & \\
\hline 70 & & ,389 \\
\hline &, 660 & 1,000 \\
\hline
\end{tabular}

\begin{tabular}{|c|c|c|}
\hline \multicolumn{2}{|c|}{ Waller-Duncan } & {$[\alpha=, 05]$} \\
\hline $\mathrm{n}$ & 1 & 2 \\
\hline 64 &, 321 & \\
\hline 268 &, 325 & \\
\hline 298 &, 342 & \\
\hline 70 & & ,389 \\
\hline
\end{tabular}

Einfluss der Person des CEO auf das Berichtersverhaliten $31-75150-3$ 
Aus Tab. 35 wird ersichtlich, dass sowohl das Alter als auch die Nationalität des CEO Einfluss auf die Strategieberichterstattung zu besitzen scheint. Demzufolge würden die Manager, die älter als der jahresspezifische Median sind, tendenziell mehr Angaben zu strategieorientierten Sachverhalten berichten als Jüngere. Zudem scheinen CEOs ausländischer Nationalität einen eher offensiveren Berichtsstil zu pflegen. Auch in Bezug auf den Ausbildungshintergrund der CEOs zeigen sich schließlich signifikante Unterschiede des Strategieberichtsverhaltens. Diese Erkenntnisse legen es nahe, die Persönlichkeitsmerkmale der CEOs ebenfalls im Rahmen regressionsanalytischer Modelle zu berücksichtigen. ${ }^{1086}$

Ein weiteres interessantes Ergebnis der Analyse eines Einflusses der Person des CEO auf das Niveau der Strategieberichterstattung ergibt sich, wenn die Anzahl unterschiedlicher Vorstandsvorsitzender innerhalb des Untersuchungszeitraumes bzw. äquivalent die Anzahl an Auswechslungen von CEOs untersucht wird. Wie Tab. 36 darstellt, weisen die Unternehmen, die mehr als ein Mal ihren CEO austauschen, ein signifikant niedrigeres Strategieberichterstattungs-Niveau auf. ${ }^{1087}$

Weiterhin ist von Interesse zu überprüfen, ob ein Wechsel per se Auswirkungen auf das Niveau der Strategieberichterstattung hat - hierzu bietet sich sodann eine Differenzbetrachtung der jeweiligen SDScores an. Wie Panel B offenbart, ist die relative Differenz des SDScores in den Jahren ${ }^{1088}$, in denen der CEO gewechselt wurde, signifikant höher als bei Unternehmen, die ihren CEO nicht austauschen. Schließlich macht Panel C in Tab. 36 ersichtlich, dass die Differenz des Niveaus der Strategieberichterstattung in jenen Fällen am höchsten ist, wenn der Wechsel des Vorstandsvorsitzenden als Entlassung zu charakterisieren ist.

1086 Der ,Ausbildungshintergrund“ wird erneut Dummy-kodiert. Dies erfolgt - aufgrund der Resultate der Einzelvergleiche - jedoch nur in Form einer einzelnen Dummy-Variable, die den Wert eins annimmt, wenn ein naturwissenschaftlicher Hintergrund vorliegt.

Weil die weiteren Merkmale als binäre Variablen vorliegen, ist eine Umkodierung nicht nötig. Die Variable ,Alter CEO` nimmt den Wert eins an, sofern der CEO älter als der Median ist, Gleiches gilt für die ,Nationalität CEO ‘ im Falle ausländischer Nationalität. Der Wert für $\mathrm{n}_{\max }$ sinkt sodann auf $\mathrm{n}_{\max }=600$, da nur sechs Differenzen ermittelbar sind. Insgesamt konnten innerhalb der Stichprobe 73 CEO-Wechsel identifiziert werden. Die Anzahl von zwei Auswechselungen eines CEO wurde als Trennwert definiert, um reine Routinewechsel, vgl. auch die nachfolgende Fn. 1089, auszuklammern.

1088 In Bezug gesetzt wird hier konsistent das Jahr des Wechsels $t$ mit dem SDIndex in $t$. Ein SDScore für $t$ ist dann derjenige Score, für den der neue CEO verantwortlich zeichnet. 
Panel A: Strategieberichterstattung in Abhängigkeit der CEO-Anzahl im Untersuchungszeitraum (t-Test)

Unternehmen mit maximal einem CEO-Wechsel Unternehmen mit mehr als einem CEO-Wechsel

\begin{tabular}{llll}
\hline SDScores & [normiert, $\{0 ; 1\}]$ & [normiert, $\{0 ; 1\}]$
\end{tabular}

\begin{tabular}{|c|c|c|c|c|c|c|c|c|c|c|c|c|c|c|}
\hline \multirow[b]{2}{*}{$\mu$} & \multicolumn{2}{|c|}{ Extrema } & \multicolumn{3}{|c|}{ Perzentile } & \multirow[b]{2}{*}{$\sigma$} & \multirow[b]{2}{*}{ n } & \multirow[b]{2}{*}{$\mu$} & \multicolumn{2}{|c|}{ Extrema } & \multicolumn{2}{|c|}{ Perzentile } & \multirow[b]{2}{*}{$\sigma$} & \multirow[b]{2}{*}{$\mathrm{n}$} \\
\hline & Min & $\operatorname{Max}$ & $25 \%$ & $50 \%$ & $75 \%$ & & & & Min & Max & $25 \%$ & $50 \% \quad 75 \%$ & & \\
\hline \multirow[t]{2}{*}{, 342} &, 080 & ,830 &, 250 &, 330 & ,408 &, 125 & 602 & ,311 &, 030 & ,580 & ,245 & ,315,380 & ,099 & 98 \\
\hline & & & & & $F$ & $p-W$ & & & & & & df & $\mathrm{p}-\mathrm{W}$ & \\
\hline \multicolumn{3}{|c|}{ Levene-Test } & & &, 1 & 025 & & t-Test & & & & 152,6 &, 006 & $* *$ \\
\hline
\end{tabular}

Panel B: Veränderung der Strategieberichterstattung in Abhängigkeit eines CEO-Wechsels (t-Test)

\begin{tabular}{|c|c|c|c|c|c|c|c|c|c|c|c|c|c|c|c|}
\hline \multicolumn{8}{|c|}{ Unternehmen ohne CEO-WechseI } & \multicolumn{8}{|c|}{ Unternehmen mit CEO-Wechsel } \\
\hline \multicolumn{3}{|c|}{ SDScores } & \multicolumn{5}{|c|}{ [Relative Veränderung, Betrag] } & \multicolumn{3}{|c|}{ SDScores } & \multicolumn{5}{|c|}{ [Relative Veränderung, Betrag } \\
\hline \multirow[b]{2}{*}{$\mu$} & \multicolumn{2}{|c|}{ Extrema } & \multicolumn{3}{|c|}{ Perzentile } & \multirow[b]{2}{*}{$\sigma$} & \multirow[b]{2}{*}{$\mathrm{n}$} & \multirow[b]{2}{*}{$\mu$} & \multicolumn{2}{|c|}{ Extrema } & \multicolumn{3}{|c|}{ Perzentile } & \multirow[b]{2}{*}{$\sigma$} & \multirow[b]{2}{*}{$\mathrm{n}$} \\
\hline & Min & Max & $25 \%$ & $\underline{50 \%}$ & $75 \%$ & & & & Min & Max & $25 \%$ & $50 \%$ & $\underline{75 \%}$ & & \\
\hline \multirow[t]{2}{*}{, 129} &, 000 &, 800 &, 040 &, 100 &, 180 &, 125 & 527 &, 175 &, 000 &, 500 &, 080 &, 130 &, 250 &, 141 & 73 \\
\hline & & & & $\mathrm{F}$ & $\mathrm{F}$ & $\mathrm{p}-\mathrm{W}$ & ert & & & & & d & If & $\mathrm{p}-\mathrm{W}$ & \\
\hline \multicolumn{3}{|c|}{ Levene-Test } & \multicolumn{3}{|c|}{3,7} & \multicolumn{2}{|c|}{, $055^{*}$} & \multicolumn{3}{|l|}{ t-Test } & & 88 & 3,3 & \multicolumn{2}{|c|}{, $009 * * *$} \\
\hline
\end{tabular}

Panel C: Veränderung der Strategieberichterstattung in Abhängigkeit der Art des Wechsels ${ }^{1089}$ (t-Test)

Routinewechsel

SDScores

[Relative Veränderung, Betrag] SDScores

Entlassung des bisherigen CEO

\begin{tabular}{|c|c|c|c|c|c|c|c|c|c|c|c|c|c|c|c|}
\hline \multirow[b]{2}{*}{$\mu$} & \multicolumn{2}{|c|}{ Extrema } & \multicolumn{3}{|c|}{ Perzentile } & \multirow[b]{2}{*}{$\sigma$} & \multirow[b]{2}{*}{$\mathbf{n}$} & \multirow[b]{2}{*}{$\mu$} & \multicolumn{2}{|c|}{ Extrema } & \multicolumn{3}{|c|}{ Perzentile } & \multirow[b]{2}{*}{$\sigma$} & \\
\hline & Min & Max & $25 \%$ & $50 \%$ & $75 \%$ & & & & Min & Max & $25 \%$ & $50 \%$ & $75 \%$ & & $\mathrm{n}$ \\
\hline, 132 & ,000 &, 400 & ,068 &, 110 & , 183 &, 111 & 42 & ,234 & ,000 & ,500 &, 110 &, 190 & ,400 &, 157 & \\
\hline
\end{tabular}

Levene-Test

$\frac{\mathrm{df}}{51,0} \frac{\mathrm{p}-\text { Wert }}{, 003 * * *}$

\section{Tabelle 36: Einfluss von CEO-Wechseln auf das Berichtsverhalten}

Auch diese Ergebnisse machen also deutlich, dass die Person des CEO Einfluss auf das Niveau der Strategieberichterstattung zu besitzen scheint. Offensichtlich wählt jeder Vorstandsvorsitzende ein individuelles Niveau der Berichterstattung, welches er im Laufe seiner Amtszeit grds. beibehält, es zumindest jedoch nicht so drastisch anpasst wie es bei einem CEO-Wechsel zu beobachten ist.

1089 Die Charakterisierung der Wechsel erfolgte in Anlehnung an Thiele (2007), S. 167f. als ,Routinewechsel' und ,Entlassung' auf Grundlage von Presserecherchen in der FactivaDatenbank. Die Identifikation von Entlassungen wird grds. dadurch erschwert, dass dies selten explizit so genannt ist, vgl. Jenter/Kanaan (2006), S. 17. Daher erfolgt die Identifikation anlehnend an Gilson (1989), S. 248ff.; Salomo (2001), S. 181f., indem Wechsel als Entlassung gewertet werden, wenn diese nicht durch Tod, Krankheit, geplante Nachfolge oder Renteneintritt (im Alter von $>60$ Jahren) sowie Beförderung begründet sind. 


\section{(b) Partielles Regressionsmodell der Unternehmenscharakteristika}

Im Anschluss an die einführenden Untersuchungen der relevanten Variablen zur Abbildung wesentlicher Unternehmenscharakteristika sind die Variablen weiterhin regressionsanalytisch auf ihren Einfluss auf das Niveau der Strategieberichterstattung zu untersuchen. Die berechneten Regressionsanalysen stellt die nachfolgende Tab. 37 dar, wobei Modell 4 erneut das Partialmodell repräsentiert.

Zunächst zeigt Modell 1 eine Regression der Untersuchungsvariablen SDIndex auf den Faktor der Unternehmensgröße. Diesem Faktor ist - gemeinsam mit der Kontrollvariablen Jahr - mit annähernd 25\% Erklärungsanteil an der Varianz des Niveaus der Strategieberichterstattung beachtlicher Einfluss zuzuschreiben. ${ }^{1090}$

Ähnliches gilt auch für das zweite Regressionsmodell der Unternehmensstammdaten Branchenzugehörigkeit und Alter, die mit Jahr einen Erklärungsanteil von ca. 18\% leisten. Mit Ausnahme der Branche ,Utilities“ besitzen die Regressionskoeffizienten negative Vorzeichen, diese Branchen weisen also im Durchschnitt niedrigere Berichtsniveaus auf als die Referenzbranche - bei insg. vier Branchen ist jener Unterschied zudem hoch signifikant. Ebenfalls mit Blick auf das Unternehmensalter können die Ergebnisse der vorherigen ANOVA in diesem Modell der Stammdaten bestätigt werden. Die im dritten Regressionsmodell zusammengefassten Regressoren bilden schließlich die im Rahmen der Untersuchung überprüften Aspekte der Unternehmenssteuerung ab: Wie Tab. 37 aufzeigt, kann der Einfluss des Typs des Abschlussprüfers - als ein Indikator der inhaltlichen Ausrichtung der Rechnungslegungspraxis - im Regressionsmodell bestätigt werden. Gleiches gilt für Persönlichkeitsmerkmale des CEO, der Einfluss des Alters und des Ausbildungshintergrundes bleiben in der Regressionsanalyse bestehen.

Schließlich inkludiert das als Partialmodell der Unternehmenscharakteristika benannte Modell 4 alle innerhalb von Abschnitt D 4.1.2 analysierten Einzelaspekte in einem gesamthaften Regressionsmodell. Dieses erreicht - insb. aufgrund des hohen Einflusses der Unternehmensgröße - ein Bestimmtheitsmaß von ca. $34 \%$. Während sich auch auf Basis von Modell 4 für alle Kategorien neben der Unter-

10\%) Dieses Resultat bzw. der errechnete Zusammenhang ist konsistent mit der einschlägigen Literatur, so z.B. Leuz (1999), Lang/Lundholm (1993) für die gesamte Berichterstattung. 
nehmensgröße Hinweise auf einen Einfluss der jeweiligen Variablen auf das Berichtsniveau zeigen, gilt dies nicht mehr für die CEO-Persönlichkeitsmerkmale.

Es ist folglich zu konstatieren, dass neben der Unternehmensgröße auch einzelne qualitative Unternehmensmerkmale Einfluss auf das Berichtsniveau besitzen.

Regressionsanalyse zum Einfluss der Unternehmenscharakteristika auf die Strategieberichterstattung

$\mathrm{F}(\mathrm{x})=$ Niveau der Strategieberichterstattung

\begin{tabular}{|c|c|c|c|c|c|c|c|c|}
\hline \multirow{3}{*}{ Unternehmensgröße } & \multicolumn{2}{|c|}{$\begin{array}{l}\text { Modell 1: } \\
\text { Größe }\end{array}$} & \multicolumn{2}{|c|}{$\begin{array}{l}\text { Modell 2: } \\
\text { Stammdaten }\end{array}$} & \multicolumn{2}{|c|}{$\begin{array}{l}\text { Modell 3: } \\
\text { Governance }\end{array}$} & \multicolumn{2}{|c|}{$\begin{array}{c}\text { Modell 4: } \\
\text { Partialmodell }\end{array}$} \\
\hline & Koeff. $\beta$ & $\mathrm{p}$ & Koeff. $\beta$ & $\mathrm{p}$ & Koeff. $\beta$ & $\mathrm{p}$ & Koeff. $\beta$ & $\mathrm{p}$ \\
\hline & & & & & & & & \\
\hline Größe [Faktor] (+) & $358 * * *$ & $(, 000)$ & & & & &, $440 * * *$ & $(.000)$ \\
\hline \multicolumn{9}{|c|}{ Unternehmensstammdaten } \\
\hline \multicolumn{9}{|c|}{ Branchenzugehörigkeit (?) } \\
\hline Information Tecl & ogy & &,$- 044^{1091}$ & $(, 510)$ & & & ,084 & $(.179)$ \\
\hline Consumer Good & & &,$- 272 * * *$ & $(.001)$ & & &,- 089 & $(.247)$ \\
\hline Consumer Servic & & &,$- 232 * * *$ & $(.001)$ & & &,$- 147 * *$ & $(, 018)$ \\
\hline Industrials & & &,$- 305 * * *$ & $(.003)$ & & &,- 039 & $(.684)$ \\
\hline Pharma \& Healtl & & &,$- 228 * * *$ & $(, 001)$ & & &,- 091 & $(, 145)$ \\
\hline Basic Materials & & &,- 087 & $(.221)$ & & & ,072 & $(.277)$ \\
\hline Utilities & & &, 005 & $(, 912)$ & & &, 025 & $(.562)$ \\
\hline \multicolumn{9}{|c|}{ Unternehmensalter (?) } \\
\hline Alter: Klasse 1 & & &, 067 & $(, 159)$ & & &, $289 * * *$ & $(.000)$ \\
\hline Alter: Klasse 2 & & &,$- 092 * *$ & $(, 046)$ & & &, $108 * *$ & $(, 017)$ \\
\hline Alter: Klasse 3 & & &, 007 & $(.881)$ & & &, 032 & $(, 439)$ \\
\hline \multicolumn{9}{|c|}{ Rechnungslegungspraxis } \\
\hline Abschluss: Standa & & & & &, 008 & $(, 827)$ &, 029 & $(.404)$ \\
\hline Abschluss: Prüfer & & & & & $165 * * *$ & $(,(000)$ &, $068 * *$ & $(, 048)$ \\
\hline \multicolumn{9}{|l|}{ Management } \\
\hline CEO: Alter (?) & & & & &, $092 * * *$ & $(.010)$ &, 025 & (.473) \\
\hline CEO: Nationalität & & & & & .036 & $(.309)$ &, 013 & (.698) \\
\hline CEO: Ausbildung & & & & &, $071 * *$ & $(, 049)$ &, 025 & $(.5(0))$ \\
\hline \multicolumn{9}{|l|}{ Kontrollvariablen } \\
\hline Konstante & & $(, 000)$ & & $(.000)$ & & $(, 000)$ & & $(.000)$ \\
\hline Jahr &, $325 * * *$ & $(, 000)$ &, $349 * * *$ & $(, 000)$ &, $343 * * *$ & $(, 000)$ &, $326 * * *$ & $(.000)$ \\
\hline$R^{2}$ & 249 & & 196 & &, 172 & & ,355 & \\
\hline$R^{2} a d j$ &, $247 * * *$ & $(.000)$ &, $184 * * *$ & $(.000)$ &, $165 * * *$ & $(.000)$ &, 339 & $(.000)$ \\
\hline Durbin-Watson $d$ & 2,002 & & 1,931 & & 1,926 & & 1,940 & \\
\hline $\mathrm{n}\left(\mathrm{n}_{\max }=700\right)$ & 700 & & 700 & & 700 & & 700 & \\
\hline
\end{tabular}

Tabelle 37: Partielles Regressionsmodell der Unternehmenscharakteristika

1091 Auf die Angabe ,n.s. ' bei insignifikanten Koeffizienten wird im Folgenden verzichtet.

Tom Sieber - 978-3-631-75150-3 


\subsubsection{Untersuchung der finanziellen Faktoren}

\section{(a) Analyse einzelner finanzieller Faktoren}

Nachdem bislang lediglich auf Basis der Unternehmensgröße quantitative Parameter auf ihren Einfluss auf das Niveau der Strategieberichterstattung überprüft wurden, sollen nun zwei weitere Bereiche der Unternehmensfinanzen untersucht werden: der finanzielle Erfolg (H 2.7) sowie die Finanzierungsstruktur (H 2.8).

Zunächst können zur Untersuchung eines Einflusses des Unternehmenserfolges auf das Niveau der Strategieberichterstattung erneut mehrere Indikatoren des Erfolges herangezogen werden, welche entweder die Profitabilität in Bezug auf die Leistung, d.h. Margengrößen, oder die Profitabilität in Bezug auf das eingesetzte Kapital, also die Rentabilität des Unternehmens, abbilden. Wie Tab. 38 aufzeigt, stehen die beiden Gruppen von Indikatoren in positivem und hoch signifikantem Zusammenhang mit dem Niveau der Strategieberichterstattung.

\section{Panel A: Korrelationsanalyse der Indikatoren des Unternehmenserfolges}

Bivariatc Korrelationsanalyse einzelner Indikatoren des Unternehmenserfolges. Werte unterhalb der Diagonale stellen die Korrelationskecilizienten nach Pearson. Wente oberhalh der Diagonale die Rang-Korrelationskoeffizienten nach Spearman dar.

\begin{tabular}{|c|c|c|c|c|c|c|c|c|}
\hline \multicolumn{3}{|c|}{$n=700$} & 1 & 2 & 3 & 4 & 5 & 6 \\
\hline 1 & SDI & $\begin{array}{l}\text { Koeffizient } \\
\text { p-Wert }\end{array}$ & & $\begin{array}{l}.023 \mathrm{n} . \mathrm{s} . \\
(.552)\end{array}$ & $\begin{array}{l}, 236 * * * \\
(.()(0))\end{array}$ & $\begin{array}{l}, 203 * * * \\
(.(0)(0))\end{array}$ & $\begin{array}{l}, 154 * * * \\
(.(0)())\end{array}$ & $\begin{array}{l}, 209 * * * \\
(.)(x))\end{array}$ \\
\hline 2 & $\begin{array}{l}\text { Return } \\
\text { on Assets }\end{array}$ & $\begin{array}{l}\text { Koeffizient } \\
\text { p-Wert }\end{array}$ & $\begin{array}{l}.106 * * * \\
(.005)\end{array}$ & & $\begin{array}{l}.584 * * * \\
(.(O)())\end{array}$ & $\begin{array}{l}, 780 * * * \\
(.(0)(0))\end{array}$ & $\begin{array}{l}, 891 * * * \\
(.(O)())\end{array}$ & $\begin{array}{l}, 754 * * * \\
(.()()))\end{array}$ \\
\hline 3 & $\begin{array}{l}\text { EBITDA- } \\
\text { Marge }\end{array}$ & $\begin{array}{l}\text { Koeffizient } \\
\text { p-Wert }\end{array}$ & $\begin{array}{l}, 187 * * * \\
(.(0)(0))\end{array}$ & $\begin{array}{l}.700 * * * \\
(.(x)(x))\end{array}$ & & $\begin{array}{l}, 893 * * * \\
(.()(x))\end{array}$ & $\begin{array}{l}, 799 * * * \\
(.(0)())\end{array}$ & $\begin{array}{l}, 947 * * * \\
(.(0)())\end{array}$ \\
\hline 4 & $\begin{array}{l}\text { EBIT- } \\
\text { Marge }\end{array}$ & $\begin{array}{l}\text { Koeffizient } \\
\text { p-Wert }\end{array}$ & $\begin{array}{l}, 149 * * * \\
(.10(0))\end{array}$ & $\begin{array}{l}.727 * * * \\
(.()(x))\end{array}$ & $\begin{array}{l}.963 * * * \\
(.0)(0))\end{array}$ & & $\begin{array}{l}, 928 * * * \\
(.(0)()))\end{array}$ & $\begin{array}{l}, 971 * * * \\
(.(0)())\end{array}$ \\
\hline 5 & $\begin{array}{l}\text { Netto- } \\
\text { Marge }\end{array}$ & $\begin{array}{l}\text { Koeffizient } \\
\text { p-Wert }\end{array}$ & $\begin{array}{l}, 110 * * * \\
(.(x) 4)\end{array}$ & $\begin{array}{l}, 744 * * * \\
(.(x(x))\end{array}$ & $\begin{array}{l}, 917 * * * \\
(.00())\end{array}$ & $\begin{array}{l}, 967 * * * \\
(.(x)(x))\end{array}$ & & $\begin{array}{l}, 932 * * * \\
(.()()))\end{array}$ \\
\hline 6 & Faktor & $\begin{array}{l}\text { Koeffizient } \\
\text { p-Wert }\end{array}$ & $\begin{array}{l}.151 * * * \\
(.0(0))\end{array}$ & $\begin{array}{l}.737 * * * \\
(.(0)(x))\end{array}$ & $\begin{array}{l}, 977^{* * * *} \\
(.0(0))\end{array}$ & $\begin{array}{l}, 994 * * * \\
(.(0)(0))\end{array}$ & $\begin{array}{l}, 978 * * * \\
(.0(0))\end{array}$ & \\
\hline
\end{tabular}

Panel B: Faktorenanalyse zur Extraktion eines Faktors des Unternehmenserfolges

l:aktorenanalyse der in Panel A gekennzeichneten lndikatoren des Untemehmenserfolges nach der Methode der Ilauptkomponentenanalyse

\begin{tabular}{|c|c|c|c|c|c|c|}
\hline \multicolumn{4}{|c|}{ Prüfgrößen } & \multicolumn{3}{|c|}{ Erklärte Gesamtvarianz } \\
\hline \multicolumn{2}{|l|}{$\mathrm{KMO}$} & \multicolumn{2}{|c|}{ Bartlett-Test } & Komp. & $\begin{array}{l}\text { Summe quadrierter } \\
\text { Faktorladungen }\end{array}$ & $\begin{array}{c}\text { Prozent } \\
\text { der Varianz }\end{array}$ \\
\hline \multirow[t]{3}{*}{ MSA } & 687 & $\mathrm{Chi}^{2}$ & $3.764,8$ & 1 & 2,898 & 96,607 \\
\hline & & $\mathrm{df}$ & 3 & $\ldots$ & & \\
\hline & & p-Wert &, $000 * * *$ & 3 & & \\
\hline
\end{tabular}


Erneut scheint eine Verdichtung der verschiedenen Indikatoren auf einen Faktor sinnvoll, um die Profitabilität im finalen Regressionsmodell zu berücksichtigen. Eine Faktorenanalyse, welche die verschiedenen Margenindikatoren umfasst, ist ebenfalls in Tab. 39 notiert. Da der sich ergebende Faktor des Unternehmenserfolges einen deutlichen Zusammenhang mit dem Rentabilitätsindikator aufweist, wird im Folgenden auf die Verwendung des ermittelten Faktors fokussiert.

Diese Vorgehensweise kann auch in Bezug auf die Indikatoren der Finanzierung Anwendung finden: Wie vermutet wurde, sind die operationalisierenden Größen miteinander hoch korreliert und weisen außerdem ähnliche Zusammenhänge mit dem Niveau der Strategieberichterstattung auf. Aus diesem Grund wird ebenfalls ein Faktor extrahiert, um die einzelnen Indikatoren gesamthaft abzubilden.

\section{Panel A: Korrelationsanalyse der Indikatoren der Finanzierungsstruktur}

Bivariate Korrelationsanalyse der Indikatoren der Finanzierungsstruktur. Werte unterhalb der Diagonale stellen die Korrelationskoeffizienten nach Pearson. Werte oberhalb der Diagonale die Rang-Korrelationskoeffizienten nach Spearman dar.

\begin{tabular}{|c|c|c|c|c|c|c|c|c|c|}
\hline & 700 & & 1 & 2 & 3 & 4 & 5 & 6 & 7 \\
\hline 1 & SDI & $\begin{array}{l}\text { Koeffizient } \\
\text { p-Wert }\end{array}$ & & $\begin{array}{l}-, 048 \text { n.s. } \\
(.209)\end{array}$ & $\begin{array}{l}, 102 * * * \\
(.007)\end{array}$ & $\begin{array}{l}, 193 * * * \\
(.000)\end{array}$ & $\begin{array}{l}, 187 * * * \\
(.000)\end{array}$ & $\begin{array}{l}, 080 * * \\
(, 035)\end{array}$ & $\begin{array}{l}, 139 * * * \\
(, 0(0))\end{array}$ \\
\hline 2 & $\begin{array}{l}\text { EK- } \\
\text { Quote }\end{array}$ & $\begin{array}{l}\text { Koeffizient } \\
\text { p-Wert }\end{array}$ & $\begin{array}{l}-, 083 * * \\
(.027)\end{array}$ & & $\begin{array}{l}-, 606 * * * \\
(.000)\end{array}$ & $\begin{array}{c}-, 507 * * * \\
(, 00())\end{array}$ & $\begin{array}{l}-, 720 * * * \\
(, 000)\end{array}$ & $\begin{array}{c}-, 598 * * * \\
(, 000)\end{array}$ & $\begin{array}{c}-, 637 * * * \\
(.000)\end{array}$ \\
\hline 3 & $\begin{array}{l}\text { Debt to } \\
\text { Assets }\end{array}$ & $\begin{array}{l}\text { Koeffizient } \\
\text { p-Wert }\end{array}$ & $\begin{array}{l}, 107 * * * \\
(.004)\end{array}$ & $\begin{array}{c}-, 605 * * * \\
(, 000)\end{array}$ & & $\begin{array}{l}, 893 * * * \\
(.000)\end{array}$ & $\begin{array}{l}, 870 * * * \\
(.000)\end{array}$ & $\begin{array}{l}, 943 * * * \\
(.000)\end{array}$ & $\begin{array}{l}, 977 * * * \\
(.000))\end{array}$ \\
\hline 4 & $\begin{array}{l}\text { LT-Debt } \\
\text { to Assets }\end{array}$ & $\begin{array}{l}\text { Koeffizient } \\
\text { p-Wert }\end{array}$ & $\begin{array}{l}, 201 * * * \\
(, 0()))\end{array}$ & $\begin{array}{c}-, 471 * * * \vdots \\
(, 000)\end{array}$ & $\begin{array}{l}, 870 * * * \\
(, 000)\end{array}$ & & $\begin{array}{l}, 932 * * * \\
(.000)\end{array}$ & $\begin{array}{l}, 819 * * * \\
(.000)\end{array}$ & $\begin{array}{l}, 937 * * * \\
(, 0(00)\end{array}$ \\
\hline 5 & $\begin{array}{l}\text { LT-Debt } \\
\text { to Equity }\end{array}$ & $\begin{array}{l}\text { Koeffizient } \\
\text { p-Wert }\end{array}$ & $\begin{array}{l}, 163 * * * \\
(, 000)\end{array}$ & \begin{tabular}{c:}
,$- 535 * * * *$ \\
\hdashline$(, 000)$
\end{tabular} & $\begin{array}{l}, 637 * * * \\
(.000)\end{array}$ & $\begin{array}{l}, 686 * * * \\
(.000)\end{array}$ & & $\begin{array}{l}, 803 * * * \\
(, 000)\end{array}$ & $\begin{array}{l}, 926 * * * \\
(.00())\end{array}$ \\
\hline 6 & $\begin{array}{l}\text { Net Debt } \\
\text { to Assets }\end{array}$ & $\begin{array}{l}\text { Koeffizient } \\
\text { p-Wert }\end{array}$ & $\begin{array}{l}, 097 * * \\
(, 011)\end{array}$ & $\begin{array}{c}-, 657 \text { **** } \\
(.000)\end{array}$ & $\begin{array}{l}, 899 * * * \\
(.000)\end{array}$ & $\begin{array}{l}, 768 * * * \\
(.000)\end{array}$ & $\begin{array}{l}, 538 * * * \\
(, 000)\end{array}$ & & $\begin{array}{l}, 947 * * * \\
(, 000)\end{array}$ \\
\hline 7 & Faktor & $\begin{array}{l}\text { Koeffizient } \\
\text { p-Wert }\end{array}$ & $\begin{array}{l}, 157 * * * \\
(.000)\end{array}$ & $\begin{array}{l}-, 632 * * * \\
(, 000)\end{array}$ & $\begin{array}{l}, 958 * * * \\
(.(000)\end{array}$ & $\begin{array}{l}, 932 * * * \\
(.000)\end{array}$ & $\begin{array}{l}, 783 * * * \\
(.000)\end{array}$ & $\begin{array}{l}, 903 * * * \\
(.000))\end{array}$ & \\
\hline
\end{tabular}

Panel B: Faktorenanalyse zur Extraktion eines Faktors der Unternehmensfinanzierung

Faktorenanalyse der in Panel A gekennzeichneten Indikatoren der Finanzierungsstruktur nach der Methode der Hauptkomponentenanalyse

Prüfgrößen

$\frac{\text { KMO }}{\text { MSA } \quad, 772} \frac{\text { Bartlett-Test }}{\text { Chi }^{2} \quad 2.597,2}$

df 6

p-Wert
Erklärte Gesamtvarianz

\begin{tabular}{|c|c|c|}
\hline Komp. & $\begin{array}{l}\text { Summe quadrierter } \\
\text { Faktorladungen }\end{array}$ & $\begin{array}{c}\text { Prozent } \\
\text { der Varianz }\end{array}$ \\
\hline & 3,215 & 80,368 \\
\hline
\end{tabular}

4 


\section{(b) Partielles Regressionsmodell der finanziellen Faktoren}

Konsistent mit den bisher durchgeführten Analysen im Rahmen des Teilmodells der Bestimmungsfaktoren ist der Einfluss der herausgearbeiteten Indikatoren mit Hilfe von Regressionsanalysen zu prüfen, die Tab. 40 im Überblick darstellt:

So kann für alle drei Indikatoren in bivariaten Regressionsanalysen ein Einfluss auf das Berichtsverhalten bestätigt werden - wobei selbstverständlich erneut für den Faktor Zeit kontrolliert wird. ${ }^{1092}$ Bei Zusammenfassung aller Indikatoren in einem partiellen Regressionsmodell (Modell 4) ergibt sich weiterhin sowohl für die Erfolgs- als auch für die Finanzierungsperspektive ein signifikanter Einfluss, jedoch kann die Eigenkapitalquote ihren Einfluss gegen den Verschuldungsgrad nicht behaupten, da - wie Tab. 39 zeigte - beide miteinander verknüpft sind.

\begin{tabular}{|c|c|c|c|c|c|c|c|c|}
\hline \multicolumn{9}{|c|}{$\begin{array}{l}\text { Regressionsanalyse zum Einfluss finanzieller Faktoren auf die Strategieberichterstattung } \\
f(x)=\text { Niveau der Strategicberichterstattung }\end{array}$} \\
\hline & \multicolumn{2}{|c|}{$\begin{array}{l}\text { Modell 1: } \\
\text { Profitabilität }\end{array}$} & \multicolumn{2}{|c|}{$\begin{array}{l}\text { Modell 2: } \\
\text { Eigenkapital }\end{array}$} & \multicolumn{2}{|c|}{$\begin{array}{l}\text { Modell 3: } \\
\text { Fremdfinanzierung }\end{array}$} & \multicolumn{2}{|c|}{$\begin{array}{l}\text { Modell 4: } \\
\text { Partialmodell }\end{array}$} \\
\hline & Koeff. $\beta$ & $\mathrm{p}$ & Koeff. $\beta$ & $\mathrm{p}$ & Koeff. $\beta$ & $\mathrm{p}$ & Koeff. $\beta$ & $\mathrm{p}$ \\
\hline \multicolumn{9}{|l|}{ Unternehmenserfolg } \\
\hline Erfolg [Faktor] (+) &, $072 * * *$ & $(.0014)$ & & & & &, $065 * *$ & (.(047) \\
\hline \multicolumn{9}{|l|}{ Finanzierungsstruktur } \\
\hline Eigenkapitalquote (-) & & &,$- 078 * *$ & (..129) & & &,- 003 & (.947) \\
\hline Verschuldungsgrad [F & aktor] (+) & & & &, $126 * * *$ & $(.000)$ &, $123 * * *$ & $(.(0) 1)$ \\
\hline \multicolumn{9}{|l|}{ Kontrollvariablen } \\
\hline Konstante & & $(.(0)(x))$ & & $(.(K))$ & & $(.(0)(x))$ & & $(.0(0))$ \\
\hline Jahr &, $341 * * *$ & $(.(X)(0))$ &, $355 * * *$ & $(.(0)(0))$ &, $348 * * *$ & $(.00(0))$ &, $342 * * *$ & $(.(0)(0))$ \\
\hline$R^{2}$ & .128 & & .128 & &, 138 & &, 144 & \\
\hline$R^{2}$ adj &, $125 * * *$ & $(.00(0))$ &, $125 * * *$ & $(.00(0))$ &, $135 * * *$ & $(.000))$ &, $139^{* * *}$ & $(.(x))$ \\
\hline Durbin-Watson $d$ & 1,911 & & 1,905 & & 1,906 & & 1,913 & \\
\hline$n\left(n_{\operatorname{nax}}=700\right)$ & 700 & & 700 & & 700 & & 700 & \\
\hline
\end{tabular}

Tabelle 40: Partielles Regressionsmodell der finanziellen Faktoren

1092 Diese Ergebnisse sind konsistent mit vergleichbaren Untersuchungen zu den Einflussfaktoren der Berichterstattung, vgl. z.B. Lang/Lundholm (1993) bzw. mit Fokus auf den dt. Kapitalmarkt Leuz (1999), ebenso Frankel et al. (1999), S. 143, welche das Volumen externer Finanzierung als signifikanten Einflussfaktor für die Durchführung von Investor Relations-Telefonkonferenzen - als Proxygröße für das Ausmaß freiwilliger Berichterstattung - ermitteln, ähnlich auch Frankel et al. (1995). 


\subsubsection{Untersuchung der Faktoren des Aktienkapitals}

\section{(a) Analyse der Einzelfaktoren des Aktienkapitals}

Da die eigene Untersuchung auf deutsche börsennotierte Unternehmen abstellt, wurden wesentliche Einflussfaktoren des Niveaus der Strategieberichterstattung zudem innerhalb zentraler Aspekte des Aktienkapitals vermutet. Im Einzelnen ist neben dem Einfluss einer Indexzugehörigkeit (H 2.9), einer Auslandsnotierung (H 2.10) sowie der jeweiligen Aktionärsstruktur (H 2.11) auch der Einfluss von sog. Insidertransaktionen (H 2.12) auf das Berichtsverhalten zu untersuchen.

Die Indexzugehörigkeit bildet als kategoriale Variable die jahresspezifische $\mathrm{Zu}$ gehörigkeit der Merkmalsträger zu einem der vier Auswahlindizes der Dt. Börse AG - also zu Dax, MDax, TecDax und SDax - oder eine Nichtberücksichtigung in diesen ab. Als Untersuchungsmethode zur Prüfung des Einflusses der Indexzugehörigkeit bietet sich eine Varianzanalyse an, die in Tab. 41 gezeigt ist. ${ }^{1093}$

\begin{tabular}{|c|c|c|c|c|c|c|c|c|c|c|}
\hline & & & Quad & summe & df & \multicolumn{2}{|c|}{$\begin{array}{l}\text { Quadrierte } \\
\text { Mittelwerte }\end{array}$} & $\mathbf{F}$ & \multicolumn{2}{|c|}{ p-Wert } \\
\hline \multicolumn{3}{|c|}{ Zwischen den Gruppen } & \multicolumn{2}{|c|}{2,308} & 4 & \multicolumn{2}{|c|}{.577} & 48,9 & \multicolumn{2}{|c|}{, $000 * * *$} \\
\hline \multicolumn{3}{|c|}{ Innerhalb der Gruppen } & & & 695 & \multicolumn{2}{|c|}{, 012} & & & \\
\hline Total & & & & & 699 & & & & & \\
\hline \multicolumn{11}{|c|}{ Panel B: Einzelvergleiche zur Indexzugehörigkeit (Post Hoc-Tests) } \\
\hline & \multicolumn{2}{|c|}{ Scheffé } & \multicolumn{3}{|c|}{ [SDScores, $\{0 ; 1\} ; \alpha=, 05]$} & \multicolumn{2}{|c|}{ Waller-Duncan } & \multicolumn{3}{|c|}{ [SDScores, $\{0 ; 1\} ; \alpha=, 05]$} \\
\hline Index & $\mathrm{n}$ & 1 & 2 & 3 & 4 & $\mathrm{n}$ & 1 & 2 & 3 & 4 \\
\hline Kein & 95 & 240 & & & & 95 &, 240 & & & \\
\hline SDax & 146 & & ,296 & & & 146 & & ,296 & & \\
\hline TecDax & 85 & & & ,339 & & 85 & & & ,339 & \\
\hline MDax & 218 & & &, 347 & & 218 & & & ,347 & \\
\hline Dax & 156 & & & &, 423 & 156 & & & & ,423 \\
\hline p-Wert & & 1,000 & 1,000 & ,989 & 1,000 & & & & & \\
\hline
\end{tabular}

Tabelle 41: Einfluss der Indexzugehörigkeit auf das Berichtsverhalten

Wie ersichtlich ist, bestehen signifikante Unterschiede zwischen den Indizes im Hinblick auf die Strategieberichterstattung. Bemerkenswert ist, dass im Rahmen

1093 Es wurde erwähnt, dass die Indizes nicht als Rangfolge anzusehen sind und die Indexzugehörigkeit nicht als ordinal skaliertes Merkmal gelten kann, vgl. Abschnitt C 3.3.3. 
der Einzelvergleiche vier homogene Untergruppen identifiziert werden können, welche die in Abb. 14 dargestellte Indexpyramide der Dt. Börse AG exakt nachbilden - interessanterweise inkl. der ,Gleichwertigkeit" von MDax und TecDax. Um die Indexzugehörigkeit innerhalb von Regressionsanalysen berücksichtigen zu können, scheint eine Bildung von vier Dummy-Variablen empfehlenswert. ${ }^{1094}$ Weiter wurde mit H 2.10 vermutet, dass eine zusätzliche Notierung der Aktien eines Unternehmens an einer ausländischen Wertpapierbörse Einfluss auf das jeweilige Niveau der Strategieberichterstattung besitzt. Dazu wurde auf die ZweitNotierungen an der US-amerikanischen New York Stock Exchange (NYSE) abgestellt und dieses mit einer dichotomen Variablen kodiert. ${ }^{1095}$ Folgerichtig kann ein t-Test angewendet werden, um potenzielle Unterschiede im Hinblick auf das Niveau der Strategieberichterstattung zwischen zusätzlich in den USA notierten Unternehmen und Gesellschaften, die nur an inländischen Börsenplätzen notiert sind, festzustellen. Die Ergebnisse zeigt die nachstehende Tab. 42.

Analyse der Strategieberichterstattung in Abhängigkeit eines Auslandslistings (t-Test)

\begin{tabular}{|c|c|c|c|c|c|c|c|c|c|c|c|c|c|c|c|}
\hline \multicolumn{8}{|c|}{ Keine Börsennotierung an der NYSE } & \multicolumn{8}{|c|}{ Zusätzliche Börsennotierung an der NYSE } \\
\hline \multicolumn{5}{|c|}{ SDScores } & \multicolumn{3}{|c|}{ [normiert, $\{0 ; 1\}]$} & \multicolumn{5}{|c|}{ SDScores } & \multicolumn{3}{|c|}{ [normiert, $\{0 ; 1\}]$} \\
\hline \multirow[b]{2}{*}{$\mu$} & \multicolumn{2}{|c|}{ Extrema } & \multicolumn{3}{|c|}{ Perzentile } & \multirow[b]{2}{*}{$\sigma$} & \multirow[b]{2}{*}{ n } & \multirow[b]{2}{*}{$\mu$} & \multicolumn{2}{|c|}{ Extrema } & \multicolumn{3}{|c|}{ Perzentile } & \multirow[b]{2}{*}{$\sigma$} & \multirow[b]{2}{*}{$n$} \\
\hline & Min & $\underline{\operatorname{Max}}$ & $25 \%$ & $50 \%$ & $75 \%$ & & & & Min & Max & $25 \%$ & $50 \%$ & $75 \%$ & & \\
\hline \multirow[t]{2}{*}{, 328} &, 030 & 750 &, 250 &, 330 & .400 &, 115 & 638 &, 441 &, 130 & .830 & 345 &, 450 &, 535 &, 152 & 62 \\
\hline & & & & F & $F$ & $\mathrm{p}-\mathrm{W}$ & & & & & & d & f & $\mathrm{p}-\mathrm{W}$ & \\
\hline \multicolumn{3}{|c|}{ Levene-Test } & & \multicolumn{2}{|c|}{9,6} & \multicolumn{2}{|c|}{, $002 * * *$} & \multicolumn{3}{|l|}{$t$-Test } & & \multicolumn{2}{|c|}{67,9} & \multicolumn{2}{|c|}{, $000 * * *$} \\
\hline
\end{tabular}

Tabelle 42: Einfluss einer Auslandsnotierung auf das Berichtsverhalten

Wie ersichtlich wird, können signifikante Differenzen hinsichtlich des Berichtsverhaltens identifiziert werden, eine Aufnahme der entsprechenden Variablen in regressionsanalytische Untersuchungen scheint also sinnhaft, um abzuklären, ob der Einfluss in einem um andere Einflussfaktoren erweiterten Kontext stabil ist.

Zur Operationalisierung einer Kapitalkonzentration - zur Prüfung von H 2.11a sind im Rahmen der Datenbeschaffung mehrere Indikatoren abgebildet worden,

1094 Es sind vier Dummy-Variablen erforderlich, da insg. fünf Kategorien zu unterscheiden sind. Als Referenzpunkt dient ,Kein Index“. Dem Resultat der ANOVA entsprechend sind ausnahmslos Regressionskoeffizienten mit positivem Vorzeichen zu erwarten. 
die jeweils unterschiedlich starke Formen der Konzentration darstellen. ${ }^{1096}$ Wie Tab. 43 zeigt, besitzen diese Indikatoren untereinander hoch signifikant positive Korrelationskoeffizienten, so dass anzunehmen ist, dass jene den gleichen Sachverhalt, namentlich eine Kapitalkonzentration, repräsentieren. Eine Verdichtung zu einem Faktor scheint folglich sinnvoll. Zusätzlich soll jedoch im Rahmen der Regressionsmodelle auch der Einzelindikator des inversen Freefloats betrachtet werden, da dieser den stärksten Zusammenhang mit SDIndex aufweist.

Panel A: Korrelationsanalyse der Indikatoren der Kapitalkonzentration

Bivariate Korrelationsanalyse der Indikatoren der Kapitalkonzentration. Werte unterhalb der Diagonale stellen die Korrelationskoeffizienten nach Pearson, Werte oberhalb der Diagonale die Rang-Korrelationskoeffizienten nach Spearman dar.

\begin{tabular}{|c|c|c|c|c|c|c|c|c|c|}
\hline & $=700$ & & 1 & 2 & 3 & 4 & 5 & 6 & 7 \\
\hline 1 & SDI & $\begin{array}{l}\text { Koeffizient } \\
\text { p-Wert }\end{array}$ & & $\begin{array}{l}-, 129 * * * \\
(, 001)\end{array}$ & $\begin{array}{l}-, 128 * * * \\
(.001)\end{array}$ & $\begin{array}{l}-, 125 * * * \\
(, 001)\end{array}$ & $\begin{array}{l}-, 119 * * * \\
(, 002)\end{array}$ & $\begin{array}{l}-, 051 \text { n.s. } \\
(, 179)\end{array}$ & $\begin{array}{l}-, 105 * * * \\
(.005)\end{array}$ \\
\hline 2 & $\begin{array}{l}\text { Inverser } \\
\text { Freefloat }\end{array}$ & $\begin{array}{l}\text { Koeffizient } \\
\text { p-Wert }\end{array}$ & $\begin{array}{l}-, 143 * * * \\
(.000)\end{array}$ & & $\begin{array}{l}, 720 * * * \\
(.000)\end{array}$ & $\begin{array}{l}, 728 * * * \\
(, 000)\end{array}$ & $\begin{array}{l}, 721 * * * \\
(, 000)\end{array}$ & $\begin{array}{l}, 683 * * * \\
(.000)\end{array}$ & $\begin{array}{l}, 722 * * * \\
(.000)\end{array}$ \\
\hline 3 & $\begin{array}{l}\text { Direktanteile } \\
\text { gesamt }\end{array}$ & $\begin{array}{l}\text { Koeffizient } \\
\text { p-Wert }\end{array}$ & $\begin{array}{l}-, 132 * * * \\
(.000)\end{array}$ & $\begin{array}{l}, 711 * * * \\
(.000)\end{array}$ & & $(.000)$ & $\begin{array}{l}(, 097 * * * \\
(, 000)\end{array}$ & $\begin{array}{l}, 911 * * * \\
(.000)\end{array}$ & $\begin{array}{l}, 992 * * * \\
(.000)\end{array}$ \\
\hline 4 & $\begin{array}{l}\text { Anteile } \\
\text { größer 5\% }\end{array}$ & $\begin{array}{l}\text { Koeffizient } \\
\text { p-Wert }\end{array}$ & $\begin{array}{l}-, 125 * * * \\
(.001)\end{array}$ & $\begin{array}{l}, 719 * * * \\
(, 000)\end{array}$ & $\begin{array}{l}, 996 * * * \\
(.000)\end{array}$ & & $\begin{array}{l}, 995 * * * \\
(, 000)\end{array}$ & $\begin{array}{l}, 922 * * * \\
(, 000)\end{array}$ & $\begin{array}{l}, 994 * * * \\
(.000)\end{array}$ \\
\hline 5 & $\begin{array}{l}\text { Anteile Top } 5 \\
\text { Aktionäre }\end{array}$ & $\begin{array}{l}\text { Koeffizient } \\
\text { p-Wert }\end{array}$ & $\begin{array}{l}-, 123 * * * \\
(.001)\end{array}$ & $\begin{array}{l}, 714 * * * \\
(, 000)\end{array}$ & $\begin{array}{l}, 996 * * * \\
(.000)\end{array}$ & $\begin{array}{l}, 996 * * * \\
(, 000)\end{array}$ & & $\begin{array}{l}, 921 * * * \\
(, 000)\end{array}$ & $\begin{array}{l}, 995 * * * \\
(, 000)\end{array}$ \\
\hline 6 & $\begin{array}{l}\text { Anteile größter } \\
\text { Aktionär }\end{array}$ & $\begin{array}{l}\text { Koeffizient } \\
\text { p-Wert }\end{array}$ & $\begin{array}{l}-, 046 \mathrm{n} . \mathrm{s} . \\
(, 221)\end{array}$ & $\begin{array}{l}, 669 * * * \\
(.000)\end{array}$ & $\begin{array}{l}, 898 * * * \\
(.000)\end{array}$ & $\begin{array}{l}, 912 * * * \\
(, 000)\end{array}$ & $\begin{array}{l}, 910 * * * \\
(, 000)\end{array}$ & & $\begin{array}{l}, 949 * * * \\
(.000)\end{array}$ \\
\hline 7 & Faktor & $\begin{array}{l}\text { Koeffizient } \\
\text { p-Wert }\end{array}$ & $\begin{array}{l}-, 109 * * * \\
(.000)\end{array}$ & $\begin{array}{l}, 717^{* * *} \\
(.0(0))\end{array}$ & $\begin{array}{l}, 991^{* * *} \\
(.00(0))\end{array}$ & $\begin{array}{l}, 995 * * * \\
(, 000)\end{array}$ & $\begin{array}{l}, 994 * * * \\
(, 000)\end{array}$ & $\begin{array}{l}, 946 * * * \\
(.000)\end{array}$ & \\
\hline
\end{tabular}

Panel B: Faktorenanalyse zur Extraktion eines Faktors der Kapitalkonzentration

Faktorenanalyse der in Panel A gekennzeichneten Indikatoren der Kapitalkonzentration nach der Methode der Hauptkomponentenanalyse

\section{Prüfgrößen}

\begin{tabular}{|c|c|c|c|}
\hline \multicolumn{2}{|l|}{$\mathrm{KMO}$} & \multicolumn{2}{|c|}{ Bartlett-Test } \\
\hline MSA &, 841 & $\mathrm{Chi}^{2}$ & $8.265,6$ \\
\hline & & df & 6 \\
\hline
\end{tabular}

p-Wert $\quad, 000 * * *$
Erklärte Gesamtvarianz

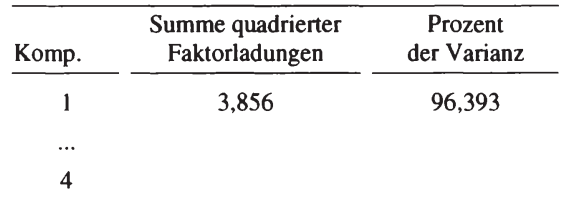

\section{Tabelle 43: Bivariate Analyse der Indikatoren der Kapitalstruktur}

1096 Vgl. die Variablendefinitionen in Tab. 5 (S. 221f.). Der ,Inverse Freefloat ' ist der Anteil des Kapitals, der nicht handelbar ist. ,Direktanteile gesamt" stellt den Anteil der Direktaktionären mit $>3 \%$ Anteil am Kapital dar. ,Anteile größer 5\%" umfasst die Anteile der Aktionäre, die $>5 \%$ des Grundkapitals halten, ,Anteile Top 5-Aktionäre“ sowie ,Anteile größter Aktionär ‘ repräsentieren den Anteil der fünf bzw. des größten Aktionärs.

Tom Sieber - 978-3-631-75150-3 
Wie ein Blick auf Tab. 43 offenbart, sind die Zusammenhänge jener Indikatoren mit dem Niveau der Strategieberichterstattung negativ definiert, so dass höhere Kapitalkonzentration tendenziell ein vermindertes Berichtsniveau erwarten lässt.

Neben den zuvor dargestellten quantitativen Daten der Kapitalkonzentration soll in diesem Kontext mit $\mathbf{H}$ 2.11b auch geprüft werden, ob der Typus des größten Einzelaktionärs Einfluss auf das Strategieberichtsverhalten besitzt. Folgerichtig wurden vier Typen von Großaktionären identifiziert und als kategoriale Variable kodiert. Eine Überprüfung möglicher Unterschiede im Berichtsverhalten erfolgt schließlich im Rahmen einer Varianzanalyse, die in Tab. 44 dargestellt ist.

\begin{tabular}{|c|c|c|c|c|c|c|}
\hline \multicolumn{7}{|c|}{ Panel A: Strategieberichterstattung in Abhängigkeit des Typus des größten Einzelaktionärs (ANOVA) } \\
\hline & Quadratsumme & df & $\begin{array}{r}\text { Quadrierte } \\
\text { Mittelwerte }\end{array}$ & \multicolumn{2}{|c|}{$\mathbf{F}$} & p-Wert \\
\hline Zwischen den Gruppen &, 501 & 4 &, 125 & \multirow{2}{*}{\multicolumn{2}{|c|}{8,7}} &, $000 * * *$ \\
\hline Innerhalb der Gruppen & 10,004 & 695 &, 014 & & & \\
\hline Total & 10,505 & 699 & & & & \\
\hline \multicolumn{7}{|c|}{ Panel B: Einzelvergleiche zum Typus des größten Einzelaktionärs (Post Hoc-Tests) } \\
\hline [SDScores, $\{0 ; 1\}]$ & \multicolumn{2}{|c|}{ Scheffé } & {$[\alpha=, 05]$} & \multicolumn{2}{|c|}{ Waller-Duncan } & {$[\alpha=, 05]$} \\
\hline Typus Großaktionär & & 1 & 2 & $\mathrm{n}$ & 1 & 2 \\
\hline Strategischer Investor & &, 318 & & 144 & .318 & \\
\hline Privat/Familie & &, 326 & & 248 &, 326 & \\
\hline Kein Großaktionär & &, 344 & & 195 &, 344 & \\
\hline Finanzinvestor & &, 348 & & 76 &, 348 & \\
\hline Staat/Öffentliche Hand & & & ,441 & 37 & &, 441 \\
\hline$p-W e r t$ & &, 573 & 1,000 & & & \\
\hline
\end{tabular}

\section{Tabelle 44: Einfluss des Großaktionärstypus auf das Berichtsverhalten}

Es zeigen sich folglich hoch signifikante Unterschiede zwischen den definierten Gruppen von Großaktionären, eindeutig scheint v.a. der Unterschied zu den von staatlichen Institutionen beherrschten Unternehmen. Es kann daher auch hier als ratsam gelten, den Typus des Großaktionärs in einem Regressionsmodell zu berücksichtigen, da ein Einfluss auf das Berichtsverhalten gegeben scheint. ${ }^{1097}$

1097 Hierzu ist eine Dummy-Kodierung erforderlich: Referenzgruppe ist die Kategorie ,Kein Großaktionär'. Für die von strategischen Investoren sowie Familien beherrschten Unternehmen sind folglich negative, sonst positive Regressionskoeffizienten zu erwarten. 
Abschließend erfolgt mit Hypothese H 2.12 die Untersuchung der Daten zu sog. Insidertransaktionen in Bezug auf ihren Einfluss auf das Niveau der Strategieberichterstattung. Dazu sind sowohl Kauf- als auch Verkaufstransaktionen für zwei Arten von Insidern auf Zusammenhänge mit dem Niveau der Strategieberichterstattung zu untersuchen. Mit offiziellen Daten der BaFin steht für diese Analyse von Insidertransaktionen zwar eine qualitativ überaus hochwertige Datengrundlage zur Verfügung, ein Zusammenhang mit SDIndex kann allerdings nicht aufgedeckt werden, wie die bivariate Korrelationsanalyse in Tab. 45 zeigt.

\begin{tabular}{|c|c|c|c|c|c|c|}
\hline \multicolumn{3}{|c|}{ Korrelationsanalyse der Indikatoren der Insidertransaktionen } & $\begin{array}{l}\text { saktionen } \\
\text {. Werte unter } \\
\text { effizienten na }\end{array}$ & $\begin{array}{l}\text { der Diagonale } \\
\text { earman dar. }\end{array}$ & en dic Korrela & koeffizienten \\
\hline $\mathrm{n}=700$ & & 1 & 2 & 3 & 4 & 5 \\
\hline $1 \mathrm{SDI}$ & $\begin{array}{l}\text { Koeffizient } \\
\text { p-Wert }\end{array}$ & & $\begin{array}{l}, 189 * * * \\
(.000)\end{array}$ & $\begin{array}{l}, 219 * * * \\
(.000)\end{array}$ & $\begin{array}{l}, 185^{* * *} \\
(, 000)\end{array}$ & $\begin{array}{l}, 215 * * * \\
(.000)\end{array}$ \\
\hline $\begin{array}{l}2 \text { Käufe aller } \\
\text { Insider (Stck.) }\end{array}$ & $\begin{array}{l}\text { Koeffizient } \\
\text { p-Wert }\end{array}$ & $\begin{array}{l}, 004 \text { n.s. } \\
(.907)\end{array}$ & & $\begin{array}{l}, 799 * * * \\
(.000)\end{array}$ & $\begin{array}{l}, 995 * * * \\
(, 000)\end{array}$ & $\begin{array}{l}, 796 * * * \\
(.000)\end{array}$ \\
\hline $\begin{array}{l}3 \text { Käufe nur } \\
\text { Mgmt. (Stck.) }\end{array}$ & $\begin{array}{l}\text { Koeffizient } \\
\text { p-Wert }\end{array}$ & $\begin{array}{l}-, 041 \text { n.s. } \\
(.280)\end{array}$ & $\begin{array}{l}, 277 * * * \\
(, 000)\end{array}$ & & $\begin{array}{l}, 789 * * * \\
(.000)\end{array}$ & $\begin{array}{l}, 997 * * * \\
(.000)\end{array}$ \\
\hline $\begin{array}{l}4 \text { Käufe aller } \\
\text { Insider (Vol.) }\end{array}$ & $\begin{array}{l}\text { Koeffizient } \\
\text { p-Wert }\end{array}$ & $\begin{array}{l}-, 018 \text { n.s. } \\
(.643)\end{array}$ & $\begin{array}{l}, 780 * * * \\
(.000)\end{array}$ & $\begin{array}{l}, 236 * * * \\
(.000)\end{array}$ & & $\begin{array}{l}, 793 * * * \\
(.000)\end{array}$ \\
\hline $\begin{array}{l}5 \text { Käufe nur } \\
\text { Mgmt. (Vol.) }\end{array}$ & $\begin{array}{l}\text { Koeffizient } \\
\text { p-Wert }\end{array}$ & $\begin{array}{l}-, 017 \text { n.s. } \\
(.657)\end{array}$ & $\begin{array}{l}, 361 * * * \\
(, 000)\end{array}$ & $\begin{array}{l}, 783 * * * \\
(.000)\end{array}$ & $\begin{array}{l}, 490 * * * \\
(.000)\end{array}$ & \\
\hline$n=700$ & & 1 & 2 & 3 & 4 & 5 \\
\hline $1 \mathrm{SDI}$ & $\begin{array}{l}\text { Koeffizient } \\
\text { p-Wert }\end{array}$ & & $\begin{array}{l}, 091 * * \\
(, 016)\end{array}$ & $\begin{array}{l}, 143 * * * \\
(.000)\end{array}$ & $\begin{array}{l}, 101 * * * \\
(, 008)\end{array}$ & $\begin{array}{l}, 149 * * * \\
(.000)\end{array}$ \\
\hline $\begin{array}{l}2 \text { Verkäufe aller } \\
\text { Insider (Stck.) }\end{array}$ & $\begin{array}{l}\text { Koeffizient } \\
\text { p-Wert }\end{array}$ & $\begin{array}{c}-, 071^{*} \\
(.059)\end{array}$ & & $\begin{array}{l}, 719 * * * \\
(.000)\end{array}$ & $\begin{array}{l}, 997 * * * \\
(.000)\end{array}$ & $\begin{array}{l}, 718 * * * \\
(.000)\end{array}$ \\
\hline $\begin{array}{l}3 \text { Verkäufe nur } \\
\text { Mgmt. (Stck.) }\end{array}$ & $\begin{array}{l}\text { Koeffizient } \\
\text { p-Wert }\end{array}$ & $\begin{array}{l}-, 058 \text { n.s. } \\
(.129)\end{array}$ & $\begin{array}{l}, 618 * * * \\
(, 000)\end{array}$ & & $\begin{array}{l}, 720 * * * \\
(.000)\end{array}$ & $\begin{array}{l}, 999 * * * \\
(.000)\end{array}$ \\
\hline $\begin{array}{l}4 \text { Verkäufe aller } \\
\text { Insider (Vol.) }\end{array}$ & $\begin{array}{l}\text { Koeffizient } \\
\text { p-Wert }\end{array}$ & $\begin{array}{l}-, 060 \text { n.s. } \\
(.115)\end{array}$ & $\begin{array}{l}, 813 * * * \\
(.000)\end{array}$ & $\begin{array}{l}, 489 * * * \\
(.000)\end{array}$ & & $\begin{array}{l}, 721 * * * \\
(, 000)\end{array}$ \\
\hline $\begin{array}{l}5 \text { Verkäufe nur } \\
\text { Mgmt. (Vol.) }\end{array}$ & $\begin{array}{l}\text { Koeffizient } \\
\text { p-Wert }\end{array}$ & $\begin{array}{l}-, 046 \mathrm{n} . \mathrm{s} . \\
(.226)\end{array}$ & $\begin{array}{l}, 606 * * * \\
(, 000)\end{array}$ & $\begin{array}{l}, 982 * * * \\
(, 000)\end{array}$ & $\begin{array}{l}, 498 * * * \\
(.000)\end{array}$ & \\
\hline
\end{tabular}

\section{Tabelle 45: Einfluss von Insidertransaktionen auf das Berichtsverhalten}

Offensichtlich steht das gewählte Berichtsverhalten eines Unternehmens folglich nicht in einem Zusammenhang mit individualökonomischen Handlungen seitens der Führungskräfte. Das Volumen der Insidertransaktionen scheint daher zur Erklärung des Niveaus der Strategieberichterstattung nicht geeignet - et vice versa. 


\section{(b) Partielles Regressionsmodell der Faktoren des Aktienkapitals}

Wie bereits für die drei vorherigen Kategorien möglicher Bestimmungsfaktoren des Niveaus der Strategieberichterstattung soll auch für die soeben behandelten Faktoren des Aktienkapitals ein partielles Regressionsmodell aufgebaut werden.

Zunächst wird jedoch eine Regressionsanalyse für die qualitativen Variablen zur Börsennotierung durchgeführt, welche als Modell 1 in Tab. 46 dargestellt ist. Es zeigt sich, dass sowohl der inländischen Indexzugehörigkeit als auch der Zweitnotierung an einer (hier: der US-amerikanischen NYSE) Auslandsbörse herausragender Einfluss auf das Berichtsverhalten zugeschrieben werden kann. ${ }^{1098}$ Jene Variablen erreichen bei Kontrolle durch Jahr ein korrigiertes Bestimmtheitsmaß von über $30 \%$. Weiterhin bestätigen einzelne Regressionsanalysen von SDIndex auf die Indikatoren der Kapitalkonzentration den Einfluss dieser Größen auf das Berichtsverhalten über strategieorientierte Inhalte. ${ }^{1099}$ Auch für die Variable des Typs eines Großaktionärs kann in einer Einfachregression ein signifikanter Einfluss bestätigt werden, die einzelnen Regressionskoeffizienten zeigen zudem die a priori erwarteten Vorzeichen. ${ }^{1100}$

Schließlich präsentiert Tab. 46 als Modell 4 das partielle Regressionsmodell der Faktoren des Aktienkapitals. Wie ersichtlich wird, ist der Einfluss der Indexzugehörigkeit in dem erweiterten Modell nach wie vor stark bzw. hoch signifikant. Darüber hinaus können auch für die Variable des Auslandslistings sowie für den Typus des Großaktionärs signifikante Regressionskoeffizienten gezeigt werden. Es ist daher weiterhin davon auszugehen, dass diese Parameter Einfluss auf das Berichtsverhalten ausüben. Das auf Basis des partiellen Regressionsmodells ermittelte korrigierte Bestimmtheitsmaß von ca. 33\% unterstreicht schließlich den hohen Einfluss der Faktoren des Aktienkapitals auf das Berichtsverhalten.

\footnotetext{
1098 Diesen Einfluss einer Auslandsnotierung zeigen Gray et al. (1995); Leuz (1999) zum dt. Kapitalmarkt; Achleitner et al. (2005) bestätigen den Einfluss der Indexzugehörigkeit.

10\%) Einen Beleg für den Einfluss dieses Parameters liefern ebenfalls Leuz (1999) bzw. auch Leuz/Verrecchia (2000), jeweils mit Fokus auf den dt. Kapitalmarkt.
}

1100) Der Terminus ,Einfachregression“ ist hier - aufgrund der vier Dummy-Variablen sowie der inkludierten Kontrollvariablen Jahr nicht vollständig korrekt, da insgesamt fünf Regressoren zu unterscheiden sind. Da es sich jedoch im Kern nur um eine interessierende unabhängige Variable handelt, kann dieser Begriff dennoch verwendet werden. 
Regressionsanalyse zum Einfluss der Faktoren des Aktienkapitals auf die Strategieberichterstattung

$\mathrm{F}(\mathrm{x})=$ Niveau der Strategieberichterstattung

\begin{tabular}{|c|c|c|c|c|c|c|c|c|}
\hline & \multicolumn{2}{|c|}{$\begin{array}{l}\text { Modell 1: } \\
\text { Börsennotierung }\end{array}$} & \multicolumn{2}{|c|}{$\begin{array}{c}\text { Modell 2: } \\
\text { Kapitalstruktur }\end{array}$} & \multicolumn{2}{|c|}{$\begin{array}{l}\text { Modell 3: } \\
\text { Eigentümer }\end{array}$} & \multicolumn{2}{|c|}{$\begin{array}{c}\text { Modell 4: } \\
\text { Partialmodell }\end{array}$} \\
\hline & Koeff. $\beta$ & $\mathrm{p}$ & Koeff. $\beta$ & $\mathrm{p}$ & Koeff. $\beta$ & $\mathrm{p}$ & Koeff. $\beta$ & $\mathrm{p}$ \\
\hline \multicolumn{9}{|c|}{ Indexzugehörigkeit (?) } \\
\hline Dax &, $510 * * *$ & $(.000)$ & & & & &, $493 * * *$ & $(, 000)$ \\
\hline MDax &, $404 * * *$ & $(, 000)$ & & & & &, $398 * * *$ & $(.000)$ \\
\hline TecDax &, $219 * * *$ & $(, 000)$ & & & & &, $211 * * *$ & $(.000)$ \\
\hline SDax &, $129 * * *$ & $(.005)$ & & & & &, $126 * * *$ & $(.006)$ \\
\hline
\end{tabular}

Auslandslisting (?)

Auslandslisting

, $082 * * \quad(, 027)$

, $085 * * \quad(, 022)$

\section{Kapitalkonzentration}

Inverser Freefloat (-)

$\begin{aligned}-, 123 * * * & (.000) \\ {[-, 105 * * *} & (.003)]^{1101}\end{aligned}$

, 006

$(.873)$

Konzentrationsgrad [Faktor] (-)

Typ größter Einzelaktionär (?)

Stratege

Privat/Familie

Finanzinvestor

Staat

$\begin{array}{llcl}-, 131 * * * & (.000) & -, 092 * * & (.036) \\ -, 076 * & (.073) & , 036 & (.414) \\ , 013 & (.733) & -, 005 & (.883) \\ , 161 * * * & (, 000) & , 098 * * * & (.005)\end{array}$

Kontrollvariablen

\begin{tabular}{|c|c|c|c|c|c|c|c|c|}
\hline Konstante & & $(.000)$ & & $(.000)$ & & $(, 000)$ & & $(, 000)$ \\
\hline Jahr &, $327 * * *$ & $(.000)$ &, $344 * * *$ & $(, 000)$ &, $363 * * *$ & $(, 000)$ &, $341 * * *$ & $(.000)$ \\
\hline$R^{2}$ & ,320 & &, 137 & &, 173 & &, 342 & \\
\hline$R^{2}$ adj. &, $314 * * *$ & $(, 000)$ &, $134 * * *$ & $(.000)$ &, $167 * * *$ & $(.000)$ &, $332 * * *$ & $(.000)$ \\
\hline Durbin-Watson $d$ & 1,960 & & 1,872 & & 1,980 & & 1,961 & \\
\hline $\mathrm{n}\left(\mathrm{n}_{\max }=700\right)$ & 700 & & 700 & & 700 & & 700 & \\
\hline
\end{tabular}

Tabelle 46: Partielles Regressionsmodell der Faktoren des Aktienkapitals

1101 Dieser Regressionskoeffizient $\beta=-, 105$ sowie der dazugehörige $\mathrm{p}$-Wert $p=, 003$ beziehen sich auf eine Regressionsanalyse mit den Regressoren Konzentrationsgrad [Faktor] bzw. $J a h r$ sowie dem Regressanden SDIndex, die hier nicht einzeln ausgewiesen wird. Diese Analyse ergab ein korrigiertes $R^{2}=, 133$ bei einem F-Wert von $F=, 000$.

Im Folgenden wird daher schwerpunktmäßig auf den inversen Freefloat abgestellt.

Tom Sieber - 978-3-631-75150-3 


\subsection{Untersuchung des Gesamtmodells der Bestimmungsfaktoren}

\subsubsection{Einleitende Anmerkungen zum Gesamtmodell}

Als Ziel des Teilmodells der Bestimmungsfaktoren wurde eingangs genannt, ein möglichst umfassendes Verständnis relevanter Einflussfaktoren auf das Niveau der Strategieberichterstattung aufzubauen. Vor diesem Hintergrund wurden die vier Kategorien von Bestimmungsfaktoren abgeleitet und im Rahmen des vorangegangenen Abschnitts D 4.1 einzeln analysiert. Auf Basis der so gewonnenen Erkenntnisse zur Relevanz einzelner Parameter soll nun das gesamthafte Modell der Bestimmungsfaktoren aufgestellt werden, welches im Untersuchungsplan in Tab. 10 als Ebene 3 der Hypothesenprüfung definiert wurde. ${ }^{1102}$

Die Ergebnisse der Regressionsanalysen sind in der nachfolgenden Tab. 47 dargestellt, wobei Tab. 47-1 zunächst nur diejenigen Prädiktoren umfasst, welche in metrischer Skalierung vorhanden sind: Hier sind neben dem Faktor der Kapitalmarktentwicklung, der Unternehmensgröße bzw. der Finanzierungsstruktur auch die Variablen der Profitabilität und der Kapitalkonzentration zu berücksichtigen. Diese Prädiktoren bilden das als Hauptmodell 1 bezeichnete Regressionsmodell, welches zudem - zur Ableitung differenzierter Aussagen - für die beiden in Abschnitt D 2.1.2 gebildeten Teil-Stichproben separat gerechnet wird. ${ }^{1103}$ Schließlich wird Hauptmodell 1 um den in Form von Dummy-Variablen kodierten Prädiktor der Indexzugehörigkeit erweitert, da dieser im Rahmen des Partialmodells in D 4.1.4 einen überaus hohen Einfluss auf SDIndex gezeigt hat.

Die anschließende Tab. 47-2 greift sodann sämtliche innerhalb des Teilmodells der Bestimmungsfaktoren untersuchten Determinanten des Strategieberichtsverhaltens auf und prüft ihren jeweiligen Einfluss im gesamthaften Kontext. Folgerichtig werden in dieser - als Hauptmodell 2 bezeichneten - Regressionsanalyse neben den metrisch skalierten Prädiktoren auch die relevanten qualitativen Prädiktoren berücksichtigt. Dieses Hauptmodell wird darüber hinaus zudem für die großen und die kleinen Unternehmen separat berechnet.

1102 Vgl. erneut den Untersuchungsplan in Tab. 10 (S. 243) oder aber Abb. 23 (S. 245).

1103 In Summe werden nach Durchführung aller Hypothesenprüfungen sieben Hauptmodelle definiert worden sein. Diese stellen den Kern der eigenen Untersuchung dar. 


\subsubsection{Berechnung des Gesamtmodells der Bestimmungsfaktoren}

Das soeben definierte und in Tab. 47-1 dargestellte Hauptmodell 1, welches die fünf metrisch skalierten Bestimmungsfaktoren des Niveaus der Strategieberichterstattung beinhaltet, erzielt auf Basis der Gesamtstichprobe ein Bestimmtheits$\mathrm{ma} ß$ von rund $26 \%$. Neben dem nach wie vor stark positiven Einfluss der Unternehmensgröße können außerdem der positive Einfluss der makroökonomischen Bedingungen - operationalisiert durch die Kapitalmarktbedingungen - sowie der negative Einfluss der Kapitalkonzentration signifikant bestätigt werden. Keinen Einfluss üben hingegen die finanziellen Faktoren des Unternehmenserfolges und der Finanzierungsstruktur bzw. des Verschuldungsgrades in diesem Modell aus.

Interessante Ergebnisse ergeben sich sodann, wenn die Betrachtung auf die zwei Teil-Stichproben begrenzt wird: Für große Unternehmen können über 30\% der Varianz der Strategieberichterstattung erklärt werden, da sämtliche quantitativen Bestimmungsfaktoren höchst signifikante Regressionskoeffizienten aufweisen mit Ausnahme des makroökonomischen Faktors. Offensichtlich orientieren sich große Unternehmen bei der Wahl ihres Berichtsniveaus folglich weniger an der ökonomischen Außenwelt als vielmehr an internen finanzwirtschaftlichen Gegebenheiten, wie die hoch signifikanten Koeffizienten des Erfolges und des Verschuldungsgrades demonstrieren. Auch die Unternehmensgröße und die Kapitalkonzentration leisten in jener Stichprobe einen deutlichen Beitrag zur Erklärung des Berichtsverhaltens im Hinblick auf strategieorientierte Informationen.

Für die Gruppe der kleinen Unternehmen hingegen gestaltet sich eine Erklärung des Berichtsverhaltens auf Basis quantitativer Faktoren komplizierter: Neben der Größe sowie den makroökonomischen Konditionen besitzt lediglich die Kapitalstruktur einen - vergleichsweise schwach - signifikant negativen Koeffizienten.

Wird die Analyse der Gesamt-Stichprobe allerdings um die Indexzugehörigkeit erweitert, was aufgrund ihres festgestellten Einflusses auf das Berichtsverhalten gerechtfertigt erscheint, verliert die Größe ihren signifikanten Einfluss. ${ }^{1104}$ Dies

1104 Trotz gewisser Zusammenhänge zwischen der Variablen Indexzugehörigkeit sowie der Variablen Unternehmensgröße wurden die definierten Grenzwerte für die Kennzahl VIF verfehlt, (perfekte) Multikollinearität ist folglich nicht festzustellen. 
kann damit erklärt werden, dass Größenaspekte auch bei der Zusammenstellung der Auswahlindizes der Dt. Börse AG eine wichtige Einflussgröße darstellen. ${ }^{1105}$ Die beschriebenen Ergebnisse präsentiert die folgende Tab. 47-1 im Überblick.

Regressionsanalyse zum Einfluss quantitativer Bestimmungsfaktoren auf die Strategieberichterstattung $I(x)=$ Niveau der Strategicberichterstattung

\begin{tabular}{|c|c|c|c|c|c|c|c|c|}
\hline & \multicolumn{2}{|c|}{ Hauptmodell 1} & \multicolumn{2}{|c|}{$\begin{array}{l}\text {... nur für große } \\
\text { Unternehmen }\end{array}$} & \multicolumn{2}{|c|}{$\begin{array}{l}\text {... nur für kleine } \\
\text { Unternehmen }\end{array}$} & \multicolumn{2}{|c|}{$\begin{array}{c}\text { Erweitertes } \\
\text { Hauptmodell } 1\end{array}$} \\
\hline & Koeff. $\beta$ & $\mathrm{p}$ & Koeff. $\beta$ & $\mathrm{p}$ & Koeff. $\beta$ & $\mathrm{p}$ & Koeff. $\beta$ & $\mathrm{p}$ \\
\hline \multicolumn{9}{|c|}{ Makroökonomische Faktoren } \\
\hline Börse [Faktor] (+) & $.120^{* * *}$ & $(.()() 3)$ &, $106^{*}$ & $(.058)$ &, $122 * *$ & $(.049)$ &, $137 * * *$ & $(.(K))$ \\
\hline \multicolumn{9}{|c|}{ Unternehmenscharakteristika } \\
\hline Größe [Faktor] (+) & $.338 * * *$ & $(.(x)(x))$ &, $214 * * *$ & $(.(0)(0)$ &, $211 * * *$ & $(.(0)(x))$ &,- 038 & $(.572)$ \\
\hline \multicolumn{9}{|l|}{ Finanzielle Faktoren } \\
\hline Erfolg [Faktor] (+) &, 020 & $(.549)$ &, $165 * * *$ & $(.(0) 1)$ &,- 016 & $(.767)$ &,- 011 & $(.740)$ \\
\hline Verschuldung $[F](+)$ &, 031 & $(.360)$ & $.159 * * *$ & $(.(0) 1)$ &,- 070 & $(.193)$ &, $100 * * *$ & $(.(0) 4)$ \\
\hline \multicolumn{9}{|c|}{ Faktoren des Aktienkapitals } \\
\hline Inv. Freefloat (-) &,$- 093 * * *$ & $(.005)$ &,$- 157 * * *$ & $(.(0)(0))$ &,$- 077 *$ & $(.094)$ &,- 001 & (.977) \\
\hline \multicolumn{9}{|l|}{ Indexzugehörigkeit (?) } \\
\hline Dax & & & & & & &, $585 * * *$ & $(.(X K))$ \\
\hline MDax & & & & & & &, $431 * * *$ & $(.0(x))$ \\
\hline TecDax & & & & & & &, $244 * * *$ & $(.(0)(x))$ \\
\hline SDax & & & & & & &, $130 * * *$ & $(.007)$ \\
\hline \multicolumn{9}{|l|}{ Kontrolle } \\
\hline Konstante & & $(.(x))$ & & $(.(0)(0))$ & & $(.()() 2)$ & & $(.()(0))$ \\
\hline Jahr & $.250 * * *$ & $(.(0)(0)$ &, $280 * * *$ & $(.0(0))$ &, $203 * * *$ & $(.(0) 1)$ &, $248 * * *$ & $(.0(0))$ \\
\hline$R^{2}$ &, 270 & &, 314 & &, 150 & &, 339 & \\
\hline$R^{2}$ adj &, $263 * * *$ & $(.(O)())$ &, $302 * * *$ & $(.0(0))$ &, $135 * * *$ & $(,(0)(0))$ &, $329 * * *$ & $(.000)$ \\
\hline Durbin-Watson $d$ & 2,001 & & 1,888 & & 2,133 & & 1,992 & \\
\hline$n\left(n_{\text {nix }}=700\right)$ & 700 & & 350 & & 350 & & 700 & \\
\hline
\end{tabular}

Tabelle 47-1: Regressionsmodell der quantitativen Bestimmungsfaktoren

11115 Strenggenommen orientiert sich die Dt. Börse AG bei ihrer Zusammenstellung der vier Indizes jedoch nicht an der Unternehmensgröße in der Form, wie sie hier für die eigene Untersuchung operationalisiert wird, sondern vielmehr an der Marktkapitalisierung des für den Handel verfügbaren Eigenkapitals, vgl. im Detail Dt. Börse AG (2009a), S. 19ff. Wie die in Anhang 13 dargestellte Korrelationsmatrix der Untersuchungsvariablen allerdings belegt, ist die Variable der Unternehmensgröße mit der Marktkapitalisierung stark positiv korreliert, vgl. Anhang 13, Feld 28/12. 
Konsequenterweise ergänzt Tab. 47-2 die Analyse um alle weiteren qualitativen Bestimmungsfaktoren, die innerhalb des Abschnitts D 4.1 bereits auf der ersten Ebene dieses Untersuchungsmodells auf ihren Einfluss auf das Berichtsverhalten hin untersucht wurden. In einem als Hauptmodell 2 bezeichneten gesamthaften Regressionsmodell, das über $40 \%$ der Varianz der Strategieberichterstattung zu erklären vermag, erreichen schließlich Faktoren aus allen definierten Kategorien signifikante Regressionskoeffizienten - mit Ausnahme finanzieller Größen. ${ }^{1106}$

Es kann also festgestellt werden, dass sowohl makroökonomische Bedingungen als auch Unternehmenscharakteristika bzw. Faktoren des Aktienkapitals das Berichtsverhalten der Unternehmen bzgl. strategieorientierter Informationen beeinflussen. Herausragende Bedeutung kommt dabei in erster Linie der Indexzugehörigkeit zu, welche für alle vier Dummy-Variablen stark positive Koeffizienten ausweist. Allgemein ist zu konstatieren, dass - in Vergleich zu Hauptmodell 1 den qualitativen Faktoren eine beachtliche Erklärungskraft zukommt, da jene zusätzlich zu quantitativen Variablen Einfluss besitzen: Neben der Indexzugehörigkeit zeigen Branchenaspekte, das Unternehmensalter, die Rechnungslegung, die Person des CEO sowie der Typus des Großaktionärs signifikante Koeffizienten.

Interessant scheint zudem erneut die separate Betrachtung der Teil-Stichproben der großen und kleinen Unternehmen. Festgestellt werden kann, dass zwar grds. vergleichbare Bestimmtheitsmaße in den einzelnen Regressionsanalysen erreicht werden, jedoch Unterschiedlichkeiten hinsichtlich der jeweils signifikanten Bestimmungsfaktoren vorliegen: Während für große Unternehmen insb. finanzielle Faktoren bedeutsame Einflussgrößen für das Berichtsverhalten darstellen, besitzt die Indexzugehörigkeit für kleine Unternehmen herausragende Bedeutung. ${ }^{107}$

Das bestätigt das verbleibende Modell in Tab. 47-2, das einzelne Variablen nicht mehr inkludiert. Mit ca. 38\% erreicht auch dieses erhebliche Erklärungskraft.

\footnotetext{
1106 Das errechnete Bestimmtheitsmaß entspricht Ergebnissen anderer Untersuchungen zum Berichtsverhalten. Leuz/Verrecchia (2000), S. 107 errechnen bspw. in ihrem Modell der Bestimmungsfaktoren des (allgemeinen) Berichtsverhaltens ein $R^{2}$ von ca. $41 \%$, ähnlich Lapointe-Antunes (2006), S. 485, die ein Bestimmtheitsmaß von ca. $46 \%$ ermitteln.

1107 Es ist darauf hinzuweisen, dass die Dummy-Variable ,Dax “ für kleine Unternehmen unberücksichtigt bleibt, da keines der Unternehmen der Teil-Stichprobe im Dax notiert ist. 
Regressionsanalyse zum Einfluss aller definierten Bestimmungsfaktoren $\quad \mathrm{I}(\mathrm{x})=$ Niveau der Strategicberichterstattung

Makroökonomische Faktoren

\section{Hauptmodell 2}

Börse [Faktor] (+)

, $139 * * *$

Unternehmenscharakteristika (?)

\begin{tabular}{lll} 
Größe [Faktor] (+) & \multicolumn{1}{c}{, $130 *$} & $(.099)$ \\
Branche: Info. Tech. &,- 002 & $(.977)$ \\
Branche: Con. Goods &,$- 168 * *$ & $(.025)$ \\
Branche: Con. Svcs. &,$- 211 * * *$ & $(.001)$ \\
Branche: Industrials &,- 146 & $(.119)$ \\
Branche: Pharma &,$- 206 * * *$ & $(.002)$ \\
Branche: Basic Mat. &,- 034 & $(.602)$ \\
Branche: Utilities &,- 001 & $(.976)$ \\
Alter: Klasse 1 &, $294 * * *$ & $(.00(0))$ \\
Alter: Klasse 2 &, $093 * *$ & $(.044)$ \\
Alter: Klasse 3 &, 019 & $(.635)$ \\
Abschluss: Standard &, 047 & $(.153)$ \\
Abschluss: Prüfer &, $058 *$ & $(.077)$ \\
CEO: Alter &, 026 & $(.445)$ \\
CEO: Nationalität &, 012 & $(.724)$ \\
CEO: Ausbildung &, $061 *$ & $(.088)$
\end{tabular}

\section{Finanzielle Faktoren}

Verschuldung $[\mathrm{F}](+), 039$

Faktoren des Aktienkapitals

Inv. Freefloat (-)

Indexzugehörigkeit (?)

\begin{tabular}{|c|c|c|c|c|c|c|c|c|}
\hline Dax &, $476 * * *$ & $(.(0)())$ &, 095 & $(.630)$ & & &, $637 * * *$ & $(.(0)(0))$ \\
\hline MDax & $478 * * *$ & $(.(O)(O))$ & 065 & $(.698)$ &, $529 * * *$ & $(.(0)(0))$ &, $466 * * *$ & $(.000)$ \\
\hline TecDax &, $230 * * *$ & $(.(X)())$ &, 003 & $(.962)$ &, $335 * * *$ & $(.(O)())$ &, $248 * * *$ & $(.00(0))$ \\
\hline SDax &, $169 * * *$ & $(.(000)$ &,- 074 & $(.480)$ &, $257 * * *$ & $(.(H(x))$ &, $137 * * *$ & $(.004)$ \\
\hline Auslandslisting (?) &, 021 & $(.599)$ & 039 & $(.557)$ &, $102 * *$ & $(.(034)$ & & \\
\hline \multicolumn{9}{|c|}{ Typ größter Einzelaktionär (?) } \\
\hline Stratege &,$- 122 * * *$ & $(.(0) 5)$ &,$- 152 * *$ & $(.018)$ &,- 059 & $(.4(1) 2)$ &,$- 092 * *$ & $(.031)$ \\
\hline Privat/Familie &, 036 & $(.414)$ &, 004 & $(.953)$ &, 066 & $(.361)$ & 055 & $(.2(2) 2)$ \\
\hline Finanzinvestor &,- 019 & $(.601)$ &,- 033 & $(.534)$ &, 032 & $(.569)$ &,- 019 & $(.6(1) 3)$ \\
\hline Staat &,- 008 & $(.832)$ &,- 023 & $(.728)$ &, 028 & $(.537)$ &, $067 *$ & $(.065)$ \\
\hline
\end{tabular}

\section{Kontrolle}

\begin{tabular}{|c|c|c|c|c|c|c|c|c|}
\hline Konstante & & $(.(0)(0))$ & & $(.(0)(0))$ & & $(.016)$ & & $(.000)$ \\
\hline Jahr & $.259 * * *$ & $(.(X)(0))$ & $.339 * * *$ & $(.(0)(0))$ & $.158 * *$ & $(.011)$ & $.263 * * *$ & $(.000)$ \\
\hline$R^{2}$ & ,443 & & ,480 & & ,402 & & ,401 & \\
\hline$R^{2}$ adj. &, $418 * * *$ & $(.(X X))$ &, $432 * * *$ & $(.000)$ &, $349 * * *$ & $(.(O)())$ &, $383 * * *$ & $(.000)$ \\
\hline Durbin-Watson $d$ & 1,962 & & 1,935 & & 2,036 & & 1,991 & \\
\hline $\mathrm{n}\left(\mathrm{n}_{\max }=700\right)$ & 700 & & 350 & & 350 & & 700 & \\
\hline
\end{tabular}




\section{3 Überblick über die Ergebnisse der Hypothesenprüfung}

Den Abschluss des Abschnitts D 4 soll ein umfassender Überblick über die zuvor auf drei Ebenen durchgeführte Hypothesenprüfung bilden. Ferner sind - auf Basis der beschriebenen Ergebnisse - Entscheidungen darüber zu treffen, ob die in C 3.2 formulierten zwölf Hypothesen angenommen werden können oder aber zu verwerfen sind. Diese Entscheidungen präsentiert Tab. 48: Wie dieser zu entnehmen ist, sind mit Ausnahme von H 2.12 alle Hypothesen zu akzeptieren - zumeist auch im gesamthaften Modell der Bestimmungsfaktoren (Ebene 3).

Die dritte der vier Forschungsfragen kann folglich als beantwortet gelten.

\begin{tabular}{|c|c|c|c|c|c|}
\hline \multicolumn{6}{|c|}{ Überblick über die Ergebnisse der Hypothesenprüfung: Teilmodell der Bestimmungsfaktoren } \\
\hline \multicolumn{2}{|l|}{ Kategorie } & \multicolumn{3}{|c|}{ Untersuchungsebene } & \multirow[t]{2}{*}{ Anmerkungen } \\
\hline Hypothese & Art & 1. Ebene & 2. Ebene & 3. Ebene ${ }^{1108}$ & \\
\hline \multicolumn{6}{|l|}{ Makroökonomie } \\
\hline H 2.1 Konjunkturelle Entwicklung & $(+)$ & $\checkmark$ & & & Nicht weiterverfolgt \\
\hline H 2.2 Börsenentwicklung & $(+)$ & $\checkmark$ & $\checkmark$ & $\checkmark$ & \\
\hline \multicolumn{6}{|l|}{ Unternehmenscharakteristika } \\
\hline H 2.3 Unternehmensgröße & $(+)$ & $\checkmark$ & $\checkmark$ & $\checkmark$ & \\
\hline H 2.4 Unternehmensstammdaten & $(?)$ & $\checkmark$ & $\checkmark$ & $\checkmark$ & Gilt für $\mathrm{H} 2.4 \mathrm{a}$ und $\mathrm{b}$ \\
\hline H 2.5 Rechnungslegung & $(?)$ & $\checkmark$ & $\checkmark$ & {$[\checkmark]$} & $\begin{array}{l}\text { Auf 3. Ebene nur } \\
\text { schwach signifikant }\end{array}$ \\
\hline H 2.6 Management/CEO & $(?)$ & $\checkmark$ & $\checkmark$ & {$[\checkmark]$} & $\begin{array}{l}\text { Auf } 3 \text {. Ebene nur } \\
\text { schwach signifikant }\end{array}$ \\
\hline \multicolumn{6}{|l|}{ Finanzielle Faktoren } \\
\hline H 2.7 Unternehmenserfolg & $(+)$ & $\checkmark$ & $\checkmark$ & {$[\checkmark]$} & $\begin{array}{l}\text { Auf } 3 \text {. Ebene nur für } \\
\text { große Unternehmen }\end{array}$ \\
\hline H 2.8 Finanzierung & $(+)$ & $\checkmark$ & $\checkmark$ & $\checkmark$ & \\
\hline \multicolumn{6}{|l|}{ Faktoren des Aktienkapitals } \\
\hline H 2.9 Indexzugehörigkeit & $(?)$ & $\checkmark$ & $\checkmark$ & $\checkmark$ & \\
\hline H 2.10 Auslandslisting & $(?)$ & $\checkmark$ & $\checkmark$ & {$[\checkmark]$} & $\begin{array}{l}\text { Auf } 3 \text {. Ebene nur für } \\
\text { kleine Unternehmen }\end{array}$ \\
\hline H 2.11 Konzentration des Aktienkapitals & $(-)$ & $\checkmark$ & $\checkmark$ & $\checkmark$ & $\begin{array}{l}\text { Gilt zugleich für Typus } \\
\text { Großaktionär (H 2.11b) }\end{array}$ \\
\hline H 2.12 Insidertransaktionen & $(+)$ & $x$ & & & \\
\hline
\end{tabular}

Tabelle 48: Ergebnisse der Hypothesenprüfung: Bestimmungsfaktoren

1108 Die 3. Ebene der Hypothesenprüfung wird durch die Hauptmodelle 1 und 2 konstituiert.

Tom Sieber - 978-3-631-75150-3 


\section{$5 \quad$ Hypothesenprüfung zu den Kapitalmarkteffekten}

\subsection{Methodische Vorbemerkung zu den Regressionsmodellen}

Ziel der sich an diese Einleitung anschließenden Ausführungen ist eine Prüfung der sieben Hypothesen des Teilmodells der Kapitalmarkteffekte und damit auch die Klärung der vierten Forschungsfrage nach den Auswirkungen der Strategieberichterstattung am Kapitalmarkt. Dabei soll analog zum ersten Teilmodell eine differenzierte Analyse vorgenommen werden: Die Kapitalmarkteffekte sind für beide Teil-Stichproben separat zu prüfen, um spezifischere Aussagen abzuleiten. Unter erneutem Rückgriff auf das mit Tab. 10 vorgestellte Untersuchungsmodell ist zudem zu vermerken, dass die Hypothesenprüfung in diesem Teilmodell grds. nur auf zwei Ebenen erfolgt. Methodisches Werkzeug ist dabei stets die lineare Regressionsanalyse, wobei auf der ersten Ebene zunächst bivariate Zusammenhänge geprüft werden, ehe multivariate Modelle unter Einschluss von Kontrollvariablen berechnet werden. Als wesentliche Kontrollvariable ist in sämtlichen Modellen die Unternehmensgröße zu inkludieren, deren erheblicher Einfluss auf das Niveau der Strategieberichterstattung im Rahmen des ersten Teilmodells belegt wurde. ${ }^{1109}$ Auf diesem Wege erfolgt schließlich zugleich eine Kontrolle für das Niveau der Berichterstattung insgesamt, das in direktem Zusammenhang mit der Unternehmensgröße steht. ${ }^{1110}$ Ergo kann unterstellt werden, dass die Untersuchungsvariable SDIndex lediglich den inkrementellen Beitrag der Strategieberichterstattung zur Erklärung einzelner Kapitalmarkteffekte abbildet.

Weiterhin ist anzumerken, dass - wie in C 3.2.4 erläutert - in diesem Teilmodell in den Beziehungen zwischen dem Regressor SDIndex und den sieben Effekten eine ,Phasenverschiebung ' zu berücksichtigen ist. Diese wurde damit begründet, dass strategierelevante Informationen aus $t$ erst zu Beginn von Periode $t+1$ dem Kapitalmarkt zur Verfügung stehen und erst dann Effekte hervorrufen können.

\footnotetext{
1109 Vgl. erneut Tab. 37 (S. 284) sowie Tab. 47 (S. 297ff.). Trotz der diskutierten Interaktion von Größe und Indexzugehörigkeit scheint Erstere als Kontrollvariable besser geeignet.

1110 Vgl. bspw. auch Wagenhofer/Ewert (2007), S. 399f. Eine regelmäßige Kontrolle für die Unternehmensgröße (operationalisiert durch finanzwirtschaftliche Parameter oder durch den Marktwert des Eigenkapitals) in den Kapitalmarkteffekt-Modellen ist auch für die in C 3.2.1 erwähnte Panelstruktur der Stichprobe bedeutsam, vgl. weiterführend D.5.4.3.

Tom Sieber - 978-3-631-75150-3
} 
Wird diese Phasenverschiebung zwischen SDIndex und den jeweiligen Kapitalmarkteffekten akzeptiert, stellt sich zugleich die Frage nach der zeitlichen Basis der erforderlichen Kontrollvariablen. Diese kann allerdings nicht generell beantwortet werden, wie an einem Beispiel deutlich wird: Mit H 3.1 wird die Anzahl der ein Unternehmen beobachtenden Analysten in Abhängigkeit der Strategieberichterstattung untersucht, annahmegemäß steht SDIndex $t$ mit der Analystenanzahl in der Folgeperiode $t+1$ in Zusammenhang. Es erscheint plausibel zu unterstellen, dass Analysten Entscheidungen über die Beobachtung von Unternehmen langfristig treffen, eine Beobachtung in Periode $t+1$ dürfte in Periode $t$ auf Basis der dann verfügbaren Informationen entschieden werden. ${ }^{111}$ Aus diesem Grund wären zusätzliche Kontrollvariablen ebenfalls in Periode $t$ zu basieren. Bei der Prüfung von H 3.3, dem Einfluss von SDIndex auf das Handelsvolumen, wären die Kontrollvariablen hingegen auf der Periode des Effekts zu basieren, da diese ebenfalls in Periode $t+l$ Einfluss auf das Handelsvolumen ausüben.

Wie erkennbar wird, ist bei der Entscheidung darüber, ob einzubeziehende Kontrollen aus derselben Periode wie der jeweilige Kapitalmarkteffekt oder der vorhergehenden Periode inkludiert werden, grds. theoriebegründet bzw. hypothesenspezifisch vorzugehen. ${ }^{1112}$ Eine Entscheidung für eine der beiden Optionen, die Abb. 24 graphisch veranschaulicht, wird aus diesem Grund im Rahmen der jeweils zu untersuchenden Hypothese getroffen. ${ }^{1113}$

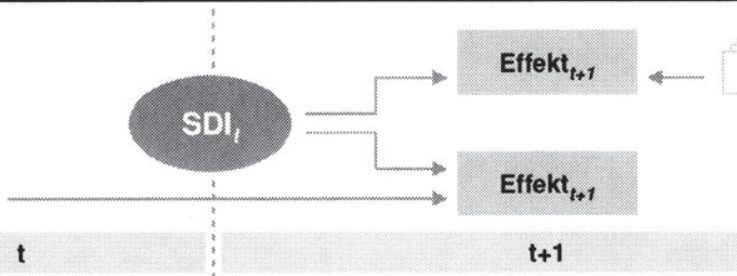

Abbildung 24: Optionen der Einbindung von Kontrollvariablen ${ }^{1114}$

1111 Vgl. zum Entscheidungskalkül von Analysten bspw. Achleitner et al. (2005), S. 262ff.

1112 In Abhängigkeit der Auswahl an Kontrollvariablen kann sich eine Reduktion der Stichprobe auf $n_{\max }=600$ ergeben, da nicht für alle Variablen Werte für 2009 vorliegen.

1113 Anhand der Symbolik $(t)$ bzw. $(t+l)$ in den Darstellungen zu den Regressionsmodellen wird im Folgenden stets erkennbar, auf welcher Periode die Kontrollvariablen basieren.

1114 Quelle: eigene Darstellung. 


\subsection{Untersuchung der einzelnen Kapitalmarkteffekte}

\subsubsection{Untersuchung der Markttransparenzeffekte}

\section{(a) Analyse der Auswirkungen auf die Anzahl beobachtender Analysten}

In der ersten von sieben Hypothesen, welche auf die Kapitalmarktwirkungen der Strategieberichterstattung abstellen, wurde postuliert, dass ein hohes Ausmaß an bereitgestellten strategieorientierten Informationen zu einem Anstieg der Anzahl der ein Unternehmen beobachtenden Analysten führen sollte (H 3.1). ${ }^{115}$

Zur Prüfung dieser Hypothese stehen monatliche Daten über die Anzahl der beobachtenden Analysten zur Verfügung, aus denen jeweils der Jahresdurchschnitt errechnet wurde. ${ }^{1116}$ Dieser Indikator ist mit der Kennzahl der Strategieberichterstattung in Beziehung zu setzen, wobei es jedoch intuitiv einleuchtend erscheint, in der Beziehung für verschiedene Parameter zu kontrollieren, für welche ebenfalls ein Einfluss auf die Anzahl der beobachtenden Analysten anzunehmen ist: In erster Linie sind dies Indikatoren der Unternehmensgröße und der Indexzugehörigkeit, die in vergleichbaren Untersuchungen ebenfalls als Kontrollvariablen vorgesehen werden. ${ }^{1117}$ Darüber hinaus soll zusätzlich für den Unternehmenserfolg sowie für die Zeit kontrolliert werden. ${ }^{118}$

Wie bereits in Abschnitt 5.1 als Beispiel ausgeführt, sind die Kontrollvariablen jedoch nicht in der Periode des Effekts, sondern in der vorhergehenden Periode basiert, da davon auszugehen ist, dass Analysten Entscheidungen über künftige Unternehmensabdeckungen langfristig treffen, d.h. in Periode $t$ wird auf Grundlage verfügbarer Informationen eine Entscheidung über die Abdeckung bzw. die Beobachtung eines bestimmten Unternehmens in der Periode $t+1$ getroffen.

1115 In C 3.1.3 (Fn. 773) wurde vermerkt, dass eine umgekehrte Kausalität grds. denkbar ist.

1116 Der Vollständigkeit halber ist zu ergänzen, dass es sich bei diesen Daten um die Anzahl sog. ,Sell-Side-Analysten" handelt, die im Auftrag von Banken sowie Investmentgesellschaften Analysen über Unternehmen erstellen. Vgl. Achleitner et al. (2005), S. 261. Vgl. u.a. Lang/Lundholm (1996), S. 483; Botosan (1997a), S. 343, zudem Achleitner et al. (2005), S. 270; O’Brien/Bhushan (1990), S. 62f. sowie Bhushan (1989), S. $261 \mathrm{f}$.

$111 \times$ Der Faktor Zeit wird ebenso im Teilmodell der Kapitalmarkteffekte regelmäßig als eine Kontrollvariable eingefügt, da in Abschnitt D 3.2 der Einfluss dieses Parameters auf das Niveau der Strategieberichterstattung aufgezeigt werden konnte. Auch wenn Jahr nicht immer explizit als Kontrollvariable erwähnt wird, ist diese dennoch stets inkludiert. 
Das so spezifizierte Modell einer Regression der Analystenanzahl auf die Kennzahl der Strategieberichterstattung und die erwähnten Kontrollvariablen ist - als Hauptmodell 3 - in Tab. 49 wiedergegeben. Es ist in der Lage, annähernd 78\% der Varianz bzgl. der Anzahl der ein Unternehmen beobachtenden Analysten zu erklären. ${ }^{1119}$ Konsistent mit früheren Arbeiten besitzt v.a. die Indexzugehörigkeit dominierenden Einfluss auf den Regressor, die Auswahlindizes Dax, MDax und TecDax erreichen stark positive und hoch signifikante Regressionskoeffizienten. Außerdem kann die Variable der Unternehmensgröße einen hohen, signifikanten Erklärungsbeitrag leisten. ${ }^{1120}$ Gleiches gilt zudem für die Untersuchungsvariable der Strategieberichterstattung, welche in dieser Analyse einen - zwar vergleichsweise geringen - jedoch signifikant positiven Regressionskoeffizienten aufweist. Folgerichtig kann auf Basis dieser Ergebnisse davon ausgegangen werden, dass ein hohes Niveau der Strategieberichterstattung einen positiven Einfluss auf die durchschnittliche Anzahl der ein Unternehmen beobachtenden Analysten besitzt, wie Hypothese H 3.1 unterstellt hat. Der Erklärungsbeitrag der Untersuchungsvariablen zeigt sich robust, auch wenn das Hauptmodell 3 um weitere Kontrollvariablen ergänzt wird: Das Hinzufügen der beiden Variablen Aktienrendite und Handelsvolumen schwächt den Einfluss von SDIndex zwar leicht ab, wie das erweiterte Hauptmodell 3 in Tab. 49 zeigt, er bleibt dennoch hoch signifikant. ${ }^{1121}$

Wird die Untersuchungsstichprobe allerdings in die zwei Teil-Stichproben aufgeteilt, offenbart sich ein differenziertes Bild: Während für große Unternehmen die Untersuchungsvariable SDI offensichtlich keinen Einfluss besitzt, ist ihr Regressionskoeffizient für die kleinen Unternehmen stärker positiv als im Falle der Gesamtstichprobe und nach wie vor statistisch signifikant. Für beide Teil-Stichproben besitzen zudem die in die Untersuchung inkludierten Kontrollvariablen

1119 Dieses Bestimmtheitsmaß ist konsistent mit anderen Untersuchungen der Analystenabdeckung, vgl. bspw. für den dt. Kapitalmarkt Achleitner et al. (2005), S. 268f. oder auch O'Brien/Bhushan (1990), S. 71 mit Blick auf den US-amerikanischen Kapitalmarkt sowie Lang/Lundholm (1996), S. 483, die ein Bestimmtheitsmaß von rund 50\% ermitteln.

1120 Erneut soll darauf hingewiesen werden, dass die beiden Variablen Unternehmensgröße und Indexzugehörigkeit nicht unabhängig voneinander sein können. Dennoch wurden in den Regressionsanalysen die definierten Grenzwerte für den VIF nicht erreicht.

1121 Diese Kontrollvariablen werden in der einschlägigen Literatur ebenfalls empfohlen, vgl. exemplarisch Achleitner et al. (2005), S. 269f. m.w.N. 
überwiegend hohe Erklärungskraft, so dass in beiden Fällen gute Bestimmtheitsmaße von ca. $75 \%$ bzw. rund $50 \%$ erzielt werden können.

Panel A: Bivariate Regressionsanalyse zum Einfluss von SDIndex auf die Anzahl der Analysten

$I:(x)=$ Anzahl beobachtender Analysten im Jahresdurchschnit $(l+I)$

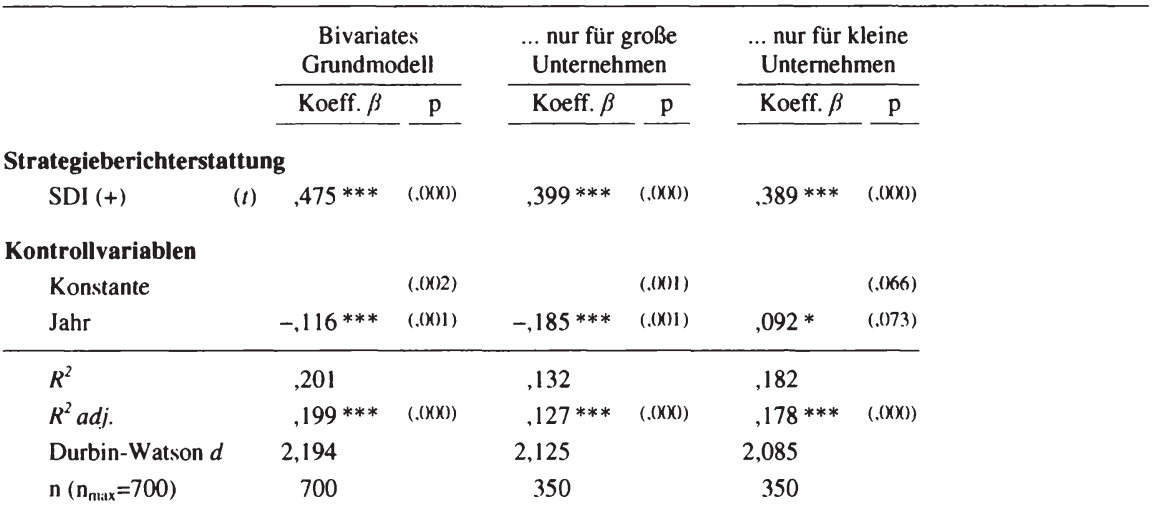

Panel B: Multivariate Regressionsanalyse zum Einfluss von SDIndex auf die Anzahl der Analysten

\begin{tabular}{|c|c|c|c|c|c|c|c|c|c|}
\hline & & \multicolumn{2}{|c|}{ Hauptmodell 3} & \multicolumn{2}{|c|}{$\begin{array}{c}\text { Erweitertes } \\
\text { Hauptmodell } 3\end{array}$} & \multicolumn{2}{|c|}{$\begin{array}{c}\text {... nur für große } \\
\text { Unternehmen }\end{array}$} & \multicolumn{2}{|c|}{$\begin{array}{c}\text {... nur für kleine } \\
\text { Unternehmen }\end{array}$} \\
\hline & & Koeff. $\beta$ & $\mathrm{p}$ & Koeff. $\beta$ & $\mathrm{p}$ & Koeff. $\beta$ & $\mathrm{p}$ & Koeff. $\beta$ & $\mathrm{p}$ \\
\hline \multicolumn{10}{|c|}{ Strategieberichterstattung } \\
\hline SDI (+) & $(t)$ &, $062 * * *$ & $(.(0) 4)$ &, $056 * * *$ & $(.010)$ &, 035 & $(.273)$ &, $109 * *$ & $(.018)$ \\
\hline \multicolumn{10}{|l|}{ Kontrollvariablen } \\
\hline Konstante & & & $(.747)$ & & $(.014)$ & & $(.00(0))$ & & $(.824)$ \\
\hline Größe [Faktor] & $(t)$ & $175 * * *$ & $(.(x))$ &, $201 * * *$ & $(.(X)())$ &, $252 * * *$ & $(.(0)(0))$ &, $140 * * *$ & $(.0(9) 9)$ \\
\hline Erfolg [Faktor] & $(t)$ &, 007 & $(.717)$ &, 026 & $(.172)$ &, $131 * * *$ & $(.(000)$ &, 041 & $(.329)$ \\
\hline Aktienrendite & (t) & & &,$- 058 * * *$ & $(.(0) 2)$ &,$- 089 * * *$ & $(.(0) 1)$ &,$- 102 * *$ & $(.010)$ \\
\hline Handelsvolumen & $(t)$ & & & $107 * * *$ & $(.(X)(X))$ &, $113 * * *$ & $(.001)$ &, $243 * * *$ & $(.(0)(0)$ \\
\hline \multicolumn{10}{|l|}{ Indexzugehörigkeit } \\
\hline $\operatorname{Dax}$ & $(t)$ &, $825 * * *$ & $(.0()(0))$ &, $740 * * *$ & $(.(0)(0))$ &, $888 * * *$ & $(.(0)(0)$ & & \\
\hline MDax & $(t)$ &, $414 * * *$ & $(.(0)(K))$ &, $366 * * *$ & $(.000)$ &, $704 * * *$ & $(.000)$ &, $431 * * *$ & $(.(0)(0))$ \\
\hline TecDax & $(t)$ &, $242 * * *$ & $(.(X)(x))$ &, $215 * * *$ & $(.(0)(0))$ &, $186 * * *$ & $(.(0)(0))$ &, $353 * * *$ & $(.(x)(x))$ \\
\hline SDax & $(t)$ &, 043 & $(.12())$ &, $046 *$ & $(.096)$ &, $161 * * *$ & $(.008)$ &, 072 & $(.191)$ \\
\hline Jahr & &,- 006 & $(.753)$ &,$- 053 * *$ & $(.015)$ &,$- 152 * * *$ & $(.(0)(0)$ &, 010 & $(.823)$ \\
\hline$R^{2}$ & &, 778 & &, 787 & & ,768 & &, 511 & \\
\hline$R^{2}$ adj & &, $775 * * *$ & $(.(\%)())$ &, $784 * * *$ & $(.(0) 0)$ &, $762 * * *$ & $(.000)$ &, $498 * * *$ & $(.(0)(x))$ \\
\hline Durbin-Watson $d$ & & 2,136 & & 2,133 & & 2,134 & & 2,022 & \\
\hline$n\left(n_{\max }=700\right)$ & & 700 & & 700 & & 350 & & 350 & \\
\hline
\end{tabular}




\section{(b) Analyse der Auswirkungen auf die Schätzungsvarianz}

Weiterhin wurde postuliert, dass ein hohes Niveau der Strategieberichterstattung zu einer Reduktion der Varianz der Schätzungen führen müsste, die von den beobachtenden Analysten vorgelegt werden (H 3.2). Hintergrund dieser Hypothese ist, dass ein höheres $\mathrm{Ma} ß$ an zukunftsorientierten Informationen, die ein Unternehmen zur Verfügung stellt, bei der Schätzung künftiger finanzwirtschaftlicher Parameter eine gewisse Leitplankenfunktionen übernehmen und in der Folge die Schwankungsbreite der Einschätzungen der Analysten reduzieren könnte. ${ }^{1122}$

Zur Prüfung jener Hypothese wird der Einfluss des Niveaus der Strategieberichterstattung auf zwei unterschiedliche Arten von Parametern betrachtet: Einerseits wird die Varianz hinsichtlich der fünfstufig untergliederten Kauf- und Verkaufsempfehlungen der Analysten und andererseits in Bezug auf die Schätzungen der zentralen finanzwirtschaftlichen Kennzahl Ergebnis je Aktie (EPS) geprüft. ${ }^{1123}$

Der erstgenannte Parameter wird sodann errechnet, indem die jahresspezifischen Analysten-Empfehlungen numerisch kodiert und die Standardabweichungen der jeweiligen Verteilungen ermittelt werden. ${ }^{1124}$ Der zweite Parameter wird als der jahresspezifische Variationskoeffizient der von den Analysten herausgegebenen

1122 Die Annahme, dass Strategieinformationen eine Leitplankenfunktion bei der Schätzung zukünftiger Zahlungsstromgrößen durch die Investoren übernehmen könnten, war Ausgangspunkt der theoretischen Ausführungen, vgl. nochmals Abschnitt B 2.3.2. Den empirischen Beleg für diese Annahme bzgl. der ,forecast dispersion“ von Finanzanalysten liefern bspw. Barron et al. (1999), S. 94.

Es muss allerdings darauf hingewiesen werden, dass die Schätzungen der Analysten, die im Folgenden auf Zusammenhänge mit der zentralen Untersuchungsvariablen SDIndex hin untersucht werden, nicht unbedingt die Meinung der Gesamtheit der Investoren am Kapitalmarkt widerspiegeln. Zwar werden Analysten oftmals als repräsentative Kapitalmarktakteure angesehen, vgl. z.B. Schipper (1991), S. 177, da sie als Informationsintermediäre die Informationen der Unternehmen aggregieren bzw. interpretieren und so ihre Entscheidungen fundieren, vgl. Healy/Palepu (2001), S. 407f. Inwieweit jedoch die Investoren der Meinung von Analysten folgen, ist hier nicht Gegenstand der Betrachtung. Diese fünf Stufen sind ,Strong Buy', ,Buy“, ,Hold “ und ,Underperform' bzw. ,Sell'. Die entsprechenden (auf Monatsbasis vorliegenden) Daten konnten der Datenbank I/B/E/S entnommen werden, verwendet wurden jeweils die Datenpunkte des Monats Dezember. Die Kodierung der Analystenempfehlungen in Punktwerten von eins - ,Strong Buy ' bis fünf - ,Sell' ist durchaus üblich, vgl. bspw. die Ausführungen der Nasdaq (2009). Letztlich zeigen sich die Resultate der so errechneten Standardabweichungen aber auch invariant gegenüber einer linearen Transformation dieser Kodierung.

Tom Sieber - 978-3-631-75150-3 
EPS-Schätzungen ermittelt, als Datengrundlage jener Berechnung dienen die jeweiligen Schätzungen des EPS für das übernächste Geschäftsjahr $(t+2) .{ }^{1125}$ Sodann können die abgeleiteten Untersuchungsparameter der Empfehlungsvarianz bzw. der Schätzungsvarianz mit Hilfe eines Regressionsmodells auf Zusammenhänge mit der Untersuchungsvariablen SDIndex geprüft werden, wobei v.a. eine Kontrolle der Unternehmensgröße und der Anzahl der beobachtenden Analysten sinnvoll erscheint. ${ }^{1126}$ Für SDIndex ist entsprechend Hypothese $\mathbf{H} 3.2$ jeweils ein negatives Vorzeichen des Regressionskoeffizienten zu erwarten.

Die Ergebnisse der Regressionsanalysen präsentiert Tab. 50 im Überblick. Wie dieser zu entnehmen ist, kann der postulierte Zusammenhang zur Empfehlungsvarianz nur bzgl. der Teil-Stichprobe großer Unternehmen statistisch signifikant bestätigt werden, für die Gesamtstichprobe gilt dies jedoch nicht. Interessanterweise zeigt die Teil-Stichprobe der kleinen Unternehmen einen - wenn auch nur schwach signifikant - positiven Zusammenhang, die Empfehlungsvarianz stünde demnach mit dem Strategieberichts-Niveau in positivem Zusammenhang. Auch besitzt die Anzahl der Analysten, für die in den einzelnen Modellen kontrolliert wird, offensichtlich einen positiven Einfluss auf die Varianz der Empfehlungen.

Für den zweiten Parameter der Schätzungsvarianz ergibt sich ein konsistenteres, der formulierten Hypothese aber dennoch widersprechendes Bild: In allen unterschiedenen Fällen führt ein höheres Niveau der Strategieberichterstattung augenscheinlich zu einer höheren Varianz der Analystenschätzungen.

Folglich kann festgehalten werden, dass der in $\mathrm{H} 3.2$ postulierte Zusammenhang für die großen Unternehmen als bestätigt angesehen werden kann - zumindest in Bezug auf den Parameter der Empfehlungsvarianz. Offensichtlich ist ein höheres Niveau der Strategieberichterstattung also tendenziell dazu geeignet, die Varianz der Meinungen der Analysten in Bezug auf große Unternehmen zu beschränken.

\footnotetext{
1125 Der Variationskoeffizient berechnet sich als der Quotient aus Standardabweichung und arithmetischem Mittelwert und stellt so ein standardisiertes Maß der Schwankungsbreite dar, vgl. Rinne (1997), S. 55. Für Periode $t$ wird also der Variationskoeffizient der EPSSchätzungen für Periode $t+2$ berechnet. Ähnlich Baetge et al. (2010), S. 77, die jedoch einen Variationskoeffizienten für Periode $t$ auf Basis von Daten der Periode $t$ ermitteln. 
Panel A: Regressionsanalyse zum Einfluss von SDIndex auf die Empfehlungsvarianz der Analysten $\mathrm{F}(\mathrm{x})=$ Varianz der Analysten-Empfehlungen $(t+1)$

\begin{tabular}{|c|c|c|c|c|c|c|c|c|c|}
\hline & & \multicolumn{2}{|c|}{$\begin{array}{c}\text { Bivariates } \\
\text { Grundmodell }\end{array}$} & \multicolumn{2}{|c|}{$\begin{array}{c}\text {... nur für große } \\
\text { Unternehmen }\end{array}$} & \multicolumn{2}{|c|}{$\begin{array}{l}\text {... nur für kleine } \\
\text { Unternehmen }\end{array}$} & \multicolumn{2}{|c|}{$\begin{array}{l}\text { Erweitert, große } \\
\text { Unternehmen }\end{array}$} \\
\hline & & Koeff. $\beta$ & $\mathrm{p}$ & Koeff. $\beta$ & $\mathrm{p}$ & Koeff. $\beta$ & $\mathrm{p}$ & Koeff. $\beta$ & $\mathrm{p}$ \\
\hline \multicolumn{10}{|c|}{ Strategieberichterstattung } \\
\hline SDI (-) & $(t)$ & 036 & $(, 415)$ &,$- 173 * * *$ & $(, 003)$ &, $113 *$ & $(, 057)$ &,$- 155 * * *$ & $(.010)$ \\
\hline \multicolumn{10}{|l|}{ Kontrollvariablen } \\
\hline Konstante & & & $(, 000)$ & & $(.000)$ & & $(.361)$ & & $(.000)$ \\
\hline Anz. Analysten & $(t+1)$ &, $105 * *$ & $(.012)$ &,- 019 & $(.716)$ &, $123 * *$ & $(.034)$ &, 013 & $(.899)$ \\
\hline Größe [Faktor] & $(t)$ & & & & & & &,- 080 & $(.332)$ \\
\hline Erfolg [Faktor] & $(t)$ & & & & & & &,$- 149 * * *$ & $(, 006)$ \\
\hline \multicolumn{10}{|l|}{ Indexzugehörigkeit } \\
\hline Dax & $(t+1)$ & & & & & & &,- 238 & $(, 429)$ \\
\hline MDax & $(t+l)$ & & & & & & &,- 298 & $(.275)$ \\
\hline TecDax & $(t+l)$ & & & & & & &,- 083 & $(.410)$ \\
\hline SDax & $(t+l)$ & & & & & & &,- 185 & $(.267)$ \\
\hline Jahr & &, $167 * * *$ & $(.000)$ &, $432 * * *$ & $(.000)$ & 053 & $(.347)$ &, $460 * * *$ & $(.000)$ \\
\hline$R^{2}$ & &, 047 & &, 156 & &, 045 & &, 178 & \\
\hline$R^{2}$ adj. & &, $043 * * *$ & $(.000)$ &, $148 * * *$ & $(, 000)$ &, $036 * * *$ & $(.002)$ & $156 * * *$ & $(.000)$ \\
\hline Durbin-Watson $d$ & & 1,988 & & 1,995 & & 2,048 & & 2,006 & \\
\hline $\mathrm{n}\left(\mathrm{n}_{\max }=700\right)$ & & 671 & & 343 & & 328 & & 343 & \\
\hline
\end{tabular}

Panel B: Regressionsanalyse zum Einfluss von SDIndex auf die Schätzungsvarianz der Analysten

$F(x)=$ Varianz der Analysten-Schätzungen des Ergebnisses je Aktie $(t+1)$

\begin{tabular}{|c|c|c|c|c|c|c|}
\hline & \multicolumn{2}{|c|}{$\begin{array}{c}\text { Bivariates } \\
\text { Grundmodell }\end{array}$} & \multicolumn{2}{|c|}{$\begin{array}{l}\text {... nur für große } \\
\text { Unternehmen }\end{array}$} & \multicolumn{2}{|c|}{$\begin{array}{l}\text {... nur für kleine } \\
\text { Unternehmen }\end{array}$} \\
\hline & Koeff. $\beta$ & $\mathrm{p}$ & Koeff. $\beta$ & $\mathrm{p}$ & Koeff. $\beta$ & $\mathrm{p}$ \\
\hline \multicolumn{7}{|c|}{ Strategieberichterstattung } \\
\hline SDI (-) &, $127 * * *$ & $(.005)$ &, $110^{*}$ & $(, 079)$ &, $136 * *$ & $(, 029)$ \\
\hline \multicolumn{7}{|l|}{ Kontrollvariablen } \\
\hline Konstante & & $(.712)$ & & $(.403)$ & & $(.716)$ \\
\hline Anz. Analysten & $(t+1)-, 071$ & $(.102)$ &,- 010 & $(.861)$ & ,096 & $(.110)$ \\
\hline Jahr &, 016 & $(.711)$ &, 050 & $(.402)$ &,- 022 & $(.710)$ \\
\hline$R^{2}$ &, 016 & & 019 & & 035 & \\
\hline$R^{2} a d j$ &, $011 * *$ & $(.016)$ &, $010 *$ & $(.096)$ &, $025 * *$ & $(, 013)$ \\
\hline Durbin-Watson $d$ & 1,726 & & 1,909 & & 1,754 & \\
\hline$n\left(n_{\max }=700\right)$ & 645 & & 340 & & 305 & \\
\hline
\end{tabular}


An diese Erkenntnisse schließt sich sodann die Frage an, ob strategieorientierte Angaben zumindest aber dazu geeignet sind, Analysten bessere Schätzungen zu ermöglichen, d.h. eine höhere Güte der Schätzungen zu bewirken.

Um diesen Nebenaspekt der Untersuchung von Hypothese H 3.2 zu prüfen, sind die von Analysten geschätzten Daten mit den im Zeitablauf nachfolgend tatsächlich realisierten Werten zu vergleichen. Dazu werden die in $t$ für $t+2$ geschätzten Werte für das EPS mit den in $t+2$ realisierten Werten verglichen und die relative Abweichung berechnet, deren Zusammenhang mit der zentralen Untersuchungsvariablen mit Hilfe der Regressionsanalyse zu ermitteln ist. ${ }^{1127}$ Das Ergebnis der Überlegungen zeigt Tab. 51. Ein erwartungsgemäß negativer sowie signifikanter Regressionskoeffizient stellt sich allerdings lediglich im bivariaten Grundmodell der kleinen Unternehmen ein, bei einer Kontrolle für die Anzahl beobachtender Analysten ist jener Einfluss schließlich nicht mehr sichtbar. Aufgrund dieser Ergebnisse und des nur schwachen Signifikanzniveaus der Modelle ist folgerichtig nicht davon auszugehen, dass verstärkte Strategieberichterstattung zu einer verbesserten Schätzgüte der beobachtenden Analysten führen kann. ${ }^{128}$

Panel A: Regressionsanalyse zum Einfluss von SDIndex auf die Güte der Analystenschätzungen $I(x)=$ (iütc der Analysten-Schälzungen des lirgebnisses je Aktie $(t+l)$ bzw. Ilöhe der Abweichung von Schätzung und realisientem Went

\begin{tabular}{|c|c|c|c|c|c|c|c|}
\hline & & \multicolumn{2}{|c|}{$\begin{array}{c}\text { Bivariates } \\
\text { Grundmodell }\end{array}$} & \multicolumn{2}{|c|}{$\begin{array}{l}\text {... nur für kleine } \\
\text { Unternehmen }\end{array}$} & \multicolumn{2}{|c|}{$\begin{array}{l}\text { Wie zuvor, } \\
\text { mit Kontrolle }\end{array}$} \\
\hline & & Koeff. $\beta$ & $\mathrm{p}$ & Koeff. $\beta$ & $\mathrm{p}$ & Koeff. $\beta$ & $\mathrm{p}$ \\
\hline \multicolumn{8}{|c|}{ Strategieberichterstattung } \\
\hline SDI (-) & $(t)$ &,- 048 & $(.344)$ &,$- 152 * *$ & $(.037)$ &,- 110 & $(.167)$ \\
\hline \multicolumn{8}{|l|}{ Kontrollvariablen } \\
\hline Konstante & & & $(.103)$ & & $(.358)$ & & $(.364)$ \\
\hline Anz. Analysten & $(t+I)$ & & & & &,- 099 & $(.189)$ \\
\hline Jahr & &,- 081 & $(.111)$ &,- 064 & $(.378)$ &,- 063 & $(.382)$ \\
\hline$R^{2}$ & & 012 & &, 034 & &, 042 & \\
\hline$R^{2}$ adj & &, $007^{*}$ & $(.077)$ &, $024 * *$ & $(.029)$ &, $028 * *$ & $(.032)$ \\
\hline Durbin-Watson $d$ & & 2,149 & & 2,003 & & 2,023 & \\
\hline $\mathrm{n}\left(\mathrm{n}_{\mathrm{n}: \mathrm{ix}}=700\right)$ & & 445 & & 211 & & 211 & \\
\hline
\end{tabular}

\section{Tabelle 51: Regressionsmodell der Schätzgüte}

1127 Ähnlich auch Baetge et al. (2010), S. 77, die den Prognosefehler der Periode $t$ allerdings auf Basis von Prognosen und realisierten EPS-Daten der Periode $t$ berechnen.

1128 Vgl. hierzu auch Byard/Shaw (2003), S. 370. 


\subsubsection{Untersuchung der Handelseffekte}

Die zweite Kategorie der Kapitalmarkteffekte der Strategieberichterstattung betrachtet die Auswirkungen auf zwei verschiedene Parameter, die den Handel der Wertpapiere der Stichproben-Unternehmen betreffen: Einerseits stehen die Auswirkungen auf das Handelsvolumen (H 3.3) und andererseits die Auswirkungen auf die Volatilität der Aktienrenditen (H 3.4) im Fokus der Untersuchung.

\section{(a) Analyse der Auswirkungen auf das Handelsvolumen}

Zur Prüfung des in H 3.3 vermuteten positiven Zusammenhangs der Strategieberichterstattung mit dem Handelsvolumen der Wertpapiere eines Unternehmens werden zunächst Daten der handelstäglichen ${ }^{1129}$ Stückumsätze der betreffenden Wertpapiere ermittelt. ${ }^{1130}$ Die ermittelten Daten werden mit Hilfe der börsentäglichen Schlusskurse in monetäre Umsatzvolumina umgewandelt und schließlich werden die Volumina der wesentlichen deutschen Börsenplätze, der Frankfurter Wertpapierbörse sowie des elektronischen Handelssystems Xetra, kumuliert. ${ }^{1131}$ Sodann werden auf dieser Basis jährliche monetäre Gesamtvolumina errechnet, die - in logarithmierter Form - als abhängige Variable verwendet werden.

Konsequenterweise ist auch im Rahmen einer Regression des Handelsvolumens auf die zentrale Untersuchungsvariable SDIndex für eine Reihe von Parametern zu kontrollieren, von denen angenommen werden kann, dass sie ihrerseits einen Zusammenhang mit dem jährlichen Handelsvolumen einer Aktie aufweisen. Im Einzelnen sind dies insb. der Marktwert des Eigenkapitals, die Indexzugehörig-

1129 Im siebenjährigen Untersuchungszeitraum von Anfang 2002 bis Ultimo 2008 sind insg. 1.781 Handelstage der Dt. Börse AG zu berücksichtigen bzw. 2.035 bis Ultimo 2009.

1130 Es werden lediglich diejenigen Wertpapiere einbezogen, die per Halbjahresultimo 2009 in einem der vier Auswahlindizes enthalten sind. Weitere Aktiengattungen werden nicht berücksichtigt, insb. werden Umsätze in verschiedenen Aktiengattungen - sofern bspw. sowohl Stamm- als auch Vorzugsaktien eines Unternehmens börsennotiert sind - nicht beachtet, sondern lediglich die Umsätze in der jeweiligen im Auswahlindex enthaltenen Gattung, vgl. auch Anhang 4 zur Benennung der jeweils relevanten Aktiengattung.

1131 Die Berechnung der monetären Volumina eliminiert den Einfluss der konkreten Aktienkurse auf die Stückvolumina, was ggf. Verzerrungen in der Analyse verursachen kann, in Anlehnung an einen Vorschlag von bspw. Leuz/Verrecchia (2000), S. 107ff.

Die Kumulierung der Börsenplätze ist weiterhin nicht nur sinnvoll, sondern erforderlich, da im Verlauf des Untersuchungszeitraumes die Umsatzbedeutung des Handelssystems Xetra zugenommen und so die Umsatzreduktion im Parketthandel kompensiert hat. 
keit, die Volatilität der Aktienrendite, die Profitabilität sowie der Anteil des für den Handel verfügbaren Eigenkapitals. ${ }^{1132}$ Für diese Variablen - mit Ausnahme der letztgenannten - ist grds. ein positiver Einfluss auf das Handelsvolumen anzunehmen. Gleichfalls ist mit $\mathbf{H} 3.3$ ein positiver Zusammenhang zwischen der Untersuchungsvariablen SDIndex und dem Handelsvolumen unterstellt worden.

Bei Durchführung der Regressionsanalyse erreicht das so spezifizierte Modell ein beachtliches Bestimmtheitsmaß $R^{2}$ von rund $85 \%$, wobei der interessierende Prädiktor SDIndex einen zwar nur geringen, aber positiven und signifikanten Erklärungsbeitrag leisten kann. ${ }^{1133}$ Das Ergebnis präsentiert sich nicht nur bei einer Konzentration auf die großen, sondern auch auf die kleinen Unternehmen als robust, in beiden Fällen leistet SDIndex einen eigenen Beitrag zur Erklärung der Varianz des jährlichen Handelsvolumens. Jener Einfluss von SDIndex zeigt sich auch dann noch robust, wenn das Modell - als Hauptmodell 4 - noch um zusätzliche Kontrollvariablen erweitert wird, hinzugefügt werden sodann die jährliche Aktienrendite sowie das Markt-Beta als Maß des Zusammenhangs von Aktienund Marktrendite. ${ }^{1134}$ Die genannten Ergebnisse stellt Tab. 52 im Detail dar. ${ }^{1135}$

1132 Hinweise auf die Relevanz dieser Kontrollvariablen finden sich u.a. bei Leuz/Verrecchia (2000), S. 107f.; Bushee et al. (2003), S. 176, hier v.a. in Bezug auf die Kapitalstruktur. Auch Bessembinder et al. (1996) sowie Tkac (1999) belegen die Bedeutung von Größe, Volatilität, Indexzugehörigkeit und Kapitalkonzentration zur Erklärung des Volumens. Es sei zudem an dieser Stelle erinnert, dass die Marktkapitalisierung und die Indexzugehörigkeit in einem Zusammenhang stehen sollten, weil die Marktkapitalisierung (neben dem Handelsvolumen) eines der Kriterien für die Indexzusammensetzung der Dt. Börse AG darstellt, vgl. erneut Dt. Börse AG (2009a), S. 21. Nichtsdestotrotz sind im Rahmen der Regressionen die Voraussetzungen für (perfekte) Multikollinearität nicht gegeben.

Das errechnete Bestimmtheitsmaß ist konsistent mit anderen Arbeiten zur Untersuchung des Handelsvolumens. Während Leuz/Verrecchia (2000) rund 40\% der Varianz der abhängigen Variablen erklären können (bei Nicht-Signifikanz ihrer Disclosure-Variablen), erreicht das Modell von Petersen/Plenborg (2006), S. 140 ein Bestimmtheitsmaß von ca. 20\% (bei Signifikanz der Disclosure-Variablen), allerdings mit einem recht ,schlanken * Aufbau, d.h. unter Einschluss von nur wenigen Kontrollvariablen, die sich zudem - abgesehen vom Marktwert des Eigenkapitals - als nicht signifikant erweisen. Vgl. grdl. zur Kennzahl des Markt-Betas Sharpe (1964), S. 425ff.

1135 Es ist nochmals anzumerken, dass bei der Durchführung von Regressionsanalysen unter Einschluss von Kontrollvariablen im Folgenden die maximale Stichprobengröße oft auf $\mathrm{n}_{\max }=600$ verringert ist, weil nicht für alle Variablen Datenpunkte für das Jahr 2009 ermittelt werden konnten, wie bspw. für ,Inv. Freefloat ' oder Datenpunkte aus Bilanz und GuV. Dies wird auch ersichtlich bei Betrachtung der Übersicht in Anhang 13. 
Panel A: Bivariate Regressionsanalyse zum Einfluss von SDIndex auf das Handelsvolumen

$\mathrm{F}(\mathrm{x})=\mathrm{Jährliches} \mathrm{monetäres} \mathrm{Handelsvolumen}(t+I)$, logarithmiert

egieberichterstattung
SDI (+)
(t) $\quad, 541 * * * \quad(, 000)$
$, 449 * * * \quad(.000) \quad, 500 * * *$
$(.000)$

Kontrollvariablen

\begin{tabular}{lcccccc} 
Konstante & & $(.141)$ & & $(.384)$ & & $(, 303)$ \\
$\mathrm{Jahr}$ &,- 048 & $(, 171)$ &,- 042 & $(, 438)$ &, 057 & $(, 243)$ \\
\hline$R^{2}$ &, 276 & &, 187 & &, 271 & \\
$R^{2}$ adj. &, $274 * * *$ & $(, 000)$ &, $182 * * *$ & $(, 000)$ &, $267 * * *$ & $(, 000)$ \\
Durbin-Watson $d$ & 1,924 & & 2,039 & & 1,973 & \\
$\mathrm{n}\left(\mathrm{n}_{\max }=700\right)$ & 685 & & 339 & & 346
\end{tabular}

Panel B: Multivariate Regressionsanalyse zum Einfluss von SDIndex auf das Handelsvolumen

\begin{tabular}{|c|c|c|c|c|c|c|c|c|c|}
\hline & & \multicolumn{2}{|c|}{$\begin{array}{l}\text { Multivariates } \\
\text { Grundmodell }\end{array}$} & \multicolumn{2}{|c|}{$\begin{array}{l}\ldots \text { nur für große } \\
\text { Unternehmen }\end{array}$} & \multicolumn{2}{|c|}{$\begin{array}{l}\text {... nur für kleine } \\
\text { Unternehmen }\end{array}$} & \multicolumn{2}{|c|}{ Hauptmodell 4} \\
\hline & & Koeff. $\beta$ & $\bar{p}$ & Koeff. $\beta$ & $\mathrm{p}$ & Koeff. $\beta$ & $\overline{\mathrm{p}}$ & Koeff. $\beta$ & $\mathrm{p}$ \\
\hline \multicolumn{10}{|c|}{ Strategieberichterstattung } \\
\hline SDI (+) & $(t)$ &, $092 * * *$ & $(.000)$ &, $058 * *$ & $(.040)$ &, $212 * * *$ & $(, 000)$ &, $077 * * *$ & $(.000)$ \\
\hline \multicolumn{10}{|l|}{ Kontrollvariablen } \\
\hline Konstante & & & $(.000)$ & & $(, 000)$ & & $(.000)$ & & $(.000)$ \\
\hline Marktwert EK & $(t+l)$ &, $439 * * *$ & $(.000)$ & $455 * * *$ & $(, 000)$ &, $287 * * *$ & $(, 000)$ &, $457 * * *$ & $(.000)$ \\
\hline Markt-Beta & $(t+1)$ & & & & & & &, $064 * * *$ & $(, 003)$ \\
\hline Aktienrendite & $(t+1)$ & & & & & & &,$- 056 * * *$ & $(, 006)$ \\
\hline Volatilität & $(t+l)$ &, $238 * * *$ & $(.000)$ &, $165 * * *$ & $(, 000)$ &, $340 * * *$ & $(, 000)$ &, $225 * * *$ & $(, 000)$ \\
\hline Erfolg [Faktor] & $(t)$ &,$- 083 * * *$ & $(, 000)$ &,$- 101 * * *$ & $(.000)$ &,$- 110 * * *$ & $(, 003)$ &,$- 086 * * *$ & $(.000)$ \\
\hline Inv. Freefloat & $(t+l)$ &,$- 113 * * *$ & $(.000)$ &,$- 103 * * *$ & $(.000)$ &,$- 162 * * *$ & $(, 000)$ &,$- 114 * * *$ & $(.000)$ \\
\hline \multicolumn{10}{|c|}{ Indexzugehörigkeit } \\
\hline Dax & $(t+l)$ &, $626 * * *$ & $(.000)$ &, $851 * * *$ & $(.000)$ & & &, $581 * * *$ & $(, 000)$ \\
\hline MDax & $(t+l)$ &, $358 * * *$ & $(, 000)$ &, $724 * * *$ & $(, 000)$ &, $345 * * *$ & $(, 000)$ &, $281 * * *$ & $(.000)$ \\
\hline TecDax & $(t+1)$ &, $226 * * *$ & $(, 000)$ &, $196 * * *$ & $(.000)$ &, $404 * * *$ & $(, 000)$ &, $189 * * *$ & $(.000)$ \\
\hline SDax & $(t+1)$ &, $102 * * *$ & $(, 000)$ &, $248 * * *$ & $(.005)$ &, $148 * * *$ & $(, 006)$ &, 020 & $(.644)$ \\
\hline Jahr & &, $120 * * *$ & $(.000)$ &, $129 * * *$ & $(, 000)$ &, $172 * * *$ & $(.000)$ &, $094 * * *$ & $(, 000)$ \\
\hline$R^{2}$ & & 854 & & 861 & &, 700 & & 849 & \\
\hline$R^{2}$ adj. & &, $851 * * *$ & $(, 000)$ &, $856 * * *$ & $(.000)$ &, $690 * * *$ & $(.000)$ &, $846 * * *$ & $(.000)$ \\
\hline Durbin-Watson & & 2,016 & & 1,977 & & 2,130 & & 1,949 & \\
\hline$n\left(n_{\max }=600\right)^{11.36}$ & & 563 & & 284 & & 279 & & 524 & \\
\hline
\end{tabular}

\section{Tabelle 52: Regressionsmodell des Handelsvolumens}

1136 Die Reduktion von $\mathrm{n}_{\max }$ führt gleichfalls zur anteiligen Reduktion der Teil-Stichproben. 


\section{(b) Analyse der Auswirkungen auf die Volatilität}

Ein weiterer interessierender Aspekt innerhalb der Kategorie der Handelseffekte adressiert die jährliche Volatilität der Aktienrenditen (H 3.4). Die entsprechende Hypothese unterstellte einen negativen Zusammenhang zwischen dem Niveau der Strategieberichterstattung und der Volatilität der Aktienkurse. Die Resultate der betrachteten Regressionsmodelle fasst Tab. 53 überblicksartig zusammen.

Panel A: Regressionsanalyse zum Einfluss von SDIndex auf die Volatilität der Aktienrenditen $I(x)=$ Volatilität der Aktienrenditen $(t+l)$, logarithmien ${ }^{1137}$

\begin{tabular}{|c|c|c|c|c|c|c|c|c|c|}
\hline & & \multicolumn{2}{|c|}{$\begin{array}{c}\text { Bivariates } \\
\text { Grundmodell }\end{array}$} & \multicolumn{2}{|c|}{$\begin{array}{l}\text { Multivariates } \\
\text { Grundmodell }\end{array}$} & \multicolumn{2}{|c|}{$\begin{array}{l}\text { Erweitertes } \\
\text { Grundmodell }\end{array}$} & \multicolumn{2}{|c|}{ Hauptmodell 5} \\
\hline & & Koeff. $\beta$ & $p$ & Koeff. $\beta$ & $p$ & Koeff. $\beta$ & $p$ & Koeff. $\beta$ & $\bar{p}$ \\
\hline \multicolumn{10}{|c|}{ Strategieberichterstattung } \\
\hline SDI (-) & $(t)$ &,$- 085 * *$ & (.(044) & 038 & $(.371)$ & 035 & $(.414)$ & 060 & $(.151)$ \\
\hline \multicolumn{10}{|l|}{ Kontrollvariablen } \\
\hline Konstante & & & $(.093)$ & & (.443) & & $(.5(1) 2)$ & & (.059) \\
\hline Inv. Freefloat & $(t+1)$ & & & 047 & $(.241)$ & 050 & $(.213)$ &, 014 & $(.731)$ \\
\hline Aktienrendite & $(t+1)$ & & &, $180 * * *$ & $(.0(0))$ &, $181 * * *$ & $(.(0)(0))$ &, $150 * * *$ & $(.(0)(0))$ \\
\hline Marktwert EK & $(t+l)$ & & &,$- 898 * * *$ & $(.000)$ &,$- 895 * * *$ & $(.000)$ &,$- 649 * * *$ & $(.0(0))$ \\
\hline Handelsvolume & $(t+l)$ & & &, $646 * * *$ & $(.(X X))$ &, $648 * * *$ & $(.(0)(0))$ &, $662 * * *$ & $(.(x))$ \\
\hline Erfolg [Faktor] & $(t)$ & & & & &,- 001 & (.986) &,- 022 & $(.539)$ \\
\hline \multicolumn{10}{|c|}{ Indexzugehörigkeit } \\
\hline $\operatorname{Dax}$ & $(1+l)$ & & & & & & &,$- 346 * * *$ & $(.0(0) 2)$ \\
\hline MDax & $(t+l)$ & & & & & & &,$- 271 * * *$ & $(.(0) 1)$ \\
\hline TecDax & $(t+l)$ & & & & & & &, 085 & $(.130)$ \\
\hline SDax & $(t+l)$ & & & & & & &,- 091 & $(.122)$ \\
\hline Jahr & &, $084 * *$ & (.047) &,- 016 & (.691) &,- 012 & $(.761)$ &,- 065 & (.114) \\
\hline$R^{2}$ & & 009 & & 352 & &, 350 & &, 404 & \\
\hline$R^{2}$ adj. & &, $006 * *$ & $(.049)$ &, $345 * * *$ & $(.(0))$ &, $341 * * *$ & $(.000))$ &, $392 * * *$ & $(.000))$ \\
\hline Durbin-Watson & & 1,992 & & 1,882 & & 1,887 & & 1,898 & \\
\hline$n\left(n_{\operatorname{mix}}=600\right)$ & & $651^{11.38}$ & & 557 & & 557 & & 557 & \\
\hline
\end{tabular}

\section{Tabelle 53: Regressionsmodell der Volatilität der Aktienrenditen}

Wie Tab. 53 zu entnehmen ist, lässt sich der postulierte Einfluss der Berichterstattung auf die Volatilität der Aktienrenditen mittels der Einfachregression bestätigen. Allerdings ist dieser Zusammenhang bei einer Erweiterung des Unter-

1137 Die vergleichbaren Resultate der Regression unlogarithmierter Werte zeigt Anhang 12.

1138 Für das bivariate Grundmodell gilt abweichend $\mathrm{n}_{\max }=700$, da sich der limitierende Einfluss einiger Kontrollvariablen nicht auswirkt. 
suchungsmodells um wesentliche Kontrollvariablen wie die Aktienrendite, den Marktwert des Eigenkapitals, das jährliche Handelsvolumen sowie die Indexzugehörigkeit nicht robust. ${ }^{1139}$ Gleichwohl errechnet sich für dieses so spezifizierte Hauptmodell 5 ein korrigiertes Bestimmtheitsmaß von ca. $40 \%$ und das Modell ist folglich in der Lage, einen erheblichen Teil der Varianz der Volatilität zu erklären. ${ }^{1140}$ Ein Einfluss der Strategieberichterstattung auf die Volatilität kann jedoch im multivariaten Modell nicht bestätigt werden, die entsprechende Hypothese H. 3.4 ist - zumindest auf Basis der multiplen Regression - abzulehnen.

\subsubsection{Untersuchung der Bewertungseffekte}

Die letzte der drei Kategorien von Kapitalmarkteffekten der Strategieberichterstattung behandelt Aspekte der Marktbewertung. Innerhalb dieser Kategorie sind drei Einzeleffekte zu überprüfen, neben dem Einfluss des Berichtsverhaltens auf die Eigenkapitalkosten (H 3.5) sowie die durchschnittlichen Geld-Brief-Spannen der Kursnotierungen (H 3.6) ist dies schließlich die Marktbewertung, welche ein Unternehmen am Kapitalmarkt erzielt (H 3.7).

\section{(a) Analyse der Auswirkungen auf die Eigenkapitalkosten}

Eine zentrale Frage in der bisherigen empirischen Forschung zu Kapitalmarkteffekten der Berichterstattung ist stets die Wirkung dieser auf die Eigenkapitalkosten eines Unternehmens. ${ }^{1141}$ Aus diesem Grund ist auch für die eigene Untersuchung explizit die entsprechende Hypothese $\mathbf{H ~} 3.5$ formuliert worden, welche sodann einen negativen Zusammenhang zwischen dem Niveau der Strategieberichterstattung und den Eigenkapitalkosten unterstellte.

1139 Anhaltspunkte für diese Kontrollvariablen finden sich u.a. bei Leuz/Verrecchia (2000), S. 108, Bushee et al. (2003), S. 176. Ein breiteres Spektrum an Kontrollvariablen sehen Bushee/Noe (2000) vor, welche auch die jährliche Aktienrendite, das Handelsvolumen, den Marktwert des Eigenkapitals und das Markt-Beta in ihrem Modell kontrollieren. Aufgrund des nicht signifikanten Resultats für das multivariate Grundmodell wird eine spezifische Untersuchung für die Teil-Stichproben nicht durchgeführt. in verschiedenen Spezifikationen Bestimmtheitsmaße von ca. 33 bis $36 \%$ ermitteln. Mit einem höheren Bestimmtheitsmaß $\left(R^{2}\right.$ adj.=89\%) vgl. Gassen/Sellhorn (2006), S. 382. 
Die Ermittlung der Eigenkapitalkosten folgte einem in der Literatur bewährten Ansatz, den u.a. auch Gebhardt et al. (2001), Lee et al. (1999) bzw. Hail (2002) darstellen, im Einzelnen: ${ }^{142}$,To compute [...] cost of capital I adopt a version of the accounting-based valuation formula often referred to as the residual in-come model. In this model firm value is represented as a function of current and forecasted accounting data subject only to the clean surplus relation. [...] I then compute [...] cost of capital as the internal rate of return that equates the intrinsic value of the firm to the current stock price." ${ }^{\text {"1143 }}$ Auf Basis von Angaben, die aus Datenbanken gewonnen werden konnten, kann folglich die Berechnung jahresspezifischer Eigenkapitalkostensätze durchgeführt werden, welche anschließend - in logarithmierter Form - als Regressand in das Modell inkludiert werden. Die Ergebnisse der bivariaten Regressionsanalysen stellt Tab. 54-1 dar.

Panel A: Bivariate Regressionsanalyse zum Einfluss von SDIndex auf die Eigenkapitalkosten

$I(x)=1$ : x-ante-Ligenkapitalkosten in PTozent $(t+I)$, logarithmiert

\begin{tabular}{|c|c|c|c|c|c|c|}
\hline & \multicolumn{2}{|c|}{$\begin{array}{c}\text { Bivariates } \\
\text { Grundmodell }\end{array}$} & \multicolumn{2}{|c|}{$\begin{array}{l}\text {... nur für große } \\
\text { Unternehmen }\end{array}$} & \multicolumn{2}{|c|}{$\begin{array}{l}\text {... nur für kleine } \\
\text { Unternehmen }\end{array}$} \\
\hline & Koeff. $\beta$ & $\mathrm{p}$ & Koeff. $\beta$ & $\mathrm{p}$ & Koeff. $\beta$ & $\mathrm{p}$ \\
\hline \multicolumn{7}{|c|}{ Strategieberichterstattung } \\
\hline SDI $(-)$ &,$- 126 * * *$ & $(.(0) 2)$ &,$- 254 * * *$ & $(.(0)(0)$ &,$- 099 *$ & $(.092)$ \\
\hline \multicolumn{7}{|l|}{ Kontrollvariablen } \\
\hline Konstante & & $(.(0) 2)$ & & $(.127)$ & & $(.039)$ \\
\hline Jahr &,$- 119 * * *$ & $(.003)$ &,- 076 & $(.180)$ &,$- 114 *$ & $(.051)$ \\
\hline$R^{2}$ &, 040 & & 086 & &, 029 & \\
\hline$R^{2}$ adj &, $037 * * *$ & $(.0(0))$ & $080 * * *$ & $(.0(0))$ &, $023 * * *$ & $(.010)$ \\
\hline Durbin-Watson $d$ & 1,874 & & 2,143 & & 2,008 & \\
\hline $\mathrm{n}\left(\mathrm{n}_{\max }=700\right)$ & 661 & & 347 & & 314 & \\
\hline
\end{tabular}

Tabelle 54-1: Regressionsmodell der Eigenkapitalkosten: bivariat

1142 Vgl. Gebhardt et al. (2001), Lee et al. (1999), Hail (2002). Es sei vermerkt, dass es sich bei den abgeleiteten Eigenkapitalkostensätzen strenggenommen um sog. Ex-ante-Eigenkapitalkostensätze handelt. Eine Darstellung der Methodik zur Berechnung der Kostensätze findet sich in Anhang 11 dieser Arbeit, Anhang 8 nennt zudem die Datenquellen.

1143 Hail (2002), S. 747. Die für die eigene Untersuchung errechneten Kostensätze sind mit den Werten bei Hail (2002) weitgehend vergleichbar: Hail ermittelt für seine Stichprobe aus nur 73 Schweizer Unternehmen einen Mittelwert von 6,18\% bei einer Standardabweichung von 1,86\%. Die eigene Berechnung führt auf Basis von 661 Datenpunkten zu einem Mittelwert von $6,78 \%$ bei einer Standardabweichung von $1,86 \%$. 
Wie Tab. 54-1 zeigt, wird der unterstellte Einfluss der zentralen Untersuchungsvariablen SDIndex auf Basis der bivariaten Regressionsanalyse sichtbar, ebenso für die beiden Teil-Stichproben der großen respektive der kleinen Unternehmen. Weiterführend ist das Modell daher um relevante Kontrollvariablen zu ergänzen, es sind insb. solche Parameter einzubeziehen, für die bereits ein Einfluss auf die Eigenkapitalkosten der Unternehmen empirisch bestätigt werden konnte: ${ }^{1144}$

Das sind neben dem Marktwert des Eigenkapitals und der Volatilität der Aktienrenditen auch der Verschuldungsgrad und die Profitabilität eines Unternehmens. Darüber hinaus sollten auch qualitative Parameter einen Einfluss auf die Eigenkapitalkosten besitzen, wie bereits bei Gebhardt et al. (2001) aufgezeigt werden konnte. Daher beinhaltet das in der nachfolgenden Tab. 54-2 dargestellte Hauptmodell 6 zusätzlich als Kontrollvariablen die Branchenzugehörigkeit, das Unternehmensalter sowie Aspekte der Rechnungslegung. ${ }^{1145}$

Das so spezifizierte Hauptmodell 6 erreicht schließlich bei der Durchführung der multivariaten Regressionsanalyse ein korrigiertes Bestimmtheitsmaß von 36\%, wobei die interessierende Untersuchungsvariable SDIndex ihrerseits einen deutlichen und hoch signifikanten Erklärungsbeitrag leisten kann, welcher außerdem die a priori vermutete Richtung aufweist. ${ }^{1146}$ Dieser Einfluss zeigt sich robust für die großen, nicht jedoch für die Teil-Stichprobe der kleinen Unternehmen.

Dennoch scheint eine Annahme der Hypothese H 3.5 auf Basis der Resultate des multivariaten Modells grds. gerechtfertigt, wenngleich eine besondere Relevanz für die Teil-Stichprobe der großen Unternehmen festgehalten werden kann.

1144 Anhaltspunkte für die einzelnen aufgeführten Kontrollvariablen finden sich bei Botosan (1997a), S. 324ff., Hail (2002), S. 760ff., Gebhardt et al. (2001), S. 138ff., weiterhin bei Botosan/Plumlee (2001), S. 34ff., Gietzman/Ireland (2005), S. 622ff.

1145 Vgl. Gebhardt et al. (2001), S. 164. Auch Botosan (1997a), Daske (2006) weisen darauf hin, dass branchenspezifische Unterschiede der Eigenkapitalkostensätze denkbar sind.

1146 Dieses Resultat scheint mit einem Bestimmtheitsmaß von ca. 30\%, welches Hail (2002), S. 762 ermittelt, konsistent zu sein. In einer Regression der Eigenkapitalkostensätze auf Markt-Beta, Verschuldungsgrad bzw. Marktwert des Eigenkapitals gelingt es ihm, einen signifikanten Beitrag seiner Kennzahl der Berichtsqualität nachzuweisen. Ähnlich auch Gietzman/Ireland (2005), S. 628 mit einem Bestimmtsheitsmaß von ca. 38\% bzw. Daske (2006), S. 358, der je nach Spezifikation seines Modells Maße von über 30\% berichtet.

Eine Regressionsanalyse für das Hauptmodell unter Verwendung von unlogarithmierten Werten weist ein inhaltlich vergleichbares Ergebnis aus. Vgl. Anhang 12 dieser Arbeit. 


\begin{tabular}{|c|c|c|c|c|c|c|c|c|c|}
\hline \multicolumn{4}{|c|}{ Panel B: Multivariate Regressionsanalyse } & \multicolumn{6}{|c|}{$\mathrm{F}(\mathrm{x})=\mathrm{l}$ ix-ante-Figenkapitalkosten in Prozent $(1+l)$, logarithmien ${ }^{11+77}$} \\
\hline & & \multicolumn{2}{|c|}{$\begin{array}{l}\text { Multivariates } \\
\text { Grundmodell }\end{array}$} & \multicolumn{2}{|c|}{ Hauptmodell 6} & \multicolumn{2}{|c|}{$\begin{array}{c}\text {... nur für große } \\
\text { Unternehmen }\end{array}$} & \multicolumn{2}{|c|}{$\begin{array}{c}\text {... nur für kleine } \\
\text { Unternehmen }\end{array}$} \\
\hline & & Koeff. $\beta$ & $\mathrm{p}$ & Koeff. $\beta$ & $\mathrm{p}$ & Koeff. $\beta$ & $\mathrm{p}$ & Koeff. $\beta$ & $\mathrm{p}$ \\
\hline \multicolumn{10}{|c|}{ Strategieberichterstattung } \\
\hline SDI (-) & $(t)$ &,$- 111 * *$ & $(.016)$ &,$- 1.54 * * *$ & $(.(0) 1)$ &,$- 224 * * *$ & $(.(0) 1)$ &,- 058 & $(.334)$ \\
\hline \multicolumn{10}{|l|}{ Kontrollvariablen } \\
\hline Konstante & & & $(.(0)(x))$ & & $(.474)$ & & $(.957)$ & & $(.847)$ \\
\hline Marktwert EK & $(t+I)$ & $-.365 * * *$ & $(.()(x))$ &,$- 159 * * *$ & $(.(0) 1)$ &,$- 252 * * *$ & $(.00(0))$ &,- 102 & $(.155)$ \\
\hline Markt-Beta & $(t+I)$ & $.187 * * *$ & $(.(O)(x))$ &,- 011 & $(.813)$ &,- 008 & $(.898)$ &,- 036 & $(.591)$ \\
\hline Volatilität & $(t+l)$ &,- 080 & $(.146)$ &,- 031 & $(.57())$ & ,057 & $(.433)$ &, 044 & $(.569)$ \\
\hline Handelsvolumen & $(t+l)$ &,$- 162 * *$ & (.027) & & & & & & \\
\hline Aktienrendite & $(t+l)$ & & &, $178 * * *$ & $(.()(x))$ &, $208 * * *$ & $(.(0) 1)$ &, $208 * * *$ & $(.(0) 1)$ \\
\hline Verschuldung $[F]$ & &, $187 * * *$ & $(.(0)(0))$ &, $294 * * *$ & $(.(0)(0))$ & $.196 * * *$ & $(.(0) 1)$ &, $281 * * *$ & $(.0(x))$ \\
\hline Erfolg [Faktor] & $(t)$ &,- 003 & $(.937)$ &,$- 109 * * *$ & $(.0(07)$ &,- 020 & $(.727)$ &,$- 113 *$ & (.)(166) \\
\hline Inv. Freefloat & $(t+I)$ & & &,$- 161 * * *$ & $(.(0)(0))$ & $-.157 * * *$ & $(.0(06)$ &,$- 257 * * *$ & $(.(x)())$ \\
\hline \multicolumn{10}{|c|}{ Branchenzugehörigkeit } \\
\hline Info. Tech. & $(t+I)$ & & & ,084 & $(.253)$ &, 100 & $(.271)$ & 032 & $(.610)$ \\
\hline Cons. Goods & $(t+I)$ & & &, 062 & $(.468)$ &, 089 & $(.317)$ & & \\
\hline Cons. Services & $(t+l)$ & & &,$- 158 * *$ & $(.025)$ &,$- 151 *$ & $(.087)$ &,$- 190^{* * *}$ & $(.006)$ \\
\hline Industrials & $(t+l)$ & & &, 167 & $(.125)$ &, 190 & $(.128)$ &,- 040 & (.627) \\
\hline Pharma \& H. & $(t+I)$ & & &, 002 & $(.9 \times 3)$ &,$- 127 *$ & $(.(996)$ &,- 045 & $(.585)$ \\
\hline Basic Materials & $(t+I)$ & & &,- 112 & $(.109)$ &,- 109 & $(.165)$ &,$- 194 * * *$ & $(.(0) 9)$ \\
\hline Utilities & $(t+I)$ & & &,- 011 & $(.818)$ &, 064 & $(.341)$ &,- 045 & $(.437)$ \\
\hline Alter: Klasse 1 & $(t+I)$ & & &,$- 120 * *$ & $(.035)$ &,- 025 & $(.711)$ &,- 126 & $(.184)$ \\
\hline Alter: Klasse 2 & $(1+1)$ & & &,$- 115 * *$ & $(.023)$ &,- 014 & $(.819)$ &,$- 172 *$ & (.056) \\
\hline Alter: Klasse 3 & $(t+I)$ & & &,$- 077 *$ & $(.096)$ &,- 029 & $(.629)$ &,$- 133 *$ & $(.073)$ \\
\hline Abschluss: Std. & $(t)$ & & &, 061 & $(.126)$ &, 070 & $(.2(1) 2)$ &, 062 & $(.306)$ \\
\hline Abschluss: Prüf. & $(t)$ & & &, $117 * * *$ & $(.004)$ &, $159 * * *$ & $(.(x) 5)$ &, $195 * * *$ & $1.001)$ \\
\hline
\end{tabular}

Indexzugehörigkeit

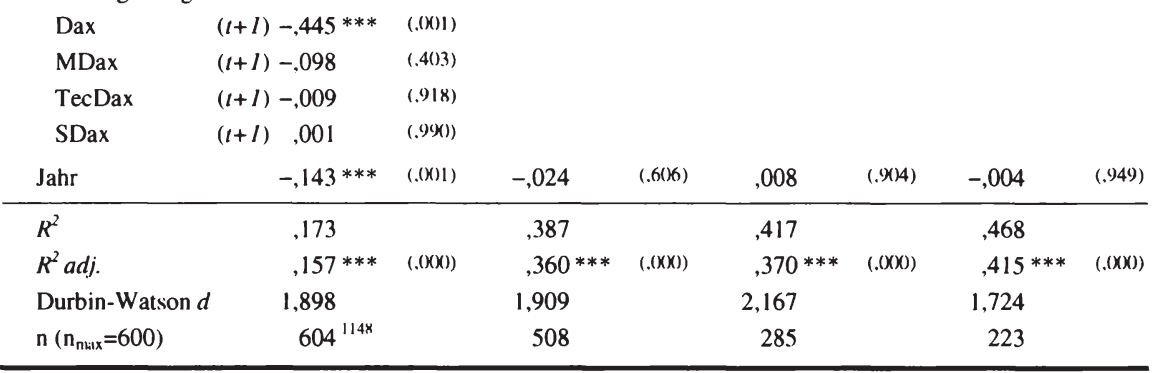

\section{Tabelle 54-2: Regressionsmodell der Eigenkapitalkosten: multivariat}

1147 Ergebnisse für Hauptmodell 6 auf Basis von unlogarithmierten Werten zeigt Anhang 12.

1148 Für das multivariate Grundmodell gilt abweichend eine Stichprobengröße $n_{\max }=700$, da sich der limitierende Einfluss einiger Kontrollvariablen nicht auswirkt. 


\section{(b) Analyse der Auswirkungen auf die Bid-Ask-Spreads}

In der Literatur gelten die durchschnittlichen Bid-Ask-Spreads üblicherweise als ein geeigneter Indikator für das Ausma $B$ der in Bezug auf ein Unternehmen bestehenden Informationsasymmetrien. ${ }^{1149}$ Daher war zur Untersuchung von Auswirkungen des Niveaus der Strategieberichterstattung auf die durchschnittlichen Bid-Ask-Spreads ${ }^{1150}$ die spezifische Hypothese $\mathbf{H}$ 3.6 formuliert worden, welche einen negativen Zusammenhang beider Größen unterstellte.

Die zur Hypothesenprüfung erforderlichen Geld-Brief-Spannen der StichprobenUnternehmen konnten auf Basis der täglichen Kursnotierungen ermittelt werden, wobei grds. die jeweilige Schlussnotierung an der Frankfurter Wertpapierbörse maßgeblich ist. Konsistent mit bisherigen Untersuchungen zu dieser abhängigen Variablen werden die jeweiligen Spannen in Relation zum Geldkurs gesetzt, um relative Spannen zu errechnen. ${ }^{1151}$ Schließlich wird über alle Handelstage eines Jahres hinweg die durchschnittliche Spanne des jeweiligen Jahres ermittelt. ${ }^{1152}$

Es erscheint auch für eine Untersuchung der Auswirkungen der Strategieberichterstattung auf die durchschnittlichen Bid-Ask-Spreads nur konsequent, für verschiedene andere Parameter zu kontrollieren, deren Einfluss auf den genannten Regressanden bekannt ist oder zumindest unterstellt werden kann. Dies sind im Einzelnen insb. die Marktbewertung des Eigenkapitals als Indikator der Unternehmensgröße sowie die Volatilität der Kursrenditen. ${ }^{153}$ Diese beiden Kontrollvariablen sind ebenfalls in Hauptmodell 7 enthalten, das Tab. 55 im Detail zeigt.

1149 Diese Argumentation findet sich u.a. bei Glosten/Milgrom (1985), Welker (1995). Dies ist auch als Begründung zu sehen, warum die Auswirkungen der Strategieberichterstattung auf die Geld-Brief-Spanne als ,Bewertungseffekt" kategorisiert wurden. In der Literatur wird grds. der Begriff der ,Bid-Ask-Spreads ' verwandt, auch in deutschsprachigen Arbeiten. In dieser Arbeit wird z.T. auch das deutsche Pendant verwendet.

1151 Jene Vorgehensweise ist konsistent mit Welker (1995), Leuz/Verrecchia (2000). Andere Autoren arbeiten hingegen mit absoluten Spannen, sehen in ihren Regressionsmodellen jedoch die Kontrollvariable Aktienkurs vor, vgl. so bspw. Coller/Yohn (1997). Auch die Bid-Ask-Spreads werden in logarithmierter Form in den Modellen verwendet. Die Kontrollvariablen sind aus der Arbeit von Leuz/Verrecchia (2000) entnommen. Die Autoren untersuchen den Einfluss der Reporting-Strategie auf die Bid-Ask-Spreads, vgl. ebenda, S. 107f. Welker (1995) kontrolliert ebenfalls für die Volatilität der Renditen sowie das Handelsvolumen, auch Coller/Yohn (1997); Healy et al. (1999), S. 504f.; Heflin et al. (2005), S. 841; Glosten/Harris (1988), S. 126f. bzgl. Kontrolle der Kapitalstruktur. 
Zusätzlich kontrolliert dieses Modell für die Indexzugehörigkeit, da anzunehmen ist, dass dieser Parameter auch einen Einfluss auf die Spannen ausübt.

Das so spezifizierte Modell ist schließlich in der Lage, über 70\% der Varianz der Bid-Ask-Spreads zu erklären, und die relevante Untersuchungsvariable SDIndex leistet hierzu einen geringen, aber signifikanten Beitrag. Wie erwartet leisten zudem die Kontrollvariablen Marktwert und Indexzugehörigkeit hohe Erklärungsbeiträge, so dass davon auszugehen ist, dass diese Einfluss auf die relativen BidAsk-Spreads besitzen. Das mit Hauptmodell 7 erzielte Bestimmtheitsmaß ist darüber hinaus auch vergleichbar mit einschlägigen Arbeiten zur Untersuchung der Spreads, bspw. errechnen Leuz/Verrecchia (2000) einen Wert von rund $81 \%$ mit ihrem Modell zur Prüfung des Einflusses des Berichterstattungsverhaltens. ${ }^{1154}$

Weiterhin zeigt Tab. 55 zusätzliche Regressionsanalysen, um die Robustheit des genannten Hauptmodells 7 zu prüfen: Zunächst erfolgt die Zerlegung der Stichprobe in die Teil-Stichproben: Während die Untersuchungsvariable im Falle der großen Unternehmen keinen eigenen Beitrag mehr leisten kann, ergibt sich für die kleinen Unternehmen ein deutlich höherer Koeffizient als im Hauptmodell. Gleichfalls robust präsentiert sich SDIndex auch in einem um weitere Kontrollvariablen ergänzten Hauptmodell. ${ }^{1155}$ An diesem ist insb. zu bemerken, dass sich auch hier die kontraproduktiv anmutende Auswirkung einer höheren Analystenbeobachtung offenbart, die bereits im Rahmen von $\mathrm{H} 3.2$ festzustellen war: Obwohl eine höhere Analystenabdeckung zu geringeren Informationsasymmetrien führen sollte, zeigt sich im Hinblick auf die Spreads erneut ein positiver Effekt.

Auf der Grundlage der robusten Resultate dieses Regressionsmodells ist folglich anzunehmen, dass der vermutete negative Einfluss der Strategieberichterstattung auf die Geld-Brief-Spannen gegeben ist. Es scheint empfehlenswert, Hypothese H 3.6 zu akzeptieren bzw. die gegensätzliche Nullhypothese zu verwerfen.

1154 Vgl. nochmals die Arbeit von Leuz/Verrecchia (2000), S. 107f. Welker (1995), S. 818ff. ermittelt ein Bestimmtheitsmaß von ca. 63\%, Heflin et al. (2005), S. 846 ca. $80 \%$ sowie Gassen/Selhorn (2006), S. 382 ein Bestimmtheitsmaß von ca. $68 \%$.

1155 Die Erweiterung des Hauptmodells um diese beiden Kontrollvariablen Handelsvolumen und Freefloat wird von Leuz/Verrecchia (2000), S. 113; Glosten/Harris (1988), S. 125ff. empfohlen. Erstgenannte ermitteln für den Freefloat einen negativen Koeffizienten; weil hier aber der inverse Freefloat verwendet wird, ist ein positives Vorzeichen zu erwarten. 


\begin{tabular}{|c|c|c|c|c|c|c|}
\hline \multicolumn{3}{|c|}{ Panel A: Bivariate Regressionsanalyse } & \multicolumn{4}{|c|}{$\mathrm{F}(\mathrm{x})=$ Relative Bid-Ask-Spreads im Jahresdurchschnitt $(t+l)$, logarithmiert ${ }^{1156}$} \\
\hline & \multicolumn{2}{|c|}{$\begin{array}{c}\text { Bivariates } \\
\text { Grundmodell }\end{array}$} & \multicolumn{2}{|c|}{$\begin{array}{l}\text {... nur für große } \\
\text { Unternehmen }\end{array}$} & $\begin{array}{c}\text {... nur für kleine } \\
\text { Unternehmen }\end{array}$ & $\begin{array}{l}\text { leine } \\
\text { nen }\end{array}$ \\
\hline & Koeff. $\beta$ & $\mathrm{p}$ & Koeff. $\beta$ & $\mathrm{p}$ & Koeff. $\beta$ & $\mathrm{p}$ \\
\hline \multicolumn{7}{|c|}{ Strategieberichterstattung } \\
\hline SDI (-) &,$- 462 * * *$ & $(.000)$ &,$- 367 * * *$ & $(.000)$ &,$- 376 * * *$ & $(.000)$ \\
\hline \multicolumn{7}{|l|}{ Kontrollvariablen } \\
\hline Konstante & & $(.120)$ & & (.543) & & $(.242)$ \\
\hline Jahr &, 055 & $(, 133)$ &,- 036 & $(, 507)$ &, 058 & $(, 280)$ \\
\hline$R^{2}$ &, 199 & &, 147 & &, 132 & \\
\hline$R^{2}$ adj. &, $197 * * *$ & $(.000)$ &, $142 * * *$ & $(, 000)$ &, $126 * * *$ & $(.000)$ \\
\hline Durbin-Watson $d$ & 1,991 & & 1,748 & & 1,869 & \\
\hline $\mathrm{n}\left(\mathrm{n}_{\max }=700\right)$ & 690 & & 350 & & 340 & \\
\hline
\end{tabular}

Panel B: Multivariate Regressionsanalyse zum Einfluss von SDIndex auf die Bid-Ask-Spreads

\begin{tabular}{|c|c|c|c|c|c|c|c|c|c|}
\hline & & \multicolumn{2}{|c|}{ Hauptmodell 7} & \multicolumn{2}{|c|}{$\begin{array}{l}\text {... nur für große } \\
\text { Unternehmen }\end{array}$} & \multicolumn{2}{|c|}{$\begin{array}{c}\text {... nur für kleine } \\
\text { Unternehmen }\end{array}$} & \multicolumn{2}{|c|}{$\begin{array}{l}\text { Erweitertes } \\
\text { Hauptmodell }\end{array}$} \\
\hline & & Koeff. $\beta$ & $\mathrm{p}$ & Koeff. $\beta$ & $\mathrm{p}$ & Koeff. $\beta$ & $\mathrm{p}$ & Koeff. $\beta$ & $\mathrm{p}$ \\
\hline \multicolumn{10}{|c|}{ Strategieberichterstattung } \\
\hline SDI (-) & $(t)$ &,$- 082 * * *$ & $(, 001)$ &,- 022 & $(, 580)$ &,$- 185 * * *$ & $(.000)$ &,$- 047 * *$ & $(.046)$ \\
\hline \multicolumn{10}{|l|}{ Kontrollvariablen } \\
\hline Konstante & & & $(, 463)$ & & $(, 007)$ & & $(, 039)$ & & $(.000)$ \\
\hline Marktwert EK & $(t+1)$ &,$- 454 * * *$ & $(.000)$ &,$- 404 * * *$ & $(.000)$ &,$- 380 * * *$ & $(.000)$ &,$- 567 * * *$ & $(.000)$ \\
\hline Volatilität & $(t+l)$ &, 007 & $(.791)$ &, 040 & $(.249)$ &, 011 & $(, 826)$ & 039 & $(.161)$ \\
\hline Aktienrendite & $(t+1)$ &, 031 & $(, 173)$ &, $067 * *$ & $(.046)$ &, 036 & $(, 450)$ &, 008 & $(, 742)$ \\
\hline Handelsvolumen & $(t+1)$ & & & & & & &,$- 078 *$ & $(.072)$ \\
\hline Anz. Analysten & $(t+I)$ & & & & & & &, $110 * *$ & $(.032)$ \\
\hline Inv. Freefloat & $(t+I)$ & & & & & & &, $208 * * *$ & $(.000)$ \\
\hline \multicolumn{10}{|l|}{ Indexzugehörigkeit } \\
\hline Dax & $(t+I)$ &,$- 398 * * *$ & $(.000)$ &,$- 459 * * *$ & $(, 001)$ & & &,$- 283 * * *$ & $(.000)$ \\
\hline MDax & $(t+1)$ &,$- 169 * * *$ & $(.000)$ &,- 162 & $(, 176)$ &,$- 214 * * *$ & $(.004)$ &,$- 149 * * *$ & $(.003)$ \\
\hline TecDax & $(t+1)$ &,$- 118 * * *$ & $(, 000)$ &,- 043 & $(.390)$ &,$- 241 * * *$ & $(, 001)$ &,$- 101 * * *$ & $(.003)$ \\
\hline SDax & $(t+1)$ &, $076 * *$ & $(.036)$ &, 125 & $(, 119)$ & ,098 & $(.141)$ &, $058 *$ & $(.095)$ \\
\hline Jahr & &,- 016 & $(.478)$ &, $098 * * *$ & $(, 007)$ &, $096 * *$ & $(.037)$ &,$- 107 * * *$ & $(, 000)$ \\
\hline$R^{2}$ & & ,724 & & ,672 & & ,471 & & ,784 & \\
\hline$R^{2} a d j$. & &, $720 * * *$ & $(.000)$ &, $663 * * *$ & $(, 000)$ &, $458 * * *$ & $(.000)$ &, $779 * * *$ & $(.000)$ \\
\hline Durbin-Watson $d$ & & 1,784 & & 1,740 & & 1,920 & & 1,872 & \\
\hline$n\left(n_{\max }=700\right)$ & & 662 & & 341 & & 321 & & $568^{1157}$ & \\
\hline
\end{tabular}

\section{Tabelle 55: Regressionsmodell der Bid-Ask-Spreads}

1156 Ergebnisse für Hauptmodell 7 auf Basis von unlogarithmierten Werten zeigt Anhang 12.

Für das erweiterte Hauptmodell gilt abweichend $n_{\max }=600$. 
(c) Analyse der Auswirkungen auf die Marktbewertung

Die abschließende Hypothese innerhalb der dritten Kategorie möglicher Kapitalmarkteffekte der Strategieberichterstattung betrachtet sodann den Einfluss dieser auf am Kapitalmarkt beobachtbare Bewertungsparameter. Mit Hypothese $\mathbf{H} 3.7$ wurde postuliert, dass sich ein höheres Niveau der Strategieberichterstattung in einer höheren Marktbewertung niederschlagen sollte.

Für die Untersuchung wird das Umsatz-Multiple, also der Quotient aus Marktwert des Eigenkapitals sowie Jahresumsatz, ausgewählt, da dieses für alle Unternehmen der Stichprobe gleichermaßen berechnet werden kann und stets positive Werte aufweist. ${ }^{1158}$ Die entsprechenden Datenpunkte werden anhand von Jahresumsatzgrößen und der Marktkapitalisierung im Jahresdurchschnitt errechnet.

Das bivariate Grundmodell zum Zusammenhang der relevanten Untersuchungsvariablen und der - wie zuvor beschrieben - operationalisierten Marktbewertung liefert schließlich das vermutete Ergebnis, gleichermaßen für große sowie kleine Unternehmen separat, wie Tab. 56 aufzeigt. Da jedoch die Analyse von UmsatzMultiplikatoren, ohne ggf. vorhandene Branchenspezifika zu berücksichtigen, zu kurz greift, werden die errechneten Werte branchenadjustiert. Der zuvor festgestellte Zusammenhang zeigt sich im bivariaten Grundmodell dann lediglich noch für die Teil-Stichprobe der kleinen Unternehmen, wo die Untersuchungsvariable SDIndex allein rund 3\% der Varianz der Marktbewertung erklären kann.

Dieser Zusammenhang stellt sich auch im multivariaten Kontext als robust dar, auch dann, wenn das Modell sukzessive um Kontrollvariablen erweitert wird: ${ }^{1159}$ Schließlich leistet SDIndex auch bei Kontrolle für die Unternehmensgröße, die Aktienrendite, die Profitabilität, das Handelsvolumen sowie die Indexzugehörigkeit weiterhin einen signifikant positiven, vergleichsweise hohen Erklärungsbei-

1158 Andere Multiplikatoren wie bspw. Multiplikatoren von Ergebnisgrößen weisen eine erheblich größere Varianz auf und nehmen zudem positive sowie auch negative Werte an. Auch sind Ergebnisgrößen per se schwankungsfreudiger sowie kurzfristiger ausgerichtet als Umsatzgrößen. Die eher längerfristige Ausrichtung der Strategie (und ihrer Berichterstattung) spricht somit gleichfalls für die Verwendung von Umsatz-Multiplikatoren.

Eine Verwendung absoluter Größen, d.h. bspw. der Marktbewertung des Eigenkapitals, wird nicht erwogen, da eine relative Betrachtung sinnvoller erscheint.

1159 Die verwendeten Kontrollvariablen finden sich insb. bei Healy et al. (1999), S. 504.

Tom Sieber - 978-3-631-75150-3 
trag. Das entsprechende Modell ist also in der Lage, rund ein Drittel der Varianz der relativen umsatzbezogenen Marktbewertung der kleinen Unternehmen zu erklären. Einzelne weitere interessante Aspekte finden sich innerhalb der Kontrollvariablen: So scheint die Unternehmensgröße ihrerseits einen negativen Einfluss auf die Bewertung zu haben, d.h. dass kleinere Unternehmen tendenziell höhere branchenadjustierte Umsatz-Multiples aufweisen als größere. Auch bestätigt die Analyse, dass die Profitabilität einen positiven Einfluss auf die Marktbewertung hat, ebenso wie eine Zugehörigkeit zu einem bestimmten Auswahlindex. Zudem scheint der Kapitalmarkt eine positive Unternehmensentwicklung zu honorieren, wie die entsprechende Kontrollvariable aufzeigen kann. ${ }^{1160}$

Als zweiter Indikator wird weiterhin die als Tobin's Q bezeichnete Kennzahl für alle Unternehmen der Stichprobe ermittelt. Diese berechnet sich als Quotient der Marktbewertung und des Buchwerts des Eigenkapitals und ist insofern - in Anlehnung an die theoretischen Ausführungen in dieser Arbeit - als ein geeigneter Indikator für eine mögliche Wertlücke zu interpretieren. ${ }^{1161}$ Konsequenterweise wird daher für diese Größe ein Regressionsmodell spezifiziert, das die gleichen Kontrollvariablen enthält wie die vorhergehenden Modelle zur Marktbewertung des Umsatzes. Wie Tab. 56 aufzeigt, ist SDIndex allerdings nicht geeignet, einen Beitrag zur Erklärung der Varianz in Tobin's Q zu leisten, während sich jedoch die zuvor ermittelten Einflüsse der Kontrollvariablen weitgehend bestätigen. ${ }^{1162}$

Festzustellen bleibt daher, dass das Niveau der Strategieberichterstattung nicht in der Lage zu sein scheint, einen konsistenten Beitrag zur Erhöhung des Marktwertes zu leisten. Gleichwohl finden sich Anzeichen, dass überlegene Strategieberichterstattung kleiner Unternehmen zu einer höheren Bewertung führen kann.

1160 Die Kontrollvariable Unternehmensentwicklung bildet sich als der Faktor des relativen Umsatz- sowie Vermögenswachstums in der Vorperiode. Den Vorschlag, für das Unternehmenswachstum im Bewertungsmodell zu kontrollieren, bringen Healy et al. (1999).

1161 Vgl. nochmals Abschnitt B 1.1.3 dieser Arbeit. Angemerkt sei, dass es sich bei den verwendeten Werten um Jahresdurchschnittswerte für Tobin's Q handelt, errechnet aus den jeweiligen börsentäglichen Werten. Zu Tobin's Q bspw. Varaiya et al. (1987), S. 487ff.

1162 Das errechnete Bestimmtheitsmaß ist mit einer Arbeit von Healy et al. (1999) vergleichbar, die mit ihrem Modell ca. 13\% der Varianz erklären können. Auf die Darstellung bivariater Ergebnisse wird aus Gründen der Übersichtlichkeit verzichtet, auch zeigt sich in diesem Kontext SDIndex nicht als signifikanter Regressor. 
Panel A: Bivariate Regressionsanalyse zum Einfluss von SDIndex auf die Marktbewertung

$I(x)=$ Bewertungsmultiplikator $\operatorname{Imsat}(t+l)$

\begin{tabular}{|c|c|c|c|c|c|c|c|c|}
\hline & \multicolumn{2}{|c|}{$\begin{array}{c}\text { Bivariates } \\
\text { Grundmodell }\end{array}$} & \multicolumn{2}{|c|}{$\begin{array}{l}\text {... nur für große } \\
\text { Unternehmen }\end{array}$} & \multicolumn{2}{|c|}{$\begin{array}{c}\text {... nur für kleine } \\
\text { Unternehmen }\end{array}$} & \multicolumn{2}{|c|}{$\begin{array}{l}\text { Wie zuvor, aber } \\
\text { adj. Multiple }\end{array}$} \\
\hline & Koeff. $\beta$ & $\mathrm{p}$ & Koeff. $\beta$ & $\mathrm{p}$ & Koeff. $\beta$ & $\mathrm{p}$ & Koeff. $\beta$ & $p$ \\
\hline \multicolumn{9}{|c|}{ Strategieberichterstattung } \\
\hline SDl (+) &, $121 * * *$ & $(.0(07)$ &, $172 * * *$ & $(.0(0) 7)$ &, $205 * * *$ & $(.(0) 1)$ & $200 * * *$ & $(.(0) 1)$ \\
\hline \multicolumn{9}{|l|}{ Kontrollvariablen } \\
\hline Konstante & & $(.96 .3)$ & & $(.760))$ & & $(.569)$ & & $(.736)$ \\
\hline Jahr &,- 002 & $(.961)$ &,- 020 & $(.754)$ &,- 036 & $(.562)$ &,- 022 & $(.717)$ \\
\hline$R^{2}$ &, 014 & &, 027 & & 038 & & ,038 & \\
\hline$R^{2}$ adj &, $011 * *$ & $(.015)$ &, $020^{* *}$ & $(.017)$ &, $031 * * *$ & $(.004)$ &, $031 * * *$ & $(.(0)(14)$ \\
\hline Durbin-Watson $d$ & 1,814 & & 2,072 & & 1,788 & & 2,068 & \\
\hline$n\left(n_{\operatorname{mix}}=600\right)$ & 586 & & 300 & & 286 & & 286 & \\
\hline
\end{tabular}

Panel B: Multivariate Regressionsanalyse zum Einfluss von SDIndex auf die Marktbewertung

\begin{tabular}{|c|c|c|c|c|c|c|c|c|c|}
\hline & \multicolumn{3}{|c|}{$\begin{array}{l}\text { Adj. Umsatz-Multiple, } \\
\text { kleine Unternehmen }\end{array}$} & \multicolumn{2}{|c|}{$\begin{array}{l}\text { Wie zuvor, } \\
\text { erweitert }\end{array}$} & \multicolumn{2}{|c|}{$\begin{array}{l}\text { Wie zuvor, } \\
\text { erweitert }\end{array}$} & \multicolumn{2}{|c|}{$\begin{array}{c}\text { Tobin's Q, } \\
\text { Gesamtstichprobe }\end{array}$} \\
\hline & & Koeff. $\beta$ & $\mathrm{p}$ & Koeff. $\beta$ & $\mathrm{p}$ & Koeff. $\beta$ & $\mathrm{p}$ & Koeff. $\beta$ & $\mathrm{p}$ \\
\hline \multicolumn{10}{|c|}{ Strategieberichterstattung } \\
\hline SDI $(+)$ & $(t)$ &, $295 * * *$ & $(.(0)(0))$ &, $231 * * *$ & $(.(0)(0))$ &, $289 * * *$ & $(.000)$ & ,038 & $(.434)$ \\
\hline \multicolumn{10}{|l|}{ Kontrollvariablen } \\
\hline Konstante & & & $(.320)$ & & $(.112)$ & & $(.365)$ & & $(.(0)(0)$ \\
\hline Größe [Faktor] & $(t+I)$ &,$- 416 * * *$ & $(.(0)(0))$ &,$- 567 * * *$ & $(.()(x))$ &,$- 546 * * *$ & $(.(0)(0))$ &,$- 568 * * *$ & $(.(0)())$ \\
\hline Aktienrendite & $(t+I)$ &, $140 * * *$ & $(.018)$ &, $144 * *$ & $(.013)$ &, $189 * * *$ & $(, 0(0) 3)$ &, $111 * *$ & $(.018)$ \\
\hline Erfolg [Faktor] & $(t)$ &, $219 * * *$ & $(.0(0))$ &, $215 * * *$ & $(.000)$ &, $256 * * *$ & $(.000)$ &, $139 * * *$ & $(.002)$ \\
\hline Handelsvolumen & $(t+I)$ & & & & &,- 125 & $(.129)$ &, $205 * * *$ & $(.010)$ \\
\hline Wachstum & $(t)$ & & & & &, $193 * * *$ & $(.(0) 1)$ &, 048 & $(.257)$ \\
\hline Markt-Beta & $(t+I)$ & & & & &, 091 & $(.136)$ &, 003 & $(.943)$ \\
\hline \multicolumn{10}{|l|}{ Indexzugehörigkeit } \\
\hline Dax & $(t+I)$ & & & & & & &, $386 * * *$ & $(.(0) 9)$ \\
\hline MDax & $(t+I)$ & & &, $294 * * *$ & $(.(x) 2)$ &, $372 * * *$ & $(.(0) 1)$ &, $332 * * *$ & $(.(0) 5)$ \\
\hline TecDax & $(t+I)$ & & &, 060 & $(.429)$ &, 144 & $(.184)$ &, 100 & $(.241)$ \\
\hline SDax & $(t+I)$ & & &, $237 * * *$ & $(.(x) 3)$ &, $299 * * *$ & $(.0(06)$ &, $199 * *$ & $(.042)$ \\
\hline Jahr & & .057 & $(.346)$ &, 095 & $(.125)$ &, 056 & $(.389)$ &, $201 * * *$ & $(.0(0))$ \\
\hline$R^{2}$ & &, 215 & &, 256 & &, 350 & &, 181 & \\
\hline$R^{2} a d j$ & &, $201 * * *$ & $(.0(x))$ &, $235 * * *$ & $(.0(0) 0)$ &, $320 * * *$ & $(.0(0)(0)$ &, $162 * * *$ & $(.000)$ \\
\hline Durbin-Watson $d$ & & 2,059 & & 2,065 & & 2,112 & & 1,933 & \\
\hline$n\left(n_{\text {nax }}=600\right)$ & & 286 & & 286 & & 250 & & 534 & \\
\hline
\end{tabular}

\section{Tabelle 56: Regressionsmodell der Indikatoren der Marktbewertung}




\section{3 Überblick über die Ergebnisse der Hypothesenprüfung}

Die im vorhergehenden Abschnitt D 5.2 erarbeiteten Resultate der Hypothesenprüfung zu den Kapitalmarkteffekten sind im Folgenden kurz zu resümieren, zudem stellt Tab. 57 die Entscheidungen bzgl. der Hypothesen überblicksartig dar.

Die Hypothesenprüfung bzgl. der Kapitalmarkteffekte hat offenbart, dass davon auszugehen ist, dass eine überlegene Strategieberichterstattung in positivem $\mathrm{Zu}$ sammenhang mit der Anzahl der ein Unternehmen beobachtenden Analysten sowie dem Handelsvolumen der jeweiligen Aktien eines Unternehmens steht. Jene Zusammenhänge zeigen sich auch beim Einschluss mehrerer Kontrollvariablen überaus robust. Gleiches gilt zudem für die offensichtlich realiter vorhandenen negativen Zusammenhänge zwischen SDIndex und den Eigenkapitalkosten bzw. den Geld-Brief-Spannen der Aktienkurse eines Unternehmens.

Darüber hinaus konnten für einzelne Teil-Stichproben sowohl in Bezug auf die Varianz der Analystenschätzungen als auch auf die Marktbewertung von Unternehmen interessante Ergebnisse ermittelt werden. Keine Evidenz zeigte sich hingegen in Bezug auf die Volatilität der Aktienrenditen, wenngleich diese als grds. erklärbar anzusehen ist - SDIndex leistet hierzu allerdings keinen Beitrag.

\begin{tabular}{|c|c|c|c|c|}
\hline \multicolumn{5}{|c|}{ Überblick über die Ergebnisse der Hypothesenprüfung: Teilmodell der Kapitalmarkteffekte } \\
\hline \multicolumn{2}{|l|}{ Kategorie } & \multicolumn{2}{|c|}{ Untersuchungsebene } & \multirow[t]{2}{*}{ Anmerkungen } \\
\hline Hypothese & Art & 1. Ebene & 2. Ebene & \\
\hline \multicolumn{5}{|l|}{ Transparenzeffekte } \\
\hline H 3.1 Analystenanzahl & $(+)$ & $\checkmark$ & $\checkmark$ & Hauptmodell 3 \\
\hline $\begin{array}{l}\text { H } 3.2 \text { Empfehlungs- bzw. Schätzungs- } \\
\text { varianz }\end{array}$ & $(-)$ & {$[\checkmark]$} & {$[\checkmark]$} & $\begin{array}{l}\text { Nur für große Unter- } \\
\text { nehmen bestätigt }\end{array}$ \\
\hline \multicolumn{5}{|l|}{ Handelseffekte } \\
\hline H 3.3 Handelsvolumen & $(+)$ & $\checkmark$ & $\checkmark$ & Hauptmodell 4 \\
\hline H 3.4 Volatilität der Aktienrenditen & $(-)$ & {$[\checkmark]$} & $x$ & Hauptmodell 5 \\
\hline \multicolumn{5}{|l|}{ Bewertungseffekte } \\
\hline H 3.5 Eigenkapitalkostensätze & $(-)$ & $\checkmark$ & $\checkmark$ & Hauptmodell 6 \\
\hline H 3.6 Geld-Brief-Spanne & $(-)$ & $\checkmark$ & $\checkmark$ & Hauptmodell 7 \\
\hline H 3.7 Marktbewertung & $(+)$ & $\checkmark$ & {$[\checkmark]$} & $\begin{array}{l}\text { Auf 2. Ebene nur für } \\
\text { kleine Unternehmen }\end{array}$ \\
\hline
\end{tabular}




\subsection{Prüfung der Aussagefähigkeit der Regressionsmodelle}

\subsubsection{Konformität mit zentralen Modellprämissen}

Der Darstellung der zentralen Prämissen des linearen Regressionsmodells in Abschnitt C 3.4.2 folgend, wurde bei der Durchführung der Regressionsanalysen zu den sieben Hauptmodellen Wert auf die stete Sicherstellung der Prämissenkonformität gelegt. Dies folgt der grdl. Erkenntnis, dass die in den vorgehenden Abschnitten erarbeiteten Ergebnisse der einzelnen Modelle letztlich keine Aussagekraft besäßen, wenn jene Modellprämissen unberücksichtigt blieben. Aus diesem Grund wurden a posteriori, d.h. nach der Durchführung der Regressionsanalysen, wesentliche Prüfstatistiken für die sieben Hauptmodelle errechnet, welche in der nachfolgenden Tab. 58 im Überblick dargestellt sind.

Prüfung der Prämissen des línearen Modells

\begin{tabular}{|c|c|c|c|c|c|c|c|c|c|}
\hline \multirow[b]{3}{*}{ Verletzung } & \multirow[b]{3}{*}{ Test } & \multirow[b]{3}{*}{ Soll } & \multicolumn{7}{|c|}{ Spezifizierte Hauptmodelle } \\
\hline & & & \multicolumn{2}{|c|}{ Teilmodell 1} & \multicolumn{5}{|c|}{ Tellmodell 2} \\
\hline & & & 1 & 2 & 3 & 4 & 5 & 6 & 7 \\
\hline \multirow{2}{*}{$\begin{array}{l}\text { Multi- } \\
\text { kollinearität }\end{array}$} & $\emptyset$ VIF-Wert ${ }^{1163}$ & $<10,0^{1164}$ & 1,235 & 3,205 & 2,881 & 2,905 & 3,665 & 2,691 & 3,172 \\
\hline & Min. Toleranz ${ }^{1165}$ & $>, 100$ & $\overline{.652}$ &, 112 & .148 &, 118 &, 170 &, 175 &, 127 \\
\hline $\begin{array}{l}\text { Hetero- } \\
\text { skedastizität }\end{array}$ & $\begin{array}{l}\text { Modifizierter } \\
\text { White-Test }^{11\left(x_{6}\right.}\end{array}$ & $\begin{array}{l}\text { Insignifikanz } \\
\text { der F-Statistik }\end{array}$ & .506 &, 950 &, 217 &, 197 &, 388 &, 340 &, 843 \\
\hline Autokorrelation & Durbin-Watson & $\{1,8 ; 2,2\}$ & 2,001 & 1,962 & 2,136 & 1,949 & 1,898 & 1,909 & 1,784 \\
\hline
\end{tabular}

Tabelle 58: Prüfstatistiken der Regressionsmodelle

Die ausgewiesenen Prüfstatistiken zur Prämissenkontrolle bestätigen schließlich, dass für jedes der spezifizierten Hauptmodelle die Konformität mit den zentralen Prämissen des linearen Regressionsmodells bejaht werden kann. ${ }^{167}$

1163 Diese Angabe wird z.B. von Achleitner et al. (2005) vorgeschlagen. Die Autoren sehen bei den von ihnen berichteten durchschnittlichen Werten von $V I F=2,40$ bzw. $V I F=3,62$ keine Hinweise auf ,außergewöhnliche Multikollinearitätsprobleme“, ebenda, S. 269.

1164 Dieser (theoretische) Grenzwert ergibt sich, wenn unterstellt wird, dass jeder Parameter einen Toleranzwert von $T=, 100$ aufweist, was einem Wert von $V I F=10,0$ entspräche.

1165. Diese relativ nahe am Grenzwert von $T=, 100$ liegenden Werte sind auf Zusammenhänge zwischen Größenindikatoren sowie der Indexzugehörigkeit zurückzuführen. Dies wurde bereits vermerkt und mit den Auswahlkriterien der Dt. Börse AG begründet, vgl. ebenda (2009a), S. 19ff. Bedeutsam ist jedoch, dass der Grenzwert nicht unterschritten wird.

1166 Die quadrierten Residuen des Modells sind auf die vorhergesagten sowie die quadrierten vorhergesagten Werte zu regressieren, vgl. Wooldridge (2009), S. 274ff. Die F-Statistik wie auch die t-Statistik der Koeffizienten ergaben gleichermaßen insignifikante Werte.

Tom Sieber - 978-3-631-75150-3 
Wie ebenfalls in C 3.4.2 angemerkt, nimmt eine Überprüfung der Exogenität des Regressors SDIndex in den einzelnen Modellen der Kapitalmarkteffekte eine gesonderte Stellung ein, weshalb dies nachfolgend explizit dargestellt werden soll.

\subsubsection{Prüfung der Untersuchungsvariablen auf Endogenität}

Innerhalb der methodischen Grundlagen wurde ausgeführt, dass eine potenzielle Endogenität einzelner Regressoren in den Modellen der Kapitalmarkteffekte ein besonderes Problem darstellt, das eine explizite Beachtung rechtfertigt. ${ }^{1168}$ Diese Ansicht findet sich wiederholt in der relevanten Literatur, die sich mit den Auswirkungen der Berichterstattung beschäftigt und methodengetreu arbeitet, wie es bspw. für Hail (2002) gilt, mit dem Hinweis: ,potential endogeneity of the disclosure variable has to be taken into account " ${ }^{\text {"169 }}$. Modelle mit endogenen Untersuchungsvariablen des Berichtsverhaltens sind in ihrer Aussagekraft stark eingeschränkt: „If researchers do not control for the determinants of disclosure policy, their inferences regarding the economic consequences of disclosure quality may be spurious“"1170, wie Lapointe-Antunes et al. (2006) anmerken.

Die Prüfung auf Endogenität soll im Rahmen dieser Arbeit wie angekündigt mit Hilfe des Tests nach Durbin-Wu-Hausman erfolgen. ${ }^{1171}$ Bei jenem Testverfahren

1167 Dies beinhaltet auch eine Prüfung auf Normalverteilung der Residuen der Regressionen, wenngleich diese nicht explizit erforderlich wäre, vgl. Tab. 7 (S. 234). Für jede einzelne Regressionsprozedur wurden die jeweiligen Residuenplots inspiziert, wie bspw. Cooke (1998), S. 210 für Untersuchungen im Rahmen der Disclosure-Forschung empfiehlt.

1168 Dies, obgleich die Modellspezifikation bereits in einer Form erfolgte, die mögliche Endogenität vermeiden helfen sollte: Einerseits wurden diverse Kontrollvariablen berücksichtigt, die im ersten Teilmodell Einfluss auf das Berichtsniveau besaßen, wie z.B. die Indexzugehörigkeit. Zusätzlich wurde durch die zeitliche Phasenverschiebung zwischen SDIndex und den Kapitalmarkteffekten potenzieller Endogenität vorgebeugt.

Vgl. zur Vermeidung bzw. Behebung von Endogenität bspw. Proppe (2007), S. 232ff.

1169 Hail (2002), S. 744f. Dass die Prüfung der Endogenität oftmals übersehen wird, stellen neben Hamilton/Nickerson (2003), S. 51f. bspw. auch Fields et al. (2001) dar.

Lapointe-Antunes et al. (2006), S. 468, unter Verweis auf Cohen et al. (2003), die feststellen: „Yet, we are only aware of a few studies that attempt to address this issue."

Eine Durchführung dieses Tests wird z.B. auch von Davidson/McKinnon (1993), S. 237 empfohlen, vgl. grdl. Hausman (1978). Für den Test liegen diverse Spezifikationen vor, vgl. Wooldridge (2002), S. 118ff., die methodisch ähnlich sind, so Nakamura/Nakamura (1981), S. 1583. Hier wird der sog. , Residuentest' verwandt, vgl. Proppe (2007), S. 235. 
wird eine Regression der potenziell endogenen unabhängigen Variablen auf alle verbleibenden unabhängigen Variablen durchgeführt, um dann die Residuen aus dieser Regression in das ursprüngliche Regressionsmodell einzubeziehen. ${ }^{1172} \mathrm{Er}$ gibt sich für diesen zusätzlichen Regressor ein signifikant von null verschiedener Regressionskoeffizient, wäre die Nullhypothese der Exogenität zu verwerfen. Es erscheint nachvollziehbar, dass angesichts des Modellaufbaus der Untersuchung primär eine potenzielle Endogenität der Kern-Untersuchungsvariablen SDIndex zu überprüfen ist: ${ }^{173}$ „Our point is that researchers should explicitly address endogeneity issues and use theory and logic to argue why endogeneity is or is not a problem in their particular study. “1174 Dieser Empfehlung zu sachlogischem Vorgehen folgend wird auf die Prüfung der Endogenität von SDIndex fokussiert. ${ }^{1175}$

Prüfung auf Endogenität nach Durbin-Wu-Hausman (Residuentest)

\begin{tabular}{|c|c|c|c|c|c|c|}
\hline \multirow[b]{2}{*}{ Gütekriterium } & \multirow[b]{2}{*}{ Symbol } & \multicolumn{5}{|c|}{ Spezifizierte Hauptmodelle (Teilmodell 2) } \\
\hline & & 3 & 4 & 5 & 6 & 7 \\
\hline Bestimmtheitsmaß des Ursprungsmodells & $R^{2}$ adj. &, 775 &, 846 & ,392 &, 360 & ,720 \\
\hline Bestimmtheitsmaß des Prüfmodells & $R^{2}$ adj. &, 775 &, 846 &, 392 &, 360 & 720 \\
\hline Signifikanz des Residuenterms (Prüfmodell) & p-Wert & ,753 & ,358 &, 114 & .606 & , 478 \\
\hline
\end{tabular}

Tabelle 59: Prüfstatistiken des Residuentests auf Endogenität

Die Ergebnisse der Durchführung des Residuentests in den relevanten Modellen der Kapitalmarkteffekte präsentiert Tab. 59. Bei keinem der - um den jeweiligen

1172 Vgl. Wooldridge (2009), S. 521f., Proppe (2007), S. 235f. Zusätzlich können weitere erklärende Parameter zur Residuenberechnung inkludiert werden, vgl. ebenda, S. 236.

1173 Vgl. hierzu nochmals Leuz/Verrecchia (2000), S. 113f., Hail (2002), S. 742f., LapointeAntunes (2006), S. 468f. Letztgenannte identifizieren in einem ihrer Modelle eine endogene Größe und verwenden sodann die Methode der ,Zweistufigen kleinsten Quadrate", die mit ,2SLS` abgekürzt wird, so Proppe (2007), S. 238f.; Wooldridge (2002), S. 83ff. Bei dieser Methode wird in einer Regression eine Instrumenten-Variable (IV) geschätzt (Stufe 1), welche genutzt wird, um den endogenen Regressor im Ursprungsmodell zu ersetzen (Stufe 2). Bei Endogenität hätte SDIndex durch die geschätzten Werte des ersten Teilmodells ersetzt werden können, vgl. Lapointe-Antunes (2006), S. 477, die ebenfalls ein ,disclosure model“" als IV berechnen. Kritisiert wird an der 2SLS oftmals, dass eine geeignete IV i.d.R. nur schwer zu bestimmen sei, vgl. Larcker/Rusticus (2007), S. 211.

1174 Chenhall/Moers (2007a), S. 174. Ähnlich auch Larcker/Rusticus (2007), S. 214.

1175 Dass SDIndex eine ,choice variable ' darstellt, muss nicht unmittelbar zur Existenz von Endogenität führen: „Presence of endogeneity depends on the specification of the model not on whether a variable is a choice variable", so Chenhall/Moers (2007a), S. 186.

Tom Sieber - 978-3-631-75150-3 
Residuenterm der Hilfsregression von SDIndex auf die übrigen Regressoren ergänzten - Prüfmodelle zeigt sich sodann ein signifikanter Regressionskoeffizient des Residuenterms. ${ }^{1176}$ Folglich entspricht die Güte dieser Prüfmodelle der Güte der Ursprungsmodelle, SDIndex dürfte daher als exogener Parameter der Untersuchungsmodelle der Kapitalmarkteffekte angesehen werden.

\subsubsection{Robustheit der Modellspezifikation}

Neben der Prämissenkonformität ist weiterhin zu prüfen, ob die berechneten Regressionsmodelle korrekt spezifiziert wurden, um schließlich die inhaltliche Aussagefähigkeit der Ergebnisse sicherzustellen. Zunächst erfolgte eine Prüfung der Modellspezifikation auf ihre Robustheit hin bereits im Rahmen der Hypothesenprüfung, indem stets mehrere verschiedene Spezifikationen definiert wurden und weiterhin die Berechnungen sowohl für die Teil-Stichprobe der großen als auch der kleinen Unternehmen separat durchgeführt wurden. ${ }^{177}$

Zusätzlich wurden, wie in Abschnitt C 3.4.2 angekündigt, Rangregressionen berechnet, um so die Robustheit der grds. angenommenen Linearität der Beziehung von Regressand und Regressoren zu überprüfen. Dazu wurden die Werte aller in den Hauptmodellen inkludierten Variablen in Rangziffern transformiert und sodann erneut Regressionsprozeduren durchgeführt, wobei „the rank of the dependent variable is predicted using the ranks of the independent variables" ${ }^{\text {1178 }}$.

Die Resultate dieser alternativen Rangregressionen präsentiert die nachfolgende Tab. 60. Wie feststellbar ist, können mit Hilfe der Rangregressionen Ergebnisse ermittelt werden, die zu den linearen Ursprungsmodellen inhaltlich überaus vergleichbar sind: Nicht nur die Bestimmtheitsmaße der Ursprungsmodelle bleiben

1176 Es wurden alternative Modelle gerechnet, bei denen zusätzliche, das Berichtsniveau ggf. erklärende Parameter einbezogen wurden, wie bspw. die Variable der Unternehmensentwicklung und die Anzahl Analysten. Indizien für Endogenität ergaben sich jedoch nicht. Dies inkludiert auch die Durchführung der Regressionsprozeduren auf Basis alternativer Variablenoperationalisierungen: So wurden u.a. sämtliche Modelle mit den Rangziffern der SDScores berechnet. Zudem wurden für einzelne Regressanden im Teilmodell der Kapitalmarkteffekte alternative Berechnungswege genutzt, vgl. auch Anhang 12. Sämtliche Resultate dieser Robustheitsprüfung sind als inhaltlich vergleichbar zu bezeichnen. 
weitgehend unverändert, auch der Einfluss von SDIndex kann bestätigt werden, sofern die Annahme linearer Beziehungen aufgegeben wird. Die Spezifikationen der abgeleiteten Hauptmodelle können folglich als robust bezeichnet werden.

\begin{tabular}{lllllll}
\hline Alternative Regressionsmodelle zur Prüifung der Robustheit der Modellspezifikationen \\
\hline
\end{tabular}

Tabelle 60: Ergebnisse alternativer Modellspezifikationen

Ergänzend zu den Rangregressionen wurden zudem sog. Fixed Effects-Modelle berechnet, um die Robustheit der ursprünglich verwendeten Regressionsmodelle zu prüfen. Dies erfolgte, um die de facto vorliegende Panelstruktur innerhalb der Untersuchungs-Stichprobe nochmals explizit zu berücksichtigen. ${ }^{1180}$ Aus diesem Grund wurden sämtliche relevanten Variablen gemäß der Within-Prozedur transformiert und sodann alternative Regressionsanalysen durchgeführt. ${ }^{1181}$ Wie die in Tab. 60 dargestellten Resultate jener Fixed Effects-Regressionen aufzeigen, kann die Robustheit der Ursprungsmodelle jedoch gleichermaßen bestätigt werden.

\footnotetext{
1179 Alle berichteten alternativen Regressionen besitzen Werte der F-Statistik von $F=, 000$.

1180) Es wurde bereits deutlich gemacht, dass die zeitliche Dimension der Panelstruktur durch stete Kontrolle für Jahr berücksichtigt wurde. Zudem wurde in sämtlichen Modellen der Kapitalmarkteffekte für die Unternehmensgröße kontrolliert, um die (beobachtbare und unbeobachtbare) Heterogenität der Objekte zu reflektieren, vgl. dazu Wagenhofer/Ewert (2007), S. 399f. und einführend zur Panelanalyse auch Schröder (2007), S. $261 \mathrm{ff}$.

1181 Vgl. ausführlich Wooldridge (2009), S. $481 \mathrm{ff}$. Bei der Within-Transformation wird jede einzelne Beobachtung einer Variablen um den jeweiligen objektspezifischen Mittelwert bereinigt, um die Heterogenität der Untersuchungsobjekte zu eliminieren. Zeitinvariante Variablen können sodann nicht mehr inkludiert werden, da sie bei einer Transformation ihre Aussagekraft einbüßen. Eine alternative Strategie besteht in der Aufnahme objektspezifischer Dummy-Variablen, was jedoch bei 100 Objekten nicht praktikabel scheint.

Tom Sieber - 978-3-631-75150-3
} 


\section{$6 \quad$ Erweiterung der Betrachtung um moderierende Effekte}

Mit den Untersuchungen im Rahmen des vorausgegangenen Abschnitts D 5 sind eindeutig spezifizierte Beziehungen zwischen den jeweiligen Regressanden und einzelnen Regressoren, d.h. der zentralen Untersuchungsvariablen SDIndex und den Kontrollvariablen, betrachtet worden. Diese Perspektive lässt sich erweitern, indem - wie in diesem Exkurs aufgezeigt - sog. Moderatoreffekte angenommen werden. ${ }^{1182}$ Es wird angenommen, dass eine konkrete Beziehung zwischen einer unabhängigen und einer abhängigen Variablen durch eine dritte Variable beeinflusst, also durch diese ,moderiert ' wird. ${ }^{1183}$ In formaler Definition liegt ein derartiger Moderatoreffekt immer dann vor, „wenn die Wirkungsintensität einer unabhängigen Variablen [...] auf eine abhängige Variable [...] von der Ausprägung einer zweiten unabhängigen Variablen [...] abhängt“" ${ }^{\text {1184 }}$. Eine Moderatorvariable kann folglich in der Lage sein, sowohl die Stärke wie auch die Richtung des $\mathrm{Zu}$ sammenhangs zweier Variablen zu beeinflussen. ${ }^{1185}$

Ein Modell zur Veranschaulichung von Moderatoreffekten zeigt Abb. 25.

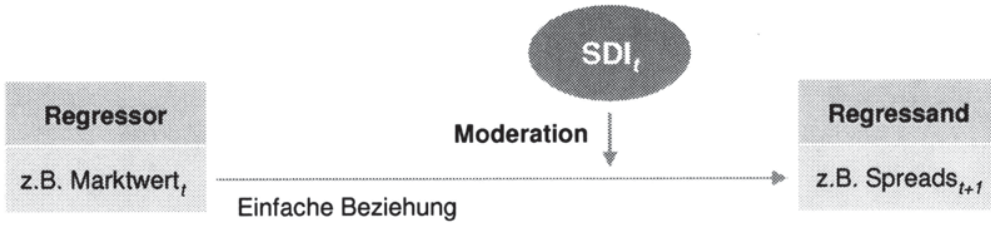

Abbildung 25: Prinzipdarstellung von Moderatoreffekten ${ }^{1186}$

Wie diese Darstellung bereits andeutet, scheinen im Kontext der eigenen Untersuchung in erster Linie die möglicherweise von der relevanten Untersuchungsvariablen SDIndex ausgehenden Moderatoreffekte von Interesse zu sein. Daher

1182 Den Vorschlag, zusätzlich auch Moderatoreffekte zu untersuchen, die durch die Berichterstattungsvariable hervorgerufen werden, ist Botosan (1997a), S. 344 zu entnehmen.

1183 Vgl. als Überblick Müller (2007), S. 245ff. Moderatoreffekte werden z.T. auch als Interaktionseffekte bezeichnet, sind von sog. Mediationseffekten aber zu unterscheiden, bei denen der Zusammenhang zweier Variablen erst durch einen Mediator zustande kommt. Müller (2007), S. 245, auch mit dem Hinweis, dass in der einschlägigen dt. Methodenliteratur i.d.R. nicht auf Moderationseffekte eingegangen wird, als Beispiel müssen auch Backhaus et al. (2008) sowie Bortz (2005) gelten.

Vgl. Baron/Kenny (1986), S. 1174.

Quelle: eigene Darstellung in Anlehnung an Müller (2007), S. 247. 
sind nachfolgend auf Basis der fünf Hauptmodelle der Kapitalmarkteffekte insg. elf Beziehungen daraufhin zu untersuchen, ob sie ggf. durch SDIndex moderiert werden. ${ }^{187}$ Die interessierenden sowie sachlogisch zu begründenden Moderatoreffekte, die anschließend zu überprüfen sind, listet Tab. 61 auf.

\begin{tabular}{|c|c|c|c|c|c|c|}
\hline \multicolumn{7}{|c|}{ Untersuchungsplan zur Prüfung einzelner Variablen-Beziehungen auf Moderatoreffekte } \\
\hline \multirow{2}{*}{\multicolumn{2}{|c|}{ Mögliche Moderatoreffekte }} & \multicolumn{5}{|c|}{ Spezifizierte Hauptmodelle (Teilmodell 2) } \\
\hline & & 3 & 4 & 5 & 6 & $7^{1188}$ \\
\hline Regressand & & $\begin{array}{c}\text { Anzahl } \\
\text { Analysten }\end{array}$ & $\begin{array}{l}\text { Handels- } \\
\text { volumen }\end{array}$ & $\begin{array}{l}\text { Volatilität } \\
\text { der Renditen }\end{array}$ & $\begin{array}{l}\text { Eigenkapital- } \\
\text { kosten }\end{array}$ & $\begin{array}{l}\text { Relative Bid- } \\
\text { Ask-Spreads }\end{array}$ \\
\hline \multicolumn{7}{|l|}{ Interaktionsterm (Regressor) } \\
\hline SDI $\times$ Größe & $(t)$ & Analyse & & & & \\
\hline SDI $\times$ Marktwert & $(t+l)$ & & Analyse & Analyse & Analyse & Analyse \\
\hline SDI $\times$ Inverser Freefloat & $(t+l)$ & & Analyse & & Analyse & \\
\hline SDI $\times$ Aktienrendite & $(t+l)$ & & & Analyse & & \\
\hline SDI $\times$ Handelsvolumen & $(t+l)$ & & & Analyse & & Analyse \\
\hline SDI $\times$ Verschuldungsgrad & $(t)$ & & & & Analyse & \\
\hline
\end{tabular}

Tabelle 61: Identifikation zu analysierender Moderatoreffekte

Aufgrund des maßgeblichen Einflusses der Unternehmensgröße, der sich in den bisherigen Regressionen zeigte, kann die Überprüfung eines moderierenden Einflusses von SDIndex auf die Beziehungen zwischen Größenindikatoren und den einzelnen Kapitalmarkteffekten zunächst als folgerichtig angesehen werden. ${ }^{1189}$

Außerdem sind für einzelne Kapitalmarkteffekte weitere spezifische Moderatoreffekte vorstellbar: Im Hinblick auf das Handelsvolumen der Aktien wäre bspw. zu unterstellen, dass der Einfluss der Kapitalkonzentration durch das Niveau der Strategieberichterstattung moderiert wird: So könnte der negative Einfluss hoher

1187 Die Auswahl von zu untersuchenden, ggf. moderierten Beziehungen hat rein unter sachlogischen Erwägungen bzw. theoriebegründet zu erfolgen. Moderatorvariablen können grds. qualitativer oder quantitativer Natur sein, vgl. Müller (2007), S. 245. Hier werden jedoch nur Moderatoreffekte der quantitativen Variablen SDIndex betrachtet.

1188 Modifiziertes Hauptmodell 7, insb. Aufnahme der Kontrollvariable ,Handelsvolumen .

1189 Durch die Gruppenvergleiche auf Basis der beiden größenabhängigen Teil-Stichproben wurden im Rahmen der Hypothesenprüfung (D 4, D 5) bereits durch die Unternehmensgröße induzierte Einflüsse auf die Zusammenhänge zwischen den Bestimmungsfaktoren und SDIndex bzw. zwischen SDIndex und den Kapitalmarkteffekten berücksichtigt. Die hier durchgeführte Analyse betrachtet schließlich den komplementären Sachverhalt, d.h. die durch SDIndex hervorgerufenen Auswirkungen auf einzelne Zusammenhänge.

Tom Sieber - 978-3-631-75150-3 
Kapitalkonzentration auf das Handelsvolumen bei umfassender Strategieberichterstattung vermindert werden. Im Hinblick auf die Volatilität der Aktienrendite erscheint es realistisch, dass SDIndex - obgleich ohne signifikanten Einfluss auf die Volatilität innerhalb des Hauptmodells - den positiven Einfluss der Aktienrendite sowie auch des Handelsvolumens auf die Volatilität reduzieren kann.

In Bezug auf die Eigenkapitalkosten sind ebenfalls moderierende Einflüsse von SDIndex denkbar: Der negative Einfluss der Kapitalkonzentration auf die Eigenkapitalkosten könnte sich noch verstärken, falls die strategische Ausrichtung des Unternehmens transparent ist für den Kapitalmarkt, gleichermaßen könnte sich der positive Einfluss der Verschuldung auf die Kapitalkosten ggf. abschwächen. Schließlich kann unterstellt werden, dass sich der negative Einfluss des Handelsvolumens auf die Spreads durch eine Moderation von SDIndex noch verstärkt.

In methodischer Hinsicht erfolgt die Analyse möglicher Moderatoreffekte durch Einbeziehung eines sog. Interaktionsterms in das jeweilige Regressionsmodell, der sich als Produkt der unabhängigen Variablen und der vermuteten Moderatorvariablen errechnet. ${ }^{1190}$ Die vorhergehende Tab. 61 nennt alle hier bedeutsamen Interaktionsterme zur Prüfung potenzieller Moderatoreffekte, den Ausführungen folgend stets unter Einschluss von SDIndex. Es scheint nachvollziehbar, dass im Falle des Hinzufügens eines Interaktionsterms in ein Regressionsmodell die Prämisse fehlender (perfekter) Multikollinearität nahezu notwendigerweise verletzt wird, daher wird in der Literatur weitgehend konsensual die Zentrierung sowohl der unabhängigen als auch der Moderatorvariablen empfohlen. ${ }^{1191}$

Die Resultate der Moderatoranalysen offenbart die nachfolgende Tab. $62 .{ }^{1192}$

\footnotetext{
1190 Diese Vorgehensweise entspricht der Prüfung von Interaktionseffekten erster Ordnung, Effekte höherer Ordnung scheinen für das eigene Untersuchungsmodell nicht relevant.

1191 Für die Zentrierung sprechen sich Cohen et al. (2003), S. 261ff.; Jaccard et al. (1990), S. 31f. aus, ablehnend Gatignon/Vosgerau (2005). Auch der Interaktionsterm ist auf Basis der zentrierten Variablen zu ermitteln. Die Zentrierung einer unabhängigen sowie einer als Moderator vermuteten Variablen verändert die Parameter eines Regressionsmodells grds. noch nicht - erst das Hinzufügen des (zentrierten) Interaktionsterms kann schließlich Veränderungen der Modellparameter hervorrufen, sofern eine Interaktion vorliegt. Zur Zentrierung und Durchführung der Moderatoranalyse vgl. Müller (2007), S. 248f.

1192 Jene Moderatoreffekte werden grds. einzeln geprüft, es wird immer nur ein Interaktionsterm in das Ausgangsmodell inkludiert, eine kumulative Berücksichtigung erfolgt nicht. 


\begin{tabular}{|c|c|c|c|c|c|c|c|c|c|c|c|}
\hline \multicolumn{12}{|c|}{ Analyse der für SDIndex vermuteten Moderatoreffekte } \\
\hline \multicolumn{2}{|l|}{ Hauptmodell } & \multicolumn{2}{|l|}{3} & \multicolumn{2}{|l|}{4} & \multicolumn{2}{|l|}{5} & \multicolumn{2}{|l|}{6} & \multicolumn{2}{|c|}{$7^{11 \times 8}$} \\
\hline \multirow{2}{*}{\multicolumn{2}{|c|}{ Regressand }} & \multicolumn{2}{|c|}{ Analysten } & \multicolumn{2}{|c|}{$\overline{\text { Handelsvolumen }}$} & \multicolumn{2}{|c|}{ Volatilität } & \multicolumn{2}{|c|}{ Kapitalkosten } & \multicolumn{2}{|c|}{ Bid-Ask-Spreads } \\
\hline & & Koeff. $\beta$ & $\mathrm{p}$ & Koeff. $\beta$ & $\mathrm{p}$ & Koeff. $\beta$ & $\mathrm{p}$ & Koeff. $\beta$ & $\mathrm{p}$ & Koeff. $\beta$ & $\mathrm{p}$ \\
\hline \multicolumn{12}{|l|}{ Ausgangsmodelle } \\
\hline SDIndex & $(t)$ &, $062 * * *$ & $(.004)$ &, $077 * * *$ & $(.(0)(0))$ &, 060 & $(.151)$ &,$- 154 * * *$ & $(.(0) 1)$ &,$- 062 * *$ & $(.015)$ \\
\hline Größe [Faktor] & $(t)$ &, $175 * * *$ & $(.(x)(x))$ & & & & & & & & \\
\hline Marktwert EK & $(t+l)$ & & &, $457 * * *$ & $(.(0)(0)$ &,$- 649 * * *$ & $(.0(0))$ &,$- 159 * * *$ & $(.(0) 1)$ &,$- 449 * * *$ & $(.000)$ \\
\hline Inv. Freefloat & $(t+1)$ & & &,$- 114 * * *$ & $(.(0)(0))$ & & &,$- 161 * * *$ & $(.(0)(0))$ & & \\
\hline Aktienrendite & $(t+l)$ & & & & &, $150 * * *$ & $(.(0)(0))$ & & & & \\
\hline Handelsvolumen & $(t+I)$ & & & & &, $662 * * *$ & $(.(K)(0))$ & & &,$- 193 * * *$ & $(.(0)(0))$ \\
\hline Verschuldung [F] & $(t)$ & & & & & & &, $294 * * *$ & $(.(0)(0))$ & & \\
\hline$R^{2}$ adj. & & $.775 * * *$ & $(.(0)(0))$ &, $846 * * *$ & $(.(0)(0))$ &, $392 * * *$ & $(.(0)(0))$ &, $360 * * *$ & $(.(x)(x))$ &, $729 * * *$ & $(.000)$ \\
\hline
\end{tabular}

\section{SDI × Größe bzw. Marktwert}

\begin{tabular}{|c|c|c|c|c|c|c|c|c|c|c|}
\hline SDIndex &, $067 * * *$ & $(.(0) 2)$ &, $078 * * *$ & $(.000)$ &, 069 & $(.1(13)$ &,$- 183 * * *$ & $(.000)$ &,$- 058 * *$ & $(., 02.3)$ \\
\hline Größe / Marktwert &, $177 * * *$ & $(.0(0))$ &, $458 * * *$ & $(.0(0))$ &,$- 649 * * *$ & $(.(0)(x))$ &,$- 176 * * *$ & $(x)$ &,$- 446 * * *$ & $(0)(0)$ \\
\hline Interaktionsterm &,$- 049 * *$ & $(.013)$ &,- 005 & $(.783)$ &,$- 067 *$ & $(.067)$ &, $111 * * *$ & $(.0(1) 6)$ &,- 029 & $(.195)$ \\
\hline &, 777 & $(0)$ &, $846 * * *$ & $(.(0)(0))$ &, $394 * * *$ & $(.(0)(0))$ &, $369 * * *$ & $(.00(0))$ &, $729 * * *$ & $(.00(0))$ \\
\hline$\backslash R^{2}$ adj. &, 002 & &, 000 & & .002 & & 009 & &, 000 & \\
\hline
\end{tabular}

SDI $\times$ Inverser Freefloat

\begin{tabular}{|c|c|c|}
\hline SDIndex &, $074 * * * \quad(.()(x))$ &,$- 165 * * * \quad(.(0)(x))$ \\
\hline Inv. Freefloat &,$- 115 * * * \quad(.0000)$ & $-, 163 * * * \quad(.0(0)))$ \\
\hline Interaktionsterm &,- 013 &,$- 073 * * \quad(.046)$ \\
\hline$R^{2}$ adj. &, $846 * * * \quad(.(0)(0))$ &, $364 * * * \quad(.(0)(0))$ \\
\hline$\backslash R^{2}$ adj &, 000 &, 004 \\
\hline
\end{tabular}

\section{SDI $\times$ Aktienrendite}

SDIndex

Aktienrendite

Interaktionsterm

$R^{2}$ adj.

$\backslash R^{2}$ adj.

SDI $\times$ Handelsvolumen

SDIndex

Handelsvolumen

Interaktionsterm

$R^{2}$ adj.

$\backslash R^{2}$ adj.

$$
\begin{array}{cc}
, 052 & (.220) \\
, 115 * * * & (.0(0)) \\
\hline-, 084 * * & (.021) \\
\hline, 397 * * * & (.0(0)) \\
, 005 &
\end{array}
$$

$$
\begin{array}{cc}
.063 & (.135) \\
.654 * * * & (.000)) \\
\hline-, 073 * * & (.049) \\
\hline .397 * * * & (.00(0)) \\
.005 &
\end{array}
$$$$
-, 062 * * \quad(.016)
$$$$
-, 192 * * * \quad(.(0)())
$$$$
-, 008 \quad(.712)
$$$$
, 729 * * * \quad(.()()())
$$$$
, 000
$$

\section{SDI $\times$ Verschuldungsgrad}

SDIndex

Verschuldungsgrad [F]

Interaktionsterm

$R^{2}$ adj.

$\backslash R^{2}$ adj.

$$
\begin{array}{ll}
-, 154 * * * & (.(00)) \\
, 293 * * * & (.(0)(0)) \\
, 008 & (.831) \\
, 360 * * * & (.(0)(0)) \\
, 000 &
\end{array}
$$


Wie Tab. 62 darzustellen vermag, ist in sechs der analysierten elf Fälle von einer Moderation der jeweiligen betrachteten Beziehung durch SDIndex auszugehen, einige interessante Feststellungen seien kurz skizziert: ${ }^{1193}$ So kann SDIndex den positiven Einfluss der Größe auf die Anzahl der beobachtenden Analysten leicht abschwächen, konkret offenbart das Ergebnis, dass für Unternehmen mit einem hohen Niveau der Strategieberichterstattung die Größe leicht geringeren Einfluss auf die Analystenabdeckung hat als für die Kontrollgruppe. Es wäre daher anzunehmen, dass Unternehmen durch Ausweitung der Strategieberichterstattung geringere Größe - in Bezug auf die Anzahl der sie beobachtenden Analysten - zumindest teilweise ausgleichen können. ${ }^{1194}$

Weiterhin gelingt es SDIndex, den positiven Einfluss der Aktienrenditen sowie den negativen Einfluss der Größe auf die Volatilität zu moderieren: Bei hohem Niveau der Strategieberichterstattung wird der negative Einfluss der Größe auf die Volatilität der Aktienrenditen verstärkt, auch besitzt bei intensiver Berichterstattung die Aktienrendite wesentlich geringeren Einfluss auf die Volatilität.

Diese Analyse zeigt insofern, dass die Bereitstellung von Strategieinformationen offensichtlich Informationsasymmetrien am Kapitalmarkt reduzieren könnte und in der Folge die Schwankungsbreite von Aktienrenditen sinkt. Eine Bestätigung liefert die Untersuchung des moderierenden Einflusses von SDIndex auf den $\mathrm{Zu}$ sammenhang des Handelsvolumens mit der Volatilität: Ein erhöhtes Niveau der Strategieberichterstattung kann den positiven Einfluss des Handelsvolumens auf die Volatilität abfedern, auch in diesem Falle bewirkt also umfassende Strategieberichterstattung die Reduktion der Schwankungsbreite von Aktienrenditen. Vor diesem Hintergrund ist sodann davon auszugehen, dass der in Hypothese $\mathbf{H} 3.4$

1193 Es sind die sechs in Tab. 62 (S. 333) markierten Interaktionsterme zu thematisieren. Zur Interpretation einer identifizierten Interaktion wird die Moderatorvariable üblicherweise künstlich dichotomisiert, da angenommen wird, dass die Regressionsgerade, die den $\mathrm{Zu}$ sammenhang von Regressor und Regressand beschreibt, nicht für alle Ausprägungen jenes Moderators identisch verläuft. Aus diesem Grunde werden zwei Regressionsgeraden definiert, eine für hohe und eine für niedrige Ausprägungen der Moderatorvariablen, als Überblick vgl. Müller (2007), S. 246f.

1194 Dieses Ergebnis deutet Tab. 49 (S. 305) bereits an, die aufzeigte, dass für die Teil-Stichprobe der kleinen Unternehmen SDIndex einen wesentlich höheren Einfluss auf die Anzahl der beobachtenden Analysten besitzt als im Gesamtmodell. 
vermutete volatilitätsmindernde Einfluss der Strategieberichterstattung, der sich im Rahmen einer Analyse der direkten Beziehung dieser beiden Parameter nicht ermitteln ließ, zumindest mittelbar dennoch besteht.

Interessant ist weiterhin das Ergebnis der Moderation von SDIndex auf den $\mathrm{Zu}$ sammenhang des Marktwertes und der Eigenkapitalkosten: Wie erkennbar wird, besitzt die Größe für Unternehmen mit geringerer Strategieberichterstattung eine wesentlich höhere Bedeutung im Hinblick auf die Kapitalkosten: Unternehmen könnten also durch Steigerung ihrer Strategieberichterstattung am Kapitalmarkt eher wie große Unternehmen wahrgenommen werden, die Bedeutung der Größe würde sich sodann abschwächen. Ebenfalls liefert die Moderation von SDIndex auf die Beziehung von Kapitalkonzentration und Kapitalkosten die bemerkenswerte Erkenntnis, dass bei intensiver Strategieberichterstattung der negative Einfluss der Kapitalkonzentration auf die Eigenkapitalkosten deutlich stärker ausgeprägt zu sein scheint: Es wäre daher zu schlussfolgern, dass der Kapitalmarkt die unternehmensspezifische Unsicherheit dann geringer einschätzt, wenn ein Großaktionär mit einem hohem Anteil vorhanden ist und dieser schließlich die für das Unternehmen angestrebte Entwicklung bzw. die Strategie transparent macht.

Für die hier untersuchten moderierenden Einflüsse der Strategieberichterstattung auf Zusammenhänge einzelner Regressoren mit dem Handelsvolumen sowie den Geld-Brief-Spannen lassen sich hingegen keine Moderatoreffekte identifizieren.

Dennoch bleibt zusammenfassend zu konstatieren, dass die Erweiterung der Betrachtung der Kapitalmarkteffekte der Strategieberichterstattung um Moderatoranalysen die zuvor identifizierte Relevanz der zentralen Untersuchungsvariablen SDIndex im Grundsatz bestätigt. Darüber hinaus macht diese Analyse deutlich, dass davon auszugehen ist, dass eine Strategieberichterstattung nicht nur direkte Effekte am Kapitalmarkt hervorruft, sondern zusätzlich - im Zusammenspiel mit anderen erklärenden Parametern - Interaktionseffekte induzieren kann, die ihrerseits die Wirkungsintensität von erklärenden Parametern determinieren könnten. Die Bedeutung einer Strategieberichterstattung für börsennotierte Unternehmen scheint sich auf Basis dieser Erkenntnisse nochmals zu bestätigen. 


\section{E Schlussbetrachtung der Arbeit und Ausblick}

\section{$1 \quad$ Gang der Arbeit in der Retrospektive}

Der prinzipielle Aufbau der vorliegenden Arbeit war zweigeteilt: Zunächst legte Hauptteil B in konzentrierter Form theoretische Grundlagen einer als ,Strategieberichterstattung' bezeichneten Bereitstellung von strategieorientierten Angaben im Lagebericht. Dabei wurden die zentralen Bausteine der Arbeit, im Einzelnen der Kapitalmarkt, die Unternehmensstrategie und die externe Rechnungslegung deutscher börsennotierter Unternehmen, thematisiert.

Aufbauend auf diesen Grundlagen oblag es Teil C, die eigene Untersuchung zu konzipieren, die das Ziel verfolgte, zu klären, ob das Niveau strategieorientierter Lageberichtsinhalte von 100 deutschen börsennotierten Unternehmen gemessen werden kann (Forschungsfrage 1). Weiterhin war angestrebt - falls die Messung möglich wäre - das Niveau der Strategieberichterstattung im Status quo bzw. im Zeitablauf von sieben Jahren aufzuzeigen (Forschungsfrage 2). Mit Hilfe der so gewonnenen Informationen sollten weiterführend zwei zusätzliche Fragen beantwortet werden, die - im Anschluss an die temporale Perspektive der Forschungsfrage 2 - eine eher kausale Blickrichtung einnahmen: Einerseits die Frage nach möglicherweise systematischen Bestimmungsfaktoren des Niveaus der Strategieberichterstattung (Forschungsfrage 3) und abschließend nach den Auswirkungen einer Strategieberichterstattung am Kapitalmarkt (Forschungsfrage 4).

Diese vier Forschungsfragen konstruierten sodann ein Untersuchungsmodell mit den drei Kernelementen ,Niveau der Strategieberichterstattung ' (Frage 1 und 2), ,Bestimmungsfaktoren“ (Frage 3) und ,Kapitalmarkteffekte` (Frage 4), welches die eigene Untersuchung strukturierte. ${ }^{1195} \mathrm{Zu}$ diesen drei Kernelementen wurden schließlich insg. 21 Forschungshypothesen abgeleitet, deren statistische Prüfung Gegenstand des Hauptteils D der vorliegenden Arbeit war. Jener Teil beinhaltete neben deskriptiven Auswertungen zu den Stichproben-Unternehmen, zur Lageberichterstattung sowie zur Erhebung des Niveaus der Strategieberichterstattung insb. auch die Ergebnisse der Überprüfung der 21 Forschungshypothesen.

1195 Vgl. Abb. 10 (S. 142) für die Darstellung der drei Elemente des Untersuchungsmodells. 


\section{Synopsis der wesentlichen Erkenntnisse der Arbeit}

Nachfolgend fasst Abschnitt 2.1 die wesentlichen Erkenntnisse der theoretischen Grundlagen zusammen, die mit Hauptteil B gelegt wurden, ehe Abschnitt 2.2 die Resultate der empirischen Untersuchung rückblickend darstellt.

\subsection{Theoretischer Hintergrund der Strategieberichterstattung}

Die theoretischen Grundlagen dieser Arbeit, welche als Fundament der eigenen Untersuchung dienten, seien im Folgenden stichpunktartig zusammengefasst:

Kapitalmärkte benötigen Informationen über Unternehmen als notwendige Voraussetzung für das Zustandekommen von Transaktionen und in der Konsequenz als wesentliche Voraussetzung für ihre generelle Funktionsfähigkeit. Besondere Relevanz für die Investoren besitzen zukunftsgerichtete Informationen, um Prognosen zukünftiger Zahlungsströme bzw. eine Bewertung von Unternehmen vorzunehmen und so letztlich Anlageentscheidungen fundieren zu können.

Die Finanzberichterstattung auf Basis der Daten der externen Rechnungslegung stellt eine bewährte, verbindliche und verlässliche sowie zudem regelmäßig vorzulegende Informationsbasis des Kapitalmarktes dar, der Gehalt an zukunftsgerichteten Angaben ist jedoch grds. als gering zu bezeichnen.

Diese ,Zukunft' stellt den Kern der Strategie dar, Unternehmen identifizieren im Rahmen ihrer strategischen Planung die künftigen Chancen sowie Risiken ihres Umfeldes, analysieren eigene Stärken sowie Schwächen und leiten anschließend eine Strategie ab, verstanden als die vom Management für das Unternehmen angestrebte Entwicklungsrichtung in der Zukunft.

Informationen über die einzelnen Phasen des strategischen Managements, trotz ihrer weitgehend qualitativ-verbalen Natur, wären für die Investoren am Kapitalmarkt insofern von Relevanz, um eine Vorstellung von der Zukunft eines Unternehmens zu erhalten, welche sodann bei der Abschätzung zukünftiger Zahlungsströme möglicherweise wertvolle informationelle Unterstützung leisten könnte.

Die Rechnungslegung der kapitalmarktorientierten Unternehmen als das zentrale Instrument der Informationsbereitstellung für den Kapitalmarkt stellt schließlich

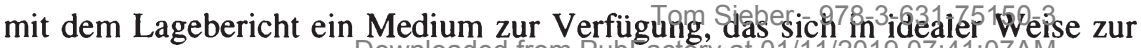


Berichterstattung über strategieorientierte Inhalte eignet. In der Diskussion um Entscheidungsnützlichkeit und Rechenschaftsablage als den zwei Basiszwecken der Rechnungslegung könnte gerade jener Lagebericht durch eine Bereitstellung prognostischer Angaben einen Beitrag zur Entscheidungsnützlichkeit leisten und in der Folge die Kapitalmarktorientierung der Rechnungslegung insgesamt verstärken. Als qualitativ-verbale Ergänzung des primär quantitativ-monetär ausgerichteten Jahresabschlusses offeriert der Lagebericht nicht nur eine ausreichende Flexibilität zur ,Strategieberichterstattung', vielmehr muss es auch verwundern, wie eine Berichterstattung zur Lage bzw. zukünftigen Entwicklung eines Unternehmens erfolgen kann, ohne jedoch - zumindest ansatzweise - die Strategie zu thematisieren. Zusätzlich sollte die Bereitstellung strategieorientierter Angaben, eingebettet in das Gesamtsystem der externen Rechnungslegung, die Problematik verringerter Verlässlichkeit prognostischer Informationen eindeutig entschärfen.

Konsequenterweise sehen daher Überlegungen zur stärker wertorientierten Ausgestaltung der Rechnungslegung nicht nur den Lagebericht als das wesentliche Medium eines ,Value Reportings ', sondern empfehlen gleichfalls konsensual die Berichterstattung zu strategieorientierten Aspekten. Empirische Arbeiten unterstützen diese Sichtweise und zeigen, dass Adressaten derlei Inhalte wünschen.

Vor diesem Hintergrund erscheint es nachvollziehbar, dass nicht nur vereinzelte Vorschläge zu einer explizit strategieorientierten Lageberichterstattung gemacht wurden, sondern sich zudem die nationalen sowie internationalen Standardsetter mit der Kodifizierung einer Strategieberichterstattung auseinandergesetzt haben. Wenngleich eine explizite Kodifizierung bis zum heutigen Tage nicht erfolgt ist, können strategieorientierte Lageberichtsinhalte auf Basis der generellen Normen zur deutschen Lageberichterstattung durchaus als gerechtfertigt, falls nicht sogar als implizit gefordert angesehen werden.

Abschließend ist also festzuhalten, dass eine Strategieberichterstattung im Lagebericht deutscher Unternehmen bis dato allenfalls freiwillig erfolgt. Der effektiv bereitgestellte Gehalt an strategiebezogenen Angaben im Lagebericht ist folglich einzig als das Resultat unternehmensindividueller Determinanten bzw. berichterstattungsstrategischer Entscheidungen anzusehen - und entwickelt sich somit zu einem eindeutig differenzierenden Kriterium der berichtenden Jiferpehsen. 


\subsection{Empirische Untersuchung der Strategieberichterstattung}

Aufbauend auf diesem zuvor kondensiert dargestellten theoretischen Fundament war es das Ziel einer eigenen empirischen Untersuchung zur Strategieberichterstattung deutscher börsennotierter Unternehmen, die vier im vorhergehenden Abschnitt E 1 skizzierten Forschungsfragen zu beantworten. Jene vier Fragen sollen die nachfolgenden Ausführungen leiten:

Zunächst galt es zu prüfen, ob eine Messung des Gehalts an strategieorientierten Lageberichtsinhalten als realistisch gelten kann. Diese Forschungsfrage 1 muss insofern als notwendige Voraussetzung für die weitergehende Beschäftigung mit der Strategieberichterstattung verstanden werden. Wie eine Auseinandersetzung mit den für die vorliegende Arbeit relevanten Literaturbereichen, der deutschen Literatur zur Lageberichterstattung, der Value Reporting- sowie der primär USamerikanischen Voluntary Disclosure-Literatur, zeigte, kann eine Messung von spezifischen Berichterstattungsinhalten als gängige Forschungsmethodik gelten, die sich insb. in der Voluntary Disclosure-Literatur breiter Anwendung erfreut.

Aus diesem Grund wurde - in methodischer Anlehnung an einzelne Vorarbeiten innerhalb der einschlägigen Literatur - als Basis der empirischen Untersuchung ein Messinstrument zur Ermittlung des Niveaus der Strategieberichterstattung in den Lageberichten konzipiert, das sich aus der inhaltsanalytischen Überprüfung von 40 strategieorientierten Berichtskriterien errechnete. Diese Berichtskriterien, die sich in ihrer Struktur an einem präskriptiven Strategieprozess mit den drei Phasen Analyse, Strategieformulierung bzw. -detaillierung und -implementierung ausrichteten und die in ihrer Gesamtheit nicht nur Umfang, sondern auch inhaltliche Qualität der Strategieberichterstattung abdeckten, wurden jeweils binär bewertet und ungewichtet summiert, um unternehmensindividuelle ,Strategy Disclosure Scores' abzuleiten, die auf den Wertebereich von null bis eins normiert wurden. Das Messinstrument des ,Strategy Disclosure Index “ wurde schließlich auf die in den sieben Jahren 2002 bis 2008 vorgelegten Lageberichte einer Stichprobe von 100 Unternehmen angewandt, welche der Gesamtheit von 160 Unternehmen entnommen wurde, die per Halbjahresultimo 2009 in den vier Auswahlindizes Dax, MDax, TecDax und SDax der Deutschen Börse AG notiert waren.

In Summe wurden demzufolge 700 Beobachtungensdese SDIndersyorgenonmen. 
Wie für derartige Instrumente zur Messung qualitativer Berichtsinhalte üblicherweise empfohlen wird, wurde nicht nur dessen inhaltliche Validität, sondern zudem die konstruktive Reliabilität des Messinstruments SDIndex überprüft. Diese Prüfung wird grds. mit Hilfe des Koeffizienten Cronbachs Alpha durchgeführt, die hier ermittelten Werte lassen den Schluss zu, dass mit SDIndex ein reliables Messinstrument zur Verfügung steht. Da eine unmittelbare externe Kennzahl zur Strategieberichterstattung zur Validierung der eigenen Messwerte nicht gegeben ist, bestand die Möglichkeit, unter Verwendung von Rohdaten des Wettbewerbs ,Der Beste Geschäftsbericht', in dessen Rahmen seit 1982 umfangreiche inhaltliche Kriterienkataloge in den Geschäftsberichten börsennotierter Unternehmen geprüft werden, alternative Messwerte zur Strategieberichterstattung im Lagebericht zu ermitteln. Diese Messwerte, die insofern auf einer - zeitlich unabhängig durchgeführten - Anwendung eines methodisch vergleichbaren Messinstruments durch externe Kodierer basierten, zeigten mit den hier ermittelten Strategy Disclosure Scores hohen statistischen Zusammenhang, so dass die Schlussfolgerung vertretbar erscheint, dass SDIndex tatsächlich dazu geeignet ist, das Niveau der Strategieberichterstattung im Lagebericht zu messen.

Da die Messung des Niveaus der Strategieberichterstattung vor dem Hintergrund der positiven Beantwortung von Frage 1 als sinnhaft anzusehen war, wurde mit Forschungsfrage 2 der konkrete Status sowie der zeitliche Verlauf des Niveaus der Strategieberichterstattung innerhalb der Lageberichte der Stichproben-Unternehmen adressiert. Dies bedeutete folglich die Anwendung des Messinstruments SDIndex auf die Lageberichte, die Bewertung der konkreten Berichtsinhalte sowie die Ermittlung der SDScores und der Teil-Scores der Analyse, der Strategieformulierung bzw. -detaillierung und der Implementierung. Wie die Auswertung der ermittelten Punktwerte offenbarte, ist ein über die Zeit zunehmendes Niveau der Strategieberichterstattung festzustellen, wenngleich sich eine erhebliche $\mathrm{Zu}$ nahme erst ab dem Jahre 2005 einstellte, also just zu dem Zeitpunkt, zu dem mit der Verabschiedung des BilReG eine Reform der Lageberichterstattung erfolgte.

Gesamthaft betrachtet ist das Niveau der Strategieberichterstattung in den sieben Jahren des Untersuchungszeitraumes als eher gering zu bezeichnen, der Durchschnitt der SDScores steigt jedoch von rund 30\% auf über $40 \%$ im Verlaufe des 
untersuchten Zeitraumes. Weiterhin ist festzustellen, dass die Strategieberichterstattung in den einzelnen Jahren beachtliche Heterogenität aufweist, die einfache Bandbreite der ermittelten Scores reicht von ca. $5 \%$ bis über $80 \%$ - gleichwohl konnte eine Normalverteilung der SDScores als gesichert angesehen werden. Im Hinblick auf die drei Teil-Scores erreichten diejenigen zu Angaben der Analysephase und zur Strategieformulierung vergleichbar hohe Messwerte, lediglich der Teil-Score zu Implementierungsangaben erzielte niedrigere Durchschnittswerte.

Die bereits festgestellte Ausweitung der Strategieberichterstattung konnte zudem mit Hilfe eines ergänzenden, einfachen Indikators untermauert werden: Während im Jahre 2002 nur in rund 20\% der untersuchten Lageberichte ein eigenständiger Gliederungspunkt mit inhaltlichen Angaben zur Strategie vorgesehen wurde, war dies im Jahre 2008 bereits bei nahezu 60\% aller Lageberichte der Fall.

Auf Grundlage dieser Auswertungen war die temporale Forschungsperspektive sodann um eine kausale Sichtweise zu erweitern: In einem ersten Schritt wurde mit Forschungsfrage 3 eine Identifikation möglicher Bestimmungsfaktoren des Niveaus der Strategieberichterstattung angestrebt, ehe sich Frage 4 mit zentralen kapitalmarktseitigen Auswirkungen derselbigen beschäftigen sollte. Aufbauend auf Vorarbeiten innerhalb der einschlägigen Literatur, welche sich mit den Determinanten des Berichterstattungsverhaltens auseinandergesetzt hat, ohne dabei jedoch einen spezifischen inhaltlichen Fokus auf Strategieinhalte zu legen, war es möglich, vier Kategorien von Bestimmungsfaktoren abzuleiten. Für diese vier Kategorien - namentlich makroökonomische Parameter, qualitative und quantitative Unternehmenscharakteristika sowie Faktoren des Aktienkapitals - mit in Summe zwölf potenziellen Bestimmungsfaktoren wurden Forschungshypothesen formuliert und mit Hilfe statistischer Testverfahren geprüft. Diese Hypothesenprüfung erfolgte auf drei Ebenen: Nach einer Prüfung jedes einzelnen möglichen Bestimmungsfaktors - je nach konkreter Art einer Hypothese auf Basis varianzbzw. regressionsanalytischer Verfahren - wurden sämtliche Einzelfaktoren einer Kategorie in partiellen Regressionsmodellen überprüft, originär nicht-metrische Daten wurden mit Hilfe der Dummy-Kodierung einer Aufnahme in Regressionsmodelle zugänglich gemacht. Abschließend wurden die Bestimmungsfaktoren in einem zusammenfassenden Regressionsmodell untersucht. 
Wie jene Hypothesenprüfung auf drei Ebenen offenbaren konnte, ist das Niveau der Strategieberichterstattung weitgehend erklärbar, das zusammenfassende Regressionsmodell kann mehr als 40\% der Varianz der Strategy Disclosure Scores erklären. Besondere Bedeutung kommt dabei neben den gegenwärtigen Kapitalmarktbedingungen, der Unternehmensgröße sowie dem Konzentrationsgrad des Aktienkapitals auch qualitativen Faktoren zu: Hervorzuheben ist insb. die Zugehörigkeit zu einem der vier Auswahlindizes der Dt. Börse AG, die einen großen Beitrag zur Erklärung der Strategieberichterstattung leisten kann. Auch Faktoren der qualitativen Unternehmenscharakteristika, bspw. die Branchenzugehörigkeit sowie Aspekte der Person des CEO und der Rechnungslegung, besitzen Einfluss auf die abhängige Variable SDIndex. Weiterhin zeigen sich spezifische Einflussfaktoren bei einer getrennten Betrachtung der großen bzw. kleinen StichprobenUnternehmen, so gewinnen bspw. für große Unternehmen finanzielle Faktoren, konkret die Profitabilität und der Verschuldungsgrad, klar an Bedeutung.

Zur Komplettierung der kausalen Perspektive der Strategieberichterstattung war im Anschluss an die Überprüfung von Bestimmungsfaktoren die Frage nach den kapitalmarktseitigen Folgen der Strategieberichterstattung zu stellen, dies abzuklären war Gegenstand von Forschungsfrage 4. Erneut wurden, den Arbeiten in der relevanten Literatur entsprechend, die sich mit kapitalmarktseitigen Effekten des gesamthaften Berichterstattungsverhaltens auseinandergesetzt hat, insg. sieben Forschungshypothesen zur gezielten Untersuchung der Kapitalmarkteffekte der Strategieberichterstattung abgeleitet. Diese sieben Hypothesen, gegliedert in drei Kategorien potenzieller Effekte, im Einzelnen Transparenz-, Handels- sowie Bewertungseffekte, konnten sodann stets mit Hilfe regressionsanalytischer Verfahren untersucht werden, da sämtliche Größen quantitativ bzw. auf metrischem Skalenniveau vorlagen. Die sieben interessierenden Kapitalmarkteffekte wurden schließlich jeweils auf zwei Ebenen geprüft, zunächst auf Basis von Einfachregressionen, anschließend in multivariaten Regressionsmodellen unter Einschluss verschiedener, in der relevanten Literatur identifizierbarer Kontrollvariablen.

Wie die Berechnung dieser multivariaten Regressionsmodelle zeigte, kann grds. davon ausgegangen werden, dass das Niveau der strategieorientierten Berichterstattung positiven Einfluss auf die Anzahl von Analysten hat, die ein berichten- 
des Unternehmen beobachten. Ebenso finden sich Anzeichen, dass eine Berichterstattung über strategieorientierte Inhalte in positivem Zusammenhang mit dem Handelsvolumen der Aktien eines berichtenden Unternehmens steht. Außerdem ist feststellbar, dass ein höheres Niveau der Strategieberichterstattung negativen Einfluss auf die Eigenkapitalkosten sowie die relativen Bid-Ask-Spreads ausübt. Bei einer spezifischen Betrachtung der interessierenden Zusammenhänge für die großen und kleinen Unternehmen der Stichprobe konnten die Erkenntnisse grds. bestätigt werden, auch zeigte sich ein negativer Einfluss der Strategieberichterstattung auf die Empfehlungsvarianz der Analysten bei großen und ein positiver Einfluss auf die branchenadjustierte Marktbewertung bei kleinen Unternehmen.

Vor dem Hintergrund jener - im Zuge der Beantwortung von Forschungsfrage 4 ermittelten - Ergebnisse scheint die Bedeutung der Strategieberichterstattung für den Kapitalmarkt offensichtlich. Jedoch kann die Perspektive der Beschäftigung mit den Wirkungen einer Berichterstattung zu Strategieinhalten am Kapitalmarkt durch die Analyse von Moderatoreffekten erweitert werden: Eine Untersuchung einzelner spezifizierter Beziehungen belegte letztlich, dass SDIndex in der Lage ist, die ursprünglichen Zusammenhänge zwischen unabhängigen Variablen und den jeweiligen Kapitalmarkteffekten zu moderieren, also sie in ihrer eigentlichen Wirkung entweder zu verstärken oder abzuschwächen. So konnte u.a. herausgefunden werden, dass der reduzierende Einfluss einer hohen Kapitalkonzentration auf die Eigenkapitalkosten in der Weise durch SDIndex moderiert wird, dass ein erhöhtes Niveau der Strategieberichterstattung den beschriebenen negativen Einfluss zusätzlich verstärkt. Weiterhin übt die Strategieberichterstattung auf mittelbarem Wege zudem einen Einfluss auf die Volatilität der Aktienrenditen aus, so wird bspw. der positive Einfluss des Handelsvolumens auf die Volatilität bei den Unternehmen mit intensiver Strategieberichterstattung deutlich abgeschwächt.

Folglich führen sowohl die Analyse der direkten Auswirkungen der Strategieberichterstattung als auch eine Untersuchung von Moderatoreffekten konsistent zu der Aussage, dass das unternehmensindividuelle Niveau der Berichterstattung zu strategieorientierten Sachverhalten Einfluss auf zentrale Kapitalmarktparameter auszuüben scheint. Eine Würdigung dieser zentralen Erkenntnis nimmt der nachfolgende Abschnitt E 3 vor, der die vorliegende Arbeit absshdießst $t_{31-75150-3}$ 


\section{$3 \quad$ Würdigung der wesentlichen Erkenntnisse der Arbeit und Anhaltspunkte für zukünftige Forschungsarbeiten}

Die vorliegende Arbeit hat das übergeordnete Ziel verfolgt, die Berichterstattung deutscher börsennotierter Unternehmen zu strategieorientierten Sachverhalten im Lagebericht theoretisch und empirisch zu untersuchen. Vor dem Hintergrund der im vorherigen Abschnitt E 2 zusammengefassten Ergebnisse scheinen die nachfolgenden vier Aussagen durchaus vertretbar: (1) Das unternehmensindividuelle Niveau der Strategieberichterstattung in Lageberichten ist messbar. (2) Über den Zeitraum 2002 bis 2008 hat sich das Niveau der Strategieberichterstattung der in den Auswahlindizes der Dt. Börse AG notierten Unternehmen erhöht, jedoch ist in den einzelnen Jahren des Untersuchungszeitraums eine enorme Heterogenität der jeweiligen Messwerte evident. (3) Das konkrete Niveau der Strategieberichterstattung börsennotierter Unternehmen ist weitgehend erklärbar, eine Reihe von Bestimmungsfaktoren, quantitativer wie qualitativer Natur, leistet einen Beitrag zur Erklärung. (4) Schließlich ist eine Berichterstattung über strategieorientierte Inhalte dazu geeignet, feststellbare Auswirkungen hinsichtlich zentraler Kapitalmarktparameter hervorzurufen.

Mit diesen Kernergebnissen liefert die vorliegende Arbeit nicht nur einen ersten Anhaltspunkt zur tatsächlichen Umsetzung - heute sowie in der Vergangenheit der theoretisch wiederholt thematisierten (Lage-) Berichterstattung zu strategieorientierten Sachverhalten am deutschen Kapitalmarkt. Die Arbeit ist außerdem in der Lage, einen empirischen Nachweis für die Relevanz und Vorteilhaftigkeit erweiterter Berichterstattung, spezifisch untersucht anhand des ,Phänomens “ der Strategieberichterstattung, vorzulegen und steht mit einer umfassenden kausalen Perspektive methodisch in der Tradition der US-amerikanischen Voluntary Disclosure-Literatur, deren eher kausale Sichtweise bislang nur geringe Beachtung am deutschen Kapitalmarkt gefunden hat.

Aus diesen Kernergebnissen lassen sich für die beiden wesentlichen Zielgruppen der vorliegenden Arbeit spezifische Implikationen ableiten, im Einzelnen für die Manager börsennotierter Unternehmen sowie für die verschiedenen für die Ausgestaltung der Lageberichterstattung in Deutschland maßgeblichen Institutionen: 
In erster Linie hält die Arbeit für die Manager börsennotierter Unternehmen die bemerkenswerte Erkenntnis bereit, dass diesen mit der Strategieberichterstattung offensichtlich ein wirksamer Aktionsparameter zur Verfügung steht, der zur Erreichung von angestrebten Kapitalmarktwirkungen eingesetzt werden kann. Die Manager börsennotierter Unternehmen könnten insofern im Sinne einer eigenen ,Kapitalmarktstrategie“ ein individuelles Niveau ihrer Strategieberichterstattung wählen, um bestimmte Ziele in Bezug auf die Kapitalmarktpräsenz zu erreichen. Es wurde folgerichtig für den deutschen Kapitalmarkt - mit spezifischem Fokus auf strategieorientierte Berichtsinhalte - aufgezeigt, dass ,evidence is consistent with the notion that firms committing to increased levels of disclosure garner economically and statistically significant benefits“" ${ }^{\text {1196 }}$.

Für Manager sollte daher gelten, dass, sofern eine umfassende strategische Analyse durchgeführt, eine klar formulierte Strategie abgeleitet und detailliert wurde bzw. implementiert wird, dies dem Kapitalmarkt unmittelbar mitzuteilen ist. Der Lagebericht innerhalb des Systems der Finanzberichterstattung erscheint als das geeignete Medium für eine Bereitstellung strategieorientierter Informationen, da jener die notwendige Flexibilität für die Aufnahme entsprechender Inhalte bietet und er zudem in der Lage ist, die Verlässlichkeit der Informationen zu erhöhen. Als inhaltlicher Leitfaden für die konkrete Umsetzung einer entsprechenden Berichterstattung wäre schließlich der in dieser Arbeit entwickelte, der empirischen Untersuchung zugrunde liegende normative Berichtskatalog verwendbar.

Eine Schlüsselrolle nimmt in diesem Kontext das Controlling ein: Als betriebswirtschaftlicher Berater des Managements gestaltet das Controlling den Prozess der Zielfindung, Planung und Steuerung und begleitet diesen inhaltlich. ${ }^{1197}$ Folglich ist zu erwarten, dass die Controller auch über den Prozess des strategischen Managements die ,Informationshoheit' besitzen und insofern in hervorragender Weise in der Lage sein sollten, die für eine Strategieberichterstattung gegenüber dem Kapitalmarkt benötigten Informationen zusammenzutragen und adressaten-

1196 Leuz/Verrecchia (2000), S. 121.

1197 Vgl. weiterführend zu den Aktionsfeldern und zum Rollenverständnis der Controller die Ausführungen bei Weißenberger (2006), S. 19ff. und auch S. 29ff. Mit ähnlicher Sichtweise auch Hahn/Hungenberg (2001), S. 265f. bzw. S. $277 f f$. 
orientiert, für die Veröffentlichung innerhalb des Lageberichts gem. HGB aufzubereiten. Den Mitarbeitern des Rechnungswesens käme sodann die Aufgabe zu, das Medium Lagebericht bereitzuhalten, die durch das Controlling zusammengestellten Informationen aufzugreifen und diese innerhalb der externen Finanzberichterstattung zu reflektieren - für die Generierung der Informationen wäre jedoch ausschließlich das Controlling, als informationeller Dienstleister des TopManagements, als verantwortlich anzusehen.

Die Unternehmen aber, die sich nicht in der Lage sehen, eine Strategieberichterstattung vorzulegen, weil es an einem entsprechend ausgestalteten strategischen Management oder aber an einer adäquaten bzw. detaillierten Strategie mangelt, dürften sich vor dem Hintergrund der ggf. am Kapitalmarkt erreichbaren Effekte aufgefordert sehen, ihr strategisches Management prozessual wie auch inhaltlich zu prüfen. ${ }^{1198}$ Positive Kapitalmarkteffekte wären in jedem Falle nur dann zu erwarten, wenn eine adäquate Strategie gegeben ist und diese kommuniziert wird. Letztlich wäre auch anzunehmen, dass der Kapitalmarkt zwischen Unternehmen, die über kein funktionsfähiges strategisches Management verfügen, und solchen, die lediglich ein vergleichsweise geringes Niveau der Strategieberichterstattung aufweisen, nicht unterscheidet - und gar nicht unterscheiden kann.

Der oftmals als Argumentation gegen die Strategieberichterstattung ins Feld geführte Hinweis auf die Wettbewerbssensitivität strategieorientierter Angaben erscheint auf Basis der in dieser Arbeit vorgelegten Ergebnisse widerlegt. ${ }^{1199}$ Die Stichproben-Unternehmen reflektieren im Durchschnitt ca. $40 \%$ des abgeleiteten normativen Kriterienkataloges, einzelne Unternehmen erreichen darüber hinaus SDScores bis zu $80 \%$. Folglich kann nicht davon ausgegangen werden, dass die Wettbewerbssensitivität der Informationen de facto einen Hinderungsgrund für eine Strategieberichterstattung darstellt. Vielmehr könnte sich dies als Schutzbe-

\footnotetext{
1198 Auch bei der Gestaltung von Prozessen und Systemen der Planung und Steuerung kann das Controlling einen Beitrag leisten, so z.B. Hahn/Hungenberg (2001), S. 277f. m.w.N.

1199 Diese Erkenntnis besitzt auch für die standardsetzenden Institutionen Relevanz: Wie in Abschnitt B 4.3 im Detail dargestellt wurde, ist die Wettbewerbssensitivität als zentrales Argument verwendet worden, um die Streichung der Berichtsanforderung zu Zielen und Strategien im Rahmen des BilReG bzw. DRS 15 zu rechtfertigen; vgl. B 4.3, u.a. S. 124. 
hauptung derjenigen Manager entlarven, die sich selbst nicht in der Lage fühlen, Angaben entsprechend dem zugrunde gelegten Strategieprozess bereitzustellen.

Schließlich wäre zu vermuten, dass die vielzitierte und oft kritisierte kurzfristige Orientierung der Kapitalmärkte nicht zuletzt auf einen schlichten Mangel an Informationen zurückzuführen ist, die - in verlässlicher Form - einen Ausblick auf die Unternehmensentwicklung über die aktuelle Periode hinaus erlauben. ${ }^{1200}$ Vor dem Hintergrund dieser Informationsbedingungen erscheint es folgerichtig, dass die Akteure an den Kapitalmärkten Informationen, die in verlässlicher Form verfügbar sind und überwiegend die kurze Frist betreffen, wie bspw. Quartalsergebnisse oder Angaben zum erwarteten Ergebnis der laufenden Periode, höher gewichten. Manager börsennotierter Unternehmen wären selbst als einzige dazu in der Lage, die Kurzfristorientierung zu überwinden, indem sie nicht nur strategieorientierte Informationen bereitstellen, sondern zudem über einen längeren Zeitraum die Glaubwürdigkeit ihrer strategischen Informationen aufzeigen sowie die eigene Kompetenz in der Disziplin ,Strategisches Management ' demonstrieren.

Daneben hält diese Arbeit auch für diejenigen Institutionen, die sich mit der dt. Lageberichterstattung auseinandersetzen bzw. für deren Ausgestaltung maßgebliche Verantwortung tragen, einige spezifische Implikationen bereit:

Zunächst wurde aufgezeigt, dass der Lagebericht in seiner gegenwärtigen Form - unabhängig der expliziten Kodifizierung einer Berichterstattung über strategieorientierte Inhalte - dank seiner Flexibilität als qualitativ-verbales Medium der Rechnungslegung ausreichende Darstellungsmöglichkeiten für eine Strategieberichterstattung bereitstellt. Insofern erscheint die Schlussfolgerung zulässig, dass eine explizite Kodifizierung nicht erforderlich ist - vielmehr wäre anzunehmen, dass es in erster Linie der freiwillige Charakter der Strategieberichterstattung ist, der den Angaben nicht nur intensive Beachtung zukommen lässt, sondern diesen

12(0) Innerhalb der Unternehmenspraxis ist daher auch die Einführung einer verpflichtenden Quartalsberichterstattung z.T. kritisch gesehen worden. Es wurde argumentiert, dass die vermeintlich kurzfristige Orientierung der Kapitalmärkte zusätzlich verstärkt würde. Als Wortführer in dieser Diskussion auf Seiten der Unternehmenspraxis kann der ehemalige Vorstandsvorsitzende der Dr. Ing. h.c. F. Porsche AG, Dr. Wendelin Wiedeking, gelten, vgl. im Detail zur Argumentation Wiedeking (2006), hier insb. S. 49f. Dieser bezeichnet Quartalsberichte als „Knebel für die Unternehmensführungen“, ebenda, S. 49. 
zudem höhere Glaubwürdigkeit verleiht. Die explizite Verpflichtung zur Bereitstellung strategieorientierter Inhalte könnte möglicherweise sogar einen Teil der Differenzierungswirkung einer Strategieberichterstattung zunichtemachen. ${ }^{1201}$

Bemühungen nationaler sowie internationaler Standardsetter, strategieorientierte Berichtsinhalte explizit zu kodifizieren, ist folglich eine Absage zu erteilen, eine Freiwilligkeit der Berichterstattung scheint vor dem Hintergrund der dargelegten Kapitalmarkteffekte überlegen. Gleichwohl ist die Aufnahme einer Empfehlung zur Bereitstellung von Informationen zu Rahmenbedingungen bzw. angestrebten Entwicklungszielen in einschlägigen Leitfäden zur Lageberichterstattung durchaus zu begrüßen - diesen Weg hat schließlich auch das IASB in seinem vor dem Abschluss stehenden Projekt, Management Commentary' gewählt.

Letztlich lassen sich die Normen zur dt. HGB-Lageberichterstattung jedoch auch dahingehend auslegen, dass die Strategieberichterstattung implizit erwartet wird, wie aufgezeigt wurde. Ein Bericht zur Lage eines Unternehmens ohne einen geeigneten Referenzpunkt, d.h. die angestrebte zukünftige Entwicklung des Unternehmens, zur Beurteilung dieser Lage darzustellen, scheint mehr als fragwürdig. Dies muss in besonderer Weise für die Vorlage einer Prognose der zukünftigen Entwicklung innerhalb des explizit kodifizierten Prognoseberichts gelten: Was, wenn nicht die Strategie eines Unternehmens, sollte diese Ausführungen leiten? Die für die Kodifizierung der Lageberichterstattung maßgeblichen Institutionen in Deutschland hätten mit ihrer impliziten Forderung nach strategieorientierten Angaben gegenüber dem IASB also eine klare Vorbildfunktion eingenommen.

Allerdings wären die dt. Lageberichtsnormen dahingehend zu überprüfen, ob die Strukturierung der Teil-Berichte noch sinnvoll ist vor dem Hintergrund, dass die Unternehmensstrategie in der Lage wäre, als strukturierendes Element alle TeilBerichte miteinander zu verknüpfen. ${ }^{1202}$ Dies würde in letzter Konsequenz auch

\footnotetext{
1201 Vgl. zu diesem Gedanken auch Fischer/Wenzel (2002), S. 328 bzw. die Ausführungen in Abschnitt B 1.2.4 zur Grundidee der Signalling-Theorie, grdl. Ross (1979). stellte Vorschlag der European Accounting Study Group zurück, ebenfalls macht Abb. 9 (S. 134) die Möglichkeit einer Lageberichterstattung entlang der Strategie deutlich - die Strategie würde insofern zum Ordnungs- und Gliederungsprinzip des Lageberichts. 
eine Prüfung der Namensgebung für diesen Baustein der Finanzberichterstattung inkludieren: Immerhin kann der Lagebericht weit mehr sein als ein Medium zur Darstellung der Lage eines Unternehmens, als umfassender Managementbericht könnte er dazu genutzt werden, das Umfeld, die Lage, die strategischen Ziele sowie die sie operationalisierende Wettbewerbsstrategie im Detail darzustellen.

Wird der soeben geäußerte Gedanke, dass die gegenwärtigen Normen zur Lageberichterstattung einen Strategiebericht bereits implizit fordern, nochmals aufgegriffen, wäre schließlich auch zu hinterfragen, weshalb - abgesehen von der aufgezeigten marktlichen ,Sanktionierung ' unzulänglicher Strategieberichte - keine rechtlichen und regulatorischen Konsequenzen aufgrund mangelhafter Strategieberichterstattung ersichtlich sind. ${ }^{1203}$ Zahlreiche der im Rahmen der empirischen Untersuchung analysierten 700 Lageberichte würden in dieser Sichtweise die an sie gestellten Berichtsanforderungen nicht erfüllen, ohne dass dies bis dato feststellbaren Einfluss auf die Erteilung eines Bestätigungsvermerks durch die Abschlussprüfer zu haben scheint. ${ }^{1204}$

Die im Rahmen der vorliegenden Arbeit erarbeiteten Erkenntnisse sowie die daraus abgeleiteten Implikationen sind allerdings ausdrücklich - wie es für die empirische Forschung durchaus üblich ist - unter gewissen Einschränkungen zu betrachten, welche nachfolgend dargestellt sind. ${ }^{1205}$ Für die eigene Untersuchung sind zwei relevante Bereiche von Limitationen zu identifizieren, aus denen sich gleichwohl spiegelbildlich interessante Anhaltspunkte für zukünftige empirische Arbeiten zur Strategieberichterstattung ergeben, wie ebenfalls zu zeigen ist.

Zunächst ist auf Limitationen einzugehen, die aus der Auswahl der Stichprobe der eigenen Untersuchung resultieren. Wie in Abschnitt C 3.2.1 im Detail ausgeführt, inkludiert die eigene Stichprobe in Summe 100 deutsche Unternehmen, die per Halbjahresultimo 2009 in einem der vier Auswahlindizes der Dt. Börse AG 
notiert waren. Wenngleich die Aussagefähigkeit dieser Untersuchungsstichprobe für die Gesamtheit der 160 in jenen vier Auswahlindizes notierten Unternehmen dargelegt werden konnte, wären auf der Grundlage dieser Stichprobe Aussagen zur Strategieberichterstattung aller börsennotierten Unternehmen in Deutschland nicht statthaft. Konsequenterweise gilt dies zudem für Aussagen zur Strategieberichterstattung aller Unternehmen in Deutschland. Zukünftige empirische Untersuchungen zum Gehalt strategieorientierter Inhalte im Lagebericht könnten sich demzufolge mit einer Erweiterung der Betrachtung um nicht in Auswahlindizes notierte oder auch um nicht börsennotierte Unternehmen befassen. ${ }^{1206}$

Darüber hinaus ist die eigene Untersuchung hinsichtlich der Branchenzugehörigkeit der Stichproben-Unternehmen undifferenziert vorgegangen. Zwar wurde der Einfluss derselbigen auf die Strategieberichterstattung untersucht, dennoch wäre es weiterhin grds. vorstellbar, ein mit dieser Untersuchung vergleichbares Untersuchungsmodell mit explizitem Fokus auf eine einzelne Branche durchzuführen, um so die Gültigkeit der hier ermittelten Ergebnisse zu überprüfen. ${ }^{1207}$

Weiterhin könnte die hier vorgenommene Konzentration auf deutsche Aktiengesellschaften hinterfragt werden. Für die vorliegende Arbeit ergab sich jene Festlegung aus dem theoretischen Fundament, da die deutsche Lageberichterstattung nach HGB in das Zentrum der Betrachtung gestellt wurde. Nichtsdestotrotz kann auch für empirische Untersuchungen zur Strategieberichterstattung gelten, „One obvious extension [...] would be to include firms from other countries “1208. Eine vergleichende Untersuchung der Strategieberichterstattung innerhalb von Lage-

\footnotetext{
1206 Insb. der letzte Aspekt scheint aussichtsreich: So wäre zu untersuchen, ob Unternehmen mit einer überlegenen Strategieberichterstattung, die nicht als kapitalmarktorientiert zu charakterisieren sind, vergleichbare Effekte im Hinblick auf ihre Finanzierung erzielen können. Gedacht sei bspw. an Konditionsvorteile bei Fremdkapitalfinanzierungen oder auch Bewertungsaufschläge im Rahmen von Private Equity-Transaktionen.

Erinnert sei an eine Botosan (1997a), S. 327 entnommene Aussage: „different industries display different patterns of disclosure." Diese Feststellung kann als Ausgangspunkt für branchenspezifische Untersuchungen der Strategieberichterstattung dienen.

Für die eigene Untersuchung wurde lediglich die Branche der Finanz-, Immobilien- und Versicherungsunternehmen aus der Betrachtung exkludiert, vgl. hier Abschnitt C 3.2.1.

Leuz/Verrecchia (2000), S. 121.
} 
berichtsinstrumenten in verschiedenen Ländern kann daher als ein wesentlicher zukünftiger Forschungsbedarf festgehalten werden.

Zusätzliche Limitationen ergeben sich aus der gewählten Forschungsmethodik der eigenen Untersuchung. Zunächst ist das unternehmensindividuelle Niveau der Strategieberichterstattung ausschließlich anhand der innerhalb der jährlichen Lageberichte bereitgestellten Inhalte zum strategischen Management hergeleitet worden, alle darüber hinausgehenden Medien zur Bereitstellung entsprechender Informationen wurden folglich von der Betrachtung ausgeschlossen. Diese Vorgehensweise stützte sich explizit auf die These von Lang/Lundholm (1993), dass der Geschäfts- bzw. Lagebericht einen überaus geeigneten Indikator für das gesamthafte Kommunikationsverhalten eines Unternehmens darstellt. ${ }^{1209}$ Künftige empirische Forschung wäre aufgefordert, zu prüfen, ob diese grdl. Annahme der Voluntary Disclosure-Literatur auch in der heutigen Zeit bestätigt werden kann.

Weiterhin hat die empirische Untersuchung zur Strategieberichterstattung keine detaillierte Unterscheidung von verpflichtend bzw. freiwillig bereitgestellten inhaltlichen Einzelaspekten vorgenommen, sondern stattdessen strategieorientierte Berichtsinhalte gesamthaft als Teil der freiwilligen Berichterstattung angesehen. Künftige empirische Forschung könnte sich in detaillierter Betrachtung mit einer derartigen Differenzierung inhaltlicher Berichtselemente auseinandersetzen.

In diesem Zusammenhang wäre es auch von Interesse zu prüfen, in welcher Beziehung freiwillige Angaben zu strategieorientierten Sachverhalten und sonstige freiwillige Berichtsinhalte stehen. In dieser Untersuchung wurde ausschließlich auf strategieorientierte Aspekte abgestellt, andere Informationen der freiwilligen Berichterstattung wurden daher vollständig ausgeblendet. Künftige Forschungsarbeiten könnten folglich die hier behandelte Strategieberichterstattung im Kontext der gesamten Berichterstattung betrachten. Dabei wäre auch zu analysieren,

1209 Vgl. die Ausführungen in Abschnitt C 3.2.2 und grdl. dazu Lang/Lundholm (1993), hier v.a. S. 263; Knutson (1992), S. 7f. Auf diese Annahme stützt sich ein großer Teil der für diese Arbeit relevanten Voluntary Disclosure-Literatur. Als Zustimmung zu jener These sind insofern auch sämtliche empirischen Arbeiten anzusehen, die auf der Analyse des Berichtsverhaltens innerhalb des Geschäftsberichts basieren. Exemplarisch für derartige Arbeiten sei auf Botosan (1997a), S. 332 sowie Hail (2002), S. 746 verwiesen. 
ob freiwillige ,Strategy Disclosures ' lediglich als ein Indikator des gesamthaften Berichtsverhaltens eines Unternehmens zu interpretieren sind oder ob diese ggf. einen besonders relevanten Bereich freiwilliger Berichterstattung repräsentieren.

Schließlich hat die eigene Untersuchung den aufgestellten normativen Berichtskatalog zum strategischen Management mit seinen insgesamt 40 Einzelkriterien unter der Prämisse akzeptiert, dass auf Basis der Gesamtheit dieser Kriterien ein umfassendes und konsistentes Bild des strategischen Managements eines Unternehmens vermittelt werden kann. Zwar wurde das auf jenem Katalog beruhende Messinstrument, der Strategy Disclosure Index bzw. die entsprechenden Scores, mit Hilfe externer Daten mit vergleichbarer inhaltlicher Perspektive validiert, jedoch obläge es zukünftigen empirischen Arbeiten, sich mit eigenen inhaltlichen Vorschlägen einer Messung des Niveaus der Strategieberichterstattung im Lagebericht anzunähern und auf diesem Wege zugleich das hier verwendete Messinstrument SDIndex kritisch zu würdigen.

Zudem besaß diese Untersuchung eine rein informationsorientierte Perspektive: Es wurde lediglich auf die Ursachen sowie Auswirkungen der Quantität und der Qualität der strategieorientierten Berichtsinhalte abgestellt, eine inhaltliche Auseinandersetzung mit der jeweils berichteten Strategie - und ebenso ihrer tatsächlichen Umsetzung - erfolgte nicht. Künftige Forschungsarbeiten sollten sich daher explizit auch mit der Frage der Interpretation strategieorientierter Berichterstattung durch die Kapitalmarktakteure auseinandersetzen. Interessant schiene in diesem Kontext insb. der empirische Nachweis für die Existenz unternehmensindividueller Interpretationsschemata für Strategieangaben sowie eine Betrachtung der Kapitalmarkteffekte strategieorientierter Informationen im Zeitablauf - unter ausdrücklicher Berücksichtigung sowohl des Inhalts als auch des Realisierungsgrades bzw. -erfolges zuvor kommunizierter Strategien.

Ein finaler Vorschlag für zukünftige empirische Arbeiten zur Strategieberichterstattung setzt schließlich ausdrücklich auf dem im Rahmen dieser Untersuchung konstruierten Messinstrument SDIndex auf: Wird akzeptiert, dass dieses tatsächlich in der Lage ist, das individuelle Niveau der Strategieberichterstattung eines Unternehmens zu messen, könnte die vorgenommene Analyse in zeitlicher Per-

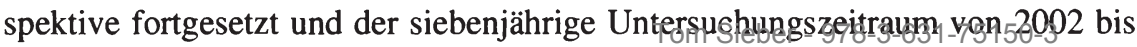


2008 um zusätzliche Jahre ausgedehnt werden. Das Messinstrument des Strategy Disclosure Index könnte sich so möglicherweise als Kennzahl am Kapitalmarkt etablieren, die nicht nur für Externe leicht nachvollzieh- und interpretierbar bzw. für Manager börsennotierter Unternehmen als Ziel- und Berichterstattungsgröße steuer- und kommunizierbar, sondern außerdem für Investoren sowie Analysten auch einforder- und kontrollierbar wäre.

Die Ausführungen zum zukünftigen Forschungsbedarf - und damit auch die vorliegende Arbeit - sollen schließlich mit der rund 40 Jahre alten Feststellung von Fama (1970) „The old saw, 'much remains to be done', is relevant here as elsewhere." ${ }^{1210}$ abgeschlossen werden - es scheint aussichtsreich und gleichermaßen wünschenswert, wenn sich das in der vorliegenden Arbeit eingehend untersuchte Phänomen der Strategieberichterstattung auch in der Zukunft ausreichender Beachtung innerhalb der wissenschaftlichen Forschung und umfangreicher Berücksichtigung in der unternehmerischen Berichterstattungspraxis erfreuen würde. 


\section{Anhang}

Anhang 1: Auswahl der Stichproben-Unternehmen................................... 355

Anhang 2: Branchensystematik der Deutschen Börse AG.......................... 357

Anhang 3-1: Branchenstruktur der Stichprobe im Detail ............................... 358

Anhang 3-2: Branchenzugehörigkeit der Stichproben-Unternehmen ............ 359

Anhang 4: Indexzugehörigkeit der Stichproben-Unternehmen.................... 361

Anhang 5: Geschäftsjahres-Zeiträume der Stichproben-Unternehmen...... 363

Anhang 6: Untersuchungsbogen zur Erhebung der SDScores .................... 365

Anhang 7-1: Ermittelte SDScores der Stichproben-Unternehmen ................ 373

Anhang 7-2: Histogramm der ermittelten SDScores ….................................. 375

Anhang 8: Zusammenfassung der Untersuchungsvariablen ....................... 376

Anhang 9: Methodik zur Ableitung von Validierungs-Scores .................... 378

Anhang 10: Zuordnung der Stichprobe zu Teil-Stichproben ........................ 380

Anhang 11: Berechnungsmethodik der Eigenkapitalkostensätze ................. 382

Anhang 12: Hauptmodelle mit unlogarithmierten Regressanden ................. 385

Anhang 13: Uni- und bivariate Statistik zentraler Variablen ........................ 386 


\section{Anhang 1: Auswahl der Stichproben-Unternehmen}

\begin{tabular}{|c|c|c|c|c|c|c|c|c|c|c|c|}
\hline \multirow{3}{*}{$\begin{array}{l}\text { Gesa } \\
\text { Nr. } \\
001\end{array}$} & \multirow{3}{*}{$\begin{array}{l}\text { Name } \\
\text { Aareal Bank AG }\end{array}$} & \multirow{3}{*}{$\frac{\text { Index }}{\text { SDax }}$} & \multirow{2}{*}{\multicolumn{2}{|c|}{$\begin{array}{l}\text { Unternehn } \\
\text { Sample }\end{array}$}} & \multirow{3}{*}{$\begin{array}{l}\text { en per } \mathbf{H} \\
G J^{b} \\
\end{array}$} & \multirow{3}{*}{$\frac{\text { Nr. }}{041}$} & \multirow{3}{*}{$\frac{\text { Name }}{\text { Dt. Börse AG }}$} & \multirow{3}{*}{$\frac{\text { Index }}{\text { Dax }}$} & \multirow{2}{*}{\multicolumn{2}{|c|}{ Sample $^{\mathrm{a}}$}} & \multirow{3}{*}{$\mathbf{G J}^{\mathrm{b}}$} \\
\hline & & & & & & & & & & & \\
\hline & & & $\mathrm{N}$ & FIRE & & & & & $\mathbf{N}$ & FIRE & \\
\hline 002 & Adidas AG & Dax & $\mathbf{J}$ & & 31.12. & 042 & Dt. Euroshop AG & MDax & $\mathrm{N}$ & FIRE & \\
\hline 003 & Air Berlin PLC & SDax & $\mathrm{N}$ & Zeit & & 043 & Dt. Lufthansa AG & Dax & $\mathrm{J}$ & & 31.12 . \\
\hline 004 & Aixtron AG & TecDax & $\mathrm{J}$ & & 31.12 & 044 & Dt. Post AG & Dax & $\mathrm{J}$ & & 31.12 . \\
\hline 005 & Allianz SE & $\operatorname{Dax}$ & $\mathrm{N}$ & FIRE & & 045 & Dt. Postbank AG & MDax & $\mathrm{N}$ & FIRE & \\
\hline 006 & Alstria Office AG & SDax & $\mathbf{N}$ & FIRE & & 046 & Dt. Telekom AG & Dax & J & & 31.12 . \\
\hline 007 & Arcandor AG & MDax & $\mathrm{J}$ & & 30.09 & 047 & Dt. Wohnen AG & SDax & $\mathbf{N}$ & FIRE & \\
\hline 008 & Arques Ind. AG & SDax & $\mathbf{N}$ & FIRE & & 048 & Deutz AG & SDax & $J$ & & 31.12 . \\
\hline 009 & Aurubis AG & MDax & $\mathbf{J}$ & & 30.09 . & 049 & DIC Asset AG & SDax & $\mathrm{N}$ & FIRE & \\
\hline 010 & Axel Springer AG & SDax & $\mathrm{J}$ & & 31.12 & 050 & Douglas Hldg. AG & MDax & J & & 30.09 . \\
\hline 011 & BASF SE & Dax & $\mathrm{J}$ & & 31.12 & 051 & Drägerwerk AG & TecDax & $J$ & & 31.12 . \\
\hline 012 & Bauer AG & MDax & $\mathrm{N}$ & Zeit & & 052 & Dürr AG & SDax & J & & 31.12 . \\
\hline 013 & Bayer AG & Dax & $\mathbf{J}$ & & 31.12 & 053 & Dyckerhoff AG & SDax & J & & 31.12 . \\
\hline 014 & BayWa AG & SDax & $\mathbf{J}$ & & 31.12. & 054 & E.On AG & Dax & $\mathrm{J}$ & & 31.12 . \\
\hline 015 & BB Biotech AG & TecDax & $\mathrm{N}$ & Ausl. ( & СH) & 055 & EADS NV & MDax & $\mathrm{N}$ & Ausl. ( & NL) \\
\hline 016 & Bechtle AG & TecDax & $\mathbf{J}$ & & 31.12 & 056 & Elexis AG & SDax & $\mathbf{J}$ & & 31.12. \\
\hline 017 & Beiersdorf AG & Dax & $\mathbf{J}$ & & 31.12 . & 057 & ElringKlinger AG & MDax & $J$ & & 31.12 . \\
\hline 018 & Bertrandt AG & SDax & $\mathbf{J}$ & & 30.09 . & 058 & Escada AG & SDax & $\mathrm{J}$ & & 31.10 . \\
\hline 019 & Bilfinger Berger AG & MDax & $\mathbf{J}$ & & 31.12. & 059 & Fielmann AG & MDax & J & & 31.12 . \\
\hline 020 & Biotest AG & SDax & $\mathbf{J}$ & & 31.12 & 060 & Fraport AG & MDax & J & & 31.12 . \\
\hline 021 & BMW AG & $\operatorname{Dax}$ & $\mathbf{J}$ & & 31.12. & 061 & Freenet AG & TecDax & $\mathbf{N}$ & Zeit & \\
\hline 022 & CAT Oil AG & SDax & $\mathrm{N}$ & Zeit & & 062 & Fres. Med. Care AG & Dax & J & & 31.12 . \\
\hline 023 & Carl Zeiss Med. AG & TecDax & $\mathbf{J}$ & & 30.09 & 063 & Fresenius SE & Dax & J & & 31.12 . \\
\hline 024 & Celesio AG & MDax & $\mathbf{J}$ & & 31.12 . & 064 & Fuchs Petrolub AG & MDax & $\mathrm{J}$ & & 31.12 . \\
\hline 025 & Centrotec Sust. AG & SDax & $\mathbf{J}$ & & 31.12 & 065 & Gagfah SA & MDax & $\mathrm{N}$ & FIRE & \\
\hline 026 & Centrotherm AG & TecDax & $\mathrm{N}$ & Zeit & & 066 & GEA Group AG & MDax & J & & 31.12 . \\
\hline 027 & Cewe Color AG & SDax & $\mathbf{J}$ & & 31.12. & 067 & Gerresheimer AG & MDax & $\mathrm{N}$ & Zeit & \\
\hline 028 & Colonia RE AG & SDax & $\mathrm{N}$ & FIRE & & 068 & Gerry Weber AG & SDax & $\mathrm{J}$ & & 30.09 . \\
\hline 029 & Comdirect Bank AG & SDax & $\mathrm{N}$ & FIRE & & 069 & Gesco AG & SDax & J & & 31.03. \\
\hline 030 & Commerzbank AG & Dax & $\mathbf{N}$ & FIRE & & 070 & GFK SE & SDax & $\mathrm{J}$ & & 31.12 . \\
\hline 031 & Conergy AG & TecDax & $\mathbf{N}$ & Zeit & & 071 & Gildemeister AG & MDax & J & & 31.12 . \\
\hline 032 & Constantin AG & SDax & $\mathrm{N}$ & Zeit & & 072 & Grammer AG & SDax & $\mathbf{J}$ & & 31.12 . \\
\hline 033 & Continental AG & MDax & $\mathbf{J}$ & & 31.12. & 073 & Grenkeleasing AG & SDax & $\mathrm{N}$ & FIRE & \\
\hline 034 & CTS Eventim AG & SDax & $\mathbf{J}$ & & 31.12. & 074 & H \& R Wasag AG & SDax & J & & 31.12 . \\
\hline 035 & Curanum AG & SDax & $\mathbf{J}$ & & 31.12. & 075 & HHLA AG & MDax & $\mathbf{N}$ & Zeit & \\
\hline 036 & Daimler AG & Dax & $\mathrm{J}$ & & 31.12 & 076 & Hannover Rück. AG & Dax & $\mathbf{N}$ & FIRE & \\
\hline 037 & Delticom AG & SDax & $\mathbf{N}$ & Zeit & & 077 & HeidelbergCem. AG & MDax & $\mathbf{J}$ & & 31.12 . \\
\hline 038 & Demag Cranes AG & MDax & $\mathbf{N}$ & Zeit & & 078 & Heidelb. Druck AG & MDax & $\mathbf{J}$ & & 31.03. \\
\hline 039 & Dt. Bank AG & Dax & $\mathbf{N}$ & FIRE & & 079 & Henkel AG \& Co. & Dax & J & & 31.12. \\
\hline 040 & Dt. Beteiligungs AG & SDax & $\mathbf{N}$ & FIRE & & 080 & Highlight Com. AG & SDax & $\mathbf{N}$ & Ausl. ( & \\
\hline
\end{tabular}

a I:IRI : = Untemehmen des Super-Sektors FIRI:, keine Berücksichtigung in Stichprobe: Ausl, = Unternehmen ausländischer Rechtsform. keine I ageberichte nach HICiB: /eit = Unternehmen nicht während des gesamten Untersuchungszeitraumes börsennotiert.

b (ieschäftsjahres-lindtermin 2008; grds. lindtermine innerhalb des ersten Halbjahres als lindtermin 31.12. des Vorjahres betrachtet.

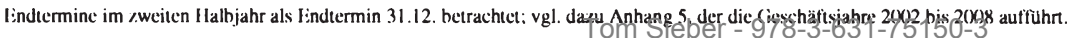




\section{Anhang 1: Auswahl der Stichproben-Unternehmen (Forts.)}

\begin{tabular}{|c|c|c|c|c|c|c|c|c|c|c|c|}
\hline \multicolumn{12}{|c|}{ Gesamtheit der HDax- und SDax-Unternehmen per Halbjahresultimo 2009 und Auswahl der Stichprobe } \\
\hline \multirow{2}{*}{$\frac{\mathrm{Nr} .}{081}$} & \multirow{2}{*}{$\begin{array}{l}\text { Name } \\
\text { Hochtief AG }\end{array}$} & \multirow{2}{*}{$\frac{\text { Index }}{\text { MDax }}$} & \multicolumn{2}{|c|}{ Sample $^{a}$} & \multirow{2}{*}{$\frac{\mathbf{G J}^{\mathrm{b}}}{31.12 .}$} & \multirow{2}{*}{$\frac{\mathrm{Nr} .}{121}$} & \multirow{2}{*}{$\begin{array}{l}\text { Name } \\
\text { Puma AG }\end{array}$} & \multirow{2}{*}{$\frac{\text { Index }}{\text { MDax }}$} & \multicolumn{2}{|c|}{ Sample $^{a}$} & \multirow{2}{*}{$\frac{\mathbf{G J}^{\mathbf{b}}}{31.12 .}$} \\
\hline & & & $\mathbf{J}$ & & & & & & $\mathbf{J}$ & & \\
\hline 082 & Homag Group AG & SDax & $\mathrm{N}$ & Zeit & & 122 & Q-Cells SE & TecDax & $\mathbf{N}$ & Zeit & \\
\hline 083 & Hugo Boss AG & MDax & $\mathrm{J}$ & & 31.12. & 123 & Qiagen NV & TecDax & $\mathbf{N}$ & Ausl. ( & NL) \\
\hline 084 & Hypo Real Est. AG & $\operatorname{MDax}$ & $\mathrm{N}$ & FIRE & & 124 & QSC AG & TecDax & $\mathbf{J}$ & & 31.12 . \\
\hline 085 & IDS Scheer AG & TecDax & $\mathbf{J}$ & & 31.12 . & 125 & Rational AG & MDax & $\mathbf{J}$ & & 31.12 . \\
\hline 086 & Indus Holding AG & SDax & $\mathbf{N}$ & FIRE & & 126 & Rheinmetall AG & MDax & $\mathbf{J}$ & & 31.12 . \\
\hline 087 & Infineon Tech. AG & TecDax & $\mathbf{J}$ & & 30.09 & 127 & Rhön-Klinikum AG & MDax & $\mathbf{J}$ & & 31.12 . \\
\hline 088 & IVG Immo. AG & MDax & $N$ & FIRE & & 128 & Rofin-Sinar Inc. & TecDax & $\mathrm{N}$ & Ausl. ( & US) \\
\hline 089 & Jenoptik AG & TecDax & $\mathbf{J}$ & & 31.12 & 129 & Roth \& RAU AG & TecDax & $\mathrm{N}$ & Zeit & \\
\hline 090 & Jungheinrich AG & SDax & $\mathbf{J}$ & & 31.12 . & 130 & RWE AG & Dax & $\mathbf{J}$ & & 31.12 . \\
\hline 091 & $\mathrm{~K}+\mathrm{S} \mathrm{AG}$ & Dax & $\mathbf{J}$ & & 31.12 & 131 & Salzgitter AG & Dax & $\mathbf{J}$ & & 31.12 . \\
\hline 092 & Klöckner \& Co. SE & MDax & $\mathrm{N}$ & Zeit & & 132 & SAP AG & Dax & $\mathbf{J}$ & & 31.12 . \\
\hline 093 & Koenig \& Bauer AG & SDax & $\mathbf{J}$ & & 31.12 . & 133 & SGL Carbon SE & MDax & $\mathbf{J}$ & & 31.12 . \\
\hline 094 & Kontron AG & TecDax & $\mathrm{J}$ & & 31.12 & 134 & Siemens AG & Dax & $\mathbf{J}$ & & 30.09 . \\
\hline 095 & Krones AG & MDax & $\mathbf{J}$ & & 31.12 & 135 & Singulus Tech. AG & TecDax & $\mathbf{J}$ & & 31.12 . \\
\hline 096 & Kuka AG & MDax & $J$ & & 31.12 & 136 & Sixt AG & SDax & $J$ & & 31.12 . \\
\hline 097 & KWS Saat AG & SDax & $\mathbf{J}$ & & 30.06 & 137 & SKW Holding AG & SDax & $\mathbf{N}$ & Zeit & \\
\hline 098 & Lanxess AG & MDax & $\mathrm{N}$ & Zeit & & 138 & SMA Solar AG & TecDax & $\mathrm{N}$ & Zeit & \\
\hline 099 & Leoni AG & MDax & $\mathbf{J}$ & & 31.12 & 139 & Smartrac NV & TecDax & $\mathbf{N}$ & Zeit & \\
\hline 100 & Linde AG & Dax & $\mathbf{J}$ & & 31.12 & 140 & Software AG & TecDax & $\mathbf{J}$ & & 31.12 . \\
\hline 101 & Loewe AG & SDax & $\mathbf{J}$ & & 31.12 & 141 & SolarWorld AG & TecDax & $\mathbf{J}$ & & 31.12 . \\
\hline 102 & MAN SE & Dax & $\mathbf{J}$ & & 31.12 . & 142 & Solon SE & TecDax & $\mathbf{J}$ & & 31.12 . \\
\hline 103 & MediGene AG & TecDax & $\mathbf{J}$ & & 31.12 & 143 & Stada AG & MDax & $\mathbf{J}$ & & 31.12 . \\
\hline 104 & Medion AG & SDax & $\mathrm{J}$ & & 31.12 & 144 & Südzucker AG & MDax & $J$ & & 28.02 . \\
\hline 105 & Merck KGaA & Dax & $\mathrm{J}$ & & 31.12 & 145 & Symrise AG & MDax & $\mathbf{N}$ & Zeit & \\
\hline 106 & Metro AG & Dax & $\mathbf{J}$ & & 31.12 & 146 & TAG Immo. AG & SDax & $\mathbf{N}$ & FIRE & \\
\hline 107 & MLP AG & MDax & $\mathrm{N}$ & FIRE & & 147 & Takkt AG & SDax & $\mathrm{J}$ & & 31.12 . \\
\hline 108 & MorphoSys AG & TecDax & $\mathrm{J}$ & & 31.12 & 148 & ThyssenKrupp AG & Dax & $\mathbf{J}$ & & 30.09 . \\
\hline 109 & MPC AG & SDax & $\mathrm{N}$ & FIRE & & 149 & Tognum AG & MDax & $\mathrm{N}$ & Zeit & \\
\hline 110 & MTU Aero Eng. AG & MDax & $\mathbf{N}$ & Zeit & & 150 & TUI AG & MDax & $\mathbf{J}$ & & 31.12 . \\
\hline 111 & Munich Re AG & Dax & $\mathrm{N}$ & FIRE & & 151 & United Internet AG & TecDax & $\mathbf{J}$ & & 31.12 . \\
\hline 112 & MVV Energie AG & SDax & $\mathbf{J}$ & & 30.09 & 152 & VBH Holding AG & SDax & J & & 31.12 . \\
\hline 113 & Nordex AG & TecDax & $\mathbf{J}$ & & 31.12 & 153 & Vivacon AG & SDax & $\mathbf{N}$ & FIRE & \\
\hline 114 & Patrizia Imm. AG & SDax & $\mathrm{N}$ & FIRE & & 154 & Volkswagen AG & Dax & $\mathrm{J}$ & & 31.12 . \\
\hline 115 & Pfeiffer Vac. AG & TecDax & $\mathrm{J}$ & & 31.12 & 155 & Vossloh AG & MDax & $\mathbf{J}$ & & 31.12 . \\
\hline 116 & Pfleiderer AG & MDax & $\mathrm{J}$ & & 31.12 & 156 & VTG AG & SDax & $\mathrm{N}$ & Zeit & \\
\hline 117 & Phoenix Solar AG & TecDax & $\mathrm{N}$ & Zeit & & 157 & Wacker Chemie AG & MDax & $\mathbf{N}$ & Zeit & \\
\hline 118 & Praktiker AG & MDax & $\mathrm{N}$ & Zeit & & 158 & Wacker Neuson SE & SDax & $\mathrm{N}$ & Zeit & \\
\hline 119 & Sky Dtl. AG & MDax & $\mathrm{N}$ & Zeit & & 159 & Wincor Nixdorf AG & MDax & $\mathrm{N}$ & Zeit & \\
\hline 120 & P7S1 Media AG & MDax & $\mathrm{J}$ & & 31.12 . & 160 & Wirecard AG & TecDax & J & & 31.12 . \\
\hline
\end{tabular}

a FIRE = Unternehmen des Super-Sektors FIRE, keine Berücksichtigung in Stichprobe; Ausl. = Unternehmen ausländischer Rechtsform, keine Lageberichte nach HGB; 7eit = Untemehmen nicht während des gesamten Untersuchungszeitraumes börsennotiert.

b Geschäftsjahres-Endtermin 2008; grds. Endtermine innerhalb des ersten Halbjahres als Endtermin 31.12. des Vorjahres betrachtet. Endtermine im zweiten Halbjahr als Endtermin 31.12. betrachtet: vgl. dazu Anhang 5 der die Geschäftsjahre 2002 bis 2008 aufführt. 


\section{Anhang 2: Branchensystematik der Deutschen Börse AG}

\section{Branchensystematik der Deutschen Börse AG auf drei Ebenen}

\begin{tabular}{|c|c|c|c|}
\hline Super-Sektor (9) & Sektor (18) & Sub-Sektor (63) & Branchenausrichtung \\
\hline \multirow[t]{7}{*}{ Basic Materials } & Basic Resources & Forest \& Paper Products & Classic \\
\hline & & Mining & Chassic \\
\hline & & Oil \& (ias & Classic \\
\hline & & Steel \& (Mher Metak & Chssic \\
\hline & Chemicals & ('hemicals. Commexdity & Classic \\
\hline & & Chemicals. Speciatty & ('lassic \\
\hline & & Industrial (iases & Classic \\
\hline \multirow[t]{10}{*}{ Consumer Goods } & Automobile & Auto Parts \& Eiquipment & Classic \\
\hline & & Aulomobile Manufacturers & Classic \\
\hline & Consumer & C'kithing \& Finotwear & Chssic \\
\hline & & Consumer H:lectronics & Classic \\
\hline & & Home Construction \& Fumishings & Chssic \\
\hline & & Houschokl Appliances \& Housewares & Chassic \\
\hline & & Leisure & Classic \\
\hline & & Personal Products & Classic \\
\hline & Food \& Beverages & Beverages & C'bssic \\
\hline & & Finsl & Classic \\
\hline \multirow{9}{*}{ Consumer Services } & Media & Advertising & Chssic \\
\hline & & Broadcasting & Classic \\
\hline & & Movies \& Enterainment & ('lassic \\
\hline & & Publishing \& Printing & Classic \\
\hline & Retail & Relail. ('atakogue & Classic \\
\hline & & Retail. Fond \& Itrug & ('lassic \\
\hline & & Retail. Intemet & ('bassic \\
\hline & & Retail. Muttiline & Classic \\
\hline & & Retail. Specialty & Chssic \\
\hline \multirow[t]{8}{*}{ FIRE } & Banks & Credit Banks & Classic \\
\hline & & Morrgage Banks & Classic \\
\hline & Financial Services & Diversifiel Financial & Chssic \\
\hline & & Private Piquity \& Venture Capital & Classic \\
\hline & & Real t:statc & Classic \\
\hline & & Securities Brokers & Classic \\
\hline & Insurance & Insurance & Classic \\
\hline & & Re-Insurance & Classic \\
\hline \multirow[t]{12}{*}{ Industrials } & Construction & Buikting Materials & Classic \\
\hline & & Construction \& I:ngineering & Classic \\
\hline & Industrial & Advanced Industrial Fiquipment & 'Technosogie \\
\hline & & Containers \& Packaging & Classic \\
\hline & & Heavy Machinery & Classic \\
\hline & & Industrial Machinery & C'bssic \\
\hline & & Industrial Proxlucts \& Services & Classic \\
\hline & & Industrial. Diversified & Classic \\
\hline & & Renewable tinergies & Technologie \\
\hline & Transportation \& Logistics & Airlines & Classic \\
\hline & & L.ogistucs & Classic \\
\hline & & Transpourtation Services & Classic \\
\hline \multirow{6}{*}{ Information Technology } & Software & Internet & Technologie \\
\hline & & IT-Services & Technokogic \\
\hline & & Softwart: & Technokogic \\
\hline & Technology & Communications Technokgy & Technologie \\
\hline & & Eilectronic Components \& Hardware & Technokogie \\
\hline & & Semiconductors & Technokogie \\
\hline Pharma \& & Pharma \& & Biotechnoksgy & Technokgie \\
\hline \multirow{2}{*}{ Healthcare } & Healthcare & Heathicare & Classic \\
\hline & & $\begin{array}{l}\text { Medical Technokgy } \\
\text { Pharmacuuticals }\end{array}$ & $\begin{array}{l}\text { 'Technokogic } \\
\text { Classic }\end{array}$ \\
\hline \multirow[t]{3}{*}{ Telecommunication } & Telecommunication & Fixed-l.ine Telecommunication & Technokggic \\
\hline & & Teleoommunication Services & Technologie \\
\hline & & Wireless Telecommunication & Technologie \\
\hline \multirow[t]{3}{*}{ Utilities } & Utilities & Electricity & Classic \\
\hline & & Muht-Utilities & Classic \\
\hline & & $\begin{array}{l}\text { Oil \& (ias (Dissribution) } \\
\text { Water TOM Sieber - } 9\end{array}$ & 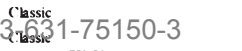 \\
\hline
\end{tabular}




\section{Anhang 3-1: Branchenstruktur der Stichprobe im Detail}

\begin{tabular}{|c|c|c|c|c|c|c|c|c|c|}
\hline \multicolumn{10}{|c|}{ Branchenstruktur der Untersuchungsstichprobe im Detail (nach Sektoren) } \\
\hline \multirow[b]{3}{*}{ Super-Sektor } & \multirow[b]{3}{*}{ Sektor } & \multicolumn{4}{|c|}{ In Bezug auf Sektoren } & \multicolumn{4}{|c|}{ In Bezug auf Super-Sektoren } \\
\hline & & \multicolumn{2}{|c|}{ Gesamtheit $(\mathrm{N})$} & \multicolumn{2}{|c|}{ Stichprobe (n) } & \multicolumn{2}{|c|}{ Gesamtheit (N) } & \multicolumn{2}{|c|}{ Stichprobe (n) } \\
\hline & & \# & in $\%$ & \# & in $\%$ & \# & in $\%$ & \# & in $\%$ \\
\hline \multirow[t]{2}{*}{ Basic Materials } & Basic Resources & 3 & $1,9 \%$ & 2 & $2,0 \%$ & \multirow{2}{*}{14} & \multirow{2}{*}{$8,8 \%$} & \multirow{2}{*}{9} & \multirow{2}{*}{$9,0 \%$} \\
\hline & Chemicals & 11 & $6,9 \%$ & 7 & $7,0 \%$ & & & & \\
\hline \multirow[t]{3}{*}{ Consumer Goods } & Automobile & 8 & $5,0 \%$ & 8 & $8,0 \%$ & \multirow{3}{*}{18} & \multirow{3}{*}{$11,3 \%$} & \multirow{3}{*}{18} & \multirow{3}{*}{$18,0 \%$} \\
\hline & Consumer & 9 & $5,6 \%$ & 9 & $9,0 \%$ & & & & \\
\hline & Food \& Beverages & 1 & $0,6 \%$ & 1 & $1,0 \%$ & & & & \\
\hline \multirow[t]{2}{*}{ Consumer Services } & Media & 5 & $3,1 \%$ & 3 & $3,0 \%$ & \multirow{2}{*}{13} & \multirow{2}{*}{$8,1 \%$} & \multirow{2}{*}{9} & \multirow{2}{*}{$9,0 \%$} \\
\hline & Retail & 8 & $5,0 \%$ & 6 & $6,0 \%$ & & & & \\
\hline \multirow[t]{3}{*}{ FIRE $^{1211}$} & Banks & 5 & $3,1 \%$ & & & \multirow{3}{*}{26} & \multirow{3}{*}{$16,3 \%$} & \multirow{3}{*}{0} & \multirow{3}{*}{$0,0 \%$} \\
\hline & Financial Services & 18 & $11,3 \%$ & & & & & & \\
\hline & Insurance & 3 & $1,9 \%$ & & & & & & \\
\hline \multirow[t]{3}{*}{ Industrials } & Construction & 6 & $3,8 \%$ & 5 & $5,0 \%$ & \multirow{3}{*}{59} & \multirow{3}{*}{$36,9 \%$} & \multirow{3}{*}{39} & \\
\hline & Industrial & 45 & $28,1 \%$ & 29 & $29,0 \%$ & & & & $39,0 \%$ \\
\hline & Transp. \& Logistics & 8 & $5,0 \%$ & 5 & $5,0 \%$ & & & & \\
\hline Information & Software & 6 & $3,8 \%$ & 6 & $6,0 \%$ & 10 & $6,3 \%$ & 9 & $9,0 \%$ \\
\hline Technology & Technology & 4 & $2,5 \%$ & 3 & $3,0 \%$ & & & & \\
\hline Pharma \& Healthcar & & 14 & $8,8 \%$ & 11 & $11,0 \%$ & 14 & $8,8 \%$ & 11 & $11,0 \%$ \\
\hline Telecommunication & & 3 & $1,9 \%$ & 2 & $2,0 \%$ & 3 & $1,9 \%$ & 2 & $2,0 \%$ \\
\hline Utilities $^{1212}$ & & 3 & $1,9 \%$ & 3 & $3,0 \%$ & 3 & $1,9 \%$ & 3 & $3,0 \%$ \\
\hline Total & & 160 & $100 \%$ & 100 & $100 \%$ & 160 & $100 \%$ & 100 & $100 \%$ \\
\hline
\end{tabular}

1211 Der Super-Sektor ,FIRE` greift die Unternehmen der Finanz- (Finance), Versicherungs(Insurance) und Immobilienbranche (Real Estate) auf. Der Begriff ,FIRE` leitet sich aus den Anfangsbuchstaben der englischsprachigen Bezeichnungen der drei Branchen ab.

1212 Die Super-Sektoren ,Pharma \& Healthcare", ,Telecommunication“ sowie ,Utilities" sind nicht in einzelne Sektoren untergliedert, eine Untergliederung des Super-Sektors in SubSektoren erfolgt dennoch, wie der vorhergehende Anhang 2 aufzeigt. 


\section{Anhang 3-2: Branchenzugehörigkeit der Stichproben-Unternehmen}

\begin{tabular}{|c|c|c|c|c|}
\hline \multicolumn{5}{|c|}{ Branchenzugehörigkeit der Stichproben-Unternehmen gem. Branchensystematik der Dt. Börse AG } \\
\hline$[\mathrm{T}=$ Technologie $; \mathrm{C}=$ Classic $]$ & Super-Sektor & Sektor & Sub-Sektor & $\mathrm{T} / \mathrm{C}$ \\
\hline Adidas AG & Consumer Goods & Consumer & Clothing \& Footwear & $\mathrm{C}$ \\
\hline Aixtron AG & Information Techn. & Technology & Semiconductors & $\mathrm{T}$ \\
\hline Arcandor AG & Consumer Services & Retail & Retail, Multiline & $\mathrm{C}$ \\
\hline Aurubis AG & Basic Materials & Basic Resources & Steel \& Other Metals & $\mathrm{C}$ \\
\hline Axel Springer AG & Consumer Services & Media & Publishing \& Printing & $\mathrm{C}$ \\
\hline BASF SE & Basic Materials & Chemicals & Chemicals, Specialty & $\mathrm{C}$ \\
\hline Baver AG & Basic Materials & Chemicals & Chemicals, Specialty & $\mathrm{C}$ \\
\hline BayWa AG & Industrials & Industrial & Industrial Prod. \& Svcs. & $\mathrm{C}$ \\
\hline Bechtle AG & Information Techn. & Software & IT-Services & $\mathrm{T}$ \\
\hline Beiersdorf AG & Consumer Goods & Consumer & Personal Products & $\mathrm{C}$ \\
\hline Bertrandt AG & Consumer Goods & Automobile & Auto Parts \& Equipment & $\mathrm{C}$ \\
\hline Bilfinger Berger AG & Industrials & Construction & Constr. \& Engineering & $\mathrm{C}$ \\
\hline Biotest AG & Pharma \& Healthcare & Pharma \& Health. & Pharmaceuticals & $\mathrm{C}$ \\
\hline BMW AG & Consumer Goods & Automobile & Autom. Manufacturers & $\mathrm{C}$ \\
\hline Carl Zeiss Meditec AG & Pharma \& Healthcare & Pharma \& Health. & Medical Technology & $\mathrm{T}$ \\
\hline Celesio AG & Consumer Services & Retail & Retail, Food \& Drug & $\mathrm{C}$ \\
\hline Centrotec Sustainable AG & Industrials & Industrial & Industrial Prod. \& Svcs. & $\mathrm{C}$ \\
\hline CeWe Color Holding AG & Consumer Goods & Consumer & Leisure & $\mathrm{C}$ \\
\hline Continental AG & Consumer Goods & Automobile & Auto Parts \& Equipment & $\mathrm{C}$ \\
\hline CTS Eventim AG & Consumer Services & Media & Movies \& Entertainment & $\mathrm{C}$ \\
\hline Curanum AG & Pharma \& Healthcare & Pharma \& Health. & Healthcare & $\mathrm{C}$ \\
\hline Daimler AG & Consumer Goods & Automobile & Autom. Manufacturers & $\mathrm{C}$ \\
\hline Deutsche Lufthansa AG & Industrials & Transp. \& Logistics & Airlines & $\mathrm{C}$ \\
\hline Deutsche Post AG & Industrials & Transp. \& Logistics & Logistics & $\mathrm{C}$ \\
\hline Deutsche Telekom AG & Telecommunication & Telecommunication & Fixed-Line & $\mathrm{T}$ \\
\hline Deutz AG & Industrials & Industrial & Heavy Machinery & $\mathrm{C}$ \\
\hline Douglas Holding AG & Consumer Services & Retail & Retail, Specialty & $\mathrm{C}$ \\
\hline Drägerwerk AG \& Co. $\mathrm{KGaA}$ & Pharma \& Healthcare & Pharma \& Health. & Medical Technology & $\mathrm{T}$ \\
\hline Dürr AG & Industrials & Industrial & Industrial Machinery & $\mathrm{C}$ \\
\hline Dyckerhoff AG & Industrials & Construction & Building Materials & $\mathrm{C}$ \\
\hline E.On AG & Utilities & Utilities & Multi-Utilities & $\mathrm{C}$ \\
\hline Elexis AG & Industrials & Industrial & Industrial Machinery & $\mathrm{C}$ \\
\hline ElringKlinger AG & Consumer Goods & Automobile & Auto Parts \& Equipment & $\mathrm{C}$ \\
\hline Escada AG & Consumer Goods & Consumer & Clothing \& Footwear & $\mathrm{C}$ \\
\hline Fielmann AG & Consumer Services & Retail & Retail, Specialty & C \\
\hline Fraport AG & Industrials & Transp. \& Logistics & Transportation Services & $\mathrm{C}$ \\
\hline Fresenius Med. Care AG \& Co. & Pharma \& Healthcare & Pharma \& Health. & Healthcare & $\mathrm{C}$ \\
\hline Fresenius SE & Pharma \& Healthcare & Pharma \& Health. & Healthcare & $\mathrm{C}$ \\
\hline Fuchs Petrolub AG & Basic Materials & Chemicals & Chemicals, Specialty & $\mathrm{C}$ \\
\hline GEA Group AG & Industrials & Industrial & Industrial, Diversified & $\mathrm{C}$ \\
\hline Gerry Weber International AG & Consumer Goods & Consumer & Clothing \& Footwear & $\mathrm{C}$ \\
\hline Gesco AG & Industrials & Industrial & Industrial, Diversified & $\mathrm{C}$ \\
\hline GfK SE & Industrials & Industrial & Industrial Products \& & $\mathrm{C}$ \\
\hline Gildemeister AG & Industrials & Industrial & Industrial Machinery & $\mathrm{C}$ \\
\hline Grammer AG & Consumer Goods & Automobile & Auto Parts \& Equipment & $\mathrm{C}$ \\
\hline H \& R Wasag AG & Basic Materials & Chemicals & Chemicals, Specialty & $\mathrm{C}$ \\
\hline HeidelbergCement AG & Industrials & Construction & Building Materials & $\mathrm{C}$ \\
\hline Heidelberger Druckmaschinen AG & Industrials & Industrial & Industrial Machinery & $\mathrm{C}$ \\
\hline Henkel AG \& Co. KGaA & Consumer Goods & Consumer & Personal Products & $\mathrm{C}$ \\
\hline Hochtief AG & Industrials & $\begin{array}{l}\text { Construction } \\
\text { Tom Siebe }\end{array}$ & $\begin{array}{l}\text { Const. \& Engineering } \\
978-3-631-75150-3\end{array}$ & $\mathrm{C}$ \\
\hline
\end{tabular}




\section{Anhang 3-2: Branchenzugehörigkeit der Stichprobe (Forts.)}

\begin{tabular}{|c|c|c|c|c|}
\hline \multicolumn{5}{|c|}{ Branchenzugehörigkeit der Stichproben-Unternehmen gem. Branchensystematik der Dt. Börse AG } \\
\hline$[\mathrm{T}=$ Technologie $; \mathrm{C}=$ Classic $]$ & Super-Sektor & Sektor & Sub-Sektor & $\mathbf{T} / \mathbf{C}$ \\
\hline Hugo Boss AG & Consumer Goods & Consumer & Clothing \& Footwear & $\mathrm{C}$ \\
\hline IDS Scheer AG & Information Techn. & Software & IT-Services & $\mathrm{T}$ \\
\hline Infineon Technologies AG & Information Techn. & Technology & Semiconductors & $\mathrm{T}$ \\
\hline Jenoptik AG & Industrials & Industrial & Advanced Industrial & $\mathrm{T}$ \\
\hline Jungheinrich AG & Industrials & Industrial & Industrial Machinery & $\mathrm{C}$ \\
\hline $\mathrm{K}+\mathrm{S} \mathrm{AG}$ & Basic Materials & Chemicals & Chemicals, Commodity & $\mathrm{C}$ \\
\hline Koenig \& Bauer AG & Industrials & Industrial & Industrial Machinery & $\mathrm{C}$ \\
\hline Kontron AG & Information Techn. & Technology & Electr. Components \& & $\mathrm{T}$ \\
\hline Krones AG & Industrials & Industrial & Industrial Machinery & $\mathrm{C}$ \\
\hline Kuka AG & Industrials & Industrial & Industrial Machinery & $\mathrm{C}$ \\
\hline KWS Saat AG & Industrials & Industrial & Industrial Prod. \& Svcs. & $\mathrm{C}$ \\
\hline Leoni AG & Consumer Goods & Automobile & Auto Parts \& Equipment & $\mathrm{C}$ \\
\hline Linde AG & Basic Materials & Chemicals & Industrial Gases & $\mathrm{C}$ \\
\hline Loewe AG & Consumer Goods & Consumer & Consumer Electronics & $\mathrm{C}$ \\
\hline MAN SE & Industrials & Industrial & Industrial, Diversified & $\mathrm{C}$ \\
\hline MediGene AG & Pharma \& Healthcare & Pharma \& Healthcare & Biotechnology & $\mathrm{T}$ \\
\hline Medion AG & Industrials & Industrial & Industrial Prod. \& Svcs. & $\mathrm{C}$ \\
\hline Merck KGaA & Pharma \& Healthcare & Pharma \& Healthcare & Pharmaceuticals & $\mathrm{C}$ \\
\hline Metro AG & Consumer Services & Retail & Retail, Multiline & $\mathrm{C}$ \\
\hline MorphoSys AG & Pharma \& Healthcare & Pharma \& Healthcare & Biotechnology & $\mathrm{T}$ \\
\hline MVV Energie AG & Utilities & Utilities & Multi-Utilities & $\mathrm{C}$ \\
\hline Nordex AG & Industrials & Industrial & Renewable Energies & $\mathrm{T}$ \\
\hline Pfeiffer Vacuum Technology AG & Industrials & Industrial & Advanced Industrial & $\mathrm{C}$ \\
\hline Pfleiderer AG & Industrials & Industrial & Industrial Prod. \& Svcs. & $\mathrm{C}$ \\
\hline ProSiebenSat.1 Media AG & Consumer Services & Media & Broadcasting & $\mathrm{C}$ \\
\hline Puma AG & Consumer Goods & Consumer & Clothing \& Footwear & $\mathrm{C}$ \\
\hline QSC AG & Telecommunication & Telecommunication & Fixed-Line & $\mathrm{T}$ \\
\hline Rational AG & Industrials & Industrial & Industrial Prod. \& Svcs. & $\mathrm{C}$ \\
\hline Rheinmetall AG & Industrials & Industrial & Industrial, Diversified & $\mathrm{C}$ \\
\hline Rhön-Klinikum AG & Pharma \& Healthcare & Pharma \& Healthcare & Healthcare & $\mathrm{C}$ \\
\hline RWE AG & Utilities & Utilities & Multi-Utilities & $\mathrm{C}$ \\
\hline Salzgitter AG & Basic Materials & Basic Resources & Steel \& Other Metals & $\mathrm{C}$ \\
\hline SAP AG & Information Techn. & Software & Software & $\mathrm{T}$ \\
\hline SGL Carbon SE & Basic Materials & Chemicals & Chemicals, Specialty & $\mathrm{C}$ \\
\hline Siemens AG & Industrials & Industrial & Industrial, Diversified & $\mathrm{C}$ \\
\hline Singulus Technologies AG & Industrials & Industrial & Advanced Industrial & $\mathrm{T}$ \\
\hline Sixt AG & Industrials & Transp. \& Logistics & Transportation Services & $\mathrm{C}$ \\
\hline Software AG & Information Techn. & Software & Software & $\mathrm{T}$ \\
\hline SolarWorld AG & Industrials & Industrial & Renewable Energies & $\mathrm{T}$ \\
\hline Solon SE & Industrials & Industrial & Renewable Energies & $\mathrm{T}$ \\
\hline Stada Arzneimittel AG & Pharma \& Healthcare & Pharma \& Healthcare & Pharmaceuticals & $\mathrm{C}$ \\
\hline Südzucker AG & Consumer Goods & Food \& Beverages & Food & $\mathrm{C}$ \\
\hline Takkt AG & Consumer Services & Retail & Retail, Catalogue & $\mathrm{C}$ \\
\hline ThyssenKrupp AG & Industrials & Industrial & Industrial, Diversified & $\mathrm{C}$ \\
\hline TUI AG & Industrials & Transp. \& Logistics & Transportation Services & $\mathrm{C}$ \\
\hline United Internet AG & Information Techn. & Software & Internet & $\mathrm{T}$ \\
\hline VBH Holding AG & Industrials & Construction & Building Materials & $\mathrm{C}$ \\
\hline Volkswagen AG & Consumer Goods & Automobile & Automobile Manufacturers & $\mathrm{C}$ \\
\hline Vossloh AG & Industrials & Industrial & Industrial Prod. \& Svcs. & $\mathrm{C}$ \\
\hline Wirecard AG & Information Techn. & $\begin{array}{l}\text { Software } \\
\text { Tom_Sieber }\end{array}$ & $\begin{array}{l}\text { IT-Services } \\
978=3=631=75150-3\end{array}$ & $\mathrm{~T}$ \\
\hline
\end{tabular}


Anhang 4: Indexzugehörigkeit der Stichproben-Unternehmen

\begin{tabular}{|c|c|c|c|c|c|c|c|c|}
\hline \multicolumn{9}{|c|}{ Zugehörigkeit der Stichproben-Unternehmen zu Auswahlindizes per Jahresultimo } \\
\hline \multicolumn{2}{|c|}{ [Aktiengattung] } & \multirow{2}{*}{$\frac{2002}{\operatorname{Dax}}$} & \multirow{2}{*}{$\frac{2003}{\operatorname{Dax}}$} & \multirow{2}{*}{$\frac{2004}{\operatorname{Dax}}$} & \multirow{2}{*}{$\frac{2005}{\operatorname{Dax}}$} & \multirow{2}{*}{$\frac{2006}{\operatorname{Dax}}$} & \multirow{2}{*}{$\frac{2007}{\operatorname{Dax}}$} & \multirow{2}{*}{$\frac{2008}{\operatorname{Dax}}$} \\
\hline Adidas AG & & & & & & & & \\
\hline Aixtron AG & & & TecDax & TecDax & TecDax & TecDax & TecDax & TecDax \\
\hline Arcandor AG & & MDax & MDax & MDax & MDax & MDax & MDax & MDax \\
\hline Aurubis AG & & MDax & MDax & MDax & MDax & MDax & MDax & MDax \\
\hline Axel Springer AG & & & & & & & SDax & SDax \\
\hline BASF SE & & Dax & Dax & Dax & Dax & $\operatorname{Dax}$ & Dax & Dax \\
\hline Baver AG & & Dax & Dax & Dax & Dax & Dax & Dax & Dax \\
\hline BayWa AG & & & SDax & SDax & SDax & SDax & SDax & SDax \\
\hline Bechtle AG & & & & TecDax & TecDax & TecDax & TecDax & TecDax \\
\hline Beiersdorf AG & & MDax & MDax & MDax & MDax & MDax & MDax & $\operatorname{Dax}$ \\
\hline \multicolumn{9}{|l|}{ Bertrandt AG } \\
\hline Bilfinger Berger AG & & MDax & MDax & MDax & MDax & MDax & MDax & MDax \\
\hline Biotest AG & {$[\mathrm{Vz}]$} & SDax & & & & & SDax & SDax \\
\hline BMW AG & {$[\mathrm{St}]$} & Dax & Dax & Dax & Dax & $\operatorname{Dax}$ & $\operatorname{Dax}$ & Dax \\
\hline Carl Zeiss Meditec AG & & & & & & & TecDax & TecDax \\
\hline Celesio AG & & MDax & MDax & MDax & MDax & MDax & MDax & MDax \\
\hline Centrotec Sustainable AG & & & & SDax & SDax & & & SDax \\
\hline CeWe Color Holding AG & & SDax & SDax & SDax & SDax & SDax & & \\
\hline Continental AG & & MDax & Dax & Dax & Dax & Dax & $\operatorname{Dax}$ & $\operatorname{MDax}$ \\
\hline CTS Eventim AG & & & & SDax & SDax & SDax & SDax & SDax \\
\hline Curanum AG & & & & & SDax & SDax & SDax & SDax \\
\hline Daimler AG & & Dax & Dax & $\operatorname{Dax}$ & Dax & Dax & Dax & Dax \\
\hline Deutsche Lufthansa AG & & Dax & Dax & Dax & Dax & Dax & $\operatorname{Dax}$ & Dax \\
\hline Deutsche Post AG & & Dax & Dax & $\operatorname{Dax}$ & Dax & Dax & Dax & Dax \\
\hline Deutsche Telekom AG & & Dax & $\operatorname{Dax}$ & Dax & Dax & Dax & $\operatorname{Dax}$ & Dax \\
\hline Deutz AG & & & SDax & SDax & SDax & MDax & MDax & SDax \\
\hline Douglas Holding AG & & MDax & MDax & MDax & MDax & MDax & MDax & MDax \\
\hline Drägerwerk AG \& Co. $\mathrm{KGaA}$ & & $\operatorname{MDax}$ & TecDax & TecDax & TecDax & TecDax & TecDax & TecDax \\
\hline Dürr AG & & MDax & SDax & SDax & & & SDax & SDax \\
\hline Dyckerhoff AG & [Vz] & MDax & MDax & SDax & SDax & SDax & SDax & SDax \\
\hline E.On AG & & Dax & Dax & $\operatorname{Dax}$ & Dax & Dax & Dax & Dax \\
\hline Elexis AG & & SDax & & SDax & SDax & SDax & SDax & SDax \\
\hline ElringKlinger $\mathrm{AG}$ & & & SDax & SDax & SDax & SDax & SDax & SDax \\
\hline Escada AG & {$[\mathrm{St}]$} & MDax & SDax & SDax & SDax & SDax & SDax & SDax \\
\hline Fielmann AG & & MDax & MDax & MDax & MDax & SDax & SDax & SDax \\
\hline Fraport AG & & MDax & MDax & MDax & MDax & MDax & MDax & MDax \\
\hline Fresenius Med. Care AG \& Co. & {$[\mathrm{St}]$} & Dax & Dax & Dax & $\operatorname{Dax}$ & Dax & $\operatorname{Dax}$ & Dax \\
\hline Fresenius SE & {$[\mathrm{Vz}]$} & MDax & MDax & MDax & MDax & $\operatorname{MDax}$ & $\operatorname{MDax}$ & MDax \\
\hline Fuchs Petrolub AG & {$[\mathrm{Vz}]$} & SDax & SDax & SDax & SDax & SDax & SDax & MDax \\
\hline GEA Group AG & & MDax & MDax & MDax & MDax & MDax & MDax & $\operatorname{MDax}$ \\
\hline Gerry Weber International AG & & MDax & SDax & SDax & SDax & SDax & SDax & SDax \\
\hline Gesco AG & & SDax & & & & & & SDax \\
\hline GfK SE & & MDax & SDax & SDax & SDax & SDax & SDax & SDax \\
\hline Gildemeister AG & & MDax & SDax & SDax & SDax & SDax & MDax & MDax \\
\hline Grammer AG & & & & & SDax & SDax & SDax & SDax \\
\hline H \& R Wasag AG & & & & SDax & SDax & SDax & SDax & SDax \\
\hline HeidelbergCement AG & & MDax & MDax & MDax & MDax & MDax & MDax & MDax \\
\hline Heidelberger Druckmaschinen $\mathrm{AC}$ & & MDax & MDax & MDax & MDax & MDax & MDax & MDax \\
\hline Henkel AG \& Co. KGaA & {$[\mathrm{Vz}]$} & Dax & Dax & Dax & Dax & Dax & Dax & Dax \\
\hline Hochtief AG & & MDax & MDax & MDax & MDax & MDax & MDax & MDax \\
\hline
\end{tabular}


Anhang 4: Indexzugehörigkeit der Stichprobe (Forts.)

\begin{tabular}{|c|c|c|c|c|c|c|c|c|}
\hline \multicolumn{9}{|c|}{ Zugehörigkeit der Stichproben-Unternehmen zu Auswahlindizes per Jahresultimo } \\
\hline \multicolumn{2}{|c|}{ [Aktiengattung] } & \multirow{2}{*}{$\frac{2002}{\mathrm{MDax}}$} & \multirow{2}{*}{$\frac{2003}{M D a x}$} & \multirow{2}{*}{$\frac{2004}{M D a x}$} & \multirow{2}{*}{$\frac{2005}{\operatorname{MDax}}$} & \multirow{2}{*}{$\frac{2006}{\operatorname{MDax}}$} & \multirow{3}{*}{ 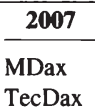 } & \multirow{3}{*}{$\begin{array}{l}2008 \\
\text { MDax } \\
\text { TecDax }\end{array}$} \\
\hline Hugo Boss AG & {$[\mathrm{Vz}]$} & & & & & & & \\
\hline IDS Scheer AG & & & TecDax & TecDax & TecDax & TecDax & & \\
\hline Infineon Technologies AG & & Dax & Dax & Dax & Dax & Dax & Dax & Dax \\
\hline Jenoptik AG & & MDax & TecDax & TecDax & TecDax & TecDax & & TecDax \\
\hline Jungheinrich AG & & MDax & SDax & SDax & SDax & SDax & SDax & SDax \\
\hline $\mathrm{K}+\mathrm{S}$ AG & & MDax & MDax & MDax & MDax & MDax & MDax & Dax \\
\hline Koenig \& Bauer AG & & MDax & MDax & SDax & SDax & SDax & SDax & SDax \\
\hline Kontron AG & & & TecDax & TecDax & TecDax & TecDax & TecDax & TecDax \\
\hline Krones AG & & MDax & MDax & MDax & MDax & MDax & MDax & MDax \\
\hline Kuka AG & & MDax & MDax & MDax & MDax & MDax & MDax & MDax \\
\hline KWS Saat AG & & & & & & SDax & SDax & SDax \\
\hline Leoni AG & & MDax & MDax & MDax & MDax & MDax & MDax & MDax \\
\hline Linde AG & & Dax & $\operatorname{Dax}$ & Dax & Dax & $\operatorname{Dax}$ & Dax & Dax \\
\hline Loewe AG & & MDax & SDax & & SDax & SDax & & SDax \\
\hline MAN SE & {$[\mathrm{St}]$} & Dax & Dax & Dax & Dax & Dax & Dax & Dax \\
\hline MediGene AG & & & & & TecDax & & & \\
\hline Medion AG & & & MDax & MDax & MDax & SDax & SDax & SDax \\
\hline Merck KGaA & & MDax & MDax & MDax & MDax & MDax & Dax & Dax \\
\hline Metro AG & {$[\mathrm{St}]$} & Dax & Dax & Dax & Dax & Dax & $\operatorname{Dax}$ & Dax \\
\hline MorphoSys AG & & & & TecDax & TecDax & TecDax & TecDax & TecDax \\
\hline MVV Energie AG & & SDax & SDax & SDax & SDax & SDax & SDax & SDax \\
\hline Nordex AG & & & & & & TecDax & TecDax & TecDax \\
\hline Pfeiffer Vacuum Technology AG & & & TecDax & TecDax & TecDax & TecDax & TecDax & TecDax \\
\hline Pfleiderer AG & & SDax & SDax & SDax & MDax & MDax & MDax & MDax \\
\hline ProSiebenSat.1 Media AG & & MDax & MDax & MDax & MDax & $\operatorname{MDax}$ & MDax & $\operatorname{MDax}$ \\
\hline Puma AG & & MDax & MDax & MDax & MDax & MDax & MDax & MDax \\
\hline OSC AG & & & & TecDax & TecDax & TecDax & TecDax & TecDax \\
\hline Rational AG & & SDax & SDax & SDax & SDax & SDax & SDax & SDax \\
\hline Rheinmetall AG & & MDax & MDax & MDax & MDax & MDax & MDax & MDax \\
\hline Rhön-Klinikum AG & & MDax & MDax & MDax & MDax & MDax & MDax & MDax \\
\hline RWE AG & {$[\mathrm{St}]$} & Dax & Dax & Dax & Dax & Dax & Dax & Dax \\
\hline Salzgitter AG & & MDax & MDax & MDax & MDax & MDax & MDax & Dax \\
\hline SAP AG & & Dax & Dax & Dax & Dax & Dax & Dax & Dax \\
\hline SGL Carbon SE & & MDax & MDax & MDax & MDax & MDax & MDax & MDax \\
\hline Siemens AG & & Dax & Dax & Dax & Dax & Dax & Dax & Dax \\
\hline Singulus Technologies AG & & & TecDax & TecDax & TecDax & TecDax & TecDax & TecDax \\
\hline Sixt AG & {$[\mathrm{St}]$} & MDax & SDax & SDax & SDax & SDax & SDax & SDax \\
\hline Software AG & & MDax & TecDax & TecDax & TecDax & TecDax & TecDax & TecDax \\
\hline SolarWorld AG & & & & TecDax & TecDax & TecDax & TecDax & TecDax \\
\hline Solon SE & & & & & & TecDax & TecDax & TecDax \\
\hline Stada Arzneimittel AG & & MDax & MDax & MDax & MDax & MDax & MDax & MDax \\
\hline Südzucker AG & & MDax & MDax & MDax & MDax & MDax & MDax & MDax \\
\hline Takkt AG & & SDax & SDax & SDax & SDax & SDax & SDax & SDax \\
\hline ThyssenKrupp AG & & Dax & Dax & Dax & Dax & Dax & Dax & Dax \\
\hline TUI AG & & $\operatorname{Dax}$ & Dax & Dax & Dax & Dax & $\operatorname{Dax}$ & MDax \\
\hline United Internet AG & & & TecDax & TecDax & TecDax & TecDax & TecDax & TecDax \\
\hline VBH Holding AG & {$[\mathrm{St}]$} & & & & & & & \\
\hline Volkswagen AG & {$[\mathrm{St}]$} & Dax & Dax & Dax & Dax & Dax & Dax & Dax \\
\hline Vossloh AG & & MDax & MDax & MDax & MDax & MDax & MDax & MDax \\
\hline Wirecard AG & & & & & & TecDax & TecDax & TecDax \\
\hline
\end{tabular}


Anhang 5: Geschäftsjahre der Stichproben-Unternehmen

\begin{tabular}{|c|c|c|c|c|c|c|c|c|c|}
\hline \multicolumn{10}{|c|}{ Geschäftsjahres-Zeiträume der Stichproben-Unternehmen (Endtermine) } \\
\hline [Vor- / Rückverschiebung & GJ] & 2002 & 2003 & 2004 & 2005 & 2006 & 2007 & 2008 & Anmerkung \\
\hline Adidas AG & & 31.12 . & 31.12. & 31.12 . & 31.12 & 31.12 & 31.12 & 31.12 . & \\
\hline Aixtron AG & & 31.12 . & 31.12. & 31.12 . & 31.12. & 31.12. & 31.12. & 31.12 . & \\
\hline Arcandor AG & {$[+]$} & 31.12. & 31.12. & 31.12. & 31.12. & 31.12. & 30.09 . & 30.09 . & RGJ07 = GJ07 \\
\hline Aurubis AG & {$[+]$} & 30.09 . & 30.09 . & 30.09 . & 30.09 . & 30.09 . & 30.09 . & 30.09 . & \\
\hline Axel Springer AG & & 31.12 . & 31.12 . & 31.12 . & 31.12 . & 31.12 & 31.12 . & 31.12 . & \\
\hline BASF SE & & 31.12 . & 31.12 & 31.12 . & 31.12 . & 31.12 & 31.12 & 31.12 . & \\
\hline Baver AG & & 31.12 . & 31.12 & 31.12 . & 31.12 & 31.12 & 31.12 & 31.12 . & \\
\hline BayWa AG & & 31.12 . & 31.12 & 31.12 . & 31.12 & 31.12 & 31.12 . & 31.12 . & \\
\hline Bechtle AG & & 31.12 . & 31.12 & 31.12 . & 31.12 & 31.12 & 31.12 & 31.12 & \\
\hline Beiersdorf AG & & 31.12 . & 31.12. & 31.12 . & 31.12 & 31.12 & 31.12 & 31.12 . & \\
\hline Bertrandt AG & {$[+]$} & 30.09 . & 30.09 & 30.09 . & 30.09 & 30.09 & 30.09 . & 30.09 . & \\
\hline Bilfinger Berger AG & & 31.12 . & 31.12 & 31.12 . & 31.12 & 31.12 & 31.12 . & 31.12 . & \\
\hline Biotest AG & & 31.12 . & 31.12 & 31.12 . & 31.12 & 31.12 & 31.12 & 31.12 . & \\
\hline BMW AG & & 31.12 . & 31.12 & 31.12 . & 31.12 & 31.12 & 31.12 & 31.12 . & \\
\hline Carl Zeiss Meditec AG & {$[+]$} & 30.09 . & 30.09 . & 30.09 . & 30.09 & 30.09 & 30.09 & 30.09 & \\
\hline Celesio AG & & 31.12 . & 31.12 & 31.12 . & 31.12 & 31.12 & 31.12 & 31.12 . & \\
\hline Centrotec Sustainable AG & & 31.12 . & 31.12. & 31.12 . & 31.12 . & 31.12 & 31.12. & 31.12 . & \\
\hline CeWe Color Holding AG & & 31.12 . & 31.12 & 31.12 . & 31.12 & 31.12 . & 31.12 & 31.12 . & \\
\hline Continental AG & & 31.12 . & 31.12 & 31.12 . & 31.12 & 31.12 & 31.12 & 31.12 . & \\
\hline CTS Eventim AG & & 31.12 & 31.12 & 31.12 . & 31.12 & 31.12 & 31.12 & 31.12 . & \\
\hline Curanum AG & & 31.12 . & 31.12 & 31.12 . & 31.12 & 31.12 & 31.12 & 31.12 . & \\
\hline Daimler AG & & 31.12 . & 31.12 . & 31.12 . & 31.12 & 31.12 & 31.12 . & 31.12 . & \\
\hline Deutsche Lufthansa AG & & 31.12 . & 31.12 . & 31.12 . & 31.12 & 31.12 & 31.12 . & 31.12 . & \\
\hline Deutsche Post AG & & 31.12 . & 31.12 & 31.12 . & 31.12 & 31.12 . & 31.12 & 31.12 & \\
\hline Deutsche Telekom AG & & 31.12 . & 31.12 & 31.12 . & 31.12 & 31.12 & 31.12 & 31.12 & \\
\hline Deutz AG & & 31.12 & 31.12 & 31.12 & 31.12 & 31.12 & 31.12 & 31.12 . & \\
\hline Douglas Holding AG & {$[+]$} & 31.12 . & 30.09 . & 30.09 . & 30.09 & 30.09 & 30.09 . & 30.09 . & RGJ03 = GJ03 \\
\hline Drägerwerk $\mathrm{AG} \& \mathrm{Co} . \mathrm{KGaA}$ & & 31.12 . & 31.12 & 31.12 . & 31.12 . & 31.12 & 31.12 & 31.12 . & \\
\hline Dürr AG & & 31.12 . & 31.12. & 31.12 & 31.12 & 31.12 & 31.12 & 31.12 . & \\
\hline Dyckerhoff AG & & 31.12 . & 31.12 & 31.12 . & 31.12. & 31.12 & 31.12 & 31.12 . & \\
\hline E.On AG & & 31.12 . & 31.12 & 31.12 . & 31.12 & 31.12 & 31.12 & 31.12 & \\
\hline Elexis AG & & 31.12 . & 31.12 & 31.12 & 31.12 & 31.12 & 31.12 & 31.12 . & \\
\hline ElringKlinger AG & & 31.12 . & 31.12. & 31.12 . & 31.12 . & 31.12 & 31.12 . & 31.12 . & \\
\hline Escada AG & {$[+]$} & 31.10 . & 31.10 & 31.10 . & 31.10 & 31.10 & 31.10 & 31.10 . & \\
\hline Fielmann AG & & 31.12 & 31.12. & 31.12 . & 31.12 & 31.12 & 31.12 & 31.12 . & \\
\hline Fraport AG & & 31.12 & 31.12 & 31.12 & 31.12 . & 31.12 & 31.12 & 31.12 . & \\
\hline Fresenius Med. Care AG \& C & & 31.12 . & 31.12 & 31.12 . & 31.12 & 31.12 & 31.12 & 31.12 & \\
\hline Fresenius SE & & 31.12 . & 31.12 & 31.12 . & 31.12 & 31.12 & 31.12 . & 31.12 & \\
\hline Fuchs Petrolub AG & & 31.12 . & 31.12 . & 31.12 . & 31.12 & 31.12 . & 31.12 . & 31.12 . & \\
\hline GEA Group AG & {$[+]$} & 30.09 . & 31.12 & 31.12 . & 31.12 & 31.12 & 31.12 & 31.12 . & RGJ02 o.W. \\
\hline Gerry Weber Intl. AG & {$[+]$} & 31.10 . & 31.10 & 31.10 . & 31.10 & 31.10 . & 31.10 & 31.10 . & \\
\hline Gesco AG & {$[-]$} & 31.03 . & 31.03 . & 31.03 . & 31.03 . & 31.03 . & 31.03 & 31.03 . & \\
\hline GfK SE & & 31.12 . & 31.12 & 31.12 . & 31.12 & 31.12 & 31.12 & 31.12 & \\
\hline Gildemeister AG & & 31.12 . & 31.12. & 31.12 . & 31.12 & 31.12 . & 31.12 . & 31.12 & \\
\hline Grammer AG & & 31.12 . & 31.12. & 31.12 . & 31.12 & 31.12 . & 31.12 . & 31.12 . & \\
\hline H \& R Wasag AG & & 31.12 . & 31.12 & 31.12 . & 31.12 & 31.12 & 31.12 . & 31.12 & \\
\hline HeidelbergCement AG & & 31.12 . & 31.12 & 31.12 & 31.12 & 31.12 & 31.12 . & 31.12 . & \\
\hline Heidelberger Druck AG & {$[-]$} & 31.03 . & 31.03 & 31.03 . & 31.03 . & 31.03 . & 31.03 . & 31.03 . & \\
\hline Henkel AG \& Co. KGaA & & 31.12 . & 31.12 . & 31.12 . & 31.12 & 31.12 & 31.12 . & 31.12 . & \\
\hline Hochtief AG & & 31.12 . & 31.12. & 31.12 . & 31.12 & 31.12 . & 31.12 & 31.12 & \\
\hline
\end{tabular}


Anhang 5: Geschäftsjahre der Stichprobe (Forts.)

\begin{tabular}{|c|c|c|c|c|c|c|c|c|c|}
\hline \multicolumn{10}{|c|}{ Geschäftsjahres-Zeiträume der Stichproben-Unternehmen (Endtermine) } \\
\hline [Vor- / Rückverschiebung & $\mathrm{GJ}]$ & 2002 & 2003 & 2004 & 2005 & 2006 & 2007 & 2008 & Anmerkung \\
\hline Hugo Boss AG & & 31.12 . & 31.12 . & 31.12 . & 31.12 . & 31.12 . & 31.12 . & 31.12 . & \\
\hline IDS Scheer AG & & 31.12. & 31.12 . & 31.12. & 31.12 . & 31.12. & 31.12. & 31.12 . & \\
\hline Infineon Technologies AG & {$[+]$} & 30.09 . & 30.09 . & 30.09 . & 30.09 . & 30.09 . & 30.09 . & 30.09 . & \\
\hline Jenoptik AG & & 31.12. & 31.12. & 31.12 . & 31.12 . & 31.12 . & 31.12 . & 31.12 & \\
\hline Jungheinrich AG & & 31.12 . & 31.12. & 31.12 . & 31.12 . & 31.12. & 31.12. & 31.12 & \\
\hline $\mathrm{K}+\mathrm{S} A \mathrm{AG}$ & & 31.12 . & 31.12. & 31.12. & 31.12 . & 31.12 . & 31.12. & 31.12. & \\
\hline Koenig \& Bauer AG & & 31.12 . & 31.12 & 31.12 & 31.12 & 31.12 & 31.12 & 31.12 . & \\
\hline Kontron AG & & 31.12 & 31.12 & 31.12 . & 31.12 & 31.12 . & 31.12 . & 31.12 . & \\
\hline Krones AG & & 31.12 . & 31.12 . & 31.12 . & 31.12 . & 31.12 . & 31.12 . & 31.12 & \\
\hline Kuka AG & & 31.12 & 31.12 . & 31.12. & 31.12 . & 31.12 & 31.12 . & 31.12. & \\
\hline KWS Saat AG & {$[+]$} & 30.06 & 30.06 . & 30.06 & 30.06 . & 30.06 & 30.06 & 30.06 & Grenzfall \\
\hline Leoni AG & & 31.12 & 31.12 . & 31.12 . & 31.12 . & 31.12 . & 31.12 . & 31.12 & \\
\hline Linde AG & & 31.12 & 31.12 & 31.12 & 31.12 & 31.12 & 31.12 & 31.12 & \\
\hline Loewe AG & & 31.12 . & 31.12 . & 31.12 . & 31.12 . & 31.12 & 31.12 . & 31.12 & \\
\hline MAN SE & & 31.12 & 31.12 . & 31.12 . & 31.12 . & 31.12 & 31.12. & 31.12. & \\
\hline MediGene AG & & 31.12 & 31.12 . & 31.12 . & 31.12 . & 31.12 & 31.12. & 31.12 & \\
\hline Medion AG & & 31.12 . & 31.12 & 31.12 . & 31.12 & 31.12 . & 31.12 . & 31.12 . & \\
\hline Merck KGaA & & 31.12 . & 31.12 . & 31.12 . & 31.12 & 31.12 & 31.12 . & 31.12 . & \\
\hline Metro AG & & 31.12 . & 31.12 & 31.12 . & 31.12 . & 31.12 . & 31.12 & 31.12 . & \\
\hline MorphoSys AG & & 31.12. & 31.12. & 31.12. & 31.12 . & 31.12 & 31.12. & 31.12 & \\
\hline MVV Energie AG & {$[+]$} & 30.09 & 30.09 . & 30.09 & 30.09 . & 30.09 . & 30.09 & 30.09 . & \\
\hline Nordex AG & {$[+]$} & 30.09 . & 30.09 . & 31.12 & 31.12 . & 31.12. & 31.12. & 31.12 & RGJ03 o.W. \\
\hline Pfeiffer Vacuum Technology & & 31.12 . & 31.12 . & 31.12 & 31.12 . & 31.12 . & 31.12 . & 31.12 & \\
\hline Pfleiderer AG & & 31.12 & 31.12 . & 31.12 . & 31.12 . & 31.12. & 31.12. & 31.12. & \\
\hline ProSiebenSat.1 Media AG & & 31.12 & 31.12 . & 31.12. & 31.12 . & 31.12 & 31.12. & 31.12. & \\
\hline Puma AG & & 31.12 . & 31.12 & 31.12. & 31.12 . & 31.12 . & 31.12 . & 31.12 . & \\
\hline QSC AG & & 31.12 . & 31.12 . & 31.12 . & 31.12 . & 31.12 . & 31.12 . & 31.12 . & \\
\hline Rational AG & & 31.12 & 31.12 . & 31.12. & 31.12 . & 31.12. & 31.12. & 31.12. & \\
\hline Rheinmetall AG & & 31.12. & 31.12 . & 31.12. & 31.12 . & 31.12. & 31.12. & 31.12. & \\
\hline Rhön-Klinikum AG & & 31.12. & 31.12 . & 31.12. & 31.12 . & 31.12 & 31.12. & 31.12. & \\
\hline RWE AG & & 31.12 & 31.12 . & 31.12. & 31.12 . & 31.12 & 31.12 . & 31.12 . & \\
\hline Salzgitter AG & & 31.12. & 31.12 . & 31.12. & 31.12 . & 31.12 & 31.12 . & 31.12 & \\
\hline SAP AG & & 31.12 . & 31.12 . & 31.12. & 31.12 . & 31.12 & 31.12. & 31.12 & \\
\hline SGL Carbon SE & & 31.12. & 31.12 . & 31.12. & 31.12 . & 31.12 & 31.12 & 31.12. & \\
\hline Siemens AG & {$[+]$} & 30.09 & 30.09 . & 30.09 & 30.09 . & 30.09 & 30.09 & 30.09 . & \\
\hline Singulus Technologies AG & & 31.12 . & 31.12 . & 31.12 . & 31.12 & 31.12 . & 31.12 . & 31.12 . & \\
\hline Sixt AG & & 31.12 . & 31.12 . & 31.12 & 31.12 . & 31.12 . & 31.12 . & 31.12 . & \\
\hline Software AG & & 31.12 & 31.12 . & 31.12. & 31.12 . & 31.12 & 31.12 & 31.12. & \\
\hline SolarWorld AG & & 31.12 & 31.12 . & 31.12. & 31.12 . & 31.12. & 31.12 & 31.12 & \\
\hline Solon SE & & 31.12 & 31.12 & 31.12 . & 31.12 . & 31.12 & 31.12 . & 31.12. & \\
\hline Stada Arzneimittel AG & & 31.12 . & 31.12 & 31.12 . & 31.12 . & 31.12 & 31.12 . & 31.12 . & \\
\hline Südzucker AG & {$[-]$} & 28.02 & 29.02 . & 28.02. & 28.02 . & 28.02 & 29.02. & 28.02 & \\
\hline Takkt AG & & 31.12. & 31.12 . & 31.12 . & 31.12 . & 31.12 & 31.12 . & 31.12 . & \\
\hline ThyssenKrupp AG & {$[+]$} & 30.09 . & 30.09 . & 30.09 . & 30.09 . & 30.09 & 30.09 & 30.09 & \\
\hline TUI AG & & 31.12 & 31.12 . & 31.12. & 31.12 . & 31.12 & 31.12 . & 31.12 & \\
\hline United Internet AG & & 31.12 & 31.12 . & 31.12 . & 31.12 . & 31.12. & 31.12. & 31.12 & \\
\hline VBH Holding AG & & 31.12. & 31.12. & 31.12. & 31.12 . & 31.12. & 31.12. & 31.12. & \\
\hline Volkswagen AG & & 31.12 . & 31.12 & 31.12 & 31.12 & 31.12 . & 31.12 . & 31.12 . & \\
\hline Vossloh AG & & 31.12 . & 31.12 & 31.12 & 31.12 & 31.12 . & 31.12 . & 31.12 . & \\
\hline Wirecard AG & & 31.12 & 31.12 & 31.12. & 31.12 . & 31.12 . & 31.12 . & 31.12 . & \\
\hline
\end{tabular}




\section{Anhang 6: Untersuchungsbogen zur Erhebung der SDScores}

\section{Strategieorientierte Berichterstattung im Lagebericht deutscher Aktiengesellschaften}

\section{Empirische Betrachtung}

Untersuchungsbogen zur Analyse der strategicorientierten Berichterstattung deutscher Aktiengesellschaften im Lagebericht

(Version: I)taillierte Berichtsanforderungen)

\section{Bearbeitungshinweise auf Seite 7 beachten!}

Gießen, 01.10 .2009 


\section{Anhang 6: Untersuchungsbogen (Seite 1/7)}

Untersuchungsbogen

Allgemeine Angaben

\begin{tabular}{|l|l|l|l|}
\hline Unternchmen & ID & \\
\hline $\begin{array}{l}\text { Geschäftsbericht } \\
\text { (Geschäftsjahr Unternehmen) }\end{array}$ & & $\begin{array}{l}\text { Geschäftsjahr } \\
\text { (Untersuchung) }\end{array}$ & \\
\hline Titel des Geschäftsberichts & & & \\
\hline
\end{tabular}

\begin{tabular}{|l|l|}
\hline Zeichnender CEO $/$ AR & \\
\hline $\begin{array}{l}\text { Rechnungsstandard } \\
\text { (Konzernabschluss) }\end{array}$ & \\
\hline Bestätigender Prüfer & \\
\hline
\end{tabular}

\begin{tabular}{|l|l|l|l|l|}
\hline Gliederung & Nr. & $\begin{array}{l}\text { Bezeichnung } \\
\text { (2. Ebene, falls, Strategie' explizit genannt) }\end{array}$ & $\begin{array}{l}\text { Seiten } \\
\text { (von / bis) }\end{array}$ & \\
\hline 1. & & \\
\hline 2. & & & \\
\hline 3. & & & \\
\hline 4. & & & \\
\hline 5. & & & \\
\hline 6. & & & \\
\hline 7. & & & \\
\hline 8 & 9 & & \\
\hline 10 & & & \\
\hline
\end{tabular}

\begin{tabular}{|c|c|c|c|}
\hline \multirow{6}{*}{$\begin{array}{l}\text { Berichtete Segmente } \\
\text { („Geschäftssegmente") } \\
\text { [Maßgebliche Segmente: Nach } \\
\text { Große geordnet, kamuliert } \\
\text { ca. } 80 \% \text { des Konzemumsatzes] }\end{array}$} & Nr. & $\begin{array}{l}\text { Bezeichnung } \\
\text { (wie im Original) }\end{array}$ & $\begin{array}{l}\text { Umsatz } \\
(€ \text { Mrd })\end{array}$ \\
\hline & 1. & & \\
\hline & 2. & & \\
\hline & 3. & & \\
\hline & 4. & & \\
\hline & 5. & & \\
\hline
\end{tabular}




\section{Anhang 6: Untersuchungsbogen (Seite 2/7)}

\section{Informationen der strategischen Analyse}

\section{Allgemeine Rahmenbedingungen}

\begin{tabular}{|c|c|c|c|c|}
\hline \multirow{3}{*}{$\begin{array}{l}\text { Gesamt- } \\
\text { unter- } \\
\text { nehmen }\end{array}$} & 1. & Sozio-ökonomische / politisch-rechtliche Rahmenbedingungen & Pkt. ${ }^{\prime}$ & Stelle $^{2}$ \\
\hline & 1.1 & $\begin{array}{l}\text { Beschreibung des relevanten Ausschnitts der Umwelt } \\
\text { [insb. Nenmung der für das Untemehmen we.sentlichen Regionen und } \\
\text { politischer bzw. gesellschaflicher Rahmenbedingungen mit Einfluss } \\
\text { auf Geschaftstatigkeit (z.B. Klimawandel, Energieeffizienz)] }\end{array}$ & & \\
\hline & 1.2 & $\begin{array}{l}\text { Annahmen zur küftigen Entwicklung der relevanten Umwelt } \\
\text { [langfristige Orientienung der Vorhersage der künftigen Entwicklung, } \\
\text { d.h. über aktuelle Periode hinaus] }\end{array}$ & & \\
\hline
\end{tabular}

\begin{tabular}{|l|l|l|l|l|}
\hline $\begin{array}{l}\text { Gesamt- } \\
\text { unter- } \\
\text { nehmen }\end{array}$ & 2. & Makroökonom ische Rahmenbedingungen & Plt. & Stelle \\
\cline { 2 - 5 } & $\mathbf{2 . 1}$ & $\begin{array}{l}\text { Beschreibung relevanter makroökonom ischer Bereiche / Regionen } \\
\text { linsb. Nenmung Weltregionen, in denen Gesamtuntemehmen tätig ist } \\
\text { und Beschreibung der gegenwärtigen makrookonomischen } \\
\text { Bedingungen tund Einflussfaktoren in diesen Regionen / Staaten] }\end{array}$ & $\begin{array}{l}\text { Annahmen des Unternehmens zur künftigen Entwicklung der } \\
\text { makroökonomischen Rahmenbedingungen in relevanten Regionen } \\
\text { [langfristige Orientienung, 2.B. unter Bezugnahme auf Vorhersagen } \\
\text { von Wirtschaftsforschungsinstituten, Angabe der eigenen Pramissen] }\end{array}$ & \\
\cline { 2 - 5 } & $\mathbf{2 . 2}$ & & \\
\hline
\end{tabular}

\begin{tabular}{|l|l|l|l|l|}
\hline $\begin{array}{l}\text { Gesamt- } \\
\text { unter- } \\
\text { nehmen }\end{array}$ & $\mathbf{3 .}$ & Strategische Ausgangslage Gesamtunternehmen & Pkt. & Stelle \\
\cline { 2 - 5 } $\begin{array}{l}\text { (Nur } \\
\text { für Multi- } \\
\text { segmentfall) }\end{array}$ & $\mathbf{3 . 1}$ & $\begin{array}{l}\text { Beschreibung der wirtschaftichen Lage des Gesamtunternehmens } \\
\text { [Kurzdarstelling Vermogens-, Finanz- und Ertragslage, prägnante } \\
\text { Beschreibung des Status quo als strategische Ausgangslage] }\end{array}$ & $\begin{array}{l}\text { Beschreibung der bestehenden Konzernstruktur und des Geschäfts- } \\
\text { segmentsportfolios sowie der Geschäftstátigkeit je Segment } \\
\text { [detaillierte Darstellung der einzelnen (relevanten) Geschafte inner- } \\
\text { halb des Gesamtuntemehmens, reine Nennung hier unzureichend] }\end{array}$ & \\
\cline { 2 - 5 } & & & & \\
\hline
\end{tabular}

\begin{tabular}{|l|l|l|l|l|}
\hline Score & I & Allgemeine Rahmenbedingungen & & 16 \\
\hline
\end{tabular}

Bewertung der jeweiligen Inhaltc, grds. maximal 1 Punkt : Kriterium Angabe der Seitenzahl im Lagebericht 


\section{Anhang 6: Untersuchungsbogen (Seite 3/7)}

\section{Geschăftsspezifische Rahmenbedingungen}

\begin{tabular}{|c|c|c|c|c|c|}
\hline \multirow{6}{*}{$\begin{array}{l}\text { Geschäfts- } \\
\text { segment } \\
\text { (Für jedes } \\
\text { maßgebliche } \\
\text { Segment) }\end{array}$} & 1. & Marktumfeld & Segmente ${ }^{3}$ & Pkt. & Stelle \\
\hline & 1.1 & $\begin{array}{l}\text { Beschreibung relevanter Markt / Marktabgrenzung } \\
\text { [insb. pragnante Darstelling der Kemleistungen des } \\
\text { Untemehmens, der adressierten Marktsegmente und } \\
\text { der jeweiligen Zielkanden in den Marktsegmenten] }\end{array}$ & & & \\
\hline & 1.2 & $\begin{array}{l}\text { Quantifizierung des Marktvolumens im Status quo } \\
\text { [je Marktsegment, auf Basis Stackzahlen / Wert] }\end{array}$ & & & \\
\hline & 13 & $\begin{array}{l}\text { Annahmen zur künftigen Entwicklung der Mârkte } \\
\text { [z.B. neue Technologien (Substitutionsgefahr?)] }\end{array}$ & & & \\
\hline & 1.4 & $\begin{array}{l}\text { Verdichtung zu wesentlichen Kern-Entwicklungen in } \\
\text { den einzelnen Märkten [z.B. relevante Schlisseltrends] }\end{array}$ & & & \\
\hline & 1.5 & $\begin{array}{l}\text { Quantifizierung der kùnftigen Marktentwicklung } \\
\text { [Basis Stuckzahlen / Wert, langfristige Orientierung] }\end{array}$ & & & \\
\hline \multirow{6}{*}{$\begin{array}{l}\text { Geschäfts- } \\
\text { segment } \\
\text { (Far jedes } \\
\text { maß̧gebliche } \\
\text { Segment) }\end{array}$} & 2. & Wettbewerbsumfeld & Segmente & Pkt. & Stelle \\
\hline & 2.1 & $\begin{array}{l}\text { Beschreibung relevantes Wettbewerbsumfeld } \\
\text { [insb. Nenming Kem-Wettbewerber, strateg. Gnuppen] }\end{array}$ & & & \\
\hline & 2.2 & $\begin{array}{l}\text { Quantifizierung des aktuellen Wettbewerbsumfeld in } \\
\text { Bezug auf Kern-Wettbewerb [zB. eigener Marktanteil] }\end{array}$ & & & \\
\hline & 2.3 & $\begin{array}{l}\text { Beschreibung gegenwärtige Bedingungen des Wettbe- } \\
\text { werbs, insb. Intensität des Wettbewerbs [i.V.m. II.2.5] }\end{array}$ & & & \\
\hline & 2.4 & $\begin{array}{l}\text { Beschreibung Eintrittsbarrieren fur neue Wettbewerber } \\
\text { sowie zentrale Erfolgsfaktoren im Wettbewerb }\end{array}$ & & & \\
\hline & 2.5 & $\begin{array}{l}\text { Annahmen zur Entwicklung des Wettbewerbsumfeldes } \\
\text { [z.B. kunftige Bedingungen, Intensitat, neue Anbieter] }\end{array}$ & & & \\
\hline
\end{tabular}

\begin{tabular}{|c|c|c|c|c|c|}
\hline \multirow{5}{*}{$\begin{array}{l}\text { Geschäfts- } \\
\text { segment } \\
\text { (Fûr jedes } \\
\text { maßgebliche } \\
\text { Segment) }\end{array}$} & 3. & Strategische Ausgangslage Geschäftsegment & Segmente & Pkt. & Stelle \\
\hline & 3.1 & $\begin{array}{l}\text { Beschreibung wirtschaftliche Lage des Segments } \\
\text { [in Erganzung zu I.3.1, jedoch spezifisch je Segment] }\end{array}$ & & & \\
\hline & 3.2 & $\begin{array}{l}\text { Beschreibung Position des Segments im Wetthewerb } \\
\text { [z.B. eigener Wettbewerbsvorteil bzw. Differenzienang] }\end{array}$ & & & \\
\hline & 3.3 & $\begin{array}{l}\text { Beschreibung zentrale Kompetenzen des Geschäfts- } \\
\text { segments mit Relevanz für Wettbewerbserfolg }\end{array}$ & & & \\
\hline & 3.4 & $\begin{array}{l}\text { Beschreibung wesentlicher Ressourcen als Fundament } \\
\text { der Kompetenzen [z.B. eigener Technologievorspning] }\end{array}$ & & & \\
\hline
\end{tabular}

\begin{tabular}{|l|l|l|l|l|}
\hline Score & II & Geschäftsspezifische Rahmenbedingungen & & $/ 14$ \\
\hline
\end{tabular}

3 Bezeichnung der Segmente, für die eine Angabe erfolgt 


\section{Anhang 6: Untersuchungsbogen (Seite 4/7)}

\section{Angaben zur Strategieformulierung}

\section{Unternehmensstrategie}

\begin{tabular}{|c|c|c|c|c|}
\hline \multirow{3}{*}{$\begin{array}{l}\text { Gesamt- } \\
\text { unter- } \\
\text { nehmen }\end{array}$} & 1. & Unternehmensstrategische Richtschnur & Pkt. & Stelle \\
\hline & 1.1 & $\begin{array}{l}\text { Angabe der Vision des Gesamtuntemehmens } \\
\text { [nicht unbedingt als, Vision' bezeichnet, jedoch besonders hervorge- } \\
\text { hobene, prägnante Darstellung des sehr langfristig angestrebten Ent- } \\
\text { wicklungsziels des Gesamtuntemehmens (langfristiger Ziel-Zustand)] }\end{array}$ & & \\
\hline & 1.2 & $\begin{array}{l}\text { Angabe der Mission / Unternehmensleitbild } \\
\text { Inicht unbedingt als, Mission' oder , Leitbild' bezeichnet, jedoch } \\
\text { pragnante Darstellung des Selbstverstandnisses des Lintemehmens } \\
\text { und der gnundsátzlichen Eckpfeiler der Geschäftstatigkeit] }\end{array}$ & & \\
\hline
\end{tabular}

\begin{tabular}{|c|c|c|c|c|}
\hline \multirow{4}{*}{$\begin{array}{l}\text { Gesamt- } \\
\text { unter- } \\
\text { nehmen } \\
\text { (Nur } \\
\text { für Multi- } \\
\text { segmentfall) }\end{array}$} & 2. & Formulierung Unternehmensstrategie & Pkt. & Stelle \\
\hline & 2.1 & $\begin{array}{l}\text { Beschreibung strategischer Entwicklungsziele Gesamtunternehmen } \\
\text { [Darstellung konkreter strategischer Ziele des Gesamtintemehmens, } \\
\text { z.B. .Positionienang als weltweit fïhrender Sportartike Lhersteller“] }\end{array}$ & & \\
\hline & 2.2 & $\begin{array}{l}\text { Quantifizierung der langfristigen Umsatzentwicklung } \\
\text { [Angabe konkreter Umsatzziele, Zielkorridor oder Wachstumsgroßen, } \\
\text { jedoch Prognose mindestens uber aktuelle Periode hinaus] }\end{array}$ & & \\
\hline & 2.3 & $\begin{array}{l}\text { Quantifizierung der langfristigen Ergebnisentwicklung } \\
\text { [Angabe konkreter Ergebnisziele (beliebige Ergebnisgroße ab } \\
\text { EBITDA), Zielkorridor oder Wachstumsgroßen, auch Margengroßen } \\
\text { moglich, jedoch Prognose mindestens iber aktuelle Periode hinaus] }\end{array}$ & & \\
\hline
\end{tabular}

\begin{tabular}{|l|l|l|l|l|}
\hline Score & III & Unternehmensstrategie & & 15 \\
\hline
\end{tabular}




\section{Anhang 6: Untersuchungsbogen (Seite 5/7)}

\section{Geschäftsstrategie}

\begin{tabular}{|c|c|c|c|c|c|}
\hline \multirow{4}{*}{$\begin{array}{l}\text { Geschäfts- } \\
\text { segment } \\
\text { (Für jedes } \\
\text { maßgebliche } \\
\text { Segment) }\end{array}$} & 1. & Formulierung Geschäftsstrategie & Seganente & Pkt. & Stelle \\
\hline & 1.1 & $\begin{array}{l}\text { Beschreibung der strategischen Entwicklungsziele } \\
\text { [siehe III.2.1, jedoch spezifisch fur ein Segment] }\end{array}$ & & & \\
\hline & 1.2 & $\begin{array}{l}\text { Quantifizierung der langfristigen Umsatzentwicklung } \\
\text { [siehe III.2.2, jedoch spezifisch fur ein Segment] }\end{array}$ & & & \\
\hline & 1.3 & $\begin{array}{l}\text { Quantifizierung der langfristigen Ergebnisentwicklung } \\
\text { [siehe III.2.3, jedoch spezifisch fur ein Segment] }\end{array}$ & & & \\
\hline
\end{tabular}

\begin{tabular}{|c|c|c|c|c|c|}
\hline \multirow{8}{*}{$\begin{array}{l}\text { Geschäfts- } \\
\text { segment } \\
\text { (Fur jedes } \\
\text { maßgebliche } \\
\text { Segment) }\end{array}$} & 2. & Konkretisierung Geschäftstrategie (Produkt-Markt) & Segmente & Pkt. & Stelle \\
\hline & 2.1 & $\begin{array}{l}\text { Beschreibung strategische Positionienung des Segments } \\
\text { [insb. angestrebte Position im Wettbewerb, Ziel- } \\
\text { Wahrnehmung der Kunden, Differenzierung des Seg- } \\
\text { ments vom Wettbewerb (,Unique Selling Proposition')] }\end{array}$ & & & \\
\hline & 2.2 & $\begin{array}{l}\text { MARKT - Beschreibung strategischer Kernmärkte } \\
\text { [insb. Darstellung der wesentlichen Markte (regionale } \\
\text { oder kandenspezifische Abgrenzung), die adressiert } \\
\text { werden; ggf. Angaben zur spezifischen Positionienng] }\end{array}$ & & & \\
\hline & 2.3 & $\begin{array}{l}\text { MARKT - Beschreibung künttiger Schwerpunkte } \\
\text { [insb. Angabe der kianftig zu adressierenden Markte } \\
\text { (regional / zielgruppenorientiert), Begnïndung für neue } \\
\text { Markte, kurze Beschreibung geplante Markteintritts- } \\
\text { strategie inkl. Hintergnundiberlegung dieser Strategie] }\end{array}$ & & & \\
\hline & 2.4 & $\begin{array}{l}\text { LEISTUNG - Beschreibung der Kernleistungen } \\
\text { [insb. Darstellung der strategisch fokussierten } \\
\text { Produkte und Dienstleistungen je Segment, mit welchen } \\
\text { die Umsatz- und Ergebnisziele erreicht werden sollen] }\end{array}$ & & & \\
\hline & 2.5 & $\begin{array}{l}\text { LEISTUNG - Beschreibung neue Geschafte bzw. } \\
\text { Forschungs- \& Entwicklungsfokus / -aktivităten } \\
\text { [z.B. strategische Schwerptenkte der Ausweitung des } \\
\text { Angebotsportfolios, Begnindung fur neue Leistungen } \\
\text { (Kundennutzen, Nachfrageverschiebung, etc.), Hinweis } \\
\text { auf entsprechende Entwicklungs-/ Aufbauaktivitaten] }\end{array}$ & & & \\
\hline & 2.6 & $\begin{array}{l}\text { Beschreibung wesentlicher Investitionsschwerpunkte } \\
\text { zur Erreichung strategischer Ziele (auch ggf. M\&A) } \\
\text { [z.B. Aufbau von Standort in neuem regionalen Markt, } \\
\text { Modemisienung Fertigung / Anlagenmodemisierung, } \\
\text { Erganzung Technologieportfolio durch Akquisition] }\end{array}$ & & & \\
\hline & 2.7 & $\begin{array}{l}\text { Beschreibung der küntigen Wertschöpfungsstrategie } \\
\text { (insb. Darstellung Schwerptonkte der Wertschopfing } \\
\text { (z.B. Einkauf. Produktion, Distribution / Logistik) so- } \\
\text { wie der kiinftigen Ausrichtung der eigenen Leistungs- } \\
\text { erbringung (z.B. Ausbau Einkaufsanteil LCC, Neubau } \\
\text { Werk in LCC. Restrukturienung Werksverbund, etc.) }\end{array}$ & & & \\
\hline
\end{tabular}

\begin{tabular}{|l|l|l|l|l|}
\hline Score & IV & Geschãftsstrategie & & $/ 10$ \\
\hline
\end{tabular}




\section{Anhang 6: Untersuchungsbogen (Seite 6/7)}

\section{Angaben zur Strategieimplementierung}

\section{Implementierung: Umsetzung und Durchsetzung}

\begin{tabular}{|c|c|c|c|c|}
\hline \multirow{3}{*}{$\begin{array}{l}\text { Gesamt- } \\
\text { unter- } \\
\text { nehmen }\end{array}$} & 1. & Durchsetzung von Strategien & Pkt. & Stelle \\
\hline & 1.1 & $\begin{array}{l}\text { Beschreibung unternehmensweites Steuerungssystem und verwendete } \\
\text { Spitzenkennzahlen } \\
\text { [insb. Ist- und Planwerte aber aktuelle Periode hinaus; Einfluss der } \\
\text { Stralegie / strategischer Zielsetzungen auf das Steuerungssystem bzw. } \\
\text { Bericksichtigung von Strategien innerhalb des Systems] }\end{array}$ & & \\
\hline & 1.2 & $\begin{array}{l}\text { Relevanz der Strategie bzw. strategischer Zielsetzungen in } \\
\text { individuellen Zielvereinbarungen des Managements } \\
\text { [insb. Angaben zur Beriacksichtigung von strategischen Zielsetzungen } \\
\text { in individuellen Zielvereinbarungen sowie Entlohmungsanteile für } \\
\text { Mitarbeit an strategischen Programmen, Aussage zur langfristigen } \\
\text { Orientienung des untemehmensweiten Steuenungs-/Anreizsystems] }\end{array}$ & & \\
\hline
\end{tabular}

\begin{tabular}{|c|c|c|c|c|}
\hline \multirow{4}{*}{$\begin{array}{l}\text { Gesamt- } \\
\text { unter- } \\
\text { nehmen } \\
\text { (Umsetzungs- } \\
\text { fokus jedoch } \\
\text { im Segment) }\end{array}$} & 2. & Umsetzung von Strategien & Pkt. & Stelle \\
\hline & 2.1 & $\begin{array}{l}\text { Prägnante, verdichtete Darstellung der strategischen Entwicklungs- } \\
\text { ziele des Gesamtunternchmens bzw. der Geschäftssegmente } \\
\text { [z.B. Name des Strategieprogramms, Ziele in Stichpunkten etc., Kem- } \\
\text { Verantwortlichkeiten im Top-Management] }\end{array}$ & & \\
\hline & 2.2 & $\begin{array}{l}\text { Beschreibung wesentlicher Maßnahmen / Maßnahmenprogramme } \\
\text { zur Umsetzung der formulierten Strategie }\end{array}$ & & \\
\hline & 2.3 & $\begin{array}{l}\text { Beschreibung Status bercits laufender Strategieprogramme sowic } \\
\text { umgesetzter Maßnahmen (-pakete) } \\
\text { [insb. Status der Zielemeichtong. Kommentienung der urspninglichen } \\
\text { Zielsetzıng sowie Begrindung fiur Erreichen / Nicht-Erreichen] }\end{array}$ & & \\
\hline
\end{tabular}

\begin{tabular}{|l|l|l|l|l|}
\hline Score & V & Strategieimplementierung & & 15 \\
\hline
\end{tabular}

\section{Gesamtergebnis}

\begin{tabular}{|l|l|l|l|l|}
\hline Score & I & Strategische Analyse: Allgemeine Rahmenbedingungen (15\%) & $/ 6$ \\
\hline Score & II & Strategische Analyse: Geschäftsspezifischer Rahmen (35\%) & $/ 14$ \\
\hline Score & III & Strategieformulierung: Unternchmensstrategic (12,5\%) & $/ \mathbf{5}$ \\
\hline Score & IV & Strategieformulierung: Geschăftsstrategie (25\%) & $/ 10$ \\
\hline Score & V & Strategieimplementierung $(12,5 \%)$ & $1 \mathbf{5}$ \\
\hline
\end{tabular}

\begin{tabular}{|l|l|l|l|}
\hline Gesamtscore & Strategieberichterstattung (100\%) & & $/ 40$ \\
\hline
\end{tabular}




\section{Anhang 6: Untersuchungsbogen (Seite 7/7)}

\section{Bearbeitungshinweise}

- Dieser Untersuchungsbogen dient der Untersuchung der Berichterstattung deutscher Aktiengesellschaften zu strategieorientierten Aspekten

- Der Untersuchungsbogen bildet einen normativen Berichtskatalog ab, der diejenigen inhaltlichen Anforderungen enthält, uber die zu berichten wăre, um ein umfassendes strategisches Profil eines Unternehmens zu zeichnen

- Zielmedium der Untersuchung sind die publizierten Geschäftsberichte der Unternehmen, spezifisch die Lageberichte

- Lüne Bewertung erfolgt ausschließlich für diejenigen Informationen, die im Lagebericht enthalten sind

- Jedes inhaltliche Kriterium wird grds. mit einem Punkt bewertet, sofern die Berichtsanforderung erfüllt wird

- Bereitgestellte Inhalte werden grds. nur einmal bewertet, mehrfache Punktvergabe aufgrund wiederholter Darstellung ist ausgeschlossen

- Bewertet werden zudem nur solche Informationen, deren zeitlicher Bezug uber die abgeschlossene Periode hinausgeht, d.h. prospektiven Charakter besitzen

- Einzelne Berichtsanforderungen beziehen sich auf Geschäftssegmente, es gilt daher:

- Monosegmentunternehmen: I.3 sowic III.2 ohne Wertung, maximal mögliche Gesamtpunktzahl daher 35 Punkte (statt 40 Punkte)

- Multisegmentuntemehmen: Die Berichtsanforderungen aus II und IV mussen für alle malßgeblichen Segmente einzeln erfullt werden. Die Gesamtzahl der Punkte wird durch die Anzahl der Segmente dividiert. Falls grundlegende Entwicklungen für mehrere Segmente gultig sind, ist eine zusammenfassende Darstellung ausreichend 


\section{Anhang 7-1: Ermittelte SDScores der Stichproben-Unternehmen}

\begin{tabular}{|c|c|c|c|c|c|c|c|c|}
\hline \multicolumn{9}{|c|}{ Ermittelte Werte des Strategy Disclosure Index für die einzelnen Jahre des Untersuchungszeitraumes } \\
\hline [SDScores normiert, $\{0 ; 1\}]$ & 2002 & 2003 & 2004 & 2005 & 2006 & 2007 & 2008 & Tendenz \\
\hline Adidas AG & 0.23 & 0.35 & 0.28 & 0.38 & 0.60 & 0.65 & 0.55 & +-+++ \\
\hline Aixtron AG & 0.20 & 0.20 & 0.23 & 0.29 & 0.34 & 0.37 & 0.43 & $=+++++$ \\
\hline Arcandor AG & 0.45 & 0.50 & 0.45 & 0.45 & 0.30 & 0.28 & 0.18 & $+-=--$ \\
\hline Aurubis AG & 0.45 & 0.48 & 0.48 & 0.48 & 0.63 & 0.45 & 0.45 & $+==+-=$ \\
\hline Axel Springer AG & 0,30 & 0,20 & 0,30 & 0.25 & 0,33 & 0.40 & 0,58 & -+-+++ \\
\hline BASF SE & 0.43 & 0.48 & 0.53 & 0.53 & 0.55 & 0.68 & 0.48 & $++=++-$ \\
\hline Baver AG & 0.35 & 0.48 & 0.48 & 0.48 & 0.55 & 0.60 & 0.50 & $+==++-$ \\
\hline BavWa AG & 0.18 & 0.15 & 0.18 & 0.20 & 0.20 & 0.18 & 0.33 & $-++=-+$ \\
\hline Bechtle AG & 0.15 & 0.15 & 0.20 & 0.25 & 0.23 & 0.40 & 0,33 & $=++-+-$ \\
\hline Beiersdorf AG & 0.28 & 0.25 & 0.23 & 0.30 & 0.33 & 0.35 & 0.35 & $--+++=$ \\
\hline Bertrandt AG & 0.08 & 0.18 & 0.15 & 0.15 & 0.23 & 0.18 & 0.15 & $+-=+--$ \\
\hline Bilfinger Berger AG & 0.13 & 0.25 & 0.30 & 0.35 & 0.40 & 0.43 & 0.40 & +++++ \\
\hline Biotest AG & 0.15 & 0.18 & 0.23 & 0.35 & 0.35 & 0.43 & 0.40 & $+++=+-$ \\
\hline BMW AG & 0.18 & 0.25 & 0.23 & 0.28 & 0.20 & 0.30 & 0.23 & +-+-+- \\
\hline Carl Zeiss Me & 0.20 & 0.23 & 0.23 & 0.25 & 0.33 & 0.25 & 0.28 & $+=++-+$ \\
\hline Celesio AG & 0.18 & 0.15 & 0.28 & 0.20 & 0.30 & 0.35 & 0.38 & -+-++ \\
\hline Centrotec Sustainable AG & 0.28 & 0.38 & 0.38 & 0.35 & 0.58 & 0.60 & 0.63 & $+=-+++$ \\
\hline CeWe Color Holding AG & 0.30 & 0.28 & 0.23 & 0.20 & 0.20 & 0.30 & 0.30 & $---=+=$ \\
\hline Continental AG & 0.25 & 0.25 & 0.28 & 0.58 & 0.50 & 0.60 & 0.55 & $=++-+$ \\
\hline CTS Eventim AG & 0,23 & 0.13 & 0.18 & 0,18 & 0,20 & 0.15 & 0,15 & $-+=+-=$ \\
\hline Curanum AG & 0.31 & 0.31 & 0.31 & 0.34 & 0.37 & 0.34 & 0.34 & $==++-=$ \\
\hline Daimler AG & 0.63 & 0.45 & 0.43 & 0.55 & 0.58 & 0.60 & 0.55 & --+++- \\
\hline Deutsche Lufthansa AG & 0.33 & 0.38 & 0.28 & 0.38 & 0.43 & 0.73 & 0.70 & +-+++- \\
\hline Deutsche Post AG & 0.55 & 0,53 & 0,55 & 0.55 & 0,63 & 0.75 & 0.73 & $-+=++-$ \\
\hline Deutsche Telekom AG & 0.43 & 0.48 & 0.53 & 0.55 & 0.50 & 0.63 & 0.63 & $+++-+=$ \\
\hline Deutz AG & 0.25 & 0.23 & 0.25 & 0.28 & 0.45 & 0.48 & 0.43 & -++++ \\
\hline Douglas Holding AG & 0.18 & 0.18 & 0.23 & 0.30 & 0.35 & 0.35 & 0.33 & $=+++=-$ \\
\hline Drägerwerk AG \& Co. KGaA & 0.28 & 0.35 & 0.30 & 0.33 & 0.35 & 0.40 & 0.33 & +-++- \\
\hline Dürr AG & 0.25 & 0.25 & 0.23 & 0.20 & 0.28 & 0.45 & 0.43 & $=--++-$ \\
\hline Dyckerhoff AG & 0.28 & 0.25 & 0.25 & 0,30 & 0.30 & 0.28 & 0.28 & $-=+=-=$ \\
\hline E.On AG & 0.38 & 0.30 & 0.43 & 0,53 & 0.50 & 0.53 & 0.53 & $-++-+=$ \\
\hline Elexis AG & 0.25 & 0.28 & 0.25 & 0.28 & 0.23 & 0.25 & 0.25 & $+-+-+=$ \\
\hline ElringKlinger AG & 0.25 & 0.35 & 0.25 & 0,30 & 0.35 & 0.30 & 0.28 & +-++-- \\
\hline Escada AG & 0.28 & 0.20 & 0.20 & 0.23 & 0.38 & 0.35 & 0.25 & $-=++--$ \\
\hline Fielmann AG & 0.37 & 0.40 & 0.34 & 0.37 & 0,40 & 0,43 & 0,34 & +-++- \\
\hline Fraport AG & 0.28 & 0.28 & 0.38 & 0.48 & 0.48 & 0.55 & 0.55 & $=+t=t=$ \\
\hline Fresenius Med. Care AG \& Co. & 0.53 & 0.53 & 0.55 & 0.58 & 0.75 & 0.83 & 0.83 & $=++++$ \\
\hline Fresenius SE & 0.23 & 0,23 & 0.20 & 0.30 & 0.28 & 0.35 & 0.30 & $=-+-+$ \\
\hline Fuchs Petrolub AG & 0.23 & 0.20 & 0.14 & 0,29 & 0.34 & 0.34 & 0.31 & $--++=$ \\
\hline GEA Group AG & 0.38 & 0.35 & 0.33 & 0.28 & 0.28 & 0.30 & 0.28 & $---=+$ \\
\hline Gerry Weber International AG & 0.23 & 0.23 & 0.23 & 0.34 & 0.29 & 0.34 & 0.29 & $==+-+-$ \\
\hline Gesco AG & 0.08 & 0.13 & 0.15 & 0.18 & 0.18 & 0.20 & 0.13 & $+++=+$ \\
\hline GfK SE & 0.30 & 0.30 & 0.38 & 0.53 & 0.43 & 0.43 & 0.38 & $=++-=-$ \\
\hline Gildemeister AG & 0.30 & 0.33 & 0.33 & 0.35 & 0.50 & 0.53 & 0.45 & $+=+++-$ \\
\hline Grammer AG & 0.20 & 0.18 & 0.23 & 0.15 & 0.25 & 0.23 & 0.18 & -+-+- \\
\hline H \& R Wasag AG & 0.15 & 0.25 & 0.33 & 0.35 & 0.38 & 0.50 & 0.45 & ++++- \\
\hline HeidelbergCement AG & 0.38 & 0.33 & 0.25 & 0.35 & 0.28 & 0.28 & 0.28 & $--+-==$ \\
\hline Heidelberger Druckmaschinen & 0.35 & 0.43 & 0.38 & 0.50 & 0.45 & 0.45 & 0.45 & $+-+-==$ \\
\hline Henkel AG \& Co. KGaA & 0.33 & 0.35 & 0.35 & 0.40 & 0.48 & 0.48 & 0.48 & $+=++=$ \\
\hline Hochtief AG & 0.33 & 0,35 & 0.45 & 0,53 & 0,50 & 0.50 & 0.43 & $+++-=$ \\
\hline
\end{tabular}


Anhang 7-1: Ermittelte SDScores (Forts.)

\begin{tabular}{|c|c|c|c|c|c|c|c|c|}
\hline \multicolumn{9}{|c|}{ Ermittelte Werte des Strategy Disclosure Index für die einzelnen Jahre des Untersuchungszeitraumes } \\
\hline [SDScores normiert, $\{0 ; 1\}]$ & 2002 & 2003 & 2004 & 2005 & 2006 & 2007 & 2008 & Tendenz \\
\hline Hugo Boss AG & 0.18 & 0.18 & 0.20 & 0,23 & 0.23 & 0.25 & 0.33 & $=++=++$ \\
\hline IDS Scheer AG & 0,23 & 0,28 & 0,23 & 0,28 & 0,33 & 0.38 & 0,25 & +-+++ \\
\hline Infineon Technologies AG & 0.38 & 0.38 & 0.30 & 0.30 & 0.35 & 0.40 & 0,28 & $=-=++-$ \\
\hline Jenoptik AG & 0.35 & 0.35 & 0.38 & 0.43 & 0.45 & 0.50 & 0.48 & $=++++-$ \\
\hline Jungheinrich AG & 0,23 & 0,20 & 0,17 & 0,23 & 0,20 & 0,29 & 0,26 & --+-+- \\
\hline $\mathrm{K}+\mathrm{S} \mathrm{AG}$ & 0.38 & 0.45 & 0.40 & 0.53 & 0,53 & 0.53 & 0.50 & $+-+==-$ \\
\hline Koenig \& Bauer AG & 0,10 & 0.18 & 0,15 & 0.23 & 0.23 & 0.25 & 0.20 & $+-+=+-$ \\
\hline Kontron AG & 0.31 & 0,26 & 0.23 & 0,20 & 0.23 & 0.26 & 0.26 & $--++=$ \\
\hline Krones AG & 0.40 & 0,38 & 0,38 & 0,35 & 0,35 & 0,40 & 0,33 & $-=-=+-$ \\
\hline Kuka AG & 0.30 & 0.30 & 0.33 & 0.40 & 0.38 & 0.58 & 0.45 & $=++-+-$ \\
\hline KWS Saat AG & 0.15 & 0,15 & 0.18 & 0,18 & 0,15 & 0.15 & 0.20 & $=+=-=+$ \\
\hline Leoni AG & 0.23 & 0.20 & 0.33 & 0.35 & 0,35 & 0.45 & 0.40 & $-++=+-$ \\
\hline Linde AG & 0.33 & 0.35 & 0.35 & 0.33 & 0.33 & 0.38 & 0.38 & $+=-=+=$ \\
\hline Loewe AG & 0.37 & 0.37 & 0,34 & 0,34 & 0,31 & 0.34 & 0.31 & $=-=-+-$ \\
\hline MAN SE & 0.20 & 0,20 & 0,25 & 0,35 & 0,45 & 0.43 & 0,38 & $=+++--$ \\
\hline MediGene AG & 0.33 & 0.33 & 0.30 & 0,30 & 0,33 & 0,30 & 0,30 & $=-=+-=$ \\
\hline Medion AG & 0.30 & 0.35 & 0.35 & 0.30 & 0.33 & 0.33 & 0.33 & $+=-+==$ \\
\hline Merck KGaA & 0,30 & 0,35 & 0.35 & 0.38 & 0,43 & 0.43 & 0.33 & $+=++=-$ \\
\hline Metro AG & 0.25 & 0.30 & 0.30 & 0.40 & 0.40 & 0.38 & 0.38 & $+=+=-=$ \\
\hline MorphoSys AG & 0,33 & 0,30 & 0,33 & 0,43 & 0,48 & 0,53 & 0,53 & $-++++=$ \\
\hline MVV Energie AG & 0,28 & 0.30 & 0,30 & 0,38 & 0,38 & 0,38 & 0,38 & $+=+===$ \\
\hline Nordex AG & 0.29 & 0.26 & 0.29 & 0.29 & 0.31 & 0.37 & 0.37 & $-+=++=$ \\
\hline Pfeiffer Vacuum Technology & 0.20 & 0.23 & 0.20 & 0.23 & 0.20 & 0.29 & 0.29 & $+-+-+=$ \\
\hline Pfleiderer AG & 0,45 & 0,48 & 0,48 & 0,40 & 0,58 & 0,50 & 0,48 & $+=-+--$ \\
\hline ProSiebenSat.1 Media AG & 0.30 & 0.33 & 0.35 & 0.40 & 0,43 & 0.45 & 0.40 & +++++ \\
\hline Puma AG & 0.23 & 0.26 & 0.29 & 0,43 & 0.37 & 0,34 & 0.31 & +++--- \\
\hline QSC AG & 0.26 & 0.29 & 0,29 & 0,34 & 0,37 & 0,40 & 0.40 & $+=+++=$ \\
\hline Rational AG & 0.29 & 0.34 & 0.37 & 0.37 & 0.40 & 0,40 & 0.34 & $++=+=-$ \\
\hline Rheinmetall AG & 0.28 & 0.28 & 0.30 & 0.33 & 0,35 & 0,33 & 0.28 & $=+++--$ \\
\hline Rhön-Klinikum AG & 0.14 & 0.14 & 0.17 & 0.17 & 0,23 & 0.23 & 0.23 & $=+=+==$ \\
\hline RWE AG & 0.28 & 0.18 & 0,33 & 0.40 & 0.45 & 0.55 & 0.55 & $-++++=$ \\
\hline Salzgitter AG & 0.20 & 0.20 & 0.23 & 0,25 & 0.40 & 0.40 & 0.38 & $=+++=-$ \\
\hline SAP AG & 0.28 & 0.35 & 0.38 & 0.43 & 0,45 & 0,50 & 0.40 & +++++- \\
\hline SGL Carbon SE & 0.20 & 0.23 & 0.23 & 0.23 & 0.33 & 0.48 & 0.48 & $+==++=$ \\
\hline Siemens AG & 0,13 & 0,15 & 0,18 & 0,20 & 0,28 & 0,40 & 0,48 & +++++ \\
\hline Singulus Technologies AG & 0.37 & 0,43 & 0,40 & 0.29 & 0.26 & 0,29 & 0.26 & +---+- \\
\hline Sixt AG & 0.23 & 0.25 & 0,30 & 0,30 & 0,38 & 0.43 & 0.38 & $++=++-$ \\
\hline Software AG & 0.20 & 0.23 & 0.33 & 0,33 & 0,50 & 0,55 & 0.50 & $++=++-$ \\
\hline SolarWorld AG & 0,30 & 0,28 & 0,38 & 0,48 & 0.58 & 0,68 & 0,65 & -++++ \\
\hline Solon SE & 0.23 & 0.23 & 0.23 & 0.26 & 0.30 & 0.35 & 0.28 & $==+++-$ \\
\hline Stada Arzneimittel AG & 0.35 & 0.35 & 0.35 & 0.38 & 0,38 & 0.40 & 0.38 & $==+=+-$ \\
\hline Südzucker AG & 0,13 & 0.15 & 0.20 & 0.23 & 0.25 & 0.28 & 0.23 & +++++ \\
\hline Takkt AG & 0.18 & 0,20 & 0.20 & 0.20 & 0.28 & 0.30 & 0.25 & $+==++-$ \\
\hline ThyssenKrupp AG & 0.30 & 0.30 & 0.35 & 0.35 & 0.48 & 0.53 & 0,48 & $=+=++-$ \\
\hline TUI AG & 0.25 & 0.28 & 0.25 & 0,43 & 0.43 & 0.40 & 0.33 & $+-+=--$ \\
\hline United Internet AG & 0.35 & 0.45 & 0.43 & 0.43 & 0.40 & 0.40 & 0.40 & $+-=-==$ \\
\hline VBH Holding AG & 0,11 & 0,11 & 0,14 & 0.14 & 0,14 & 0.20 & 0.17 & $=+==+-$ \\
\hline Volkswagen AG & 0.30 & 0,33 & 0.33 & 0.30 & 0.40 & 0.45 & 0.45 & $+=-++=$ \\
\hline Vossloh AG & 0.35 & 0.35 & 0.28 & 0.33 & 0.33 & 0.40 & 0.40 & $=-+=+=$ \\
\hline Wirecard AG & 0,03 & 0,06 & 0,11 & 0,14 & 0,26 & 0,43 & 0,43 & $++t+t=$ \\
\hline
\end{tabular}




\section{Anhang 7-2: Histogramm der ermittelten SDScores}

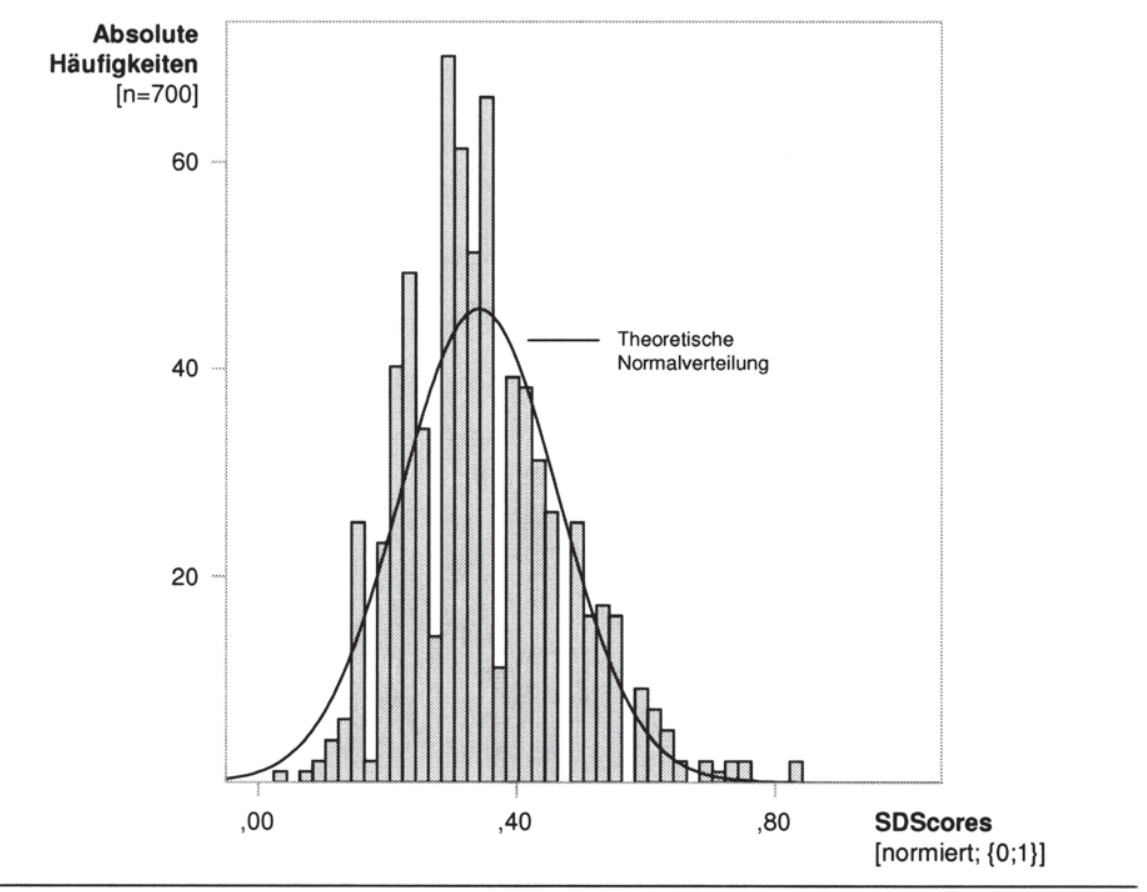

Obige Abbildung zeichnet die Verteilung der ermittelten Werte für den Strategy Disclosure Index (SDScores) der Jahre 2002 bis 2008 auf und stellt diese sodann einer theoretischen Normalverteilung gegenüber. 


\section{Anhang 8: Zusammenfassung der Untersuchungsvariablen}

\begin{tabular}{|c|c|c|c|}
\hline \multicolumn{4}{|c|}{ Bestimmungsfaktoren: Überblick über die verwendeten Variablen } \\
\hline Einzelfaktor und Variablen & Bezeichnung & Zeitraum & Quelle $^{\mathrm{i} 213}$ \\
\hline \multicolumn{4}{|l|}{ Bestimmungsfaktoren } \\
\hline \multicolumn{4}{|l|}{ Makroökonomische Faktoren } \\
\hline \multicolumn{4}{|l|}{ H 2.1: Konjunkturentwicklung } \\
\hline BIP (Volumen) & Mak_BIPStand (DE, EU, OECD) & $2002-09$ & OECD \\
\hline \multicolumn{4}{|l|}{ H 2.2: Börsenentwicklung } \\
\hline Indexstand & $\begin{array}{l}\text { Mak_IndexStand (Dax, MDax, TecDax, } \\
\text { SDax, Euro-Stoxx, Dow Jones) }\end{array}$ & 2001-09 & DS \\
\hline \multicolumn{4}{|l|}{ Unternehmenscharakteristika } \\
\hline \multicolumn{4}{|l|}{ H 2.3: Unternehmensgröße } \\
\hline Größenindikatoren & $\begin{array}{l}\text { Unt_(Ln)Sls, Unt_(Ln)Ass, Unt_(Ln)Mita } \\
\text { Bew_(Ln)MktCap }\end{array}$ & 2002-08 & wS \\
\hline \multicolumn{4}{|l|}{ H 2.4: Stammdaten } \\
\hline Klassisch vs. Technologie & Unt_BraTC & 2002-09 & Dt. Börse AG \\
\hline Sektorenlogik der Dt. Börse & Unt_BraSupSek, Unt_BraSekSek & 2002-09 & Dt. Börse AG \\
\hline Unternehmensalter & Unt_Alter & $2002-09$ & WS / GB \\
\hline \multicolumn{4}{|l|}{ H 2.5: Rechnungslegung } \\
\hline Zeitpunkt Wechsel auf IFRS & Acc_Philo & $2002-08$ & GB \\
\hline Verwendeter ReLe-Standard & Acc_Std & $2002-08$ & GB \\
\hline Abschlussprüfer & Acc_Prüf & $2002-08$ & $\mathrm{~GB}$ \\
\hline \multicolumn{4}{|l|}{ H 2.6: Management / CEO } \\
\hline $\begin{array}{l}\text { Persönlichkeitsmerkmale CEO } \\
\text { (Alter, Ausbildung, Nationalität) }\end{array}$ & CEO_Alter, CEO_Ausb, CEO_Nati & 2002-08 & $\mathrm{GB} / \mathrm{PR}$ \\
\hline $\begin{array}{l}\text { Verantwortlichkeit } \\
\text { (Anzahl, Wechselzeitpunkt) }\end{array}$ & CEO_Anz / CEO_Nr / CEO_Wechs & $2002-08$ & $\mathrm{~GB} / \mathrm{PR}$ \\
\hline Hintergrund CEO-Wechsel & CEO_WechsGrund & $2002-08$ & $\mathrm{~GB} / \mathrm{PR}$ \\
\hline \multicolumn{4}{|l|}{ Finanzielle Faktoren } \\
\hline \multicolumn{4}{|l|}{ H 2.7: Unternehmenserfolg } \\
\hline Umsatzprofitabilität / Marge & Perf_EBIT(DA)M, Perf_NETM & $2002-08$ & wS \\
\hline Kapitalrentabilität & Perf_ROA & $2002-08$ & wS \\
\hline Unternehmensentwicklung & Perf_SlsGr, Perf_AssGr & $2002-08$ & WS \\
\hline \multicolumn{4}{|l|}{ H 2.8: Finanzierung } \\
\hline Eigenkapitalquote & Fin_EKQ & $2002-08$ & wS \\
\hline $\begin{array}{l}\text { Relative (langfristige) } \\
\text { Verschuldung }\end{array}$ & Fin_(LT)DbtAss, Fin_(LT)Dbt_Equi & $2002-08$ & wS \\
\hline Relative Nettoverschuldung & Fin_NDbtAss & $2002-08$ & ws \\
\hline \multicolumn{4}{|l|}{ Faktoren des Aktienkapitals } \\
\hline \multicolumn{4}{|l|}{ H 2.9: Indexzugehörigkeit } \\
\hline Zugehörigkeit zu dt. Auswahlindex & Index_ZugDE & 2002-08 & Dt. Börse AG \\
\hline \multicolumn{4}{|l|}{ H 2.10: Auslandslisting } \\
\hline Zweit-Listing an der NYSE & Index_Ausli & $2002-08$ & $\mathrm{~GB} / \mathrm{PR}$ \\
\hline \multicolumn{4}{|l|}{ H 2.11: Kapitalkonzentration } \\
\hline Summe fest gehaltener Aktien & Akt_InvFF (Inverser Freefloat) & $2002-08$ & DS \\
\hline Anteil direkter Großaktionäre & Akt_DirSumAnt, Akt_Dir10Max etc. & $2002-08$ & BaFin \\
\hline Typ größter Einzelaktionär & Akt_Dir10MaxTyp & $2002-08$ & BaFin \\
\hline \multicolumn{4}{|l|}{ H 2.12: Insidertransaktionen } \\
\hline Volumen relativ zu Marktwert & Ins_StckGF, Ins_StckAll (Kauf / Verkauf) & $2002-08$ & BaFin \\
\hline Stücke relativ zu Aktienanzahl & Ins_VolGF, Ins_VolAH_Kauf_/Verkaug 78 & $2092-08$ & BaFin \\
\hline
\end{tabular}




\section{Anhang 8: Zusammenfassung der Variablen (Forts.)}

\begin{tabular}{|c|c|c|c|}
\hline \multicolumn{4}{|c|}{ Strategieberichterstattung: Überblick über die verwendeten Variablen } \\
\hline Variable & Bezeichnung & Zeitraum & Quelle $^{1213}$ \\
\hline \multicolumn{4}{|l|}{ Strategieberichterstattung } \\
\hline $\begin{array}{l}\text { H 1: (Veränderung des) Niveau(s) } \\
\text { der Strategieberichterstattung }\end{array}$ & $\begin{array}{l}\text { SDI_TotalNorm (inkl. Teil-Scores), } \\
\text { SDI_Rang bzw. alternative Scores/Ränge; } \\
\text { SDI_TotalNormDiffRel (Betrag) }\end{array}$ & $2002-08$ & GB \\
\hline H 2: Zeitliche Veränderung & Jahr & $2002-08$ & \\
\hline
\end{tabular}

Kapitalmarkteffekte: Überblick über die verwendeten Variablen

\begin{tabular}{llll}
\hline Einzeleffekte und Variablen & Bezeichnung & Zeitraum & Quelle \\
\hline
\end{tabular}

\section{Kapitalmarkteffekte}

Markttransparenzeffekte

H 3.1: Anzahl beobachtender Analysten

\begin{tabular}{|c|c|c|c|}
\hline Anzahl Analysten im Schnitt p.a. & Ana_FollAvg & $2002-09$ & I/B/E/S \\
\hline \multicolumn{4}{|l|}{ H 3.2: Schätzungsvarianz } \\
\hline Varianz der Empfehlungen & Ana_RecVar & $2002-09$ & I/B/E/S \\
\hline Variation der Schätzungen & Ana_VarEPS & $2002-09$ & I/B/E/S \\
\hline Güte der Schätzungen & Ana_GütEPS & $2002-08$ & L/B/E/S, WS \\
\hline
\end{tabular}

H 3.3: Handelsvolumen

\begin{tabular}{|c|c|c|c|}
\hline Jährl. Handelsvolumen der Aktie & Hdl_Vol bzw. Hdl_LnVol & 2002-09 & DS \\
\hline \multicolumn{4}{|l|}{ H 3.4: Volatilität } \\
\hline Schwankungsbreite Aktienkurse & Hdl_Vola bzw. Hdl_LnVola & 2002-09 & DS \\
\hline
\end{tabular}

H 3.5: Eigenkapitalkosten

$\begin{array}{llll}\text { Berechnete Eigenkapitalkosten } & \text { Bew_EKK bzw. Bew_LnEKK } & 2002-09 & \text { I/B/E/S, DS } \\ \text { Beta } & \text { Bew_Beta } & 2002-09 & \text { DS }\end{array}$

H 3.6: Bid-Ask-Spreads

Jährl. Durchschnitt Bid-Ask-

Spreads (relativ zu Bid-Kurs)

H 3.7: Marktbewertung

Marktwert-/Buchwert-Ratio

Bew_RelBAS bzw. Bew_LnRelBAS 2002-09 DS

Multiplikator-Bewertung

(in Bezug auf Umsatz)

$\begin{array}{lll}\text { Bew_TobQ } & 2002-08 & \text { DS, WS } \\ \text { Bew_SIsMul } & 2002-08 & \text { WS }\end{array}$

1213 Die Datenquellen wurden aus Gründen der Übersichtlichkeit abgekürzt: OECD = Daten der OECD zu Parametern der wirtschaftlichen Entwicklung, DS = Datastream-Datenbank, WS = Worldscope-Datenbank, GB = Geschäftsberichte der Unternehmen, PR = Presse-Recherche (Factiva-Datenbank), BaFin = Datenbereitstellung durch die Bundesanstalt für Finanzdienstleistungaufsicht, $\mathrm{I} / \mathrm{B} / \mathrm{E} / \mathrm{S}=$ Datenbank zu Analystenschätzungen.

Tom Sieber - 978-3-631-75150-3 


\section{Anhang 9: Methodik zur Ableitung von Validierungs-Scores}

Zur Validierung der einzelnen Messwerte des Strategy Disclosure Index scheint insb. die Überprüfung des statistischen Zusammenhangs mit einem anderen, vergleichbaren Messinstrument geeignet.

Da jedoch ein vergleichbares Messinstrument mit Fokus auf strategieorientierte Berichtsinhalte nicht bekannt ist, kann ein Messinstrument zur Validierung verwendet werden, das die Berichterstattung gesamthaft misst. Das renommierteste Instrument zur Messung des Niveaus der Berichterstattung deutscher börsennotierter Gesellschaften ist der Wettbewerb um den ,Besten Geschäftsbericht", der bereits seit 1982 durchgeführt wird und daher auch für den relevanten Untersuchungszeitraum, 2002 bis 2008, über entsprechende Messwerte verfügt. Diese Messwerte wurden seitens des ,Forschungsteams Baetge', das die Durchführung des Wettbewerbs verantwortet, freundlicherweise bereitgestellt. Die Vorgehensweise zur Ableitung von Validierungs-Scores im Einzelnen:

- Identifikation der Stichproben-Unternehmen innerhalb der sieben Wettbewerbs-Datensätze: Validierung für 625 von 700 Beobachtungen möglich

- Identifikation der strategieorientierten Berichtskriterien in den jährlichen Berichtskatalogen zu Lageberichtsinhalten ${ }^{1214}$, vgl. die Tabelle auf S. 379

- Da der Wettbewerb eine graduelle Ausprägung bewertet (d.h. 0-100\% Erfüllungsgrad eines Kriteriums) ${ }^{1215}$, Setzen eines Schwellenwerts von $60 \%$ : Punktvergabe für Kriterium nur dann, wenn mindestens $60 \%$ erreicht $^{1216}$

- Summation und Normierung auf Wertebereich von null bis eins

1214 Jener Wettbewerb umfasst drei Berichtskataloge, je einen für den Anhang, den Lagebericht und für sonstige Angaben im Geschäftsbericht. Neben einer Prüfung des betriebswirtschaftlichen Inhalts werden auch Gestaltung und Sprache bewertet, was hier jedoch nicht relevant ist. Für den Katalog des Wettbewerbs 2009 (Geschäftsberichte 2008) vgl. Baetge (2009), frühere Kataloge wurden durch das ,Team Baetge‘ bereitgestellt.

1215 Strenggenommen werden im Rahmen des Wettbewerbs die Inhalte des Berichtskatalogs ,Lagebericht" auch dann bewertet, wenn sich jene nicht im Lagebericht, sondern z.B. im freien Teil befinden. Auf Basis einer stichprobenhaften Prüfung wurde festgestellt, dass dieser methodische Unterschied keine bedeutsamen Verzerrungen verursacht und daher für bewertete Inhalte unterstellt werden kann, dass sie im Lagebericht platziert waren.

1216 Auch bei alternativen Werten $(50 \%, 75 \%, 80 \%)$ wurden zu den in D 2.4 .2 dargestellten Korrelationskoeffizienten vergleichbare Resultate erzielt ( $r>, 504$ (Pearson) bei $p=, 000$ ).

Tom Sieber - 978-3-631-75150-3 


\section{Anhang 9: Methodik zur Validierung (Forts.)}

\begin{tabular}{|c|c|c|c|c|c|c|c|}
\hline \multicolumn{8}{|c|}{ Ausgewählte Kriterien der jährlichen Berichtskataloge des Wettbewerbs ,Bester Geschäftsbericht‘ ${ }^{1217}$} \\
\hline \multirow{2}{*}{$\begin{array}{l}\begin{array}{l}\text { Teil- } \\
\text { bericht }\end{array} \\
\text { Wirtschaft }\end{array}$} & \multirow{2}{*}{$\begin{array}{l}\text { Inhaltliche } \\
\text { Kategorie } \\
\text { Umfeld }\end{array}$} & Einzelkriterium & 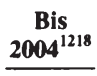 & \multirow{2}{*}{$\frac{2005}{1}$} & \multirow{2}{*}{$\frac{2006}{1}$} & \multirow{2}{*}{$\frac{2007}{1}$} & \multirow{2}{*}{$\frac{2008}{1}$} \\
\hline & & Gesamtwirtschaftliche Rahmenbedingungen & 1 & & & & \\
\hline Wirtschaft & Umfeld & Rechtliche, wirtschaftliche Einflussfaktoren & & 1 & 1 & 1 & 1 \\
\hline Wirtschaft & Umfeld & Wesentliche Absatzmärkte und Position & & 1 & 1 & 1 & 1 \\
\hline Wirtschaft & Umfeld & Branchenspezifische Rahmenbedingungen & 1 & 1 & 1 & 1 & 1 \\
\hline Wirtschaft & Unternehmen & Beurteilung der wirtschaftlichen Lage & & 1 & 1 & 1 & 1 \\
\hline Wirtschaft & Unternehmen & Strategische Konzernstruktur & & 1 & 1 & 1 & 1 \\
\hline Wirtschaft & Unternehmen & Geschäftsfelder / Organisationsstruktur & & 1 & 1 & 1 & 1 \\
\hline Wirtschaft & Unternehmen & Beschreibung des Geschäftsmodells & & 1 & 1 & 1 & 1 \\
\hline Wirtschaft & Unternehmen & Wichtige Produkte, Prozesse & 1 & 1 & 1 & 1 & 1 \\
\hline Wirtschaft & Unternehmen & Verwendete Steuerungskennzahlen & & 1 & 1 & 1 & 1 \\
\hline Prognose & Entwicklung & Künftige gesamtwirtschaftliche Situation & 1 & 1 & 1 & 1 & 1 \\
\hline Prognose & Entwicklung & Gesamtaussage zur voraus. Entwicklung & & 1 & 1 & 1 & 1 \\
\hline Prognose & Entwicklung & Geplante Änderungen Geschäftspolitik & 1 & 1 & 1 & 1 & 1 \\
\hline Prognose & Entwicklung & Künftige Branchensituation & 1 & 1 & 1 & 1 & 1 \\
\hline Prognose & Entwicklung & Künftige Absatzmärkte & & 1 & 1 & 1 & 1 \\
\hline Prognose & Entwicklung & Künftige Produkte / Dienstleistungen & 1 & 1 & 1 & 1 & 1 \\
\hline Prognose & Entwicklung & Künftige Verwendung Technologien & 1 & 1 & 1 & 1 & 1 \\
\hline Prognose & Entwicklung & Voraussichtliche Umsatzentwicklung & & 1 & 1 & 1 & 1 \\
\hline Prognose & Entwicklung & Voraussichtliche Ergebnisentwicklung & 1 & 1 & 1 & 1 & 1 \\
\hline Prognose & Chance/Risiko & Umfeld- und Branchenrisiken & 1 & 1 & 1 & 1 & 1 \\
\hline Prognose & Chance/Risiko & Chancen aus Entwicklung des Umfeldes & & 1 & 1 & 1 & 1 \\
\hline Prognose & Chance/Risiko & Unternehmensstrategische Chancen & & 1 & 1 & 1 & 1 \\
\hline Prognose & Chance/Risiko & Unternehmensstrategische Risiken & & 1 & 1 & 1 & 1 \\
\hline Prognose & Chance/Risiko & Leistungswirtschaftliche Chancen & & 1 & 1 & 1 & 1 \\
\hline Prognose & Chance/Risiko & Leistungswirtschaftliche Risiken & 1 & 1 & 1 & 1 & 1 \\
\hline Prognose & Chance/Risiko & Sonstige Chancen & & 1 & 1 & 1 & 1 \\
\hline FuE & - & Ausrichtung der FuE-Aktivitäten & $2^{1219}$ & 1 & 1 & 1 & 1 \\
\hline \multicolumn{3}{|c|}{ Anzahl berücksichtigter Berichtskriterien } & 13 & 27 & 27 & 27 & 27 \\
\hline \multicolumn{3}{|c|}{ Gesamtanzahl Kriterien im Berichtskatalog Lagebericht } & 36 & 93 & 88 & 88 & 88 \\
\hline \multicolumn{3}{|c|}{ Quote berücksichtigter Berichtskriterien } & $36 \%$ & $29 \%$ & $31 \%$ & $31 \%$ & $31 \%$ \\
\hline
\end{tabular}

1217 Es handelt sich um die Kriterienkataloge ,Industrie- und Handelsunternehmen`. Weitere Kataloge für ,Banken' sowie ,Versicherungen“ wurden nicht berücksichtigt.

1218 Der Katalog wurde im Vorfeld der Wettbewerbsrunde 2005 inhaltlich angepasst, um die Einflüsse des BilReG abzubilden. Die Zusammenstellung wurde grds. durch empirische Arbeiten abgesichert, vgl. bspw. Krumbholz (1994), Armeloh (1996), Heumann (2005).

1219 Der Kriterienkatalog des Wettbewerbs ,Der Beste Geschäftsbericht “ der Jahre 2002 bis 2004 unterscheidet zwei Kriterien, die hier beide in der Wertung berücksichtigt werden: ,Ziele und Schwerpunkte der FuE' sowie ,Künftige FuE‘. 
Anhang 10: Zuordnung der Stichprobe zu Teil-Stichproben

\begin{tabular}{|c|c|c|c|c|c|c|c|c|}
\hline Zugehörigkeit zu Teil-Stichproben, ge & ildet $n$ & ch der & Interne & imensg & iße (Bil & anzsum & & \\
\hline [1 = klein, 2 = groß] & 2002 & 2003 & 2004 & 2005 & 2006 & 2007 & 2008 & Wechsel \\
\hline Adidas AG & 2 & 2 & 2 & 2 & 2 & 2 & 2 & \\
\hline Aixtron AG & 1 & 1 & 1 & 1 & 1 & 1 & 1 & \\
\hline Arcandor AG & 2 & 2 & 2 & 2 & 2 & 2 & 2 & \\
\hline Aurubis AG & 1 & 1 & 1 & 1 & 2 & 2 & 2 & 2006 \\
\hline Axel Springer AG & 2 & 2 & 2 & 2 & 2 & 2 & 2 & \\
\hline BASF SE & 2 & 2 & 2 & 2 & 2 & 2 & 2 & \\
\hline Baver AG & 2 & 2 & 2 & 2 & 2 & 2 & 2 & \\
\hline BayWa AG & 2 & 2 & 2 & 2 & 2 & 2 & 2 & \\
\hline Bechtle AG & 1 & 1 & 1 & 1 & 1 & 1 & 1 & \\
\hline Beiersdorf AG & 2 & 2 & 2 & 2 & 2 & 2 & 2 & \\
\hline Bertrandt AG & 1 & 1 & 1 & 1 & 1 & 1 & 1 & \\
\hline Bilfinger Berger AG & 2 & 2 & 2 & 2 & 2 & 2 & 2 & \\
\hline Biotest AG & 1 & 1 & 1 & 1 & 1 & 1 & 1 & \\
\hline BMW AG & 2 & 2 & 2 & 2 & 2 & 2 & 2 & \\
\hline Carl Zeiss Meditec AG & 1 & 1 & 1 & 1 & 1 & 1 & 1 & \\
\hline Celesio AG & 2 & 2 & 2 & 2 & 2 & 2 & 2 & \\
\hline Centrotec Sustainable AG & 1 & 1 & 1 & 1 & 1 & 1 & 1 & \\
\hline CeWe Color Holding AG & 1 & 1 & 1 & 1 & 1 & 1 & 1 & \\
\hline Continental AG & 2 & 2 & 2 & 2 & 2 & 2 & 2 & \\
\hline CTS Eventim AG & 1 & 1 & 1 & 1 & 1 & 1 & 1 & \\
\hline Curanum AG & 1 & 1 & 1 & 1 & 1 & 1 & 1 & \\
\hline Daimler AG & 2 & 2 & 2 & 2 & 2 & 2 & 2 & \\
\hline Deutsche Lufthansa AG & 2 & 2 & 2 & 2 & 2 & 2 & 2 & \\
\hline Deutsche Post AG & 2 & 2 & 2 & 2 & 2 & 2 & 2 & \\
\hline Deutsche Telekom AG & 2 & 2 & 2 & 2 & 2 & 2 & 2 & \\
\hline Deutz AG & 2 & 1 & 1 & 1 & 1 & 1 & 1 & 2003 \\
\hline Douglas Holding AG & 2 & 2 & 2 & 2 & 2 & 2 & 1 & 2008 \\
\hline Drägerwerk AG \& Co. KGaA & 1 & 2 & 2 & 2 & 2 & 1 & 1 & $2003 / 2007$ \\
\hline Dürr AG & 2 & 2 & 2 & 1 & 1 & 1 & 1 & 2005 \\
\hline Dyckerhoff AG & 2 & 2 & 2 & 2 & 2 & 2 & 2 & \\
\hline E.On AG & 2 & 2 & 2 & 2 & 2 & 2 & 2 & \\
\hline Elexis AG & 1 & 1 & 1 & 1 & 1 & 1 & 1 & \\
\hline ElringKlinger AG & 1 & 1 & 1 & 1 & 1 & 1 & 1 & \\
\hline Escada AG & 1 & 1 & 1 & 1 & 1 & 1 & 1 & \\
\hline Fielmann AG & 1 & 1 & 1 & 1 & 1 & 1 & 1 & \\
\hline Fraport AG & 2 & 2 & 2 & 2 & 2 & 2 & 2 & \\
\hline Fresenius Med. Care AG \& Co. $\mathrm{KGaA}$ & 2 & 2 & 2 & 2 & 2 & 2 & 2 & \\
\hline Fresenius SE & 2 & 2 & 2 & 2 & 2 & 2 & 2 & \\
\hline Fuchs Petrolub AG & 1 & 1 & 1 & 1 & 1 & 1 & 1 & \\
\hline GEA Group AG & 2 & 2 & 2 & 2 & 2 & 2 & 2 & \\
\hline Gerry Weber International AG & 1 & 1 & 1 & 1 & 1 & 1 & 1 & \\
\hline Gesco AG & 1 & 1 & 1 & 1 & 1 & 1 & 1 & \\
\hline GfK SE & 1 & 1 & 1 & 2 & 1 & 1 & 1 & $2005 / 2006$ \\
\hline Gildemeister AG & 1 & 1 & 1 & 1 & 1 & 1 & 1 & \\
\hline Grammer AG & 1 & 1 & 1 & 1 & 1 & 1 & 1 & \\
\hline H \& R Wasag AG & 1 & 1 & 1 & 1 & 1 & 1 & 1 & \\
\hline HeidelbergCement AG & 2 & 2 & 2 & 2 & 2 & 2 & 2 & \\
\hline Heidelberger Druckmaschinen AG & 2 & 2 & 2 & 2 & 2 & 2 & 2 & \\
\hline Henkel AG \& Co. KGaA & 2 & 2 & 2 & 2 & 2 & 2 & 2 & \\
\hline Hochtief AG & 2 & 2 & 2 & $\mathrm{~m}^{2} \mathrm{Si \epsilon}$ & $e^{2}-$ & $3-3-6$ & $-^{2}+51$ & \\
\hline
\end{tabular}




\section{Anhang 10: Zuordnung zu Teil-Stichproben (Forts.)}

\begin{tabular}{|c|c|c|c|c|c|c|c|c|}
\hline Zugehörigkeit zu Teil-Stichprobe & ildet $\mathbf{n}$ & ch der & Interne & imensgr & iße (Bil & anzsum & & \\
\hline$[1$ = klein, 2 = groß] & 2002 & 2003 & 2004 & 2005 & 2006 & 2007 & 2008 & Wechsel \\
\hline Hugo Boss AG & 1 & 1 & 1 & 1 & 1 & 1 & 1 & \\
\hline IDS Scheer AG & 1 & 1 & 1 & 1 & 1 & 1 & 1 & \\
\hline Infineon Technologies AG & 2 & 2 & 2 & 2 & 2 & 2 & 2 & \\
\hline Jenoptik AG & 2 & 2 & 2 & 2 & 1 & 1 & 1 & 2006 \\
\hline Jungheinrich AG & 2 & 2 & 2 & 2 & 2 & 2 & 2 & \\
\hline$K+S$ AG & 2 & 2 & 2 & 2 & 2 & 2 & 2 & \\
\hline Koenig \& Bauer AG & 2 & 2 & 2 & 1 & 1 & 1 & 1 & 2005 \\
\hline Kontron AG & 1 & 1 & 1 & 1 & 1 & 1 & 1 & \\
\hline Krones AG & 1 & 1 & 1 & 1 & 1 & 1 & 1 & \\
\hline Kuka AG & 2 & 2 & 2 & 2 & 1 & 1 & 1 & 2006 \\
\hline KWS Saat AG & 1 & 1 & 1 & 1 & 1 & 1 & 1 & \\
\hline Leoni AG & 1 & 1 & 1 & 1 & 1 & 1 & 2 & 2008 \\
\hline Linde AG & 2 & 2 & 2 & 2 & 2 & 2 & 2 & \\
\hline Loewe AG & 1 & 1 & 1 & 1 & 1 & 1 & 1 & \\
\hline MAN SE & 2 & 2 & 2 & 2 & 2 & 2 & 2 & \\
\hline MediGene AG & 1 & 1 & 1 & 1 & 1 & 1 & 1 & \\
\hline Medion AG & 1 & 1 & 1 & 1 & 1 & 1 & 1 & \\
\hline Merck KGaA & 2 & 2 & 2 & 2 & 2 & 2 & 2 & \\
\hline Metro AG & 2 & 2 & 2 & 2 & 2 & 2 & 2 & \\
\hline MorphoSys AG & 1 & 1 & 1 & 1 & 1 & 1 & 1 & \\
\hline MVV Energie AG & 2 & 2 & 2 & 2 & 2 & 2 & 2 & \\
\hline Nordex AG & 1 & 1 & 1 & 1 & 1 & 1 & 1 & \\
\hline Pfeiffer Vacuum Technology AG & 1 & 1 & 1 & 1 & 1 & 1 & 1 & \\
\hline Pfleiderer AG & 1 & 1 & 1 & 2 & 1 & 2 & 1 & 2005-2007 \\
\hline ProSiebenSat.1 Media AG & 2 & 2 & 2 & 2 & 2 & 2 & 2 & \\
\hline Puma AG & 1 & 1 & 1 & 1 & 2 & 2 & 2 & 2006 \\
\hline OSC AG & 1 & 1 & 1 & 1 & 1 & 1 & 1 & \\
\hline Rational AG & 1 & 1 & 1 & 1 & 1 & 1 & 1 & \\
\hline Rheinmetall AG & 2 & 2 & 2 & 2 & 2 & 2 & 2 & \\
\hline Rhön-Klinikum AG & 1 & 1 & 1 & 2 & 2 & 2 & 2 & 2005 \\
\hline RWE AG & 2 & 2 & 2 & 2 & 2 & 2 & 2 & \\
\hline Salzgitter AG & 2 & 2 & 2 & 2 & 2 & 2 & 2 & \\
\hline SAP AG & 2 & 2 & 2 & 2 & 2 & 2 & 2 & \\
\hline SGL Carbon SE & 2 & 2 & 2 & 1 & 1 & 1 & 1 & 2005 \\
\hline Siemens AG & 2 & 2 & 2 & 2 & 2 & 2 & 2 & \\
\hline Singulus Technologies AG & 1 & 1 & 1 & 1 & 1 & 1 & 1 & \\
\hline Sixt AG & 1 & 1 & 1 & 1 & 2 & 2 & 2 & 2006 \\
\hline Software AG & 1 & 1 & 1 & 1 & 1 & 1 & 1 & \\
\hline SolarWorld AG & 1 & 1 & 1 & 1 & 1 & 1 & 2 & 2008 \\
\hline Solon SE & 1 & 1 & 1 & 1 & 1 & 1 & 1 & \\
\hline Stada Arzneimittel AG & 1 & 1 & 1 & 1 & 2 & 2 & 2 & 2006 \\
\hline Südzucker AG & 2 & 2 & 2 & 2 & 2 & 2 & 2 & \\
\hline Takkt AG & 1 & 1 & 1 & 1 & 1 & 1 & 1 & \\
\hline ThyssenKrupp AG & 2 & 2 & 2 & 2 & 2 & 2 & 2 & \\
\hline TUI AG & 2 & 2 & 2 & 2 & 2 & 2 & 2 & \\
\hline United Internet AG & 1 & 1 & 1 & 1 & 1 & 1 & 1 & \\
\hline VBH Holding AG & 1 & 1 & 1 & 1 & 1 & 1 & 1 & \\
\hline Volkswagen AG & 2 & 2 & 2 & 2 & 2 & 2 & 2 & \\
\hline Vossloh AG & 1 & 1 & 1 & 1 & 1 & 1 & 1 & \\
\hline Wirecard AG & 1 & 1 & 1 & $\mathrm{om}^{1} \mathrm{Sie}$ & 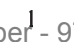 & $8-3-6$ & $1-\frac{1}{7} 5_{1}$ & \\
\hline
\end{tabular}




\section{Anhang 11: Berechnungsmethodik der Eigenkapitalkostensätze}

Die Berechnung der Eigenkapitalkostensätze der Unternehmen folgt einem Vorschlag von Hail (2002), der sich wiederum auf eine Arbeit von Gebhardt et al. (2001) stützt. ${ }^{1220}$ Wesentliche Grundlagen dieser Berechnungsmethodik lieferten Edwards/Bell (1961), Ohlson (1995) sowie Feltham/Ohlson (1995) mit der von ihnen vorgeschlagenen ,accounting based valuation formula“1221, für welche in der Literatur z.T. auch die Bezeichnung ,Edwards-Bell-Ohlson-Formel (EBO) verwendet wird. ${ }^{1222}$ Diese Formel lehnt sich methodisch an den Residualgewinnmodellen an, die bereits Preinreich (1938) und Lücke (1955) vorstellten. ${ }^{1223}$

Die Berechnung der sog. impliziten Eigenkapitalkostensätze erfolgt als interne Zinssätze, welche die Identität der fundamentalen Unternehmenswerte sowie der aktuellen Aktienkurse bewirken. ${ }^{1224}$ Zunächst ist also die Residualgewinnformel zur Berechnung des Unternehmenswertes $V$ abzuleiten, was ausgehend vom allgemeinen Dividenden-Diskontierungsmodell erfolgen kann:

$$
V_{t}=\sum_{\tau=1}^{\infty} E_{t}\left[\frac{D_{t+\tau}}{(1+r)^{\tau}}\right]
$$

Bei unterstellter Gültigkeit des Postulats eines ,Clean Surplus Accountings`, das besagt, dass Änderungen des Buchwerts des Eigenkapitals EK nur aufgrund einbehaltener Gewinne $G$ sowie aufgrund von Kapitaltransfers $D$ erfolgen, gilt:

$$
E K_{t}=E K_{t-1}+G_{t}-D_{t}
$$

Durch Umformung von (2) und Einsetzen von (2) in (1) ergibt sich:

$$
V_{t}=E K_{t}+\sum_{\tau=1}^{\infty} E_{t}\left[\frac{G_{t+\tau}-r \times E K_{t+\tau-1}}{(1+r)^{\tau}}\right]=E K_{t}+\sum_{\tau=1}^{\infty} E_{t}\left[\frac{\left(g_{t+\tau}-r\right) \times E K_{t+\tau-1}}{(1+r)^{\tau}}\right]
$$

1220 Vgl. grdl. Hail (2002) und Gebhardt et al. (2001). Diesem Vorschlag Hails folgen bspw. Gietzman/Ireland (2005).

1221 Gietzman/Ireland (2005), S. 609.

1222 Vgl. grdl. Edwards/Bell (1961), Ohlson (1995), Feltham/Ohlson (1995). Das Akronym ,EBO‘ wird u.a. von Botosan (1997a), Botosan/Plumlee (2002) verwendet.

Vgl. im Detail Preinreich (1938), in der deutschsprachigen Literatur Lücke (1955).

Vgl. Stromann (2002), S. 5 mit dem Hinweis, dass dies strenggenommen eine Annahme der neoklassischen Denkweise ist; auch Weißenberger (2003), S. 145f. 


\section{Anhang 11: Berechnung der Eigenkapitalkostensätze (Forts.)}

Formel (3) zeigt, dass der Unternehmenswert der Summe aus berichtetem Buchwert des Eigenkapitals sowie aller zukünftigen, diskontierten Residualgewinne im unendlichen Betrachtungszeitraum - entspricht. Zur Berechnung des Unternehmenswertes werden folglich ausschließlich Größen der Rechnungslegung, im Einzelnen zukünftig erwartete Gewinne und Eigenkapital-Buchwerte, benötigt.

Da in einem effizienten Markt der intrinsische Unternehmenswert $V_{1}$ exakt dem Aktienkurs $P_{l}$ entsprechen würde, kann (3) mit dem Aktienkurs $P_{t}$ gleichgesetzt und nach dem internen Zinssatz $r$ aufgelöst werden. ${ }^{1225}$ Es werden sog. Ex-anteEigenkapitalkostensätze ermittelt, die zu Beginn von Periode $t$ gelten:

(4) $\quad V_{t}=E K_{t}+\sum_{\tau=1}^{\infty} E_{t}\left[\frac{\left(x_{t+\tau}-r\right) \times E K_{t+\tau-1}}{(1+r)^{\tau}}\right] \rightarrow P_{t} \quad$ für $\quad T \rightarrow \infty$

Da Ausdruck (4) jedoch eine Prognose von zukünftigen Residualgewinnen und Eigenkapitalbuchwerten für einen infiniten Zeitraum erforderlich machen würde, schlagen Gebhardt et al. (2001) und Hail (2002) ein dreiphasiges Vorgehen vor: In einer ersten Phase werden explizite Gewinnprognosen der Analysten für die nächsten drei Jahre zur Berechnung des Residualgewinns genutzt. In der zweiten Phase von insg. neun Jahren werden zukünftige Gewinngrößen durch ,linearly fading year $t+3[\ldots]$ return on book value of equity to the median market return on equity“ “226 errechnet. In der abschließenden, dritten Phase wird der Residualgewinn der letzten diskret geplanten Periode als ewige Rente angenommen.

Die dreistufige Berechnungsformel stellt sich wie folgt dar:

$$
\begin{aligned}
P_{t}=E K_{t} & +\sum_{\tau=1}^{n} \frac{\left(x_{t+\tau}-r_{e} \times E K_{t+\tau-1}\right)}{\left(1+r_{e}\right)^{\tau}}+\ldots \\
& \ldots \sum_{\tau=n+1}^{T} \frac{\left(x_{t+\tau}-r_{e} \times E K_{t+\tau-1}\right)}{\left(1+r_{e}\right)^{\tau}}+\frac{\left(x_{t+\tau+1}-r_{e} \times E K_{t+\tau}\right)}{r_{e} \times\left(1+r_{e}\right)^{T}}
\end{aligned}
$$

\footnotetext{
1225 Wenngleich Hail (2002), S. 748 von einem ,iterative process“ der Berechnung spricht, scheint in praxi die Verwendung des sog. ,Excel Solvers“ als geeigneter und effizienter Weg zur Berechnung der individuellen Eigenkapitalkostensätze. Dieser Weg wurde im Rahmen dieser Untersuchung eingeschlagen.
} 


\section{Anhang 11: Berechnung der Eigenkapitalkostensätze (Forts.)}

Die dreistufige Berechnung der Eigenkapitalkosten erscheint insofern vorteilhaft zu sein, als diese vorgenommene ,disaggregation along the timeline attempts to capture our superior knowledge about the near-term future as well as the effect of dissipating economic rents within a [...] horizon of reasonable length“"1227.

Als zentraler Vorteil der Berechnungsmethodik muss weiterhin gelten, dass nur wenige, für börsennotierte Unternehmen i.d.R. gut zugängliche Datenpunkte erforderlich sind: Neben dem Buchwert des Eigenkapitals $E K_{t}$ sowie dem Aktienkurs $P_{t}$ sind dies die durchschnittlichen Gewinnprognosen der Analysten für die nächsten drei Geschäftsjahre sowie eine durchschnittliche Dividendenquote.

Jene Daten konnten - soweit für jedes der 100 Unternehmen verfügbar - für die jeweiligen Jahre einschlägigen Datenbanken ${ }^{1228}$ entnommen werden, die durchschnittliche Marktrendite wurde auf Grundlage der realisierten Rendite des Dax seit Beginn seiner Berechnung per Ultimo 1987 mit ca. $8 \%$ p.a. errechnet. ${ }^{1229}$

\begin{tabular}{|c|c|c|}
\hline \multicolumn{3}{|c|}{ Zusammenfassung der Symbolerläuterungen } \\
\hline Symbol & Erläuterung & Formel \\
\hline$V_{t}$ & Intrinsischer Unternehmenswert in Periode $t$ & $(1),(3),(4)$ \\
\hline$D_{t}$ & Dividende, die in der Periode $(t-1 ; t)$ gezahlt wird & $(1),(2)$ \\
\hline$r$ & Diskontierungsfaktor, risikofreier Zinssatz & $(1),(3),(4)$ \\
\hline$r_{e}$ & Ex-ante-Eigenkapitalkostensatz als interner Zinssatz, der die Gleichung $P_{t}=V_{t}$ löst & $(5)$ \\
\hline$E K_{t}$ & Buchwert des Eigenkapitals in Periode $t$ & $(2),(3),(4),(5)$ \\
\hline$E K_{t+r}$ & $\begin{array}{l}\text { Erwarteter Buchwert des Eigenkapitals in } t+\tau \text {, bei Gültigkeit der ,Clean Surplus'- } \\
\text { Annahme. Die Dividendengröße } D_{t} \text { errechnet sich aus der durchschnittlichen Aus- } \\
\text { zahlungsquote der letzten fünf Jahre (bereinigt um Ausreißer), multipliziert mit } G_{t}\end{array}$ & $(3),(4),(5)$ \\
\hline$G_{t}$ & Gewinngröße der Periode $(t-1 ; t)$ & (2), (3) \\
\hline$g_{t}$ & Eigenkapitalrendite der Periode $(t-l ; t)$ & (3) \\
\hline$P_{t}$ & Durchschnittlicher Aktienkurs der Periode $(t-1 ; t)$ & $(4),(5)$ \\
\hline$x_{t+r}$ & $\begin{array}{l}\text { Erwartete zukünftige Gewinne, entweder ermittelt durch explizite } \\
\text { Analystenprognose für die nächsten drei Jahre (Phase 1), adjustiert um einen } \\
\text { linearen Reduktionsfaktor (Phase 2) oder als konstante Größe (Phase 3) }\end{array}$ & $(4),(5)$ \\
\hline
\end{tabular}
Hail (2002), S. 749. Vgl. dort auch für eine tiefergehende kritische Beurteilung der vorgestellten Vorgehensweise. Zur Kritik bspw. Easton (2006). Daten für die jeweils aktuelle Periode aus Datastream, vgl. C 3.2.3 sowie Anhang 8. Abweichend zu Hail (2002) wurde hier nicht der Median der Marktrendite verwendet. 


\section{Anhang 12: Hauptmodelle mit unlogarithmierten Regressanden}

Multivariate Regressionsanalysen der Hauptmodelle 5, 6 und 7

$\mathrm{l}(\mathrm{x})=\mathrm{J}$ eweilige Regressanden mit unlogarithmienen Werten

\begin{tabular}{|c|c|c|c|c|c|c|c|}
\hline & & \multicolumn{2}{|c|}{$\begin{array}{l}\text { Hauptmodell } 5 \\
\text { Volatilität }\end{array}$} & \multicolumn{2}{|c|}{$\begin{array}{c}\text { Hauptmodell } 6 \\
\text { Eigenkapitalkosten }\end{array}$} & \multicolumn{2}{|c|}{$\begin{array}{l}\text { Hauptmodell } 7 \\
\text { Bid-Ask-Spreads }\end{array}$} \\
\hline & & Koeff. $\beta$ & $\mathrm{p}$ & Koeff. $\beta$ & $\mathrm{p}$ & Koeff. $\beta$ & $\mathrm{p}$ \\
\hline \multicolumn{8}{|c|}{ Strategieberichterstattung } \\
\hline SDI (-) & $(t)$ & .048 & $(.238)$ &,$- 163 * * *$ & $(.(0)(0))$ &,$- 113 * * *$ & $(.(0) 1)$ \\
\hline \multicolumn{8}{|l|}{ Kontrollvariablen } \\
\hline Konstante & & & $(.(499)$ & & $(.(093)$ & & $(.39())$ \\
\hline Marktwert EK & $(t+l)$ &,$- 643 * * *$ & $(.(O)(0))$ &,$- 161 * * *$ & $(.(K) 1)$ &,$- 386 * * *$ & $(.(0)(0))$ \\
\hline Markt-Beta & $(t+l)$ & & &, 001 & $(.978)$ & & \\
\hline Volatilität & $(t+l)$ & & &,- 037 & $(.505)$ & ,034 & $(.312)$ \\
\hline Handelsvolumen & $(t+l)$ &, $701 * * *$ & $(.()(x))$ & & & & \\
\hline Aktienrendite & $(t+l)$ & $184 * * *$ & $(.0(0))$ &, $190 * * *$ & $(.()(x))$ &, 031 & $(.293)$ \\
\hline Verschuldung [F] & $(t)$ & & &, $251 * * *$ & $(.(0)(0))$ & & \\
\hline Erfolg [Faktor] & $(t)$ &,- 025 & $(.471)$ &,$- 088 * *$ & $(.(128)$ & & \\
\hline Inv. Freefloat & $(t+l)$ &, 035 & $(.377)$ &,$- 132 * * *$ & $(.(k) 1)$ & & \\
\hline \multicolumn{8}{|c|}{ Branchenzugehörigkeit } \\
\hline Info. Tech. & $(t+l)$ & & &, 115 & $(.115)$ & & \\
\hline Cons. Goods & $(t+I)$ & & &, 109 & $(.199)$ & & \\
\hline Cons. Services & $(1+l)$ & & &,$- 135^{*}$ & $(.054)$ & & \\
\hline Industrials & $(t+l)$ & & & $.212 *$ & $(.052)$ & & \\
\hline Pharma \& H. & $(t+I)$ & & &, 003 & $(.964)$ & & \\
\hline Basic Materials & $(t+I)$ & & &,- 105 & $(.131)$ & & \\
\hline Utilities & $(t+I)$ & & &, 006 & $(.9(x))$ & & \\
\hline Alter: Klasse 1 & $(t+l)$ & & &,$- 113 * *$ & $(.(045)$ & & \\
\hline Alter: Klasse 2 & $(t+l)$ & & &,- 081 & $(.1(x)$ & & \\
\hline Alter: Klasse 3 & $(t+I)$ & & &,- 062 & $(.178)$ & & \\
\hline Abschluss: Std. & $(t)$ & & & .049 & $(.223)$ & & \\
\hline Abschluss: Prüf. & $(t)$ & & &, $105 * * *$ & $(.(0)(5))$ & & \\
\hline \multicolumn{8}{|c|}{ Indexzugehörigkeit } \\
\hline Dax & $(t+l)$ &,$- 383 * * *$ & $(.(0) 1)$ & & &,$- 361 * * *$ & $(,(0)(0))$ \\
\hline MDax & $(t+l)$ &,$- 304 * * *$ & $(.(x)(x))$ & & &,$- 363 * * *$ & $(.00())$ \\
\hline TecDax & $(t+I)$ & $.094 *$ & (.086) & & &,$- 287 * * *$ & $(.000)$ \\
\hline SDax & $(t+I)$ &,$- 104 *$ & $(.068)$ & & &,- 039 & $(.412)$ \\
\hline Jahr & &,- 061 & $(.127)$ &,- 070 & $(.126)$ &, 033 & $(.272)$ \\
\hline$R^{2}$ & &, 435 & &, 391 & &, 531 & \\
\hline$R^{2}$ adj & &, $424 * * *$ & $(.(0)(0))$ &, $365 * * *$ & $(.(0)(0))$ &, $524 * * *$ & $(.(0(x))$ \\
\hline Durbin-Watson $d$ & & 1,898 & & 1,894 & & 1,733 & \\
\hline $\mathrm{n}\left(\mathrm{n}_{\mathrm{nwax}}=600 \mathrm{bzw}\right.$. & D0) & 557 & & 508 & & 662 & \\
\hline
\end{tabular}

Ursprungsmodell (logarithmierte Regressanden)

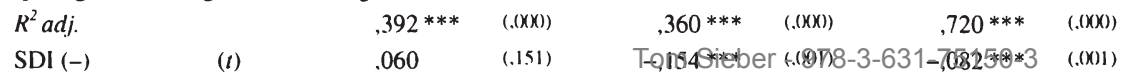


Anhang 13: Uni- und bivariate Statistik zentraler Variablen

\begin{tabular}{|c|c|c|c|c|c|c|c|c|c|c|c|c|}
\hline \multicolumn{13}{|c|}{ Univariate Statistik der zentralen Variablen des Untersuchungsmodells } \\
\hline \multirow[b]{2}{*}{ Kategorie } & \multirow[b]{2}{*}{ Variable } & \multirow[b]{2}{*}{ Zeit } & \multirow[b]{2}{*}{$\mathrm{n}$} & \multirow[b]{2}{*}{$\mu$} & \multirow[b]{2}{*}{$\sigma$} & \multicolumn{2}{|c|}{ Extrema } & \multicolumn{5}{|c|}{ Perzentile } \\
\hline & & & & & & Min & Max & 1 & 25 & 50 & 75 & 99 \\
\hline- & SDI & $(t)$ & 700 & 0,338 & 0,12 & 0,030 & 0,830 & 0,110 & 0,250 & 0,330 & 0,400 & 0,700 \\
\hline Aktie & Inv. Freefloat & $(t)$ & 700 & 34,26 & 25,6 & 0,000 & 98,800 & 0,000 & 10,103 & 31,73 & 54,595 & 89,39 \\
\hline Aktie & Inv. Freefloat & $(t+1)$ & 600 & 33,84 & 25,3 & 0,000 & 93,130 & 0,000 & 10,103 & 31,34 & 54,234 & 88,36 \\
\hline Aktie & Konzentration $[\mathrm{F}]$ & $(t)$ & 700 & 0,000 & 1,00 & $-1,346$ & 2,246 & $-1,346$ & $-0,948$ & $-0,056$ & 0,768 & 2,227 \\
\hline Analysten & Anzahl & $(t)$ & 700 & 16,79 & 11,5 & 0,000 & 47,333 & 0,000 & 7,583 & 14,17 & 25,396 & 43,66 \\
\hline Analysten & Anzahl & $(t+1)$ & 700 & 16,99 & 10,9 & 0,000 & 46,417 & 0,000 & 7,938 & 14,75 & 25,229 & 42,58 \\
\hline Analysten & Empfehlungsvar. & $(t+I)$ & 671 & 1,045 & 0,26 & 0,000 & 1,915 & 0,000 & 0,898 & 1,042 & 1,208 & 1,682 \\
\hline Analysten & Schätzvarianz & $(t+l)$ & 645 & 0,059 & 0,04 & 0,002 & 0,322 & 0,006 & 0,027 & 0,045 & 0,075 & 0,275 \\
\hline Analysten & Schätzgüte & $(t+l)$ & 445 & 0,360 & 0,27 & 0,000 & 0,994 & 0,006 & 0,124 & 0,288 & 0,568 & 0,984 \\
\hline Bewertung & Markt-Beta & $(t+1)$ & 651 & 0,897 & 0,34 & 0,026 & 2,094 & 0,189 & 0,670 & 0,856 & 1,104 & 1,837 \\
\hline Bewe & EK-Kosten & $(t+l)$ & 661 & 6,782 & 1,86 & 1,270 & 13,52 & 2,162 & 5,685 & 6,610 & 7,790 & 12,09 \\
\hline Bewertung & Marktwert (Ln) & $(t)$ & 700 & 20,92 & 1,85 & 14,30 & 25,33 & 16,90 & 19,57 & 20,66 & 22,19 & 24,91 \\
\hline Bewertung & Marktwert (Ln) & $(t+1)$ & 700 & 21,06 & 1,78 & 15,94 & 25,33 & 17,49 & 19,76 & 20,81 & 22,34 & 24,91 \\
\hline Bewertung & Umsatzmultiple & $(t+I)$ & 586 & 0,917 & 0,91 & 0,028 & 6,709 & 0,086 & 0,313 & 0,627 & 1,186 & 5,257 \\
\hline Bewertung & Ums & $(t+l)$ & 586 & 0,091 & 0,90 & $-2,936$ & 5,619 & $-2,345$ & $-0,495$ & $-0,230$ & 0,172 & 3,450 \\
\hline $\mathrm{hg}$ & Tobin's Q & $(t+1)$ & 582 & 8 & 1,29 & 6 & 3 & 42 & 1,386 & 2,018 & 2,700 & 7,021 \\
\hline Finanz. & EK-Quote & $(t)$ & 700 & 38,01 & 17,9 & $-8,504$ & 90,74 & 3,068 & 24,64 & 35,12 & 48,65 & 84,82 \\
\hline Finanz. & Verschuldung $[\mathrm{F}]$ & $(t)$ & 700 & 0,000 & 1,00 & $-1,827$ & 4,792 & $-1,645$ & $-0,792$ & $-0,095$ & 0,670 & 2,843 \\
\hline Finanz. & Verschuldung $[\mathrm{F}]$ & $(t+1)$ & 600 & 0,008 & 1,00 & $-1,827$ & 4,792 & $-1,663$ & $-0,788$ & $-0,126$ & 0,668 & 2,940 \\
\hline Handel & Volumen p.a. (Ln) & $(t)$ & 700 & 20,44 & 2,49 & 13,30 & 26,40 & 14,80 & 18,70 & 20,10 & 22,30 & 25,69 \\
\hline Handel & Volumen p.a. (Ln) & $(t+I)$ & 700 & 20,63 & 2,38 & 13,30 & 26,40 & 15,70 & 18,91 & 20,20 & 22,50 & 25,70 \\
\hline Handel & Volatilität & $(t+1)$ & 651 & 30,45 & 8,31 & 14,73 & 59,15 & 16,15 & 24,68 & 28,902 & 35,06 & 54,27 \\
\hline Handel & Bid-Ask-Spreads & $(t+1)$ & 690 & 0,010 & 0,00 & 0,001 & 0,044 & 0,001 & 0,004 & 0,008 & 0,014 & 0,039 \\
\hline Erfolg & Aktienrendite & $(t)$ & 700 & 16,94 & 70,2 & $-88,00$ & 638,1 & $-80,09$ & $-22,05$ & 9,650 & 41,10 & 248,8 \\
\hline Erfolg & Aktienrendite & $(t+1)$ & 700 & 25,67 & 70,9 & $-94,50$ & 638,1 & $-79,94$ & $-8,375$ & 17,50 & 44,90 & 305,4 \\
\hline Erfolg & Profitabilität [F] & $(t)$ & 698 & 0,000 & 1,00 & $-12,65$ & 1,799 & $-5,624$ & $-0,167$ & 0,050 & 0,315 & 1,208 \\
\hline Erfolg & Profitabilität $[\mathrm{F}]$ & $(t+1)$ & 599 & 0,058 & 0,77 & $-9,152$ & 1,799 & $-3,205$ & $-0,149$ & 0,081 & 0,344 & 1,214 \\
\hline Größe & Größe (Ln) [F] & $(t)$ & 699 & 0,000 & 1,00 & $-2,999$ & 2,231 & $-2,208$ & $-0,742$ & $-0,121$ & 0,753 & 2,143 \\
\hline Größe & Größe (Ln) [F] & $(t+1)$ & 600 & 0,015 & 0,98 & $-2,999$ & 2,231 & $-2,181$ & $-0,731$ & $-0,108$ & 0,772 & 2,143 \\
\hline Makro & Börsenentw. [F] & $(t)$ & 700 & 0,000 & 1,00 & $-1,403$ & 1,644 & $-1,403$ & $-0,670$ & $-0,369$ & 1,146 & 1,644 \\
\hline Makro & Konjunktur $[\mathrm{F}]$ & $(t)$ & 700 & 0,000 & 1,00 & $-1,529$ & 1,549 & $-1,529$ & $-0,875$ & $-0,191$ & 1,120 & 1,549 \\
\hline - & Jahr & - & 700 & & & & & & & & & \\
\hline
\end{tabular}


Anhang 13: Uni- und bivariate Statistik zentraler Variablen (Forts.)

\section{Korrelationsmatrix der zentralen Variablen des Untersuchungsmodells}

Angaben in Klammern repräsentieren die zu den jeweiligen Korrelationskexeffizienten zugehörigen p-Werte. Keine separate Ausweisung der StichprobengröBen. jedech gilt stets $\mathrm{n}>500$.

Wente unterhalb der Diagonale stellen die Korrelationskoeffizienten nach Pearson. Wene oberhalh der Diagonale die Rang-Korrelationskoeffizienten nach Spearman dar.

\begin{tabular}{|c|c|c|c|c|c|c|c|c|c|c|c|c|c|c|c|c|c|c|c|c|c|c|c|c|c|c|c|c|c|c|c|c|c|c|}
\hline & & & & & & & & & & & & & & & & & & & & & & & & & & & & & & & & & & \\
\hline & SDI & 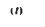 & & 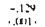 & into & - & : स: & 年 & 11.8. & $\begin{array}{l}.161 \\
\text {.1010). }\end{array}$ & - & $\lim _{0,3}$ & $\frac{316}{2010}$ & (3) & . Whe & . & . & : & (4) & . 130 & 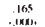 & (3in & s.su & . & - intin & 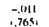 & -.144 & in & . 147 & $3 \times s$ & (3) & : & w & (1i) \\
\hline & w. Irecthoral & $(n)$ & in & & . & :ii: & 每. & 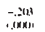 & s: & 103 & (191, & ini & 等 & (1) & whents & int & Nisi. & . & .153 & 年 & 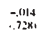 & (x) & . & 表 & .xy & - & 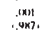 & Nat & , & 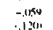 & 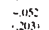 & 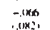 & - & 年 \\
\hline katis & w. Frevefhos & $u+1$ & & . & & 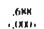 & 集 & (x) & 年 & & $377_{1}$ & 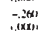 & 年 & 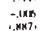 & . & 管 & ${ }_{1,30}$ & (1) & & $=0$ & 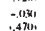 & 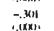 & . & & . 3401 & .1 & ; & 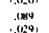 & & & & & 管 & tr: \\
\hline & Kondentration & 1 in & & .177 & . & & $-\ldots+4$ & & 正S & 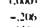 & $-.15 \%$ & $=$ & $-x_{\infty}$ & in: & .10 .4 & 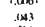 & . & . & - & $=., 4 k a \mathrm{~A}$ & $\sinh 2 y$ & 36 : & .... & 年 & 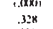 & .1.1 & (27ks & 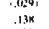 & & & & & (1110. & . 1603 \\
\hline & Anzahl (W) & (i) & .4 & - . & -2.13 & -.24 & & .474 & . & & & XIIM & & & & & & & & & & & $7 \times 4$ & & & & & & & & & & & \\
\hline & & & & 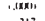 &. $\ln 611$ & , $x \times 101$ & & 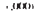 & . & $7 \mathrm{nk}$. & $\therefore$ & $44:=$ & $.6 x$ & 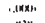 & atsis) & tit & sox: & N & 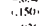 & (1) & 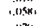 & 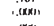 & (xiv) & wi & (1) & . it & & . & & & in & & 201. & 等, \\
\hline & Anzahl & & . & 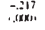 & 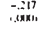 & . & (4787) & & . & 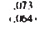 & $\begin{array}{r}-1.31 \\
.10161\end{array}$ & 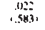 & , & (3) & 每: & .131: & 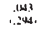 & . & -0.1368 & .15: & . & $=0 \times 10$ & 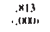 & $a x$ & (3) & 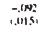 & (xil. & 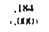 & . & (in. & in. & & , & 年 \\
\hline & Emprechlum & $(t+1)$ & & - & . & (1) & . & . 11106 & & . & . & 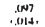 & - & . & 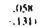 & $\begin{array}{l}-1313 \\
.1112\end{array}$ & . & 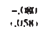 & 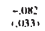 & $=$ & $\begin{array}{l}-1,131 \\
., 46.1\end{array}$ & $\begin{array}{l}.13 \% \\
.18 \times, 1\end{array}$ & . 1477. & $\begin{array}{l}.064 \\
.1110 .\end{array}$ &. & 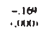 & $\begin{array}{l}0.1 \\
\text { ISt. }\end{array}$ & $(x)=$ & - & (x). & . & & 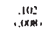 & .1313 \\
\hline alyst & Schälrvarian & $(t+1$ & . & . & 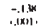 & 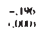 & 等: & 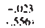 & $\underset{180}{180}$ & & $\begin{array}{l}.116 \\
.1017\end{array}$ & . 1,160 & : & 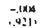 & 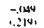 & . & 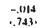 & - & in & 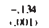 & 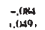 & . & 年 & 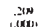 & (1) & -1 & ition & 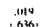 & & 1640 & so & & .116 & (111) \\
\hline & Schäluguthe & $1+1$ & 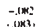 & 333 & n & & 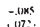 & . & (1): & .110.: & & . & 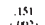 & $1 \omega$ & int & -1 & 40 & - & & 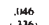 & 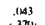 & & 年 & th & wi & $-x$ & 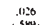 & $\therefore$ & & & & & 1 & . \\
\hline & Markl-Beta & ${ }^{t}(+) \mid$ & 1060 & 列 & $\cdots$ & & $-.0 \times 2 \times$ & 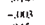 & .079 & .133 & . & & 128 & & - & $-\ldots+c-c$ & (1II) & . & & 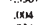 & & & 187 & . & & & & & & & & & & 等: \\
\hline & & & & & & & & & & & & & & & & & & & & & & & & & & & & & & & & & & \\
\hline & & & . & inta & . & (1.137. & , i.txpin & xat. & tit & 10.0. & 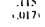 & . & & . & 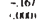 & $\therefore$ & 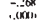 & 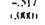 & . & 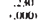 & . & 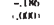 & - & $\therefore 6$ & & i. & wis. & 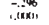 & & & tis & & & (11) \\
\hline & Marktwic & (t) & 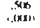 & 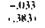 & 等 & 13.1. & 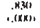 & 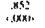 & $x_{3}^{x,}$ & iii & 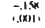 & . & $\begin{array}{l}-.143 \\
. .4 \times 1\end{array}$ & & 然 & . 140 & t3: & 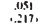 & $\begin{array}{l}10 x \\
x+2,2\end{array}$ & 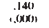 & $\begin{array}{l}1.165 \\
.1 \times 2 n\end{array}$ & & . 7601 & $\therefore$ & & $\therefore$ & & 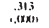 & . & & $\therefore$ & & (1). & 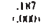 \\
\hline & arkiwen (IIn & ${ }^{(t+1}$ & (x) & 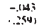 & 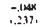 & 年 & (4) & 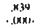 & 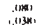 & - & (. $(x) 1$. & ${ }_{74}$ & $\begin{array}{l}-1.140 \\
.(1 \times 1 \times n\end{array}$ & 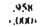 & & a & 踏. & . & 120 & 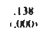 & - & 年4 & (A) & 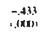 & (ist) & , on? & (NS) & , 8,170 & & & & & 1318. & \\
\hline & Intiph & $1+1$ & $\operatorname{sim}_{x \rightarrow 0}$ & (1) & 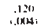 & (iin. & 47. & . & 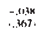 & : & (3). & . & iixix & , & . & & (101010 & 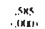 & (a) & (x) & . ix $3>>2$ & 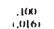 & (1)19i: & 3 & 917 & itit & & IIIX & & & & & 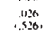 & . \\
\hline & Cinsult,nult a & $(1+1$ & 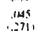 & ivis & 等, & $7 \pi$ & isti & . & 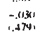 & 然, & 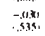 & ith. & . & 桨, & (1)1 & . & & . & 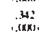 & : & ain & (ax) & 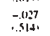 & $\begin{array}{l}-.6117 \\
.60 \% 4\end{array}$ & (6. & (i) & & 等 & & & & & 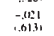 & - \\
\hline & so & " & . & & (1) & 要 & 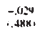 & 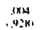 & 2, & & v. & IIII, & . it & & , 11677 & $\because \pi$ & .460 & & $\therefore$ & ixxin & (17). & & & 100 & & & & & & & & & & \\
\hline & Quore & " & & & (14) & & $\lim _{i, 2}$ & & & & & 14 & & & & & & 23 & & & & & & & & & & & & & & & & \\
\hline & & $(t)$ & & & & & & & & & & & & & & & & & & & & & & & & & & & & & & & & \\
\hline & $v_{c e}$ & $(t)$ & 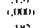 & .376 & . & 步 & 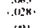 & 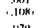 & 14. & & .115 & inis & i. 1000 & & . & & 禁 & (IX) & $x=1$ & & 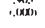 & & (x) & & & & & & & & & & & 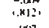 \\
\hline & rseh & 1 & (10:2) & $(0,3)$ & 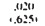 & & $\begin{array}{l}\text { (N) } \\
\text { (N) }\end{array}$ & .1. & & & .1774 & - & 157 & & .10 & $-3 x$ & - rax & 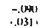 & in & . & & 153,3 & Tiis & 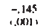 & & & & $\begin{array}{l}w_{1} \\
x_{1}\end{array}$ & & & & & & 47 \\
\hline & Volumen p.... & b) & & & & & , ture & & & & .0 & ii. & & & ; & $x_{0.03}$ & & .1401, & & in & . & & & & & & & & & & & & & \\
\hline & Volumen p.a. & 1) $(1+1$ & & & & & & & & & & & & & & & & & & & & & & & & & & & & & & & & \\
\hline & & & & & & & & & & & & & & & & & & $\therefore 12+2$ & & & & & & & & & & & & & & & & \\
\hline & Volatilit & ${ }^{11+1}$ & & II): & (ix): & & & & & & , & (x)in, & & & & & $1,15 \%$. & 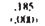 & & & . $103 \times 1$ & . & tit & & $x$ & & & & & & & & & \\
\hline & Bi & & . & & tixx & 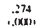 & . (1001) & & & .4\$3. & $\{(1013.3$ & 24. & , 1473 & & it & & $11+1$ & & $\therefore$ & & (1)1 & & r. & it & & & & & & & & & & , ix \\
\hline & Adaienrendat & in & & & & & & & & & $-\because$ & 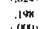 & iil & & & & & 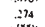 & & & & & & & & & & & & & & & & \\
\hline & $A_{1}$ & & & & $-\infty$ & & & & & & & & & & & & & & & & & & & & & .0018 & & & & & & & & \\
\hline & & & & & & & & & & & & & & & & & & & & & & & & & & & & & & & & & & \\
\hline & & & & & & th & 先 & 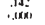 & sis: & & iti & & $\therefore$ & & & $\therefore$ & & & & & & . & & & & . & & & & & & & & \\
\hline & Profrabilikat If & "t & (n) & & 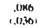 & $\frac{1}{x}$ & . & it & 管 & & 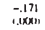 & , & 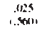 & & & , th & & & & & $\therefore$ & & & & & & & & & & & & & \\
\hline & Bee (I., n) IF & (n) & in & & & & : & : & & & . & & & & & & & ii & 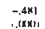 & 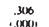 & & & & & & & & & & & & & 年 & \\
\hline & & & & & & & & & & & & & & & & & & & & & & & & & & & & & & & & & & \\
\hline & & & & & & & & $.10 \mathrm{x}-2$ & & & & & & & & & & & & & & & & & & & & & & & & & & \\
\hline & & & ist & & . & 然 & (1) & s. & ; & . & $\pi$ & 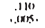 & & & & & & & $\therefore$ & & & & & & & & & & & (1) & & & (XII) & $\alpha(x)$ \\
\hline & $\mathrm{k}$ & & . & & . & -818 & & $\therefore$ & $\therefore$ & & .1 & & & & & & & & & & & & & & & & & & & & & & & \\
\hline & & & & & , & sitivi & & & (inn & & & & & & & & & & & & & & & & & & & & & & & & & \\
\hline
\end{tabular}




\section{Literaturverzeichnis}

Abell, Derek F. (1980): Defining the Business: The Starting Point of Strategic Planning, Englewood Cliffs

Aboody, David / Kasznik, Ron (2000): CEO Stock Option Awards and the Timing of Corporate Voluntary Disclosures, in: Journal of Accounting \& Economics, 29. Jg., Nr. 1, S. 73-100

Aboody, David / Lev, Baruch (1998): The Value-Relevance of Intangibles: The Case of Software Capitalization, in: Journal of Accounting Research, 36. Jg., Nr. 3 (Supplement), S. 161-191

Achleitner, Ann-Kristin / Bassen, Alexander / Pietzsch, Luisa (2001): Kapitalmarktkommunikation von Wachstumsunternehmen, Stuttgart

Achleitner, Ann-Kristin / Bassen, Alexander / Pietzsch, Luisa / Wichels, Daniel (2002): Effiziente Kapitalmarktkommunikation mit Finanzanalysten: Gestaltungsempfehlungen für Wachstumsunternehmen, in: Finanz Betrieb, 4. Jg., Nr. 1, S. 29-44

Achleitner, Ann-Kristin / Groth, Thorsten / Pietzsch, Luisa (2005): Bestimmungsfaktoren der Analystenabdeckung, in: Finanz Betrieb, 7. Jg., Nr. 4, S. 261-272

Adam, Dietrich (1996): Planung und Entscheidung. Modelle, Ziele, Methoden, 4. Auflage, Wiesbaden

Agca, Ahmed / Oender, Serife (2007): Voluntary Disclosures in Turkey: A Study on Firms listed in Istanbul Stock Exchange, in: Problems and Perspectives in Management, 5. Jg., Nr. 3, S. 241-251

Aglietta, Michel / Rebérioux, Antoine (2005): Corporate Governance Adrift. A Critique of Shareholder Value, Cheltenham

Ahmed, Kamran (1995): The Effect of Corporate Characteristics on Disclosure Quality in Corporate Annual Reports: A Meta Analysis, Working Paper, Victoria University of Wellington, New Zealand

Ahmed, Kamran / Courtis, John K. (1999): Associations between Corporate Characteristics and Disclosure Levels in Annual Reports: A Meta Analysis, in: British Accounting Review, 31. Jg., Nr. 1, S. 35-61 
AICPA [American Institute of Certified Public Accountants, Hrsg.] (1994): Improving Business Reporting. A Customer Focus, Special Committee on Financial Reporting, Final Report

Quelle: http://www.aicpa.org/Professional+Resources/... Accounting+and+Auditing/Accounting+Standards/ibr/ (Stand am 19.10.2009)

Ajinkya, Bipin B. / Gift, Michael (1984): Corporate Managers' Earnings Forecasts and Symmetrical Adjustments of Market Expectations, in: Journal of Accounting Research, 22. Jg., Nr. 2, S. 425-444

Akerlof, George A. (1970): The Market for 'Lemons': Quality Uncertainty and the Market Mechanism, in: Quarterly Journal of Economics, 84. Jg., Nr. 3, S. 488-500

Alford, Andrew / Jones, Jennifer / Leftwich, Richard / Zmijewski, Mark (1993): The Relative Informativeness of Accounting Disclosures in Different Countries, in: Journal of Accounting Research, 31. Jg., Nr. 3 (Supplement), S. 183-223

Ali, Ashiq / Chen, Tai-Yuan / Radhakrishnan, Suresh (2007): Corporate Disclosures by Family Firms, in: Journal of Accounting and Economics, 44. Jg., Nr. 1-2, S. 238-286

Alvarez, Manuel / Wotschofsky, Stefan (2000a): Zwischenberichterstattung nach Börsenrecht, IAS und US-GAAP, Bielefeld 2000

Alvarez, Manuel / Wotschofsky, Stefan (2000b): Zur Bedeutung der Zwischenberichtspublizität, in: Deutsches Steuerrecht, 38. Jg., Nr. 42, S. 1789-1796

Alvarez, Manuel / Wotschofsky, Stefan (2000c): Zwischenberichterstattung: Unterjährige Erfolgsabgrenzung, in: Finanz Betrieb, 2. Jg., Beilage, Nr. 1, S. 35-43

AAA [American Accounting Association, Hrsg.] (2001): Equity Valuation Models and Measuring Goodwill Impairment, in: Accounting Horizons, 15. Jg., Nr. 2, S. 161-170

Amihud, Yakov / Mendelson, Haim (1986): Asset Pricing and the Bid-Ask Spread, in: Journal of Financial Economics, 17. Jg., Nr. 2, S. 223-249

Amir, Eli / Lev, Baruch (1996): Value-Relevance of Nonfinancial Information: The Wireless Communication Industry, in: Journal of Accounting and Economics, 22. Jg., Nr. 1-3 (Conference Issue on Contemporary Financial Reporting Issues), S. 3-30

Anderson, Ronald C. / Reeb, David M. (2003): Founding-Family Ownership and Firm Performance: Evidence from the S\&P 500, in: Journal of Finance, 58. Jg., Nr. 3, S. $1301-1328$

Andrews, Kenneth R. (1987): The Concept of Corporate Strategy, 3. Auflage, Homewood Ansoff, H. Igor (1965): Corporate Strategy, New York 
Ansoff, H. Igor (1975): Managing Strategic Surprise by Response to Weak Signals, in: California Management Review, 18. Jg., Nr. 2, S. 21-33

Ansoff, H. Igor (1980): Strategic Issue Management, in: Strategic Management Journal, 1. Jg., Nr. 2, S. 131-148

Ansoff, H. Igor (1991): Critique of Henry Mintzberg's 'The Design School: Reconsidering the Basic Premises of Strategic Management', in: Strategic Management Journal, 12. Jg., Nr. 6, S. 449-461

Ansoff, H. Igor / McDonnell, Edward J. (1990): Implanting Strategic Management, 2. Auflage, New York

Ansoff, H. Igor / Declerck, Roger P. / Hayes, Robert, L. (1999): From Strategic Planning to Strategic Management, in: Hahn/Taylor [Hrsg.], Strategische Unternehmungsplanung - Strategische Unternehmungsführung, 8. Auflage, Heidelberg, S. 105-143

AK DVFA [Arbeitskreis „DVFA“ der Schmalenbach-Gesellschaft für Betriebswirtschaft e.V., Hrsg.] (2003): Empfehlungen zur Ermittlung prognosefähiger Ergebnisse, in: Der Betrieb, 56. Jg., Nr. 36, S. 1913-1917

AKEU [Arbeitskreis ,Externe Unternehmensrechnung“ der Schmalenbach-Gesellschaft für Betriebswirtschaft e.V., Hrsg.] (2001): Die Zukunft der Rechnungslegung aus Sicht von Wissenschaft und Praxis - Fachprogramm des Arbeitskreises Externe Unternehmensrechnung im Rahmen des 54. Deutschen Betriebswirtschafter-Tages, in: Der Betrieb, 54. Jg., Nr. 4, S. 160-161

AKEU [Arbeitskreis ,Externe Unternehmensrechnung“ der Schmalenbach-Gesellschaft für Betriebswirtschaft e.V., Hrsg.] (2002): Grundsätze für das Value Reporting, in: Der Betrieb, 55. Jg., Nr. 45, S. 2337-2340

Armeloh, Karl-Heinz (1998): Die Berichterstattung im Anhang: Eine theoretische und empirische Untersuchung der Qualität der Berichterstattung im Anhang börsennotierter Kapitalgesellschaften, Düsseldorf

Arrow, Kenneth J. (1983): The Organization of Economic Activity: Issues Pertinent to the Choice of Market versus Nonmarket Allocation, in: Collected Papers of Kenneth J. Arrow, General Equilibrium, 2. Auflage, Cambridge, S. 133-155

Auer, Ludwig von (2005): Ökonometrie. Eine Einführung, 3. Auflage, Berlin Axe, Emerson Wirt / Flinn, Harold M. (1925): An Index of General Business Conditions for Germany, 1898-1914, in: The Review of Economic Statistics, 7. Jg., Nr. 4, S. 263-287

Bach, Norbert (2000): Mentale Modelle als Basis von Implementierungs-strategien. Konzepte für ein erfolgreiches Chance Management,eWhesbaden-631-75150-3 
Backhaus, Klaus / Erichson, Bernd / Plinke, Wulff / Weiber, Rolf (2008): Multivariate Analysemethoden - Eine anwendungsorientierte Einführung, 12. Auflage, Heidelberg

Baetge, Jörg (1970): Möglichkeiten der Objektivierung des Jahreserfolges, Düsseldorf

Baetge, Jörg (1992): Der beste Geschäftsbericht, in: Baetge, Jörg [Hrsg.]: Rechnungslegung und Prüfung, Düsseldorf, S. 199-230

Baetge, Jörg (1993): Lagebericht, in: Chmielewicz, Klaus / Schweitzer, Marcell [Hrsg.]: Handwörterbuch des Rechnungswesens, 3. Auflage, Stuttgart, Sp. 1327-1334

Baetge, Jörg [Hrsg.] (2009): Checkliste zu „Der beste Geschäftsbericht 2009“, Betriebswirtschaftlicher Inhalt, Branche: Industrie/Handel Quelle: http://www.wiwi.uni-muenster.de/baetge/geschaeftsbericht/... daten/ChecklisteIndustrie2009.pdf (Stand am 09.08.2009)

Baetge, Jörg / Beermann, Thomas (1998): Die Bilanzierung von Vermögenswerten in der Bilanz nach International Accounting Standards und der dynamischen Bilanztheorie Schmalenbachs, in: Betriebswirtschaftliche Forschung und Praxis, 50. Jg., Nr. 2, S. 154-168

Baetge, Jörg / Brötzmann, Ingo (2003): Die Geschäftsberichterstattung - Anforderungen und empirische Befunde, in: Albach, Horst / Kraus, Horst / Kraus, Willy [Hrsg.]: Werte, Wettbewerb und Wandel, Gedenkschrift Zimmerer, Wiesbaden, S. 9-40

Baetge, Jörg / Hollmann, Sebastian (2004): Zur Zuverlässigkeit der Rechnungslegung nach IFRS, in: Döring, Ulrich / Kussmaul, Heinz [Hrsg.]: Spezialisierung und Internationalisierung - Entwicklungstendenzen der deutschen Betriebswirtschaftslehre, Festschrift Wöhe, Wiesbaden, S. 349-378

Baetge, Jörg / Heumann, Rainer (2006a): Value Reporting in Konzernlageberichten, in: Zeitschrift für internationale Rechnungslegung, 1. Jg., Nr. 1, S. 39-47

Baetge, Jörg / Heumann, Rainer (2006b): Wertorientierte Berichterstattung Anforderungen des Kapitalmarkts und Umsetzung in der Konzernlageberichterstattung, in: Der Betrieb, 59. Jg., Nr. 7, S. 345-350

Baetge, Jörg / Hippel, Boris (2009): Berichterstattung über Nachhaltigkeits-indikatoren (,Sustainable Development-Key Performance Indicators“) in Geschäftsberichten unter besonderer Berücksichtigung von Best Practices, in: Bub, Wolf-Rüdiger / Mehle, Volkmar / Schumann, Ekkehard [Hrsg.]: Recht und Politik, Festschrift Gauweiler, München, S. 545-564 
Baetge, Jörg / Kirchhoff, Klaus Rainer (1997): Der Geschäftsbericht: Die Visitenkarte des Unternehmens, Wien

Baetge, Jörg / Kümmel, Jens (2003): Shareholder Value Reporting mit Hilfe wertorientierter Unternehmenskennzahlen, in: Rathgeber, Andreas / Tebroke, Hermann-Josef / Wallmeier, Martin [Hrsg.]: Finanzwirtschaft, Kapitalmarkt und Banken, Festschrift Steiner, S. 47-66

Baetge, Jörg / Noelle, Jennifer (2001): Shareholder-Value-Reporting sowie Prognose- und Performancepublizität, in: Zeitschrift für kapitalmarktorientierte Rechnungslegung, 1. Jg., Nr. 4, S. 174-180

Baetge, Jörg / Prigge, Cord (2006): Anforderungen an verpflichtende, empfohlene und freiwillige Angaben des Konzernlageberichts, in: Der Betrieb, 59. Jg., Nr. 6, S. 401407

Baetge, Jörg / Schulze, Dennis (1998): Möglichkeiten der Objektivierung der Lageberichterstattung über Risiken der künftigen Entwicklung: Ein Vorschlag zur praktischen Umsetzung der vom KonTraG verlangten Berichtspflichten, in: Der Betrieb, 51. Jg., Nr. 19, S. 937-948

Baetge, Jörg / Fischer, Thomas R. / Paskert, Dierk (1989): Der Lagebericht. Aufstellung, Prüfung und Offenlegung, Stuttgart

Baetge, Jörg / Armeloh, Karl-Heinz / Schulze, Dennis (1997): Anforderungen an die Geschäftsberichtserstattung aus betriebswirtschaftlicher und handelsrechtlicher Sicht, in: Deutsches Steuerrecht, 35. Jg., Nr. 5, S. 176-180

Baetge, Jörg / Kirsch, Hans-Jürgen / Thiele, Stefan (2009a): Konzernbilanzen, 8. Auflage, Düsseldorf

Baetge, Jörg / Kirsch, Hans-Jürgen / Thiele, Stefan (2009b): Bilanzen, 10. Auflage, Düsseldorf

Baetge, Jörg / Glaum, Martin / Grothe, Alexander / Oberdörster, Tatjana (2010): Lohnt sich ,gute Berichterstattung“ am Kapitalmarkt? - Die Qualität der Konzernanhänge und -lageberichte deutscher Unternehmen und Gewinnschätzungen von Analysten, in: Zeitschrift für Betriebswirtschaft, 80. Jg., Sonderheft 3/2010, S. 65-105

Bagnoli, Mark / Watts, Susan G. (2007): Financial Reporting and Supplemental Voluntary Disclosures, in: Journal of Accounting Research, 45. Jg., Nr. 5, S. 885-913

Baiman, Stanley / Verrecchia, Robert E. (1995): Earnings and Price-Based Compensation Contracts in the Presence of Discretionary Trading and Incomplete Contracting, in: Journal of Accounting and Economics, 20. Jg., Nr. 1, S. 93-121 
Baiman, Stanley / Verrecchia, Robert E. (1996): The Relation among Capital Markets, Financial Disclosure, Production Efficiency, and Insider Trading, in: Journal of Accounting Research, 34. Jg., Nr. 1, S. 1-22

Ball, Ray / Brown, Philip (1968): An Empirical Evaluation of Accounting Income Numbers, in: Journal of Accounting Research, 6. Jg., Nr. 2, S. 159-178

Ballwieser, Wolfgang (1985a): Ergebnisse der Informationsökonomie zur Informationsfunktion der Rechnungslegung, in: Stöppler, Siegmar [Hrsg.]: Information und Produktion. Beiträge zur Unternehmenstheorie und Unternehmensplanung, Festschrift Wittmann, Stuttgart, S. 21-40

Ballwieser, Wolfgang (1985b): Informationsökonomie, Rechnungslegungstheorie und Bilanzrichtlinie-Gesetz, in: Zeitschrift für betriebswirtschaftliche Forschung, 37. Jg., Nr. 1, S. 47-66

Ballwieser, Wolfgang (1987): Kapitalmarkt und Informationsversorgung mit Jahresabschlüssen, in: Claussen, Carsten P. / Hübl, Lothar / Schneider, Hans-Peter [Hrsg.]: Zweihundert Jahre Geld und Brief. Herausforderungen an die Kapitalmärkte, Festgabe an die Niedersächsische Börse zu Hannover aus Anlass ihres 200jährigen Bestehens, Frankfurt, S. 163-178

Ballwieser, Wolfgang (1991): Das Rechnungswesen im Lichte ökonomischer Theorie, in: Ordelheide, Dieter / Rudolph, Bernd / Büsselmann, Elke [Hrsg.]:

Betriebswirtschaftslehre und Ökonomische Theorie, Stuttgart, S. 97-124

Ballwieser, Wolfgang (1997a): Die Lageberichte der DAX-Gesellschaften im Lichte der Grundsätze ordnungsgemäßer Lageberichterstattung, in: Fischer, Thomas / Hömberg, Reinhold [Hrsg.]: Jahresabschluss und Jahresabschlussprüfung, Festschrift Baetge, Düsseldorf, S. 153-187

Ballwieser, Wolfgang (1997b): Grenzen des Vergleichs von Rechnungslegungssystemen dargestellt anhand von HGB, US-GAAP und IAS, in: Forster, Karl-Heinz [Hrsg.]: Aktien- und Bilanzrecht, Festschrift Kropff, Düsseldorf, S. 372-391

Ballwieser, Wolfgang (2001a): Konzernrechnungslegung und Wettbewerb. Kapitalkosten, Netzwerkeffekte, Rechnungslegung, Regulierung, Signalling, Wettbewerb, in: Die Betriebswirtschaft, 61. Jg., Nr. 6, S. 640-657

Ballwieser, Wolfgang (2001b): Anforderungen des Kapitalmarktes an Bilanzansatz- und Bilanzbewertungsregeln, in: Zeitschrift für kapitalmarktorientierte Rechnungslegung, 2. Jg., Nr. 4, S. 160-164 
Ballwieser, Wolfgang (2002a): Informations-GoB - auch im Lichte von IAS und US-GAAP, in: Zeitschrift für kapitalmarktorientierte Rechnungslegung, 3. Jg. (2002), Nr. 3, S. $115-121$

Ballwieser, Wolfgang (2002b): Rechnungslegung im Umbruch, in: Der Schweizer Treuhänder, 75. Jg., Nr. 4, S. 295-304

Ballwieser, Wolfgang (2003): Rahmenkonzepte der Rechnungslegung: Funktionen, Vergleich, Bedeutung, in: Der Konzern, 1. Jg., Nr. 5, S. 336-348

Ballwieser, Wolfgang (2004): Unternehmensbewertung. Prozess, Methoden und Probleme, Stuttgart

Ballwieser, Wolfgang (2005): Die Entwicklungen beim Lagebericht, in: Baetge, Jörg / Kirsch, Hans-Jürgen [Hrsg.]: Anpassung des deutschen Bilanzrechts an internationale Standards - Bilanzrechtsreformgesetz und Bilanzkontrollgesetz, Düsseldorf, S. 1-10

Ballwieser, Wolfgang (2006): IFRS-Rechnungslegung. Konzept, Regeln und Wirkungen, München

Ballwieser, Wolfgang / Küting, Karlheinz / Schildbach, Thomas (2004): Fair value erstrebenswerter Wertansatz im Rahmen einer Reform der handelsrechtlichen Rechnungslegung?, in: Betriebswirtschaftliche Forschung und Praxis, 56. Jg., Nr. 6 , S. 529-549

Bamberg, Günter / Coenenberg, Adolf G. (2006): Betriebswirtschaftliche Entscheidungslehre, 13. Auflage, München

Banghoj, Jesper / Plenborg, Thomas (2008): Value Relevance of Voluntary Disclosure in the Annual Report, in: Accounting and Finance, 48. Jg., Nr. 2, S. 159-180

Barberis, Nicholas (2000): Investing for the Long Run when Returns are Predictable, in: Journal of Finance, 55 Jg., Nr. 1, S. 225-264

Barckow, Andreas (1999): Der Abschluss des Core Set of Standards durch das IASC Inhalte, Bewertungen, Folgen, in: Der Betrieb, 52. Jg., Nr. 23, S. 1173-1181

Barnard, Chester I. (1974): The Functions of the Executive, 30. Auflage, Cambridge

Barney, Jay B. (1991): Firm Resources and Sustained Competitive Advantage, in: Journal of Management, 17. Jg., Nr. 1, S. 99-120

Barney, Jay B. (1996): Gaining and Sustaining Competitive Advantage, Reading

Barney, Jay B. (2001): Is the Resource-Based 'View' a Useful Perspective for Strategic Management Research? Yes, in: Academy of Management Review, 26. Jg., Nr. 1, S. 41-56 
Baron, Reuben M. / Kenny, David A. (1986): The Moderator-Mediator Variable Distinction in Social Psychological Research. Conceptual, Strategic, and Statistical Considerations, in: Journal of Personality and Social Psychology, 51. Jg., Nr. 6, S. $1173-1182$

Barron, Orie E. / Kile, Charles O. / O'Keefe, Terence B. (1999): MD\&A Quality as Measured by the SEC and Analysts' Earnings Forecasts, in: Contemporary Accounting Research, 16. Jg., Nr. 1, S. 75-109

Barry, Christopher B. / Brown, Stephen J. (1985): Differential Information and Security Market Equilibrium, in: Journal of Financial and Quantitative Analysis, 20. Jg., Nr. 4, S. 407-422

Barth, Daniela (2009): Prognoseberichterstattung. Praxis, Determinanten und Kapitalmarktwirkungen bei deutschen börsennotierten Unternehmen, Frankfurt/Main

Barth, Mary E. / Clinch, Greg / Shibano, Toshi (1999): International Accounting Harmonization and Global Equity Markets, in: Journal of Accounting and Economics, 26. Jg., Nr. 1-3, S. 201-235

Barth, Mary E. / Cram, Donald P. / Nelson, Karen K. (2001): Accruals and the Prediction of Future Cash Flows, in: The Accounting Review, 76. Jg., Nr. 1, 2001, S. 27-58

Barth, Mary E. / Landsman, Wayne R. (1995): Fundamental Issues related to Using Fair Value Accounting for Financial Reporting, in: Accounting Horizons, 9. Jg., Nr. 4, S. 97-107

Bauchowitz, Hans (1979): Die Lageberichtspublizität der deutschen Aktiengesellschaft. Eine empirische Untersuchung zum Stand der Berichterstattung gem. § 160 Abs. 1 AktG, Frankfurt

Bea, Franz Xaver / Haas, Jürgen (2005): Strategisches Management, 4. Auflage, Stuttgart

Beaver, William H. (1968): The Information Content of Annual Earnings Announcements, in: Journal of Accounting Research, 6. Jg., Nr. 3 (Supplement), S. 67-92

Beaver, William H. / Kennelly, John W. / Voss, William M. (1968): Predictive Ability as a Criterion for the Evaluation of Accounting Data, in: The Accounting Review, 43. Jg., Nr. 4, S. 675-683

Beaver, William H. (1983): Zur Effizienz des Kapitalmarktes: Gegenwärtiger Stand der Forschung, in: Betriebswirtschaftliche Forschung und Praxis, 35. Jg., Nr. 3, S. 344374

Becker, Fred G. (1987): Anreizsysteme für Führungskräfte im Strategischen Management, 2. Auflage, Bergisch Gladbach 
Beermann, Klaus / Fülling, Friedhelm / Sperl, Andreas (1976): Zusatzinformationen zum Jahresabschluss, in: Baetge, Jörg / Moxter, Adolf / Schneider, Dieter [Hrsg.]: Bilanzfragen, Festschrift Leffson, S. 191-203

Begley, Joy / Feltham, Gerald A. (2002): The Relation between Market Values, Earnings Forecasts, and Reported Earnings, in: Contemporary Accounting Research, 19. Jg., Nr. 1, S. 1-48

Beiersdorf, Kati / Buchheim, Regine (2006): IASB-Diskussionspapier ,Management Commentary“ - Export des deutschen Lageberichts als Managementbericht?, in: Betriebs-Berater, 61. Jg., Nr. 2, S. 96-100

Benjamin, James J. / Stanga, Keith G. (1977): Differences in Disclosure Needs of Major Users of Financial Statements, in: Accounting and Business Research, 7. Jg., Nr. 3, S. $187-192$

Berelson, Bernard (1952): Content Analysis in Communication Research, New York

Berndsen, Hans-Peter (1978): Unternehmenspublizität in Deutschland: Stand der empirischen Forschung, in: Die Betriebswirtschaft, 38. Jg., Nr. 1, S. 121-134

Berthel, Jürgen (1992): Informationsbedarf, in: Frese, Erich [Hrsg.], Handwörterbuch der Organisation, 3. Auflage, Stuttgart, S. 872-886

Besanko, David / Dranove, David / Shanley, Mark / Schaefer, Scott (2003): Economics of Strategy, 3. Auflage, New York

Bessembinder, Hendrik / Chan, Kalok / Seguin, Paul J. (1996): An Empirical Examination of Information, Differences of Opinion, and Trading Activity, in: Journal of Financial Economics, 40. Jg., Nr. 1, S. 105-134

Bessler, Wolfgang (1989): Zinsrisikomanagement in Kreditinstituten, Wiesbaden

Bharadwaj, Sundar G. / Varadarajan, P. Rajan / Fahy, John (1993): Sustainable Competitive Advantage in Service Industries: A Conceptual Model and Research Propositions, in: Journal of Marketing, 57. Jg., Nr. 4, S. 83-99

Bhojraj, Sanjeev / Blacconiere, Walter G. / D'Souza, Julia D. (2004): Voluntary Disclosure in a Multi-Audience Setting: An Empirical Investigation, in: The Accounting Review, 79. Jg., Nr. 4, S. 921-947

Bhushan, Ravi (1989): Firm Characteristics and Analyst Following, in: Journal of Accounting and Economics, 11. Jg., Nr. 2, S. 255-274

Biddle, Gary C. / Saudagaran, Shahrokh M. (1991): Foreign Stock Listings: Benefits, Costs, and the Accounting Policy Dilemma, in: Accounting Horizons, 5. Jg., Nr. 3, S. 69-80 
Bieker, Marcus (2006): Ökonomische Analyse des Fair Value Accounting, Frankfurt Bieker, Marcus / Lackmann, Julia / Lenz, Thomas (2009): Stand und Perspektiven der Lageberichterstattung, in: Wagner, Franz W. / Schildbach, Thomas / Schneider, Dieter [Hrsg.]: Private und öffentliche Rechnungslegung, Festschrift Streim, Wiesbaden, S. 23-39

Bieker, Marcus / Schmidt, Lars (2002): Der Vorschlag der Europäischen Kommission zur Änderung der Bilanzrichtlinien, in: Zeitschrift für kapitalmarktorientierte Rechnungslegung, 2. Jg., Nr. 5, S. 206-219

Bischof, Stefan / Molzahn, Sybille (2006): Value Reporting und Jahresabschlussprüfung, in: Zeitschrift für Controlling \& Management, 50. Jg., Sonderheft 3, S. 85-96

Black, Andrew / Wright, Philip / Bachman, John E. (2001): In Search of Shareholder Value: Managing the Drivers of Performance, 2. Auflage, London

Blackwell, David A. (1951): Comparison of Experiments, in: Neyman, Jerzy [Hrsg.]: Proceedings of the Second Berkeley Symposium in Mathematical Statistics and Probability, Berkeley, S. 93-102

Blalock, Hubert M. (1968): Theory Building and Causal Inferences, in: Blalock, Hubert M. I Blalock, Ann B. [Hrsg.]: Methodology in Social Research, New York, S. 155-198

Bleicher, Knut (1994): Normatives Management, Frankfurt

Bleymüller, Josef / Gehlert, Günther / Gülicher, Herbert (2002): Statistik für Wirtschaftswissenschaftler, 13. Auflage, München

Böcking, Hans-Joachim (1998): Zum Verhältnis von Rechnungslegung und Kapitalmarkt: Vom ,financial accounting“ zum ,business reporting“, in: Ballwieser, Wolfgang / Schildbach, Thomas [Hrsg.]: Rechnungslegung und Steuern international, in: Zeitschrift für betriebswirtschaftliche Forschung, 50. Jg., Sonderheft 40, S. 17-53

Böcking, Hans-Joachim (2001): Rechnungslegungsstandards, in: Gerke, Wolfgang / Steiner, Manfred [Hrsg.]: Handwörterbuch des Bank- und Finanzwesens, 3. Auflage, Stuttgart, Sp. 1775-1786

Böcking, Hans-Joachim / Dutzi, Andreas (2003): Corporate Governance und Value Reporting, in: Seicht, Gerhard [Hrsg.]: Jahrbuch für Controlling und Rechnungswesen, Wien, S. 213-239

Böcking, Hans-Joachim / Müssig, Anke (2003): Neue Herausforderungen für den Konzernlagebericht durch das TransPuG sowie den Deutschen Corporate Governance Kodex?, in: Der Konzern, 1. Jg., Nr. 1, S. 38-49

Böcking, Hans-Joachim / Nowak, Karsten (1999): Das Konzept des Economic Value Added, in: Finanz Betrieb, 1. Jg., Nr. 10, S. 281-288 eber - 978-3-631-75150-3 
Böcking, Hans-Joachim / Wesner, Peter (2004): Value Reporting und Corporate Governance - Anreizkompatible Vergütung, Performancemessung und Unternehmensüberwachung, in: Die Wirtschaftsprüfung, 57. Jg., Sonderheft, S. 98106

Böcking, Hans-Joachim / Herold, Christian / Wiederhold, Philipp (2003):

Modernisierung des HGB in Richtung IAS/IFRS - Auswirkungen der Änderungen der 4. und 7. EU-Richtlinie vom 06. Mai 2003, in: Der Konzern, 1. Jg., Nr. 6, S. 394408

Bode, Jürgen (1997): Der Informationsbegriff in der Betriebswirtschaftslehre, in: Zeitschrift für betriebswirtschaftliche Forschung, 49. Jg., Nr. 5, S. 449-468

Bonse, Andreas (2004): Informationsgehalt von Konzernabschlüssen nach HGB, IAS und US-GAAP. Eine empirische Analyse aus Sicht der Eigenkapitalgeber, Frankfurt

Bortz, Jürgen (2005): Statistik für Human- und Sozialwissenschaftler, 6. Auflage, Heidelberg

Botosan, Christine A. (1997a): Disclosure Level and the Cost of Equity Capital, in: The Accounting Review, 52. Jg., Nr. 3, S. 332-349

Botosan, Christine A. (1997b): Appendix 1 - Disclosure Index Scoring Sheet, zu: Disclosure Level and the Cost of Equity Capital, in: The Accounting Review, 72. Jg., Nr. 3

Botosan, Christine A. (2000): Evidence that Greater Disclosure Lowers the Cost of Equity Capital, in: Journal of Applied Corporate Finance, 12. Jg., Nr. 4, S. 60-69

Botosan, Christine A. (2006): Disclosure and the Cost of Capital: What do we know?, in: Accounting and Business Research, 36. Jg., Sonderheft International Accounting Policy Forum, S. 31-40

Botosan, Christine A. / Plumlee, Marlene A. (2002): A Re-examination of Disclosure Level and the Expected Cost of Equity Capital, in: Journal of Accounting Research, 40. Jg., Nr. 1, S. 21-40

Bowen, Robert M. / Burgstrahler, David / Daley, Lane A. (1987): The Incremental Information Content of Accrual versus Cash Flows, in: The Accounting Review, 62. Jg., Nr. 4, S. 723-747

Bozzolan, Saverio / Trombetta, Marco / Beretta, Sergio E. (2008): Forward-Looking Disclosures, Financial Verifiability and Analysts' Forecasts: A Study of Cross-Listed European Firms, in: European Accounting Review, 18. Jg., Nr. 3, S. 435-473

Bracker, Jeffrey (1980): The Historical Development of the Strategic Management Concept, in: The Academy of Management Review, 5. Jg., Nr. 2, S. 219-224 
Bracklo, Marcus / Bilstein, Axel (2002): Value Reporting, Kapitalmarkt und Unternehmensbewertung, in: Küting, Karlheinz / Weber, Claus-Peter [Hrsg.]: Vom Financial Accounting zum Business Reporting: Kapitalmarktorientierte Rechnungslegung und integrierte Unternehmenssteuerung, Stuttgart, S. 219-233

Brealey, Richard A. / Myers, Stewart C. (2000): Principles of Corporate Finance, 6. Auflage, New York

Brennan, Michael J. / Tamarowski, Claudia (2000): Investor Relations, Liquidity, and Stock Prices, in: Journal of Applied Corporate Finance, 12. Jg., Nr. 4, S. 26-37

Bretzke, Wolf-Rüdiger (1979): Inhalt und Prüfung des Lageberichtes: Anmerkungen zur gegenwärtigen und zukünftigen Praxis der Prognosepublizität, in: Die Wirtschaftsprüfung, 32. Jg., Nr. 4, S. 337-349

Bretzke, Wolf-Rüdiger (1983): Homo Oeconomicus. Bemerkungen zur Rehabilitation einer Kunstfigur ökonomischen Denkens, in: Kappler, Ekkehard [Hrsg.]: Rekonstruktion der Betriebswirtschaftslehre als Ökonomische Theorie, Spardorf, S. 27-64

Brockman, Paul / Khurana, Inder K. / Martin, Xiumin (2008): Voluntary Disclosures around Share Repurchases, in: Journal of Financial Economics, 89. Jg., Nr. 1, S. 175191

Brooks, Raymond M. / Johnson, Marilyn F. / Su, Tie (1997): CEO Presentations to Financial Analysts: Much Ado About Nothing?, in: Financial Practice and Education, 7. Jg., Nr. 2, S. 19-28

Brosius, Felix (2007): SPSS für Dummies, Weinheim

Brotte, Jörg (1997): US-amerikanische und deutsche Geschäftsberichte. Notwendigkeit, Regulierung und Praxis jahresabschlussergänzender Informationen, Wiesbaden

Brown, Shona L. / Eisenhardt, Kathleen M. (1997): The Art of Continuous Change: Linking Complexity Theory and Time-paced Evolution in Relentlessly Changing Organizations, in: Administrative Science Quarterly, 42. Jg., Nr. 1, S. 1-34

Buchheim, Regine / Knorr, Liesel (2006): Der Lagebericht nach DRS 15 und internationale Entwicklungen, in: Die Wirtschaftsprüfung, 59. Jg., Nr. 7, S. 413-425

Buchheim, Regine / Ulbrich, Philipp (2004): EU-Transparenz-Richtlinie: Neuregelung der periodischen und laufenden Berichterstattung kapitalmarktorientierter Unternehmen, in: Zeitschrift für kapitalmarktorientierte Rechnungslegung, 57. Jg., Nr. 7, S. 273287

Buchheim, Regine / Gröner, Susanne / Kühne, Mareike (2004): Übernahme von IAS/IFRS in Europa: Ablauf und Wirkung des Komitologieverfahrens auf die

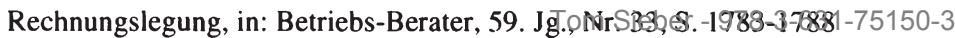


Bühl, Achim (2006): SPSS 14 - Einführung in die moderne Datenanalyse, 10. Auflage, München

Bühner, Thomas / Bünger, Katja / Kaserer, Christoph (2003): Financial Reporting on the Internet by Swiss Companies: An Empirical Investigation, in: Die Unternehmung, 57. Jg., o. Nr., S. 201-215

Bunge, Mario (1987): Kausalität. Geschichte und Probleme, Tübingen

Bushee, Brian J. / Noe, Christopher F. (2000): Corporate Disclosure Practices, Institutional Investors, and Stock Return Volatility, in: Journal of Accounting Research, 38. Jg., Nr. 3 (Supplement), S. 171-202

Bushee, Brian J. / Matsumoto, Dawn A. / Miller, Gregory S. (2003): Open versus Closed Conference Calls: The Determinants of Broadening Access to Disclosure, in: Journal of Accounting and Economics, 34. Jg., Nr. 1-3, S. 149-180

Bushee, Brian J. / Miller Gregory S. (2005): Investor Relations, Firm Visibility and Investor Following, Working Paper

Bushman, Robert M. / Indjejikian, Raffi J. (1995): Voluntary Disclosures and the Trading Behavior of Corporate Insiders, in: Journal of Accounting Research, 33. Jg., Nr. 2, S. 293-316

Busse von Colbe, Walther (1968): Prognosepublizität von Aktiengesellschaften, in: Angehrn, Otto / Künzi, Hans Paul [Hrsg.]: Beiträge zur Lehre von der Unternehmung, Festschrift Käfer, Stuttgart, S. 91-118

Busse von Colbe, Walther (1987): Die neuen Rechnungslegungsvorschriften aus betriebswirtschaftlicher Sicht, in: Zeitschrift für betriebswirtschaftliche Forschung, 39 Jg., Nr. 11, S. 191-205

Busse von Colbe, Walther (1993): Die Entwicklung des Jahresabschlusses als Informationsinstrument, in: Wagner, Franz W. [Hrsg.]: Ökonomische Analyse des Bilanzrechts: Entwicklungslinien und Perspektiven, in: Zeitschrift für betriebswirtschaftliche Forschung, 45. Jg., Sonderheft 32, S. 11-29

Busse von Colbe, Walther (1994): Unternehmenskontrolle durch Rechnungslegung, in: Sandrock, Otto / Jäger, Wilhelm [Hrsg.]: Internationale Unternehmenskontrolle und Unternehmenskultur, Tübingen, S. 37-57

Busse von Colbe, Walther (1995): Das Rechnungswesen im Dienste einer kapitalmarktorientierten Unternehmensführung, in: Die Wirtschaftsprüfung, 48. Jg., Nr. 21, S. 713-720

Busse von Colbe, Walther (1996): Accounting and the Business Economics Tradition in

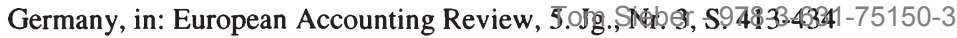


Busse von Colbe, Walther (2002): Vorschlag der EG-Kommission zur Anpassung der Bilanzrichtlinien an die IAS - Abschied von der Harmonisierung?, in: BetriebsBerater, 57. Jg., Nr. 31, S. 1530-1536

Buzby, Stephen L. (1974): Selected Items of Information and Their Disclosure in Annual Reports, in: The Accounting Review, 49. Jg., Nr. 3, S. 423-435

Buzby, Stephen L. (1975): Company Size, Listed Versus Unlisted Stock, and the Extent of Financial Disclosure, in: Journal of Accounting Research, 13. Jg., Nr. 1, S. 16-37

Byard, Donal / Shaw, Kenneth W. (2003): Corporate Disclosure Quality and Properties of Analysts' Information Environment, in: Journal of Accounting, Auditing \& Finance, 18. Jg., Nr. 3, S. 355-378

C\&L Deutsche Revision [Hrsg.] (1998): Kapitalmarktorientierung deutscher Unternehmungen - Ergebnisse einer empirischen Untersuchung, Frankfurt/Main

Calvo-Mora, Arturo / Leal, Antonio / Roldan, José (2005): Relationships between the EFQM Model Criteria. A Study in Spanish Universities, in: Total Quality Management and Business Excellence, 16. Jg., Nr. 6, S. 741-770

Carmines, Edward G. / Zeller, Richard A. (1979): Reliability and Validity Assessment, Newbury Park

Celik, Orhan / Ecer, Alaattin / Karabacak, Hakan (2006): Disclosure of Forward Looking Information: Evidence from Listed Companies on Istanbul Stock Exchange (ISE), in: Investment Management and Financial Innovations, 3. Jg., Nr. 2, S. 197-216

Cerf, Alan Robert (1961): Corporate Reporting and Investment Decisions, University of California, Berkeley

CFA Institute [Hrsg.] (2009): History of CFA Institute, Online-Publikation Quelle: http://www.cfainstitute.org/aboutus/overview/history/.index.htm (Stand am 28.09.2009)

Chan, Louis K. G. / Lakonishok, Josef (1995): The Behavior of Stock Prices Around Institutional Trades, in: Journal of Finance, 50. Jg., Nr. 4, S. 1147-1174

Chan, Su Han / Martin, John D. / Kensinger, John W. (1990): Corporate Research and Development Expenditures and Share Value, in: Journal of Financial Economics, 26. Jg., Nr. 2, S. 255-276

Chandler, Alfred D. (1966): Strategy and Structure, 3. Auflage, Cambridge

Chang, Lucia S. / Most, Kenneth S. / Brain, Carlos W. (1983): The Utility of Annual Reports: An International Study, in: Journal of International Business Studies, 14. Jg., Nr. 1, S. 63-84 
Chatterjee, Sayan / Wernerfelt, Birger (1991): The Link between Resources and Type of Diversification: Theory and Evidence, in: Strategic Management Journal, 12. Jg., Nr. 1, S. 33-48

Chau, Gerald K. / Gray, Sidney J. (2002): Ownership Structure and Corporate Voluntary Disclosure in Hong Kong and Singapore, in: International Journal of Accounting, 37. Jg., Nr. 2, S. 247-265

Chen, Charles J. P. / Jaggi, Bikki (2000): Association between Independent Non-Executive Directors, Family Control and Financial Disclosures in Hong Kong, in: Journal of Accounting and Public Policy, 19. Jg., Nr. 4-5, S. 285-310

Chen, Shuping / DeFond, Mark L. / Park, Chul W. (2002): Voluntary Disclosure of Balance Sheet Information in Quarterly Earnings Announcements, in: Journal of Accounting and Economics, 33. Jg., Nr. 2, S. 229-251

Chen, Shuping / Chen, Xia / Cheng, Qiang (2008): Do Family Firms Provide More or Less Voluntary Disclosure?, in: Journal of Accounting Research, 46. Jg., Nr. 3, S. 499536

Cheng, Eugene C. M. / Courtenay, Stephen M. (2006): Board Composition, Regulatory Regime and Voluntary Disclosure, in: The International Journal of Accounting, 41. Jg., Nr. 3, S. 262-289

Cheng, Qiang / Lo, Kin (2006): Insider Trading and Voluntary Disclosures, in: Journal of Accounting Research, 44. Jg., Nr. 5, S. 815-848

Chenhall, Robert H. / Moers, Frank (2007a): The Issue of Endogeneity within TheoryBased, Quantitative Management Account Research, in: European Accounting Review, 16. Jg., Nr. 1, S. 173-195

Chenhall, Robert H. / Moers, Frank (2007b): Endogeneity: A Reply to Two Different Perspectives, in: European Accounting Review, 16. Jg., Nr. 1, S. 217-221

Choi, Frederick D. S. (1973): Financial Disclosure and Entry to the European Capital Market, in: Journal of Accounting Research, 11. Jg., Nr. 2, S. 159-175

Chong, Beng Soon / Ho, Kim Wai (2007): Lockup and Voluntary Earnings Forecast Disclosure in IPOs, in: Financial Management, 36. Jg., Nr. 3, S. 63-80

Chow, Chee W. / Wong-Boren, Adrian (1987): Voluntary Financial Disclosure by Mexican Corporations, in: The Accouting Review, 62. Jg., Nr. 3, S. 533-541

Chung, Kee H. / Jo, Hoje (1996): The Impact of Security Analysts' Monitoring and Marketing Functions on the Market Value of Firms, in: Journal of Financial and Quantitative Analysis, 31.Jg., Nr. 4, S. 493-512 
Chwallek, Constanze (1999): Bewertungsrelevanz veröffentlichter Kapitalflussrechnungen börsennotierter deutscher Unternehmen, Frankfurt

Clarkson, Pete / Guedes, Jose / Thomson, Rex (1996): On the Diversification, Observability, and Measurement of Estimation Risk, in: Journal of Financial and Quantitative Analysis, 31.Jg., Nr. 1, S. 69-84

Clarkson, Peter M. / Kao, Jennifer L. / Richardson, Gordon D. (1999): Evidence That Management Discussion and Analysis (MD\&A) is a Part of a Firm's Overall Disclosure Package, in: Contemporary Accounting Research, 16. Jg., Nr. 1, S. 111-134

Clausewitz, Carl von (1905): Vom Kriege, Hinterlassenes Werk des Generals Carl von Clausewitz, 5. Auflage, Berlin

Coase, Ronald H. (1937): The Nature of the Firm, in: Economica, 4. Jg., S. 386-405

Coenenberg, Adolf G. (1974): Jahresabschlussinformation und Kapitalmarkt. Zur Diskussion empirischer Forschungsansätze und -ergebnisse zum Informationsgehalt von Jahresabschlüssen für Aktionäre, in: Zeitschrift für betriebswirtschaftliche Forschung, 26. Jg., o. Nr., S. 647-657

Coenenberg, Adolf G. (1995): Einheitlichkeit oder Differenzierung von internem und externem Rechnungswesen: Die Anforderungen der internen Steuerung, in: Der Betrieb, 48. Jg., Nr. 42, S. 2077-2083

Coenenberg, Adolf G. (2005): Jahresabschluss und Jahresabschlussanalyse. Betriebswirtschaftliche, handelsrechtliche, steuerrechtliche und internationale Grundsätze - HGB, IAS/IFRS und US-GAAP, DRS, 20. Auflage, Stuttgart

Coenenberg, Adolf G. / Alvarez, Manuel (2002): Zwischenberichterstattung, in: Ballwieser, Wolfgang et al. [Hrsg.]: Handwörterbuch der Rechnungslegung und Prüfung, Stuttgart, Sp. 2758-2774

Coenenberg, Adolf G. / Moeller, Peter (1979): Entscheidungswirkungen von Jahresabschlussinformationen vor und nach der Aktienrechtsreform von 1965, in: Betriebswirtschaftliche Forschung und Praxis, 31. Jg., Nr. 5, S. 438-454

Coenenberg, Adolf G. / Schultze, Wolfgang (2002): Unternehmensbewertung: Konzeptionen und Perspektiven, in: Die Betriebswirtschaft, 62. Jg., Nr. 6, S. 597-621

Coenenberg, Adolf G. / Straub, Barbara (2008): Rechenschaft versus

Entscheidungsunterstützung: Harmonie oder Disharmonie der Rechnungszwecke, in: Zeitschrift für kapitalmarktorientierte Rechnungslegung, 8. Jg., Nr. 1, S. 17-26

Coenenberg, Adolf G. / Berndsen, Hans-Peter / Möller, Peter / Schmidt, Franz (1978):

Empirische Bilanzforschung in Deutschland. Eine Bestandsaufnahme, in: Die Betriebswirtschaft, 38. Jg., Nr. 4, S. 495-507 Tom Sieber - 978-3-631-75150-3 
Cohen, Jacob / Cohen, Patricia / West, Stephen G. / Aiken, Leona S. (2003): Applied Multiple Regression/Correlation. Analysis for the Behavioral Sciences, 3. Auflage, Mahwah (NJ)

Coleman, Ian / Eccles, Robert G. (1997): Pursuing Value: Reporting Gaps in the United Kingdom, PricewaterhouseCoopers Papers, o.O.

Coles, Jeffrey L. / Loewenstein, Uri (1988): Equilibrium Pricing and Portfolio Composition in the Presence of Uncertain Parameters, in: Journal of Financial Economics, 22. Jg., Nr. 2, S. 279-303

Coles, Jeffrey L. / Loewenstein, Uri / Suay, Jose ( 1995): On Equilibrium Pricing under Parameter Uncertainty, in: Journal of Financial and Quantitative Analysis, 30. Jg., Nr. 3, S. 347-364

Coller, Maribeth / Yohn, Teri Lombardi (1997): Management Forecasts and Information Asymmetry: An Examination of Bid-Ask Spreads, in: Journal of Accounting Research, 35. Jg., Nr. 2, S. 181-191

Colley, John L. / Doyle, Jacqueline L. / Hardie, Robert D. (2002): Corporate Strategy, New York

Collingwood, Harris (2001): The Earnings Game, in: Harvard Business Review, 79. Jg., Nr. 6, S. 65-74

Collins, Denton L. / Pasewark, William R. / Strawser, Jerry R. (2002): Characteristics Influencing Perceptions of Accounting Pronouncement Quality, in: Accounting Horizons, 16. Jg., Nr. 2, S. 137-151

Conover, William J. / Iman, Ronald J. (1981): Rank Transformations as a Bridge Between Parametric and Nonparametric Statistics, in: The American Statistician, 35. Jg., Nr. 3, S. 124-129

Cooke, Terry (1989): Voluntary Corporate Disclosure by Swedish Companies, in: Journal of International Financial Management and Accounting, 1. Jg., Nr. 2, S. 171-195

Cooke, Terry E. (1991): An assessment of voluntary disclosure in the annual report of Japanese corporations, in: International Journal of Accounting, 26. Jg., Nr. 3, S. 174189

Cooke, Terry E. (1992): The Impact of Size, Stock Market Listing and Industry Type on Disclosure in Annual Reports of Japanese Listed Corporations, in: Accounting and Business Research, 22. Jg., Nr. 87, S. 229-237

Cooke, Terry E. (1998): Regression Analysis in Accounting Disclosure Studies, in: Accounting and Business Research, 28. Jg., Nr. 3, S. 209-224 
Cooke, Terry E. / Wallace, R.S. Olusegun (1989): Global Surveys of Corporate Disclosure Practices and Audit Firms: A Review Essay, in: Accounting and Business Research, 20. Jg., Nr. 76, S. 47-57

Copeland, Thomas E. / Galai, Dan (1983): Information Effects on the Bid-Ask Spread, in: The Journal of Finance, 38. Jg., Nr. 5, S. 1457-1469

Copeland, Thomas E. / Koller, Tim / Murrin, Jack (2000): Valuation, 3. Auflage, New York

Copeland, Thomas E. / Koller, Tim / Murrin, Jack (2002): Unternehmenswert, 3. Auflage, Frankfurt/Main

Cormier, Denis / Magnan, Michel L. (1999): Corporate Environmental Disclosure Strategies: Determinants, Costs and Benefits, in: Journal of Accounting, Auditing and Finance, 14. Jg., Nr. 3, S. 215-241

Cormier, Denis / Magnan, Michel L. (2005): From Accounting to 'Forecounting', in: Canadian Accounting Perspectives, 4. Jg., Nr. 2, S. 243-255

Cowles, Michael / Davis, Caroline (1982): On the Origins of the 0.05 Level of Significance, in: American Psychologist, 37. Jg., Nr. 5, S. 553-558

Coy, David / Dixon, Keith (2004): The Public Accountability Index: Crafting a Parametric Disclosure Index for Annual Reports, in: British Accounting Review, 36. Jg., Nr. 1, S. 79-106

Coyne, Kevin P. (1986): Sustainable Competitve Advantage - What It Is, What It Isn't, in: Business Horizons, 29. Jg., Nr. 1, S. 54-61

Crasselt, Nils / Pellens, Bernhard / Schremper, Ralf (2000): Konvergenz wertorientierter Erfolgskennzahlen - Teil I, in: Das Wirtschaftsstudium, 29. Jg., Nr. 1, S. 72-78; Teil II, in: Das Wirtschaftsstudium, 29. Jg., Nr. 2, S. 205-208

Cronbach, L. (1951): Coefficient Alpha and Internal Structure of Tests, in: Psychometrika, 16. Jg., Nr. 3, S. 297-334

Cureton, Edward E. / D’Agostino, Ralph B. (1993): Factor Analysis. An Applied Approach, Hillsdale (NJ)

D'Aveni, Richard A. (1994): Hypercompetition, New York

Damodaran, Aswath (2001): Valuation, New York

Daniel, Kent / Hirshleifer, David / Subrahmanyam, Avanidhar (1998): Investor Psychology and Security Market Under- and Overreactions, in: The Journal of Finance, 53. Jg., Nr. 6, S. 1839-1885 
Danner, Marc (2003): Strategisches Nischenmanagement. Entstehung und Bearbeitung von Marktnischen, Wiesbaden

Darrough, Masako N. / Stoughton, Neal M. (1990): Financial Disclosure Policy in an Entry Game, in: Journal of Accounting and Economics, 12. Jg., Nr. 1-3, S. 219-243

Daske, Holger (2006): Economic Benefits of Adopting IFRS or US-GAAP: Have the Expected Cost of Equity Capital Really Decreased?, in: Journal of Business Finance \& Accounting, 33. Jg., Nr. 3/4, S. 329-373

Davidson, Russell / MacKinnon, James G. (1993): Estimation and Inference in Econometrics, New York

Day, George S. (1998): Wettbewerbsvorsprünge wahren: Schaffung und Aufrechterhaltung von Wettbewerbsvorteilen in dynamischen Wettbewerbsumgebungen, in: Day, George S. / Reibstein, David J. [Hrsg.], Wharton, Düsseldorf, S. 67-98

Day, George S. / Wensley, Robin (1988): Assessing Advantage: A Framework for Diagnosing Competitive Superiority, in: Journal of Marketing, 52. Jg., Nr. 2, S. 1-20

Day, Judith F. S. (1986): The Use of Annual Reports by UK Investment Analysts, in: Accounting and Business Research, 16. Jg., Nr. 3, S. 295-307

Debrency, Roger / Gray, Glen L. / Rahman, Asheq (2002): The Determinants of Internet Financial Reporting, in: Journal of Accounting and Public Policy, 21. Jg., Nr. 4-5, S. 371-394

del Guercio, Diane (1996): The distorting effect of the prudent-man laws on institutional equity investments, in: Journal of Financial Economics, 40. Jg., Nr. 1, S. 31-62

del Sol, Patricio / Ghemawat, Pankaj (1999): Strategic Valuation of Investment under Competition, in: Interfaces, 29. Jg., Nr. 6, S. 42-56

Deloitte / Economist Intelligence Unit [Hrsg.] (2004): In the Dark: What many Boards and Executives don't know about the Health of their Businesses, New York

Deloitte / Economist Intelligence Unit [Hrsg.] (2007): In the Dark II: What many Boards and Executives STILL don't know about the Health of their Businesses, New York Quelle: http://www.deloitte.com/assets/Dcom-Global/... Local\%20Assets/Documents/dtt_Audit_IntheDark033007.pdf (Stand am 23.06.2009)

Demmler, Horst (2000): Grundlagen der Mikroökonomie, 4. Auflage, München 
Dempsey, Stephen J. / Gatti, James F. / Grinnell, D. Jacques / Cats-Baril, William L.

(1997): The Use of Strategic Performance Variables as Leading Indicators in

Financial Analysts' Forecasts, in: Journal of Financial Statement Analysis, 2. Jg., Nr.

4, S. $61-80$

Demski, Joel S. (1976): Uncertainty and Evaluation Based on Controllable Performance, in: Journal of Accounting Research, 14. Jg., Nr. 2, S. 230-254

Denis, David J. / Sarin, Atulya (1999): Ownership and Board Structures in Publicly Traded Corporations, in: Journal of Financial Economics, 52. Jg., Nr. 2, S. 187-223

Denis, David J. / Denis, Diane K. (1994): Majority Owner-Managers and Organizational Efficiency, in: Journal of Corporate Finance, 1. Jg., Nr. 1, S. 91-118

Deutsche Börse AG [Hrsg.] (2009a): Leitfaden zu den Aktienindizes der Deutschen Börse, Version 6.12 (August 2009), Frankfurt

Quelle: http://deutsche-boerse.com/INTERNET/EXCHANGE/... zpd.nsf/KIR+Web+Publikationen/CPOL-5DVBPY/\$FILE/... Equity_L_6_12_d.pdf (Stand am 14.09.2009)

Deutsche Börse AG [Hrsg.] (2009b): Historical Index Compositions of the Equity- and Strategy Indices of Deutsche Börse, Version 3.11 (September 2009), Frankfurt

Quelle: http://deutsche-boerse.com/INTERNET/EXCHANGE/... zpd.nsf/PublikationenID/CPOL-66CENG/\$FILE/... Historical_Index_Compositions_3_11.pdf (Stand am 14.09.2009)

Deutsche Börse AG [Hrsg.] (2009c): Cash Market: Monthly Statistics, Ausgabe Dezember 2009 , Frankfurt

Quelle: http://deutsche-boerse.com/INTERNET/IP/...

ip_stats.nsf/(KIR+Monatsstatistik+Kassamarkt+E)/... 6853BEA777A80D76C12576A30055CF98/\$FILE/... fwb_monthly.pdf?OpenElement (Stand am 15.01.2010)

Deutsche Börse AG [Hrsg.] (2010): Börsenordnung (BörsO) für die Frankfurter Wertpapierbörse, Stand 08.03.2010, Frankfurt

Quelle: http://deutsche-boerse.com/INTERNET/EXCHANGE/... zpd.nsf/Web+Publikationen/...

HAMN-52CDY7?OpenDocument 
Diamond, Douglas W. / Verrecchia, Robert E. (1991): Disclosure, Liquidity, and the Cost of Capital, in: Journal of Finance, 46. Jg., Nr. 4, S. 1325-1359

Diekmann, Andreas (2004): Empirische Sozialforschung. Grundlagen, Methoden, Anwendungen, 11. Auflage, Hamburg

Dietsche, Marcel / Fink, Christian (2008): Die Qualität der Lageberichterstattung in Deutschland - Empirische Analyse der Unternehmen des HDAX, in: Zeitschrift für kapitalmarktorientierte Rechnungslegung, 8. Jg., Nr. 4, S. 250-261

Dillon, Ray D. / Owers, James E. (1997): EVA as a Financial Metric: Attributes, Utilization, and Relationship to NPV, in: Financial Practice and Education, 7. Jg., Nr. 1, S. 32-40

Dörner, Dietrich (1996): Der Prognosebericht nach § 289 Abs. 2 Nr. 2 HGB - Überlegungen zur Verminderung der Diskrepanz zwischen Publizitätsanforderungen und Publizitätspraxis, in: Baetge, Jörg [Hrsg.]: Rechnungslegung, Prüfung und Beratung - Herausforderungen für den Wirtschaftsprüfer, Festschrift Ludewig, Düsseldorf, S. $217-251$

Doukas, John A. / Kim, Chansog / Pantzalis, Christos (2000): Security Analysis, Agency Costs, and Company Characteristics, in: Financial Analysts Journal, 56. Jg., Nr. 6, S. 54-63

Drill, Michael (1995): Investor Relations, Bern

Durö, Robert / Sandström, Bjorn (1986): Marketing-Kampfstrategien, Landsberg/Lech

Durbin, James (1954): Errors in Variables, in: Review of the International Statistical Institute, 22. Jg. Nr. 1-3, S. 23-32

Durbin, James / Watson, Geoffrey S. (1950): Testing for Serial Correlation in Least Squares Regression I, in: Biometrika, 37. Jg. Nr. 3-4, S. 409-428

Durbin, James / Watson, Geoffrey S. (1951): Testing for Serial Correlation in Least Squares Regression II, in: Biometrika, 38. Jg. Nr. 1-2, S. 159-178

Duve, Christian / Basak, Denis (2005): Welche Zukunft hat die Organaußenhaftung für Kapitalmarktinformationen? Bestandsaufnahme und Ausblick nach der Rücknahme des Gesetzentwurfes eines Kapitalmarktinformationshaftungsgesetzes und dem EM.TV-Urteil des BGH, in: Betriebs-Berater, 60. Jg., Nr. 52, S. 2645-2651

Dye, Ronald A. (1998): Investor Sophistication and Voluntary Disclosures, in: Review of Accounting Studies, 3. Jg., Nr. 3, S. 261-287

Dye, Ronald A. / Verrecchia, Robert E. (1995): Discretion versus Uniformity: Choices among GAAP, in: The Accounting Review, 70. Jg., Nr. 3, S. 389-416 
Dye, Ronald A. (1985): Disclosure of Nonproprietary Information, in: Journal of Accounting Research, 23. Jg., Nr. 1, S. 123-145

Dye, Ronald A. (1986): Proprietary and Nonproprietary Disclosures, in: The Journal of Business, 59. Jg., Nr. 2, Teil 1, S. 331-366

Dziuban, Charles D. / Shirkey, Edwin C. (1974): When Is a Correlation Matrix Appropriate for Factor Analysis?, in: Psychological Bulletin, 81. Jg., Nr. 6, S. 358-361

Easley, David / O'Hara, Maureen (2004): Information and the Cost of Capital, in: Journal of Finance, 59. Jg., Nr. 4, S. 1553-1583

Easley, David / Kiefer, Nicholas M. / O'Hara, Maureen / Paperman, Joseph B. (1996):

Liquidity, Information, and Infrequently Traded Stocks, in: Journal of Finance, 51. Jg., Nr. 4, S. 1405-1436

Easton, Peter (2006): Use of Forecasts of Earnings to Estimate and Compare Cost of Capital across Regimes, in: Journal of Business Finance and Accounting, 33. Jg., Nr. 3/4, S. 374-394

Eccles, Robert G. / Herz, Robert H. / Keegan, E. Mary / Phillips, David H. M. (2001): The ValueReporting Revolution: Moving Beyond the Earnings Game, New York

Eccles, Robert G. / Herz, Robert H. / Keegan, E. Mary / Phillips, David H. M. (2002):

Die ValueReporting Revolution: Neue Wege in der kapitalmarktorientierten Unternehmensberichterstattung, Weinheim

Eccles, Robert G. / Kahn, Harold D. (1998): Pursuing Value: The Information Reporting Gap in the U.S. Capital Markets

Quelle: $\quad$ http://store.barometersurveys.com/docs/...

US\%20Captains\%20of\%20industry.pdf

(Stand am 06.09.2009)

Eccles, Robert G. / Weibel, Peter F. (2002): Wertsteigerung durch Reporting: Lücken in der Berichterstattung am Schweizer Kapitalmarkt, in: Siegwart, Martin / Mahari, Julian / Ruffner, Markus [Hrsg.]: Corporate Governance, Shareholder Value \& Finance, Basel, S. 695-717

Edwards, Edgar O. / Bell, Philip W. (1961): The Theory and Measurement of Business Income, Berkley

Eichner, Tobias (2009): Restructuring and Turnaround of Distressed Manufacturing Firms An International Empirical Study, Frankfurt/Main

Einhorn, Eti (2005): The Nature of Interaction between Mandatory and Voluntary Disclosures, in: Journal of Accounting Research, 43. Jg., Nr. 4, S. 593-621 
Einhorn, Eti (2007): Voluntary Disclosure under Uncertainty about the Reporting Objective, in: Journal of Accounting and Economics, 43. Jg., Nr. 2-3, S. 245-274

Einhorn, Eti / Ziv, Amir (2008): Intertemporal Dynamics of Corporate Voluntary Disclosures, in: Journal of Accounting Research, 46. Jg., Nr. 3, S. 567-589

Ellrot, Helmut (2006): $\$ 289$ HGB, in: Ellrot, Helmut [Hrsg.]: Beck’scher BilanzKommentar, 6. Auflage, München

Ernst \& Young [Hrsg.] (1997): Measures that Matter, New York

Ernst, Edgar / Gassen, Joachim / Pellens, Bernhard (2009): Verhalten und Präferenzen deutscher Aktionäre. Eine Befragung von privaten und institutionellen Anlegern zum Informationsverhalten, zur Dividendenpräferenz und zur Wahrnehmung von Stimmrechten, in: Rosen, Rüdiger von [Hrsg.]: Studien des Deutschen Aktieninstituts, Heft 42

Esch, Franz-Rudolf (2004): Strategie und Technik der Markenführung, 2. Auflage, München Eschenbach, Rolf / Eschenbach, Sebastian / Kunesch, Hermann (2003): Strategische Konzepte. Management-Ansätze von Ansoff bis Ulrich, 4. Auflage, Stuttgart

Ettredge, Michael / Richardson, Vernon J. / Scholz, Susan (2002): Dissemination of Information for Investors at Corporate Web Sites, in: Journal of Accounting and Public Policy, 21. Jg., Nr. 4-5, S. 357-369

EFRAG [European Financial Reporting Advisory Group, Hrsg.] (2007):

Stewardship/Accountability as an Objective of Financial Reporting: A Comment on the IASB/FASB Conceptual Framework Project, in: Pro-Active Accounting Activities in Europe (PAAinE), Juni 2007

Quelle: http://www.frc.org.uk/documents/pagemanager/asb/... PAAinE\%20Stewardship\%20paper.pdf (Stand am 13.07.2009)

Evered, Roger (1983): So What is Strategy?, in: Long Range Planning, 16. Jg., Nr. 3, S. 5772

Ewert, Ralf (1986): Rechnungslegung, Gläubigerschutz und Agency-Probleme, Wiesbaden

Ewert, Ralf (1989): Bilanzielle Publizität im Lichte der Theorie vom gesellschaftlichen Wert öffentlich verfügbarer Information, in: Betriebswirtschaftliche Forschung und Praxis, 41. Jg., Nr. 3, S. 245-263

Ewert, Ralf (1993): Rechnungslegung, Wirtschaftsprüfung, rationale Akteure und Märkte. Ein Grundmodell zur Analyse der Qualität von Unternehmenspublikationen, in: Zeitschrift für betriebswirtschaftliche Forschung, 45. Jg., Nr. 9, S. 715-747 
Ewert, Ralf (1999): Rechnungslegung, Globalisierung und Kapitalkosten, in: Männel, Wolfgang / Küpper, Hans-Ulrich [Hrsg.]: Integration der Unternehmensrechnung, in: Kostenrechnungspraxis, 43. Jg., Sonderheft 3, S. 39-46

Ewert, Ralf / Wagenhofer, Alfred (1992): Unternehmenspublizität und Konkurrenzwirkungen, in: Zeitschrift für Betriebswirtschaft, 62. Jg., Nr. 3, S. 297-324

Ewert, Ralf / Wagenhofer, Alfred (2000): Rechnungslegung und Kennzahlen für das wertorientierte Management, in: Wagenhofer, Alfred / Hrebicek, Gerhard [Hrsg.]: Wertorientiertes Management. Konzepte und Umsetzungen zur Unternehmenswertsteigerung, Stuttgart, S. 3-64

Fama, Eugene F. (1970): Efficient Capital Markets: A Review of Theory and Empirical Work, in: Journal of Finance, 25. Jg., Nr. 2, S. 383-417

Feldhoff, Michael (1992): Die Regulierung der Rechnungslegung. Eine systematische Darstellung der Grundlagen mit einer Anwendung auf die Frage der Publizität, Frankfurt

Feldmann, Horst (1995): Eine institutionalistische Revolution? Zur dogmenhistorischen Bedeutung der modernen Institutionenökonomik, Berlin

Feltham, Gerald A. / Ohlson, James A. (1995): Valuation and Clean Surplus Accounting for Operating and Financial Activities, in: Contemporary Accounting Research, 11. Jg., Nr. 2, S. 689-731

Feltham, Gerald A. / Xie, Jim Z. (1993): Voluntary Financial Disclosure in an Entry Game with Continua of Types, in: Contemporary Accounting Research, 9. Jg., Nr. 1, S. 4680

Ferguson, Michael J. / Lam, Kevin C. / Lee, Grace Meina (2002): Voluntary Disclosure by State-owned Enterprises Listed on the Stock Exchange of Hong Kong, in: Journal of International Financial Management and Accounting, 13. Jg., Nr. 2, S. 125-152

Ferreira, Daniel / Rezende, Marcelo (2007): Corporate Strategy and Information Disclosure, in: RAND Journal of Economics, 38. Jg., Nr. 1, S. 164-184

Fey, Gerd (1994): Die Angabe bestehender Zweigniederlassungen im Lagebericht nach § 289 Abs. 2 Nr. 4 HGB, in: Der Betrieb, 47. Jg., Nr. 10, S. 485-487

Fey, Gerd (2001): Adressatenorientierte US-Rechnungslegung: Vom „Financial Reporting“ zum „Business Reporting“?, in: Baetge, Jörg [Hrsg.]: Internationale Grundsätze für Rechnungslegung und Prüfung, Düsseldorf, S. 31-67

Fey, Gerd / Deubert, Michael (2006): Befreiender IFRS-Einzelabschluss nach $§ 325$ Abs. 2a HGB für Zwecke der Offenlegung, in: Zeitschrift für kapitalmarktorientierte Rechnungslegung, 6. Jg., Nr. 2, S. 92-101 Tom Sieber-978-3-631-75150-3 
Fink, Christian (2006): Management Commentary: Eine Diskussionsgrundlage zur internationalen Lageberichterstattung, in: Zeitschrift für kapitalmarktorientierte Rechnungslegung, 6. Jg., Nr. 3, S. 141-152

Fink, Christian (2007): Lageberichterstattung und Erfolgspotenzialanalyse. Eignung der Lageberichterstattung nach deutschem Recht und IFRS für die strategische Unternehmensanalyse, Augsburg

Fink, Christian / Keck, Barbara (2004): Lageberichterstattung nach E-DRS 20: Kritische Würdigung aus Sicht der Unternehmensanalyse, in: Die Wirtschaftsprüfung, 57. Jg., Nr. 19, S. 1077-1091

Fink, Christian / Keck, Barbara (2005): Lageberichterstattung nach BilReG und DRS 15: Eine kritische Würdigung, in: Zeitschrift für kapitalmarktorientierte Rechnungslegung, 5. Jg., Nr. 4, S. 137-146

Firth, Michael A. (1978): Study of the Consensus of the Perceived Importance of Disclosure of Individual Items in Corporate Annual Reports, in: International Journal of Accounting Education and Research, 14. Jg., Nr. 1, S. 57-70

Firth, Michael A. (1979): The Impact of Size, Stock Market Listing and Auditors on Voluntary Disclosure in Corporate Annual Reports, in: Accounting and Business Research, 9. Jg., Nr. 9, S. 273-280

Fischer, Alexander (2003): Shareholder Value Reporting mittels jahresabschlussergänzender Angaben: Untersuchung ökonomischer Wirkungsweisen der Investor Relations im Rahmen einer wertorientierten Unternehmensführung, Bern

Fischer, Thomas / Beckmann, Stefanie (2009): Corporate Governance - Inhalt und Qualität der Regelberichterstattung für die Mitglieder von Aufsichtsräten, in: Der Betrieb, 62. Jg., Nr. 32, S. 1661-1669

Fischer, Thomas / Klöpfer, Elisabeth (2006): Entwicklung und Perspektiven des Value Reporting, in: Zeitschrift für Controlling \& Management, 50. Jg., Sonderheft 3, S. 414

Fischer, Thomas / Vielmeyer, Uwe (2004): Analyse von Risk Disclosure Scores: Risikoorientierte Unternehmenspublizität der Dax 100-Unternehmen, in: Zeitschrift für kapitalmarktorientierte Rechnungslegung, 4. Jg., Nr. 11, S. 459-474

Fischer, Thomas / Wenzel, Julia (2002): DBW-Stichwort: Value Reporting, in: Die Betriebswirtschaft, 62. Jg., Nr. 3, S. 327-332

Fischer, Thomas / Wenzel, Julia (2004): Publizität von Werttreibern im Value Reporting. Ergebnisse einer empirischen Studie, in: Controlling, 16. Jg., Nr. 6, S. 305-314 
Fischer, Thomas / Wenzel, Julia (2005): Value Reporting - Ergebnisse einer empirischen Studie von börsennotierten deutschen Unternehmen, Arbeitspapier des Lehrstuhls für ABWL, Controlling und Wirtschaftsprüfung der Wirtschaftswissenschaftlichen Fakultät der Katholischen Universität Eichstätt-Ingolstadt, 2005

Fischer, Thomas / Wenzel, Julia / Kühn, Christian (2001a): Value Reporting Wertorientierte Berichterstattung in den Nemax 50-Unternehmen, in: Der Betrieb, 54. Jg., Nr. 23, S. 1209-1216

Fischer, Thomas / Becker, Sabrina / Wenzel, Julia (2001b): Internetbasierte wertorientierte Berichterstattung (Web-Based Value Reporting) - Eine empirische Untersuchung der DAX 30-Unternehmen, in: Der Betrieb, 54. Jg., Nr. 38, S. 2001-2007

Fischer, Thomas / Becker, Sabrina / Wenzel, Julia (2002): Wertorientierte Berichterstattung - Ein empirischer Vergleich der internetbasierten Geschäftsberichte von DAX 30- und Nemax 50-Unternehmen, in: Zeitschrift für kapitalmarktorientierte Rechnungslegung, 2. Jg., Nr. 1, S. 14-25

Fochler, Randolf / Fugger, Wolfgang (1997): Freiwillige verbale Informationen und Kennzahlen im Jahresbericht am Beispiel der Böhler Uddeholm AG, in: Mittermair, Klaus / Pernsteiner, Helmut [Hrsg.]: Freiwillige Unternehmensinformationen: Möglichkeiten aktiver Rechnungslegungspolitik, Wien, S. 123-137

Foster, George (1973): Stock Market Reactions to Estimates of Earnings per Share by Company Officials, in: Journal of Accounting Research, 11. Jg., Nr. 1, S. 25-37

Foster, George (1986): Financial Statement Analysis, Englewood Cliffs

Francis, Jennifer / Hanna, J. Douglas / Philbrick, Donna R. (1997): Management Communications with Securities Analysts, in: Journal of Accounting and Economics, 24. Jg., Nr. 3, S. 363-394

Francis, Jennifer / Olsson, Per / Oswald, Dennis R. (2000): Comparing The Accuracy and Explainability of Dividend, Free Cash Flow and Abnormal Earnings Equity Valuation Estimates, in: Journal of Accounting Research, 38. Jg., Nr. 1, S. 45-70

Francis, Jennifer / LaFond, Ryan / Olsson Per / Schipper, Katherine (2004): Costs of Equity and Earnings Attributes, in: The Accounting Review, 79. Jg., Nr. 4, S. 9671010

Francis, Jennifer / Nanda, Dhananjay / Olsson, Per (2008): Voluntary Disclosure, Earnings Quality, and Cost of Capital, in: Journal of Accounting Research, 46. Jg., Nr. 1, S. 53-99

Franke, Günter / Hax, Herbert (2004): Finanzwirtschaft des Unternehmens und Kapitalmarkt, 5. Auflage, Berlin 
Frankel, Richard / McNicols, Maureen / Wilson G. Peter (1995): Discretionary Disclosure and External Financing, in: The Accounting Review, 70. Jg., Nr. 1, S. 135-150

Frankel, Richard / Johnson, Marilyn / Skinner, Douglas J. (1999): An Empirical Examination of Conference Calls as a Voluntary Disclosure Medium, in: Journal of Accounting Research, 37. Jg., Nr. 1, S. 133-150

Freeman, R. Edward (1984): Strategic Management. A Stakeholder Approach, Marshfield

Frei, Norbert (1998): Investor Relations - Wie hege und pflege ich meinen Aktionär heute und morgen?, in: Frei, Norbert / Schlienkamp, Christoph [Hrsg.]: Aktie im Aufwind: Von der Kursprognose zum Shareholder Value, Wiesbaden, S. 163-183

Freidank, Carl-Christian / Steinmeyer, Volker (2005): Fortentwicklung der Lageberichterstattung nach dem BilReG aus betriebswirtschaftlicher Sicht, in: Betriebs-Berater, 60. Jg., Nr. 46, S. 2512-2517

Frey, Lutz (2001): Bilanzrechtliche Aspekte, in: Kirchhoff, Klaus Rainer / Piwinger, Manfred [Hrsg.]: Die Praxis der Investor Relations, Neuwied, S. 163-183

Friedlaender, Ernst / Stabernack, Marc G. (1998): Investor Relations und Shareholder Value, in: Müller, Michael / Leven, Franz-Josef [Hrsg.]: Shareholder Value Reporting. Veränderte Anforderungen an die Berichterstattung von Unternehmen, Wien, S. 45-62

Friedrichs, Jürgen (1990): Methoden empirischer Sozialforschung, 14. Auflage, Opladen

Froot, Kenneth A. / Perold, Andre F. / Stein, Jeremy C. (1992): Shareholder Trading Practices and Corporate Investment Horizons, in: Journal of Applied Corporate Finance, 5. Jg., Nr. 2, S. 42-58

Frost, Carol A. / Pownall, Grace (1994): Disclosure Practices in the United States and the United Kingdom, in: Journal of Accounting Research, 32. Jg., Nr. 1, S. 75-102

Frost, Carol A. / Kinney, William R. (1996): Disclosure Choices of Foreign Registrants in the United States, in: Journal of Accounting Research, 34. Jg., Nr. 1, S. 67-84

Fuchs, Markus / Stibi, Bernd (2000): IOSCO - SEC - EU-Kommission, in: Finanz Betrieb, 2. Jg., Beilage Nr. 1, S. 1-9

Fülbier, Rolf Uwe (1999): Regulierung. Ökonomische Betrachtung eines allgegenwärtigen Phänomens, in: Wirtschaft \& Steuern, 28. Jg., Nr. 9, S. 468-473

Gälweiler, Aloys (2005): Strategische Unternehmensführung, 3. Auflage, Frankfurt

Gassen, Joachim / Sellhorn, Thorsten (2006): Applying IFRS in Germany - Determinants and Consequences, in: Betriebswirtschaftliche Forschung und Praxis, 58. Jg., Nr. 4, S. $365-386$ 
Gassen, Joachim / Fischkin, Michael / Hill, Verena (2008): Das Rahmenkonzept-Projekt des IASB und des FASB: Eine normendeskriptive Analyse des aktuellen Stands, in: Die Wirtschaftsprüfung, 61. Jg., Nr. 18, S. 874-882

Gatignon, Hubert / Vosgerau, Joachim (2005): Moderating Effects: The Myth of Mean Centering, Working Paper, INSEAD, Fontainebleau

Gebhardt, William R. / Lee, Charles M. C. / Swaminathan, Bhaskaran (2001): Toward an Implied Cost of Capital, in: Journal of Accounting Research, 39. Jg., Nr. 1, S. 135-176

Gelb, David S. (2000): Managerial Ownership and Accounting Disclosure: An Empirical Study, in: Review of Quantitative Finance and Accounting, 15. Jg., Nr. 2, S. 169-185

Gerber, Olaf (2004): Die Haftung für unrichtige Kapitalmarktinformationen. Zugleich eine Besprechung der BGH-Entscheidung vom 19.07.2004 „Informatec“, in: Deutsches Steuerrecht, 42. Jg., Nr. 42, S. 1793-1798

Gibbins, Michael / Richardson, Alan / Waterhouse, John (1990): The Management of Corporate Financial Disclosure: Opportunism, Ritualism, Policies, and Processes, in: Journal of Accounting Research, 28. Jg., Nr. 1, S. 121-143

Gibson, Charles (1987): How Chartered Financial Analysts View Financial Ratios, in: Financial Analysts Journal, 43. Jg., Nr. 3, S. $74-76$

Gietzman, Miles B. / Trombetta, Marco (2003): Disclosure Interactions: Accounting Policy Choice and Voluntary Disclosure Effects on the Cost of Raising Outside Capital, in: Accounting and Business Research, 33. Jg., Nr. 3, S. 187-205

Gietzman, Miles B. / Ireland, Jen C. (2005): Cost of Capital, Strategic Disclosures and Accounting Choice, in: Journal of Business Finance \& Accounting, 32. Jg., Nr. 3-4, S. 599-634

Gilson, Stuart C. (1989): Management Turnover and Financial Distress, in: Journal of Financial Economics, 25. Jg., Nr. 2, S. 241-262

Ginter, Peter M. / Duncan, W. Jack (1990): Macroenvironmental Analysis for Strategic Management, in: Long Range Planning, 23. Jg, Nr. 6, S. 91-100

Gjesdal, Froystein (1981): Accounting for Stewardship, in: Journal of Accounting Research, 19. Jg., Nr. 1, S. 208-231

Glaum, Martin (2000): Bridging the GAAP: The Changing Attitude of German Managers towards Anglo-American Accounting and Accounting Harmonization, in: Journal of International Financial Management and Accounting, 11. Jg., Nr. 1, S. 23-46 
Glaum, Martin / Friedrich, Nico (2006): After the "Bubble": Valuation of

Telecommunications Companies by Financial Analysts, in: Journal of International Financial Management and Accounting, 17. Jg., Nr. 2, S. 161-174

Glaum, Martin / Thomaschewski, Dieter / Weber, Silke (2006): Auswirkungen des Sarbanes-Oxley Acts auf deutsche Unternehmen: Kosten, Nutzen, Folgen für USBörsennotierungen, in: Rosen, Rüdiger von [Hrsg.]: Studien des Deutschen Aktieninstituts, Heft 33, Frankfurt

Glejser, Herbert A. (1969): A New Test for Heteroskedasticity, in: Journal of the American Statistical Association, Band 64, Nr. 325, S. 316-323

Glöckler, Thomas (1995): Strategische Erfolgspotentiale durch Corporate Identity, Wiesbaden

Glosten, Lawrence R. / Harris, Lawrence E. (1988): Estimating the Components of the Bid/Ask Spread, in Journal of Financial Economics, 21. Jg., Nr. 1, S. 123-142

Glosten, Lawrence R. / Milgrom, Paul R. (1985): Bid, Ask, and Transaction Prices in a Specialist Market with Heterogeneously Informed Traders, in: Journal of Financial Economics, 14. Jg., Nr. 1, S. 71-100

Goldfeld, Stephen M. / Quandt, Richard E. (1978): Asymptotic Tests for the Constancy of Regressions in the Heteroscedastic Case, in: Research Memorandum No. 229, Econometric Research Program, Princeton University

Gonedes, Nicholas J. / Dopuch, Nicholas (1974): Capital Market Equilibrium, Information Production, and Selecting Accounting Techniques: Theoretical Framework and Review of Empirical Work, in: Journal of Accounting Research, 12. Jg., Nr. 3 (Supplement): Studies on Financial Accounting Objectives, S. 48-129

Görling, Helmut (1993): Die Verbreitung zwei- und mehrstufiger Unternehmensverbindungen - Ergebnisse einer empirischen Untersuchung, in: Die Aktiengesellschaft, 38. Jg., Nr. 12, S. 538-547

Grammig, Joachim / Schiereck, Dirk / Theissen, Erik (1999): Informationsbasierter Aktienhandel über IBIS, in: Zeitschrift für be-triebswirtschaftliche Forschung, 52. Jg., Nr. 11, S. 619-642

Grant, Robert M. (1991): The Resource-Based Theory of Competitive Advantage: Implications for Strategy Formulation, in: California Management Review, 33. Jg., Nr. 3, S. 114-135

Grant, Robert M. (2000): Contemporary Strategy Analysis, 3. Auflage, Malden 
Gray, Sidney / Meek, Gary K. / Roberts, Clare (1995): International Capital Market Pressure and Voluntary Annual Report Disclosures by U.S. and U.K. Multinationals, in: Journal of International Financial Management and Accounting, 6. Jg., Nr. 1, S. 43-68

Greinert, Markus (2004): Weitergehende Anforderungen an den Konzernlagebericht durch E-DRS 20 sowie das Bilanzrechtsreformgesetz, in: Zeitschrift für kapitalmarktorientierte Rechnungslegung, Nr. 2, S. 51-60

Gregoire, Timothy G. / Driver Beverly L. (1987): Analysis of Ordinal Data to Detect Population Differences, in: Psychological Bulletin, 101. Jg., Nr. 1, S. 159-165

Grote, Michael H. / Kube, Florian / Küchen, Michael (2009): „Home Sweet Home“ - Die Entwicklung des Handelsvolumens deutscher Aktien im Ausland, in: Kredit und Kapital, 42. Jg., Nr. 1, S. 25-54

Günther, Thomas / Beyer, Dirk (2001): Value Based Reporting - Entwicklungspotenziale der externen Unternehmensberichterstattung, in: Betriebs-Berater, 56. Jg., Nr. 32, S. $1623-1630$

Günther, Thomas / Otterbein, Simone (1996): Die Gestaltung der Investor Relations am Beispiel führender deutscher Aktiengesellschaften, in: Zeitschrift für Betriebswirtschaft, 66. Jg., Nr. 4, S. 389-417

Günther, Thomas / Beyer, Dirk / Menninger, Jutta (2003): Externe Berichterstattung über strategierelevante Informationen bei Unternehmen der ,new economy“, in: Zeitschrift für kapitalmarktorientierte Rechnungslegung, 3. Jg., Nr. 10, S. 448-458

Gujarati, Damodar N. (1995): Basic Econometrics, 3. Auflage, New York

Hachmeister, Dirk (2002): Lagebericht, in: Ballwieser, Wolfgang / Coenenberg, Adolf G. I Wysocki, Klaus [Hrsg.]: Handwörterbuch der Rechnungslegung und Prüfung, Stuttgart, Sp. 1431-1446

Häger, Ralf (1993): Das Publizitätsverhalten mittelgroßer Kapitalgesellschaften, Frankfurt/Main

Hahn, Dietger (1999a): Stand und Entwicklungstendenzen der strategischen Planung, in: Hahn, Dietger / Taylor, Bernhard [Hrsg.], Strategische Unternehmungsplanung Strategische Unternehmungsführung, 8. Auflage, Heidelberg, S. 1-27

Hahn, Dietger (1999b): Strategische Unternehmungsführung - Grundkonzept, in: Hahn, Dietger / Taylor, Bernhard [Hrsg.], Strategische Unternehmungsplanung Strategische Unternehmungsführung, 8. Auflage, Heidelberg, S. 28-50 
Hahn, Dietger (1999c): Strategische Kontrolle, in: Hahn, Dietger / Taylor, Bernhard [Hrsg.], Strategische Unternehmungsplanung - Strategische Unternehmungsführung, 8. Auflage, Heidelberg, S. 892-906

Hahn, Dietger / Hungenberg, Harald (2001): PuK. Planung und Kontrolle, Planungs- und Kontrollsysteme, Planungs- und Kontrollrechnung, 6. Auflage, Wiesbaden

Hahn, Dietger / Klausmann, Walter (1989): Entwicklung der betriebswirtschaftlichen Planung, in: Szyperski, Norbert (1989): Handwörterbuch der Planung, Stuttgart, Sp. 406-420

Hahn, Dietger / Krystek, Ulrich (1979): Betriebliche und überbetriebliche Frühwarnsysteme in der Industrie, in: Zeitschrift für betriebswirtschaftliche Forschung, 31. Jg., Nr. 1, S. 76-88

Hahn, Dietger / Simanek, Astrid (2000): Entwicklung strategischen Denkens im angloamerikanischen und deutschsprachigen Raum, in: Welge, Martin / Al-Laham, Andreas / Kajüter, Peter [Hrsg.]: Praxis des Strategischen Managements. Konzepte, Erfahrungen, Perspektiven, Wiesbaden, S. 17-38

Hail, Luzi (2002): The Impact of Voluntary Disclosures on the Ex-ante Cost of Capital for Swiss Firms, in: European Accounting Review, 11. Jg., Nr. 4, S. 741-773

Hail, Luzi (2003): The Relationship between Voluntary Annual Report Disclosures and Firm Characteristics in Switzerland, in: Die Unternehmung, 57. Jg., o. Nr., S. 273-290

Hail, Luzi / Leuz, Christian (2005): Cost of Capital and Cash-Flow Effects of U.S. CrossListings, Arbeitspapier University of Pennsylvania

Haller, Axel / Dietrich, Ralph (2001a): Intellectual Capital-Bericht als Teil des Lageberichts, in: Der Betrieb, 54. Jg., Nr. 20, S. 1045-1052

Haller, Axel / Dietrich, Ralph (2001b): Freiwillige Unternehmensberichterstattung in den USA - Ergebnisse des Business Reporting Research Project des FASB, in: Zeitschrift für kapitalmarktorientierte Rechnungslegung, 1. Jg., Nr. 5, S. 206-211

Haller, Axel / Dietrich, Ralph (2001c): Kapitalmarktorientierte Gestaltung der Lageberichterstattung, in: Zeitschrift für kapitalmarktorientierte Rechnungslegung, 1. Jg., Nr. 4, S. 164-174

Haller, Axel / Walton, Peter (2000): Unternehmenspublizität im Spannungsfeld nationaler Prägung und internationaler Harmonisierung, in: Haller, Axel / Raffournier, Bernard / Walton, Peter [Hrsg.]: Unternehmenspublizität im internationalen Wettbewerb, Stuttgart, S. 3-72

Hamilton, Barton H. / Nickerson, Jackson A. (2003): Correcting for Endogeneity in

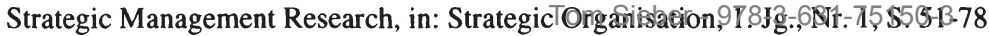


Hammer, Richard (1998): Unternehmungsplanung. Lehrbuch der Planung und strategischen Unternehmungsführung, 7. Auflage, München/Wien

Haniffa, R. Mohamad / Cooke, Terry E. (2002): Culture, Corporate Governance and Disclosure in Malaysian Corporations, in: Abacus, 38. Jg., Nr. 3, S. 317-349

Hank, Benno (1999): Informationsbedürfnisse von Kleinaktionären - Zur Gestaltung von Investor Relations, Frankfurt

Hardy, Melissa A. (1993): Regression with Dummy Variables, in: Sage University Paper Series on Quantitative Applications in the Social Sciences, Nr. 07-093, Newbury Park (CA)

Harris, Trevor S. / Möller, Hans-Peter /Lang, Mark (1994): The Value Relevance of German Accounting Measures: An Empirical Analysis, in: Journal of Accounting Research, 32. Jg., Nr. 2, S. 187-209

Harris, Mary Stanford (1998): The Association between Competition and Managers' Business Segment Reporting Decisions, in: Journal of Accounting Research, 36. Jg., Nr. 1, S. 111-128

Hartmann, Christina (2006): Internationalisierung der Lageberichterstattung. Darstellung und Vergleich des deutschen Lageberichts und der US-amerikanischen MD\&A, Marburg

Hartmann-Wendels, Thomas (1991): Rechnungslegung der Unternehmen und Kapitalmarkt aus informationsökonomischer Sicht, Heidelberg

Hartung, Joachim / Epelt, Bärbel / Klösener, Karl-Heinz (2005): Statistik. Lehr- und Handbuch der angewandten Statistik, 14. Auflage, München

Harwell, Michael R. / Gatti, Guido G. (2001): Rescaling Ordinal Data to Interval Data in Educational Research, in: Review of Educational Research, 71. Jg., Nr. 1, S. 105-131

Hasan, Iftekhar / Simaan, Yusif (2000): A Rational Explanation for Home Country Bias, in: Journal of International Money and Finance, 19. Jg., Nr. 3, S. 331-361

Haubrok, Axel / Duda, Alexandra (2001): Investor Relations, in: Achleitner, Ann-Kristin / Thoma, Georg F. [Hrsg.]: Handbuch Corporate Finance. Konzepte, Strategien und Praxiswissen für das moderne Finanzmanagement, 2. Auflage, Köln (Abschnitt 4.9.1)

Hausman, Jerry A. (1978): Specification Tests in Econometrics, in: Econometrica, 46. Jg., Nr. 6, S. 1251-1271

Hax, Arnoldo A. / Majluf, Nicolas S. (1996): The Strategy Concept and Process, 2. Auflage, Upper Saddle River 
Hax, Herbert (1988): Rechnungslegungsvorschriften - Notwendige Rahmenbedingungen für den Kapitalmarkt?, in: Domsch, Michel / Eisenführ, Franz / Ordelheide, Dieter / Pertlitz, Manfred [Hrsg.]: Unternehmenserfolg. Planung, Ermittlung, Kontrolle, Festschrift Busse von Colbe, Wiesbaden, S. 187-201

Hax, Herbert (1989): Investitionsrechnung und Periodenerfolgsrechnung, in: Delfmann, Werner et al. [Hrsg.] Der Integrationsgedanke in der Betriebswirtschaftslehre, Festschrift Koch, S. 153-170

Hax, Herbert (1991): Theorie der Unternehmung - Information, Anreize und Vertragsgestaltung, in: Ordelheide, Dieter / Rudolph, Bernd / Büsselmann, Elke [Hrsg.]: Betriebswirtschaftslehre und ökonomische Theorie, Stuttgart, S. 51-72

Hayn, Sven (2005): Entwicklungstendenzen im Rahmen der Anwendung von IFRS in der Konzernrechnungslegung, in: Betriebswirtschaftliche Forschung und Praxis, 57. Jg., Nr. 6, S. 424-439

Hayn, Sven / Matena, Sonja (2005): Prüfung des Value Reporting durch den Abschlussprüfer, in: Zeitschrift für Planung \& Unternehmenssteuerung, 16. Jg., Nr. 4, S. 425-449

Healy, Paul M. / Palepu, Krishna G. (2001): Information Asymmetry, Corporate Disclosure, and the Capital Markets: A Review of the Empirical Disclosure Literature, in: Journal of Accounting and Economics, 31. Jg., Nr. 1-3, S. 405-440

Healy, Paul M. / Hutton, Amy P. / Palepu, Krishna G. (1999): Stock Performance and Intermediation Changes Surrounding Sustained Increases in Disclosure, in: Contemporary Accounting Research, 16. Jg., Nr. 3, S. 485-520

Healy, Paul M. / Wahlen, James M. (1999): A Review of Earnings Management Literature and Its Implications for Standard Setting, in: Accounting Horizons, 13. Jg., Nr. 4, S. 365-384

Heflin, Frank L. / Shaw, Kenneth W. / Wild, John W. (2005): Disclosure Policy and Market Liquidity: Impact of Depth Quotes and Order Sizes, in: Contemporary Accounting Research, 22. Jg., Nr. 4, S. 829-865

Heinen, Karl-Christoph (2002): Die Berücksichtigung von Kosten in der Konkurrenzanalyse, Frankfurt

Held, Martin / Nutzinger, Hans G. (2003): Perspektiven einer allgemeinen Institutionenökonomik, in: Schmid, Michael / Maurer, Andrea [Hrsg.]: Ökonomischer und soziologischer Institutionalismus. Interdisziplinäre Beiträge und Perspektiven der Institutionentheorie und -analyse, Marburg, S. 117-137 
Hennrichs, Joachim (1997): Die Bedeutung der EG-Bilanzrichtlinie für das deutsche Handelsbilanzrecht, in: Zeitschrift für Unternehmens- und Gesellschaftsrecht, 26. Jg., Nr. 1, S. 66-88

Henselmann, Klaus (2005): Value Reporting und Konkurrenzanalyse, in: Betriebswirtschaftliche Forschung und Praxis, 57. Jg., Nr. 3, S. 296-305

Henzler, Herbert A. (1988a): Vision und Führung, in: Henzler, Herbert A. [Hrsg.]: Handbuch Strategischer Führung, Wiesbaden, S. 17-33

Henzler, Herbert A. (1988b): Von der strategischen Planung zur strategischen Führung: Versuch einer Positionsbestimmung, in: Zeitschrift für Betriebswirtschaft, 58. Jg., Nr. 12, S. 1286-1307

Hergert, Michael / Morris, Deigan (1989): Accounting Data for Value Chain Analysis, in: Strategic Management Journal, 10. Jg., Nr. 2, S. 175-188

Heumann, Rainer (2005): Value Reporting in IFRS-Abschlüssen und Lageberichten, Düsseldorf

Heumann, Rainer (2006): Möglichkeiten zur praktischen Ausgestaltung eines Value Reporting in Geschäftsberichten, in: Zeitschrift für kapitalmarktorientierte Rechnungslegung, 6. Jg., Nr. 4, S. 259-266

Hinterhuber, Hans H. (1990): Wettbewerbsstrategie, 2. Auflage, Berlin

Hinterhuber, Hans H. (1999): Struktur und Dynamik der strategischen Unternehmensführung, in: Hahn, Dietger / Taylor, Bernhard [Hrsg.]: Strategische Unternehmungsplanung - Strategische Unternehmungsführung, 8. Auflage, Heidelberg, S. 51-74

Hinterhuber, Hans H. (2004): Strategische Unternehmensführung I, Strategisches Denken. Vision, Unternehmenspolitik, Strategie, 7. Auflage, Berlin

Hirschey, Mark / Richardson, Vernon J. / Scholz, Susan (2001): Value Relevance of Nonfinancial Information: The Case of Patent Data, in: Review of Quantitative Finance \& Accounting, 17. Jg., Nr. 3, S. 223-235

Hirschey, Mark / Weygandt, Jerry (1985): Amortization Policy for Advertising and Research and Development Expenditures, in: Journal of Accounting Research, 23. Jg., Nr. 1, S. 326-335

Hitz, Jörg M. (2005): Rechnungslegung zum Fair Value: Konzeption und Entscheidungsnützlichkeit, Frankfurt

Ho, Simon S. M / Wong, K. Shun (2001): A Study on the Relationship between Corporate Governance Structures and the Extent of Voluntary Disclosure, in: Journal of

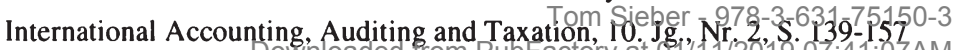


Hofer, Charles W. / Schendel, Dan (1984): Strategy Formulation: Analytical Concepts, St. Paul

Hoffjan, Andreas (2003a): Competitor Accounting - Controlling im Dienste der Konkurrenzanalyse, in: Zeitschrift für Controlling \& Management, 47. Jg., Nr. 6, S. 379-390

Hoffjan, Andreas (2003b): Competitor Accounting - Nutzen des Jahresabschlusses in der Konkurrenzanalyse, in: Betriebs-Berater, 58. Jg., Nr. 28/29, S. 1494-1498

Hoffman, Nicole P. (2000): An Examination of the "Sustainable Competitive Advantage“ Concept: Past, Present, and Future, in: Academy of Marketing Science Review, 1. Jg., Nr. 4, S. 1-16

Holdhof, Glenny (1988): Das Bilanzierungsverhalten mittelständischer Unternehmen: Eine empirische Untersuchung, Stuttgart

Holler, Manfred J. / Illing, Gerhard (2006): Einführung in die Spieltheorie, 6. Auflage, Berlin

Homburg, Christian / Sütterlin, Stefan (1992): Strategische Gruppen: Ein Survey, in: Zeitschrift für Betriebswirtschaft, 62. Jg., Nr. 6, S. 635-662

Hommelhoff, Peter (2002): § 289 HGB, in: Canaris, Claus-Wilhelm / Schilling, Wolfgang / Ulmer, Peter [Hrsg.]: Handelsgesetzbuch, Großkommentar, Berlin, S. 900-947

Hope, Ole Kristian (2002): Disclosure Practices, Enforcement of Accounting Standards and Analysts' Forecast Accuracy: An International Study, Arbeitspapier, University of Toronto (mit umfangreicheren statistischen Auswertungen als der ähnliche Artikel von Hope (2003))

Hope, Ole Kristian (2003): Disclosure Practices, Enforcement of Accounting Standards and Analysts' Forecast Accuracy: An International Study, in: Journal of Accounting Research, 41. Jg., Nr. 2, S. 235-273

Horovitz, Jacques H. (1979): Strategic Control: A New Task for Top Management, in: Long Range Planning, 12. Jg., Nr. 3, S. 2-7

Horváth, Péter / Kaufmann, Lutz (1998): Balanced Scorecard - ein Werkzeug zur Umsetzung von Strategien, in: Harvard Business Manager, 20. Jg., Nr. 5, S. 39-48.

Hossain, M. / Tan, L.M. / Adams, M. (1994): Voluntary Disclosure in an Emerging Capital Market: Some Empirical Evidence from Companies listed on the Kuala Lumpur Stock Exchange, in: International Journal of Accounting, 29. Jg., Nr. 3, S. 334-351

Hossain, Mohammad / Perera, M.B. Hector / Rahman, Asheq R. (1995): Voluntary Disclosure in the Annual Report of New Zealand Companies, in: Journal of

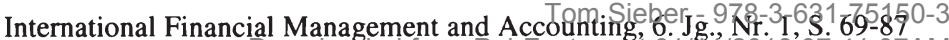


Hüffer, Uwe (2006): Aktiengesetz, 7. Auflage, München

Hughes, K. E. (2000): The Value Relevance of Nonfinancial Measures of Air Pollution in the Electric Utility Industry, in: The Accounting Review, 75. Jg., Nr. 2, S. 109-128

Hundhausen, Carl (1957): Industrielle Publizität als Public Relations, Essen

Hungenberg, Harald (1999): Anreizsysteme für Führungskräfte - Theoretische Grundlagen und praktische Ausgestaltungsmöglichkeiten, in: Hahn, Dietger / Taylor, Bernhard [Hrsg.]: Strategische Unternehmungsplanung - Strategische Unternehmungsführung, 8. Auflage, Heidelberg, S. 720-735

Hungenberg, Harald (2001): Strategisches Management in Unternehmen, 2. Auflage, Wiesbaden

Hungenberg, Harald (2002): Strategische Planung, in: Küpper, Hans-Ulrich / Wagenhofer, Alfred [Hrsg.]: Handwörterbuch Unternehmensrechnung und Controlling, Stuttgart, Sp. 1888-1899

Hütten, Christoph (2000): Der Geschäftsbericht als Informationsinstrument, Düsseldorf

Hütten, Christoph / Küting, Karlheinz (2001): Geschäftsbericht, in: Achleitner, AnnKristin / Bassen, Alexander [Hrsg.]: Investor Relations am Neuen Markt, Stuttgart, S. $489-508$

Hutton, Amy P. (2001): Four Rules for Taking Your Message to Wall Street, in: Harvard Business Review, 79. Jg., Nr. 5, S. 125-132

Hutton, Amy P. / Miller, Gregory S. / Skinner, Douglas J. (2003): The Role of Supplementary Statements with Management Earnings Forecasts, in: Journal of Accounting Research, 41. Jg., Nr. 5, S. 867-890

Ijiri, Yuji (1975): Theory of Accounting Measurement, in: American Accounting Association [Hrsg.]: Studies in Accounting Research, Nr. 10, Sarasota (Fla)

Iman, Ronald L. / Conover, William J. (1979): The Use of Rank Transform in Regression, in: Technometrics, 21. Jg., Nr. 4, S. 499-509

IOSCO [International Organization of Securities Commissions, Hrsg.] (2003): General Principles Regarding Disclosure of Management's Discussion and Analysis of Financial Condition and Results of Operations, o.O.

Quelle: http://www.iosco.org/library/pubdocs/pdf/ioscopd 141.pdf (Stand am 13.07.2009)

Israeloff, Robert L. (1995): The Forward-looking Data Debate, in: CFO, 11. Jg., Nr. 3, S. 15-16 
Jaccard, James / Wan, Choi K. / Turrisi, Robert (1990): The Detection and Interpretation of Interaction Effects between Continuous Variables in Multiple Regression, in: Multivariate Behaviorial Research, 25. Jg., Nr. 4, S. 467-478

Jäger, Rainer / Himmel, Holger (2003): Die Fair Value-Bewertung immaterieller Vermögensgegenstände vor dem Hintergrund der Umsetzung internationaler Rechnungslegungsstandards, in: Betriebswirtschaftliche Forschung und Praxis, 55. Jg., Nr. 4, S. 417-440

Jaggi, Bikki (1978): A Note on the Information Content of Corporate Annual Earnings Forecasts, in: The Accounting Review, 53. Jg., Nr. 4, S. 961-967

Janssen, Jürgen / Laatz, Wilfried (2007): Statistische Datenanalyse mit SPSS für Windows. Eine anwendungsorientierte Einführung in das Basissystem und das Modul Exakte Tests, 6. Auflage, Berlin

Jenkins, Edmund L. (1994): An Information Highway in Need of Capital Improvements. Users' Critical External Reporting Needs are not being met, in: Journal of Accountancy, 177. Jg., Nr. 5, S. 77-82

Jensen, Michael C. (1983): Organization Theory and Methodology, in: The Accounting Review, 58. Jg., Nr. 2, S. 319-339

Jensen, Michael C. / Meckling, William H. (1976): Theory of the Firm: Managerial Behavior, Agency Costs and Ownership Structure, in: Journal of Financial Economics, 3. Jg., Nr. 4, S. 305-360

Jenter, Dirk / Kanaan, Fadi (2006): CEO Turnover and Relative Performance Evaluation, Working Paper, MIT Sloan School of Management, Cambridge

Jones, Denise A. (2007): Voluntary Disclosure in R\&D-Intensive Industries, in: Contemporary Accounting Research, 24. Jg., Nr. 2, S. 489-522

Jörg, Petra / Loderer, Claudio / Roth, Lukas (2004): Shareholder Value Maximization: What Managers say and what they do, in: Die Betriebswirtschaft, 64. Jg., Nr. 3, S. 357-377

Jorgensen, Bjorn (1998): Hedging and Performance Evaluation, Arbeitspapier, Harvard Business School

Jose, Manuel L. / Nichols, Len M. / Stevens, Jerry L. (1986): Contributions of Diversification, Promotion, and R\&D to the Value of Multiproduct Firms: A Tobin's Q Approach, in: Financial Management, 15. Jg., Nr. 4, S. 33-42

Jostarndt, Philipp (2007): Financial Distress, Corporate Restructuring, and Firm Survival: An Empirical Analysis of German Panel Data, Wiesbaden. 
Julian, Scott D. (1993): Toward a Comprehensive Framework for Strategic Control,

Proceedings of the Annual Meeting of the Academy of Management Proceedings, S. $17-21$

Kahle, Holger (2002): Informationsversorgung des Kapitalmarktes über internationale Rechnungslegungsstandards, in: Zeitschrift für kapitalmarktorientierte Rechnungslegung, 2. Jg., Nr. 2, S. 95-107

Kaiser, Henry F. (1970): A Second Generation Little Jiffy, in: Psychometrika, 35. Jg., Nr. 4, S. 401-415

Kaiser, Karin (2005a): Auswirkungen des Bilanzrechtsreformgesetzes auf die zukunftsorientierte Lageberichterstattung, in: Die Wirtschaftsprüfung, 58. Jg., Nr. 8, S. 405418

Kaiser, Karin (2005b): Erweiterung der zukunftsorientierten Lageberichterstattung: Folgen des Bilanzrechtsreformgesetzes für Unternehmen, in: Der Betrieb, 58. Jg., Nr. 7, S. 345-353

Kajüter, Peter (2001): Risikoberichterstattung: Empirische Befunde und Entwurf des DSR 5, in: Der Betrieb, 54. Jg., Nr. 3, S. 105-111

Kajüter, Peter (2002): Prüfung der Risikoberichterstattung im Lagebericht, in: BetriebsBerater, 57. Jg., Nr. 5, S. 243-249

Kajüter, Peter (2004a): Der Lagebericht als Instrument einer kapitalmarktorientierten Rechnungslegung. Umfassende Reformen nach dem Entwurf zum BilReG und EDRS 20, in: Der Betrieb, 57. Jg., Nr. 5, S. 197-203

Kajüter, Peter (2004b): Berichterstattung über Chancen und Risiken im Lagebericht. Auswirkungen des Referentenentwurfs für das Bilanzrechtsreformgesetz, in: Betriebs-Berater, 59. Jg., Nr. 5, S. 427-433

Kajüter, Peter / Guttmeier, Matthias (2009): Der Exposure Draft des IASB zum Management Commentary. Kritische Analyse und Vergleich mit DRS 15, in: Der Betrieb, 62. Jg., Nr. 44, S. 2333-2339

Kajüter, Peter / Winkler, Carsten (2003): Die Risikoberichterstattung der Dax 100Unternehmen im Zeitvergleich, in: Zeitschrift für kapitalmarktorientierte Rechnungslegung, 3. Jg., Nr. 5, S. 217-228 
Kappler, Marcus / Westerheide, Peter (2003): Aktienmärkte und Beschäftigung. Eine Analyse aus makro- und mikroökonomischer Perspektive, Mannheim

Quelle: http://deutsche-boerse.com/INTERNET/EXCHANGE/... zpd.nsf/PublikationenID/RJAN-5MPL6L/\$FILE/... research_paper.pdf?OpenElement (Stand am 03.01.2010)

Karamanou, Irene / Vafeas, Nikos (2005): The Association between Corporate Boards, Audit Committees, and Management Earnings Forecasts: An Empiricial Analysis, in: Journal of Accounting Research, 43. Jg., Nr. 3, S. 453-486

Kellinghusen, Georg / Irrgang, Wolfgang (1978): Der optimale Geschäftsbericht, in: Der Betrieb, 31. Jg., Nr. 48, S. 2277-2283

Kennedy, Peter (2003): A Guide to Econometrics, Cambridge

Kent, Pamela / Ung, Karen (2003): Voluntary Disclosure of Forward-Looking Earnings Information in Australia, in: Australian Journal of Management, 28. Jg., Nr. 3, S. 273-285

Kersting, Mark O. / Sohbi, Hassan (1998): Haftungsrechtliche Aspekte einer vorausschauenden Berichterstattung, in: Müller, Michael / Leven, Franz-Josef [Hrsg.]: Shareholder Value Reporting: Veränderte Anforderungen an die Berichterstattung börsennotierter Unternehmen, Wien, S. 293-312

Keselman, Harvey J. / Games, Paul A. / Rogan, Joanne C. (1979): Protecting the Overall Rate of Type I Errors for Pairwise Comparisons with an Omnibus Test Statistic, in: Psychological Bulletin, 86. Jg., Nr. 4, S. 884-888

Kessler, Harald (2005): Ist der Fair Value fair?, in: Bieg, Hartmut / Heyd, Reinhard [Hrsg.]: Fair Value. Bewertung in Rechnungswesen, Controlling und Finanzwirtschaft, München, S. 51-81

Kim, Oliver / Verrecchia, Robert E. (1994): Market Liquidity and Volume around Earnings Announcements, in: Journal of Accounting and Economics, 17. Jg., Nr. 1/2, S. 41-68

Kindler, Peter / Horstmann, Hendrik (2004): Die EU-Übernahmerichtlinie. Ein „europäischer“ Kompromiss, in: Deutsches Steuerrecht, 42. Jg., Nr. 20-21, S. 866873

Kirchhoff, Klaus Rainer (2001): Grundlagen der Investor Relations, in: Kirchhoff, Klaus Rainer / Piwinger, Manfred [Hrsg.]: Die Praxis der Investor Relations: Effiziente Kommunikation zwischen Unternehmen und Kapitalmarkt, 2. Auflage, Neuwied, S. 25-55 
Kirchner, Christian (2000): Der Wettbewerbsfaktor „Entscheidungsnützlichkeit von Rechnungslegungsinformationen“: Eine institutionenökonomische Analyse, in: Zeitschrift für betriebswirtschaftliche Forschung, 52. Jg., Sonderheft Nr. 45: Schildbach, Thomas / Wagenhofer, Alfred [Hrsg.]: Wettbewerb und Unternehmensrechnung, S. 41-68

Kirchner, Christian (2002): Publizität, in: Ballwieser, Wolfgang / Coenenberg, Adolf G. I Wysocki, Klaus [Hrsg.]: Handwörterbuch der Rechnungslegung und Prüfung, Stuttgart, Sp. 1938-1950

Kirsch, Hans-Jürgen (1990): Die Equity-Methode im Konzernabschluss: Der Charakter der deutschen Regelungen vor dem Hintergrund der internationalen Entwicklung, Düsseldorf

Kirsch, Hans-Jürgen (2002): Vom Bilanzrichtlinien-Gesetz zum Transparenz- und Publizitätsgesetz: Die Entwicklung der deutschen Bilanzierungsnormen in den vergangenen 20 Jahren, in: Die Wirtschaftsprüfung, 55. Jg., Nr. 14, S. 743-755

Kirsch, Hans-Jürgen (2003): Zur Frage der Umsetzung der Mitgliedstaatenwahlrechte der EU-Verordnung zur Anwendung der IAS/IFRS, in: Die Wirtschaftsprüfung, 56. Jg., Nr. 6, S. 275-278

Kirsch, Hans-Jürgen / Dohrn, Matthias (2005): Umsetzung der Fair Value-Richtlinie in Deutschland, in: Bieg, Hartmut / Heyd, Reinhard [Hrsg.]: Fair Value. Bewertung in Rechnungswesen, Controlling und Finanzwirtschaft, München, S. 129-154

Kirsch, Hans-Jürgen / Köhrmann, Hannes (2007): Grundlagen der Lageberichterstattung, in: Böcking, Hans-Joachim / Castan, Edgar / Heymann, Gerd / Pfitzer, Norbert / Scheffler, Eberhard [Hrsg.]: Beck'sches Handbuch der Rechnungslegung, Band II, München, B 510

Kirsch, Hans-Jürgen / Scheele, Alexander (2003): E-DRS 20: Ausweitung der Lageberichterstattung zum Value Reporting?, in: Betriebs-Berater, 58. Jg., Nr. 51-52, S. $2733-2739$

Kirsch, Hans-Jürgen / Scheele, Alexander (2004): Die Auswirkungen der Modernisierungsrichtlinie auf die (Konzern-) Lageberichterstattung - unter Berücksichtigung von E-DRS 20 und des Entwurf eines Bilanzrechtsreformgesetzes vom 15.12.2003, in: Die Wirtschaftsprüfung, 57. Jg., Nr. 1-2, S. 1-12

Kirsch, Hans-Jürgen / Scheele, Alexander (2005): Neugestaltung von Prognose- und Risikoberichterstattung im Lagebericht durch das Bilanzrechtsreformgesetz, in: Die Wirtschaftsprüfung, 58. Jg., Nr. 21, S. 1149-1154 
Kirsch, Hans-Jürgen / Scheele, Alexander (2006): Diskussionspapier des IASB zum „Management Commentary“, in: Die Wirtschaftsprüfung, 59. Jg., Nr. 3, S. 89-91

Kirsch, Werner (1969): Die Unternehmungsziele aus organisationstheoretischer Sicht, in: Zeitschrift für betriebswirtschaftliche Forschung, 21. Jg., o. Nr., S. 665-675

Klausmann, Walter (1982): Entwicklung der Unternehmungsplanung, Gießen: Verlag der Ferber'schen Universitätsbuchhandlung

Kleinmanns, Herrmann (2004): „Enhanced Business Reporting“ - Aktuelle Bestrebungen des AICPA im Bereich der externen Rechnungslegung, in: Steuern und Bilanzen (StuB), 6. Jg., Nr. 22, S. 1021-1024

Kley, Karl-Ludwig (2001): Die Fair Value-Bilanzierung in der Rechnungslegung nach den International Accounting Standards (IAS), in: Der Betrieb, 54. Jg., Nr. 43, S. $2257-$ 2262

Kley, Karl-Ludwig (2003): Informationsvermittlung durch Value Reporting?, in: Der Betrieb, 56. Jg., Nr. 16, S. 840-843

Klingebiel, Norbert (2000): Externe Berichterstattung via Balanced Scorecard, in: Controller Magazin, 25. Jg., Nr. 2, S. 175-179

Kloos, Gerhard (1993): Die Transformation der 4. EG-Richtlinie (Bilanzrichtlinie) in den Mitgliedstaaten der Europäischen Gemeinschaft. Eine Analyse der verbliebenen Rechnungslegungsunterschiede aufgrund von nationalen Wahlrechtsausnutzungen, Berlin

Kmenta, Jan (1997): Elements of Econometrics, 2. Auflage, New York

Knauer, Thorsten / Wömpener, Andreas (2010): Prognoseberichterstattung gemäß DRS 15. Eine empirische Analyse der Unternehmen des Prime Standards, in: Corporate Finance biz, 1. Jg., Nr. 2, S. 84-92

Knorr, Liesl (2001): Zwischenberichterstattung, in: Betriebswirtschaftliche Forschung und Praxis, 53. Jg., Nr. 1, S. 1-6

Knutson, Peter H. (1992): Financial Reporting in the 1990s and Beyond, Association for Investment Management Research, New York

Knyphausen-Aufsess, Dodo zu (1993): „Why are Firms different?“. Der „Ressourcenorientierte Ansatz“ im Mittelpunkt einer aktuellen Kontroverse im Strategischen Management, in: Die Betriebswirtschaft, 53. Jg., Nr. 6, S. 771-792

Knyphausen-Aufsess, Dodo zu (2002): Strategien, in: Küpper, Hans-Ulrich / Wagenhofer, Alfred [Hrsg.]: Handwörterbuch Unternehmensrechnung und Controlling, 4. Auflage, Stuttgart, Sp. 1868-1879 
Köhler, Annette G. / Meyer, Stephanie / Mauelshagen, Jan (2004): BB-

Gesetzgebungsreport: Umsetzungsstand des 10-Punkte-Plans der Bundesregierung zur Stärkung des Anlegerschutzes und der Unternehmensintegrität, in: BetriebsBerater, 59. Jg., Nr. 48, S. 2623-2631

Köster, Harald (1992): Grundsätze ordnungsgemäßer Zwischenberichter-stattung börsennotierter Aktiengesellschaften, Düsseldorf

Kolks, Uwe (1990): Strategieimplementierung. Ein anwenderorientiertes Konzept, Wiesbaden

Koller, Tim / Goedhart, Marc / Wessels, David (2005): Valuation: Measuring and Managing the Value of Companies, 4. Auflage, New York

Korn, Evelyn / Schiller, Ulf (2003): Voluntary Disclosure of Nonproprietary Information: A Complete Equilibrium Characterization, in: Journal of Business Finance and Accounting, 30. Jg., Nr. 9/10, S. 1327-1339

Kosiol, Erich (1967): Zur Problematik der Planung in der Unternehmung, in: Zeitschrift für Betriebswirtschaft, 37. Jg., Nr. 1, S. 77-96

Kothari, Sunil P. (2001): Capital Markets Research in Accounting, in: Journal of Accounting and Economics, 31. Jg., Nr. 1-3, S. 105-231

Kotler, Philip / Achrol, Ravi Singh (1984): Marketing Strategy and the Science of Warfare, in: Lamb, Robert Boyden [Hrsg.]: Competitive Strategic Management, Englewood Cliffs, S. 94-133

Krause, Hartmut (2004): Die EU-Übernahmerichtlinie - Anpassungsbedarf im Wertpapiererwerbs- und Übernahmegesetz, in: Betriebs-Berater, 59. Jg., Nr. 3, S. 113-119

Krawitz, Norbert (2006): Erweiterte Berichterstattungspflichten nach dem Bilanzrechtsreformgesetz und Vorstandsvergütungs-Offenlegungsgesetz, in: Siecht, Gerhard [Hrsg.]: Jahrbuch für Controlling und Rechnungswesen, Wien, S. 219-244

Krawitz, Norbert / Hartmann, Christina (2003): Internationalisierung der Lageberichterstattung, in: Wollmert, Peter / Schönbrunn, Norbert / Jung, Udo / Siebert, Hilmar / Henke, Michael [Hrsg.]: Wirtschaftsprüfung und Unternehmensüberwachung, Festschrift Lück, Düsseldorf, S. 287-303

Kreikebaum, Hartmut / Grimm, Ulrich (1983): Die Analyse strategischer Faktoren und ihre Bedeutung für die strategische Planung, in: Wirtschaftswissenschaftliches Studium, 12. Jg., Nr. 1, S. 6-12

Kroeber-Riel, Werner / Esch, Franz-Rudolf (2000): Strategie und Technik der Werbung. Verhaltenswissenschaftliche Ansätze, 5. Auflage, Stuttgart

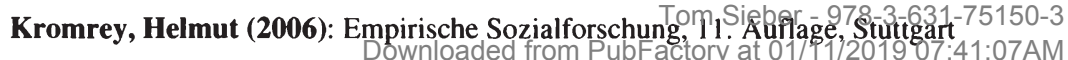


Kropff, Bruno (1980): Der Lagebericht nach geltendem und künftigen Recht, in: Betriebswirtschaftliche Forschung und Praxis, 32. Jg., Nr. 6, 514-532

Krüger, Wilfried (1989): Hier irrten Peters und Waterman, in: Harvard Business Manager, 11. Jg., Nr. 1, S. 13-18

Krüger, Wilfried (1994): Organisation der Unternehmung, 3. Auflage, Stuttgart

Krüger, Wilfried (2009): Excellence in Change. Wege zur strategischen Erneuerung, 4. Auflage, Wiesbaden

Krüger, Wilfried / Homp, Christian (1997): Kernkompetenz-Management. Steigerung von Flexibilität und Schlagkraft im Wettbewerb, Wiesbaden.

Krüger, Wilfried / Schwarz, Gunther (1990): Konzeptionelle Analyse und praktische Bestimmung von Erfolgsfaktoren und Erfolgspotentialen, in: Bleicher, Knut / Gomez, Peter [Hrsg.]: Zukunftsperspektiven der Organisation, Festschrift Staerkle, Bern, S. 179-209

Krumbholz, Marcus (1994): Die Qualität publizierter Lageberichte: Ein empirischer Befund zur Unternehmenspublizität, Düsseldorf

Krystek, Ulrich / Müller, Michael (1998): Zur Relevanz des Shareholder Value Reporting als Frühaufklärungsinformation für den Wettbewerb, in: Müller, Michael / Leven, Franz-Josef [Hrsg.]: Shareholder Value Reporting: Veränderte Anforderungen an die Berichterstattung börsennotierter Unternehmen, Wien, S. 241-266

Krystek, Ulrich / Müller-Stewens, Günter (1999): Strategische Frühaufklärung, in: Hahn, Dietger / Taylor, Bernhard [Hrsg.], Strategische Unternehmungsplanung Strategische Unternehmungsführung, 8. Auflage, S. 175-193

Küpper, Hans-Ulrich (2001): Controlling: Konzeption, Aufgaben und Instrumente, 3. Auflage, Stuttgart

Kussmaul, Heinz (1999): Informationen des betrieblichen Rechnungswesens für das Management, in: Deutsches Steuerrecht, 37. Jg., Nr. 38, S. 1579-1588

Küting, Karlheinz (2000a): Perspektiven der externen Rechnungslegung, in: Der Schweizer Treuhänder, 74. Jg., Nr. 3, S. 153-168

Küting, Karlheinz (2000b): Perspektiven der externen Rechnungslegung, in: Der BetriebsBerater, 55. Jg., Nr. 9, S. 451-456

Küting, Karlheinz (2002): Von der Bilanzanalyse zur Unternehmensanalyse - dargestellt am Beispiel der Beurteilung von Unternehmen der neuen Ökonomie, in: Deutsches Steuerrecht, 57. Jg., Nr. 32, Beihefter, S. 1-19 
Küting, Karlheinz (2005): IFRS: Schöne neue Bilanzwelt?, in: Betriebs-Berater, 60. Jg., Nr. 47, S. 1

Küting, Karlheinz / Dawo, Sascha (2003): Die Bilanzierung immaterieller Vermögenswerte nach IAS 38 - Gegenwärtige Regelungen und geplante Änderungen: Ein Beispiel für die Polarität von Vollständigkeitsprinzip und Objektivierungsprinzip, in: Betriebswirtschaftliche Forschung und Praxis, 55. Jg., Nr. 4, S. 397-406

Küting, Karlheinz / Hütten, Christoph (1996): Der Geschäftsbericht als Publizitätsinstrument, in: Der Betriebs-Berater, 51. Jg., Nr. 51/52, S. 2671-2679

Küting, Karlheinz / Hütten, Christoph (1997): Die Lageberichterstattung über Risiken der künftigen Entwicklung, in: Die Aktiengesellschaft, 42. Jg., Nr. 6, S. 250-256

Küting, Karlheinz / Hütten, Christoph (2000): Darstellung und Prüfung der künftigen Entwicklungsrisiken und -chancen im Lagebericht, in: Lachnit, Laurenz / Freidank, Carl-Christian [Hrsg.]: Investororientierte Unternehmenspublizität. Neue Entwicklungen von Rechnungslegung, Prüfung und Jahresabschlussanalyse, Wiesbaden, S. 399-431

Küting, Karlheinz / Weber, Claus-Peter (2003): Der Konzernabschluss: Lehrbuch zur Praxis der Konzernrechnungslegung, 8. Auflage, Stuttgart

Küting, Karlheinz / Hütten, Christoph / Lorson, Peter (1995a): Shareholder Value: Grundüberlegungen zu Benchmarks der Kommunikationsstrategie in der externen Berichterstattung (Teil 1), in: Deutsches Steuerrecht, 33. Jg., Nr. 46, S. 1805-1809

Küting, Karlheinz / Hütten, Christoph / Lorson, Peter (1995b): Shareholder Value: Grundüberlegungen zu Benchmarks der Kommunikationsstrategie in der externen Berichterstattung (Teil 2), in: Deutsches Steuerrecht, 33. Jg., Nr. 47, S. 1846-1851

Labhart, Peter A. (1999): Value Reporting. Informationsbedürfnisse des Kapitalmarktes und Wertsteigerung durch Reporting, Zürich

Labhart, Peter A. / Volkart, Rudolf (2001): Wertorientiertes Reporting, in: Klingebiel, Norbert [Hrsg.]: Performance Measurement \& Balanced Scorecard, München, S. $111-130$

Laitinen, Erkki K. (2004): Nonfinancial Factors as Predictors of Value Creation: Finnish Evidence, in: Review of Accounting and Finance, 3. Jg., Nr. 3, S. 84-130

Lakhal, Faten (2007): Ownership Structure and Voluntary Disclosures: The Case of Frenchlisted Firms, in: Corporate Ownership \& Control, 5. Jg., Nr. 5, S. 131-138

Lakonishok, Joseph (1993): Is Beta Dead or Alive?, in: The CAPM Controversy: Policy and Strategy Implications for Investment Management, Association for Investment Management and Research, New York Tom Sieber - 978-3-631-75150-3 
Lambert, Richard / Leuz, Christian / Verrecchia, Robert E. (2007): Accounting Information, Disclosure, and the Cost of Capital, in: Journal of Accounting Research, 45. Jg., Nr. 2, S. $385-420$

Landsman, Wayne R. (2007): Is Fair Value Accounting Information relevant and reliable? Evidence from Capital Market Research, in: Accounting and Business Research, 37. Jg., Special Issue: International Accounting Policy Forum, S. 19-30.

Lanfermann, Georg (2004): EU-Richtlinienvorschlag zur Änderung der Vierten Gesellschaftlichen Richtlinie im Einzel- und Konzernabschluss, in: Betriebs-Berater, 59. Jg., BB-Special 06/2004, S. 2-5

Lang, Mark H. / Lundholm, Russell J. (1993): Cross-sectional Determinants of Analyst Ratings of Corporate Disclosures, in: Journal of Accounting Research, 31. Jg., Nr. 2, S. 246-271

Lang, Mark H. / Lundholm, Russell J. (1996): Corporate Disclosure Policy and Analyst Behaviour, in: The Accounting Review, 71. Jg., Nr. 4, S. 467-492

Lang, Mark H. / Lundholm, Russell J. (2000): Voluntary Disclosure and Equity Offerings: Reducing Information Asymmetry or Hyping the Stock?, in: Contemporary Accounting Research, 17. Jg., Nr. 4, S. 623-662

Langerfeldt, Michael (2003): Neue Institutionenökonomik, in: Das Wirtschaftsstudium, 32. Jg., Nr. 1, S. 55-58

Lapointe-Antunes, Pascale / Cormier, Denis / Magnan, Michel / Gay-Angers, Sophie (2006): On the Relationship between Voluntary Disclosure, Earnings Smoothing and the Value-Relevance of Earnings: The Case of Switzerland, in: European Accounting Review, 15. Jg., Nr. 4, S. 465-505

Larcker, David F. / Rusticus, Tjomme O. (2007): Endogeneity and Empirical Accounting Research, in: European Accounting Review, 16. Jg., Nr. 1, S. 207-215

Laux, Helmut (2006): Unternehmensrechnung. Anreiz und Kontrolle. Die Messung, Zurechnung und Steuerung des Erfolges als Grundprobleme der Betriebswirtschaftslehre, 3. Auflage, Heidelberg

Lee, Charles M. C. / Myers, James N. / Swaminathan, Bhaskaran (1999): What is the Intrinsic Value of the Dow?, in: Journal of Finance, 54. Jg., Nr. 5, S. 1693-1741

Leffson, Helmut (1986): Wesentlich, in: Leffson, Ulrich / Rückle, Dieter / Großfeld, Bernhard [Hrsg.]: Handwörterbuch unbestimmter Rechtsbegriffe im Bilanzrecht des HGB, Köln, S. 434-436

Leffson, Ulrich (1987): Die Grundsätze ordnungsgemäßer Buchführung, 7. Auflage, Düsseldorf 
Leftwich, Richard W. / Watts, Ross L. / Zimmermann, Jerold L. (1981): Voluntary Corporate Disclosure: The Case of Interim Reporting, in: Journal of Accounting Research, 19. Jg., Nr. 3 (Supplement), S. 50-77

Lehner, Ulrich (2003): Finanzkommunikation und Corporate Governance, in: Zeitschrift für Organisation, 72. Jg., S. 210-219

Lehner, Ulrich (2004): Rechnungslegung als Teil der Finanzkommunikation, in: Baetge, Jörg [Hrsg.]: Übergang der Rechnungslegung von HGB zu IFRS, Düsseldorf, S. 1-24

Lennard, Andrew (2007): Stewardship and the Objectives of Financial Statements: A Comment on IASB's Preliminary Views on an Improved Conceptual Framework for Financial Reporting: The Objective of Financial Reporting and Qualitative Characteristics of Decision-useful Financial Reporting Information, in: Accounting in Europe, 4. Jg., Nr. 1, S. 51-66

Lentfer, Thies / Weber, Stefan C. (2006): Das Corporate Governance Statement als neues Publizitätsinstrument, in: Der Betrieb, 59. Jg., Nr. 44, S. 2357-2363

Lerch, Hans (1971): Aktienkursindizes und Konjunkturverlauf, Freiburg (CH)

Leuz, Christian (1999): Proprietary versus Non-Proprietary Disclosures: Voluntary Cash Flow Statements and Business Segment Reports in Germany, Working Paper, University of Pennsylvania

Leuz, Christian (2003): Discussion of ADRs, Analysts, and Accuracy: Does Cross-Listing in the United States Improve a Firm's Information Environment and Increase Market Value?, in: Journal of Accounting Research, 41. Jg., Nr. 2, S. 347-362

Leuz, Christian / Verrecchia, Robert E. (2000): The Economic Consequences of Increased Disclosure, in: Journal of Accounting Research, 38. Jg., Nr. 3 (Supplement), S. 91 124

Lev, Baruch (1988): Toward a Theory of Equitable and Efficient Accounting Policy, in: The Accounting Review, 63. Jg., Nr. 1, S. 1-22

Lev, Baruch / Ohlson, James A. (1982): Market-Based Empirical Research in Accounting: A Review, Interpretation and Extension, in: Journal of Accounting Research, 20. Jg., Nr. 3 (Supplement), S. 249-322

Lev, Baruch / Penman, Stephen H. (1990): Voluntary Forecast Disclosure, Nondisclosure, and Stock Prices, in: Journal of Accounting Research, 28. Jg., Nr. 1, S. 49-76

Lev, Baruch / Sougiannis, Theodore (1996): The Capitalization, Amortization, and Valuerelevance of R\&D, in: Journal of Accounting and Economics, 21. Jg., Nr. 1, S. 107138 
Lev, Baruch / Zarowin, Paul (1999): The Boundaries of Financial Reporting and How to Extend Them, in: Journal of Accounting Research, 37. Jg., Nr. 2, S. 353-385

Levine, Carolyn B. / Smith, Michael J. (2003): Ex Post Voluntary Disclosure Strategies for Insiders, in: Contemporary Accounting Research, 20. Jg., Nr. 4, S. 719-746

Lewis, Thomas G. (1995): Steigerung des Unternehmenswertes, 2. Auflage, Landsberg

Löchel, Horst (1995): Institutionen, Transaktionskosten und wirtschaftliche Entwicklung. Ein Beitrag zur Neuen Institutionenökonomik und zur Theorie von Douglas C. North, Berlin

Loistl, Otto (2001): Kapitalmarkttheorie, in: Achleitner, Ann-Kristin / Thoma, Georg F. [Hrsg.]: Handbuch Corporate Finance. Konzepte, Strategien und Praxiswissen für das moderne Finanzmanagement, 2. Auflage, Köln (Abschnitt 3.3)

Long, J. Scott (1997): Regression Models for Categorial and Limited Dependent Variables, Thousand Oaks

Lorek, Kenneth S. / Willinger, G. Lee (1996): A Multivariate Time-Series Prediction Model for Cash-Flow Data, in: The Accounting Review, 71. Jg., Nr. 1, S. 81-101

Low, Jonathan / Siesfeld, Tony (1998): Measures That Matter. Non-financial Performance, in: Strategy \& Leadership, 26. Jg., Nr. 2, S. 24-38

Lück, Wolfgang (1986): Kommentar zu § 289 HGB, in: Küting, Karlheinz / Weber, ClausPeter [Hrsg.]: Handbuch der Rechnungslegung, Kommentar zur Bilanzierung und Prüfung, 1. Auflage, Stuttgart

Lücke, Wolfgang (1955): Investitionsrechnungen auf der Grundlage von Ausgaben oder Kosten, in: Zeitschrift für handelswissenschaftliche Forschung (heute: zfbf), 7. Jg., o. Nr., S. 310-324

Luckenbach, Helga (2000): Theoretische Grundlagen der Wirtschaftspolitik, 2. Auflage, München

Macharzina, Klaus / Wolf, Joachim (2005): Unternehmensführung. Das internationale Managementwissen. Konzepte, Methoden, Praxis, 5. Auflage, Wiesbaden

Maddala, Gangadharrao S. (2001): Introduction to Econometrics, 3. Auflage, New York

Mak, Yuen Teen (1991): Corporate Characteristics and the Voluntary Disclosure of Forecast Information: A Study of New Zealand Prospectuses, in: British Accounting Review, 23. Jg., Nr. 4, S. 305-327

Makridakis, Spyros / Reschke, Hasso / Wheelwright, Steven C. (1980): Prognosetechniken für Manager, Wiesbaden 
Malone, David / Fries, Clarence / Jones, Thomas (1993): An Empirical Investigation of the Extent of Corporate Financial Disclosure in the Oil and Gas Industry, in: Journal of Accounting and Auditing \& Finance, 8. Jg., Nr. 3, S. 249-275

Marston, Claire (2008): Investor relations meetings: Evidence from Top 500 UK companies, in: Accounting and Business Research, 38. Jg., Nr. 1, S. 22-48

Marston, Claire L. / Shrives, Philip J. (1991): The Use of Disclosure Indices in Accounting Research: A Review Article, in: British Accounting Review, 23. Jg., Nr. 3, S. 195210

Martin, Philippe / Rey, Helene (2000): Financial integration and asset returns, in: European Economic Review, 44. Jg., Nr. 7, S. 1327-1350

Mascarenhas, Briance / Aaker, David A. (1989): Mobility Barriers and Strategic Groups, in: Strategic Management Journal, 10. Jg., Nr. 5, S. 475-485

Maul, Karl-Heinz (1984): Der Lagebericht nach der 4. EG-Richtlinie und dem Entwurf des Bilanzrichtlinie-Gesetzes, in: Die Wirtschaftsprüfung, 37. Jg., Nr. 7, S. 187-193

Maul, Silja / Muffat-Jeandet, Daniele (2004): Die EU-Übernahmerichtlinie: Inhalt und Umsetzung in nationales Recht (Teil I und Teil II), in: Die Aktiengesellschaft, 49. Jg., Nr. 6, S. 221-234 sowie S. 306-318

May, Axel (1991): Zum Stand der empirischen Forschung über Informationsverarbeitung am Aktienmarkt - Ein Überblick, in: Zeitschrift für betriebswirtschaftliche Forschung, 43. Jg., Nr. 4, S. 313-335

McConnell, John J. / Muscarella, Chris J. (1985): Corporate Capital Expenditure Decisions and the Market Value of the Firm, in: Journal of Financial Economics, 14. Jg., Nr. 3, S. $399-422$

McGee, John / Thomas, Howard (1986): Strategic Groups: Theory, Research and Taxonomy, in: Strategic Management Journal, 7. Jg., Nr. 2, S. 141-160

McKee, Daryl / Varadarajan, P. Rajan (1995): Special Issue on Sustainable Competitive Advantage, in: Journal of Business Research, 33. Jg., Special Issue, S. 77-79

McNally, Graeme M. / Eng, Lee Hock / Hasseldine, C. Roy (1982): Corporate Financial Reporting in New Zealand: An Analysis of User Preferences, Corporate Characteristics, and Disclosure of Discretionary Information, in: Accounting and Business Research, 12. Jg., Nr. 46, S. 11-20

McNamara, Gerry / Vaaler, Paul M. / Devers, Cynthia (2003): Same as It Ever Was: The Search for Evidence of Increasing Hypercompetition, in: Strategic Management Journal, 24. Jg., Nr. 3, S. 261-278 
Meek, Gary K. / Gray, Sidney J. (1989): Globalization of Stock Markets and Foreign Listing Requirements: Voluntary Disclosures by Continental European Companies Listed on the London Stock Exchange, in: Journal of International Business Studies, 20. Jg., Nr. 2, S. 315-336

Meek, Gary K. / Saudagaran, Shahrokh, M. (1990): A Survey of Research on Financial Reporting in a Transnational Context, in: Journal of Accounting Literature, 9. Jg., o. Nr., S. 145-182

Meek, Gary K. / Roberts, Clare B. / Gray, Sidney J. (1995): Factors Influencing Voluntary Annual Report Disclosures by U.S., U.K. and Continental Multinational Corporations, in: Journal of International Business Studies, 26. Jg., Nr. 3, S. 555-572

Meisinger, Reiner / Wenzler, Christian (1992): Diskrepanzen bei der Lageberichtspublizität, in: Die Wirtschaftsprüfung, 45. Jg., Nr. 15/16, S. 445-451

Mendes da Silva, Wesley / De Lira Alves, Luiz Alberto (2004): The Voluntary Disclosure of Financial Information on the Internet and the Firm Value Effect in Companies across Latin America, Discussion Paper, 13th International Symposium on Ethics, Business and Society at Universidad Navarra Barcelona, January 2004

Quelle: http://papers.ssrn.com/sol3/papers.cfm?abstract_id=493805 (Stand am 11.09.2009)

Menard, Scott (2001): Applied Logistic Regression Analysis, Thousand Oaks

Merkt, Hanno (2001): Unternehmenspublizität: Offenlegung von Unter-nehmensdaten als Korrelat der Marktteilnahme, Tübingen 2001

Merkt, Hanno / Göthel, Stephan R. (2003): Vorschriften und Ansätze der Quartalsberichterstattung: Vergleich USA - Deutschland, in: Recht der internationalen Wirtschaft, 49. Jg., Nr. 1, S. 23-32

Merten, Klaus (1995): Inhaltsanalyse. Einführung in Theorie, Methode und Praxis, 2. Auflage, Opladen

Merton, Robert (1987): A Simple Model of Capital Market Equilibrium with Incomplete Information, in: Journal of Finance, 42. Jg., Nr. 3, S. 483-510

Meyer, Claus (1997): Geschäftsbericht: Ein Leitfaden für Aufstellung, Gestaltung und Offenlegung, 2. Auflage, Stuttgart

Meyer, Marco (2005): Unternehmenswertorientierte Berichterstattung auf Basis der IAS/IFRS. Eine bilanztheoretische und bilanzpolitische Betrachtung aus deutscher Sicht, Wiesbaden

Mintzberg, Henry (1990): The Design School: Reconsidering the Basic Premises of

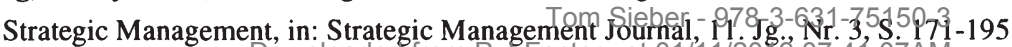


Mintzberg, Henry / Ahlstrand, Bruce / Lampel, Joseph (2003): Strategy Safari. Eine Reise durch die Wildnis des strategischen Managements, Frankfurt

Mitenthal, Daniel / Anders, Dietmar (2003): Erste Erfahrungen mit den neuen Aktienmarktsegmenten der Frankfurter Wertpapierbörse, in: Deutsches Steuerrecht, 41. Jg., Nr. 44, S. 1893-1900

Möller, Hans-Peter / Hüfner, Bernd (2002): Zur Bedeutung der Rechnungslegung für den deutschen Aktienmarkt - Begründung, Messprobleme und Erkenntnisse empirischer Forschung, in: Seicht, Gerhard [Hrsg.]: Jahrbuch für Controlling und Rechnungswesen, Wien, S. 405-463

Möller, Hans Peter / Keller, Erich (1999): Financial Reporting and the Stock Market in Germany, in: Bühler, Wolfgang / Hax, Herbert / Schmidt, Reinhart [Hrsg.]: Empirical Research on the German Capital Market, Heidelberg, S. 135-150

Moore, Michael L. / Buzby, Stephen (1972): The Quality of Corporate Financial Disclosure: A Comment, in: The Accounting Review, 47. Jg., Nr. 3, S. 581-584

Morck, Randall / Shleifer, Andrei / Vishny, Robert W. (1988): Management ownership and market valuation: An empirical analysis, in: Journal of Financial Economics, 22. Jg., Nr. 1, S. 293-315

Moxter, Adolf (1962): Der Einfluss von Publizitätsvorschriften auf das unternehmerische Verhalten, Köln/Opladen

Moxter, Adolf (1966): Die Grundsätze ordnungsgemäßer Bilanzierung und der Stand der Bilanztheorie, in: Zeitschrift für betriebswirtschaftliche Forschung, 18. Jg., o. Nr., S. 28-59

Moxter, Adolf (1982): Betriebswirtschaftliche Gewinnermittlung, Tübingen

Moxter, Adolf (1984): Bilanzlehre, Band I: Einführung in die Bilanztheorie, 3. Auflage, Wiesbaden

Moxter, Adolf (1986): Bilanzlehre, Band II: Einführung in das neue Bilanzrecht, 3. Auflage, Wiesbaden

Moxter, Adolf (1995): Standort Deutschland: Zur Überlegenheit des deutschen Rechnungslegungsrechts, in: Peemöller, Volker H. / Uecker, Peter [Hrsg.]: Standort Deutschland: Grundsatzfragen und aktuelle Perspektiven für die Besteuerung, die Prüfung und das Controlling, Festschrift Heigl, Berlin, S. 31-41

Moxter, Adolf (1999): Bilanzrechtsprechung, 5. Auflage, Tübingen

Moxter, Adolf (2003): Die Grundsätze ordnungsgemäßer Rechnungslegung, Düsseldorf 
Müller, Michael (1998): Shareholder Value Reporting - Ein Konzept wertorientierter Kapitalmarktinformation, in: Müller, Michael / Leven, Franz-Josef [Hrsg.]: Shareholder Value Reporting. Veränderte Anforderungen an die Berichterstattung börsennotierter Unternehmen, Wien, S. 123-144

Müller, Dirk (2007): Moderatoren und Mediatoren in Regressionen, in: Albers, Sönke / Klapper, Daniel / Konradt, Udo / Walter, Achim / Wolf, Joachim [Hrsg.]: Methodik der empirischen Forschung, 2. Auflage, Wiesbaden, S. 245-260

Müller-Stewens, Günter / Lechner, Christoph (2005): Strategisches Management, 3. Auflage, Stuttgart

Müßig, Anke (2008): Lagebericht und Value Reporting, in: Funk, Wilfried / Rossmanith, Jonas [Hrsg.]: Internationale Rechnungslegung und Internationales Controlling. Herausforderungen, Handlungsfelder, Erfolgspotenziale, Wiesbaden, S. 189-217

Muthén, Bengt / Kaplan, David (1985): A Comparison of some Methodologies for the Factor Analysis of non-normal Likert Variables, in: British Journal of Mathematical and Statistical Psychology, 38. Jg., o. Nr., S. 171-189

Nakamura, Alice / Nakamura, Masao (1981): On the Relationships among Several Specification Error Tests Presented by Durbin, Wu, and Hausman, in: Econometrica, 49. Jg., Nr. 6, S. 1583-1588

Narayanan, Ranga (2000): Insider trading and the voluntary disclosure of information by firms, in: Journal of Banking \& Finance, 24. Jg., Nr. 3, S. 395-425

Nasdaq [Hrsg.] (2010): NASDAQ Stock Market Glossary (Januar 2010), New York Quelle: http://www.nasdaq.com/reference/glossary.stm, Stichwort: Consensus Rating (Stand am 18.01.2010)

Neubürger, Heinz-Joachim (2000): Wertorientierte Unternehmensführung bei Siemens, in: Zeitschrift für betriebswirtschaftliche Forschung, 52. Jg., Nr. 3, S. 188-196

Neubürger, Hein-Joachim / Sen, Michael (2001): Wertorientierte Unternehmens- und Geschäftsführung im Siemens-Konzern, in: Hahn, Dietger / Hungenberg, Harald [Hrsg.]: PuK. Planung und Kontrolle, Planungs- und Kontrollsysteme, Planungs- und Kontrollrechnung, 6. Auflage, Wiesbaden, S. 1035-1102

Neufeld, Thorsten (2003): Die neue Indexwelt der Deutschen Börse, in: Die Bank, o. Jg., Nr. 1, S. 18-21

Niehus, Rudolf J. (1985): Zur Transformation der 4. EG-(Bilanz-) Richtlinien in den Mitgliedstaaten der Europäischen Gemeinschaft: Überblick und erste Würdigung, in:

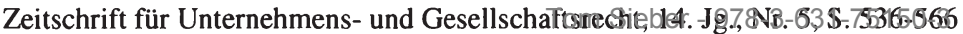


NIVRA [Koninklijk Nederlands Instituut van Registeraccountants, Hrsg.] (2000):

Management's Analysis of the Business. A Position Paper issued for comment by the European Accounting Study Group, Amsterdam

Noe, Christopher F. (1999): Voluntary Disclosures and Insider Transactions, in: Journal of Accounting and Economics, 27. Jg., Nr. 3, S. 305-326

Noll, Daniel J. / Weygandt, Jerry J. (1997): Business Reporting: What Comes Next?, in: Journal of Accountancy, 112. Jg., Nr. 2, S. 59-62

Nunnally, Jum C. (1994): Psychometric Theory, 3. Auflage, New York

O'Brien, Patricia C. / Bhushan, Ravi (1990): Analyst Following and Institutional Ownership, in: Journal of Accounting Research, 28. Jg., Nr. 3 (Supplement), S. 55-82

Oberdörster, Tatjana (2009): Finanzberichterstattung und Prognosefehler von Finanzanalysten, Wiesbaden

OECD [Organization for Economic Co-operation and Development, Hrsg.] (2009): About the OECD, Paris

Quelle: $\quad$ http://www.oecd.org/pages/... 0,3417,en_36734052_36734103_1_1_1_1_1,00.html (Stand am 26.12.2009)

Oetinger, Bolko von / Ghyczy, Tiha von / Bassford, Christopher (2003): Strategie denken. Das Boston Consulting Group Strategie-Buch, Düsseldorf

Ohlson, James A. (1999): On Transitory Earnings, in: Review of Accounting, 4. Jg., Nr. 3-4, S. $145-162$

Ohlson, James A. (1995): Earnings, Book Value and Dividends in Security Valuation, in: Contemporary Accounting Research, 11. Jg., Nr. 1, S. 661-687

Ordelheide, Dieter (1993): Institutionelle Theorie und Unternehmung, in: Wittmann, Waldemar / Kern, Werner / Köhler, Richard / Küpper, Hans-Ulrich / Wysocki, Klaus von [Hrsg.]: Handwörterbuch der Betriebswirtschaft, 5. Auflage, Sp. 1838-1855

Ordelheide, Dieter (1995): Entwicklung und Arbeit des Accounting Advisory Forums der EU-Kommission, in: Förschle, Gerhart / Kaiser, Klaus / Moxter, Adolf [Hrsg.]: Rechenschaftslegung im Wandel, Festschrift Budde, München, S. 483-504

Ordelheide, Dieter (1997): Regulierung der Rechnungslegung. Ökonomische Zwänge und kulturelle Unterschiede, in: Engelhard, Johann [Hrsg].: Interkulturelles Management. Theoretische Fundierung und funktionsbereichsspezifische Konzepte, Wiesbaden, S. 235-259 
Ordelheide, Dieter (1998): Rechnungslegung und internationale Aktienanalyse, in: Möller, Hans-Peter / Schmidt, Franz [Hrsg.]: Rechnungswesen als Instrument für Führungsentscheidungen: Festschrift Coenenberg, Stuttgart, S. 505-524

Pagano, Marco / Röell, Alisa A. / Zechner, Josef (2002): The Geography of Equity Listing: Why Do Companies List Abroad?, in: The Journal of Finance, 57. Jg., Nr. 6, S. 2651-2694

Pakes, Ariel (1985): On Patents, R\&D, and the Stock Market Rate of Return, in: Journal of Political Economy, 93. Jg., Nr. 2, S. 390-409

Patel, Sandeep L. / Bwakira, Liliane / Balic Amra (2002): Measuring transparency and disclosure at firm-level in emerging markets, in: Emerging Markets Review, 3. Jg., Nr. 4, S. 325-337

Patell, James M. (1976): Corporate Forecasts of Earnings per Share and Stock Price Behavior: Empirical Tests, in: Journal of Accounting Research, 14. Jg., Nr. 2, S. 246276

Patelli, Lorenzo / Prencipe, Annalisa (2007): The Relationship between Voluntary

Disclosure and Independent Directors in the Presence of a Dominant Shareholder, in: European Accounting Review, 16. Jg., Nr. 1, S. 5-33

Pearce, John A. (1981): An Executive-Level Perspective on the Strategic Management Process, in, California Management Review, 24. Jg., Nr. 1, S. 39-48

Pearce, John A. / Robinson, Richard B. (2000): Strategic Management, 7. Auflage, New York

Pellens, Bernhard (2001): Publizität, in: Gerke, Wolfgang / Steiner, Manfred [Hrsg.]: Handwörterbuch des Bank- und Finanzwesens, 3. Auflage, Stuttgart, Sp. 1742-1754

Pellens, Bernhard / Tomaszewski, Claude (1999): Kapitalmarktreaktionen auf den Rechnungslegungswechsel zu IAS bzw. US-GAAP, in: Gebhardt, Günther / Pellens, Bernhard [Hrsg.]: Rechnungswesen und Kapitalmarkt, Zeitschrift für betriebswirtschaftliche Forschung, 51. Jg., Sonderheft 41, S. 199-228

Pellens, Bernhard / Fülbier, Uwe / Gassen, Joachim (2004): Internationale Rechnungslegung. IFRS/IAS mit Beispielen und Fallstudien, 5. Auflage, Stuttgart

Pellens, Bernhard / Fülbier, Uwe / Gassen, Joachim (2006a): Internationale Rechnungslegung. IFRS 1 bis 7, IAS 1 bis 41, IFRIC-Interpretationen, Standardentwürfe. Mit Beispielen, Aufgaben und Fallstudien, 6. Auflage, Stuttgart 
Pellens, Bernhard / Gassen, Joachim / Neuhaus, Stefan / Schmidt, André (2006b): Die Zukunft der Unternehmensberichterstattung, in: Börsig, Clemens / Wagenhofer, Alfred [Hrsg.]: IFRS in Rechnungswesen und Controlling. KongressDokumentation, 59. Deutscher Betriebswirtschafter-Tag 2005, Stuttgart, S. 19-35

Pellens, Bernhard / Hillebrandt, Franca / Tomaszewski, Claude (2000a): Value Reporting. Eine empirische Analyse der DAX-Unternehmen, in: Wagenhofer, Alfred / Hrebicek, Gerhard [Hrsg.] (2000): Wertorientiertes Management: Konzepte und Umsetzungen zur Unternehmenswertsteigerung, Stuttgart, S. 177-207

Pellens, Bernhardt / Nölte, Uwe / Berger, Ole (2007): Ergebnisprognosen durch das Management - Sind die Managementprognosen der DAX-Unternehmen zu pessimistisch?, in: Finanz Betrieb, 7. Jg., Nr. 1, S. 24-29

Pellens, Bernhard / Tomaszewski, Claude / Weber, Nicholas (2000b): Wertorientierte Unternehmensführung in Deutschland - Eine empirische Untersuchung der Dax 100 Unternehmen, in: Der Betrieb, 53. Jg., Nr. 36, S. 1825-1833

Penman, Stephen H. (1980): An Empirical Investigation of the Voluntary Disclosure of Corporate Earnings Forecasts, in: Journal of Accounting Research, 18. Jg., Nr. 1, S. $132-160$

Penrose, Edith T. (1980): The Theory of the Growth of the Firm, 2. Auflage, Oxford Perridon, Louis / Steiner, Manfred (2003): Finanzwirtschaft der Unternehmung, 12. Auflage, München

Peters, Thomas J. / Waterman Robert H. (2000): Auf der Suche nach Spitzenleistungen, 8. Auflage, Landsberg

Petersen, Christian / Plenborg, Thomas (2006): Voluntary Disclosure and Information Asymmetry in Denmark, in: Journal of International Accounting, Auditing and Taxation, 15. Jg., Nr. 2, S. 127-149

Pfaff, Dieter (1989): Zur allokativen Begründung von Ausschüttungskompetenzen, in: Zeitschrift für betriebswirtschaftliche Forschung, 41. Jg., Nr. 12, S. 1013-1028

Pfohl, Hans-Chrisitian / Zettelmeyer, Bernd (1987): Strategisches Controlling?, in: Zeitschrift für Betriebswirtschaft, 57. Jg., Nr. 2, S. 145-175

Picot, Arnold (1991): Ökonomische Theorie der Organisation. Ein Überblick über neuere Ansätze und deren betriebswirtschaftliches Anwendungspotential, in: Ordelheide, Dieter / Rudolph, Bernd / Büsselmann, Elke [Hrsg.]: Betriebswirtschaftslehre und Ökonomische Theorie, Stuttgart, S. 143-170 
Pike, Richard / Meerjanssen, Johannes / Chadwick, Leslie (1993): The Appraisal of Ordinary Shares by Investment Analysts in the UK and Germany, in: Accounting and Business Research, 23. Jg., Nr. 92, S. 489-499

Popper, Karl Raimund (1969): Logik der Forschung, 4. Auflage, Tübingen

Porter, Michael E. (1979a): How Competitive Forces Shape Strategy, in: Harvard Business Review, 57. Jg., Nr. 2, S. 137-145

Porter, Michael E. (1979b): The Structure within Industries and Companies' Performance, in: Review of Economics \& Statistics, 61. Jg., Nr. 2, S. 214-227

Porter, Michael E. (1987): From Competitive Advantage to Corporate Strategy, in: Harvard Business Review, 65. Jg., Nr. 3, S. 43-59

Porter, Michael E. (1994): Towards a Dynamic Theory of Strategy, in: Rummelt, R. Paul / Schendel, Dan E. / Teece, David J. [Hrsg.]: Fundamental Issues in Strategy, Boston, S. 423-461

Porter, Michael E. (1996): What is Strategy?, in: Harvard Business Review, 74. Jg., Nr. 6, S. 61-78

Porter, Michael E. (1999): Wettbewerbsstrategie, 10. Auflage, Frankfurt/Main

Porter, Michael E. (2000): Wettbewerbsvorteile, 6. Auflage, Frankfurt/Main

Prahalad, Coimbatore K. / Hamel, Gary (1990): The Core Competence of the Corporation, in: Harvard Business Review, 68. Jg., Nr. 3, S. 79-91

Preble, John F. (1992): Towards a Comprehensive System of Strategic Control, in: Journal of Management Studies, 29. Jg., Nr. 4, S. 391-409

Preinreich, Gabriel A. D. (1938): Annual Survey of Economic Theory: The Theory of Depreciation, in: Econometrica, 6. Jg. Nr. 3, S. 219-241

Previts, Gary John / Bricker, Robert J. / Robinson, Thomas R. / Young, Stephen J. (1994): A Content Analysis of Sell-Side Financial Analyst Company Reports, in: Accounting Horizons, 8. Jg., Nr. 2, S. 55-70

PricewaterhouseCoopers (PwC) (1999): ValueReporting ${ }^{\mathrm{TM}}$ Forecast 2000, New York

Priem, Richard L. / Butler, John E. (2001): Is the Resource-Based 'View' a Useful Perspective for Strategic Management Research?, in: Academy of Management Review, 26. Jg., Nr. 1, S. 22-40

Prigge, Cord (2006): Konzernlageberichterstattung vor dem Hintergrund einer Bilanzierung nach IFRS, Düsseldorf 
Proppe, Dennis (2007): Endogenität und Instrumentenschätzer, in: Albers, Sönke / Klapper, Daniel / Konradt, Udo / Walter, Achim / Wolf, Joachim [Hrsg.]: Methodik der empirischen Forschung, 2. Auflage, Wiesbaden

Prytulak, Lubomyr S. (1975): Critique of S.S. Stevens' Theory of Measurement Scales Classification, in: Perceptual and Motor Skills, 41. Jg., Nr. 3, S. 3-28

Quick, Reiner / Reus, Michael (2009): Zur Qualität der Prognoseberichterstattung der DAX 30-Gesellschaften, in: Zeitschrift für kapitalmarktorientierte Rechnungslegung, 9. Jg., Nr. 1, S. 18-32

Raffournier, Bernhard (1995): The Determinants of Voluntary Financial Disclosure by Swiss Listed Companies, in: European Accounting Review, 4. Jg., Nr. 2, S. 261-280

Ramsey, Philip H. (1981): Power of Univariate Pairwise Multiple Comparison Procedures, in: Psychological Bulletin, 90. Jg., Nr. 2, S. 352-366

Ramsey, Philip H. (2002): Comparison of Closed Testing Procedures for Pairwise Testing of Means, in: Psychological Methods, 7. Jg., Nr. 4, S. 504-523

Rao, Hayagreeva / Sivakumar, Kumar (1999): Institutional Sources of Boundary-Spanning Structures: The Establishment of Investor Relations Departments in the Fortune 500 Industrials, in: Organization Science, 10. Jg., Nr. 1, S. 27-42

Rappaport, Alfred (1986): Linking Competitive Strategy and Shareholder Value Analysis, in: The Journal of Business Strategy, 7. Jg., Nr. 4, S. 58-67

Rappaport, Alfred (1998): Shareholder Value. Ein Handbuch für Manager und Investoren, 2. Auflage, Stuttgart

Read, Ann S. (2000): Inside Information Goes Public, in: The Internal Auditor, 57. Jg., Nr. 3, S. 11-13

Reittinger, Wolfgang J. (1983): Die Prüfung des Lageberichts nach Aktienrecht und nach den Vorschriften der 4. EG-Richtlinie, Frankfurt

Richter, Rudolf / Bindseil, Ulrich (1995): Neue Institutionenökonomik, in: Wirtschaftswissenschaftliches Studium, 24. Jg., Nr. 3, S. 132-140

Richter, Rudolf / Furubotn, Eirik G. (1996): Neue Institutionenökonomik. Eine Einführung und kritische Würdigung, Tübingen

Riley, Richard A. / Pearson, Timothy A. / Trompeter, Greg (2003): The value relevance of non-financial performance variables and accounting information: The case of the airline industry, in: Journal of Accounting and Public Policy, 22. Jg., Nr. 3, S. 231254

Rinne, Horst (1997): Taschenbuch der Statistik, 2. Auflage Frankfurt/Main 
Rodriguez, Miguel A. / Ricart, Joan E. / Sanchez, Pablo (2002): Sustainable Development and the Sustainability of Competitive Advantage: A Dynamic and Sustainable View of the Firm, in: Creativity and Innovation Management, 11. Jg., Nr. 3, S. 135-146

Rolvering, Andrea (2002): Zwischenberichterstattung börsennotierter Kapitalgesellschaften: Eine empirische Untersuchung zur Qualität der Unternehmenspublizität, Berlin

Rosenfield, Paul (1974): Stewardship, in: Cramer, Joe Jewel / Sorter, George H. [Hrsg.]: Objectives of Financial Statements, Selected Papers, AICPA Durham, S. 123-140

Ross, Stephen A. (1979): Disclosure Regulation in Financial Markets: Implications of Modern Finance Theory and Signalling Theory, in: Edwardy, Franklin R. [Hrsg.]: Issues in Financial Regulation, New York, S. 177-202

Rühle, Alf-Sibrand (1991): Aktienindizes in Deutschland, Wiesbaden

Ruhwedel, Franca / Schultze, Wolfgang (2002a): Value Reporting: Theoretische Konzeption und Umsetzung bei den Dax-100-Unternehmen, in: Zeitschrift für betriebswirtschaftliche Forschung, 54. Jg., Nr. 11, S. 602-631

Ruhwedel, Franca / Schultze, Wolfgang (2002b): Value Reporting: Theoretische Konzeption und Umsetzung bei den Dax 100-Unternehmen, hier: Zugrundeliegender Kriterienkatalog der Bearbeitung

Quelle: Zusendung durch die Autorin

Ruhwedel, Franca / Schultze, Wolfgang (2004): Konzeption des Value Reporting und Beitrag zur Konvergenz im Rechnungswesen, in: Controlling, 16. Jg., Nr. 8-9, S. 489-495

Ruhwedel, Franca / Sellhorn, Thorsten / Lerchenmüller, Julia (2009): Prognoseberichterstattung in Aufschwung und Krise - Eine empirische Untersuchung der Dax-Unternehmen, in: Der Betrieb, 62. Jg., Nr. 25, S. 1305-1313

Ryan, Thomas A. (1980): Comment on „Protecting the Overall Rate of Type I Errors for Pairwise Comparisons with an Omnibus Test Statistic“, in: Psychological Bulletin, 88. Jg., Nr. 2, S. 354-355

Salomo, Sören (2001): Wechsel der Spitzenführungskraft und Unternehmenserfolg, Berlin Samuelson, Paul A. / Nordhaus, William D. (2001): Economics, 17. Auflage, New York Sarris, Viktor (1967): Zum Problem der Kausalität in der Psychologie. Ein

Diskussionsbeitrag, in: Psychologische Beiträge, 10. Jg., o. Nr., S. 173-186

Saudagaran, Shahrokh M. (1988): An Empirical Study of Selected Factors Influencing the Decision to List on Foreign Stock Exchanges, in: Journal of International Business Studies, 19. Jg., Nr. 1, S. 101-127 
Saudagaran, Shahrokh M. / Meek, Gary K. (1997): A Review of Research on the Relationship between International Capital Markets and Financial Reporting by Multinational Firms, in: Journal of Accounting Literature, 16. Jg., o. Nr., S. 127-159

Scheele, Alexander (2006): Strategieorientierte Lageberichterstattung. Eine kritische Analyse internationaler Entwicklungen vor dem Hintergrund des Management Commentary des IASB, Lohmar/Köln

Scheffé, Henry (1953): A Method of Judging all Contrasts in the Analysis of Variance, in: Biometrika, 40. Jg., Nr. 1/2, S. 87-104

Scheffé, Henry (1963): The Analysis of Variance, New York

Schildbach, Thomas (1975): Analyse des betrieblichen Rechnungswesens aus der Sicht der Unternehmensbeteiligten - dargestellt am Beispiel der Aktiengesellschaft, Wiesbaden

Schildbach, Thomas (1986): Jahresabschluss und Markt, Berlin/Heidelberg

Schildbach, Thomas (1987): Die neue Generalklausel für den Jahresabschluss von Kapitalgesellschaften, Betriebswirtschaftliche Forschung und Praxis, 39. Jg., Nr. 1, S. $1-15$

Schildbach, Thomas (2007): IFRS - Irreführendes Rechnungslegungs-System, in: Zeitschrift für internationale Rechnungslegung, 2. Jg., Nr. 1, S. 9-16

Schildbach, Thomas / Beermann, Michael / Feldhoff, Markus (1990): Lagebericht und Publizitätspraxis, in: Betriebs-Berater, 45. Jg., Nr. 33, S. 2297-2301

Schipper, Katherine (1991): Analysts' Forecasts, in: Accounting Horizons, 5. Jg., Nr. 4, S. $105-121$

Schipper, Katherine / Vincent, Linda (2003): Earnings Quality, in: Accounting Horizons, 17. Jg., Supplement, S. 97-110

Schira, Josef (2009): Statistische Methoden der VWL und BWL. Theorie und Praxis, München

Schlienkamp, Christoph (1998): Shareholder Value - Anforderungen aus Analystensicht, in: Müller, Michael / Leven, Franz-Josef [Hrsg.]: Shareholder Value Reporting: Veränderte Anforderungen an die Berichterstattung von Unternehmen, Wien, S. 213-224

Schmalenbach, Eugen (1963): Kostenrechnung und Preispolitik, 8. Auflage, Köln/Opladen Schmalenbach, Eugen (1966): Die Beteiligungsfinanzierung, Köln/Opladen 
Schmidt, André / Wulbrand, Hanno (2007): Umsetzung der Anforderungen an die Lageberichterstattung nach dem BilReG und DRS 15 - Eine empirische Untersuchung der DAX-Unternehmen, in: Zeitschrift für kapitalmarktorientierte Rechnungslegung, 7. Jg., Nr. 7/8, S. 417-426

Schmidt, Matthias (2000): Konzept einer kapitalmarktorientierten Rechnungslegung: Legitimation, Ableitung einer Sollvorstellung und Brauchbarkeit nationaler und internationaler Regelungen, Bielefeld

Schmidt, Reinhard H. (1982): Rechnungslegung als Informationsproduktion auf nahezu effizienten Kapitalmärkten, in: Zeitschrift für betriebswirtschaftliche Forschung, 34. Jg., Nr. 8/9, S. 728-748

Schmitz, Rudolf (1988): Die Bilanzrichtlinie und ihr Beitrag zur Harmonisierung der Rechnungslegung in den EG-Staaten. Ein Überblick, in: Albach, Horst / Klein, Günter [Hrsg.]: Harmonisierung der Rechnungslegung in Europa. Die Umsetzung der 4. EG-Richtlinie in das nationale Recht der Mitgliedstaaten der EG. Ein Überblick, Zeitschrift für Betriebswirtschaft, 58. Jg., Ergänzungsheft Nr. 1, Wiesbaden, S. 1-35

Schneider, Dieter (1974): Entwicklungsstufen der Bilanztheorie, in: Wirtschaftswissenschaftliches Studium , 3. Jg., Nr. 4, S. 158-164

Schneider, Dieter (1981): Kapitalmarkteffizienz durch Jahresabschlussreformen, in: Becker, Wolf-Dieter / Falk, Reinhold [Hrsg.]: Schriften des Verbandes öffentlicher Banken, Heft 8, Göttingen, S. 1-42

Schneider, Dieter (1997): Betriebswirtschaftslehre, Band 2: Rechnungswesen, 2. Auflage, München

Schneider, Sven / Schneider, Uwe (2005): Vorstandshaftung im Konzern, in: Die Aktiengesellschaft, 50. Jg., Nr. 3, S. 57-66

Schnell, Rainer / Hill, Paul B. / Esser, Elke (2005): Methoden der empirischen Sozialforschung, 7. Auflage, München

Scholes, Myron S. (1970): A Test of the Competitive Market Hypothesis. The Market for New Issues and Secondary Offerings, Chicago

Scholz, Christian (1987): Strategisches Management, Berlin

Schössler, Dietmar (1991): Carl von Clausewitz, Reinbek bei Hamburg

Schreyögg, Georg (1984): Unternehmensstrategie. Grundfragen einer Theorie strategischer Unternehmensführung, Berlin

Schreyögg, Georg / Steinmann, Horst (1985): Strategische Kontrolle, in: Zeitschrift für betriebswirtschaftliche Forschung, 37. Jg., Nr. 3, S. Sigher 198 878-3-631-75150-3 
Schröder, Arne (2007): Prinzipien der Panelanalyse, in: Albers, Sönke / Klapper, Daniel / Konradt, Udo / Walter, Achim / Wolf, Joachim [Hrsg.]: Methodik der empirischen Forschung, 2. Auflage, Wiesbaden, S. 261-276

Schultze, Wolfgang (2005): Value-relevant Disclosures: Conceptual Framework and Evidence form German listed Companies, Working Paper, University of Augsburg

Schulz von Thun, F. Friedemann (2006): Miteinander reden, 45. Auflage, Reinbek bei Hamburg

Schulz, Michael (1999): Aktienmarketing, Sternenfeld

Schumpeter, Joseph A. (2005): Kapitalismus, Sozialismus und Demokratie, Stuttgart

SEC [United States Securities and Exchange Commission, Hrsg.] (2010): Electronic Code of Federal Regulations, Title 17: Commodity and Securities Exchange, Volume 2, Chapter II (Securities and Exchange Commission)

Quelle: http://ecfr.gpoaccess.gov/cgi/t/text/text-idx?c=ecfr\&tpl=\%2Findex.tpl (Stand am 31.01.2010)

Seidler, Lee J. (1999): The old Ways don't hold Water, in: The CPA Journal, 69. Jg., Nr. 5, S. $22-24$

Selch, Barbara (2003): Der Lagebericht, Risikoberichterstattung und Aufstellung nach IDW RS HFA 1, Wiesbaden

Semler, Johannes (1980): Erläuterungs- und Lagebericht, Quartalsbericht sowie Formen der Publizität, in: Bierich, Markus / Busse von Colbe, Walther / Lassmann, Gert / Lutter, Marcus [Hrsg.]: Rechnungslegung nach neuem Recht, Zeitschrift für betriebswirtschaftliche Forschung, 32. Jg., Sonderheft 10/1980, S. 177-210

Sengupta, Partha (1998): Corporate Disclosure Quality and the Cost of Debt, in: The Accounting Review, 73. Jg., Nr. 4, S. 459-474

Sharpe, William F. (1963): A Simplified Model for Portfolio Analysis, in: Management Science, 9. Jg., Nr. 1, S. 277-293

Sharpe, William F. (1964): Capital Asset Prices: A Theory of Market Equilibrium under Conditions of Risk, in: Journal of Finance, 19. Jg., Nr. 3, S. 425-442

Shevlin, Terry (1991): The Valuation of R\&D Firms with R\&D Limited Partnerships, in: The Accounting Review, 66. Jg., Nr. 1, S. 1-21

Siegel, Sidney / Castellan, N. John (1988): Non-parametric Statistics for the Behavioral Sciences, New York 
Siegel, Theodor (1986): Wahlrecht, in: Leffson, Ulrich / Rückle, Dieter / Großfeld, Bernhard [Hrsg.]: Handwörterbuch unbestimmter Rechtsbegriffe im Bilanzrecht des HGB, Köln, S. 417-427

Siegert, Theo (1995): Shareholder Value als Lenkungsinstrument, in: Zeitschrift für betriebswirtschaftliche Forschung, 47. Jg., Nr. 6, S. 580-607

Simmonds, Kenneth (1988): Strategic Management Accounting, in: Cowe, Roger [Hrsg.], Handbook of Management Accounting, 2. Auflage, Aldershot, S. 14-36

Simon, Herbert A. (1967): Models of Man. Social and Rational. Mathematical Essays on Rational Human Behavior in a Social Setting, New York

Simon, Herbert A. (1997): Administrative Behavior. A Study of Decision-Making Processes in Administrative Organizations, 4. Auflage, New York

Simon, Hermann (1988): Management strategischer Wettbewerbsvorteile, in: Simon, Hermann [Hrsg.], Wettbewerbsvorteile und Wettbewerbsfähigkeit, Stuttgart, S. 1-17

Simpson, Ana Vidolovska (2009): Analysts' Use of Non-Financial Information Disclosures, Arbeitspapier der London School of Economics and Political Science, Department of Accounting

Quelle: http://papers.ssrn.com/sol3/papers.cfm?abstract_id=1133182

(Stand am 14.09.2009)

Singhvi, Surendra S. / Desai, Harsha B. (1971): An Empirical Analysis of the Quality of Corporate Financial Disclosure, in: The Accounting Review, 46. Jg., Nr. 1, S. 129138

Skinner, Douglas J. (1994): Why Firms Voluntarily Disclose Bad News, in: Journal of Accounting Research, 32. Jg., Nr. 1, S. 38-60

Smith, Malcolm (2003): Research Methods in Accounting, London

Smith, Clifford W. / Warner, Jerold B. (1979): On Financial Contracting: An Analysis of Bond Covenants, in: Journal of Financial Economics, 7. Jg., Nr. 2, S. 117-161

Solfrian, Gregor (2005): Änderungen in der Lageberichterstattung durch das Bilanzrechtsreformgesetz sowie den DRS 15, in: Steuern und Bilanzen (StuB), 7. Jg., Nr. 21, S. 911-918

Sougiannis, Theodore (1994): The Accounting Based Valuation of Corporate R\&D, in: The Accounting Review, 69. Jg., Nr. 1, S. 44-68

Spero, Leslie L. (1979): The Extent and Causes of Voluntary Disclosure of Financial Information in Three European Capital Markets: An Explanatory Study (Doctoral Dissertation, Harvard University) 
Stabell, Charles B. / Fjeldstad, Ǿystein D. (1998): Configuring Value for Competitive Advantage: On Chains, Shops, and Networks, in: Strategic Management Journal, 19. Jg., Nr. 5, S. 413-437

Staehle, Wolfgang (1999): Management. Eine verhaltenswissenschaftliche Perspektive, 8. Auflage, München

Stark, Andrew W. (1997): Linear Information Dynamics, Dividend Irrelevance, Corporate Valuation and the Clean Surplus Relationship, in: Accounting \& Business Research, 27. Jg., Nr. 3, S. 219-228

Stauber, Jürgen (2004): Voluntary Value Reporting auf Basis der IFRS/IAS. Grundlagen, Inhalte, qualitative Beurteilung, Frankfurt

Steck, Kai-Uwe / Schmitz, Rainer (2005): Das Kapitalmarktrecht nach dem Anlegerschutzverbesserungsgesetz - Änderungen von WpHG und VerkProspG, in: Finanz Betrieb, 7. Jg., Nr. 3, S. 187-196

Steiner, Manfred / Bruns, Christoph (2000): Wertpapiermanagement, 7. Auflage, Stuttgart

Steinmann, Horst / Hasselberg, Frank (1988): Der strategische Managementprozeß Vorüberlegung für eine Neuorientierung, in: Zeitschrift für Betriebswirtschaft, 58. Jg., Nr. 12, S. 1308-1322

Steinmann, Horst / Schreyögg, Georg (2000): Management, 5. Auflage, Wiesbaden

Steinmeyer, Volker (2009): Der Lagebericht als publizitätspolitisches Instrument börsennotierter Aktiengesellschaften. Eine Untersuchung zur Weiterentwicklung der Lageberichterstattung aus betriebswirtschaftlicher Sicht, Hamburg

Stevens, Stanley S. (1946): On the Theory of Scales of Measurement, in: Science, 103. Jg., Nr. 2684, S. 677-680

Stewart, David W. (1981): The Application and Misapplication of Factor Analysis in Marketing Research, in: Journal of Marketing Research, 18. Jg., Nr. 1, S. 51-62

Stewart, G. Bennet III (1991): The Quest for Value: The EVA Management Guide, New York

Stobbe, Thomas (1988): Der Lagebericht, in: Der Betriebsberater, 43. Jg., Nr. 20 (Beilage), S. $303-312$

Stocken, Phillip C. (2000): Credibility of Voluntary Information, in: RAND Journal of Economics, 31. Jg., Nr. 2, S. 359-374 
Streim, Hannes (1994): Die Generalnorm des § 264 Abs. 2 HGB - Eine kritische Analyse, in: Ballwieser, Wolfgang / Böcking, Hans-Joachim / Drukarczyk, Jochen / Schmidt, Reinhard H. [Hrsg.]: Bilanzrecht und Kapitalmarkt, Festschrift Moxter, Düsseldorf, S. 391-406

Streim, Hannes (1995): Zum Stellenwert des Lageberichts im System der handelsrechtlichen Rechnungslegung, in: Elschen, Rainer / Siegel, Theodor / Wagner, Franz W. [Hrsg.]: Unternehmenstheorie und Besteuerung, Festschrift Schneider, Wiesbaden, S. 703721

Streim, Hannes (2000): Die Vermittlung von entscheidungsnützlichen Informationen durch Bilanz und GuV - Ein nicht einlösbares Versprechen der internationalen Standardsetter, in: Betriebswirt-schaftliche Forschung und Praxis, 52. Jg., Nr. 2, S. 111-131

Streim, Hannes / Bieker, Marcus / Esser, Maik (2003): Vermittlung entscheidungsnützlicher Informationen durch Fair Values - Sackgasse oder Licht am Horizont?, in: Betriebswirtschaftliche Forschung und Praxis, 55. Jg., Nr. 4, S. 457479

Strieder, Thomas / Ammedick, Oliver (2007): Die periodische unterjährige externe Rechnungslegung nach dem TUG und dem künftigen DRS 16, in: Zeitschrift für kapitalmarktorientierte Rechnungslegung, 7. Jg., Nr. 5, S. 285-292

Stromann, Hilke (2002): The Value-Relevance of Current Accounting Data According to US-GAAP and German Code Law. An Empirical Assessment of the FelthamOhlson-Model, Arbeitspapier PwC / Otto-Beisheim School of Management (WHU), 11.01.2002, Vallendar

Subramanian, Rami / Ishak, Samir T. (1998): Competitor Analysis Practices of US Companies: An Empirical Investigation, in: Management International Review, 38. Jg., Nr. 17, S. 7-23

Sünner, Eckart (2004): Ungereimtheiten des Entwurfs eines Kapitalmarktinformationshaftungsgesetz, in: Der Betrieb, 57. Jg., Nr. 46, S. 24602463

Tasker, Sarah C. (1998): Bridging the Information Gap: Quarterly Conference Calls as a Medium for Voluntary Disclosure, in: Review of Accounting, 3. Jg., Nr. 1-2, S. 137 167

Teece, David J. / Pisano, Gary / Shuen, Amy (1997): Dynamic Capabilities and Strategic Management, in: Strategic Management Journal, 18. Jg., Nr. 7, S. 509-533 
Theisen, Manuel René (2007): Information und Berichterstattung des Aufsichtsrats, 4. Auflage, Stuttgart

Thiele, Reynaldo Valle (2007): Top-Manager-Nachfolge und Unternehmens-erfolg. Eine strategische Analyse, Hamburg

Thompson, Arthur A. / Strickland, A.J. Lonnie (2003): Strategic Management, 13. Auflage, New York

Tiemann, Karsten (1997): Investor Relations: Bedeutung für neu am Kapitalmarkt eingeführte Publikumsgesellschaften, Wiesbaden

Tkac, Paula A. (1999): A Trading Volume Benchmark: Theory and Evidence, in: Journal of Financial and Quantitative Analysis, 34. Jg., Nr. 2, S. 89-114

Ulrich, Peter / Fluri, Edgar (1997): Management. Eine konzentrierte Einführung, 7. Auflage, Bern

Vaivio, Juhani (1999): Exploring a "Non-Financial” Management Accounting Change, in: Management Accounting Research, 10. Jg., Nr. 4, S. 409-437

van Lent, Laurence (2007): Endogeneity and Empirical Accounting Research: A Comment, in: European Accounting Review, 16. Jg., Nr. 1, S. 197-205

Vanstraelen, Ann / Zarzeski, Marilyn T. / Robb, Sean W. G. (2003): Corporate Nonfinancial Disclosure Practices and Financial Analyst Forecast Ability Across Three European Countries, in: Journal of International Financial Management and Accounting, 14. Jg., Nr. 3, S. 250-278

Varaiya, Nikhil / Kerin, Roger A. / Weeks, David (1987): The Relationship between Growth, Profitability, and Firm Value, in: Strategic Management Journal, 8. Jg., Nr. 5, S. 487-497

Vasu, Ellen Storey (1979): Non Normality in Regression Analysis: A Monte Carlo Investigation under the Condition of Multicollinearity, in: Institute for Research in Social Science, University of North Carolina at Chapel Hill [Hrsg.]: Working Papers in Methodology, Nr. 9

Venkataraman, N. Venkat / Camillus, John C. (1984): Exploring the Concept of Fit in Strategic Management, in: Strategic Management Journal, 9. Jg., Nr. 3, S. 513-525.

Vergoossen, Ruud G. A. (1993): The Use and Perceived Importance of Annual Reports by Investment Analysts in the Netherlands, in: European Accounting Review, 2. Jg., Nr. 3, S. 219-244

Verrecchia, Robert E. (1983): Discretionary Disclosure, in: Journal of Accounting and Economics, 5. Jg., Nr. 1, S. 179-194 
Verrecchia, Robert E. (1990): Information Quality and Discretionary Disclosure, in: Journal of Accounting and Economics, 12. Jg., Nr. 4, S. 365-380

Verrecchia, Robert E. (1999): Disclosure and the Cost of Capital: A Discussion, in: Journal of Accounting and Economics, 26. Jg., Nr. 1-3, S. 271-283

Verrecchia, Robert E. (2001): Essays on Disclosure, in: Journal of Accounting and Economics, 32. Jg., Nr. 1-3, S. 97-180

Voigt, Stefan (2002): Institutionenökonomik. Neue Ökonomische Bibliothek, München

Volkhart, Rudolf / Labhart, Peter A. / Sutter, Reto (1998): Unternehmensbewertung auf EVA-Basis, in: Der Schweizer Treuhänder, 72. Jg., Nr. 4, S. 355-366

Wagenhofer, Alfred (1990a): Informationspolitik im Jahresabschluss. Freiwillige Informationen und strategische Bilanzanalyse, Heidelberg

Wagenhofer, Alfred (1990b): Voluntary Disclosure with a Strategic Opponent, in: Journal of Accounting and Economics, 12. Jg., Nr. 4, S. 341-363

Wagenhofer, Alfred (1996): Vorsichtsprinzip und Managementanreize, Zeitschrift für betriebswirtschaftliche Forschung, 48. Jg., Nr. 12, S. 1051-1074

Wagenhofer, Alfred (2008): Fair Value-Bewertung: Führt sie zu einer nützlicheren Finanzberichterstattung?, in: Zeitschrift für betriebswirtschaftliche Forschung, 60. Jg., Nr. 3, S. 185-194

Wagenhofer, Alfred / Ewert, Ralf (2007): Externe Unternehmensrechnung, Berlin und Heidelberg

Wagner, Franz W. (1982): Zur Informations- und Ausschüttungsbemessungsfunktion des Jahresabschlusses auf einem organisierten Kapitalmarkt, in: Zeitschrift für betriebswirtschaftliche Forschung, 34. Jg., Nr. 8/9, S. 749-771

Wagner, Franz W. (1993a): Vorwort, in: Wagner, Franz W. [Hrsg.]: Ökonomische Analyse des Bilanzrechts: Entwicklungslinien und Perspektiven, in: Zeitschrift für betriebswirtschaftliche Forschung, 45. Jg., Sonderheft 32, S. VII-VIII

Wagner, Franz W. (1993b): Theorie und Praxis der Rechnungslegung: Lehren aus drei Jahrzehnten, in: Wagner, Franz W. [Hrsg.]: Ökonomische Analyse des Bilanzrechts: Entwicklungslinien und Perspektiven, in: Zeitschrift für betriebswirtschaftliche Forschung, 45. Jg., Sonderheft 32, S. 1-10

Waller, Ray A. / Duncan, David B. (1969): A Bayes Rule for the Symmetric Multiple Comparisons Problem, in: Journal of the American Statistical Association, 64. Jg., Nr. 328, S. 1484-1503 
Walmsley, Tom / Yadav, Pradeep K. / Rees, William P. (1992): The Information Content of the Company Meeting Programme of the Society of Investment Analysts: 19851990, in: Journal of Business Finance and Accounting, 19. Jg., Nr. 4, S. 571-584

Walz, Rainer (1993): Ökonomische Regulierungstheorien vor den Toren des Bilanzrechts, in: Wagner, Franz W. [Hrsg.]: Ökonomische Analyse des Bilanzrechts: Entwicklungslinien und Perspektiven, in: Zeitschrift für betriebswirtschaftliche Forschung, 45. Jg., Sonderheft 32, S. 85-106

Wang, Kun / O, Sewon / Claiborne, M. Cathy (2008): Determinants and Consequences of Voluntary Disclosure in an Emerging Market: Evidence from China, in: Journal of International Accounting, Auditing and Taxation, 17. Jg., Nr. 14, S. 14-30

Watts, Ross L. (1977): Corporate Financial Statements: A Product of the Market and Political Process, in: Australien Journal of Management, 2. Jg., Nr. 1, S. 53-76

Waymire, George (1984): Additional Evidence on the Information Content of Management Earnings Forecasts, in: Journal of Accounting Research, 22. Jg., Nr. 2, S. 703-718

Weber, Christoph (2007): Strompreismodellierung - Berücksichtigung empirischer Verteilungen für nicht-speicherbare Güter am Beispiel Elektrizität, in: Essener Unikate: Empirische Wirtschaftsforschung, o. Jg., Nr. 29, S. 89-97

Weidenfeld, Werner / Wessels, Wolfgang (2006): Europa von A bis Z, Schriftenreihe der Bundeszentrale für politische Bildung, Band 393, 9. Auflage, Bonn

Weißenberger, Barbara E. (1997): Die Informationsbeziehung zwischen Management und Rechnungswesen, Wiesbaden

Weißenberger, Barbara E. (2002): Controlling als Teilgebiet der Betriebswirtschaftslehre Konzeptionelle Einordnung und Konsequenzen für Forschung und Lehre, in: Weber, Jürgen / Hirsch, Bernhard [Hrsg.]: Controlling als akademische Disziplin. Eine Bestandsaufnahme, Wiesbaden, S. 389-408

Weißenberger, Barbara E. (2003): Anreizkompatible Erfolgsrechnung im Konzern. Grundmuster und Gestaltungsalternativen, Wiesbaden

Weißenberger, Barbara E. (2004): Theoretische Grundlagen der Erfolgsmessung im Controlling, Arbeitspapier der Professur für Betriebswirtschaftslehre mit dem Schwerpunkt industrielles Management und Controlling, Gießen

Weißenberger, Barbara E. (2006): Controller und IFRS - Konsequenzen für die Controlleraufgaben durch die Finanzberichterstattung nach IFRS, in: International Group of Controlling [IGC, Hrsg.]: Schriftenreihe des IGC, Freiburg i. Br. 
Weißenberger, Barbara E. (2007): Zum grundsätzlichen Verhältnis von Controlling und externer Finanzberichterstattung unter IFRS, in: Der Konzern, 5. Jg., Nr. 5, S. 321 331

Weißenberger, Barbara E. / Maier, Michael (2006): Der Management Approach in der IFRS-Rechnungslegung: Fundierung der Finanzberichterstattung durch Informationen aus dem Controlling, in: Der Betrieb, 59. Jg., Nr. 39, S. 2077-2083

Weizsäcker, Carl-Christian von (1982): Staatliche Regulierung - Positive und normative Theorie, in: Schweizerische Zeitschrift für Volkswirtschaft und Statistik, 118. Jg., Nr. 3, S. 325-343

Welge, Martin / Al-Laham, Andreas (1993): Der Prozess der strategischen Planung, in: Das Wirtschaftsstudium, 22. Jg., Nr. 3, S. 193-200

Welge, Martin / Al-Laham, Andreas (2003): Strategisches Management. Theoretische Grundlagen, Prozess, Implementierung, 4. Auflage, Wiesbaden

Welker, Michael (1995): Disclosure Policy, Information Asymmetry, and Liquidity in Equity Markets, in: Contemporary Accounting Research, 11. Jg., Nr. 2, S. 801-827

Wenzel, Julia (2005): Wertorientierte Berichterstattung (Value Reporting) aus theoretischer und empirischer Perspektive, Frankfurt/Main

Wernerfelt, Birger (1984): A Resource-Based View of the Firm, in: Strategic Management Journal, 5. Jg., Nr. 2, S. 171-180

Wheelen, Thomas L. / Hunger, J. David (1992): Strategic Management and Business Policy, 4. Auflage

White, Halbert (1980): Nonlinear Regression on Cross-Section Data, in: Econometrica, 48. Jg., Nr. 3, S. 721-746

Whittington, Richard (2001): What is Strategy - and does it matter?, 2. Auflage, London

Wichels, Daniel (2002): Gestaltung der Kapitalmarktkommunikation mit Finanzanalysten, Wiesbaden

Wiedeking, Wendelin (2006): Anders ist besser: Ein Versuch über neue Wege in Wirtschaft und Politik, München

Wild, Jürgen (1973): Organisation und Hierarchie, in: Zeitschrift für Organisation, 42. Jg., Nr. 1, S. 45-54

Wild, Jürgen (1982): Grundlagen der Unternehmungsplanung, 4. Auflage, Opladen

Winand, Udo (1989): Erfolgspotentialplanung, in: Szyperski, Norbert [Hrsg.], Handwörterbuch der Planung, Stuttgart, S. 439-451 
Winter, Stefan (1996): Prinzipien der Gestaltung von Managementanreizsystemen, Wiesbaden

Witte, Eberhard (1973): Organisation für Innovationsentscheidungen: Das PromotorenModell, Göttingen

Wittenberg, Reinhard (1998): Grundlagen computergestützter Datenanalyse, 2. Auflage, Stuttgart

Wittmann, Waldemar (1959): Unternehmung und unvollkommene Information. Unternehmerische Voraussicht - Ungewissheit und Planung, Köln/Opladen

Wolk, Harry I. / Dodd, James L. / Tearney, Michael (2001): Accounting Theory: Conceptual Issues in a Political and Economic Environment, 5. Auflage, Cincinnati (Ohio)

Wooldridge, Jeffrey M. (2002): Econometric Analysis of Cross Section and Panel Data, Cambridge (Mass.)

Wooldridge, Jeffrey M. (2009): Introductory Econometrics. A Modern Approach, 4. Auflage, Cincinnati, (Ohio)

Woolridge, J. Randall (1988): Competitive Decline and Corporate Restructuring: Is a Myopic Stock Market to Blame?, in: Journal of Applied Corporate Finance, 1. Jg., Nr. 1, S. 23-36

Wu, De Min (1973): Alternative Tests of Independence between stochastic Regressors and Disturbances, in: Econometrica, 41. Jg., Nr. 4, S. 733-750

Wysocki, Klaus von (1976): Ergebnisse empirischer Untersuchungen über das Publizitätsverhalten deutscher Unternehmen, in: Zeitschrift für betriebswirtschaftliche Forschung, 28. Jg., o. Nr., S. 744-755

Zahn, Erich (1979): Strategische Planung zur Steuerung der langfristigen Unternehmensentwicklung, Berlin

Zajac, Edward J. / Kraatz, Matthew S. / Bresser, Rudi K. F. (2000): Modeling the Dynamics of Strategic Fit: A Normative Approach to Strategic Fit, in: Strategic Management Journal, 21. Jg., Nr. 4, S. 429-453

Zeller, Richard A. / Carmines, Edward G. (1980): Measurement in the Social Sciences. The Link between Theory and Data, Cambridge

Zettelmeyer, Bernd (1984): Strategisches Management und strategische Kontrolle, Darmstadt

Ziemons, Hildegard (2004): Neuerungen im Insiderrecht und bei der Ad-hoc-Publizität durch die Marktmissbrauchsrichtlinie und das Gesetz zur Verbesserung des Anlegerschutzes, in: Neue Zeitschrift für Gesellschaftsrecht, 7 Ig., $\mathrm{Nr}_{3}$ 12 


\section{Bundesrepublik Deutschland: Gesetzgebung}

\section{Aktiengesetz (AktG)}

Aktiengesetz vom 06.09.1965 (BGBl. I 1965, S. 1089-1184),

zuletzt geändert durch Gesetz vom 31.07.2009 (BGBl. I 2009, S. 2509-2511),

Quelle: www.gesetze-im-internet.de/aktg/index.html

\section{Börsengesetz (BörsG)}

Börsengesetz vom 22.06.1896 (RGBl. I 1896, S. 157-175),

zuletzt geändert durch Gesetz vom 20.03.2009 (BGBl. I 2009, S. 607-629)

Quelle: http://www.gesetze-im-internet.de/b_rsg_2007/index.html

\section{Handelsgesetzbuch (HGB)}

Handelsgesetzbuch vom 10.05.1897 (RGBl. 1897, S. 219-436),

zuletzt geändert durch Gesetz vom 31.07.2009 (BGBl. I 2009, S. 2512-2520)

Quelle: $\quad$ www.gesetze-im-internet.de/hgb/index.html

\section{Einführungsgesetz zum Handelsgesetzbuch (EGHGB)}

Einführungsgesetz zum HGB vom 10.05.1987 (RGB1. 1897, S. 437), zuletzt geändert durch Gesetz vom 31.07.2009 (BGBl. I 2009, S. 2512-2520)

Quelle: www.gesetze-im-internet.de/hgbeg/index.html

\section{Publizitätsgesetz (PublG)}

Gesetz über die Rechnungslegung von bestimmten Unternehmen und Konzernen vom 15.08.1969 (BGBI. I 1969, S. 1189-1199), zuletzt geändert durch Gesetz vom 25.05.2009 (BGBI. I 2009, S. 1102-1137)

Quelle: www.gesetze-im-internet.de/publg/index.html

\section{Wertpapierhandelsgesetz (WpHG)}

Gesetz über den Wertpapierhandel (Wertpapierhandelsgesetz) vom 09.09.1998 (BGB1. I 1998, S. 2708-2725), zuletzt geändert durch Gesetz vom 31.07.2009 (BGB1. I 2009, S. 2512-2520)

Quelle: $\quad$ www.gesetze-im-internet.de/wphg/index.html 


\section{Bundesrepublik Deutschland: Änderungsgesetze}

\section{Bilanzrechtsmodernisierungsgesetz (BilMoG)}

Gesetz zur Modernisierung des Bilanzrechts vom 25.05.2009

Quelle: Bundesgesetzblatt BGBI. ${ }^{1230}$ I 2009, S. 1 102-1137

\section{Bilanzrechtsreformgesetz (BilReG)}

Gesetz zur Einführung internationaler Rechnungslegungsstandards und zur

Sicherung der Qualität der Abschlussprüfung (Bilanzrechtsreformgesetz) vom 04.12 .2004

Quelle: Bundesgesetzblatt BGBI. I 2004, S. 3166-3182

\section{Bilanzrichtliniengesetz (BiRiLiG)}

Gesetz zur Durchführung der Vierten, Siebenten und Achten Richtlinie des Rates der Europäischen Gemeinschaft zur Koordinierung des Gesellschaftsrechts (Bilanzrichtliniengesetz) vom 19.12.1985

Quelle: Bundesgesetzblatt BGB1. I 1985, S. 2355-2433

\section{Gesetz zur Kontrolle und Transparenz (KonTraG)}

Gesetz zur Kontrolle und Transparenz im Unternehmensbereich vom 27.04.1998

Quelle: Bundesgesetzblatt BGBI. I 1998, S. 786-794

\section{Kapitalgesellschaften- und Co.-Richtliniengesetz (KapCoRiLiG)}

Gesetz zur Durchführung der Richtlinie des Rates der Europäischen Union zur Änderung der Bilanz- und der Konzernbilanzrichtlinie hinsichtlich ihres Anwendungsbereichs (90/605/EWG), zur Verbesserung der Offenlegung von Jahresabschlüssen und zur Änderung anderer handelsrechtlicher Bestimmungen (Kapitalgesellschaften- und Co.-Richtliniengesetz) vom 24.02.2000

Quelle: Bundesgesetzblatt BGBI. I 2000, S. 154-162

1230) Alle genannten Quellen, die dem Bundesgesetzblatt (BGBI.) entnommen sind, wurden unter http://www.bgbl.de/xaver/start.xav (Veröffentlichung BGBl. seit 1949) bezogen. 


\section{Bundesrepublik Deutschland: Änderungsgesetze (Forts.)}

\section{Übernahmerichtlinien-Umsetzungsgesetz}

Gesetz zur Umsetzung der Richtlinie 2004/25/EG des Europäischen Parlaments und des Rates vom 21.04 .2004 betreffend Übernahmeangebote (ÜbernahmerichtlinienUmsetzungsgesetz) vom 08.07.2006

Quelle: Bundesgesetzblatt BGBI. I 2006, S. 1426-1433

\section{Viertes Finanzmarktförderungsgesetz (4. FiMaFöG)}

Gesetz zur weiteren Fortentwicklung des Finanzplatzes Deutschland

(Finanzmarktförderungsgesetz) vom 21.06.2002

Quelle: Bundesgesetzblatt BGBl. I 2002, S. 2010-2072

Vorstandsvergütungs-Offenlegungsgesetz (VorstOG)

Gesetz über die Offenlegung der Vorstandsvergütungen

(Vorstandsvergütungsoffenlegungsgesetz) vom 03.08.2005

Quelle: Bundesgesetzblatt BGBl. I 2005, S. 2267-2268 


\section{Bundesrepublik Deutschland: Sonstige Veröffentlichungen}

\section{Referentenentwurf BilReG (RefE-BilReG)}

Entwurf eines Gesetzes zur Einführung internationaler Rechnungslegungsstandards und zur Sicherung der Qualität der Abschlussprüfung (Bilanzrechtsreformgesetz BilReG), Stand: Dezember 2003

Quelle: $\quad$ http://www.bmj.de/media/archive/512.pdf

(Stand am 07.09.2009)

\section{Regierungsentwurf BilReG (RegE-BilReG)}

Entwurf eines Gesetzes zur Einführung internationaler Rechnungslegungsstandards und zur Sicherung der Qualität der Abschlussprüfung (Bilanzrechtsreformgesetz BilReG)

Quelle: Deutscher Bundestag-Drucksache ${ }^{1231}$ 15/3419 vom 24.06.2004

\section{Beschlussempfehlung zum BilReG}

Beschlussempfehlung und Bericht des Rechtsausschusses (6. Ausschuss) zu dem Gesetzentwurf der Bundesregierung - Drucksache 15/3419 - Entwurf eines Gesetzes zur Einführung internationaler Rechnungslegungsstandards und zur Sicherung der Qualität der Abschlussprüfung (Bilanzrechtsreformgesetz - BilReG)

Quelle: Deutscher Bundestag-Drucksache 15/4054 vom 27.10.2004

\section{Beschlussempfehlung zum KapAEG}

Beschlussempfehlung und Bericht des Rechtsausschusses (6. Ausschuss) zu dem Gesetzentwurf der Bundesregierung - Drucksache 13/7141 - Entwurf eines Gesetzes zur Verbesserung der Wettbewerbsfähigkeit deutscher Konzerne an internationalen Kapitalmärkten und zur Erleichterung der Aufnahme von Gesellschafterdarlehen (Kapitalaufnahmeerleichterungsgesetz - KapAEG)

Quelle: Deutscher Bundestag-Drucksache 13/9909 vom 12.02.1998

1231 Alle genannten Quellen, die den Drucksachen des Deutschen Bundestages entnommen sind, wurden unter http://drucksachen.bundestag.de/drucksachen/index.php bezogen. 


\section{Bundesrepublik Deutschland: Sonstige Veröffentlichungen (Forts.)}

\section{Regierungsentwurf zum Übernahmerichtlinie-Umsetzungsgesetz}

Entwurf eines Gesetzes zur Umsetzung der Richtlinie 2004/25/EG des Europäischen

Parlaments und des Rates vom 21.04.2004 betreffend Übernahmeangebote

(Übernahmerichtlinie-Umsetzungsgesetz)

Quelle: Deutscher Bundestag-Drucksache 16/1003 vom 17.03.2006

\section{Deutscher Corporate Governance Kodex (DCGK)}

Veröffentlichung der durch das BMJ eingesetzten Regierungskommission

Deutscher Corporate Governance Kodex, verabschiedet am 26.02.2002, zuletzt geändert am 18. Juni 2002

Quelle: http://www.corporate-governance-code.de/ger/download/... kodex_2009/D_CorGov_Endfassung_Juni_2009.pdf

(Stand am 15.07.2009)

\section{Börsenzulassungsverordnung (BörsZulV)}

Verordnung über die Zulassung von Wertpapieren zum regulierten Markt einer Wertpapierbörse vom 15.04.1987 in der Fassung der Bekanntmachung vom 09.11.1998 (BGBl. I 1998, S. 2832-2852), zuletzt geändert durch Gesetz vom 21.12.2007 (BGBl. I 2007, S. 3089-3139)

Quelle: http://www.gesetze-im-internet.de/b_rszulv/index.html (Stand am 15.07.2009) 


\section{Nationaler Standardsetter: Verlautbarungen}

\section{Deutscher Rechnungslegungs Standard Nr. 1 (DRS 1)}

„Befreiender Konzernabschluss ( $\$ 292 \mathrm{a} \mathrm{HGB)“,}$ verabschiedet durch den Deutschen Standardisierungs Rat (DSR) am 29.10.1999, Bekanntmachung gem. § 342 Abs. 2 HGB durch das Bundesministerium der Justiz (BMJ) im Bundesanzeiger am 22.07.2000

Aufhebung durch Beschlussfassung am 07.12.2004 (DRÄS Nr. 2)

\section{Deutscher Rechnungslegungs Standard Nr. 5 (DRS 5)}

„Risikoberichterstattung“, verabschiedet durch den Deutschen Standardisierungs Rat (DSR) am 03.04.2001, Bekanntmachung gem. $\S 342$ Abs. 2 HGB durch das Bundesministerium der Justiz (BMJ) im Bundesanzeiger am 29.05.2001

Verabschiedung der aktuellen Fassung durch den DSR am 05.01.2010, Bekanntmachung gem. $\S 342$ Abs. 2 HGB durch das Bundesministerium der Justiz (BMJ) im Bundesanzeiger am 18.02.2010

\section{Deutscher Rechnungslegungs Standard Nr. 5-10 (DRS 5-10)}

„Risikoberichterstattung von Kredit- und Finanzdienstleistungs-instituten“, verabschiedet durch den Deutschen Standardisierungs Rat (DSR) am 29.08.2000, Bekanntmachung gem. $\S 342$ Abs. 2 HGB durch das Bundesministerium der Justiz (BMJ) im Bundesanzeiger am 30.12.2000

Verabschiedung der aktuellen Fassung durch den DSR am 05.01.2010, Bekanntmachung gem. $\S 342$ Abs. 2 HGB durch das Bundesministerium der Justiz (BMJ) im Bundesanzeiger am 18.02.2010 


\section{Nationaler Standardsetter: Verlautbarungen (Forts.)}

\section{Deutscher Rechnungslegungs Standard Nr. 5-20 (DRS 5-20)}

„Risikoberichterstattung von Versicherungsunternehmen“, verabschiedet durch den Deutschen Standardisierungs Rat (DSR) am 03.04.2001, Bekanntmachung gem. § 342 Abs. 2 HGB durch das Bundesministerium der Justiz (BMJ) im Bundesanzeiger am 29.05.2001

Verabschiedung der aktuellen Fassung durch den DSR am 05.01.2010, Bekanntmachung gem. § 342 Abs. 2 HGB durch das Bundesministerium der Justiz (BMJ) im Bundesanzeiger am 18.02.2010

\section{Deutscher Rechnungslegungs Standard Nr. 6 (DRS 6)}

„Zwischenberichterstattung“, verabschiedet durch den Deutschen Standardisierungs Rat (DSR) am 11.01.2001, Bekanntmachung gem. $\S 342$ Abs. 2 HGB durch das Bundesministerium der Justiz (BMJ) im Bundesanzeiger am 13.02.2001

Aufhebung durch Bekanntmachung DRS 16 am 24.07.2008

\section{Deutscher Rechnungslegungs Standard Nr. 15 (DRS 15)}

„Lageberichterstattung“, verabschiedet durch den Deutschen Standardisierungs Rat (DSR) am 07.12.2004, Bekanntmachung gem. $\S 342$ Abs. 2 HGB durch das Bundesministerium der Justiz (BMJ) im Bundesanzeiger am 26.02.2005

Verabschiedung der Neufassung (DRS 15 n.F.) durch den Deutschen Standardisierung Rat (DSR) am 05.01.2010, Bekanntmachung gem. $\S 342$ Abs. 2 HGB durch das Bundesministerium der Justiz (BMJ) im Bundesanzeiger am 18.02.2010 als Deutscher Rechnungslegungs Änderungsstandard Nr. 4 (DRÄS 5)

DRÄS 5 beinhaltet Anpassungen nach dem BilMoG in den Standards der Lageberichterstattung (DRS 5, 5-10, 5-20, 15 und 16 sowie die Außerkraftsetzung des DRS 15a) 


\section{Nationaler Standardsetter: Verlautbarungen (Forts.)}

\section{Deutscher Rechnungslegungs Standard Nr. 15a (DRS 15a)}

„Übernahmerechtliche Angaben und Erläuterungen im Konzernlagebericht“, verabschiedet durch den Deutschen Standardisierungs Rat (DSR) am 07.12.2007, Bekanntmachung gem. § 342 Abs. 2 HGB durch das Bundesministerium der Justiz (BMJ) im Bundesanzeiger am 05.06.2008

Aufhebung durch Bekanntmachung DRS 15 n.F. am 18.02.2010

\section{Deutscher Rechnungslegungs Standard Nr. 16 (DRS 16)}

„Zwischenberichterstattung“,

verabschiedet durch den Deutschen Standardisierungs Rat (DSR) am 05.05.2008, Bekanntmachung gem. $§ 342$ Abs. 2 HGB durch das Bundesministerium der Justiz (BMJ) im Bundesanzeiger am 24.07.2008

Verabschiedung der aktuellen Fassung durch den DSR am 05.01.2010,

Bekanntmachung gem. $\S 342$ Abs. 2 HGB durch das Bundesministerium der Justiz (BMJ) im Bundesanzeiger am 18.02.2010

\section{Deutscher Rechnungslegungs Standard Nr. 17 (DRS 17)}

„Berichterstattung über die Vergütung der Organmitglieder", verabschiedet durch den Deutschen Standardisierungs Rat (DSR) am 07.12.2007, Bekanntmachung gem. $§ 342$ Abs. 2 HGB durch das Bundesministerium der Justiz (BMJ) im Bundesanzeiger am 05.06.2008 


\section{Nationaler Standardsetter: Sonstige Veröffentlichungen}

DSR (2003) [Hrsg.]: Entwurf DRS Nr. 20 (E-DRS 20),

Entwurf Deutscher Rechnungslegungs Standard Nr. 20 (E-DRS 20),

„Lageberichterstattung“, Stand: 13.11.2003

Quelle: http://www.standardsetter.de/drsc/docs/press_releases/...

E-DRS\%2020_website_131103.pdf

(Stand am 07.09.2009)

DSR (2004a) [Hrsg.]: Protokoll des Diskussionsforums zu E-DRS 20

„Lageberichterstattung“, Protokoll der Diskussion am 09.02.2004 in Berlin

Quelle: http://www.standardsetter.de/drsc/docs/presentations/...

2004-02-09_minutes.htm

(Stand am 16.07.2009)

DSR (2004b) [Hrsg.]: Überarbeiteter Entwurf DRS Nr. 20 (E-DRS 20 n.F.),

Entwurf Deutscher Rechnungslegungs Standard Nr. 20 (E-DRS 20),

„Lageberichterstattung“, Stand: 20.07.2004

Quelle: http://www.standardsetter.de/drsc/docs/press_releases/...

E-DRS\%2020_revised_150704.pdf

(Stand am 07.09.2009)

DSR (2006) [Hrsg.]: Stellungnahme zum IASB-Discussion Paper „Management

Commentary“, Stand: 10.04.2006

Quelle: http://www.standardsetter.de/drsc/docs/press_releases/...

cl_GASB_MC_100406.pdf

(Stand am 06.03.2010)

DSR (2009) [Hrsg.]: Hinweis zum Prognosebericht gemäß DRS 15 „Lageberichterstattung“,

Stand: 27.03.2009

Quelle: http://www.standardsetter.de/drsc/docs/press_releases/...

090327_Prognosebericht_DRS15.pdf

(Stand am 16.10.2009) 


\section{Europäische Union: Verordnungen}

\section{Verordnung (EG) Nr. 1606/2002 (IAS-Verordnung)}

Verordnung (EG) Nr. 1606/2002 des Europäischen Parlaments und des Rates vom 19.07.2002 betreffend die Anwendung internationaler Rechnungslegungsstandard

Quelle: $\quad$ Amtsblatt der EG ${ }^{1232}$, Nr. L 243 vom 11.09.2002, S. 1-4

1232 Alle genannten Quellen, die dem Amtsblatt der Europäischen Gemeinschaft bzw. Union entnommen sind, wurden unter http://eur-lex.europa.eu/rech_reference_pub.do bezogen. 


\section{Europäische Union: Richtlinien}

\section{Richtlinie 78/660/EWG (Vierte Richtlinie, Bilanzrichtlinie)}

Vierte Richtlinie des Europäischen Rates vom 25.07.1978 aufgrund von Artikel 54

Absatz 3 Buchstabe g) des Vertrages über den Jahresabschluss von Gesellschaften bestimmter Rechtsformen (78/660/EWG)

Quelle: $\quad$ Amtsblatt der EG, Nr. L 222 vom 14.08.1978, S. 11-31

\section{Richtlinie 83/349/EWG (Siebente Richtlinie, Konzernbilanzrichtlinie)}

Siebente Richtlinie des Europäischen Rates vom 13.06.1983 aufgrund von Artikel 54 Absatz 3 Buchstabe g) des Vertrages über den konsolidierten Abschluss (83/349/EWG)

Quelle: $\quad$ Amtsblatt der EG, Nr. L 193 vom 18.07.1983, S. 1-17

\section{Richtlinie 89/666/EWG (Zweigniederlassungsrichtlinie)}

Elfte Richtlinie 89/666/EWG des Europäischen Rates vom 21.12.1989 über die Offenlegung von Zweigniederlassungen, die in einem Mitgliedstaat von Gesellschaften bestimmter Rechtsformen errichtet wurden, die dem Recht eines anderen Staates unterliegen

Quelle: $\quad$ Amtsblatt der EG, Nr. L 395 vom 30.12.1989, S. 36-39

\section{Richtlinie 90/604/EWG (Mittelstandsrichtlinie)}

Richtlinie 90/604/EWG des Europäischen Rates vom 08.11.1990 zur Änderung der Richtlinie 78/660/EWG über den Jahresabschluss und der Richtlinie 83/349/EWG über den konsolidierten Abschluss hinsichtlich der Ausnahmen für kleine und mittlere Gesellschaften sowie der Offenlegung von Abschlüssen in Ecu Quelle: $\quad$ Amtsblatt der EG, Nr. L 317 vom 16.11.1990, S. 57-59

\section{Richtlinie 90/605/EWG (Kapitalgesellschaften- und Co.-Richtlinie)}

Richtlinie des Europäischen Rates vom 08.11.1990 zur Änderung der Richtlinien 78/660/EWG und 83/349/EWG über den Jahresabschluss bzw. den konsolidierten Abschluss hinsichtlich ihres Anwendungsbereiches

Quelle: $\quad$ Amtsblatt der EG, Nr. L 317 vom 16.11.1990, S. 60 


\section{Europäische Union: Richtlinien (Forts.)}

\section{Richtlinie 2001/65/EG (Fair-Value-Richtlinie)}

Richtlinie 2001/65/EG des Europäischen Parlaments und des Rates vom 27.09.2001 zur Änderung der Richtlinien 78/660/EWG, 83/349/EWG und 86/635/EWG des Rates im Hinblick auf die im Jahresabschluss bzw. im konsolidierten Abschluss von Gesellschaften bestimmter Rechtsformen und von Banken und anderen Finanzinstituten zulässigen Wertansätze

Quelle: $\quad$ Amtsblatt der EU, Nr. L 283 vom 27.10.2001, S. 28-32

\section{Richtlinie 2003/38/EG (Schwellenwert-Richtlinie)}

Richtlinie 2003/38/EG des Europäischen Rates vom 13.05.2003 zur Änderung der Richtline 78/660/EWG über den Jahresabschluss von Gesellschaften bestimmter Rechtsformen hinsichtlich der in Euro ausgedrückten Beträge

Quelle: $\quad$ Amtsblatt der EU, Nr. L 120 vom 15.05.2003, S. 22-23

\section{Richtlinie 2003/51/EG (Modernisierungsrichtlinie)}

Richtlinie 2003/51/EG des Europäischen Parlaments und des Rates vom 18.06.2003 zur Änderung der Richtlinien 78/660/EWG, 83/349/EWG, 86/635/EWG und 91/674/EWG über den Jahresabschluss und den konsolidierten Abschluss von Gesellschaften bestimmter Rechtsformen und von Banken und anderen Finanzinstituten sowie von Versicherungsunternehmen

Quelle: $\quad$ Amtsblatt der EU, Nr. L 178 vom 17.07.2003, S. 16-22

\section{Richtlinie 2004/25/EG (Übernahmerichtlinie)}

Richtlinie 2004/25/EG des Europäischen Parlaments und des Rates vom 21.04.2004 betreffend Übernahmeangebote

Quelle: Amtsblatt der EU, Nr. L 142 vom 30.04.2004, S. 12-23 


\section{Europäische Union: Richtlinien (Forts.)}

\section{Richtlinie 2004/109/EG (Transparenzrichtlinie)}

Richtlinie 2004/109/EG des Europäischen Parlaments und des Rates vom 15.12.2004 zur Harmonisierung der Transparenzanforderungen in Bezug auf Informationen über Emittenten, deren Wertpapiere zum Handel auf einem geregelten Markt zugelassen sind, und zur Änderung der Richtlinie 2001/34/EG

Quelle: $\quad$ Amtsblatt der EU, Nr. L 390 vom 31.12.2004, S. 38-57

\section{Richtlinie 2006/46/EG (Änderungsrichtlinie)}

Richtlinie 2006/46/EG des Europäischen Parlaments und des Rates vom 14.06.2006 zur Änderung der Richtlinien des Rates 78/660/EWG über den Jahresabschluss von Gesellschaften bestimmter Rechtsformen, 83/349/EWG über den konsolidierten Abschluss, 86/635/EWG über den Jahresabschluss und den konsolidierten Abschluss von Banken und anderen Finanzinstituten und 91/674/EWG über den Jahresabschluss und den konsolidierten Abschluss von Versicherungsunternehmen Quelle: $\quad$ Amtsblatt der EU, Nr. L 224 vom 16.08.2006, S. 1-7 


\section{Internationale Standardsetter - FASB: Verlautbarungen}

FASB (2006a) [Hrsg.]: Original Pronouncements, Accounting Standards, Volume I bis

Volume III, hier insb. Volume III: FASB Concepts Statements (SFAC), New York 


\section{Internationale Standardsetter - FASB: Sonstige Veröffentlichungen}

\section{Projekt: Improving Business Reporting}

FASB (2001a) [Hrsg.]: Improving Business Reporting. Insights into Enhancing Voluntary

Disclosures, Steering Committee Report, Business Reporting Research Project

Quelle: http://www.fasb.org/cs/ContentServer?c=Document_C\&... pagename=FASB\%2FDocument_C\%2FDocumentPage \&... cid $=1176156460184$

(Stand am 30.09.2009)

FASB (2001b) [Hrsg.]: Challenges from the New Economy, Business Reporting Research Project, Special Report on New Economy, Financial Accounting Series, Nr. 219 A (April 2001)

Quelle: http://www.fasb.org/articles\&reports/sr_new_economy.pdf (Stand am 30.09.2009)

\section{Projekt: Conceptual Framework}

FASB (2006b) [Hrsg.]: Preliminary Views - Conceptual Framework for Financial Reporting. Objective of Financial Reporting and Qualitative Characteristics of Decision-Useful Financial Reporting Information (Conceptual Framework Project)

Quelle: http://www.fasb.org/draft/pv_conceptual_framework.pdf (Stand am 30.09.2009)

FASB (2007) [Hrsg.]: Minutes of the August 29, 2007. Conceptual Framework Board Meeting

Quelle: http://www.fasb.org/jsp/FASB/Page/08-29-07_cf.pdf (Stand am 30.09.2009) 


\section{Internationale Standardsetter - IASB: Verlautbarungen}

IASB (2009a) [Hrsg.]: Framework for the Preparation and Presentation of Financial

Statements, angenommen vom IASB im April 2001

Quelle: http://eifrs.iasb.org/eifrs/bnstandards/en/framework.pdf (Stand am 30.12.2009)

IASB (2009b) [Hrsg.]: Preface to International Financial Reporting Standards, angenommen vom IASB im April 2002, zuletzt geändert im Januar 2008

Quelle: http://eifrs.iasb.org/eifrs/bnstandards/en/preface.pdf (Stand am 30.12.2009)

IASB (2009c) [Hrsg.]: International Accounting Standard 1. Presentation of Financial Statements, zuletzt geändert in November 2009

Quelle: http://eifrs.iasb.org/eifrs/bnstandards/en/ias1.pdf (Stand am 30.12.2009)

IASB (2009d) [Hrsg.]: International Accounting Standard 38. Intangible Assets, zuletzt geändert in November 2009

Quelle: http://eifrs.iasb.org/eifrs/bnstandards/en/ias38.pdf (Stand am 30.12.2009) 


\section{Internationale Standardsetter - IASB: Sonstige Veröffentlichungen}

\section{Projekt: Conceptual Framework}

IASB (2006) [Hrsg.]: Discussion Paper: Preliminary Views on an Improved Framework for

Financial Reporting: The Objective of Financial Reporting and Qualitative

Characteristics of Decision-useful Financial Reporting Information (Conceptual

Framework Project)

Quelle: $\quad$ http://www.iasb.org/NR/rdonlyres/...

4651 ADFC-AB83-4619-A75A-4F279C175006/0/...

DP_ConceptualFramework.pdf

(Stand am 30.12.2009)

IASB (2007a) [Hrsg.]: Conceptual Framework, Phase A: Objective of Financial Reporting and Qualitative Characteristics, Comment Letter Summary,

Information for Observers, 20.02.2007

Quelle: $\quad$ http://www.iasb.org/Current+Projects/IASB+Projects/...

Conceptual+Framework/Discussion+Paper+and+...

Comment+Letters+-+Phase+A/Comment+Letters/...

Comment+Letters.htm

(Stand am 30.12.2009) 


\section{Internationale Standardsetter - IASB: Sonstige Veröffentlichungen}

\section{Projekt: Management Commentary}

IASB (2005) [Hrsg.]: Management Commentary: Discussion Paper, April 2006

Quelle: http://www.iasb.org/NR/rdonlyres/...

1CAEA05A-0651-42B8-A40A-6ED23E46A876/...

0/DPManagementCommentary.pdf

(Stand am 30.12.2009)

IASB (2007b) [Hrsg.]: Management Commentary: Detailed Comment Letter Analysis, Januar 2007

Quelle: $\quad$ http://www.iasb.org/NR/rdonlyres/...

4FAC5FFD-F017-46FF-95A2-5E1AABA95E51/...

0/MC070lbl lbobs.pdf

(Stand am 30.12.2009)

IASB (2009e) [Hrsg.]: Management Commentary: Exposure Draft ED/2009/06, Juni 2009

Quelle: http://www.iasb.org/NR/rdonlyres/...

53DC9B3B-34A5-400F-B4B5-4F2FF24F231E/...

0/EDManagementCommentary.pdf

(Stand am 30.12.2009)

Diverse (2006) [Hrsg.]: Einzelne Comment Letters deutscher Institutionen

Quelle: http://www.iasb.org/Current+Projects/lASB+Projects/...

Management+Commentary/...

Discussion+Paper++Management+Commentary/...

Comment+Letters/Comment+Letters.htm

(Stand am 30.12.2009)

Im Einzelnen: Allianz SE, Arbeitskreis Externe Unternehmensrechnung der Schmalenbach-Gesellschaft für Betriebswirtschaft e.V. (AKEU), Institut der Wirtschaftsprüfer (IDW), Munich Re Group AG, Volkswagen AG 


\title{
Controlling \& Business Accounting
}

\author{
Herausgegeben von Prof. Dr. Barbara E. Weißenberger
}

Band 1 Michael Maier: Der Management Approach. Herausforderungen für Controller und Abschlußprüfer im Kontext der IFRS-Finanzberichterstattung. 2009.

Band 2 Christoph Gehrig: Anwendungssystemgestütztes strategisches Controlling. Konzeption und empirische Erkenntnisse. 2009.

Band 3 Hendrik Angelkort: Integration des Rechnungswesens als Erfolgsfaktor für die Controllerarbeit. Eine empirische Untersuchung deutscher Großunternehmen. 2010.

Band 4 Benjamin W. Löhr: Integriertes Risikocontrolling für Industrieunternehmen. Eine normative Konzeption im Kontext der empirischen Controllingforschung von 1990 bis 2009. 2010.

Band 5 Jochen A. Hönninger: Wertorientierte Steuerung dezentraler Entscheidungsträger im Produktlebenszyklus. Integration von wertorientierter Unternehmenssteuerung und strategischem Kosten- und Erlösmanagement auf Produktebene. 2010.

Band 6 Sebastian Wolf: Management Accountants' Business Orientation and Involvement in Incentive Compensation. Empirical Results from a Cross-Sectional Survey. 2011.

Band 7 Timo Schmidt: Corporate Governance, Controlling und Unternehmenserfolg. Konzeptionelle Gestaltung und empirische Analyse. 2011.

Band 8 Tom Sieber: Strategieorientierte Berichterstattung im Lagebericht. Eine empirische Untersuchung börsennotierter Unternehmen in Deutschland. 2011.

www.peterlang.de 